\title{
LOAD AND RESISTANCE FACTOR DESIGN OF DRILLED SHAFTS SUBJECTED TO LATERAL LOADING AT SERVICE LIMIT STATE
}

\author{
A Dissertation \\ presented to \\ the Faculty of the Graduate School \\ at the University of Missouri-Columbia \\ In Partial Fulfillment \\ of the Requirements for the Degree \\ Doctor of Philosophy \\ by \\ MINH DINH UONG \\ Dr. Erik Loehr, Dissertation Supervisor
}

JULY, 2018 
C Copyright by Minh Uong 2018

All Rights Reserved 
The undersigned, appointed by the dean of the Graduate School, have examined the dissertation entitled

\section{LOAD AND RESISTANCE FACTOR DESIGN OF DRILLED SHAFTS SUBJECTED TO LATERAL LOADING AT SERVICE LIMIT STATE}

presented by Minh Dinh Uong,

a candidate for the degree of Doctor of Philosophy, and hereby certify that, in their opinion, it is worthy of acceptance.

Dr. Erik Loehr, P.E., Dissertation Supervisor

Department of Civil and Environmental Engineering

Dr. John Bowders, P.E., Committee Member

Department of Civil and Environmental Engineering

Dr. Brent Rosenblad, P.E., Committee Member

Department of Civil and Environmental Engineering

Dr. Robert Winholtz, Committee Member

Department of Mechanical and Aerospace Engineering 
To my family...

This dissertation is dedicated to my wife, Mai Vu, for her love, her encouragement and her unconditional support. It is also dedicated to my lovely daughters, Anna, Leah and Sophia Uong, for the time I, as a father, could not stand by them due to work. Thanks to my parents, Chat Uong and Phuong Nguyen, and my sister, Lan Uong, for never stop believing, inspiring and supporting me. 


\section{ACKNOWLEDGEMENTS}

I would like to express my deepest gratitude to my advisor, Dr. Erik Loehr for his excellent guidance, patience, enthusiasm and understanding during my studying at the University of Missouri-Columbia, and especially during my work for the dissertation. Dr. Erik Loehr not only provided me an excellent environment and atmosphere for doing research, but also helped me develop my critical thinking, expand my knowledge and improve my academic performance.

I would like to express my appreciation to Dr. John Bowders, who always be there when I need advices for my career in civil engineering and who can spend hours listening to my troubles in life. Special thanks to Dr. Brent Rosenblad for his advices on my teaching roles at $\mathrm{MU}$, for his feedbacks on my work and for his stories when we traveled to serve the Missouri reconnaissance team. Last but not least, thanks to Dr. Robert Winholtz, who was willing to participate in my final committee and provide helpful recommendations at the last moment.

I would also like to say "thank you" to Andrew Boeckmann, Dan Ding, Taylor Day, Sarah Myers and Thuy Vu for the teamwork and providing helps on my research project.

Lastly, I am very grateful for the MUGEO and very proud to be part of the geotechnical family at MU. I would never have been able to finish my dissertation without the conscientious guidance of my committee members, the enthusiastic help from my friends and the sentimental encouragement from my family. 


\section{TABLE OF CONTENTS}

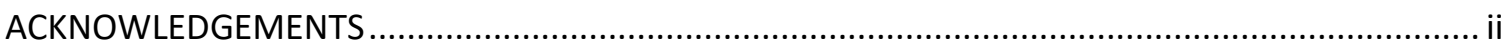

LIST OF FIGURES

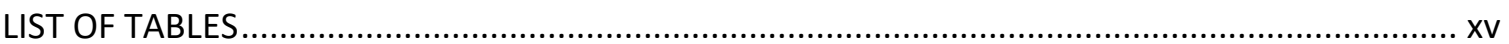

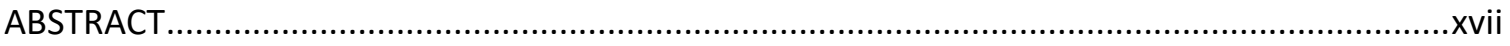

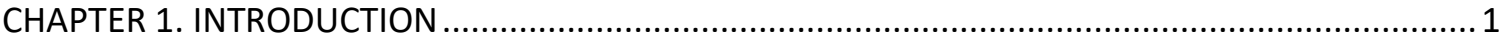

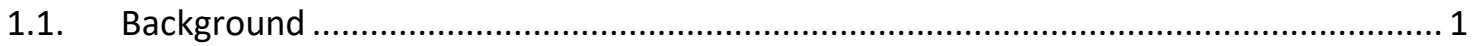

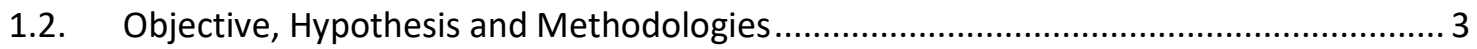

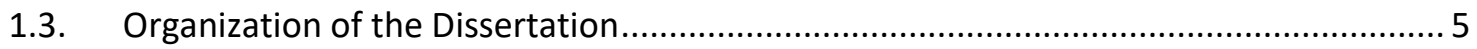

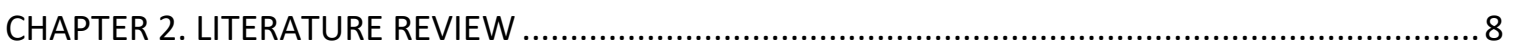

2.1. Allowable Stress Design (ASD) versus Load and Resistance Factor Design (LRFD) .......... 8

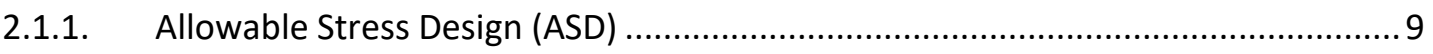

2.1.2. Load and Resistance Factor Design (LRFD) …................................................... 10

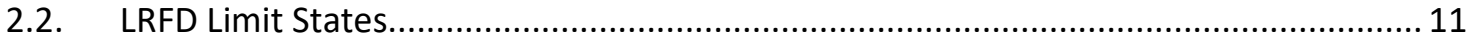

2.2.1. LRFD Ultimate Limit State (ULS) or Strength Limit State ....................................11

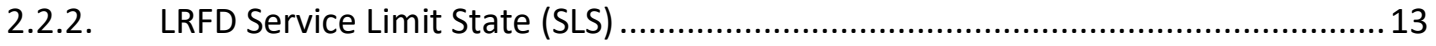

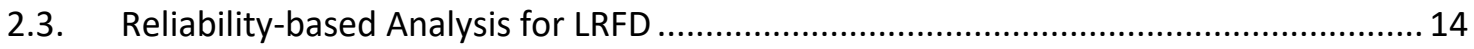

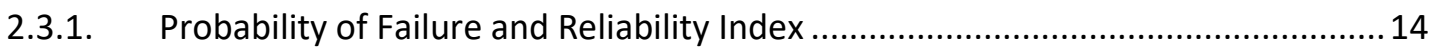

2.3.2. Displacement-based Performance Function for Reliability-based Analyses .........17

2.3.3. Factoring Displacement, Factoring Parameter \& Factoring Resistance Methods 17

2.4. Methods for Developing p-y Curves from Experimental Measurements...................... 20

2.4.1. Deriving p-y Curves from Direct Interpretation ...................................................24

2.4.2. Deriving $\mathrm{p}-\mathrm{y}$ Curves from a Bending Moment Function ......................................25

2.4.3. Deriving $p-y$ Curves from a Displacement Function..............................................26

2.4.4. Deriving $\mathrm{p}-\mathrm{y}$ Curves from Optimizing a Lateral Load Transfer Model.....................27

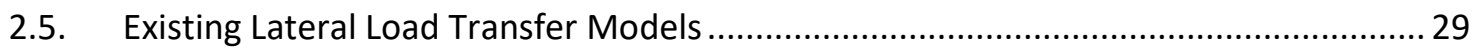

2.5.1. Reese's Stiff Clay with No Free Water (1972) .......................................................29

2.5.2. Reese's Interim Recommendations for $p$-y Curves for Weak Rock (1997) ............. 31

2.5.3. KDOT's p-y Curve for Sandstone and Sandy Shale (1987) .................................... 33

2.6. Probabilistic Approaches for LRFD Calibration and Reliability-Based Design.................35

2.6.1. First Order Second Moment (FOSM) Method ….................................................. 35 
2.6.2. First Order Reliability Method (FORM) ............................................................ 36

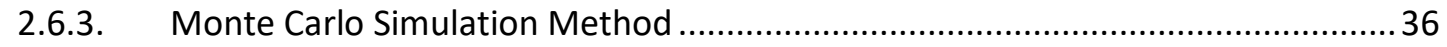

2.7. Methods for designing drilled shafts subjected to lateral loading .............................. 38

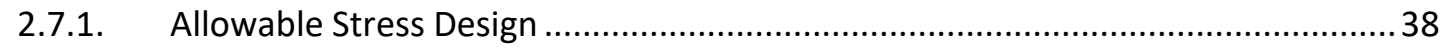

2.7.2. LRFD Bridge Design Specifications (AASHTO 2007) ............................................... 40

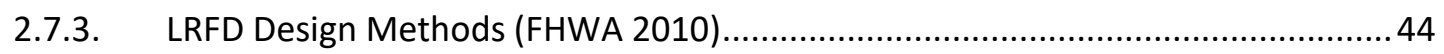

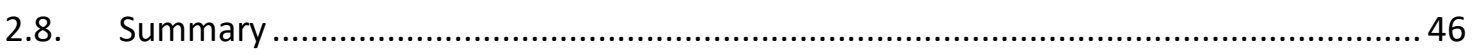

CHAPTER 3. LATERAL LOAD TEST FOR DRILLED SHAFTS IN SHALE ..........................................47

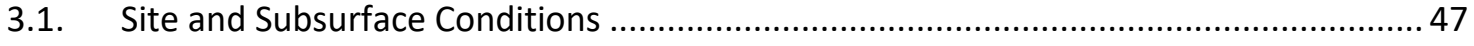

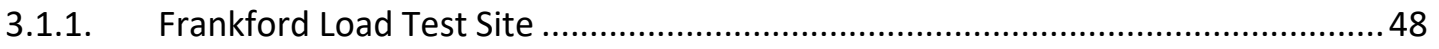

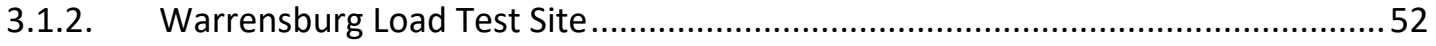

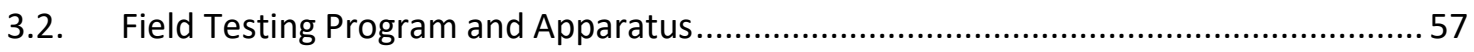

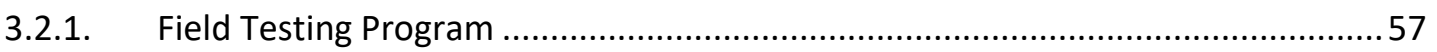

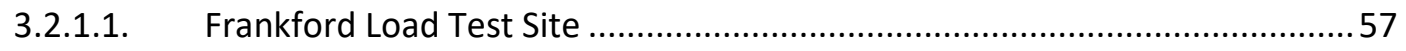

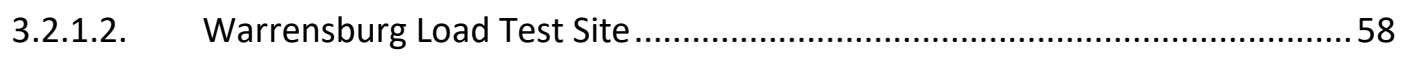

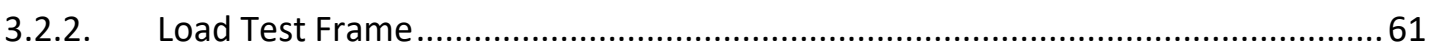

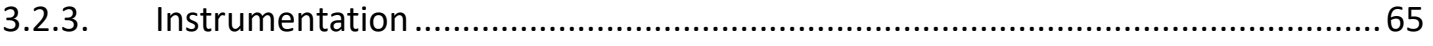

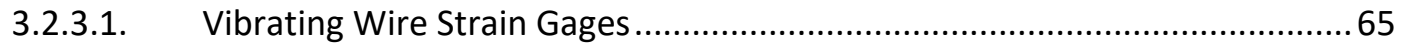

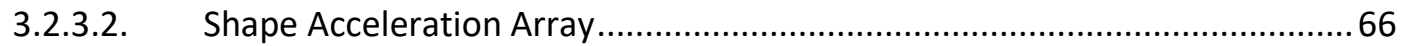

3.2.3.3. Vibrating Wire Displacement Transducers ..............................................67

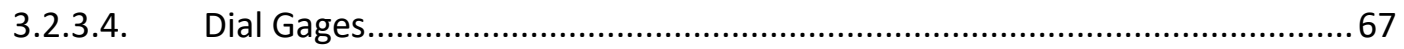

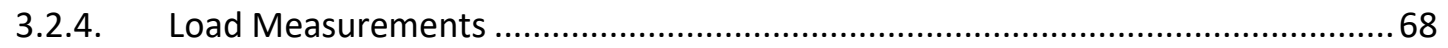

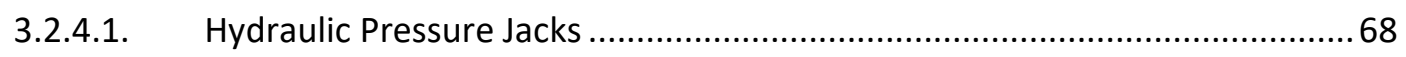

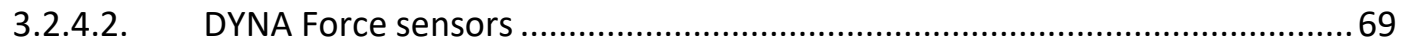

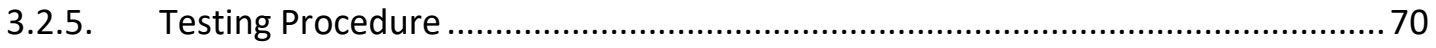

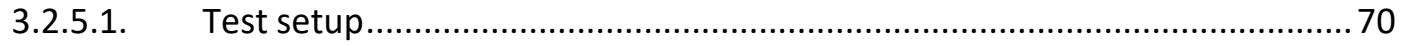

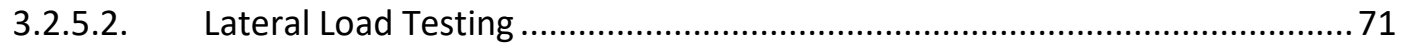

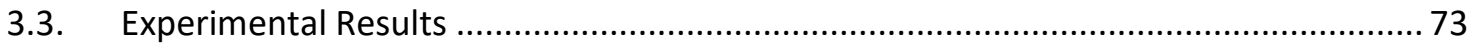

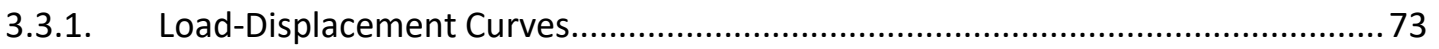

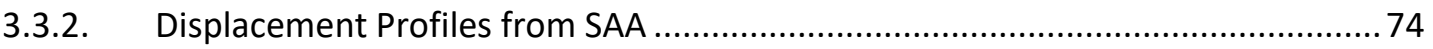

3.3.3. Methodology for Analysis of Bending Moment Data .......................................... 76

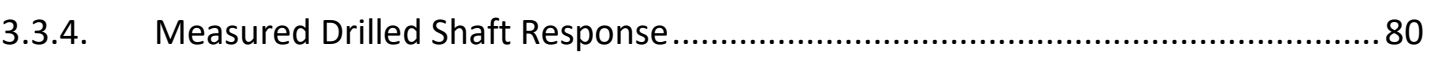

3.3.4.1. Comparison of Bending Moments from SAA and strain gage data ...............80 


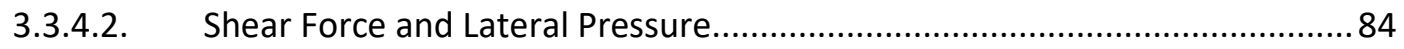

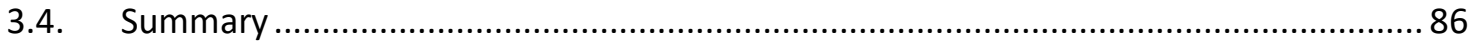

CHAPTER 4. INTERPRETATION OF SHAFT RESPONSE USING NUMERICAL MODEL.......................8 88

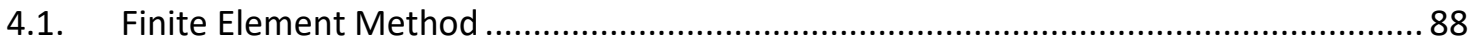

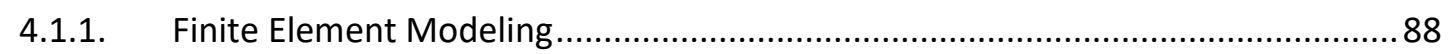

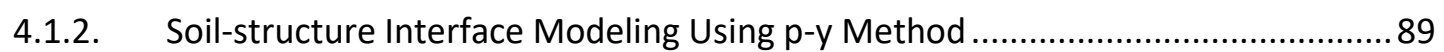

4.1.3. Finite Element Formulations.......................................................................... 91

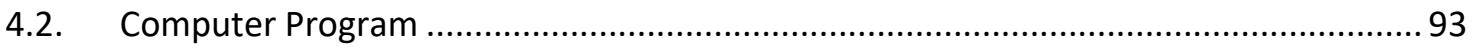

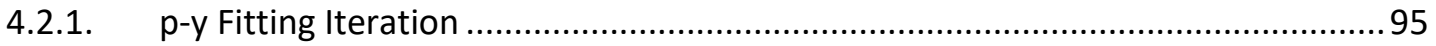

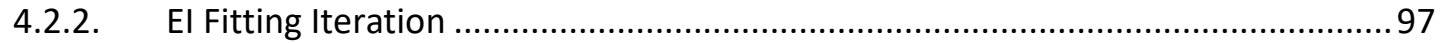

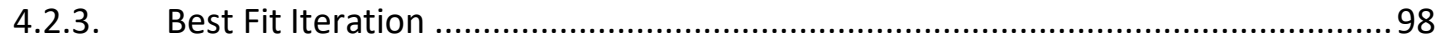

4.2.4. Predicted Results Output from Computer Program ..........................................103

4.2.4.1. Predicted Results in Terms of Shaft Response ...........................................103

4.2.4.2. Predicted Results in Terms of Lateral Soil Response .................................. 104

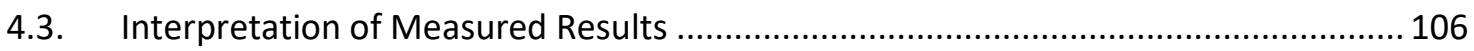

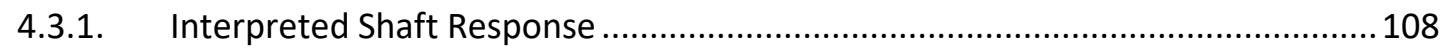

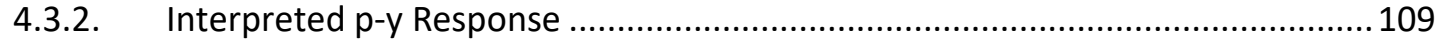

4.4. Evaluation of Non-linear Bending Stiffness .......................................................... 111

4.4.1. Effect of Non-linear Bending Stiffness on Interpreted Lateral Displacement .....112

4.4.2. Effect of Non-linear Bending Stiffness on Interpreted Bending Moment ............113

4.4.3. Effect of Non-linear Bending Stiffness on Interpreted p-y Response ...................114

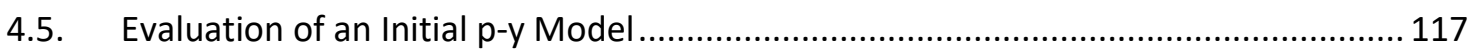

4.5.1. Effect of Different Initial p-y Model on Interpreted Shaft Response...................117

4.5.2. Effect of Different Initial p-y Model on Interpreted p-y Response......................119

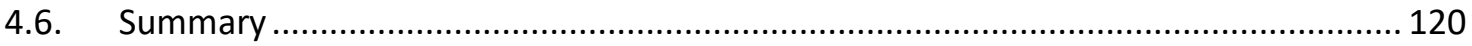

CHAPTER 5. DEVELOPMENT OF LATERAL LOAD TRANSFER MODEL........................................122

5.1. Proposed Lateral Load Transfer Model (p-y Model) .................................................. 122

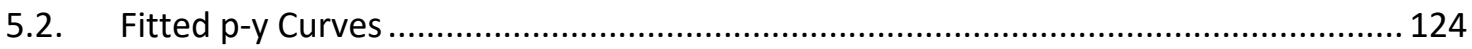

5.2.1. Fitted p-y Curves Using Data According to Stratum ......................................... 124

5.2.2. Fitted p-y Curves Using Data According to Depth .............................................129

5.2.3. Fitted $\mathrm{p}$-y Curves Using Data According to Individual Load Test .........................136

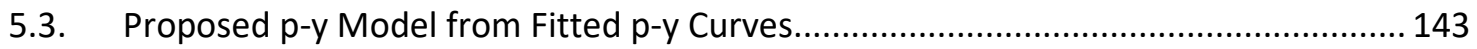

5.3.1. Approach 1: Depth-independent Model Using Data According to Stratum.........143 
5.3.2. Approach 2: Depth-dependent Model Using Data According to Depth. 146

5.3.3. Approach 3: Depth-dependent Model Using Data According to Individual Test 148

5.3.4. Comparison Between Three Approaches and Final Proposed p-y Model ............151

5.4. Comparison of Proposed Model with Existing Models.............................................. 155

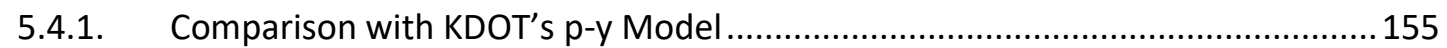

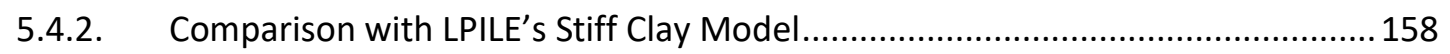

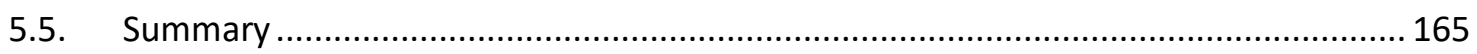

CHAPTER 6. PROBABILISTIC CALIBRATION OF RESISTANCE FACTORS FOR LOAD AND RESISTANCE

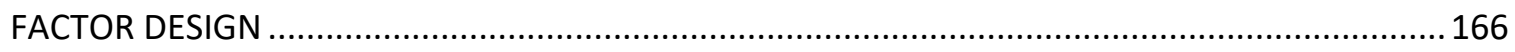

6.1. Design Procedure for Load and Resistance Factor Design at Service Limit State........ 166

6.2. Monte Carlo Simulation Method to Calibrate Resistance Factor ................................ 168

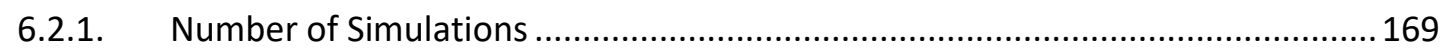

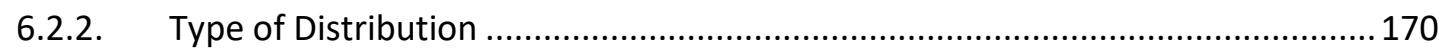

6.2.2.1. Generation of Normally Distributed Parameter Values............................... 171

6.2.2.2. Generation of Lognormally Distributed Parameter Values ......................... 172

6.3. Modeling the Variability and Uncertainty in $\mathrm{p}$-y Responses..................................... 174

6.4. Model Uncertainty versus Total Variability and Uncertainty ................................... 177

6.5. Evaluation of Probabilistic Variables in p-y Responses............................................ 179

6.5.1. Evaluation of Probabilistic Variables according to $1^{\text {st }}$ Approach ......................... 180

6.5.2. Evaluation of Probabilistic Variables according to $2^{\text {nd }}$ Approach .......................... 183

6.5.3. Evaluation of Probabilistic Variables according to $3^{\text {rd }}$ Approach......................... 185

6.5.4. Comparison Probabilistic Variables in p-y Responses using Three Approaches.. 187

6.6. Final Probabilistic and Deterministic Variables for Monte-Carlo Simulation .............. 200

6.7. Calibration of Resistance Factors for Service Limit State ….................................... 202

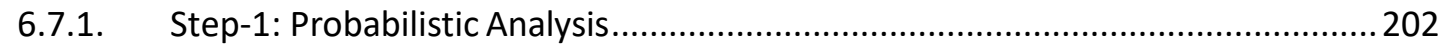

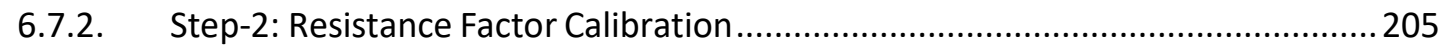

6.7.3. Calibrated Resistance Factors for Service Limit State..........................................207

6.7.4. Comparison between Four Options and Recommended Resistance Factors......211

6.8. Evaluation of other Monte Carlo simulation parameters......................................... 215

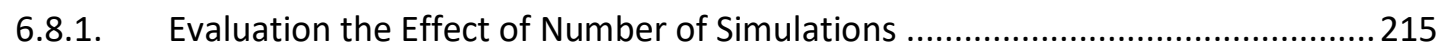

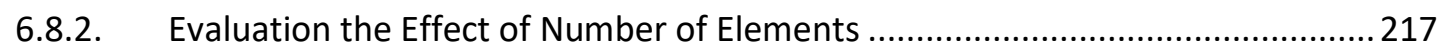

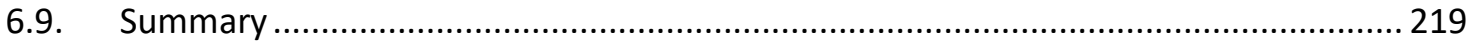

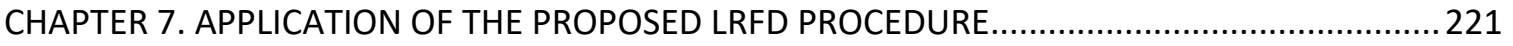


7.1. Implementation of Proposed LRFD Procedure for Service Limit State

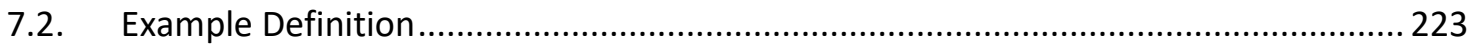

7.3. Example 1: Comparison of Proposed and Conventional Design Methods .................. 227

7.4. Example 2: Comparison of Designs using UCS with Different Reliability ..................... 230

7.5. Example 3: Comparison of Designs using Different Shaft Stiffness ............................. 232

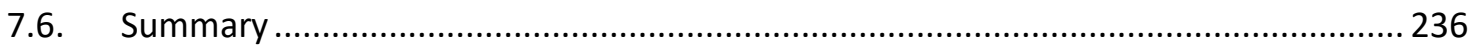

CHAPTER 8. EVALUATION OF PROPOSED SERVICE LIMIT STATE DESIGN METHOD FOR LATERALLY LOADED DRILLED SHAFTS

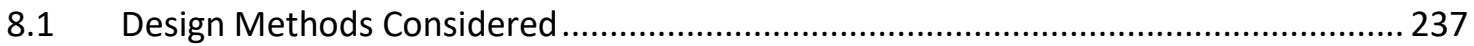

8.2 Nine Different Cases to evaluate the proposed LRFD.............................................. 239

8.2.1 Structural Characteristics of Drilled Shafts ......................................................... 239

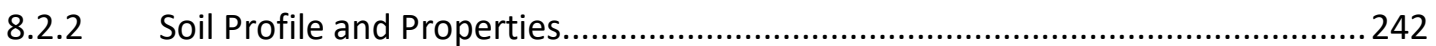

8.2.3 Configuration of Shaft Lengths \& Soil Layers Depths for Nine Different Cases... 242

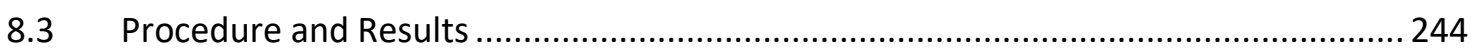

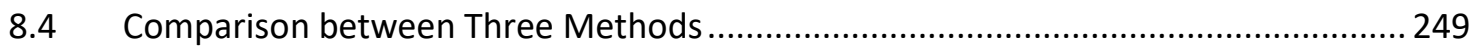

8.4.1 Comparison of the Results Obtained from Three Methods when the RBD Target

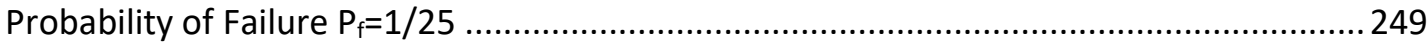

8.4.2 Comparison of the Results Obtained from Three Methods when the RBD target

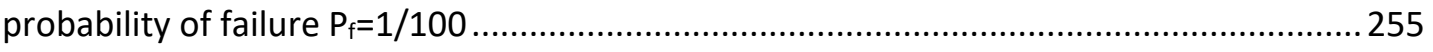

8.5 Load Ratio and Nominal Lateral Load calculated from Strength Limit State............... 261

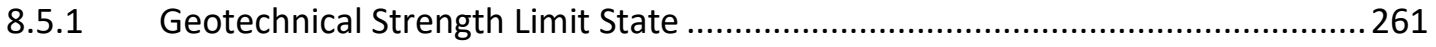

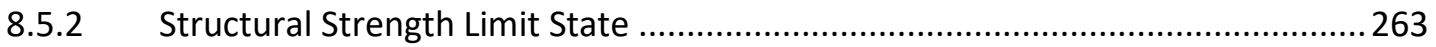

8.6 Comparison between 3 Methods using Nominal Loads from Strength Limit State .... 272

8.6.1 Comparison of the Results Obtained from 3 Methods Using Calculated Nominal

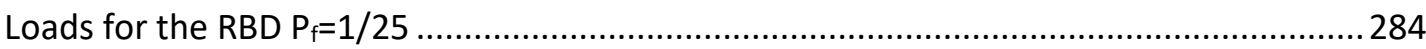

8.6.2 Comparison of the $P_{f}$ Obtained from 3 Methods Using Calculated Nominal Loads

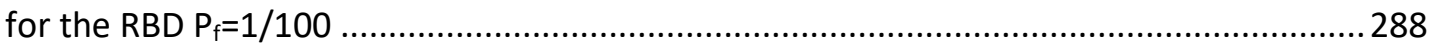

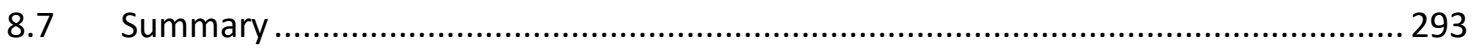

CHAPTER 9. SUMMARY, FINDINGS, FINAL CONCLUSIONS AND RECOMMENDATIONS ..............295

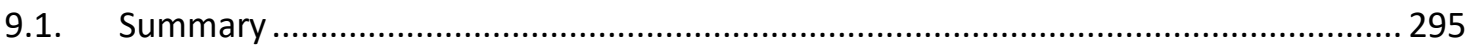

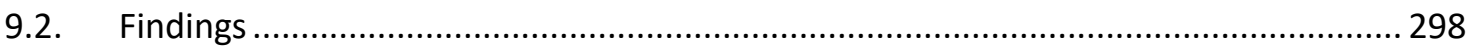

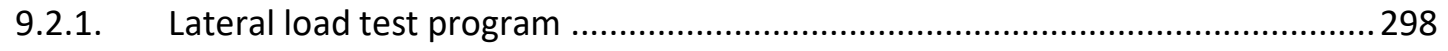

9.2.2. Predicted shaft responses and interpreted lateral load-transfer model..............298

9.2.3. Proposed lateral load-transfer model................................................................298 
9.2.4. Probabilistic calibrated resistance factors.....

9.2.5. Proposed LRFD procedure for drilled shafts subjected to lateral loading at SLS 300

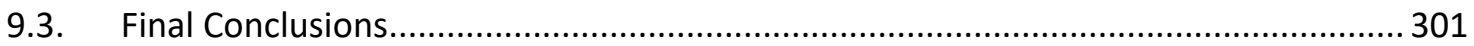

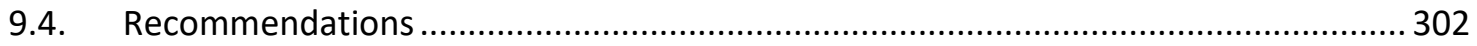

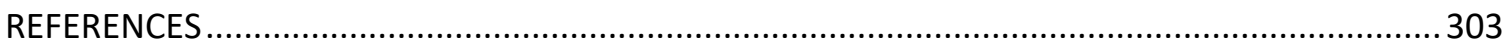

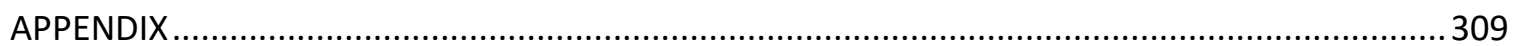

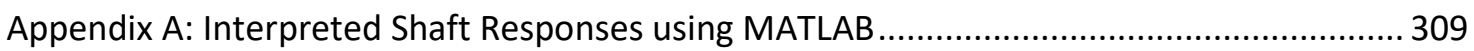

Appendix B: Interpreted p-y Responses and Fitted p-y Curves for each Load Test ................ 413

Appendix C: Probabilistic Variables in p-y Responses using Three Approaches....................... 457

Appendix D: Proposed LRFD, AASHTO LRFD and RBD methods with different P/Pult .............500

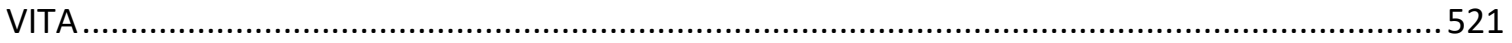




\section{LIST OF FIGURES}

Figure 1.1 - Methodologies to evaluate Hypothesis ................................................................. 4

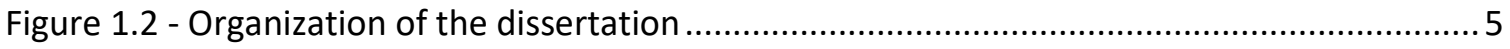

Figure 2.1 - Probability of failure and reliability index (from Allen, 2005). ................................. 16

Figure 2.2 - Lateral loaded drilled shaft model, forces and reactions ..........................................21

Figure 2.3 - Model of lateral loaded drilled shaft showing concept of $p-y$ curves ........................23

Figure 2.4 - p-y curve for static loading in stiff clay with no free water (Reese's 1972). ...............30

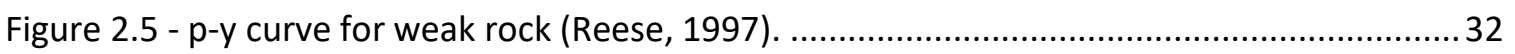

Figure 2.6 - $p$-y curve for Sandstone and Sandy Shale (KDOT, 1987) ..........................................34

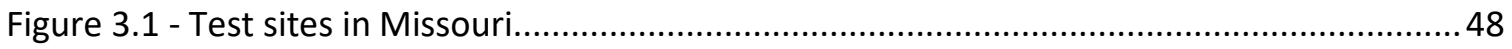

Figure 3.2 - Location of Frankford Load Test Site. ................................................................. 49

Figure 3.3 - Cross-section of the Frankford Lateral Load Test Site showing measured values of UCS.

Figure 3.4 - Measured values of UCS shown with mean and standard deviation values for

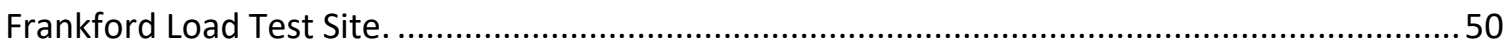

Figure 3.5 - Layout of test shafts at Frankford Load Test Site. ..................................................51

Figure 3.6 - Cross-section B-B' of the Frankford Load Test Site showing the drilled shafts. ..........51

Figure 3.7 - Location of Warrensburg Load Test Site.................................................................52

Figure 3.8 - Cross-section of the Warrensburg Lateral Load Test Site showing measured values of UCS.

Figure 3.9 - Measured values of UCS shown with mean and standard deviation values for

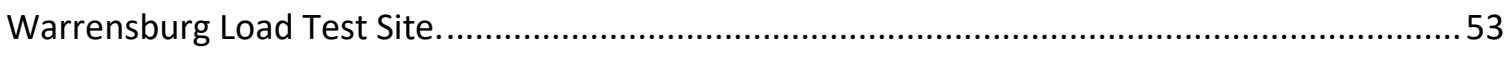

Figure 3.10 - Layout of test shafts at Warrensburg Load Test Site..............................................5

Figure 3.11 - Warrensburg site cross-section A-A' showing the drilled shafts .............................55

Figure 3.12 - Warrensburg site cross-section B-B' showing the drilled shafts .............................55

Figure 3.13 - Warrensburg site cross-section C-C' showing the drilled shafts .............................56

Figure 3.14 - Layout of the test shaft pairs at the Frankford Load Test Site with rectangles

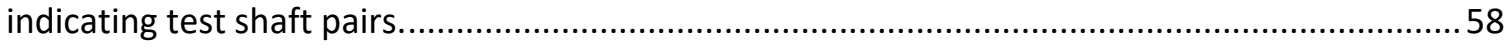

Figure 3.15 - Layout of the test shaft pairs at the Warrensburg Load Test Site with rectangles

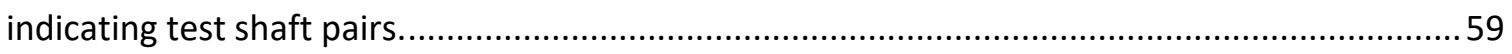

Figure 3.16 - Soil removal by drilling holes next to drilled shafts.............................................. 60

Figure 3.17 - Drilled holes adjacent to the shaft prior to retesting............................................60

Figure 3.18 - One side of lateral load test frame in place at Frankford Load Test Site. ................61

Figure 3.19 - Plan and elevation views of lateral load test frame. .............................................62 
Figure 3.20 - Plan and elevation view of lateral load test frame seating detail. .63

Figure 3.21 - The beam, seating, and bearing in place around W2. .64

Figure 3.22 - Beam and seating in place without bearing. .64

Figure 3.23 - Vibrating wire strain gage mounted on reinforcing cage......................................65

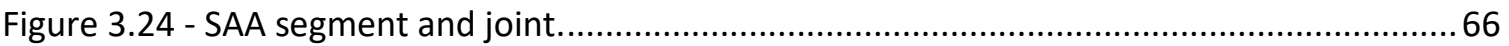

Figure 3.25 - Vibrating wire LVDTs attached to the reference beam. .......................................67

Figure 3.26 - Dial gage mounted to the head of the drilled shaft. ..............................................68

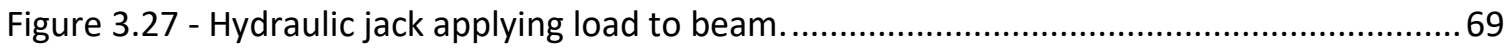

Figure 3.28 - DYNA Force sensors connected to each of four load frame rods........................... 70

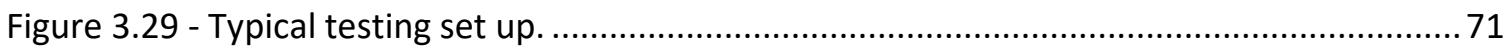

Figure 3.30 - Load-displacement curves for test of shaft W11 at Warrensburg test site..............74

Figure 3.31 - Displacement profiles from SAA data for test of shafts (a) W10 and (b) W11 .........76

Figure 3.32 - Example of bending stiffness versus bending curvature for shaft W7.................... 78

Figure 3.33 - Comparison of bending moments in test shaft F4 at Frankford test site from (a) SAA

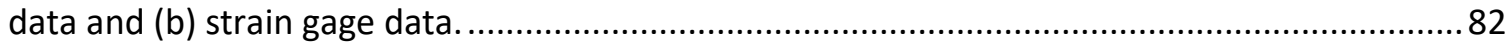

Figure 3.34 - Comparison of bending moments in test shaft W3 at Warrensburg test site before soil removal from (a) SAA data and (b) strain gage data.

Figure 3.35 - Comparison of bending moments in test shaft W3 at Warrensburg test site after soil removal from (a) SAA data and (b) strain gage data.

Figure 3.36 - Example of interpreting shear force and unit lateral pressure from SAA data (Frankford shaft F4). .85

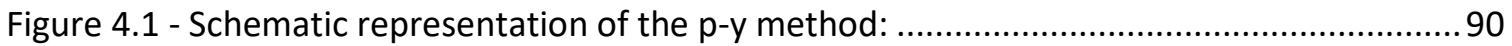

Figure 4.2 - Conceptual p-y curve (Reese et al., 2006)..............................................................90

Figure 4.3 - Flow chart outlining operation of FEM computer code. ...........................................94

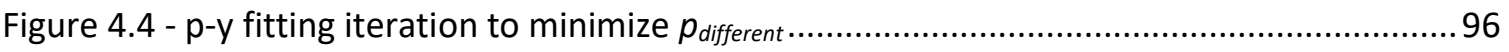

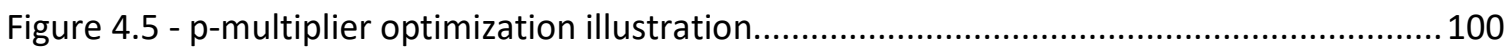

Figure 4.6 - p-multiplier optimization using displacement or bending moment norm ...............101

Figure 4.7 - Shaft responses comparison between p-multiplier optimized using ....................... 102

Figure 4.8 - Shaft responses for different values of $p$-multiplier in terms of: ............................. 104

Figure 4.9 - Optimum p-y curves and soil responses calculated at different depths ..................105

Figure 4.10 - Interpreted shaft responses under different loads for shaft $\mathrm{W}-9 . \ldots \ldots \ldots \ldots \ldots \ldots \ldots \ldots . . . . . . . . . . .108$

Figure 4.11 - $\mathrm{p}$-y response interpreted from experimental results (shaft $\mathrm{W}-9, \mathrm{z}=2 \mathrm{ft}$ )..............109

Figure 4.12 - $p$-y responses interpreted from the experimental results ...................................110

Figure 4.13 - Example of linear and non-linear bending stiffness for shaft W9 .......................... 111

Figure 4.14 - Interpreted and measured shaft responses for shaft W-9 @ 319.2kips using linear and non-linear El assumptions 
Figure 4.15 - Interpreted $p-y$ response using linear and non-linear bending stiffness assumptions at $(\mathrm{a})$ depth $=2 \mathrm{ft} ;(\mathrm{b})$ depth $=5 \mathrm{ft}$ 115

Figure 4.16 - Interpreted $p-y$ response using linear and non-linear bending stiffness assumptions at $(\mathrm{a})$ depth $=10 \mathrm{ft} ;(\mathrm{b})$ depth $=12 \mathrm{ft}$. 115

Figure 4.17 - Interpreted shaft responses using different initial p-y model. 118

Figure 4.18 - interpreted $p$-y responses using three different initial p-y models... 119

Figure 5.1 - $p$-y curves fitted to interpreted $p$-y responses using different functions 123

Figure 5.2 - Fitted p-y curve for Maquoketa A layer at Frankford Load Test Site ....................... 126

Figure 5.3 - Fitted p-y curve for Maquoketa B layer at Frankford Load Test Site........................ 126

Figure 5.4 - Fitted p-y curve for Maquoketa C layer at Frankford Load Test Site........................ 127

Figure 5.5 - Fitted p-y curve for Silty Clay layer at Warrensburg Load Test Site ......................... 127

Figure 5.6 - Fitted p-y curve for Sandy Shale layer at Warrensburg Load Test Site ....................128

Figure 5.7 - Fitted p-y curves for Maquoketa A layer at Frankford Load Test Site ....................... 130

Figure 5.8 - Fitted p-y curves for Maquoketa B layer at Frankford Load Test Site ...................... 131

Figure 5.9 - Fitted p-y curves for Maquoketa C layer at Frankford Load Test Site ...................... 132

Figure 5.10 - Fitted p-y curves for Silty Clay layer at Warrensburg Load Test Site ......................133

Figure 5.11 - Fitted p-y curves for Sandy Shale layer at Warrensburg Load Test Site .................134

Figure 5.12 - Fitted p-y curves for Lateral load test $\mathrm{W}-2$ at:..................................................... 137

Figure 5.13 - fitted p-y curves for Lateral load test W-11 at: ................................................... 137

Figure 5.14 - Fitted p-y curves for Lateral load test F-1 ......................................................... 138

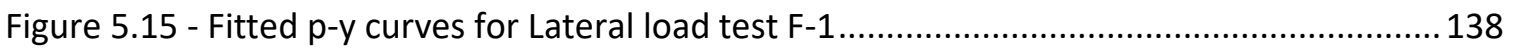

Figure 5.16 - $P_{\text {ult }}$ as a function of UCS using data according to stratum (Approach 1) ................144

Figure 5.17 - $K_{\text {py }}$ as a function of UCS using data according to stratum (Approach 1) ................145

Figure 5.18 - $\mathrm{P}_{\text {ult }}$ as a function of UCS using data according to depth (Approach 2) ...................147

Figure $5.19-K_{\text {py }}$ as a function of UCS \& $\sigma_{v}$ using data according to depth (Approach 2) ...........147

Figure 5.20 - $\mathrm{P}_{\mathrm{ult}}$ as a function of UCS using data according to individual load test (Approach 3) 149

Figure 5.21 - $K_{p y}$ as a function of UCS \& $\sigma_{v}$ using data according to individual load test (Approach 3) 150

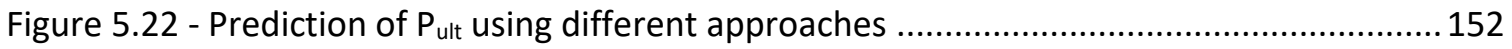

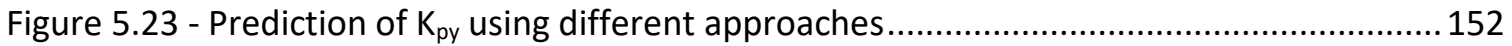

Figure 5.24 - Proposed relationship between Pult and UCS compared to KDOT (1987) ..............156

Figure 5.25 - Proposed relationship between $\mathrm{K}_{\text {py }}$ and UCS compared to KDOT (1987)...............156

Figure 5.26 - Comparison of p-y curves at Frankford Load Test Site for depths of (a) $5 \mathrm{ft}$ and (b) 7 $\mathrm{ft}$. 
Figure 5.27 - Comparison of p-y curves at Frankford Load Test Site for depths of (a) $10 \mathrm{ft}$ and (b) $12 \mathrm{ft}$ 160

Figure 5.28 - Comparison of p-y curves at Frankford Load Test Site for depths of (a) $16 \mathrm{ft}$ and (b) $18 \mathrm{ft}$ .161

Figure 5.29 - Comparison of p-y curves at Warrensburg Load Test Site for depths of (a) $2 \mathrm{ft}$, (b) 5

$\mathrm{ft}$, (c) $10 \mathrm{ft}$, and (d) $12 \mathrm{ft}$. 162

Figure 5.30 - Comparison of p-y curves at Warrensburg Load Test Site for depths of (a) $16 \mathrm{ft}$, (b) $20 \mathrm{ft}$, (c) $22 \mathrm{ft}$, and (d) $25 \mathrm{ft}$. 163

Figure 6.1 - Conceptual diagram of Monte Carlo method (Vu, 2013) 169

Figure 6.2 - (a) Normal distribution and (b) Lognormal distribution (Vu, 2013) 171

Figure 6.3 - Model and Total Bounds for predicting Pult with respect to UCS ..... 181

Figure 6.4 - Model and Total Bounds for predicting $\log \left(\mathrm{K}_{\mathrm{py}} / \sigma_{\mathrm{v}}\right)$ with respect to UCS .181

Figure 6.5 - Model and Total Bounds for predicting lateral soil response (p) with respect to lateral displacement (y) at Frankford, Maquoketa $\mathrm{A}$, depth=5ft. 184

Figure 6.6 - Comparison between 3 approaches for Model Uncertainty (Warrensburg Site, Silty Clay layer, depth=2ft) 189

Figure 6.7 - Comparison between 3 approaches for Model Uncertainty (Frankford Site, Maquoketa A layer, depth=7ft) 191

Figure 6.8 - Comparison between 3 approaches for Total Variability and Uncertainty (Warrensburg Site, Silty Clay layer, depth $=2 \mathrm{ft}$ ) 194

Figure 6.9 - Comparison between 3 approaches for Total Variability and Uncertainty (Warrensburg Site, Silty Clay layer, depth=2ft) 196

Figure 6.10 - Selection of Constant Standard Deviation for Monte-Carlo Simulation. 198

Figure 6.11 - Histogram and probability density curve for top shaft displacement. 203

Figure 6.12 - Shaft Head Displacement Histogram. 204

Figure 6.13 - Calibrated Resistance Factors for Service Limit State using $1^{\text {st }}$ Option ..................209

Figure 6.14 - Calibrated Resistance Factors for Service Limit State using $2^{\text {nd }}$ Option .................209

Figure 6.15 - Calibrated Resistance Factors for Service Limit State using $3^{\text {rd }}$ Option ..................210

Figure 6.16 - Calibrated Resistance Factors for Service Limit State using $4^{\text {th }}$ Option ..................210

Figure 6.17 - Resistance Factor for different options of assignment probabilistic parameters .. 212

Figure 6.18 - Final Recommended Resistance Factors for Service Limit State Design ................214

Figure 6.19 - Resistance Factors for different number of simulations ......................................216

Figure 6.20 - Resistance Factor for different number of elements .........................................218

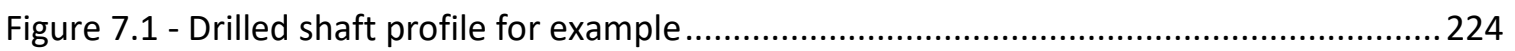

Figure 7.2 - Nonlinear Bending stiffness for Casing and Non-Casing sections ............................226

Figure 7.3 - Example 1: Comparison of Proposed and Conventional Design Methods ...............228 
Figure 7.4 - Example 2: Comparison of Design using UCS with Different Reliability 231

Figure 7.5 - Example 3: Comparison of Designs using Different Shaft Stiffness 234

Figure 8.1 - Typical shaft profile with cased and uncased sections. 240

Figure 8.2 - Nonlinear Bending stiffness for Cased and Uncased sections. 241

Figure 8.3 - Configuration of shaft lengths and soil layers depths for nine different cases ........243

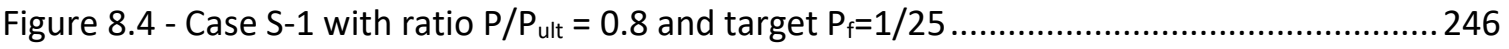

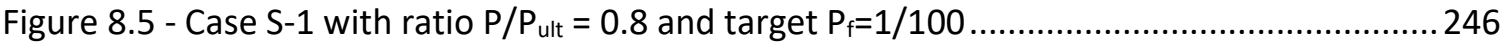

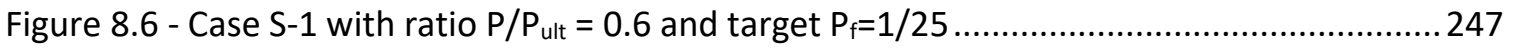

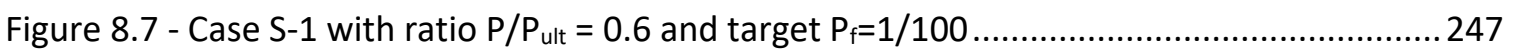

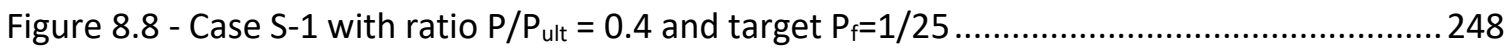

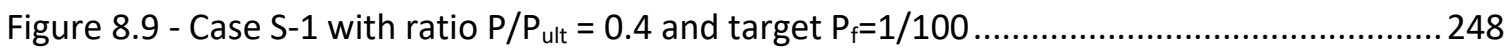

Figure 8.10 - Change of displacement with respect to RBD displacement (in inches) for $P_{f}=1 / 25$ 251

Figure 8.11 - Change of displacement with respect to RBD displacement (in \%) for $\mathrm{Pf}=1 / 25$....251 Figure 8.12 - Change of probability of failure with respect to the RBD target $\mathrm{Pf}=1 / 25$ (in ratio) 254 Figure 8.13 - Change of displacement with respect to RBD displacement (in inches) for $P_{f}=1 / 100$

Figure 8.14 - Change of displacement with respect to RBD displacement (in \%) for $\mathrm{P}_{\mathrm{f}}=1 / 100 \ldots 257$ Figure 8.15 - Change of probability of failure with respect to the RBD target $P_{f}=1 / 100$ (in ratio) 260

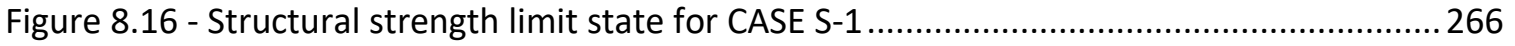

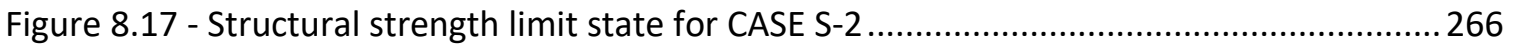

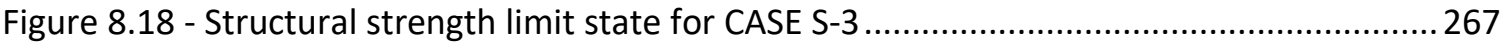

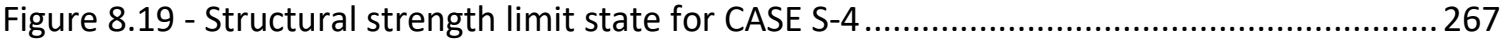

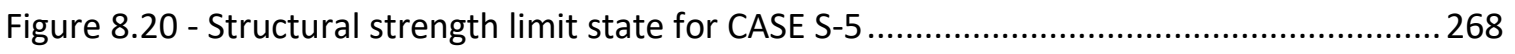

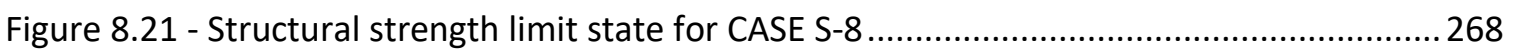

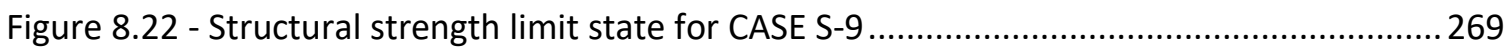

Figure 8.23 - Load Ratio calculated from different Strength Limit State....................................271

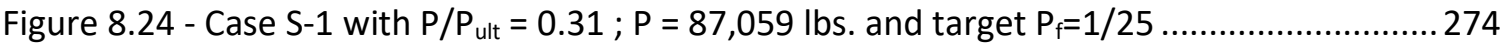

Figure 8.25 - Case $\mathrm{S}-1$ with $\mathrm{P} / \mathrm{P}_{\text {ult }}=0.31 ; \mathrm{P}=87,059$ lbs. and target $\mathrm{P}_{\mathrm{f}}=1 / 100 \ldots \ldots \ldots \ldots \ldots \ldots \ldots \ldots . . .274$

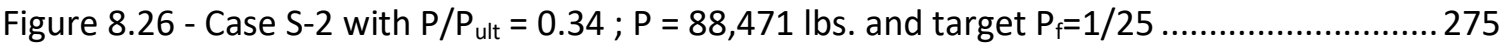

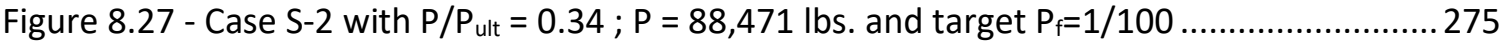

Figure 8.28 - Case S-3 with $\mathrm{P} / \mathrm{P}_{\text {ult }}=0.39 ; \mathrm{P}=115,294 \mathrm{lbs}$. and target $\mathrm{P}_{\mathrm{f}}=1 / 25 \ldots \ldots \ldots \ldots \ldots \ldots \ldots \ldots . . .276$

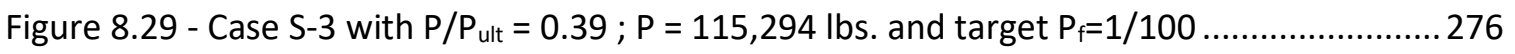

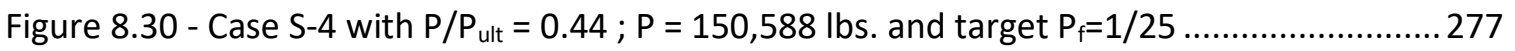

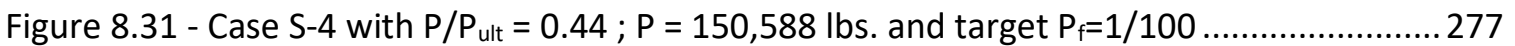




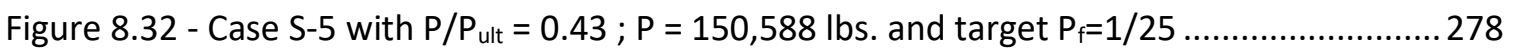

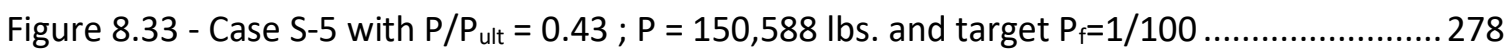

Figure 8.34 - Case $\mathrm{G}-6$ with $\mathrm{P} / \mathrm{P}_{\mathrm{ult}}=0.47 ; \mathrm{P}=117,500 \mathrm{lbs}$. and target $\mathrm{P}_{\mathrm{f}}=1 / 25 \ldots \ldots \ldots \ldots \ldots \ldots \ldots \ldots . . .279$

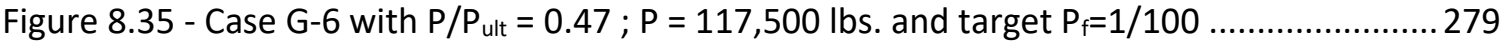

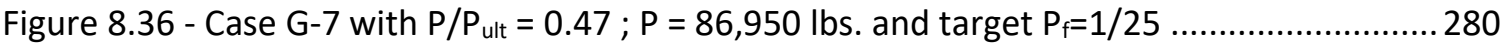

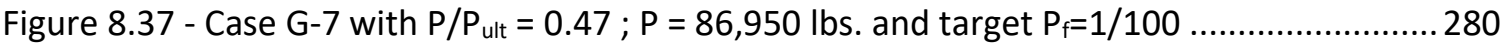

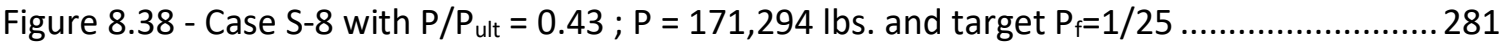

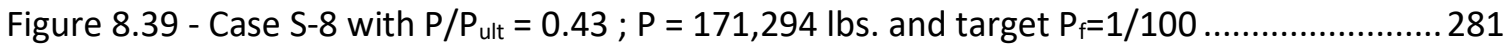

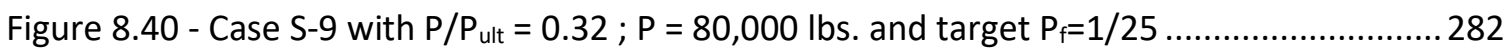

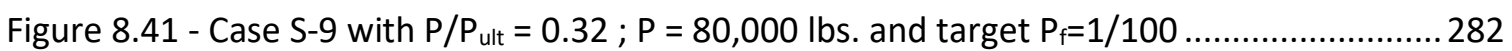

Figure 8.42 - Change of displacement with respect to RBD displacement (in inches) for $P_{f}=1 / 25$,

using calculated nominal loads

.285

Figure 8.43 - Change of displacement with respect to RBD displacement (in \%) for $\mathrm{Pf}=1 / 25$, using calculated nominal loads .285

Figure 8.44 - Change of probability of failure with respect to the RBD target $\mathrm{P}_{\mathrm{f}}=1 / 25$ (in ratio) using calculated nominal loads

Figure 8.45 - Change of displacement with respect to RBD displacement (in inches) for $\mathrm{Pf}=1 / 100$ using calculated nominal loads

Figure 8.46 - Change of displacement with respect to RBD displacement (in \%) for $\mathrm{Pf}=1 / 100$ using calculated nominal loads.....

Figure 8.47 - Change of probability of failure with respect to the RBD target $\mathrm{Pf}=1 / 100$ (in ratio) using calculated nominal loads 


\section{LIST OF TABLES}

Table 2.1 - Target Probability of Failure for Service Limit State (Huaco et al. 2012) .....................17

Table 2.2 - Minimum factors of safety for ASD foundation design (IBC, 2012) ............................39

Table 2.3 - Load combinations and load factors (after AASHTO 2007, Table 3.4.1-1) ..................41

Table 2.4 - Load factors for permanent loads $\gamma_{p}$ (after AASHTO 2007, Table 3.4.1-2) ..................42

Table 2.5 - Resistance Factors for Geotechnical Resistance of Drilled Shafts ............................... 43

Table 2.6 - Summary of Resistance Factors for LRFD Design of Drilled Shaft Foundation ............. 45

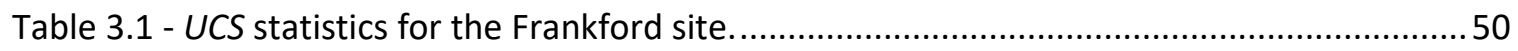

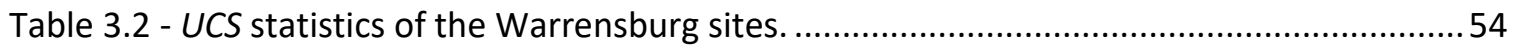

Table 3.3 - Summary of field observations from lateral load tests............................................. 72

Table 5.1 - Summary of model fitting parameters for each stratum ........................................ 128

Table 5.2 - Summary of model fitting parameters for each depth ............................................ 135

Table 5.3 - Summary of model fitting parameters for each lateral load test .............................. 139

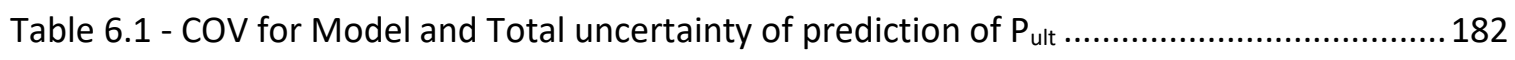

Table 6.2 - COV for Model and Total uncertainty of prediction of $\log _{\mathrm{e}}\left(\mathrm{K}_{\mathrm{py}} / \sigma_{\mathrm{v}}\right) \ldots \ldots \ldots \ldots \ldots \ldots \ldots \ldots . . . . . . . . . . .182$

Table 6.3 - Constant COV for Model and Total uncertainty of prediction of $\mathrm{p}$-y curve................184

Table 6.4 - Constant STD for Model and Total uncertainty of prediction of $p$-y curve ................186

Table 6.5 - Comparison between Three Approaches for Model Uncertainty .............................. 192

Table 6.6 - Comparison between Three Approaches for Total Variability \& Uncertainty ............197

Table 6.7 - Selection of Constant Standard Deviation for Monte-Carlo Simulation.................... 199

Table 6.8 - Final Probabilistic and Deterministic Variables for Monte-Carlo Simulation ............ 201

Table 6.9 - Characteristics of Four Options to Calibrate Resistance Factors ............................... 208

Table 6.10 - Summary of probabilistic parameters assignments for all four options .................211

Table 6.11 - Probabilistic Parameters for different number of simulations ................................ 216

Table 6.12 - Probabilistic Parameters for different number of elements .................................218

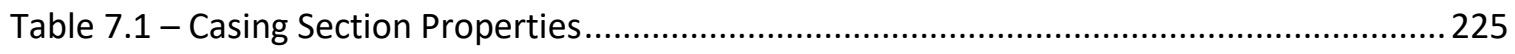

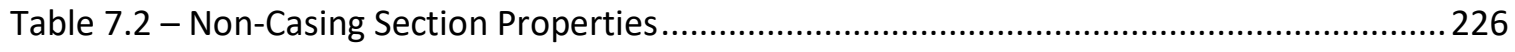

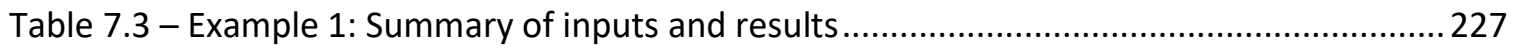

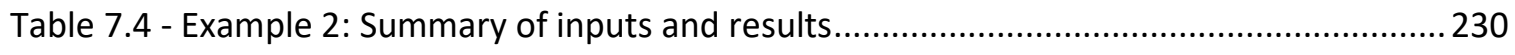

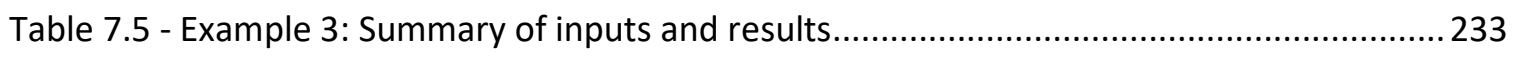

Table 8.1 - Structural Characteristics for Cased Section ........................................................... 239

Table 8.2 - Structural Characteristics for Uncased Section.................................................... 240

Table 8.3 - Ultimate Lateral Load and Lateral Loads for nine different cases .............................. 244

Table 8.4 - Displacement comparison between 3 methods with Target $P_{f}=1 / 25 \ldots \ldots \ldots \ldots \ldots \ldots \ldots . . .250$ 
Table 8.5 - Probability of Failure comparison between 3 methods with Target $\mathrm{Pf}=1 / 25 \ldots \ldots \ldots .253$

Table 8.6 - Displacement comparison between 3 methods with Target Pf $=1 / 100$...................256

Table 8.7 - Probability of Failure comparison between 3 methods with Target $P_{f}=1 / 100 \ldots \ldots . .259$

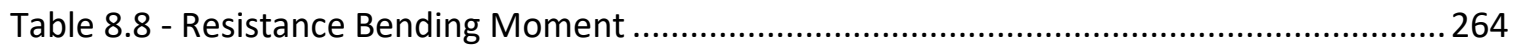

Table 8.9 - Ultimate Lateral Load and Lateral Loads for nine different cases ............................270

Table 8.10 - Nominal Lateral Loads used for Service Limit State for nine different cases ..........272

Table 8.11 - Displacement comparison between 3 methods using calculated nominal loads with

Target $P_{f}=1 / 25$

Table 8.12 - Probability of Failure comparison between 3 methods using calculated nominal loads with Target $P_{f}=1 / 25$

Table 8.13 - Displacement comparison between 3 methods using calculated nominal loads with

Target Pf $=1 / 100$ 289

Table 8.14 - Probability of Failure comparison between 3 methods using calculated nominal loads with Target $P_{f}=1 / 100$. .291 


\title{
LOAD AND RESISTANCE FACTOR DESIGN OF DRILLED SHAFTS \\ SUBJECTED TO LATERAL LOADING AT SERVICE LIMIT STATE \\ Minh Dinh Uong \\ Dr. Erik Loehr, Dissertation Supervisor
}

\begin{abstract}
Since 2007, the American Association of State Highway Administration Officials (AASHTO) has made utilization of Load and Resistance Factor Design (LRFD) mandatory on all federally-funded new bridge projects (AASHTO, 2007). However, currently, there are no guidelines implementing LRFD techniques for design of drilled shaft subjected to lateral loads using reliability-based analysis. On a national level, the AASHTO LRFD Bridge Design Specifications (AASHTO, 2012) specify that a resistance factor of 1.0 be used for design of drilled shafts subjected to lateral loading at service limit state, which means reliability-based analyses for calibration of resistance factors have not been performed. Therefore, there is a need to create a LRFD procedure for drilled shafts subjected to lateral loading at service limit state that has reliability-based calibrated resistance factors applicable for future projects.

The research focuses on the reliability-based analysis of drilled shaft subjected to lateral loading, characterize lateral load transfer model of drilled shafts in shale, probabilistic calibrate resistance factor and contribute to the development of design procedure using LRFD. The objective of this work is to improve the design of drilled shaft subjected to lateral loading using LRFD at service limit state by providing a more reliable design procedure than the current AASHTO LRFD procedure for drilled shafts subjected to lateral loading at service limit state.
\end{abstract}




\section{CHAPTER 1. INTRODUCTION}

In this chapter, the background of load and resistance factor design of drilled shafts subjected to lateral loading at service limit state is described. Next, the objectives and hypothesis of this dissertation are addressed. Then, the methodologies to evaluate the hypothesis are discussed. Lastly, the organization of the dissertation is also provided in this chapter.

\subsection{Background}

Geotechnical engineers recently have been working to transition from Allowable Stress Design (ASD) to Load and Resistance Factor Design (LRFD). In allowable stress design, which has been used for many years, every input parameter is treated as deterministic, and the uncertainty in each design step is combined into one global factor called "factor-of-safety". Allowable Stress Design is the traditional design method, and its safety margin has gained public acceptance. The factor of safety for each type of structure is chosen based on experience. However, design engineers seldom know the reliability of their designs or the probability of failure with ASD. On the other hand, LRFD often is linked explicitly to reliability analysis. An LRFD design often is targeted at a known level of reliability, or targeted probability of failure. LRFD, therefore, provides the potential to achieve more consistent and rational reliability. Instead of a single factor-of-safety, LRFD replaces with a set of partial safety factors acting on individual components of resistance

and load (Taylor, 1948; Freudenthal, 1951, 1956; Brinch-Hansen, 1953, 1956). Those 
factors include load factors, resistance factors and could be derived from reliability-based analyses for calibration.

Since 2007, the American Association of State Highway Administration Officials (AASHTO) has made utilization of LRFD mandatory on all federally-funded new bridge projects (AASHTO, 2007). However, currently, there are no guidelines implementing LRFD techniques for design of drilled shaft subjected to lateral loads using reliability-based analysis. On a national level, the AASHTO LRFD Bridge Design Specifications (AASHTO, 2012) specify that a resistance factor of 1.0 be used for design of drilled shafts subjected to lateral load. The resistance factor of 1.0 is using because reliability-based analyses for calibration of resistance factors have not been performed. Others have proposed resistance factors that are less than 1.0, for example, the FHWA/NHI Drilled Shaft Manual (Brown et al., 2010) recommends use of a resistance factor of 0.67 , but this factor is based on the authors' judgment rather than a reliability-based calibration study. Therefore, there is a need to create a LRFD procedure for drilled shafts subjected to lateral loading at service limit state that has reliability-based resistance factors applicable for future projects. 


\subsection{Objective, Hypothesis and Methodologies}

This research focuses on the reliability-based analysis of drilled shaft subjected to lateral loading, probabilistic characterize lateral load transfer models and contribute to the development of design procedure using LRFD. The objective of this work is to improve the design of drilled shaft subjected to lateral loading using LRFD in shale.

It is hypothesized that the proposed LRFD procedure for design of laterally loaded drilled shafts at the service limit state, with probabilistically calibrated resistance factors, more consistently achieves the target reliability than current AASHTO procedure that uses existing $p-y$ models and a resistance factor of 1.0. The resistance factors of drilled shafts subjected to lateral loading can be calibrated using reliability-based analyses and with the proposed lateral load transfer model. Therefore, a geotechnical engineer, with those resistance factors, can design the drilled shafts subjected to lateral loading using the proposed LRFD procedure and achieves some level of probability of failure, in which conventional procedure is not be able to perform.

In order to evaluate the hypothesis and establish a load and resistance factor design procedure (i.e., the objective) for drilled shafts subjected to lateral loading at service limit state, the following methodologies (Figure 1.1) are performed.

1) First of all, the lateral load transfer model is probabilistically characterized (as discussed in Chapter 5) for drilled shafts subjected to lateral loading in shale using experimental and predicted data (Chapters 3 and 4). 
2) Secondly, three interrelated processes to calibrate the associated resistance factors using reliability-based analysis are engaged. One, identifying the targeted probability of failure based on failure consequences. Two, quantifying variability in soil strength properties that are necessary for reliability-based analysis. Three, a sensitivity study was conducted to understand the deterministic and/or probabilistic characteristic of load and structural properties. Monte-Carlo simulation is performed to put together these three processes and calibrate the associated resistance factors for Service Limit State (Chapter 6).

3) Lastly, to improve the design of drilled shafts subjected to lateral loading, a proposed LRFD procedure for drilled shafts subjected to lateral loading at service limit state is established (Chapter 7) and then be evaluated by comparing with the AASHTO LRFD procedure and the Reliability-based Design (Chapter 8).

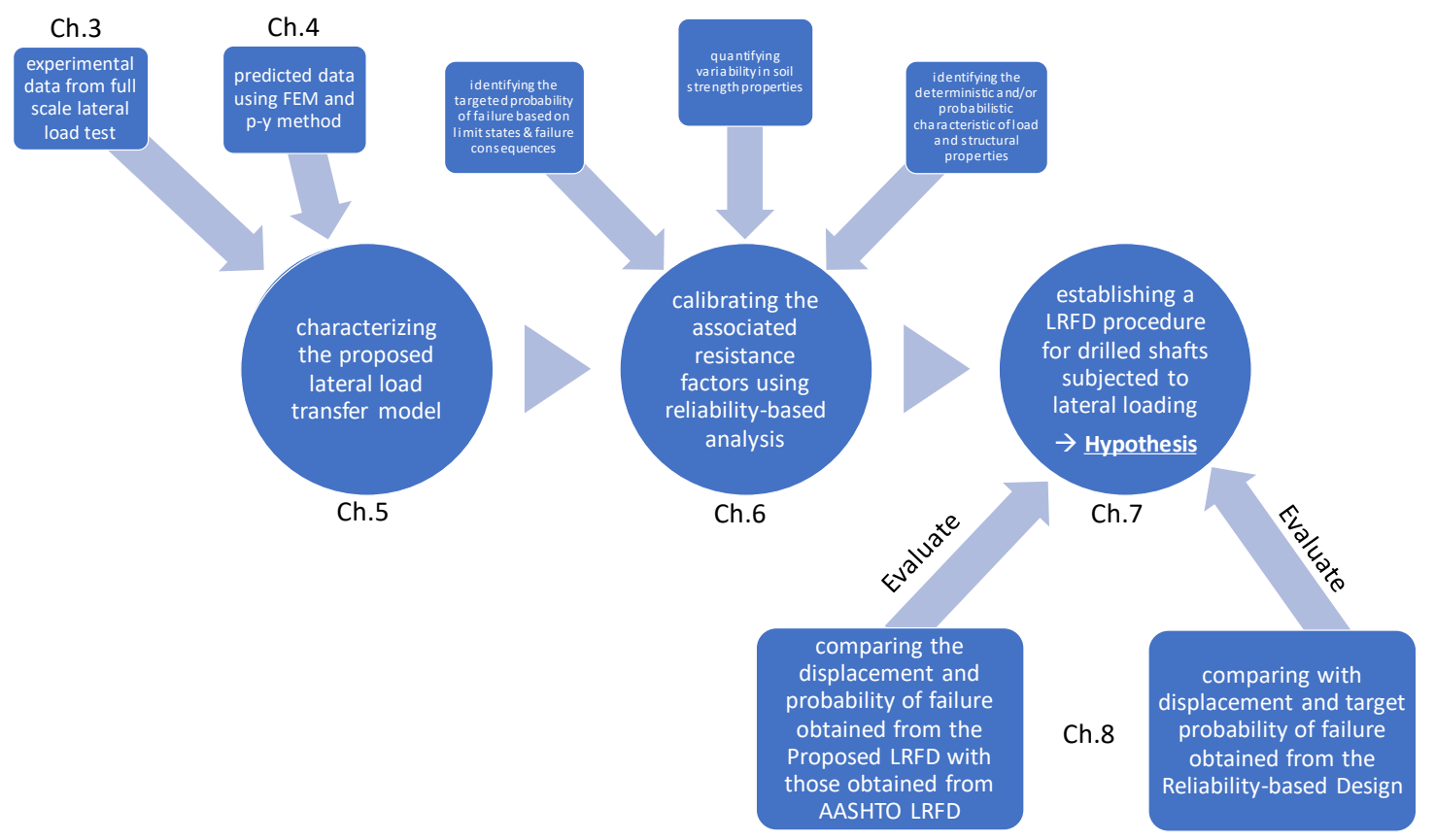

Figure 1.1 - Methodologies to evaluate Hypothesis 


\subsection{Organization of the Dissertation}

This document describes the work performed to evaluate the hypotheses and to develop an approach to improve the design for drilled shaft subjected to lateral loading using reliability-based analysis. The document is organized into nine chapters (Figure 1.2).

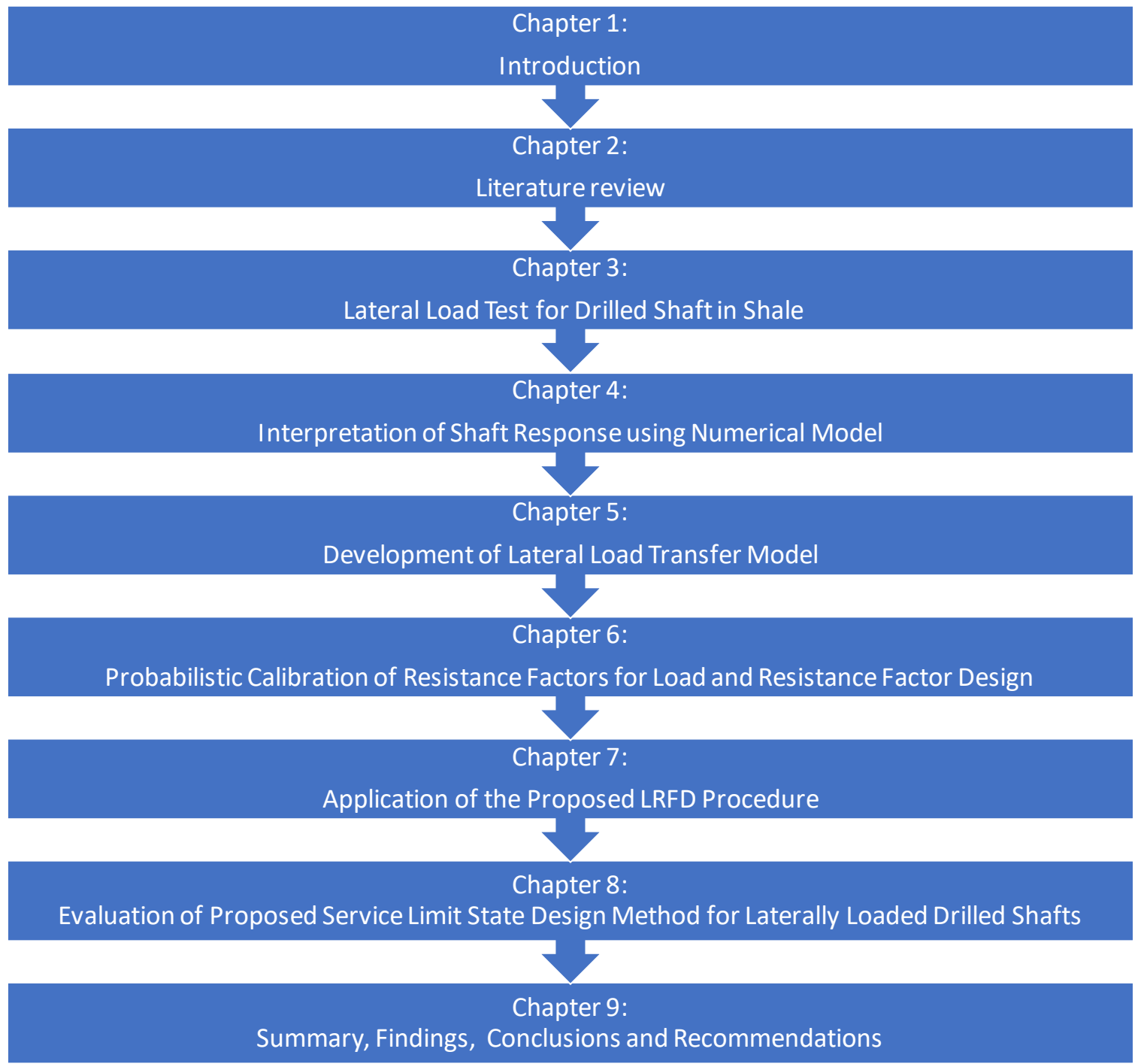

Figure 1.2 - Organization of the dissertation 
The dissertation starts with Chapter 1, which provides the background of load and resistance factor design for drilled shafts subjected to lateral loading at service limit state. The problem objective, hypotheses and processes of methodology are addressed. The organization of the dissertation is also discussed in this chapter.

A review of relevant literature is presented in Chapter 2. The chapter covers several methods used to develop deterministic prediction of drilled shafts responses under lateral loading and the choices involved in those methods. The chapter also provides some probabilistic tools available and several studies on resistance factors for laterally loaded drilled shafts.

Chapter 3 presents lateral load test for drilled shafts in shale. Site and subsurface conditions are introduced, as well as the field testing program and apparatus. Experimental results in terms of drilled shafts responses are interpreted from strain gage data and from shape acceleration array (SAA) data.

Chapter 4 presents the interpretation of shaft responses using numerical model. The $p-y$ method which can determine responses of a drilled shaft based on a lateral load transfer model is embedded. Modelling and computational program using finite element method are developed to predict the shaft responses, which are matching with experimental results.

The development of lateral load transfer model is presented in Chapter 5. This chapter covers the development of mathematical models for lateral load transfer curves in shale. 
Statistical analyses are conducted to determine load transfer curves' characteristics. The variation of the load transfer curves is also quantified and presented in this chapter. Also, an approach of modeling and generating lateral load transfer model was proposed. The proposed lateral load transfer model is evaluated with experimental test data and is compared with current lateral load transfer model using predicted shaft responses.

Chapter 6 presents probabilistic aspects of resistance factors calibration. The method using Monte-Carlo simulation is introduced in detail. A computer code is written for probabilistic analysis to calibrate the resistance factor for a drilled shaft subjected to lateral loading at service limit state.

Chapter 7 discusses a proposed LRFD design procedure for service limit state which makes use of the probabilistic calibrated resistance factors. This procedure can free LRFD drilled shaft under lateral loading design from case-by-case basis. A step-by-step procedure for the design is described with an illustrative example.

In Chapter 8, comparisons between the AASHTO LRFD method, the proposed LRFD method and the Reliability-based Design method for drilled shafts subjected to lateral loading at Service Limit State are performed to evaluate the proposed LRFP procedure.

Chapter 9 is the summary, findings, conclusion and practical implications of this dissertation. Recommendations for future research are also presented in this last chapter. 


\section{CHAPTER 2. LITERATURE REVIEW}

This chapter contains the background and basis for the research. Fundamentals of reliability-based analysis for load and resistance factor design (LRFD) will be discussed. This chapter also introduces several concepts, including LRFD limit states, target probability of failure, reliability index and factored strength versus factored resistance design approaches.

Several methods of deriving lateral load transfer curves from experimental measurements are covered, as well as the available lateral load transfer models using for shale. Probabilistic approaches for LRFD resistance factor calibration processes in service limit state (SLS) will be introduced. Finally, discussions of the current state of the art for load and resistance factor design for drilled shafts subjected to lateral loading are included.

\subsection{Allowable Stress Design (ASD) versus Load and Resistance Factor Design (LRFD)}

Geotechnical engineers recently have been working to transition from Allowable Stress Design (ASD) to Load and Resistance Factor Design (LRFD). Since 2007, the American Association of State Highway Administration Officials (AASHTO) has made utilization of LRFD mandatory on all federally-funded new bridge projects (AASHTO, 2007). In this section, basic definition and comparison between ASD and LRFD will be given. 


\subsubsection{Allowable Stress Design (ASD)}

Allowable Stress Design is a design philosophy used by civil engineers. The designer ensures that the anticipated stresses developed in a structure due to service loads do not exceed the allowable stress, which considers the elastic strength of materials only. To ensure that stresses remain within allowable stress, the use of Factors of Safety will be given. Alternative definition could be the load applied to structure does not exceed the allowable load or resistance as showing in the following equation:

$$
F_{S} Q \leq R
$$

Eq. 2.1

where: $\quad F_{S}=$ Factor of Safety

$$
\begin{aligned}
& Q=\text { Load } \\
& R=\text { Resistance }
\end{aligned}
$$

Several characteristics of ASD include:

- Factor of Safety $\left(F_{S}\right)$ based on experience and observed performance

- Simple, all uncertainty combined into a single factor

- Many years of empirical experience

- Does not include the estimation of failure probability, thus difficult to get a sense for probability of failure 


\subsubsection{Load and Resistance Factor Design (LRFD)}

Load and Resistance Factor Design (LRFD) replaces a single factor of safety with a set of partial safety factors (load and resistance factors) acting on individual components of load and resistance. In LRFD, force effects caused by factored loads are not permitted to exceed the factored resistance of the components. The general governing equation that can be applied to several different limit states using LRFD is as following:

$$
\sum n_{i} \gamma_{i} Q_{i} \leq \phi R_{n}=R_{r}
$$

Eq. 2.2

where: $\quad n_{i}=$ load modifier: a factor relating to ductility, redundancy, and operational classification

$$
\begin{aligned}
& \gamma_{i}=\text { load factor: a multiplier applied to force effects } \\
& Q_{i}=\text { nominal load } \\
& \phi=\text { resistance factor: a multiplier applied to nominal resistance } \\
& R_{n}=\text { nominal resistance } \\
& R_{r}=\text { factored resistance }\left(R_{r}=\phi R_{n}\right) .
\end{aligned}
$$

Several characteristics of LRFD include:

- Accounts for load and resistance uncertainties separately 
- Provides means to introduce reliability-based analyses benefits into geotechnical design. For instance, construction under low failure consequence (low risk) can be designed more efficiency and more economical than same construction under higher failure consequence problem. Another example is the advantage of increasing investigation effort.

\subsection{LRFD Limit States}

LRFD usually is separated into the Ultimate (or Strength) Limit State and the Service Limit State.

\subsubsection{LRFD Ultimate Limit State (ULS) or Strength Limit State}

Ultimate Limit States or Strength Limit States are limit states relating to strength and stability during the design life. ULS shall be taken to ensure that strength and stability, both local and global, are provided to resist the specified load combinations that a construction is expected to experience in its design life. The governing equation applied to Ultimate Limit State using LRFD is as following:

$$
\sum n_{u i} \gamma_{u i} Q_{u i} \leq \phi_{u} R_{n u}=R_{r u}
$$

Eq. 2.3

where: $\quad n_{u i}=$ ULS load modifier

$$
\gamma_{u i}=\text { ULS load factor }
$$




$$
\begin{aligned}
& Q_{u i}=\text { nominal load effect for a given ULS } \\
& \phi_{u}=\text { resistance factor for ULS } \\
& R_{n u}=\text { ULS nominal resistance } \\
& R_{r u}=\text { ULS factored resistance }\left(R_{r u}=\phi_{u} R_{n u}\right) .
\end{aligned}
$$

Design of foundations at ULS includes consideration of the nominal geotechnical and structural resistances of the foundation elements. Design at ULS does not consider the deformations required to mobilize the nominal resistance, unless a definition of failure based on deformation is specified.

The design of drilled shaft foundations at ULS also considers:

- Axial compression resistance for single drilled shafts,

- Shaft group compression resistance,

- Uplift resistance for single shafts,

- Uplift resistance for shaft groups,

- Single shaft and shaft group lateral resistance,

- Shaft punching failure into a weaker stratum below the bearing stratum, and

- Constructability, including method(s) of shaft construction. 


\subsection{2. $L R F D$ Service Limit State (SLS)}

Service Limit States are limit states relating to stress, deformation, and cracking under regular operating conditions. SLS shall be taken as restrictions on stress, deformation, and crack width under regular service conditions. The equation for LRFD at Service Limit State can be expressed as following:

$$
\sum n_{s i} \gamma_{s i} Q_{s i} \leq \phi_{s} R_{n s}=R_{r s}
$$

Eq. 2.4

where: $\quad n_{s i}=$ SLS load modifier

$$
\begin{aligned}
& \gamma_{s i}=\text { SLS load factor } \\
& Q_{s i}=\text { nominal load effect for a given SLS } \\
& \phi_{s}=\text { resistance factor for SLS } \\
& R_{n s}=\text { SLS nominal resistance } \\
& R_{r s}=\text { SLS factored resistance }\left(R_{r s}=\phi_{S} R_{n s}\right) .
\end{aligned}
$$

One aspect of foundation design at service limit state is foundation movements, which include all movements from settlement, horizontal movement and rotation. Considering of foundation movements is based on structure tolerance to total and differential movements, rideability and economy.

Different methods for addressing the service limit state using LRFD include factoring resistance, factoring strength, and factoring displacement methods. In factoring resistance method, the resistance factor which accounts for the uncertainty and 
variability is applied to geomaterial resistance parameters. In factoring strength method, the resistance factor is applied to structural strength parameters. In factoring displacement method, an overall resistance factor is applied directly to the unfactored displacement.

\subsection{Reliability-based Analysis for LRFD}

The transition from Allowable Stress Design (ASD) to Load and Resistance Factor Design (LRFD) follows an evident general trend. However, not all LRFD procedures are using reliability-based analysis. For instance, AASHTO 2007 specify that the resistance factors for LRFD of drilled shaft subjected to lateral loading are equal to 1.0, which means that reliability-based analyses for calibration of resistance factors have not been performed. Only the LRFD using reliability-based analysis might take all the advantages over the ASD, includes quantifying probability of failure, probabilistic calibrating resistance factors to account for uncertainty rationally and consistently.

\subsubsection{Probability of Failure and Reliability Index}

A limit state design must be based on a performance function. In a general form, performance function, denoted as $\mathrm{g}$, is the difference between the actual resistance and the actual load as:

$$
g=R-Q
$$


When the performance function $\mathrm{g}$ is equal to or less than zero, it defines an unsatisfactory performance in which load is higher than resistance; and g larger than zero indicates a satisfactory performance where load is smaller than resistance.

For reliability-based analyses, resistance $\mathrm{R}$ and load $\mathrm{Q}$ are probabilistic parameters and have their own distributions as shown in Figure 2.1a. The performance function $\mathrm{g}$, therefore, takes on a probability distribution as shown in Figure 2.1b. The overlap area under the two curves in Figure $2.1 \mathrm{a}$ is associated with the failure region (where performance function is equal to or less than zero in Figure 2.1b), which is the probability of failure of the design $\left(P_{f}\right)$. Another way to represent the probability that resistance is smaller than load effect is the using of reliability index $(\beta)$, which is the ratio between mean and standard deviation of the performance function, as shown in Figure $2.1 \mathrm{~b}$ using the following equation:

$$
\beta=\frac{\bar{u}}{\sigma}
$$

where: $\quad \beta=$ reliability index

$$
\begin{aligned}
& \bar{u}=\text { mean of the performance function } g \\
& \sigma=\text { standard deviation of the performance function } g
\end{aligned}
$$




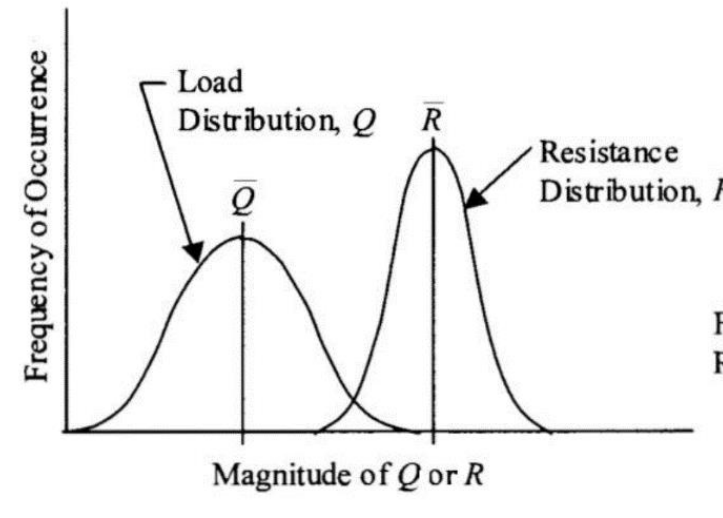

a) Frequency distributions for random values of $Q$ and $R$

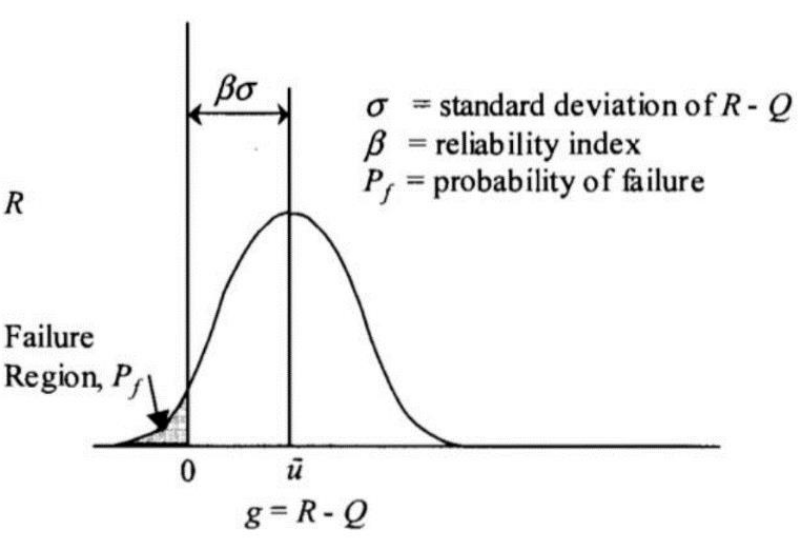

b) Distribution of limit state function values

Figure 2.1 - Probability of failure and reliability index (from Allen, 2005).

The relationship between probability of failure and reliability index depends on the distribution type of the variable (Allen, 2005). Probability of failure, $P_{f}$, directly as its name indicates, represents what the probability is for a limit state failure to happen. For instance, an SLS failure happens when the shaft head displacement under lateral loading is larger than the predefined allowable displacement. The reliability index $\beta$, on the other hand, is an indirect way of expressing probability of failure. The higher the reliability index is, the safer the design.

Based on the definition of probability of failure and reliability index, reliabilitybased analysis uses the target probability of failure or the target reliability index as a limit to ensure that probability of failure is equal or higher than the target probability of failure, or the reliability index is equal or less than the target reliability index. The target probability of failure for SLS usually is less than that for ULS and often lies in the range of $1 / 15$ to $1 / 150$. For SLS, the target reliability index is assigned from $1.5\left(P_{f}\right.$ of 0.067$)$ in Eurocode (Orr \& Farrell, 1999) to $2.6\left(P_{f}\right.$ of 0.0047$)$ (Phoon et al., 1995). Huaco et 
al. (2012) recommended four different values of target probability of failure from 0.01 to 0.04, for a drilled shaft at SLS for different bridge categories as presented in Table 2.1.

Table 2.1 - Target Probability of Failure for Service Limit State (Huaco et al. 2012)

\begin{tabular}{cc}
\hline Type/importance of structure & $P_{f}$ \\
\hline Bridges on Minor Roads & $1 / 25$ \\
Bridges on Major Roads & $1 / 50$ \\
Major Bridges (less than $\$ 100$ millions) & $1 / 75$ \\
Major Bridges (greater than $\$ 100$ millions) & $1 / 100$ \\
\hline
\end{tabular}

\subsubsection{Displacement-based Performance Function for Reliability-based Analyses}

For reliability-based analyses for SLS, the performance function using Eq. 2.5 is applied on displacement to produce the displacement-based performance function. In this research, the maximum displacement at top of the shaft produced from lateral loaded drilled shaft will be use as a performance function for reliability-based analyses. Using the displacement-based performance function distribution with the corresponding target probability of failure, the reliability-based displacement (factored displacement to achieve target probability of failure) can be obtained.

\subsubsection{Factoring Displacement, Factoring Parameter \& Factoring Resistance Methods}

According to Becker 1996, there are two approaches to applying resistance factor to achieve a certain level of probability for LRFD: 1) the factored resistance approach, in which an overall resistance factor is applied to the resistance for each applicable limit state; 2) the factored strength approach, in which partial factors are 
applied directly to only the strength parameters contributing to overall resistance for each applicable limit state (Becker, 1996).

Becker (1996) stated that the factored strength approach follows the original work of Brinch Hansen and the Danish Code where specified partial factors are applied to the individual soil strength properties of cohesion and internal friction prior to using them in the model or calculation for factored resistance. The approach has been used widely in Europe. On the other hand, in North America where the factored resistance approach is using extensively, the nominal resistance is firstly calculated using unfactored strength parameters, then it is multiplied by a single resistance factor to obtain the factored resistance for design.

In LRFD for service limit state, using either factored resistance or factored strength approach, different methods to calculate the factored displacement include: factoring displacement method; factoring parameter method and factoring resistance method.

Firstly, factoring displacement method is based on factored resistance approach in SLS. In this criterion, the overall resistance factor is applied directly to the unfactored maximum displacement. This overall resistance factor accounts for all the uncertainty and variability in resistance with the use similar to that of the factor of safety. In the use of the displacement-based performance function (Eq. 2.5) for SLS, the factored displacement is obtained using reliability-based analysis. The LRFD for SLS using factoring displacement method can be expressed as follows: 


$$
y^{*}=\phi_{y} * y \leq y_{a}
$$

Eq. 2.7

where: $\quad y=$ unfactored displacement calculated from nominal load

$$
\begin{aligned}
& \phi_{y}=\text { resistance factor applied to the unfactored displacement } \\
& y^{*}=\text { factored displacement } \\
& y_{a}=\text { allowable displacement }
\end{aligned}
$$

Secondly, factoring parameter method applies the resistance factor only to the partial geomaterial or structural strength parameters, which is similar to the factored strength approach. The geomaterial parameters can be cohesion, friction angle or uniaxial compressive strength (UCS). The structural strength parameters can be axial shaft stiffness or bending stiffness. The factored shaft resistance under nominal load produces factored displacement, which needs to be satisfied in service limit state by comparing with the allowable displacement.

Lastly, the factoring resistance method applies the resistance factor only to the lateral soil resistance, which contribute to the overall shaft resistance under lateral loading. The factored resistance under nominal load produces factored displacement, which will be compared with the allowable displacement to satisfy the service limit state condition. 
The factoring resistance method was chosen for use in this research. The SLS resistance factor is applied to the lateral soil resistance of the lateral load transfer model in order to obtain the factored lateral soil resistance for use in SLS design.

$$
p_{p-y}^{*}=\phi_{p-y} \times p_{p-y}
$$

Eq. 2.8

where:

$$
\begin{aligned}
& p_{p-y}=\text { lateral soil resistance } \\
& \phi_{p-y}=\text { resistance factor for SLS } \\
& p_{p-y}^{*}=\text { factored lateral soil resistance }
\end{aligned}
$$

Then using factored lateral soil resistance $\left(p_{p-y}^{*}\right)$ to compute the factored displacement $\left(y^{*}\right)$ at nominal load, the last step is to check the service limit state condition:

$$
y^{*} \leq y_{a}
$$

Eq. 2.9

\subsection{Methods for Developing p-y Curves from Experimental Measurements}

An elementary analytical model used for modeling the behavior of a laterallyloaded drilled shaft is the semi-infinite beam on a Winkler foundation. The model is defined on a coordinate system with origin at the ground elevation. The depth variable $z$ increases downward along the $z$-axis, which lateral displacement $y$ is measured along the y-axis (Figure 2.2) 


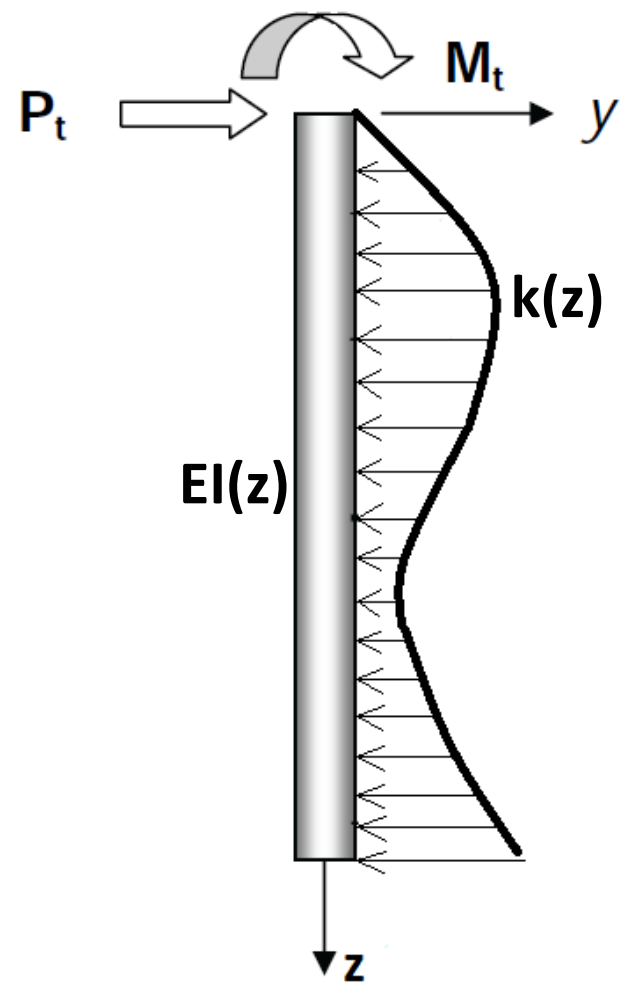

Figure 2.2 - Lateral loaded drilled shaft model, forces and reactions

The basic differential relationship from beam theory is expressed as:

$$
E I \frac{d^{4} y}{d z^{4}}+k y=0
$$

Eq. 2.10

where: $\quad E I=$ bending stiffness,

$$
k=\text { lateral soil stiffness }
$$

$y=f(z)=$ a continuous, differentiable function of depth.

Multiplying the second, third, and fourth derivative of this displacement function, respectively, by $E I$ yields functions for the moment $M$, shear $V$, and lateral reaction $p$, respectively: 


$$
M=E I \frac{d^{2} y}{d z^{2}}
$$

Eq. 2.11

$$
V=E I \frac{d^{3} y}{d z^{3}}
$$

$$
p=E I \frac{d^{4} y}{d z^{4}}
$$

Eq. 2.13

If both $E I$ and $k$ are constants, closed-form solutions to $\mathrm{Eq} .2 .10$ have been derived for a number of boundary conditions, including an applied point load and applied moment at the free end of a semi-infinite beam, which are of greatest interest in modeling a laterally-loaded pile, Hete'nyi (1946). However, more complicated problems involving lateral soil stiffness which is variable not only with depth, but also with displacement (non-linear soil stiffness), especially if combined with a non-constant El, do not have closed-form solutions available.

McClelland and Focht (1958) developed the concept of $p-y$ curves, in which the lateral soil reaction per unit length $\mathrm{p}$ is plotted versus the pile displacement $\mathrm{y}$ at discrete depths. Other important work on theoretical solutions and instrumentation was developed by Matlock et al. (1956), Matlock and Ripperger (1958), and Matlock and Reese (1962). The application of lateral load to a drilled shaft must result in some lateral deflection. This deflection causes a lateral soil reaction that acts in a direction opposite to the deflection. The magnitude of the lateral soil reaction along the length of the drilled 
shaft is a nonlinear function of the deflection, and the deflection is dependent on the lateral soil reaction. The "p-y" method is so named because the soil resistance is modeled as a nonlinear spring in which the force due to lateral soil resistance, $p$, develops as a function of deflection, $y$, and the relations between the two are represented as $p-y$ curves. In numerical modelling of drilled shaft subjected to lateral loading, $p-y$ curves are modeled as nonlinear springs attached at nodes along the length of the shaft to determine the lateral soil reaction (Figure 2.3).

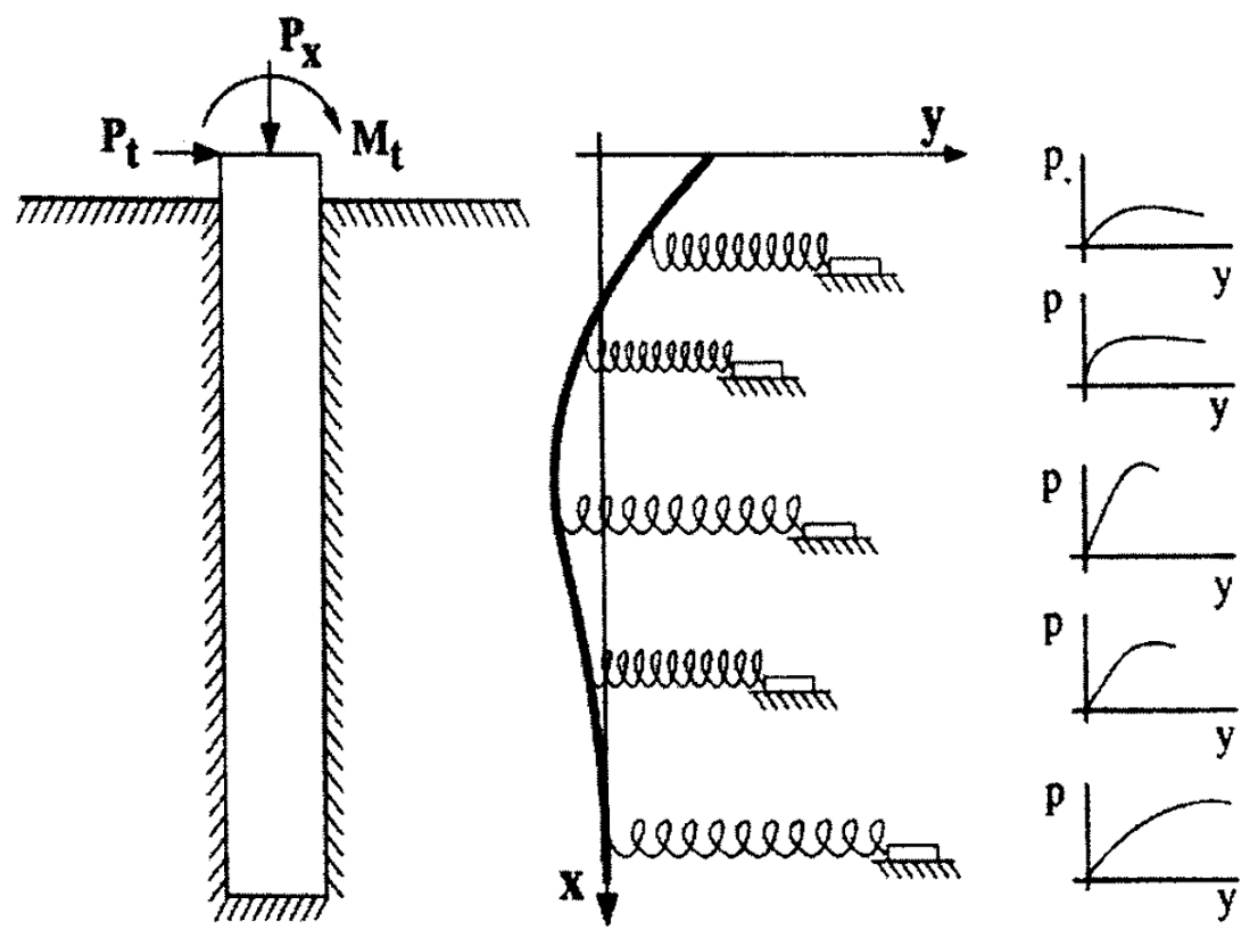

Figure 2.3 - Model of lateral loaded drilled shaft showing concept of $p-y$ curves

The $p$-y criteria are simply a means of associating the soil resistance mobilized as a nonlinear function of displacement at various points along a drilled shaft. Although there may exist a theoretical basis in many cases, the criteria used in design are empirical in that the final form of the models used are derived from experiments (instrumented 
load tests). Thus $p-y$ curves are most commonly derived from experimental measurements to be used in p-y analyses of lateral loaded drilled shaft.

For lateral load test, the typical experimental data includes strain gages measurements and pile displacement measurements. Several alternative approaches have been adopted for establishing $p-y$ curves from experimental measurements of the response of laterally loaded piles. The following sections describe these alternatives, along with their advantages and limitations.

\subsubsection{Deriving $p-y$ Curves from Direct Interpretation}

Typically, instrumentations are embedded in deep foundations, that are then tested laterally to ascertain behavior under lateral load. First, based on strain gage measurements, bending moment is derived from bending curvature using direct interpretation. Second, lateral displacement $(y)$ and lateral soil resistance $(p)$ are obtained by double integrating and double differentiating the bending moment as a function of depth, respectively. Finally, p-y curves are derived from lateral displacement (y) and lateral soil resistance $(p)$.

However, the sensitivity of high-order differentiation procedure to derive lateral soil resistance $(p)$ from bending moment will be the limitation. Double differentiation of discrete data points would result in amplification of measurement errors and consequently inaccurate lateral soil resistance. Moreover, strain gage instruments are located at discrete depths, which may not correspond to the points of inflection, 
maximum bending, p-y curves at specific locations, etc., which would be of greatest interest in characterizing the pile response to lateral load. Fitting of analytical curves to discrete data points is a method to cope with these limitations. Once an analytical function is curve-fit to the data, it may be used to investigate pile behavior and produce p-y curves at any depth.

\subsubsection{Deriving $p-y$ Curves from a Bending Moment Function}

Yang \& Liang (2007) summarized different techniques to minimize errors due to high-order differentiation. Those techniques assume a form of bending moment and try to fit with measured bending moment from strain gage measurements. Different techniques use different fitting procedures under different forms of bending moments. However, limitations are still present.

Piecewise cubic polynomial curve fitting technique by Matlock et al. (1956) and Dunnavant (1986) was employed to fit discrete moment data, which were interpreted from strain gage measurement, with bending moment function, which was assumed as a piecewise cubic polynomial. Then lateral displacement $(y)$ and lateral soil resistance $(p)$ are obtained respectively at any depth by double integrating and double differentiating the bending moment function. This technique provides reasonable results of deduced $p$ y curves but has some errors on predicted maximum moments (Yang \& Liang, 2007).

Fifth-order global polynomial curve fitting technique from Reese \& Welch (1975) and Wilson (1998) provides largest errors of deduced p-y curves and predicted maximum 
moments. Weighted residual technique by Wilson (1998) and smooth weighted residual technique by Yang et al. (2005) are not capable of producing reasonable soil resistance (p) versus depth profiles due to negative soil resistance and irregular spikes (Yang \& Liang, 2007).

\subsubsection{Deriving $p-y$ Curves from a Displacement Function}

Alternatively, instead of assuming form of bending moment (M), many authors have implemented curve fitting to experimental measurements using an assumption that the lateral displacement $(\mathrm{y})$ can be expressed as a function of depth (z) using appropriate equations. McVay et al. (2009) used the assumption that the displacement function can be approximated by a polynomial of sufficiently high-order as shown in Eq. 2.14. Displacement function then can be fitting with the measured displacements, which are obtained from inclinometer or shape acceleration array. The return values are polynomial coefficients $a_{i}$

$$
y=f(z)=\sum_{i=0}^{m} a_{i} z^{i}
$$

Eq. 2.14

where: $\quad y=$ displacement function of depth $z$

$$
\begin{aligned}
& m=\text { order of the displacement polynomial } \\
& a_{i}=\text { polynomial coefficient }
\end{aligned}
$$

However, one disadvantage is that subsequent derivatives of the polynomial function geometrically compound any errors in the original curve-fit. Taking the fourth 
derivative of lateral displacement $(y)$ equation can result in irrationality when plugged back into Eq. 2.10. To overcome this, Sinnerich et al. (2014) added exponential and trigonometric components to the polynomial displacement function for better representation of lateral displacement $(y)$ and better fitting with different sources of measured data. The displacement function to derive $p-y$ curves according to Sinnerich et al. (2014) is presented in Eq. 2.15. After the fitting process, polynomial coefficients $a_{i}$ and trigonometric component $\lambda$ will be returned. However, misrepresentation of some measured data points can lead to significant changes of $a_{i}$ and $\lambda$ and therefore misinterpretation of the derived $p-y$ curves.

$$
y=f(z)=e^{-\lambda} \sum_{i=0}^{m} a_{i} z^{i}
$$

Eq. 2.15

where: $\quad y=$ displacement function of depth $z$

$$
\begin{aligned}
& m=\text { order of the displacement polynomial } \\
& a_{i}=\text { polynomial coefficient } \\
& \lambda=\text { trigonometric component }
\end{aligned}
$$

\subsubsection{Deriving p-y Curves from Optimizing a Lateral Load Transfer Model}

As one possible alternative, Brown et al. (1994) proposed refining assumed p-y curves by optimizing the input parameters of a computer model until the model output matches inclinometer data. In this approach, first, a p-y model is assumed. Second, using that $p-y$ model to predict the displacement profile along the shaft. Then, geomaterial 
strength parameters of assumed $\mathrm{p}-\mathrm{y}$ model are optimized by fitting the predicted displacement with the measured displacement obtained from inclinometer. Lastly, an assumed $p-y$ model and optimized geomaterial strength parameters are used to derive the $p-y$ curves. Limitation includes the optimized $p-y$ curve is assumed from theoretical $p$ y curve criteria (e.g., Matlock (1970), Reese et al. (1974), Reese and Welch (1975)) thus it might work with small lateral deflection but might not with large deflection and vice versa. Besides, this inverse approach makes indirect use of the inclinometer data but does not include other potential data sources such as strain gages.

Overall, limitations of all the literature approaches include the sensitivity of second-order differentiation of discrete bending moment data points or bending moment fitting function as well as of forth-order differentiation of displacement fitting function would result in amplification of measurement errors and consequently inaccurate lateral soil resistance. The approach proposed by Brown et al. (1994) overcomes this limitation but has a disadvantage of dependence on the theoretical $p-y$ curve and optimized geomaterial strength parameters do not cover all different ranges of lateral deflection at a time.

Since all the literature approaches for deriving $p-y$ curves from experimental measurements have disadvantages as discussed earlier, a more advanced approach is necessary in order to be able to derive accurate $p-y$ responses from experimental data. 


\subsection{Existing Lateral Load Transfer Models}

The experimental p-y curves discussed in Section 2.4 play an important role in probabilistic characterizing lateral load transfer models. This section provides an overview of existing $p-y$ models used for design of drilled shafts subjected to lateral loads in shale or stiff clay. The advantages and comparison between the existing and the proposed lateral load transfer models will be presented more details in Chapter 5.

\subsubsection{Reese's Stiff Clay with No Free Water (1972)}

A lateral-load test was performed at a site in Houston to develop both the static and cyclic $p-y$ curves. The experiments and the interpretations are discussed by Welch and Reese (1972) and Reese and Welch (1975). The p-y curves at this site were relatively regular in shape and yielded to an analysis that allowed the increase in deflection due to cyclic loading to be formulated in terms of the stress level and the number of loading cycles. Thus, the analyst can specify a number of loading cycles in doing the computations for a particular design.

The following procedure to derive $p-y$ curves is for short-term static loading and is illustrated in Figure 2.4.

1. Compute points describing the $p-y$ curve from the following relationship:

$$
\frac{p}{P_{u l t}}=0.5\left(\frac{y}{y_{50}}\right)^{0.25}
$$

Eq. 2.16 
2. Compute the ultimate soil resistance $P_{\text {ult }}$ per unit length of pile using the smaller of the values given by those two equations below (the shear strength is taken as the average from the ground surface to the depth being considered and $J$ is taken as 0.5)

$$
\begin{gathered}
P_{u l t}=\left[3+\frac{\gamma^{\prime}}{c} z+\frac{J}{b} z\right] c b \\
P_{u l t}=9 c b
\end{gathered}
$$

Eq. 2.18

3. Compute the deflection $y_{50}$ at one-half of the ultimate soil resistance from following equation:

$$
y_{50}=2.5 \varepsilon_{50} b
$$

4. Beyond $y=16 y_{50}, p$ is equal to $P_{\text {ult }}$ for all values of $y$.

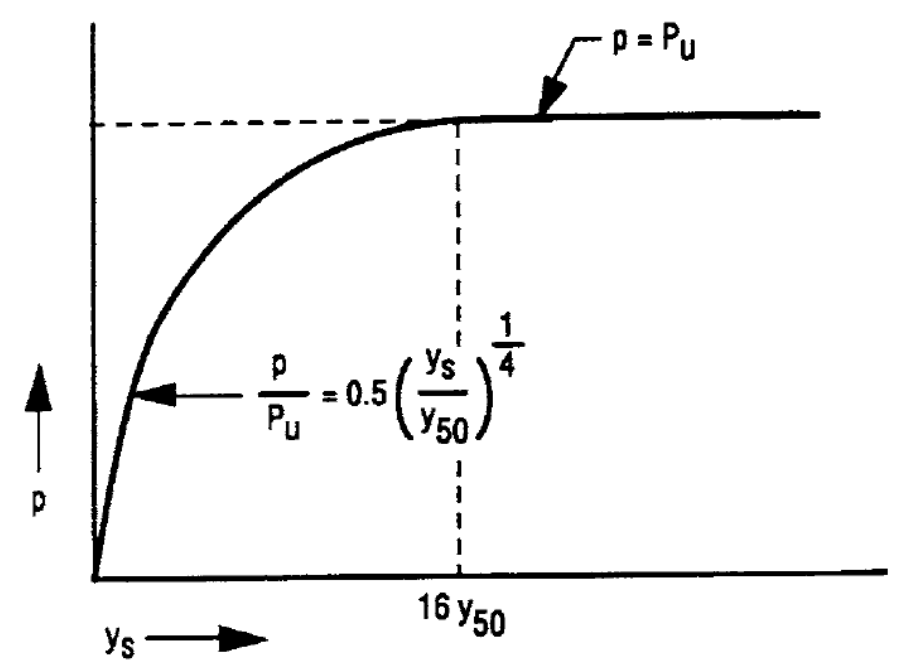

Figure 2.4 - p-y curve for static loading in stiff clay with no free water (Reese's 1972). 


\subsubsection{Reese's Interim Recommendations for $p$-y Curves for Weak Rock (1997)}

The p-y curve shown in Figure 2.5 is characteristic of the family representing the behavior of weak rock. The $\mathrm{p}-\mathrm{y}$ model is formed in three segments: one for $y \leq y_{A}$, another for $y \geq y_{A}, p \leq P_{u r}$, and a third for $p=P_{u r}$. With guidelines for computing the ultimate resistance $P_{u r}$ and the initial modulus $K_{i r}$ (Reese 1997), the equations for the three segments to derive $p-y$ curves for weak rock can be computed as following:

$$
p=K_{\text {ir }} y \text { for } y \leq y_{A}
$$

Eq. 2.20

$$
p=\frac{P_{u r}}{2}\left(\frac{y}{y_{r m}}\right)^{0.25} \text { for } y \geq y_{A} ; p \leq P_{u r}
$$

$$
p=P_{u r}
$$

where: $\quad y_{r m}=k_{r m} b$

$$
\begin{aligned}
& k_{r m}=\text { a constant ranging from } 0.00005 \text { to } 0.0005 \\
& b=\text { diameter of the pile } \\
& y_{A}=\left(\frac{P_{u r}}{2\left(y_{m}\right)^{0.25} k_{\text {ir }}}\right)^{1.333}
\end{aligned}
$$




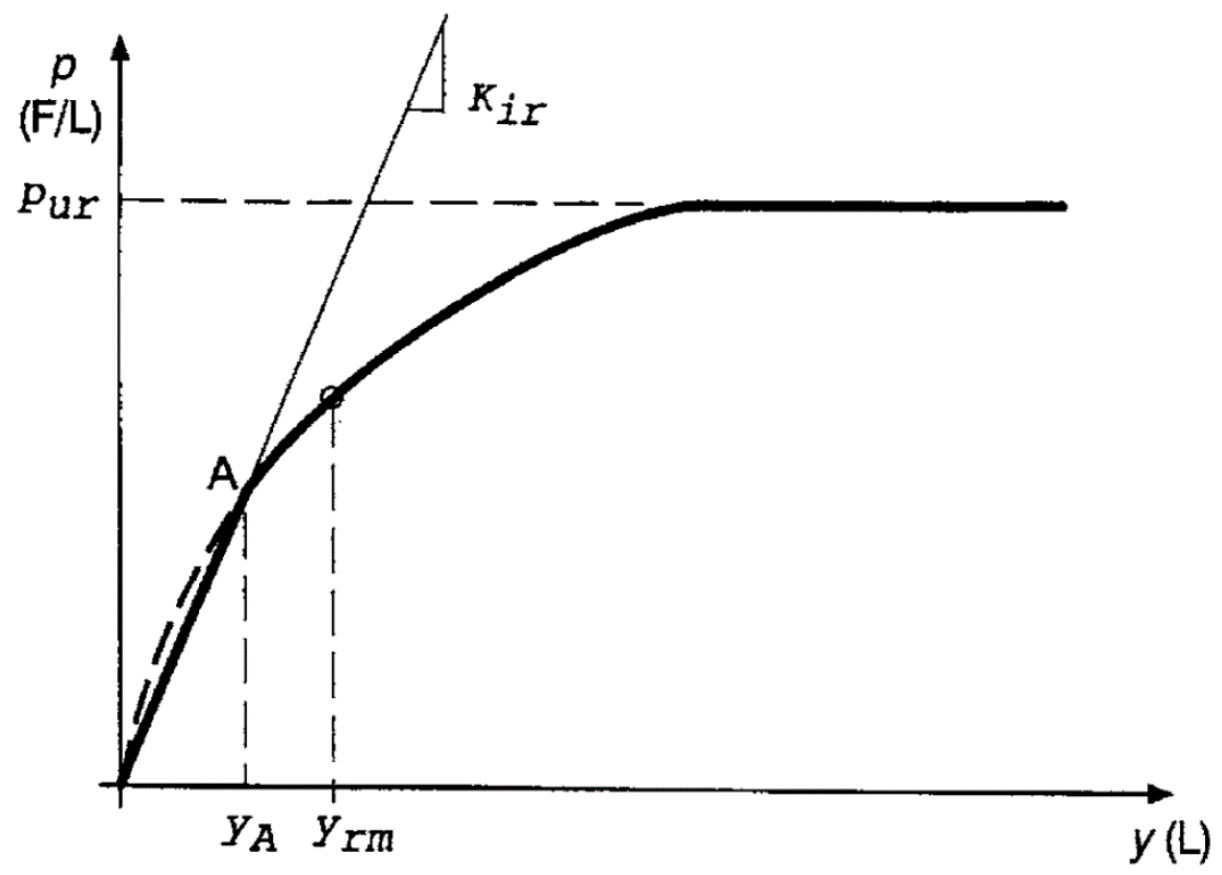

Figure 2.5 - p-y curve for weak rock (Reese, 1997).

The expression for the ultimate resistance $P_{u r}$ (Reese 1997) for rock is derived from the mechanics for the ultimate resistance of a wedge of rock at its surface.

$$
P_{u r}=\alpha_{r} q_{u r} b\left(1+1.4 \frac{z_{r}}{b}\right) \quad \text { for } 0 \leq z_{r} \leq 3 b
$$

Eq. 2.23

$$
P_{u r}=5.2 \alpha_{r} q_{u r} b \quad \text { for } z_{r}>3 b
$$

Eq. 2.24

where: $\quad q_{u r} \quad=$ compressive strength of the rock, usually lower-bound, as a function of depth,

$$
\begin{aligned}
& \alpha_{r} \quad=\text { strength reduction factor }, \\
& b \quad=\text { diameter of the pile, and }
\end{aligned}
$$


$z_{r} \quad=$ depth below the rock surface.

The initial modulus $K_{\text {ir }}$ may be shown to have the following value:

$$
K_{i r} \cong k_{\text {ir }} E_{\text {ir }}
$$

Eq. 2.25

where: $\quad E_{\text {ir }} \quad=$ initial modulus of the rock, and

$k_{\text {ir }} \quad=$ dimensionless constant, calculated as following:

$$
\begin{gathered}
k_{i r}=\left(100+\frac{400 z_{r}}{3 b}\right) \text { for } 0 \leq z_{r} \leq 3 b \\
k_{i r}=500 \text { for } z_{r}>3 b
\end{gathered}
$$

\subsubsection{KDOT's p-y Curve for Sandstone and Sandy Shale (1987)}

The Kansas Department of Transportation published a report in 1987 that documented p-y curves from a series of lateral load tests of 8-in. piles installed in weak rock at four sites in the Kansas City area. Based on the results for shallow depths (up to 2 $\mathrm{ft}$ ), the authors recommended a lateral load transfer model (Figure 2.6) with an initial linear region, a less steep linear transition region, and a constant ultimate region. The initial stiffness was defined as 80 times the undrained strength of the material (consistent units), and the ultimate resistance was defined as the diameter of the pile times the undrained strength (also consistent units). 


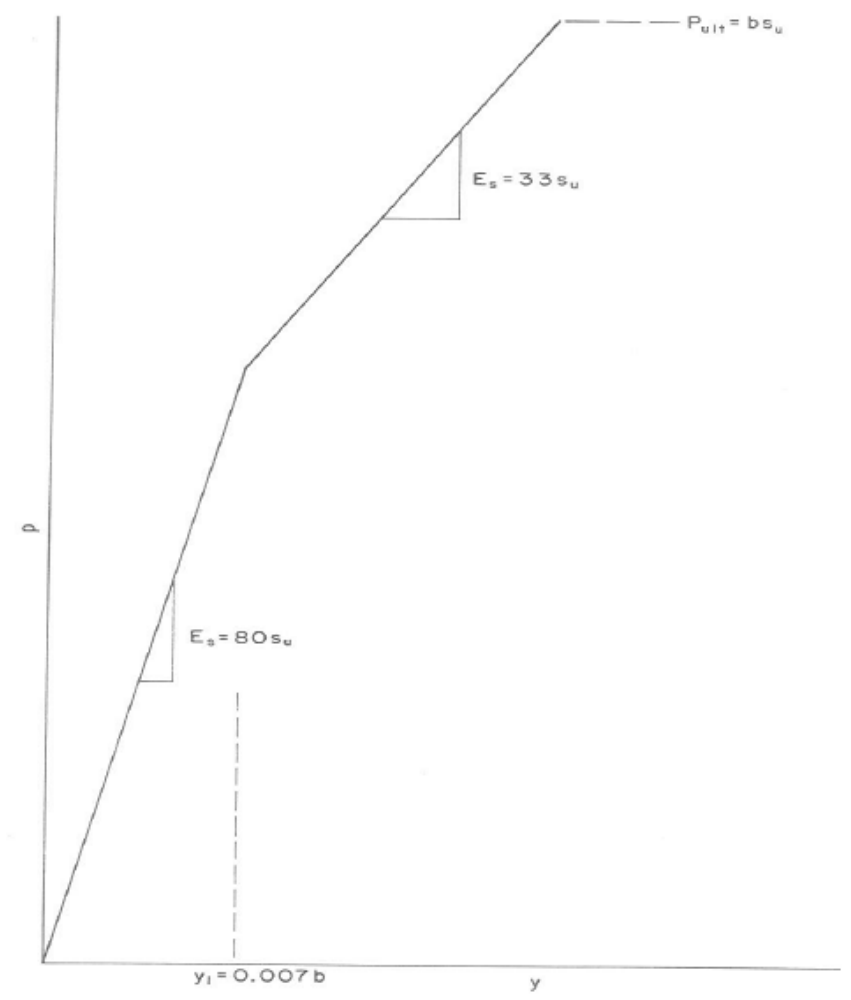

Figure 2.6 - p-y curve for Sandstone and Sandy Shale (KDOT, 1987)

Following procedure to derive $p-y$ curves for sandstone and sandy shale using the ultimate soil response $\boldsymbol{P}_{\boldsymbol{u l t}}$ and soil modulus $\boldsymbol{E}_{\boldsymbol{s}}$ :

$$
p=E_{s-1} * y \text { for } y \leq y_{1}
$$

Eq. 2.26

$$
p=E_{s-2} * y \text { for } y \geq y_{1} ; p \leq P_{u l t}
$$

$$
p=P_{u l t}=b * s_{u}
$$

Eq. 2.28

where: $\quad y_{1}=0.007 b$ in which $b=$ diameter of the pile

$$
\begin{aligned}
& E_{s-1}=80 * s_{u} \text { in which } s_{u}=\text { undrained shear strength } \\
& E_{s-1}=33 * s_{u}
\end{aligned}
$$




\subsection{Probabilistic Approaches for LRFD Calibration and Reliability-Based Design}

Several probabilistic approaches often are used in reliability-based design and in the LRFD resistance factor calibration process. The most frequently used methods are the First Order Second Moment (FOSM) method, the First Order Reliability Method (FORM), and the Monte Carlo Simulation method. Details about the methods have been discussed in the literature (Ang \& Tang, 2004; Baecher \& Christian, 2003; Griffiths \& Fenton, 2007; Harr, 1987). Brief descriptions of the methods follow.

\subsubsection{First Order Second Moment (FOSM) Method}

The FOSM is an approximate method (Baecher and Christian, 2003) based on Taylor series expansion of a performance function, g (Eq. 2.5). Several steps are involved in the method. The first step is to find mean values, variances, correlation coefficients and auto correlation lengths of all probabilistic input variables. After computing the expected value of the performance function $E[g]$, find the partial derivatives of the function with respect to the variables. This step usually employs some form of numerical differencing. The contributions of each variable to the systematic and spatial variance for the performance function are calculated next. The last step is to compute the variance in the performance function, and based on the variance, to compute the reliability index $\beta$, using the following equation:

$$
\beta=\frac{E[g]-1}{\sigma_{g}}
$$

Eq. 2.29 
where: $\quad E[g]=$ expected value of the performance function

$\sigma_{g} \quad=$ spatial variance for the performance function

\subsubsection{First Order Reliability Method (FORM)}

The first order reliability method (FORM) is a linear approximation of a limit state (Phoon et al., 2003; Phoon, 2008). It utilizes a performance function $g$ that is defined to be zero at the limit state. The approach is based on assumptions that all input parameters are normally distributed, and that the limit state also is a normally distributed variable. The approach requires transforming the original random variables into independent, standard normal variables. Then an approximate linear limit state function is used instead of the actual limit state function. The nearest point from the origin to the approximate linear limit state function is the most likely failure point and is called "the design point." In the new standard space, a reliability index is determined by the distance from the origin to the design point.

\subsubsection{Monte Carlo Simulation Method}

The Monte Carlo simulation method utilizes random number simulation to calculate probability density function values (Baecher and Christian, 2003; Harr, 1995). The inputs for a simulation process for a variable are its mean value, standard deviation or coefficient of variation (COV), and type of distribution. In the Monte Carlo simulation method, any input can be set as a probabilistic variable as long as its mean value, standard of deviation or COV, and distribution function type are provided. The major disadvantage 
is that the results converge slowly. However, according to Baecher and Christian (2003), the Monte Carlo technique has the advantage that it is relatively easy to implement on a computer and can deal with a wide range of functions. Besides, Monte Carlo technique does not restrict the types of distributions that can be used for inputs, or the distribution of the output like is assumed for FOSM and FORM. The method is flexible and is gaining popular use in geotechnical reliability-based design. More detailed descriptions about the Monte Carlo approach are in Chapter 6.

The first order second moment and the first order reliability method cannot be used with different types of variable distributions. Also, these usually provide some 'first order' approximates. The Monte Carlo simulation method is flexible and rigorous, and if enough simulations are generated, the results approach exact solutions; however, the drawback is that it requires a large number of simulations for the results to converge. Despite the heaviness of its calculation, Monte-Carlo is still chosen in this research for probabilistic analyses. 


\subsection{Methods for designing drilled shafts subjected to lateral loading}

Several methods for designing drilled shafts subjected to lateral loading have been described in the literature, which include Allowable Stress Design, LRFD Bridge Design Specifications (AASHTO 2007) and LRFD Design Methods (FHWA 2010). Details follow.

\subsubsection{Allowable Stress Design}

All structural and foundation design approaches have one common objective: structural safety. The Allowable Stress Design approach to provide adequate safety of foundations has been to apply a global factor of safety. For design of drilled shafts subjected to lateral loading using Allowable Stress Design at strength limit state, the design load needs to be smaller than the allowable load, which is equal to the ultimate capacity of the shaft divided by the Factor of Safety, as presented in the following equation:

$$
Q_{\text {design }} \leq Q_{\text {allow }}=\frac{Q_{\text {ultimate }}}{F S}
$$

Eq. 2.30

where: $\quad Q_{\text {design }}=$ design lateral load applied to the drilled shaft

$$
\begin{aligned}
& Q_{\text {allow }}=\text { allowable load } \\
& Q_{\text {ultimate }}=\text { ultimate load capacity } \\
& F S=\text { global factor of safety. } F S \geq 1.0
\end{aligned}
$$


Different design code uses different values of $F S$ for Allowable Stress Design at strength limit state. For instance, 2012 International Building Code (IBC, 2012) uses the following FS as presented in Table 2.2.

Table 2.2 - Minimum factors of safety for ASD foundation design (IBC, 2012)

\begin{tabular}{|c|c|c|c|c|}
\hline \multirow[t]{2}{*}{ Load Group } & \multirow[t]{2}{*}{ Method } & \multicolumn{3}{|c|}{$\begin{array}{l}\text { *Minimum Geotechnical Factor } \\
\text { of Safety, FS }\end{array}$} \\
\hline & & $\begin{array}{l}\text { Spread } \\
\text { Footings }\end{array}$ & Shafts & Piles \\
\hline \multirow{6}{*}{$\begin{array}{l}\text { ASD (un- } \\
\text { factored DL+ } \\
\text { LL, or service } \\
\text { load level) }\end{array}$} & $\begin{array}{l}\text { Static shear strength analysis from soil/rock properties, } \\
\text { (compression) }\end{array}$ & 3.0 & 2.5 & 2.5 \\
\hline & Static analysis from soil/rock properties, (uplift) & & 3.0 & 3.0 \\
\hline & $\begin{array}{l}\text { Load test conducted (number of tests } \\
\text { depends on uniformity of conditions) }\end{array}$ & & 2.0 & 2.0 \\
\hline & FHWA Gates Equation driving formula & & & 3.0 \\
\hline & Wave Equation & & & 2.5 \\
\hline & $\begin{array}{l}\text { PDA with CAPWAP (min. one per pier and } 2 \text { to } 5 \% \text { of the } \\
\text { piles }\end{array}$ & & & 2.25 \\
\hline
\end{tabular}

For design of drilled shafts subjected to lateral loading using Allowable Stress Design at serviceability limit state, the maximum displacement at design load needs to be smaller than the allowable displacement, which is equal to the ultimate displacement since the Factor of Safety is equal to 1.0. ASD in serviceability limit state is presented in the following equation:

$$
y_{\text {design }} \leq y_{\text {allow }}=\frac{y_{\text {ultimate }}}{F S}=y_{\text {ultimate }}
$$

Eq. 2.31

where: $\quad y_{\text {design }}=$ maximum displacement of drilled shaft under design lateral load 


$$
\begin{aligned}
& y_{\text {allow }}=\text { allowable displacement } \\
& y_{\text {ultimate }}=\text { ultimate displacement } \\
& F S=\text { global factor of safety. } F S=1.0 \text { for serviceability limit state }
\end{aligned}
$$

\subsubsection{LRFD Bridge Design Specifications (AASHTO 2007)}

Pile foundations are subjected to lateral loads due to wind, traffic loads, bridge curvature, stream flow, vessel or traffic impact and earthquake. Batter piles are sometimes used but they are somewhat more expensive than vertical piles and vertical piles are more effective against dynamic loads. The design for lateral loaded drilled shafts subjected to lateral loading needs to satisfy both strength and service limit states. For strength limit state, it is required that structural capacity exceed the combined factored axial load and moment. For service limit state, shaft deformation is required to be less than allowable value. The design should ensure that strength limit state considerations are satisfied before checking service limit state considerations.

Methods of analysis that use manual computation were developed by Broms (1964a and 1964b). They are discussed in detail by Hannigan et al. (2006). Reese developed analysis methods that model the horizontal soil resistance using $p$-y curves. This analysis has been well developed and software is available for analyzing single piles and pile groups (Reese, 1986; Williams et al., 2003; and Hannigan et al., 2006). 
When strength limit state is performed, the loads are factored for different load combination and limit state. Load factors can be found from Table 2.3 and Table 2.4. The resistances as represented by horizontal geotechnical resistance of single shaft or shaft group are factored using resistance factor presented in Table 2.5. For lateral loaded drilled shafts subjected to lateral loading at strength limit state, resistance factor is equal to 1.0. When service limit state is performed, the loads are equal to nominal loads since all the load factors are equal to 1.0, according to Table 2.3. According to Section 10.5.5.1 in AASHTO, 2007, resistance factors for the service limit states shall be taken as 1.0. Thus, shaft deformation obtained using nominal loads needs to be less than allowable value, without multiplying to the resistance factors.

Table 2.3 - Load combinations and load factors (after AASHTO 2007, Table 3.4.1-1)

\begin{tabular}{|c|c|c|c|c|c|c|c|c|c|c|c|c|c|}
\hline \multirow{2}{*}{$\begin{array}{c}\text { Load } \\
\text { Combination } \\
\text { Limit State } \\
\end{array}$} & \multirow[b]{2}{*}{$P L$} & \multirow[b]{2}{*}{$L L$} & \multirow[b]{2}{*}{$W A$} & \multirow[b]{2}{*}{$W S$} & \multirow[b]{2}{*}{$W L$} & \multirow[b]{2}{*}{$F R$} & \multirow[b]{2}{*}{$T C S$} & \multirow[b]{2}{*}{$T G$} & \multirow[b]{2}{*}{$S E$} & \multicolumn{4}{|c|}{ Use one of these at a time } \\
\hline & & & & & & & & & & $E Q$ & $I C$ & $C T$ & $C V$ \\
\hline Strength I & $\gamma_{\mathrm{p}}$ & 1.75 & 1.00 & - & - & 1.00 & $0.50 / 1.20$ & $\gamma_{\mathrm{TG}}$ & $\gamma_{\mathrm{SE}}$ & - & - & - & - \\
\hline Strength II & $\gamma_{\mathrm{p}}$ & 1.35 & 1.00 & - & - & 1.00 & $0.50 / 1.20$ & $\gamma_{\mathrm{TG}}$ & $\gamma_{\mathrm{SE}}$ & - & - & - & - \\
\hline Strength III & $\gamma_{p}$ & - & 1.00 & 1.40 & - & 1.00 & $0.50 / 1.20$ & $\gamma_{\mathrm{TG}}$ & $\gamma_{\mathrm{SE}}$ & - & - & - & - \\
\hline Strength IV & $\gamma_{p}$ & - & 1.00 & - & - & 1.00 & $0.50 / 1.20$ & - & - & - & - & - & - \\
\hline Strength V & $\gamma_{\mathrm{p}}$ & 1.35 & 1.00 & 0.40 & 1.00 & 1.00 & $0.50 / 1.20$ & $\gamma_{\mathrm{TG}}$ & $\gamma_{\mathrm{SE}}$ & - & - & - & - \\
\hline Extreme Event I & $\gamma_{p}$ & $\gamma_{\mathrm{EQ}}$ & 1.00 & - & - & 1.00 & - & - & - & 1.00 & - & - & - \\
\hline Extreme Event II & $\gamma_{p}$ & 0.50 & 1.00 & - & - & 1.00 & - & - & - & - & 1.00 & 1.00 & 1.00 \\
\hline Service I & 1.00 & 1.00 & 1.00 & 0.30 & 1.00 & 1.00 & $1.00 / 1.20$ & $\gamma_{\mathrm{TG}}$ & $\gamma_{\mathrm{SE}}$ & - & - & - & - \\
\hline Service II & 1.00 & 1.30 & 1.00 & - & - & 1.00 & $1.00 / 1.20$ & - & - & - & - & - & - \\
\hline Service III & 1.00 & 0.80 & 1.00 & - & - & 1.00 & $1.00 / 1.20$ & $\gamma_{\mathrm{TG}}$ & $\gamma_{\mathrm{SE}}$ & - & - & - & - \\
\hline Service IV & 1.00 & - & 1.00 & 0.70 & - & 1.00 & $1.00 / 1.20$ & - & 1.00 & - & - & - & - \\
\hline Fatigue & - & 0.75 & - & - & - & - & - & - & - & - & - & - & - \\
\hline permal & & & & & $W L$ & & $\mathrm{n}$ live lo & & & $E Q$ & & ? & \\
\hline live loa & & & & & $F R$ & fric & & & & $I C$ & & & \\
\hline water lo & and & ream & ess & & $T G$ & tem & erature & Ien & & $C T$ & & cular & \\
\hline wind lo & on str & ucture & & & $S E$ & settl & ement & & & $C V$ & ves & el coll & \\
\hline
\end{tabular}


Table 2.4 - Load factors for permanent loads $\gamma_{p}$ (after AASHTO 2007, Table 3.4.1-2)

\begin{tabular}{|l|c|c|}
\hline \multicolumn{1}{|c|}{ Type of Load } & \multicolumn{2}{c|}{ Load Factor, $\gamma_{\mathbf{p}}$} \\
\cline { 2 - 3 } & Maximum & Minimum \\
\hline$D C:$ Components and Attachments & 1.25 & 0.90 \\
$D C:$ Strength IV only & 1.50 & 0.90 \\
\hline$D D:$ Downdrag & 1.25 & 0.35 \\
\hline$D W:$ Wearing surfaces and utilities & 1.50 & 0.65 \\
\hline$E H:$ Horizontal earth pressure & & \\
Active & 1.50 & 0.90 \\
\hline At-Rest & 1.35 & 0.90 \\
\hline$E L:$ Locked-in stresses & 1.00 & 1.00 \\
\hline$E V:$ Vertical earth pressure & & \\
Overall stability & 1.00 & N/A \\
Retaining walls and abutments & 1.35 & 1.00 \\
Rigid buried structure & 1.30 & 0.90 \\
\hline Rigid frames & 1.35 & 0.90 \\
Flexible buried structures other than metal box culverts & 1.95 & 0.90 \\
\hline Flexible metal box culverts & 1.50 & 0.90 \\
\hline$E S:$ Earth surcharge & 1.50 & 0.75 \\
\hline
\end{tabular}


Table 2.5 - Resistance Factors for Geotechnical Resistance of Drilled Shafts

(after AASHTO 2007, Table 10.5.5.2.4-1)

\begin{tabular}{|c|c|c|c|}
\hline \multicolumn{3}{|c|}{ Method/Soil/Condition } & Resistance Factor \\
\hline \multirow{9}{*}{$\begin{array}{l}\text { Nominal } \\
\text { Axial } \\
\text { Compressive } \\
\text { Resistance } \\
\text { of Single- } \\
\text { Drilled } \\
\text { Shafts, } \varphi_{\text {stat }}\end{array}$} & Side resistance in clay & $\begin{array}{l}\alpha \text {-method } \\
\text { (Brown et al., 2010) }\end{array}$ & 0.45 \\
\hline & Tip resistance in clay & $\begin{array}{l}\text { Total Stress } \\
\text { (Brown et al., 2010) }\end{array}$ & 0.40 \\
\hline & Side resistance in sand & $\begin{array}{l}\beta \text {-method } \\
\text { (Brown et al., 2010) }\end{array}$ & 0.55 \\
\hline & Tip resistance in sand & Brown et al. (2010) & 0.50 \\
\hline & $\begin{array}{l}\text { Side resistance in } \\
\text { cohesive }\end{array}$ & Brown et al. (2010) & 0.60 \\
\hline & $\begin{array}{l}\text { Tip resistance in } \\
\text { cohesive }\end{array}$ & Brown et al. (2010) & 0.55 \\
\hline & Side resistance in rock & $\begin{array}{l}\text { Kulhawy et al. (2005) } \\
\text { Brown et al. (2010) }\end{array}$ & 0.55 \\
\hline & Side resistance in rock & Carter and Kulhawy (1988) & 0.50 \\
\hline & Tip resistance in rock & $\begin{array}{l}\text { Canadian Geotechnical Society } \\
\text { (1985) } \\
\text { Pressuremeter Method } \\
\text { (Canadian Geotechnical } \\
\text { Society, 1985) Brown et al. }\end{array}$ & 0.50 \\
\hline Block Failure, $\varphi_{b 1}$ & \multicolumn{2}{|l|}{ Clay } & 0.55 \\
\hline \multirow{3}{*}{$\begin{array}{l}\text { Uplift Resistance } \\
\text { of Single-Drilled } \\
\text { Shafts, } \varphi_{u p}\end{array}$} & Clay & $\begin{array}{l}\alpha \text {-method } \\
\text { (Brown et al., 2010) }\end{array}$ & 0.35 \\
\hline & Sand & $\begin{array}{l}\beta \text {-method } \\
\text { (Brown et al., 2010) }\end{array}$ & 0.45 \\
\hline & Rock & $\begin{array}{l}\text { Kulhawy et al. (2005) } \\
\text { Brown et al. (2010) }\end{array}$ & 0.40 \\
\hline $\begin{array}{l}\text { Group Uplift } \\
\text { Resistance, } \varphi_{u g}\end{array}$ & \multicolumn{2}{|l|}{ Sand and clay } & 0.45 \\
\hline $\begin{array}{l}\text { Horizontal } \\
\text { Geotechnical } \\
\text { Resistance of } \\
\text { Single Shaft or } \\
\text { Shaft Group }\end{array}$ & \multicolumn{2}{|l|}{ All materials } & 1.0 \\
\hline $\begin{array}{l}\text { Static Load Test } \\
\text { (compression), } \varphi_{\text {load }}\end{array}$ & \multicolumn{2}{|l|}{ All Materials } & 0.70 \\
\hline $\begin{array}{l}\text { Static Load Test } \\
\text { (uplift), } \varphi_{\text {upload }}\end{array}$ & \multicolumn{2}{|l|}{ All Materials } & 0.60 \\
\hline
\end{tabular}




\subsubsection{LRFD Design Methods (FHWA 2010)}

For drilled shafts subjected to lateral loading, the design can be controlled by geotechnical strength, structural strength or serviceability limit states. These conditions are described as follows:

For geotechnical strength limit state, the shaft should be of sufficient size and penetrate to sufficient depth to support the factored lateral loads without collapse due to shaft's overturning. For structural strength limit state, the shaft should be of sufficient size and constructed with the necessary reinforcement to resist the bending moment, shear and axial loads that will be imposed on the drilled shaft. In FHWA 2010, the load factors for both strength limit states are adopted from AASHTO 2007, which can be obtained from Table 2.3 and Table 2.4. However, the resistance factors, which presented in Table 2.6 , are different from AASHTO for strength limit state under lateral loading.

For service limit state, the shaft should be of sufficient size and penetrate to sufficient depth so that the lateral deformations under service load conditions are within tolerable levels of the structure at the critical locations (typically at the top of the column). Design of lateral loaded drilled shafts in service limit state uses load factors are equal to 1.0 according to Table 2.3 means the nominal lateral loads will be applied to produce the nominal displacement. Moreover, according to Table 2.6, the resistance factors for service limit state of drilled shafts subjected to lateral loading are also equal to 1.0. Thus, nominal displacement should be compared directly to allowable displacement to verify the service limit state condition. 
Table 2.6 - Summary of Resistance Factors for LRFD Design of Drilled Shaft Foundation

(after FHWA 2010, Table 10.5)

\begin{tabular}{|c|c|c|c|c|}
\hline Limit State & $\begin{array}{l}\text { Component } \\
\text { of }\end{array}$ & Geomaterial & \begin{tabular}{|l|} 
Equation, \\
Method, or
\end{tabular} & $\begin{array}{c}\text { Resistance } \\
\text { Factor, } \phi\end{array}$ \\
\hline \multirow{3}{*}{$\begin{array}{l}\text { Strength I } \\
\text { through Strength } \\
\text { V } \\
\text { Geotechnical } \\
\text { Lateral } \\
\text { Resistance }\end{array}$} & $\begin{array}{l}\text { Pushover of individual } \\
\text { elastic shaft; head free to } \\
\text { rotate }\end{array}$ & All geomaterials & $\begin{array}{l}p-y \text { method } \\
\text { pushover }\end{array}$ & $0.67^{(1)}$ \\
\hline & $\begin{array}{l}\text { Pushover of single row, } \\
\text { retaining wall or abutment; } \\
\text { head free to rotate }\end{array}$ & All geomaterials & $p-y$ pushover analysis & $0.67^{(1)}$ \\
\hline & $\begin{array}{l}\text { Pushover of elastic shaft } \\
\text { within multiple-row group, } \\
\text { with moment connection to } \\
\text { cap }\end{array}$ & All geomaterials & $p-y$ pushover analysis & $0.80^{(1)}$ \\
\hline \multirow{11}{*}{$\begin{array}{l}\text { Strength I } \\
\text { through } \\
\text { Strength V } \\
\text { Geotechnical } \\
\text { Axial } \\
\text { Resistance }\end{array}$} & \multirow{4}{*}{$\begin{array}{l}\text { Side resistance in } \\
\text { compression/uplift }\end{array}$} & Cohesionless soil & $\begin{array}{l}\text { Beta method } \\
\text { (Eqs. 13-5 to 13- }\end{array}$ & $0.55 / 0.45$ \\
\hline & & Cohesive soil & $\begin{array}{l}\text { Alpha } \\
\text { method }\end{array}$ & $0.45 / 0.35$ \\
\hline & & Rock & Eq. $13-20^{(2)}$ & $0.55 / 0.45^{(3)}$ \\
\hline & & Cohesive IGM & $\begin{array}{l}\text { Modified alpha } \\
\text { method (Eq. 13-28) }\end{array}$ & $0.60 / 0.50^{(1)}$ \\
\hline & \multirow{3}{*}{ Base resistance } & Cohesionless soil & N-value (Eq. 13-16) & 0.50 \\
\hline & & Cohesive soil & $\begin{array}{l}\text { Bearing capacity } \\
\text { eq. (Eq. 13-18) }\end{array}$ & 0.40 \\
\hline & & $\begin{array}{l}\text { Rock and } \\
\text { Cohesive IGM }\end{array}$ & $\begin{array}{l}\text { 1. Eq. 13-22 } \\
\text { 2. CGS, } 1985 \text { (Eq. 13- }\end{array}$ & 0.50 \\
\hline & $\begin{array}{l}\text { Static compressive } \\
\text { resistance from load tests }\end{array}$ & \multicolumn{2}{|c|}{ All geomaterials } & $<0.7^{(4)}$ \\
\hline & $\begin{array}{l}\text { Static uplift resistance from } \\
\text { load tests }\end{array}$ & \multicolumn{2}{|c|}{ All geomaterials } & 0.60 \\
\hline & Group block failure & \multicolumn{2}{|c|}{ Cohesive soil } & 0.55 \\
\hline & Group uplift resistance & \multicolumn{2}{|c|}{ Cohesive and cohesionless soil } & 0.45 \\
\hline \multirow{3}{*}{$\begin{array}{l}\text { Strength I } \\
\text { through Strength } \\
\text { V; Structural } \\
\text { Resistance of R/C }\end{array}$} & \multicolumn{3}{|c|}{ Axial compression } & 0.75 \\
\hline & \multicolumn{3}{|c|}{ Combined axial and flexure } & 0.75 to 0.90 \\
\hline & \multicolumn{3}{|c|}{ Shear } & 0.90 \\
\hline Service I & \multicolumn{2}{|l|}{ All cases, all geomaterials } & Ch. 13, Appendix B & 1.00 \\
\hline \multirow{3}{*}{$\begin{array}{l}\text { Extreme Event I } \\
\text { and Extreme } \\
\text { Event II }\end{array}$} & $\begin{array}{l}\text { Axial geotechnical uplift } \\
\text { resistance }\end{array}$ & All geomaterials & $\begin{array}{l}\text { Methods cited above } \\
\text { for Strength Limit }\end{array}$ & 0.80 \\
\hline & $\begin{array}{l}\text { Geotechnical } \\
\text { lateral resistance }\end{array}$ & All geomaterials & $\begin{array}{l}p-y \text { method } \\
\text { pushover analysis; }\end{array}$ & $0.80^{(1)}$ \\
\hline & All other cases & All geomaterials & $\begin{array}{l}\text { Methods cited above } \\
\text { for Strength Limit }\end{array}$ & 1.00 \\
\hline
\end{tabular}


AASHTO 2007 and FHWA 2010 use LRFD for design of drilled shafts subjected to lateral loading. However, for service limit state, both of them uses resistance factors equal to 1.0 , which means resistance factors have not been calibrated from probabilistic analyses. Thus, a new LRFD procedure for design of drilled shafts subjected to lateral loading at service limit state should be proposed, which can take an advantage of reliability-based analyses to probabilistically calibrate the resistance factors for service limit state.

\subsection{Summary}

This chapter presents a basic background and provides some literatures for load and resistance factor design of drilled shaft subjected to lateral loading. Different methods for deriving $\mathrm{p}-\mathrm{y}$ curves from experimental results have been covered to illustrate the need of a new method to develop p-y curves, which will be used to characterize a py model for shale.

Probabilistic tools available for reliability-based analyses have been reviewed to calibrate the resistance factors. Finally, three different methods for designing drilled shafts subjected to lateral loading have been discussed to clarify the objective of this research, which is proposing a new LRFD procedure for design of drilled shafts subjected to lateral loading in shale at service limit state, using the probabilistic calibrated resistance factors obtained from reliability-based analysis. 


\section{CHAPTER 3. LATERAL LOAD TEST FOR DRILLED SHAFTS IN SHALE}

This chapter documents full-scale lateral load test programs at two research sites. Information about site locations and subsurface conditions, test instrumentation and test

procedure are briefly described. An example of experimental shaft responses in terms of lateral displacements and bending moments along the length of the shaft is presented.

\subsection{Site and Subsurface Conditions}

Lateral load tests were performed on drilled shafts at two sites in Missouri. All test shafts were founded in shale. Locations of the two sites are shown in Figure 3.1. One site is referred to as the "Frankford Load Test Site" and the other as the "Warrensburg Load Test Site." Ten shafts were constructed at the Frankford site; fifteen shafts were constructed at the Warrensburg site. Ground conditions and the uniaxial compressive strength (UCS), are described as follows. 


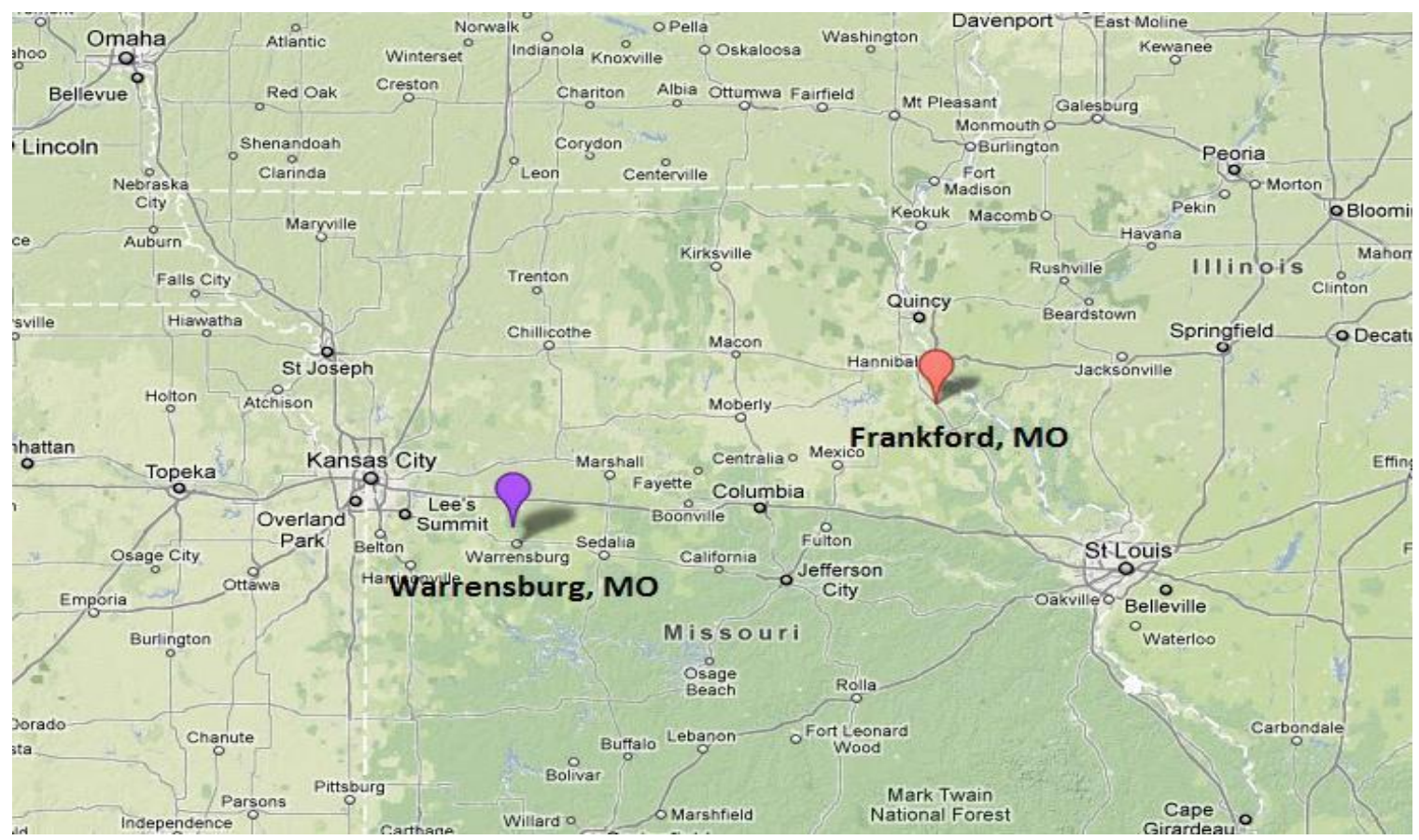

Figure 3.1 - Test sites in Missouri

\subsubsection{Frankford Load Test Site}

The Frankford Load Test site is located near Frankford, Missouri along U.S. Highway 61 northwest of St. Louis as shown in Figure 3.2. The Frankford site is a relatively uniform site with three shale strata designated as Maquoketa Formations A, B, and C. The UCS profile of the Frankford site is shown in Figure 3.3 and Figure 3.4. The weathered shales, Maquoketa Formations A and B, have UCS from 3 to $10 \mathrm{ksf}$, and the unweathered shale, Maquoketa Formation C, has UCS from 50 to 100 ksf. The standard deviation of UCS varies from 0.48 to $14.1 \mathrm{ksf}$. Table 3.1 summarizes the mean value, standard deviation, and distribution of UCS in each stratigraphic layer. 


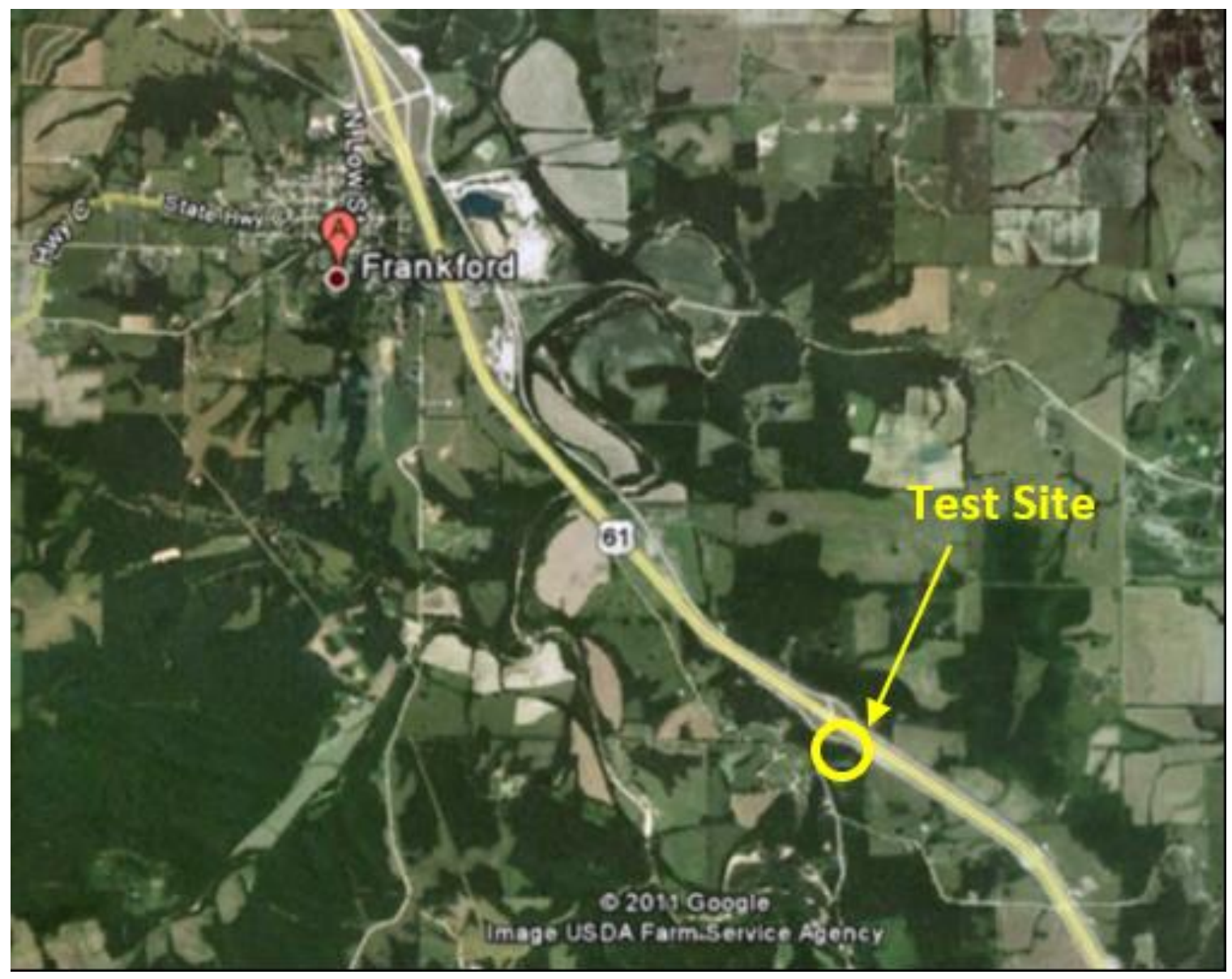

Figure 3.2 - Location of Frankford Load Test Site.

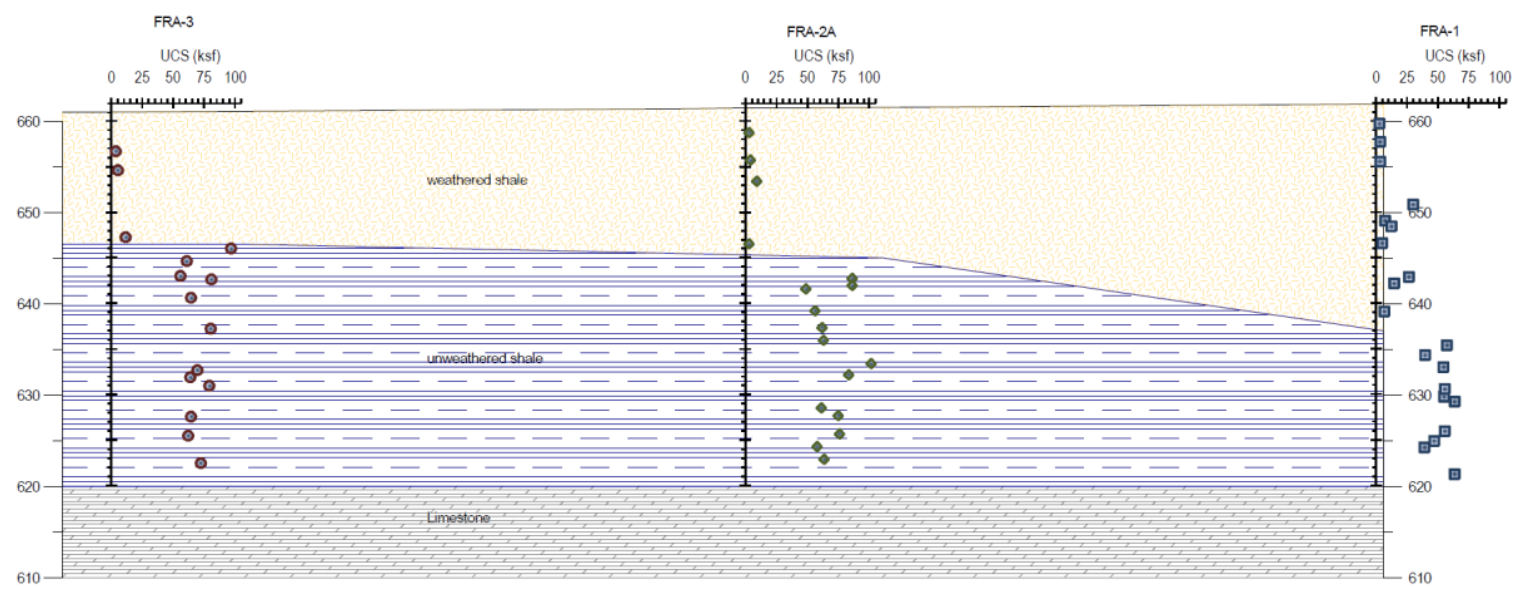

Figure 3.3 - Cross-section of the Frankford Lateral Load Test Site showing measured values of UCS. 


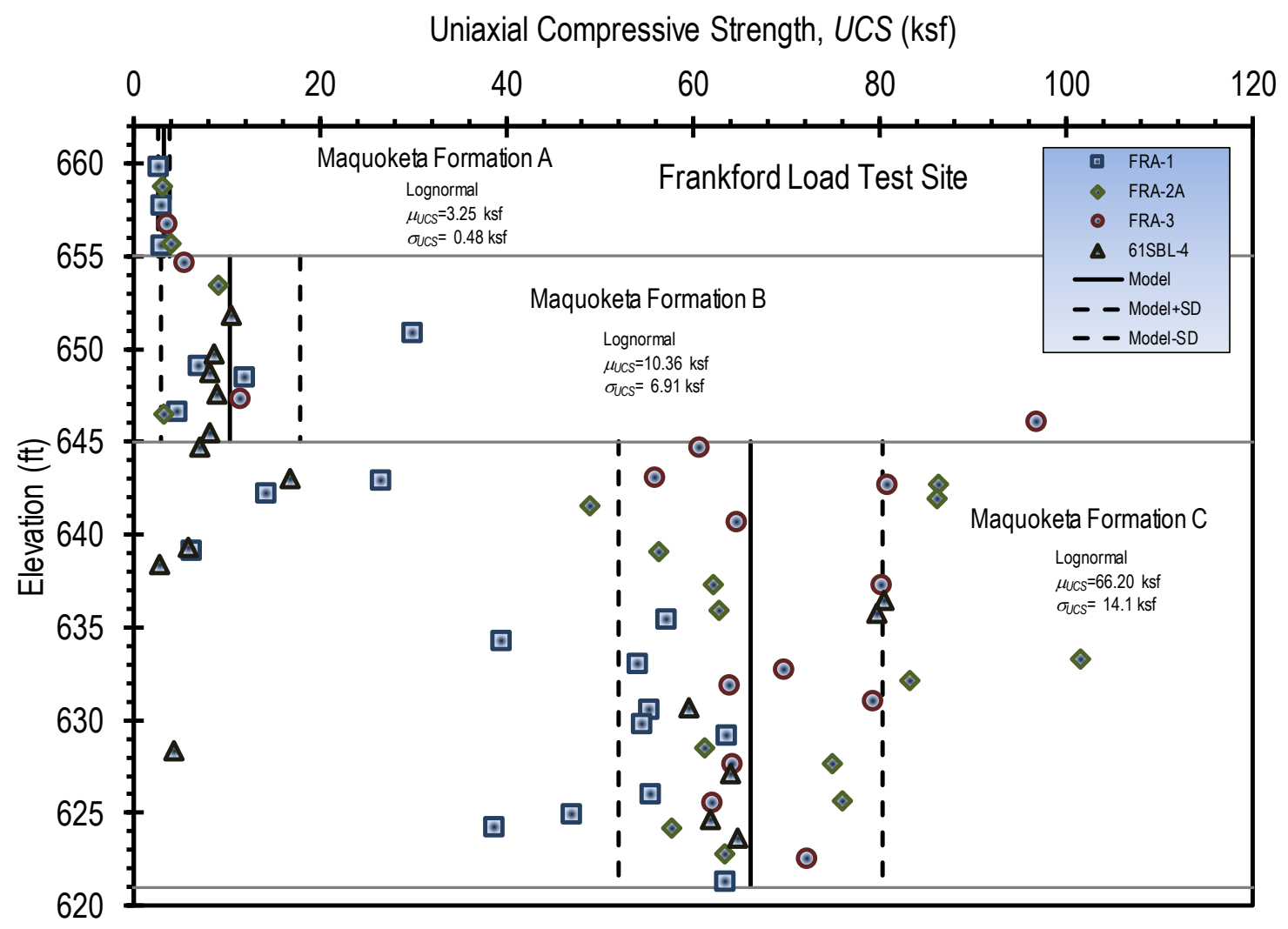

Figure 3.4 - Measured values of UCS shown with mean and standard deviation values for Frankford Load Test Site.

Table 3.1 - UCS statistics for the Frankford site.

\begin{tabular}{|c|c|c|c|}
\hline \multirow{2}{*}{ Frankford Site } & \multicolumn{3}{|c|}{ UCS Statistics } \\
\cline { 2 - 4 } & Mean (ksf) & Standard deviation (ksf) & Distribution type \\
\hline Maquoketa Formation A & 3.25 & 0.48 & Lognormal \\
\hline Maquoketa Formation B & 10.36 & 6.91 & Lognormal \\
\hline Maquoketa Formation C & 66.20 & 14.1 & Lognormal \\
\hline
\end{tabular}


Ten drilled shafts, designated F1, F2, ..., F10, were constructed with diameters ranging from 3 to $5 \mathrm{ft}$ and lengths ranging from 20 to $35 \mathrm{ft}$. The test shafts were arranged in a straight-line parallel with U.S. 61 as shown in Figure 3.5 and Figure 3.6.

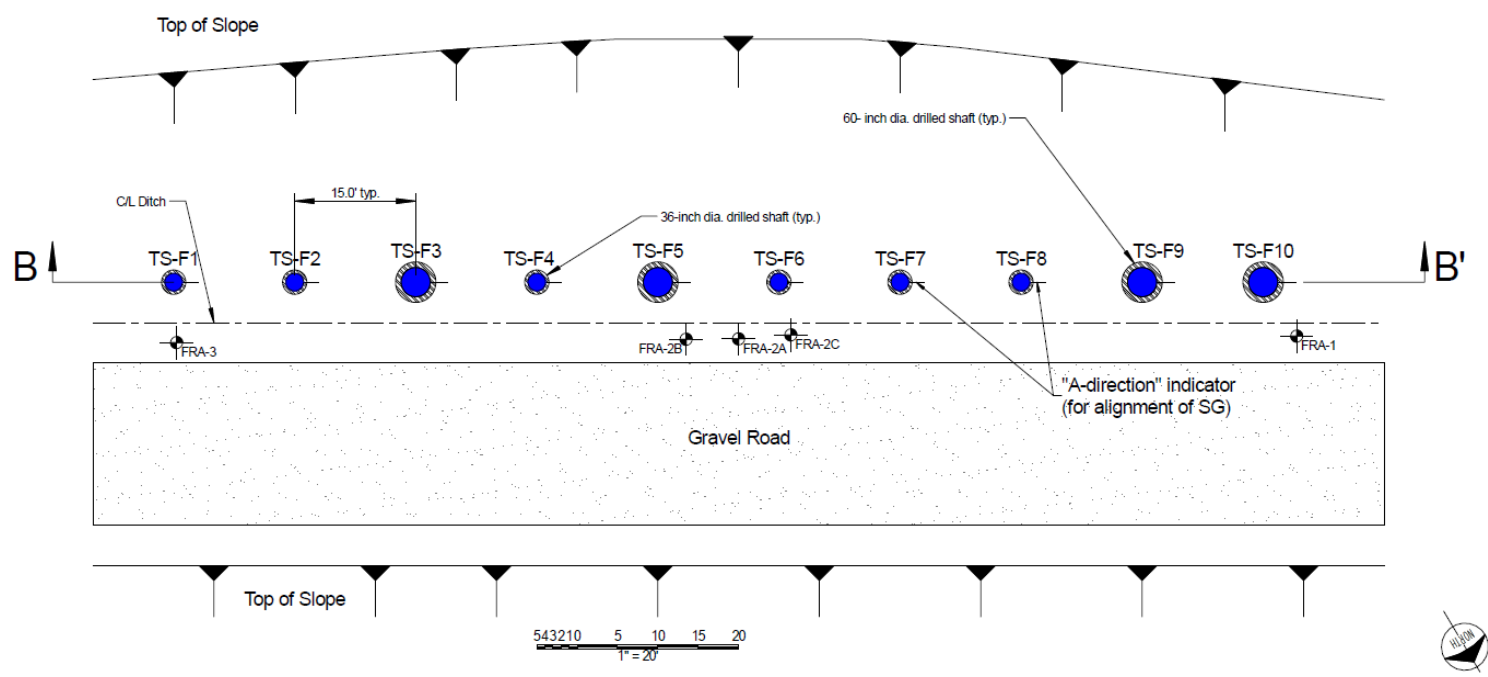

Figure 3.5 - Layout of test shafts at Frankford Load Test Site.

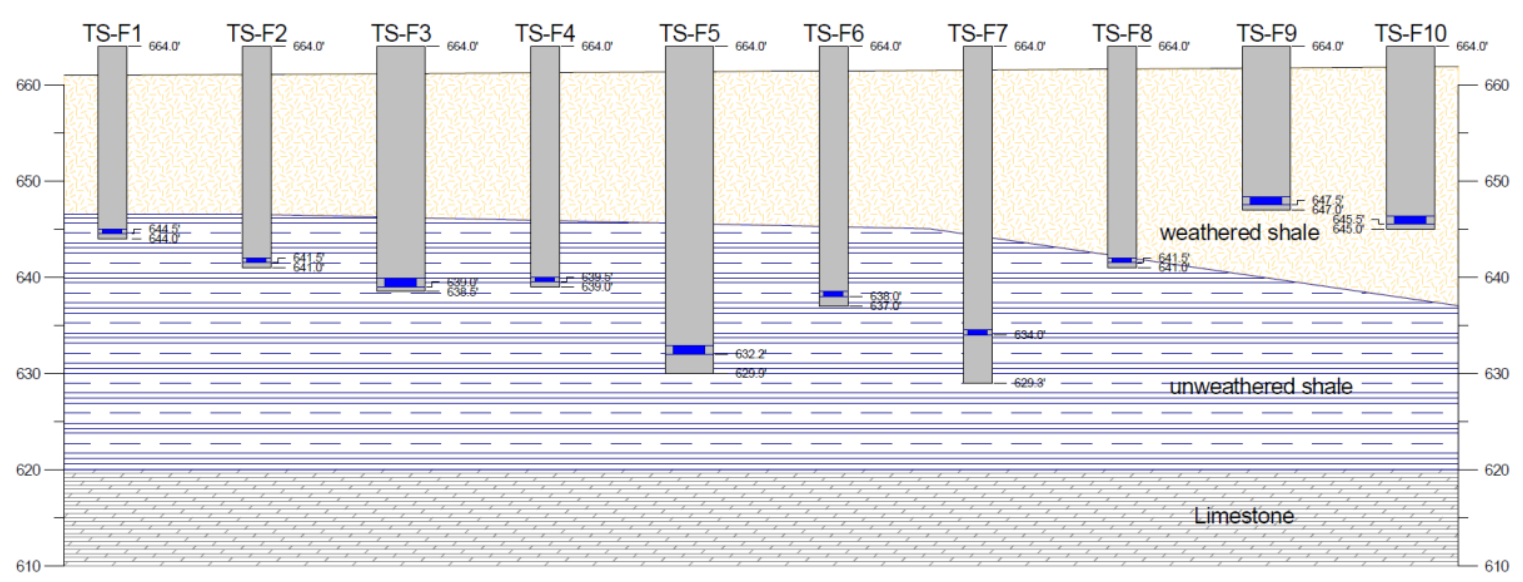

Figure 3.6 - Cross-section B-B' of the Frankford Load Test Site showing the drilled shafts. 


\subsubsection{Warrensburg Load Test Site}

The Warrensburg Load Test site is located near the city of Warrensburg, in westcentral Missouri, approximately 60 miles east of Kansas City as shown in Figure 3.7. Warrensburg site includes: stiff clay overburden; the Croweburg and Fleming Formations; Mineral Formation A; Mineral Formation B; and the Scammon Formation. The measured values of UCS are high variability, which is shown in Figure 3.8 and Figure 3.9. The UCS values of the soil vary from 3 to $205 \mathrm{ksf}$, with the standard deviation varying from 1.31 to $498.10 \mathrm{ksf}$. The mean value of UCS, standard of deviation and distribution of UCS in each soil layer for the Warrensburg site are summarized in Table 3.2.

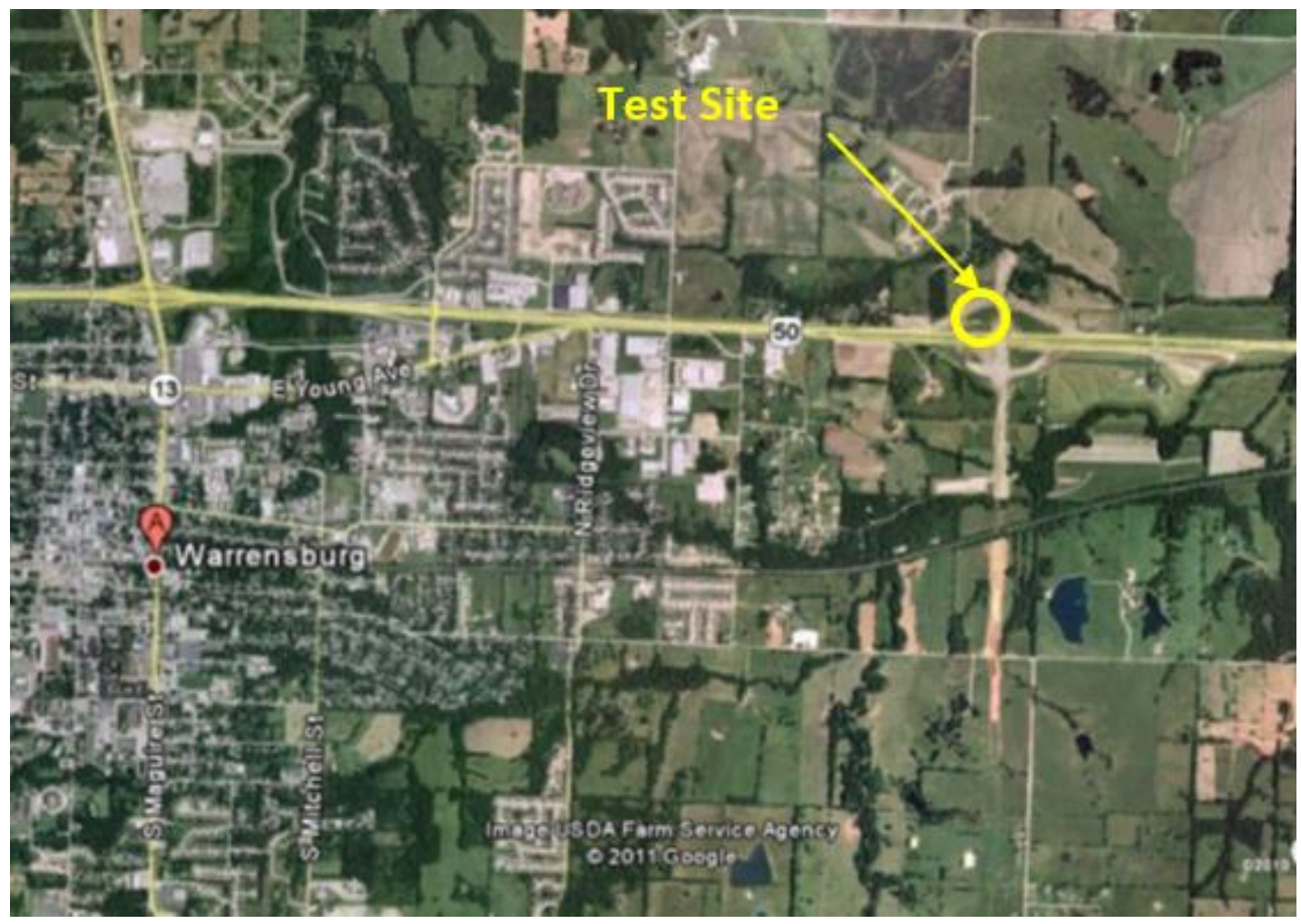

Figure 3.7 - Location of Warrensburg Load Test Site. 
UCS (ksf) UCS (ksf) UCS (ksf) UCS (ksf)

$0 \quad 50100150200 \quad 0 \quad 50 \quad 1001502000 \quad 50 \quad 1001502000 \quad 50 \quad 100150200$

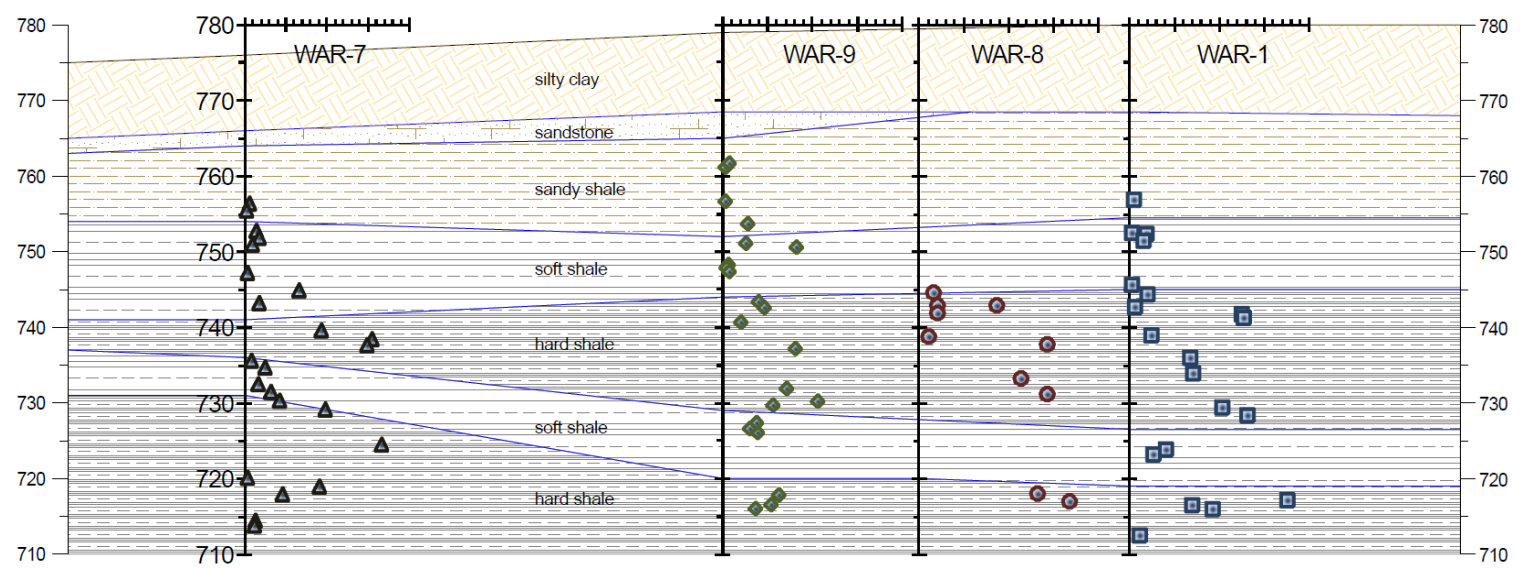

Figure 3.8 - Cross-section of the Warrensburg Lateral Load Test Site showing measured values of UCS.

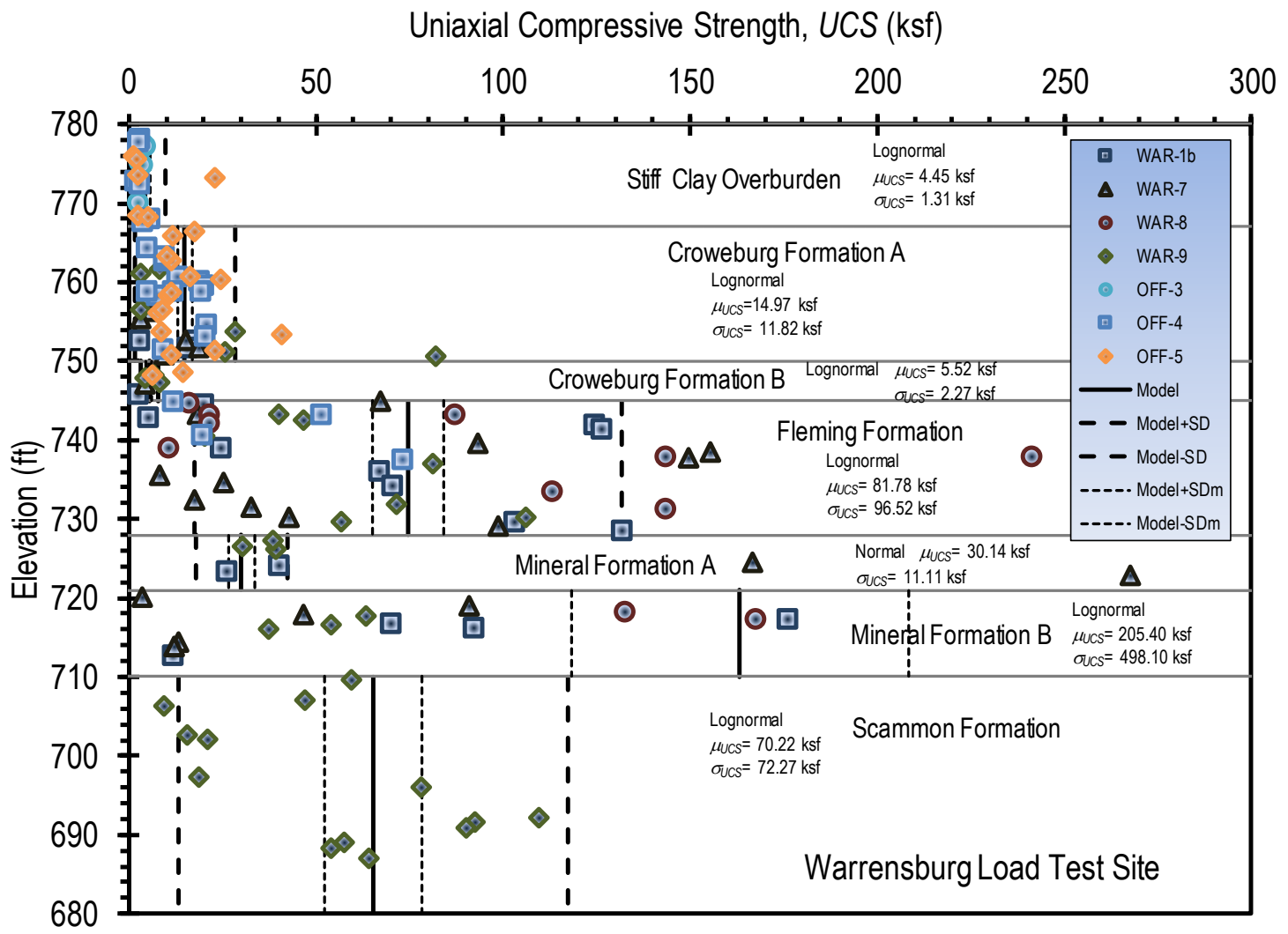

Figure 3.9 - Measured values of UCS shown with mean and standard deviation values for Warrensburg Load Test Site. 
Table 3.2 - UCS statistics of the Warrensburg sites.

\begin{tabular}{|l|c|c|c|}
\hline \multirow{2}{*}{ Warrensburg site } & \multicolumn{3}{c|}{ UCS Statistics } \\
\cline { 2 - 4 } & Mean (ksf) & Standard deviation (ksf) & Distribution type \\
\hline Stiff clay overburden & 4.45 & 1.31 & Lognormal \\
\hline Croweburg Formation A & 14.97 & 11.82 & Lognormal \\
\hline Croweburg Formation B & 5.52 & 2.27 & Lognormal \\
\hline Fleming Formation & 81.78 & 96.52 & Lognormal \\
\hline Mineral Formation A & 30.14 & 11.11 & Normal \\
\hline Mineral Formation B & 205.40 & 498.10 & Lognormal \\
\hline Scammon Formation & 70.22 & 72.27 & Lognormal \\
\hline
\end{tabular}

Fifteen shafts, designated W1, W2, ..., W15, were constructed with a diameter of $3 \mathrm{ft}$ and ranging from 30 to $50 \mathrm{ft}$ in length. For all shafts, typically 3.5-ft diameter casing were used from top of shafts down to bottom of the overburden layer. The test shafts were constructed in three rows of five shafts between U.S. 50 and the westbound entrance ramp to U.S. 50 as shown in Figure 3.10 to Figure 3.13.

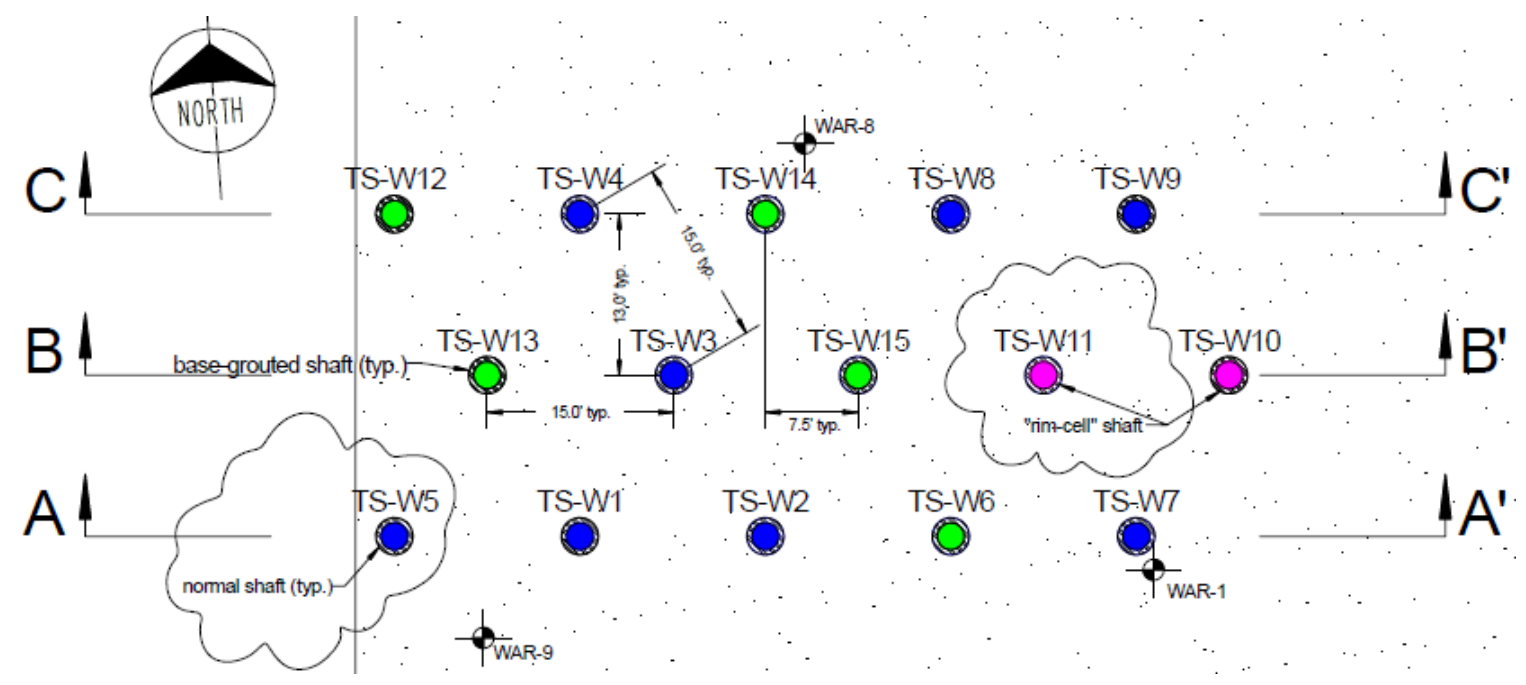

Figure 3.10 - Layout of test shafts at Warrensburg Load Test Site. 


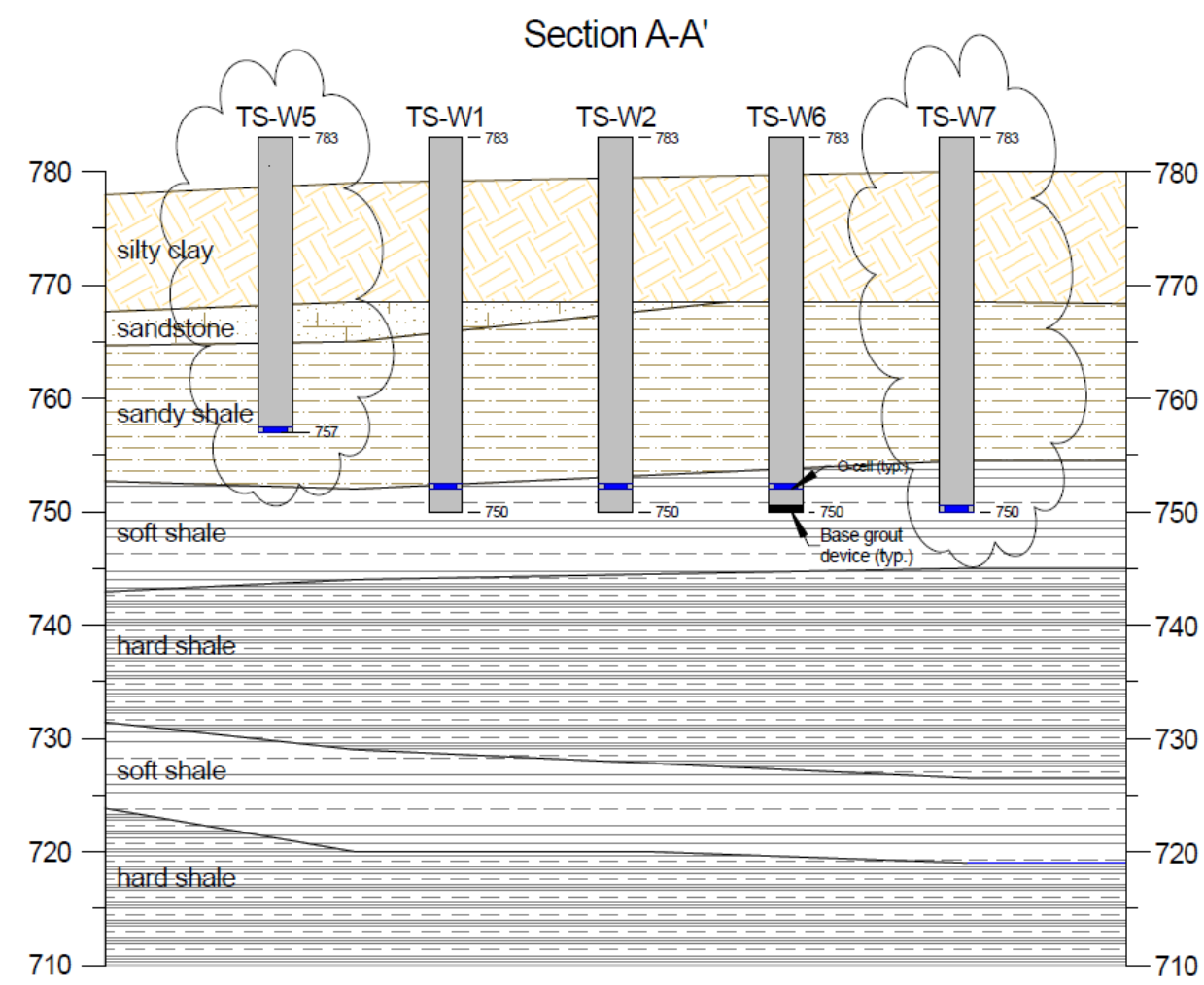

Figure 3.11 - Warrensburg site cross-section $A-A^{\prime}$ showing the drilled shafts

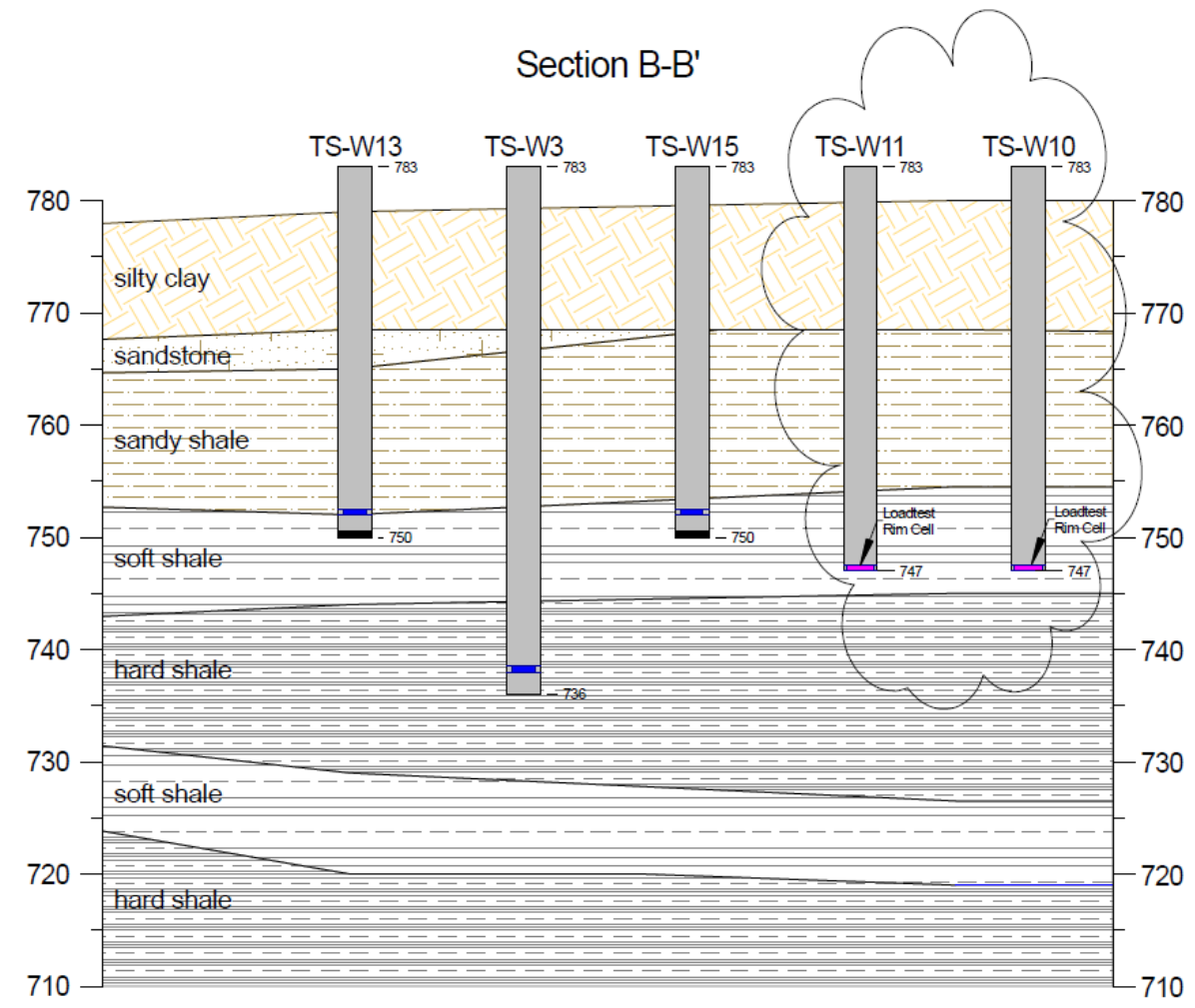

Figure 3.12 - Warrensburg site cross-section B-B' showing the drilled shafts 


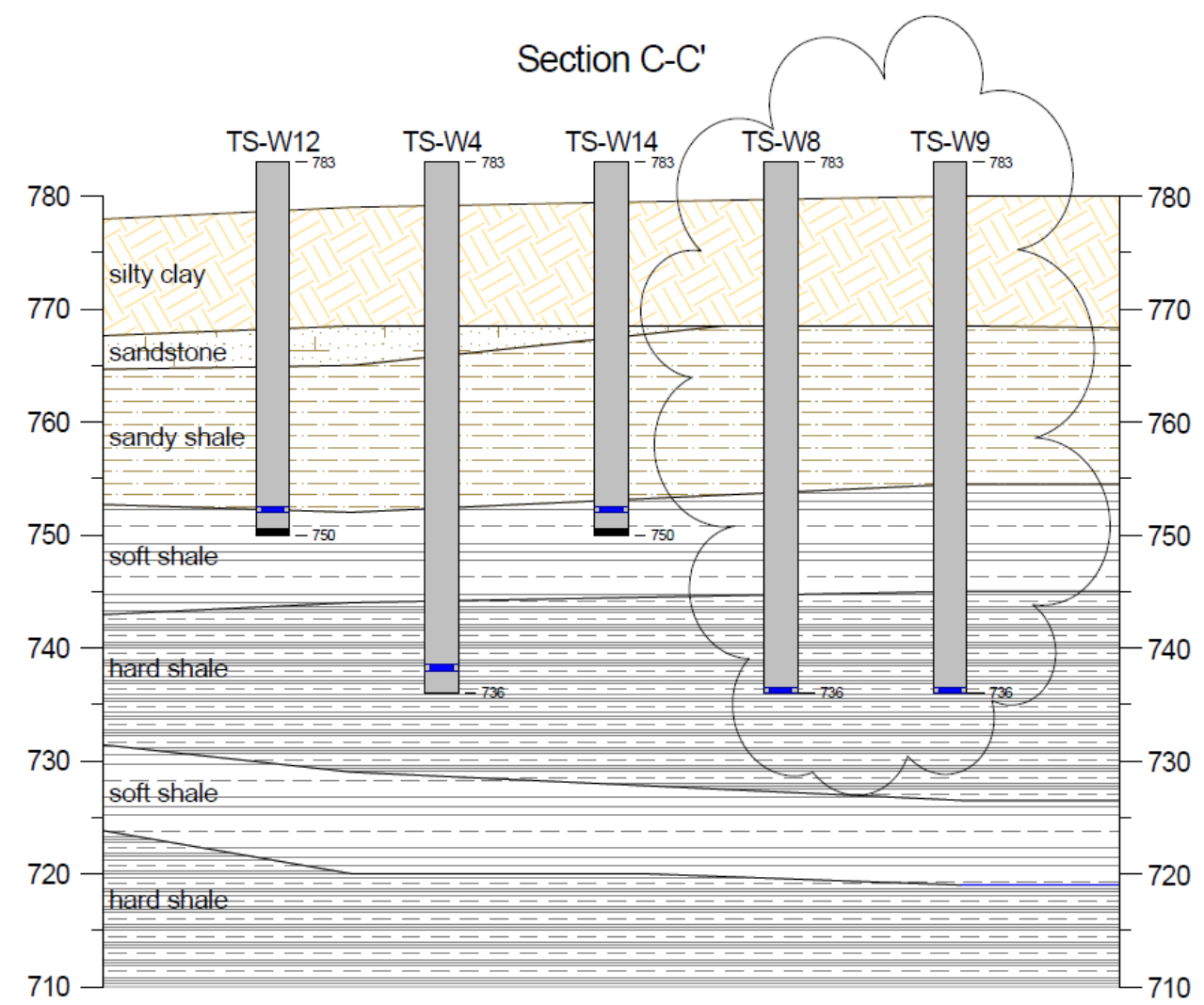

Figure 3.13 - Warrensburg site cross-section C-C' showing the drilled shafts 


\subsection{Field Testing Program and Apparatus}

Three lateral load tests were performed at the Frankford Load Test Site and thirteen lateral load tests were performed at the Warrensburg Load Test Site. The details of the field testing program, load test frame, instrumentation, and testing procedure are provided as following.

\subsubsection{Field Testing Program}

The primary focus of the lateral load testing program was to measure the response of the foundations to static lateral loading. All lateral load tests were performed by pulling two shafts together, so that two foundations were loaded and monitored simultaneously, producing two sets of shaft test results for one individual lateral load test. Shafts pairs for each test were determined primarily by location, but consideration was also given to pairing shafts of similar length.

\subsubsection{Frankford Load Test Site}

Three lateral load tests were performed at the Frankford Load Test Site as shown in Figure 3.14. Test shaft F1 was paired with F2, F7 was paired with F8, and F4 was paired with F6 in a test that spanned around F5. Test shafts F3, F5, F9 and F10 are 5-ft diameter shafts, which were not tested because the reaction frame was not big enough. The spacing between shafts was $15 \mathrm{ft}$ (30 ft for the F4-F6 shaft pair), which is comparable to the recommendation of a clear distance of 5 shaft diameters from ASTM D3966 (2007). 


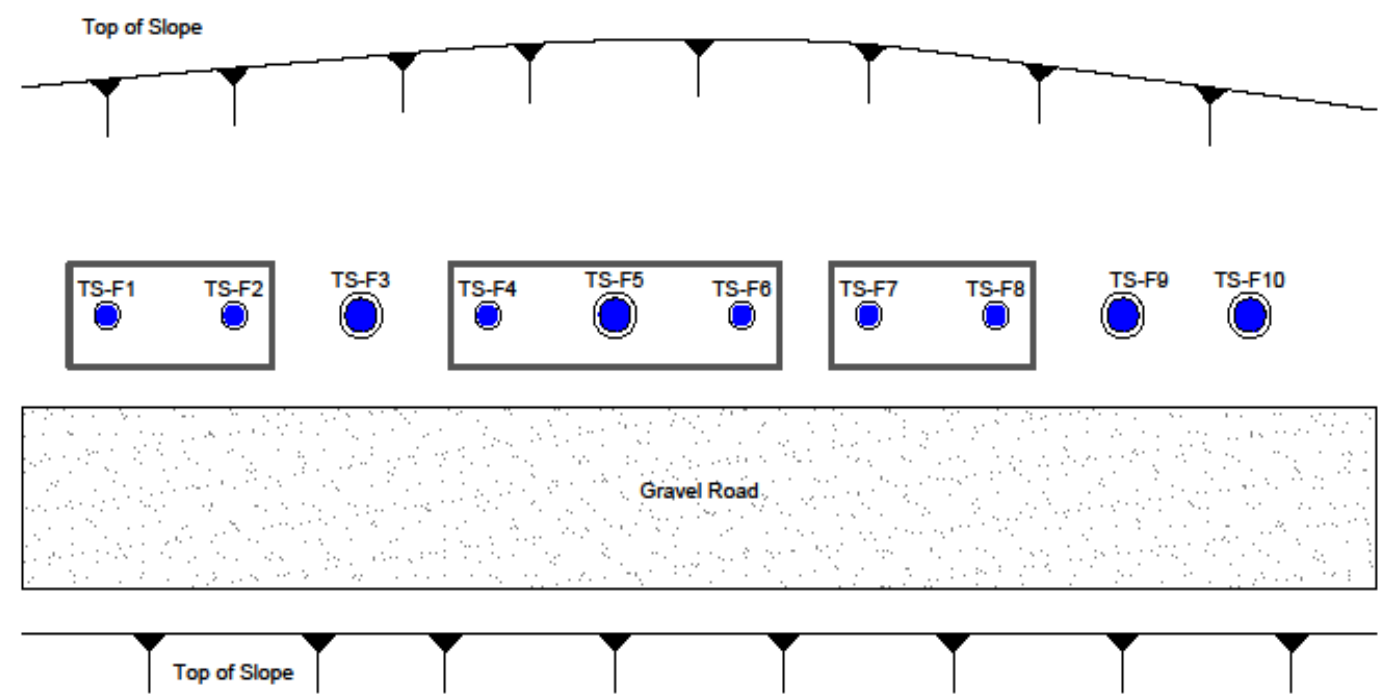

Figure 3.14 - Layout of the test shaft pairs at the Frankford Load Test Site with rectangles indicating test shaft pairs.

\subsubsection{Warrensburg Load Test Site}

Thirteen lateral load tests were performed at the Warrensburg Load Test Site as shown in Figure 3.15. Spacing of the shafts at the Warrensburg Load Test Site is $15 \mathrm{ft}$. Test shafts W1 and W2 were paired together; test shaft W1 was also paired with W5 in a subsequent test. The other pairings were W3 with W4, W6 with W7, W8 with W9, W10 with W11, W12 with W13, and W14 with W15. Test pairs W1-W2, W3-W4, W6-W7, W8W9 ang W10-W11 were test two times, before and after the soil removal process. The reason is because it is difficult to transfer lateral load to the shale layers, which are overlain by 10 to $15 \mathrm{ft}$ of stiff clay overburden. Stiff clay layer with that thickness can absorb most of the applied lateral load and not provide enough mobilized lateral displacement, results in small lateral soil response in the shale layer. Therefore, after an 
initial set of tests, soil was removed in order to soften the lateral load response of the overburden. By drilling 5 or 6 holes approximately 15 -ft deep between test pairs, soil was removed as shown in Figure 3.16 and Figure 3.17. The holes were drilled as close as possible to the shafts and in the direction of the opposing shaft of the pairing. Due to schedule issues, test pairs W12-W13, W14-W15, and W1-W5 were not tested prior to the soil removal process.

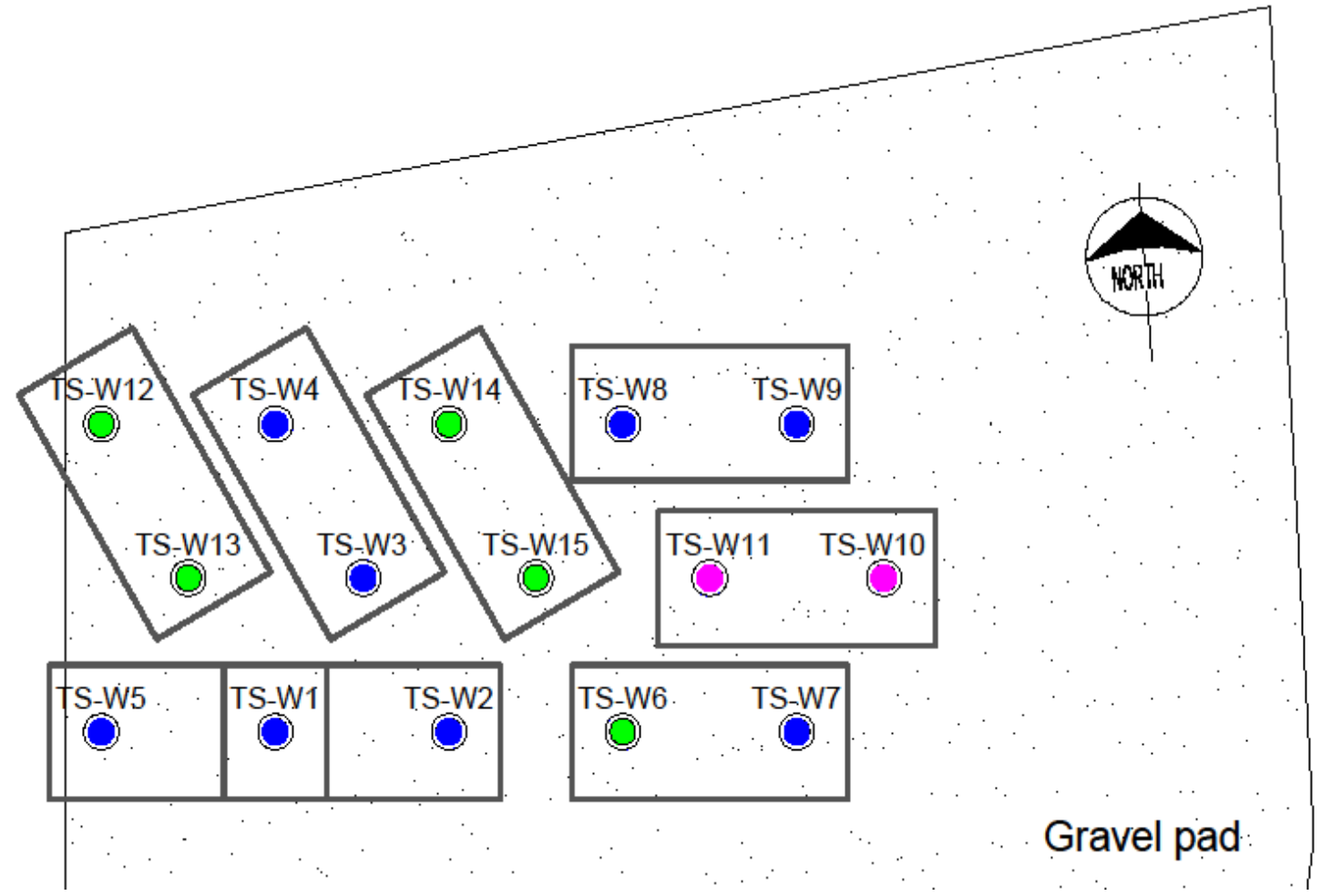

Figure 3.15 - Layout of the test shaft pairs at the Warrensburg Load Test Site with rectangles indicating test shaft pairs. 


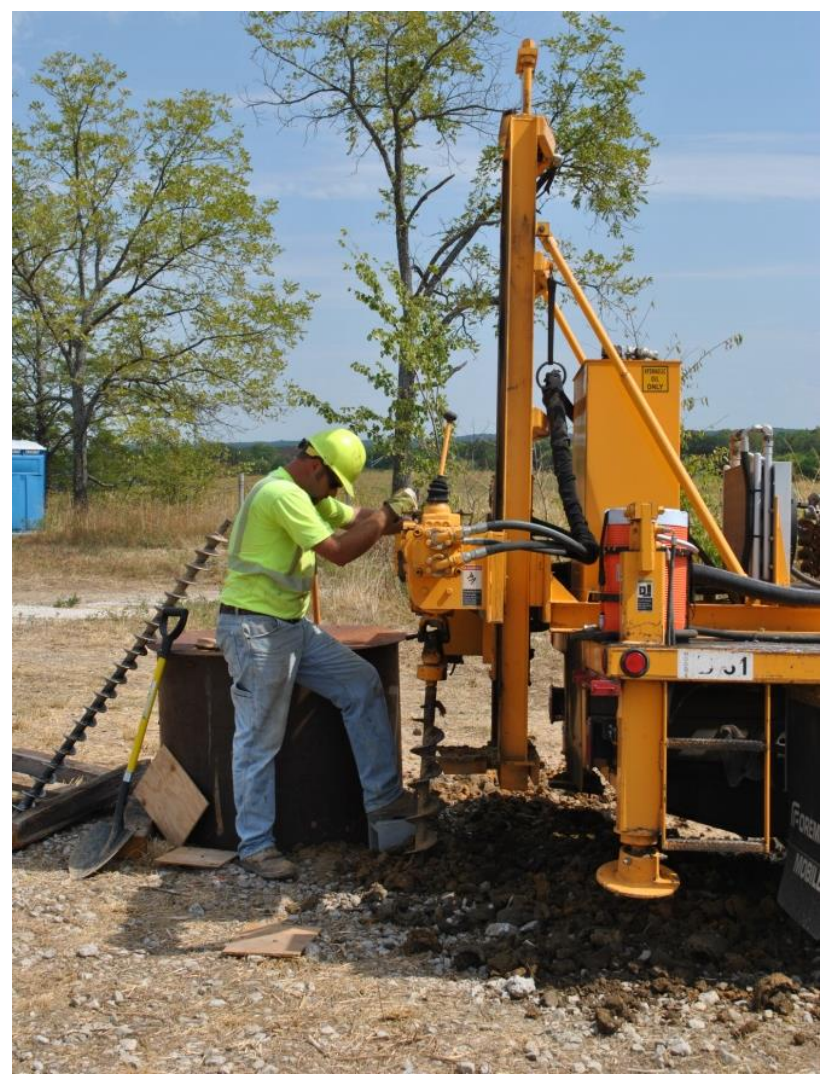

Figure 3.16 - Soil removal by drilling holes next to drilled shafts.

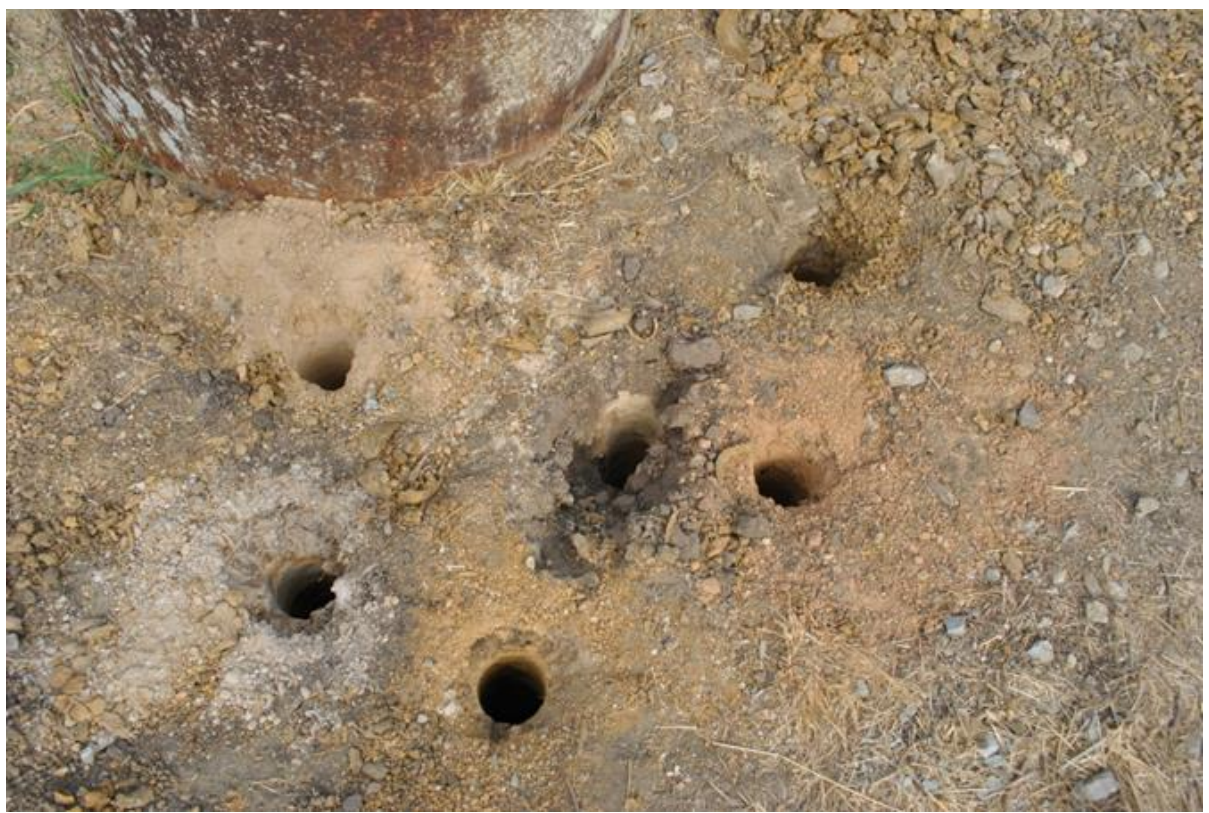

Figure 3.17 - Drilled holes adjacent to the shaft prior to retesting. 


\subsubsection{Load Test Frame}

Testing consisted of pulling the paired shafts together using four hydraulic jacks as shown in Figure 3.18. The center-hole jacks (110 MP series 03) were used to tension Grade 150 steel. The bars were installed through the flanges of two beams, one behind each shaft as shown in Figure 3.18 and in the loading frame plan of Figure 3.19. Application of pressure to the jacks tensioned the bars, which loaded the beams, which in turn applied load to seatings that were placed around each shaft, thereby loading the test shafts.

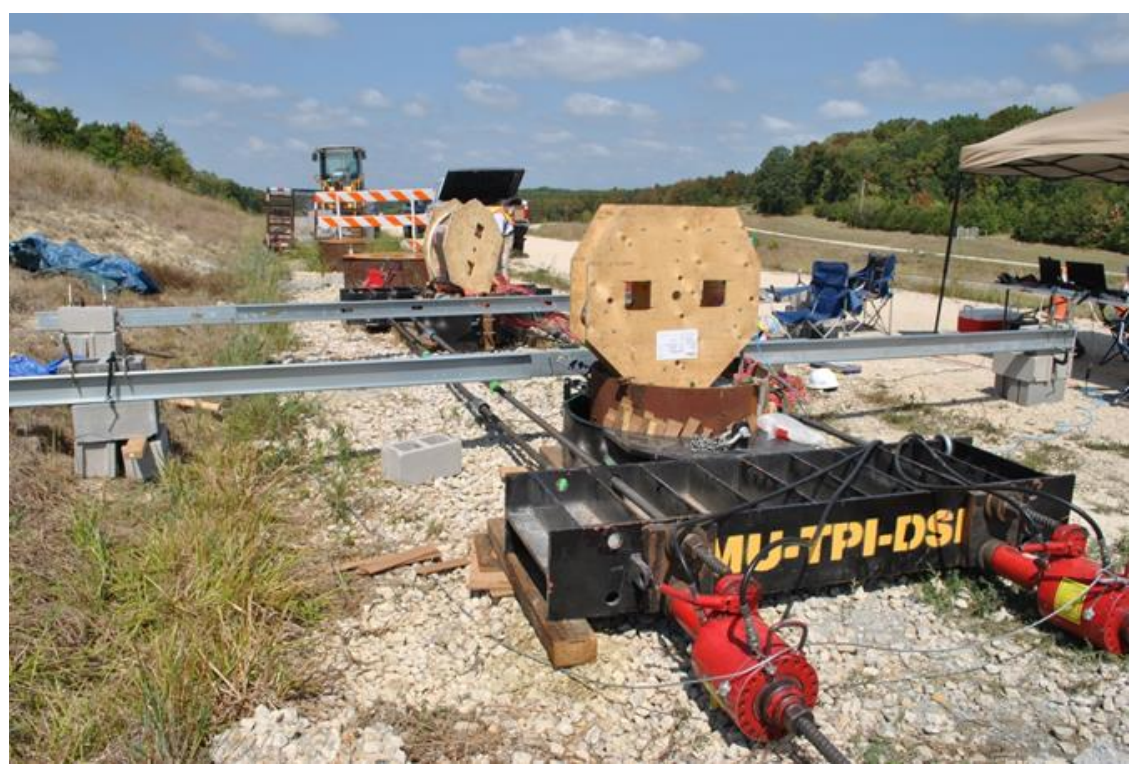

Figure 3.18 - One side of lateral load test frame in place at Frankford Load Test Site. 


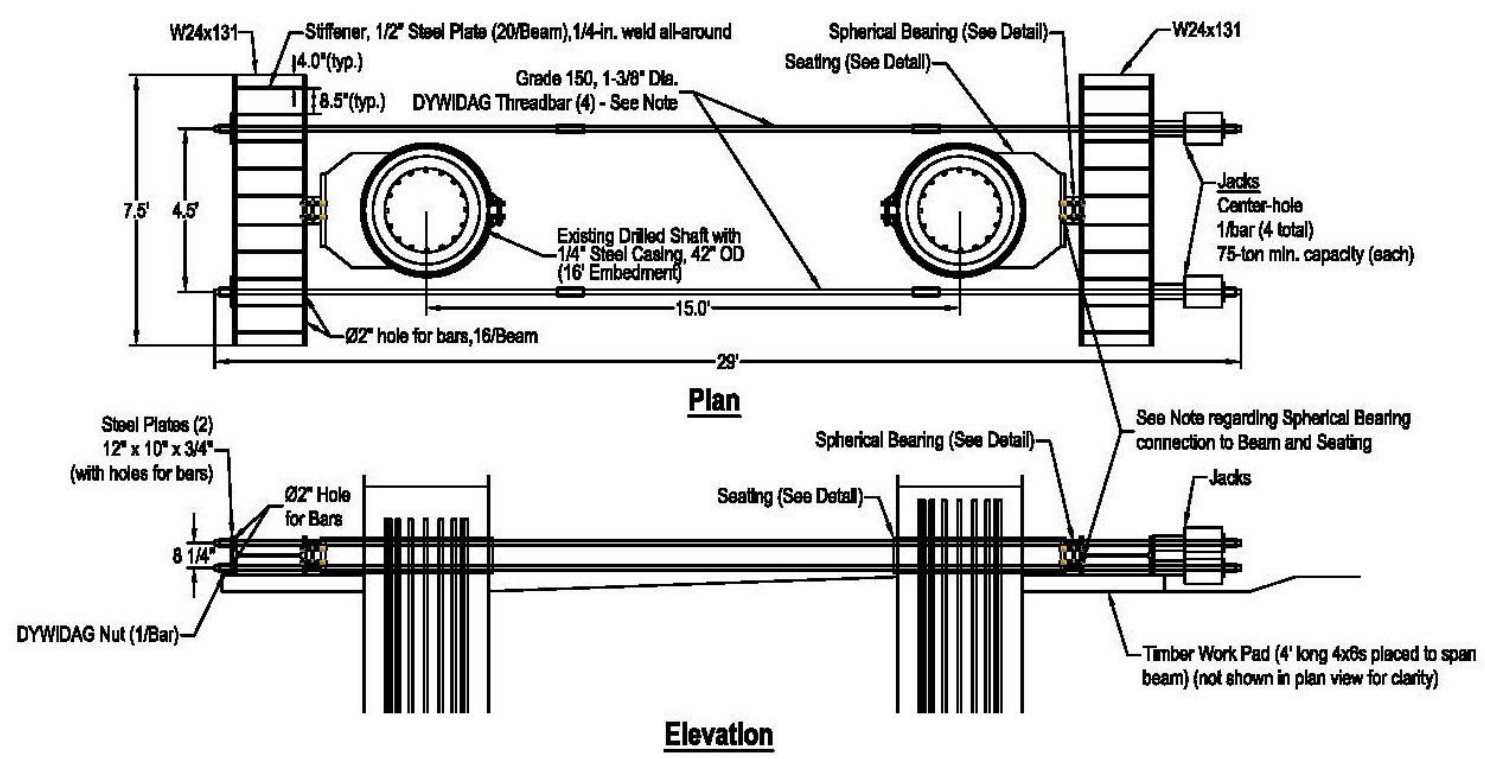

Figure 3.19 - Plan and elevation views of lateral load test frame.

Together, the two beams, two seatings, and four bars compose the steel loading frame, which is shown in plan set drawings in Figure 3.19 and Figure 3.20. Each seating consisted of three plates designed to transfer load from the beam to the shaft via a pipe section collared around the shaft. The same seatings were used for tests of $3.5-\mathrm{ft}$ diameter shafts at Warrensburg and 3-ft diameter shafts at Frankford. For the Frankford shafts, Masonite shims were used to fill the annular space between the collar and the shaft to improve the load distribution. For the initial tests, a spherical bearing shown in Figure 3.21 was used between the beam and the seating to ensure proper alignment during the tests as the shafts deflected and rotated. The bearing was removed for subsequent tests as shown in Figure 3.22 since it allowed too much independence of movement, particularly considering the length of the bars, which began to buckle in the initial tests. The tests without the bearings were successful and proved to be self-aligning. 
The loading frame was designed for an ultimate load of 600 kips. Design checks for the loading frame included shear and bending moment capacity of the beam and axial capacity and deflection of the bars. The beams were W24x131, and multiple plate stiffeners were included to increase the shear resistance. In addition, bearing plates were placed between the jacks and beams to reduce stress concentrations at the points of load application.

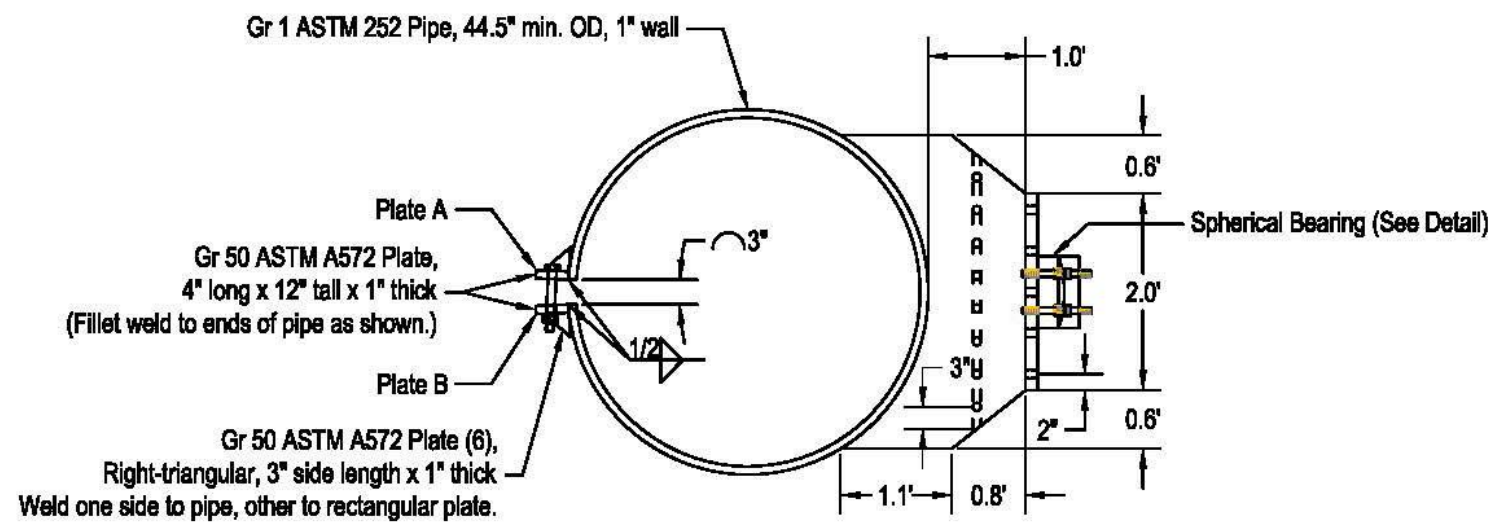

Plan

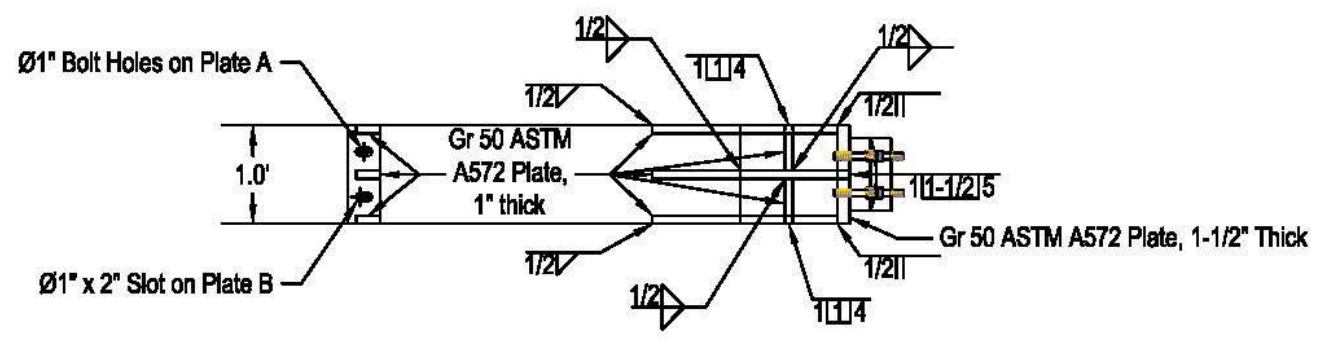

Elevation

Figure 3.20 - Plan and elevation view of lateral load test frame seating detail. 


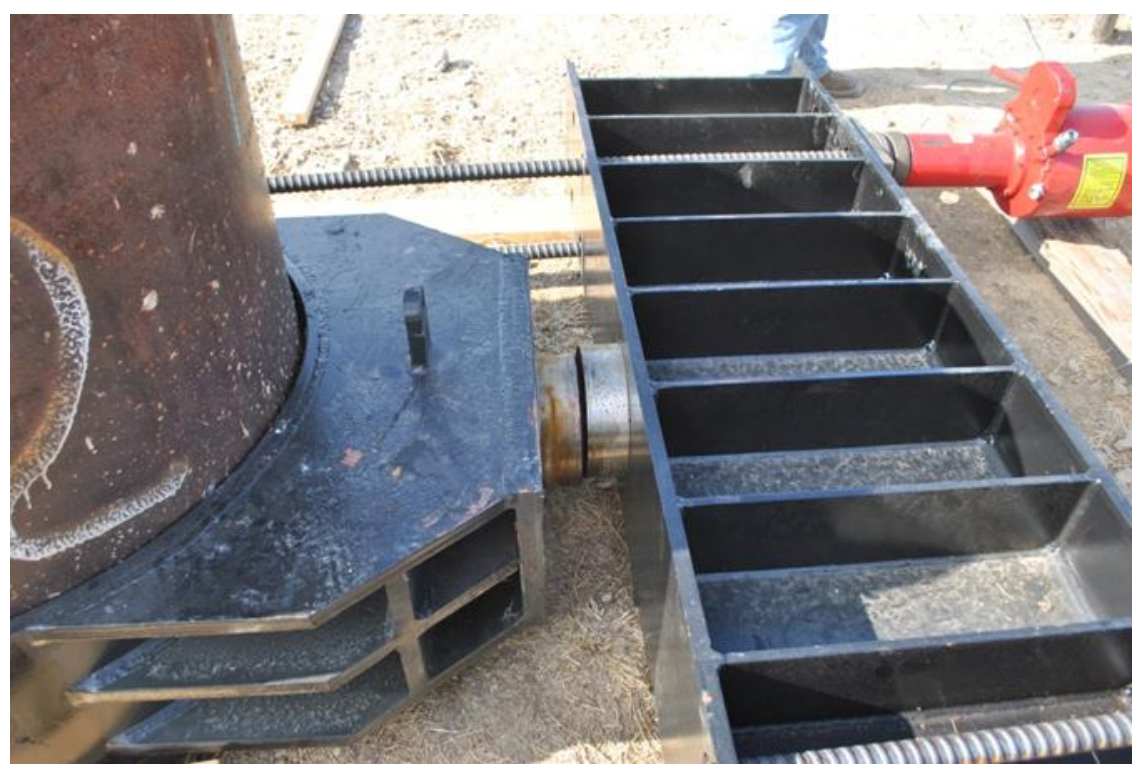

Figure 3.21 - The beam, seating, and bearing in place around W2.

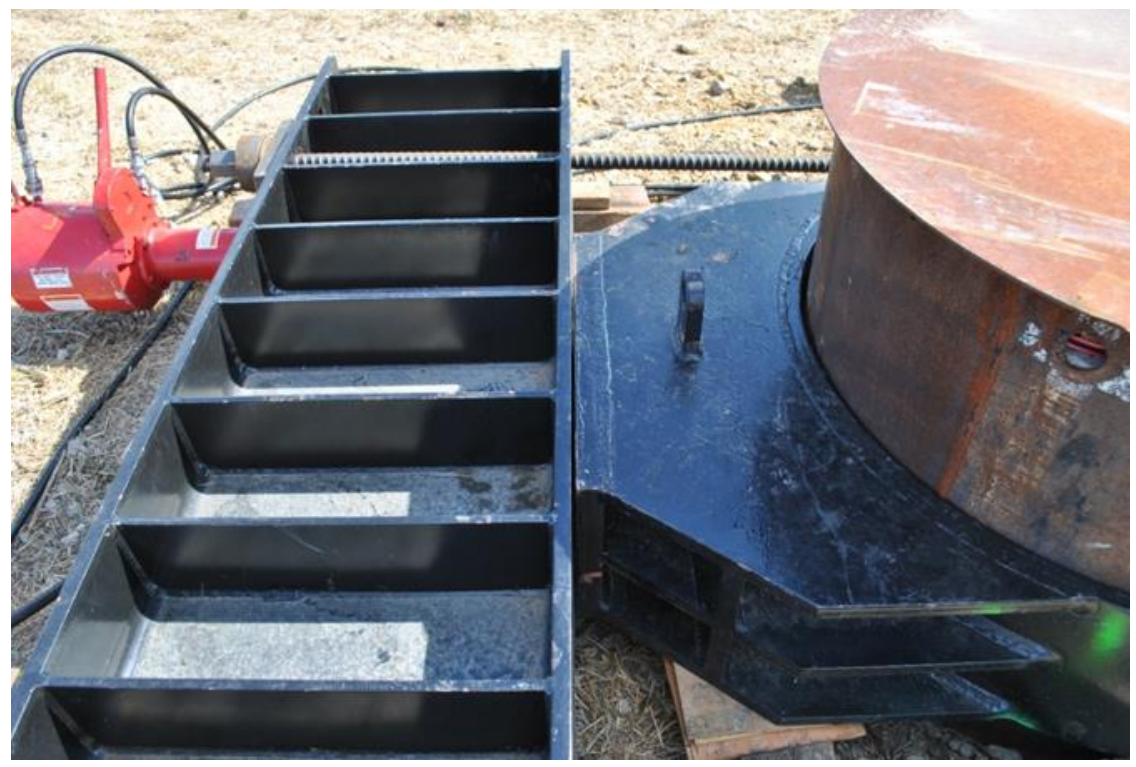

Figure 3.22 - Beam and seating in place without bearing. 


\subsubsection{Instrumentation}

Shafts were instrumented using Linear Variable Differential Transformer (LVDT), Dial Gages, vibrating wire Strain Gages and Shape Acceleration Array (SAA) to measure the displacement of the shaft head and the structural response of each shaft. Displacement and bending moment profiles were interpreted from Strain Gage data as well as from SAA data.

\subsubsection{Vibrating Wire Strain Gages}

The strain gages were vibrating wire, concrete embedment gages (Geokon Model 4200) attached to u-brackets welded inside the reinforcing cage as shown in Figure 3.23. All shafts were instrumented with four gages at each of six different level ( 24 gages per shaft).

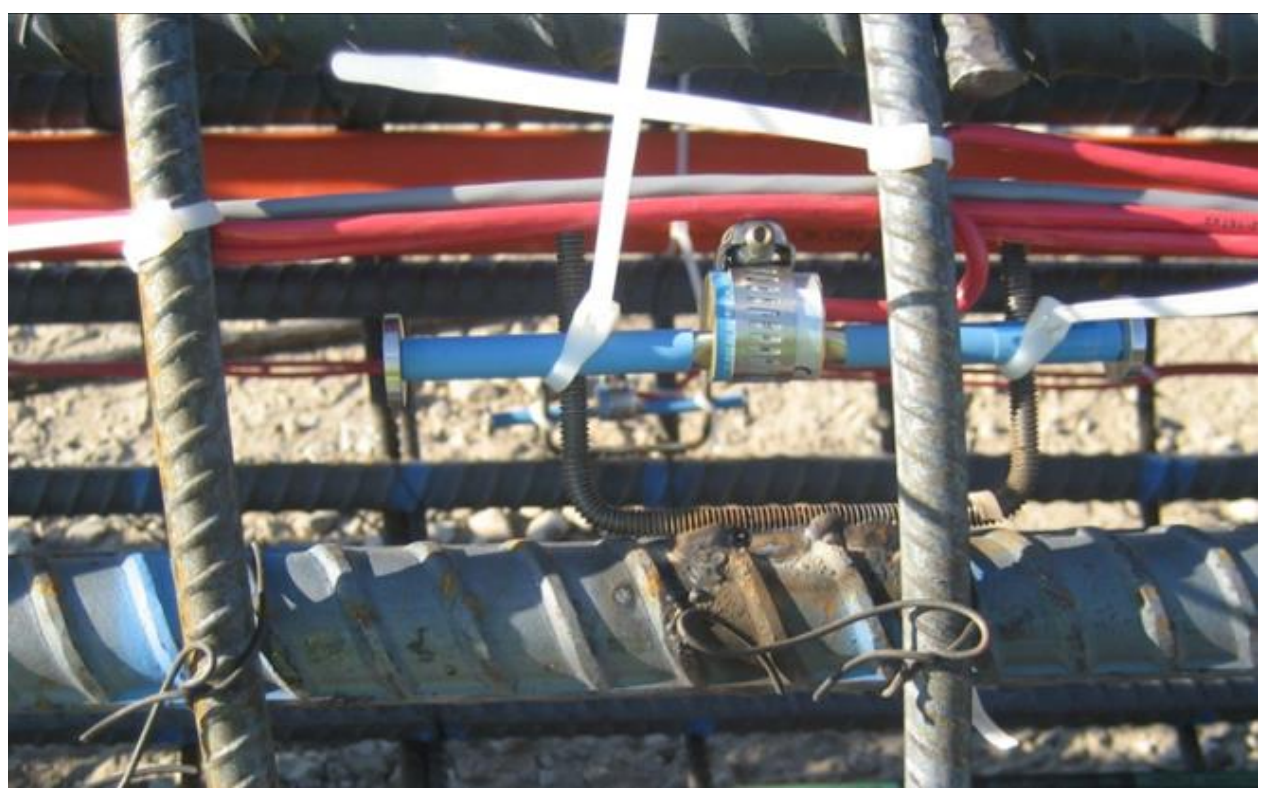

Figure 3.23 - Vibrating wire strain gage mounted on reinforcing cage. 


\subsubsection{Shape Acceleration Array}

The Shape Acceleration Array (SAA) devices, as shown in Figure 3.24, were used to measure deflection profiles in lieu of a conventional inclinometer. The SAA is a chain of rigid segments with sensors that use MEMS (microelectromechanical systems) technology to measure the tilt of each segment/joint (Measurand, 2012). The measuring principle of the SAA is therefore similar to that of the inclinometer, but the SAA provides a continuous record of the deflection of the shaft. This presents safety, reliability, and time advantages compared with taking manual readings with the conventional inclinometer at the end of each load step.

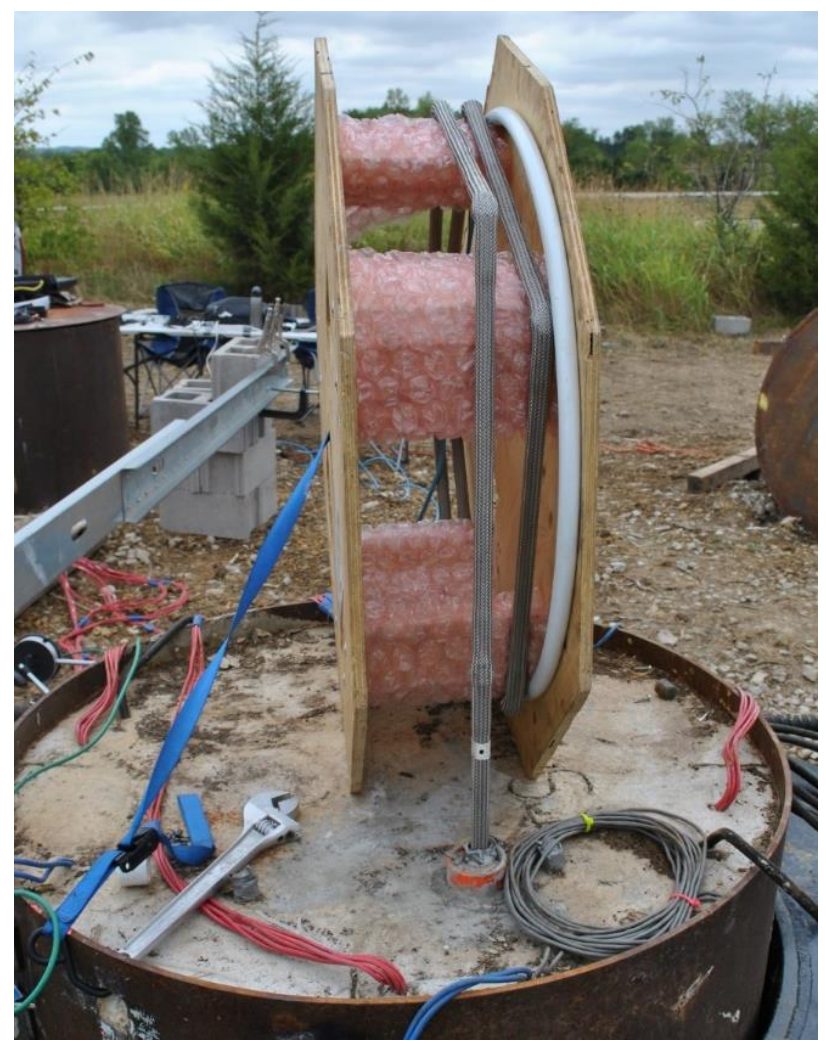

Figure 3.24 - SAA segment and joint. 


\subsubsection{Vibrating Wire Displacement Transducers}

The vibrating wire displacement transducers (LVDTs) were Geokon model 4450. As shown in Figure 3.25, the displacement transducers were connected between the steel casing of the shaft and the reference beam. Mounting the transducers above one another allowed for interpretation of shaft head rotation and displacement at the ground surface. Data from the vibrating wire displacement transducers were recorded continuously by the data logger DataTaker ${ }^{\mathrm{TM}}$ DT85G.

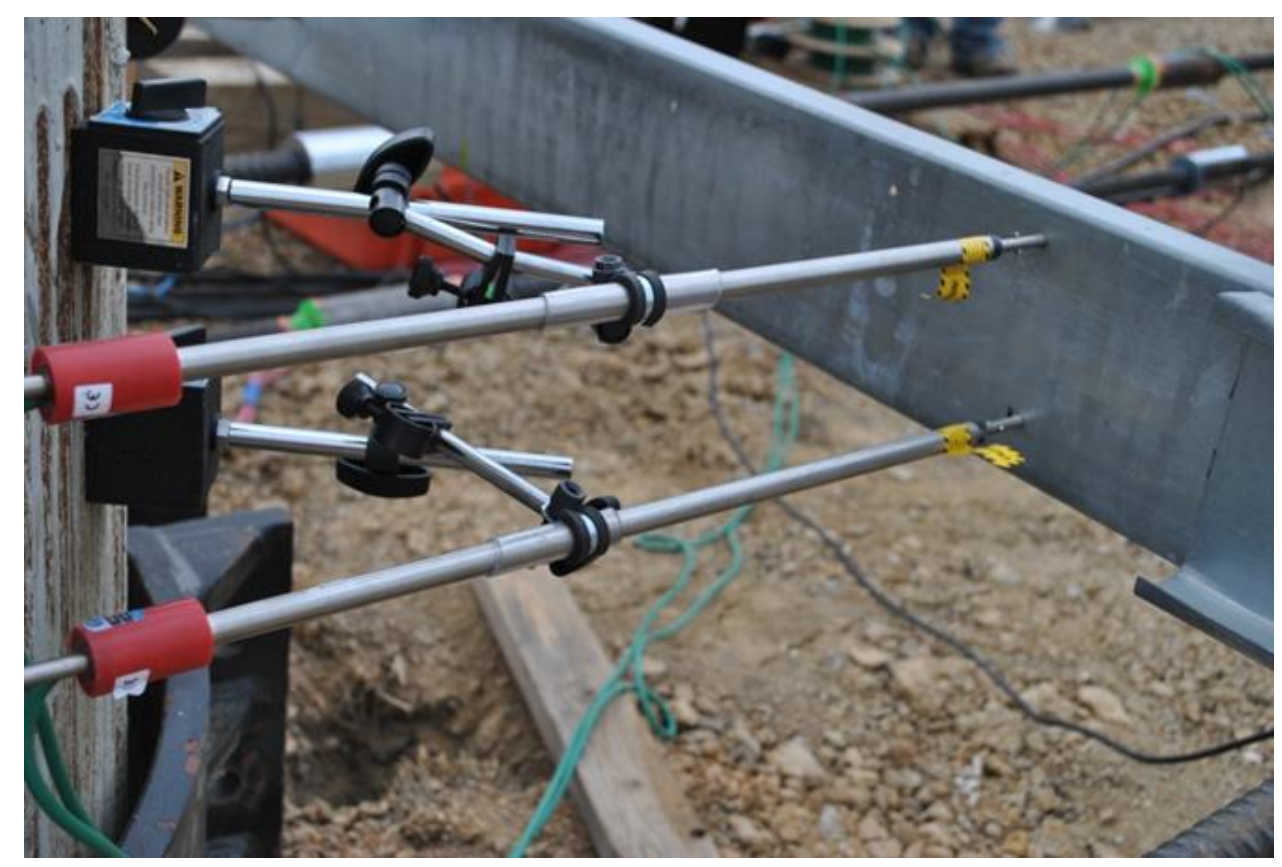

Figure 3.25 - Vibrating wire LVDTs attached to the reference beam.

\subsubsection{Dial Gages}

One dial gage was mounted on each shaft during each test. Like the displacement transducers, the dial gages were mounted between the drilled shaft casing and the 
reference beam as shown in Figure 3.26. Dial gage measurements were recorded manually in one-minute intervals during testing.

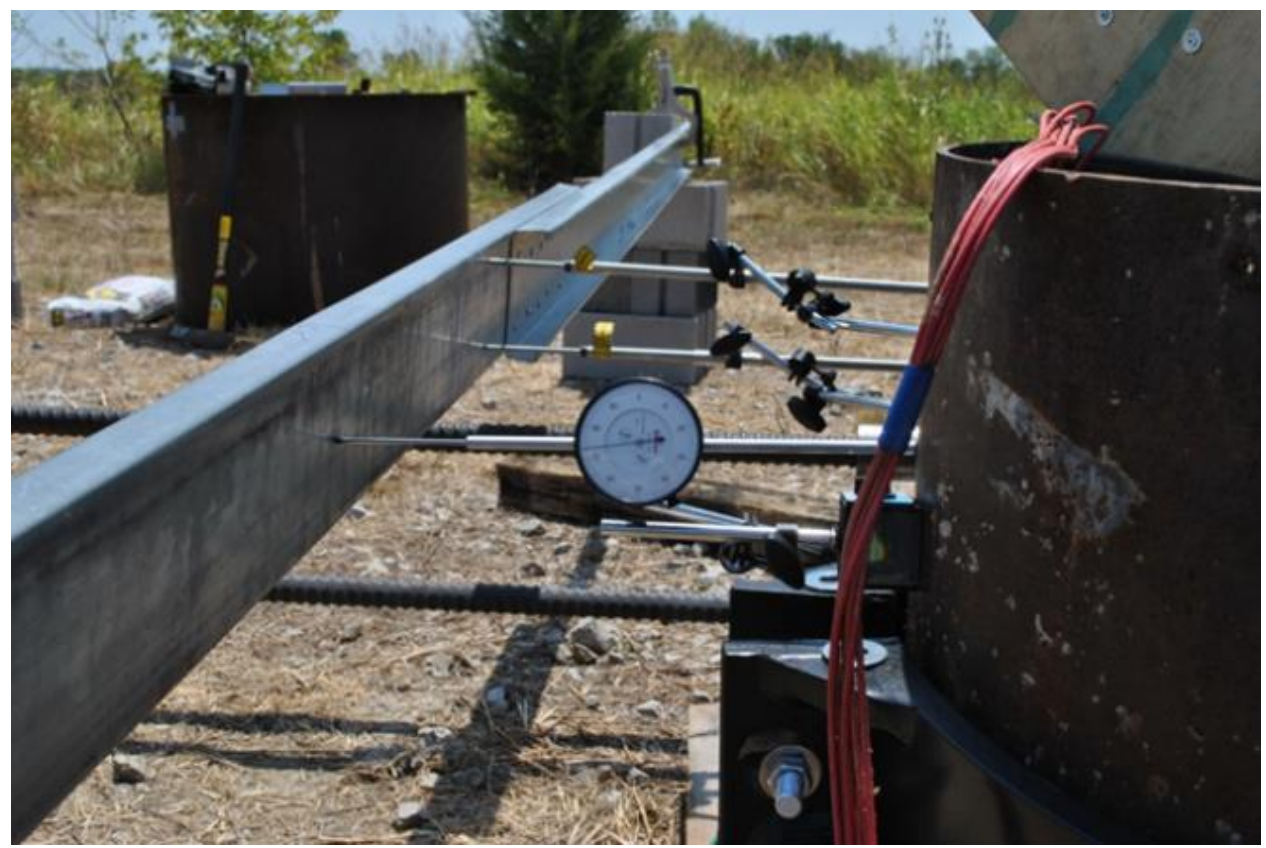

Figure 3.26 - Dial gage mounted to the head of the drilled shaft.

\subsubsection{Load Measurements}

\subsubsection{Hydraulic Pressure Jacks}

Two measurements of load applied to the shafts were recorded. The first was from the hydraulic pressure applied to each jack by the pump as shown in Figure 3.27. Pressure readings were recorded manually for each load step. The pressure gage for the pump had a maximum recordable pressure of 10,000 psi, corresponding to a maximum load of approximately 1500 kips using four jacks. Typically, the load was increased in 200 psi increments, corresponding to 29 kips using four jacks, up to a maximum load typically 
around 300 kips at a pressure of 2000 psi. The pressure gage was marked in 100 psi increments.

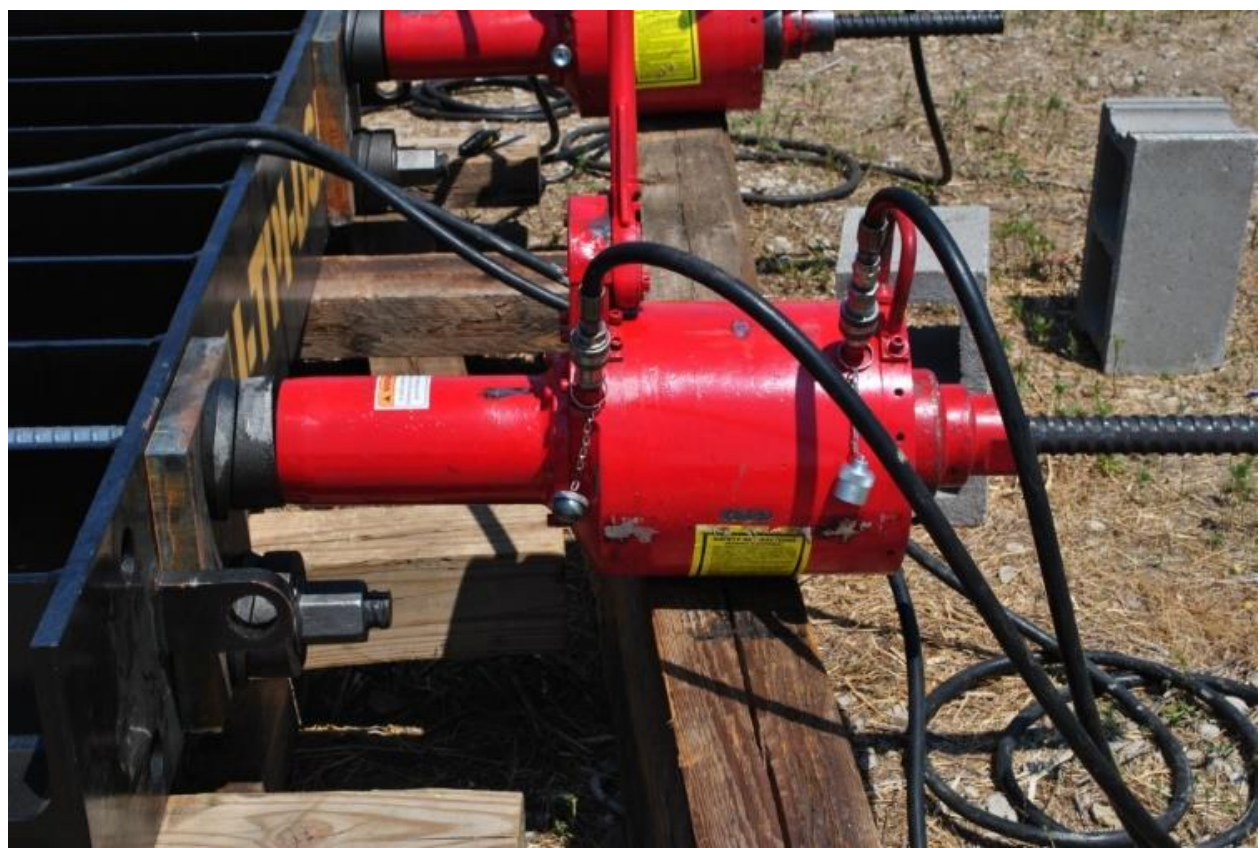

Figure 3.27 - Hydraulic jack applying load to beam.

\subsubsection{DYNA Force sensors}

A second measure of the load was recorded by DYNA Force sensors. According to DSI (2013), DYNA Force sensors "are based on the magneto-elastic properties of ferrous material. The permeability of steel in a magnetic field changes with the stress level in the steel. By measuring the change in permeability, the stress in the steel element can be determined." Each testing pair contained four DYNA force sensors as shown in Figure 3.28. Readings from the sensors were recorded at the beginning and end of each loading stage. 


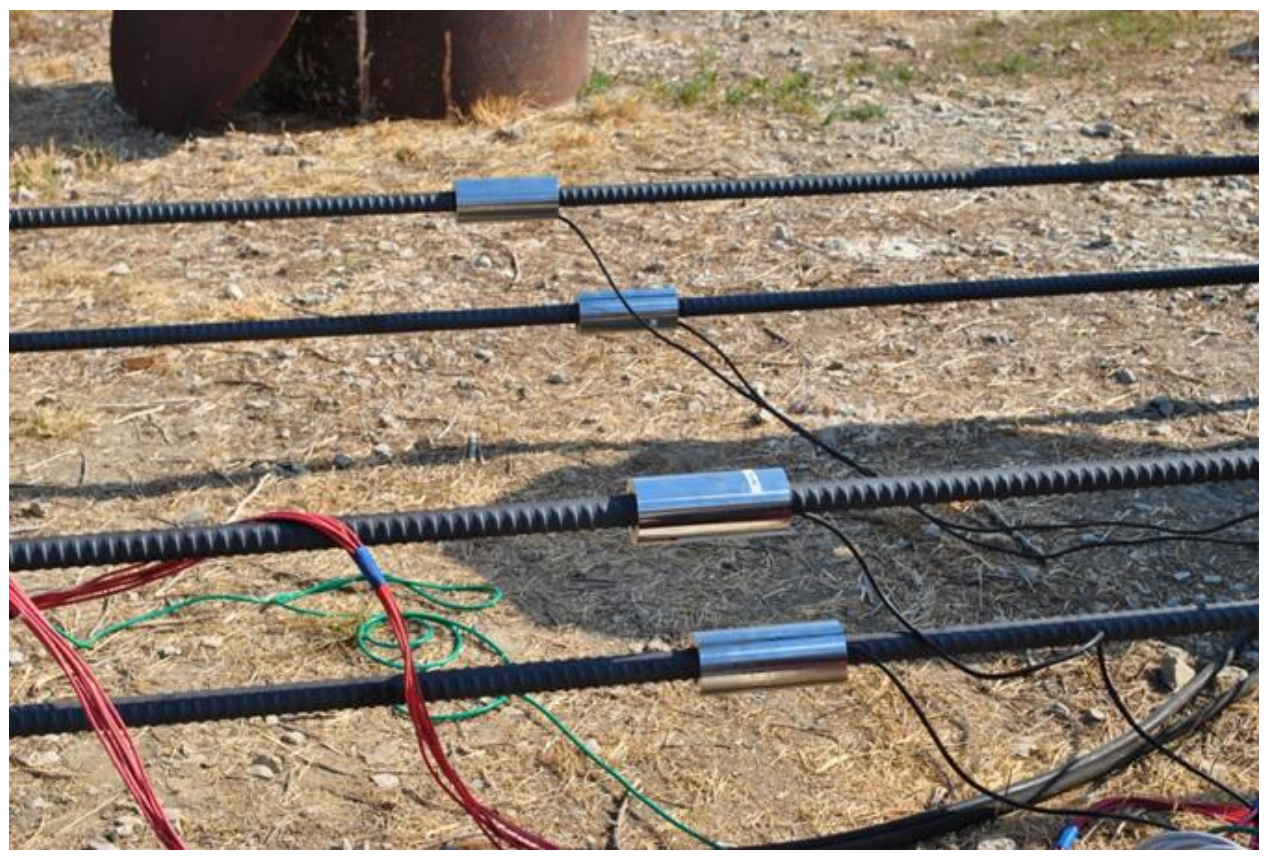

Figure 3.28 - DYNA Force sensors connected to each of four load frame rods.

\subsubsection{Testing Procedure}

The testing procedure typically required one day of test set up for the frame and instruments and one day for conducting the test. Both procedures are described in detail in this section.

\subsubsection{Test setup}

Figure 3.29 shows the typical test setup for the lateral load test program. Instrumentation for each test pair was installed on the day of testing (typically the day after loading frame installation), with the exception of the DYNA Force sensors, which had to be installed on the thread bars as the frame was assembled. One SAA was placed on top each shaft. The LVDTs and dial gages were attached to the shaft casing with magnetic bases. The strain gages and LVDTs cables were connected to the DataTaker ${ }^{\mathrm{TM}}$ multiplexer. 


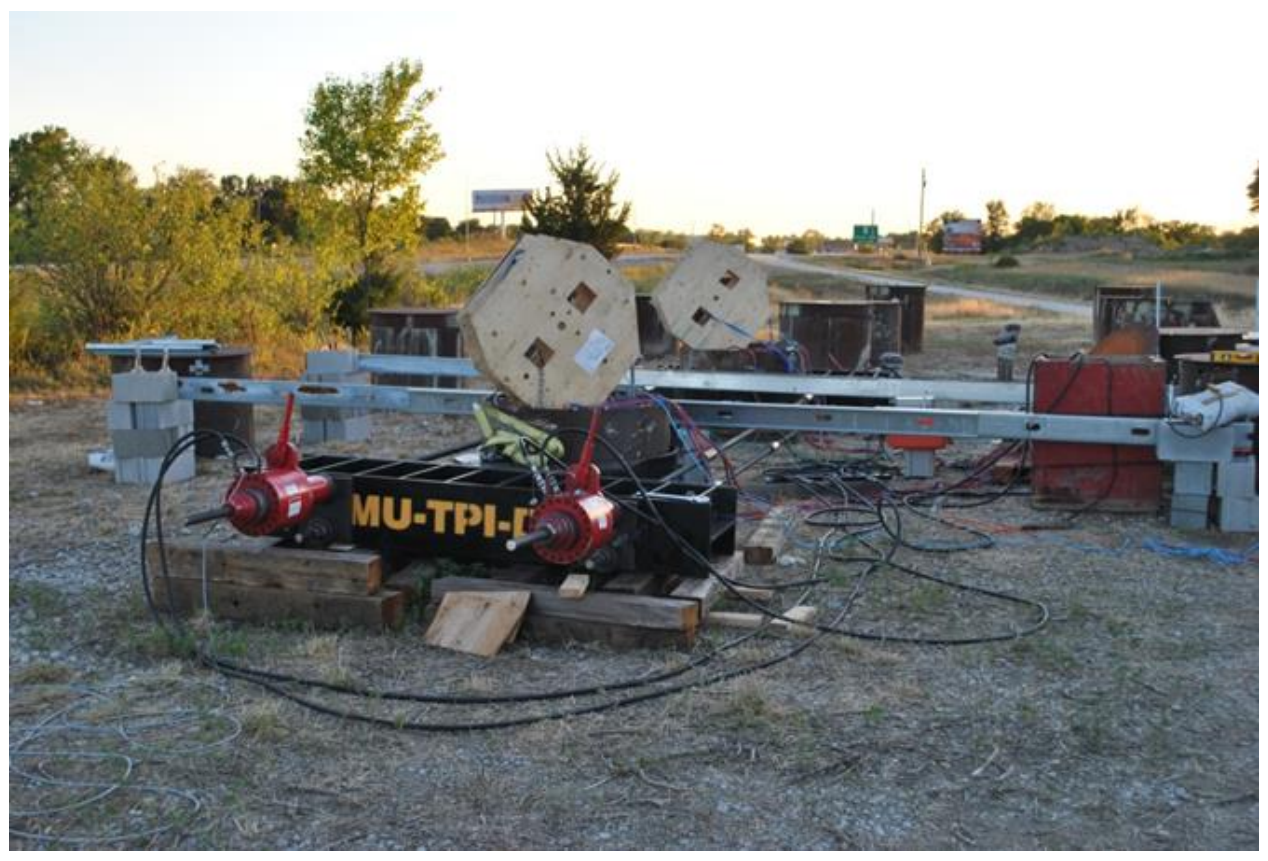

Figure 3.29 - Typical testing set up.

\subsubsection{Lateral Load Testing}

The primary focus of the lateral loaded testing was to measure the response of the foundations subjected to static lateral loading. All tests were performed by pulling two shafts together, so that two foundations were loaded and monitored simultaneously, producing two sets of shaft test results for one individual lateral load test. Shafts pairs were determined primarily by location, but consideration was also given to pairing shafts of similar length.

In general, the lateral load testing followed ASTM D3966 (2007). The loads were applied for each test following the loading sequence of Procedure B for Static Excess Loading. Loads were applied using the hydraulic system following the provided operating instructions including preparation, bleeding the jack, and stressing. For each load test, the 
pressure was increased in 200-psi increments, corresponding to approximately 30 kips using four jacks. The raw data from strain gages, SAA and LVDTs were recorded continuously with data acquisition devices. Readings from dial gages were recorded every minute. A summary of the lateral load testing field results including final loads and displacements is presented in Table 3.3.

Table 3.3 - Summary of field observations from lateral load tests.

\begin{tabular}{lccc}
\hline Test Pair & $\begin{array}{c}\text { Number of } \\
\text { Load Increments }\end{array}$ & $\begin{array}{c}\text { Maximum } \\
\text { Loads (kips) }\end{array}$ & $\begin{array}{c}\text { Maximum } \\
\text { Displacement (in.) }\end{array}$ \\
\hline F1-F2 & 11 & 306 & 8.18 \\
\hline F4-F6 & 11 & 321 & 9.02 \\
\hline F7-F8 & 13 & 365 & 7.31 \\
\hline W1-W2 & 16 & 321 & 3.94 \\
\hline W1-W2 with Soil Removed & 10 & 277 & 4.36 \\
\hline W1-W5 with Soil Removed & 12 & 350 & 9.23 \\
\hline W3-W4 & 11 & 321 & 4.65 \\
\hline W3-W4 with Soil Removal & 10 & 292 & 5.13 \\
\hline W6-W7 & 8 & 175 & 1.62 \\
\hline W6-W7 with Soil Removed & 11 & 306 & 6.59 \\
\hline W8-W9 & 20 & 117 & 0.96 \\
\hline W8-W9 with Soil Removed & 12 & 350 & 7.79 \\
\hline W10-W11 & 20 & 146 & 0.94 \\
\hline W10-W11 with Soil Removed & 9 & 262 & 5.96 \\
\hline W12-W13 with Soil Removed & 8 & 233 & 11.14 \\
\hline W14-W15 with Soil Removed & 9 & 262 & 7.10 \\
\hline & & & \\
\hline
\end{tabular}




\subsection{Experimental Results}

Instrumentation measurements were analysed to produce the measured response

of each tested shaft. The shaft response is characterized by the load-displacement behaviour at the top of the shaft, the displacement profiles and the bending moment profiles along the length of the shaft.

\subsubsection{Load-Displacement Curves}

The displacement of the top of each shaft was measured with two LVDTs, one above the other, and with one dial gage. In addition, the SAA data provided a fourth measure of the displacement of the top of each shaft. The total load applied to the shaft, which was interpreted from the pressure gage on the hydraulic pump, was plotted versus each of the measures of displacement of the top of the shaft. An example of resulting load-displacement curves for one shaft is shown in Figure 3.30.

The load-displacement curves measured from dial gage, top and bottom LVDTs are very close to each other since they were all measured directly from the reference beam and the distance from top of the shaft to the measuring points for that three instrumentations were about the same. For SAA measurement, the displacements of the top of the shaft were slightly bigger than those from dial gage or LVDT since they were calculated from position data of a segment end, which usually at higher elevation than the measuring points above. 


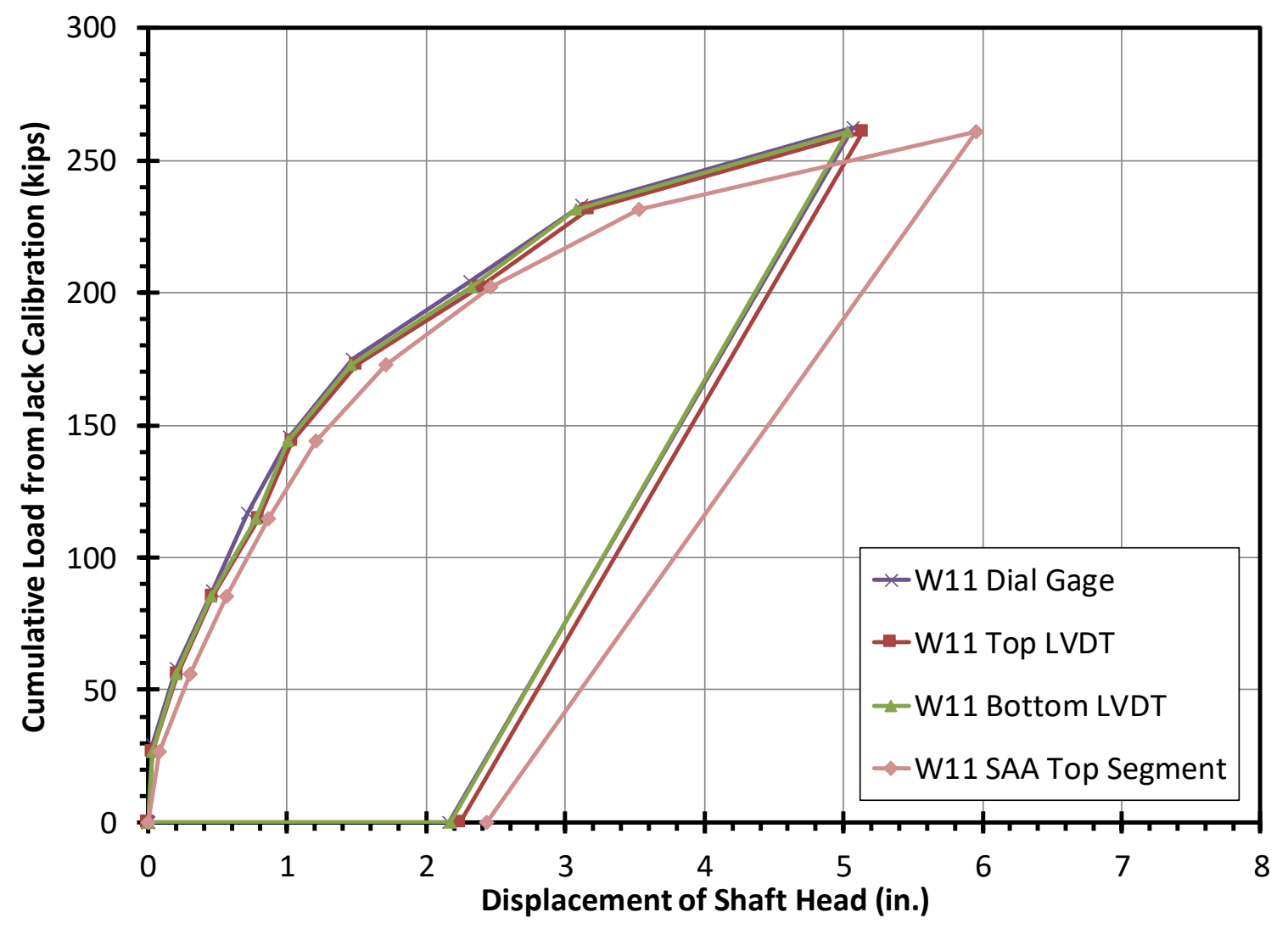

Figure 3.30 - Load-displacement curves for test of shaft W11 at Warrensburg test site.

\subsubsection{Displacement Profiles from SAA}

The SAAs used for these tests consist of a chain of 30 segments, each $500 \mathrm{~mm}$ (19.7 in.) in length. Position data for each segment were recorded by SAA software in three dimensions, with the cross section of the shaft defined on the horizontal $x$ and $y$ axes and the vertical $z$ axis. Transverse displacement values at the end of each load increment were calculated from the differential movement in the $\mathrm{x}$ and $\mathrm{y}$ directions:

$$
\delta_{i}=\sqrt{\left(x_{i}-x_{i 0}\right)^{2}+\left(y_{i}-y_{i 0}\right)^{2}}
$$

Eq. 3.1. 
where, $\delta_{i}=$ total transverse displacement of the $\mathrm{i}^{\text {th }}$ segment of the SAA; $x_{i}=$ position of the $\mathrm{i}^{\text {th }}$ segment along the $\mathrm{x}$-axis; $x_{i 0}=$ initial (zero load) position of the $\mathrm{i}^{\text {th }}$ segment along the $x$-axis; $y_{i}=$ position of the $i^{\text {th }}$ segment along the $y$-axis and $y_{i 0}=$ initial (zero load) position of the $\mathrm{i}^{\text {th }}$ segment along the $\mathrm{y}$-axis. This calculation is necessary since the direction in which the shafts were pulled was aligned somewhere between the $\mathrm{x}$ and $\mathrm{y}$ axes. Presumably, the total displacement occurred along the line between the center of the two test shafts.

Profiles of displacement with depth for each load step were calculated according to Eq. 3.1 for each shaft. An example of displacement profiles for shaft W10 with soil removal is presented in Figure 3.31 with all profiles for shaft W10 and the one pairing with it (W11) are presented side-by-side in the same plot. For all other lateral load tests, profiles of displacement can be found from Appendix $\mathrm{C}$ of the report by Boeckmann et. al (2014), with all profiles for one shaft test contained in the same plot and with plots from the test shaft pairings (e.g. W1 and W2, F4 and F6) presented side-by-side. 

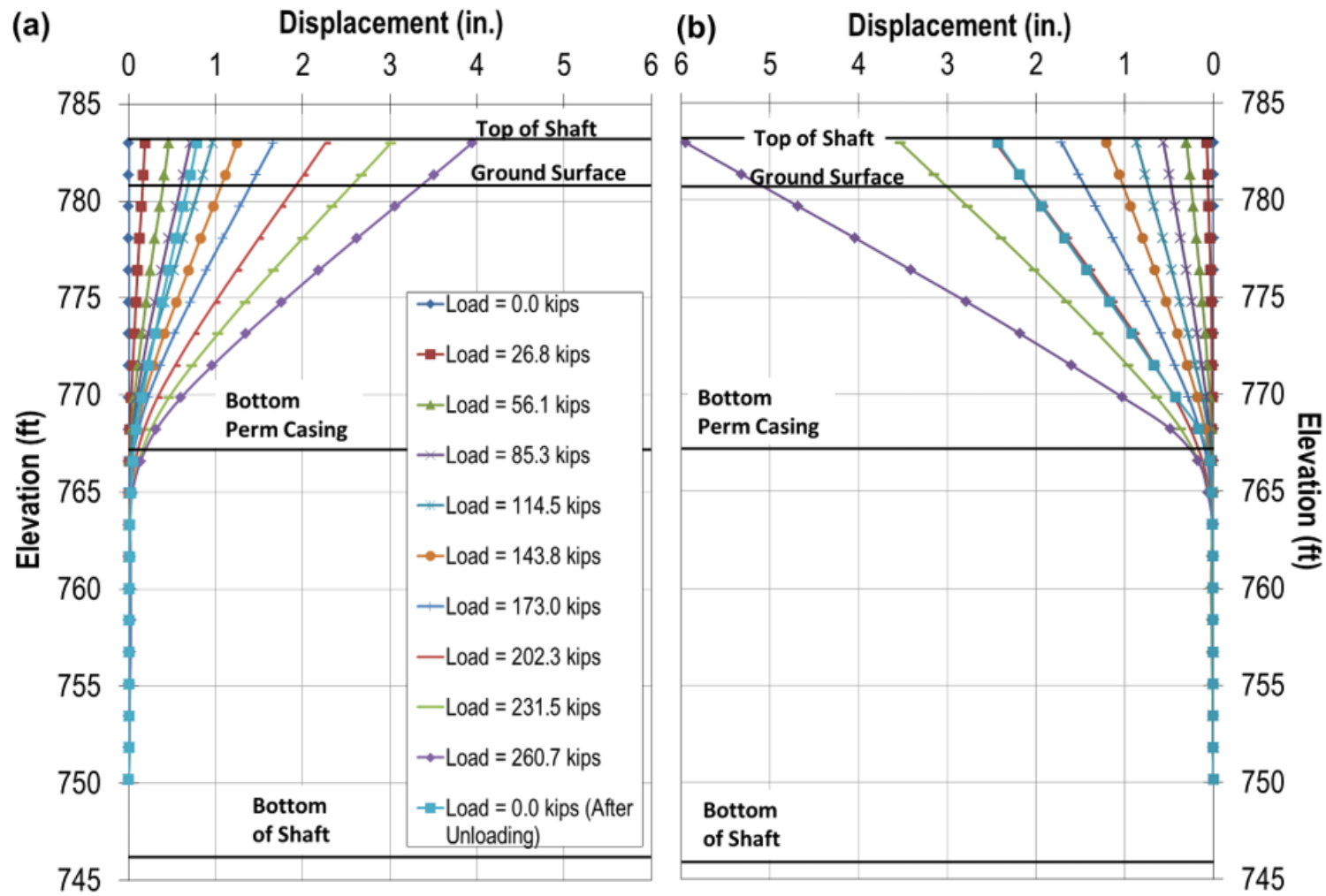

Figure 3.31 - Displacement profiles from SAA data for test of shafts (a) W10 and (b) W11

\subsubsection{Methodology for Analysis of Bending Moment Data}

Analysis of bending moments from measurements of strain (via strain gages) and displacement (via SAA) is a nontrivial exercise, primarily because the bending stiffness, El, is nonlinear and greatly influenced by concrete cracking, which is difficult to predict. The procedure used here predicted values of bending stiffness along the length of the shaft as a function of the bending curvature, which was interpreted from the SAA displacement data. Values for bending stiffness as a function of curvature were computed using Ensoft LPile v2012, which incorporated the non-linearity of concrete behavior considering uncracked, partially cracked and fully cracked sections. 
The predicted values of bending stiffness were used to calculate bending moment profiles from SAA data and from strain gage data, and the bending moment profiles were differentiated in an attempt to determine shear force and lateral pressure profiles. Each of these steps is described in more detail in the sections below.

The displacement profiles interpreted from the SAA data were differentiated to calculate profiles of cross-sectional rotation of the shaft:

$$
\theta_{i}=\frac{d \delta}{d z} \approx \tan ^{-1}\left(\frac{\delta_{i}-\delta_{i-1}}{L}\right)
$$

Eq. 3.2.

where $\theta_{i}=$ cross-sectional rotation of the $i^{\text {th }}$ segment of the SAA, radians

$$
L=\text { SAA segment length }(500 \mathrm{~mm}=19.7 \mathrm{in} \text {. }
$$

The rotation profiles were then differentiated to calculate profiles of bending curvature of the shaft:

$$
\kappa_{i}=\frac{1}{\rho_{i}}=\frac{d^{2} \delta}{d z^{2}}=\frac{d \theta}{d z} \approx \frac{\theta_{i}-\theta_{i-1}}{L}
$$

Eq. 3.3.

where $\kappa_{i}=$ bending curvature of the $i^{\text {th }}$ segment of the SAA, radians per unit length

$\rho_{i}=$ radius of curvature of the $i^{\text {th }}$ segment of the SAA, consistent units of length

$L=$ SAA segment length $(500 \mathrm{~mm}=19.7 \mathrm{in}$. 
LPile was used to establish the relationship between nonlinear $E I$ and bending curvature for a given cross-section. Then that relation was used with the computed profiles of bending curvature to establish the bending stiffness along the length of the shaft. The procedure employed by LPile to provide El versus bending curvature relationship is documented in the program's technical manual (Isenhower \& Wang, 2011). In summary, LPile iterates the location of the neutral axis until force equilibrium is satisfied, accounting for concrete cracking. Cracking of the concrete is predicted as a function of the compressive strength of the concrete, which was estimated from compression tests performed on cylinders from each shaft pour. An example of the shaft bending stiffness predicted by LPile as a function of the bending curvature is shown in Figure 3.32. The bending stiffness decreases abruptly at small values of curvature, which initiate cracking of the concrete. After the concrete cracks, the decrease in stiffness is more gradual as the steel yields.

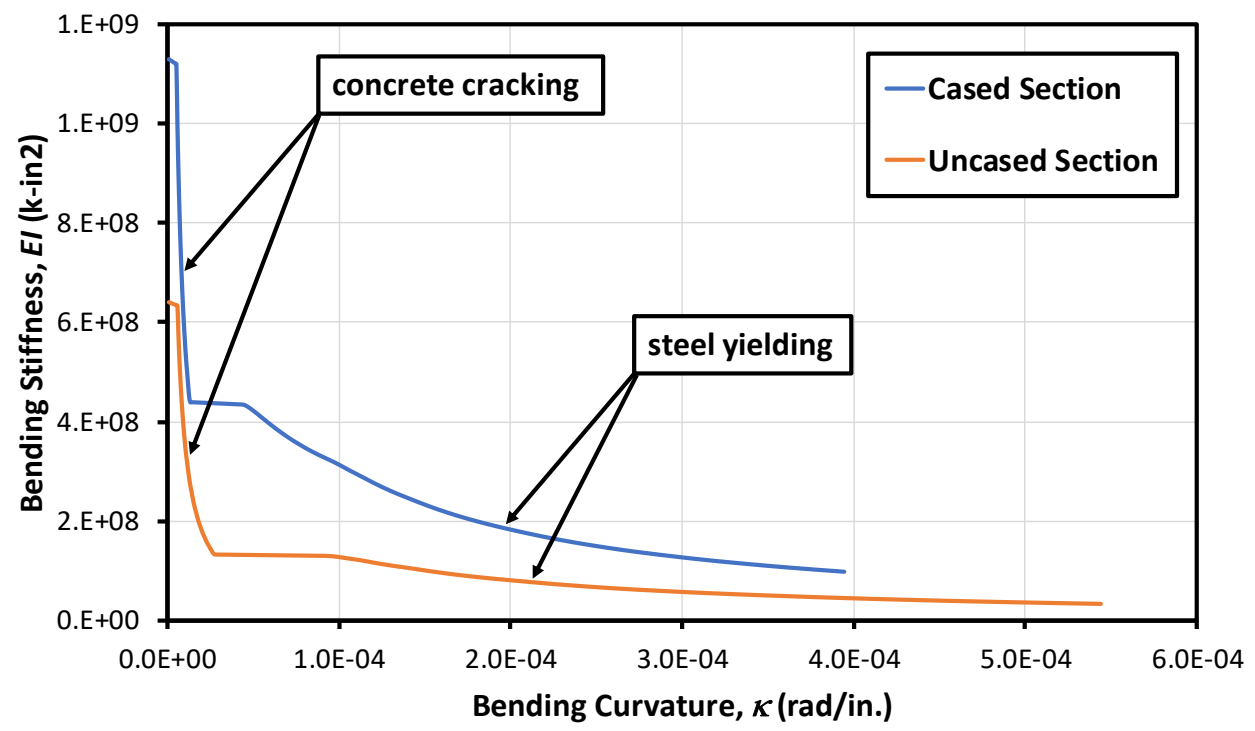

Figure 3.32 - Example of bending stiffness versus bending curvature for shaft W7. 
The estimated bending stiffness from LPile was used to calculate two profiles of bending moment along the length of the shaft, one from the SAA data and the other from strain gage data. Based on SAA data, bending moment was calculated from the computed bending curvature and the estimated bending stiffness from LPile, as showing in Eq. 3.4. On the other hand, based on strain gage data, bending moment was calculated from the bending strain measured from strain gages and the estimated bending stiffness from LPile, as showing in Eq. 3.5.

$$
M_{i}=\kappa_{i} \cdot E I_{i} \quad \text { (consistent units) }
$$

Eq. 3.4.

where $M_{i}=$ bending moment of the $i^{\text {th }}$ segment of the SAA

$\kappa_{i}=$ bending curvature of the $i^{\text {th }}$ segment of the SAA

$E I_{i}=$ shaft bending stiffness at the $i^{\text {th }}$ segment of the SAA

$$
M_{j}=\frac{\varepsilon_{j} \cdot E I_{j}}{c_{j}} \quad \text { (consistent units) }
$$

Eq. 3.5.

where $M_{j}=$ bending moment at the level of the $j^{\text {th }}$ strain gage

$\varepsilon_{j}=$ bending strain measured by the $j^{\text {th }}$ strain gage

$E I_{j}=$ shaft bending stiffness at the $j^{\text {th }}$ strain gage

$c_{j}=$ distance from compressive edge of shaft to neutral axis at $j^{\text {th }}$

strain gage 
For all calculations, the bending stiffness at a particular depth was limited to its minimum historic value if the LPile analysis indicated concrete cracking had ever occurred at that depth. For example, if the curvature at a depth of $10 \mathrm{ft}$ was great enough to initiate concrete cracking for an applied lateral load of 100 kips, the bending stiffness used to calculate the bending moment for subsequent loads was limited to a maximum value of the stiffness calculated for the 100-kip load, even if the bending curvature at a subsequent load was less than it had been at a load of 100 kips. This reasoning was extended to the shafts at Warrensburg that were tested twice, once before drilling out soil between shafts and once after.

\subsubsection{Measured Drilled Shaft Response}

The methodology and equations presented in Section 3.3.3 were used to create profiles with depth of (1) displacement, (2) cross-sectional rotation, and bending moments from (3) SAA data and (4) strain gage data. Each of the four profiles was calculated for each load step of each shaft test. The results can be found from Appendix D of the report by Boeckmann et. al (2014), with all four profiles for each shaft test presented side-by-side. Example profiles are presented and discussed in this section.

\subsubsection{Comparison of Bending Moments from SAA and strain gage data}

Section 3.3.3 presented two methods for interpreting bending moment from the collected data. The first involves differentiating the displacement profiles measured by the SAA twice and then multiplying the resulting bending curvature by the calculated bending stiffness. For the second method, the bending moment was calculated directly 
from the strain measured by the strain gages and the computed bending stiffness. Bending moment profiles from both data sources are presented side-by-side for Frankford (Figure 3.33), Warrensburg before soil removal (Figure 3.34), and Warrensburg after soil removal (Figure 3.35).

Both sets of bending moment profiles for Frankford test shaft F4 (Figure 3.33) show similar shapes and magnitudes below the permanent casing and in the uppermost shale layer, where the strain gage data suggest the maximum moment occurs. The bending moment profile from the SAA data shows considerably more "noise" than the strain gage profile. This could perhaps be partially explained because there are more SAA segments than there are strain gages, but the noise is better explained by having to differentiate the SAA data twice to calculate bending moment, whereas the strain gages provide a more direct measurement of the bending moment. The large negative bending moments shown near the ground surface for SAA data are also most likely a result of taking the second derivatives. The strain gages provide a more realistic bending moment profile.

The same observations apply to the Warrensburg data before (Figure 3.34) and after (Figure 3.35) soil removal. For both tests shown, the shape and magnitudes from SAA and strain gage data are similar, but interpretation of the SAA data produces considerably more noise and unreasonable values toward the top of the shaft. Observations arise from comparing the results before and after soil removal show that after soil removal, the bending moment in the soil was decreased considerably while the 
bending moment in the rock increased, producing a flatter bending moment profile that extends deeper than before soil removal. This indicates the drilling operation was successful for increasing the depth of load transfer.
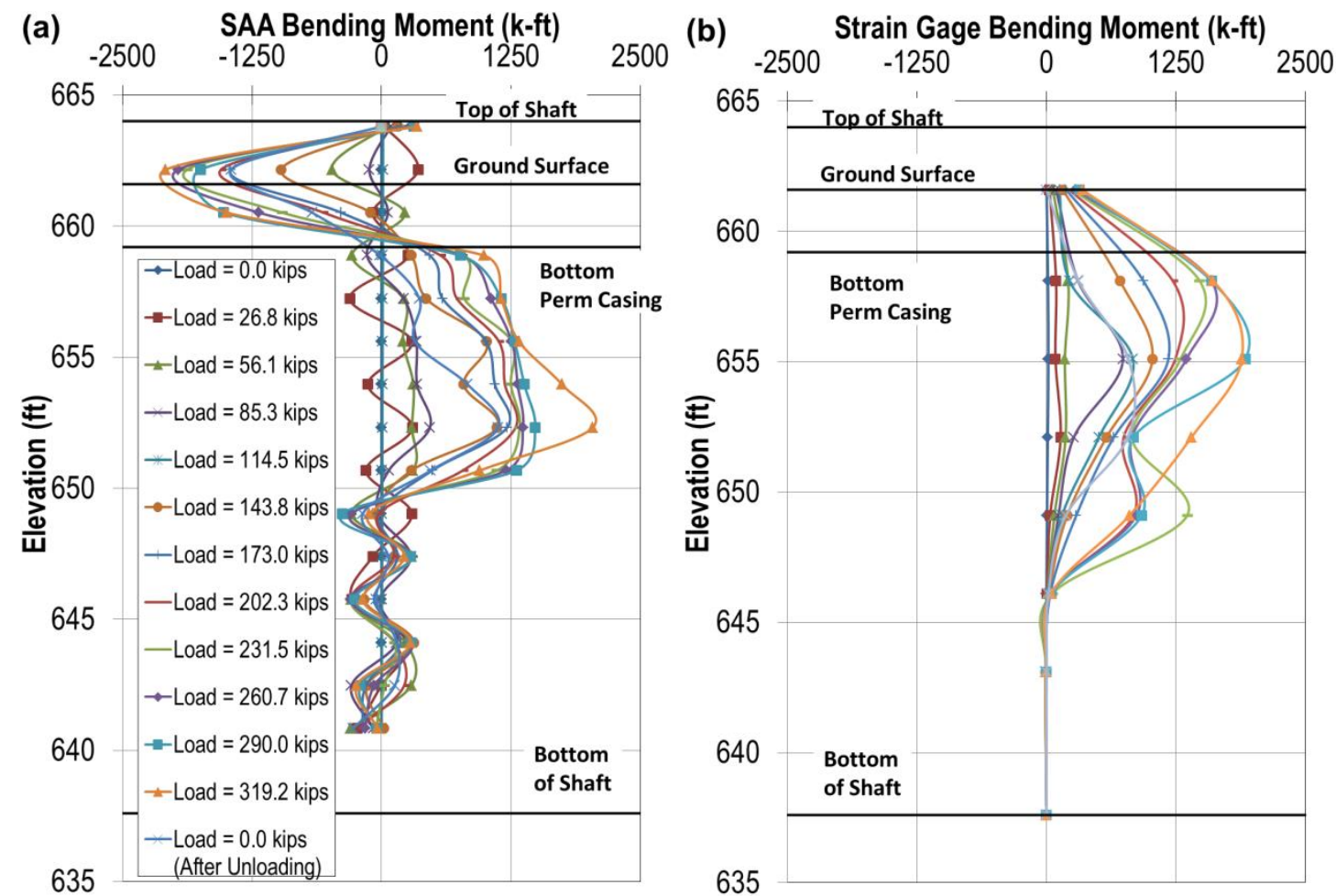

Figure 3.33 - Comparison of bending moments in test shaft F4 at Frankford test site from (a) SAA data and (b) strain gage data. 

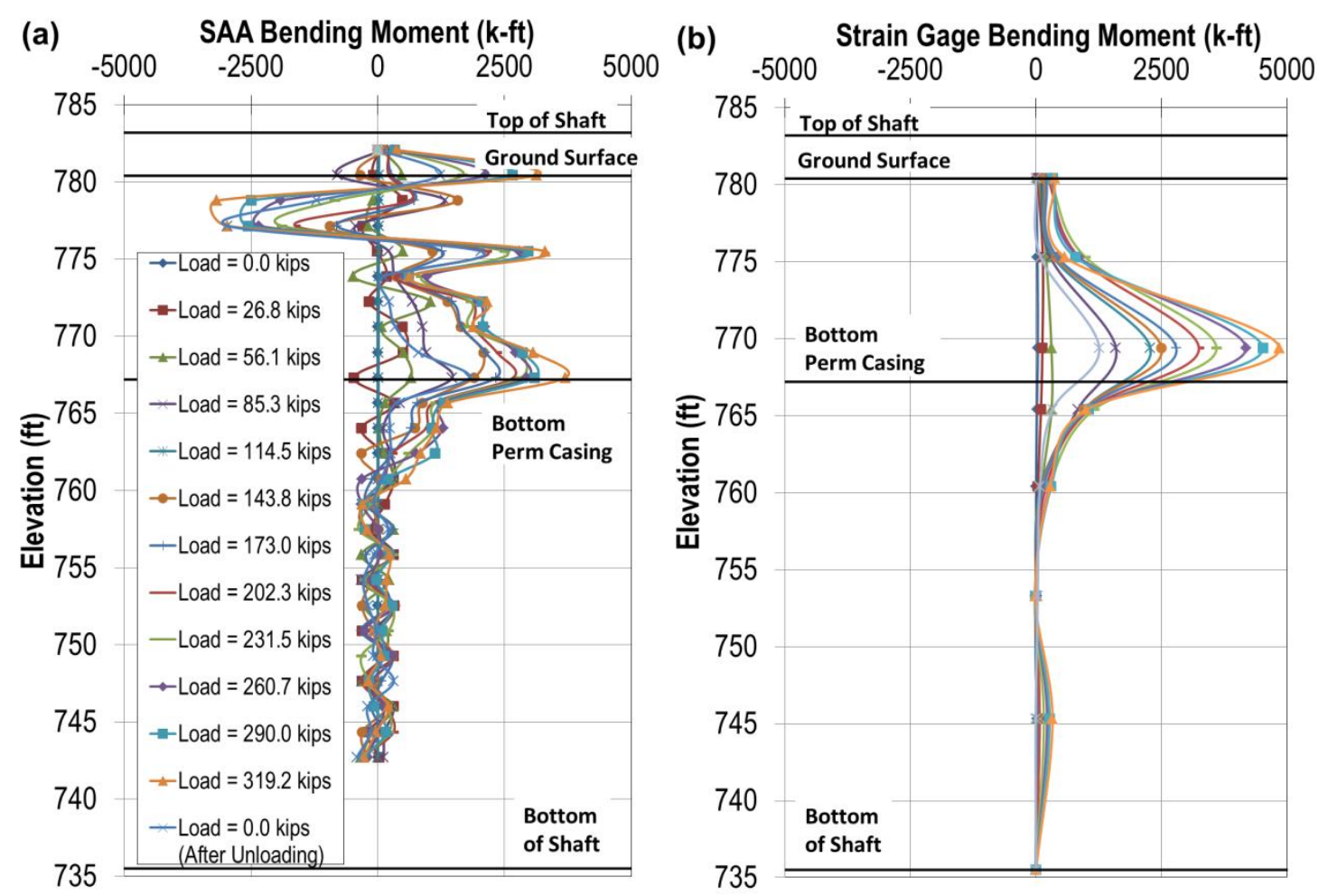

Figure 3.34 - Comparison of bending moments in test shaft W3 at Warrensburg test site before soil removal from (a) SAA data and (b) strain gage data. 

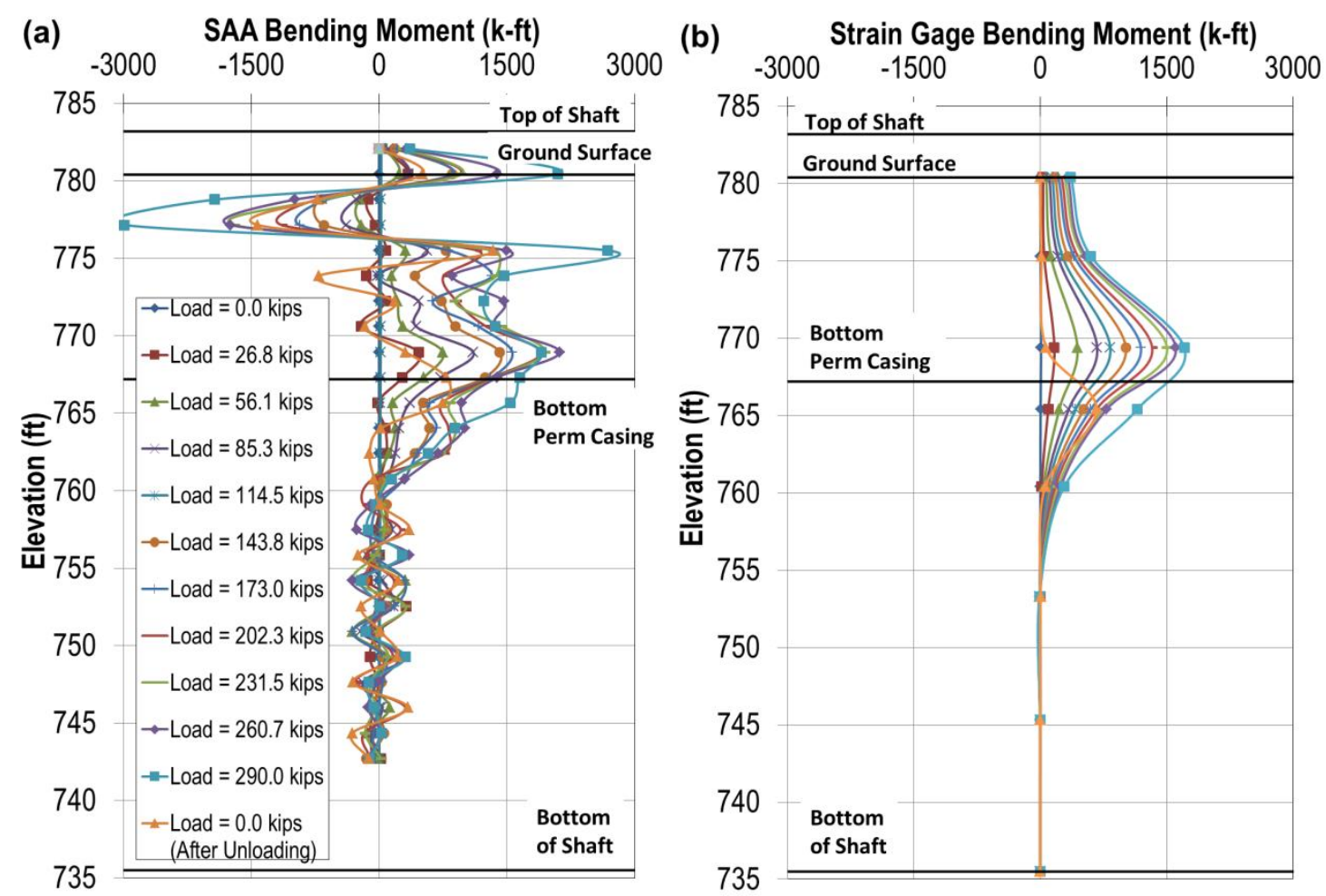

Figure 3.35 - Comparison of bending moments in test shaft W3 at Warrensburg test site after soil removal from (a) SAA data and (b) strain gage data.

\subsubsection{Shear Force and Lateral Pressure}

The interpretation technique described in Section 3.3.3 can be extended to calculate profiles of shear force and unit lateral pressure as the first and second derivatives, respectively, of bending moment. The results of such a calculation are presented for test shaft F4 from the Frankford site in Figure 3.36. The shear force and unit lateral pressure profiles are noisy to the point of not being useful. This is consistent with the findings of Section 3.3.4.1; measurement limitations make it very difficult to produce meaningful results for second and higher-order derivative quantities. Differentiating the strain gage bending moment profiles is similarly challenging; each differentiation 
effectively removes a data point, and with only six levels of strain gages to begin with, the resulting shear and unit lateral pressure profiles almost certainly will not capture the shapes of the true profiles. The limitations of numerical differentiation provided a large motivation for using the computer model documented in the next chapter to further interpret the test results.
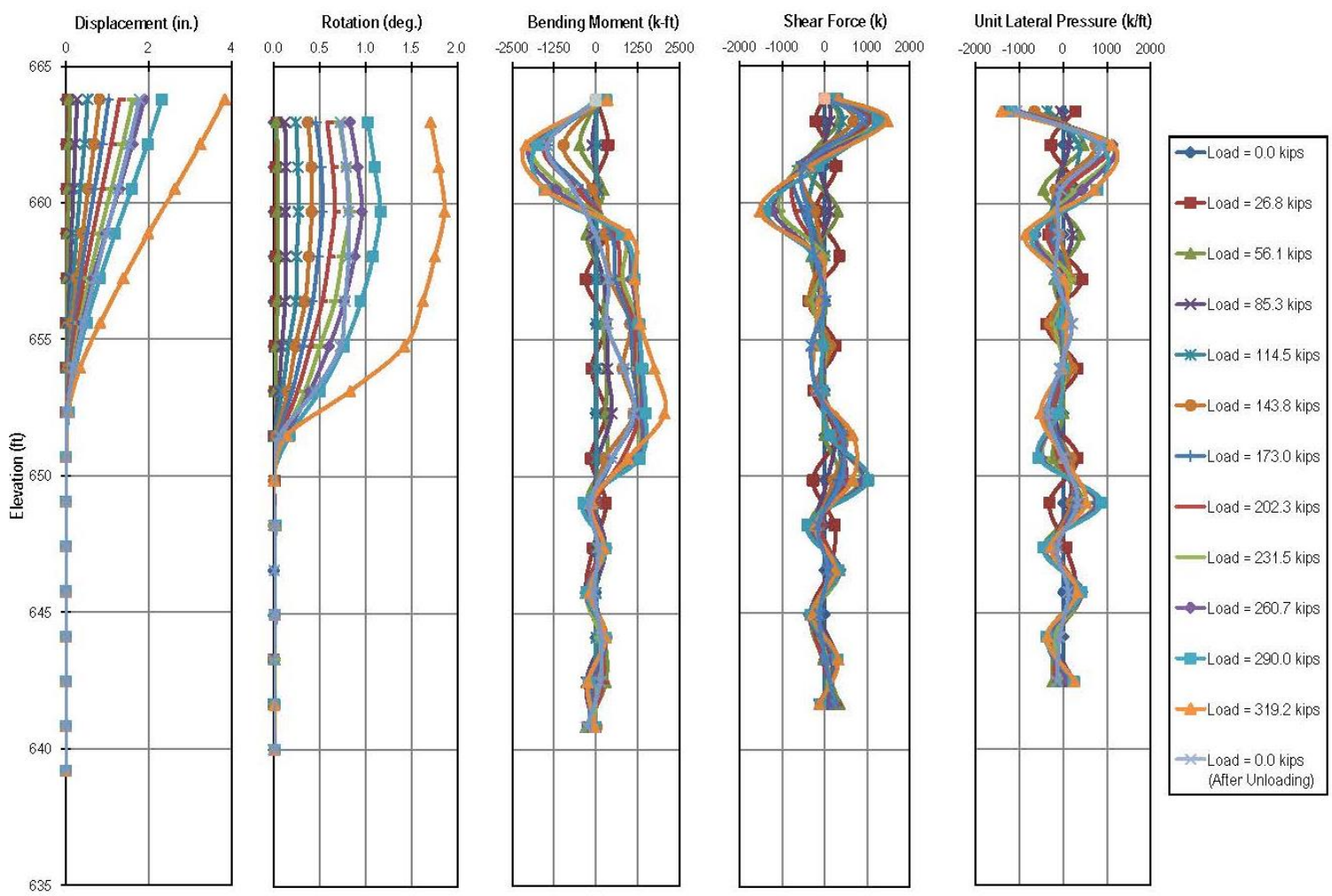

Figure 3.36 - Example of interpreting shear force and unit lateral pressure from SAA data (Frankford shaft F4). 


\subsection{Summary}

This chapter presented the lateral load test for drilled shafts in shale, which involved 16 shaft-pair tests. Shafts were instrumented with dial gage, LVDTs, SAA and strain gages. Instrumentation measurements were analysed to measure the response of each tested shaft, which was characterized by the load-displacement behaviour at the top of the shaft, the displacement profiles and the bending moment profiles along the length of the shaft.

The load-displacement behaviour at the top of the shaft was computed from dial gage, top and bottom LVDTs and the SAA segment at the top of the shaft. The results from 4 different instrumentations were consistent with the one calculated from SAA often be slightly higher than the others due to the difference in measuring elevations.

The displacement profile along the length of a shaft was calculated directly using SAA data for each load sequence. Displacement profiles were differentiated to calculate the rotation profiles and then differentiated one more time to obtain the bending curvatures along the shaft.

LPile procedure which involving the nonlinearity of bending stiffness due to concrete cracking were used to establish the relationship between bending stiffness and bending curvature. Based on that relationship, drilled shaft responses in terms of bending moment, shear and lateral pressure were calculated based on calculated bending stiffness and data from two different sources: SAA or strain gage. 
The bending moment profile from the SAA data shows considerably more "noise" than that from strain gage data because of the differentiation process. Thus, strain gages provide a more realistic bending moment profile. However, when calculating shear and lateral pressure profile, the drawback of high-order differentiation when using SAA and the limitation of measurement data point when using strain gage raise difficulties to produce reliable results. Therefore, computational program should be using to provide a better way of interpretation load test data. 


\section{CHAPTER 4. INTERPRETATION OF SHAFT RESPONSE USING}

\section{NUMERICAL MODEL}

A finite element computer program has been developed using MATLAB to analyze drilled shafts subjected to lateral loading. The program determines $p-y$ curves that best match of the observed shaft response for a given shaft geometry and loading. This chapter describes the finite element method, the methodology of the computer program and the interpreted results. A complete set of interpreted shaft response and interpreted $p-y$ response along with measured results is included in the Appendix.

\subsection{Finite Element Method}

Finite element method is implemented in the computer program to model the drilled shafts subjected to lateral loading and predict the shaft responses. First of all, drilled shaft is modeled using 2D beam elements. Secondly, the soil-structure interaction interface is simulated using $p-y$ method. Finally, finite element formulations are used to calculate the shaft responses in terms of displacements, bending moments and shear forces.

\subsubsection{Finite Element Modeling}

A finite element model to simulate the response of a single drilled shaft subjected to lateral loading in shale is presented here. The typical finite element model uses 2D beam element to model a drilled shaft subjected to lateral loading. The number of beam 
elements has been chosen at the initial process. Each beam contains of two nodes so the number of nodes is equal to number of beams plus one. Each node is able to deform in lateral, vertical and rotational directions. Based on the length of shaft and the number of beam elements, the length of beam will be calculated.

\subsubsection{Soil-structure Interface Modeling Using p-y Method}

The program implements the p-y method (e.g. Reese et al., 2006; Isenhower and Wang, 2011) to model the soil-structure interaction interface. The $p$-y method can be implemented through the finite element method, with the shaft modeled with beam elements with two nodal ends and the soil modeled as a series of non-linear springs acting on each nodal end as shown in Figure 4.1. Each spring is governed by a non-linear $p-y$ curve, where $p$ is the soil resistance on a unit length of the shaft (force/length) and $y$ is the relative lateral deflection between the soil and the shaft (length). An example of $p-y$ curve is shown in Figure 4.2. 


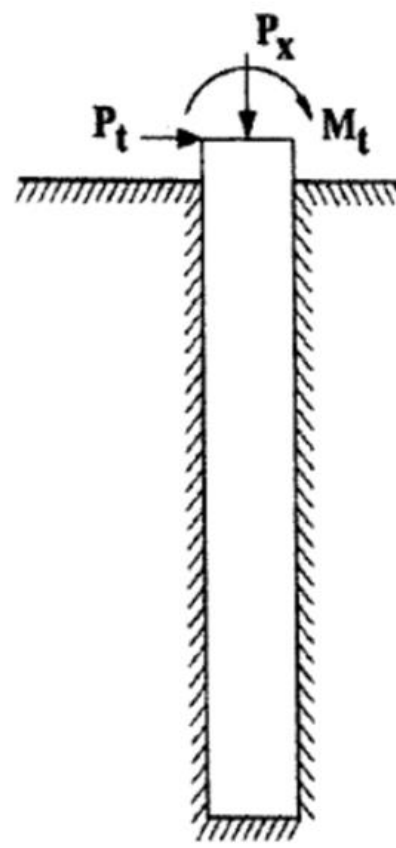

(a)

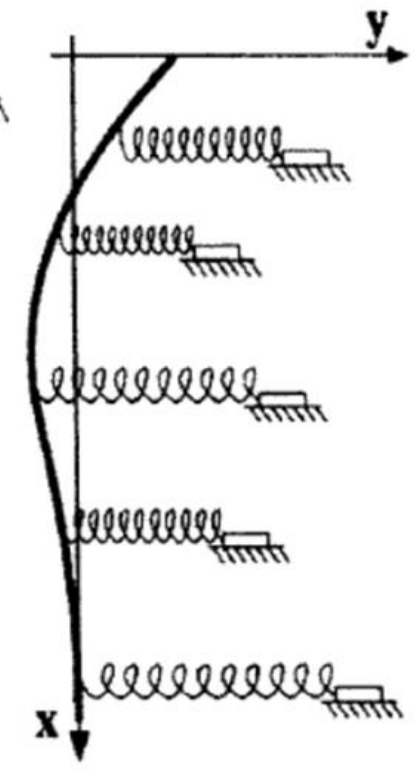

(b)
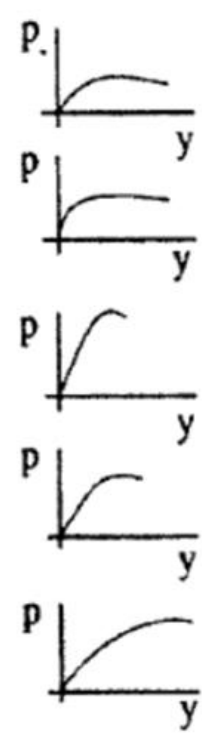

(c)

Figure 4.1 - Schematic representation of the $p-y$ method:

(a) drilled shaft subjected to lateral loading, (b) soil modeled as a series of springs, and (c) p-y curves governing spring stiffness (Reese et al., 2006).

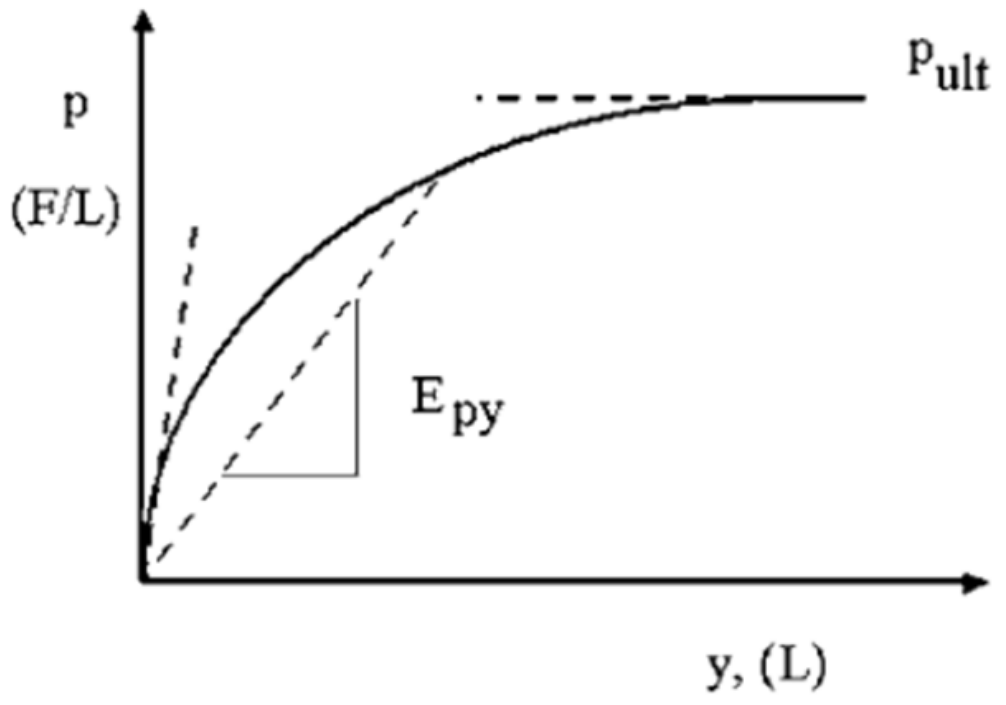

Figure 4.2 - Conceptual p-y curve (Reese et al., 2006). 
The characteristic of $p-y$ curves depends on soil properties. The Reese's stiff clay with no free water $\mathrm{p}-\mathrm{y}$ model as described in Section 2.5.1 has been used to generate the initial lateral load-transfer model implementing in the computational program. Soil properties in terms of uniaxial compressive strength (UCS) and other $p$-y parameters such as $\varepsilon_{50}$ and $J$ are used to derive $\mathrm{p}$-y curves using equations presented in Section 2.5.1.

\subsubsection{Finite Element Formulations}

The governed finite element formulation is presented using the following equation:

$$
\left(\left[K_{p}\right]+\left[K_{s}\right]\right)\left\{y_{p}\right\}=\{F\}
$$

Eq. 4.1

where: $\left[K_{p}\right]=$ soil stiffness matrix represented by $\mathrm{p}-\mathrm{y}$ model

$\left[K_{S}\right]=$ stiffness matrix for all the beam elements forming the drilled shaft

$\left\{y_{p}\right\}=$ vector of nodal deflections at the shaft nodes

$\{F\}=$ vector of lateral forces acting on the shaft

The finite element method uses finite element formulation (Eq. 4.1) to produce the vector of nodal deflections. Displacements, bending moments and shear forces are then calculated using nodal deflections and based on an assumed shape functions as presented in following equations: 


$$
y_{e}=N * d e
$$

Eq. 4.2

$$
M_{e}=E I_{e} * B * d e
$$

$$
V_{e}=E I_{e} * S * d e
$$

Eq. 4.4

where: $d e=$ vector of nodal deflections for each beam element

$$
\begin{aligned}
& y_{e} \quad=\text { displacements for each beam element } \\
& M_{e} \quad=\text { bending moments for each beam element } \\
& V_{e} \quad=\text { shear forces for each beam element } \\
& E I_{e} \quad=\text { bending stiffness of each beam element } \\
& N \quad=\text { shape function } \\
& B \quad=\text { second derivative of shape function } \\
& S \quad=\text { third derivative of shape function }
\end{aligned}
$$




\subsection{Computer Program}

The computer program uses finite element method to predict drilled shaft responses under lateral loading. The program implements the $p-y$ method in a manner similar to that described by Reese et al. (2006). The code optimizes a p-multiplier to compute the $p-y$ curve that produces the best fit to measured displacement data. The $p$ multiplier simply factors the values of $p$ on the $p$-y curves. In this research, $p$-multiplier is consistent over the entire length of the shaft although one could consider alternatives, such as different $\mathrm{p}$-multiplier for each different node or using consistent $\mathrm{p}$-multiplier over each soil layer.

From an optimized p-multiplier, shaft responses in terms of displacement, bending moment and shear force are calculated. Moreover, the interpreted p-y curves can be obtained at the end of the process. A single operation of the computer program considers just one load of one shaft, so many operations are required to fit all the data collected for the test program.

Three iterative routines are embedded to model non-linear $p$-y curves, model nonlinear bending stiffness and produce the best fit to measured displacement data, as shown in the flow chart of Figure 4.3. The routines are embedded such that each iteration of the third routine requires a full pass through the second, and each iteration of the second routine requires a full pass through the first routine. The first routine iterates values of the secant modulus to implement a non-linear $p-y$ curve. The second routine iterates values of non-linear bending stiffness to implement the bending stiffness- 
bending curvature relationship described in Section 3.3.3. The third routine iterates values of the p-multiplier to minimize the difference between measured and predicted displacements.

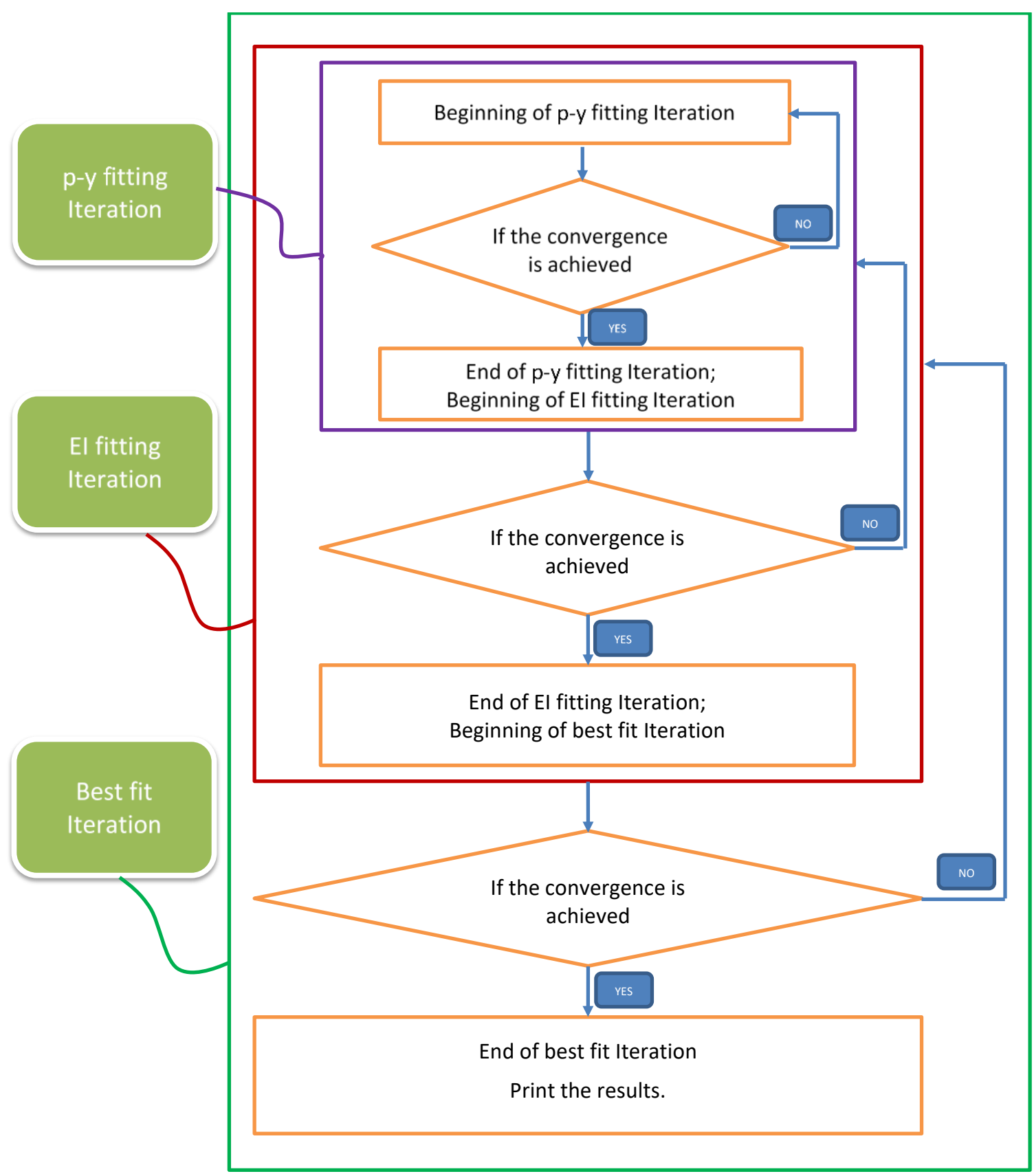

Figure 4.3 - Flow chart outlining operation of FEM computer code. 


\subsection{1. $p$-y Fitting Iteration}

The conceptual p-y curve of Figure 4.2 also shows a dashed line labeled $E_{p y}$, which is the secant modulus of the $p-y$ curve. The secant modulus is used to account for the non-linear response of the soil to deflection, as implemented in the following procedure:

1. Select trial values of the secant modulus $E_{p y}$.

2. Calculate structural and soil stiffness matrices implemented in computer program.

3. Solve Eq. 4.1 for a given loading to find the nodal displacements and nodal rotations of the shaft.

4. From lateral displacement $(y)$, calculate the soil resistance $\left(p_{E_{p y}}\right)$ using values of $E_{p y}$ (Figure 4.4).

5. From lateral displacement $(y)$, back-calculate the soil resistance ( $\left.p_{p-y \text { curve }}\right)$ using p-y model (Figure 4.4) and stored in a vector. For the work presented in this dissertation, the Reese's stiff clay with no free water $p-y$ model (Reese, 1972) was used.

6. For each node, the difference between $p_{E_{p y}}$ and $p_{p-y c u r v e}$ is calculated $\left(p_{\text {different }}\right)$ as shown in Figure 4.4 and stored in a difference vector. Calculate the approximate relative error of the difference vector using the following equation: 


$$
p_{\text {error }}=\frac{\operatorname{norm}\left(p_{\text {different }}\right)}{\operatorname{norm}\left(p_{p-y \text { curve }}\right)}
$$

Eq. 4.5

where: $\quad \operatorname{norm}\left(p_{\text {different }}\right) \quad=$ Euclidean norm of $p_{\text {different }}$ vector

$$
\operatorname{norm}\left(p_{p-y \text { curve }}\right) \quad=\text { Euclidean norm of } p_{p-y \text { curve vector }}
$$

7. If $p_{\text {error }}$ is higher than 0.001 , calculate the new value of $E_{p y}$ using following equation and repeat steps 2 through 6.

$$
E_{\text {py-new }}=\frac{p_{p-y \text { curve }}}{y}
$$

Eq. 4.6

8. If $p_{\text {error }}$ is equal or smaller than 0.001 , the convergence is achieved. The $p-y$ fitting Iteration is finished and can be moved to the El fitting Iteration.

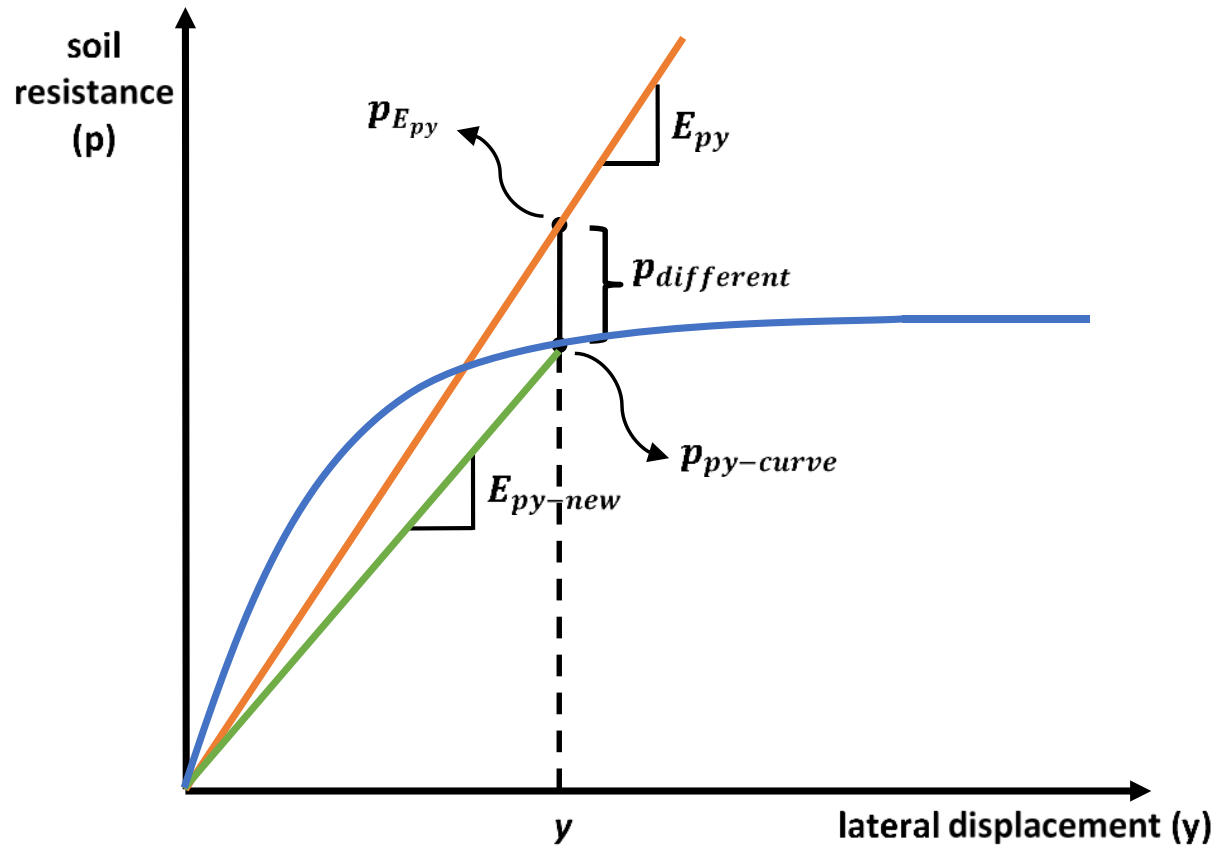

Figure $4.4-p-y$ fitting iteration to minimize $p_{\text {different }}$ 


\subsubsection{El Fitting Iteration}

As described in Section 3.3.3 and shown in Figure 3.32, the bending stiffness of the shaft is a non-linear function of bending curvature. LPile was used to define the relationship between bending stiffness and bending curvature for each shaft. The second Iteration used by the computer program establishes the bending stiffness according to the relationship from LPile. The steps are outlined below.

1. An initial bending stiffness value of $1.0 \times 10^{12} \mathrm{kips}-\mathrm{in}^{2}$ is assigned to each element of the shaft $\left(E I_{\text {assigned }}=E I_{\text {initial }}=1.0 \times 10^{12} \mathrm{kips}-i \mathrm{n}^{2}\right)$.

2. At the end of the $p-y$ fitting Iteration, calculate the bending curvature $(\kappa)$ from the nodal deflections using the following equation:

$$
\kappa_{e}=S * d e
$$

Eq. 4.7

$$
\begin{aligned}
& \text { where: } \kappa_{e} \quad=\text { bending curvature for each beam element } \\
& \qquad \begin{aligned}
d e & =\text { vector of nodal deflections for each beam element } \\
B & =\text { second derivative of shape function }(N)
\end{aligned}
\end{aligned}
$$

3. Obtain improved values of bending stiffness $\left(E I_{\text {improved }}\right)$ using the calculated bending curvature from Step 2 and the non-linear relationship between bending stiffness versus bending curvature from LPile.

4. For each element, calculate the approximate relative error of the difference between $E I_{\text {assigned }}$ and $E I_{\text {improved }}$ using the following equation: 


$$
E I_{\text {error }}=\frac{E I_{\text {improved }}-E I_{\text {assigned }}}{E I_{\text {improved }}}
$$

Eq. 4.8

5. If maximum value of $E I_{\text {error }}$ for all elements is higher than 0.01 , use $E I_{\text {improved }}$ as the new values of $E I_{\text {assigned }}$ and repeat steps 2 through 4.

6. If maximum value of $E I_{\text {error }}$ for all elements is equal or smaller than 0.01 , the convergence is achieved. The $E I$ fitting Iteration is finished and can be moved to the best fit Iteration.

\subsubsection{Best Fit Iteration}

The third, outer iteration involves varying the $p$-y model to produce a "best fit" match between the measured and predicted shaft response. The program is capable of matching results of the displacement profile from SAA or bending moments from the strain gages, but all the results in this dissertation are based on matching the displacement profiles. The best fit iteration involves minimizing the difference between the shaft response predicted using finite element equations with non-linear $p-y$ curves and non-linear $E I$ and the response measured by the SAA, as outlined in the steps below.

1. Assume a range of $p$-multiplier values to be used as an input for the program. The $p$-multiplier simply factors the values of $p$ on the $p$-y curves (essentially stretching or shrinking the vertical axis of Figure 4.2).

2. For each value of $p$-multiplier, calculate the difference between the measured and predicted displacements for each node $\left(y_{\text {different }}\right)$ and store the values 
in a vector. Calculate the Euclidean norm of each difference vector according to each value of $p$-multiplier using the following equation:

$$
N O R M_{-} \text {difference }=\sqrt{\sum_{i=1}^{\text {number of nodes }}\left(y_{\text {different }}\right)_{i}^{2}}
$$

Eq. 4.9

3. Plot the norm of the difference vector versus the p-multiplier as shown in the example in Figure 4.5. The example would output a p-multiplier value between 1.0 and 1.2 .

4. If the curve does not have a minimum, adjust the range of $p$-multiplier values in step 1 and repeat steps 2 and 3.

5. Fit a high-order polynomial through the norm-p-multiplier curve. The value of the p-multiplier that minimizes the norm is taken to be the best fit of the measured data. The example in Figure 4.5 results an optimum p-multiplier from this operation of the FEM code which is equal to 1.157 . 


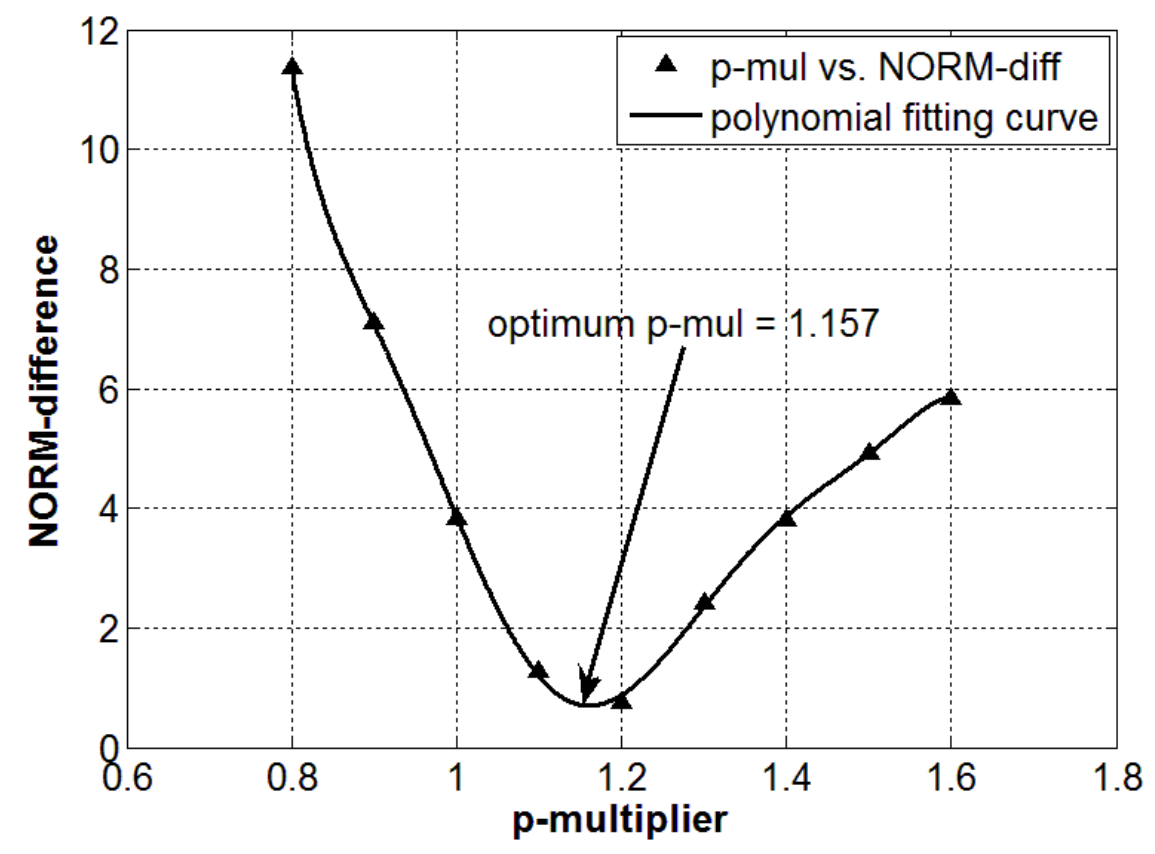

Figure 4.5 - p-multiplier optimization illustration

The computational program is able to optimize $p$-multiplier based on norm of errors calculated from either displacement only or bending moment only or both. Figure 4.6 shows an example of the displacement norm and bending moment norm for the same range of $\mathrm{p}$-multiplier. The optimum $\mathrm{p}$-multiplier using displacement norm and bending moment is different. However, experience with interpretations performed for drilled shaft load tests indicate the procedure based on bending moment only is less sensitive than the one based on displacement only.

The bending moment norm versus $\mathrm{p}$-multiplier curve is much flatter, meaning that selecting the optimum p-multiplier associated with the optimum bending moment norm would produce a poor match with displacements. As illustrated in Figure 4.6, using the bending moment norm optimization, the optimum $p$-multiplier ( $p$-mul 2.9) will 
correspond to the smallest bending moment norm (M-norm 810 kips-ft.) but a large value of displacement norm (du-norm $\sim 4.2$ in.).

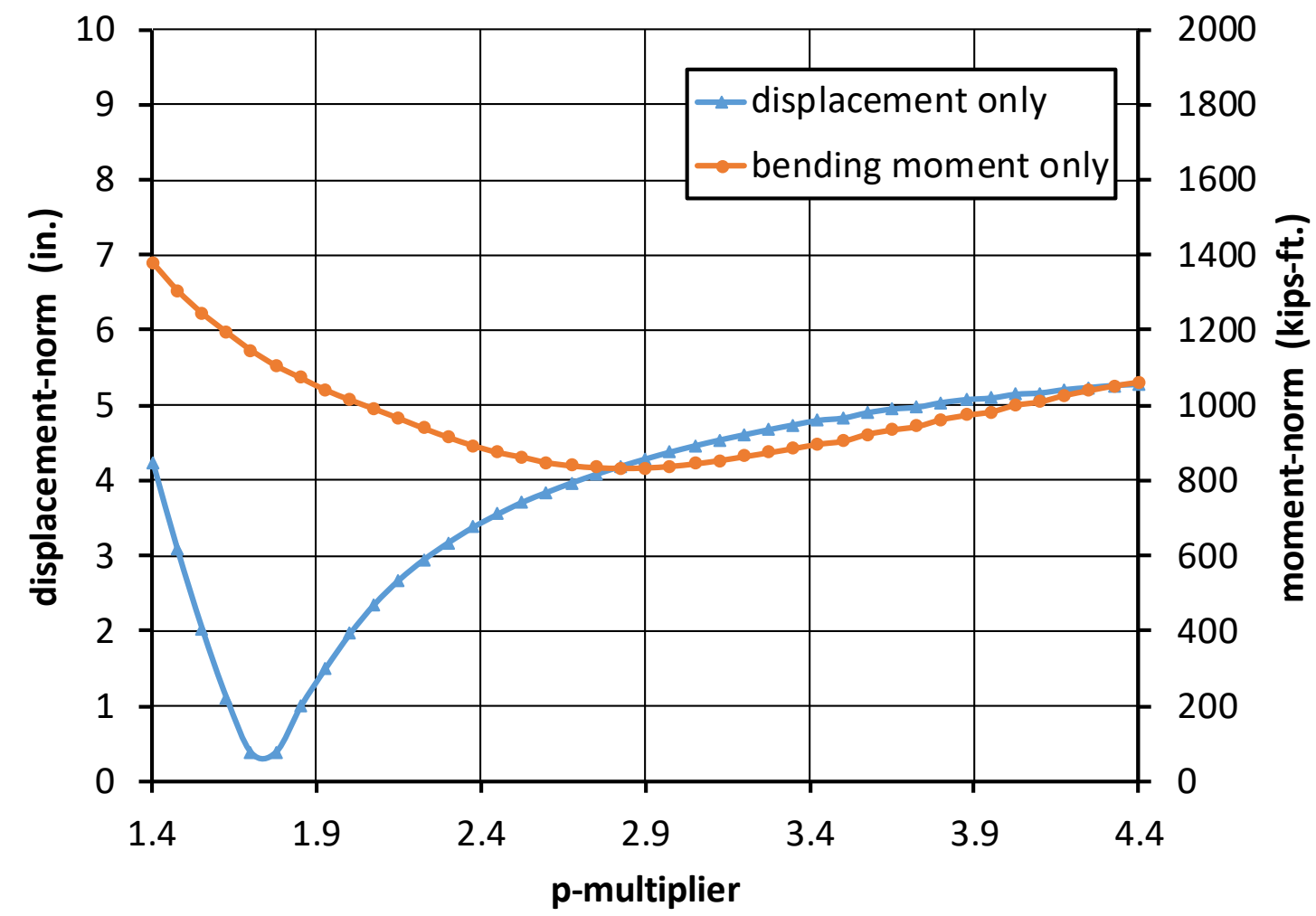

Figure 4.6 - p-multiplier optimization using displacement or bending moment norm

On the other hand, the optimum p-multiplier ( $p$-mul 1.7) calculated based on displacement norm optimization will correspond to the smallest displacement norm (dunorm 0.3in.) and a relatively small value of bending moment norm (M-norm 1500 kipsft.). Thus, selecting p-multiplier associated with displacement norm makes more sense and produces a better overall match to the data.

Figure 4.7 shows the predicted displacement and predicted bending moment profiles as well as measured values using the p-multipliers associated with the optimum 
displacement or bending moment norm. Using p-multiplier associated with displacement norm ( $p$-mul=1.7 in this example), the predicted displacements match with measured displacement while the predicted bending moments are not far from measured ones. However, using $p$-multiplier associated with bending moment norm ( $p$-mul=2.9 in this example), the predicted bending moments match with measured values but the predicted displacement is far underestimate from measured displacements. Therefore, in this research we only minimize the displacement norm but not the bending moment norm to find the best fit with measurements.
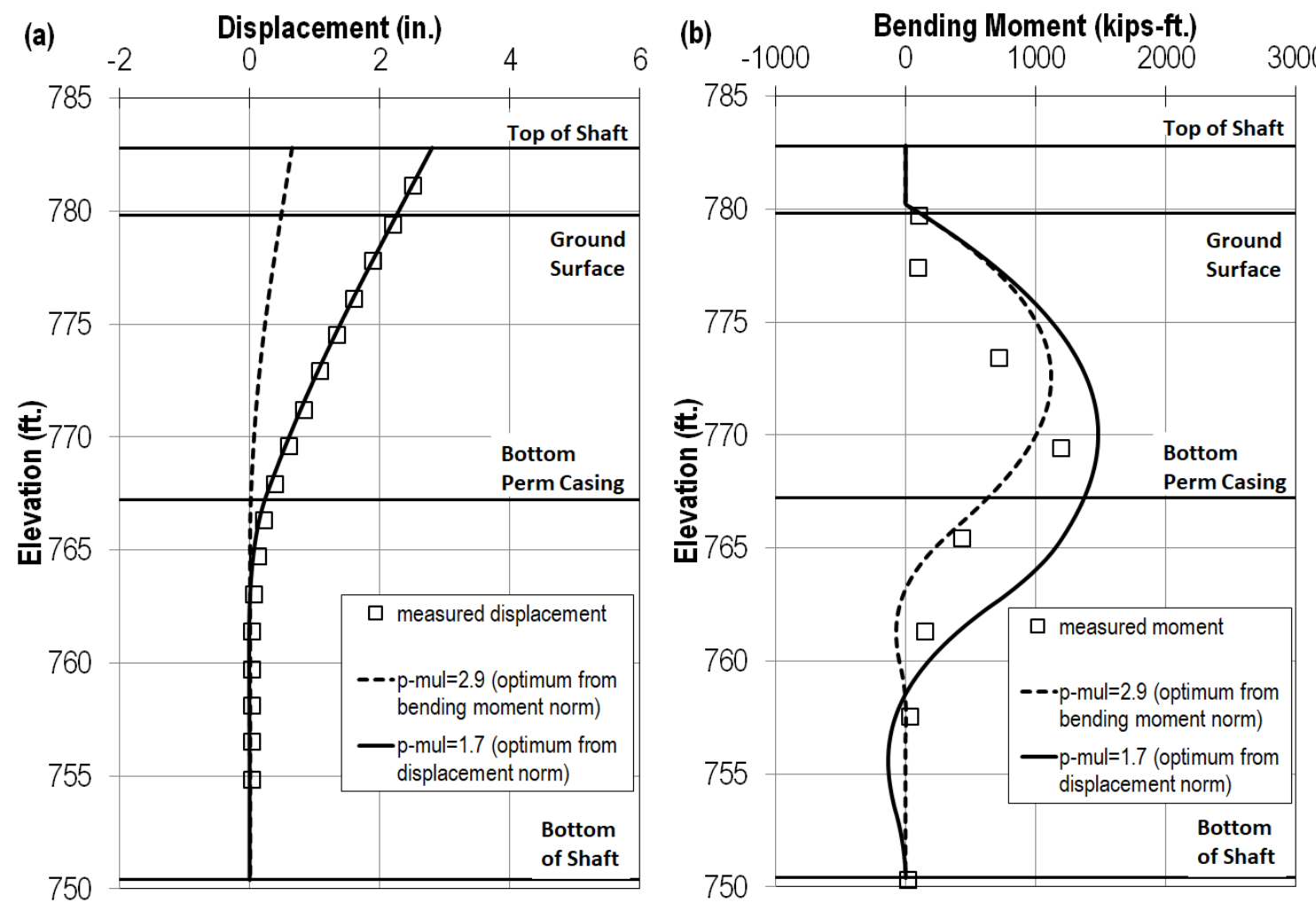

Figure 4.7 - Shaft responses comparison between p-multiplier optimized using displacement norm and bending moment norm

(a) displacement comparison

(b) bending moment comparison 


\subsubsection{Predicted Results Output from Computer Program}

Successful completion of the procedure described above produces predicted shaft responses in terms of displacement and bending moment, as well as the predicted lateral soil responses. These results correspond to a single loading of each shaft. An example of predicted results is discussed below.

\subsubsection{Predicted Results in Terms of Shaft Response}

An example computer code output for one load of one shaft is shown in Figure 4.8, where several predicted shaft responses in term of lateral displacement and bending moment have been presented for different values of $p$-multiplier. For a given shaft configuration and at a given load, the optimum p-multiplier obtained from the process above shows the best match between the predicted shaft responses and the experimental measurements. Figure 4.8a shows values of displacement measured with the SAA as well as values predicted by the FEM code. Figure $4.8 \mathrm{~b}$ shows values of bending moment interpreted from the strain gage data as well as values predicted by the FEM code. The example results shown in Figure 4.10 includes a good fit to the measured displacement from the shape acceleration array as well as a reasonably good fit to the measured bending moments obtained from the strain gage data. 

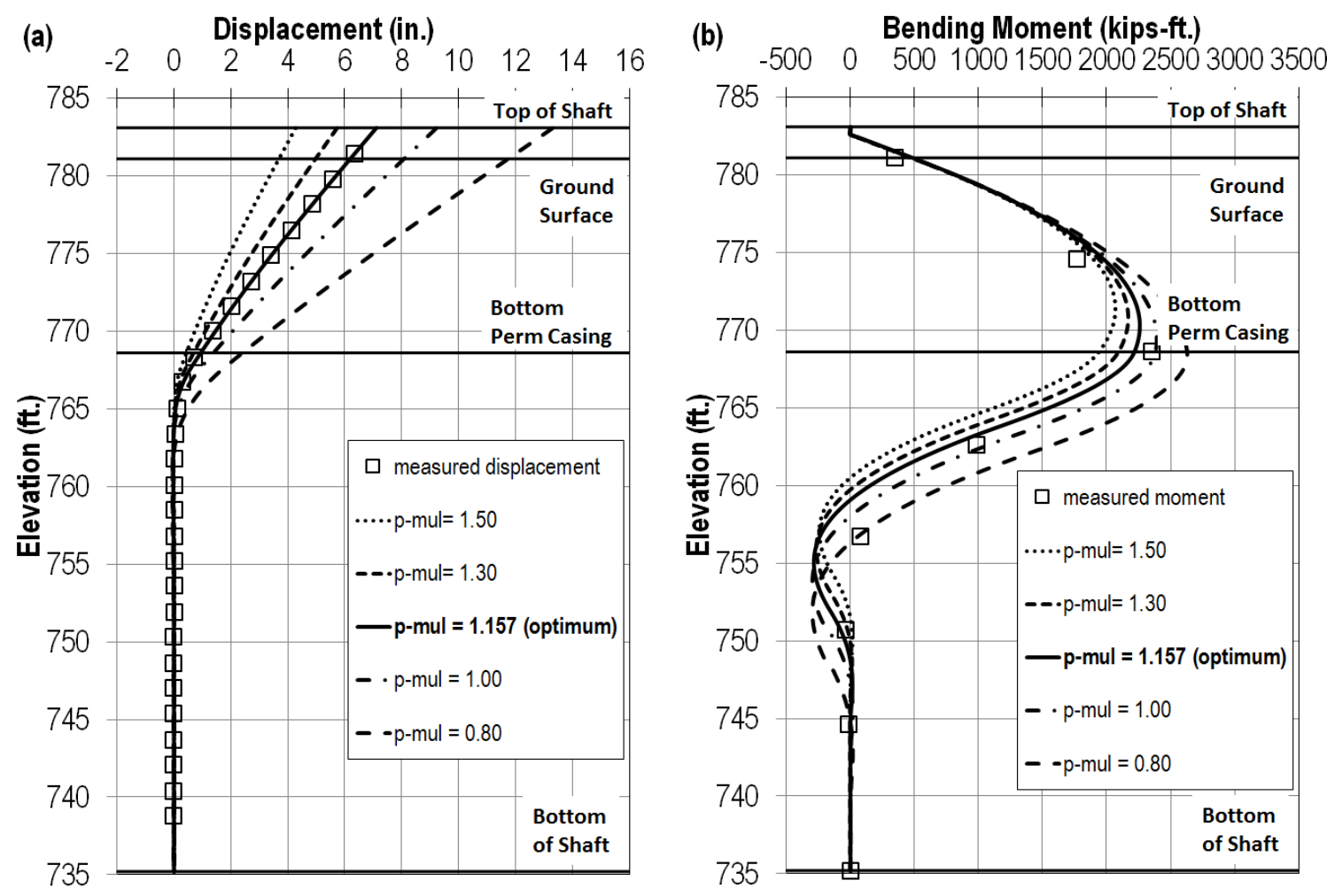

Figure 4.8 - Shaft responses for different values of p-multiplier in terms of:

(a) Displacement

(b) Bending Moment

\subsubsection{Predicted Results in Terms of Lateral Soil Response}

Values of lateral soil response (p) are calculated from the predicted lateral displacement $(y)$ at any depth using the $p-y$ model and the optimum $p$-multiplier that provide best fit between the predicted and measured displacement. Figure 4.9 shows an example of soil responses calculated from lateral displacements at different depths. Using shaft responses in terms of displacement (Figure 4.8a) to extract the lateral displacements at depths of interest. Then $p$-y curve at each different depth is used to back-calculate the soil response from corresponding lateral displacement. All the $p-y$ curves have been formed using the initial $p-y$ model with the same optimum $p$-multiplier applied. 


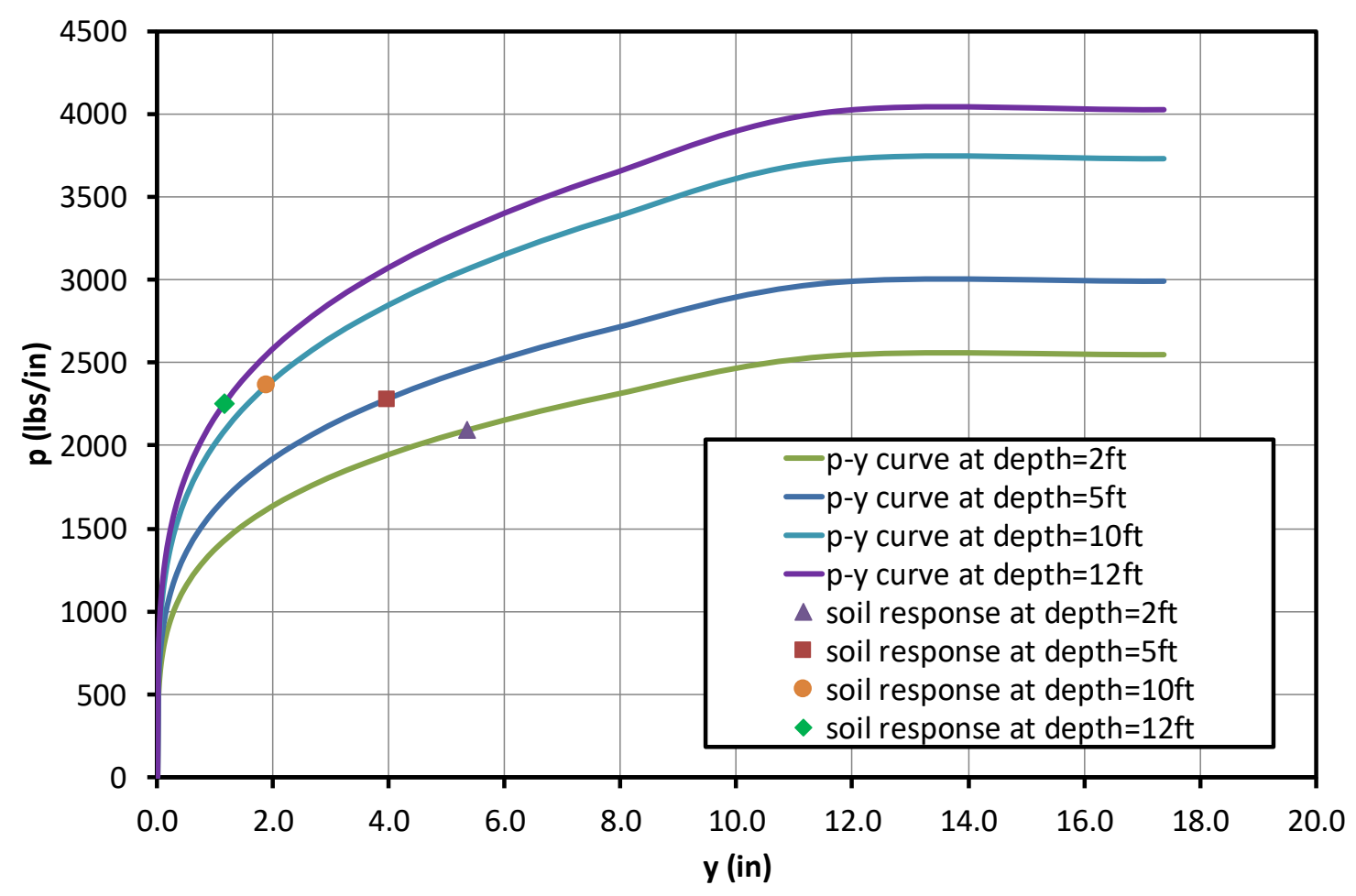

Figure 4.9 - Optimum p-y curves and soil responses calculated at different depths 


\subsection{Interpretation of Measured Results}

The analyses using computer program described in Section 4.2 have been conducted for all of the different shafts with all different loads. For all the shafts, the number of beam elements is chosen to be equal to 200 and the length of each beam element can be calculated by dividing shaft length to the number of beam elements as shown in Table 4.1.

Table 4.1 - Summary of beam elements lengths for each drilled shaft

\begin{tabular}{|c|c|c|c|c|c|}
\hline $\begin{array}{c}\text { Shaft } \\
\text { Number }\end{array}$ & $\begin{array}{c}\text { Top } \\
\text { Elevation } \\
\text { (ft.) }\end{array}$ & $\begin{array}{c}\text { Tip } \\
\text { Elevation } \\
\text { (ft.) }\end{array}$ & $\begin{array}{l}\text { Length } \\
\text { (ft.) }\end{array}$ & $\begin{array}{l}\text { Number } \\
\text { of beam } \\
\text { elements }\end{array}$ & $\begin{array}{c}\text { Length of each } \\
\text { beam element } \\
\text { (ft.) }\end{array}$ \\
\hline W1 & 782.8 & 750.4 & 32.4 & 200 & 1.94 \\
\hline W2 & 782.9 & 749.7 & 33.2 & 200 & 1.99 \\
\hline W3 & 782.9 & 735.5 & 47.4 & 200 & 2.84 \\
\hline W4 & 782.9 & 733.5 & 49.4 & 200 & 2.96 \\
\hline W5 & 783.4 & 756.4 & 27.0 & 200 & 1.62 \\
\hline W6 & 782.8 & 749.7 & 33.1 & 200 & 1.99 \\
\hline W7 & 782.9 & 749.1 & 33.8 & 200 & 2.03 \\
\hline W8 & 783.1 & 735.1 & 48.0 & 200 & 2.88 \\
\hline W9 & 783.1 & 735.2 & 47.9 & 200 & 2.87 \\
\hline W10 & 783.0 & 746.2 & 36.8 & 200 & 2.21 \\
\hline W11 & 783.0 & 745.9 & 37.1 & 200 & 2.23 \\
\hline W12 & 782.8 & 749.3 & 33.5 & 200 & 2.01 \\
\hline W13 & 782.8 & 749.9 & 32.9 & 200 & 1.97 \\
\hline W14 & 782.8 & 750.1 & 32.7 & 200 & 1.96 \\
\hline W15 & 782.9 & 749.6 & 33.3 & 200 & 2.00 \\
\hline $\mathrm{F} 1$ & 663.8 & 643.2 & 20.6 & 200 & 1.24 \\
\hline $\mathrm{F} 2$ & 663.7 & 640.9 & 22.8 & 200 & 1.37 \\
\hline $\mathrm{F} 4$ & 663.8 & 637.6 & 26.2 & 200 & 1.57 \\
\hline F6 & 663.9 & 636.6 & 27.3 & 200 & 1.64 \\
\hline F7 & 663.8 & 629.3 & 34.5 & 200 & 2.07 \\
\hline F8 & 663.7 & 640.4 & 23.3 & 200 & 1.40 \\
\hline
\end{tabular}


Soil strength properties in terms of uniaxial compressive strength (UCS) and p-y model parameters in terms of $\varepsilon_{50}$ and $J$ for different soil types in both load test locations are presented in Table 4.2 .

Table 4.2 - Summary of soil properties and p-y model parameters

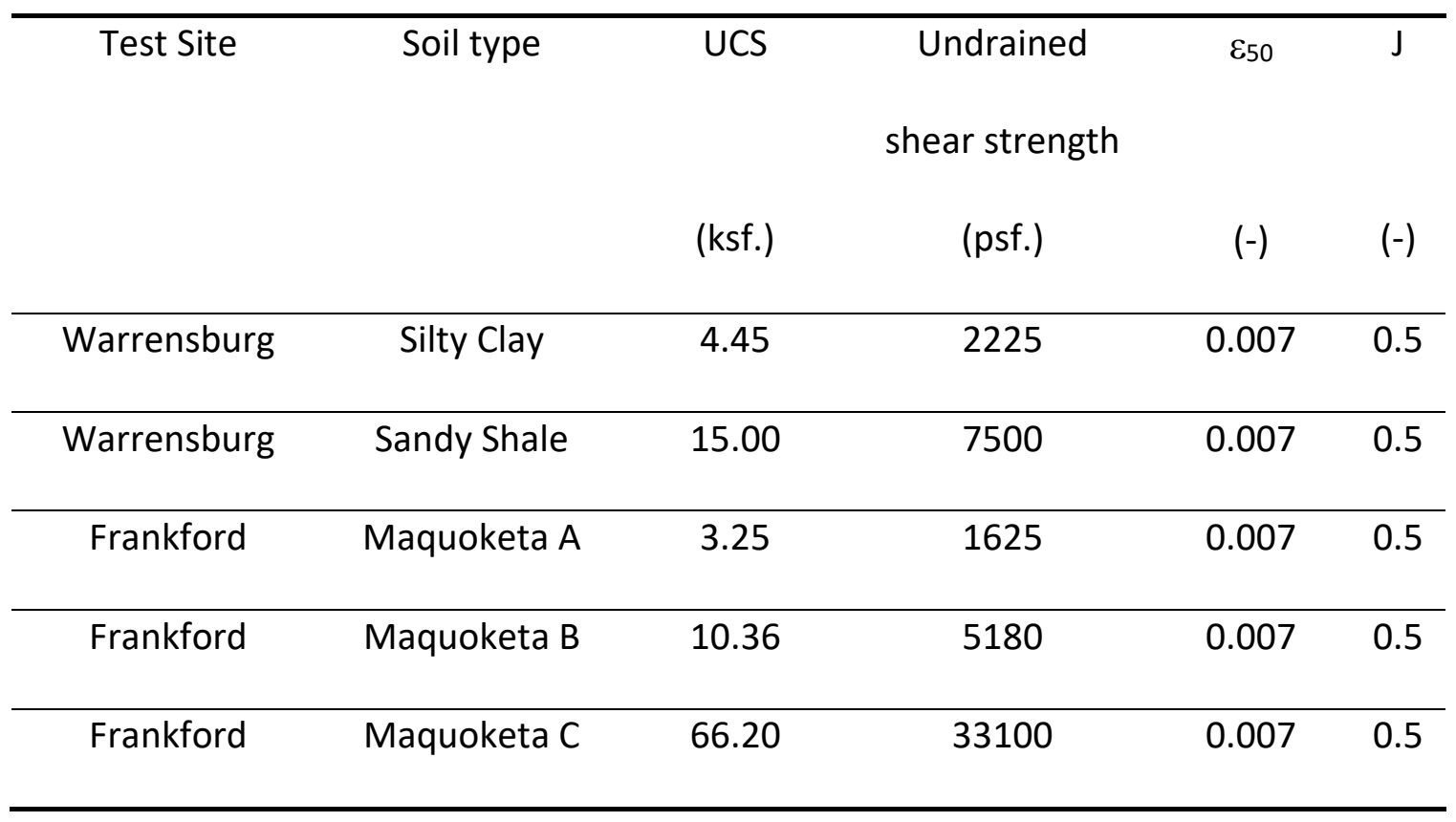

Interpretation of experimental measurements using the procedure described in Section 4.2 has been run for a shaft with the applied lateral load to produce profile plots of displacement and bending moment. Running the procedure for all load steps of a single test shaft results in one interpreted $p$-y response for each analysis depth. The complete set of interpreted $p-y$ responses at representative depths is obtained from repeating the procedure at different depths.

Additional runs through the computer program for a different shaft are required. An example set of profile plots and p-y response for shaft $W-9$ is discussed below, and a complete set of interpreted results for all other shafts is included in the Appendix A \& B. 


\subsubsection{Interpreted Shaft Response}

An example of the interpretation of measured results to provide shaft response for one shaft under all loads is shown in Figure 4.10, where several shaft responses in term of lateral displacement and bending moment profiles have been presented for different values of lateral loading. Figure 4.10a and Figure 4.10b shows values of best fit displacement and best fit bending moment interpreted by the FEM code. The values of optimum p-multiplier to provide best fit between measured and predicted displacement are different for different loads, but the interpreted results show reasonable trend where displacement or bending moment increasing with the load increasing.

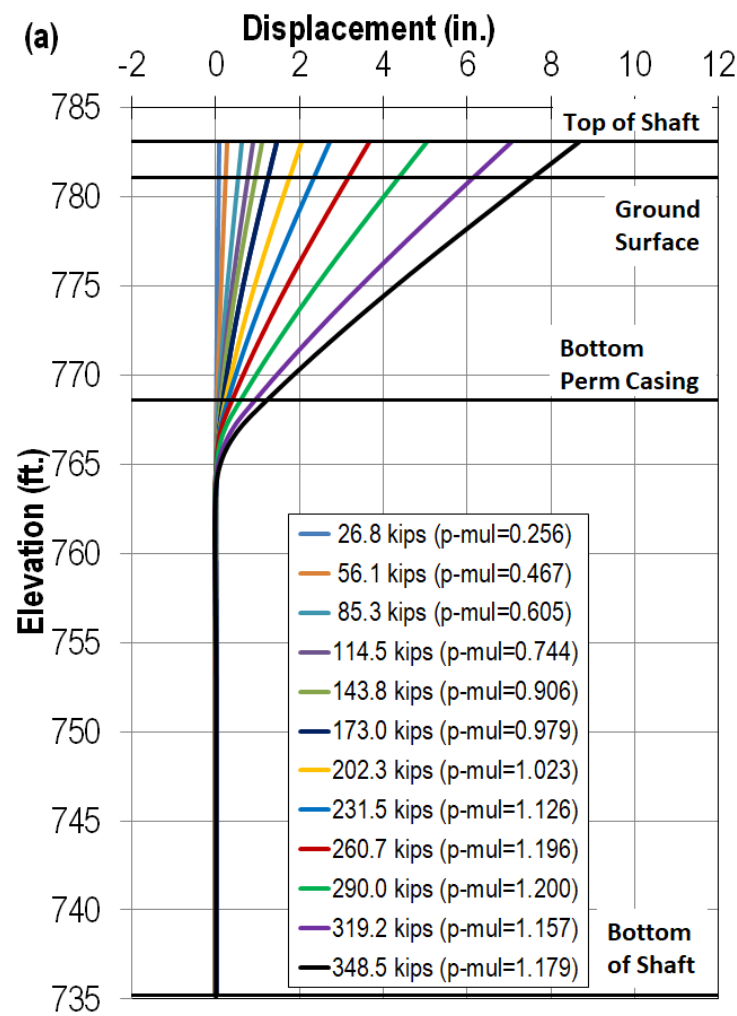

(b) Bending Moment (kips-ft.)

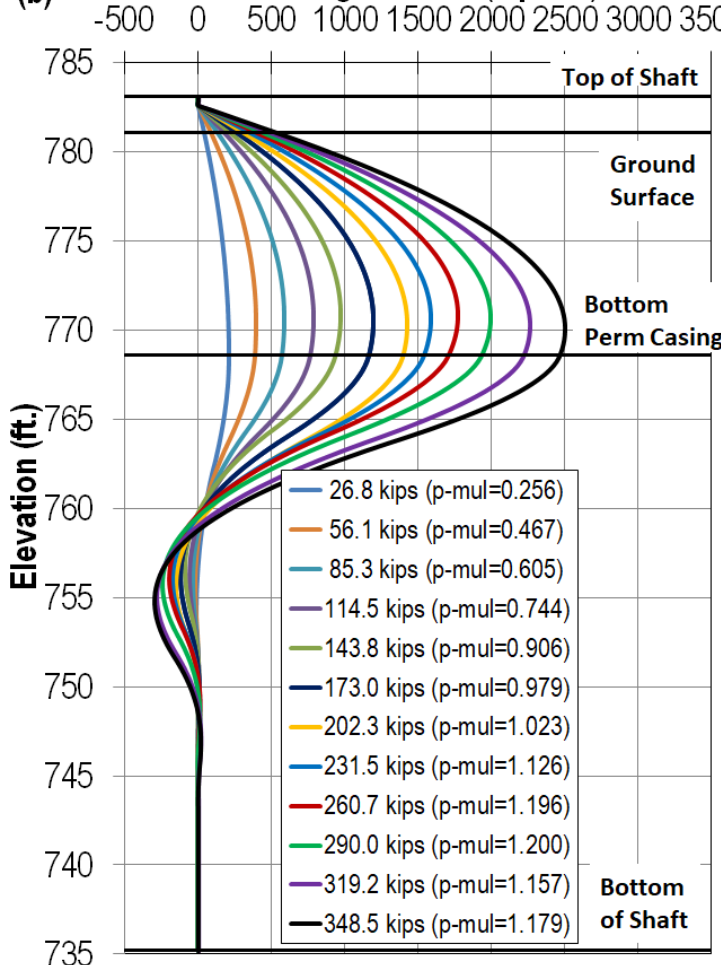

Figure 4.10 - Interpreted shaft responses under different loads for shaft W-9 


\subsubsection{Interpreted $p$-y Response}

The methodology of the computational program to interpreting the $p-y$ response starts with applying a $p$-multiplier to an initial $p-y$ model to produce the best fit of experimental measurement shaft responses. Under a given load and at a given depth, a value of lateral soil response $(p)$ is relative to the lateral displacement (p). From series of applied loads, the interpreted $p$-y response for that given depth can be derived, as show in Figure 4.11. The example shown in Figure 4.11 is performed with shaft $W-9$, for series of applied loads starting from 26.8kips to $348.5 \mathrm{kips}$ and at depth is equal to $2 \mathrm{ft}$. For each given load, value of optimum p-multiplier is presented and each data point represents value of lateral deflection between the soil and the shaft, $y$, and the corresponding soil resistance on a unit length of the shaft, $p$.

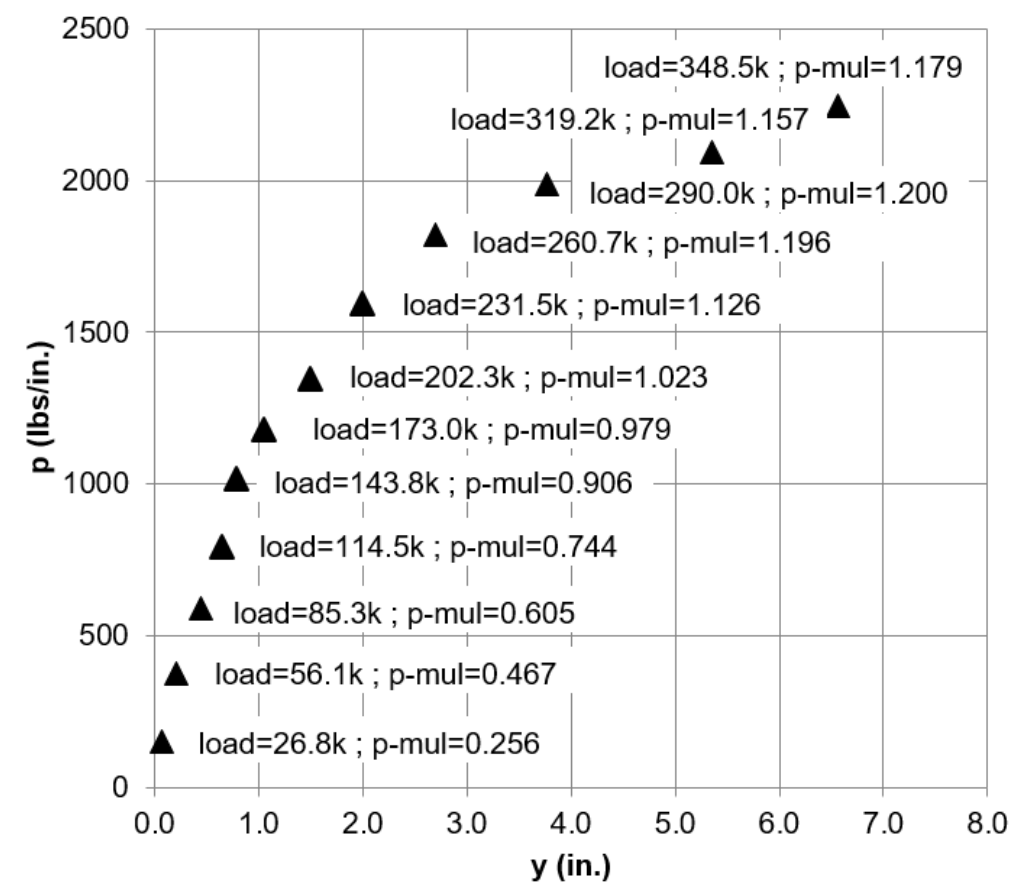

Figure 4.11 - $p-y$ response interpreted from experimental results (shaft $W-9, z=2 \mathrm{ft}$ ). 
Different interpreted $p$-y responses for the same shaft but at different depths can be derived easily since the optimum p-multiplier and the shaft responses are unchanged. The lateral deflection (y) for a different depth need to be obtained from the interpreted shaft responses and new value of lateral soil resistance $(p)$ is calculated as presented in Section 4.2.4.2. Repeat the procedure for all the applied loads to derive the interpreted p-y responses for different depths.

Figure 4.12 shows different interpreted $p-y$ responses for the same shaft $W-9$ at four different depths of $2 \mathrm{ft}, 5 \mathrm{ft}, 10 \mathrm{ft}$ and $12 \mathrm{ft}$.

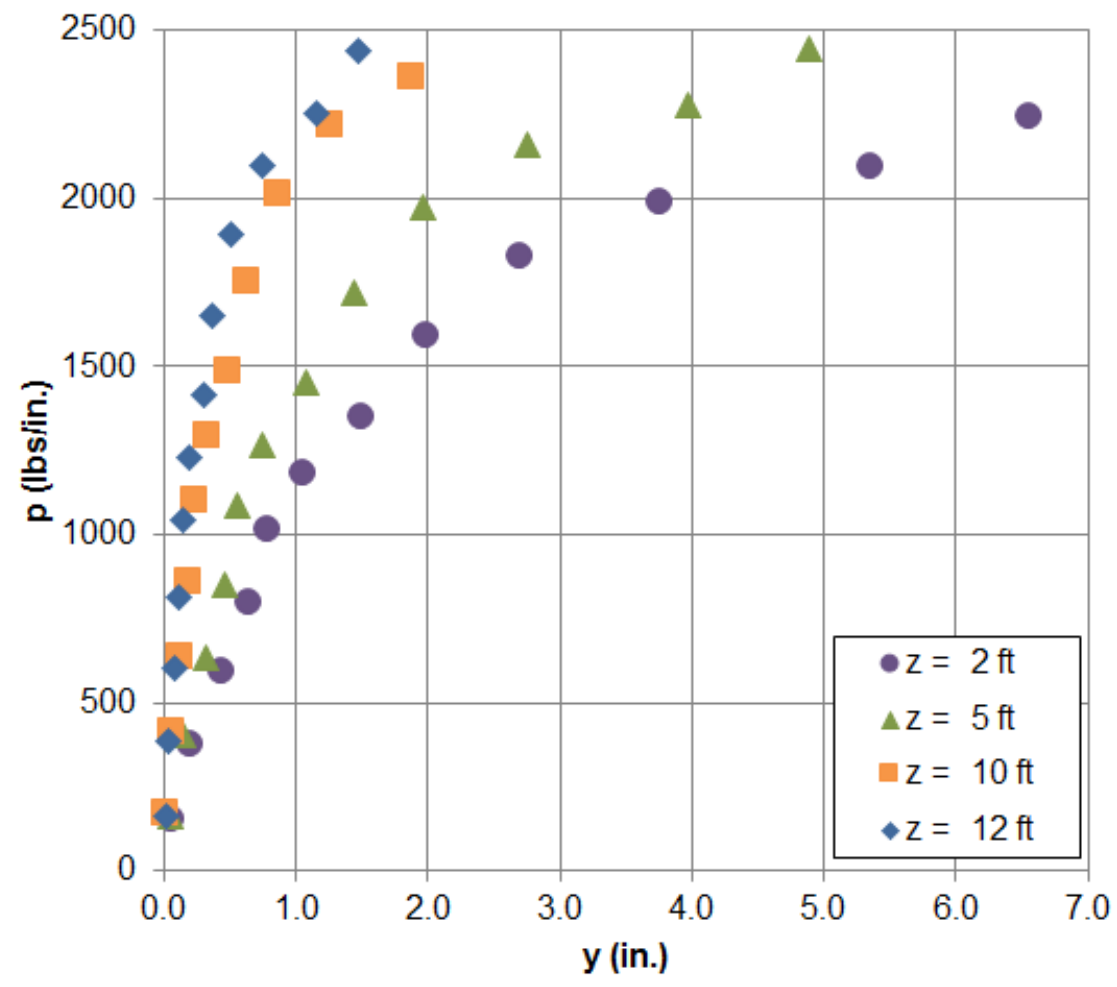

Figure 4.12 - $p-y$ responses interpreted from the experimental results

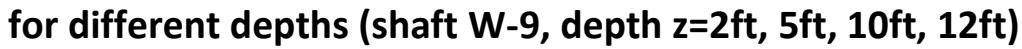




\subsection{Evaluation of Non-linear Bending Stiffness}

The bending stiffness, El, is non-linear and greatly influenced by concrete cracking, which is difficult to predict. To evaluate the procedure of using non-linear bending stiffness, which is implemented in the computational program to derive shaft responses as discussed in Section 4.2, two assumptions of bending stiffness have been presented.

The first assumption of bending stiffness simply considers cross section geometry and material properties of the drilled shaft. Assume no cracking of concrete is given during the lateral loaded test, the bending stiffness will be linear along shaft length. As a result, bending stiffness will remain constant and does not depend on bending curvature as shown in Figure 4.13.

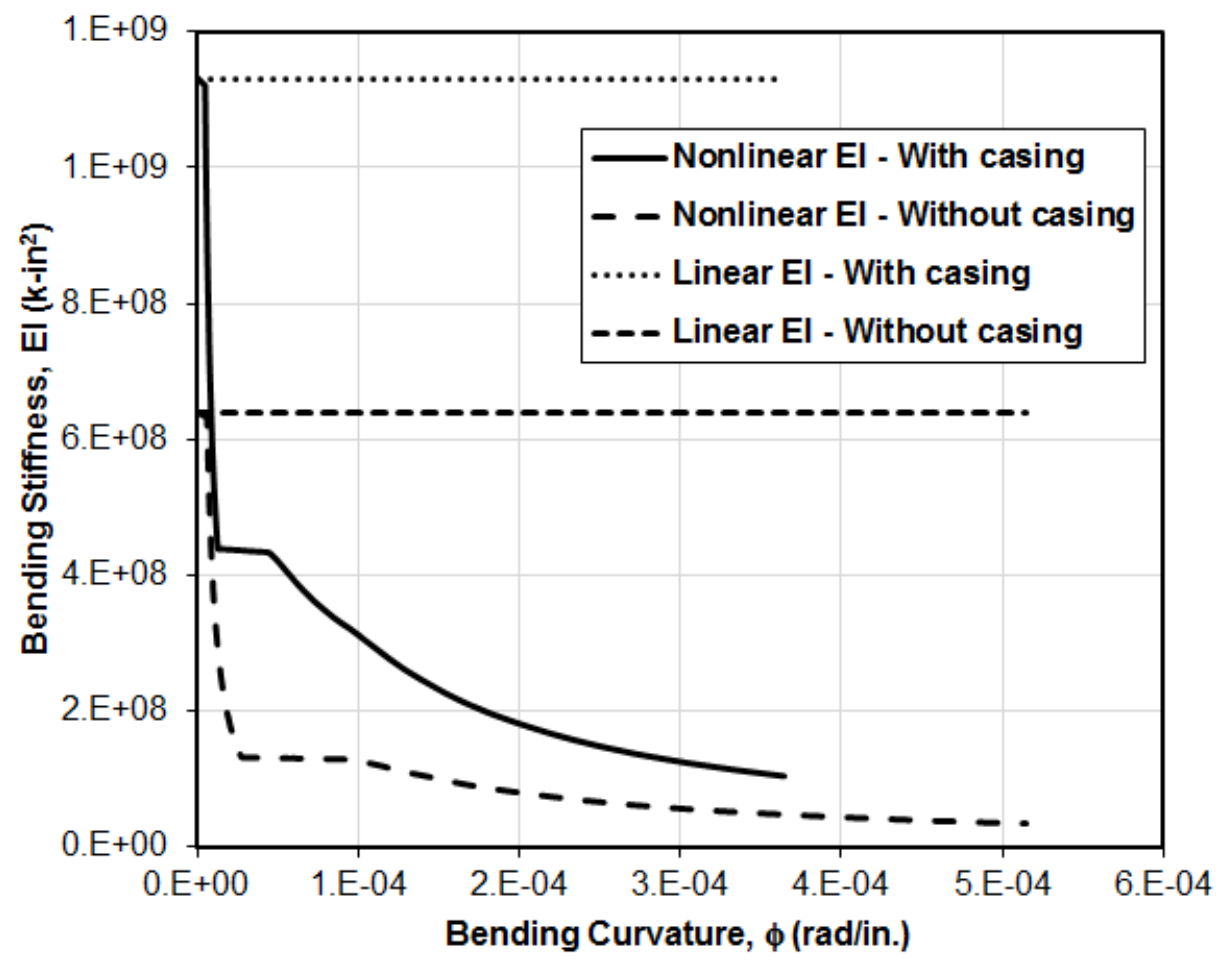

Figure 4.13 - Example of linear and non-linear bending stiffness for shaft W9 
The second assumption of bending stiffness considers the non-linear properties due to the cracking of concrete sections. The routine employed by LPile is documented in the program's technical manual (Isenhower \& Wang, 2011). In summary, LPile iterates the location of the neutral axis until force equilibrium is satisfied, accounting for concrete cracking. Cracking of the concrete is predicted as a function of the compressive strength of the concrete, which was estimated from compression tests performed on cylinders from each shaft pour. An example of the non-linear shaft bending stiffness predicted by LPile as a function of the bending curvature is shown in Figure 4.13. The non-linear bending stiffness decreases abruptly at small values of curvature because of the concrete cracking. After the concrete cracks, the decrease in stiffness is more gradual as the steel yields.

The interpretation of experimental measurements explained in the previous section is applied to a shaft to evaluate the effect of using non-linear bending stiffness. Interpreted displacement, bending moment and $\mathrm{p}-\mathrm{y}$ response based on linear and nonlinear bending stiffness assumptions will be compared. Example results are presented and discussed below.

\subsubsection{Effect of Non-linear Bending Stiffness on Interpreted Lateral Displacement}

Figure 4.14a shows the difference between interpreted lateral displacement using two different assumptions of bending stiffness: linear and non-linear. The measured lateral deflection obtained from SAA measurements has been presented also in order to compare with the interpreted ones. 
The shapes of the interpreted displacement profiles indicate that by using nonlinear bending stiffness assumption, the interpreted displacements are fit with the measured ones. While the linear bending stiffness assumption shows the substantial differences between interpreted and measured ones.

Interpreted displacement profiles obtained using non-linear bending stiffness assumption show that the respective shaft is essentially fixed around the elevation of $765 \mathrm{ft}$ below the top of the shaft, which is the same as the shaft responses fixed elevation obtained from experimental measurements.

\subsubsection{Effect of Non-linear Bending Stiffness on Interpreted Bending Moment}

Figure $4.14 \mathrm{~b}$ shows values of the bending moment measured from the strain gage measurements as well as values interpreted by the computational program using linear and non-linear bending stiffness assumptions.

The interpreted bending moments using the assumption of non-linear bending stiffness show a reasonably good fit to the measured bending moments obtained from strain gage measurements. While the linear bending stiffness assumption shows much

differences between interpreted and measured displacements. Reason is the much higher values of linear bending stiffness results in higher values of bending moments. 

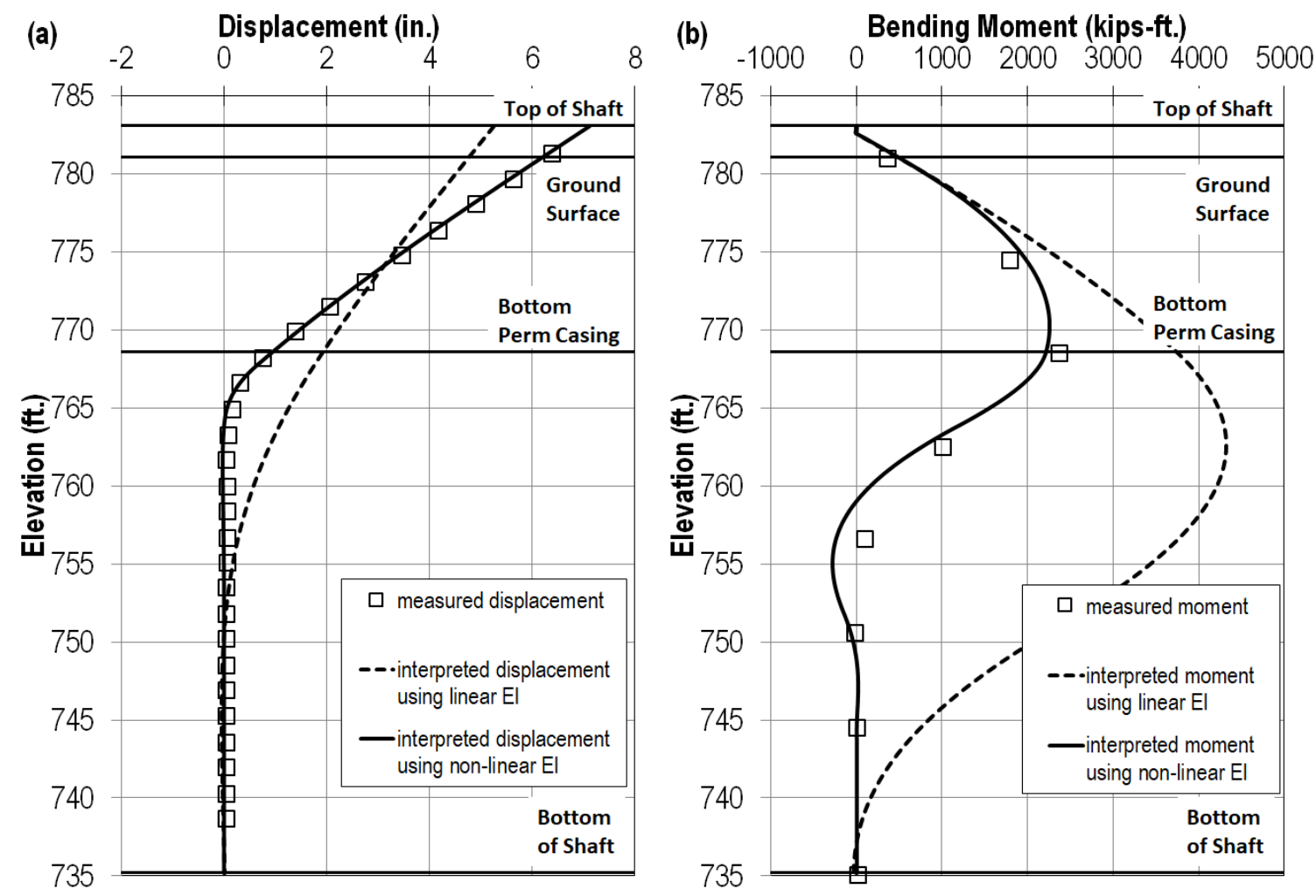

Figure 4.14 - Interpreted and measured shaft responses for shaft W-9 @ 319.2kips using linear and non-linear El assumptions

(a) Displacement profiles

(b) Bending moment profiles

\subsubsection{Effect of Non-linear Bending Stiffness on Interpreted $p$-y Response}

Figure 4.15 and Figure 4.16 shows the difference between interpreted $p-y$ responses at given depths using two different assumptions of bending stiffness: linear and non-linear. The conventional p-y curves (Reese et al., 2006; Isenhower and Wang, 2011) have been presented also in order to compare with the interpreted $p-y$ responses. 

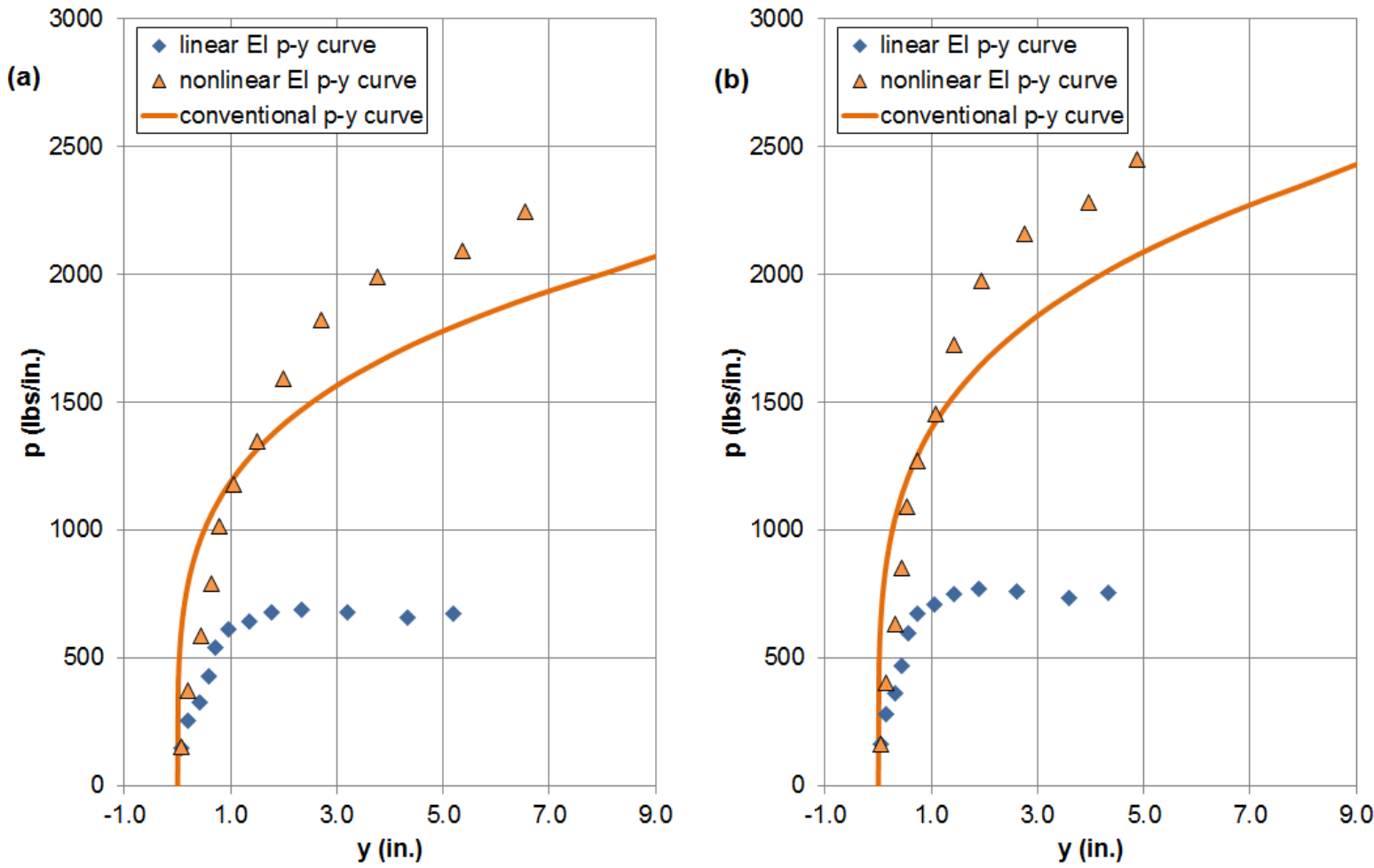

Figure 4.15 - Interpreted p-y response using linear and non-linear bending stiffness assumptions at $(\mathrm{a})$ depth $=2 \mathrm{ft} ;(\mathrm{b})$ depth $=\mathbf{5 f t}$
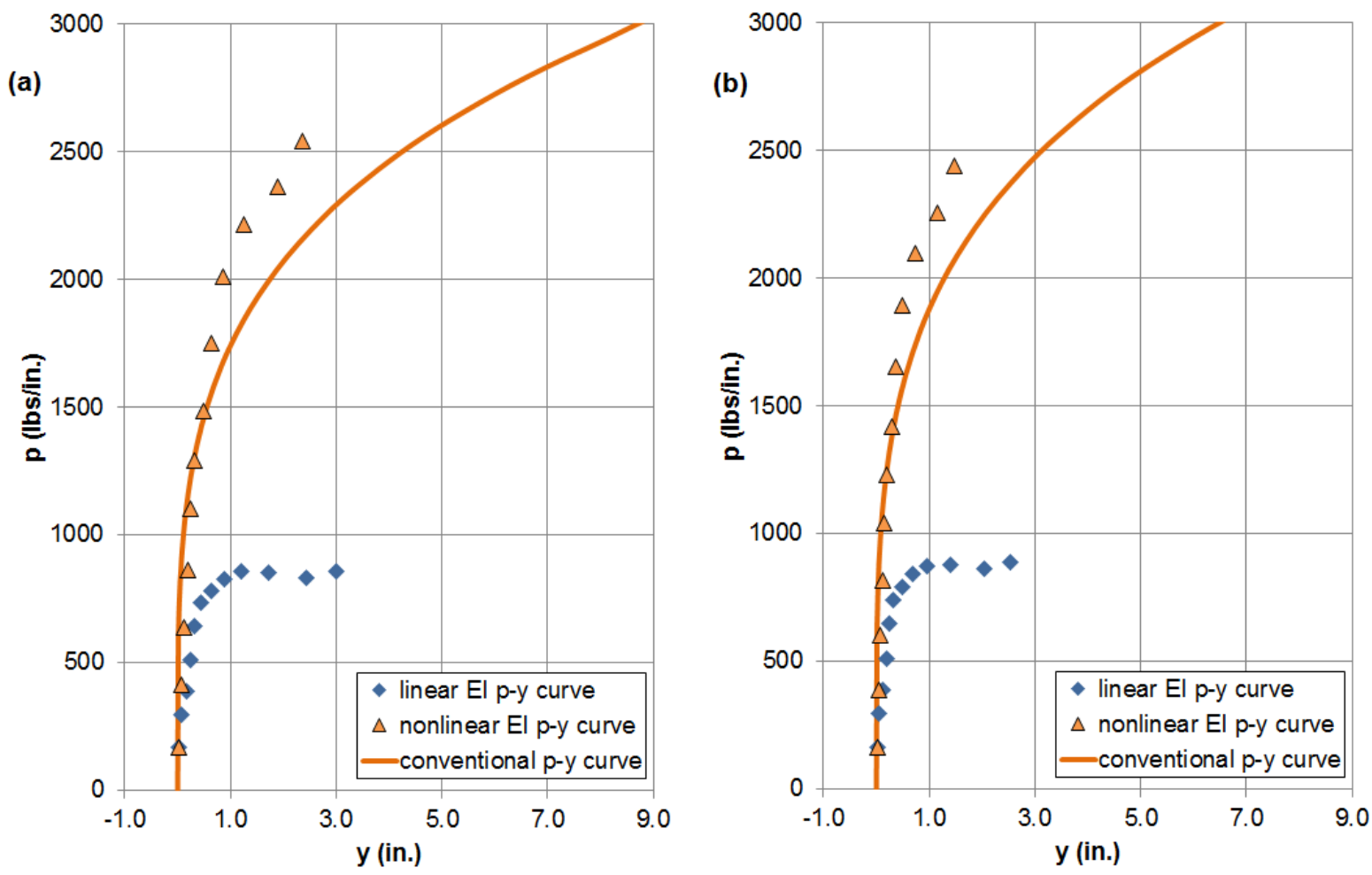

Figure 4.16 - Interpreted p-y response using linear and non-linear bending stiffness assumptions at (a) depth $=10 \mathrm{ft} ;(\mathrm{b})$ depth $=12 \mathrm{ft}$ 
There is a significant difference between the interpreted $p-y$ responses using two different assumptions of bending stiffness as shown in Figure 4.15 and Figure 4.16. The interpreted $p-y$ response using non-linear bending stiffness assumption has much higher ultimate value of lateral response since the linear bending stiffness assumptions reasonably represents the bending stiffness which is much higher than stiffness represented by using the non-linear bending stiffness assumption. As a result, structure will provide higher stiffness to resist the lateral loading and therefore soil response will be lower compared to that of using non-linear bending stiffness assumption.

The $p-y$ responses interpreted from experimental measurements are compared to the conventional $p-y$ curves for stiff clay with no free water model (Reese et al., 2006; Isenhower and Wang, 2011). Interpretation of data from Figure 4.15 and Figure 4.16 indicate close agreement between the interpreted p-y response using non-linear bending stiffness assumption and the conventional $p$-y curve in terms of initial slope of $p-y$ curves. Interpreted $p-y$ responses using non-linear bending stiffness assumption follow the initial slopes of $p-y$ curves derived from conventional $p-y$ model for depth of $10 \mathrm{ft}$ and $12 \mathrm{ft}$. However, interpreted $p-y$ responses using linear bending stiffness assumption do not follow the initial slopes and provide much lower ultimate soil resistance compared to conventional p-y model. 


\subsection{Evaluation of an Initial p-y Model}

The methodology of the computational program presented in Section 4.2 starts with implement an initial $p-y$ model to simulate the soil-structure interaction and then applying a p-multiplier to produce the best fit of experimental measurement shaft responses. Thus, initial p-y model plays an important role in the process. To evaluate the effect of initial $p-y$ model, three different $p-y$ models have been assumed and performed. Linear model assumes linear relationship between lateral deflection (y) and soil response (p). Stiff clay model uses the conventional $p-y$ curve for stiff clay with no free water (Reese et al., 2006; Isenhower and Wang, 2011). Calibration model assumes exponential relationship between $(y)$ and $(p)$, with model coefficients obtained from calibration processes, which will be described in more details in the next chapter.

Using the computational procedure with three different initial $p-y$ models implemented, shaft response and $p-y$ response are interpreted from experimental measurements and can be used to compare and evaluate those models.

\subsubsection{Effect of Different Initial p-y Model on Interpreted Shaft Response}

In Figure 4.17, three different interpreted shaft responses in term of lateral displacement and bending moment profiles have been presented for three initial $p-y$ models. For lateral displacement, all three models match between interpreted shaft responses and experimental measurements. For bending moment, the stiff clay and the 
calibration models show good match between interpreted shaft responses and experimental measurements, while linear model only fits well with maximum bending moment.
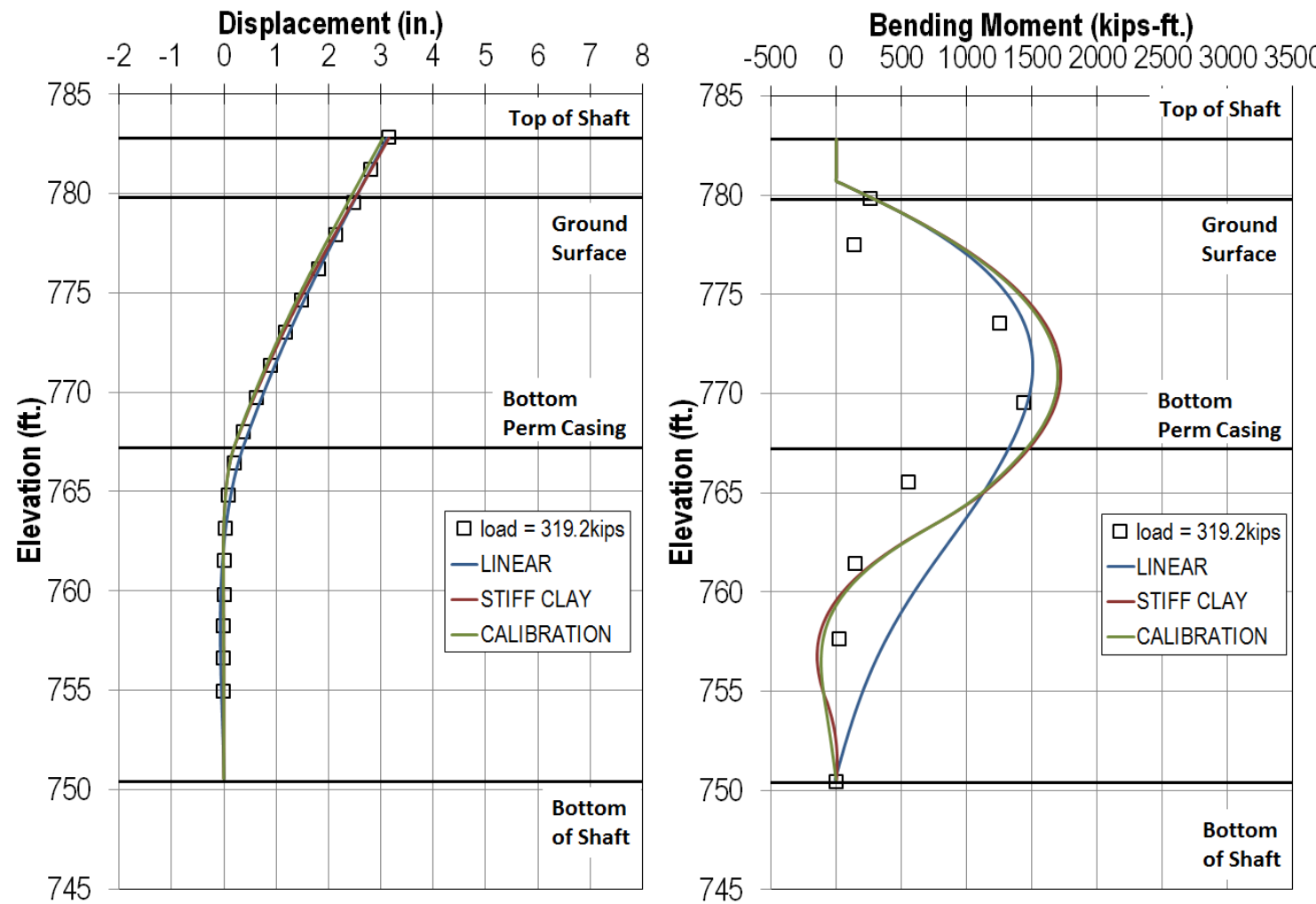

Figure 4.17 - Interpreted shaft responses using different initial p-y model

(shaft W-1, load = 319.2kips)

(a) Displacement

(b) Bending moment 


\subsubsection{Effect of Different Initial $p$-y Model on Interpreted $p$-y Response}

The procedure presented in Section 4.3.2 has been used for three initial p-y models. The example shown in Figure 4.18 is performed with shaft $\mathrm{W}-1$, for series of applied loads starting from 26.8kips to $319.2 \mathrm{kips}$ and at depth is equal to $2 \mathrm{ft}$. For each model, values of optimum p-multiplier are obtained corresponding to different applied loads and each data point represents value of lateral deflection (y) and the corresponding soil resistance $(p)$. Running the same procedure for all the applied loads to produce the three different interpreted $p-y$ responses using three initial $p-y$ models.

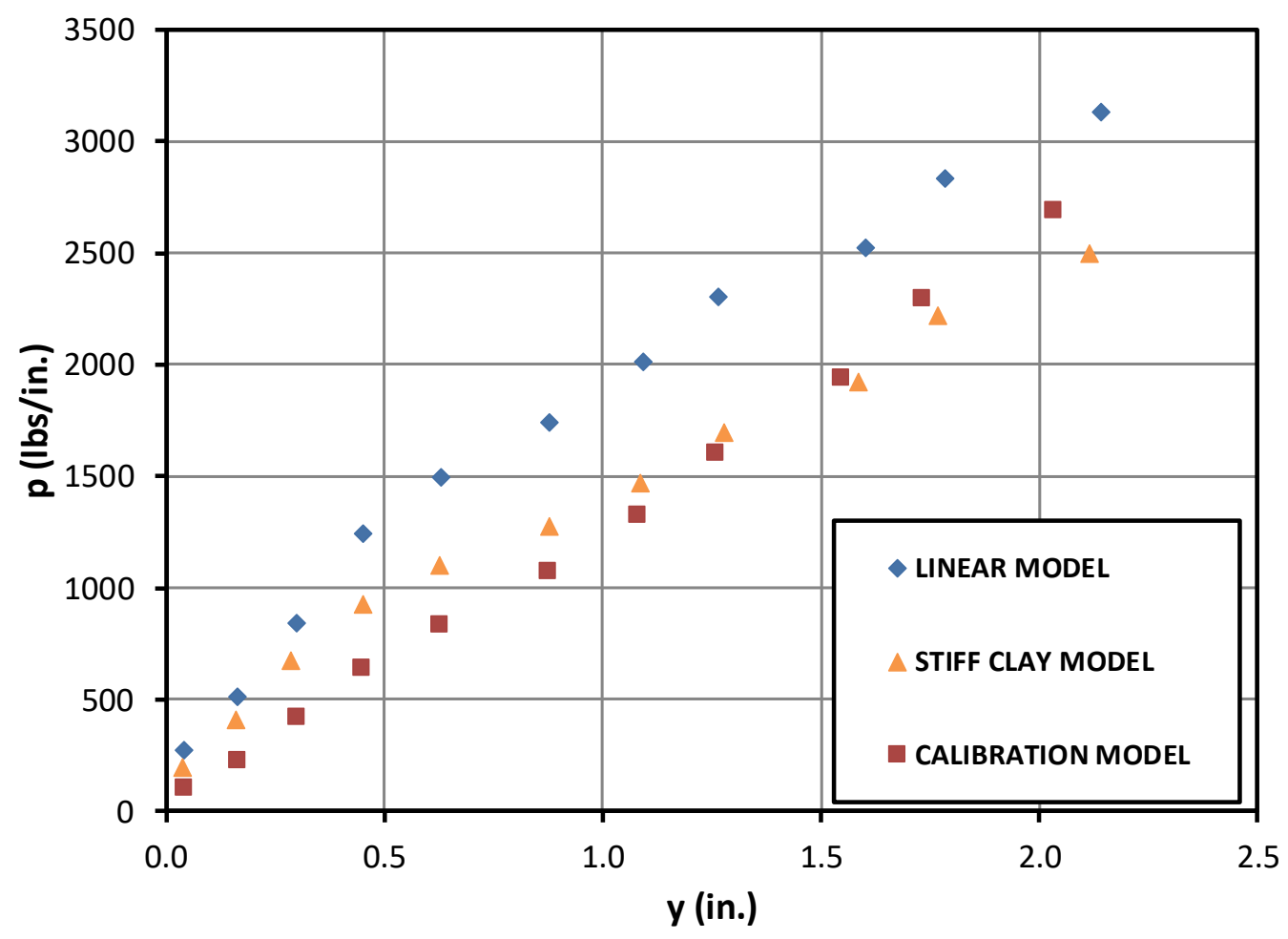

Figure 4.18 - interpreted $p-y$ responses using three different initial $p-y$ models (LINEAR, STIFF CLAY and CALIBRATION) for shaft $\mathrm{W}-1$, depth $\mathrm{z}=\mathbf{2 \mathrm { ft }}$ 
In general, the interpreted $p-y$ responses produced using three different initial p-y models follow the similar trend in which increasing lateral displacement corresponded to increase in soil resistance. Because soil resistance $(p)$ is calculated from lateral displacement $(\mathrm{y})$ using optimum $\mathrm{p}-\mathrm{y}$ model and since the lateral displacement profiles matches with experimental measurements for all three initial p-y models as shown in Figure 4.17, the three interpreted $p-y$ responses are not very different. The interpreted $p-y$ responses produced using stiff clay and calibration models match with each other. However, the interpreted $p-y$ response using linear model is slightly stiffer than the other two models.

\subsection{Summary}

Computational program using finite element method with the implementation of initial p-y model is success to simulate drilled shafts subjected to lateral loading. In this research, conventional p-y model for stiff clay with no free water (Reese et al., 2006; Isenhower and Wang, 2011) has been used as initial p-y model because of the compatibility between stiff clay and shale properties. The method of optimizing $\mathrm{p}$ multiplier based on minimizing the differences between predicted and measured displacements is the key to provide the best fit with experimental measurements.

Interpreted structure response in terms of lateral displacement shows a good fit to the measured displacement from SAA while interpreted bending moment shows a reasonably good fit to the measured bending moment obtained from the strain gage data. 
Using the interpreted lateral displacement (y) from computational programming analyses for all the loads to calculate the corresponding soil resistance $(p)$ based on the optimum $p-y$ model. Finally, interpreted $p-y$ responses can be derived for any given depth.

The characteristic of shafts' bending stiffness is important to provide a good match between interpreted and measured shaft responses. In this research, the bending stiffness, El, is greatly influenced by concrete cracking and should be considered as nonlinear El.

The interpreted shaft response in terms of lateral displacement generally does not depend on the initial p-y model. However, interpreted shaft responses in terms of bending moment and interpreted $\mathrm{p}-\mathrm{y}$ responses are different with using of different initial p-y models. 


\section{CHAPTER 5. DEVELOPMENT OF LATERAL LOAD TRANSFER MODEL}

The analyses described in Chapter 4 produced interpreted $p-y$ responses for multiple depths along each of the 25 test shafts. This chapter describes the development of a $p-y$ model to represent lateral load transfer in shale. First of all, fitted $p-y$ curves derived using different sets of interpreted $p-y$ responses will be presented. Then, three approaches to develop a $p-y$ model based on fitted $p-y$ curves will be proposed and the comparison between them will be given to select the most appropriate proposed $p-y$ model. Finally, comparison of proposed $p-y$ model with existing $p-y$ models will be addressed.

\subsection{Proposed Lateral Load Transfer Model ( $p-y$ Model)}

The interpreted $p-y$ responses obtained from the previous chapter show a general characteristic of lateral load transfer in shale, which should have a constant maximum value of soil response (p) when lateral displacement $(y)$ is big enough and an initial slope of $p-y$ relationship at small lateral displacement.

Several different forms of equations were investigated to provide a best fit with interpreted $p-y$ responses. An example in Figure 5.1 shows three different forms of function to fit with the interpreted $p-y$ responses collected at Frankford site for representative depth of $5 \mathrm{ft}$. The exponential function is able to provide a good fit with the interpreted $p-y$ responses for all the range of lateral displacement $(y)$. The power function shows good fit for initial $p-y$ responses, however soil resistance $(p)$ increases 
significantly with large lateral displacement $(y)$. The $2^{\text {nd }}$ order polynomial function does not provide good fit for initial $p-y$ responses and soil resistance $(p)$ decreases dramatically with large lateral displacement (y). Another advantage of the exponential function is that its parameters are easily related to the more familiar terms $P_{u l t}$, the ultimate lateral soil resistance and $K_{p y}$, the initial slope of the p-y curve.

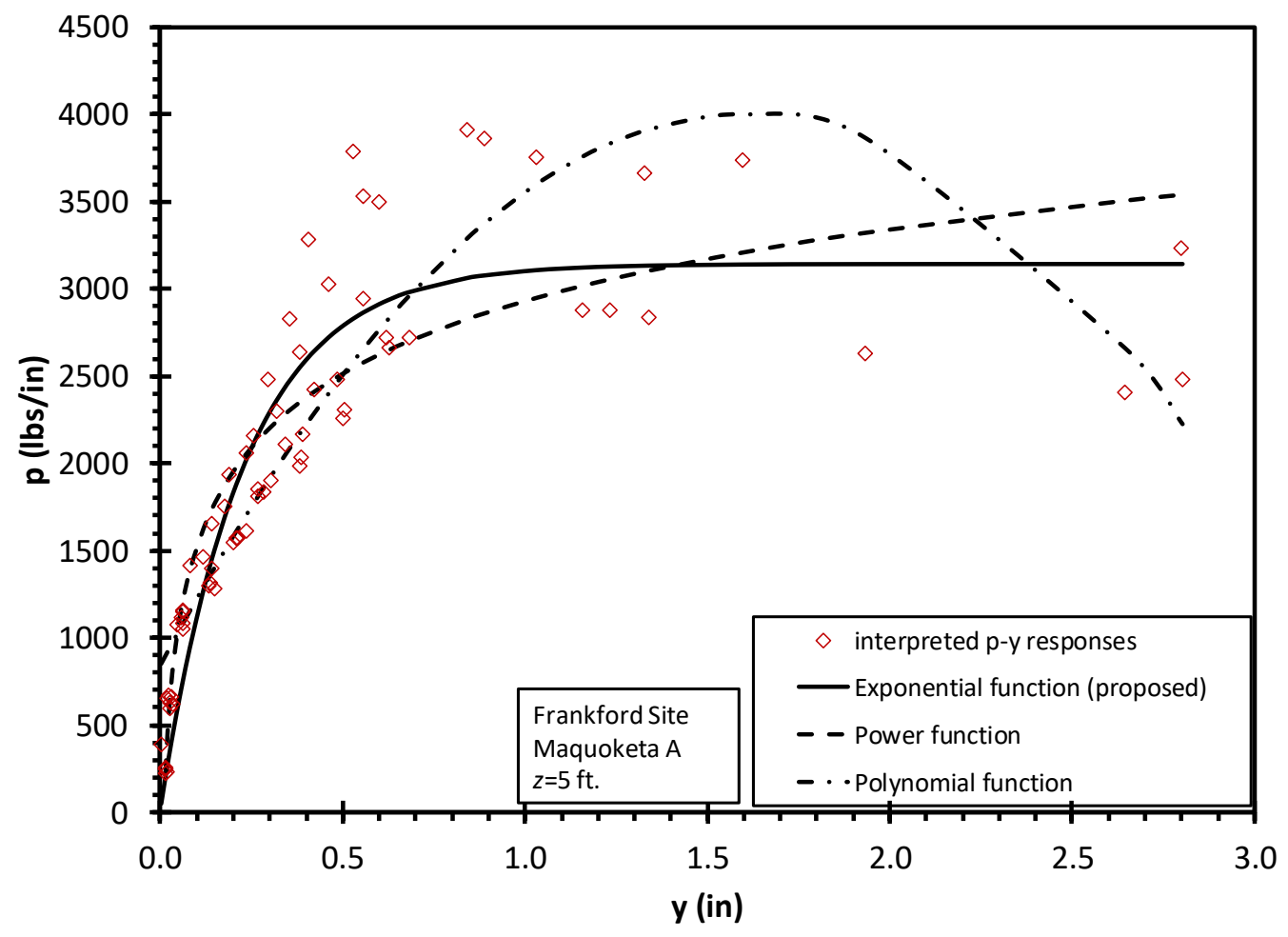

Figure $5.1-p-y$ curves fitted to interpreted $p-y$ responses using different functions

A scaled exponential function has been selected to develop a $p-y$ model that can represent lateral load transfer in shale, as presented in the following equation:

$$
p=P_{u l t}\left(1-\exp \left(-\frac{K_{p y}}{P_{u l t}} * y\right)\right)
$$

Eq. 5.1 
where: $\quad p=$ lateral soil response

$$
\begin{aligned}
& y=\text { lateral displacement } \\
& P_{u l t}=\text { ultimate soil response } \\
& K_{p y}=\text { initial slope of } p-y \text { curve }
\end{aligned}
$$

\subsection{Fitted p-y Curves}

In order to develop p-y model that accurately reflect the performance observed in field load tests, $p-y$ curves were fit to the interpreted $p-y$ responses established as described in Chapter 4. Using the p-y model proposed in Section 5.1, fitted p-y curves will be derived using different options to group the data, which is discussed in the following sections.

\subsubsection{Fitted $p$-y Curves Using Data According to Stratum}

The first option uses interpreted $p-y$ responses collecting within an individual stratum. For this option, the collections of interpreted $p-y$ responses are grouped together for each soil layer of Frankford or Warrensburg site. The derived fitted $p$-y curves as well as experimental data are plotted in Figure 5.2 (Frankford Maquoketa A), Figure

5.3 (Frankford Maquoketa B), Figure 5.4 (Frankford Maquoketa C), Figure 5.5 (Warrensburg Silty Clay), and Figure 5.6 (Warrensburg Sandy Shale). 
Curve fitting procedures were implemented in MATLAB to fit the exponential function of Eq. 5.1 to each set of interpreted p-y responses. These best fit lines are plotted with interpreted $\mathrm{p}-\mathrm{y}$ responses along with bounds corresponding to one standard deviation from the model values.

The results of model fitting for each soil layer at both sites are presented in Table 5.1. For the Warrensburg site, model parameters for the Silty Clay layer are from tests without soil removal, and model parameters for the Sandy Shale layer are from tests with soil removal.

For different soil layer, as the uniaxial compressive strength (UCS) increases, both the ultimate lateral soil resistance, $P_{u l t}$, and the initial slope of the $\mathrm{p}-\mathrm{y}$ curve, $K_{p y}$, increase. However, $P_{u l t}$ increases gradually while $K_{p y}$ rises dramatically. For instance, as UCS of Maquoketa layers at Frankford increases from 3.25 to 10.4 to $66.2 \mathrm{ksf}, P_{\text {ult }}$ only increase slowly from 2.92 to 4.93 and then to $11.2 \mathrm{kips} /$ in but $K_{p y}$ increases significantly from 20.6 to 1,022 and finally to $287,309 \mathrm{kips} / \mathrm{in}^{2}$. 


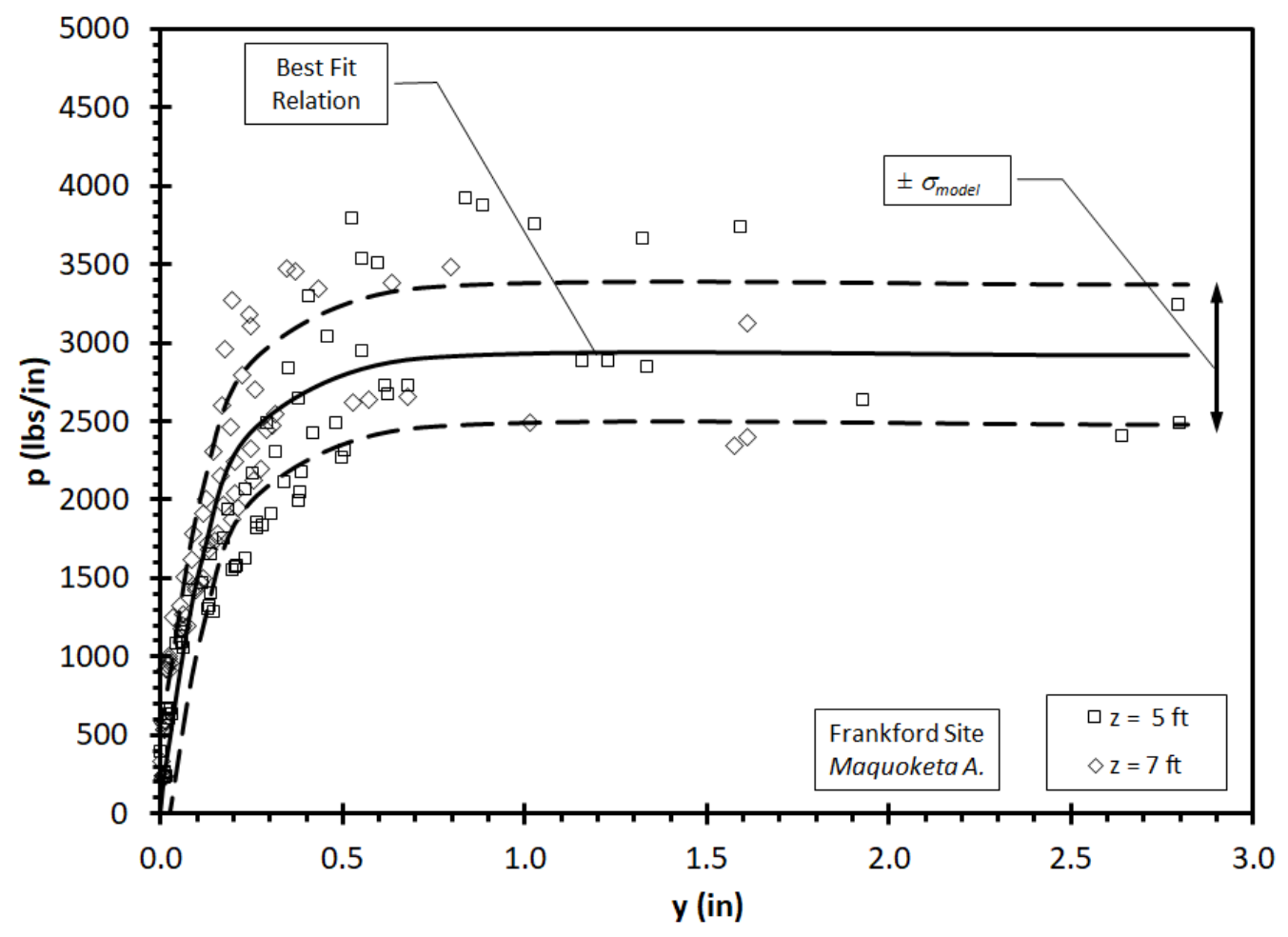

Figure 5.2 - Fitted p-y curve for Maquoketa A layer at Frankford Load Test Site

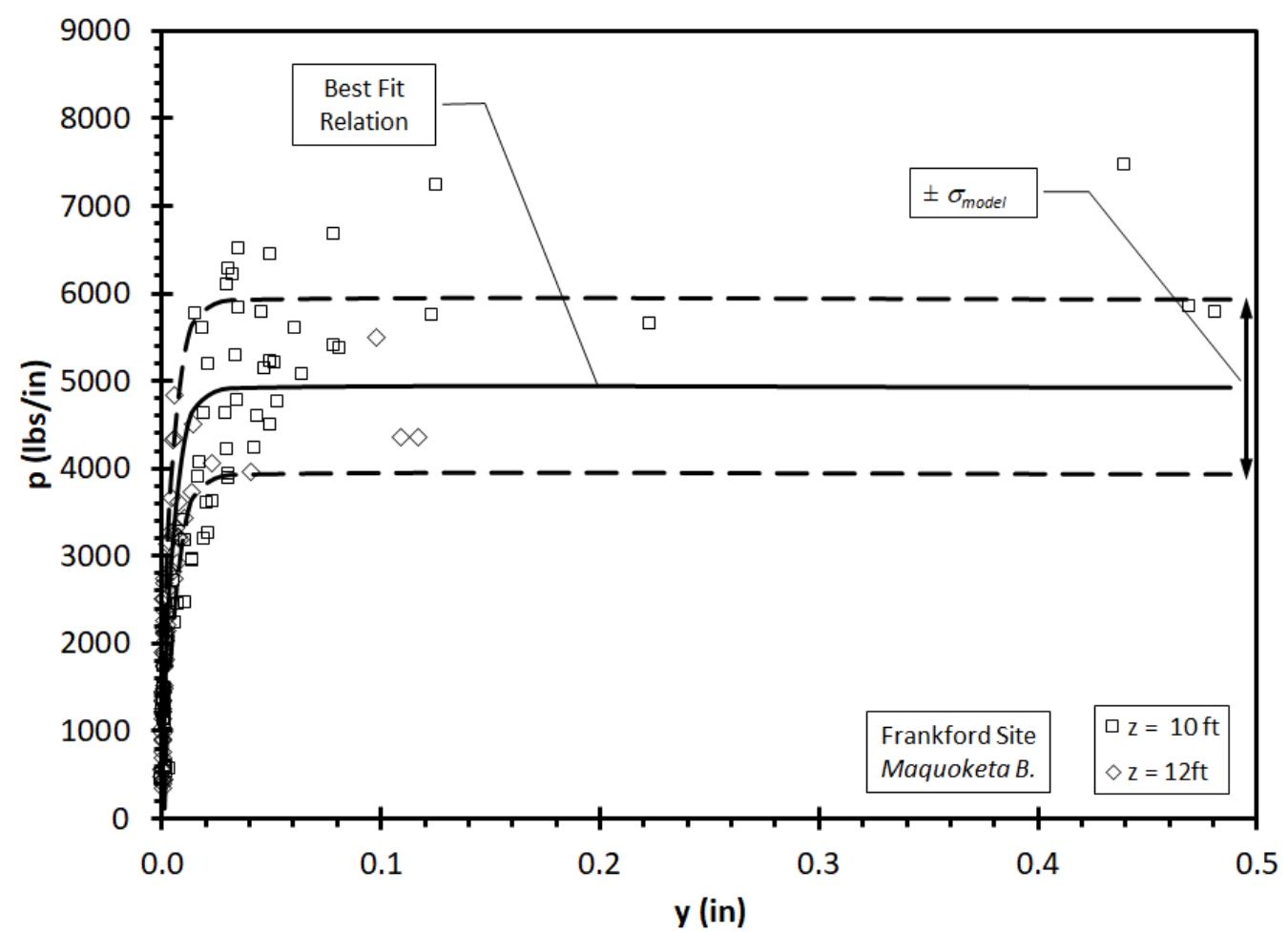

Figure 5.3 - Fitted p-y curve for Maquoketa B layer at Frankford Load Test Site 


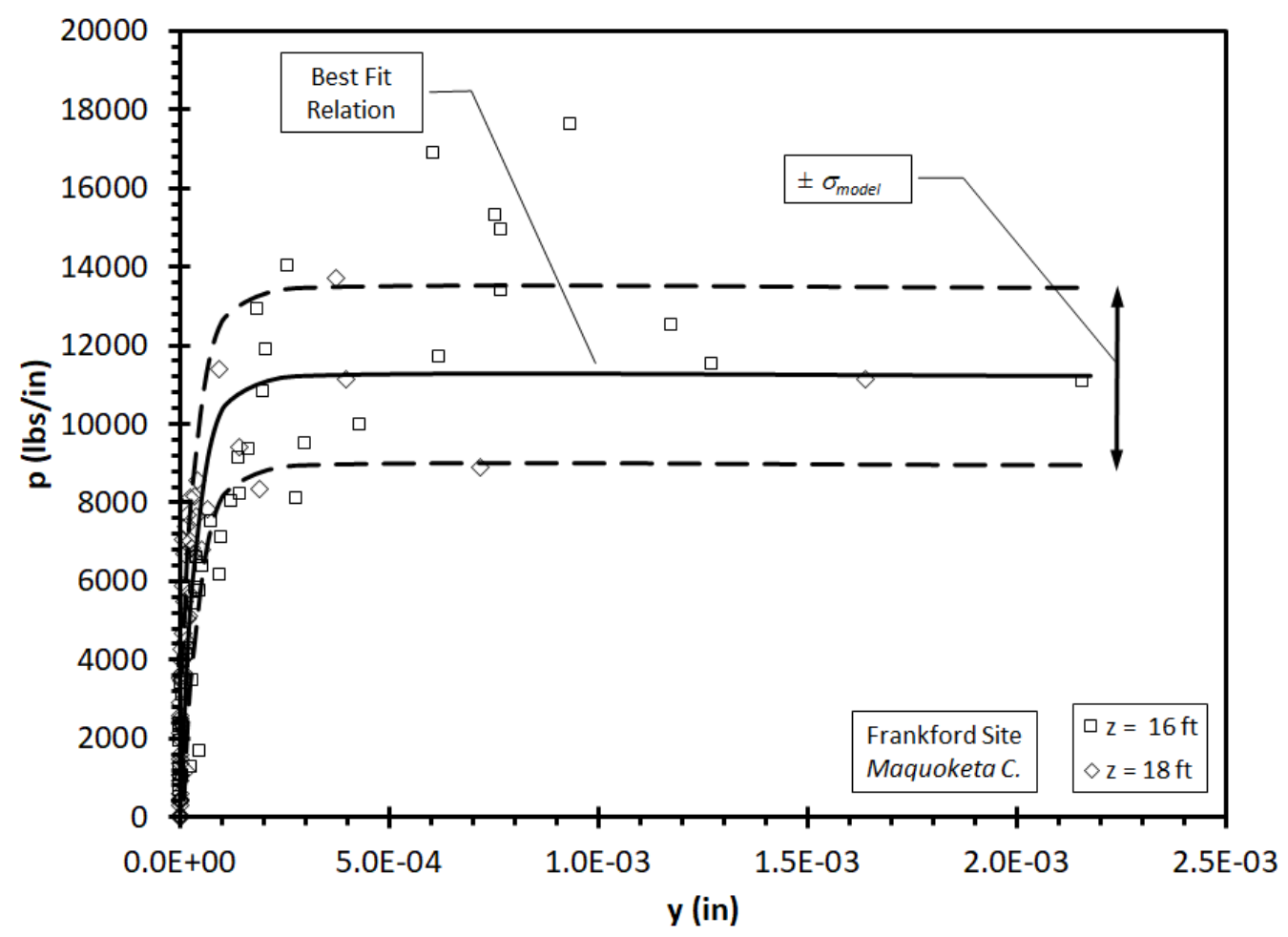

Figure 5.4 - Fitted p-y curve for Maquoketa C layer at Frankford Load Test Site

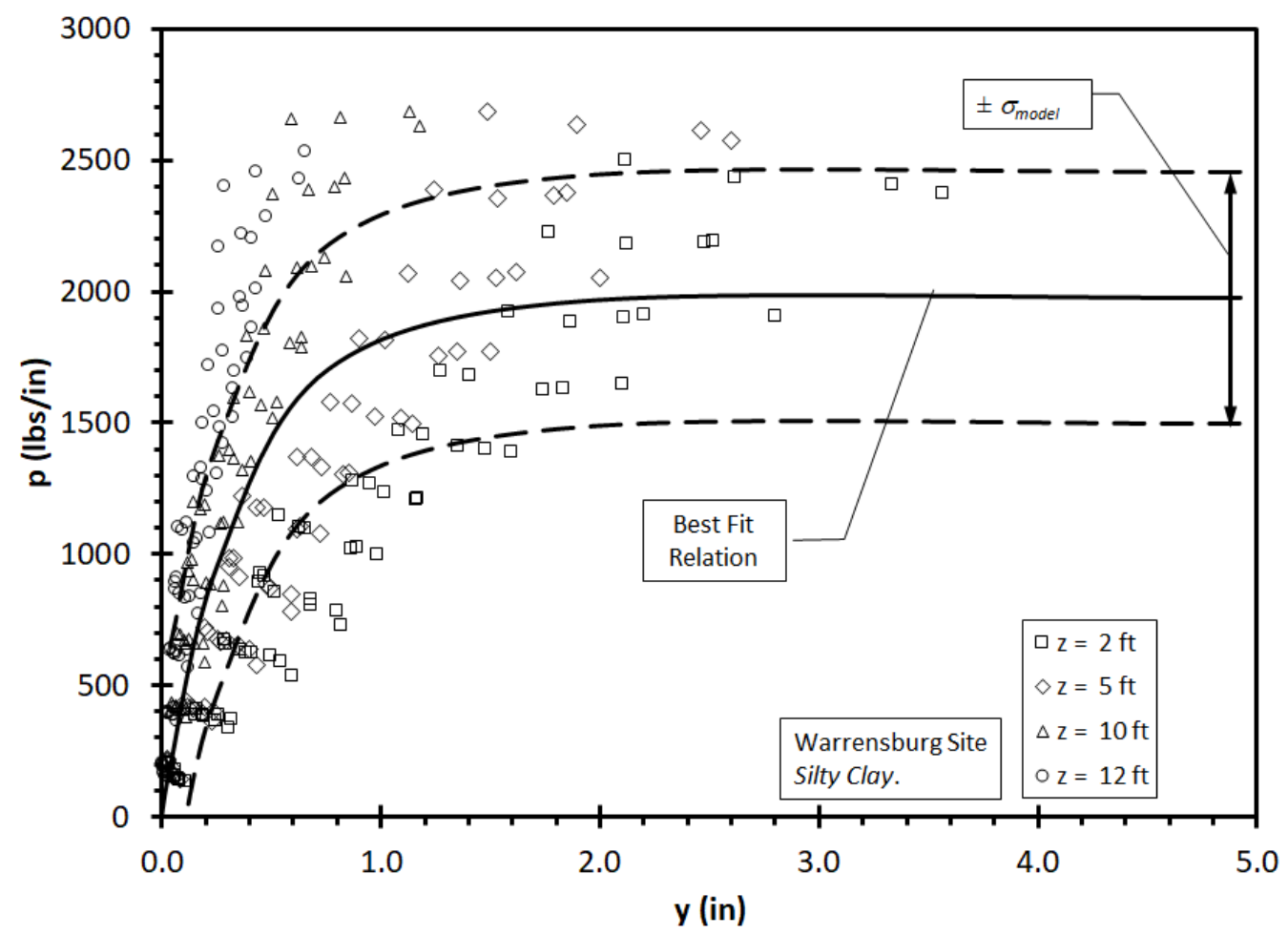

Figure 5.5 - Fitted p-y curve for Silty Clay layer at Warrensburg Load Test Site 


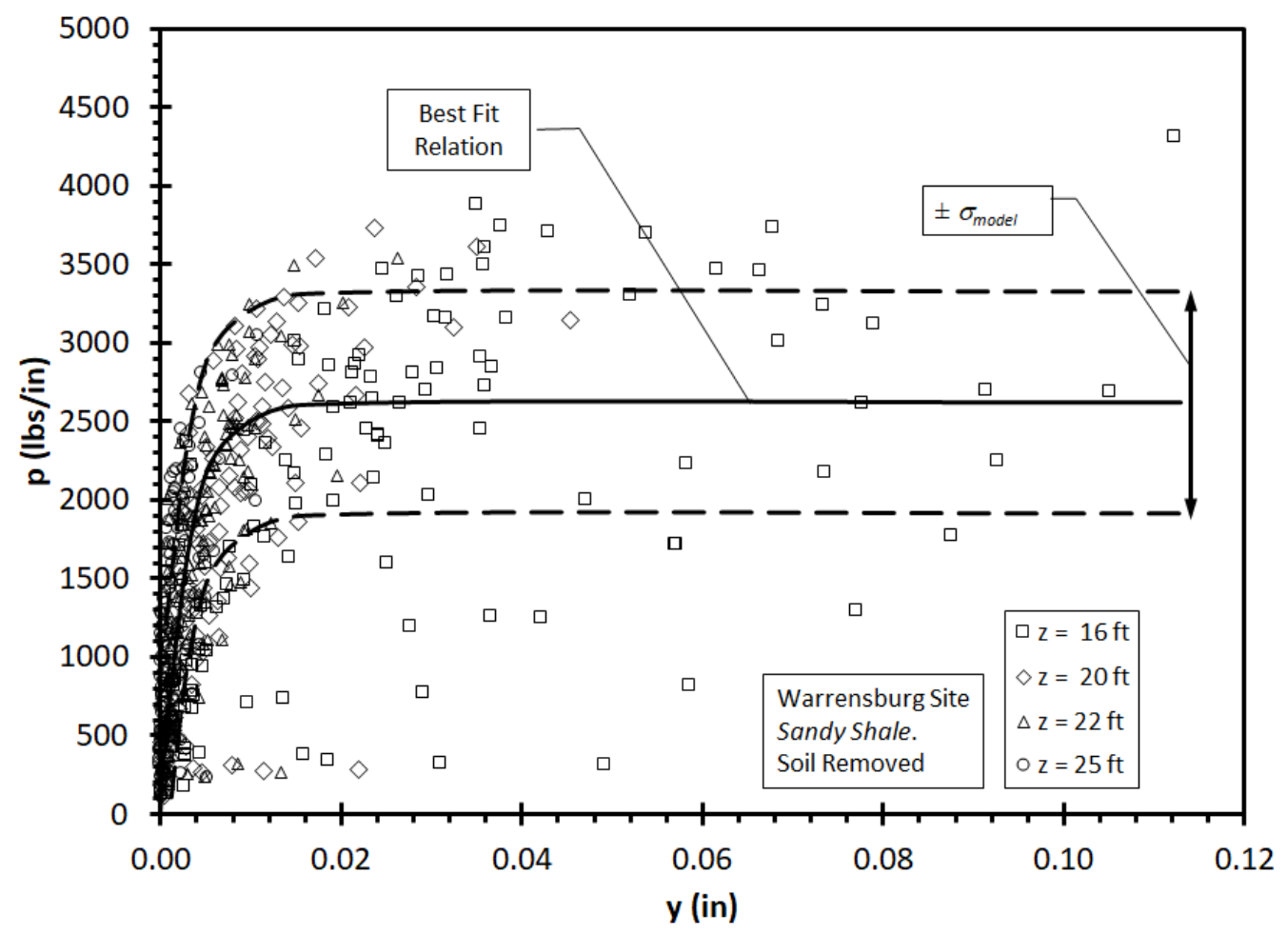

Figure 5.6 - Fitted p-y curve for Sandy Shale layer at Warrensburg Load Test Site

\section{Table 5.1 - Summary of model fitting parameters for each stratum}

\begin{tabular}{|c|c|c|c|c|}
\hline Site & Layer & $\begin{array}{r}\text { UCS } \\
\text { ksf }\end{array}$ & $\begin{array}{r}\text { Pult } \\
\text { kips/in. }\end{array}$ & $\begin{array}{r}K_{p y} \\
\text { kips/in. }{ }^{2}\end{array}$ \\
\hline \multirow{3}{*}{ Frankford } & Maquoketa A & 3.25 & 2.92 & 20.6 \\
\hline & Maquoketa B & 10.4 & 4.93 & 1,022 \\
\hline & Maquoketa C & 66.2 & 11.2 & 287,309 \\
\hline \multirow{2}{*}{ Warrensburg } & Silty Clay & 4.45 & 1.98 & 5.14 \\
\hline & Sandy Shale & 15.0 & 2.62 & 867 \\
\hline
\end{tabular}




\subsubsection{Fitted $p-y$ Curves Using Data According to Depth}

The second option is grouping interpreted $p-y$ responses according to depth. In this option, the collections of interpreted $p-y$ responses are grouped together by different depth at each stratum. The fitted $p-y$ curves corresponding to each set of interpreted $p-y$ responses are plotted in Figure 5.7 (Frankford Maquoketa A), Figure 5.8 (Frankford Maquoketa B), Figure 5.9 (Frankford Maquoketa C), Figure 5.10 (Warrensburg Silty Clay), and Figure 5.11 (Warrensburg Sandy Shale), with one standard deviation upper and lower bounds from the model. The results of model fitting for all depths and layers at both sites are presented in Table 5.2 in terms of ultimate lateral soil resistance, $P_{u l t}$, and the initial slope of the p-y curve, $K_{p y}$. Moreover, depth $(z)$, vertical stress $\left(\sigma_{v}\right)$ and ratio between $K_{p y}$ and $\sigma_{v}$ are also presented.

Figure 5.7 to Figure 5.11 shows fitted p-y curves provide a better fit with data grouped by depth, compare to the fitted $p-y$ curves using data according to stratum only. The standard deviation for each fitted $p-y$ curve using the second option is smaller than that using the first option. Moreover, Table 5.2 shows an influence of UCS and depth on $P_{u l t}$ and $K_{p y}$. While $P_{u l t}$ does not vary with depth within one stratum, $K_{p y}$ does. For instance, $P_{\text {ult }}$ values for fitted $\mathrm{p}$-y curves at Warrensburg site and within Silty Clay layer remain about the same ( $2.7-2.9 \mathrm{kips} / \mathrm{in})$ while $K_{p y}$ increases from 1.69 to $9.69 \mathrm{kips} / \mathrm{in}^{2}$ as depth increases from 2 to $12 \mathrm{ft}$. However, similarity to $P_{u l t}$, ratio between $K_{p y}$ and $\sigma_{v}$ does not depend on depth and directly proportional to the UCS of each stratum. 

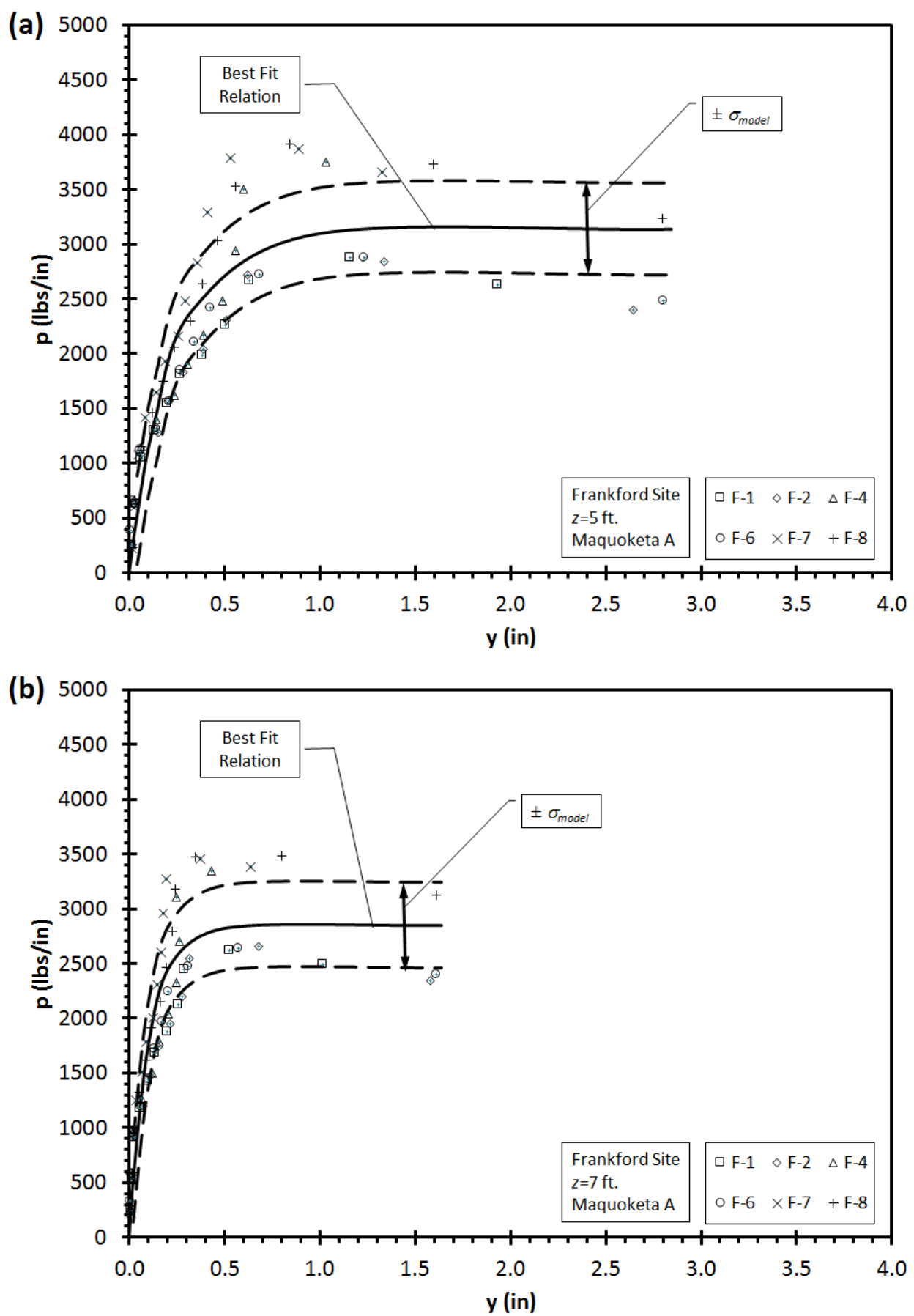

Figure 5.7 - Fitted p-y curves for Maquoketa A layer at Frankford Load Test Site for depths of (a) $5 \mathrm{ft}$ and (b) $7 \mathrm{ft}$. 

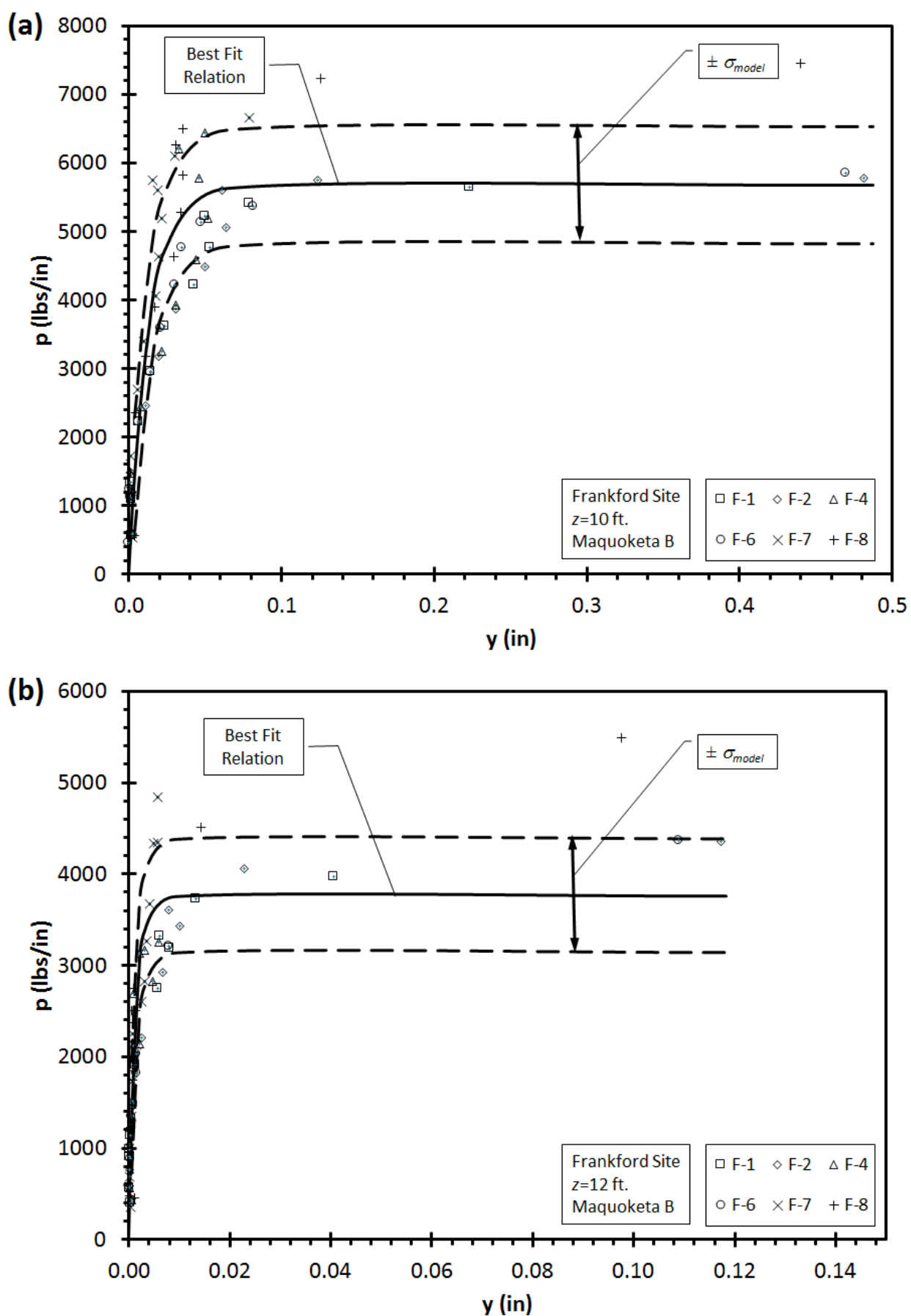

Figure 5.8 - Fitted p-y curves for Maquoketa B layer at Frankford Load Test Site for depths of (a) $10 \mathrm{ft}$ and (b) $12 \mathrm{ft}$. 

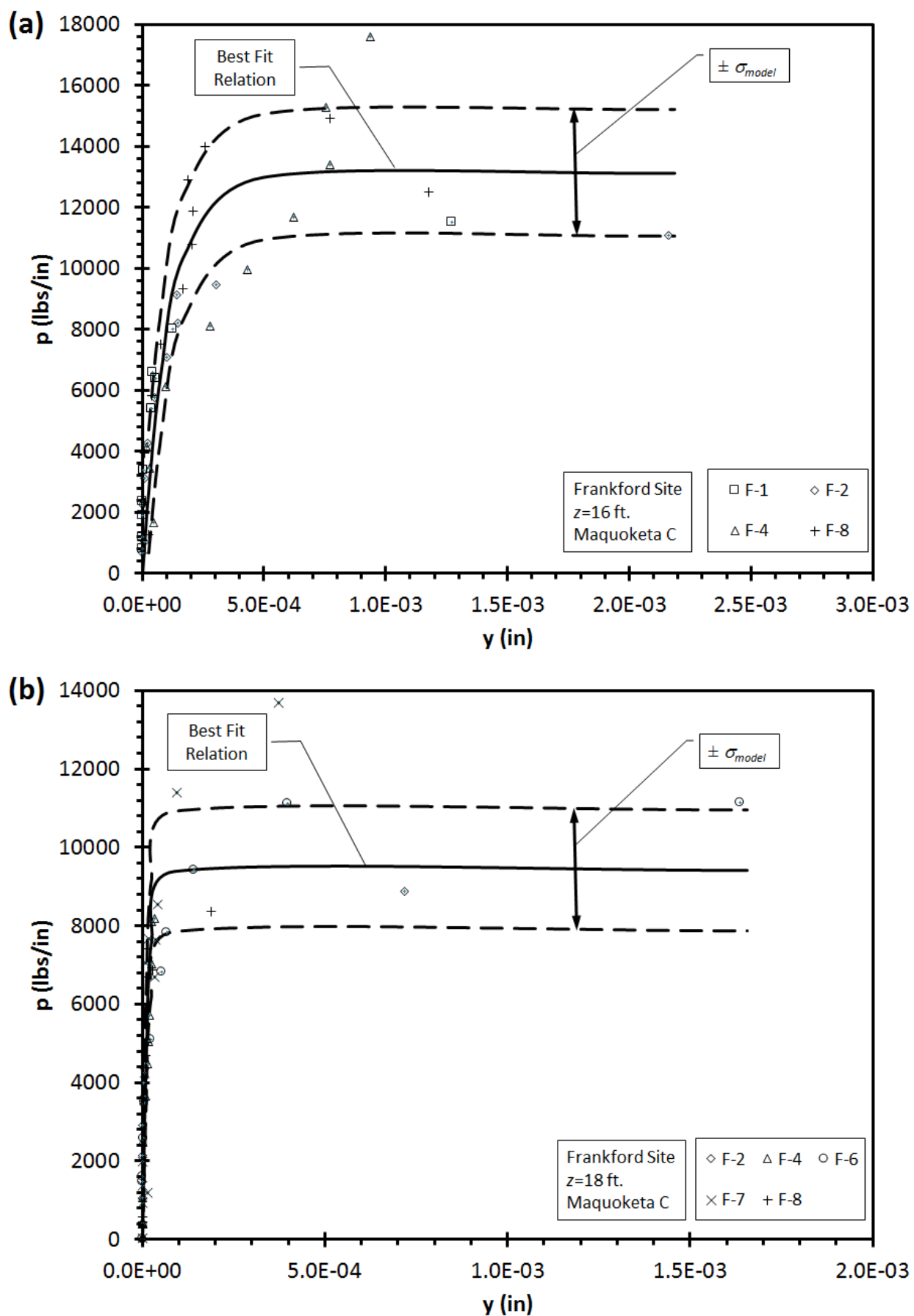

Figure 5.9 - Fitted p-y curves for Maquoketa C layer at Frankford Load Test Site for depths of (a) $16 \mathrm{ft}$ and (b) $18 \mathrm{ft}$. 

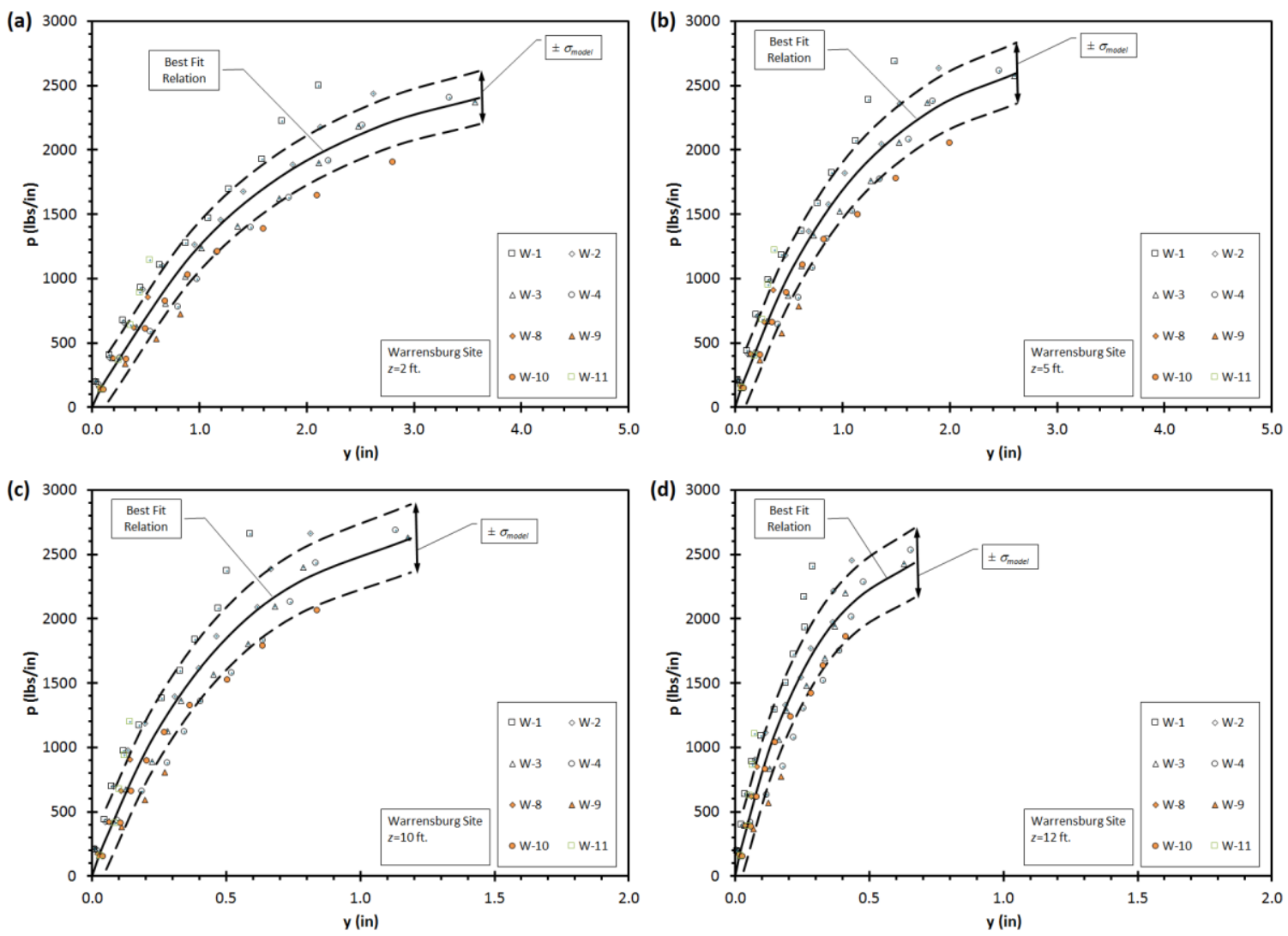

Figure 5.10 - Fitted p-y curves for Silty Clay layer at Warrensburg Load Test Site for depths of (a) $2 \mathrm{ft}$, (b) $5 \mathrm{ft}$, (c) $10 \mathrm{ft}$, and (d) $12 \mathrm{ft}$. 

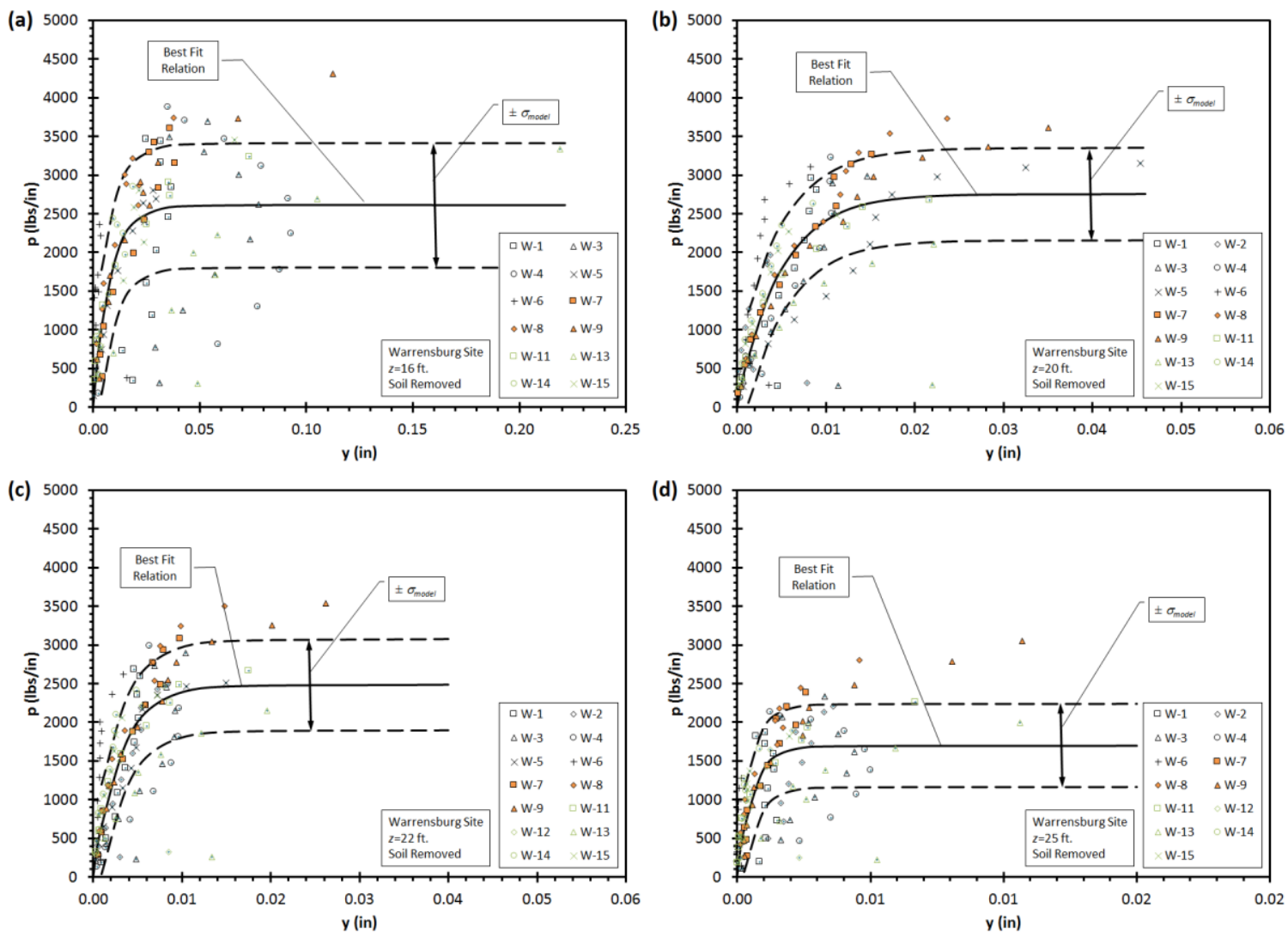

Figure 5.11 - Fitted p-y curves for Sandy Shale layer at Warrensburg Load Test Site

for depths of (a) $16 \mathrm{ft}$, (b) $20 \mathrm{ft}$, (c) $22 \mathrm{ft}$, and (d) $25 \mathrm{ft}$. 
Table 5.2 - Summary of model fitting parameters for each depth

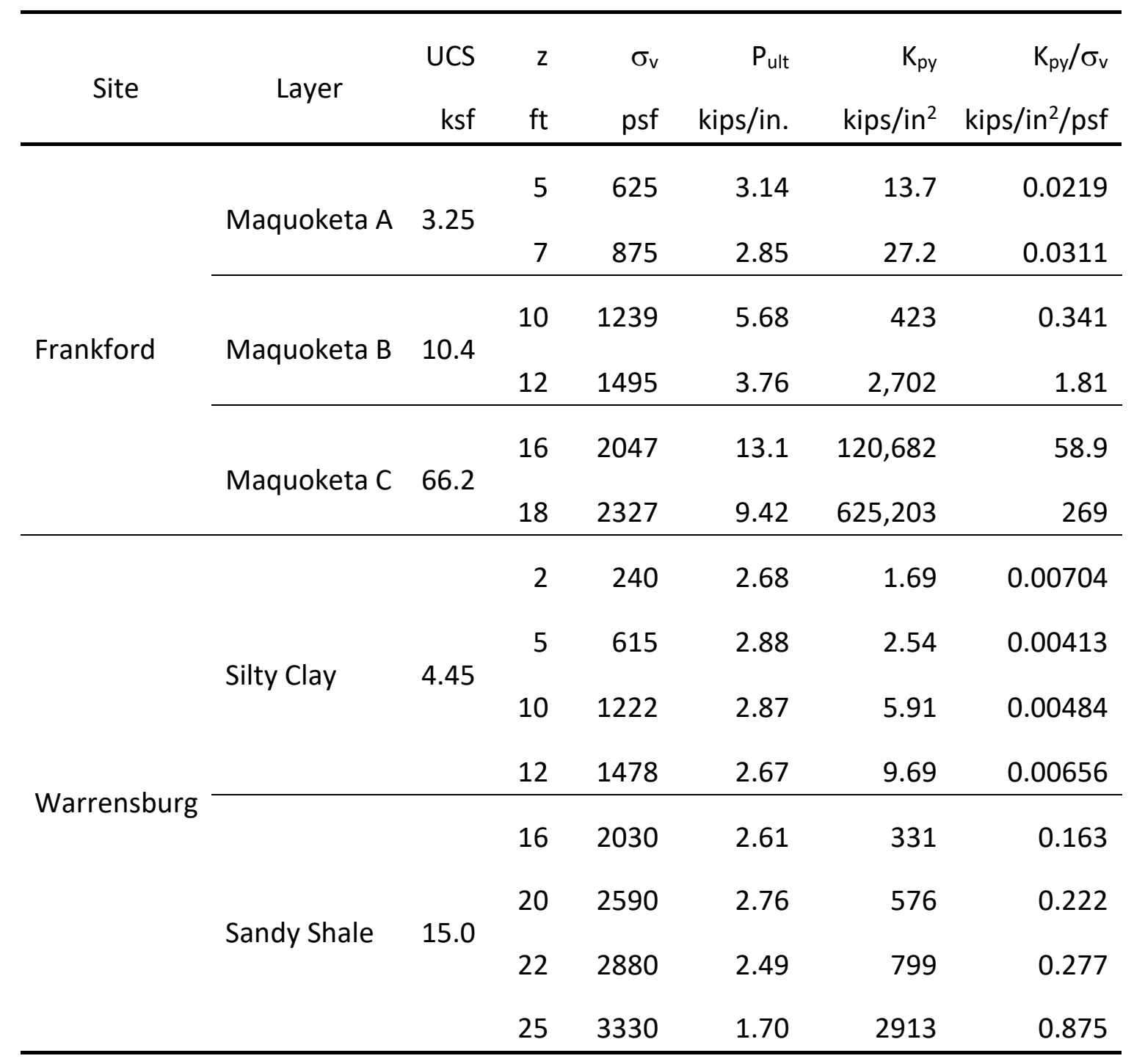




\subsubsection{Fitted $p$-y Curves Using Data According to Individual Load Test}

In this alternative option, interpreted $p-y$ responses are not grouped together by site and depth, but separated by each lateral load test. The fitted $p$-y curve corresponding to each interpreted $p-y$ response is plotted. Examples of interpreted $p-y$ response and fitted $p$-y curve with one standard deviation upper and lower bounds for each lateral load test are shown in Figure 5.12 to Figure 5.15. Remaining figures are presented in the Appendix B. Curve fitting procedures were implemented in MATLAB to fit the exponential function of Eq. 5.1 to each interpreted p-y response. The results of model fitting in terms of ultimate lateral soil resistance, $P_{u l t}$, and the initial slope of $\mathrm{p}-\mathrm{y}$ curve, $K_{p y}$ for each lateral load test are presented in Table 5.3. Moreover, depth $(z)$, ratio between initial slope of $\mathrm{p}-\mathrm{y}$ curve and vertical stress $\left(K_{p y} / \sigma_{v}\right)$, and the logarithm of that ratio $\left(\log \left(K_{p y} / \sigma_{v}\right)\right)$ are also presented.

For this option, fitted $p-y$ curves using data according to individual lateral load test provide the best fit with interpreted $p$-y responses, compared to the two options where fitted p-y curves using data according to stratum and depth. $P_{\text {ult }}$ does not vary with depth within one stratum and directly proportional to the UCS of each stratum. Similarity to option 2 , there is an influence of depth on $K_{p y}$ but the ratio $\left(K_{p y} / \sigma_{v}\right)$ does not depend on depth. However, the relationship between $\left(K_{p y} / \sigma_{v}\right)$ and UCS should be best represent by using the logarithm of that ratio $\left(\log \left(K_{p y} / \sigma_{v}\right)\right)$, since the values of $\left(K_{p y} / \sigma_{v}\right)$ itself vary not gradually but dramatically with UCS. 


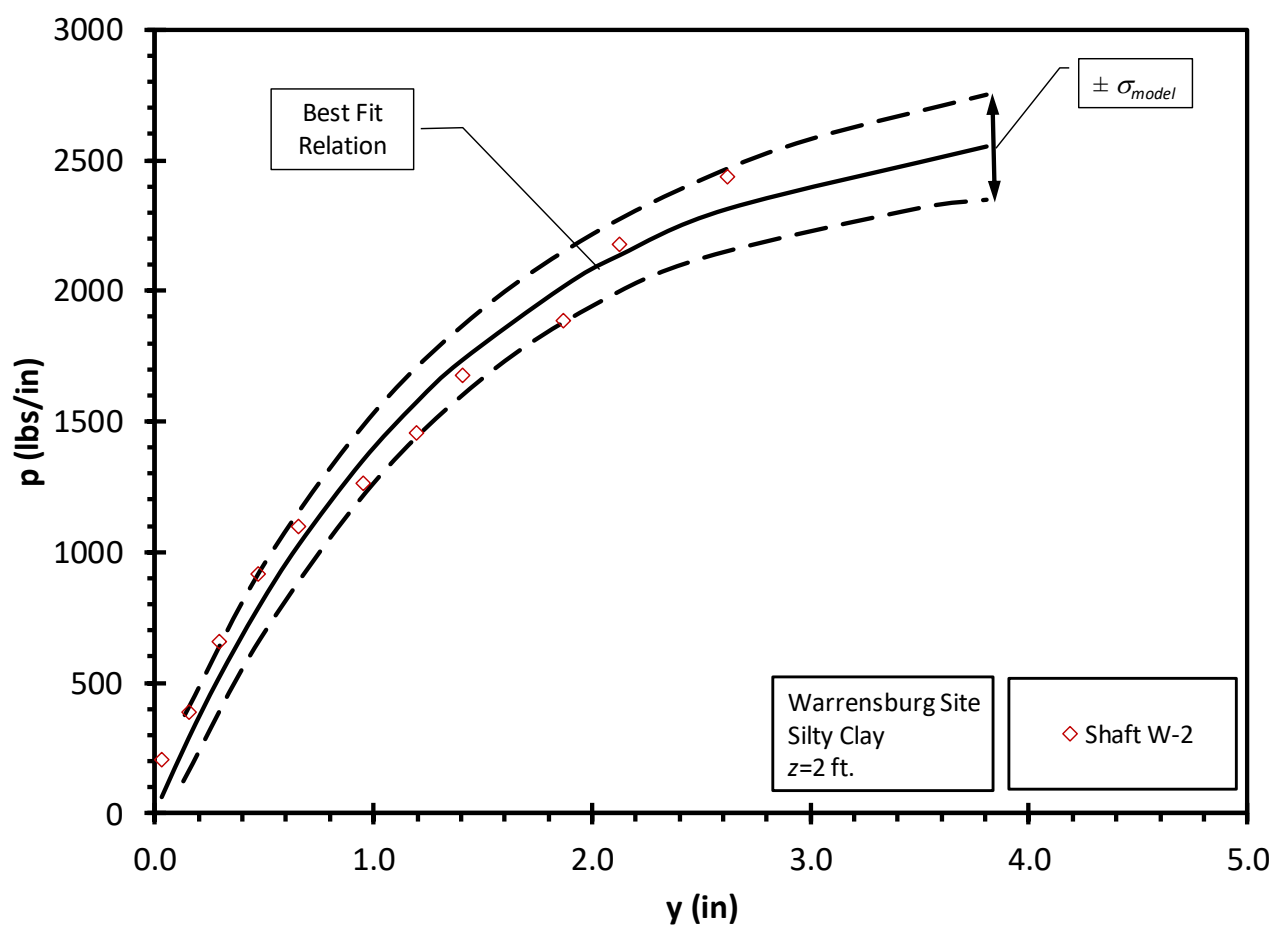

Figure 5.12 - Fitted $p-y$ curves for Lateral load test $\mathrm{W}-2$ at:

Warrensburg site, Silty Clay layer, Depth $=\mathbf{2 f t}$

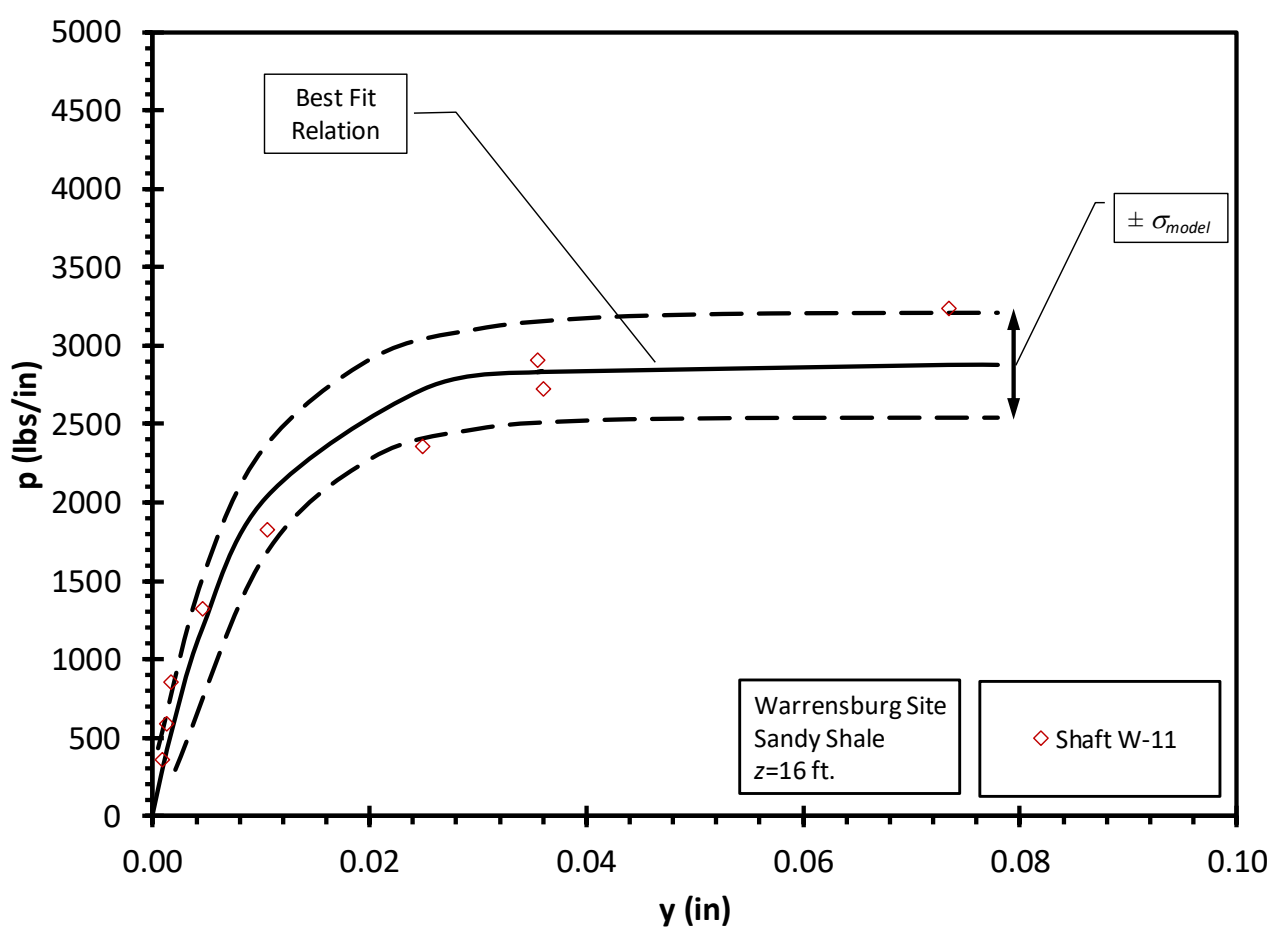

Figure 5.13 - fitted p-y curves for Lateral load test W-11 at:

Warrensburg site, Sandy Shale layer, Depth $=16 \mathrm{ft}$ 


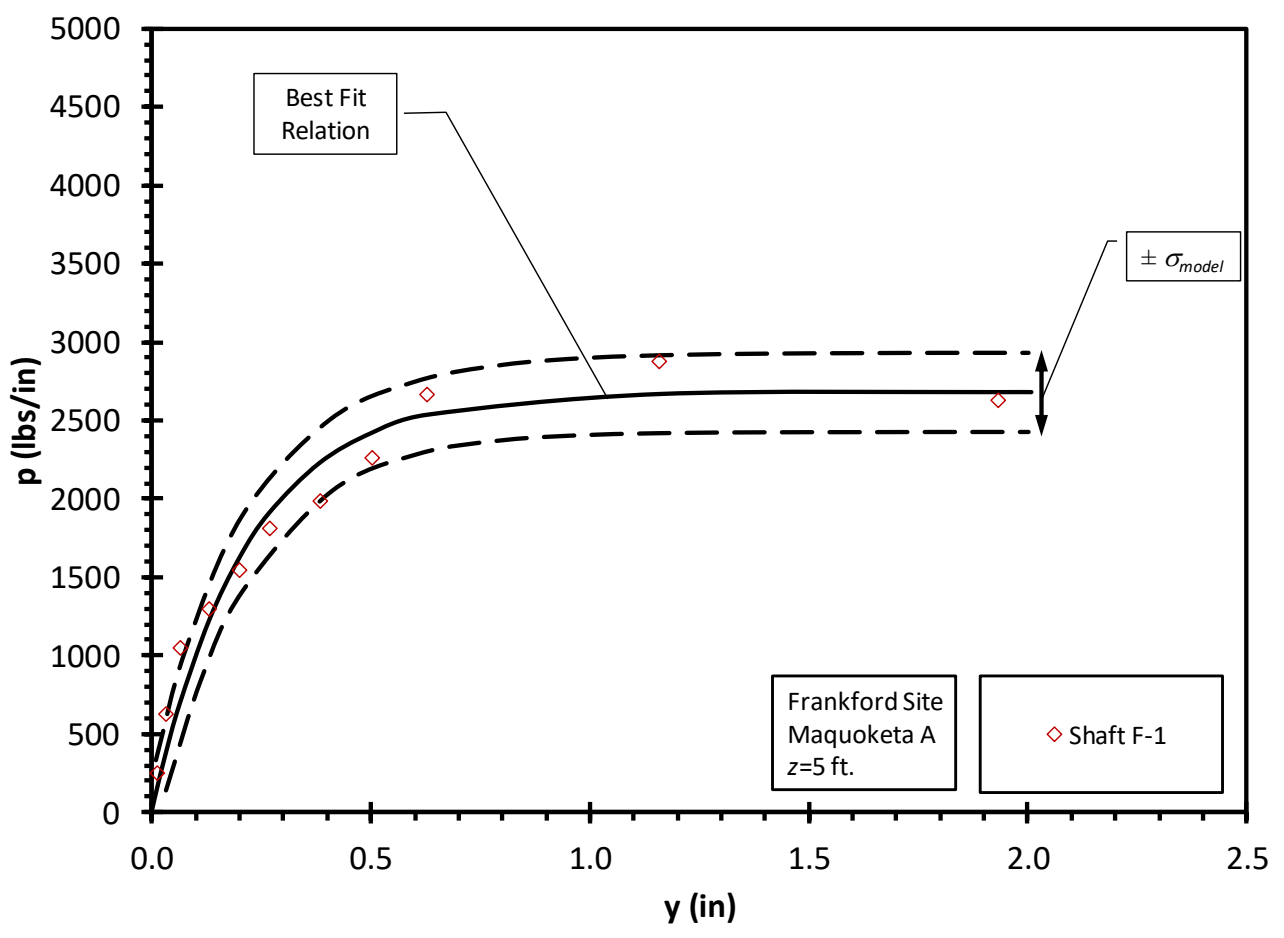

Figure 5.14 - Fitted $p$-y curves for Lateral load test F-1

Frankford site, Maquoketa A layer, Depth $=5 \mathrm{ft}$

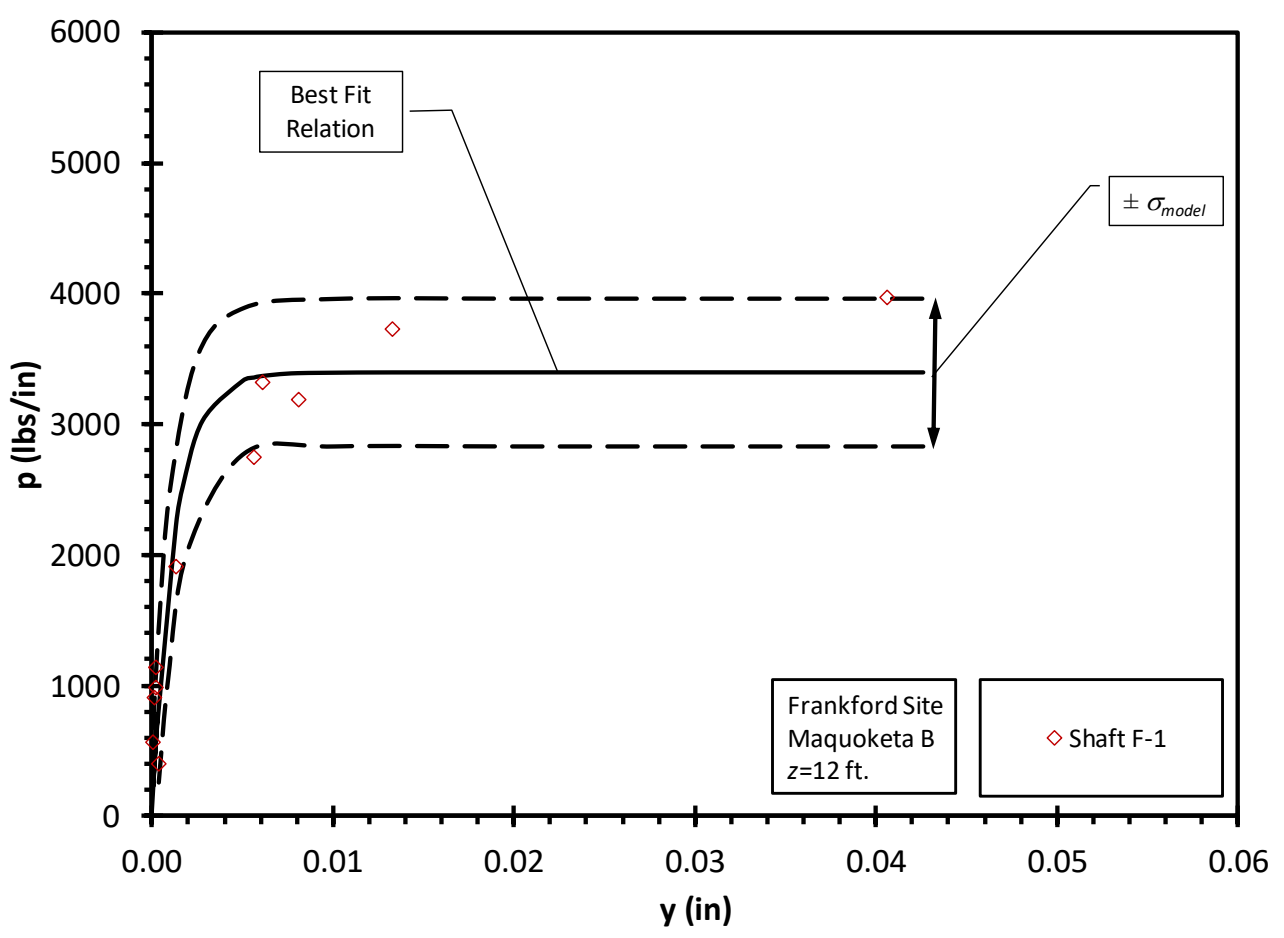

Figure 5.15 - Fitted $p$-y curves for Lateral load test F-1

Frankford site, Maquoketa B layer, Depth $=12 \mathrm{ft}$ 
Table 5.3 - Summary of model fitting parameters for each lateral load test

\begin{tabular}{|c|c|c|c|c|c|c|c|c|}
\hline Site & Layer & $\begin{array}{l}\text { UCS } \\
\text { ksf. }\end{array}$ & $\begin{array}{c}\mathrm{z} \\
\mathrm{ft}\end{array}$ & $\begin{array}{c}\text { Test } \\
\text { no. }\end{array}$ & $\begin{array}{l}P_{\text {ult }} \\
\text { kips/in. }\end{array}$ & $\begin{array}{r}K_{p y} \\
\text { kips/in }{ }^{2}\end{array}$ & $\begin{array}{r}\mathrm{K}_{\mathrm{py}} / \sigma_{\mathrm{v}} \\
\mathrm{kips} / \mathrm{in}^{2} / \mathrm{psf}\end{array}$ & $\log _{e}\left(K_{p y} / \sigma_{v}\right)$ \\
\hline \multirow{33}{*}{ 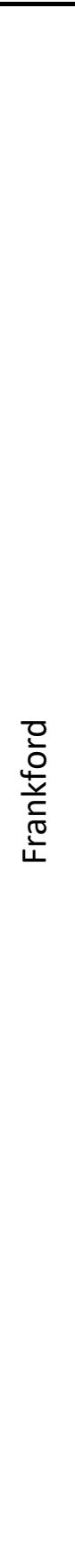 } & \multirow{12}{*}{$\begin{array}{l}\varangle \\
0 \\
\frac{0}{0} \\
\frac{0}{0} \\
\frac{0}{\partial} \\
\frac{0}{0} \\
\sum \\
\sum\end{array}$} & \multirow{12}{*}{3.25} & \multirow{6}{*}{5} & $\mathrm{~F}-1$ & 2.68 & 12.43 & 0.0199 & -3.92 \\
\hline & & & & $\mathrm{F}-2$ & 2.61 & 12.70 & 0.0203 & -3.90 \\
\hline & & & & $\mathrm{F}-4$ & 4.11 & 9.50 & 0.0152 & -4.19 \\
\hline & & & & F-6 & 2.67 & 13.80 & 0.0221 & -3.81 \\
\hline & & & & $\mathrm{F}-7$ & 3.86 & 15.77 & 0.0253 & -3.68 \\
\hline & & & & $F-8$ & 3.64 & 14.34 & 0.0230 & -3.77 \\
\hline & & & \multirow{6}{*}{7} & $\mathrm{~F}-1$ & 2.47 & 24.30 & 0.0278 & -3.58 \\
\hline & & & & $\mathrm{F}-2$ & 2.47 & 22.96 & 0.0263 & -3.64 \\
\hline & & & & $\mathrm{F}-4$ & 3.68 & 18.58 & 0.0212 & -3.85 \\
\hline & & & & F-6 & 2.49 & 26.13 & 0.0299 & -3.51 \\
\hline & & & & $F-7$ & 3.48 & 31.90 & 0.0365 & -3.31 \\
\hline & & & & $\mathrm{F}-8$ & 3.37 & 27.37 & 0.0313 & -3.46 \\
\hline & \multirow{12}{*}{ 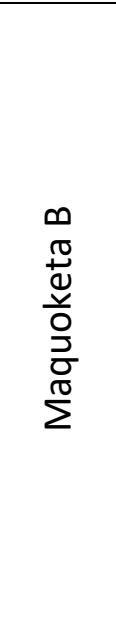 } & \multirow{12}{*}{10.4} & \multirow{6}{*}{10} & $\mathrm{~F}-1$ & 5.23 & 319.1 & 0.257 & -1.36 \\
\hline & & & & $\mathrm{F}-2$ & 5.61 & 248.1 & 0.200 & -1.61 \\
\hline & & & & $\mathrm{F}-4$ & 5.98 & 321.2 & 0.259 & -1.35 \\
\hline & & & & F-6 & 5.52 & 316.0 & 0.255 & -1.37 \\
\hline & & & & $\mathrm{F}-7$ & 6.45 & 557.0 & 0.449 & -0.80 \\
\hline & & & & $\mathrm{F}-8$ & 6.50 & 412.6 & 0.333 & -1.10 \\
\hline & & & \multirow{6}{*}{12} & $\mathrm{~F}-1$ & 3.40 & 2,673 & 1.788 & 0.58 \\
\hline & & & & $\mathrm{F}-2$ & 3.88 & 1,335 & 0.893 & -0.11 \\
\hline & & & & $\mathrm{F}-4$ & 3.08 & 3,416 & 2.285 & 0.83 \\
\hline & & & & F-6 & 3.74 & 2,435 & 1.629 & 0.49 \\
\hline & & & & $\mathrm{F}-7$ & 4.73 & 1,953 & 1.306 & 0.27 \\
\hline & & & & $\mathrm{F}-8$ & 4.94 & 3,046 & 2.037 & 0.71 \\
\hline & \multirow{9}{*}{ 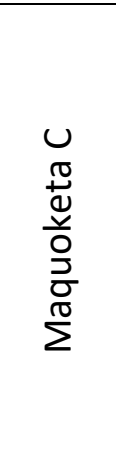 } & \multirow{9}{*}{66.2} & \multirow{4}{*}{16} & $\mathrm{~F}-1$ & 12.40 & 170,872 & 83.48 & 4.42 \\
\hline & & & & $\mathrm{F}-2$ & 11.35 & 111,105 & 54.28 & 3.99 \\
\hline & & & & $\mathrm{F}-4$ & 13.79 & 74,742 & 36.51 & 3.60 \\
\hline & & & & $\mathrm{F}-8$ & 12.05 & 93,653 & 45.75 & 3.82 \\
\hline & & & & $\mathrm{F}-2$ & 13.50 & $1,053,675$ & 452.8 & 6.12 \\
\hline & & & & $\mathrm{F}-4$ & 13.50 & 393,390 & 169.0 & 5.13 \\
\hline & & & 18 & F-6 & 12.10 & 145,321 & 62.45 & 4.13 \\
\hline & & & & F-7 & 15.28 & 471,540 & 202.6 & 5.31 \\
\hline & & & & $F-8$ & 13.50 & 636,930 & 273.7 & 5.61 \\
\hline
\end{tabular}


Table 5.3 - Summary of model fitting parameters for each lateral load test (cont.)

\begin{tabular}{|c|c|c|c|c|c|c|c|c|}
\hline Site & Layer & $\begin{array}{l}\text { UCS } \\
\text { ksf. }\end{array}$ & $\begin{array}{c}\mathrm{z} \\
\mathrm{ft} .\end{array}$ & $\begin{array}{r}\text { Test } \\
\text { no. }\end{array}$ & $\begin{array}{r}\text { Pult } \\
\text { kips/in. }\end{array}$ & $\begin{array}{r}K_{p y} \\
\text { kips/in }{ }^{2}\end{array}$ & $\begin{array}{r}K_{p y} / \sigma_{v} \\
\text { kips/in } 2 / p s f\end{array}$ & $\log _{e}\left(K_{p y} / \sigma_{v}\right)$ \\
\hline \multirow{32}{*}{$\begin{array}{l}\frac{00}{3} \\
\frac{0}{2} \\
0 \\
\frac{1}{d} \\
\frac{2}{\pi} \\
3\end{array}$} & \multirow{32}{*}{ 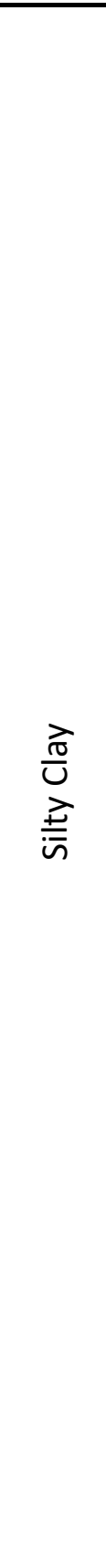 } & \multirow{8}{*}{\multicolumn{2}{|c|}{2}} & W-1 & 3.29 & 2.00 & 0.0083 & -4.79 \\
\hline & & & & W-2 & 2.73 & 1.96 & 0.0082 & -4.81 \\
\hline & & & & W-3 & 2.82 & 1.51 & 0.0063 & -5.07 \\
\hline & & & & W-4 & 3.71 & 1.21 & 0.0050 & -5.29 \\
\hline & & & & W-8 & 2.07 & 2.06 & 0.0086 & -4.76 \\
\hline & & & & W-9 & 3.00 & 1.02 & 0.0043 & -5.46 \\
\hline & & & & W-10 & 3.00 & 1.72 & 0.0072 & -4.94 \\
\hline & & & & W-11 & 3.00 & 2.27 & 0.0095 & -4.66 \\
\hline & & \multirow{8}{*}{\multicolumn{2}{|c|}{4.45}} & W-1 & 3.50 & 3.08 & 0.0050 & -5.30 \\
\hline & & & & W-2 & 2.93 & 2.96 & 0.0048 & -5.34 \\
\hline & & & & W-3 & 3.03 & 2.27 & 0.0037 & -5.60 \\
\hline & & & & W-4 & 4.02 & 1.79 & 0.0029 & -5.84 \\
\hline & & & & W-8 & 2.55 & 3.09 & 0.0050 & -5.29 \\
\hline & & & & W-9 & 3.20 & 1.54 & 0.0025 & -5.99 \\
\hline & & & & W-10 & 3.20 & 2.65 & 0.0043 & -5.45 \\
\hline & & & & W-11 & 3.20 & 3.49 & 0.0057 & -5.17 \\
\hline & & & \multirow{8}{*}{10} & W-1 & 3.41 & 7.56 & 0.0062 & -5.09 \\
\hline & & & & W-2 & 2.91 & 6.95 & 0.0057 & -5.17 \\
\hline & & & & W-3 & 3.10 & 5.14 & 0.0042 & -5.47 \\
\hline & & & & W-4 & 4.32 & 3.89 & 0.0032 & -5.75 \\
\hline & & & & W-8 & 4.10 & 7.04 & 0.0058 & -5.16 \\
\hline & & & & W-9 & 3.50 & 3.40 & 0.0028 & -5.88 \\
\hline & & & & W-10 & 3.50 & 6.18 & 0.0051 & -5.29 \\
\hline & & & & W-11 & 3.50 & 8.38 & 0.0069 & -4.98 \\
\hline & & & \multirow{8}{*}{12} & W-1 & 3.06 & 13.12 & 0.0089 & -4.72 \\
\hline & & & & W-2 & 2.66 & 11.56 & 0.0078 & -4.85 \\
\hline & & & & W-3 & 2.95 & 8.43 & 0.0057 & -5.17 \\
\hline & & & & W-4 & 4.61 & 5.88 & 0.0040 & -5.53 \\
\hline & & & & W-8 & 5.52 & 11.22 & 0.0076 & -4.88 \\
\hline & & & & W-9 & 3.70 & 5.15 & 0.0035 & -5.66 \\
\hline & & & & W-10 & 3.70 & 10.04 & 0.0068 & -4.99 \\
\hline & & & & W-11 & 3.70 & 13.93 & 0.0094 & -4.66 \\
\hline
\end{tabular}


Table 5.3 - Summary of model fitting parameters for each lateral load test (cont.)

\begin{tabular}{|c|c|c|c|c|c|c|c|c|}
\hline Site & Layer & $\begin{array}{l}\text { UCS } \\
\text { ksf. }\end{array}$ & $\begin{array}{r}\mathrm{z} \\
\mathrm{ft} .\end{array}$ & $\begin{array}{r}\text { Test } \\
\text { no. }\end{array}$ & $\begin{array}{r}\text { Pult } \\
\text { kips/in. }\end{array}$ & $\begin{array}{r}K_{p y} \\
\text { kips/in }{ }^{2} \\
\end{array}$ & $\begin{array}{r}\mathrm{K}_{\mathrm{py}} / \sigma_{\mathrm{v}} \\
\mathrm{kips} / \mathrm{in}^{2} / \mathrm{psf} \\
\end{array}$ & $\log _{e}\left(K_{p y} / \sigma_{v}\right)$ \\
\hline \multirow{25}{*}{$\begin{array}{l}\frac{00}{20} \\
\frac{0}{3} \\
\frac{0}{n} \\
\frac{1}{d} \\
\frac{2}{2} \\
3\end{array}$} & \multirow{25}{*}{$\begin{array}{l}\frac{0}{N} \\
\frac{1}{n} \\
\frac{\lambda}{0} \\
\frac{c}{0} \\
\sim\end{array}$} & \multirow{25}{*}{15.0} & \multirow{12}{*}{16} & W-1 & 3.40 & 126.58 & 0.0624 & -2.77 \\
\hline & & & & W-3 & 3.81 & 68.80 & 0.0339 & -3.38 \\
\hline & & & & W-4 & 2.54 & 305.29 & 0.1504 & -1.89 \\
\hline & & & & W-5 & 2.94 & 252.73 & 0.1245 & -2.08 \\
\hline & & & & W-6 & 3.40 & 958.12 & 0.4721 & -0.75 \\
\hline & & & & W-7 & 4.48 & 172.31 & 0.0849 & -2.47 \\
\hline & & & & W-8 & 3.56 & 351.45 & 0.1732 & -1.75 \\
\hline & & & & W-9 & 4.02 & 212.54 & 0.1047 & -2.26 \\
\hline & & & & W-11 & 2.88 & 335.17 & 0.1651 & -1.80 \\
\hline & & & & W-13 & 3.72 & 40.69 & 0.0200 & -3.91 \\
\hline & & & & W-14 & 3.10 & 317.65 & 0.1565 & -1.85 \\
\hline & & & & W-15 & 3.42 & 204.55 & 0.1008 & -2.29 \\
\hline & & & \multirow{13}{*}{20} & W-1 & 3.30 & 450.12 & 0.1738 & -1.75 \\
\hline & & & & W-2 & 3.30 & 477.84 & 0.1845 & -1.69 \\
\hline & & & & W-3 & 3.82 & 281.39 & 0.1087 & -2.22 \\
\hline & & & & W-4 & 3.30 & 434.61 & 0.1678 & -1.78 \\
\hline & & & & W-5 & 3.46 & 238.77 & 0.0922 & -2.38 \\
\hline & & & & W-6 & 3.12 & 1076.02 & 0.4155 & -0.88 \\
\hline & & & & W-7 & 3.88 & 448.41 & 0.1732 & -1.75 \\
\hline & & & & W-8 & 3.87 & 486.21 & 0.1877 & -1.67 \\
\hline & & & & W-9 & 3.54 & 404.72 & 0.1563 & -1.86 \\
\hline & & & & W-11 & 2.58 & 593.00 & 0.2290 & -1.47 \\
\hline & & & & W-13 & 2.08 & 339.32 & 0.1310 & -2.03 \\
\hline & & & & W-14 & 2.82 & 849.70 & 0.3281 & -1.11 \\
\hline & & & & W-15 & 2.55 & 840.92 & 0.3247 & -1.12 \\
\hline
\end{tabular}


Table 5.3 - Summary of model fitting parameters for each lateral load test (cont.)

\begin{tabular}{|c|c|c|c|c|c|c|c|c|}
\hline Site & Layer & $\begin{array}{l}\text { UCS } \\
\text { ksf. }\end{array}$ & $\begin{array}{r}\mathrm{z} \\
\mathrm{ft} .\end{array}$ & $\begin{array}{r}\text { Test } \\
\text { no. }\end{array}$ & $\begin{array}{r}\text { Pult } \\
\text { kips/in. }\end{array}$ & $\begin{array}{r}K_{p y} \\
\text { kips/in }\end{array}$ & $\begin{array}{r}\mathrm{K}_{\mathrm{py}} / \sigma_{\mathrm{v}} \\
\mathrm{kips} / \mathrm{in}^{2} / \mathrm{psf}\end{array}$ & $\log _{\mathrm{e}}\left(K_{\mathrm{py}} / \sigma_{\mathrm{v}}\right)$ \\
\hline \multirow{27}{*}{ 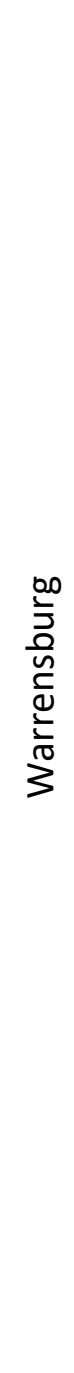 } & \multirow{27}{*}{ 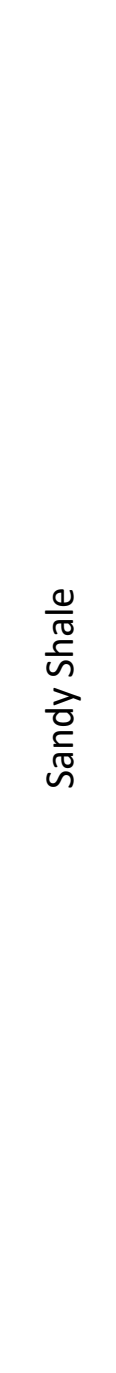 } & \multirow{27}{*}{15.0} & \multirow{14}{*}{22} & W-1 & 3.00 & 672.00 & 0.2334 & -1.46 \\
\hline & & & & W-2 & 3.00 & 529.50 & 0.1839 & -1.69 \\
\hline & & & & W-3 & 3.00 & 384.00 & 0.1333 & -2.01 \\
\hline & & & & W-4 & 2.57 & 496.33 & 0.1724 & -1.76 \\
\hline & & & & W-5 & 2.75 & 585.14 & 0.2032 & -1.59 \\
\hline & & & & W-6 & 2.83 & 2292.41 & 0.7961 & -0.23 \\
\hline & & & & W-7 & 3.83 & 619.31 & 0.2151 & -1.54 \\
\hline & & & & W-8 & 3.55 & 778.24 & 0.2703 & -1.31 \\
\hline & & & & W-9 & 3.41 & 589.26 & 0.2046 & -1.59 \\
\hline & & & & W-11 & 2.49 & 877.52 & 0.3047 & -1.19 \\
\hline & & & & W-12 & 1.71 & 1279.29 & 0.4442 & -0.81 \\
\hline & & & & W-13 & 1.51 & 477.94 & 0.1660 & -1.80 \\
\hline & & & & W-14 & 2.80 & 1194.78 & 0.4149 & -0.88 \\
\hline & & & & W-15 & 2.46 & 1190.18 & 0.4133 & -0.88 \\
\hline & & & \multirow{13}{*}{25} & W-1 & 3.00 & 1324.50 & 0.3978 & -0.92 \\
\hline & & & & W-2 & 3.00 & 887.10 & 0.2664 & -1.32 \\
\hline & & & & W-3 & 1.91 & 1087.92 & 0.3267 & -1.12 \\
\hline & & & & W-4 & 3.00 & 579.60 & 0.1741 & -1.75 \\
\hline & & & & W-6 & 3.00 & 7332.00 & 2.2020 & 0.79 \\
\hline & & & & W-7 & 2.96 & 1797.54 & 0.5399 & -0.62 \\
\hline & & & & W-8 & 2.68 & 2567.44 & 0.7711 & -0.26 \\
\hline & & & & W-9 & 2.84 & 1558.82 & 0.4682 & -0.76 \\
\hline & & & & W-11 & 1.91 & 3726.32 & 1.1191 & 0.11 \\
\hline & & & & W-12 & 3.00 & 1145.10 & 0.3439 & -1.07 \\
\hline & & & & W-13 & 1.66 & 563.71 & 0.1693 & -1.78 \\
\hline & & & & W-14 & 1.90 & 4828.51 & 1.4501 & 0.37 \\
\hline & & & & W-15 & 1.85 & 4363.94 & 1.3106 & 0.27 \\
\hline
\end{tabular}




\subsection{Proposed $p-y$ Model from Fitted $p-y$ Curves}

In order to develop a means to predict parameters based on other measurements, three different approaches to collectively interpret the fitted parameters based on different fitted $p-y$ curves are presented. Comparison between three approaches will be given to select the most appropriate $p$-y model that can represent the lateral load transfer in shale.

\subsubsection{Approach 1: Depth-independent Model Using Data According to Stratum}

In this approach, the $p-y$ model parameters in terms of ultimate soil resistance and initial slope of $p-y$ curve are predicted from uniaxial compressive strength (UCS). The fitted parameters $P_{u l t}$ and $K_{p y}$ obtained from fitted p-y curved using data according to stratum (Table 5.1) are plotted versus the uniaxial compressive strength (UCS), as shown in Figure 5.16 and Figure 5.17, respectively.

A linear function for $P_{u l t}$ and a power function for $K_{p y}$ with respect to UCS have been chosen to provide a best fit with fitted parameters. Functions are characterized in following equations and have been plotted in Figure 5.16 and Figure 5.17, together with the fitted parameters.

$$
P_{u l t}=\frac{U C S}{7.27}+2.00
$$

$P$ ult in kip/in.; UCS in ksf

$3 \mathrm{ksf}<\mathrm{UCS}<100 \mathrm{ksf}$

Eq. 5.2 


$$
K_{p y}=\frac{U C S^{3.48}}{8.16}
$$

$K_{p y}$ in kip/in. ${ }^{2}$; UCS in ksf

$3 \mathrm{ksf}<U C S<100 \mathrm{ksf}$

Eq. 5.3

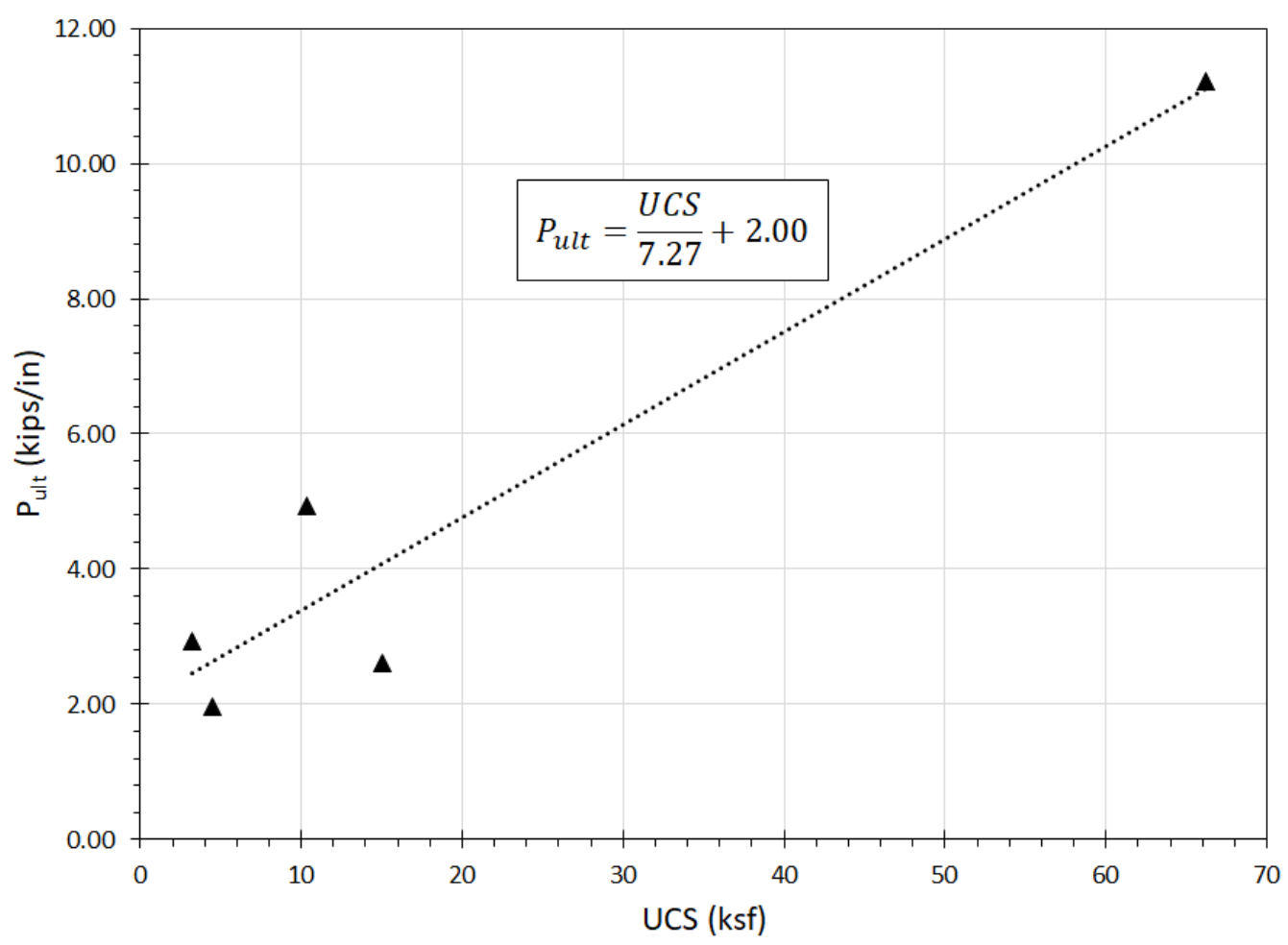

Figure 5.16 - Pult as a function of UCS using data according to stratum (Approach 1) 


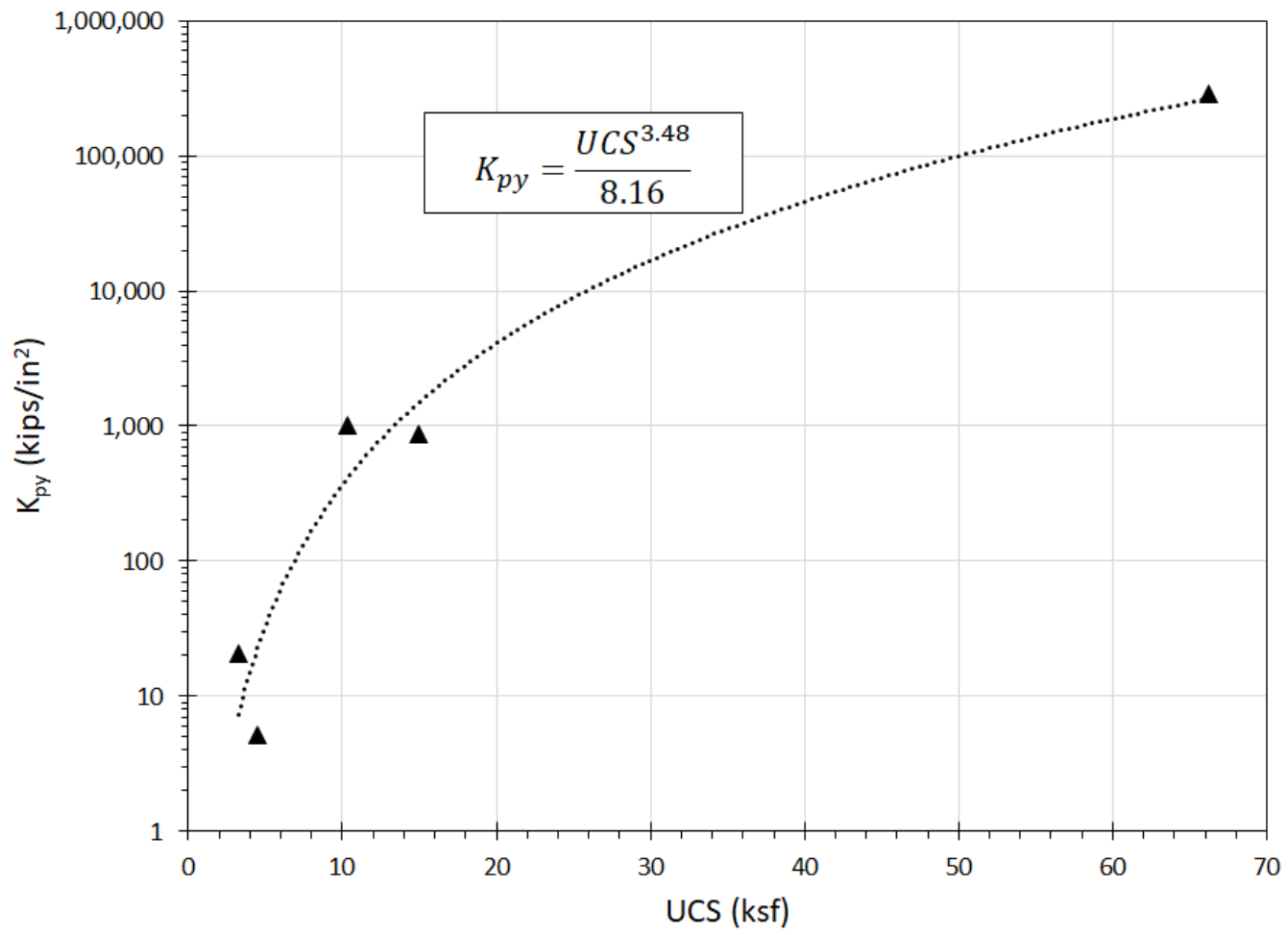

Figure $5.17-K_{p y}$ as a function of UCS using data according to stratum (Approach 1)

For a given UCS, $P_{\text {ult }}$ and $K_{p y}$ can be calculated from Eq. 5.2 and Eq. 5.3 and finally, a p-y model can be derived from proposed model format (Eq. 5.1) using the calculated parameters $P_{u l t}$ and $K_{p y}$. Both $P_{u l t}$ and $K_{p y}$ are independent from depth therefore p-y model will also be independent from depth. 


\subsubsection{Approach 2: Depth-dependent Model Using Data According to Depth}

In this approach, the ultimate soil resistance is predicted from uniaxial compressive strength while the initial slope of $p-y$ curve is predicted from both uniaxial compressive strength and depth or vertical stress. First of all, the fitted parameters $P_{\text {ult }}$ and $K_{p y}$ are obtained from fitted $\mathrm{p}$-y curves using data according to depth as presented in Table 5.2. Since $P_{\text {ult }}$ varies with UCS but not with depth, the fitted parameter $P_{u l t}$ is plotted versus the uniaxial compressive strength (UCS), as shown in Figure 5.18. On the other hand, $K_{p y}$ is depend on both UCS and depth, thus the ratio between fitted parameters and vertical stress $\left(K_{p y} / \sigma_{v}\right)$ is plotted versus the uniaxial compressive strength (UCS), as shown in and Figure 5.19.

A linear function for $P_{u l t}$ and a power function for $K_{p y} / \sigma_{v}$ with respect to UCS have been chosen to provide a best fit with fitted parameters. Functions are characterized in following equations and have been plotted in Figure 5.18 and Figure 5.19.

$$
\begin{array}{cl}
P_{u l t}=\frac{U C S}{7.37}+1.89 & P_{u l t} \text { in kip/in.; UCS in ksf } \\
& 3 \mathrm{ksf}<U C S<100 \mathrm{ksf} \\
\frac{K_{p y}}{\sigma_{v}}=\frac{U C S^{3.19}}{8414.71} & k_{p y} \text { in kip/in. }{ }^{2} ; U C S \text { in ksf; } \sigma_{v} \text { in psf } \\
& 3 \mathrm{ksf}<U C S<100 \mathrm{ksf}
\end{array}
$$




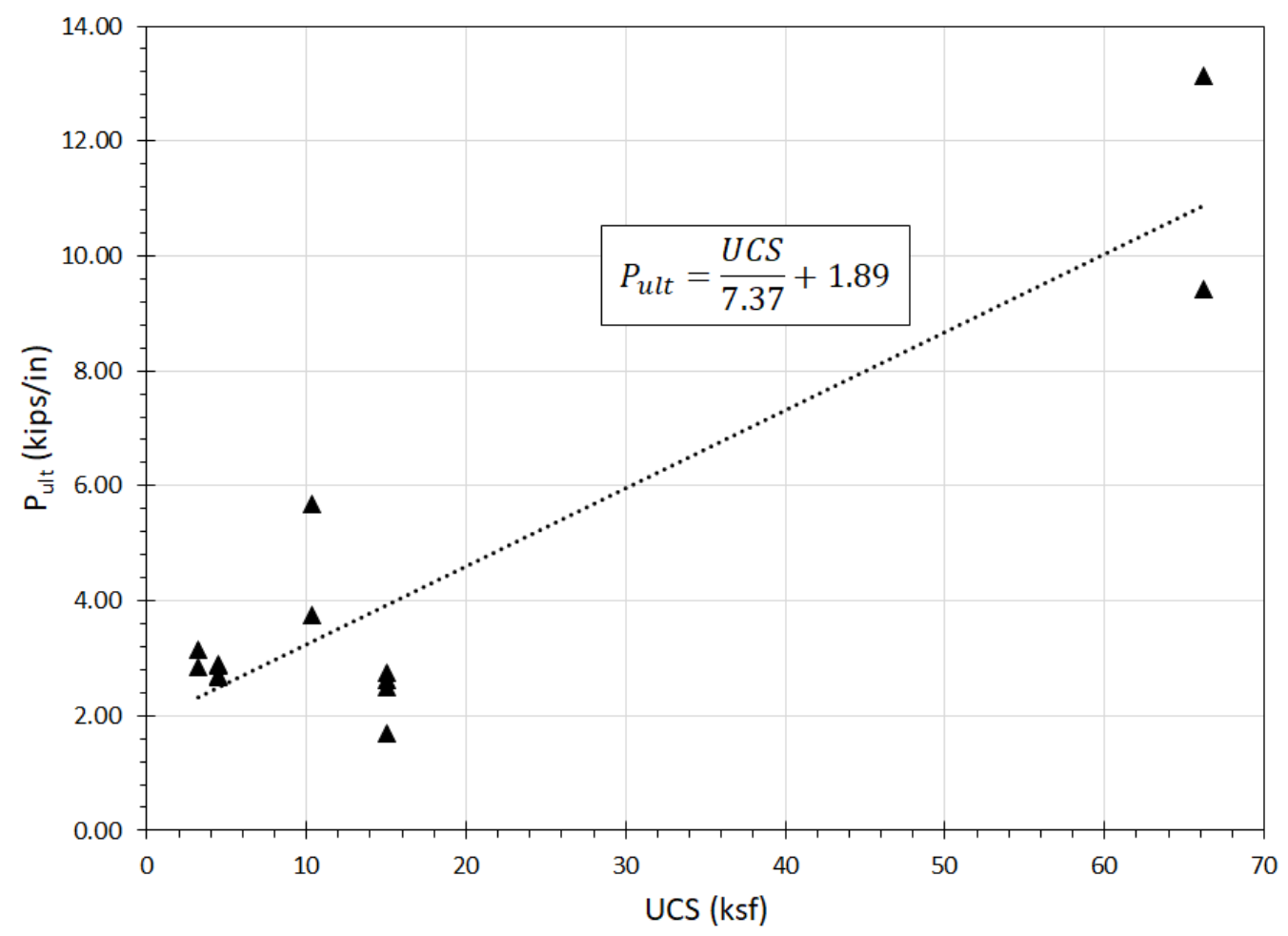

Figure 5.18 - Pult as a function of UCS using data according to depth (Approach 2)

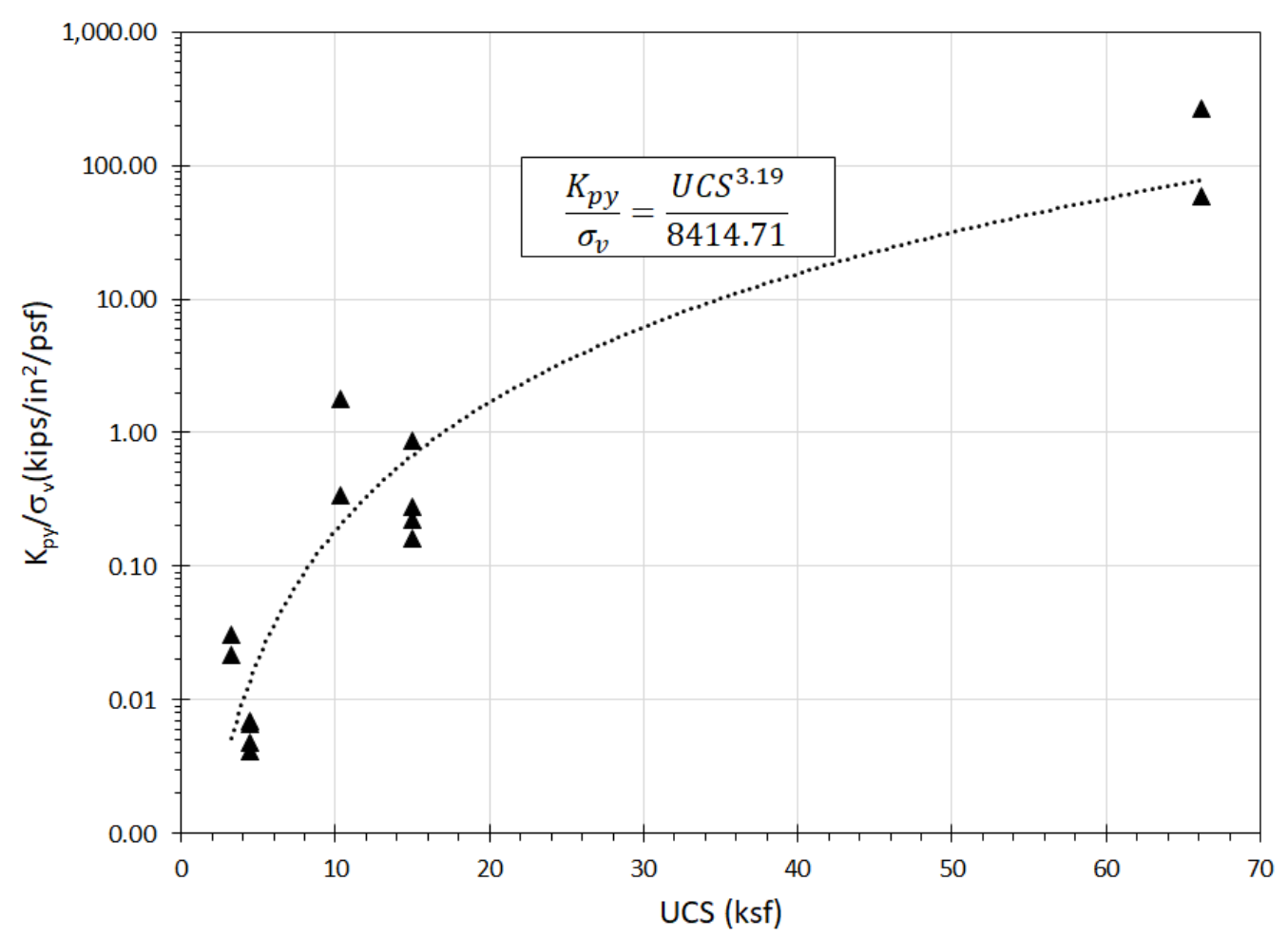

Figure 5.19 - $K_{p y}$ as a function of UCS \& $\sigma_{v}$ using data according to depth (Approach 2) 
For a given UCS at a given depth, $P_{u l t}$ and $K_{p y}$ can be predicted using Eq. 5.4 and Eq. 5.5. Finally, a p-y model can be derived from proposed model format (Eq. 5.1) and the predicted p-y model parameters $P_{u l t}$ and $K_{p y}$. For this model, $P_{u l t}$ is independent from depth but $K_{p y}$ is dependent on depth therefore proposed p-y model will also be dependent on depth.

\subsubsection{Approach 3: Depth-dependent Model Using Data According to Individual Test}

This approach is similar to approach 2, where the ultimate soil resistance is predicted from uniaxial compressive strength and the initial slope of $p$-y curve is predicted from both uniaxial compressive strength and depth or vertical stress. However, the fitted parameters $P_{u l t}$ and $K_{p y}$ are obtained from fitted $\mathrm{p}$-y curves using data according to individual lateral load test as presented in Table 5.3. $P_{\text {ult }}$ varies with UCS but not with depth, thus the fitted parameter $P_{u l t}$ is plotted versus the uniaxial compressive strength (UCS), as shown in Figure 5.20. $K_{p y}$ is depend on both UCS and depth, which will be represented using the logarithm of ratio between fitted parameters and vertical stress $\log \left(K_{p y} / \sigma_{v}\right)$ versus uniaxial compressive strength (UCS), as shown in and Figure 5.21.

A linear function for $P_{u l t}$ and a rational function for $\log _{e}\left(K_{p y} / \sigma_{v}\right)$ with respect to UCS have been selected to provide a best fit with fitted parameters. Functions are characterized in following equations and have been plotted in Figure 5.20 and Figure 5.21. 


$$
\begin{array}{cl}
P_{u l t}=\frac{U C S}{6.50}+1.86 & \begin{array}{c}
P_{u l t} \text { in kip/in.; UCS in ksf } \\
3 \mathrm{ksf}<\mathrm{UCS}<100 \mathrm{ksf}
\end{array} \\
\log _{e}\left(K_{p y} / \sigma_{v}\right)=\frac{9.83 * U C S-201.82}{U C S+31.14} & \begin{array}{c}
K_{p y} \text { in kip/in. }{ }^{2} ; \text { UCS in ksf; } \sigma_{v} \text { in psf } \\
3 \mathrm{ksf}<U C S<100 \mathrm{ksf}
\end{array}
\end{array}
$$$$
\text { Eq. } 5.6
$$

Eq. 5.7

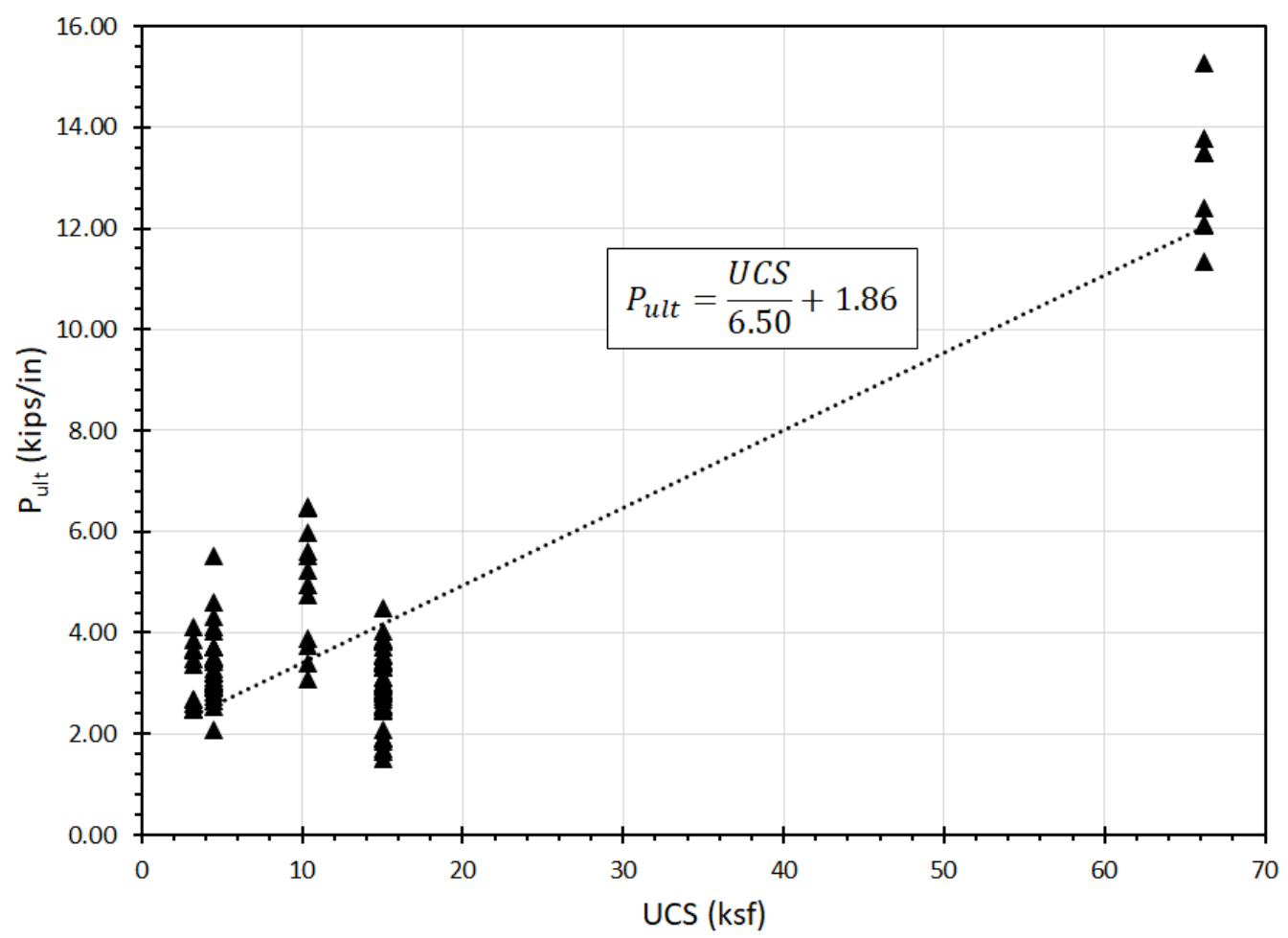

Figure 5.20 - $P_{\text {ult }}$ as a function of UCS using data according to individual load test (Approach 3) 


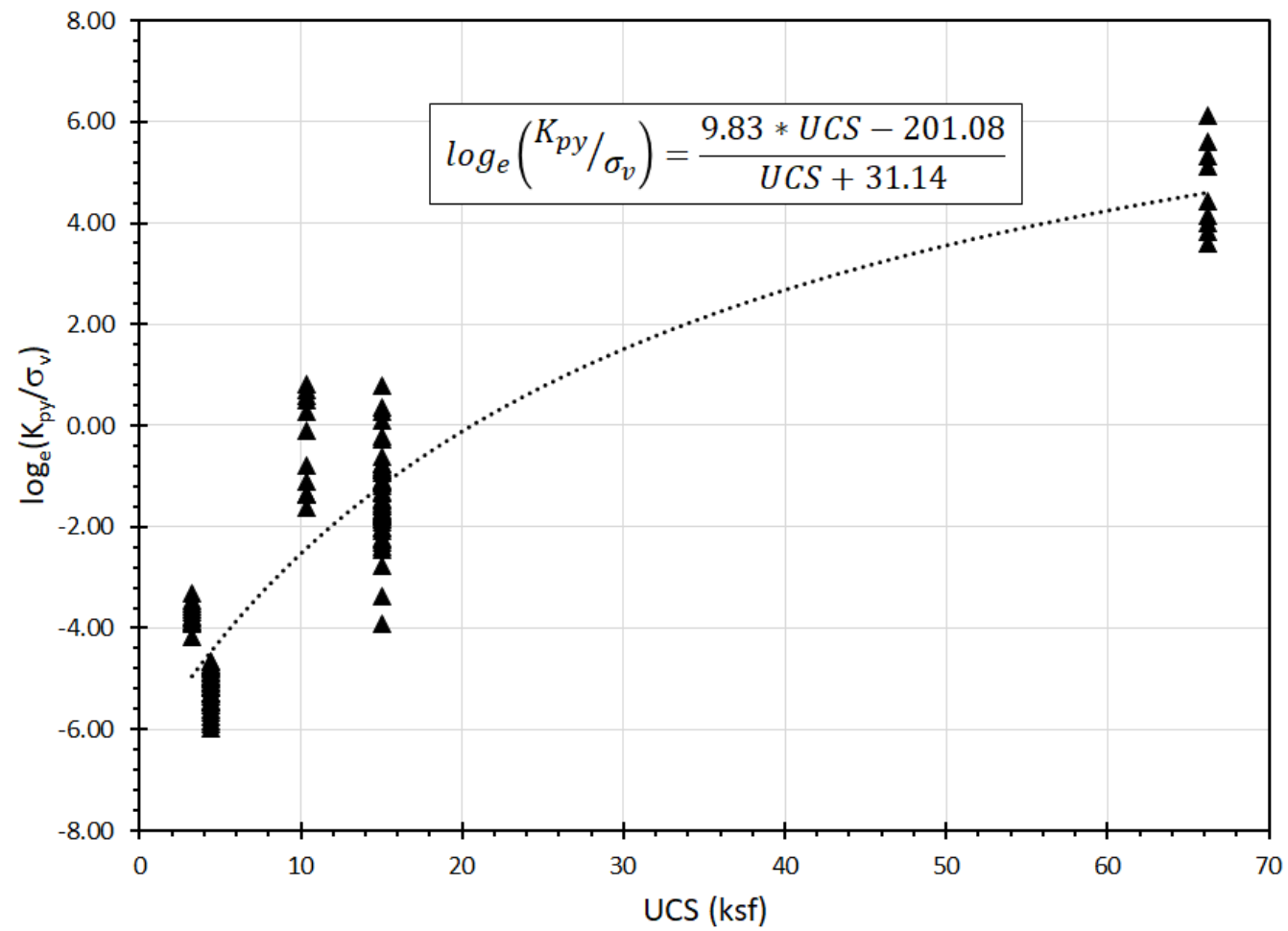

Figure 5.21 - $K_{p y}$ as a function of UCS \& $\sigma_{v}$ using data according to individual load test (Approach 3)

For a given UCS at a given depth, $P_{u l t}$ and $K_{p y}$ can be predicted using Eq. 5.6 and Eq. 5.7. A p-y model can be derived from proposed model format (Eq. 5.1) and the predicted p-y model parameters $P_{u l t}$ and $K_{p y}$. For this model, $P_{u l t}$ is independent from depth but $K_{p y}$ is dependent on depth therefore proposed p-y model will also be dependent on depth. 


\subsubsection{Comparison Between Three Approaches and Final Proposed p-y Model}

All three approaches provide $p$-y model for lateral load transfer in shale based on the same proposed $p-y$ model but using different fitted $p-y$ curves to characterize the $p$ y model parameters $\left(P_{u l t}\right.$ and $\left.K_{p y}\right)$. The difference between three approaches is the way to combine interpreted $p-y$ responses in order to establish fitted $p-y$ curves. The first approach groups interpreted $\mathrm{p}-\mathrm{y}$ responses within each stratum. The second approach uses interpreted $p$-y responses according to each depth. The third approach fits $p$-y curve to each interpreted $p-y$ response of each lateral load test. One more difference between three approaches is the formulations to predict p-y model parameters $P_{u l t}$ and $K_{p y}$ based on UCS and depth or vertical stress. (Eq. 5.2 to Eq. 5.7).

Figure 5.22 present the regression predictions for ultimate soil resistance $P_{u l t}$ with respect to uniaxial compressive strength (UCS) using the three different approaches. Figure 5.23 present the regression predictions for ratio between initial slope of $p$-y curve

and vertical stress ( $K_{p y} / \sigma_{v}$ ) with respect to the uniaxial compressive strength (UCS) using the approach 2 and 3. For both figures, the fitted $p-y$ model parameters obtained from fitted $p$-y curves at Frankford and Warrensburg are also plotted. 


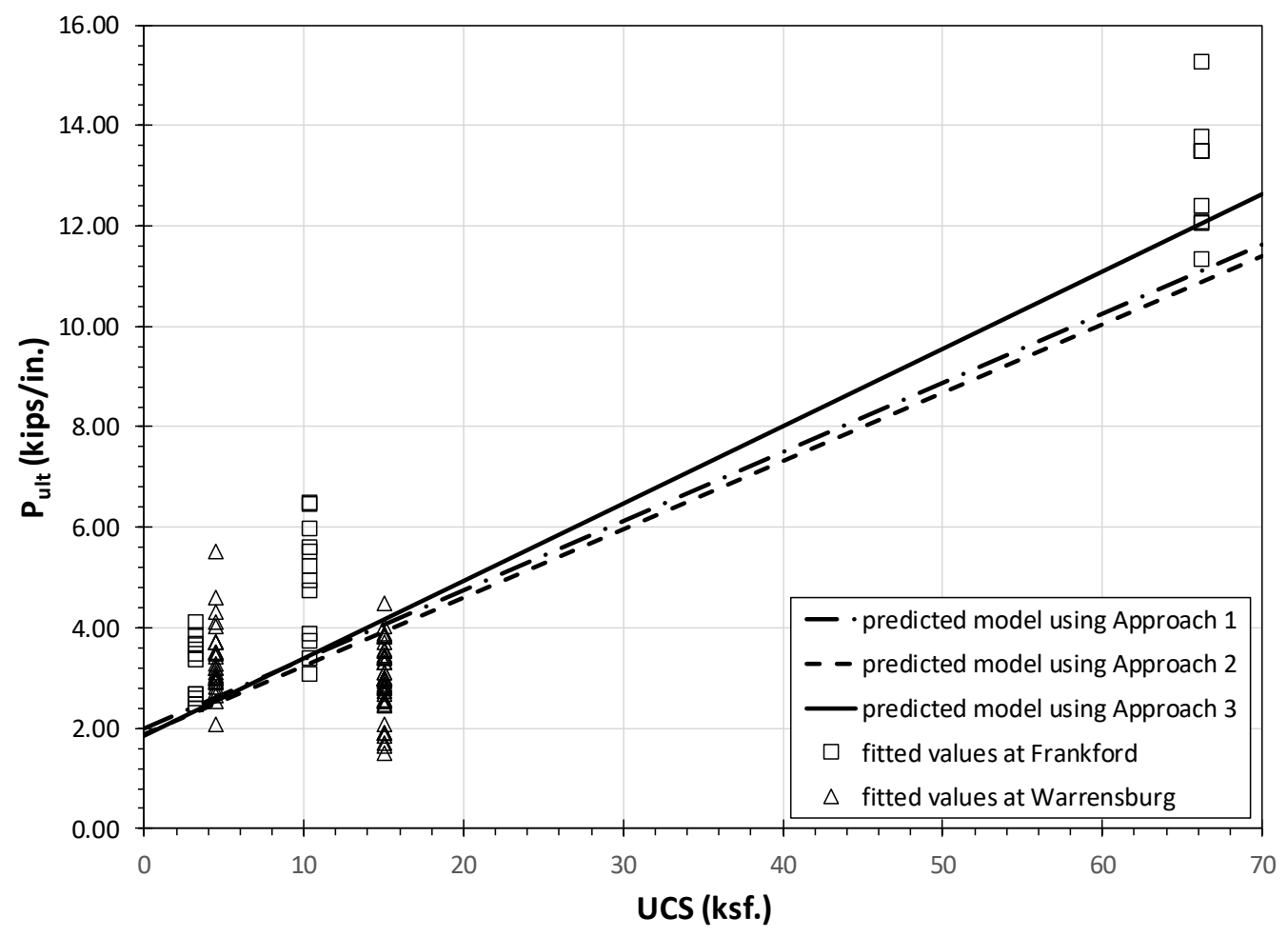

Figure 5.22 - Prediction of $\mathrm{P}_{\text {ult }}$ using different approaches

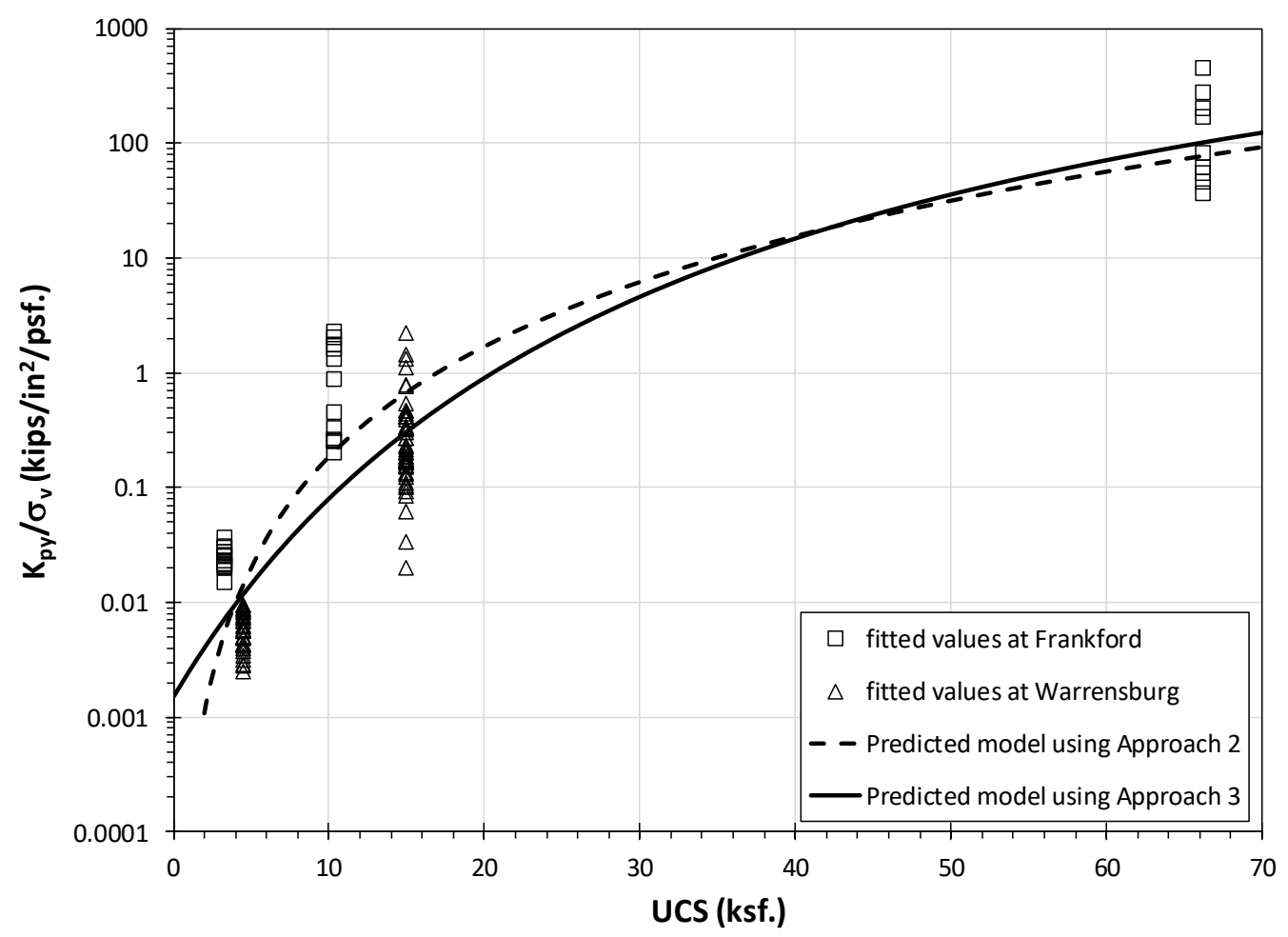

Figure 5.23 - Prediction of $K_{p y}$ using different approaches 
In general, the data from Warrensburg are below the regression model predictions, while the data from Frankford are above the regression model predictions, as can be seen in Figure 5.22 and Figure 5.23. The recommended range for the models, UCS between 3 and $100 \mathrm{ksf}$, is representative of the stiff clay and shale materials that were tested at Frankford and Warrensburg. Tests of other materials (e.g. clay with UCS less than $3 \mathrm{ksf}$, or tests in strong rock) should be conducted rather than extending the models outside the recommended range.

For approach 1, the data of Table 5.1 suggest $K_{p y}$ increases with depth as well as UCS, but the model only reflects the effect of UCS. Thus, the p-y model predicted using approach 1 likely would benefit from a multiple regression model to include the effect of depth, such as approach 2 or 3.

Approach 3, which used linear function of $P_{u l t}$ and rational function of $\log _{e}\left(K_{p y} / \sigma_{v}\right)$ with respect to UCS shows better fit with observed data at Frankford and Warrensburg because:

- For $P_{\text {ult }}$ Vs. UCS, approach 3 is able to catch the fitted $P_{\text {ult }}$ for very high values of UCS ( 66ksf.) (see Figure 5.22)

- For $K_{p y}$ vs. UCS, with very small values of UCS, approach 3 is able to predict reasonable values of $K_{p y}$, which are close to the trend of fitted $K_{p y}$. On the other hand, approach 2 produces values of $K_{p y}$, which are dramatically decreased with small values of UCS. (see Figure 5.23) 
In conclusion, using approach 3 to predict $p$-y model parameters has more advantages over approach 1 and 2 . First, approach 3 represents the influence of depth or vertical stress on initial slope of $\mathrm{p}-\mathrm{y}$ curve $\left(K_{p y}\right)$, in which approach 1 does not. Secondly, approach 3 is able to catch the fitted $P_{\text {ult }}$ for all values of UCS in the recommended range ( 3 to $100 \mathrm{ksf}$ ) while approach 1 and 2 are not be able to catch with fitted $P_{u l t}$ at very high values of UCS. Lastly, approach 3 is able to predict reasonable values of $K_{p y}$ at reasonably small values of UCS, while approach 2 is not been able.

Thus, approach 3 has been selected to obtain the proposed $p$-y model parameters $P_{u l t}$ and $K_{p y}$ from Eq. 5.6 and Eq. 5.7, respectively. Then proposed lateral load transfer models (proposed p-y models) are developed from Eq. 5.1. 


\subsection{Comparison of Proposed Model with Existing Models}

The proposed p-y model presented in Section 0 is compared to the LPILE's stiff clay with no free water model (Reese, 1972) and to p-y curves presented by the Kansas Department of Transportation (KDOT, 1987) for weak rock. The comparisons are useful for perspective on how the test data align with models commonly assumed in practice.

\subsubsection{Comparison with KDOT's p-y Model}

The Kansas Department of Transportation published a report in 1987 that documented $p-y$ curves from a series of lateral load tests of 8 -in. piles installed in weak rock at four sites in the Kansas City area. Based on the results for shallow depths (up to 2 $\mathrm{ft})$, the authors recommended a $\mathrm{p}-\mathrm{y}$ model with an initial linear region, a less steep linear transition region, and a constant ultimate region. The initial stiffness was defined as

function of the undrained strength of the material (consistent units), and the ultimate resistance was defined as the diameter of the pile times the undrained strength (also consistent units). These recommendations are plotted with the proposed $p-y$ model in Figure 5.24 and Figure 5.25. 


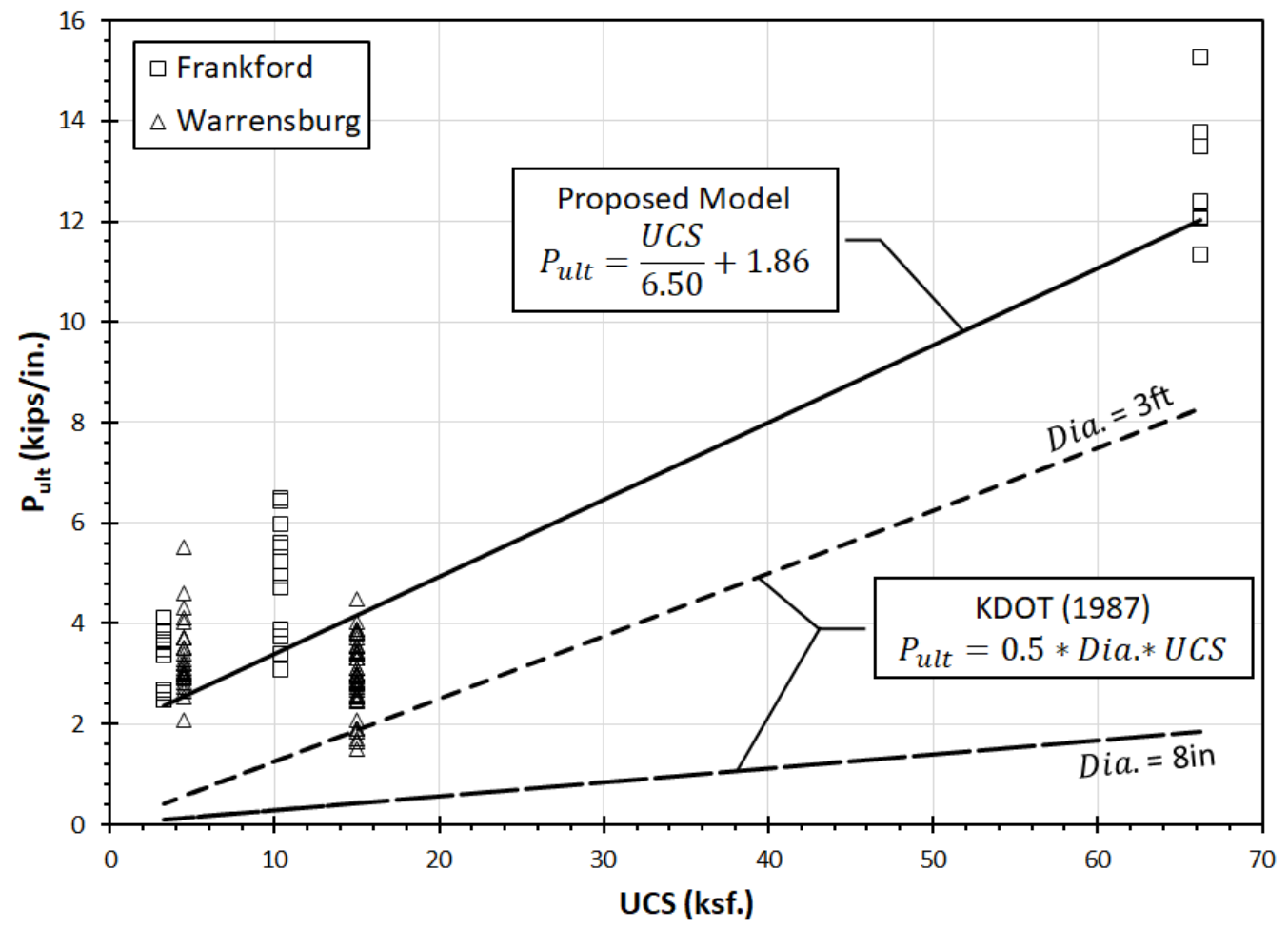

Figure 5.24 - Proposed relationship between $P_{\text {ult }}$ and UCS compared to KDOT (1987)

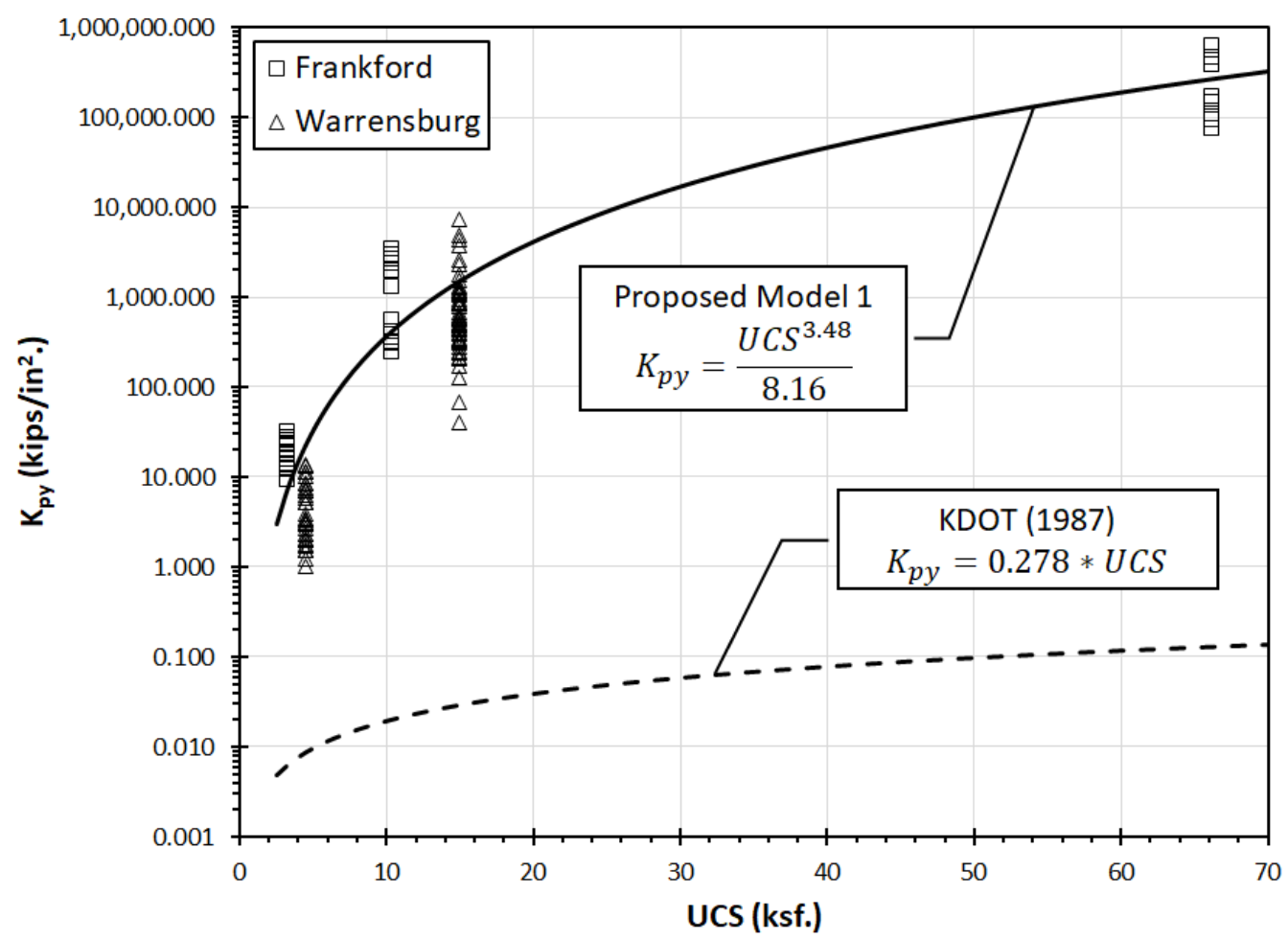

Figure 5.25 - Proposed relationship between $K_{p y}$ and UCS compared to KDOT (1987) 
The KDOT values of $\mathrm{Pult}_{\mathrm{u}}$ for a diameter of $3 \mathrm{ft}$ (like the shafts documented in this report) are less than those proposed in Eq. 5.6, as can be seen in Figure 5.24, with a similar slope with respect to material strength but no $y$-intercept. For a diameter of 8 in. (like the KDOT piles), the KDOT values of pult are significantly less than those proposed in Eq. 5.6.

For KDOT models, the initial stiffness is independent from depth, thus $p-y$ model using approach 1 (Section 5.3.1) has been used to compare with KDOT model. Using $K_{p y}$ equation from approach 1 (Eq. 5.3) instead of $\log _{e}\left(K_{p y} / \sigma_{v}\right)$ equation from approach 3 (Eq. 5.7), will be equivalent since approach 1 also provide good fit with observed data calibrated from approach 3 and vice-versa, as shown in Figure 5.25.

The initial stiffness, $K_{p y}$, of the KDOT model is significantly less than that proposed in Eq. 5.3, as can be seen in Figure 5.25. Moreover, the benefit of using proposed model to include the effect of depth is not described in KDOT research.

In general, the results of using proposed lateral load transfer model produce significantly greater resistance to lateral loads than that predicted by the KDOT models. However, the proposed p-y model more closely predicts the observed response from the field tests. Scale effects (8-in. piles for KDOT vs. 3- or 3.5-ft shafts for this work) may account for much of the difference, but the test shafts at Frankford and Warrensburg are more representative of shafts that would be used for bridge foundations. 


\subsubsection{Comparison with LPILE's Stiff Clay Model}

In order to compare the proposed p-y model with LPILE's stiff clay model, the p-y curves are plotted in Figure 5.26 to Figure 5.30 for different depth and different stratum at Frankford and Warrensburg. Three different $p-y$ curves have been shown in each figure, as well as the interpreted $p-y$ responses are also presented. First, fitted $p$-y curves are obtained using interpreted $p-y$ responses as described in Section 5.2. Second, LPILE's stiff clay p-y curves are generated from LPILE's stiff clay model (Reese, 1972). Last, proposed p-y curves are developed using proposed p-y model as presented in Section 5.3. Figure 5.26 to Figure 5.28 show p-y curves for different stratum (Maquoketa $A, B$ and C) at Frankford load test site. Figure 5.29 and Figure 5.30 show p-y curves for Silty Clay and Sandy Shale layers at Warrensburg load test site. 

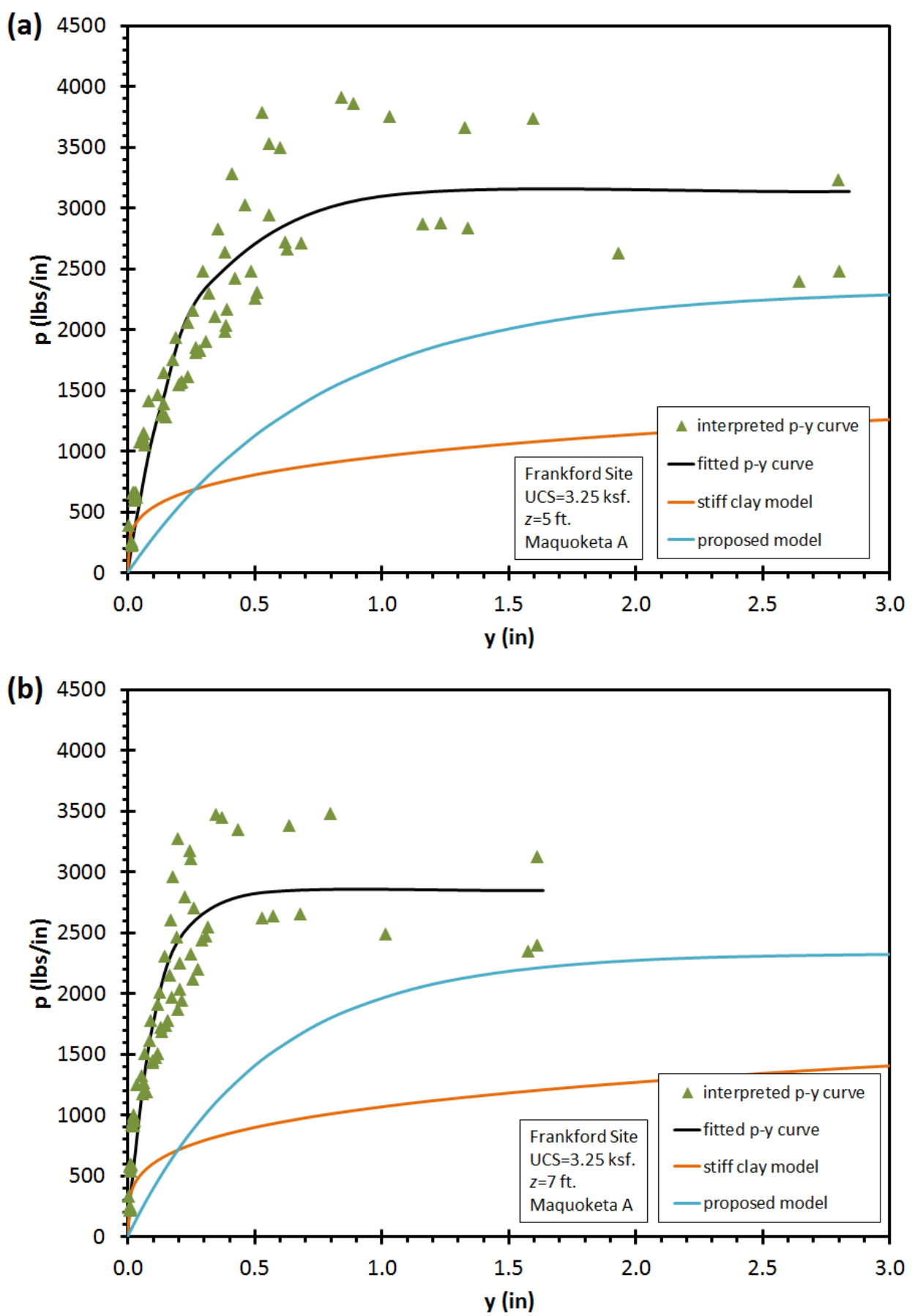

Figure 5.26 - Comparison of p-y curves at Frankford Load Test Site for depths of (a) $5 \mathrm{ft}$ and (b) $7 \mathrm{ft}$ 

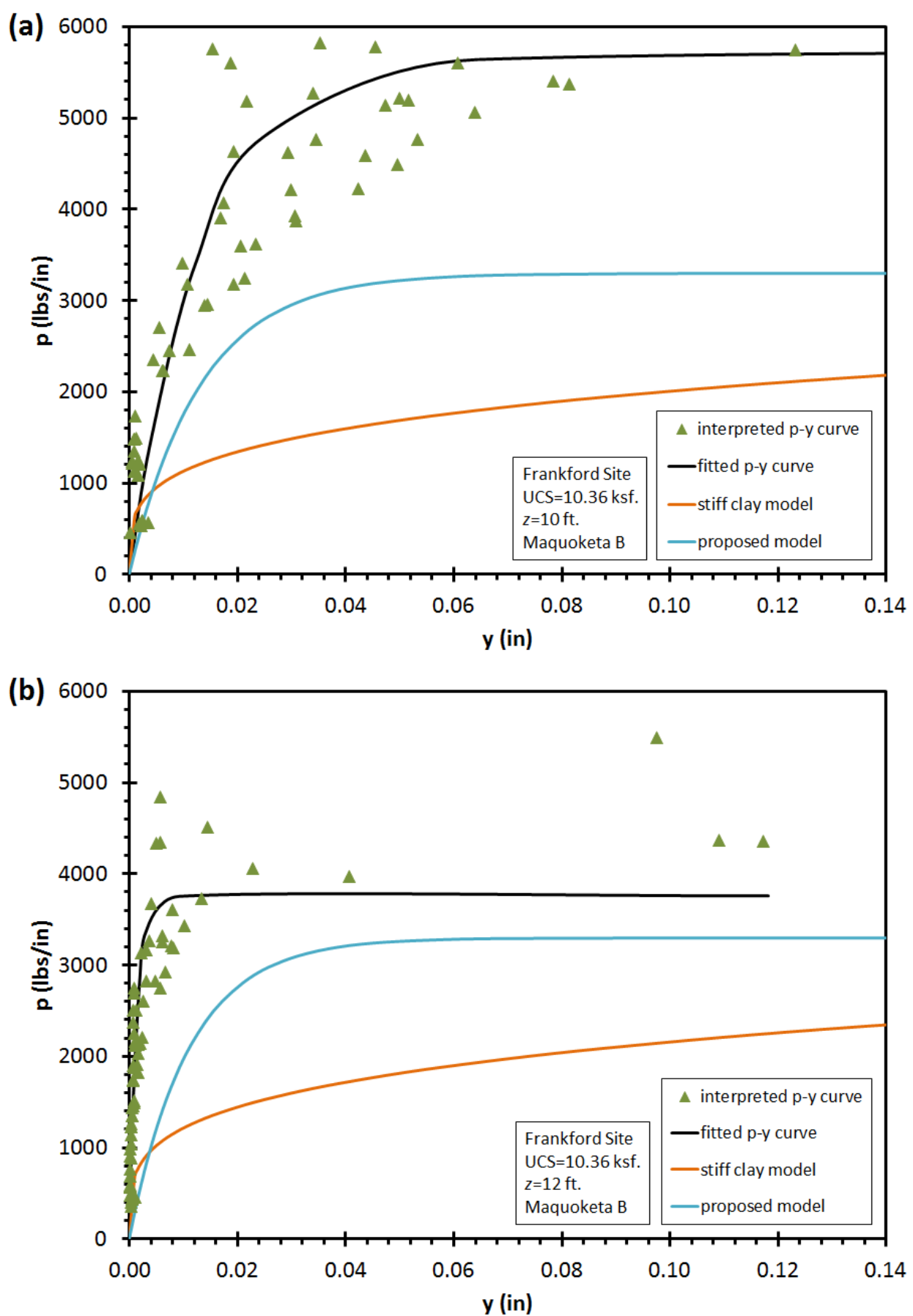

Figure 5.27 - Comparison of p-y curves at Frankford Load Test Site for depths of (a) 10 $\mathrm{ft}$ and (b) $12 \mathrm{ft}$ 

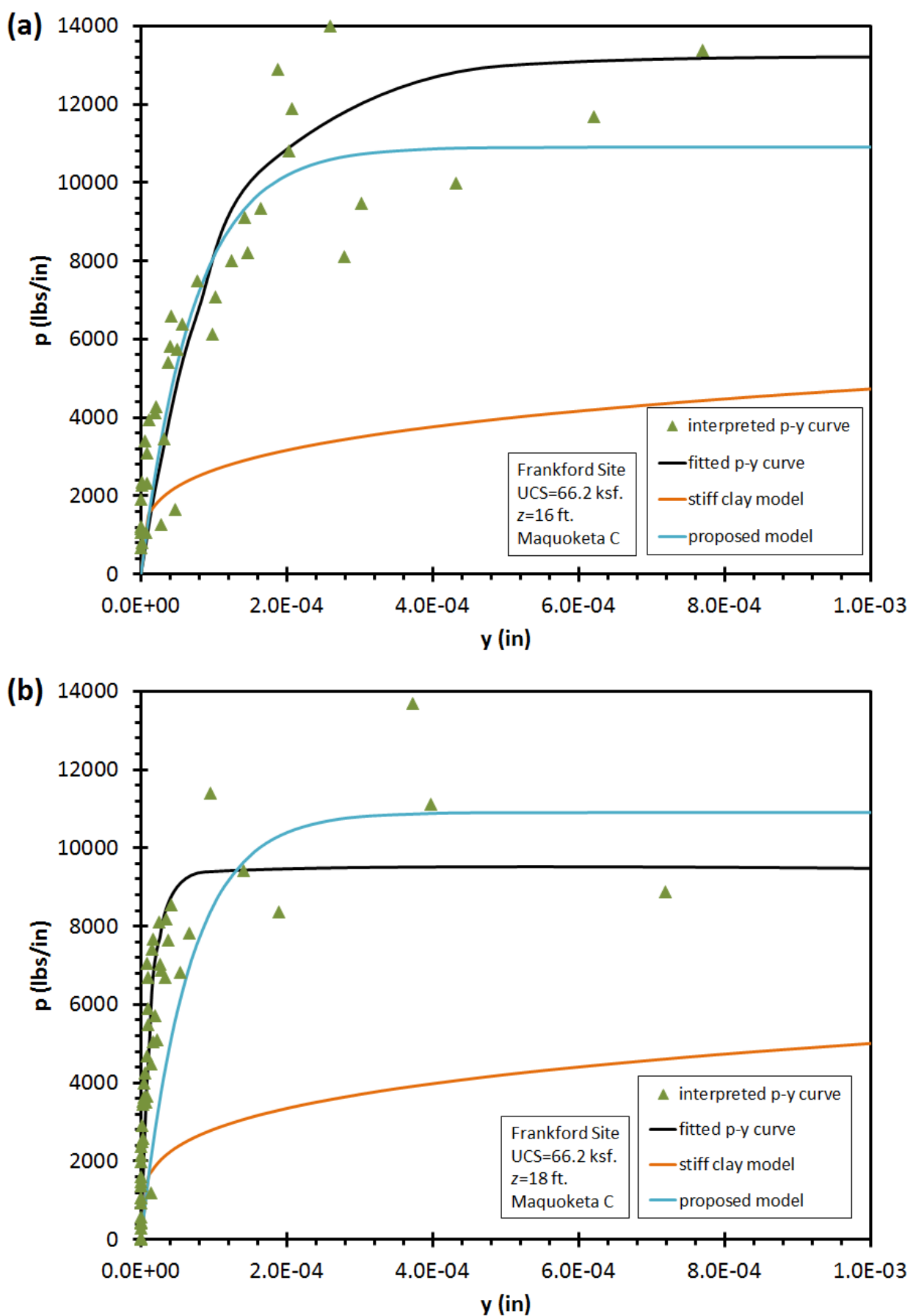

Figure 5.28 - Comparison of $p-y$ curves at Frankford Load Test Site for depths of (a) 16 $\mathrm{ft}$ and (b) $18 \mathrm{ft}$ 

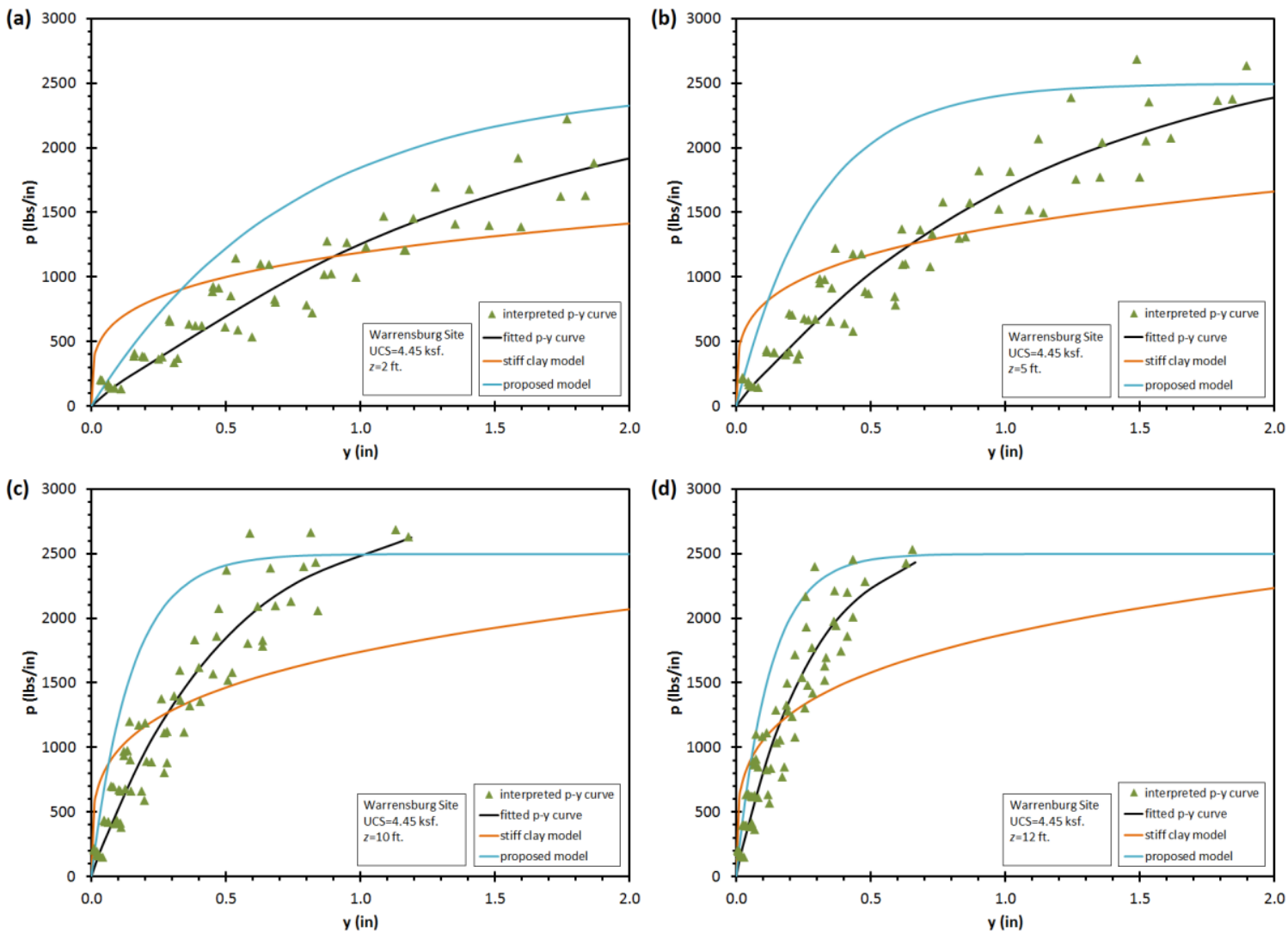

Figure 5.29 - Comparison of p-y curves at Warrensburg Load Test Site for depths of (a) $2 \mathrm{ft}$, (b) $5 \mathrm{ft}$, (c) $10 \mathrm{ft}$, and (d) $12 \mathrm{ft}$. 

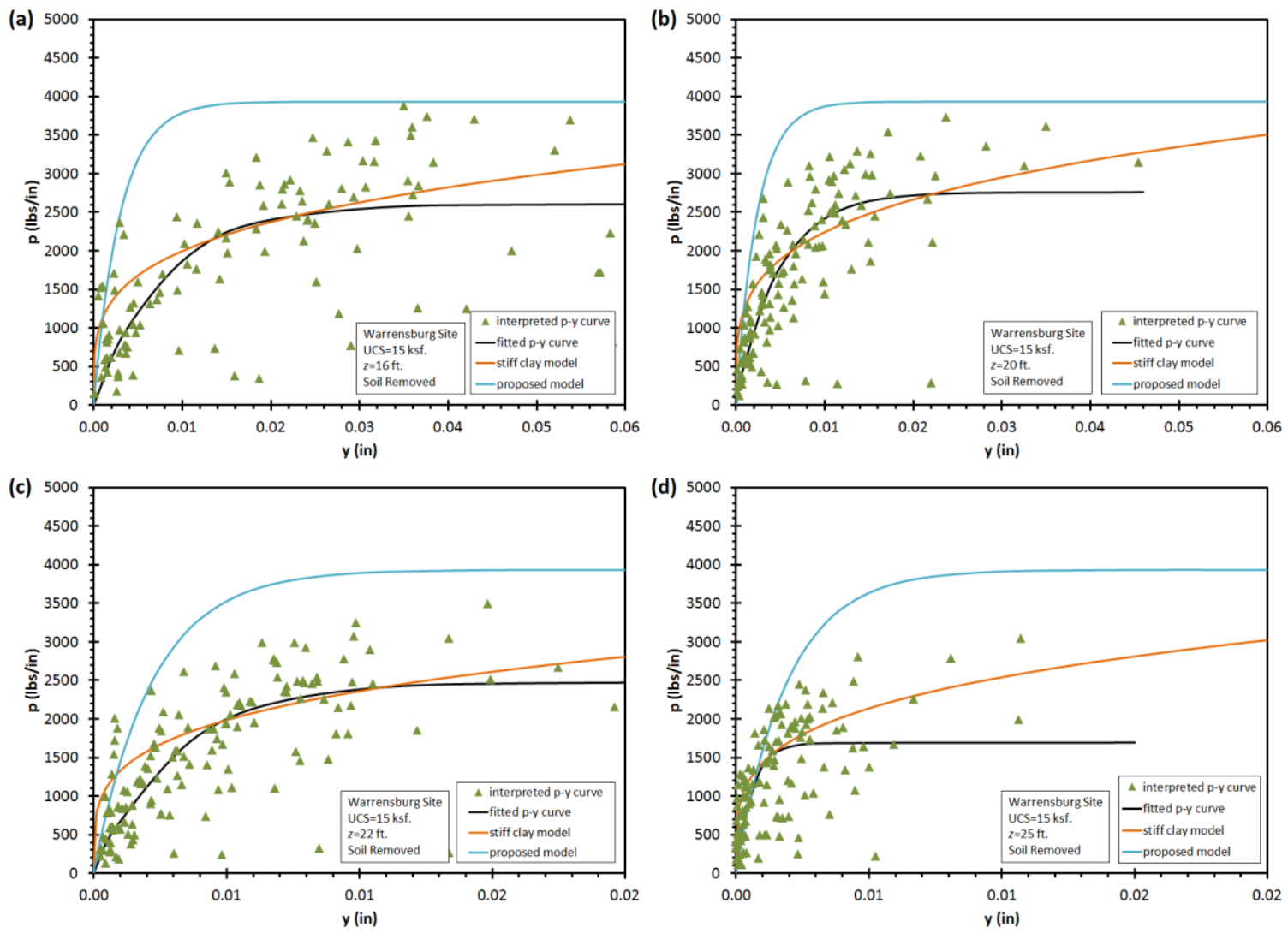

Figure 5.30 - Comparison of p-y curves at Warrensburg Load Test Site for depths of (a) $16 \mathrm{ft}$, (b) $20 \mathrm{ft}$, (c) $22 \mathrm{ft}$, and (d) $25 \mathrm{ft}$.

For Frankford site, the proposed p-y curves indicate significantly greater lateral resistance (i.e. higher values of $\mathrm{p}$ ) than predicted by the LPILE's stiff clay model. This is especially true at high displacements; the values of ultimate lateral resistance $\left(P_{u l t}\right)$ predicted using proposed p-y model are much greater than those predicted by the LPILE's stiff clay model. The initial slope of $\mathrm{p}-\mathrm{y}$ curve $\left(K_{p y}\right)$ values obtained from proposed $\mathrm{p}-\mathrm{y}$ model are generally smaller than those from fitted $p-y$ curves at small values of UCS (Figure 5.26 and Figure 5.27) but are matching with fitted p-y curves $K_{p y}$ at high values of UCS (Figure 5.28). $K_{p y}$ obtained from LPILE's stiff clay model seems to match better with 
fitted p-y curves' values. However, the initial slope of LPILE's p-y curve are very short, which is not representing the initial slope of fitted $p-y$ curves based on actual interpreted p-y responses.

Results from the Warrensburg tests indicate some differences between the proposed $p-y$ curves and LPILE's stiff clay $p-y$ curves. For the silty clay layer, $p-y$ curves generally indicate greater values of $P_{u l t}$ but lower values of $K_{p y}$ for the proposed p-y model compared to LPILE's stiff clay model (Figure 5.29). However, fitted p-y curves also indicate that the proposed $p-y$ curves follow the generally trend of interpreted $p-y$ responses while the LPILE's stiff clay $p-y$ curves do not. For the sandy shale layer, the proposed p-y curves provide higher values of $P_{u l t}$ compared to fitted p-y curves, but $K_{p y}$ values are matching with the ones from fitted $p$-y curves (Figure 5.30). On the other hand, LPILE's stiff clay model provide higher values of $K_{p y}$ compared to fitted p-y curves.

In conclusion, the proposed lateral load transfer model generally produces greater values of $P_{u l t}$ but lower values of $K_{p y}$ compared to the predictions using LPILE's stiff clay model. However, the proposed p-y model more closely predicts the interpreted p-y responses from the field tests. 


\subsection{Summary}

The development of a $p$-y model to represent lateral load transfer in shale has been described in this chapter. Fitted $p$-y curves are derived using different options of grouping interpreted $\mathrm{p}-\mathrm{y}$ responses according to either stratum, depth or individual lateral load test.

Three approaches to develop a p-y model based on fitted p-y curves are proposed. The most appropriate proposed $p$-y model using approach 3 has been selected based on the comparison between three approaches. Approach 3 uses linear function of $P_{u l t}$ and rational function of $\log _{e}\left(K_{p y} / \sigma_{v}\right)$ with respect to UCS to provide the best fit with observed data at both Frankford and Warrensburg load test site. Then the proposed $p-y$ model has been developed using the proposed exponential function.

The proposed p-y model represents the influence of depth or vertical stress on initial slope of $\mathrm{p}-\mathrm{y}$ curve $\left(K_{p y}\right)$ and be able to catch the observed values of ultimate soil resistance $\left(P_{\text {ult }}\right)$ for all values of UCS in the recommended range (3 to $100 \mathrm{ksf}$ ). Moreover, proposed p-y model is able to predict reasonable values of $K_{p y}$ at reasonably small values of UCS.

Comparison of the proposed lateral load transfer model with KDOT's weak rock and LPILE's stiff clay models indicates that the proposed $p-y$ model more closely predicts the observed lateral load responses from the field tests in shale. 


\section{CHAPTER 6. PROBABILISTIC CALIBRATION OF RESISTANCE FACTORS FOR LOAD AND RESISTANCE FACTOR DESIGN}

This chapter presents the results of resistance factor calibration based on Monte Carlo simulations using the computer code presented in Chapter 5. The resistance factors presented in this chapter are intended to be applied to the p-y curves directly, i.e. by factoring the $p$ values, which can be implemented using $p$-multipliers. This approach is different and, in the author's opinion, more rational than the approach of applying the resistance factor as an additional load factor, which is the approach presented in the FHWA Drilled Shafts manual (USDOT, 2010).

\subsection{Design Procedure for Load and Resistance Factor Design at Service Limit State}

The Service Limit State (SLS) resistance factor is applied to the lateral soil resistance of the lateral load transfer model in order to obtain the factored lateral soil resistance for use in SLS design, as described in the following equation. Resistance factor accounts for possible sources of uncertainty so that the design can achieve some level of reliability or some target probability of failure.

$$
p^{*}=\phi_{p-y} \times p
$$

$$
\text { where: } \quad \begin{array}{ll}
p & =\text { lateral soil resistance } \\
\phi_{p-y} & =\text { resistance factor for SLS } \\
p^{*} & =\text { factored lateral soil resistance }
\end{array}
$$


Then using factored lateral soil resistance $\left(p^{*}\right)$ to compute the factored deformation $\left(y^{*}\right)$ at nominal load, the last step is to check the service limit state condition:

$$
y^{*} \leq y_{a}
$$

Eq. 6.2

where: $\quad y^{*}=$ factored deformation

$$
y_{a}=\text { allowable deformation }
$$

The resistance factor is to be used in a newly proposed design procedure of the Service Limit State design for drilled shaft. The steps for the proposed design procedure are:

1. Find shaft length and shaft diameter following Strength Limit State procedure.

2. Use given probabilistic and deterministic parameters to obtain Service Limit State resistance factor.

3. Determine the factored lateral load transfer model using Eq. 6.1.

4. Use shaft dimensions, shaft stiffness, soil properties, given loads, and factored lateral load transfer model to calculate the factored shaft deformation. This value of deformation is associated with the given target probability of failure. 
5. Compare the factored shaft deformation with an allowable shaft deformation (Eq. 6.2). If the factored shaft deformation is less than or equal to the allowable shaft deformation, the Service Limit State is satisfied. If not, increase shaft dimension or shaft stiffness and repeat steps 2 to 5 until Eq. 6.2 is satisfied and the Service Limit State LRFD procedure is complete.

\subsection{Monte Carlo Simulation Method to Calibrate Resistance Factor}

Resistance factors were calibrated using Monte Carlo Simulation method. The Monte Carlo method is shown conceptually in Figure 6.1. The Monte Carlo method is a numerical approach to reliability analyses that is useful when the distribution of outcomes

(e.g. displacement, bending moment, etc.) is unknown and is a function of other random variables (e.g. material strength, structural stiffness, model uncertainty, etc.). The numerical approach involves running many model simulations with input parameters assigned randomly according to their probability distributions. The probability of failure can be calculated from the number of simulations that limit state being exceeded. 


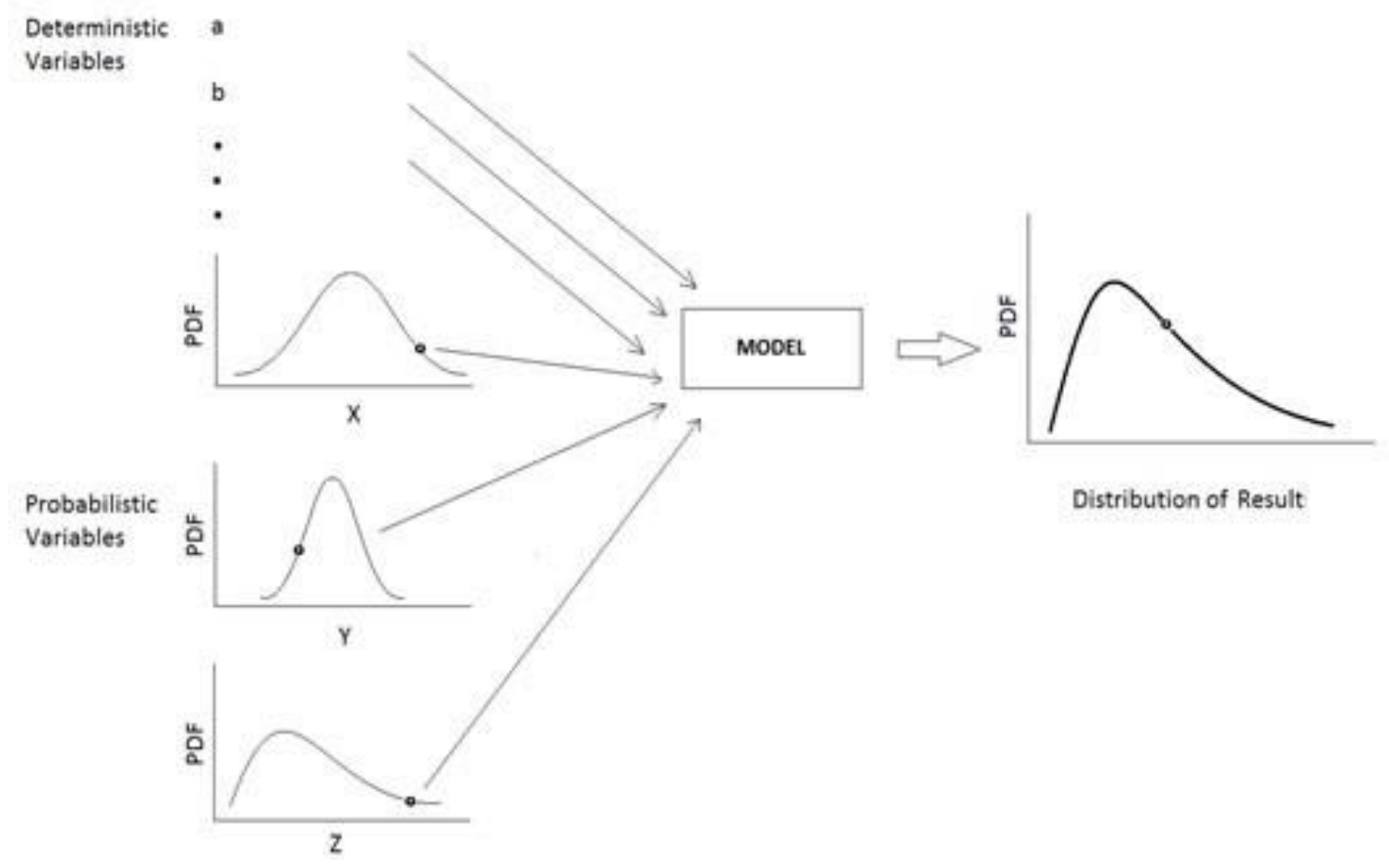

Figure 6.1 - Conceptual diagram of Monte Carlo method (Vu, 2013)

\subsubsection{Number of Simulations}

The Monte Carlo Simulation method is an approximate method. The accuracy of the Monte Carlo analyses is largely dictated by the number of simulations that are performed. Thus, one important aspect of a Monte Carlo analysis is establishing the number of simulations needed to accurately determine the probabilistic distribution of an output parameter.

The effect of number of simulations has been evaluated and presented at the end of this chapter. In this research, in order to be confident with reasonable accuracy, and to account for possible different input variability sources, the number of simulations chosen was 10,000 . The accuracy approaches a true solution as the number of simulations 
increases. Allen et al. (2005) stated that 5,000 to 10,000 simulations or more are needed to adequately define the distribution of the limit state function for a target probability index of $\beta_{T}=2.3$ to 3.0 , which is more than the usual target probability index required for Service Limit State.

\subsubsection{Type of Distribution}

An important consideration in probability analyses is the type of distribution used to represent variability and uncertainty in the input parameters. In geotechnical engineering, the most frequently used distribution types of probabilistic variables are normal and log-normal distributions (Phoon and Kulhawy, 1999; Duncan, 2000; Baecher and Christian, 2003; Allen et al., 2005).

The appeals of normal distribution are that it is mathematically convenient, it accurately reflects many measurements, and it is commonly used in practice. Normal distribution is bell-shaped (Figure 6.2a). However normal distribution often includes some negative values which are impractical and unacceptable for an SLS design problem, e.g., it is not appropriate for strength or stiffness parameters acquire negative values. In some cases, when the number of negative values is relatively small (e.g., when the distribution is narrow, or the mean is quite large), normal distribution can be used effectively, and it often is a reasonable representation of variability and uncertainty. However, when the number of negative values is larger, it poses challenges and may not reflect the variability and uncertainty of many parameters very well. This is true despite its popularity for random number generation. 
Lognormal distribution type is when the natural logarithms of the data are normally distributed. The shape of the bell is eccentric and has a much longer tail (Figure 6.2b). This type of distribution is strictly non-negative and is usually preferred to be assumed and is used more often in practice than normal distribution.

The use of either a normal or a lognormal distribution depends upon which is a better reflection of the variability and uncertainty for parameters. In later probabilistic analyses, the types of distribution for variables are chosen based on data, or they are taken from well-established literature.

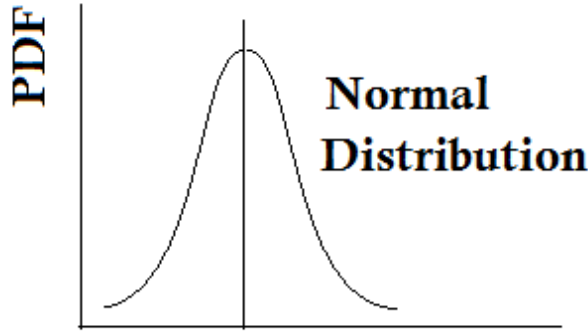

Data

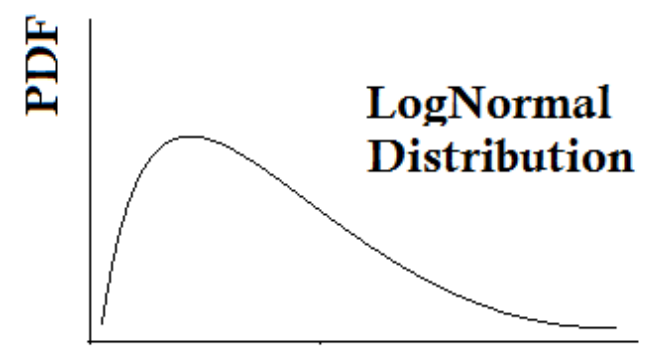

Data

Figure 6.2 - (a) Normal distribution and (b) Lognormal distribution (Vu, 2013)

\subsubsection{Generation of Normally Distributed Parameter Values}

If the mean, standard of deviation, and distribution type of a parameter are known, the Monte Carlo approach is able to simulate $\mathrm{n}$ numbers of random parameter values that have the same mean, standard of deviation and distribution type. In MATLAB, for normal type of distribution with mean $(\mu)$ and standard deviation $(\sigma)$, a random parameter value set from $\mathrm{n}$ simulations will be produced using the following equation: 


$$
X=\mu+\sigma * \operatorname{randn}(1, n)
$$

Eq. 6.3

where: $\quad$ randn is a function to generate an array of $\mathrm{n}$ random numbers that have standard normal distribution with mean of zero and standard deviation of unity.

If the data are highly variable and the standard of deviation $(\sigma)$ is large, it is possible for the process to produce negative values that are impossible to obtain in real data. Those impossible values must be removed from the population or replaced with positive, close-to-zero values, and the calculation process continues. Another way is using the lognormal distribution, which is more beneficial than normal distribution in those situations.

\subsubsection{Generation of Lognormally Distributed Parameter Values}

A lognormal distribution is a continuous probability distribution of a random variable whose logarithm is normally distributed. In order to generate a set of values for a random variable $L$ (i.e., Lognormal) that is lognormally distributed with mean $(\mu)$ and standard of deviation $(\sigma)$, a transformation step must be performed. The logarithm of variable $L$ is $N=\ln (L)$ is a normally distributed variable with mean $(\lambda)$ and standard of

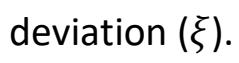


$\lambda$ and $\xi$ are the mean and standard deviation of the natural log of the values. When that is the case, then $\mu$ and $\sigma$ are the mean and standard deviation of the actual values, that happen to be lognormally distributed. And the following equations represent the relation among these values:

$$
\lambda=\ln \left(\frac{\mu}{\sqrt{1+\frac{\sigma^{2}}{\mu^{2}}}}\right)
$$

Eq. 6.4

$$
\xi=\sqrt{\ln \left(1+\frac{\sigma^{2}}{\mu^{2}}\right)}
$$

Eq. 6.5

Variable $\mathrm{N}$ can be generated using following function:

$$
N=\lambda+\xi * \operatorname{randn}(1, n)
$$

Eq. 6.6

The final step to get the values of a variable $L$ is by taking the exponential of $N$ :

$$
L=e^{N}
$$

The generated parameter values were used in the Monte-Carlo simulation and probabilistic analyses. The Monte-Carlo simulation can be implemented in many different 
software. For this research, first of all, MATLAB is used to execute Monte Carlo simulation and generate the distributed parameter values based on the variability and uncertainty of probabilistic variables. Then, the probabilistic variables are randomly simulated and implemented into the finite element computer code, which then produces a distribution of lateral deformation values as output. Finally, resistance factors are calibrated based on lateral deformation distribution and the target probability of failure. Details about the procedure is described in Section 6.7.

\subsection{Modeling the Variability and Uncertainty in $p-y$ Responses}

Three approaches have been performed to model the variability and uncertainty in $\mathrm{p}$-y responses. The first approach randomly simulate the ultimate soil resistance, $P_{u l t}$, and

the initial slope of p-y curve, $K_{p y}$, using the coefficient of variation of $P_{u l t}\left(\operatorname{COV}_{P_{u l t}}\right)$ and the coefficient of variation of $K_{p y}\left(C O V_{K_{p y}}\right)$, which are defined using following equations:

$$
\operatorname{COV}_{P_{u l t}}=\frac{\sigma_{P_{u l t}}}{\mu_{P_{u l t}}}
$$

Eq. 6.8

where: $\sigma_{P_{u l t}}=$ standard deviation of $P_{u l t}$

$$
\begin{aligned}
& \mu_{P_{u l t}}=\text { mean of } P_{u l t} \\
& \qquad \operatorname{COV}_{K_{p y}}=\frac{\sigma_{K_{p y}}}{\mu_{K_{p y}}}
\end{aligned}
$$

Eq. 6.9

where: $\sigma_{K_{p y}}=$ standard deviation of $K_{p y}$ 


$$
\mu_{K_{p y}}=\text { mean of } K_{p y}
$$

Using probabilistic uncertainty factors $\operatorname{COV}_{P_{u l t}}$ and $\operatorname{COV}_{K_{p y^{\prime}}}$ the ultimate soil resistance $\left(P_{u l t}\right)$ and the initial slope of $\mathrm{p}-\mathrm{y}$ curve $\left(K_{p y}\right)$ are simulated probabilistically according to Eq. 5.6 and Eq. 5.7. Then, p-y curves are generated based on $P_{u l t}, K_{p y}$ and the proposed lateral load transfer model (Eq. 5.1).

The second approach randomly simulate p-y curves based on Eq. 5.1 using the following equation:

$$
p=m_{p y} * P_{u l t}\left(1-\exp \left(-\frac{K_{p y}}{P_{u l t}} * y\right)\right)
$$

Eq. 6.10

where $m_{p y}$ is the factor to represent the uncertainty in $\mathrm{p}$-y curve and is calculated using the coefficient of variation of $\mathrm{p}-\mathrm{y}$ curve $\left(C O V_{p y}\right)$, which is defined using the following equation:

$$
\operatorname{COV}_{p y}=\frac{\sigma_{p y}}{\mu_{p y}}
$$

Eq. 6.11

where: $\sigma_{p y}=$ standard deviation of py curve

$$
\mu_{p y}=\text { mean of py curve }
$$


In this approach, the coefficient of variation of $p-y$ curve $\left(C O V_{p y}\right)$ is assumed to be a constant. As a consequence, $m_{p y}$ is also equal to a constant for different values of lateral displacement $(y)$.

First of all, the ultimate soil resistance $\left(P_{u l t}\right)$ and the initial slope of $\mathrm{p}-\mathrm{y}$ curve $\left(K_{p y}\right)$ are calculated based on Eq. 5.6 and Eq. 5.7. Then, using uncertainty factor $m_{p y}, \mathrm{p}$-y curves are simulated probabilistically according to Eq. 6.10.

Similarity to the second approach, the third approach randomly simulate $p-y$ curves using Eq. 6.10. However, in this approach, the factor to represent the uncertainty in $\mathrm{p}-\mathrm{y}$ curve $\left(m_{p y}\right)$ is calculated using the standard deviation $\left(\sigma_{p y}\right)$ and the mean of $\mathrm{p}-\mathrm{y}$ curve $\left(\mu_{p y}\right)$. The standard deviation of $\mathrm{p}$-y curve $\left(\sigma_{p y}\right)$ is assumed to be a constant but the mean of $\mathrm{p}-\mathrm{y}$ curve $\left(\mu_{p y}\right)$ is not a constant for different values of lateral displacement $(y)$ since it is calculated using Eq. 5.1. Thus, $m_{p y}$ in the third approach is not a constant.

The ultimate soil resistance $\left(P_{u l t}\right)$ and the initial slope of $\mathrm{p}$-y curve $\left(K_{p y}\right)$ are calculated based on Eq. 5.6 and Eq. 5.7. Next, mean value of p-y curve $\left(\mu_{p y}\right)$ is obtained using Eq. 5.1. Then, the uncertainty in p-y curve $\left(m_{p y}\right)$ is calculated from the standard deviation $\left(\sigma_{p y}\right)$ and the mean of $\mathrm{p}-\mathrm{y}$ curve $\left(\mu_{p y}\right)$. Finally, $\mathrm{p}-\mathrm{y}$ curves are simulated probabilistically according to Eq. 6.10 . 


\subsection{Model Uncertainty versus Total Variability and Uncertainty}

In chapter 5, the development of a p-y model to represent lateral load transfer in shale has been described. The proposed exponential $p-y$ model uses linear function of $P_{u l t}$ and rational function of $\log _{e}\left(K_{p y} / \sigma_{v}\right)$ with respect to UCS to provide the best fit with observed data at both Frankford and Warrensburg load test site.

In this chapter, proposed models developed from chapter 5 will be used to create the predicted $p$-y curves. Depend on the different approaches to model the variability and uncertainty in p-y responses as described in Section 6.3, predicted curves will be represented in terms of ultimate lateral soil resistance $\left(P_{u l t}\right)$, initial slope of $p$-y curve $\left(K_{p y}\right)$, or p-y curve itself, as presented using following equations:

- $\quad$ Predicted curve for ultimate lateral soil response $\left(P_{u l t}\right)$ is following Eq. 5.6:

$$
P_{u l t}=\frac{U C S}{c_{1}}+c_{2}=\frac{U C S}{6.50}+1.86
$$

Eq. 6.12

- Predicted curve for initial slope of $\mathrm{p}$-y curve $\left(K_{p y}\right)$ is represented using values of $\log _{e}\left(K_{p y} / \sigma_{v}\right)$ as a function of $U C S$, as described in Eq. 5.7:

$$
\log _{e}\left(K_{p y} / \sigma_{v}\right)=\frac{c_{1} * U C S+c_{2}}{U C S+c_{3}}=\frac{9.83 * U C S-201.82}{U C S+31.14}
$$

Eq. 6.13 
- Predicted curve for p-y model itself is following Eq. 5.1, repeated as below:

$$
p=P_{u l t} *\left(1-\exp \left(-\frac{K_{p y}}{P_{u l t}} * y\right)\right)
$$

Eq. 6.14

In order to evaluate the probabilistic variables in $p-y$ responses using different approaches presented in Section 6.3, the model uncertainty or the total variability and uncertainty for each predicted curve above will be investigated. Model uncertainty represent the confidence in model while total variability and uncertainty combine the model uncertainty with the variability in measurements.

Model and total bounds represent the model uncertainty or the total variability and uncertainty of the predicted curve with respect to the observations. Those bounds define the lower and upper values of the associated interval and show the width of the interval. The width of the interval indicates how uncertain you are about the predicted function.

The bounds are defined with a level of certainty (or uncertainty) that you specify. The level of certainty (confidence level) can be any value such as $68 \%, 95 \%, 99.7 \%$, and corresponding to the level of uncertainty equals to $32 \%, 5 \%, 0.3 \%$. In statistics, the $68-$ 95-99.7 is a shorthand used to remember the percentage of values that lie within a band around the mean in a normal distribution with a width of two, four and six standard deviations, respectively. More accurately, $68 \%, 95 \%$ and $99.7 \%$ of the values lie within 
one, two and three standard deviations of the mean, respectively. In this research, model and total bounds with the same level of certainty equals to $68 \%$ (one standard deviation of the mean) have been used to calculate the model uncertainty and the total variability and uncertainty in p-y responses.

\subsection{Evaluation of Probabilistic Variables in p-y Responses}

The three approaches discussed in Section 6.3 have been applied to evaluate the probabilistic variables in $p-y$ response. The first approach uses ultimate soil resistance,

$P_{u l t}$, and initial slope of p-y curve, $K_{p y}$, as probabilistic variables while the second and third approaches use lateral soil response, $p$, as probabilistic variable.

The model and total bounds for model uncertainty and total variability and uncertainty are shown in Figure 6.3, Figure 6.4 and Figure 6.5. Each graph contains three curves: the predicted curve, the model bounds and the total bounds. The predicted curve is generated using Eq. 6.12 to Eq. 6.14. Both the model and total prediction bounds reflect a $68 \%$ of confidence level. Note that the intervals associated with total bounds are wider than the model one because of the additional variability in measurements to predict a new response value (the curve plus random errors). 


\subsubsection{Evaluation of Probabilistic Variables according to $1^{\text {st }}$ Approach}

For the first approach, ultimate soil resistance, $P_{\text {ult }}$, and initial slope of $p$-y curve, $K_{p y}$, are probabilistic variables and the uncertainty of those variables are represented by the coefficient of variation $(\mathrm{COV})$. Uncertainty of $P_{\text {ult }}$ will be represented by using $C O V_{P_{u l t}}$ for predicting $P_{u l t}$ with respect to $U C S$. Uncertainty for predicting $K_{p y}$ with respect to UCS and depth will be represented by using $C O V$ of $\log _{e}\left(K_{p y} / \sigma_{v}\right)$.

For each soil layer, the mean value of UCS will be used to calculate the values of predicted $P_{u l t}$ and predicted $\log _{e}\left(K_{p y} / \sigma_{v}\right)$ using Eq. 6.12 and Eq. 6.13. The predicted curves, model and total bounds and fitted data are plotted in Figure 6.3 and Figure 6.4.

The standard deviation (STD) corresponding to model and total uncertainty of

prediction of $P_{u l t}$ and $\log _{e}\left(K_{p y} / \sigma_{v}\right)$ will be obtained from Figure 6.3 and Figure 6.4. Then $\mathrm{COV}$ will be calculated by dividing $\sigma$ to predicted values. All the calculations are based on data according to stratum (Silty Clay, Sandy Shale at Warrensburg or Maquoketa A, B, C at Frankford). 


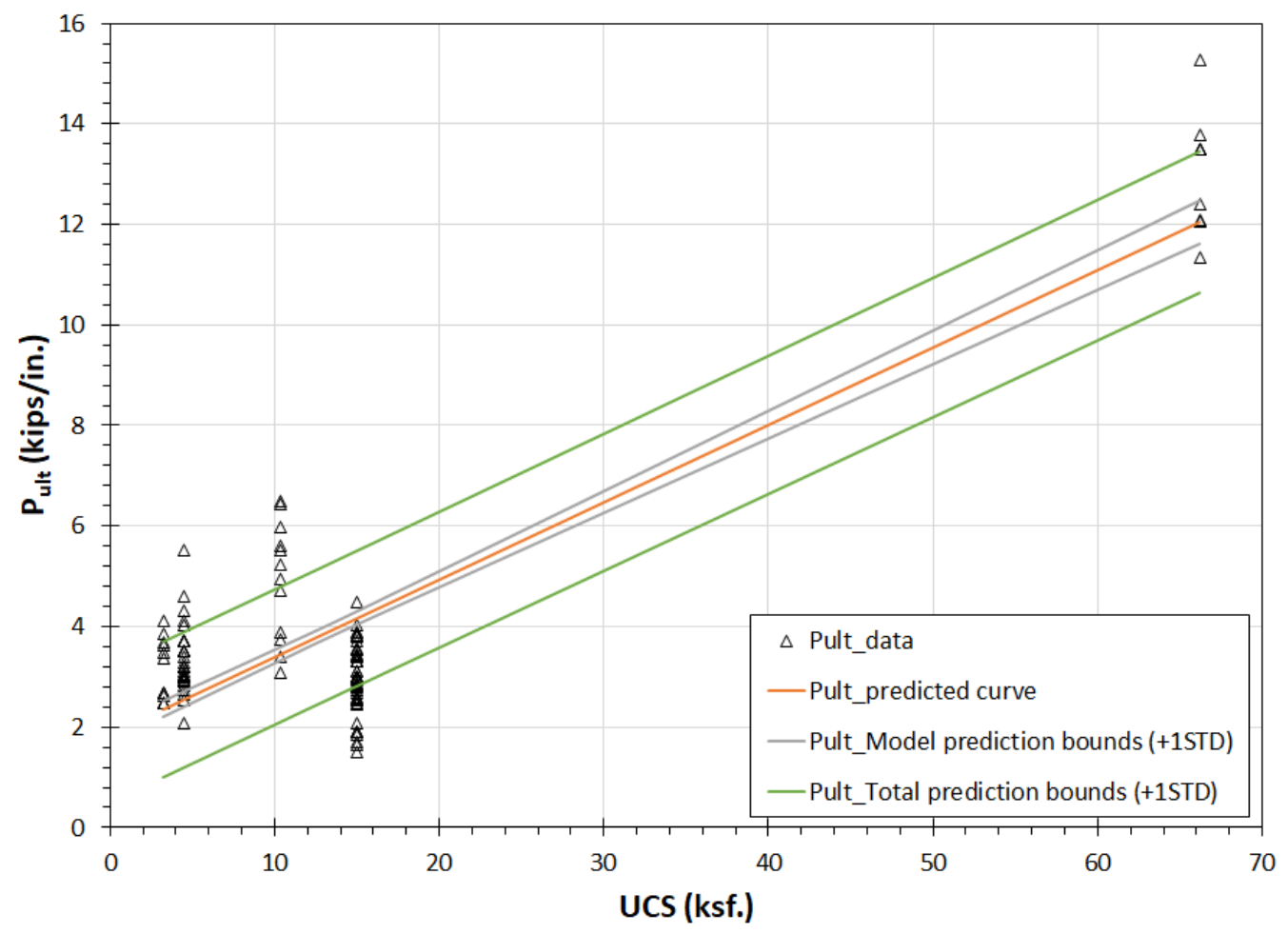

Figure 6.3 - Model and Total Bounds for predicting $P_{\text {ult }}$ with respect to UCS

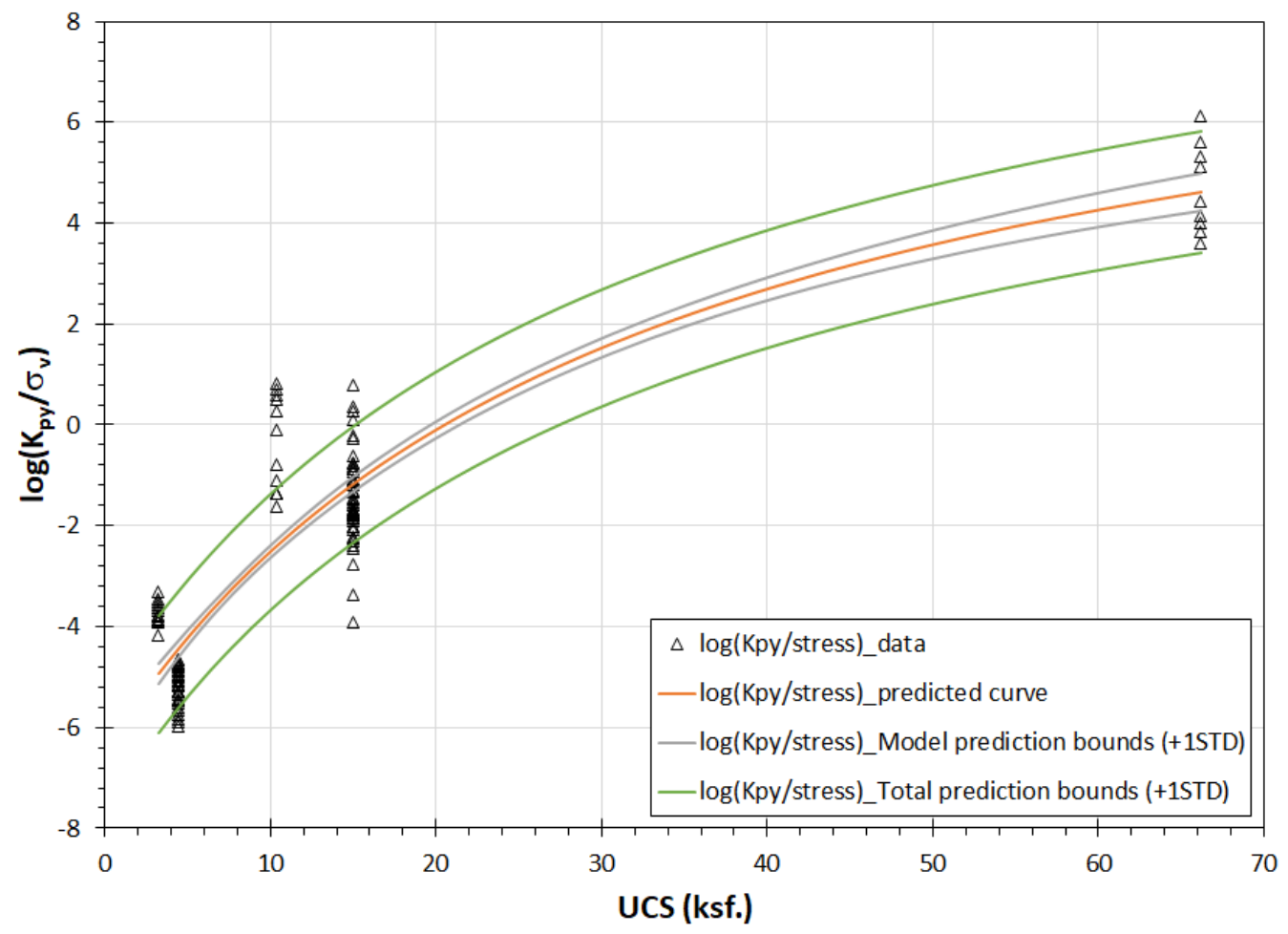

Figure 6.4 - Model and Total Bounds for predicting $\log \left(\mathrm{K}_{\mathrm{py}} / \sigma_{\mathrm{v}}\right)$ with respect to UCS 
Table 6.1 summarizes values of $U C S$, predicted $P_{u l t}$, the standard deviation (STD) and coefficient of variation $(\mathrm{COV})$ for model and total uncertainty of prediction of $P_{\text {ult }}$.

Table 6.1 - COV for Model and Total uncertainty of prediction of $\mathrm{P}_{\text {ult }}$

\begin{tabular}{|c|c|c|c|c|c|c|c|}
\hline \multirow[b]{2}{*}{ Site } & \multirow[b]{2}{*}{ Soil layer } & \multirow[b]{2}{*}{ UCS } & \multirow[b]{2}{*}{ Pult_fitted } & \multicolumn{2}{|c|}{ MODEL } & \multicolumn{2}{|c|}{ TOTAL } \\
\hline & & & & STD model & CoV model & STD total & cov total \\
\hline & & ksf & kips/in & & & & \\
\hline \multirow[t]{3}{*}{ Frankford } & Maquoketa A & 3.25 & 2.3580 & 0.1515 & 0.0643 & 1.3471 & 0.5713 \\
\hline & Maquoketa B & 10.36 & 3.4518 & 0.1282 & 0.0371 & 1.3447 & 0.3896 \\
\hline & Maquoketa C & 66.19 & 12.0408 & 0.4230 & 0.0351 & 1.4039 & 0.1166 \\
\hline \multirow[t]{2}{*}{ Warrensburg } & Silty Clay & 4.45 & 2.5426 & 0.1463 & 0.0576 & 1.3466 & 0.5296 \\
\hline & Sandy Shale & 15 & 4.1656 & 0.1243 & 0.0298 & 1.3443 & 0.3227 \\
\hline
\end{tabular}

Table 6.2 summarizes values of UCS, predicted $\log _{e}\left(K_{p y} / \sigma_{v}\right)$, the standard deviation $(S T D)$ and coefficient of variation $(\mathrm{COV})$ for model and total uncertainty of prediction of $\log _{e}\left(K_{p y} / \sigma_{v}\right)$

Table 6.2 - COV for Model and Total uncertainty of prediction of $\log _{e}\left(K_{p y} / \sigma_{v}\right)$

\begin{tabular}{|c|c|c|c|c|c|c|c|}
\hline \multirow[b]{2}{*}{ Site } & \multirow[b]{2}{*}{ Soil layer } & \multirow[b]{2}{*}{ UCS } & \multirow[b]{2}{*}{$\log \left(K_{p y} / \sigma_{v}\right) \_$fitted } & \multicolumn{2}{|c|}{ MODEL } & \multicolumn{2}{|c|}{ TOTAL } \\
\hline & & & & STD model & COV model & STD total & cov total \\
\hline & & ksf. & & & & & \\
\hline \multirow[t]{3}{*}{ Frankford } & Maquoketa A & 3.25 & -4.9396 & 0.1998 & 0.0404 & 1.1669 & 0.2362 \\
\hline & Maquoketa B & 10.36 & -2.4087 & 0.1253 & 0.0520 & 1.1565 & 0.4801 \\
\hline & Maquoketa C & 66.19 & 4.6131 & 0.3804 & 0.0825 & 1.2110 & 0.2625 \\
\hline \multirow[t]{2}{*}{ Warrensburg } & Silty Clay & 4.45 & -4.4415 & 0.1625 & 0.0366 & 1.1611 & 0.2614 \\
\hline & Sandy Shale & 15 & -1.1776 & 0.1489 & 0.1264 & 1.1593 & 0.9844 \\
\hline
\end{tabular}




\subsubsection{Evaluation of Probabilistic Variables according to $2^{\text {nd }}$ Approach}

For the second approach, lateral soil response, $p$, is considered to be probabilistic variable and the uncertainty of those variables are represented by the coefficient of variation $(\mathrm{COV})$ of the $\mathrm{p}-\mathrm{y}$ curve.

For each soil layer, the mean value of $U C S$ will be used to calculate the values of predicted $P_{u l t}$ and predicted $\log _{e}\left(K_{p y} / \sigma_{v}\right)$ using Eq. 6.12 and Eq. 6.13. Predicted $K_{p y}$ will then be calculated from predicted $\log _{e}\left(K_{p y} / \sigma_{v}\right)$ and the vertical stress $\sigma_{v}$. Next, the predicted $P_{u l t}$ and predicted $K_{p y}$ will be used to calculate the predicted lateral soil response $(p)$ with respect to a set of lateral displacement $(y)$ using Eq. 6.14. An example of predicted curves, model and total bounds, and fitted data for Frankford load site, Maquoketa A layer and at depth is equal to $5 \mathrm{ft}$ are plotted in Figure 6.5.

After that, a set of standard deviation (STD) for model and total uncertainty of prediction of lateral soil response $(p)$ will be obtained from Figure 6.5. Then $C O V$ for each value of predicted lateral soil response $(p)$ will be calculated by dividing STD to predicted values. Finally, the constant coefficient of variation (avgCOV) of $\mathrm{p}-\mathrm{y}$ curve will be calculated by taking the average of all values of COVs. All the probabilistic variables will be calculated using data according to depth ( $5 \mathrm{ft}$ and $7 \mathrm{ft}$ of Maquoketa $\mathrm{A}, 10 \mathrm{ft}$ and $12 \mathrm{ft}$ of Maquoketa B, $16 \mathrm{ft}$ and $18 \mathrm{ft}$ of Maquoketa $\mathrm{C}$ at Frankford or $2 \mathrm{ft}, 5 \mathrm{ft}, 10 \mathrm{ft}, 12 \mathrm{ft}$ of Silty Clay and $16 \mathrm{ft}, 20 \mathrm{ft}, 22 \mathrm{ft}, 25 \mathrm{ft}$ of Sandy Shale at Warrensburg). 


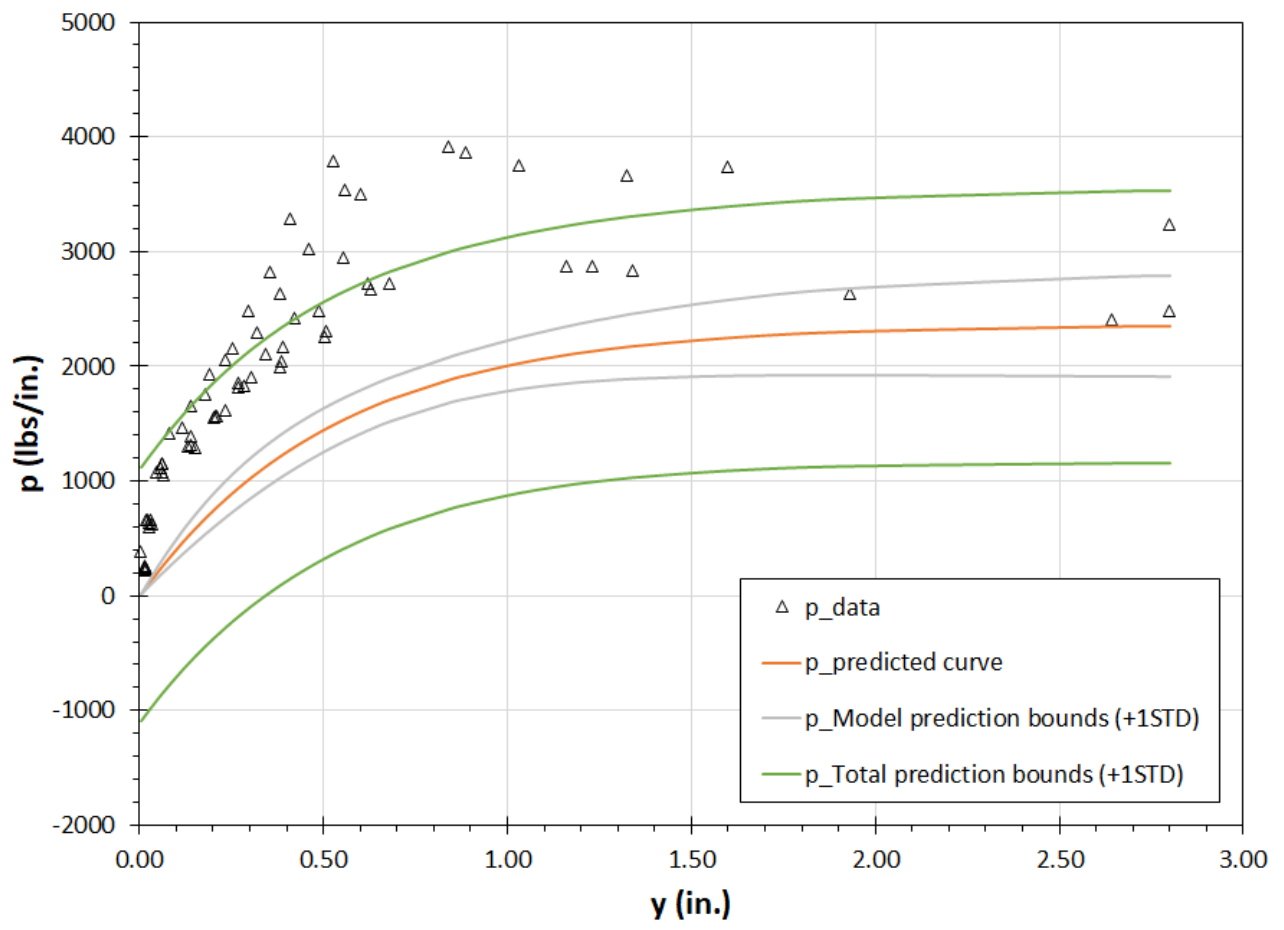

Figure 6.5 - Model and Total Bounds for predicting lateral soil response (p) with respect to lateral displacement $(y)$ at Frankford, Maquoketa $A$, depth $=5 \mathrm{ft}$

Table 6.3 summarizes values of UCS, predicted lateral soil response $(p)$ and the constant coefficient of variation ( $a v g C O V$ ) of model and total uncertainty of prediction p-y curve.

Table 6.3 - Constant COV for Model and Total uncertainty of prediction of $p$-y curve

\begin{tabular}{|c|c|c|c|c|c|c|c|c|}
\hline \multirow[t]{2}{*}{ Site } & \multirow[t]{2}{*}{ Soil layer } & \multirow{2}{*}{$\begin{array}{c}\mathrm{z} \\
(\mathrm{ft})\end{array}$} & \multirow{2}{*}{$\begin{array}{l}\text { UCS } \\
\text { (psf) }\end{array}$} & \multirow{2}{*}{$\begin{array}{c}\mathbf{P}_{\text {ult }} \\
\text { (lbs/in.) } \\
\end{array}$} & \multirow[t]{2}{*}{$\log \left(\mathrm{K}_{\mathrm{py}} / \sigma_{\mathrm{v}}\right)$} & \multirow{2}{*}{$\begin{array}{c}\mathrm{K}_{\mathrm{py}} \\
\left(\mathrm{lbs} / \mathrm{in}^{2}\right)\end{array}$} & \multicolumn{2}{|c|}{ avg (COV) } \\
\hline & & & & & & & Model & Total \\
\hline \multirow[t]{6}{*}{ Frankford } & Maquoketa A & 5 & 3250 & 2360.00 & -4.94 & 4,470 & 0.19 & 4.47 \\
\hline & & 7 & 3250 & 2360.00 & -4.94 & 6,259 & 0.23 & 7.16 \\
\hline & Maquoketa B & 10 & 10400 & 3460.00 & -2.40 & 112,722 & 0.27 & 14.27 \\
\hline & & 12 & 10400 & 3460.00 & -2.40 & 136,018 & 0.54 & 39.15 \\
\hline & Maquoketa C & 16 & 66200 & 12044.62 & 4.61 & $206,420,234$ & 0.09 & 10.33 \\
\hline & & 18 & 66200 & 12044.62 & 4.61 & $234,659,676$ & 0.12 & 18.92 \\
\hline \multirow[t]{8}{*}{ Warrensburg } & Silty Clay & 2 & 4450 & 2544.62 & -4.44 & 2,827 & 0.06 & 0.62 \\
\hline & & 5 & 4450 & 2544.62 & -4.44 & 7,240 & 0.08 & 0.68 \\
\hline & & 10 & 4450 & 2544.62 & -4.44 & 14,389 & 0.07 & 0.67 \\
\hline & & 12 & 4450 & 2544.62 & -4.44 & 17,404 & 0.06 & 0.59 \\
\hline & Sandy Shale & 16 & 15000 & 4167.69 & -1.18 & 625,172 & 0.08 & 0.95 \\
\hline & & 20 & 15000 & 4167.69 & -1.18 & 797,658 & 0.06 & 0.94 \\
\hline & & 22 & 15000 & 4167.69 & -1.18 & 886,982 & 0.06 & 0.89 \\
\hline & & 25 & 15000 & 4167.69 & -1.18 & $1,025,587$ & 0.07 & 10.38 \\
\hline
\end{tabular}




\subsubsection{Evaluation of Probabilistic Variables according to $3^{\text {rd }}$ Approach}

The method to use constant coefficient of variation $(a v g C O V)$ for predicting $\mathrm{p}-\mathrm{y}$ curve according to the second approach has a disadvantage when averaging values of $\mathrm{COV}$ for total variability and uncertainty since those $\mathrm{COV}$ values vary significantly. On the other hand, the values of standard deviation $(S T D)$ for total variability and uncertainty are consistent about average value $(\operatorname{avgSTD})$. Thus, the third approach has been established in order to have better representation of the total variability and uncertainty for predicting p-y curve.

Similarity to the second approach, for each soil layer, the values of $P_{u l t}$ and $K_{p y}$ will be predicted using Eq. 6.12 and Eq. 6.13. Then, the predicted $P_{u l t}$ and predicted $K_{p y}$ will be used to calculate the predicted lateral soil response $(p)$ with respect to a set of lateral displacement $(y)$ using Equation 5.3. Figure 6.5 shows an example of predicted curves, model and total bounds, and fitted data for Frankford load site, Maquoketa A layer and at depth is equal to $5 \mathrm{ft}$.

A set of standard deviation (STD) for model and total uncertainty of prediction of lateral soil response $(p)$ will be obtained from Figure 6.5. Finally, the constant standard deviation (avgSTD) of p-y curve will be calculated by taking the average of all values of STD. Again, all the probabilistic variables will be calculated using data according to depth (5ft and $7 \mathrm{ft}$ of Maquoketa $\mathrm{A}, 10 \mathrm{ft}$ and $12 \mathrm{ft}$ of Maquoketa $\mathrm{B}, 16 \mathrm{ft}$ and $18 \mathrm{ft}$ of Maquoketa C at Frankford or $2 \mathrm{ft}, 5 \mathrm{ft}, 10 \mathrm{ft}, 12 \mathrm{ft}$ of Silty Clay and $16 \mathrm{ft}, 20 \mathrm{ft}, 22 \mathrm{ft}, 25 \mathrm{ft}$ of Sandy Shale at Warrensburg). 
Table 6.4 summarizes values of $U C S$, predicted lateral soil response $(p)$ and the constant standard deviation (avgSTD) of model and total uncertainty of prediction $p$-y curve.

Table 6.4 - Constant STD for Model and Total uncertainty of prediction of $p$-y curve

\begin{tabular}{|c|c|c|c|c|c|c|c|c|}
\hline \multirow[t]{2}{*}{ Site } & \multirow[t]{2}{*}{ Soil layer } & \multirow[t]{2}{*}{$\begin{array}{c}z \\
(\mathrm{ft})\end{array}$} & \multirow[t]{2}{*}{$\begin{array}{l}\text { UCS } \\
\text { (psf) }\end{array}$} & \multirow[t]{2}{*}{$\begin{array}{c}P_{\text {ult }} \\
\text { (lbs/in.) }\end{array}$} & \multirow[t]{2}{*}{$\log \left(K_{p y} / \sigma_{v}\right)$} & \multirow[t]{2}{*}{$\begin{array}{c}K_{p y} \\
\left(\text { llbs/in }^{2}\right)\end{array}$} & \multicolumn{2}{|c|}{$\begin{array}{c}\text { avg (STD) } \\
\text { (lbs/in.) }\end{array}$} \\
\hline & & & & & & & Model & Total \\
\hline \multirow[t]{6}{*}{ Frankford } & Maquoketa A & 5 & 3250 & 2360.00 & -4.94 & 4,470 & 157.84 & 401.44 \\
\hline & & 7 & 3250 & 2360.00 & -4.94 & 6,259 & 155.21 & 703.17 \\
\hline & Maquoketa B & 10 & 10400 & 3460.00 & -2.40 & 112,722 & 338.23 & 608.94 \\
\hline & & 12 & 10400 & 3460.00 & -2.40 & 136,018 & 206.36 & 463.96 \\
\hline & Maquoketa C & 16 & 66200 & 12044.62 & 4.61 & $206,420,234$ & 425.40 & 1570.41 \\
\hline & & 18 & 66200 & 12044.62 & 4.61 & $234,659,676$ & 290.22 & 1062.92 \\
\hline \multirow[t]{8}{*}{ Warrensburg } & Silty Clay & 2 & 4450 & 2544.62 & -4.44 & 2,827 & 63.79 & 972.87 \\
\hline & & 5 & 4450 & 2544.62 & -4.44 & 7,240 & 116.05 & 740.05 \\
\hline & & 10 & 4450 & 2544.62 & -4.44 & 14,389 & 99.96 & 1118.85 \\
\hline & & 12 & 4450 & 2544.62 & -4.44 & 17,404 & 74.71 & 1171.55 \\
\hline & Sandy Shale & 16 & 15000 & 4167.69 & -1.18 & 625,172 & 193.93 & 2414.42 \\
\hline & & 20 & 15000 & 4167.69 & -1.18 & 797,658 & 120.22 & 2019.26 \\
\hline & & 22 & 15000 & 4167.69 & -1.18 & 886,982 & 104.93 & 2325.07 \\
\hline & & 25 & 15000 & 4167.69 & -1.18 & $1,025,587$ & 69.89 & 2213.20 \\
\hline
\end{tabular}




\subsubsection{Comparison Probabilistic Variables in p-y Responses using Three Approaches}

In order to compare the probabilistic variables in $p-y$ responses obtained using three different approaches, the predicted $p-y$ curves are generated based on the variability and uncertainty of $\mathrm{p}-\mathrm{y}$ responses. Using data according to depth $(5 \mathrm{ft}$ and $7 \mathrm{ft}$ of Maquoketa $\mathrm{A}, 10 \mathrm{ft}$ and $12 \mathrm{ft}$ of Maquoketa $\mathrm{B}, 16 \mathrm{ft}$ and $18 \mathrm{ft}$ of Maquoketa $\mathrm{C}$ at Frankford or $2 \mathrm{ft}, 5 \mathrm{ft}, 10 \mathrm{ft}, 12 \mathrm{ft}$ of Silty Clay and $16 \mathrm{ft}, 20 \mathrm{ft}, 22 \mathrm{ft}, 25 \mathrm{ft}$ of Sandy Shale at Warrensburg), predicted curves will be compared between three approaching in relationship with measured p-y responses and fitted p-y curves, as shown in Figure 6.6 to Figure 6.9 and in Appendix C. Moreover, the comparison will be made between model uncertainty versus total variability and uncertainty. Finally, the most appropriate approach will be selected to model the probabilistic variables in $\mathrm{p}-\mathrm{y}$ responses, in order to be used for calibration of resistance factors, as will be described in the next sections of chapter 6 .

Figure 6.6a to Figure 6.9a are plotted based on the first approach to predict $p-y$ curves by simulating the ultimate soil resistance, $P_{u l t}$, and the initial slope of $p$-y curve, $K_{p y}$, using the coefficient of variation of $P_{u l t}\left(\operatorname{COV}_{P_{u l t}}\right)$ and the coefficient of variation of $K_{p y}\left(C O V_{K_{p y}}\right)$, which are calculated and presented in Table 6.1 and Table 6.2. Figure 6.6b to Figure $6.9 \mathrm{~b}$ are plotted based on the second approach to simulate $\mathrm{p}$-y curves by using the constant coefficients of variation ( $\operatorname{vvg} \mathrm{COV})$, which are calculated and presented in Table 6.3. Figure $6.6 \mathrm{c}$ to Figure $6.9 \mathrm{c}$ are plotted based on the third approach to simulate p-y curves by using the constant standard deviation (avgSTD), which are calculated and presented in Table 6.4. 

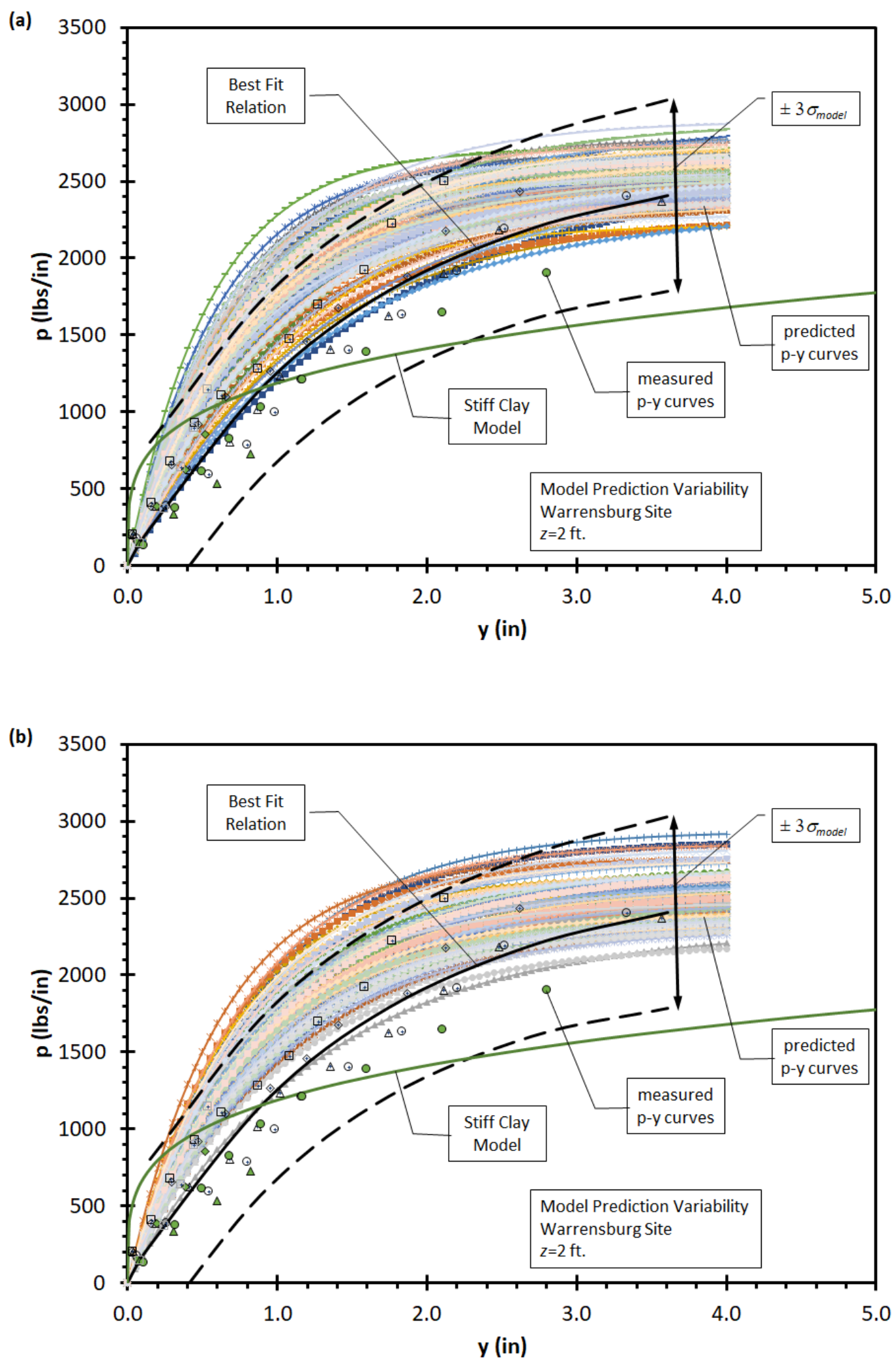


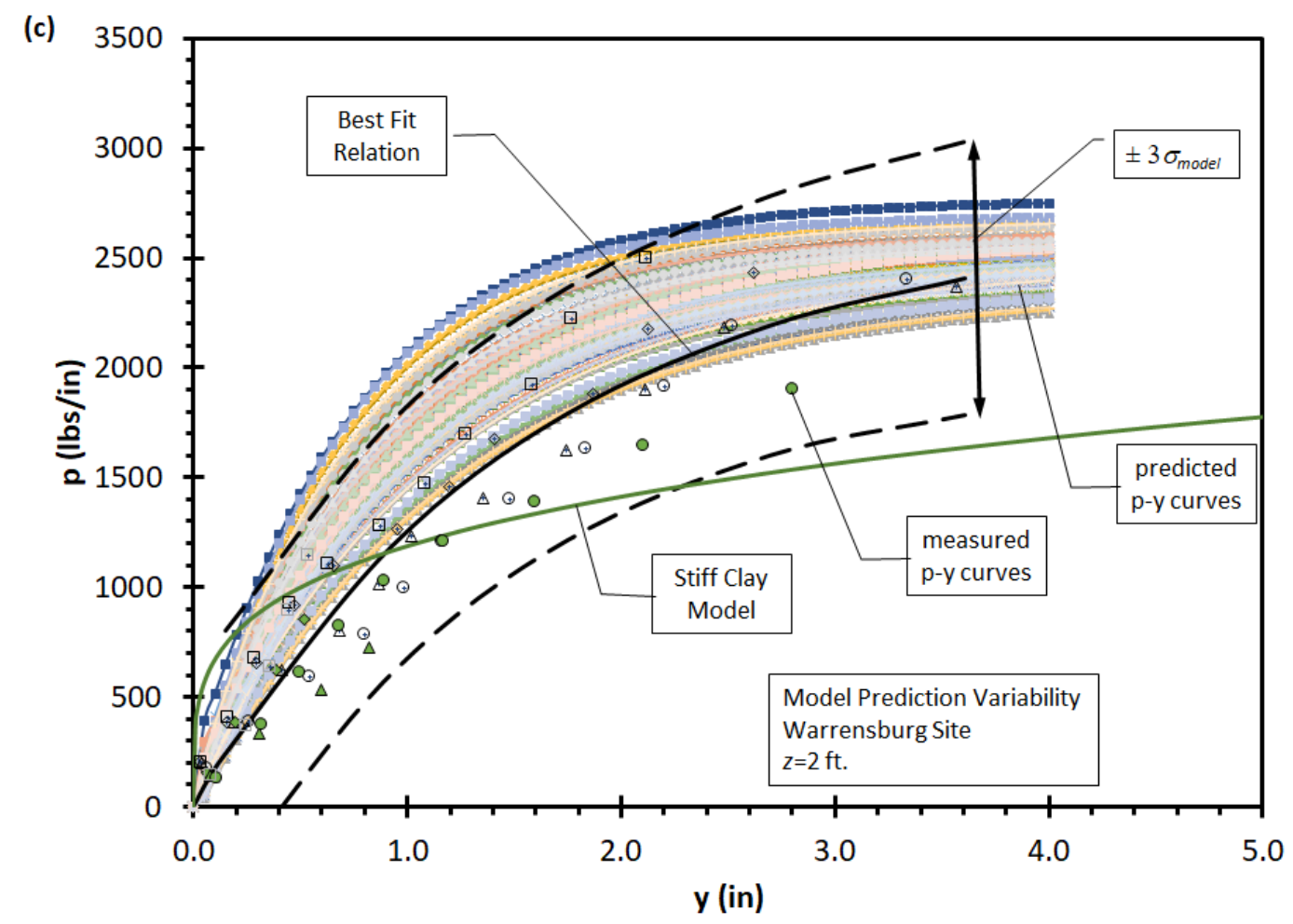

Figure 6.6 - Comparison between 3 approaches for Model Uncertainty (Warrensburg Site, Silty Clay layer, depth=2ft)
(a) Approach 1
(b) Approach 2
(c) Approach 3 

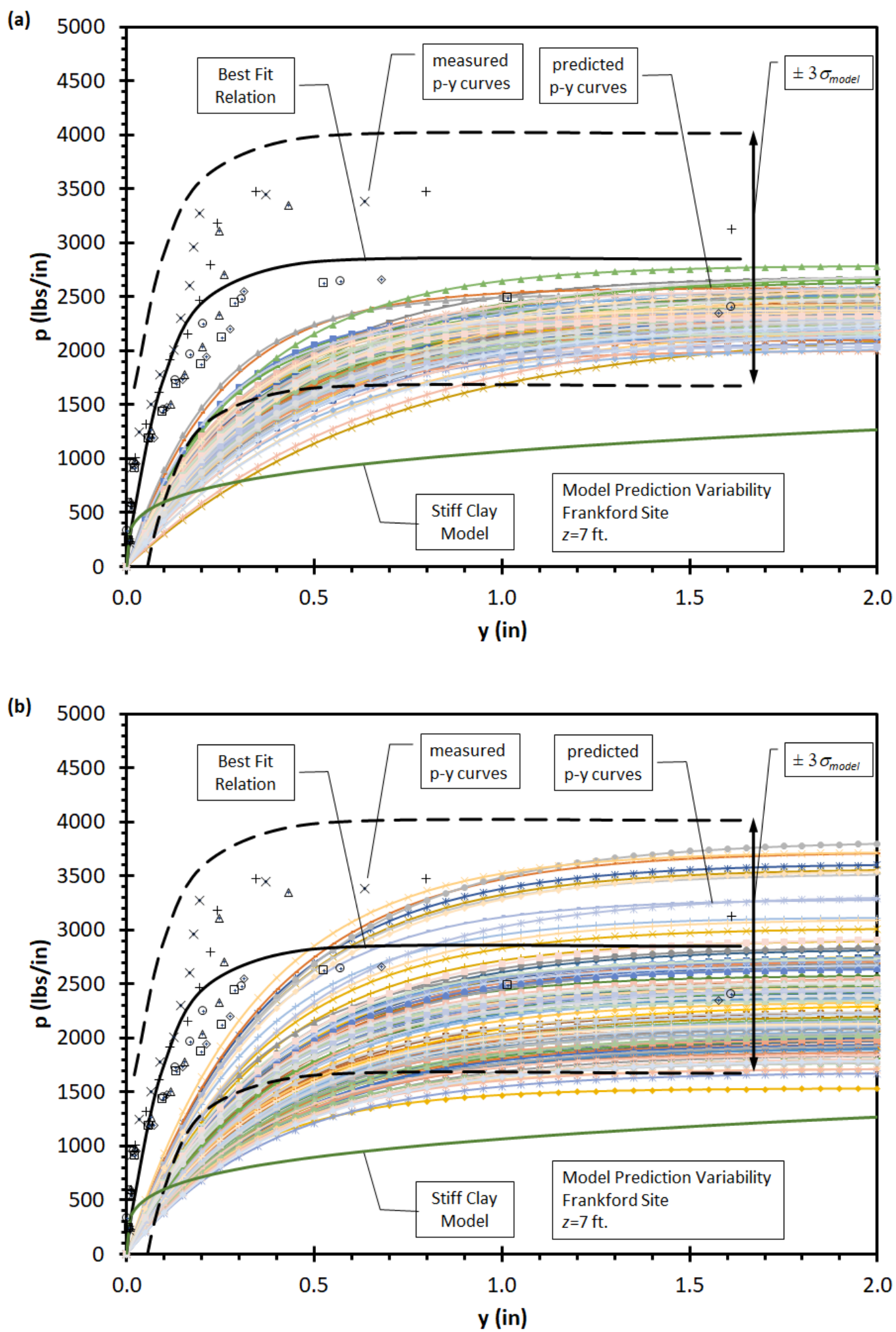


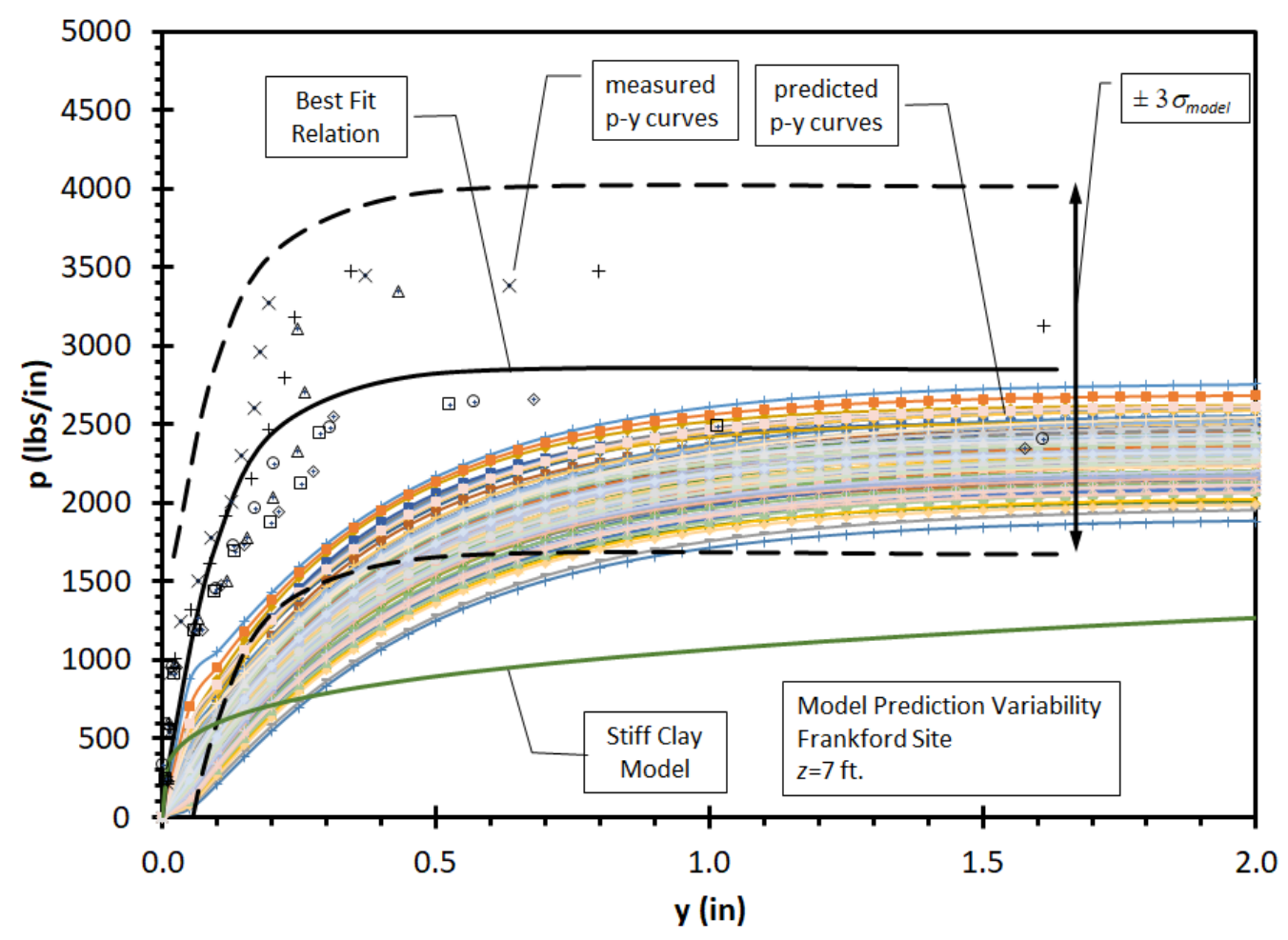

Figure 6.7 - Comparison between 3 approaches for Model Uncertainty (Frankford Site, Maquoketa A layer, depth=7ft)
(a) Approach 1
(b) Approach 2
(c) Approach 3

The comparison of probabilistic variables in $p-y$ responses obtained using three different approaches for model uncertainty has been summarized in Table 6.5. In which, the predicted variability is represented by number of simulation predicted $p-y$ curves while the observed variability is represented by fitted $p-y$ curve (best fit relation) and the range between three standard deviation of fitted p-y model, as shown in Figure 6.6 and Figure 6.7. 
Table 6.5 - Comparison between Three Approaches for Model Uncertainty

\begin{tabular}{|c|c|c|c|}
\hline & Approach 1 & Approach 2 & Approach 3 \\
\hline Variabilities & $P_{u l t}, K_{p y}$ & p-y curves $(a v g C O V)$ & p-y curves (avgSTD) \\
\hline $\begin{array}{c}\text { Model } \\
\text { Uncertainty }\end{array}$ & $\begin{array}{l}\text { - predicted variability is } \\
\text { consistent with } \\
\text { observed variability but } \\
\text { MEAN doesn't always } \\
\text { match observations. } \\
\text { (Fig. 6.6a \& Fig. 6.7a) } \\
\text { - Frankford: predictions } \\
\text { tend to be low } \\
\text { compared to } \\
\text { measurements. (Fig. } \\
6.7 a) \\
\text { measurements. (Fig. } \\
\text { depth. } \\
\text { high compared to } \\
\text { - Warrensburg: } \\
\text { predictions tend to be } \\
\text { - Both improve with } \\
\text { mat }\end{array}$ & $\begin{array}{l}\text { - greater predicted } \\
\text { variability than Approach } \\
1 \text { \& Approach } 3 \text { for } \\
\text { Frankford. (Fig. 6.7b) } \\
\text { - similar predicted } \\
\text { variability to Approach } 1 \\
\text { for Warrensburg. (Fig. } \\
6.6 \mathrm{~b}) \\
\text { - Frankford: predictions } \\
\text { tend to be low but } \\
\text { improve with depth. (Fig. } \\
6.6 \mathrm{~b} \text { ) } \\
\text { predicted } P_{\text {ult }} \text { are better, } \\
\text { - Warrensburg: predicted }\end{array}$ & $\begin{array}{l}\text { - predicted variability is } \\
\text { slightly less than } \\
\text { Approach } 1 \text { \& Approach } \\
\text { 2. (Fig. 6.6c \& Fig 6.7c) } \\
\text { - other observations are } \\
\text { similar to Approach } 1\end{array}$ \\
\hline
\end{tabular}



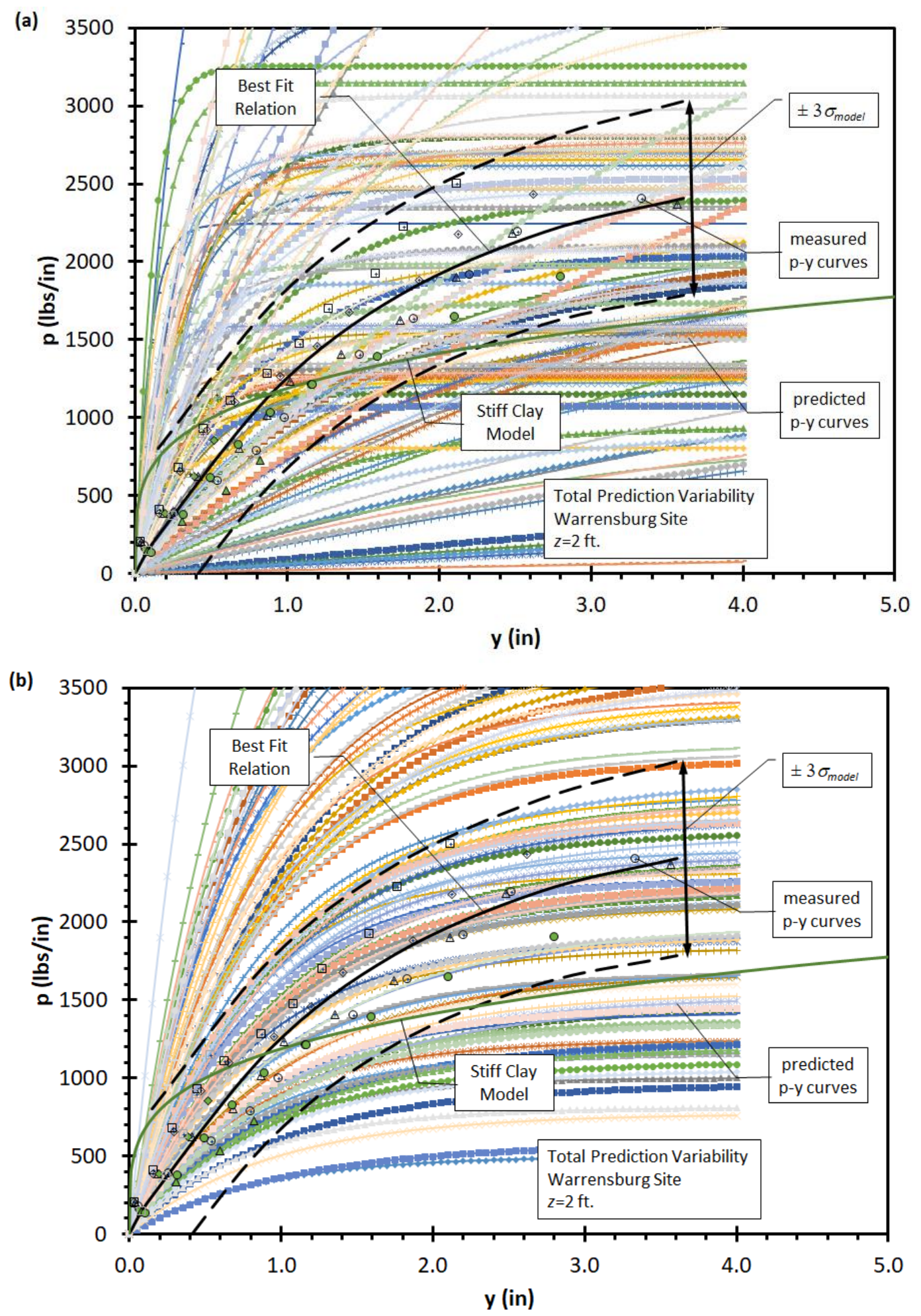




Figure 6.8 - Comparison between 3 approaches for Total Variability and Uncertainty (Warrensburg Site, Silty Clay layer, depth=2ft)
(a) Approach 1
(b) Approach 2
(c) Approach 3 

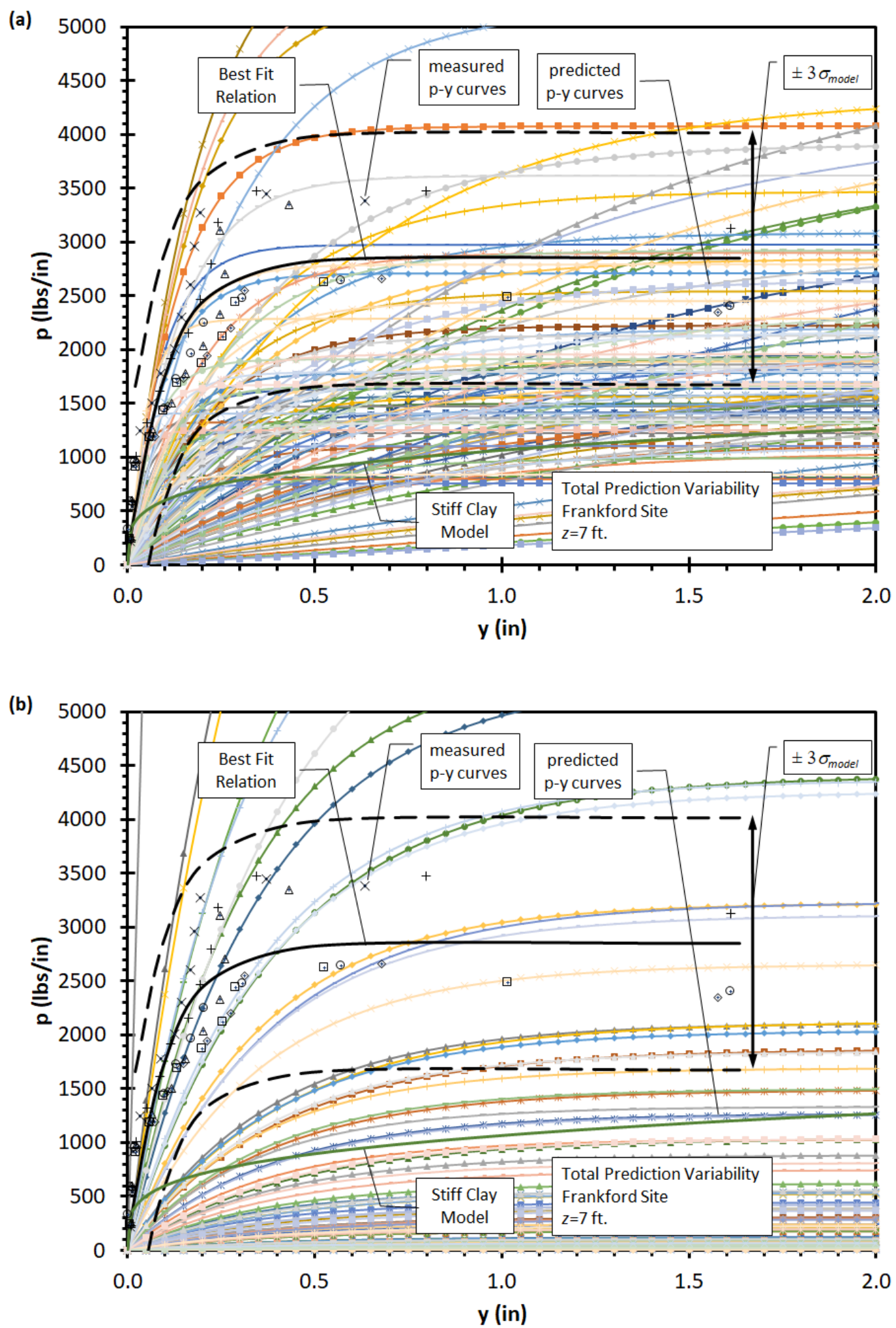


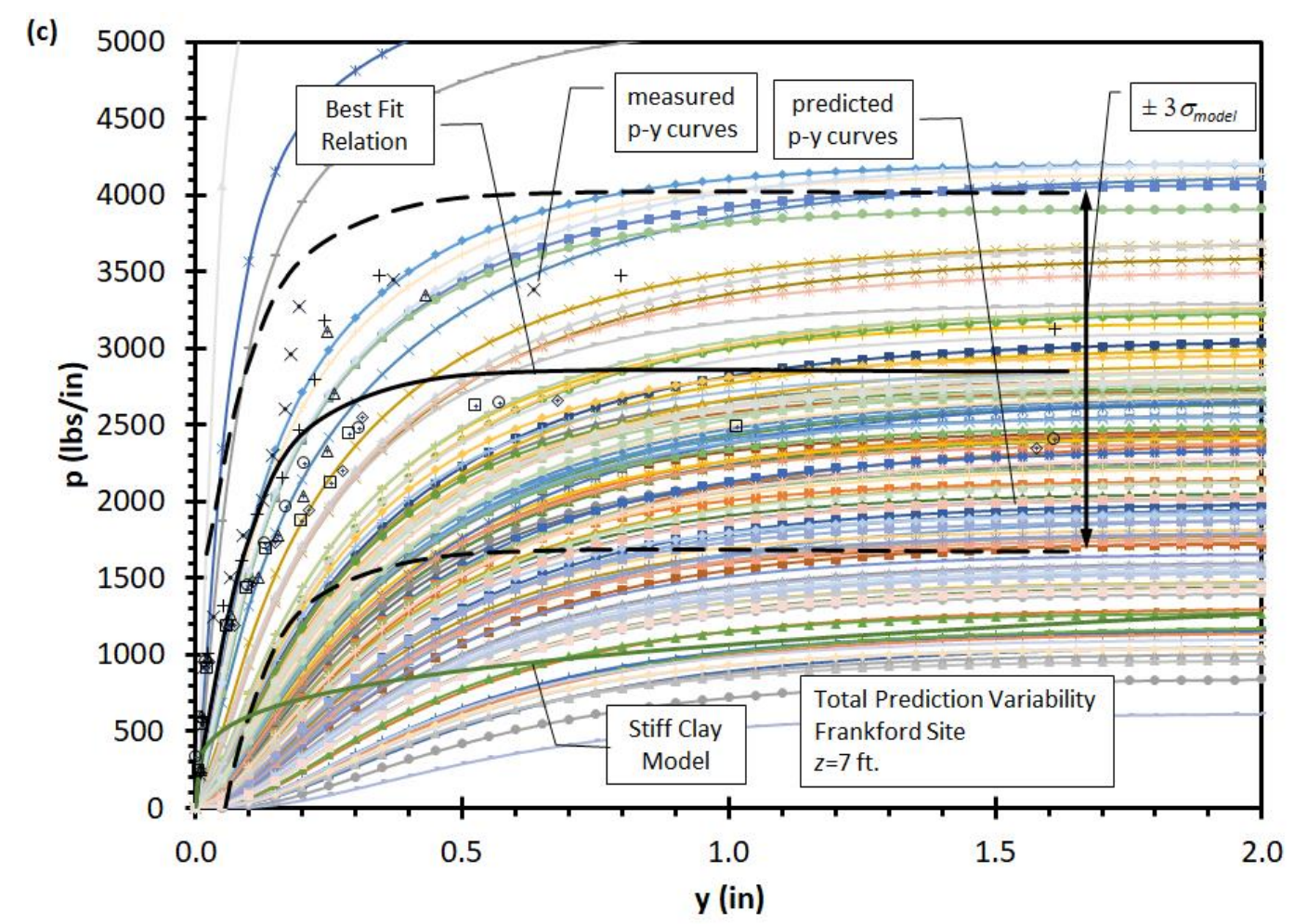

Figure 6.9 - Comparison between 3 approaches for Total Variability and Uncertainty (Warrensburg Site, Silty Clay layer, depth=2ft)
(a) Approach 1
(b) Approach 2
(c) Approach 3

The comparison of probabilistic variables in $p-y$ responses obtained using three different approaches for total variability and uncertainty has been summarized in Table 6.6. Similarity, the predicted variability is represented by number of simulation predicted $p-y$ curves while the observed variability is represented by fitted $p-y$ curve (best fit relation) and the range between three standard deviation of fitted $p-y$ model, as shown in Figure 6.8 and Figure 6.9. 
Table 6.6 - Comparison between Three Approaches for Total Variability \& Uncertainty

\begin{tabular}{|c|c|c|c|}
\hline & Approach 1 & Approach 2 & Approach 3 \\
\hline Variabilities & $P_{u l t}, K_{p y}$ & p-y curves (avgCOV) & p-y curves (avgSTD) \\
\hline $\begin{array}{l}\text { Total } \\
\text { Variability } \\
\text { and } \\
\text { Uncertainty }\end{array}$ & $\begin{array}{l}\text { - predicted variability is } \\
\text { much greater than } \\
\text { observed variability at } \\
\text { each site. (Fig. 6.8a \& } \\
\text { Fig 6.9a) } \\
\text { - Frankford: } \\
\text { measurements tend to } \\
\text { fall near upper bound of } \\
\text { predictions. (Fig. 6.9a) } \\
\text { Fig 6.9a) } \\
\text { - Warrensburg: } \\
\text { measurements tend to } \\
\text { meastions are much } \\
\text { fall in middle of } \\
\text { predictions. (Fig. } 6.8 \text { a) }\end{array}$ & $\begin{array}{l}\text { - predicted variability is } \\
\text { much greater than } \\
\text { Approach } 1 \text { \& Approach } \\
\text { 3. (Fig. 6.8b \& Fig 6.9b) } \\
\text { - substantial number of } \\
\text { predictions that seem } \\
\text { unrepresentative: } \\
\text { Frankford predictions are } \\
\text { too low (Fig 6.9b); } \\
\text { Warrensburg predictions } \\
\text { are too high (Fig 6.8b). }\end{array}$ & $\begin{array}{l}\text { - predicted variability is } \\
\text { slightly greater than } \\
\text { observed variability. } \\
\text { (Fig. 6.8c \& Fig 6.9c) } \\
\text { - Frankford: } \\
\text { measurements tend to } \\
\text { fall into upper half of } \\
\text { predictions. (Fig 6.9b) } \\
\text { Approach } 1 . \\
\text { - Warrensburg: } \\
\text { measurements tend to } \\
\text { fall into lower half of } \\
\text { predictions. (Fig. } 6.8 \mathrm{~b} \text { ) } \\
\text { - do Notremely low }\end{array}$ \\
\hline
\end{tabular}


Based on the comparison between three approaches, it is recommended to use Approach 3 to assign probabilistic distributions for $p-y$ curves according to Eq. 6.1 with the probabilistic model uncertainty factors using constant standard deviation (avgSTD). Moreover, for predicting soil resistance subjected to lateral loads, it is necessary to use total variability and uncertainty for new observations rather than model uncertainty. Thus finally, Approach 3 with total variability and uncertainty will be used for all the probabilistic analysis to calibrate the resistance factors.

It is important to make the selection for the constant standard deviation of $p-y$ curves to run the Monte Carlo simulation. Table 6.7 summarizes the values of UCS and constant STD for different depths at both Warrensburg and Frankford. The final value of constant standard deviation has been selected by averaging all values of constant $S T D$, as presented in Table 6.7 and Figure 6.10.

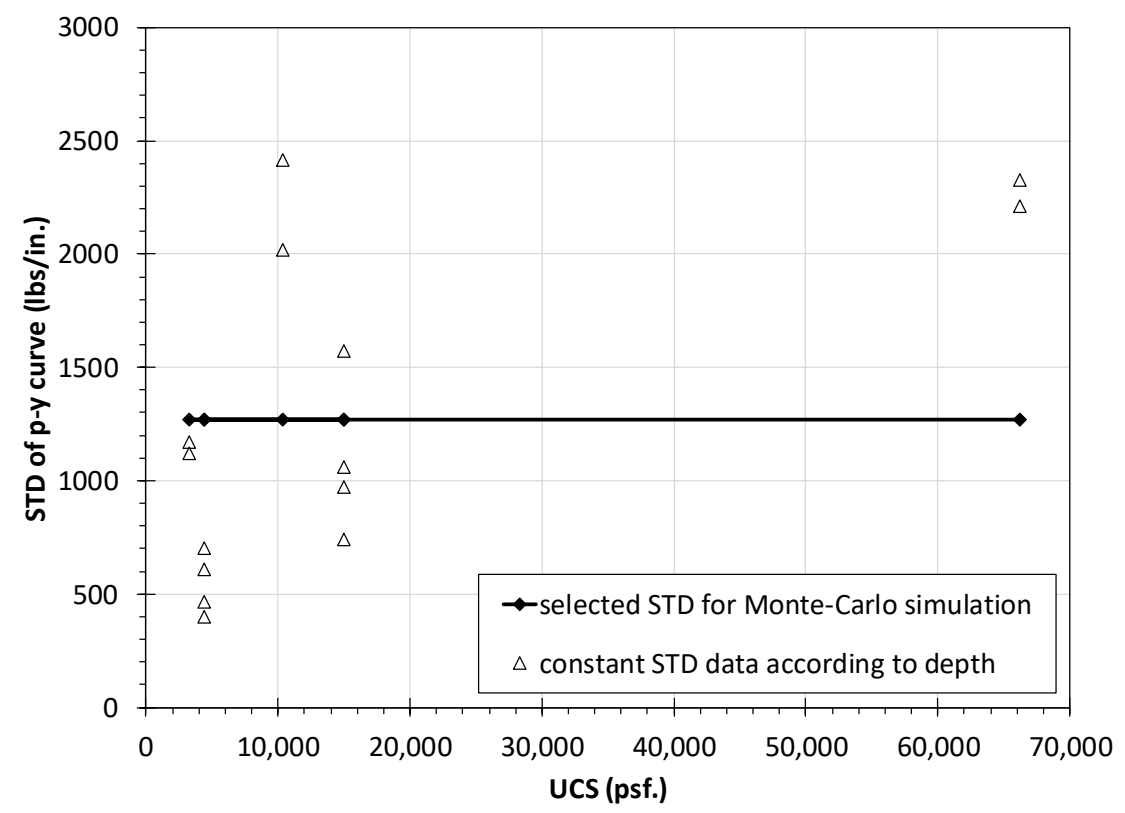

Figure 6.10 - Selection of Constant Standard Deviation for Monte-Carlo Simulation 
Table 6.7 - Selection of Constant Standard Deviation for Monte-Carlo Simulation

\begin{tabular}{|c|c|c|c|c|c|}
\hline \multirow[b]{2}{*}{ Site } & \multirow[b]{2}{*}{ Soil layer } & \multirow{2}{*}{$\begin{array}{l}\text { Depth z } \\
\text { (ft.) }\end{array}$} & \multirow{2}{*}{$\begin{array}{l}\text { UCS } \\
\text { (psf) }\end{array}$} & \multirow{2}{*}{$\begin{array}{c}\text { constant } S T D \\
\text { (lbs/in.) }\end{array}$} & \multirow{2}{*}{$\begin{array}{c}\text { selected } S T D \\
\text { (lbs/in.) }\end{array}$} \\
\hline & & & & & \\
\hline \multirow[t]{8}{*}{ Warrensburg } & Silty Clay & 2 & 4,450 & 401.44 & 1270.00 \\
\hline & & 5 & 4,450 & 703.17 & 1270.00 \\
\hline & & 10 & 4,450 & 608.94 & 1270.00 \\
\hline & & 12 & 4,450 & 463.96 & 1270.00 \\
\hline & Sandy Shale & 16 & 15,000 & 1570.41 & 1270.00 \\
\hline & & 20 & 15,000 & 1062.92 & 1270.00 \\
\hline & & 22 & 15,000 & 972.87 & 1270.00 \\
\hline & & 25 & 15,000 & 740.05 & 1270.00 \\
\hline \multirow[t]{6}{*}{ Frankford } & Maquoketa A & 5 & 3,250 & 1118.85 & 1270.00 \\
\hline & & 7 & 3,250 & 1171.55 & 1270.00 \\
\hline & Maquoketa B & 10 & 10,400 & 2414.42 & 1270.00 \\
\hline & & 12 & 10,400 & 2019.26 & 1270.00 \\
\hline & Maquoketa C & 16 & 66,200 & 2325.07 & 1270.00 \\
\hline & & 18 & 66,200 & 2213.20 & 1270.00 \\
\hline
\end{tabular}




\subsection{Final Probabilistic and Deterministic Variables for Monte-Carlo Simulation}

The Monte Carlo simulation is similar to the load test scenario: a shallow soil layer overlying a weak rock with a lateral load applied at the top of the shaft. The loading and shaft length were assumed to be deterministic. The load applied to the top of the shaft for the simulation, 200 kips, is approximately 70 percent of the ultimate load encountered

during the lateral load test program (Chapter 3). The geomaterial strength (UCS) and bending stiffness $(E I)$ are assigned probabilistic lognormal distributions. The bending stiffness is calculated consistent with the approach of Section 4.3, and a probabilistic model uncertainty factor of bending stiffness is applied by using the coefficient of variation $\left(C O V_{E I}\right)$, which is equal to 0.2 based on Tyler (2010).

The probabilistic variables for $p$-y responses uses results from Section 6.5 with the probabilistic model uncertainty factor of $p-y$ curve is applied by using selected standard deviation (selected $S T D$ ), which is equal to 1270 according to Table 6.7.

The final probabilistic and deterministic variables for Monte-Carlo simulation have been presented in Table 6.8 included load, UCS, non-linear bending stiffness $E I$, ultimate lateral soil response $P_{u l t}$, initial slope of $\mathrm{p}$-y curve $K_{p y}$ and the p-y curve itself. 
Table 6.8 - Final Probabilistic and Deterministic Variables for Monte-Carlo Simulation

\begin{tabular}{|c|c|c|c|}
\hline Variable & Assumed Distribution & Mean & COV or STD \\
\hline Load & (Deterministic) & 200 kips & 0 \\
\hline UCS-soil & Lognormal & $5 \mathrm{ksf}$ & $C O V_{U C S}=$ \\
\hline UCS-rock & Lognormal & $50 \mathrm{ksf}$ & $0.1,0.3,0.5,0.7,0.9$ \\
\hline$E I$ & Lognormal & calculated & $C O V_{E I}=0.2$ \\
\hline$P_{\text {ult }}$ & (Deterministic) & Eq. 5.6 & 0 \\
\hline$K_{p y}$ & (Deterministic) & Eq. 5.7 & 0 \\
\hline$p-y$ curve & Lognormal & Eq. 5.1 & selected $S T D=1270$ \\
\hline
\end{tabular}




\subsection{Calibration of Resistance Factors for Service Limit State}

The procedure to calibrate Resistance Factors for Service Limit State is divided into two steps. The first step presents the probabilistic analysis of how to obtain a shaft head displacement histogram. The second step presents a step-by-step procedure for SLS resistance factor calibration.

\subsubsection{Step-1: Probabilistic Analysis}

Deterministic and probabilistic variables for the SLS analysis are in Table 6.8. The $p-y$ models, geomaterial strength $(U C S)$ and non-linear bending stiffness $(E I)$ are considered probabilistic variables with their variabilities and uncertainties represented by either standard of deviation or coefficient of variation.

Probabilistic analyses were performed using random number simulation technique, i.e., Monte Carlo simulation, for probabilistic variables. The generated lateral load transfer model followed the procedure described in Chapter 5. The product of the probabilistic analysis is a set of shaft head lateral displacements, which are shown in a histogram (Figure 6.11). 


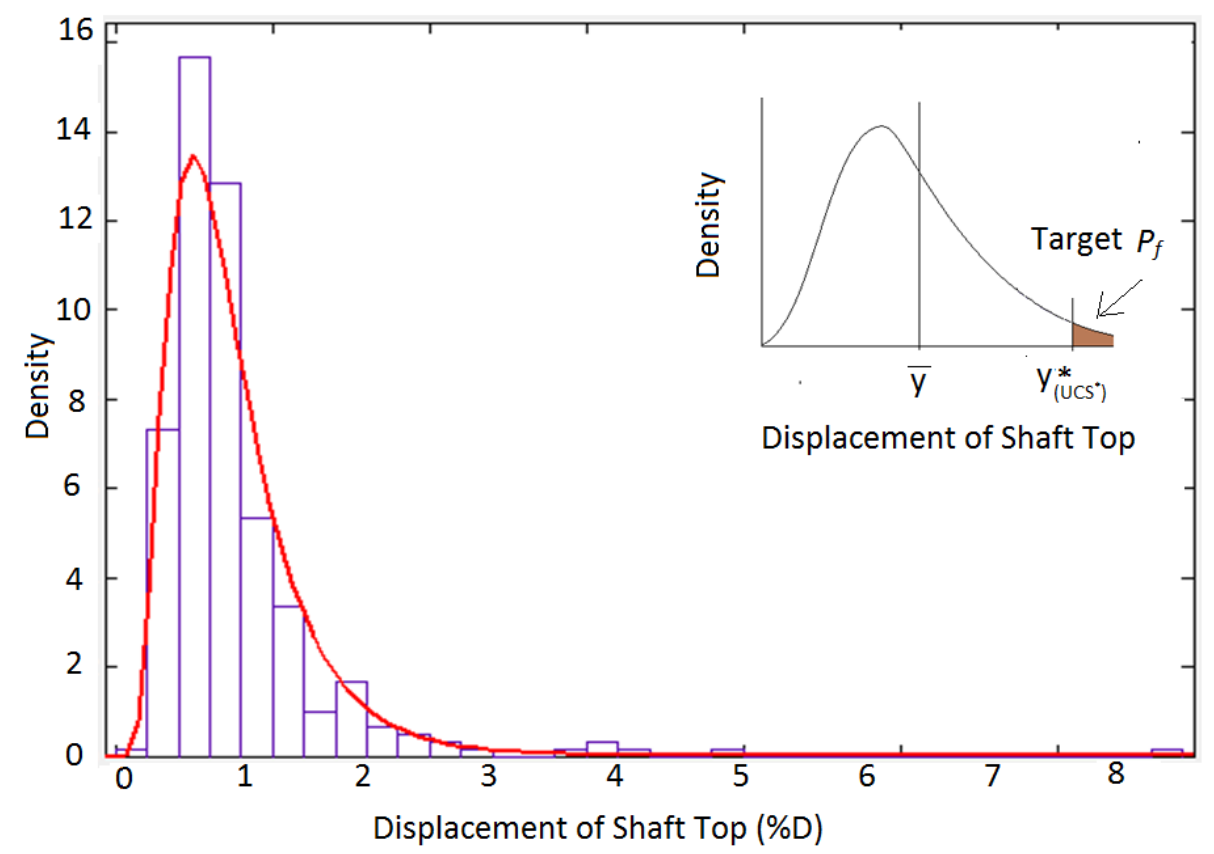

Figure 6.11 - Histogram and probability density curve for top shaft displacement.

The probabilistic analysis used the Monte Carlo approach with the number of simulation $n$ equal to 10,000 . The detailed procedure is as follows:

1. Start with a $C O V$ of $U C S$;

2. Generate a set of $n=10,000$ values of UCS using the mean value of UCS and its $\mathrm{COV}$. This is a probabilistic calculation with the Monte Carlo simulation technique as discussed in Section 0.

3. Generate a set of $n=10,000$ values of shaft stiffness $E I$ using the mean value of $E I$ and its $C O V$ from Table 6.8 .

4. Generate two sets of $n=10,000$ values of ultimate lateral soil resistance Pult and initial slope of p-y model Kpy using the mean values of UCS and Eq. 6.12 and Eq. 6.13. 
5. Generate a set of $n=10,000$ values of lateral load transfer curves from the proposed p-y model (Eq. 6.14) and their selected standard of deviation from Table 6.8.

6. For one simulation, based on one value of a randomly generated UCS, EI, $P_{u l t}, K_{p y}$ and $\mathrm{p}-\mathrm{y}$ model, as well as the load and geometric configuration of the drilled shaft, the FEM computational method was used to determine one value of shaft head displacement.

7. For 10,000 simulations, a number of 10,000 values of shaft head displacements were obtained. These values of shaft head displacements were used to create the shaft head displacement histogram, which is the product of the probabilistic analyses, as can be seen in Figure 6.12.

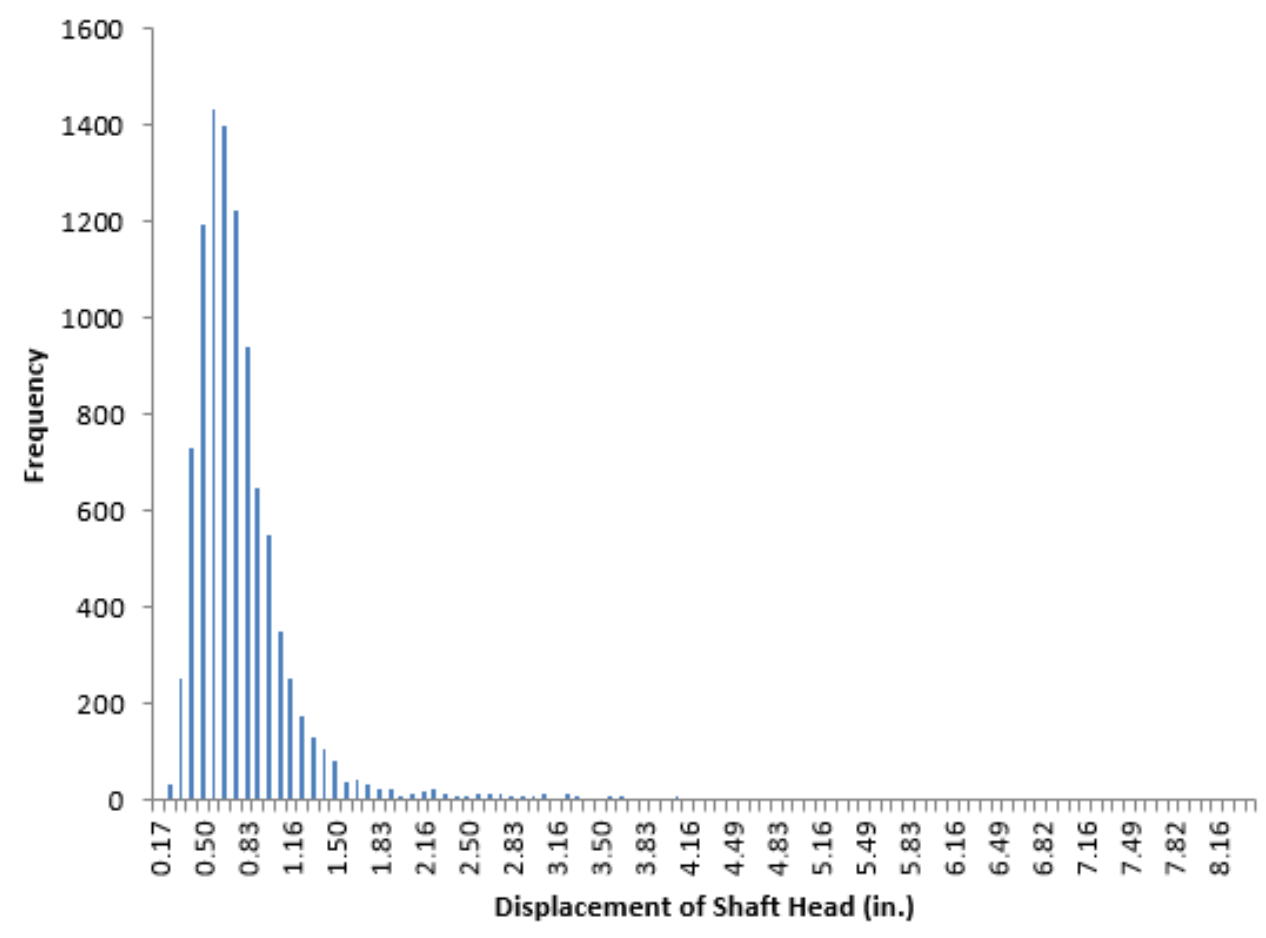

Figure 6.12 - Shaft Head Displacement Histogram 


\subsubsection{Step-2: Resistance Factor Calibration}

From the displacement histogram obtained from the probabilistic analysis described in the previous section, a SLS resistance factor can be calibrated. In general, from the histogram, a specific value of displacement (Figure 6.11) that associates with the target probability of failure $P_{f}$ is determined. Then a $p$-multiplier, which is used to provide the factor lateral soil resistance from the input $p-y$ curve, will be computed based on the following condition: If a SLS design uses the factored lateral soil resistance, the design produces the factored displacement that equals to a specific value of displacement associated with the target probability of failure $P_{f}$. The description of the procedure follows.

1. Determine number of "SLS failure cases" associated with the target probability of failure $P_{f}$. The number of failure cases is equal to the target $P_{f}$ multiplied by the number of simulation $n$, which is 10,000 .

$$
n_{f}=n * P_{f}=10,000 * P_{f}
$$

2. Find the factored displacement $y^{*}$ (Figure 6.11) that associates with the number of failure cases $n_{f}$. This can be done by sorting the displacement vector in descending order; then, take the $\left(n_{f}+1\right)^{\text {th }}$ displacement value as $y^{*}$. This $y^{*}$ associates with the target probability of failure $P_{f}$ as:

$$
P_{\left(y>y^{*}\right)}=P_{f}
$$

3. Determine the factored lateral soil resistance $p_{p-y}^{*}$ that produces $y^{*}$. This step is done by optimizing the values of lateral soil resistance $p$-multipliers. Use a range 
of $p$-multipliers and FEM computational program to calculate the corresponding range of new shaft top displacements. Optimize set of p-multipliers until the displacement is equal to factored displacement $y^{*}$. These calculations are deterministic using the mean values for all parameters.

4. Find the SLS resistance factor $\phi_{S L S}$, which is equal to the optimized p-multiplier.

The SLS resistance factor ( $\phi_{S L S}$ or p-multiplier) is calibrated to apply to the $\mathrm{p}$-y model in SLS design. Applying the resistance factor reduces the lateral soil response so that a design using the nominal values (or mean values) of all parameters and the factored lateral soil response produces factored shaft top displacement that associates with the target probability of failure. The resistance factor depends upon the histogram of the shaft head displacement, which in turn depends on the nominal values and variability of the input variables.

MATLAB ${ }^{\circledR}$ was used to write a computational program which employs the finite element method described in Chapter $4, P_{u l t}, K_{p y}$ and $p-y$ models and their development procedure established in Chapter 5, Monte Carlo simulation described in Section 0 and the probability analyses as well as the resistance factor calibration procedures presented in Section 6.7.

The resistance factor in this study is presented versus the coefficient of variation of uniaxial compressive strength (COV of $U C S$ ). The $C O V$ of $U C S$ is a parameter that has a wide range of change and is often obtained during site investigations, or if not, can be assumed using engineering judgment. 


\subsubsection{Calibrated Resistance Factors for Service Limit State}

Four options of calibrating resistance factors for service limit state were established using the analysis of the Monte Carlo simulations. The first option corresponds to probabilistic parameters for all the nodes are assigned COLLECTIVELY for each simulation (denoted as COL_UCS \& COL_p-y). Results for the first option are shown in Figure 6.13. The second option corresponds to probabilistic parameters for UCS are assigned INDIVIDUALLY but those for $p-y$ curve are assigned COLLECTIVELY for each simulation (denoted as IND_UCS \& COL_p-y). Results for the second option are shown in Figure 6.14. The third option corresponds to probabilistic parameters for UCS are assigned COLLECTIVELY but those for $p-y$ curve are assigned INDIVIDUALLY for each simulation (denoted as COL_UCS \& IND_p-y). Results for the third option are shown in Figure 6.15. The fourth option corresponds to probabilistic parameters for each node are assigned INDIVIDUALLY for each simulation (denoted as IND_UCS \& IND_p-y). Results for the fourth option are shown in Figure 6.16. Summarize of characteristics for 4 sets of resistance factors calibration is presented in Table 6.9.

The target probabilities of failure used for the analyses correspond to those for bridge foundations and approach embankments (Huaco, 2014). Alternative values should potentially be considered. The resistance factors are intended to be applied directly to the lateral soil resistance predicted by the $p-y$ models. This can be implemented through the p-multiplier concept explained in Chapter 4 and available in L-PILE. 


\section{Table 6.9 - Characteristics of Four Options to Calibrate Resistance Factors}

\begin{tabular}{cccc}
\hline & \multicolumn{2}{c}{ Probabilistic Parameters' assigned } \\
\cline { 2 - 3 } Option \# & UCS & p-y curve & Denotation \\
& (COV of UCS) & (STD of $p$-y model) \\
\hline 1 & Collectively & Collectively & COL_UCS \& COL_p-y \\
\hline 2 & Individually & Collectively & IND_UCS \& COL p-y \\
\hline 3 & Collectively & Individually & COL_UCS \& IND_p-y \\
\hline 4 & Individually & Individually & IND_UCS \& IND_p-y \\
\hline
\end{tabular}

All sets of resistance factors may seem low, especially considering current AASHTO guidance (6th Ed., 2012 with 2013 Interim Revisions) includes a resistance factor of 1.0, but the proposed models presented in Chapter 5 predict greater resistance than existing models. These findings likely will offset one another for many cases. Moreover, any differences between previous design approaches (i.e. either L-PILE's stiff clay model or KDOT curves with a resistance factor of 1.0) and the models and resistance factors presented in this report are rational and should improve the state of practice for MoDOT since the recommended models are based on full-scale load tests and the resistance factors achieve target levels of reliability. 


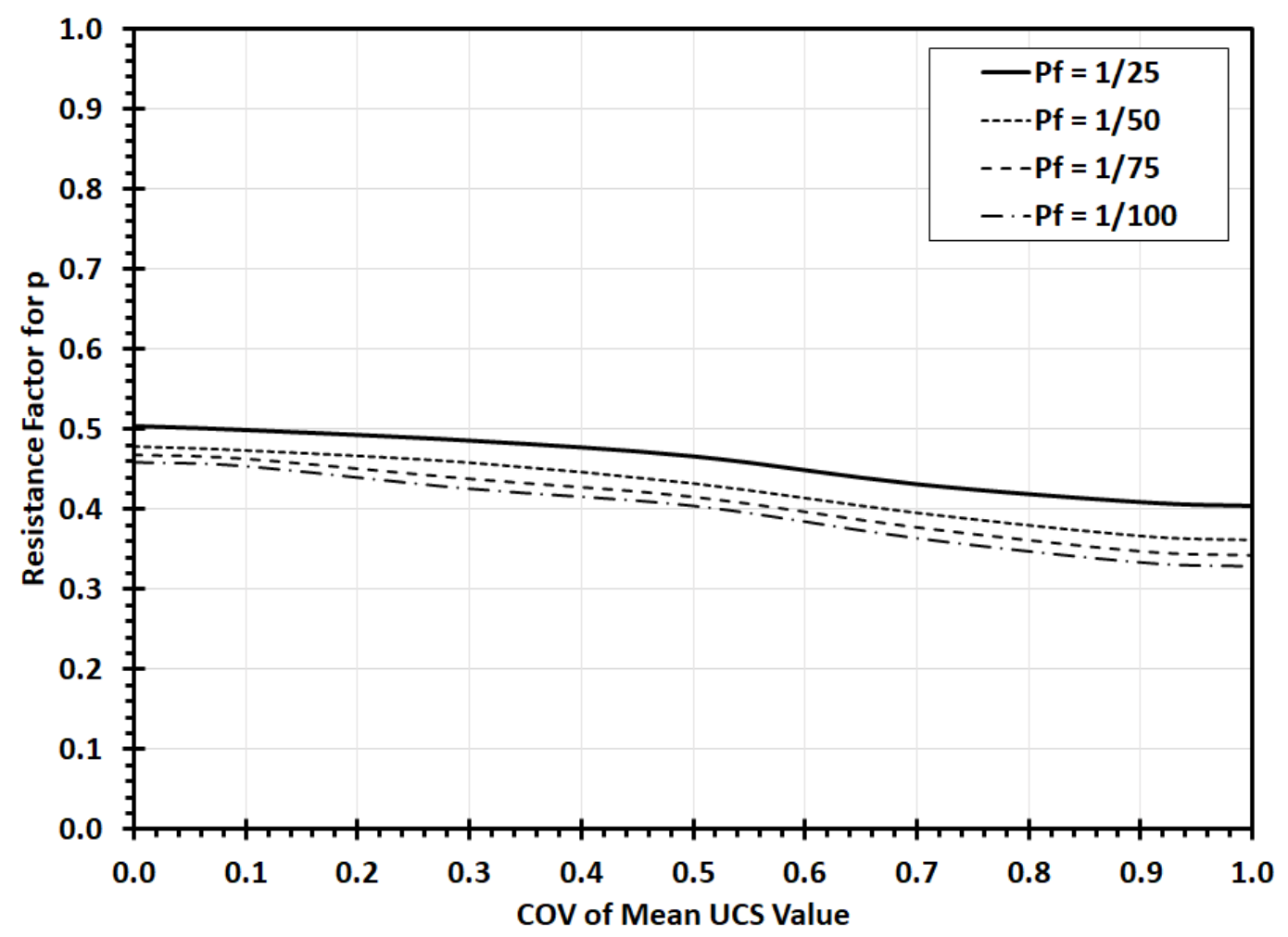

Figure 6.13 - Calibrated Resistance Factors for Service Limit State using $1^{\text {st }}$ Option

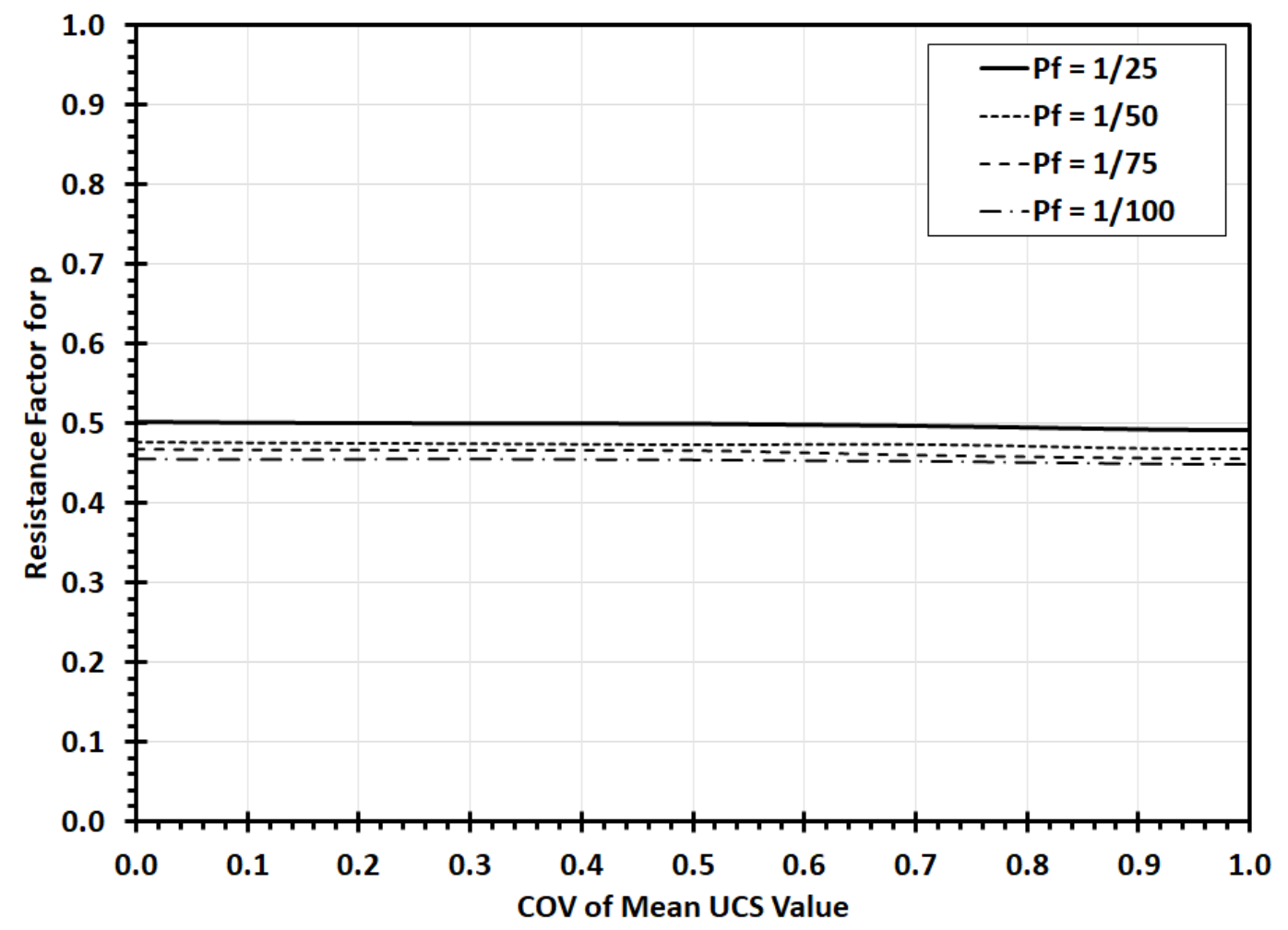

Figure 6.14 - Calibrated Resistance Factors for Service Limit State using $2^{\text {nd }}$ Option 


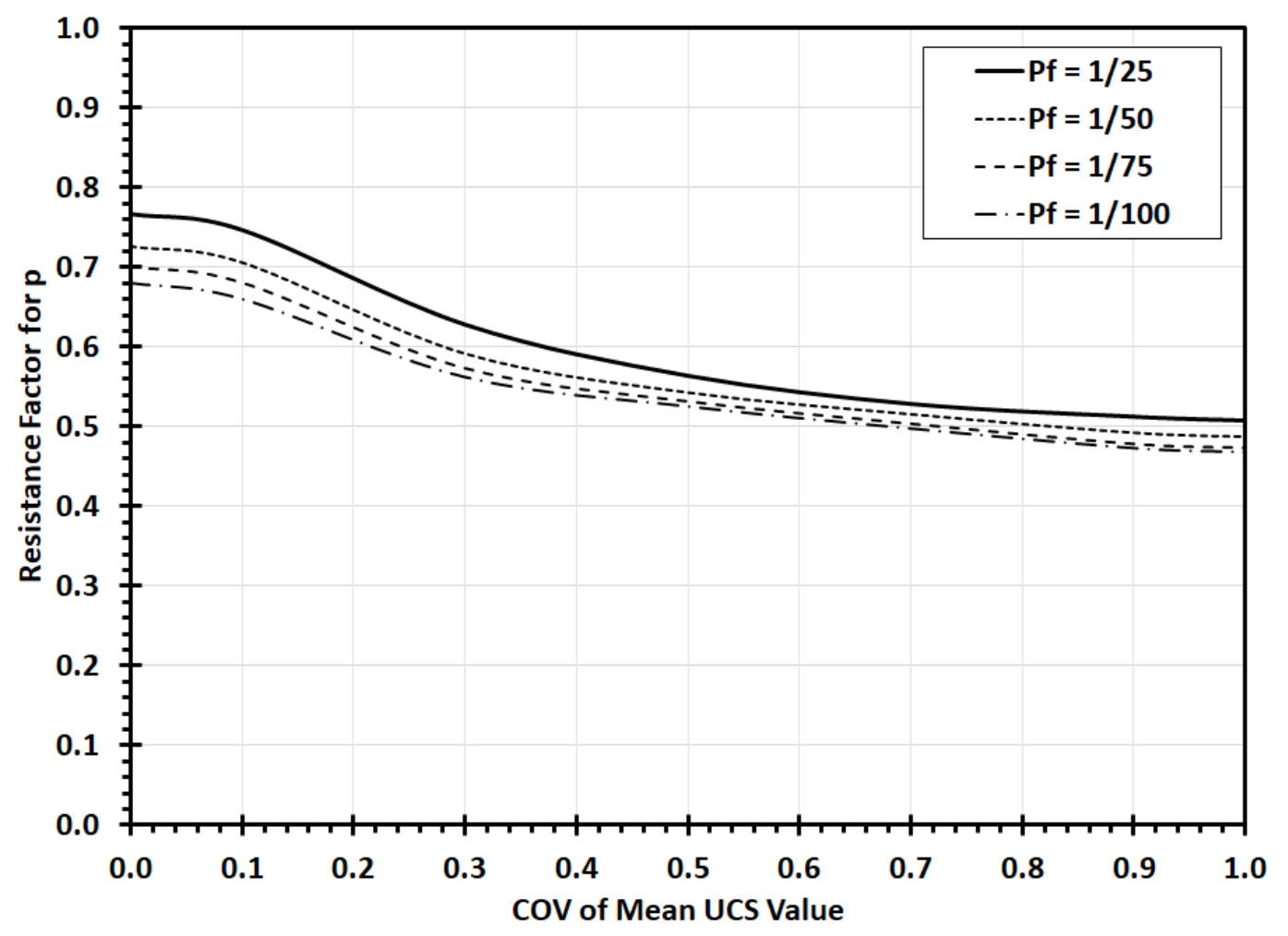

Figure 6.15 - Calibrated Resistance Factors for Service Limit State using $3^{\text {rd }}$ Option

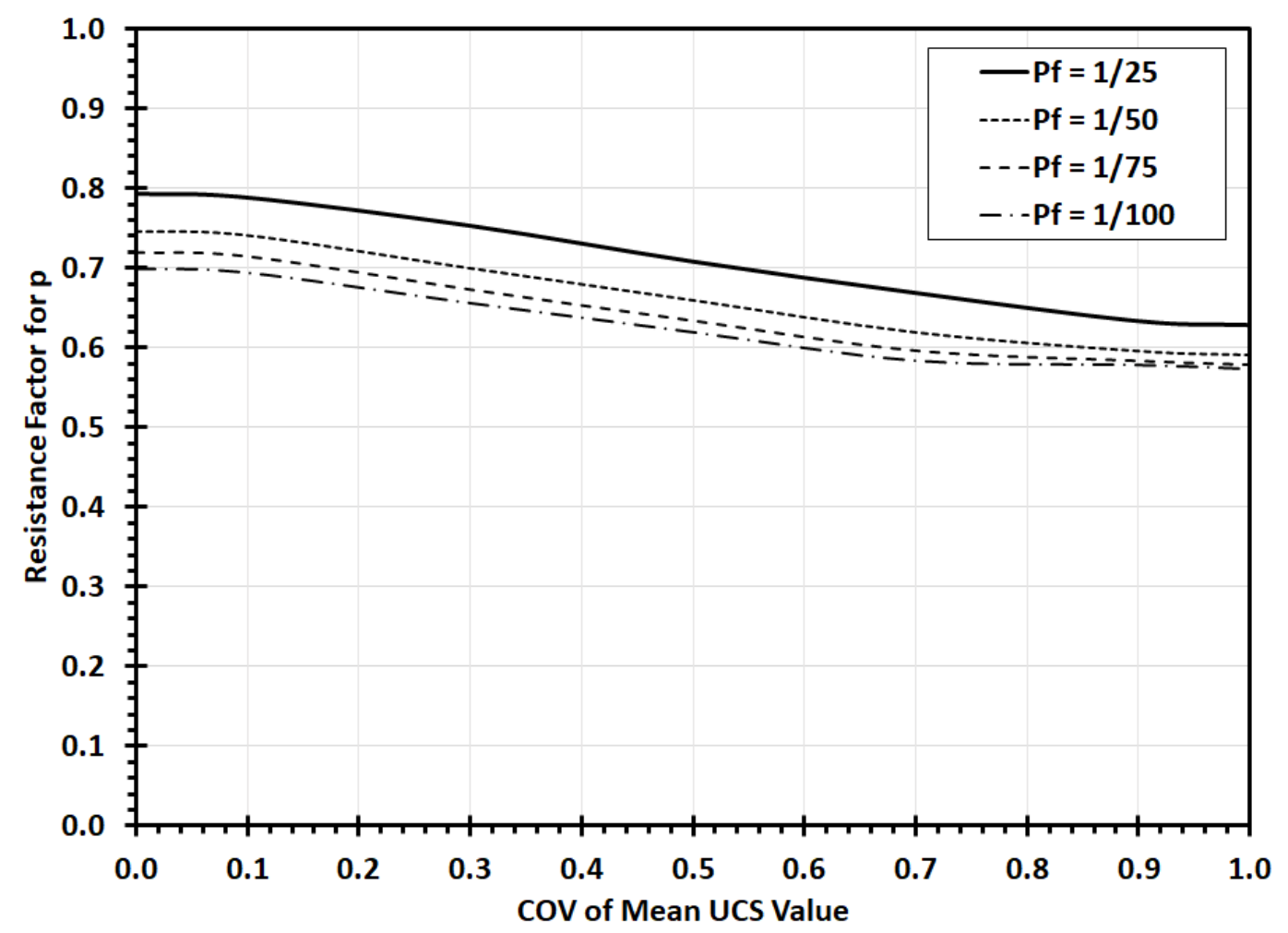

Figure 6.16 - Calibrated Resistance Factors for Service Limit State using $4^{\text {th }}$ Option 


\subsubsection{Comparison between Four Options and Recommended Resistance Factors}

The probabilistic parameters and how they are assigned to each element of the drilled shaft have been summarized in Table 6.10. All the four options are using the same number of simulations equals to 10,000 and number of elements for drilled shaft modelling equals to 200, as it will be discussed lately in Section 0 .

It has been shown from the results of resistance factors Figure 6.17 that the resistance factors from Option 1 are smallest, increasing with Option 2 to Option 3 and highest with Option 4. The reason should relate to the fact that Option 1 is using totally COLLECTIVE while Option 4 is using totally INDIVIDUAL assigning the variability of UCS and p-y curves. Assigning collectively means averaging the variability of probabilistic parameters and could decrease the calibrated resistance factors.

Table 6.10 - Summary of probabilistic parameters assignments for all four options

\begin{tabular}{|c|c|c|c|c|c|c|c|c|c|}
\hline \multirow[b]{3}{*}{ Option } & \multirow{3}{*}{$\begin{array}{l}\text { Number } \\
\text { of } \\
\text { Simulations }\end{array}$} & \multirow{3}{*}{$\begin{array}{l}\text { Number } \\
\text { of Nodes }\end{array}$} & \multicolumn{7}{|c|}{ Probabilistic Parameters } \\
\hline & & & \multicolumn{2}{|c|}{ Bending Stiffness EI } & \multicolumn{2}{|c|}{ Soil Strength UCS } & \multicolumn{3}{|c|}{ p-y curve models } \\
\hline & & & cov & m_El_array size & $\operatorname{cov}$ & m_UCS_array size & $\begin{array}{c}\text { correlated } \\
\text { avgSTD }\end{array}$ & $\begin{array}{c}\text { probability } \\
\text { factor }\end{array}$ & $\begin{array}{c}\text { probability } \\
\text { factor } \\
\text { array size }\end{array}$ \\
\hline COL_UCS & & & & & & & & & \\
\hline COL_p-y & 10,000 & 201 & 0.2 & $10000 \times 1$ & $0.1-0.9$ & $10000 \times 1$ & 1270 & $0-1$ & $10000 \times 1$ \\
\hline $\begin{array}{l}\text { IND_UCS } \\
\&\end{array}$ & & & & & & & & & \\
\hline COL_p-y & 10,000 & 201 & 0.2 & $10000 \times 1$ & $0.1-0.9$ & $10000 \times 201$ & 1270 & $0-1$ & $10000 \times 1$ \\
\hline $\begin{array}{l}\text { COL_UCS } \\
\&\end{array}$ & & & & & & & & & \\
\hline IND_p-y & 10,000 & 201 & 0.2 & $10000 \times 1$ & $0.1-0.9$ & $10000 \times 1$ & 1270 & $0-1$ & $10000 \times 201$ \\
\hline $\begin{array}{l}\text { IND_UCS } \\
\& \\
\text { IND p-y }\end{array}$ & 10,000 & 201 & 07 & $10000 \times 1$ 1 & $01-0.9$ & $10000 \times 201$ 工 & 1270 & $0-1$ & $10000 \times 201$ \\
\hline
\end{tabular}



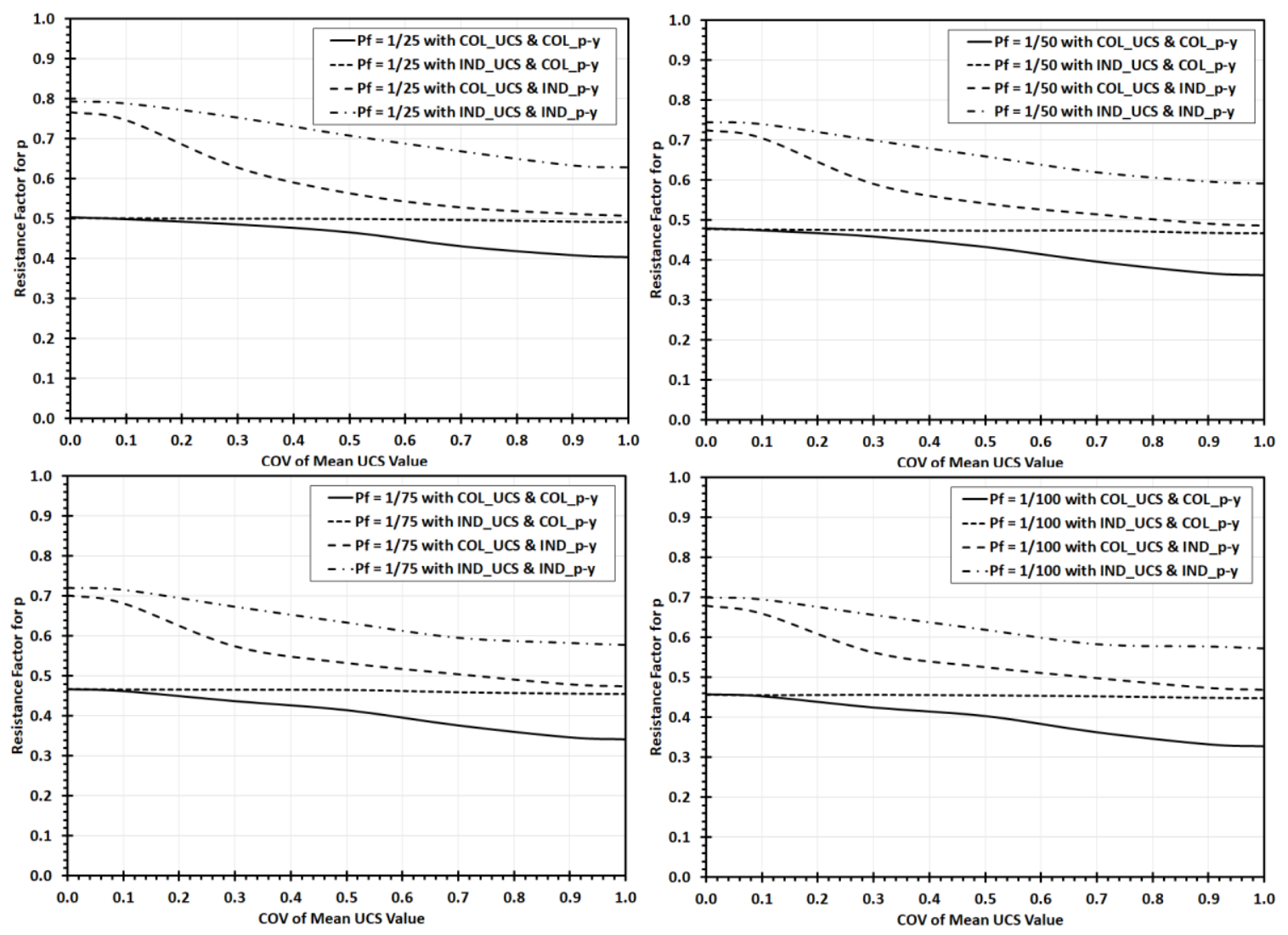

Figure 6.17 - Resistance Factor for different options of assignment probabilistic parameters 
Since soil strength parameter in terms of UCS will likely increase with depth, COLLECTIVELY assigning the variability of UCS through the length of the drilled shaft will eliminate the extreme cases when soil layers above have much higher UCS than deeper layers, which is not reasonable. The other reason is the variability of UCS will be vary from very small range (COV of UCS $=0.1)$ to the very large range $(\mathrm{COV}$ of $U C S=0.9)$. And with great variability of UCS, the disadvantage of using INDIVIDUALLY assigning the variability of UCS will be significant. Thus Option 2 and Option 4 which assign the variability of UCS will not be recommended.

For the $p-y$ curve, assigning the variability of $p$-y model INDIVIDUALLY with each element might represent the lateral soil resistance more reasonable due to the fact the lateral soil response varies dependently on UCS and vertical stress.

In conclusion, Option 3 in which probabilistic parameters for UCS have been assigned COLLECTIVELY and probabilistic parameters for $p-y$ curve have been assigned INDIVIDUALLY will be recommended as the design resistance factors for LRFD at Service Limit State. Those resistance factors are shown in Figure 6.18. 


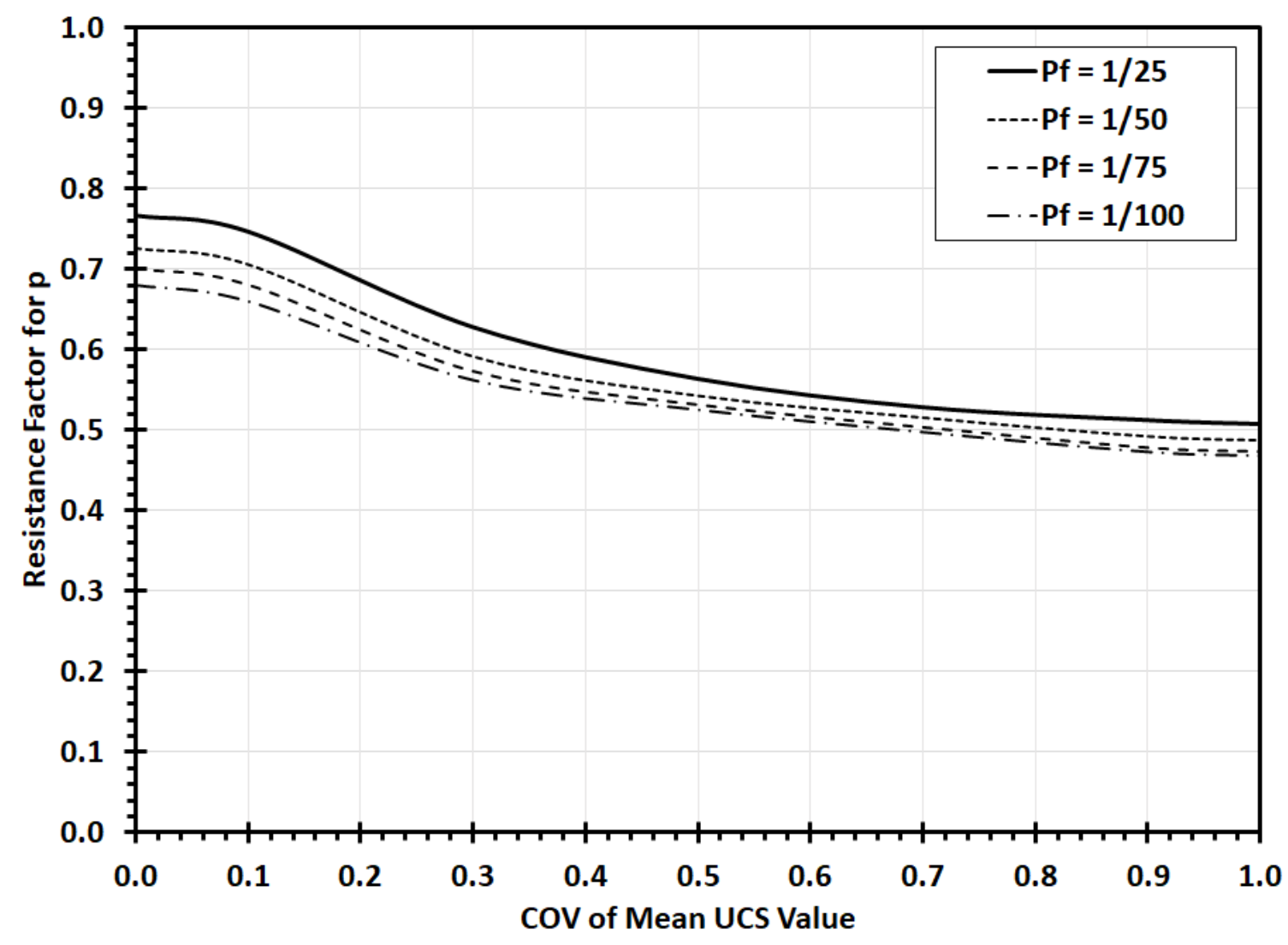

Figure 6.18 - Final Recommended Resistance Factors for Service Limit State Design 


\subsection{Evaluation of other Monte Carlo simulation parameters}

Other Monte Carlo simulation parameters might affect the results of calibrated resistance factors, including number of simulations or number of elements in FEM. In this section, the same procedure for calibration resistance factors using Monte Carlo simulation will be performed with different number of simulations or different number of elements. Details are described as follow.

\subsubsection{Evaluation the Effect of Number of Simulations}

Different number of simulations $(1000 ; 10,000$ and 20,000$)$ have been using with the COLLECTIVE probabilistic parameters for both UCS and p-y curve. The probabilistic parameters are summarized in Table 6.11 and the results of resistance factors are shown in Figure 6.19. It is indicated that there are almost identical resistance factors between the number of simulations equals to 10,000 and 20,000 . However, with number of simulations is equal to 1000 , the resistance factors are decreasing when the variability of UCS is high enough (COV of UCS $\approx 0.7$ to 0.9 ).

That evidence is consistent with the discussion in Section 6.2.1. To provide the most accuracy solution without using too much resources when increasing the number of simulations, 10,000 simulations has been chosen. 
Table 6.11 - Probabilistic Parameters for different number of simulations

\begin{tabular}{|c|c|c|c|c|c|c|c|c|}
\hline \multirow{3}{*}{$\begin{array}{c}\text { Number of } \\
\text { Simulations }\end{array}$} & \multirow{3}{*}{$\begin{array}{c}\text { Number } \\
\text { of } \\
\text { Elements }\end{array}$} & \multicolumn{7}{|c|}{ Probabilistic Parameters } \\
\hline & & \multicolumn{2}{|c|}{ Bending Stiffness El } & \multicolumn{2}{|c|}{ Soil Strength UCS } & \multicolumn{3}{|c|}{ p-y curve models } \\
\hline & & $\mathrm{cov}$ & m_El_array size & cov & m_UCS_array size & $\begin{array}{c}\text { correlated } \\
\text { avgSTD }\end{array}$ & $\begin{array}{c}\text { probability } \\
\text { factor }\end{array}$ & $\begin{array}{c}\text { probability } \\
\text { factor } \\
\text { array size }\end{array}$ \\
\hline 20,000 & 200 & 0.2 & $20000 \times 1$ & $0.1-0.9$ & $20000 \times 1$ & 1270 & $0-1$ & $20000 \times 1$ \\
\hline 10,000 & 200 & 0.2 & $10000 \times 1$ & $0.1-0.9$ & $10000 \times 1$ & 1270 & $0-1$ & $10000 \times 1$ \\
\hline 1,000 & 200 & 0.2 & $1000 \times 1$ & $0.1-0.9$ & $1000 \times 1$ & 1270 & $0-1$ & $1000 \times 1$ \\
\hline
\end{tabular}
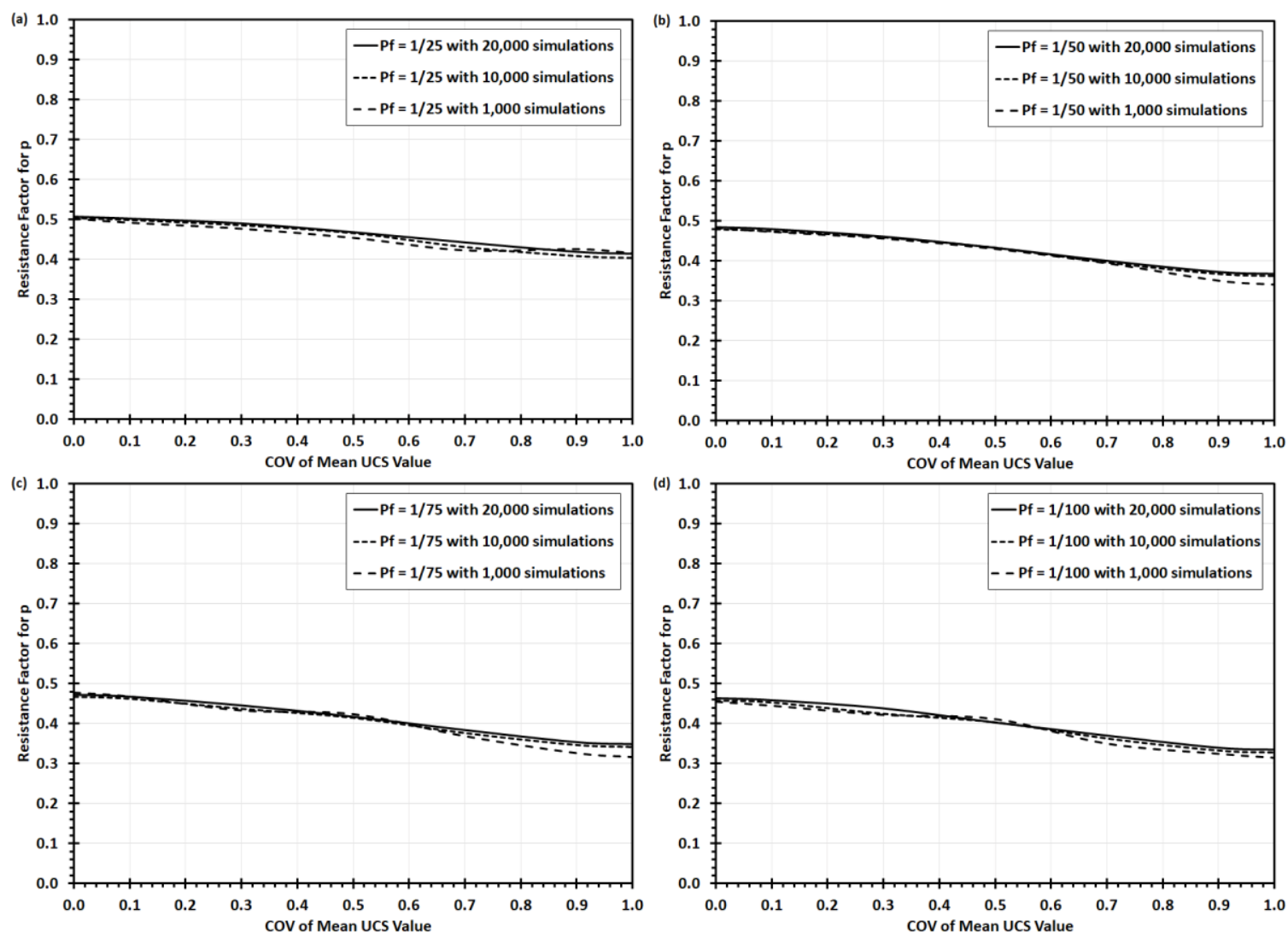

Figure 6.19 - Resistance Factors for different number of simulations 


\subsubsection{Evaluation the Effect of Number of Elements}

Different number of elements to model the drilled shaft (20; 50 and 200 elements) have been using with the COLLECTIVE probabilistic parameters for both UCS and $p-y$ curve. The probabilistic parameters are summarized in Table 6.12 and the results of resistance factors are shown in Figure 6.20.

There is not much difference of resistance factors between the three-different number of elements analyses. However, it has been shown that using 50 elements, the resistance factors curves are decreasing proportional with using 200 elements, which indicates that increasing number of elements does improve the performance of the drilled shaft and therefore does increase the resistance factors.

Using small number of elements (20 elements) shows inconsistent resistance factors with the other cases because of higher resistance factors for small variability of UCS (COV of UCS $\approx 0.1$ to 0.5 ) but smaller resistance factors for large variability of UCS (COV of UCS $\approx 0.5$ to 0.9 ). The reason could be the stiffness of drilled shaft model is not performing as the same in reality.

In conclusion, to provide the most accuracy solution, 200 elements model has been chosen. 
Table 6.12 - Probabilistic Parameters for different number of elements

\begin{tabular}{|c|c|c|c|c|c|c|c|c|}
\hline \multirow{3}{*}{$\begin{array}{c}\text { Number } \\
\text { of } \\
\text { Simulations }\end{array}$} & \multirow{3}{*}{$\begin{array}{c}\text { Number } \\
\text { of } \\
\text { Elements }\end{array}$} & \multicolumn{7}{|c|}{ Probabilistic Parameters } \\
\hline & & \multicolumn{2}{|c|}{ Bending Stiffness EI } & \multicolumn{2}{|c|}{ Soil Strength UCS } & \multicolumn{3}{|c|}{ p-y curve models } \\
\hline & & $\mathrm{cov}$ & m_El_array size & cov & m_UCS_array size & $\begin{array}{c}\text { correlated } \\
\text { avgSTD }\end{array}$ & $\begin{array}{c}\text { probability } \\
\text { factor }\end{array}$ & $\begin{array}{c}\text { probability } \\
\text { factor } \\
\text { array size }\end{array}$ \\
\hline 10,000 & 20 & 0.2 & $10000 \times 1$ & $0.1-0.9$ & $10000 \times 1$ & 1270 & $0-1$ & $10000 \times 1$ \\
\hline 10,000 & 50 & 0.2 & $10000 \times 1$ & $0.1-0.9$ & $10000 \times 1$ & 1270 & $0-1$ & $10000 \times 1$ \\
\hline 10,000 & 200 & 0.2 & $10000 \times 1$ & $0.1-0.9$ & $10000 \times 1$ & 1270 & $0-1$ & $10000 \times 1$ \\
\hline
\end{tabular}
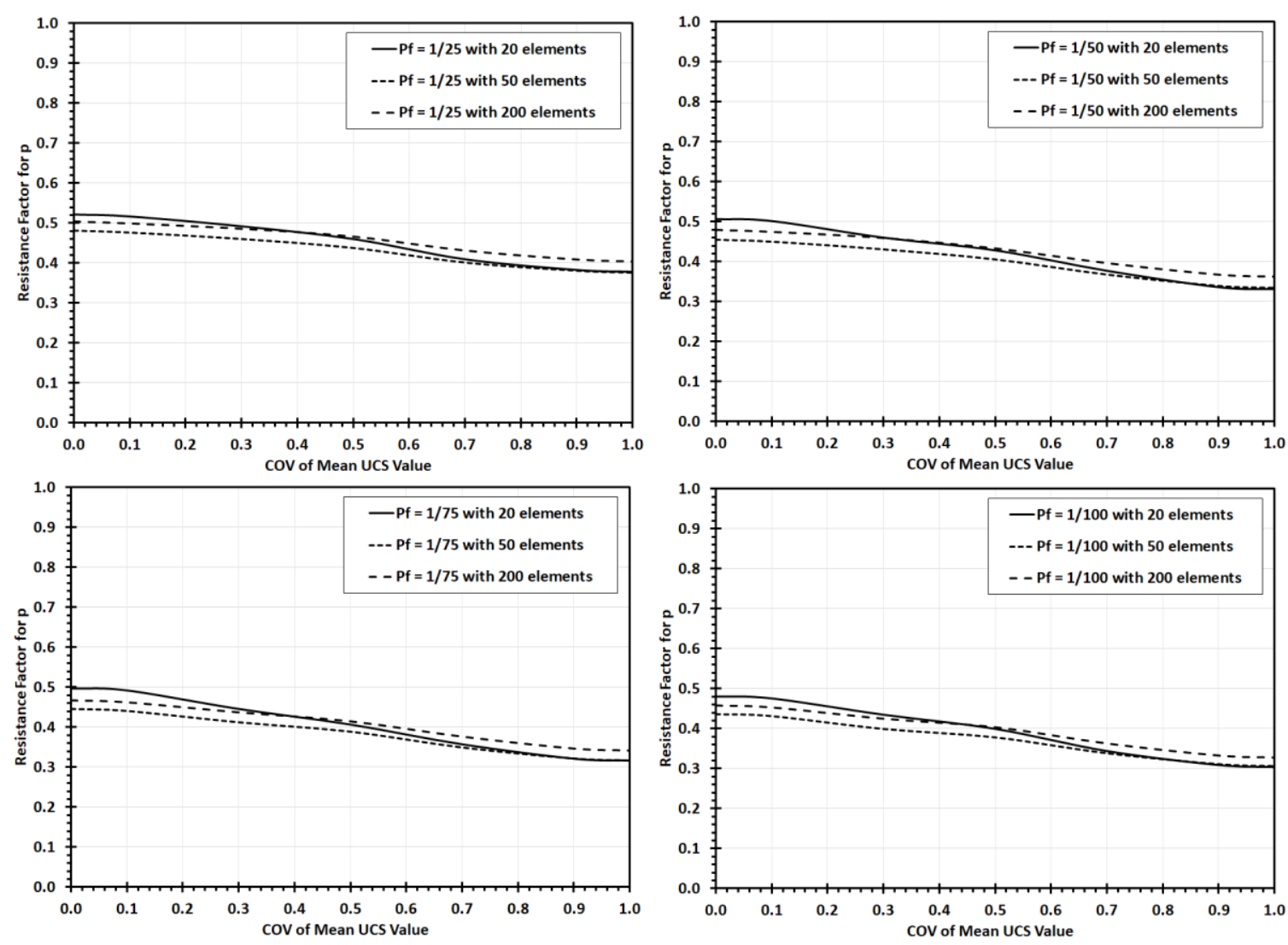

Figure 6.20 - Resistance Factor for different number of elements 


\subsection{Summary}

Resistance factors for LRFD of drilled shafts subjected to lateral loading at service limit state have been calibrated using probabilistic analysis. The deterministic and probabilistic variables used for probabilistic analysis through Monte Carlo simulation include load, shaft length, geomaterial strength $(U C S)$, non-linear bending stiffness $(E I)$, ultimate lateral soil response $\left(P_{u l t}\right)$, initial slope of $\mathrm{p}$-y curve $\left(K_{p y}\right)$ and the $\mathrm{p}$-y curve itself, as presented in Table 6.8.

Different approaches have been proposed to model the variability and uncertainty in $\mathrm{p}-\mathrm{y}$ responses using ultimate lateral soil response $\left(P_{u l t}\right)$, initial slope of $\mathrm{p}$-y curve $\left(K_{p y}\right)$ and the $p$-y curve itself. Approach 3 shows better predicted variability of $p$-y curves, which is matching closer with observed p-y responses, compared to Approach 1 and 2. Finally, Approach 3 using selected standard deviation of the $p-y$ curve has been chosen to model the total variability and uncertainty in $p-y$ responses, used in Monte Carlo simulation.

Different options to assign the probabilistic parameters to each element of the drilled shaft have been discussed. Probabilistic parameter for geomaterial strength $\left(C O V_{U C S}\right)$ will likely increase with depth, thus collectively assigning the variability of UCS through the length of the drilled shaft will eliminate the extreme cases when soil layers above have much higher UCS than deeper layers, which is not reasonable. For the $\mathrm{p}-\mathrm{y}$ curve, assigning the variability of $p-y$ model individually with each element represent the lateral soil resistance more reasonable due to the fact the lateral soil response varies dependently on UCS and depth or vertical stress. In conclusion, Option 3 in which 
probabilistic parameters for UCS have been assigned collectively and probabilistic parameters for $p$-y curve have been assigned individually will be recommended to use in Monte Carlo simulation.

Monte-Carlo simulation produces the displacement histogram. Then, from the histogram, a specific value of displacement that associates with the target probability of failure $P_{f}$ is determined. After that, a $p$-multiplier, which is used to provide the factor lateral soil resistance from the input $p$-y curve, will be optimized based on matching the factored displacement with the specific value of displacement associated with the target probability of failure $P_{f}$. The resistance factor for LRFD of drilled shafts subjected to lateral loading at Service Limit State $\left(\phi_{S L S}\right)$ is equal to that optimized $p$-multiplier.

The proposed resistance factors for LRFD of drilled shafts subjected to lateral loading at Service Limit State have been shown in Figure 6.18. 


\section{CHAPTER 7. APPLICATION OF THE PROPOSED LRFD PROCEDURE}

This chapter illustrates the application of the proposed LRFD procedure for drilled shaft subjected to lateral loading at service limit state using the calibrated resistance factors based on Monte Carlo simulations presented in Chapter 6. Moreover, the comparison of the proposed procedure to alternative procedures is provided.

\subsection{Implementation of Proposed LRFD Procedure for Service Limit State}

The key steps of the design procedure are presented in Section 6.1. In this section, a more detailed LRFD procedure using the proposed resistance factor chart is presented. The proposed design procedure relies on direct comparison between factored shaft head displacement and allowable displacement. The steps for the proposed design procedure are:

1. Develop drilled shaft characteristics in terms of shaft dimensions and amount of reinforcement steel that satisfy the strength limit state.

2. Select resistance factor $\left(\phi_{p-y}\right.$ or $\left.p_{\text {multiplier }}\right)$ from the proposed resistance factor chart (Figure 6.18). The resistance factor is a function of coefficient of variation of the mean value of uniaxial compressive strength (COV of mean UCS) and target probability of failure $\left(P_{f}\right)$.

3. Calculate factored $p-y$ curves for each individual stratum. First, the ultimate lateral soil resistance $\left(P_{u l t}\right)$ and the initial slope of p-y curve $\left(K_{p y}\right)$ are calculated from Eq. 5.6 and Eq. 5.7, respectively. Then the lateral soil 
resistance $(p)$ are generated from Eq. 5.1. The factored lateral soil resistance $\left(p^{*}\right)$ is calculated from the lateral soil resistance $(p)$ multiply by the resistance factor $\left(\phi_{p-y}\right)$, according to Eq. 6.1.

4. Calculate the factored shaft head displacement $\left(y^{*}\right)$ using the factored $\mathrm{p}-\mathrm{y}$ curves for the appropriate factored load and drilled shaft characteristics established in Step 1. This step could be accomplished using the computer code developed for the present project or using L-Pile or other commercial software that allows for user defined $p-y$ curves.

5. The factored shaft head displacement $\left(y^{*}\right)$ computed in Step 4 is then compared to the allowable shaft head displacement $\left(y_{a}\right)$ to determine whether the service limit state is satisfied. If the factored shaft head displacement is less than the allowable displacement, the service limit state is satisfied. The probability of having shaft head displacement that exceed the allowable displacement is less than or equal to the target probability of failure. If the factored shaft head displacement is greater than the allowable settlement, couple improving methods can be considered includes increasing shaft stiffness and/or decreasing the variability of uniaxial compressive strength. After that, repeating steps 2 through 5 until the factored shaft head displacement is less than the allowable displacement, thereby completing the design procedure for Load and Resistance Factor Design at Service Limit State. 
In the above proposed procedure, the resistance factors have been obtained from the recommended chart presented in Chapter 6 , based on the target probability of failure and the variability of soils strength. The design procedure uses the resistance factors developed from proposed lateral load-transfer model derived empirically from lateral field testing data on shale. However, the proposed design procedure can be used for any soil/shale that shows similar lateral load-transfer characteristics. The analyses principles can be further applied for any type of soil or rock as long as its lateral load transfer models and the calibrated resistance factors are given.

\subsection{Example Definition}

Couple of examples are presented to illustrate the design procedure for load and resistance factor design of drilled shafts subjected to lateral loading at service limit state. All examples are based on the lateral load test on drilled shaft number W-1 at Warrensburg testing site as shown in Figure 7.1. 


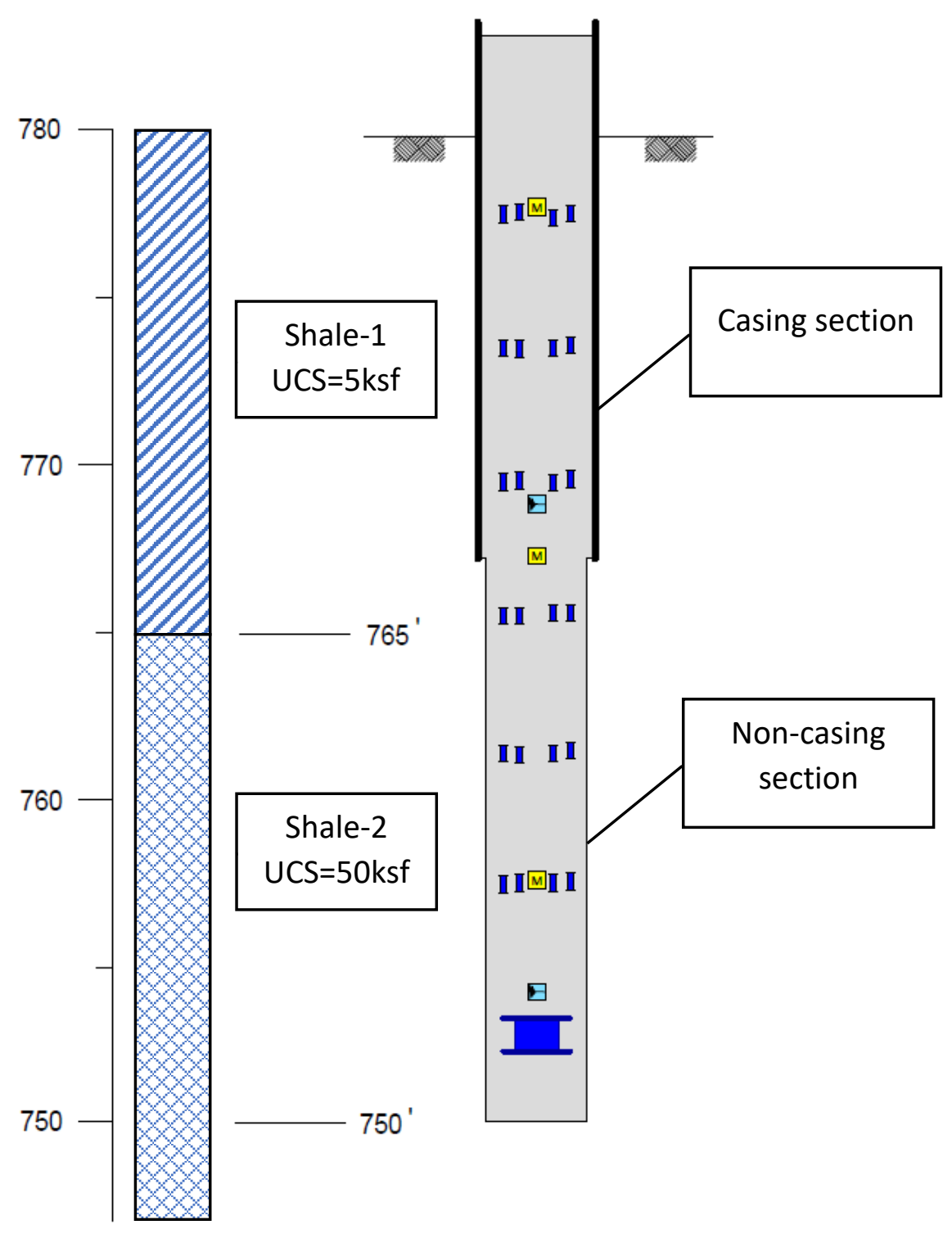

Figure 7.1 - Drilled shaft profile for example

The length of drilled shaft is assumed to be equal to 33 feet. The top of shaft is 3 feet above ground surface. Soil layers include the soft shale layer (Shale-1) and stiff shale layer (Shale-2). Shale-1 has the uniaxial compression strength (UCS) is equal to $5 \mathrm{ksf}$. Depth from ground surface to bottom of Shale-1 layer is equal to 12 feet. Shale- 2 has the UCS is equal to 50ksf. Depth of Shale-2 layer is equal or greater than 50 feet. The shaft consists 
of permanent casing section and non-casing section, which are summarized in Table 7.1 and Table 7.2.

The drilled shaft has been subjected to lateral load only (no axial load and no bending moment) with magnitude is equal to 210 kips. The target probability of failure equals to $1 / 25$ will be assumed for this example.

Table 7.1 - Casing Section Properties

\begin{tabular}{ccc}
\hline Length of Casing Section & 15 & $\mathrm{ft}$. \\
Outer Diameter of Casing & 42 & $\mathrm{in}$. \\
Casing Wall Thickness & 0.25 & $\mathrm{in}$. \\
Cross-sectional Area of Steel Casing & 32.79 & $\mathrm{in}^{2}$ \\
Yield Stress of Casing & 36 & $\mathrm{ksi}$. \\
Elastic Modulus of Casing & 29000 & $\mathrm{ksi}$. \\
\hline Number of Reinforcing Bars & 16 & - \\
Bar Size according to US Standard & $\# 10$ & - \\
Area of Single Reinforcing Bar & 1.27 & $\mathrm{in}^{2}$ \\
Cross-sectional Area of all Reinforcing Bars & 20.32 & $\mathrm{in}^{2}$ \\
Yield Stress of Reinforcing Bars & 60 & $\mathrm{ksi}$. \\
Elastic Modulus of Reinforcing Bars & 29000 & $\mathrm{ksi}^{2}$ \\
\hline Area of Concrete & 1332.33 & $\mathrm{in}^{2}$ \\
Compressive Strength of Concrete & 5.942 & $\mathrm{ksi}^{2}$ \\
Modulus of Elasticity of Concrete & 4393.81 & $\mathrm{ksi}^{2}$ \\
\hline Area of All Steel (Casing and Bars) & 53.11 & $\mathrm{in}^{2}$ \\
Area Ratio of All Steel & 3.99 & $\%$ \\
\hline
\end{tabular}


Table 7.2 - Non-Casing Section Properties

\begin{tabular}{ccc}
\hline Length of Non-Casing Section & 18 & $\mathrm{ft}$. \\
Shaft Diameter (Diameter of Non-Casing) & 37.63 & $\mathrm{in.}$ \\
Concrete Cover Thickness & 4.816 & $\mathrm{in}$. \\
\hline Number of Reinforcing Bars & 16 & - \\
Bar Size according to US Standard & $\# 10$ & - \\
Area of Single Reinforcing Bar & 1.27 & $\mathrm{in}^{2}$ \\
Cross-sectional Area of all Reinforcing Bars & 20.32 & $\mathrm{in}^{2}$ \\
Yield Stress of Reinforcing Bars & 60 & $\mathrm{ksi}$. \\
Elastic Modulus of Reinforcing Bars & 29000 & $\mathrm{ksi}$. \\
\hline Area of Concrete & 1112.14 & $\mathrm{in}^{2}$ \\
Compressive Strength of Concrete & 5.942 & $\mathrm{ksi}$ \\
Modulus of Elasticity of Concrete & 4393.81 & $\mathrm{ksi}$ \\
\hline Area Ratio of Steel Reinforcement & 1.83 & $\%$ \\
\hline
\end{tabular}

The non-linear bending stiffness of both casing and non-casing section have been calculated in Chapter 4, as shown in Figure 7.2.

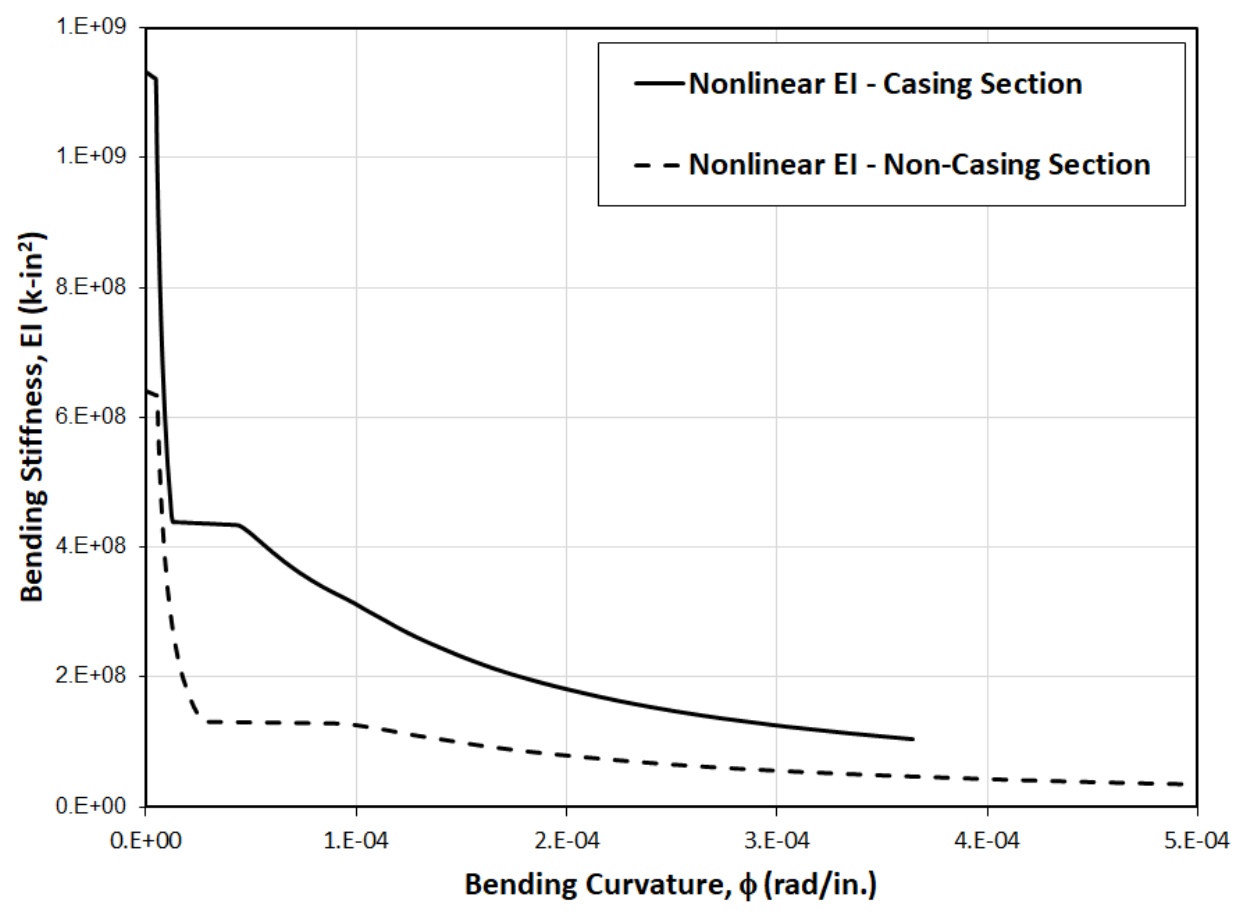

Figure 7.2 - Nonlinear Bending stiffness for Casing and Non-Casing sections 


\subsection{Example 1: Comparison of Proposed and Conventional Design Methods}

Different design methods are used to illustrate the difference between the proposed LRFD procedure and the conventional design method for drilled shaft under lateral loading. The first method is using AASHTO LRFD design procedure and the proposed p-y model developed for this work. The second method is using the proposed LRFD procedure as discussed in Section 7.1. The third one is using AASHTO LRFD design procedure with the conventional models. Summary of each method inputs and results are presented in the following Table 7.3 and Figure 7.3.

Table 7.3 - Example 1: Summary of inputs and results

\begin{tabular}{ccccc}
\hline Example 1: Method \# & & 1 & 2 & 3 \\
\hline Lateral load-transfer model & & proposed & proposed & stiff clay \\
& & model & model & model \\
\hline Lateral Load & kips. & 210 & 210 & 210 \\
Shaft Length & ft. & 33 & 33 & 33 \\
Shaft height above ground & ft. & 3 & 3 & 3 \\
Depth of casing (from ground) & ft. & 12 & 12 & 12 \\
Depth of layer Shale-1 (from ground) & ft. & 15 & 15 & 15 \\
UCS of layer Shale-1 & psf. & 5,000 & 5,000 & 5,000 \\
Depth of layer Shale-2 & ft. & 50 & 50 & 50 \\
UCS of layer Shale-2 & psf. & 50,000 & 50,000 & 50,000 \\
\hline CoV of UcS & - & $\mathbf{0 . 1 8}$ & $\mathbf{0 . 1 8}$ & $\mathbf{0 . 1 8}$ \\
Resistance Factor & - & $\mathbf{1 . 0}$ & $\mathbf{0 . 7}$ & $\mathbf{1 . 0}$ \\
\hline Factored Shaft head displacement $\left(y^{*}\right)$ & in. & 1.08 & 1.98 & 2.21 \\
Shaft head allowable displacement $\left(y_{a}\right)$ & in. & 2.00 & 2.00 & 2.00 \\
SLS Criterion $\left(y^{*} \leq y_{a}\right)$ & - & satisfied & satisfied & not satisfied \\
\hline
\end{tabular}




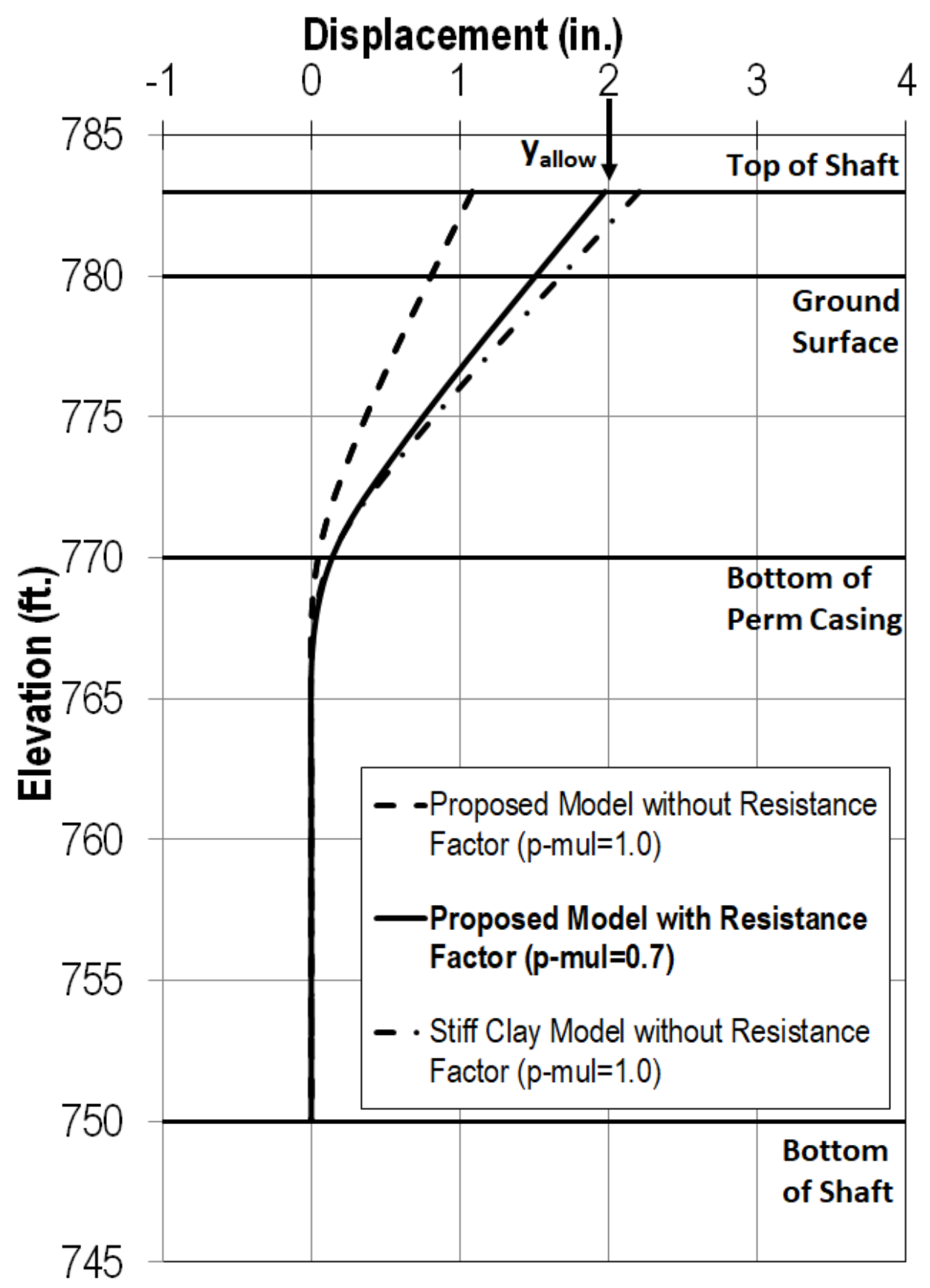

Figure 7.3 - Example 1: Comparison of Proposed and Conventional Design Methods 
According to the results, AASHTO method with conventional stiff clay model produces shaft head displacement equals to $2.21 \mathrm{inch}$, which is greater than either other method and also greater than the allowable displacement ( 2 inch) in this example. Moreover, AASHTO LRFD procedure does not consider the probabilistic calibrated resistance factor in calculation, which means the probability of failure is unknown.

When using the AASHTO provisions with the proposed $p-y$ model, the factored shaft head displacement equals to 1.08 inch, which is the least lateral deflection between three methods. It means that an engineer can reduce the stiffness of the drilled shaft (by using smaller shaft diameter or reducing the amount of reinforcement steels) while still satisfying SLS design criterion. However, by not using the resistance factor in design, AASHTO method with the proposed p-y model does not provide the reliability specifically.

On the other hand, when using the proposed method with the proposed $p-y$ model, the factored shaft head displacement equals to 1.98 inch, which satisfied the SLS design criterion in this example. The proposed method produces an intermediate lateral deflection that has a $1 / 25$ chance of being exceeded. 


\subsection{Example 2: Comparison of Designs using UCS with Different Reliability}

In this example, the variability of UCS has been considered in 3 different levels of reliability to satisfy the design and to take advantage of the economically benefit. Different designs use COV of mean UCS equal to $0.02,0.18$, and 0.60 , which represent a really low value, and typical value, and a really high value of reliability, respectively. Based on the proposed resistance factor chart from Figure 6.18, resistance factors for three different designs are obtained and equal to $0.77,0.70$ and 0.61 . Summary of each design inputs and results are presented in the following Table 7.4 and Figure 7.4.

Table 7.4 - Example 2: Summary of inputs and results

\begin{tabular}{ccccc}
\hline Example 2: Design \# & & 1 & 2 & 3 \\
Lateral load-transfer model & & proposed & proposed & proposed \\
Lateral Load & & model & model & model \\
Shaft Length & kips. & 210 & 210 & 210 \\
Shaft height above ground & ft. & 33 & 33 & 33 \\
Depth of casing (from ground) & ft. & 3 & 3 & 3 \\
Depth of layer Shale-1 (from ground) & ft. & 12 & 12 & 12 \\
UCS of layer Shale-1 & psf. & 5,000 & 5,000 & 5,000 \\
Depth of layer Shale-2 & ft. & 50 & 50 & 50 \\
UCS of layer Shale-2 & psf. & 50,000 & 50,000 & 50,000 \\
\hline Cov of UCS & - & $\mathbf{0 . 0 2}$ & $\mathbf{0 . 1 8}$ & $\mathbf{0 . 3 7}$ \\
Resistance Factor & - & $\mathbf{0 . 7 7}$ & $\mathbf{0 . 7 0}$ & $\mathbf{0 . 6 1}$ \\
\hline Factored Shaft head displacement $\left(y^{*}\right)$ & in. & 1.59 & 1.98 & 3.31 \\
Shaft head allowable displacement $\left(y_{a}\right)$ & in. & 2.00 & 2.00 & 2.00 \\
SLS Criterion $\left(y^{*} \leq y_{a}\right)$ & - & satisfied & satisfied & not satisfied \\
\hline
\end{tabular}




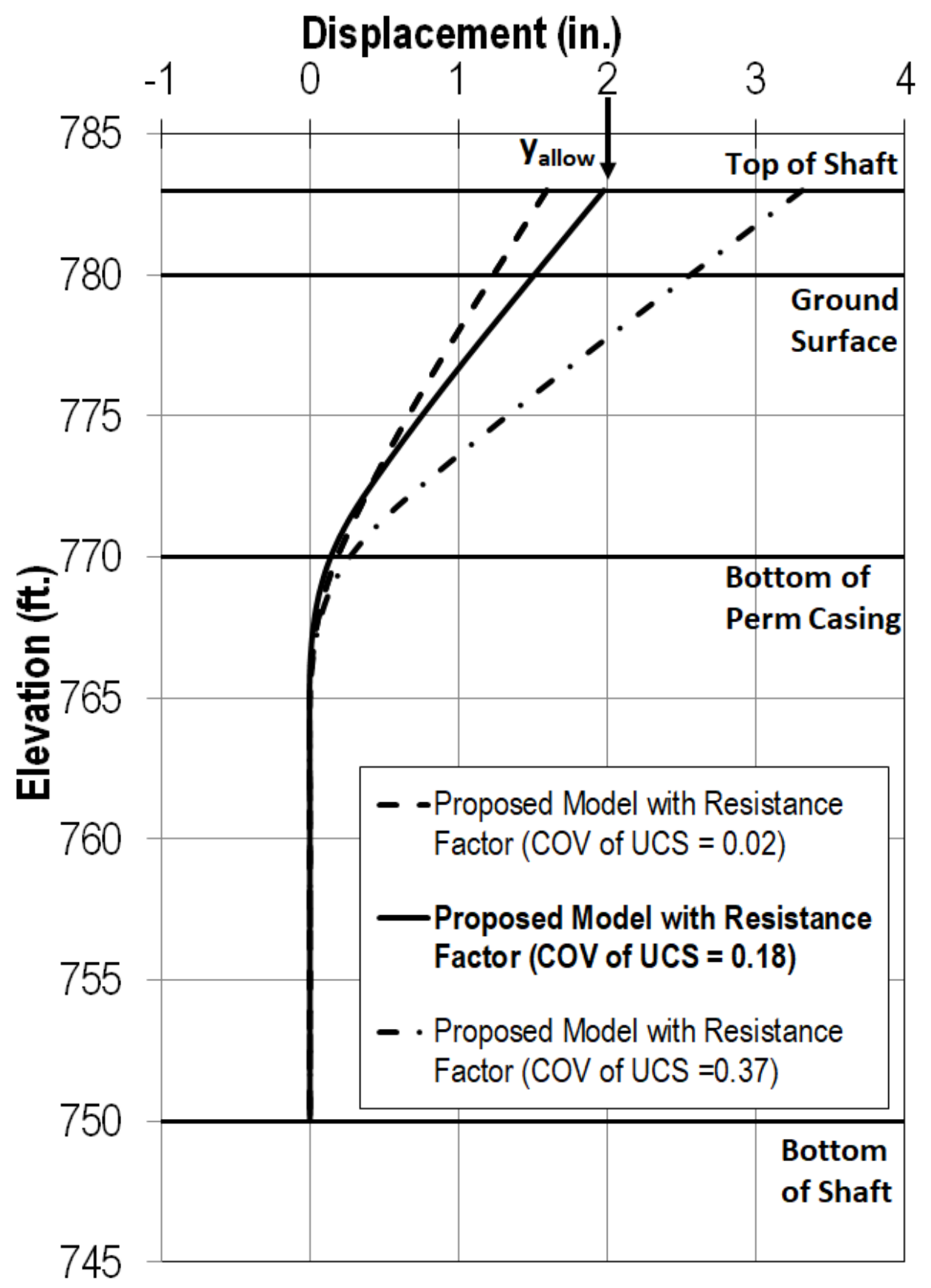

Figure 7.4 - Example 2: Comparison of Design using UCS with Different Reliability 
According to the results, the design with highest value of reliability for UCS (COV of UCS is equal to 0.37 ) produces the biggest factored shaft displacement and in this example, it does not satisfy the SLS design criterion. However, due to the benefit of load and resistance factor design, an engineer can choose to reduce the variability of UCS by running more field/lab soil strength tests to increase the resistance factor as seen the other two designs. Using a higher resistance factor in design means providing more lateral soil resistance, thus reduce the factored lateral displacement.

When comparing the design with very low and typical value of reliability for UCS, it is shown that a higher resistance factor (or lower COV of UCS), a lower factored shaft displacement. However, going from typical to very low COV of UCS, the displacement only reduces from 1.98 inch to 1.59 inch (corresponding to resistance factor increases from 0.70 to 0.77 ), but COV of UCS needs to dramatically drop from 0.18 to 0.02 , which requires a lot of more works and resources. In conclusion, increasing resistance factor by reducing the variability of soil strength (COV of UCS) is recommended in some cases but not always going with economically benefit.

\subsection{Example 3: Comparison of Designs using Different Shaft Stiffness}

The last example using a different way to adjust the load and resistance factor design, by not changing the variability of soils strength but varying the drilled shaft stiffness. Many different methods to vary the shaft stiffness can be considered, such as adjusting the shaft diameter, adjusting the amount of reinforcement steels or using different type of steels. In this example, just by changing the length of casing section, the 
shaft stiffness can be considered differently, since the difference between Casing section and Non-Casing section is very significant according to Figure 7.2.

All the designs in this example use the identical proposed load and resistance factor design procedure with the using of resistance factor is equal to 0.70 , which obtained from Figure 6.15 based on the COV of UCS $=0.18$. The differences between designs are the shaft stiffness since the length of cased section calculated from ground surface is increasing from $10-\mathrm{ft}$ to $12-\mathrm{ft}$ and then 14-ft. Summary of Example-3 designs inputs and results are presented in the following Table 7.5 and Figure 7.5.

Table 7.5 - Example 3: Summary of inputs and results

\begin{tabular}{|c|c|c|c|c|}
\hline Example 3: Design \# & & 1 & 2 & 3 \\
\hline Lateral load-transfer model & & proposed & proposed & proposed \\
\hline Lateral Load & kips. & 210 & 210 & 210 \\
\hline Shaft Length & ft. & 33 & 33 & 33 \\
\hline Shaft height above ground & $\mathrm{ft}$. & 3 & 3 & 3 \\
\hline Depth of casing (from ground) & ft. & 14 & 12 & 10 \\
\hline Depth of layer Shale-1 (from ground) & $\mathrm{ft}$. & 15 & 15 & 15 \\
\hline UCS of layer Shale-1 & psf. & 5,000 & 5,000 & 5,000 \\
\hline Depth of layer Shale-2 & $\mathrm{ft}$. & 50 & 50 & 50 \\
\hline UCS of layer Shale- 2 & psf. & 50,000 & 50,000 & 50,000 \\
\hline COV of UCS & - & 0.18 & 0.18 & 0.18 \\
\hline Resistance Factor & - & 0.70 & 0.70 & 0.70 \\
\hline Factored Shaft head displacement $\left(y^{*}\right)$ & in. & 1.59 & 1.98 & 2.40 \\
\hline Shaft head allowable displacement $\left(y_{a}\right)$ & in. & 2.00 & 2.00 & 2.00 \\
\hline SLS Criterion $\left(y^{*} \leq y_{a}\right)$ & - & satisfied & satisfied & not satisfied \\
\hline
\end{tabular}




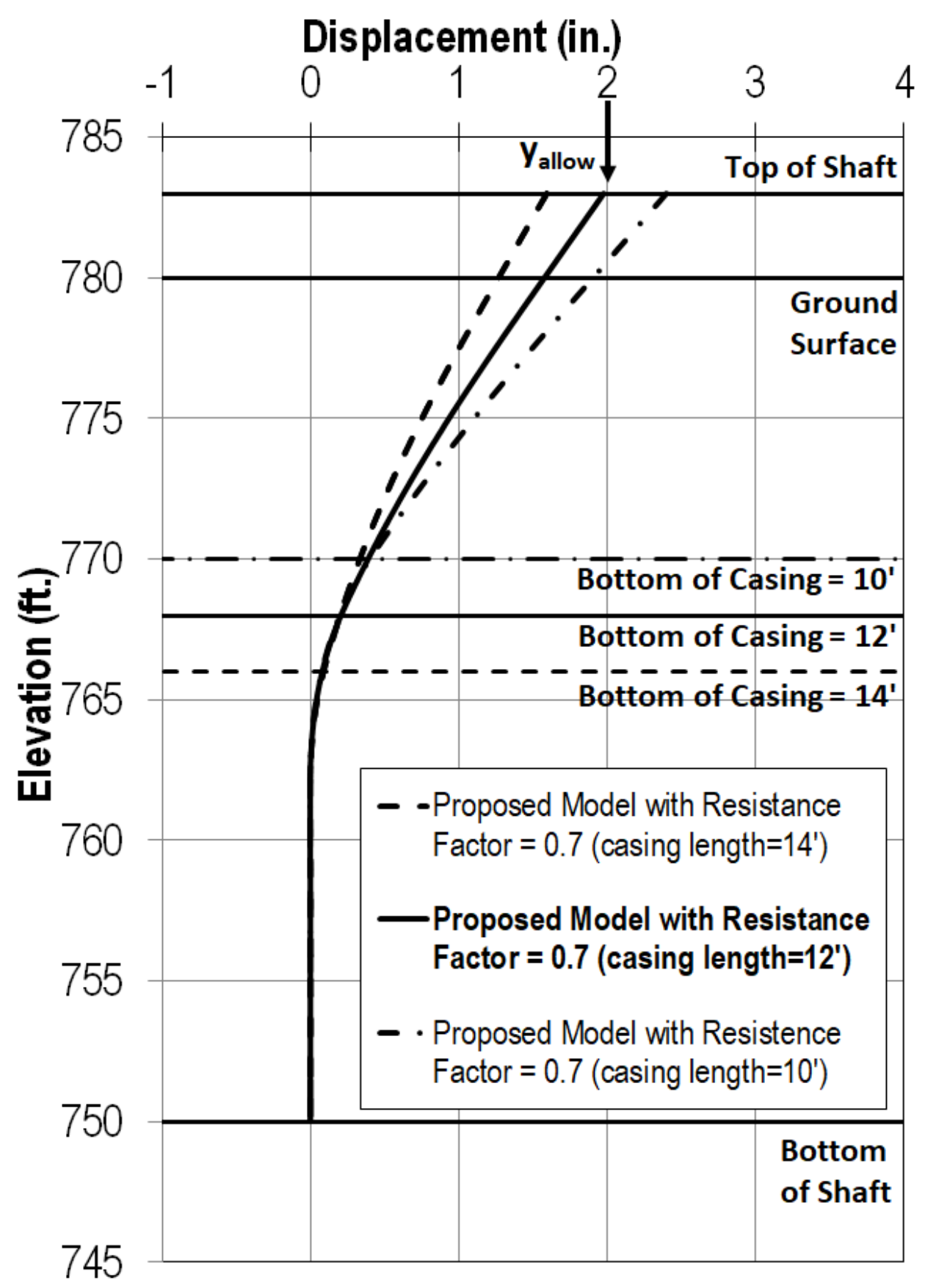

Figure 7.5 - Example 3: Comparison of Designs using Different Shaft Stiffness 
According to the results, design with $10-\mathrm{ft}$ cased section produces the highest factored shaft head displacement, which equals to 2.40 inches and for this example, it does not satisfy the SLS design criterion. By just increasing the cased section length deeper to the soil layer, the factored shaft head displacement can be easily decreasing and therefore the design can satisfy the SLS criterion, as illustrated in the design with 12$\mathrm{ft}$ and 14-ft to produce factored shaft head displacement equals to 1.98 inches and 1.59 inches, respectively.

Example 2 and 3 show different design methods to reduce the factored shaft head displacement and as a consequence, to satisfy the SLS design criterion. It is easier to do that by stiffening the shaft rather than by reducing uncertainty in UCS. However, the method of increasing shaft stiffness can have limitations. First of all, shaft stiffness or shaft properties are calculated from the premier design step using strength limit state criterion. Thus, increasing shaft stiffness to satisfy the service limit state can make the design overconservation for strength limit state. Secondly, increasing stiffness by increasing cased section might not work since it depends on type of soils and capability of equipment. Lastly, applying the changing in stiffness on the very large scale for number of shafts might lead to the huge economical loss. On the other hand, reducing uncertainty in UCS to increase the resistance factor requires extra works, resources and sometimes can be very costly. However, it does not have the limitations as shaft stiffening method. Moreover, depends on the current level of the uncertainty in UCS, this method might work better or not in both aspects: safety design and economical benefit. 


\subsection{Summary}

This chapter illustrates the use of the proposed LRFD method for design of drilled shafts subjected to lateral loading at service limit state. Comparison of results between the proposed method with existing methods has been made. Evaluations on the sensitivity of the results to uncertainty in mean of UCS and to shaft stiffness have been presented. The proposed LRFD procedure creates benefit of using proposed resistance factor as a function of uncertainty in mean of UCS for designing lateral loaded drilled shaft in shale at service limit state. Proposed LRFD method can adjust the variability of soil strength in order to satisfy the service limit state criterion and provide some level of confidence in design, in which the current AASHTO LRFD cannot.

Illustrative examples, which includes the comparison between proposed design and conventional design, along with the effects of modifying shaft stiffness and/or adjusting the variability of soils strength, have been presented to demonstrate the benefits of a new design procedure in both safe-concerned and economic-concerned aspects. For the very high level of uncertainty in UCS, decreasing the variability of soils strength has a big effect in increasing the resistance factor and thus provide a lot of improvement for the SLS design, although it requires extra works on site characterization. However, for typical to very low level of uncertainty in UCS, this effect is little and not cost-effective . On the other hand, increasing shaft stiffness is easy and straight-forward. However, there are limitations on this method such as over-design for strength limit state, effectiveness depends on soil profiles and be economically disadvantage when applying on large numbers of shafts. 


\section{CHAPTER 8. EVALUATION OF PROPOSED SERVICE LIMIT STATE DESIGN METHOD FOR LATERALLY LOADED DRILLED SHAFTS}

This chapter describes evaluation of the proposed service limit state design method for drilled shafts subjected to lateral loading. By comparing the results from three different methods, it is evaluated that the proposed LRFD procedure for design of drilled shafts subjected to lateral loading at the service limit state with resistance factors calibrated from reliability-based analysis more consistently achieves the target reliability than the current AASHTO LRFD procedure.

Nine different cases have been examined to evaluate the proposed load and resistance factor design of drilled shafts subjected to lateral loading at the service limit state.

\subsection{Design Methods Considered}

Three different design methods were considered to evaluate the proposed service limit state LRFD procedure for laterally loaded drilled shafts: the proposed LRFD method for laterally loaded drilled shafts at the Service Limit State using proposed p-y model, the current AASHTO LRFD method using Reese's stiff clay model and the Reliability-based design for laterally loaded drilled shafts at the Service Limit State using proposed $p-y$ model. 
According to the current AASHTO LRFD Bridge Design Specification, the resistance factor for designing of drilled shafts subjected to lateral loading at the Service limit State is equals to 1.0 while the proposed LRFD method for laterally loaded drilled shafts at the Service Limit State uses the probabilistic calibrated resistance factor presented in Chapter 6. (Figure 6.18). Load factors equal to 1.0 were used for both the proposed and AASHTO design methods. Finally, the Reliability-based Design (RBD) method for laterally loaded drilled shafts at the Service Limit State uses probabilistic analyses to determine the displacement with a given reliability. RBD method produces accurate results for all cases and thus is considered to be the reference value for comparison with values from the proposed method and the AASHTO method. Comparisons are made between the three methods in terms of the maximum lateral displacements at shaft head and the probability of failure. 


\subsection{Nine Different Cases to evaluate the proposed LRFD}

Nine different cases were analyzed to evaluate the proposed method for design of drilled shafts subjected to lateral loading at service limit state. All different cases were developed to represent a reasonable range of conditions for what the proposed method might be utilized. And, as such, the cases represent a rational test of the proposed method.

\subsubsection{Structural Characteristics of Drilled Shafts}

The shaft consists of permanent cased section and uncased section, as shown in Figure 8.1. Structural characteristics of cased and uncased sections are summarized in Table 8.1 and Table 8.2.

Table 8.1 - Structural Characteristics for Cased Section

\begin{tabular}{ccc}
\hline Outer Diameter of Cased & 42 & in. \\
Cased Wall Thickness & 0.25 & in. \\
Cross-sectional Area of Steel Cased & 32.79 & $\mathrm{in}^{2}$ \\
Yield Stress of Cased & 36 & $\mathrm{ksi}$. \\
Elastic Modulus of Cased & 29000 & $\mathrm{ksi}$. \\
\hline Number of Reinforcing Bars & 16 & - \\
Bar Size according to US Standard & $\# 10$ & - \\
Area of Single Reinforcing Bar & 1.27 & $\mathrm{in}^{2}$ \\
Cross-sectional Area of all Reinforcing Bars & 20.32 & $\mathrm{in}^{2}$ \\
Yield Stress of Reinforcing Bars & 60 & $\mathrm{ksi}$. \\
Elastic Modulus of Reinforcing Bars & 29000 & $\mathrm{ksi}$. \\
\hline Area of Concrete & 1332.33 & $\mathrm{in}^{2}$ \\
Compressive Strength of Concrete & 5.942 & $\mathrm{ksi}$ \\
Modulus of Elasticity of Concrete & 4393.81 & $\mathrm{ksi}^{2}$ \\
\hline Area of All Steel (Cased and Bars) & 53.11 & $\mathrm{in}^{2}$ \\
Area Ratio of All Steel & 3.99 & $\%$ \\
\hline
\end{tabular}


Table 8.2 - Structural Characteristics for Uncased Section

\begin{tabular}{ccc}
\hline Shaft Diameter (Diameter of Uncased) & 37.63 & in. \\
Concrete Cover Thickness & 4.816 & in. \\
\hline Number of Reinforcing Bars & 16 & - \\
Bar Size according to US Standard & $\# 10$ & - \\
Area of Single Reinforcing Bar & 1.27 & $\mathrm{in}^{2}$ \\
Cross-sectional Area of all Reinforcing Bars & 20.32 & $\mathrm{in}^{2}$ \\
Yield Stress of Reinforcing Bars & 60 & $\mathrm{ksi}$ \\
Elastic Modulus of Reinforcing Bars & 29000 & $\mathrm{ksi}^{2}$ \\
\hline Area of Concrete & 1112.14 & $\mathrm{in}^{2}$ \\
Compressive Strength of Concrete & 5.942 & $\mathrm{ksi}$ \\
Modulus of Elasticity of Concrete & 4393.81 & $\mathrm{ksi}$ \\
\hline Area Ratio of Steel Reinforcement & 1.83 & $\%$ \\
\hline
\end{tabular}

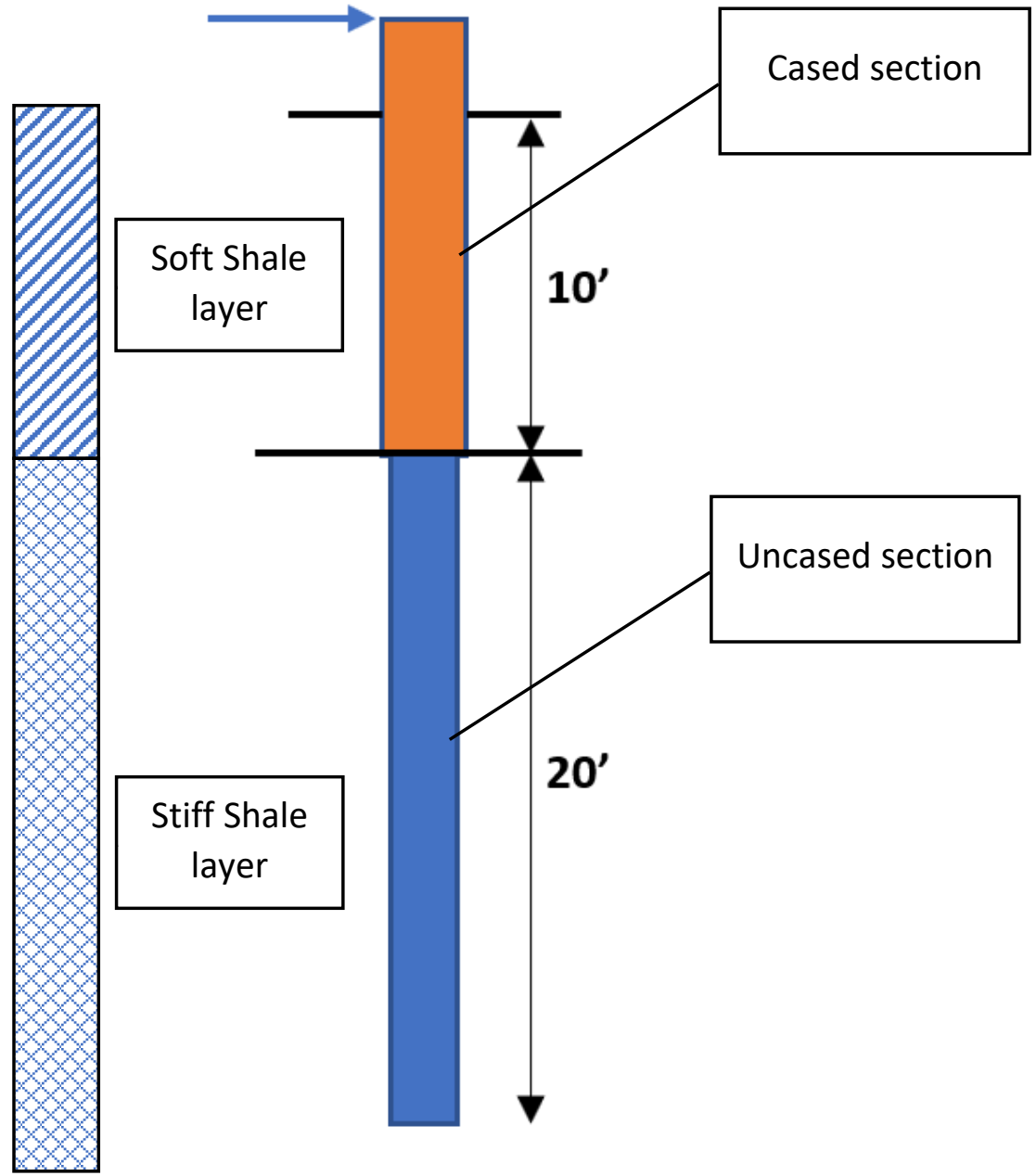

Figure 8.1 - Typical shaft profile with cased and uncased sections 
The non-linear bending stiffness for both the cased and uncased sections have been calculated based on the methodology presented in Chapter 4, as shown in Figure 8.2.

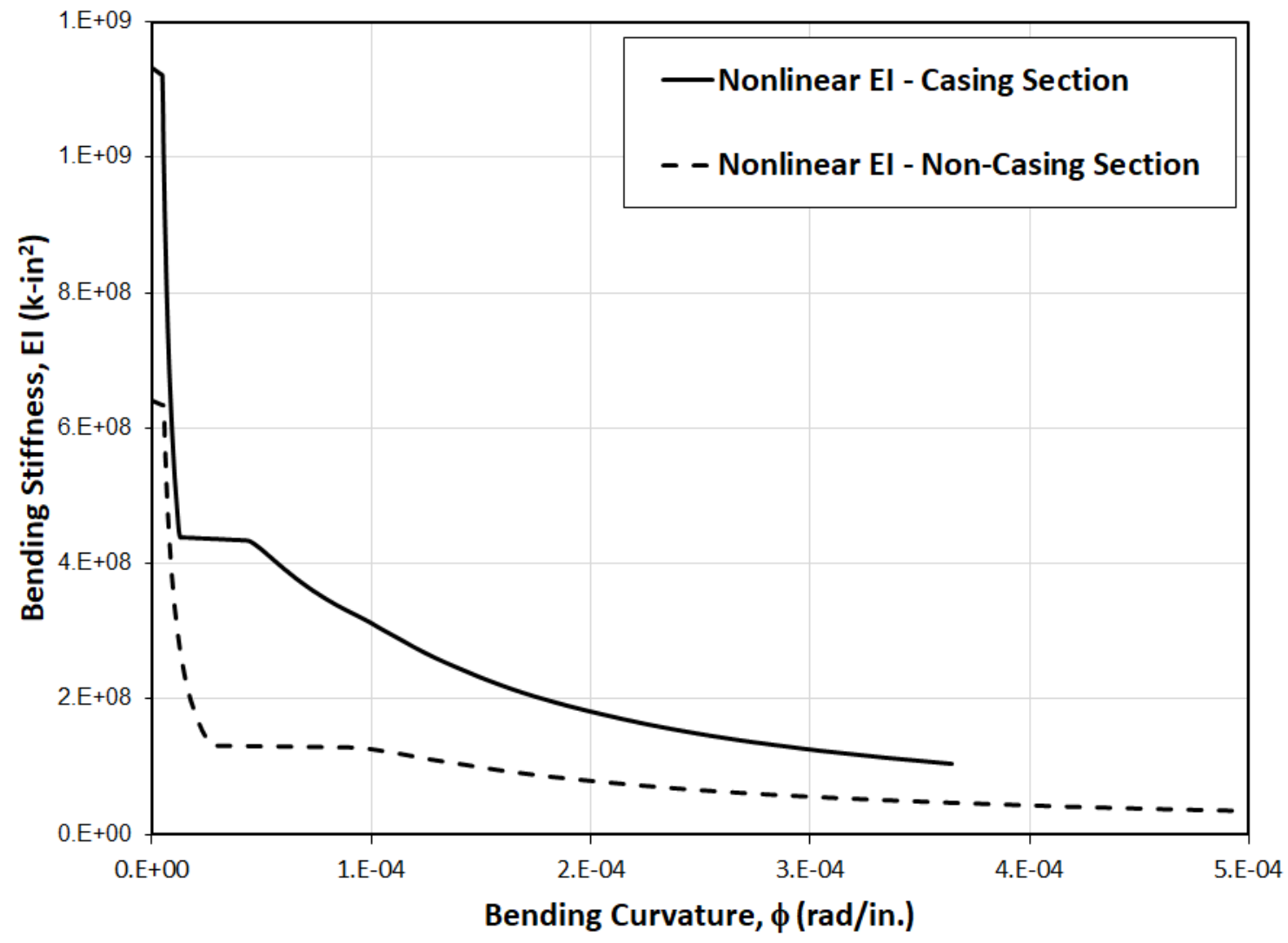

Figure 8.2 - Nonlinear Bending stiffness for Cased and Uncased sections 


\subsubsection{Soil Profile and Properties}

The top of the shaft for each case is 3 feet above ground surface 3 feet. Most of the cases include soft shale layer overlying a stiff shale layer. The softer shale layer generally has the uniaxial compressive strength is equal to $5 \mathrm{ksf}$ while the stiffer shale layer has the uniaxial compressive strength is equal to 50ksf. The two extreme cases are Case S- 8 where the whole soil profile is stiff shale with the uniaxial compressive strength is equal to $25 \mathrm{ksf}$ and Case S-9 where the whole soil profile is very soft shale with the uniaxial compressive strength is equal to $2 \mathrm{ksf}$.

\subsubsection{Configuration of Shaft Lengths \& Soil Layers Depths for Nine Different Cases}

Nine cases are sharing the same shaft structural properties for cased and uncased, but they are different in shaft lengths and soil layers depths, as shown in Figure 8.3. Case S-1 to S-4 are all 30-ft long calculated from the ground surface. However, the depths of soft shale layer increase and the depths of stiff shale layer decrease from S-1 to S-4. Case $\mathrm{S}-5$ is 25 - $\mathrm{ft}$ long from the ground surface with 20 -ft of cased and 5 uncased sections. All the first five cases have the transition from cased to uncased section at exactly the interaction level between soft and stiff shale layers. Case G-6 and G-7 indicate shafts with geotechnical failure, in which both of them have only soft soil layer, with depths of the cased shafts from the ground surface equal to $20-\mathrm{ft}$ and $15-\mathrm{ft}$, respectively. Case S-8 and S-8 have the shaft configuration which is identical with S-2, while soil profiles are different as described above. 


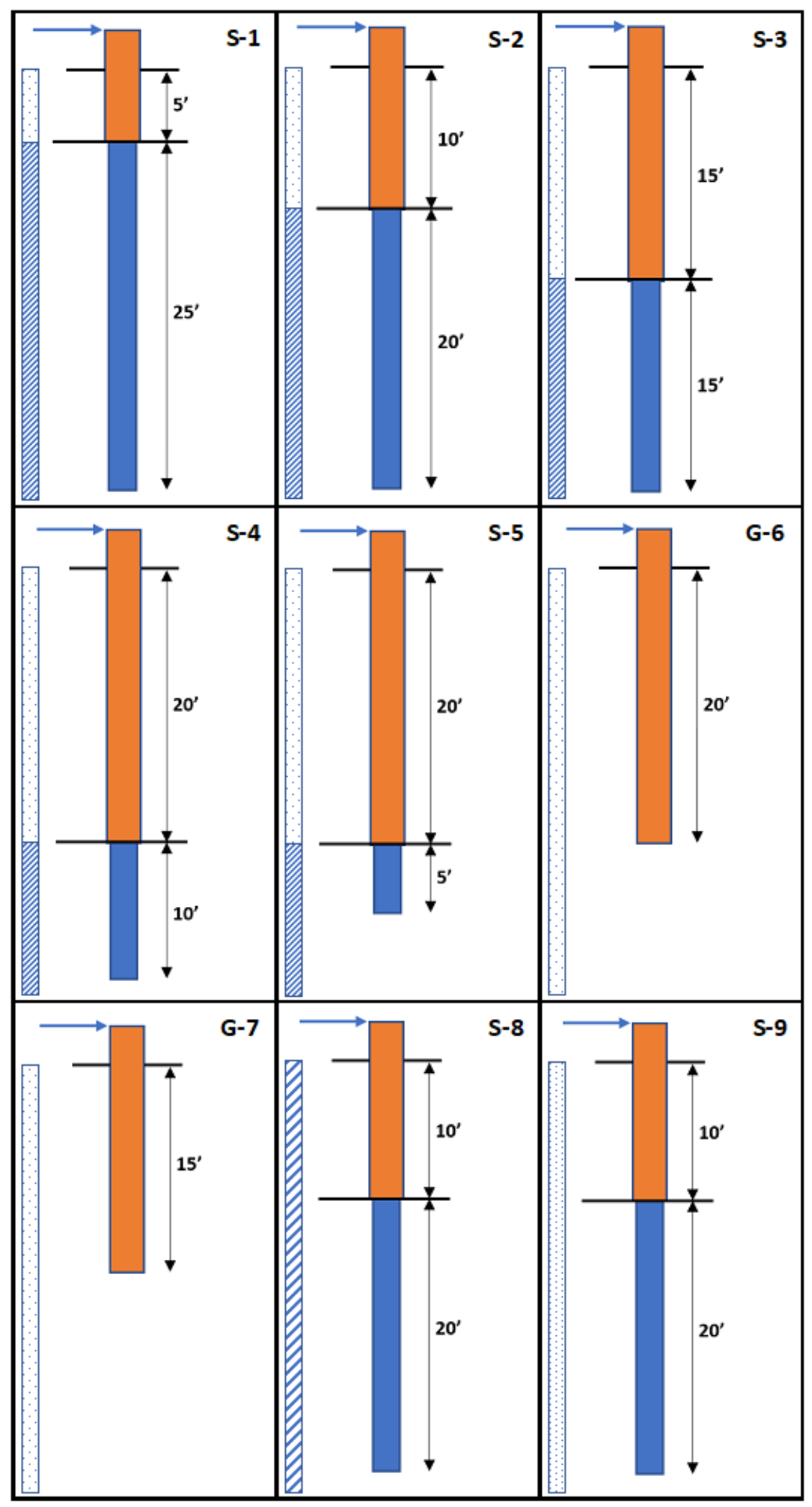

Figure 8.3 - Configuration of shaft lengths and soil layers depths for nine different cases 


\subsection{Procedure and Results}

First of all, the deterministic evaluation for each Case has been made to find the ultimate load $\left(\mathrm{P}_{\mathrm{ult}}\right)$ which is the maximum lateral load the drilled shafted can hold before failure under given conditions. Pult for each case depends on the differences on shaft lengths and soil layers depths. For seven cases, $\mathrm{P}_{\text {ult }}$ is dictated by structural failure of the drilled shafts, while for the remaining two cases, $P_{\text {ult }}$ is governed by geotechnical failure of the shafts.

Analyses were performed for nominal loads equal to $0.4 * P_{\text {ult, }} 0.6^{*} \mathrm{P}_{\text {ult, }}$ and $0.8 * \mathrm{P}_{\text {ult }}$ to evaluate how the loading level influences the results. Besides, analyses were also performed for target probabilities of failure equal to $1 / 25$ and $1 / 100$. Summary of the ultimate lateral load and the lateral loads for nine different Cases has been presented in Table 8.3.

Table 8.3 - Ultimate Lateral Load and Lateral Loads for nine different cases

\begin{tabular}{|c|c|c|c|c|}
\hline Case \# & $\begin{array}{l}\text { Ultimate Lateral } \\
\qquad \begin{array}{c}\text { Load (Pult) } \\
\text { (lbs.) }\end{array}\end{array}$ & $\begin{array}{l}\text { Lateral Load } \\
\text { with } \\
\mathrm{P} / \mathrm{P}_{\text {ult }}=0.4 \\
\text { (lbs.) }\end{array}$ & $\begin{array}{l}\text { Lateral Load } \\
\text { with } \\
\mathrm{P} / \mathrm{P}_{\text {ult }}=0.6 \\
\text { (lbs.) }\end{array}$ & $\begin{array}{c}\text { Lateral Load } \\
\text { with } \\
\mathrm{P} / \mathrm{P}_{\text {ult }}=0.8 \\
\text { (Ibs.) }\end{array}$ \\
\hline S-1 & 280,000 & 112,000 & 168,000 & 224,000 \\
\hline S-2 & 260,000 & 104,000 & 156,000 & 208,000 \\
\hline$S-3$ & 295,000 & 118,000 & 177,000 & 236,000 \\
\hline S-4 & 345,000 & 138,000 & 207,000 & 276,000 \\
\hline S-5 & 350,000 & 140,000 & 210,000 & 280,000 \\
\hline G-6 & 250,000 & 100,000 & 150,000 & 200,000 \\
\hline G-7 & 185,000 & 74,000 & 111,000 & 148,000 \\
\hline$S-8$ & 400,000 & 160,000 & 240,000 & 320,000 \\
\hline$S-9$ & 250,000 & 100,000 & 150,000 & 200,000 \\
\hline
\end{tabular}


Figure 8.4 through Figure 8.9 show results for the three different design methods for Case S-1. Each figure shows a histogram of computed lateral displacements determined from Monte Carlo simulations performed for the RBD method. Values for lateral displacements determined using the proposed design method, the AASHTO design method, and the RBD method are indicated in each figure, along with the associated probability of failure for the computed lateral displacement. Results for all other cases are provided in Appendix D.

The displacement and probability of failure produced from the proposed LRFD method close to the displacement and the target probability of failure from RBD method for the ratio of $P$ over $P_{\text {ult }}$ equals to 0.8 . Reducing the ratio of $P$ over $P_{\text {ult }}$ to 0.6 and then 0.4, displacement and probability of failure produced from the proposed LRFD method tend to underestimate the displacement and the target probability of failure from RBD method. For any ratio of $\mathrm{P}$ over $\mathrm{P}_{\mathrm{ult}}$, displacement obtained from the AASHTO design method always over underestimate the RBD displacement. Moreover, probability of failure obtained from the AASHTO design method does not change depend on the RBD target probability of failure.

Most importantly, for all three load ratios, the displacement and probability of failure obtained from proposed LRFD method are closer to the RBD displacement and target probability of failure than those obtained from AASHTO LRFD method. Thus, the proposed LRFD method consistently achieves the target reliability than the AASHTO LRFD method. 


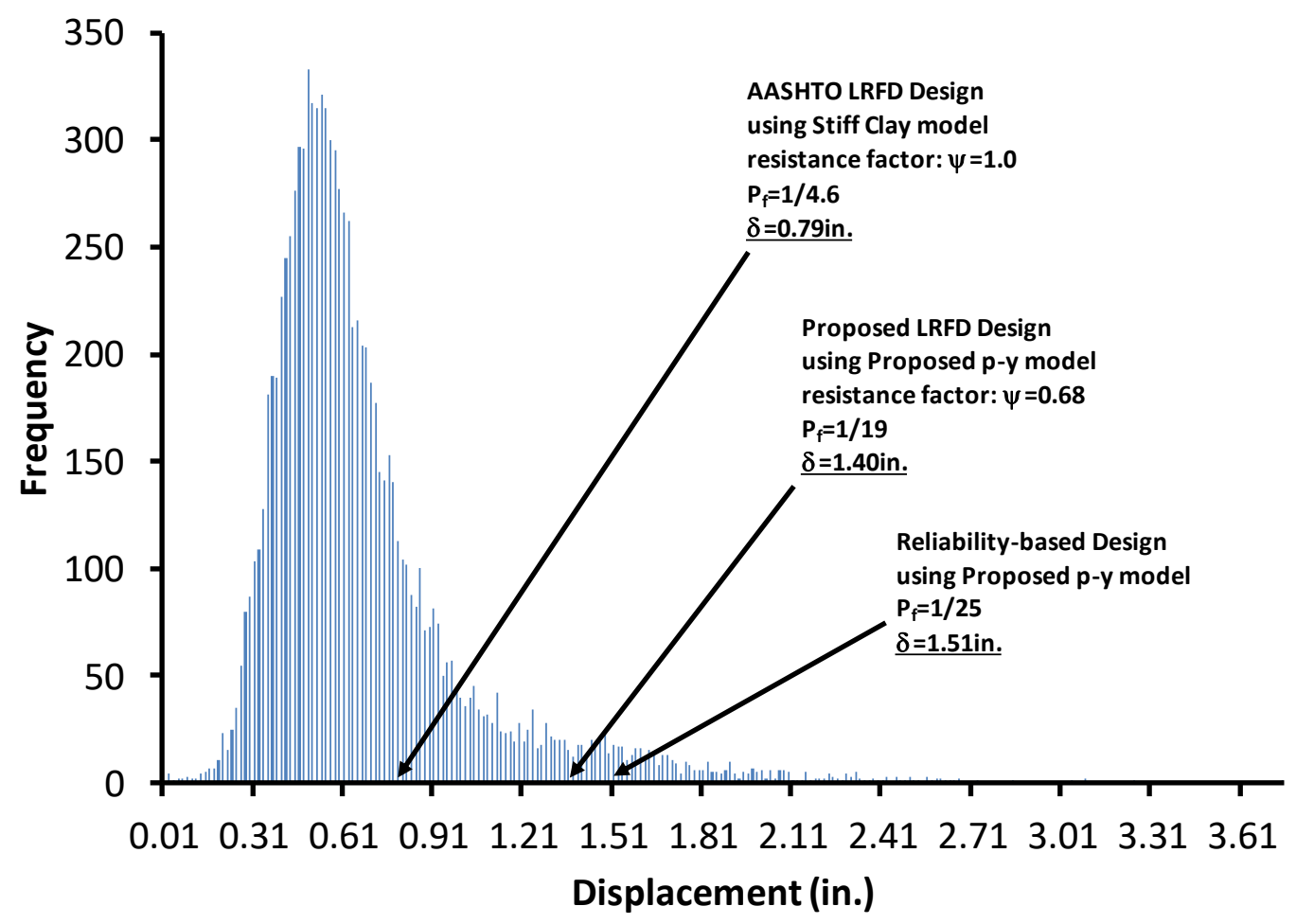

Figure 8.4 - Case S-1 with ratio $P / P_{\text {ult }}=0.8$ and target $P_{f}=1 / 25$

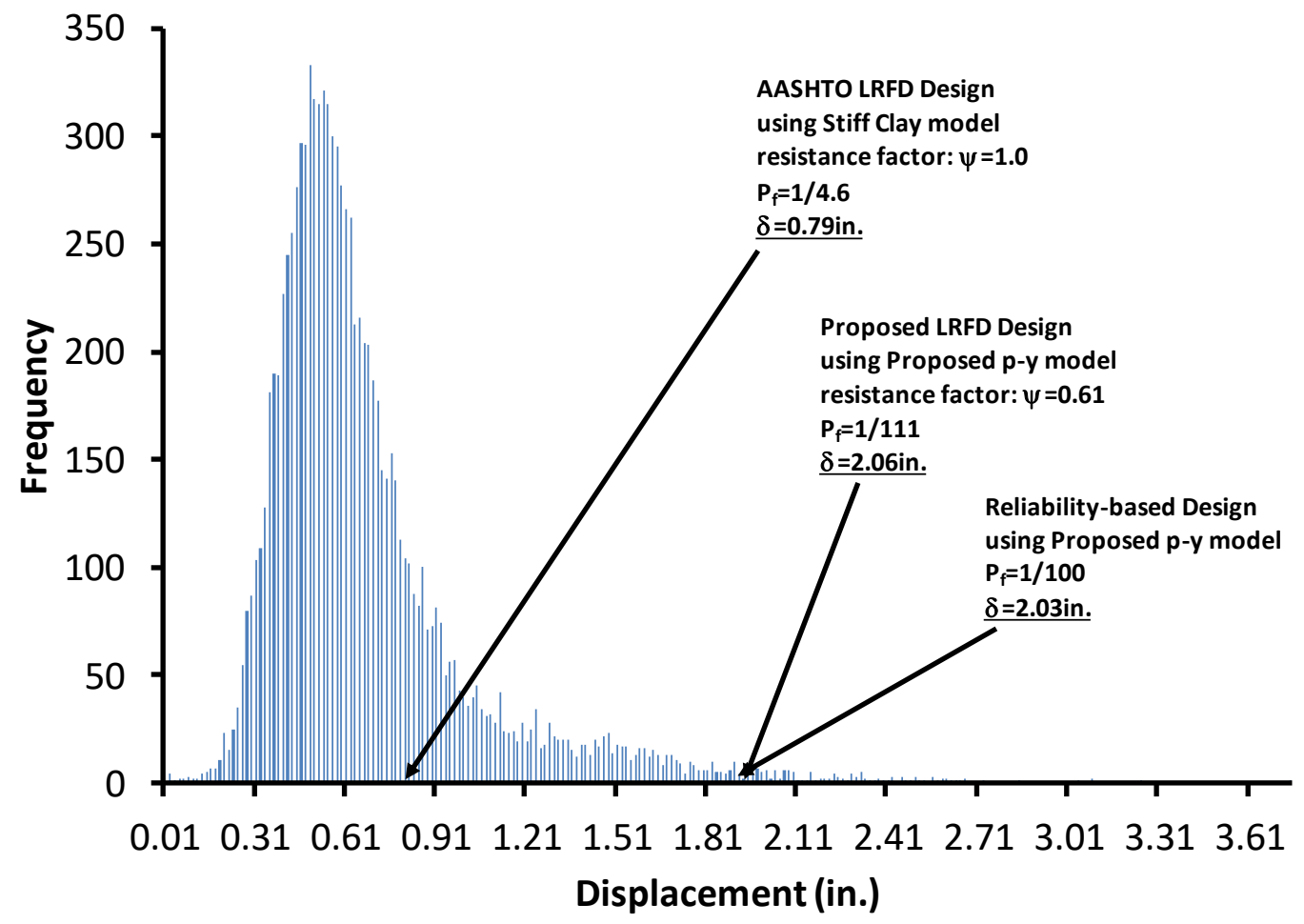

Figure 8.5 - Case S-1 with ratio $P / P_{u l t}=0.8$ and target $P_{f}=1 / 100$ 


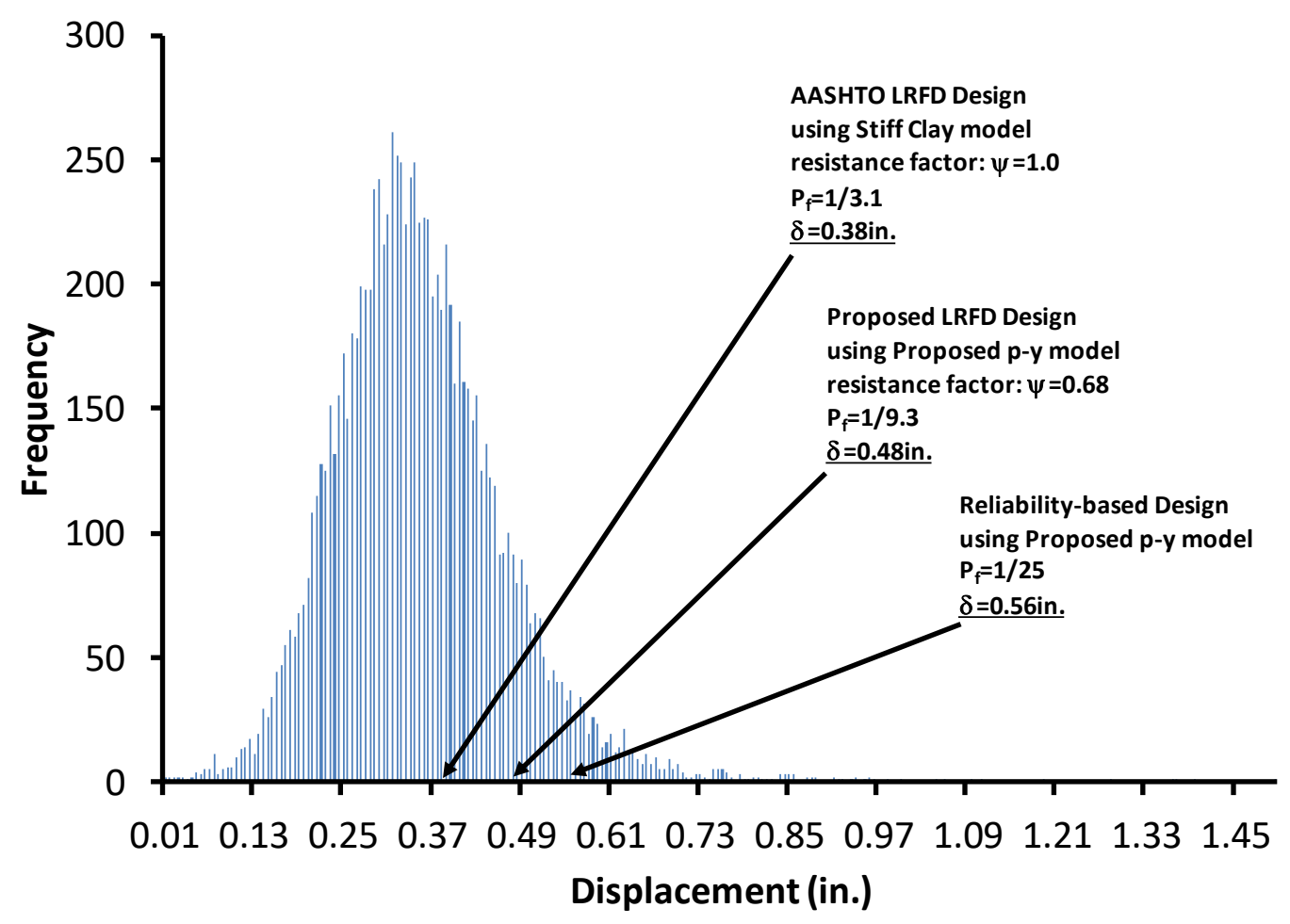

Figure 8.6 - Case S-1 with ratio $P / P_{u l t}=0.6$ and target $P_{f}=1 / 25$

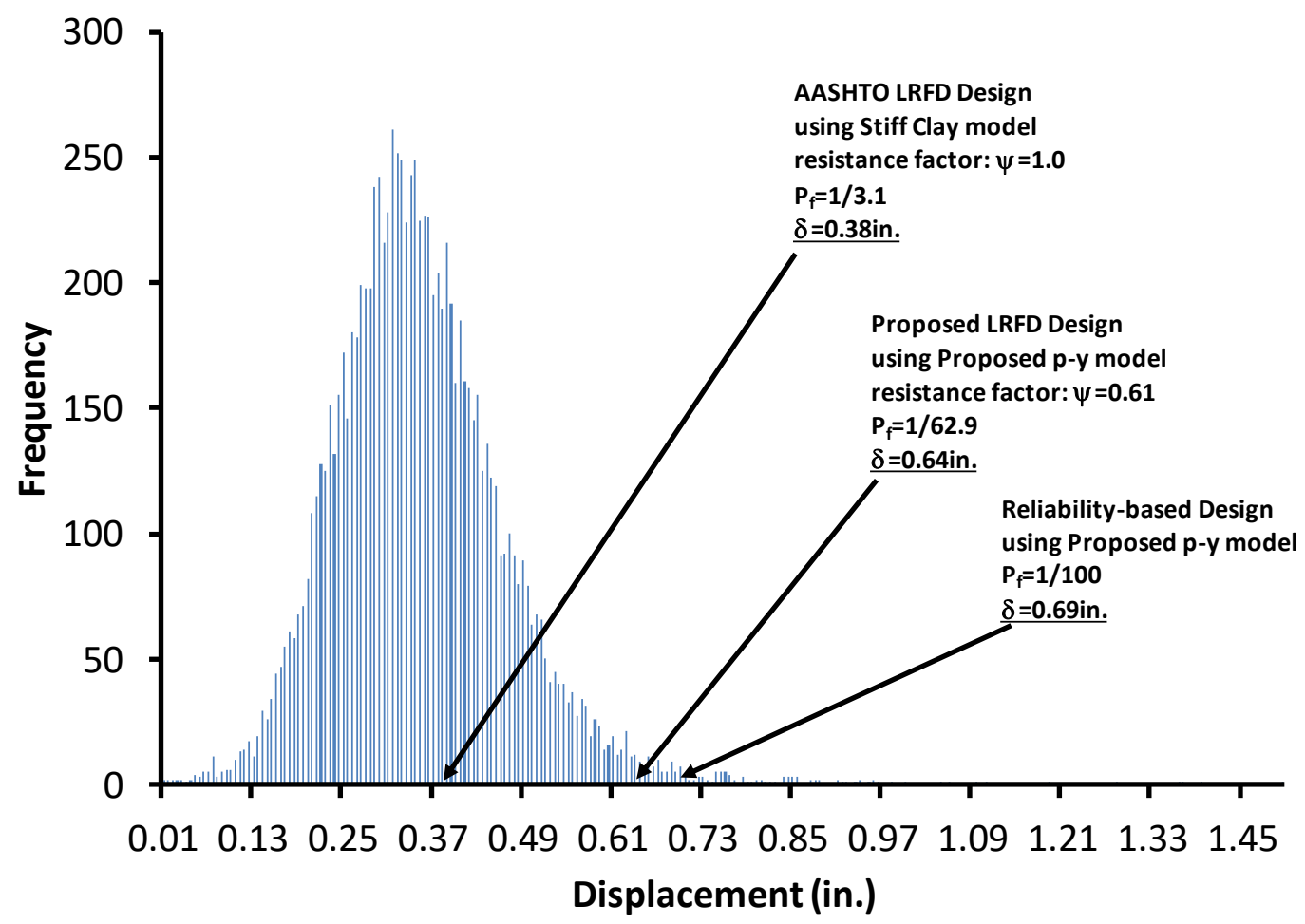

Figure 8.7 - Case S-1 with ratio $P / P_{u l t}=0.6$ and target $P_{f}=1 / 100$ 


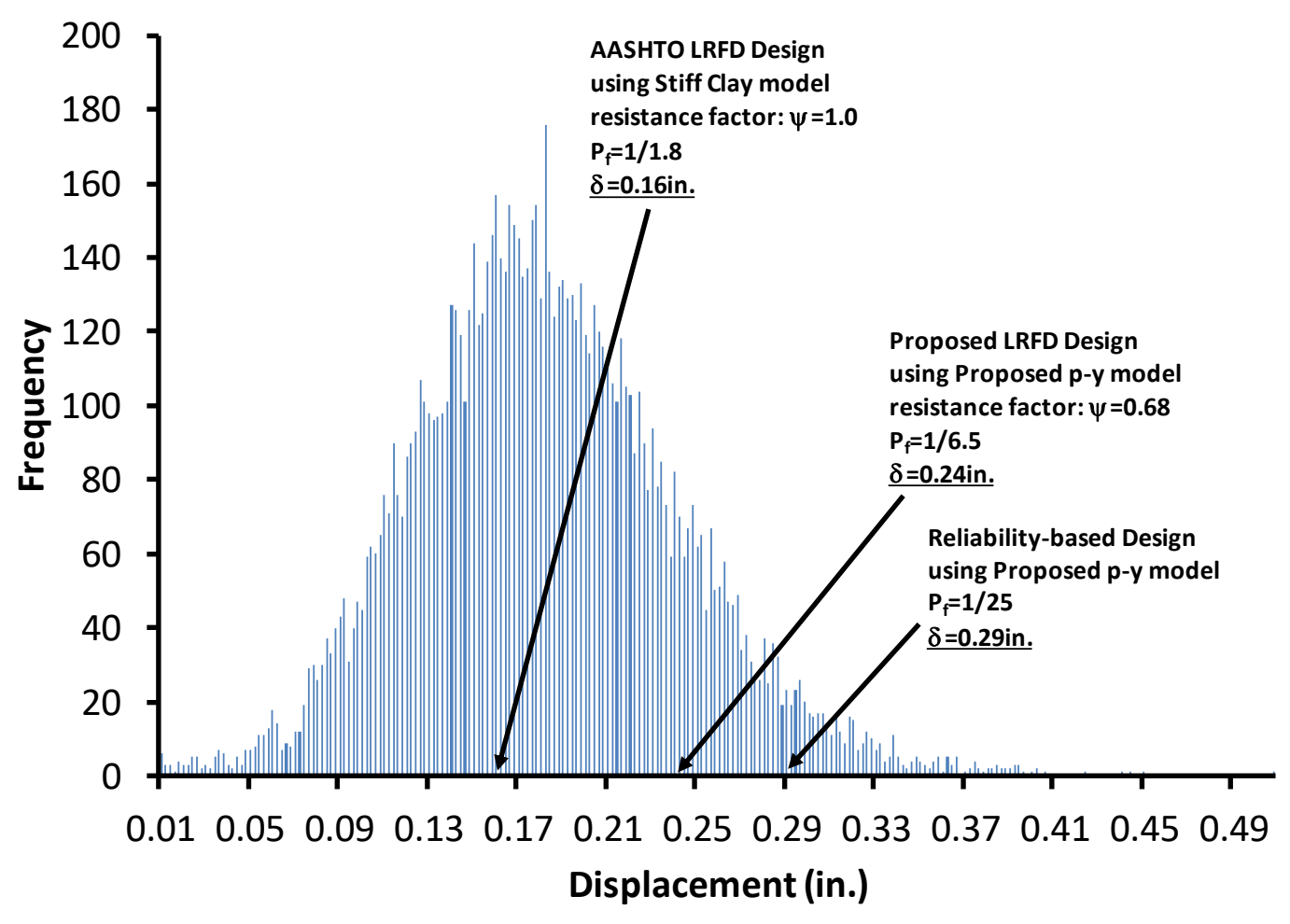

Figure 8.8 - Case $S-1$ with ratio $P / P_{\text {ult }}=0.4$ and target $P_{f}=1 / 25$

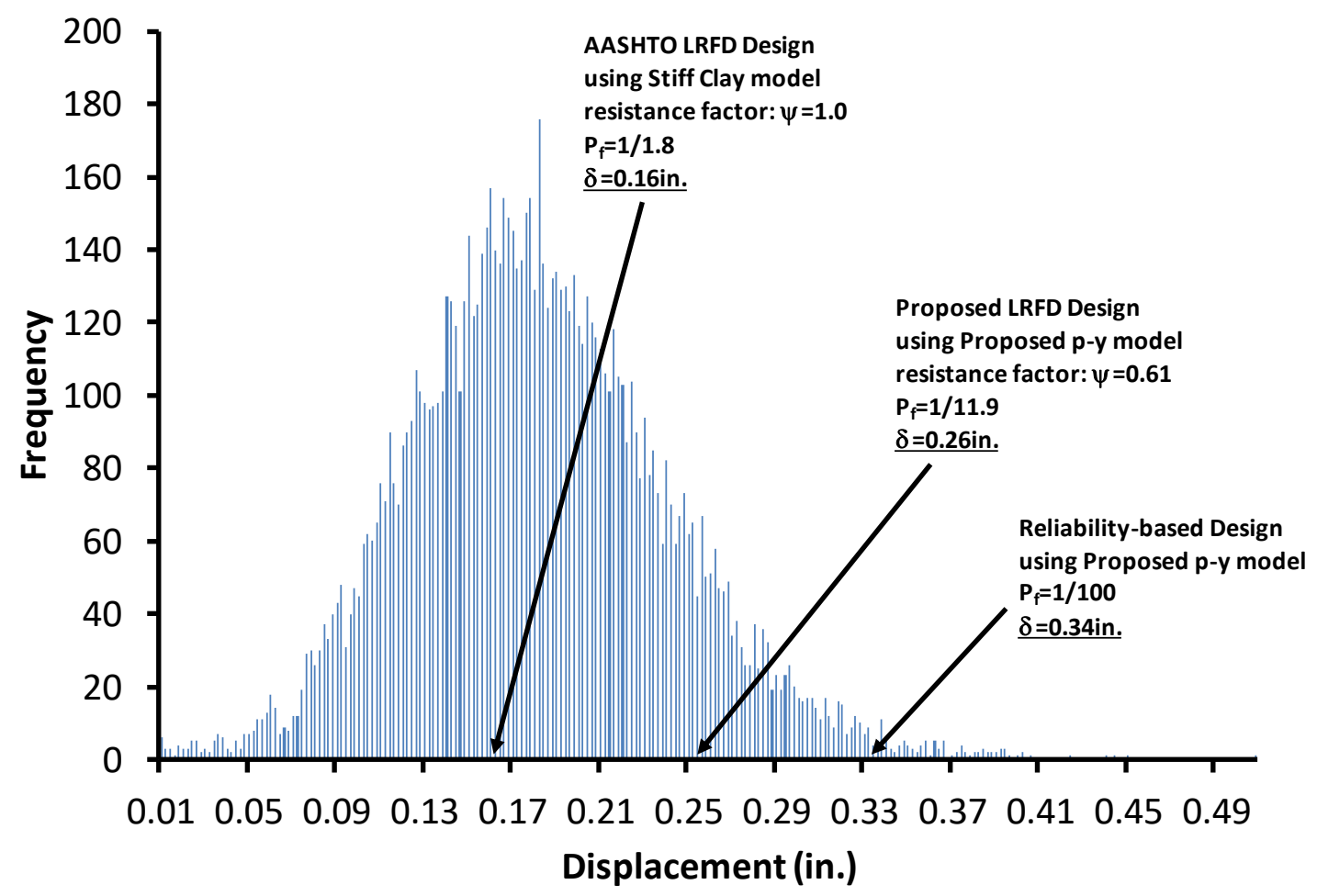

Figure 8.9 - Case S-1 with ratio $P / P_{\text {ult }}=0.4$ and target $P_{f}=1 / 100$ 


\subsection{Comparison between Three Methods}

Comparison of the results from the three different design methods in terms of maximum displacement at shaft head and probability of failure results are presented for different values of RBD target probability of failure.

\subsubsection{Comparison of the Results Obtained from Three Methods when the RBD Target} Probability of Failure $P_{f}=1 / 25$

The RBD displacement has been used as a reference to calculate the changes of displacement using AASHTO and Proposed LFRD. Table 8.4 shows the displacements produced by three methods; the difference in values and the change in percentage between displacements from the proposed and AASHTO methods compared to the RBD displacement. Figure 8.10 and Figure 8.11 plot the change of proposed and AASHTO displacements with respect to RBD displacement for the target probability of failure equals to $1 / 25$, in inches and in percentage, respectively. 
Table 8.4 - Displacement comparison between 3 methods with Target $P_{f}=1 / 25$

\begin{tabular}{|c|c|c|c|c|c|c|c|c|}
\hline \multirow{2}{*}{$\begin{array}{c}\text { Case } \\
\#\end{array}$} & \multirow{2}{*}{$\frac{P}{P_{u l t}}$} & \multicolumn{3}{|c|}{ Factored $\delta$ (in.) } & \multicolumn{2}{|c|}{ Change of $\delta$ (in) } & \multicolumn{2}{|c|}{ Change of $\delta(\%)$} \\
\hline & & AASHTO & Proposed & RBD & AASHTO & Proposed & AASHTO & Proposed \\
\hline \multirow{3}{*}{$S-1$} & 0.4 & 0.16 & 0.24 & 0.29 & 0.13 & 0.05 & 44.83 & 17.24 \\
\hline & 0.6 & 0.38 & 0.48 & 0.56 & 0.18 & 0.08 & 32.14 & 14.29 \\
\hline & 0.8 & 0.79 & 1.40 & 1.51 & 0.72 & 0.11 & 47.68 & 7.28 \\
\hline \multirow{3}{*}{$S-2$} & 0.4 & 0.29 & 0.35 & 0.43 & 0.14 & 0.08 & 32.56 & 18.60 \\
\hline & 0.6 & 0.65 & 0.68 & 0.73 & 0.08 & 0.05 & 10.96 & 6.85 \\
\hline & 0.8 & 1.26 & 1.34 & 1.36 & 0.10 & 0.02 & 7.35 & 1.47 \\
\hline \multirow{3}{*}{$S-3$} & 0.4 & 0.32 & 0.42 & 0.49 & 0.17 & 0.07 & 34.69 & 14.29 \\
\hline & 0.6 & 0.73 & 0.76 & 0.83 & 0.10 & 0.07 & 12.05 & 8.43 \\
\hline & 0.8 & \multicolumn{7}{|c|}{ Cannot satisfy service limit state } \\
\hline \multirow{3}{*}{$S-4$} & 0.4 & 0.39 & 0.42 & 0.55 & 0.16 & 0.13 & 29.09 & 23.64 \\
\hline & 0.6 & 0.84 & 0.87 & 0.97 & 0.13 & 0.10 & 13.40 & 10.31 \\
\hline & 0.8 & \multicolumn{7}{|c|}{ Cannot satisfy service limit state } \\
\hline \multirow{3}{*}{$S-5$} & 0.4 & 0.42 & 0.48 & 0.58 & 0.16 & 0.10 & 27.59 & 17.24 \\
\hline & 0.6 & 0.89 & 0.92 & 1.02 & 0.13 & 0.10 & 12.75 & 9.80 \\
\hline & 0.8 & \multicolumn{7}{|c|}{ Cannot satisfy service limit state } \\
\hline \multirow{3}{*}{ G-6 } & 0.4 & 0.20 & 0.39 & 0.48 & 0.28 & 0.09 & 58.33 & 18.75 \\
\hline & 0.6 & 0.57 & 0.77 & 0.85 & 0.28 & 0.08 & 32.94 & 9.41 \\
\hline & 0.8 & \multicolumn{7}{|c|}{ Cannot satisfy service limit state } \\
\hline \multirow{3}{*}{ G-7 } & 0.4 & 0.07 & 0.41 & 0.52 & 0.45 & 0.11 & 86.54 & 21.15 \\
\hline & 0.6 & 0.29 & 0.83 & 0.91 & 0.62 & 0.08 & 68.13 & 8.79 \\
\hline & 0.8 & \multicolumn{7}{|c|}{ Cannot satisfy service limit state } \\
\hline \multirow{3}{*}{$\mathrm{S}-8$} & 0.4 & 0.023 & 0.03 & 0.04 & 0.02 & 0.01 & 51.06 & 30.62 \\
\hline & 0.6 & 0.11 & 0.14 & 0.16 & 0.05 & 0.02 & 31.25 & 12.50 \\
\hline & 0.8 & 0.34 & 0.81 & 0.78 & 0.44 & 0.03 & 56.41 & 3.85 \\
\hline \multirow{3}{*}{$S-9$} & 0.4 & 1.30 & 0.85 & 0.99 & 0.31 & 0.14 & 31.31 & 14.14 \\
\hline & 0.6 & 2.46 & 1.57 & 1.70 & 0.76 & 0.13 & 44.71 & 7.65 \\
\hline & 0.8 & \multicolumn{7}{|c|}{ Cannot satisfy service limit state } \\
\hline
\end{tabular}




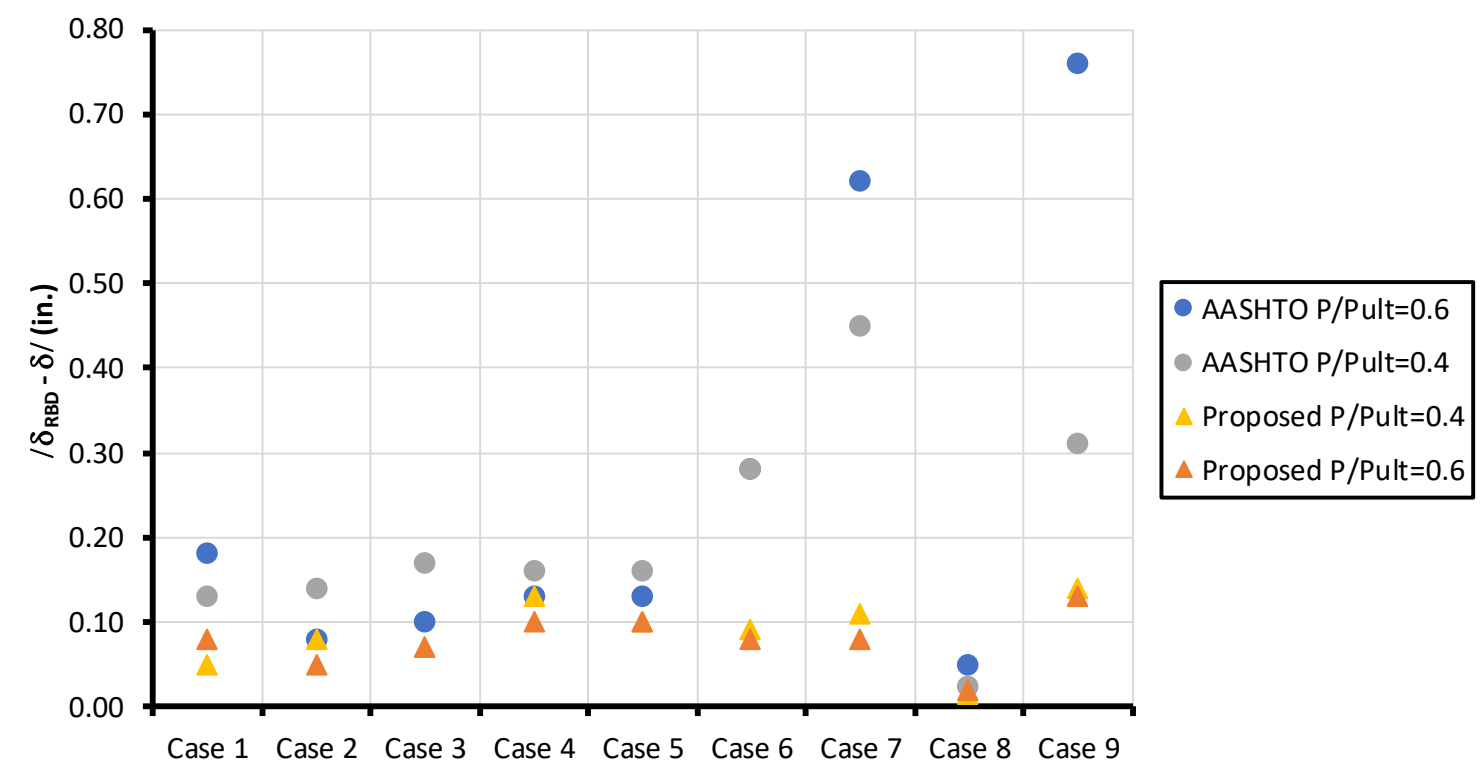

Figure 8.10 - Change of displacement with respect to RBD displacement (in inches) for

$$
P_{f}=1 / 25
$$

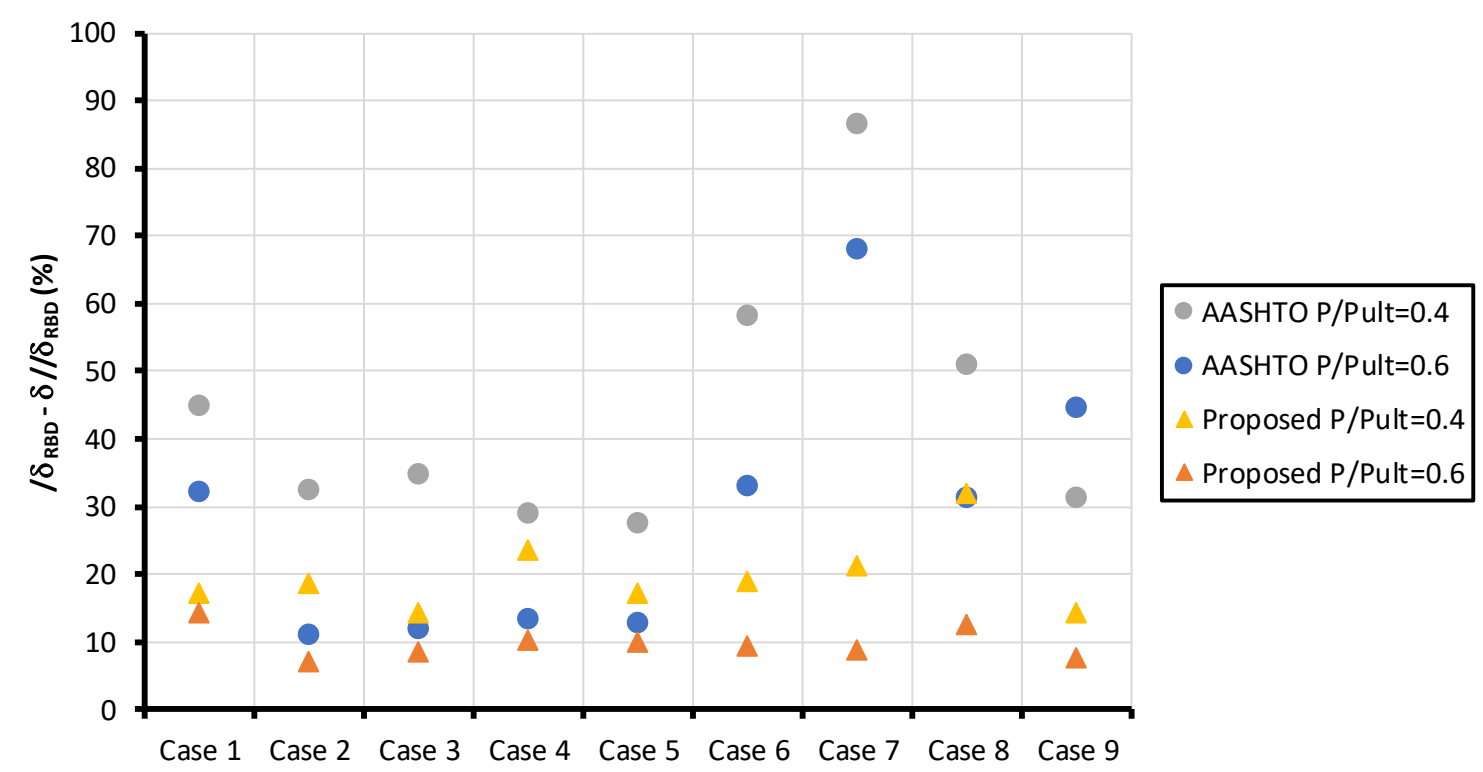

Figure 8.11 - Change of displacement with respect to RBD displacement (in \%) for

$$
P_{f}=1 / 25
$$


The displacement produced by AASHTO LRFD method is much smaller than the one derived from RBD method. The differences are in between 0.10in to 0.60in (Figure 8.10) except the two extreme cases S-8 and S-9. Besides, AASHTO LRFD method produces displacements which vary from $7 \%$ to $86 \%$ smaller than RBD method (Figure 8.11 ). On the other hand, the Proposed LRFD method produces displacements which are closer to RBD displacements than AASHTO LRFD. The maximum displacement difference is only 0.15in (Figure 8.10). Moreover, depends on the P over Pult ratio, the Proposed LRFD method produces displacements which are about $10 \%$ (corresponding to $\mathrm{P} / \mathrm{P}_{\mathrm{ult}}=0.6$ ) and about 20\% (corresponding to $\mathrm{P} / \mathrm{P}_{\text {ult }}=0.4$ ) smaller than RBD displacement (Figure 8.11).

The RBD target probability of failure which is equal to 1 over 25 has been used as a reference to calculate the differences of probability of failure using AASHTO LRFD and Proposed LFRD methods. Table 8.5 shows the probability of failure produced by the Proposed and the AASHTO design methods, as well as the RBD target probability of failure. The ratios between the probability of failure from the Proposed and AASHTO methods and the RBD target probability of failure have been presented., as shown in Table 8.5 and Figure 8.12. 
Table 8.5 - Probability of Failure comparison between 3 methods with Target $P_{f}=1 / 25$

\begin{tabular}{|c|c|c|c|c|c|c|}
\hline \multirow{2}{*}{$\begin{array}{c}\text { Case } \\
\#\end{array}$} & \multirow{2}{*}{$\frac{P}{P_{u l t}}$} & \multicolumn{3}{|c|}{ Probability of Failure } & \multicolumn{2}{|c|}{ Change of $P_{f}$ (ratio) } \\
\hline & & AASHTO & Proposed & RBD & AASHTO & Proposed \\
\hline \multirow{3}{*}{ S-1 } & 0.4 & $1 / 1.8$ & $1 / 6.5$ & $1 / 25$ & 13.89 & 3.85 \\
\hline & 0.6 & $1 / 3.1$ & $1 / 9.3$ & $1 / 25$ & 8.06 & 2.69 \\
\hline & 0.8 & $1 / 4.6$ & $1 / 19$ & $1 / 25$ & 5.43 & 1.32 \\
\hline \multirow{3}{*}{ S-2 } & 0.4 & $1 / 3.2$ & $1 / 6.4$ & $1 / 25$ & 7.81 & 3.91 \\
\hline & 0.6 & $1 / 10.9$ & $1 / 14.6$ & $1 / 25$ & 2.29 & 1.71 \\
\hline & 0.8 & $1 / 18.3$ & $1 / 24$ & $1 / 25$ & 1.37 & 1.04 \\
\hline \multirow{3}{*}{ S-3 } & 0.4 & $1 / 3.0$ & $1 / 7.8$ & $1 / 25$ & 8.33 & 3.21 \\
\hline & 0.6 & $1 / 9.4$ & $1 / 12$ & $1 / 25$ & 2.66 & 2.08 \\
\hline & 0.8 & \multicolumn{5}{|c|}{ Cannot satisfy strength limit state } \\
\hline \multirow{3}{*}{ S-4 } & 0.4 & $1 / 3.6$ & $1 / 4.5$ & $1 / 25$ & 6.94 & 5.56 \\
\hline & 0.6 & $1 / 8.9$ & $1 / 11.6$ & $1 / 25$ & 2.81 & 2.16 \\
\hline & 0.8 & \multicolumn{5}{|c|}{ Cannot satisfy strength limit state } \\
\hline \multirow{3}{*}{ S-5 } & 0.4 & $1 / 3.7$ & $1 / 6.5$ & $1 / 25$ & 6.76 & 3.85 \\
\hline & 0.6 & $1 / 8.7$ & $1 / 11.2$ & $1 / 25$ & 2.87 & 2.23 \\
\hline & 0.8 & \multicolumn{5}{|c|}{ Cannot satisfy strength limit state } \\
\hline \multirow{3}{*}{ G-6 } & 0.4 & $1 / 1.5$ & $1 / 7.5$ & $1 / 25$ & 16.67 & 3.33 \\
\hline & 0.6 & $1 / 3.7$ & $1 / 14$ & $1 / 25$ & 6.76 & 1.79 \\
\hline & 0.8 & \multicolumn{5}{|c|}{ Cannot satisfy strength limit state } \\
\hline \multirow{3}{*}{ G-7 } & 0.4 & $1 / 1.1$ & $1 / 7.4$ & $1 / 25$ & 22.73 & 3.38 \\
\hline & 0.6 & $1 / 1.4$ & $1 / 15.2$ & $1 / 25$ & 17.86 & 1.64 \\
\hline & 0.8 & \multicolumn{5}{|c|}{ Cannot satisfy strength limit state } \\
\hline \multirow{3}{*}{$\mathrm{S}-8$} & 0.4 & $1 / 3.4$ & $1 / 7.4$ & $1 / 25$ & 7.35 & 3.38 \\
\hline & 0.6 & $1 / 7.8$ & $1 / 12.1$ & $1 / 25$ & 3.21 & 2.07 \\
\hline & 0.8 & $1 / 3.5$ & $1 / 27$ & $1 / 25$ & 7.14 & 0.93 \\
\hline \multirow{3}{*}{ S-9 } & 0.4 & $1 / 2000$ & $1 / 5.5$ & $1 / 25$ & 0.0125 & 4.55 \\
\hline & 0.6 & $1 / 2000$ & $1 / 10.5$ & $1 / 25$ & 0.0125 & 2.38 \\
\hline & 0.8 & \multicolumn{5}{|c|}{ Cannot satisfy strength limit state } \\
\hline
\end{tabular}




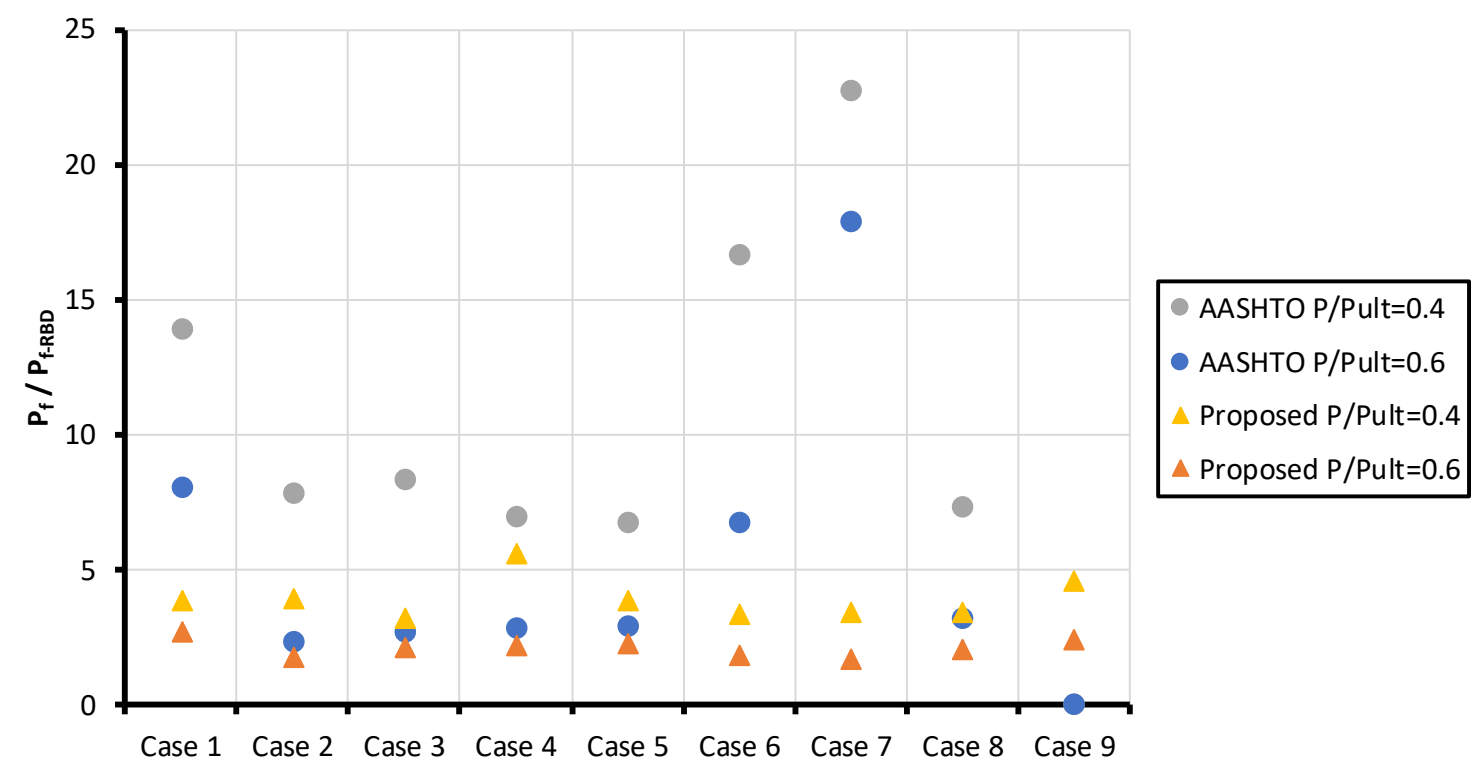

Figure 8.12 - Change of probability of failure with respect to the RBD target $P_{f}=1 / 25$ (in ratio)

The probability of failure produced by AASHTO LRFD method varies from 1/1.1 to $1 / 18.3$, which is relatively higher than the RBD target probability of failure (1 over 25 in this cases). The ratio between AASHTO LRFD probability of failure and RBD target probability of failure are in between 1.4 and 22.7 (Figure 8.12). The exception is extreme Case S-9 where AASHTO LRFD using Reese's stiff clay model produces probability of failure equals to 1 over 2000 based on the very soft shale layer.

On the other hand, the Proposed LRFD method produces probability of failure which are closer to RBD target probability of failure than AASHTO method. Depends on the $\mathrm{P}$ over $\mathrm{P}_{\text {ult }}$ ratio, the ratio between Proposed LRFD probability of failure and RBD target probability of failure is equal to about 2 (corresponding to $\mathrm{P} / \mathrm{P}_{\mathrm{ult}}=0.6$ ) and equal to about 4 (corresponding to $\mathrm{P} / \mathrm{Pult}_{\mathrm{u}}=0.4$ ) (Figure 8.12). 
8.4.2 Comparison of the Results Obtained from Three Methods when the RBD target probability of failure $P_{f}=1 / 100$

Table 8.6 shows the displacements produced by three methods; the difference in values and the change in percentage between displacements from the proposed and AASHTO methods compared to the RBD displacement for the target probability of failure equals to $1 / 100$. Figure 8.13 and Figure 8.14 plot the change of proposed and AASHTO displacements with respect to RBD displacement for the target probability of $1 / 100$, in inches and in percentage, respectively. 
Table 8.6 - Displacement comparison between 3 methods with Target $P_{f}=1 / 100$

\begin{tabular}{|c|c|c|c|c|c|c|c|c|}
\hline \multirow{2}{*}{$\begin{array}{c}\text { Case } \\
\#\end{array}$} & \multirow{2}{*}{$\frac{P}{P_{u l t}}$} & \multicolumn{3}{|c|}{ Factored $\delta$ (in.) } & \multicolumn{2}{|c|}{ Change of $\delta$ (in) } & \multicolumn{2}{|c|}{ Change of $\delta(\%)$} \\
\hline & & AASHTO & Proposed & RBD & AASHTO & Proposed & AASHTO & Proposed \\
\hline \multirow{3}{*}{ S-1 } & 0.4 & 0.16 & 0.26 & 0.34 & 0.18 & 0.08 & 52.94 & 23.53 \\
\hline & 0.6 & 0.38 & 0.64 & 0.69 & 0.31 & 0.05 & 44.93 & 7.25 \\
\hline & 0.8 & 0.79 & 2.06 & 2.03 & 1.24 & 0.03 & 61.08 & 1.48 \\
\hline \multirow{3}{*}{$\mathrm{S}-2$} & 0.4 & 0.29 & 0.39 & 0.49 & 0.20 & 0.10 & 40.82 & 20.41 \\
\hline & 0.6 & 0.65 & 0.77 & 0.84 & 0.19 & 0.07 & 22.62 & 8.33 \\
\hline & 0.8 & 1.26 & 1.81 & 1.85 & 0.59 & 0.04 & 31.89 & 2.16 \\
\hline \multirow{3}{*}{$S-3$} & 0.4 & 0.32 & 0.47 & 0.57 & 0.25 & 0.10 & 43.86 & 17.54 \\
\hline & 0.6 & 0.73 & 0.91 & 0.96 & 0.23 & 0.05 & 23.96 & 5.21 \\
\hline & 0.8 & \multicolumn{7}{|c|}{ Cannot satisfy service limit state } \\
\hline \multirow{3}{*}{$\mathrm{S}-4$} & 0.4 & 0.39 & 0.55 & 0.64 & 0.25 & 0.09 & 39.06 & 14.06 \\
\hline & 0.6 & 0.84 & 1.07 & 1.11 & 0.27 & 0.04 & 24.32 & 3.60 \\
\hline & 0.8 & \multicolumn{7}{|c|}{ Cannot satisfy service limit state } \\
\hline \multirow{3}{*}{$S-5$} & 0.4 & 0.42 & 0.54 & 0.67 & 0.25 & 0.13 & 37.31 & 19.40 \\
\hline & 0.6 & 0.89 & 1.13 & 1.17 & 0.28 & 0.04 & 23.93 & 3.42 \\
\hline & 0.8 & \multicolumn{7}{|c|}{ Cannot satisfy service limit state } \\
\hline \multirow{3}{*}{ G-6 } & 0.4 & 0.20 & 0.46 & 0.58 & 0.38 & 0.12 & 65.52 & 20.69 \\
\hline & 0.6 & 0.57 & 0.95 & 1.01 & 0.44 & 0.06 & 43.56 & 5.94 \\
\hline & 0.8 & \multicolumn{7}{|c|}{ Cannot satisfy service limit state } \\
\hline \multirow{3}{*}{ G-7 } & 0.4 & 0.07 & 0.49 & 0.62 & 0.55 & 0.13 & 88.71 & 20.97 \\
\hline & 0.6 & 0.29 & 1.01 & 1.09 & 0.80 & 0.08 & 73.39 & 7.34 \\
\hline & 0.8 & \multicolumn{7}{|c|}{ Cannot satisfy service limit state } \\
\hline \multirow{3}{*}{$\mathrm{S}-8$} & 0.4 & 0.023 & 0.04 & 0.06 & 0.04 & 0.02 & 64.06 & 32.97 \\
\hline & 0.6 & 0.11 & 0.21 & 0.23 & 0.12 & 0.02 & 52.17 & 8.70 \\
\hline & 0.8 & 0.34 & 1.69 & 1.5 & 1.16 & 0.19 & 77.33 & 12.67 \\
\hline \multirow{3}{*}{ S-9 } & 0.4 & 1.30 & 0.95 & 1.09 & 0.21 & 0.14 & 19.27 & 12.84 \\
\hline & 0.6 & 2.46 & 1.82 & 1.89 & 0.57 & 0.07 & 30.16 & 3.70 \\
\hline & 0.8 & \multicolumn{7}{|c|}{ Cannot satisfy service limit state } \\
\hline
\end{tabular}




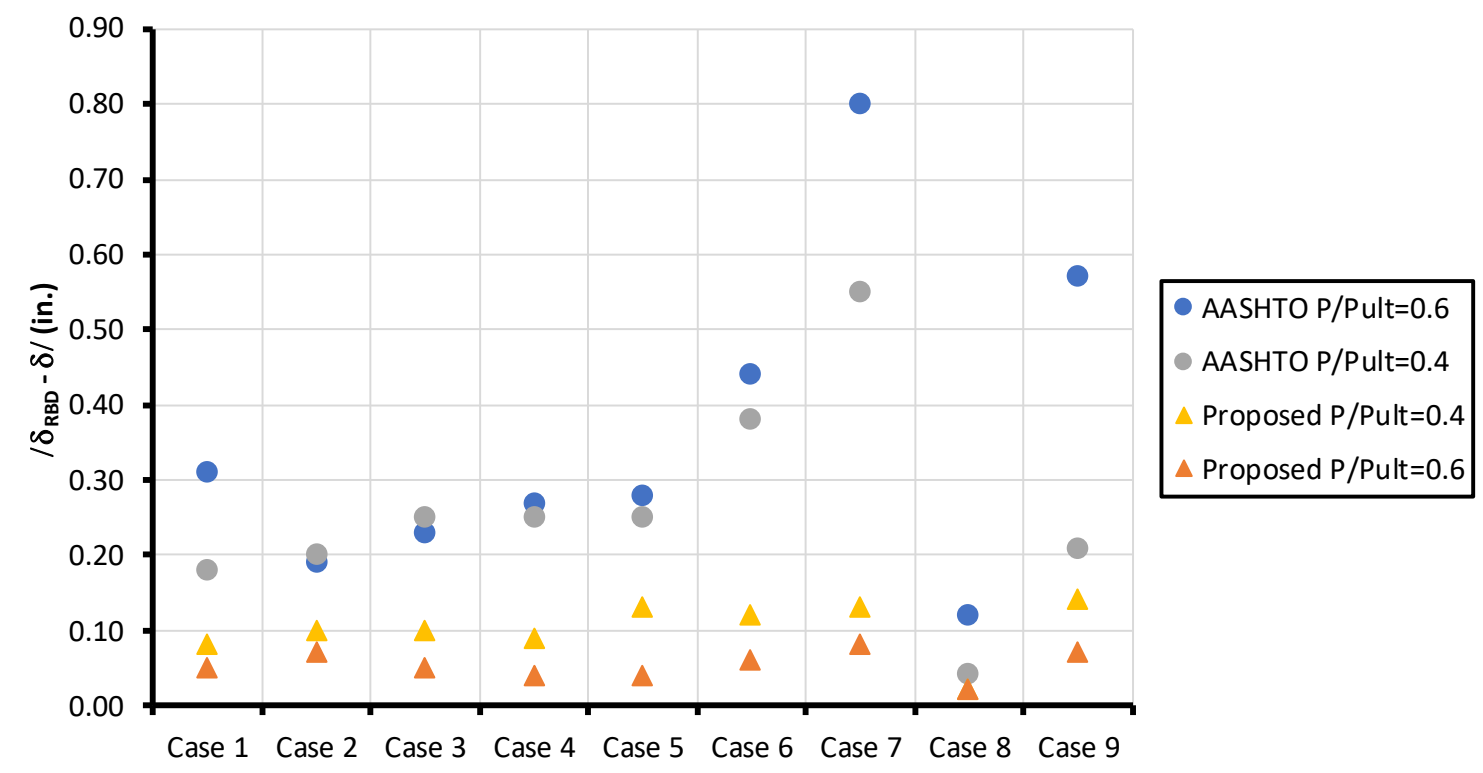

Figure 8.13 - Change of displacement with respect to RBD displacement (in inches) for $P_{f}=1 / 100$

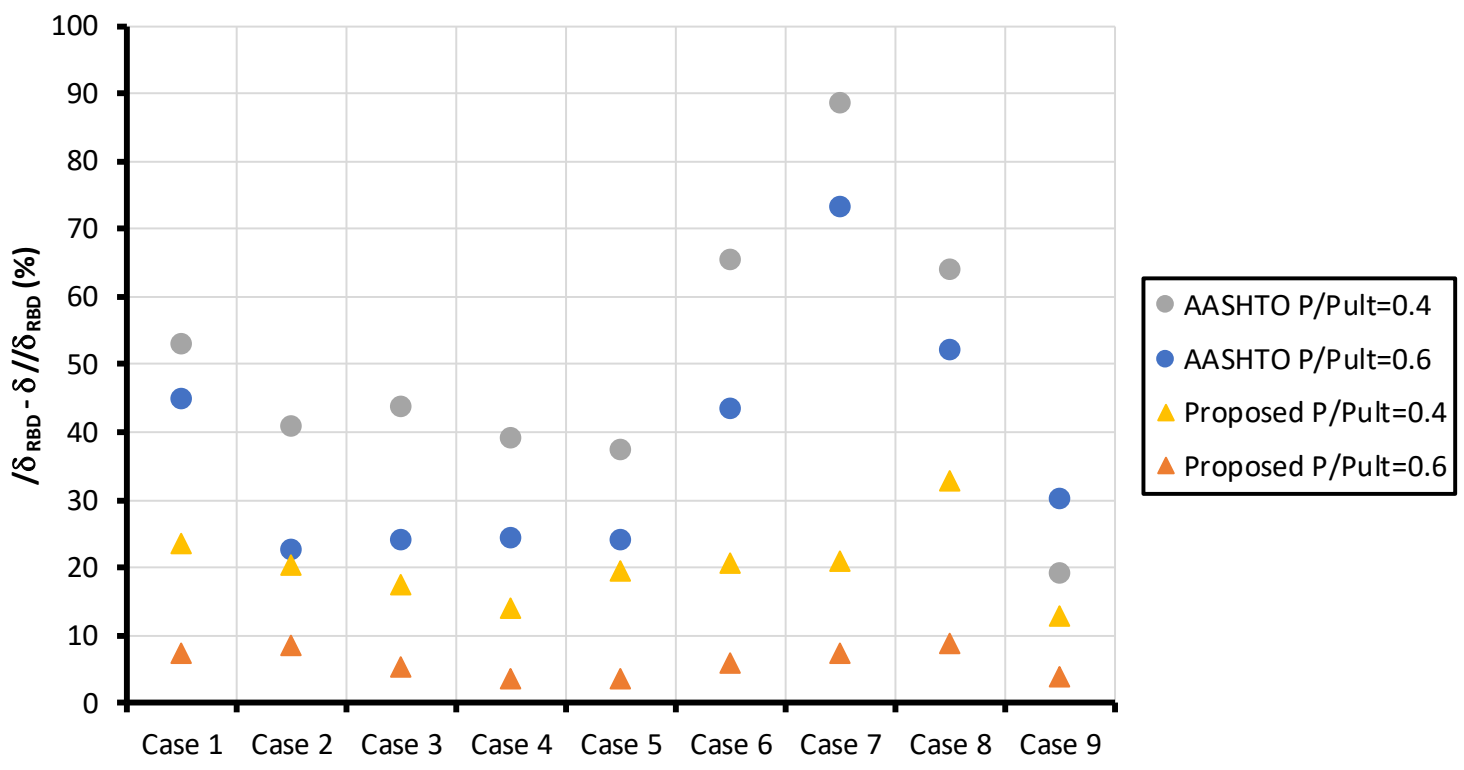

Figure 8.14 - Change of displacement with respect to RBD displacement (in \%) for $P_{f}=1 / 100$ 
The displacement produced by AASHTO LRFD is much smaller than the one derived from Reliability-based design. The differences are in between 0.18in to 0.80in (Figure 8.13) except the two extreme cases S-8 and S-9. Besides, AASHTO LRFD produces displacements which are 20 to $90 \%$ smaller than RBD (Figure 8.14). On the other hand, the Proposed LRFD produces displacements which are smaller but closed to RBD displacements. The maximum displacement difference is only 0.15in (Figure 8.13). Moreover, depends on the P over Pult ratio, the Proposed LRFD produces displacements which are less than $10 \%$ (corresponding to $\mathrm{P} / \mathrm{P}_{\mathrm{ult}}=0.6$ ) and about $20 \%$ (corresponding to $\mathrm{P} / \mathrm{P}_{\text {ult }}=0.4$ ) smaller than RBD (Figure 8.14).

The target RBD which is equal to 1 over 100 has been used as a reference to calculate the differences of probability of failure using AASHTO LRFD and Proposed LFRD methods. Table 8.7 shows the probability of failure produced by the Proposed and the AASHTO design methods, as well as the RBD target probability of failure, which is equal to $1 / 100$. The ratios between the probability of failure from the Proposed and AASHTO methods and the RBD target probability of failure have been presented, as shown in Table 8.7 and Figure 8.15 . 
Table 8.7 - Probability of Failure comparison between 3 methods with Target $P_{f}=$ $1 / 100$

\begin{tabular}{|c|c|c|c|c|c|c|}
\hline \multirow{2}{*}{$\begin{array}{c}\text { Case } \\
\#\end{array}$} & \multirow{2}{*}{$\frac{P}{P_{u l t}}$} & \multicolumn{3}{|c|}{ Probability of Failure } & \multicolumn{2}{|c|}{$\begin{array}{c}\text { Change of Pf } \\
\text { (ratio) }\end{array}$} \\
\hline & & AASHTO & Proposed & RBD & AASHTO & Proposed \\
\hline \multirow{3}{*}{ S-1 } & 0.4 & $1 / 1.8$ & $1 / 11.9$ & $1 / 100$ & 55.56 & 8.40 \\
\hline & 0.6 & $1 / 3.1$ & $1 / 62.9$ & $1 / 100$ & 32.26 & 1.59 \\
\hline & 0.8 & $1 / 4.6$ & $1 / 111$ & $1 / 100$ & 21.74 & 0.90 \\
\hline \multirow{3}{*}{ S-2 } & 0.4 & $1 / 3.2$ & $1 / 11.4$ & $1 / 100$ & 31.25 & 8.77 \\
\hline & 0.6 & $1 / 10.9$ & $1 / 41.8$ & $1 / 100$ & 9.17 & 2.39 \\
\hline & 0.8 & $1 / 18.3$ & $1 / 93$ & $1 / 100$ & 5.46 & 1.08 \\
\hline \multirow{3}{*}{$\mathrm{S}-3$} & 0.4 & $1 / 3.0$ & $1 / 16.9$ & $1 / 100$ & 33.33 & 5.92 \\
\hline & 0.6 & $1 / 9.4$ & $1 / 51$ & $1 / 100$ & 10.64 & 1.96 \\
\hline & 0.8 & \multicolumn{5}{|c|}{ Cannot satisfy strength limit state } \\
\hline \multirow{3}{*}{$\mathrm{S}-4$} & 0.4 & $1 / 3.6$ & $1 / 8.2$ & $1 / 100$ & 27.78 & 12.20 \\
\hline & 0.6 & $1 / 8.9$ & $1 / 68$ & $1 / 100$ & 11.24 & 1.47 \\
\hline & 0.8 & \multicolumn{5}{|c|}{ Cannot satisfy strength limit state } \\
\hline \multirow{3}{*}{$S-5$} & 0.4 & $1 / 3.7$ & $1 / 13.2$ & $1 / 100$ & 27.03 & 7.58 \\
\hline & 0.6 & $1 / 8.7$ & $1 / 70.4$ & $1 / 100$ & 11.49 & 1.42 \\
\hline & 0.8 & \multicolumn{5}{|c|}{ Cannot satisfy strength limit state } \\
\hline \multirow{3}{*}{ G-6 } & 0.4 & $1 / 1.5$ & $1 / 17.2$ & $1 / 100$ & 66.67 & 5.81 \\
\hline & 0.6 & $1 / 3.7$ & $1 / 53$ & $1 / 100$ & 27.03 & 1.89 \\
\hline & 0.8 & \multicolumn{5}{|c|}{ Cannot satisfy strength limit state } \\
\hline \multirow{3}{*}{ G-7 } & 0.4 & $1 / 1.1$ & $1 / 17$ & $1 / 100$ & 90.91 & 5.88 \\
\hline & 0.6 & $1 / 1.4$ & $1 / 49.3$ & $1 / 100$ & 71.43 & 2.03 \\
\hline & 0.8 & \multicolumn{5}{|c|}{ Cannot satisfy strength limit state } \\
\hline \multirow{3}{*}{$\mathrm{S}-8$} & 0.4 & $1 / 3.4$ & $1 / 18.9$ & $1 / 100$ & 29.41 & 5.29 \\
\hline & 0.6 & $1 / 7.8$ & $1 / 69.4$ & $1 / 100$ & 12.82 & 1.44 \\
\hline & 0.8 & $1 / 3.5$ & $1 / 130$ & $1 / 100$ & 28.57 & 0.77 \\
\hline \multirow{3}{*}{$S-9$} & 0.4 & $1 / 2000$ & $1 / 13.9$ & $1 / 100$ & 0.05 & 7.19 \\
\hline & 0.6 & $1 / 2000$ & $1 / 52.4$ & $1 / 100$ & 0.05 & 1.91 \\
\hline & 0.8 & \multicolumn{5}{|c|}{ Cannot satisfy strength limit state } \\
\hline
\end{tabular}




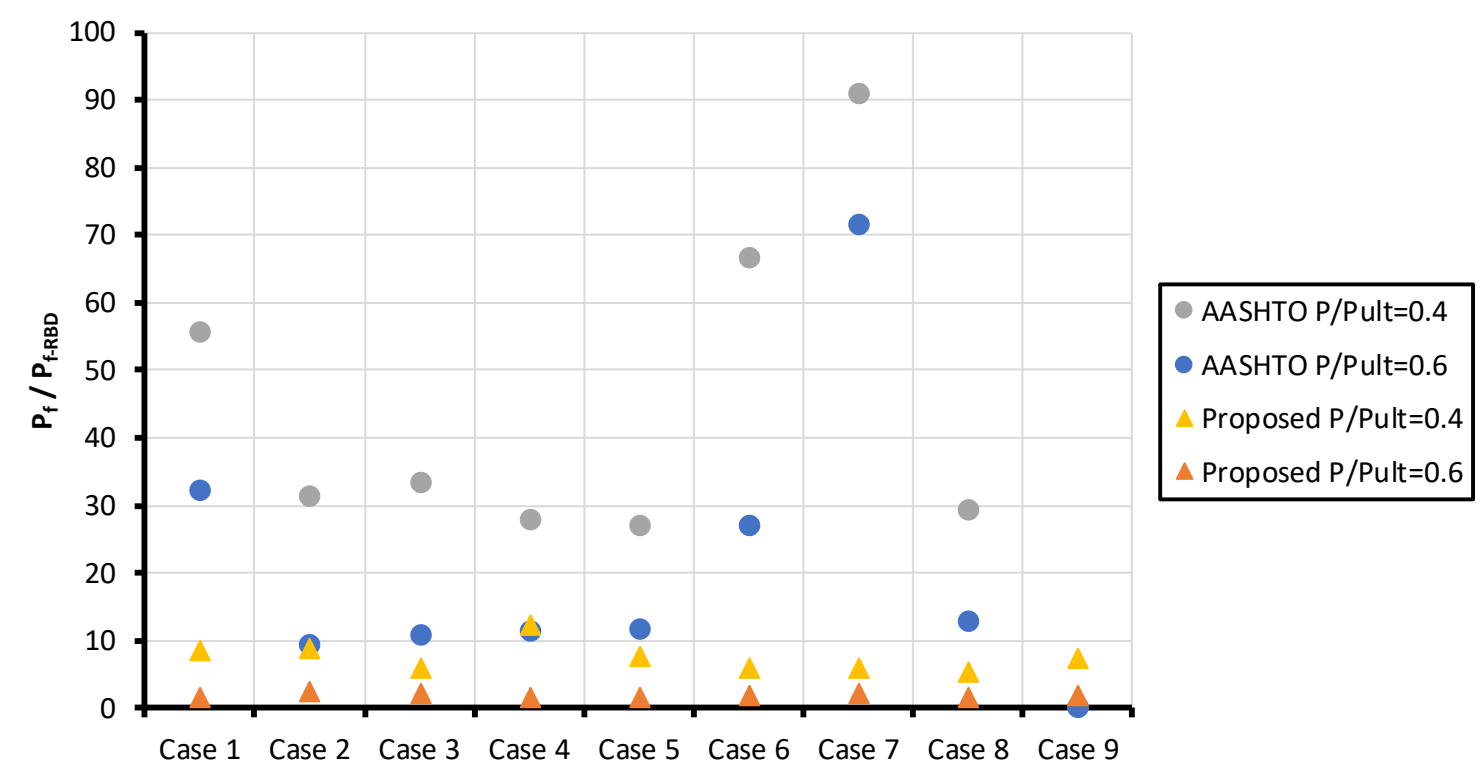

Figure 8.15 - Change of probability of failure with respect to the RBD target $P_{f}=1 / 100$ (in ratio)

The probability of failure produced by AASHTO LRFD method varies from 1.1 to $1 / 18.3$, which is much higher than the RBD target probability of failure (1 over 100 in this cases). The ratio between AASHTO LRFD probability of failure and RBD target probability of failure are in between 10 and 90 (Figure 8.15). The exception is extreme Case S-9 where AASHTO LRFD using Reese's stiff clay model produces probability of failure equals to 1 over 2000 based on the very soft shale layer.

On the other hand, the Proposed LRFD method produces probability of failure which are closer to RBD target probability of failure than AASHTO method. Depends on the $\mathrm{P}$ over $\mathrm{P}_{\text {ult }}$ ratio, the ratio between Proposed LRFD probability of failure and RBD target probability of failure is equal to about 2 (corresponding to $\mathrm{P} / \mathrm{P}_{\mathrm{ult}}=0.6$ ) and equal to about 6 (corresponding to $\mathrm{P} / \mathrm{P}_{\mathrm{ult}}=0.4$ ) (Figure 8.15). 


\subsection{Load Ratio and Nominal Lateral Load calculated from Strength Limit State}

In the previous section, the Proposed LRFD for drilled shaft subjected to lateral loading at Service Limit State has been evaluated using the comparison between the three methods and the assumed ratio between nominal lateral load and ultimate lateral load. In this section, Strength Limit State analysis will be performed to calculate the nominal lateral load corresponding to each given Case. Those nominal lateral loads will be used in Service Limit State analysis. Thus, comparison and evaluation of the proposed LRFD will be more reliable. Due to different modes of failure, Strength Limit State analysis will be divided into Geotechnical Strength Limit State and Structural Strength Limit State.

\subsubsection{Geotechnical Strength Limit State}

Geotechnical Strength Limit State used the factored load and resistance factor to satisfy the following load-resistance criterion:

$$
\gamma_{D L} Q_{D L}+\gamma_{L L} Q_{L L} \leq \varphi R
$$

where: $\quad Q_{D L}$ and $Q_{L L}=$ Dead and Live loads

$$
\begin{aligned}
& \gamma_{D L} \text { and } \gamma_{L L}=\text { Dead and Live load factors } \\
& R=\text { Resistance load= Ultimate load } \\
& \varphi=\text { resistance factor }
\end{aligned}
$$

According to AASHTO LRFD Bridge Design Specifications, the resistance factor for Geotechnical Strength Limit State shall be equal to 1.0 for laterally loaded drilled shafts. 
For all nine cases, dead load factor will be specified to equal to 1.25 and live load factor will be specified to equal to 1.75 , which are required in the AASHTO LRFD Bridge Design Specifications. The ratio between dead load and live load will be assumed to equal to $2.0\left(\frac{Q_{D L}}{Q_{L L}}=2\right.$ or $\left.Q_{L L}=\frac{Q_{D L}}{2}\right)$. The ultimate lateral load will be obtained using computational program for those Cases in which geotechnical strength limit state occurs (Case G-6 and G-7).

For cases where the Strength Limit State is governed by geotechnical failure, the ratio between the nominal load and the ultimate load will be calculated based on the Strength Limit State criterion, in which the sum of factored dead load and live load is equal to the factored resistance, as described below. That ratio between the nominal load and the ultimate load will be calculated as following and will be used for Service Limit State analysis in the next sections.

$$
\begin{gathered}
\gamma_{D L} Q_{D L}+\gamma_{L L} Q_{L L}=\varphi R=\varphi P_{u l t} \\
1.25 Q_{D L}+1.75 \frac{Q_{D L}}{2}=1.0 P_{u l t} \\
1.25 P+0.875 P=P_{u l t} \\
\frac{P}{P_{u l t}}=0.47
\end{gathered}
$$




\subsubsection{Structural Strength Limit State}

Structural Strength Limit State used the factored load and resistance factor to satisfy the following load-resistance criterion:

$$
M_{\text {max }} \leq \varphi M_{\text {resistance }}
$$

where: $\quad M_{\max }=$ maximum bending moment calculated from factored lateral load $\left(\gamma_{D L} Q_{D L}\right.$ and $\left.\gamma_{L L} Q_{L L}\right)$ in which: $\quad Q_{D L}$ and $Q_{L L}=$ Dead and Live loads

$$
\begin{aligned}
& \qquad \gamma_{D L} \text { and } \gamma_{L L}=\text { Dead and Live load factors } \\
& M_{\text {resistance }}=\text { Resistance bending moment } \\
& \varphi=\text { resistance factor }
\end{aligned}
$$

According to FHWA 2010 Drilled Shaft Manual, the resistance factor for Structural Strength Limit State shall be equal to 0.67.

For all nine cases, dead load factor will be specified to equal to 1.25 and live load factor will be specified to equal to 1.75 , which are required in the AASHTO LRFD Bridge Design Specifications. The ratio between dead load and live load will be assumed to equal to 2.0 $\left(\frac{Q_{D L}}{Q_{L L}}=2\right.$ or $\left.Q_{L L}=\frac{Q_{D L}}{2}\right)$.

The resistance bending moment will be obtained using computational program for those Cases in which structural strength limit state occurs (Case S-1 to S-5 and S-8 to S-9). 
The factored lateral load to satisfy structural strength limit state was calculated using two different criteria:

- Criterion 1: $M_{\text {resistance }}=M_{\text {ult }}=$ ultimate bending moment where concrete compression strain $>0.003$ and reinforcement tensile strain $>0.015$. For cased and uncased section, those ultimate bending moment have been calculated and presented in Table 8.8 .

- Criterion 2: $M_{\text {resistance }}=M_{\text {yield }}=$ yielding bending moment where reinforcement stress $=$ yielding stress. For cased and uncased section, those yielding bending moment have been calculated and presented in Table 8.8 .

Table 8.8 - Resistance Bending Moment

\begin{tabular}{ccccc}
\hline Criterion & $\begin{array}{c}\text { Mresistance } \\
\text { lbs-in }\end{array}$ & $\begin{array}{c}\text { M resistance } \\
\text { kip-ft }\end{array}$ & $\begin{array}{c}0.67 \text { Mresistance } \\
\text { lbs-in }\end{array}$ & $\begin{array}{c}0.67 \text { Mresistance } \\
\text { kip-ft }\end{array}$ \\
\hline$M_{\text {ult }}$ (cased section) & $36,000,000$ & 3,000 & $24,120,000$ & 2,010 \\
$M_{\text {ult }}$ (uncased section) & $16,600,000$ & 1,383 & $11,122,000$ & 927 \\
$M_{\text {yield }}$ (cased section) & $25,678,000$ & 2,140 & $17,204,260$ & 1,434 \\
$M_{\text {yield }}$ (uncased section) & $9,800,000$ & 817 & $6,566,000$ & 547 \\
\hline
\end{tabular}

Analysis for Structural Strength Limit State on Case S-1 to S-5 and S-8 to S-9 have been performed and presented in Figure 8.16 to Figure 8.22. For each Case, three bending moment profiles have been plotted and the corresponding factored lateral loads $\left(\mathrm{P}^{*}\right)$ have been labeled. In each Figure, the blue curve is bending moment profile where $M_{\text {resistance }}=M_{\text {ult; }}$ the grey curve is bending moment profile where factored $M_{\text {resistance }}=$ 
$0.67 * \mathrm{M}_{\text {ult }}$ and the orange curve is bending moment profile where factored $\mathrm{M}_{\text {resistance }}=$ $0.67 * \mathrm{M}_{\text {yield. }}$. For each curve, there are two values of maximum bending moments correspond to cased or uncased sections. Those values are shown in comparison with ultimate (for blue and grey curves) and yielding (for orange curve) bending moment. The values in shaded area shows whether maximum bending moment for each curve satisfied the conditions above and where it occurs in cased or in uncased section. Based on the results, factored lateral loads will be collected to use for calculating the nominal lateral load as well as the ratio between nominal and ultimate lateral load. 


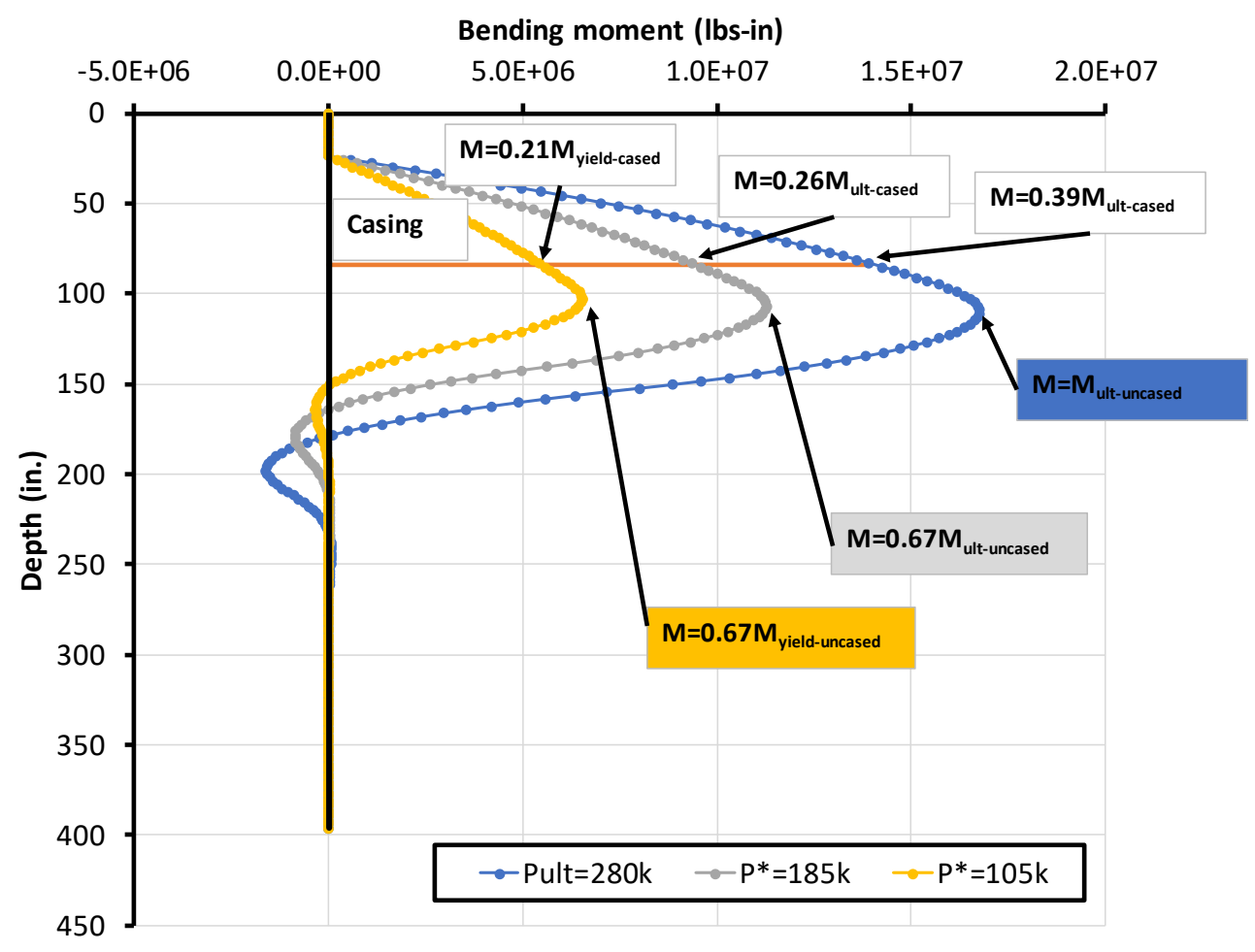

Figure 8.16 - Structural strength limit state for CASE S-1

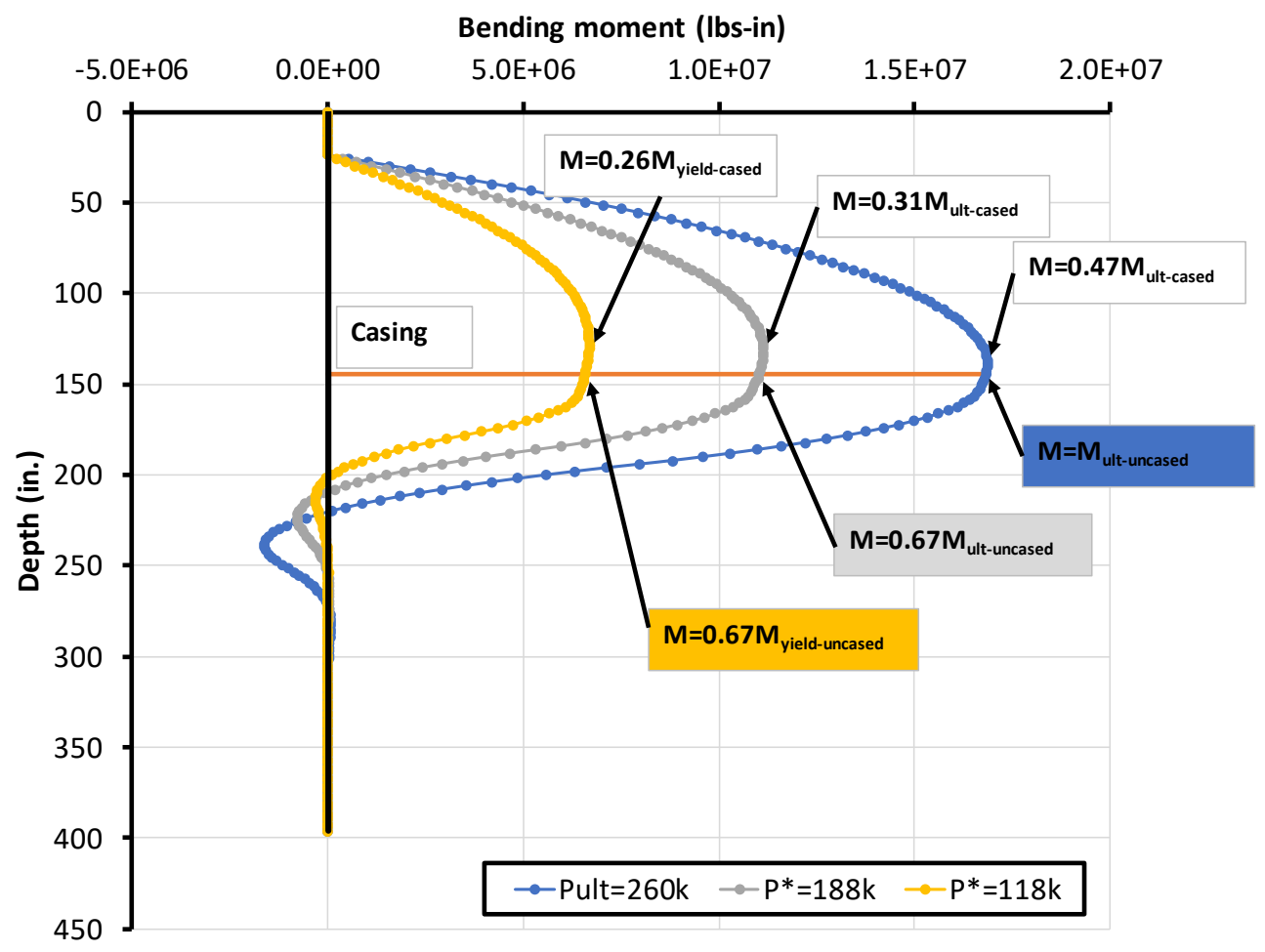

Figure 8.17 - Structural strength limit state for CASE S-2 


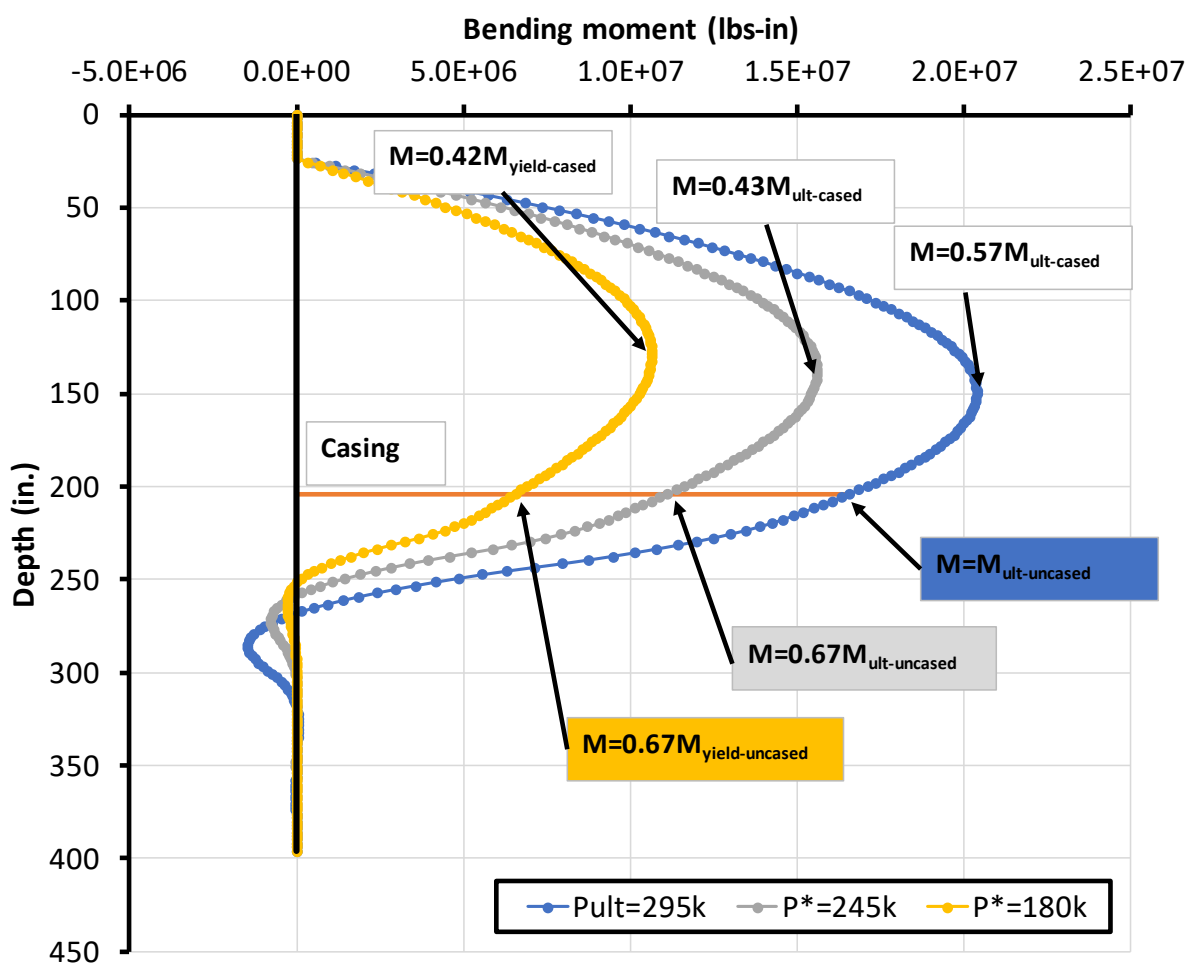

Figure 8.18 - Structural strength limit state for CASE S-3

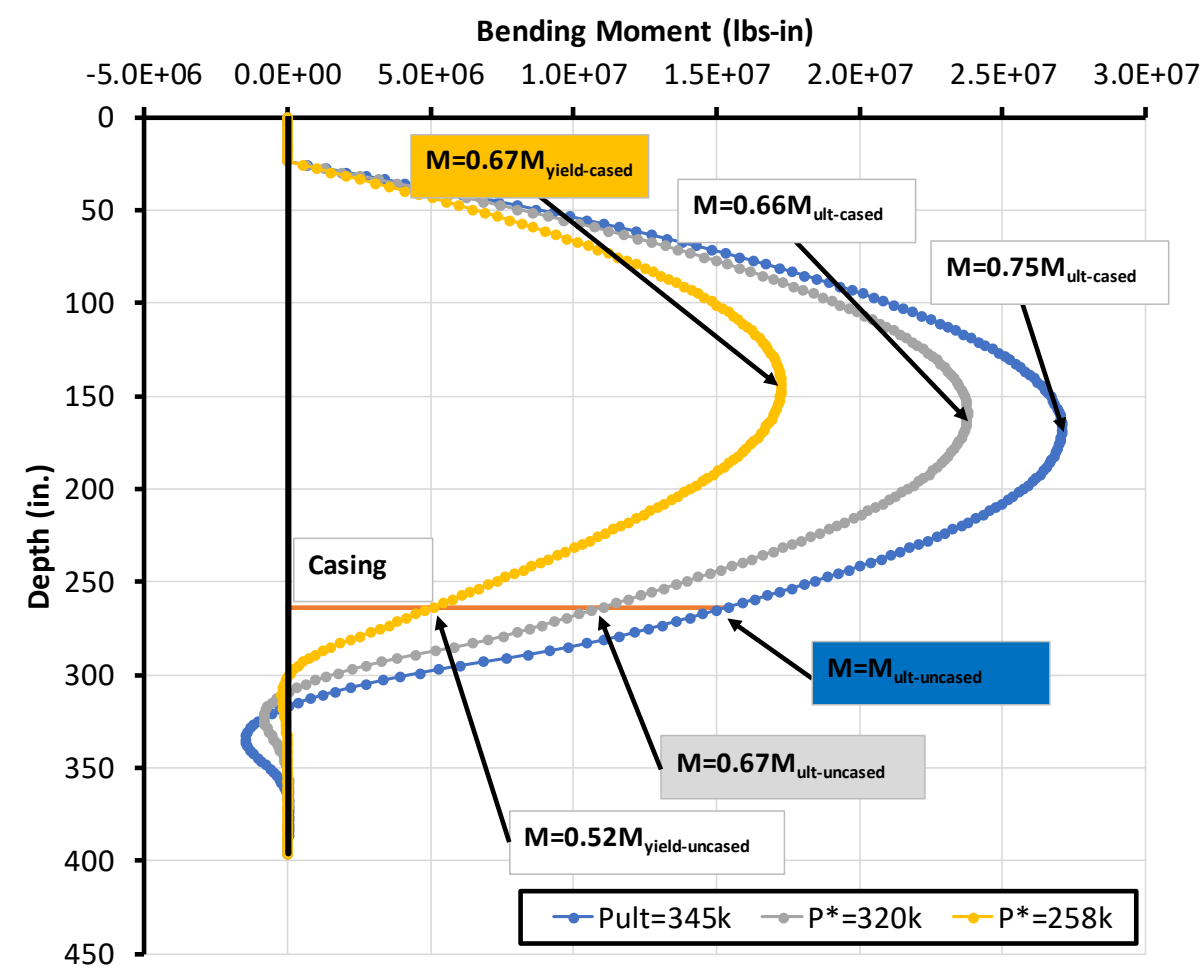

Figure 8.19 - Structural strength limit state for CASE S-4 


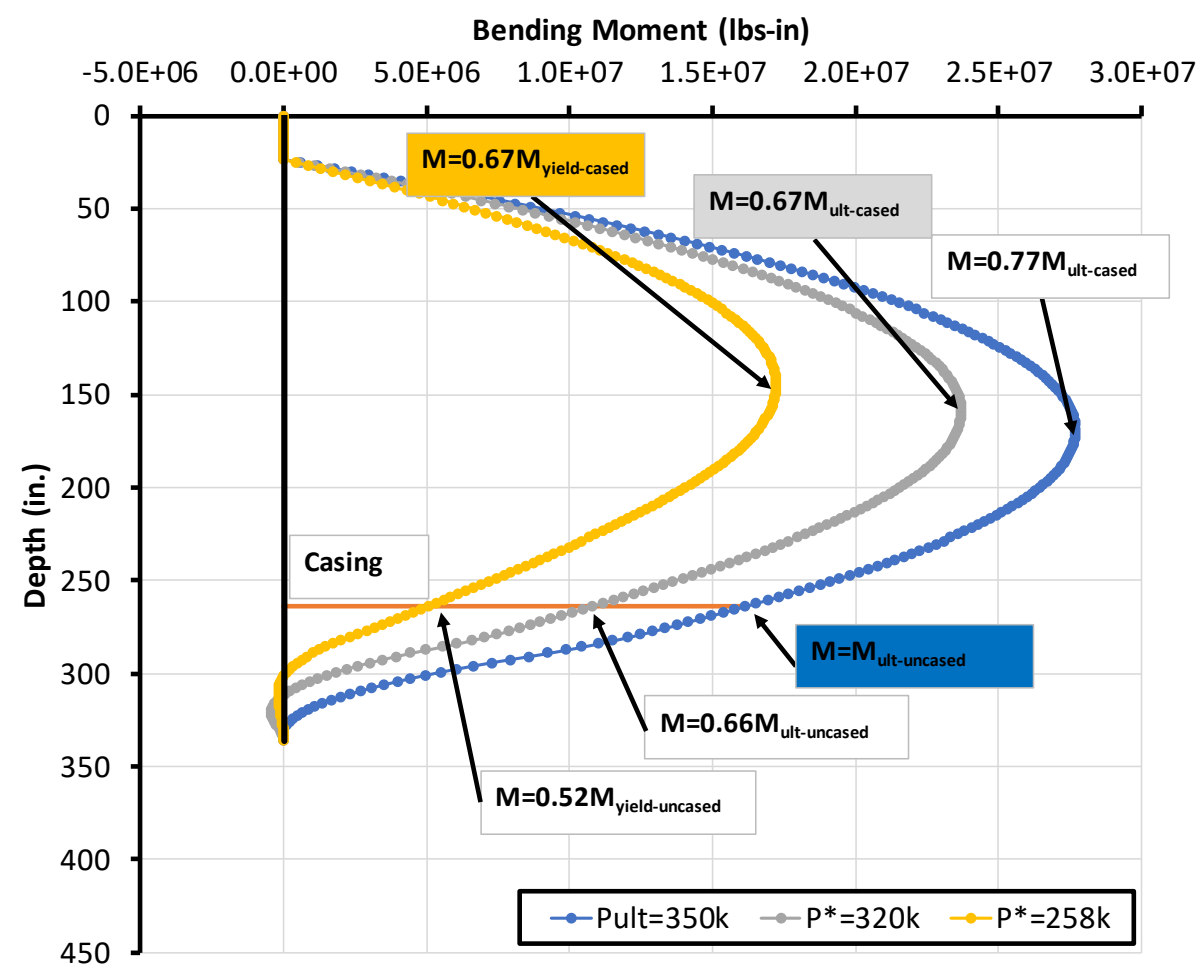

Figure 8.20 - Structural strength limit state for CASE S-5

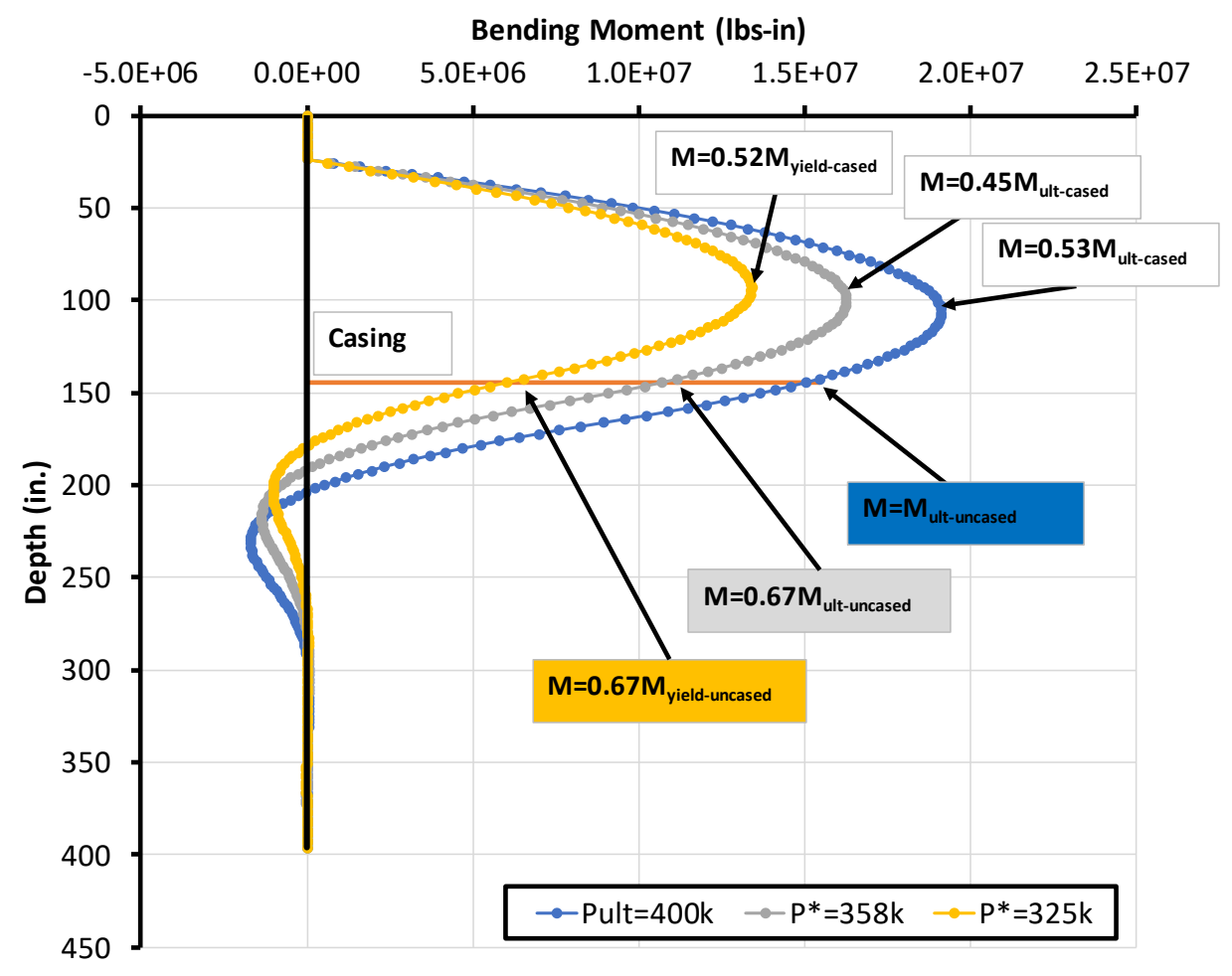

Figure 8.21 - Structural strength limit state for CASE S-8 


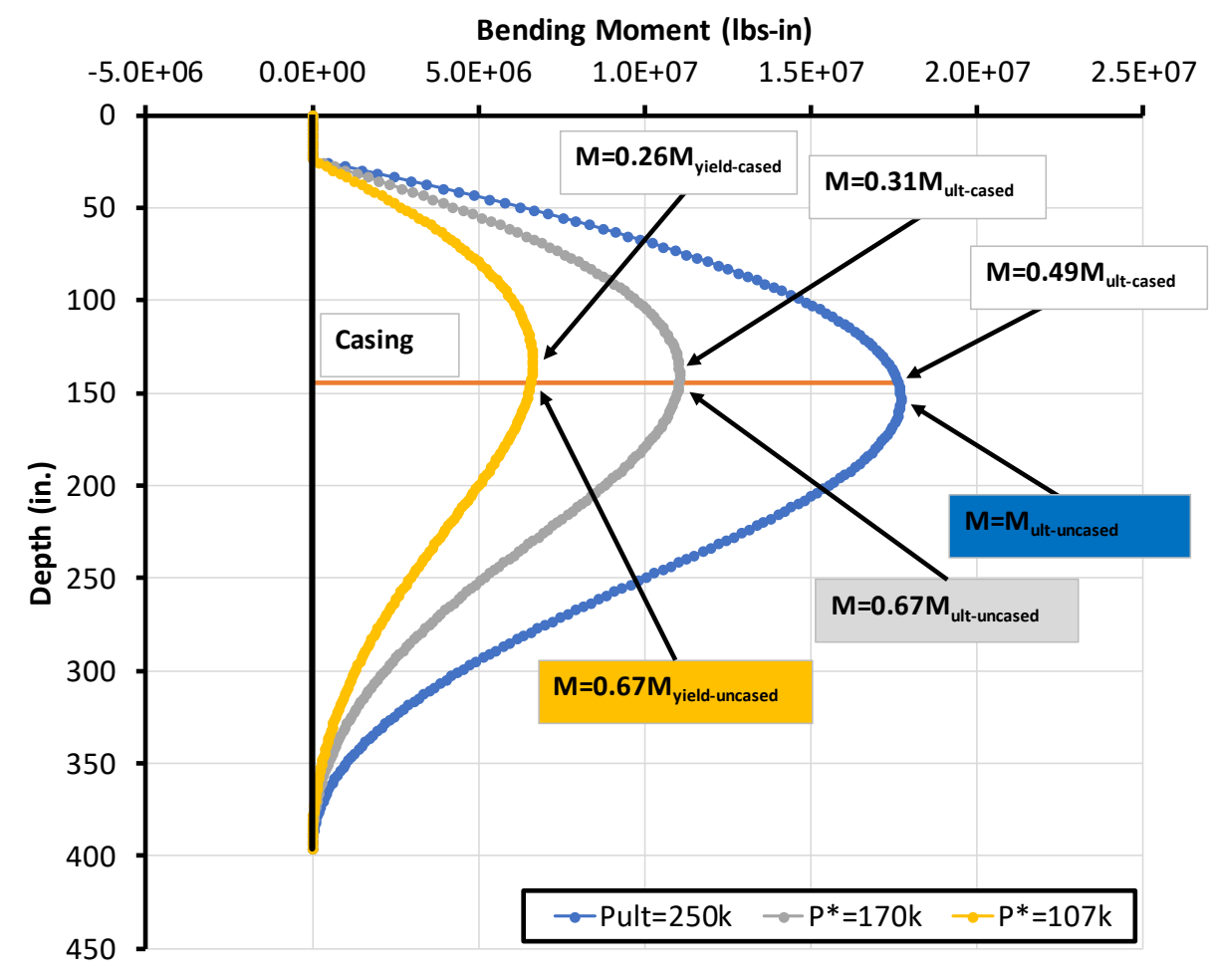

Figure 8.22 - Structural strength limit state for CASE S-9

The nominal lateral load $(P)$ for each case can be calculated from the factored lateral load $\left(\mathrm{P}^{*}\right)$ as following, using the dead load factor equals to 1.25; dead load factor equals to 1.75 and the ratio between dead load and live load equals to 2.0.

$$
\begin{gathered}
\gamma_{D L} Q_{D L}+\gamma_{L L} Q_{L L}=P^{*} \\
1.25 Q_{D L}+1.75 \frac{Q_{D L}}{2}=P^{*} \\
1.25 P+0.875 P=P^{*} \\
P=\frac{P^{*}}{2.125}
\end{gathered}
$$


Summary of the ultimate lateral load and factored lateral load used for Structural Strength Limit State (for both ultimate and yielding strength) for Case S-1 to S-5 and S-8 to S-9 have been presented in Table 8.9. Nominal lateral and load ratio between nominal and ultimate load to be used in Service Limit State Analysis have been calculated and presented in the same Table.

\section{Table 8.9 - Ultimate Lateral Load and Lateral Loads for nine different cases}

\begin{tabular}{|c|c|c|c|c|c|c|c|}
\hline $\begin{array}{c}\text { Case } \\
\#\end{array}$ & $\begin{array}{c}\text { Ultimate } \\
\text { Lateral } \\
\text { Load } \\
\text { Pult } \\
\\
\text { (lbs.) }\end{array}$ & $\begin{array}{c}\text { Factored } \\
\text { Lateral } \\
\text { Load } \\
\mathrm{P}^{*} \\
\text { (ultimate } \\
\text { strength) } \\
\text { (lbs.) }\end{array}$ & $\begin{array}{c}\text { Nominal } \\
\text { Lateral } \\
\text { Load } \\
\mathrm{P} \\
\text { (ultimate } \\
\text { strength) } \\
\text { (lbs.) }\end{array}$ & $\begin{array}{c}\text { Load } \\
\text { Ratio } \\
\text { P/Pult } \\
\text { (ultimate } \\
\text { strength) } \\
(-)\end{array}$ & $\begin{array}{c}\text { Factored } \\
\text { Lateral } \\
\text { Load } \\
\mathrm{P}^{*} \\
\text { (yielding } \\
\text { strength) } \\
\text { (lbs.) }\end{array}$ & $\begin{array}{l}\text { Nominal } \\
\text { Lateral } \\
\text { Load } \\
\text { P } \\
\text { (yielding } \\
\text { strength) } \\
\text { (lbs.) }\end{array}$ & $\begin{array}{c}\text { Load } \\
\text { Ratio } \\
\\
\text { P/Pult } \\
\text { (yielding } \\
\text { strength) } \\
(-) \\
\end{array}$ \\
\hline S-1 & 280,000 & 185,000 & 87,059 & 0.31 & 105,000 & 49,412 & 0.18 \\
\hline S-2 & 260,000 & 188,000 & 88,471 & 0.34 & 118,000 & 55,529 & 0.21 \\
\hline$S-3$ & 295,000 & 245,000 & 115,294 & 0.39 & 180,000 & 84,706 & 0.29 \\
\hline S-4 & 345,000 & 320,000 & 150,588 & 0.44 & 258,000 & 121,412 & 0.35 \\
\hline S-5 & 350,000 & 320,000 & 150,588 & 0.43 & 258,000 & 121,412 & 0.35 \\
\hline $\mathrm{S}-8$ & 400,000 & 364,000 & 171,294 & 0.43 & 325,000 & 152,941 & 0.38 \\
\hline S-9 & 250,000 & 170,000 & 80,000 & 0.32 & 107,000 & 50,353 & 0.20 \\
\hline
\end{tabular}

The above results have been combined with results obtained from Geotechnical Strength Limit State, in which the load ratio between Nominal and Ultimate Lateral Load for Case G-6 and Case G-7 equals to 0.47. Load Ratios calculated from both Geotechnical and Structural Strength Limit State have been presented in Figure 8.23. Those load ratios will be used to calculate the Nominal Lateral Loads using for Service Limit State Analysis 
in the next section. For Case S-1 to S-5 and S-8 to S-9, calculated load ratio from Structural Strength Limit State using ultimate strength criterion will be used. For Case G-6 and G-7, load ratio equals to 0.47 obtained from Geotechnical Strength Limit State.

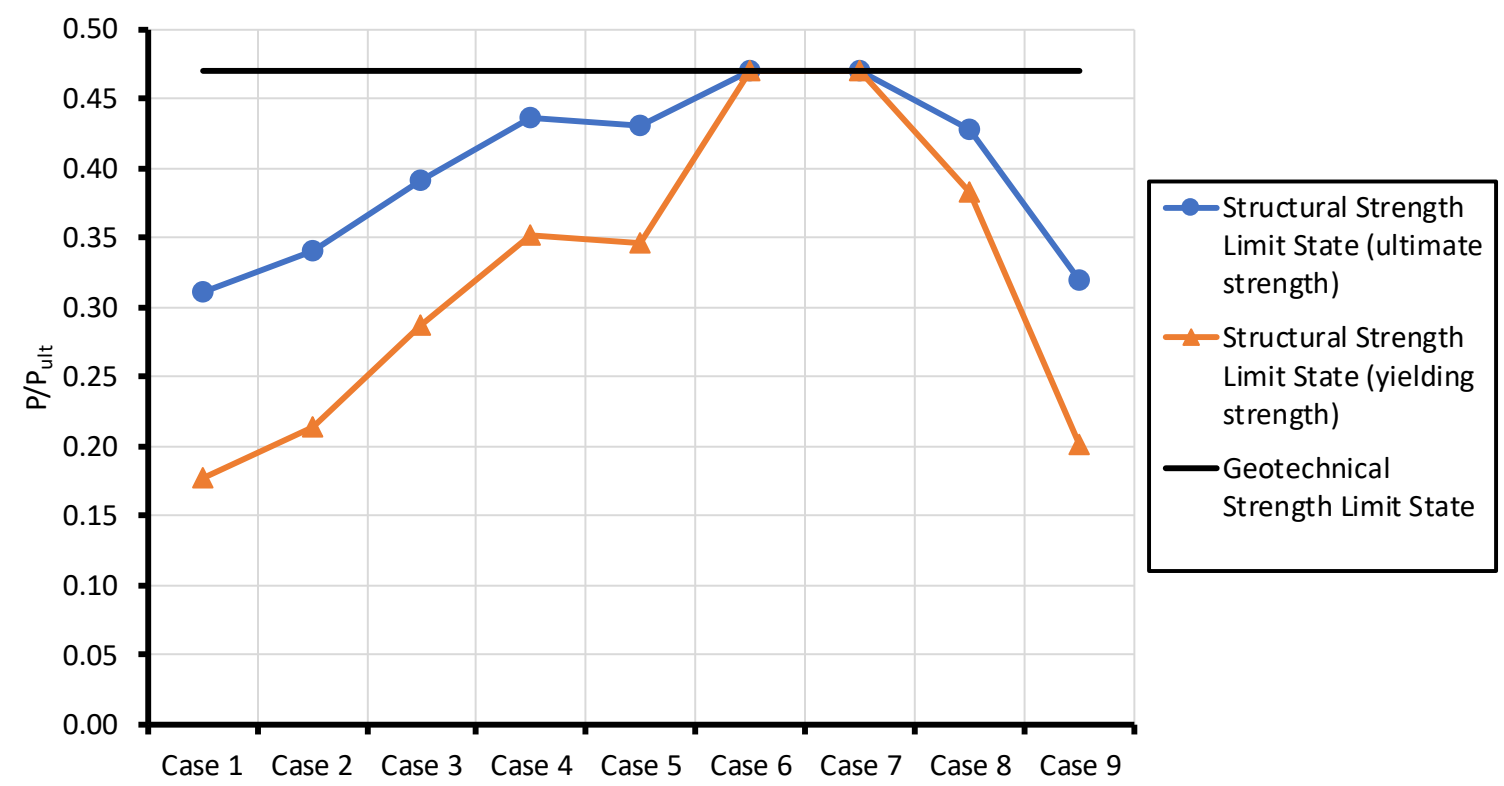

Figure 8.23 - Load Ratio calculated from different Strength Limit State 


\subsection{Comparison between 3 Methods using Nominal Loads from Strength Limit State}

Based on the ultimate lateral load and the load ratio calculated from Strength Limit State, the nominal lateral load has been calculated and nine different cases have been analyses for Service Limit State using AASHTO LRFD, Proposed LRFD and RBD. For each case, 2 sets of the target probably of failure have been given $\left(P_{f}=1 / 100\right.$ and $P_{f}=$ 1/25). Summary of the ultimate lateral load, load ratio calculated from Strength Limit State and the nominal lateral loads used for Service Limit State for nine different Cases have been presented in Table 8.10.

Table 8.10 - Nominal Lateral Loads used for Service Limit State for nine different cases

\begin{tabular}{cccc}
\hline Case \# & $\begin{array}{c}\text { Ultimate } \\
\text { Lateral Load }\end{array}$ & $\begin{array}{c}\text { Load Ratio } \\
\text { calculated from } \\
\text { Strength } \\
\text { Limit State } \\
\text { P/Pult } \\
(-)\end{array}$ & $\begin{array}{c}\text { Nominal } \\
\text { Lateral Load } \\
\text { used for Service } \\
\text { Limit State }\end{array}$ \\
\hline S-1 & $\begin{array}{c}\text { Pult } \\
\text { (lbs.) }\end{array}$ & $\begin{array}{c}\text { P } \\
\text { (lbs.) }\end{array}$ \\
S-2 & 280,000 & 0.31 & 87,059 \\
S-3 & 260,000 & 0.34 & 88,471 \\
S-4 & 295,000 & 0.39 & 115,294 \\
S-5 & 345,000 & 0.44 & 150,588 \\
G-6 & 350,000 & 0.43 & 150,588 \\
G-7 & 250,000 & 0.47 & 117,500 \\
S-8 & 185,000 & 0.47 & 86,950 \\
S-9 & 400,000 & 0.43 & 171,294 \\
\hline
\end{tabular}


For each Case, the results from all three methods will be presented in the same figure with respect to different target probability of failure and using the calculated nominal lateral load, as shown in Figure 8.24 to Figure 8.41. Each figure shows a histogram of computed lateral displacements determined from Monte Carlo simulations performed for the RBD method using the Proposed $p-y$ model. Values for shaft head displacements obtained from the Proposed LRFD method using the Proposed $p-y$ model, the AASHTO design method using Stiff Clay model, and the RBD method are indicated in each figure, along with the associated probability of failure for the computed lateral displacement. 


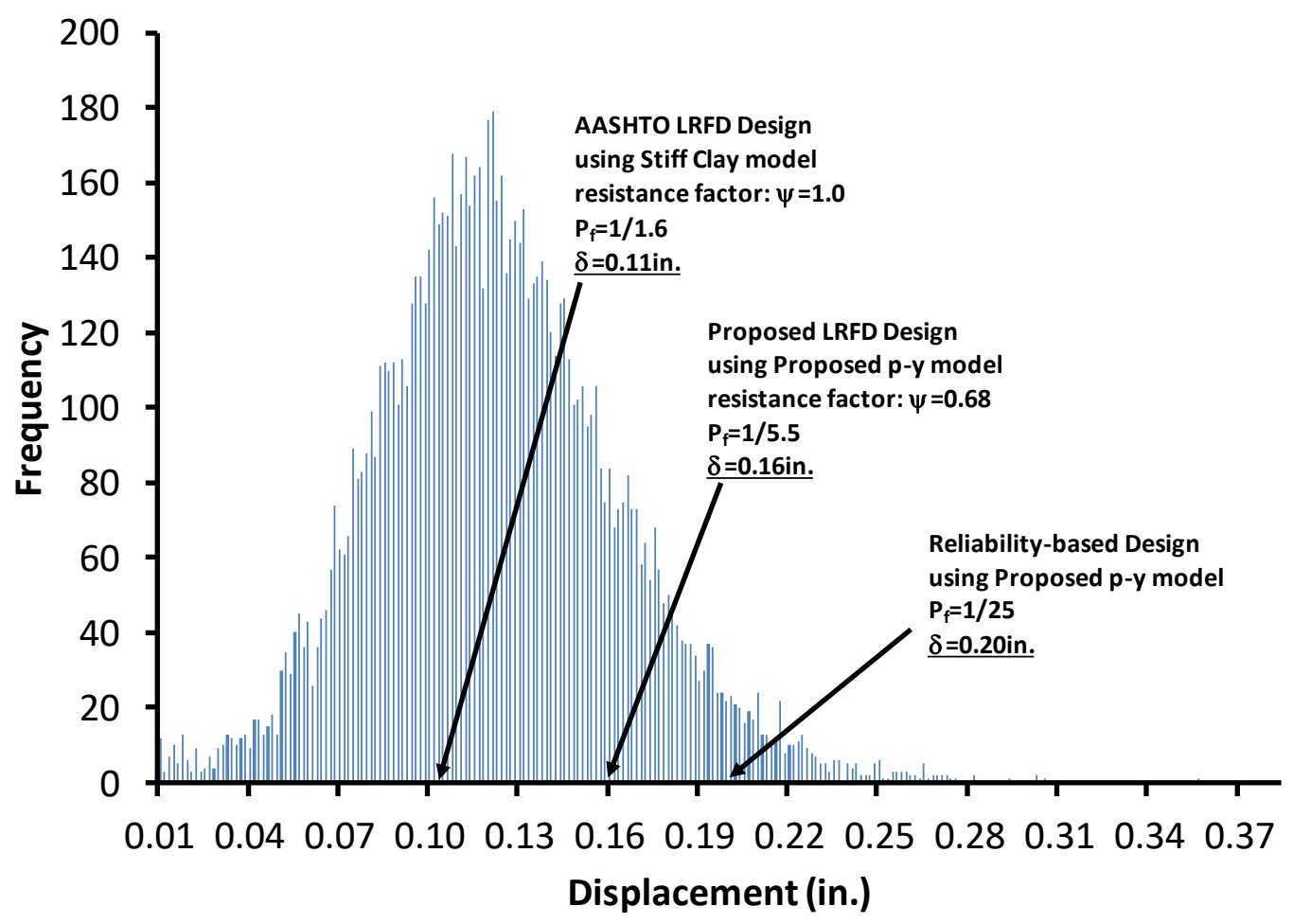

Figure 8.24 - Case $S-1$ with $P / P_{u l t}=0.31 ; P=87,059$ lbs. and target $P_{f}=1 / 25$

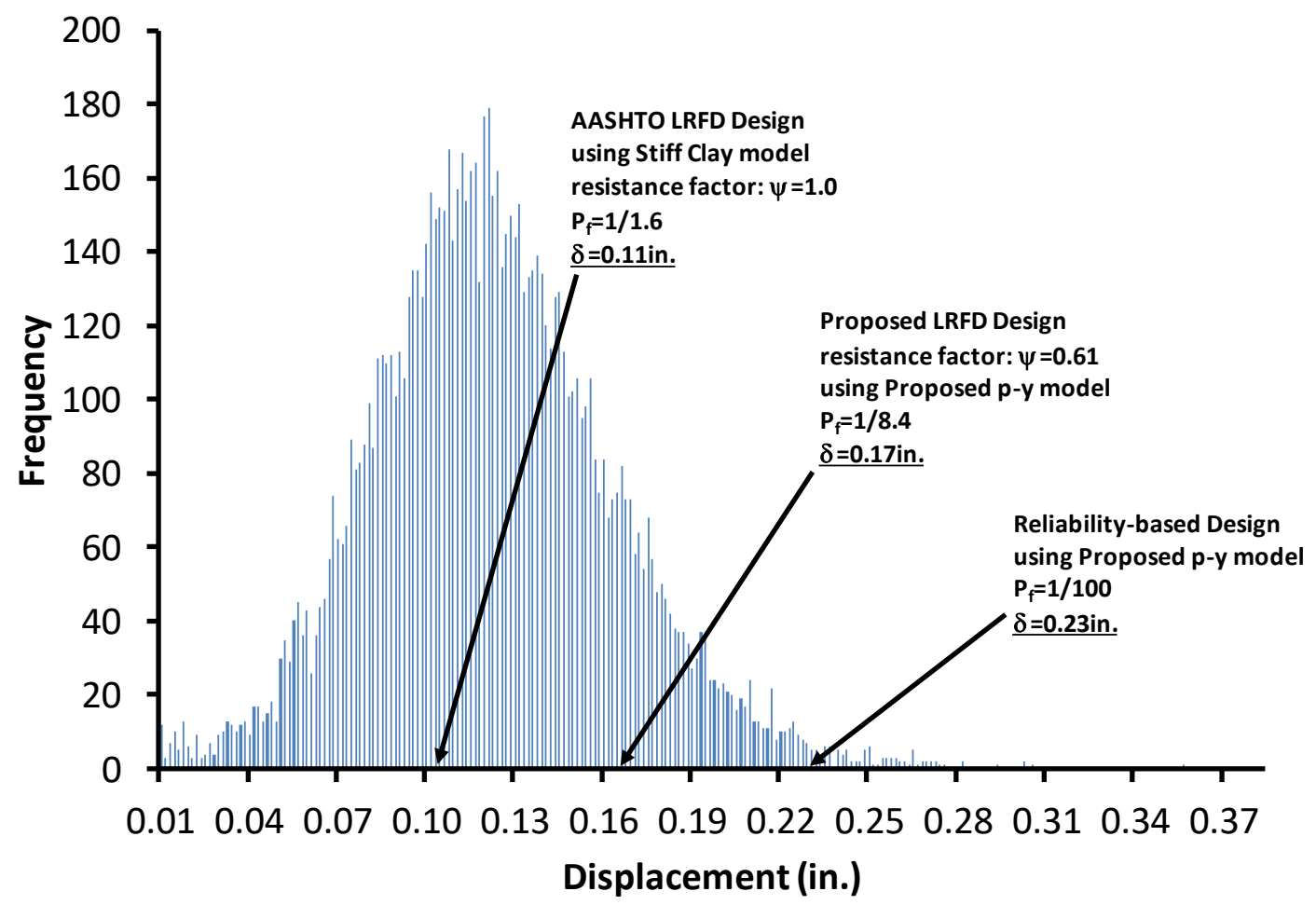

Figure 8.25 - Case $S-1$ with $P / P_{\text {ult }}=0.31 ; P=87,059 \mathrm{lbs}$. and target $\mathrm{P}_{\mathrm{f}}=1 / 100$ 


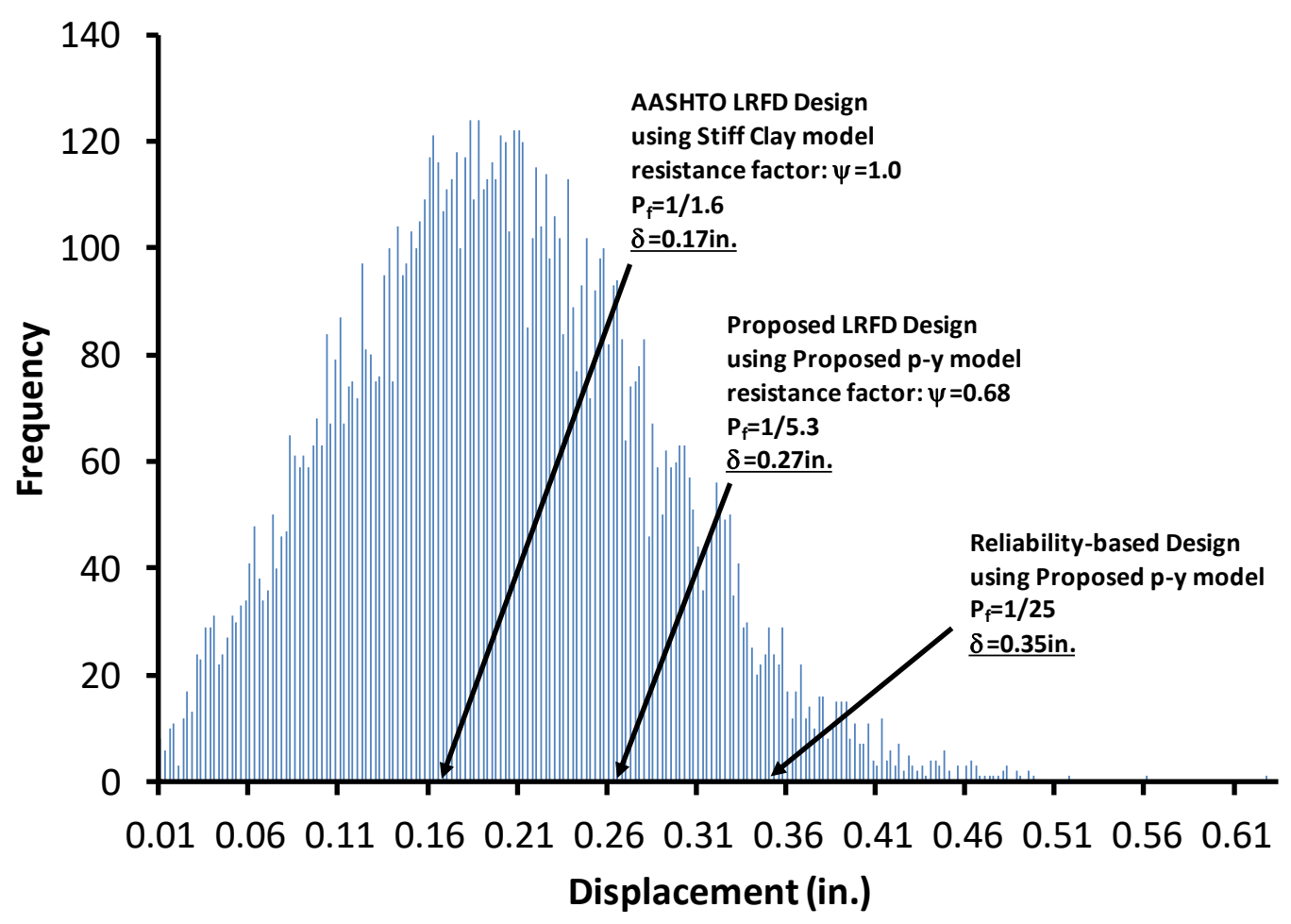

Figure 8.26 - Case $S-2$ with $P / P_{u l t}=0.34 ; P=88,471$ lbs. and target $P_{f}=1 / 25$

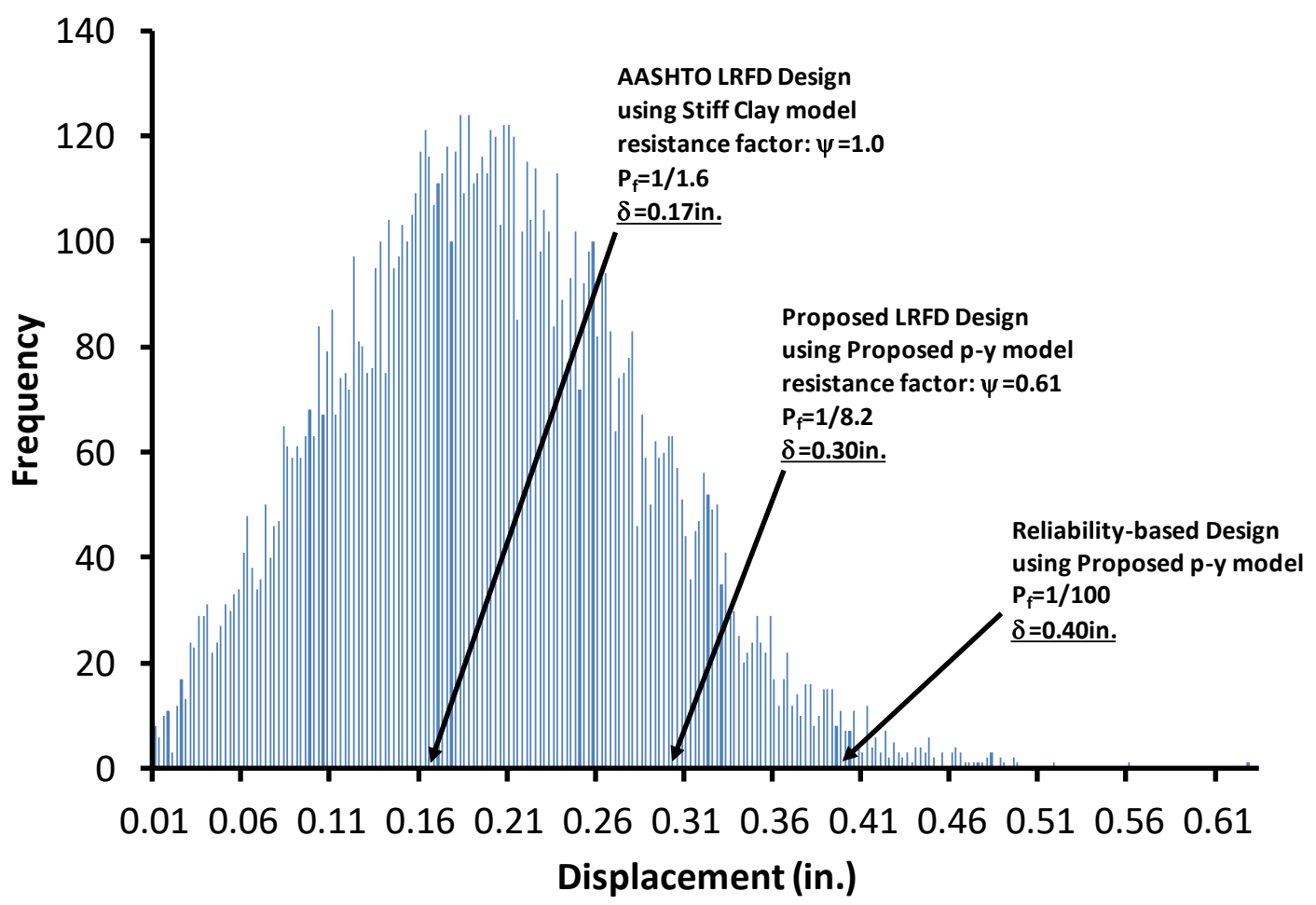

Figure 8.27 - Case S-2 with $P / P_{\text {ult }}=0.34 ; P=88,471 \mathrm{lbs}$. and target $\mathrm{P}_{\mathrm{f}}=1 / 100$ 


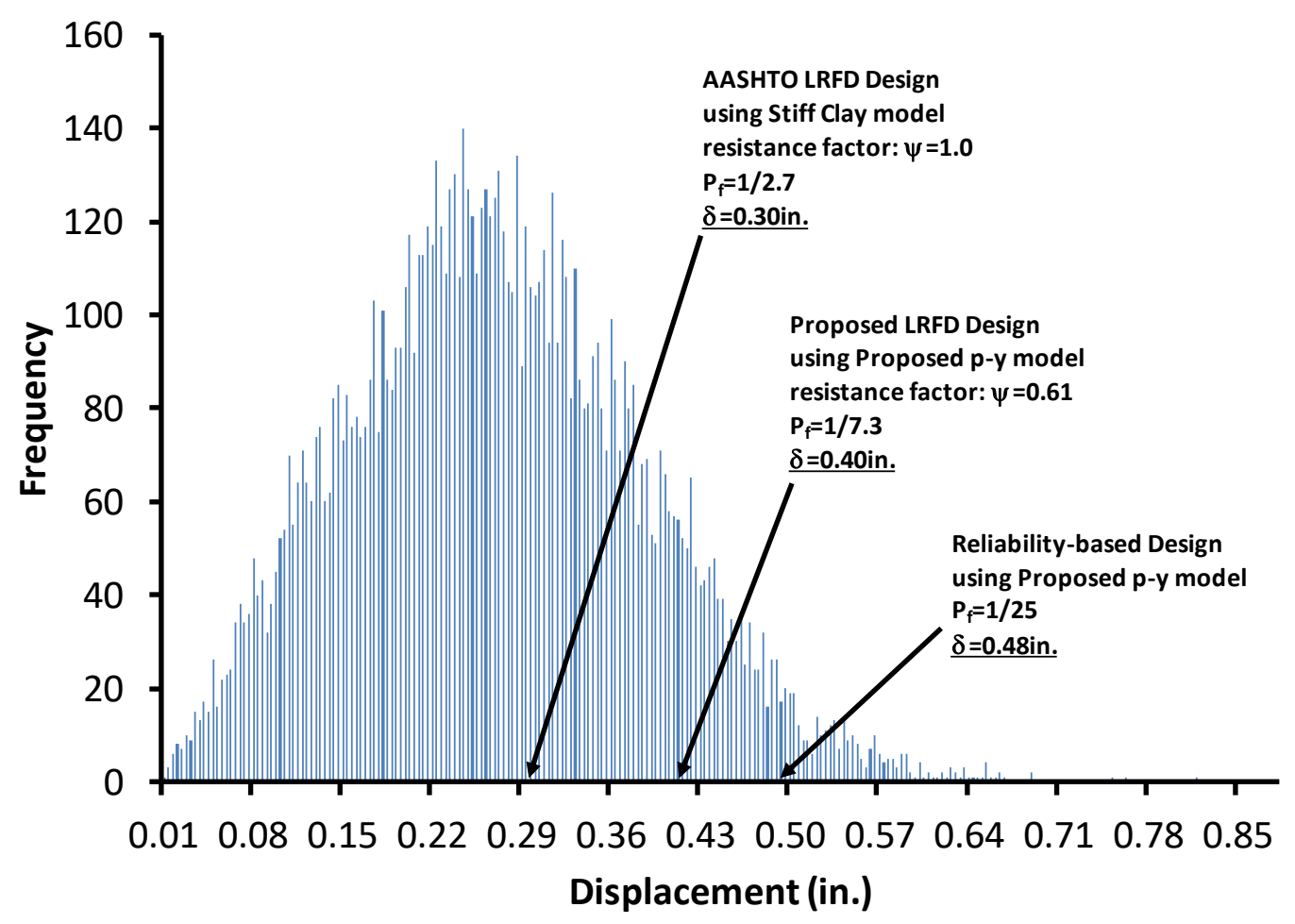

Figure 8.28 - Case S-3 with $P / P_{\text {ult }}=0.39 ; P=115,294$ lbs. and target $P_{f}=1 / 25$

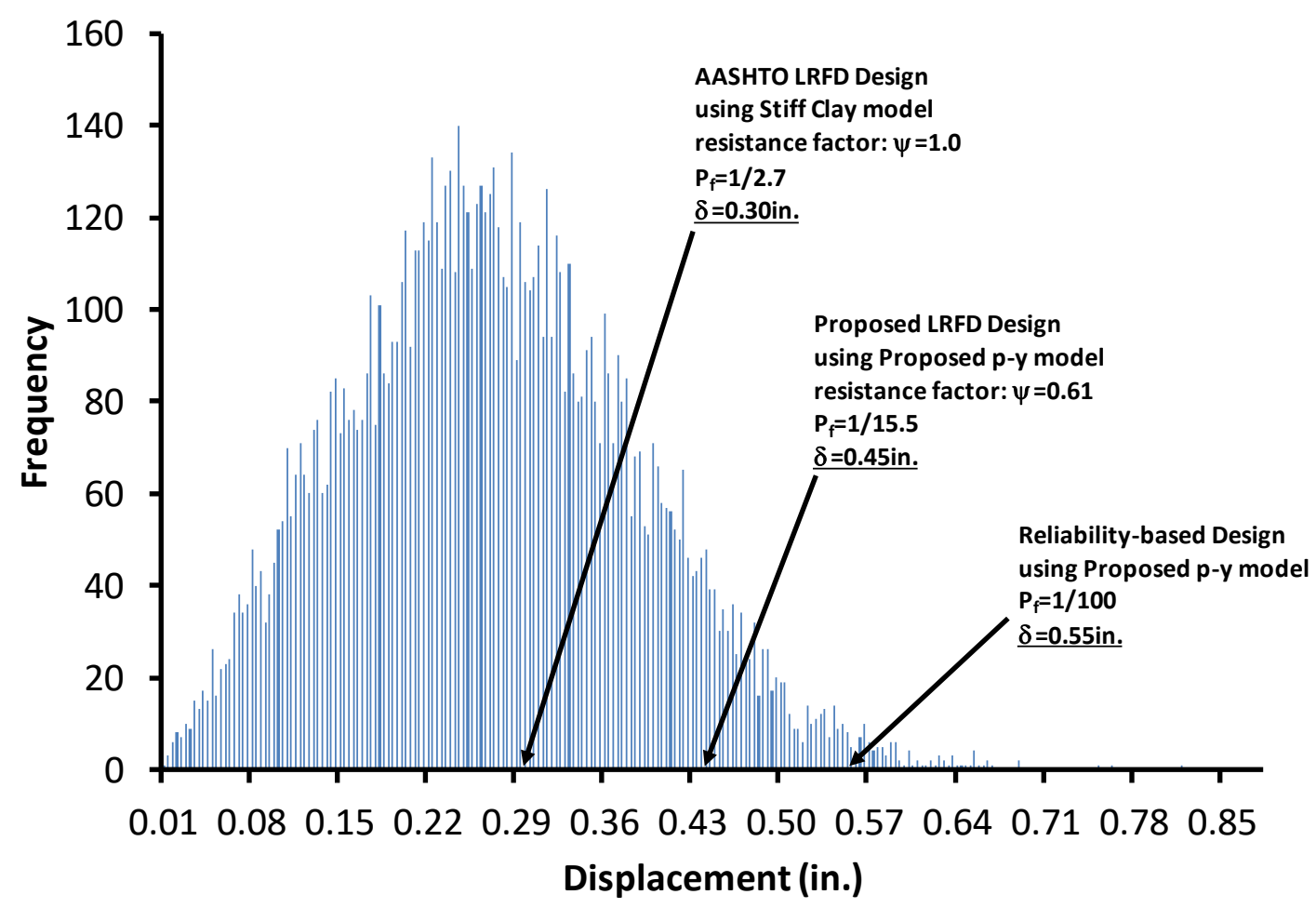

Figure 8.29 - Case $S-3$ with $P / P_{\text {ult }}=0.39 ; P=115,294$ lbs. and target $P_{f}=1 / 100$ 


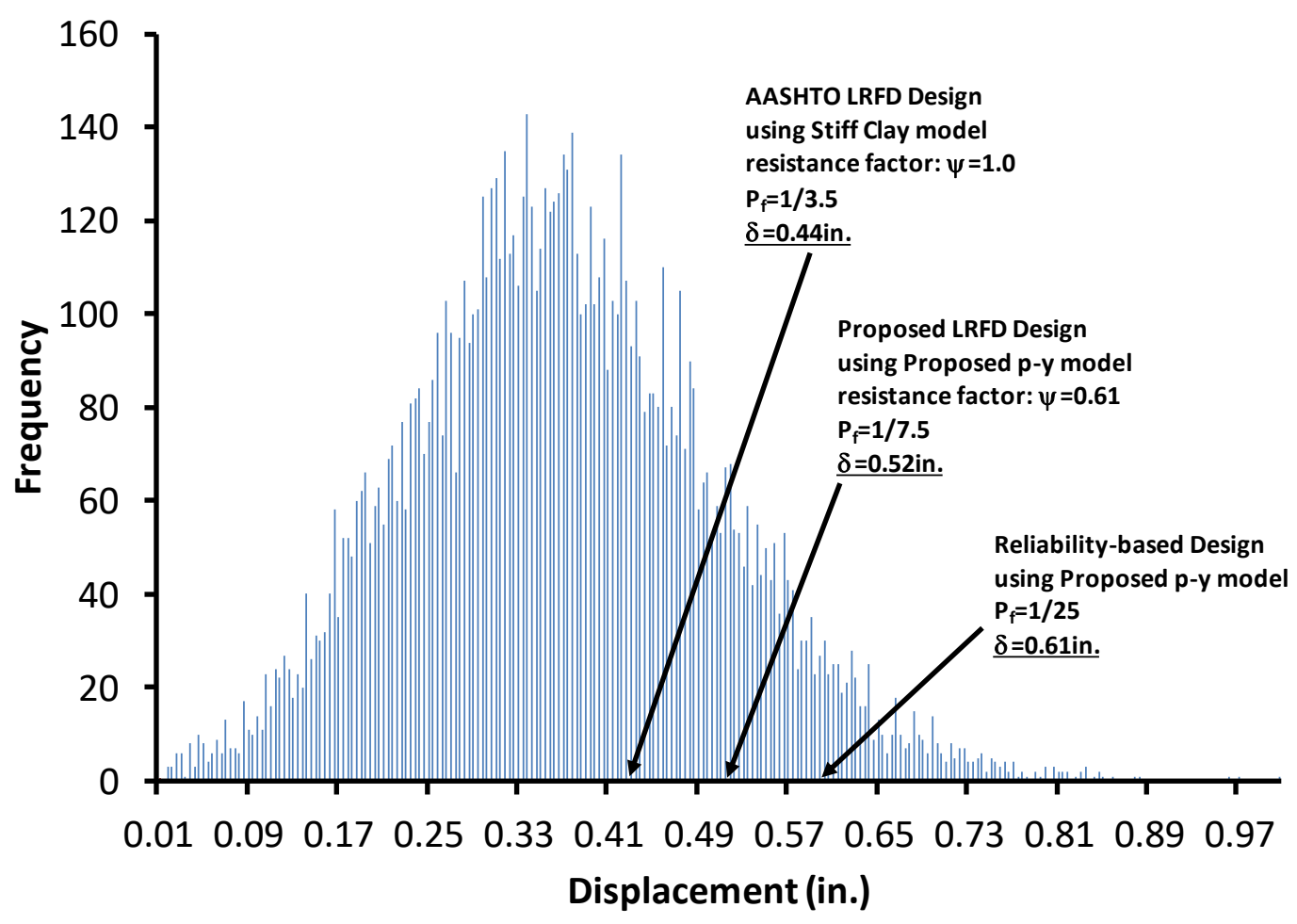

Figure 8.30 - Case $\mathrm{S}-4$ with $\mathrm{P} / \mathrm{P}_{\text {ult }}=0.44 ; \mathrm{P}=150,588 \mathrm{lbs}$. and target $\mathrm{P}_{\mathrm{f}}=1 / 25$

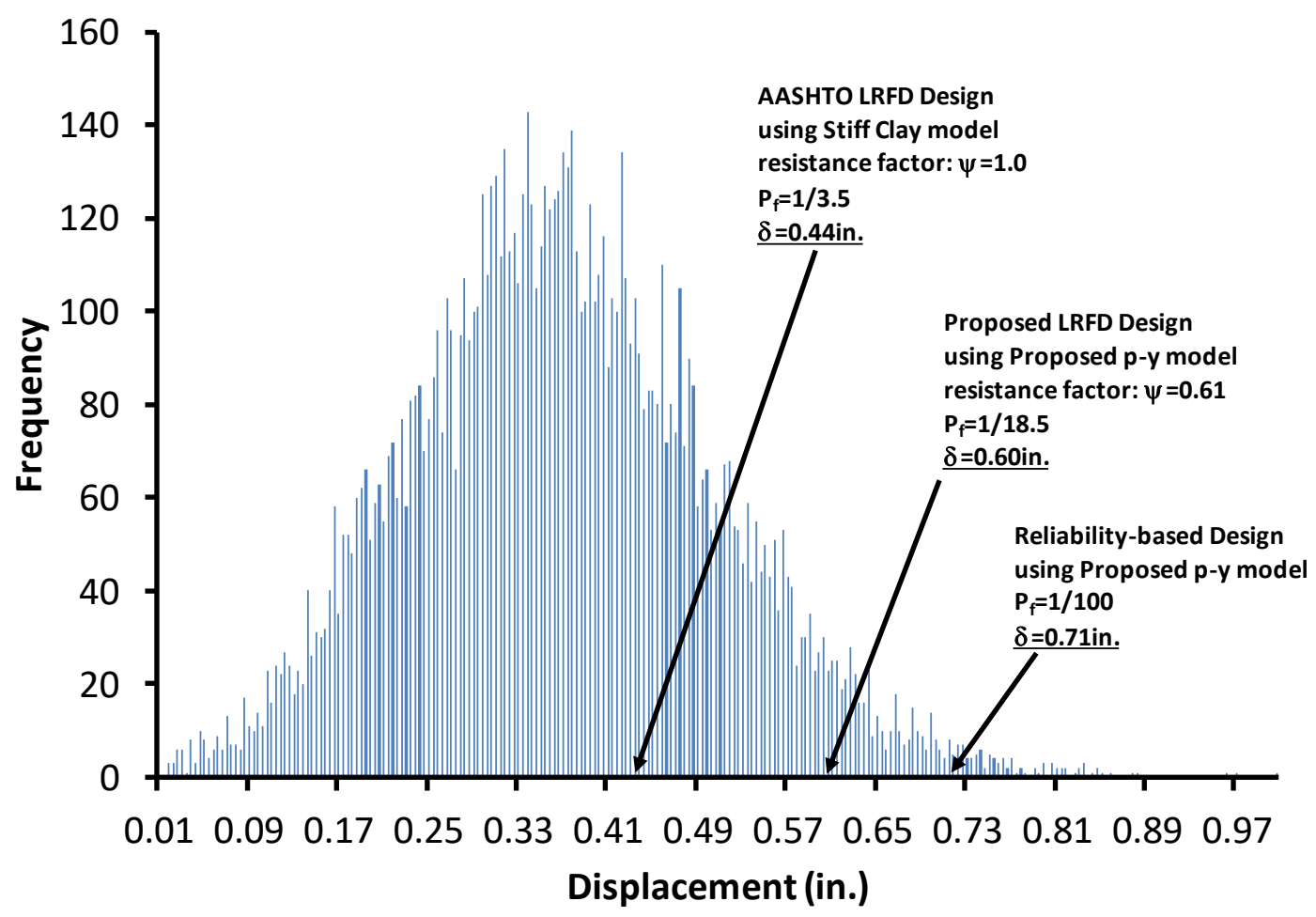

Figure 8.31 - Case $S-4$ with $P / P_{u l t}=0.44 ; P=150,588$ lbs. and target $P_{f}=1 / 100$ 


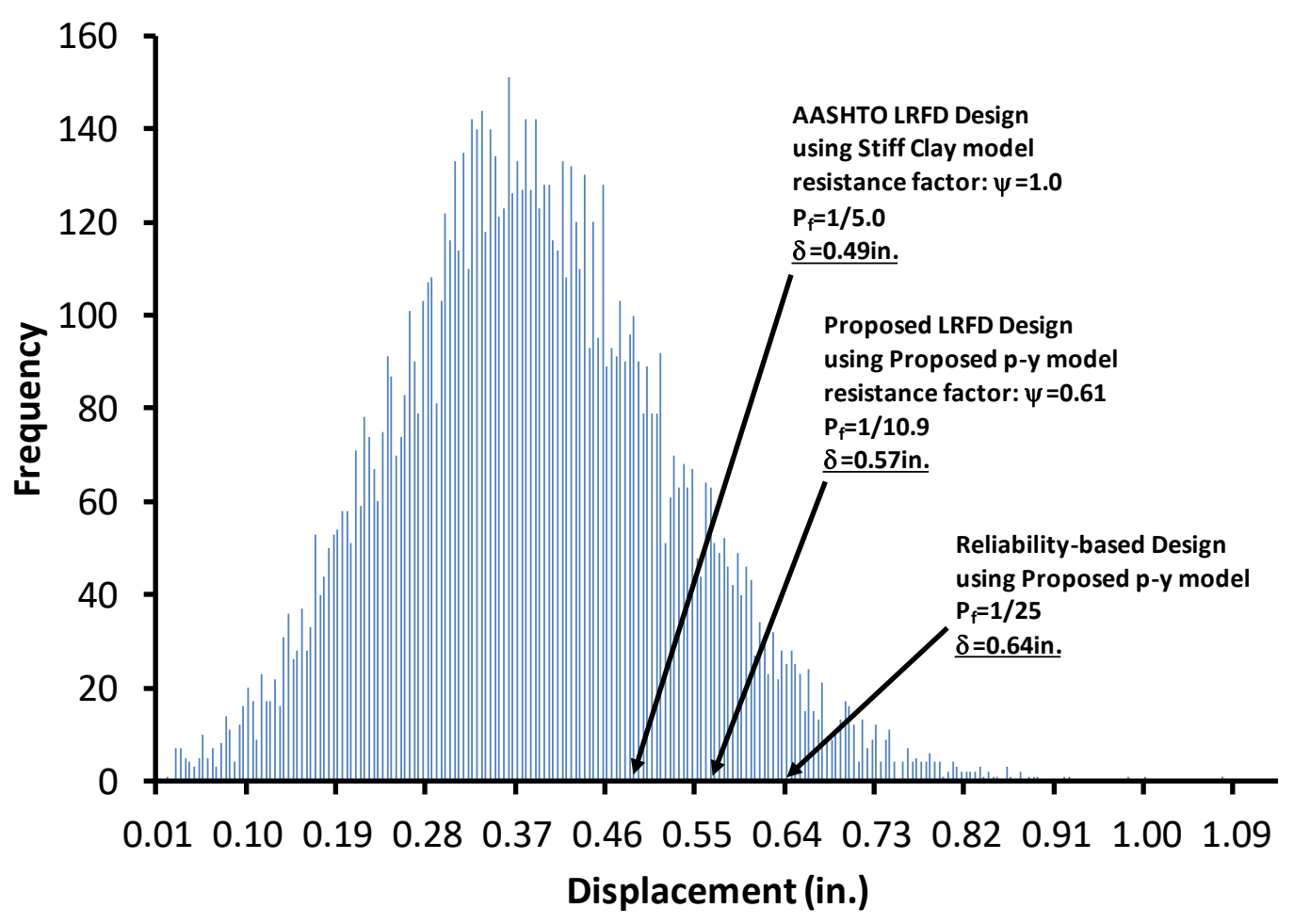

Figure 8.32 - Case S-5 with $P / P_{\text {ult }}=0.43 ; P=150,588$ lbs. and target $P_{f}=1 / 25$

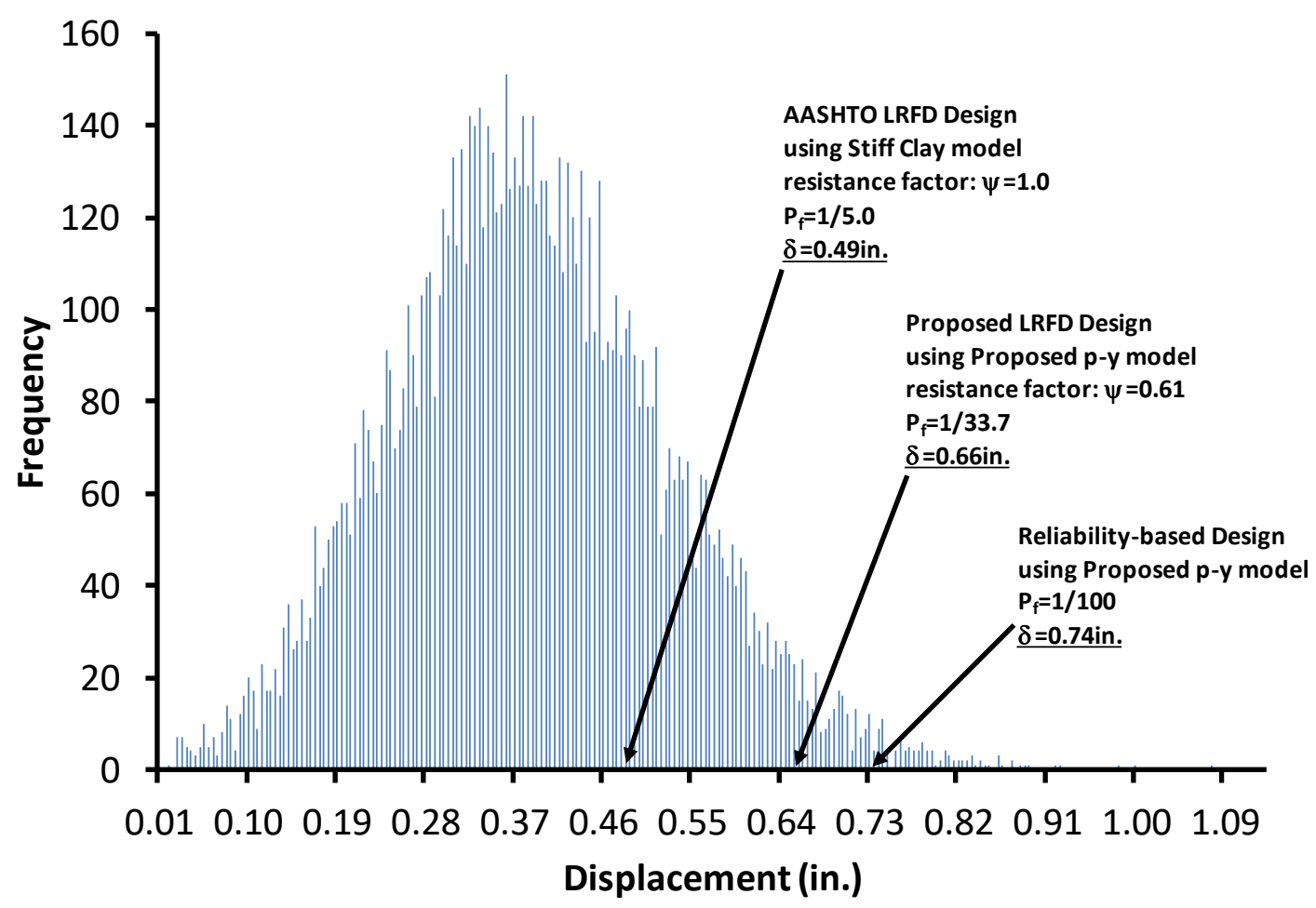

Figure 8.33 - Case S-5 with $P / P_{\text {ult }}=0.43 ; P=150,588$ lbs. and target $P_{f}=1 / 100$ 


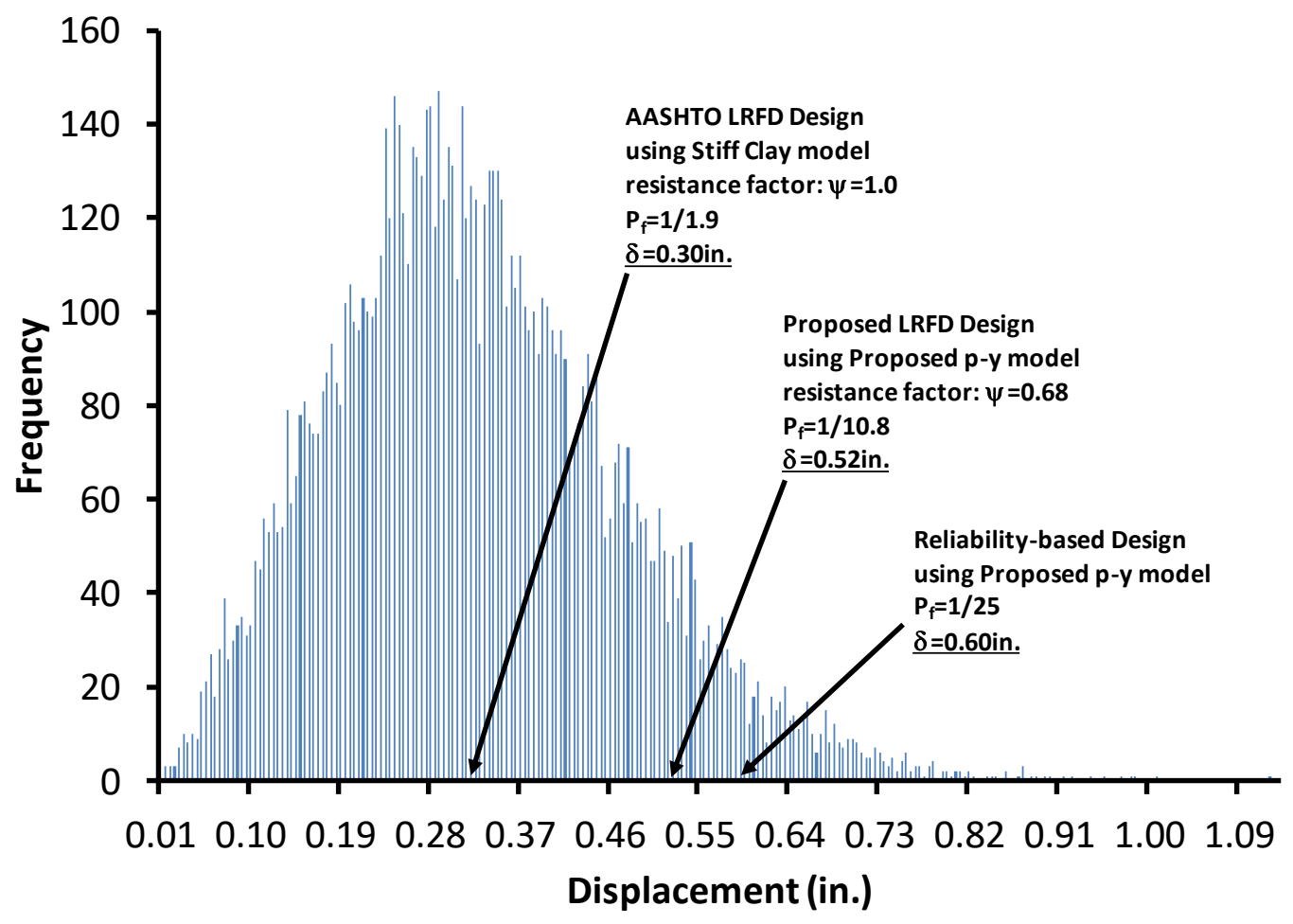

Figure 8.34 - Case G-6 with $P / P_{\text {ult }}=0.47 ; P=117,500$ lbs. and target $P_{f}=1 / 25$

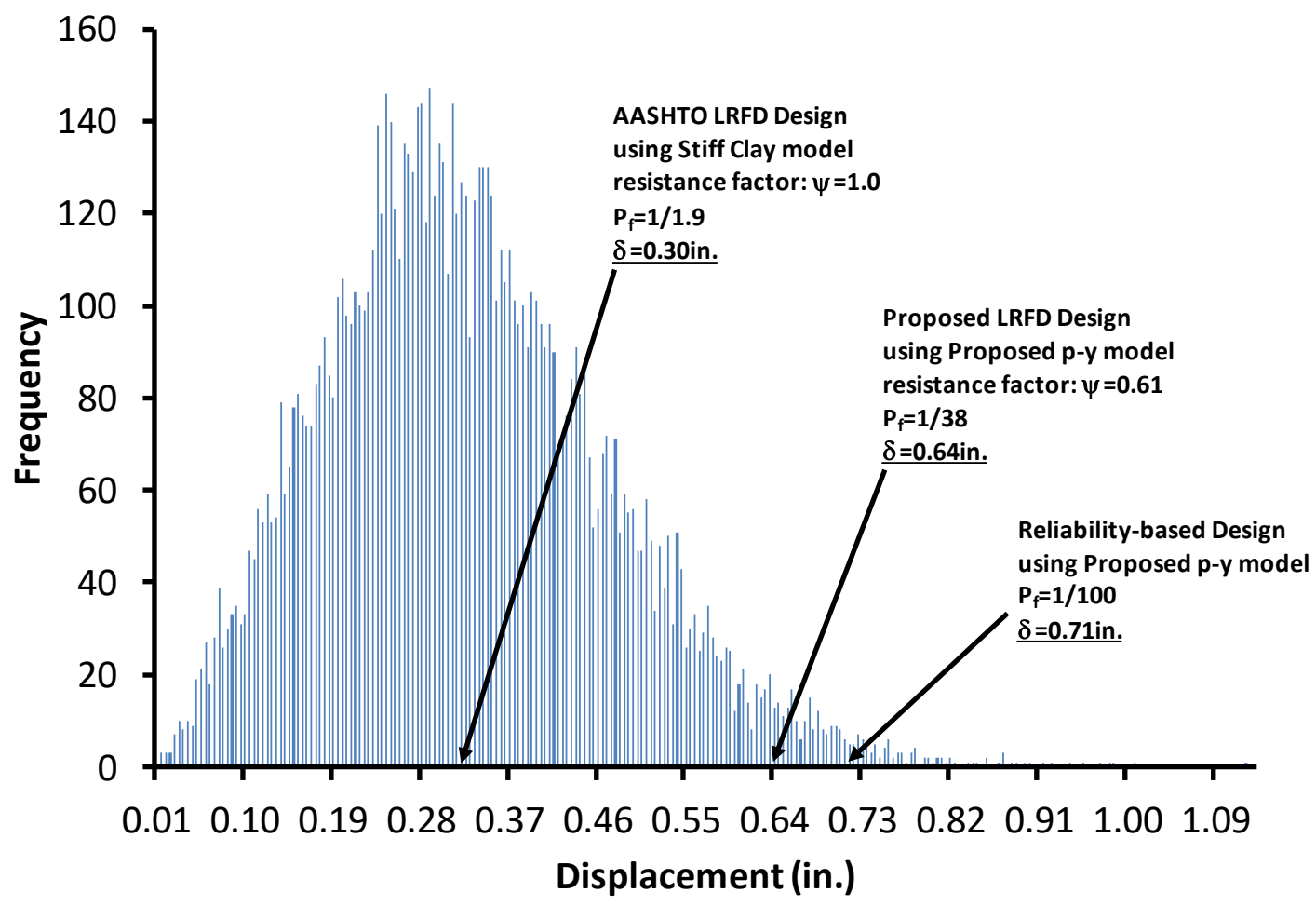

Figure 8.35 - Case G-6 with $P / P_{u l t}=0.47 ; P=117,500$ lbs. and target $P_{f}=1 / 100$ 


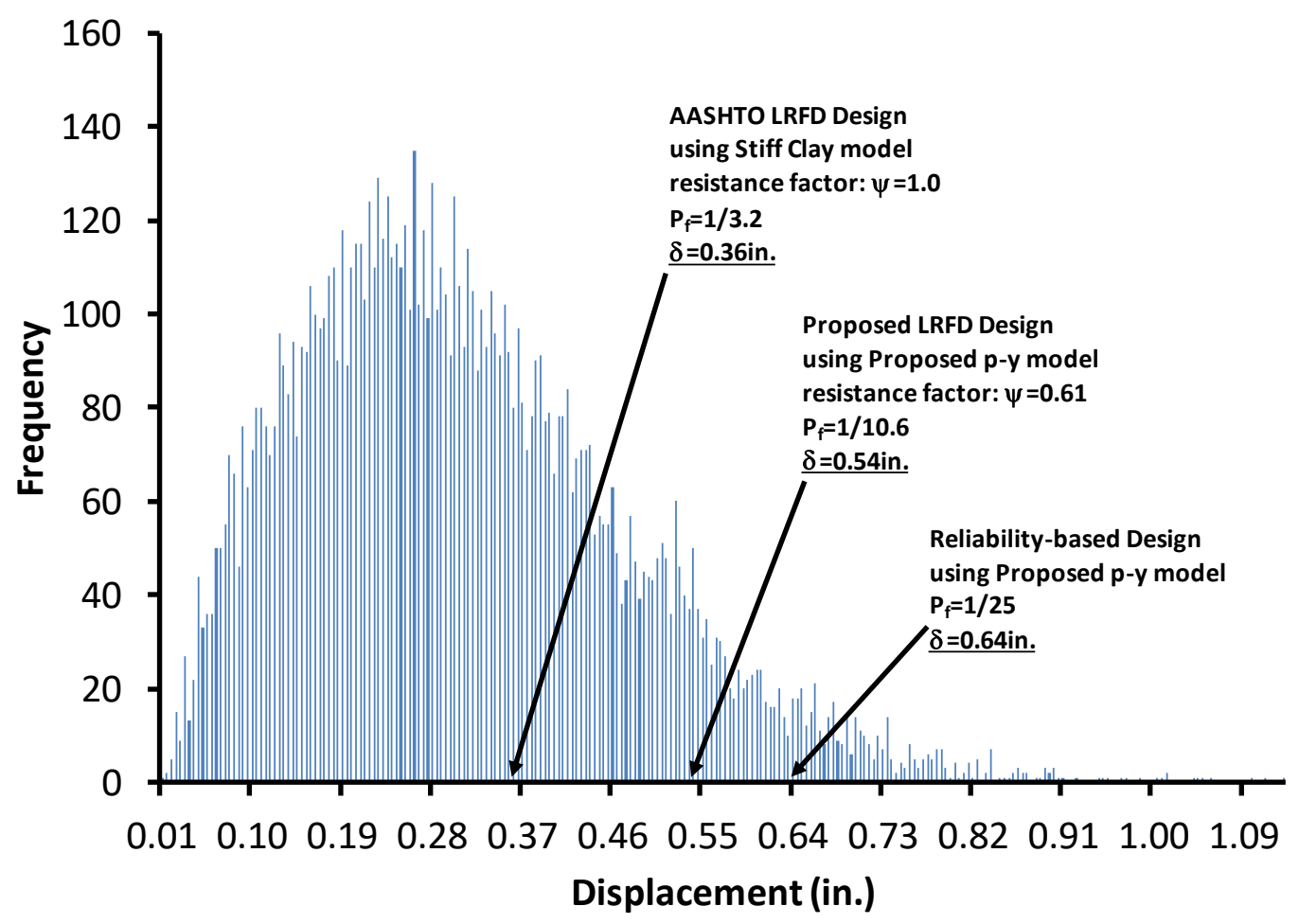

Figure 8.36 - Case G-7 with $P / P_{u l t}=0.47 ; P=86,950$ lbs. and target $P_{f}=1 / 25$

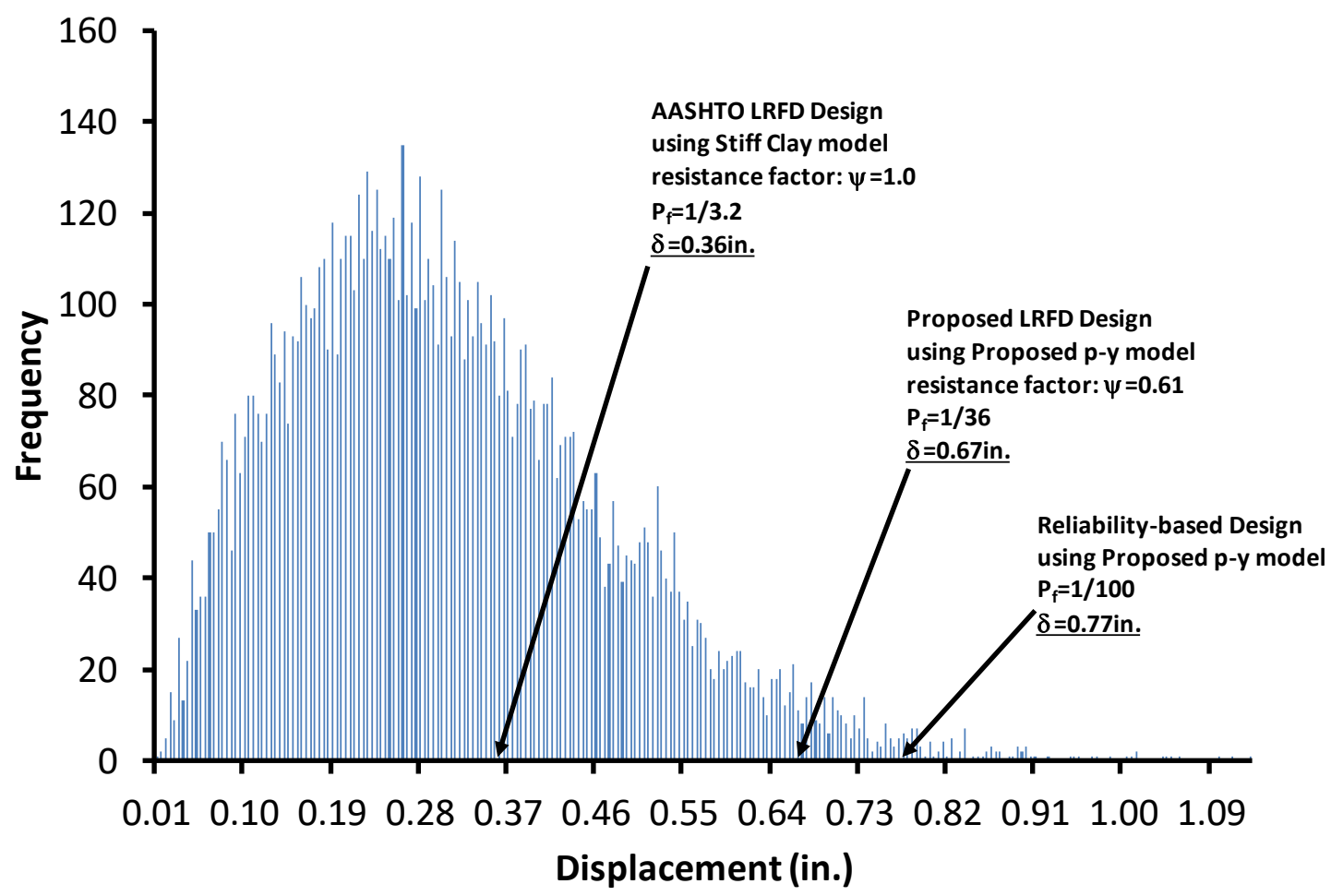

Figure 8.37 - Case G-7 with $P / P_{\text {ult }}=0.47 ; P=86,950$ lbs. and target $P_{f}=1 / 100$ 


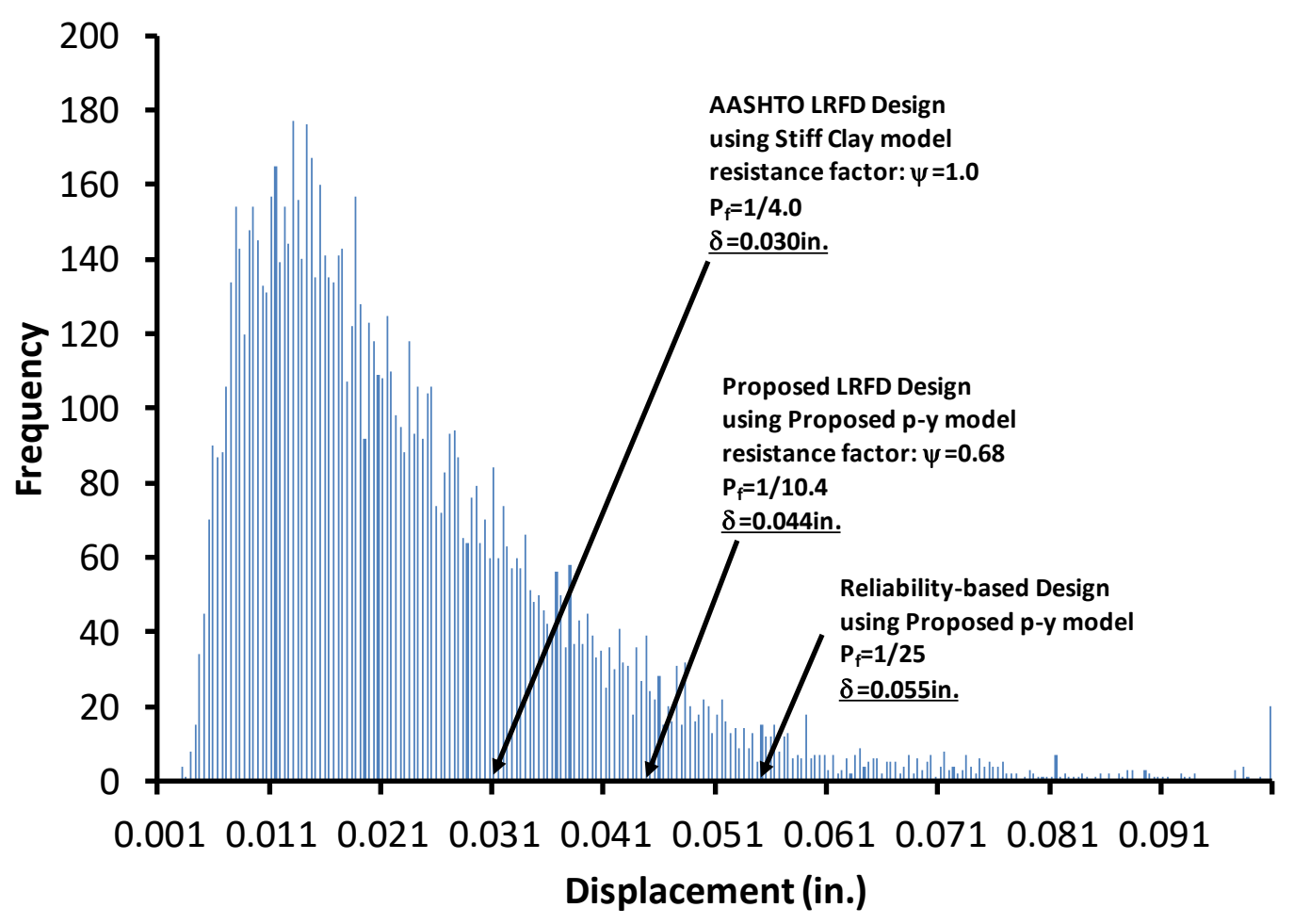

Figure 8.38 - Case S-8 with $P / P_{\text {ult }}=0.43 ; P=171,294 \mathrm{lbs}$. and target $P_{f}=1 / 25$

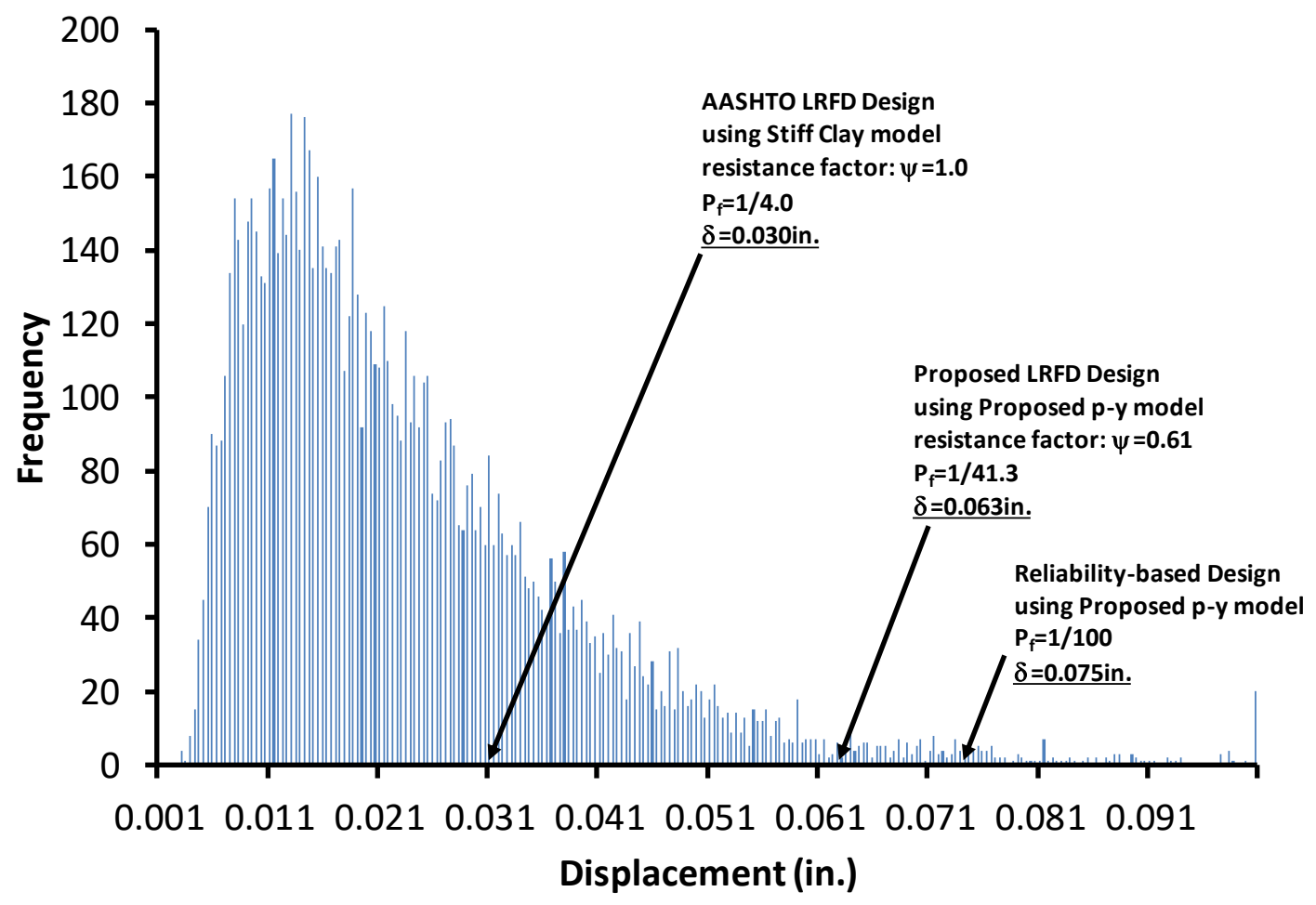

Figure 8.39 - Case S-8 with $P / P_{u l t}=0.43 ; P=171,294 \mathrm{lbs}$. and target $P_{f}=1 / 100$ 


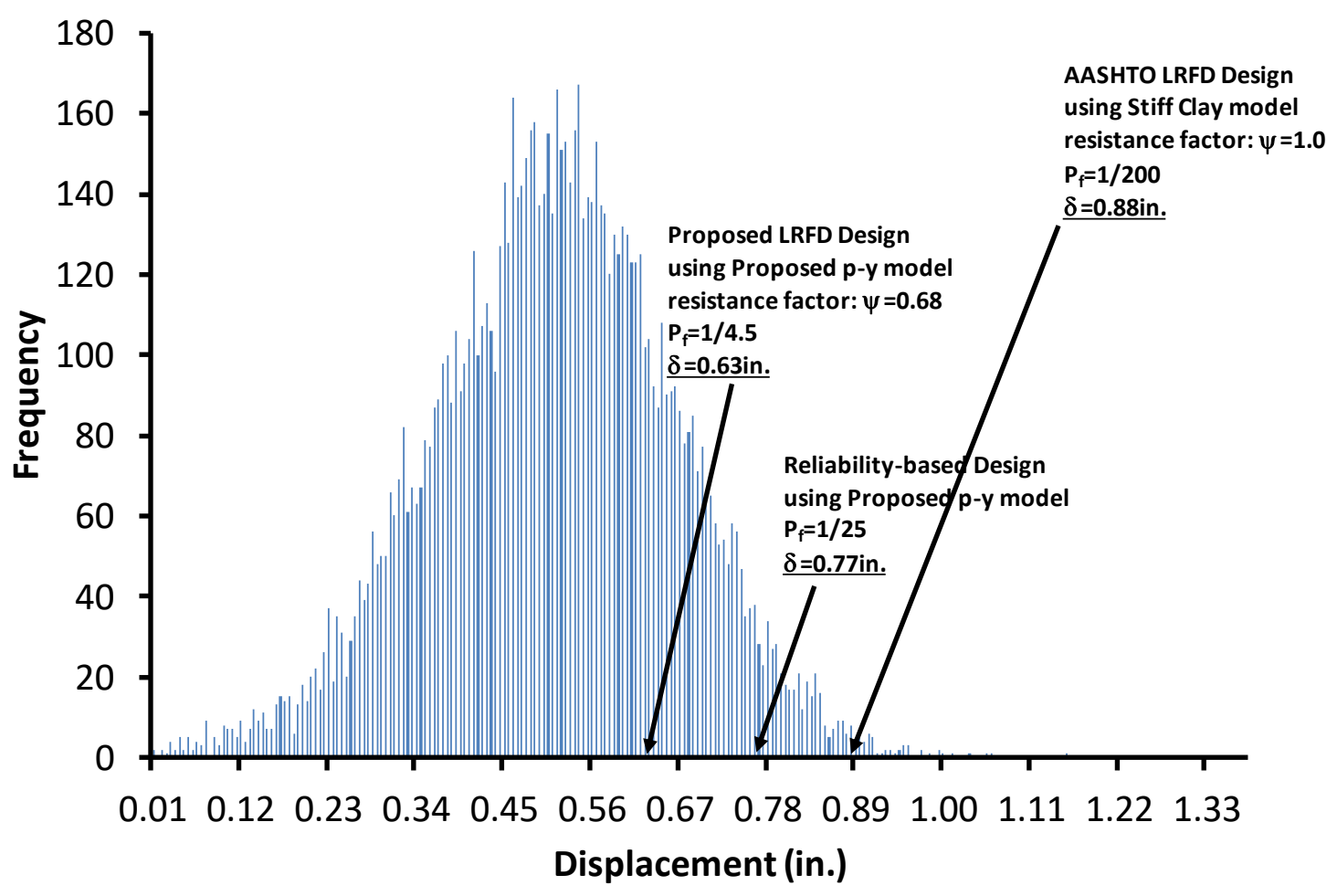

Figure 8.40 - Case $S-9$ with $P / P_{u l t}=0.32 ; P=80,000$ lbs. and target $P_{f}=1 / 25$

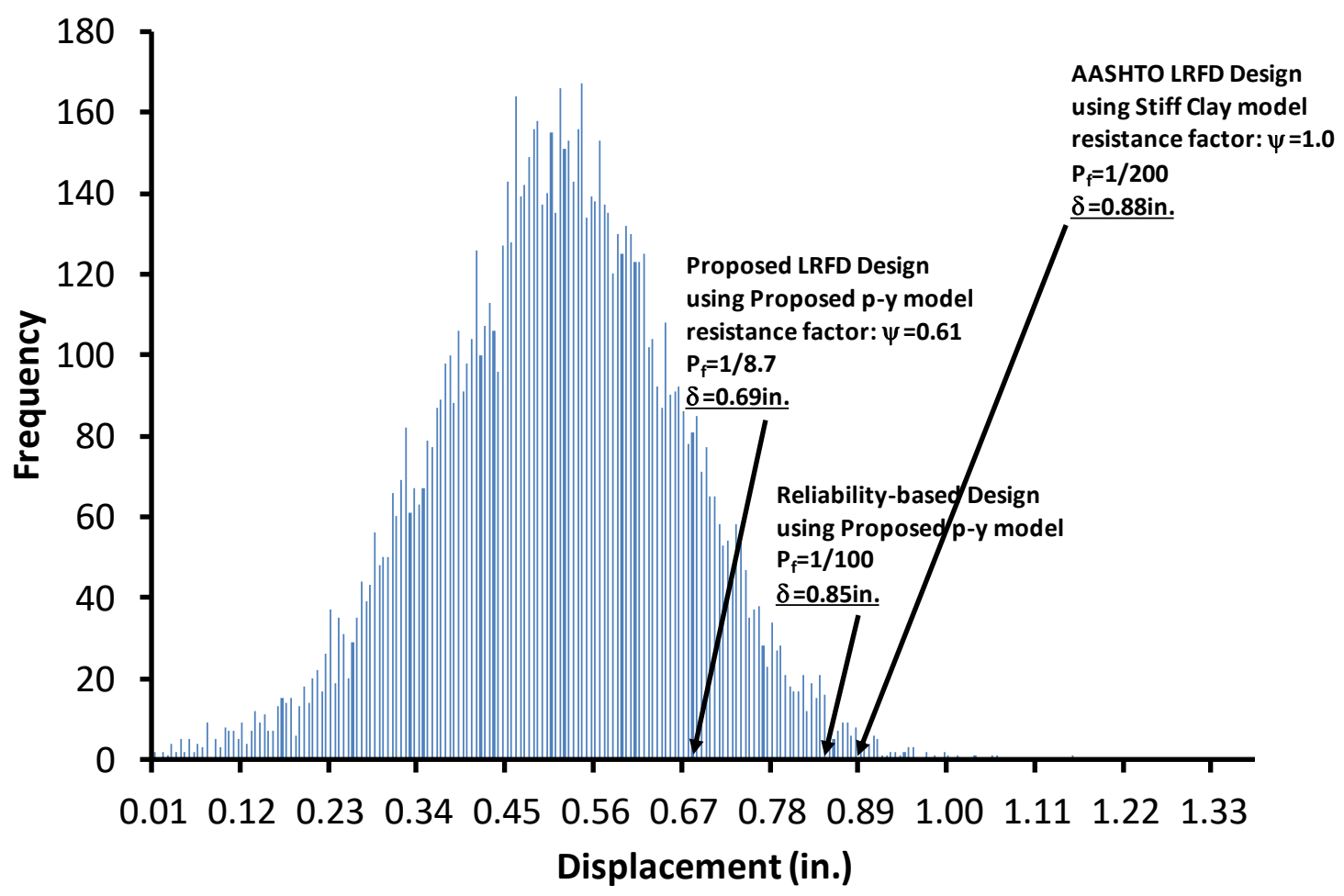

Figure 8.41 - Case $S-9$ with $P / P_{u l t}=0.32 ; P=80,000$ lbs. and target $P_{f}=1 / 100$ 
The results from Figure 8.24 through Figure 8.41 show that displacement produced from the proposed LRFD method is smaller than the displacement from RBD method but higher than that from AASHTO LRFD method. Probability of failure produced from the proposed LRFD method is higher than the RBD target probability of failure but smaller than that from AASHTO LRFD method. For almost all cases, displacement obtained from the AASHTO LRFD method always over underestimate the RBD displacement. Moreover, probability of failure obtained from the AASHTO LRFD method is much higher than the RBD target probability of failure. The only exception is extreme Case S-9 where AASHTO LRFD using Reese's stiff clay model produces displacement higher than the RBD displacement and produces probability of failure equals to 1 over 200 because of the effect of using Stiff Clay model to represent lateral load transfer on the very soft shale layer.

In summary, using the Proposed LRFD at Service Limit State, which does not require reliability-based analysis, one can produce the displacement and probability of failure which are closer to the RBD values than those obtained from AASHTO method. Therefore, the Proposed LRFD method more consistently achieves the target reliability than current AASHTO LRFD method.

Displacement and probability of failure calculated using AASHTO LRFD method depend only on the Nominal Lateral Load, but not the RBD target probability of failure. The RBD target probability of failure does affect the displacement and probability of failure calculated using the proposed LRFD method. However, the effects are very small and does not change the above conclusions of using proposed LRFD procedure. 


\subsubsection{Comparison of the Results Obtained from 3 Methods Using Calculated Nominal}

Loads for the $R B D P_{f}=1 / 25$

The RBD displacement has been used as a reference to calculate the changes of displacement using AASHTO and Proposed LFRD. Table 8.11 shows the displacements produced by three methods under the calculated nominal loads; the difference in values and the change in percentage between displacements from the proposed and AASHTO methods compared to the RBD displacement. Figure 8.42 and Figure 8.43 plot the change of the proposed and AASHTO displacements with respect to the RBD displacement for the target probability of failure equals to $1 / 25$, in inches and in percentage, respectively.

Table 8.11 - Displacement comparison between 3 methods using calculated nominal loads with Target $P_{f}=1 / 25$

\begin{tabular}{c|c|ccc|cc|cc}
\hline Case & $P$ & \multicolumn{3}{|c|}{ Factored $\delta$ (in.) } & \multicolumn{2}{c}{ Change of $\delta$ (in) } & \multicolumn{2}{c}{ Change of $\delta(\%)$} \\
$\#$ & $\frac{P}{P_{u l t}}$ & AASHTO & Proposed & RBD & AASHTO & Proposed & AASHTO & Proposed \\
\hline S-1 & 0.31 & 0.11 & 0.16 & 0.20 & 0.09 & 0.04 & 45.00 & 20.00 \\
S-2 & 0.34 & 0.17 & 0.27 & 0.35 & 0.18 & 0.08 & 51.43 & 22.86 \\
S-3 & 0.39 & 0.30 & 0.4 & 0.48 & 0.18 & 0.08 & 37.50 & 16.67 \\
S-4 & 0.44 & 0.44 & 0.52 & 0.61 & 0.17 & 0.09 & 27.87 & 14.75 \\
S-5 & 0.43 & 0.49 & 0.57 & 0.64 & 0.15 & 0.07 & 23.44 & 10.94 \\
G-6 & 0.47 & 0.30 & 0.52 & 0.60 & 0.30 & 0.08 & 50.00 & 13.33 \\
G-7 & 0.47 & 0.36 & 0.54 & 0.64 & 0.28 & 0.10 & 43.75 & 15.63 \\
S-8 & 0.43 & 0.030 & 0.044 & 0.055 & 0.03 & 0.01 & 45.45 & 20.00 \\
S-9 & 0.32 & 0.88 & 0.63 & 0.77 & 0.11 & 0.14 & 14.29 & 18.18 \\
\hline
\end{tabular}




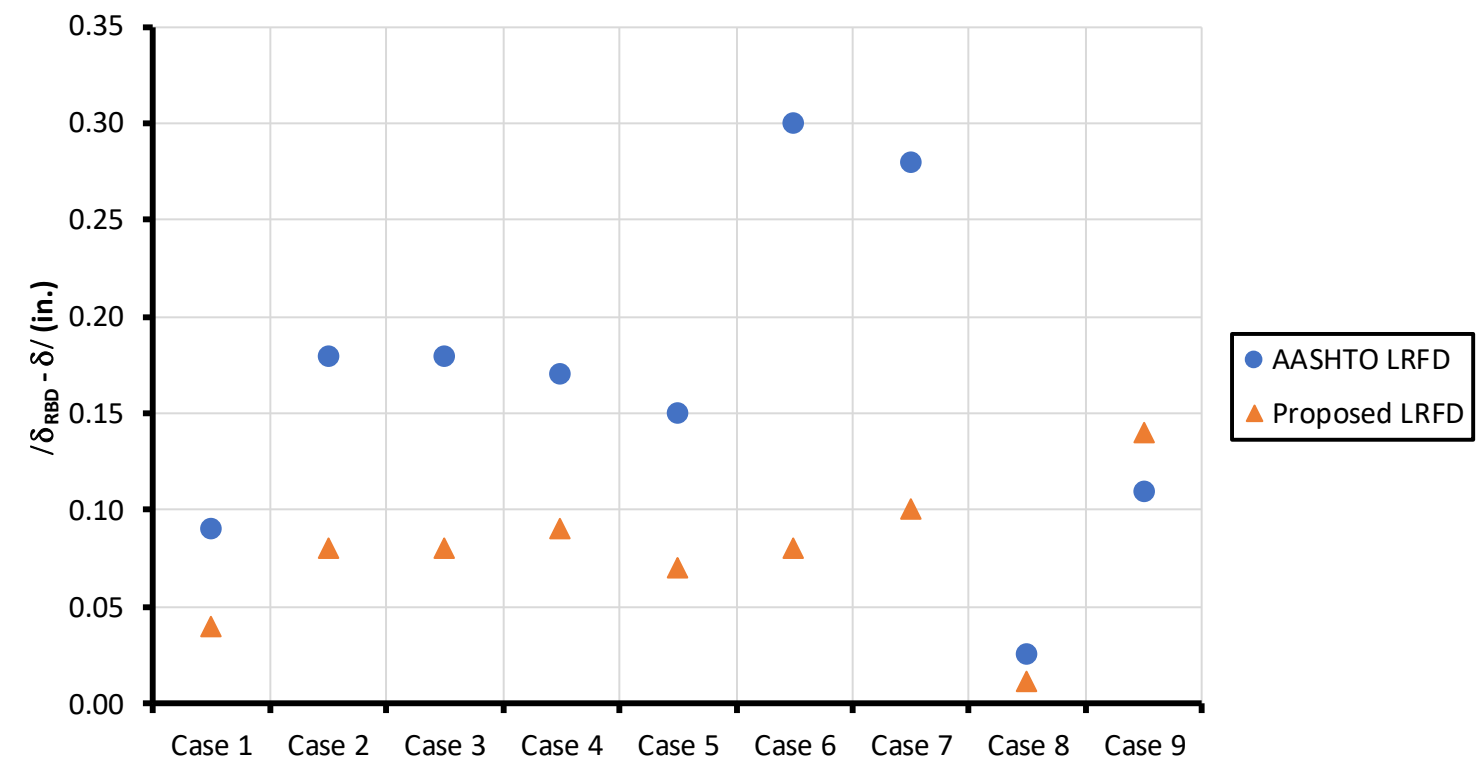

Figure 8.42 - Change of displacement with respect to RBD displacement (in inches) for $P_{f}=1 / 25$, using calculated nominal loads

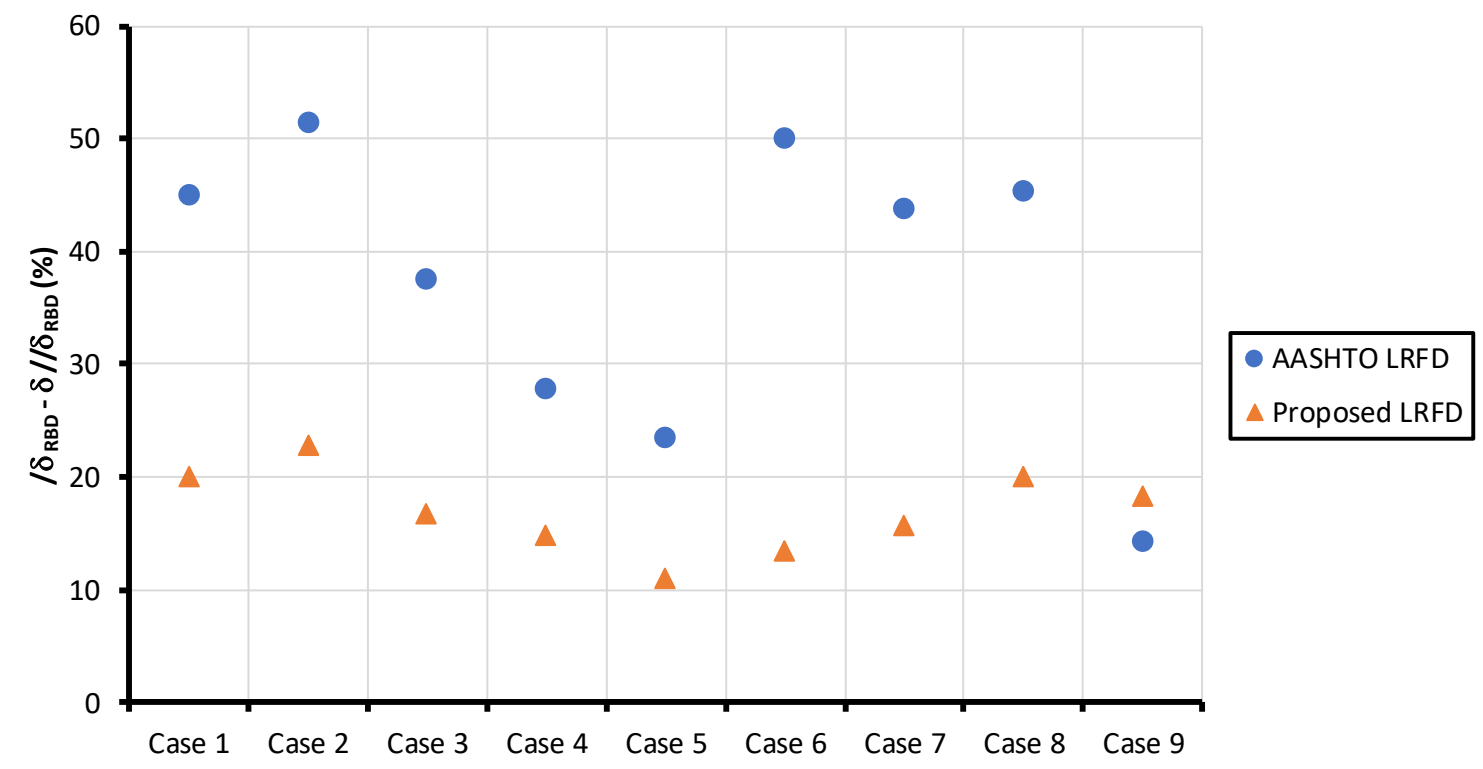

Figure 8.43 - Change of displacement with respect to RBD displacement (in \%) for $P_{f}=1 / 25$, using calculated nominal loads 
The displacement produced by AASHTO LRFD method is much smaller than the RBD displacement. The differences are in between about 0.10in to 0.30in (Figure 8.42) except for the two extreme cases S-8 and S-9. Besides, AASHTO LRFD method produces displacements which are 22 to 51\% smaller than RBD displacements (Figure 8.43). On the other hand, the Proposed LRFD method produces displacements which are closer to RBD displacements than AASHTO values. The average displacement difference is about 0.08in (Figure 8.42). Moreover, the Proposed LRFD method produces displacements which are less than $22 \%$ of RBD displacement (Figure 8.43).

The RBD target probability of failure which is equal to 1 over 25 has been used as a reference to calculate the differences of probability of failure obtained using AASHTO and Proposed LFRD methods. Table 8.12 shows the probability of failure produced by the Proposed and the AASHTO design methods, as well as the RBD target probability of failure. The ratios between the probability of failure from the Proposed and AASHTO methods and the RBD target probability of failure have been presented, as shown in Table 8.12 and Figure 8.44 . 
Table 8.12 - Probability of Failure comparison between 3 methods using calculated nominal loads with Target $P_{f}=1 / 25$

\begin{tabular}{c|c|ccc|cc}
\hline Case & $P$ & \multicolumn{3}{|c|}{ Probability of Failure } & \multicolumn{2}{c}{$\begin{array}{c}\text { Change of } P_{f} \\
\text { (ratio) }\end{array}$} \\
\cline { 5 - 6 } & $\frac{P}{P_{u l t}}$ & AASHTO & Proposed & RBD & AASHTO & Proposed \\
\hline S-1 & 0.31 & $1 / 1.6$ & $1 / 5.5$ & $1 / 25$ & 15.63 & 4.55 \\
S-2 & 0.34 & $1 / 1.6$ & $1 / 5.3$ & $1 / 25$ & 15.63 & 4.72 \\
S-3 & 0.39 & $1 / 2.7$ & $1 / 7.3$ & $1 / 25$ & 9.26 & 3.42 \\
S-4 & 0.44 & $1 / 3.5$ & $1 / 7.5$ & $1 / 25$ & 7.14 & 3.33 \\
S-5 & 0.43 & $1 / 5.0$ & $1 / 10.9$ & $1 / 25$ & 5.00 & 2.29 \\
G-6 & 0.47 & $1 / 1.9$ & $1 / 10.8$ & $1 / 25$ & 13.16 & 2.31 \\
G-7 & 0.47 & $1 / 3.2$ & $1 / 10.6$ & $1 / 25$ & 7.81 & 2.36 \\
S-8 & 0.43 & $1 / 4.0$ & $1 / 10.4$ & $1 / 25$ & 6.25 & 2.40 \\
S-9 & 0.32 & $1 / 200$ & $1 / 4.5$ & $1 / 25$ & 0.13 & 5.56 \\
\hline
\end{tabular}

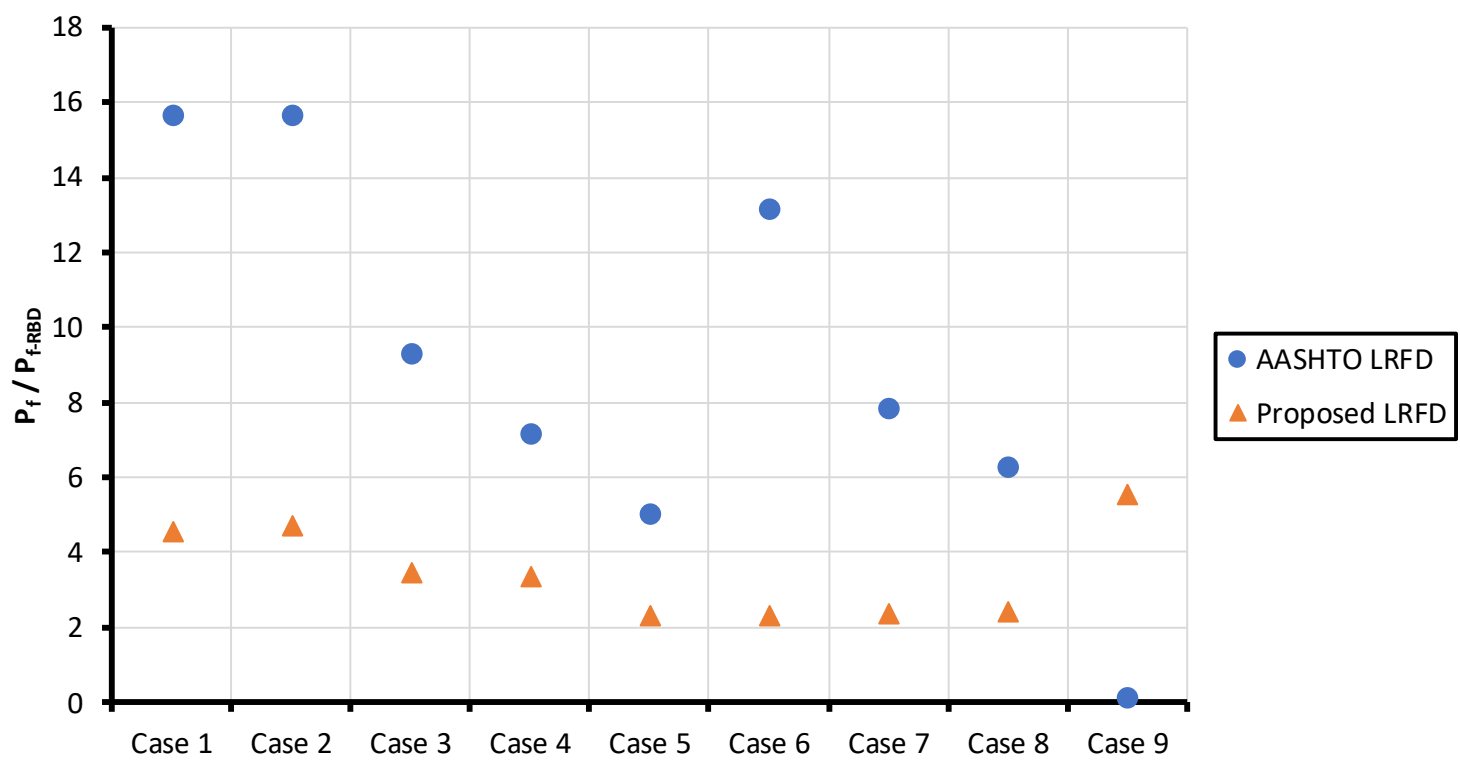

Figure 8.44 - Change of probability of failure with respect to the RBD target $P_{f}=1 / 25$ (in ratio) using calculated nominal loads 
The probability of failure produced by AASHTO LRFD method is much higher than the RBD target probability of failure (1 over 25 in this cases) except for the extreme case S-9. The ratios between AASHTO LRFD probability of failure and RBD target probability of failure are in between 5.0 and 15.6 (Figure 8.44). On the other hand, the Proposed LRFD method produces probability of failure which are closer to RBD target probability of failure than AASHTO values. The ratios between Proposed LRFD probability of failure and RBD target probability of failure are in between 2.3 and 5.6 (Figure 8.44 ) except for the extreme case S-9.

\subsubsection{Comparison of the $P_{f}$ Obtained from 3 Methods Using Calculated Nominal Loads for the $R B D P_{f}=1 / 100$}

Table 8.13 shows the displacements produced by three methods using the calculated nominal loads; the difference in values and the change in percentage between displacements from the proposed and AASHTO methods compared to the RBD displacement for the target probability of failure equals to $1 / 100$. Figure 8.45 and Figure 8.46 plot the change of proposed and AASHTO displacements with respect to RBD displacement for the target probability of $1 / 100$, in inches and in percentage, respectively. 
Table 8.13 - Displacement comparison between 3 methods using calculated nominal loads with Target $P_{f}=1 / 100$

\begin{tabular}{c|c|ccc|cc|cc}
\hline Case & $P$ & \multicolumn{3}{|c|}{ Factored $\delta$ (in.) } & \multicolumn{2}{c|}{ Change of $\delta$ (in) } & \multicolumn{2}{c}{ Change of $\delta(\%)$} \\
$\#$ & $P_{u l t}$ & AASHTO & Proposed & RBD & AASHTO & Proposed & AASHTO & Proposed \\
\hline S-1 & 0.31 & 0.11 & 0.17 & 0.23 & 0.12 & 0.06 & 52.17 & 26.09 \\
S-2 & 0.34 & 0.17 & 0.30 & 0.40 & 0.23 & 0.10 & 57.50 & 25.00 \\
S-3 & 0.39 & 0.30 & 0.45 & 0.55 & 0.25 & 0.10 & 45.45 & 18.18 \\
S-4 & 0.44 & 0.44 & 0.60 & 0.71 & 0.27 & 0.11 & 38.03 & 15.49 \\
S-5 & 0.43 & 0.49 & 0.66 & 0.74 & 0.25 & 0.08 & 33.78 & 10.81 \\
G-6 & 0.47 & 0.30 & 0.64 & 0.71 & 0.41 & 0.07 & 57.75 & 9.86 \\
G-7 & 0.47 & 0.36 & 0.67 & 0.77 & 0.41 & 0.10 & 53.25 & 12.99 \\
S-8 & 0.43 & 0.030 & 0.063 & 0.075 & 0.05 & 0.01 & 60.00 & 16.00 \\
S-9 & 0.32 & 0.88 & 0.69 & 0.85 & 0.03 & 0.16 & 3.53 & 18.82 \\
\hline
\end{tabular}

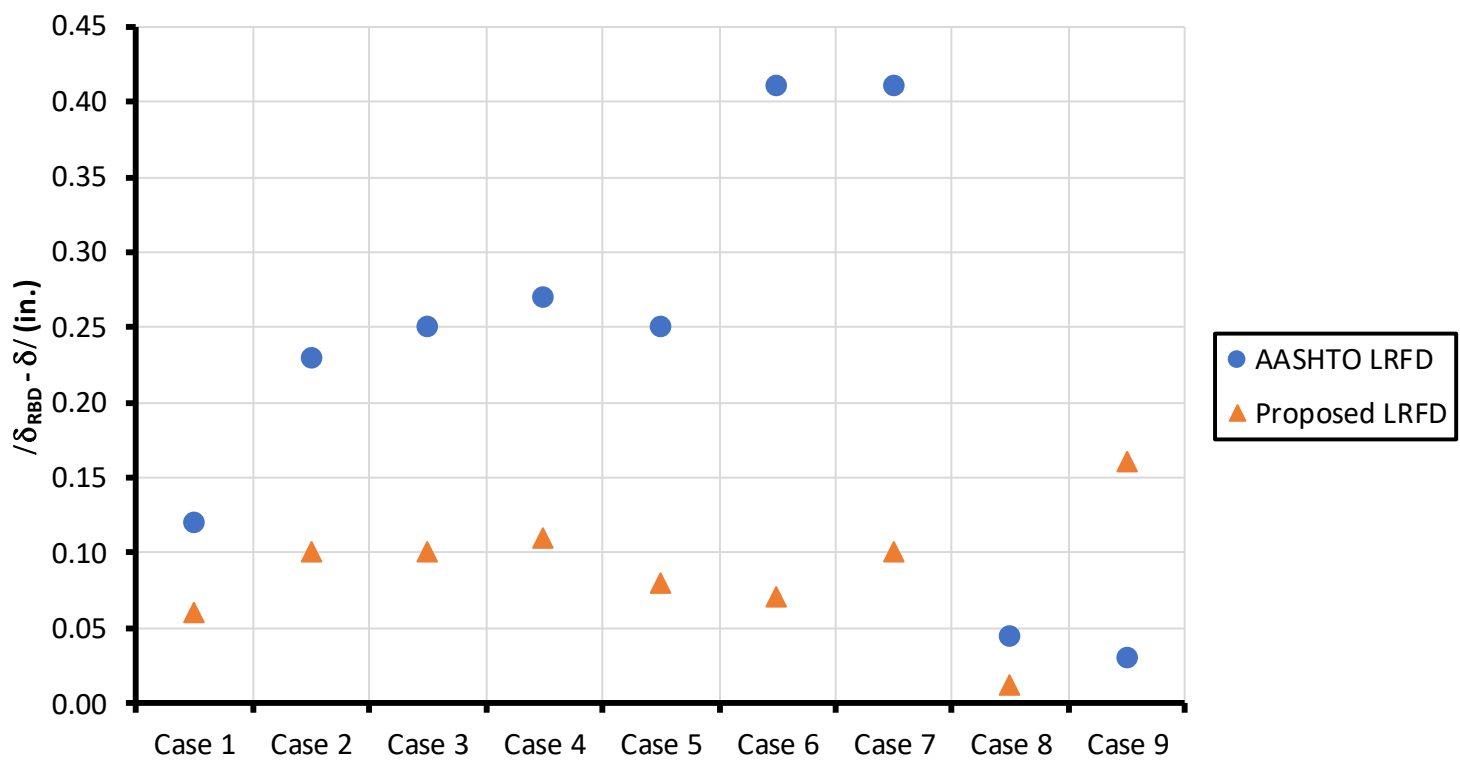

Figure 8.45 - Change of displacement with respect to RBD displacement (in inches) for $P_{f}=1 / 100$ using calculated nominal loads 


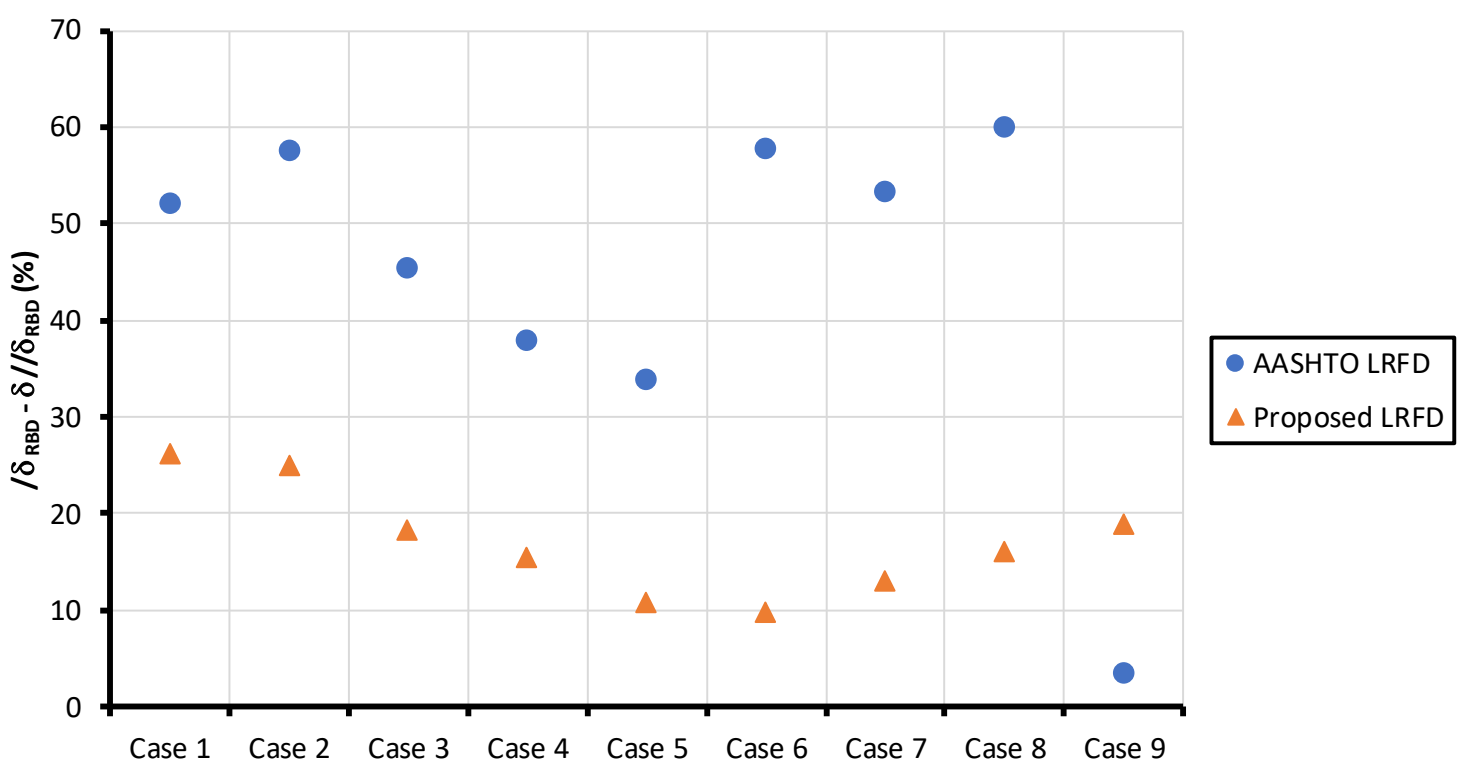

Figure 8.46 - Change of displacement with respect to RBD displacement (in \%) for $P_{f}=1 / 100$ using calculated nominal loads

The displacement produced by AASHTO LRFD method using the calculated nominal load is much smaller than the one derived from RBD method. The differences are in between about 0.12in to 0.41 in (Figure 8.45) except for the two extreme cases S-8 and S-9. Besides, AASHTO LRFD method produces displacements which are about 33 to $60 \%$ smaller than RBD (Figure 8.46). On the other hand, the Proposed LRFD model produces displacements which are closer to RBD displacements than AASHTO values. The average displacement difference is about 0.10in (Figure 8.45). Moreover, the Proposed LRFD method produces displacements which are less than 26\% of RBD displacement (Figure 8.46).

The RBD target probability of failure which is equal to 1 over 100 has been used as a reference to calculate the differences of probability of failure using AASHTO LRFD and Proposed LFRD methods. Table 8.14 shows the probability of failure produced by the 
Proposed and the AASHTO design methods, as well as the RBD target probability of failure, which is equal to $1 / 100$. The ratios between the probability of failure from the Proposed and AASHTO methods and the RBD target probability of failure have been presented, as shown in Table 8.14 and Figure 8.47.

Table 8.14 - Probability of Failure comparison between 3 methods using calculated nominal loads with Target $P_{f}=1 / 100$

\begin{tabular}{c|c|ccc|cc}
\hline Case & $P$ & \multicolumn{3}{|c|}{ Probability of Failure } & \multicolumn{2}{c}{$\begin{array}{c}\text { Change of Pf } \\
\text { (ratio) }\end{array}$} \\
$\#$ & $\frac{P_{u l t}}{P_{n}}$ & AASHTO & Proposed & RBD & AASHTO & Proposed \\
\hline S-1 & 0.31 & $1 / 1.6$ & $1 / 8.4$ & $1 / 100$ & 62.50 & 11.90 \\
S-2 & 0.34 & $1 / 1.6$ & $1 / 8.2$ & $1 / 100$ & 62.50 & 12.20 \\
S-3 & 0.39 & $1 / 2.7$ & $1 / 15.5$ & $1 / 100$ & 37.04 & 6.45 \\
S-4 & 0.44 & $1 / 3.5$ & $1 / 18.5$ & $1 / 100$ & 28.57 & 5.41 \\
S-5 & 0.43 & $1 / 5.0$ & $1 / 33.7$ & $1 / 100$ & 20.00 & 2.97 \\
G-6 & 0.47 & $1 / 1.9$ & $1 / 38.0$ & $1 / 100$ & 52.63 & 2.63 \\
G-7 & 0.47 & $1 / 3.2$ & $1 / 36.0$ & $1 / 100$ & 31.25 & 2.78 \\
S-8 & 0.43 & $1 / 4.0$ & $1 / 41.3$ & $1 / 100$ & 25.00 & 2.42 \\
S-9 & 0.32 & $1 / 200$ & $1 / 8.7$ & $1 / 100$ & 0.50 & 11.49 \\
\hline
\end{tabular}




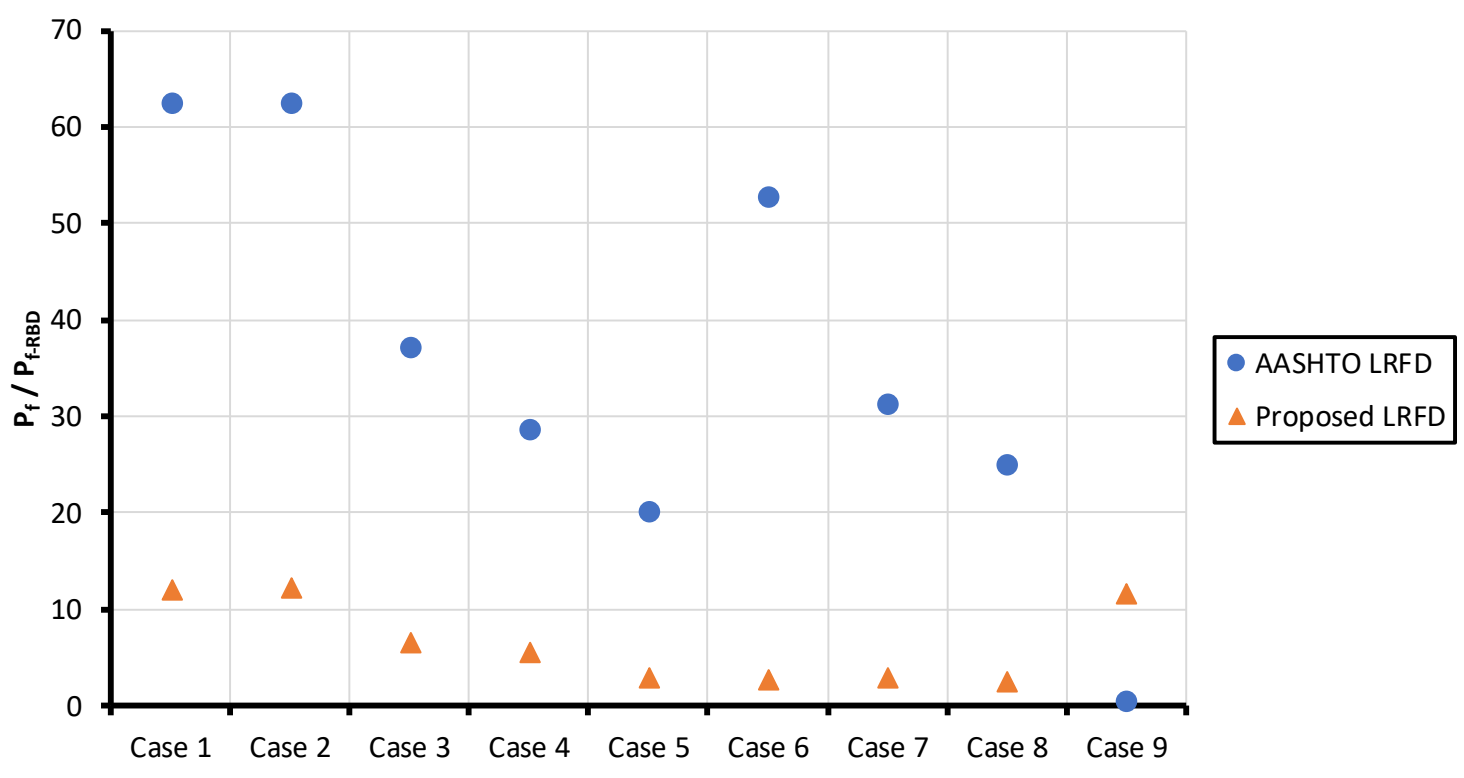

Figure 8.47 - Change of probability of failure with respect to the RBD target $P_{f}=1 / 100$ (in ratio) using calculated nominal loads

The probability of failure produced by AASHTO LRFD method using the calculated nominal loads is much higher than the RBD target probability of failure (1 over 100 in this cases) except for the extreme cases S-9. The ratios between AASHTO LRFD probability of failure and RBD target probability of failure are in between 20.0 and 62.5 (Figure 8.47). On the other hand, the Proposed LRFD method produces probability of failure which are much closer to RBD target probability of failure than AASHTO values. The ratios between Proposed LRFD probability of failure and RBD target probability of failure are in between 2.4 and 12.2 (Figure 8.47). 


\subsection{Summary}

In this Chapter, the proposed LRFD method for drilled shaft subjected to lateral loading at Service Limit State has been evaluated using the comparison with the AASHTO LRFD method as well as the Reliability-based Design method. The proposed LRFD method more consistently achieves the target reliability than the current AASHTO LRFD method that uses existing $p-y$ models and a resistance factor of 1.0 based on following conclusions:

- Using the calculated nominal load from the Strength Limit State, maximum displacement at shaft head produced from the proposed LRFD method is about 10 to $26 \%$ less than the displacement from the RBD method while displacement from AASHTO LRFD method is over underestimate the RBD displacement (about 22 to $60 \%$ less than RBD displacement).

- For the RBD target probability of failure equals to $1 / 25$, probability of failure produced from the proposed LRFD is about 2.3 to 5.6 times higher than RBD values while AASHTO LRFD probability of failure is 5.0 to 15.6 times higher than RBD target probability of failure.

- When reducing the RBD target probability of failure equals to $1 / 100$, the proposed LRFD probability of failure produced is higher than RBD target probability of failure but the ratio does not change much (from 2.3 to 5.6 times higher for $P_{f}=1 / 25$ to 2.4 to 12.2 times higher for $\left.P_{f}=1 / 100\right)$. However, AASHTO LRFD probability of failure is changing dramatically with target $P_{f}$ reducing (from 5.0 to 15.6 times higher for $P_{f}=1 / 25$ to 20.0 to 62.5 times higher for $\left.P_{f}=1 / 100\right)$. The reason is 
AASHTO LRFD produces the probability of failure which does not depend on the RBD target probability of failure. Thus, when the RBD target probability of failure decrease, the ratio between RBD target probability of failure and AASHTO LRFD probability of failure increase.

- On the other hand, probability of failure calculated using the proposed LRFD does depend only on the RBD target probability of failure. However, the ratio between proposed LRFD probability of failure and RBD target probability of failure does not depend on the target probability of failure but depends on the ratio between nominal load and ultimate load.

In conclusion, for service limit state design of laterally loaded drilled shafts, the proposed LRFD procedure using probabilistically calibrated resistance factors and the proposed $p-y$ model more consistently achieves the target reliability than current AASHTO procedure that uses existing $p-y$ models. 


\section{CHAPTER 9. SUMMARY, FINDINGS, FINAL CONCLUSIONS AND RECOMMENDATIONS}

This chapter presents a summary of the work described, and findings and final conclusions derived from the research. Recommendations for future research are also given at the end of this chapter.

\subsection{Summary}

Geotechnical engineers have been working to transition from traditional Allowable Stress Design (ASD) to Load and Resistance Factor Design (LRFD). Since 2007, the American Association of State Highway Administration Officials (AASHTO) has made utilization of LRFD mandatory on all new federally-funded bridge projects (AASHTO, 2007). However, there are currently no guidelines for implementing LRFD techniques for design of drilled shaft subjected to lateral loads using probabilistic calibrated load and resistance factors. On a national level, the AASHTO LRFD Bridge Design Specifications (7th Ed., 2015 with 2016 Interim Revisions) assign a resistance factor of 1.0 for lateral loading of drilled shafts, while the FHWA Drilled Shaft Manual (Brown et al, 2010) recommends a factor of 0.67 for the strength limit state, but this factor is based on the authors' judgment rather than a reliability study.

A research project involving a significant drilled shaft load testing program was undertaken to develop a LRFD procedure for design of drilled shafts subjected to lateral loading at the service limit state. Another objective of the research was to improve the 
characterization and reduce the uncertainty of the lateral resistance provided by shale by establishing a new lateral load transfer model.

Chapter 1 provides background regarding load and resistance factor design of drilled shaft subjected to lateral loading. The research objective, hypotheses and methodology are described.

A review of relevant literature is presented in Chapter 2. The chapter covers several methods used for deterministic prediction of drilled shafts responses under lateral loading and the choices involved in those methods. The chapter also describes some probabilistic tools available and several studies on resistance factor for drilled shafts.

Chapter 3 presents an interpretation of experimental results from full scale lateral load tests. Site and subsurface conditions are described, as well as the field testing program and apparatus. Experimental results in terms of drilled shafts responses are interpreted from strain gage data and from shape acceleration array (SAA) data.

Chapter 4 presents a numerical method for predicting shaft responses from given load. The p-y method is a rigorous method which can determine responses of a drilled shaft based on a load transfer model. A computer program developed to predict the shaft responses and match with experimental results is described.

Probabilistic characterization of lateral load-transfer model is presented in Chapter 5. This chapter covers the development of mathematical models for lateral loadtransfer curves. The variability of the load transfer curves is also quantified and presented 
in this chapter. The proposed lateral load-transfer model is evaluated with experimental test data and is compared with existing lateral load-transfer model using predicted shaft responses.

Chapter 6 presents probabilistic aspects of resistance factors calibration. The Monte-Carlo simulation method is introduced in detail. A computer code developed for probabilistic analysis to find the resistance factor for a drilled shaft subjected to lateral loading at service limit state is also described.

Chapter 7 discusses the proposed LRFD procedure of drilled shaft subjected to lateral loading at service limit state. A step-by-step procedure for design is described with illustrative examples, which include comparison between proposed design procedure and conventional design procedure, along with the effects of modifying shaft stiffness and/or adjusting the variability of soil strength.

Chapter 8 evaluate the proposed LRFD procedure for service limit state by comparing with AASHTO LRFD and the Reliability-based Design methods. Nine different cases have been analyzed to illustrate the outcomes of using the Proposed LRFD method. Reliability-based Design maximum displacement at shaft head and target probability of failure are used as the reference to compare with results from AASHTO LRFD and Proposed LRFD methods. 


\subsection{Findings}

\subsubsection{Lateral load test program}

The experimental shaft's deflection and experimental shaft's responses were interpreted from the lateral load test data successfully with the combination of both strain gage and SAA data, as well as the benefit of implementing nonlinear shaft's bending stiffness.

\subsubsection{Predicted shaft responses and interpreted lateral load-transfer model}

The predicted shaft responses matched closely with experimental results using modelling and computational finite element program. Nonlinear characteristic of bending stiffness significantly impacts the predicted shaft responses in terms of lateral displacements and bending moments, as well as the interpreted lateral load-transfer model. By using nonlinear bending stiffness considered the cracking of concrete section and the methodology to derive lateral load-transfer model implemented in the computational program, the interpreted lateral load-transfer model can be established reasonably and practicably.

\subsubsection{Proposed lateral load-transfer model}

The proposed lateral load-transfer model format provided a reasonable fit to the interpreted lateral load-transfer models. As a result, a probabilistic characterization

process, which includes linear regression for $P_{u l t}$, rational regression for $\log _{e}\left(K_{p y} / \sigma_{v}\right)$ 
and exponential regression for $p-y$ curve, was successfully produced the proposed lateral load transfer model (proposed p-y model) for shale. The established lateral load-transfer model improves the characterization and reduces the uncertainty of the lateral resistance provided by shale, compared with LPILE's stiff clay model and KDOT's weak rock model (KDOT, 1987).

The proposed $\mathrm{p}$-y model had significantly greater values of $P_{\text {ult }}$ than LPILE's stiff clay model, which mean that the proposed model predicts significantly greater resistance to lateral loading than the resistance predicted by the LPILE's stiff clay model. In addition, $p-y$ curves predicted from the proposed $p-y$ model better represented the interpreted $p$ y curves obtained from lateral load test measurements, while LPILE's stiff clay model could not.

The ultimate lateral soil resistance, $P_{u l t}$, and the initial stiffness, $K_{p y}$, of the KDOT's weak rock model is significantly less than that calculated using proposed $p-y$ model. Moreover, the benefit of using proposed model to include the effect of depth is not described in KDOT research.

\subsubsection{Probabilistic calibrated resistance factors}

The recommended probabilistic calibrated resistance factors range from 0.48 to 0.77 for service limit state. These resistance factors are to be implemented by directly factoring the lateral soil resistance predicted by the proposed $p-y$ curves. This can be accomplished using the p-multiplier concept explained in Chapter 5 and available in 
LPILE's software. This approach is different and, in the authors' opinion, more rational than the approach of applying the resistance factor as an additional load factor, which is the approach presented in the FHWA Drilled Shafts manual (USDOT, 2010).

\subsubsection{Proposed LRFD procedure for drilled shafts subjected to lateral loading at SLS}

When the applied load is 80 percent of the ultimate lateral load, maximum displacement at shaft head and probability of failure produced from the proposed LRFD method are approximately equal to the displacement and the target probability of failure obtained from the Reliability-based Design (RBD) method. As the ratio between applied load and ultimate lateral load decreases, maximum displacement at shaft head and probability of failure produced from the proposed LRFD method is moving further from the RBD displacement and target probability of failure. However, they are still better match compared with those from current AASHTO method that uses existing $p$-y models.

AASHTO LRFD method produces the probability of failure which is much higher than RBD target probability of failure. The displacement obtained using AASHTO LRFD method is over underestimate the RBD displacement.

The proposed LRFD procedure for drilled shaft subjected to lateral loading at Service Limit State created benefits of designing lateral loaded drilled shaft in shale with the flexibility of adjusting either shaft stiffness or variability of soil strength in order to satisfy the service limit state verification check and provide some level of confidence in design (provide probability of failure). 


\subsection{Final Conclusions}

The proposed LRFD procedure for design of laterally loaded drilled shafts at the service limit state, with probabilistic calibrated resistance factor, more consistently achieves the target reliability than current AASHTO LRFD procedure that uses existing lateral load transfer models and a resistance factor of 1.0. Displacement and probability of failure obtained using the proposed LRFD are closer to the RBD displacement and target probability of failure than those produced from AASHTO LRFD procedure.

A new LRFD procedure proposes the using of resistance factors range from 0.48 to 0.77 for design of drilled shafts subjected to lateral loading at the service limit state. Those resistance factors are calibrated using probabilistic analyses while AASHTO LRFD procedure uses resistance factor is equal to 1.0, which means probabilistic analyses for calibration of resistance factors have not been performed.

A geotechnical engineer, with the recommended probabilistic calibrated resistance factors, can design the drilled shafts subjected to lateral loading using the proposed LRFD procedure and achieve some level of probability of failure, in which conventional procedures such as ASD or AASHTO are not be able to provide. Besides, the proposed LRFD method does not require as much resources as using RBD method.

The proposed p-y model benefits knowledge, reduces the uncertainty associated with lateral resistance in shale, thus, provide a lateral load transfer model specifically working for shale, rather than using LPILE's stiff clay or KDOT's weak rock models. 


\subsection{Recommendations}

There are some areas in this study that can be extended or improved. Recommendations for future work are as follows:

- $\quad$ The proposed lateral load-transfer model would benefit from additional testing from materials with uniaxial compressive strength (UCS) between 15 and 65 ksf.

- $\quad$ Additional test data with greater displacement from shale layers would also be beneficial.

- The resistance factor calibration process considered geomaterial as one layer with all the variability/uncertainty of the geomaterial strength represented by its average standard of deviation. The calibrated resistance factors should further consider multi-layer geomaterial and be fully developed.

- $\quad$ The probabilistic calibrated resistance factors proposed in this research were based on lateral load transfer data for drilled shafts in shale. The methodology can be extended to other soil types such as clay or sand, and for other types of foundations.

- The resistance factors for Strength Limit State can be calibrated as well as the LRFD procedure for drilled shaft subjected to lateral loading under Strength Limit State can be established using the same methodologies. 


\section{REFERENCES}

AASHTO (2007). AASHTO LRFD Bridge Design Specification: Customary U.S. Units. American Association of State Highway and Transportation Officials, Fourth Edition with 2008 and 2009 Interim Revisions.

AASHTO (2012). AASHTO LRFD Bridge Design Specification: Customary U.S. Units. American Association of State Highway and Transportation Officials, Fifth Edition.

Allen, T. M., Nowak, A. S., \& Bathurst, R. J. (2005). Calibration to determine load and resistance factors for geotechnical and structural design. Transportation Research E-Circular(E-C079).

ASTM Standard D3966 (2007). Standard Test Methods for Deep Foundations Under Lateral Load. ASTM International, West Conshohocken, PA, 2007, DOI: 10.1520/D3966-07.

Becker, D.E. (1996). Eighteenth Canadian Geotechnical Colloquium: Limit States Design for Foundations. Part I. An Overview of the Foundation Design Process. Can. Geotech. J. 33, pp 956-983.

Boeckmann, A., Myers, S., Uong, M. and Loehr, J.E. (2014). Load and Resistance Factor Design of Drilled Shafts in Shale for Lateral Loading. Report to Missouri Department of Transportation. 
Brown, D. A., Hidden, S. A., and Zhang, S. (1994). Determination of $p-y$ Curves Using Inclinometer Data. ASTM Geotech. Test. J., Vol. 17, No. 2, pp. 150-158.

Dunnavant, T. W. (1986). Experimental and Analytical Investigation of the Behavior of Single Piles in Overconsolidated Clay Subjected to Cyclic Lateral Loads. Ph.D. Dissertation, University of Houston, TX.

Dywidag-Systems International (DSI) (2013). DYNA Force ${ }^{\circledR}$ Elasto-Magnetic Sensor: Force Monitoring of Post-Tensioned Steel Elements. Product Brochure. Accessed December 9, 2013.

Franklin, J. N. and Scott, R. F. (1979). Beam Equation with Variable Foundation Coefficient. J. Eng. Mech. Div., Vol. 105, No. 5, pp. 811-827.

Frantzen, J. and Stratton, F.W. (1987). p-y Curve Data for Laterally Loaded Piles in Shale and Sandstone. Report No. FHWA-KS-87-2 by Kansas Department of Transportation.

Geokon (2012). Model 4200 Series Vibrating Wire Strain Gages Instruction Manual. Document Rev. P.

Hete'nyi, M. (1946). Beams on Elastic Foundation. University of Michigan Press, Ann Arbor, MI. 
Huaco, D. R., Bowders, J. J. and Loehr, J. E. (2012). Method to Develop Target Levels of Reliability for Design Using LRFD. Paper presented at the Transportation Research Board 91st Annual Meeting.

Isenhower, W.M. and Wang, S.T. (2011). Technical Manual for LPILE, Version 6.

McClelland, B. and Focht, J. (1958). Soil Modulus for Laterally Loaded Piles. Trans. Am. Soc. Civ. Eng., Vol. 123, pp. 1049-1086.

Matlock, H., Ripperger, E. A., and Fitzgibbon, D. P. (1956). Static and Cyclic Lateral Loading of an Instrumented Pile. Report to Shell Oil Company, Shell Oil, Austin, TX.

Matlock, H. and Ripperger, E. A. (1958). Procedures and Instrumentation for Tests on a Laterally Loaded Pile. Proceedings of the 8th Texas Conference on Soil Mechanics and Foundation Engineering, University of Texas, Austin, TX.

Matlock, H. and Reese, L. (1962). Generalized Solutions for Laterally Loaded Piles. Trans. Am. Soc. Civ. Eng., Vol. 127, pp. 1220-1246.

Matlock, H. (1970). Correlations for Design of Laterally Loaded Piles in Soft Clay. 2nd Offshore Technology Conference, Houston, Texas, pp. 577-594.

McVay, M. C., Wasman, S. J., Consolazio, G. R., Bullock, P. J., Cowan, D. G., and Bollman, H. T. (2009). Dynamic Soil-Structure Interaction of Bridge Substructure Subject to Vessel Impact. J. Bridge Eng., Vol. 14, No. 1, pp. 7-16. 
Misra, A., Roberts, L.A. and Levorson, S.M. (2006). Reliability Analysis of Drilled Shaft Behavior using Finite Difference Method and Monte Carlo Simulation. Geotech. Geol. Eng., Vol. 25, pp 65-77.

Missouri Department of Transportation (2011). Engineering Policy Guide, LRFD Bridge Design Guidelines for Drilled Shafts. EPG 751.37.

Nip, D.C. N. and Ng, C. W. W. (2005). Back-Analysis of Laterally Loaded Bored Piles. Proc. Inst. Civ. Eng.-Geotech. Eng., Vol. 158, No. 2, pp. 63-73.

Phoon, K. K., Kulhawy, F. H. and Grigoriu, M.D. (1995) "Reliability-Based Design of Foundations for Transmission Line Structures", Report TR-105000, Electric Power Research Institute, Palo Alto, CA, , 380 p.

Pierce, M.D., Loehr, J.E. and Rosenblad, B.L. (2014). Load and Resistance Factor Design of Drilled Shafts in Shale Using SPT and TCP Measurements. Report to Missouri Department of Transportation.

Reese, L. C. (1997). Analysis of Laterally Loaded Piles in Weak Rock. J. Geotech. Geoenviron. Eng., Vol. 123, No. 11, pp. 1010-1017.

Reese, L. C., Cox, W. R., and Koop, F. D. (1974). Analysis of Laterally Loaded Piles in Sand. Proceedings of 6th Offshore Technical Conference, Houston, TX, Vol. 2, pp. 473483. 
Reese, L. C., Cox, W. R., and Koop, F. D. (1975). Field Testing and Analysis of Laterally Loaded Piles in Stiff Clay. 7th Offshore Technology Conference, pp. 671-690.

Reese, L.C., Isenhower, W.M. and Wang, S.T. (2006). Shallow and Deep Foundations. John Wiley \& Sons, Hoboken, New Jersey.

Reese, L. C., Wang, S. T., Isenhower, W. M., Arrellaga, J. A., and Hendrix, J. (2004). User's Manual of LPILE plus 5.0 for Windows. Ensoft, Inc., Austin, TX.

Reese, L. C. and Welch, R. C. (1975). Lateral Loadings of Deep Foundations in Stiff Clay. J. Geotech. Eng. Div., Am. Soc. Civ. Eng., ASCE, Vol. 101, No. 7, pp. 633-649.

Roberts, L. A. and Misra, A. (2009). Load and Resistance Factor Design (LRFD) of Deep Foundations using a Performance-based Design Approach. Journal of GeoEngineering, Vol. 4, No. 3, pp. 87-92.

Sinnreich, J. and Ayithi, A., (2014). Derivation of p-y Curves from Lateral Pile Load Test Instrument Data. ASTM Geotech. Test. J., Vol. 37, No. 6.

Tyler, H. L. (2010). Influence of Parameter Variability on Side Shear Values Determined from O-cell Testing of Drilled Shafts. Master Thesis, University of MissouriColumbia.

USDOT FHWA (2010). Drilled Shafts: Construction Procedures and LRFD Design Methods. FHWA-NHI-10-016. 
Vu, T. T. (2013). Load and Resistance Factor Design for Drilled Shafts at Service Limit State. Ph.D. Dissertation, University of Missouri-Columbia.

Wang, S. T. and Reese, L. C. (1993). COM624P-Laterally Loaded Pile Analysis Program for the Microcomputer. Version 3, Publication No. FHWA-SA-91-048, Federal Highway Administration.

Welch, R.C. and Reese, L.C. (1972). Lateral Load Behavior of Drilled Shafts. Report to The Texas Highway Department.

Wilson, D. (1998). Soil-Pile-Superstructure Interaction in Liquefying Sand and Soft Clay. Ph.D. Dissertation, University of California at Davis.

Yang, K. and Liang, R. (2005). Lateral Response of Large Diameter Drilled Shafts in Clay. Proceedings of Deep Foundations Institute 30th Annual Conference on Deep Foundations, Chicago, IL, pp. 117-126.

Yang, K., Liang, R., and Nusairat, J. (2006). Evaluation of Lateral Response of Drilled Shafts in Rock. ASCE Geotechnical Special Publication No. 153, "Foundation Analysis and Design Innovative Methods," pp. 249-256.

Yang, K. and Liang, R. (2007). Methods for Deriving p-y Curves from Instrumented Lateral Load Tests. ASTM Geotech. Test. J., Vol. 30, No. 1. 


\section{APPENDIX}

Appendix A

Interpreted Shaft Responses using MATLAB 

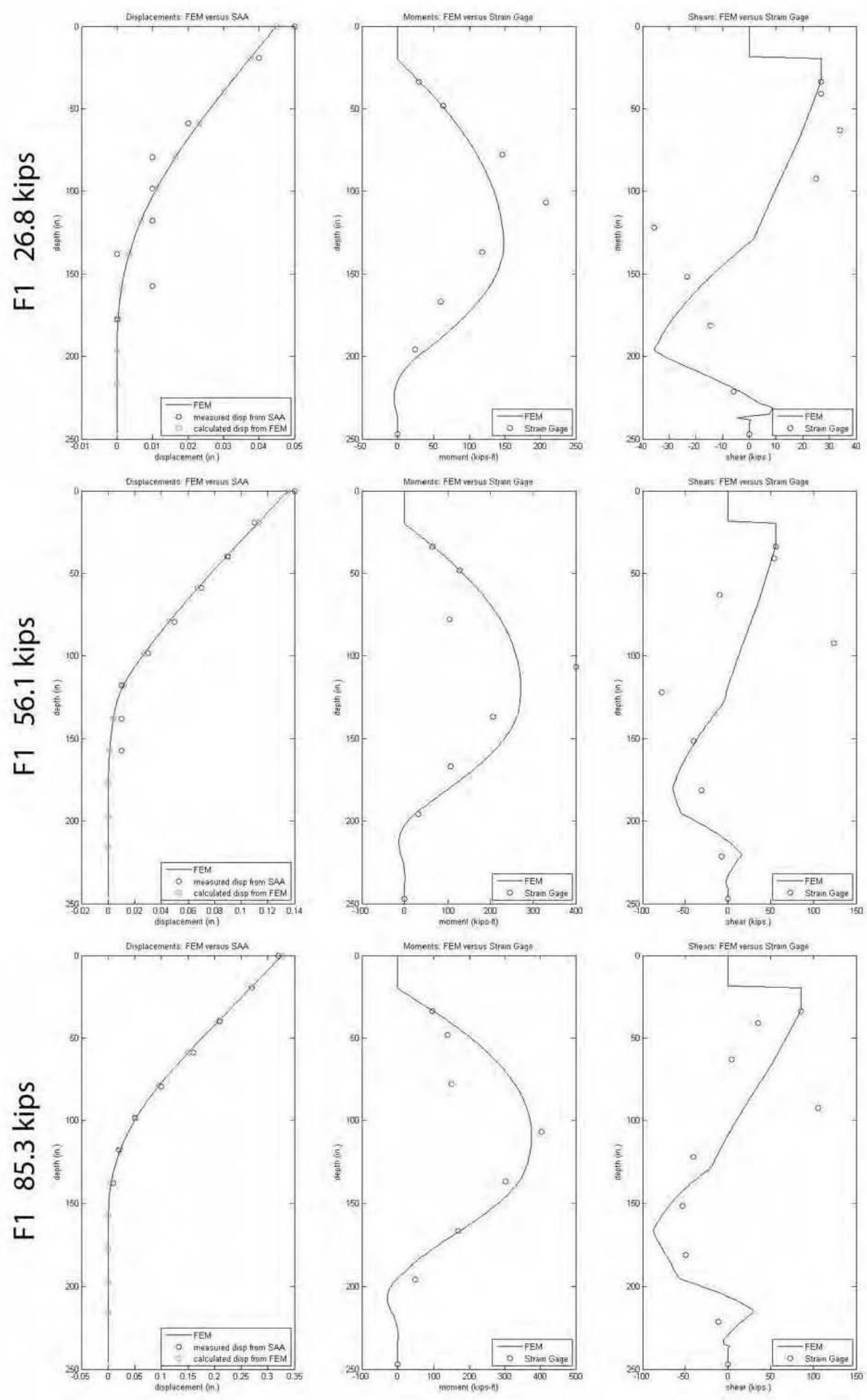

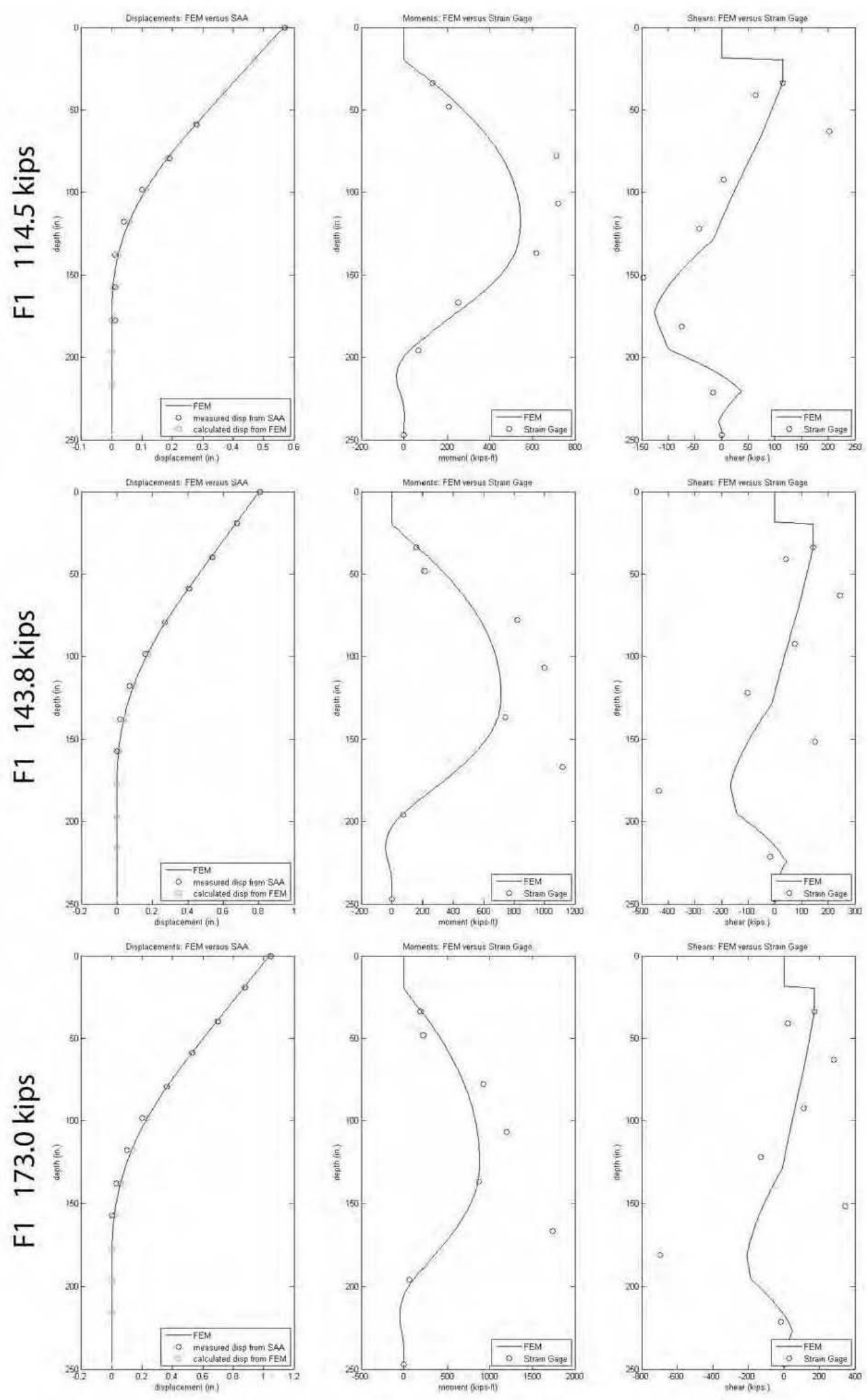

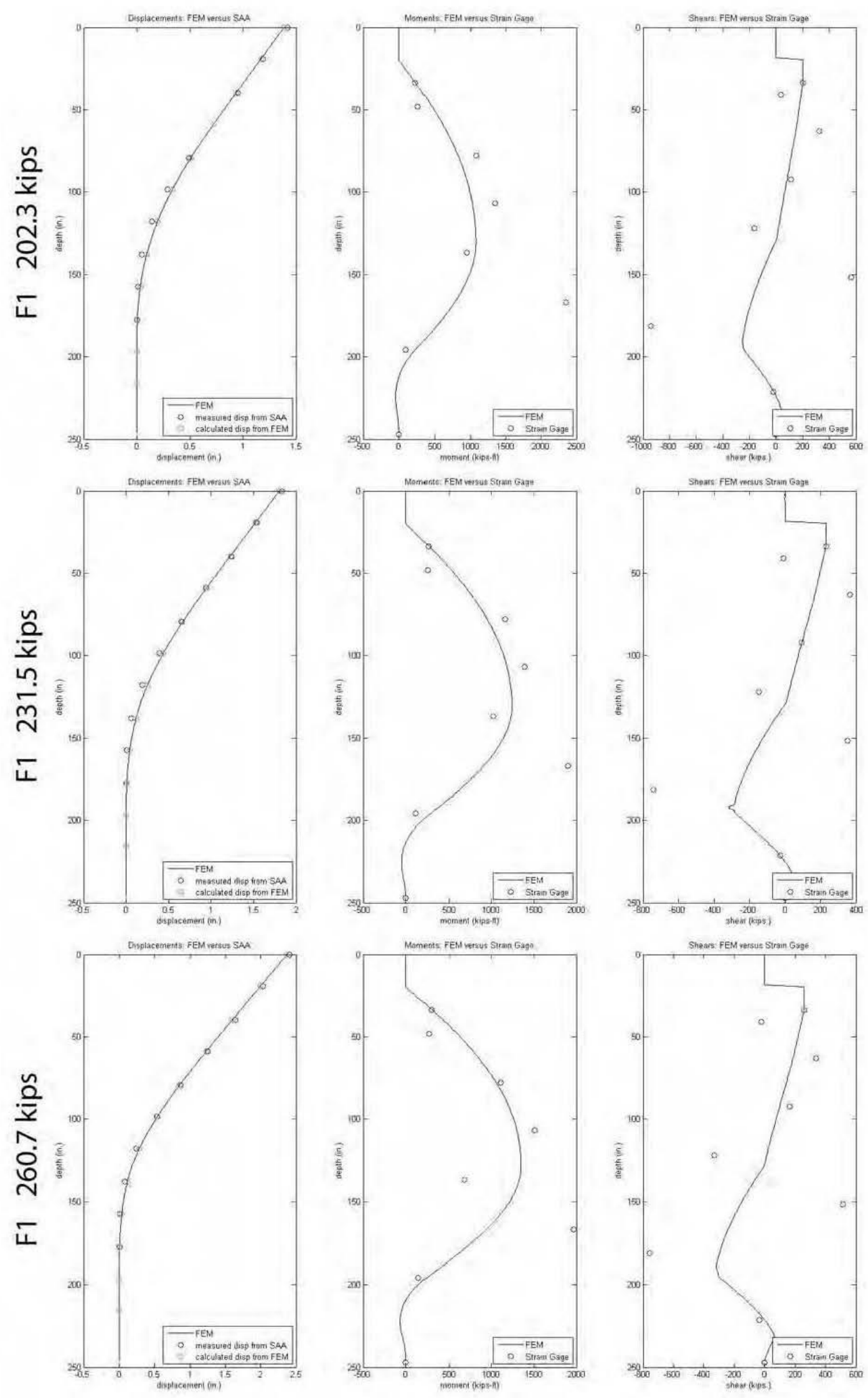

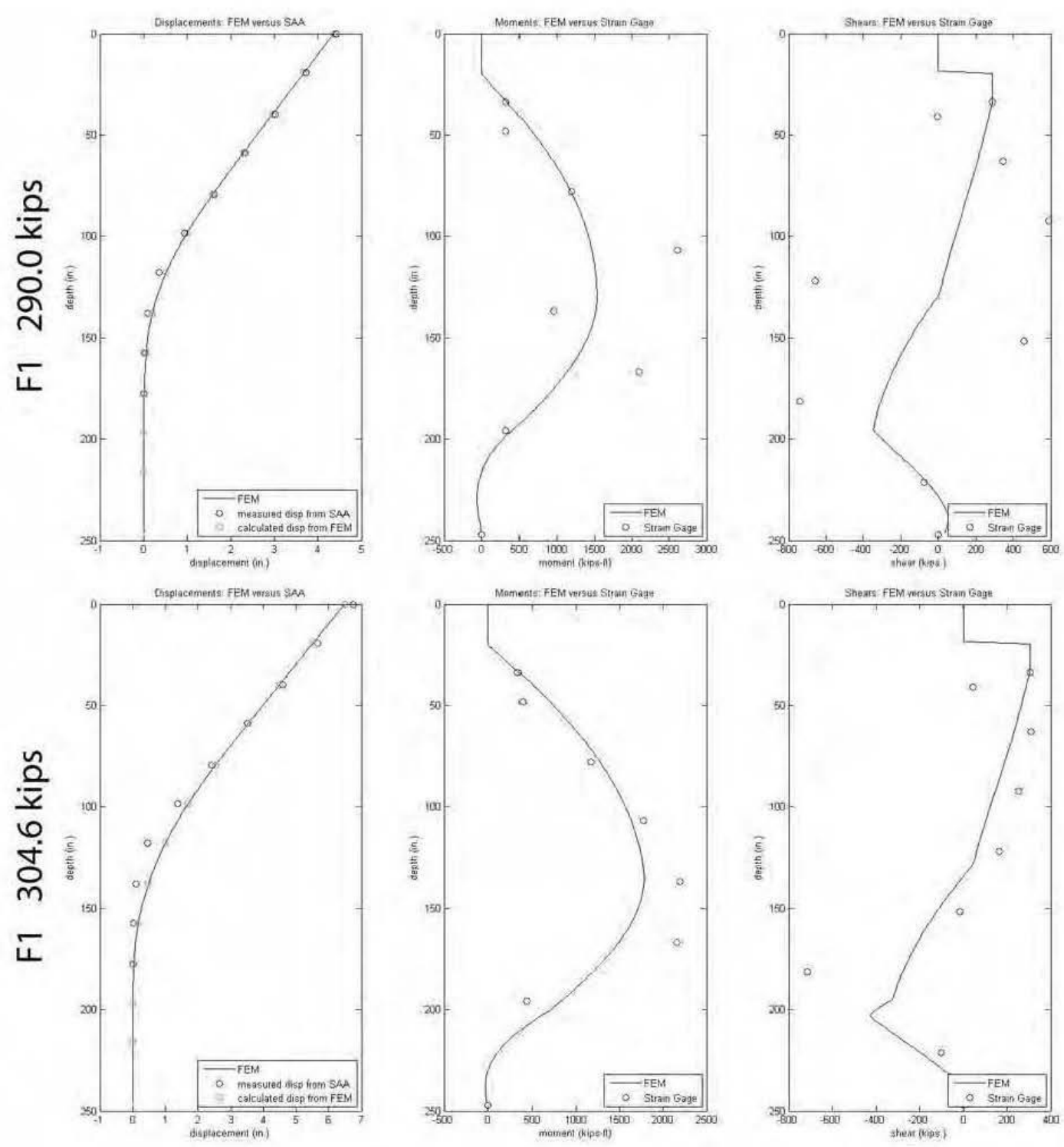

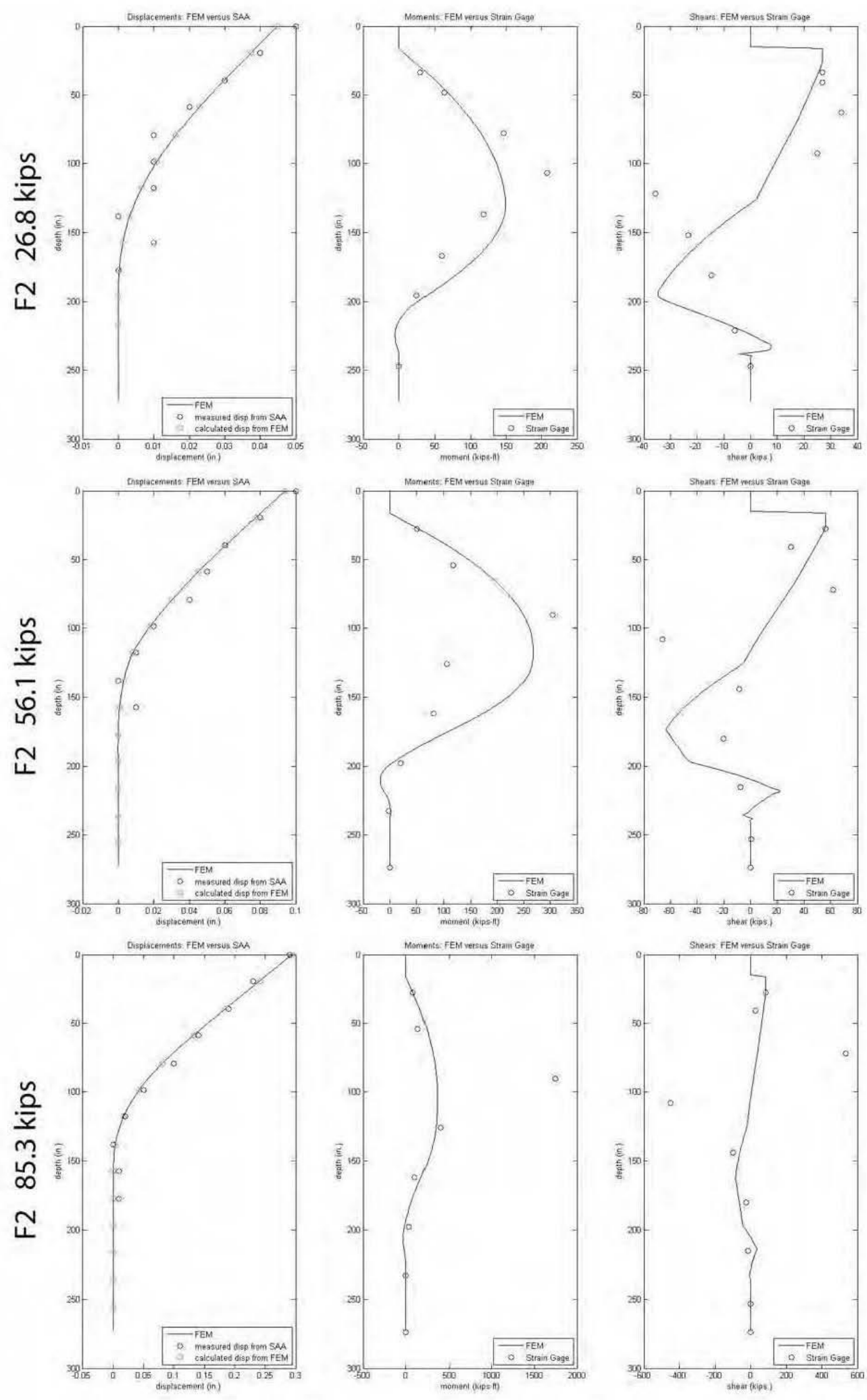

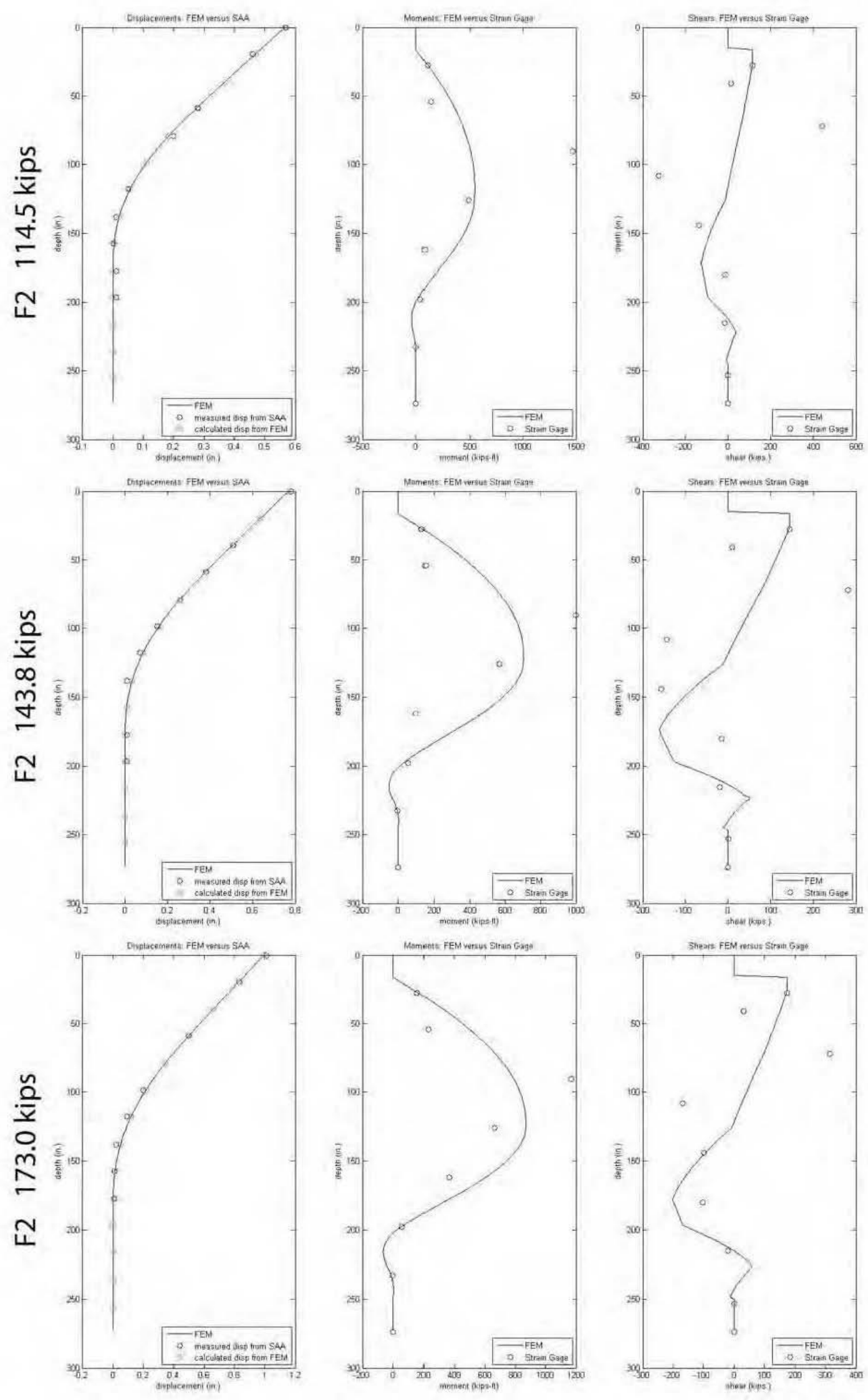

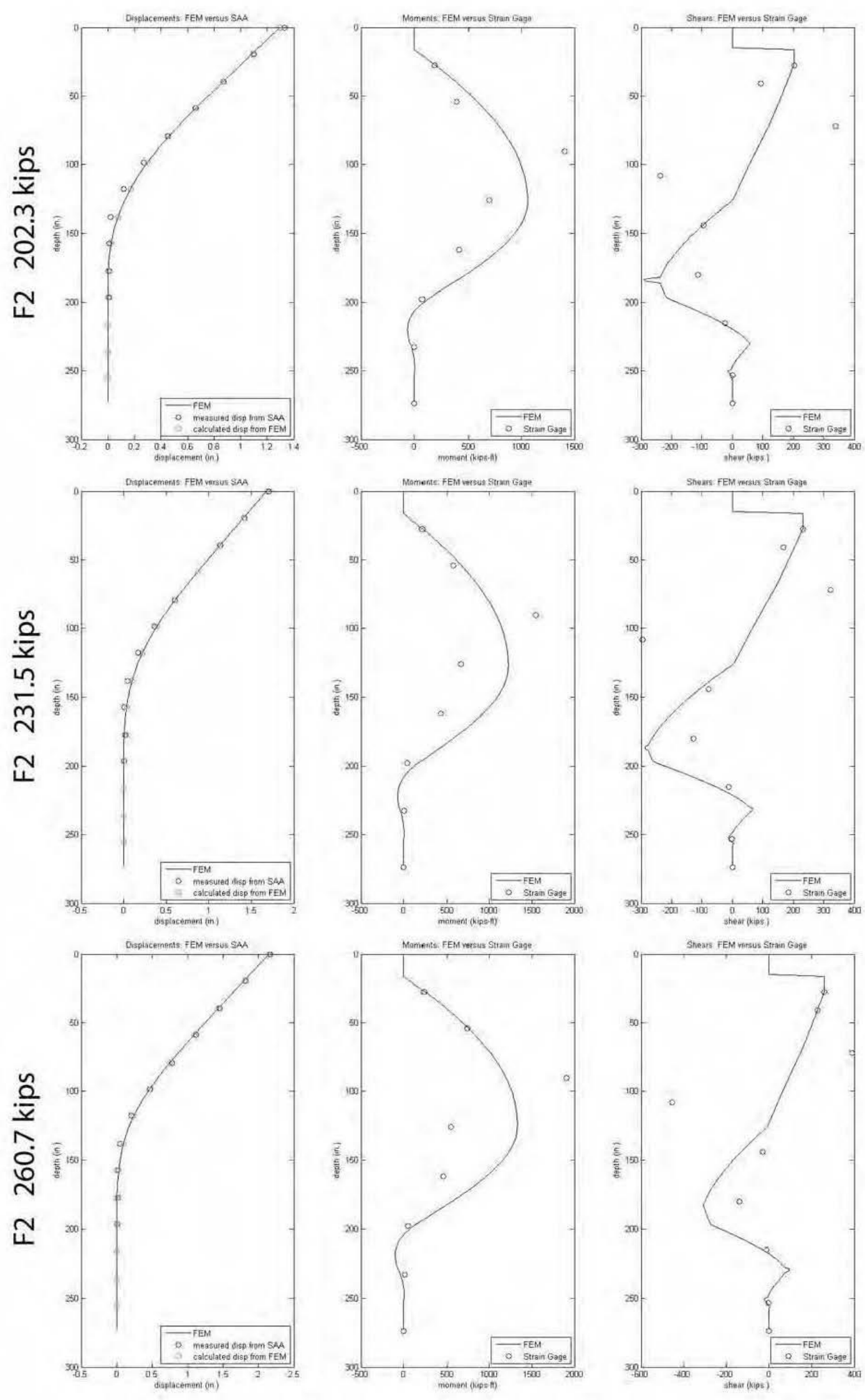

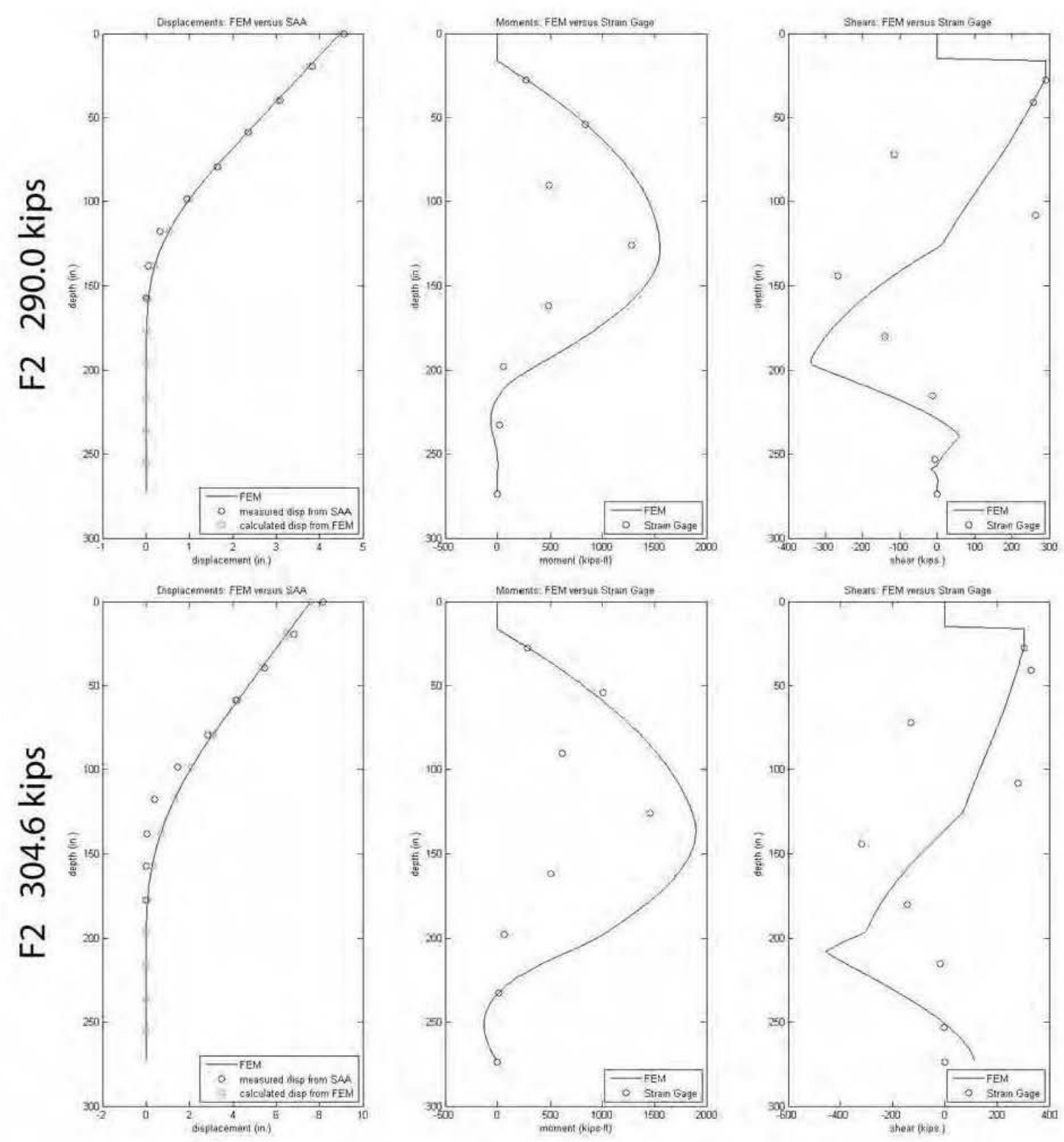

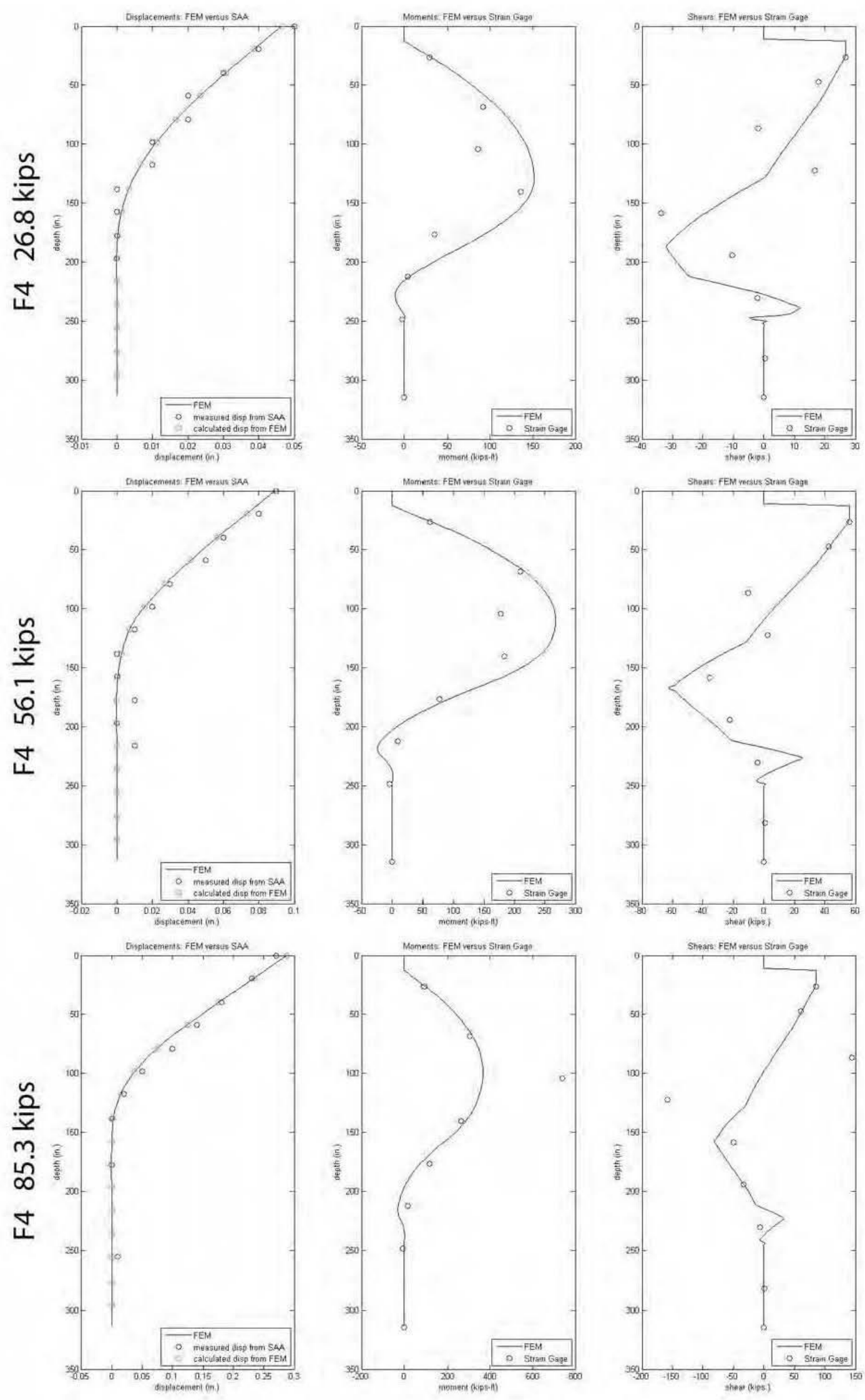

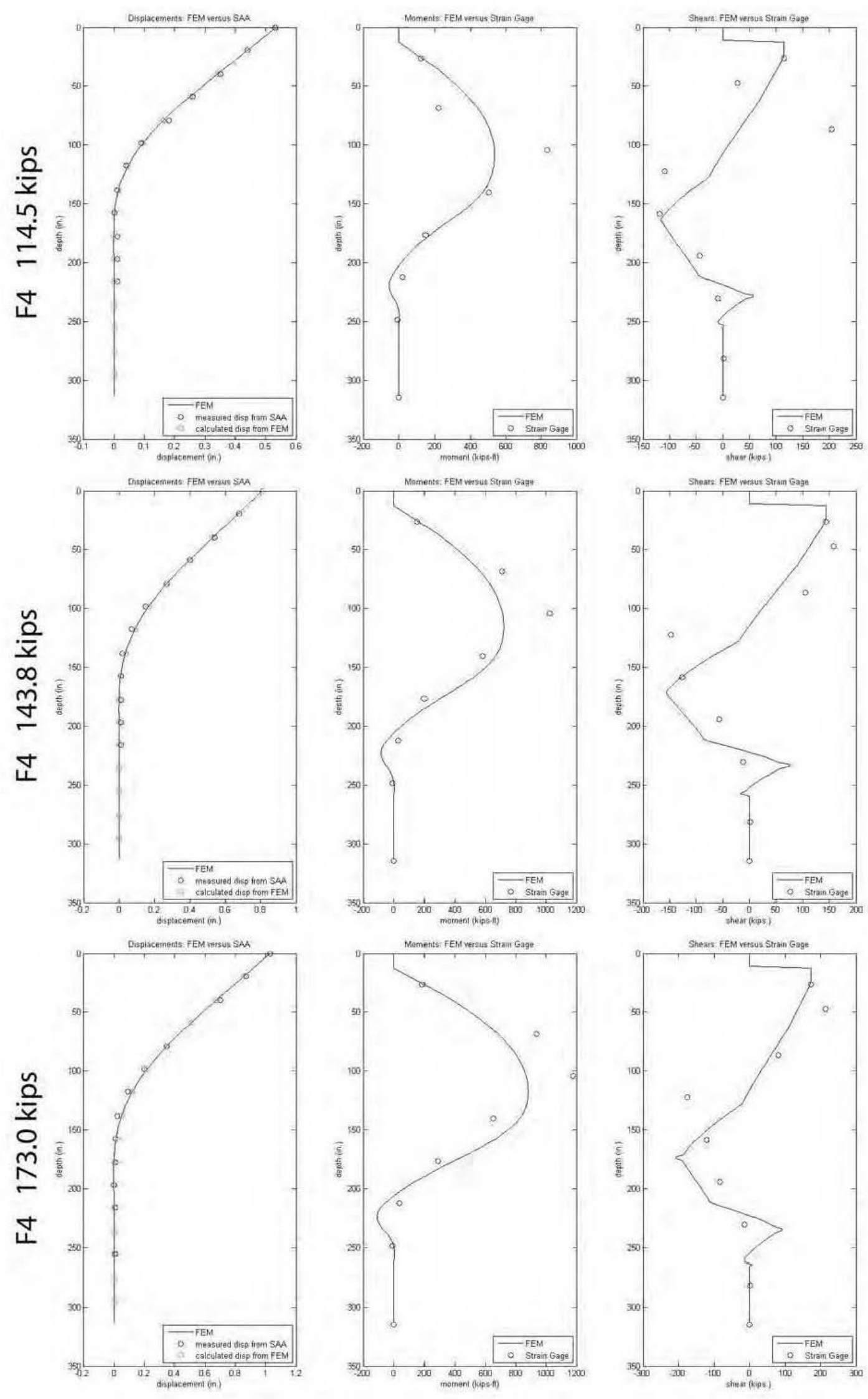

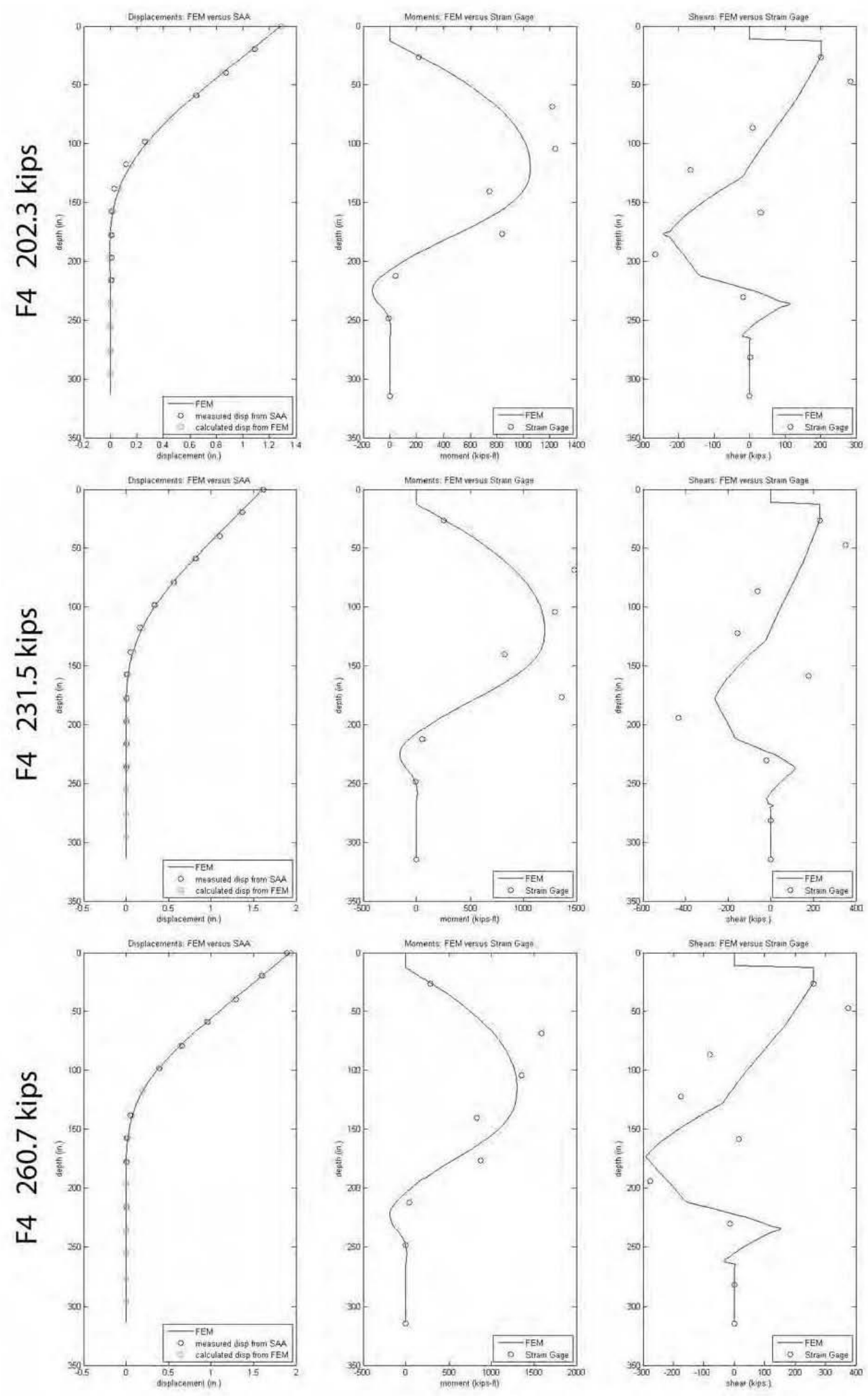

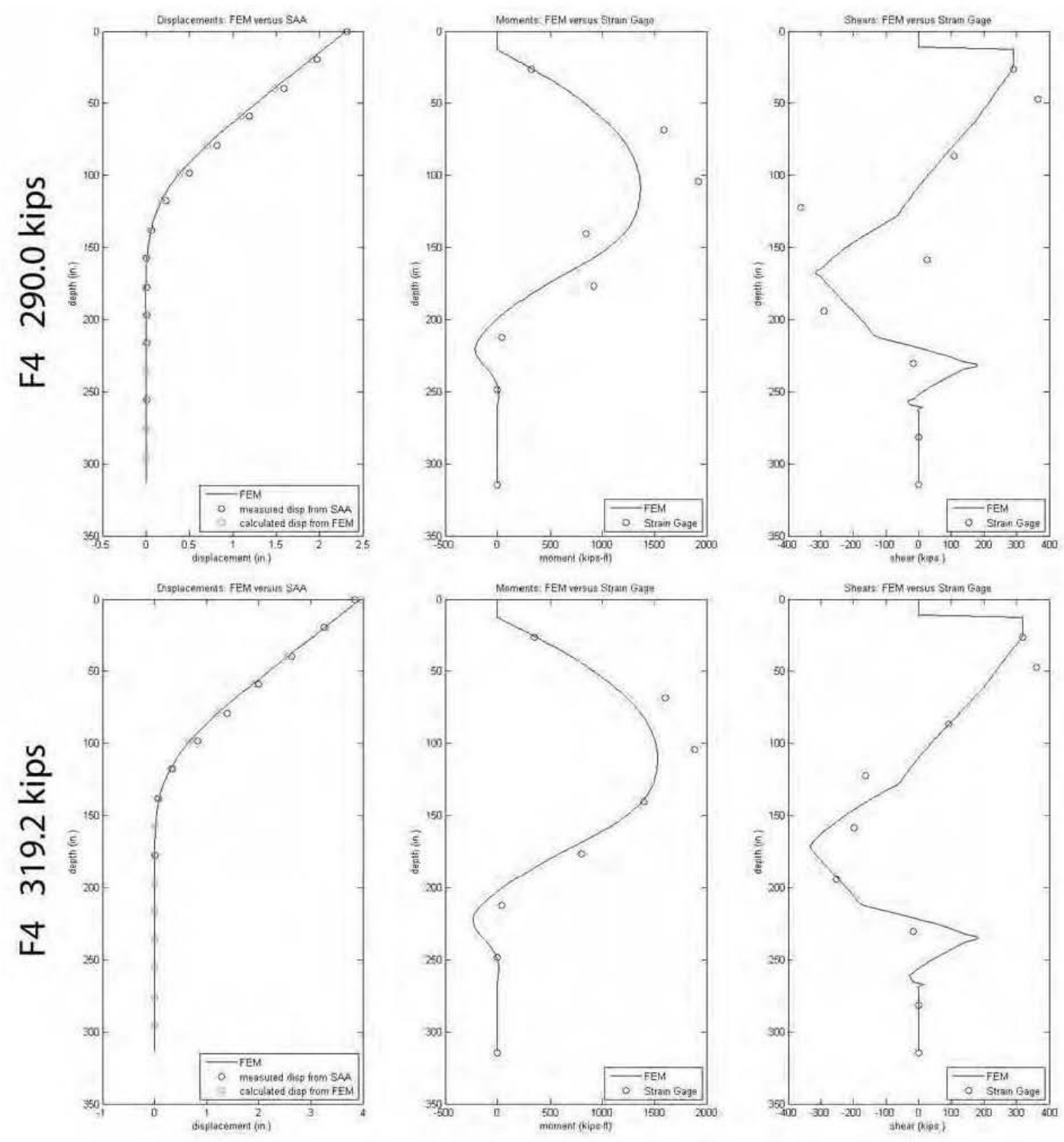

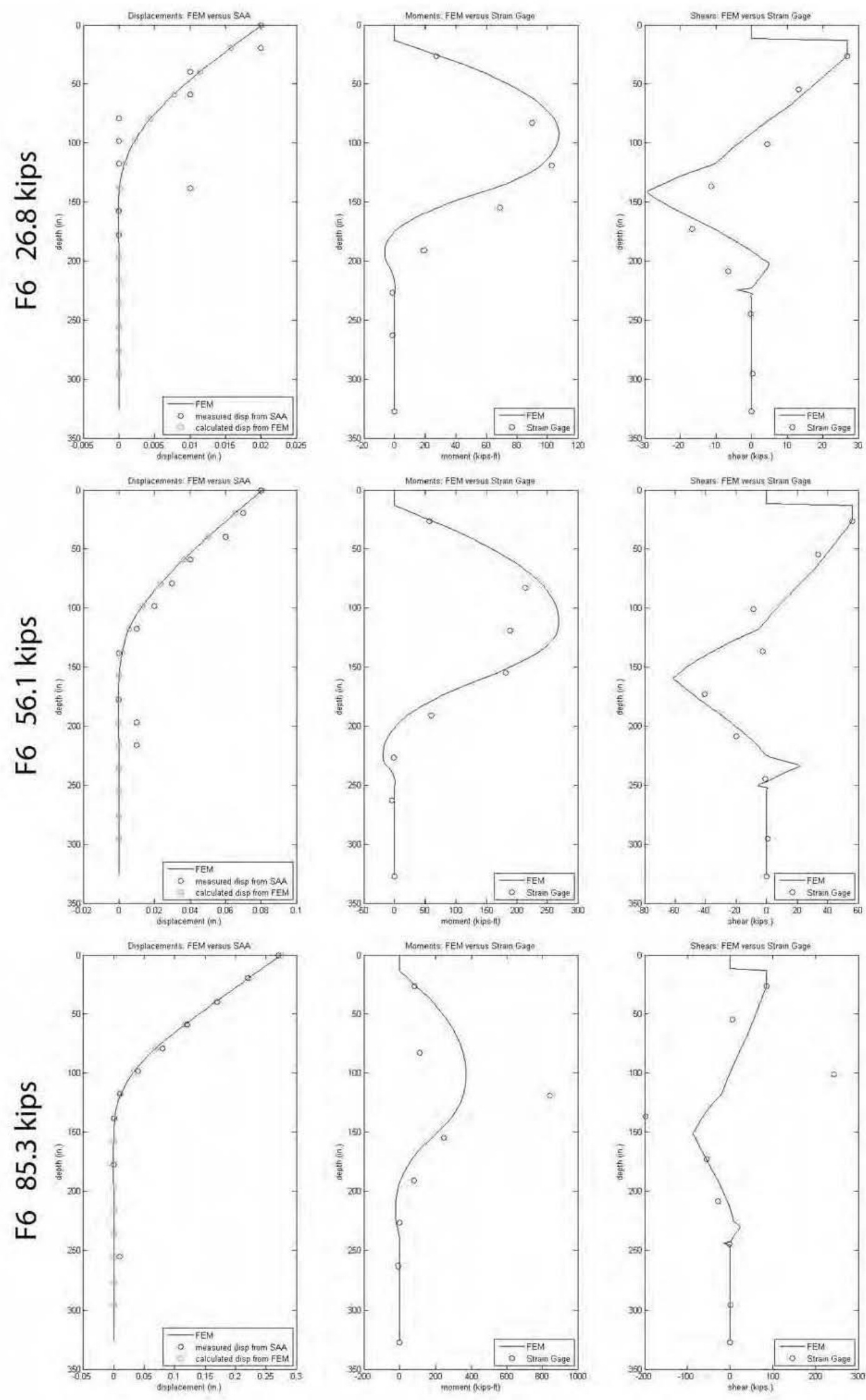

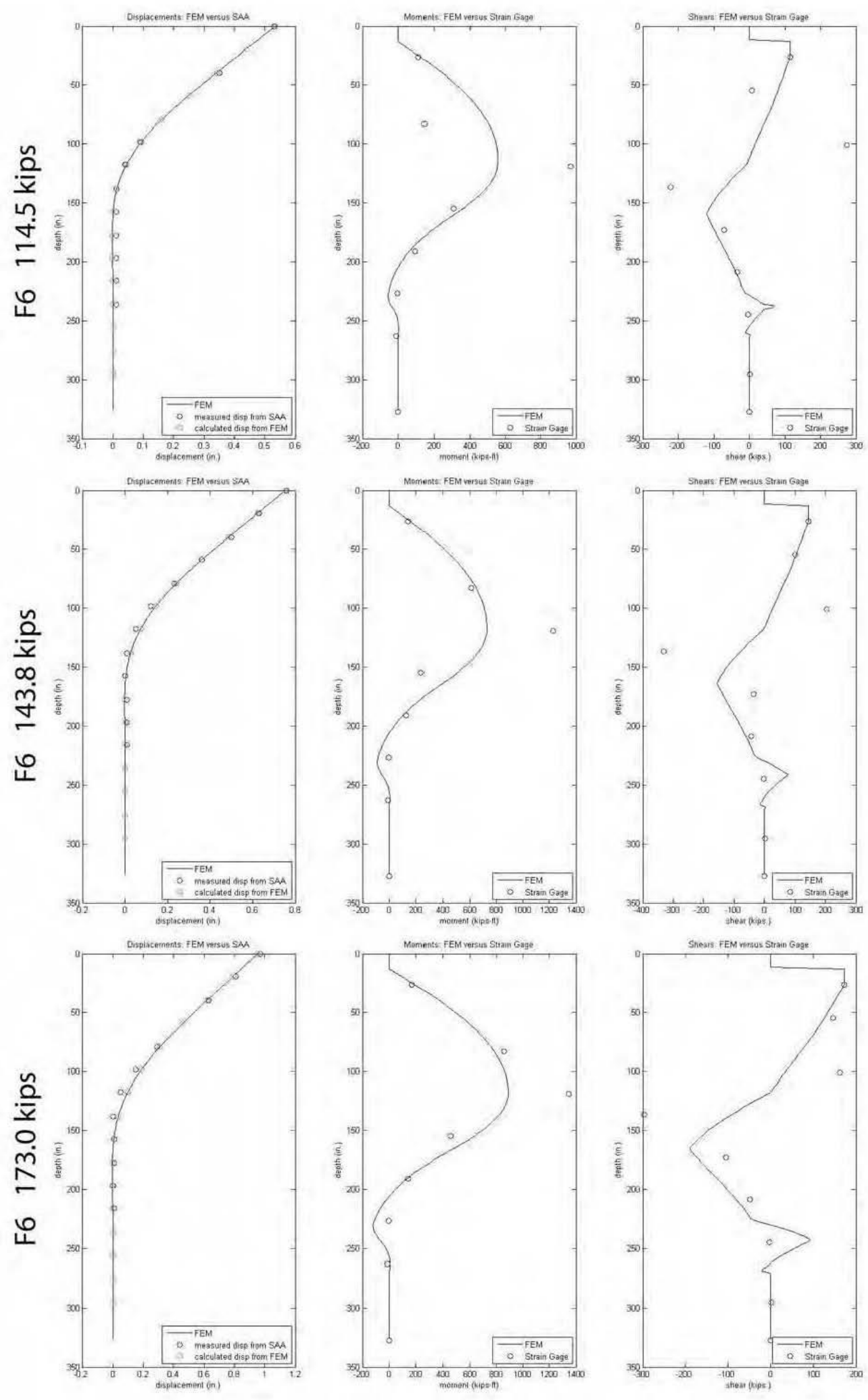

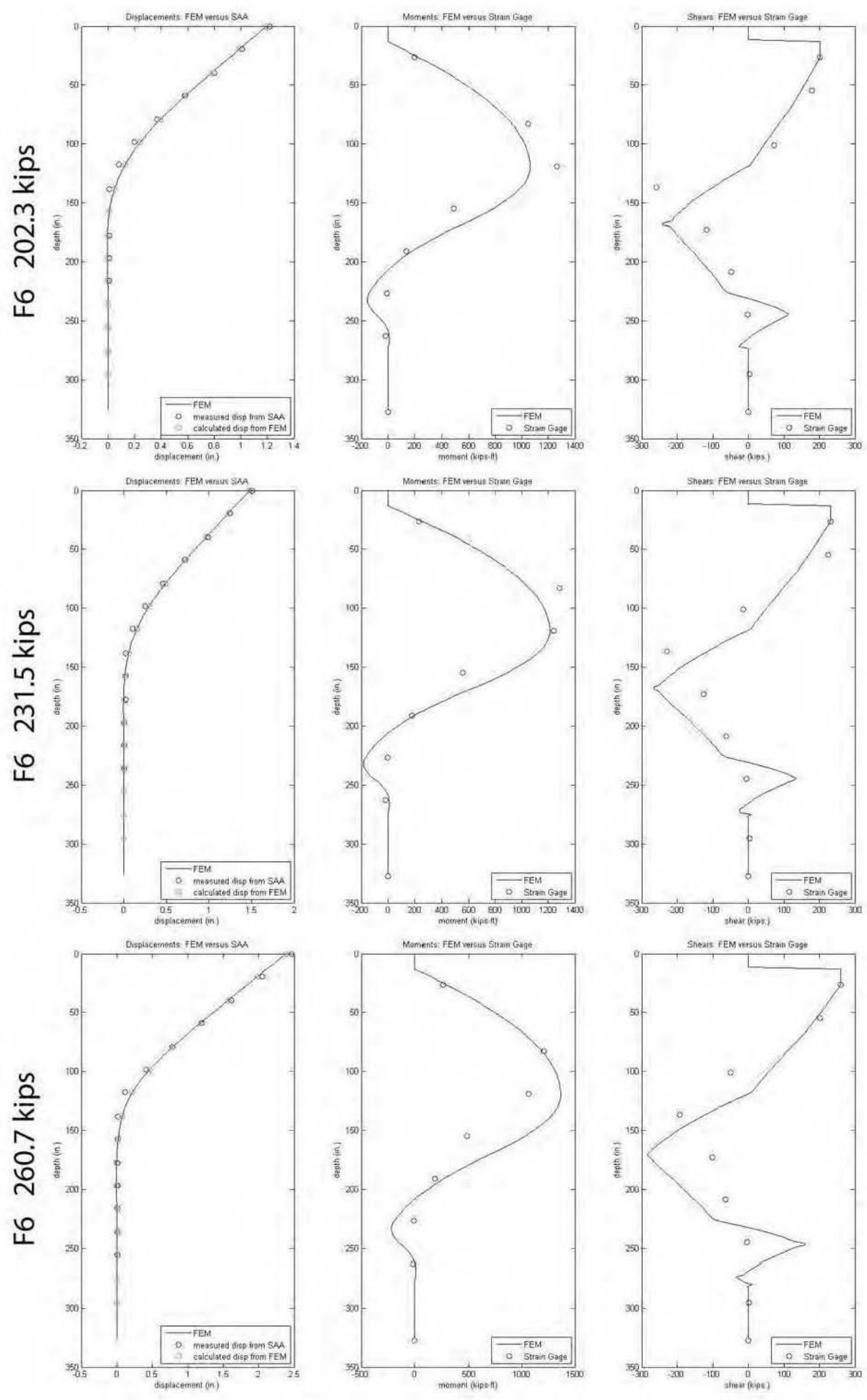

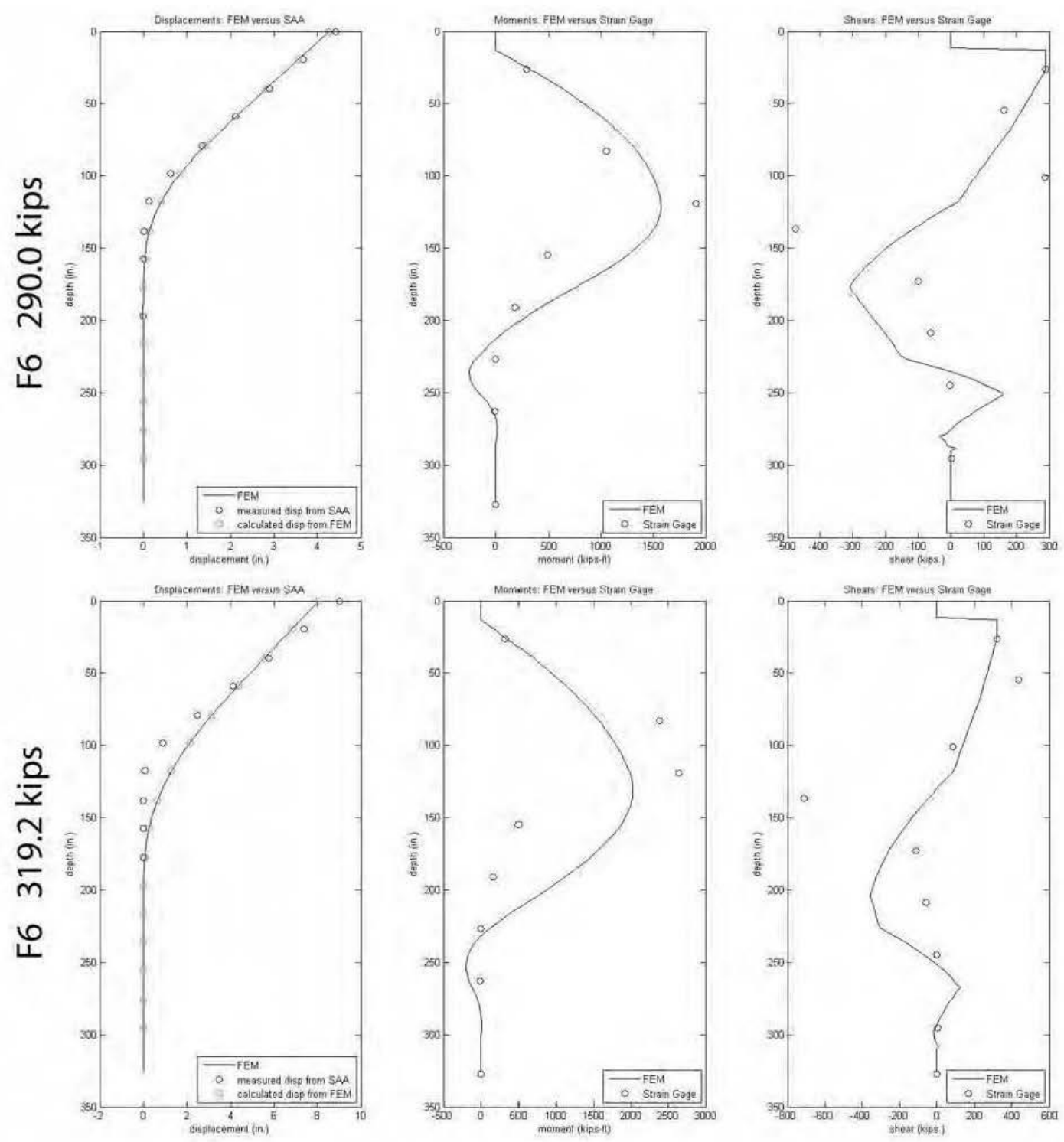

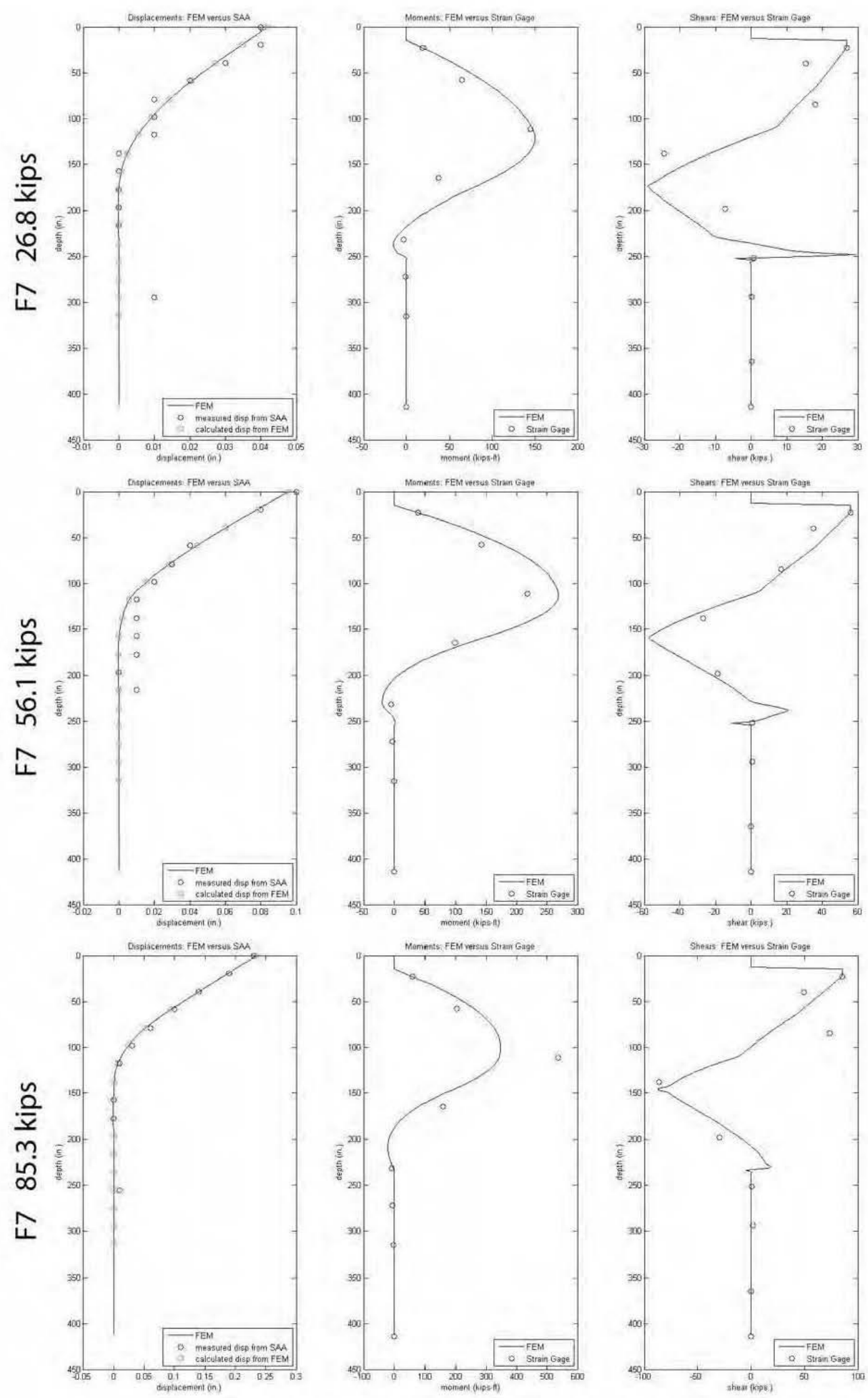

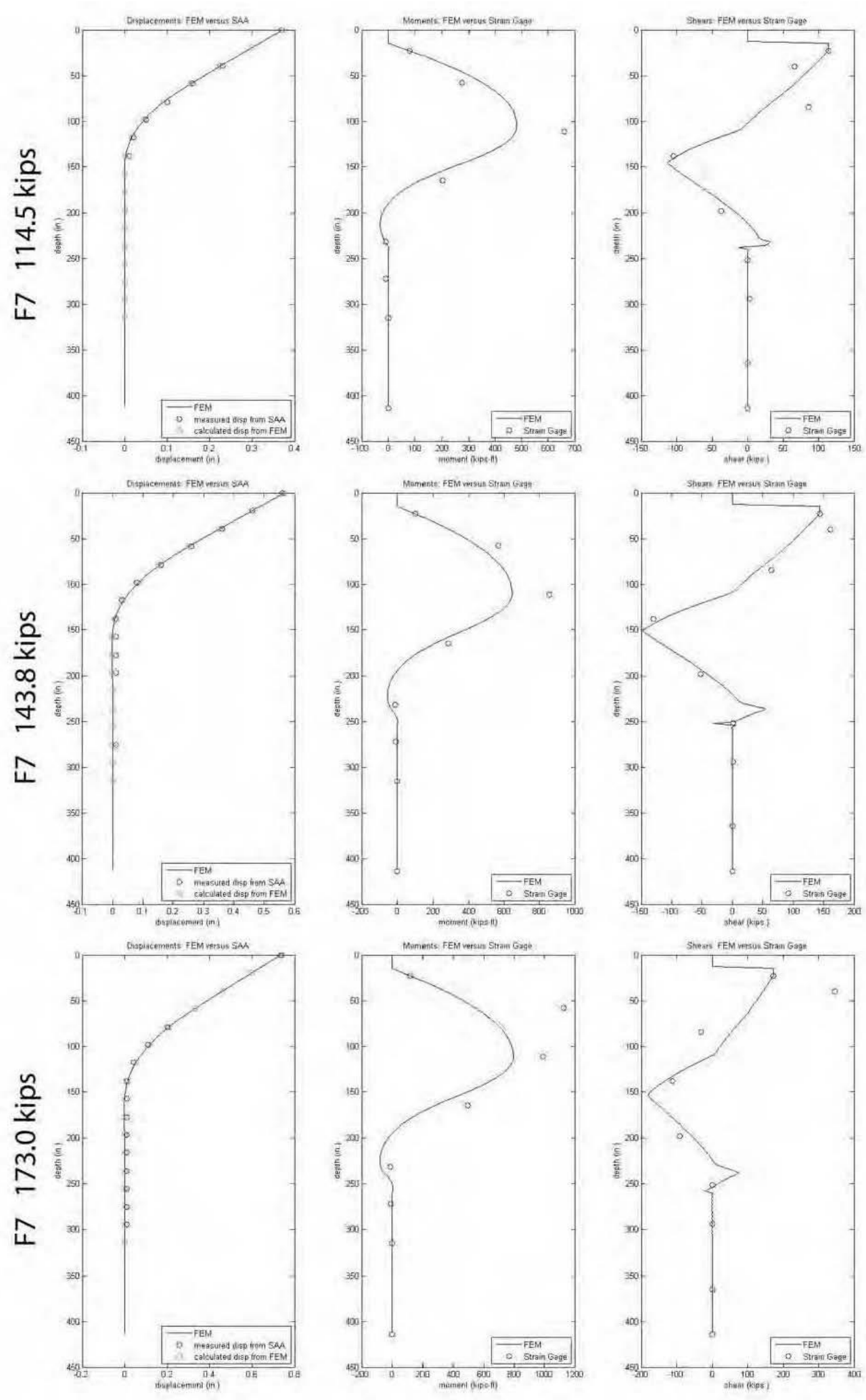

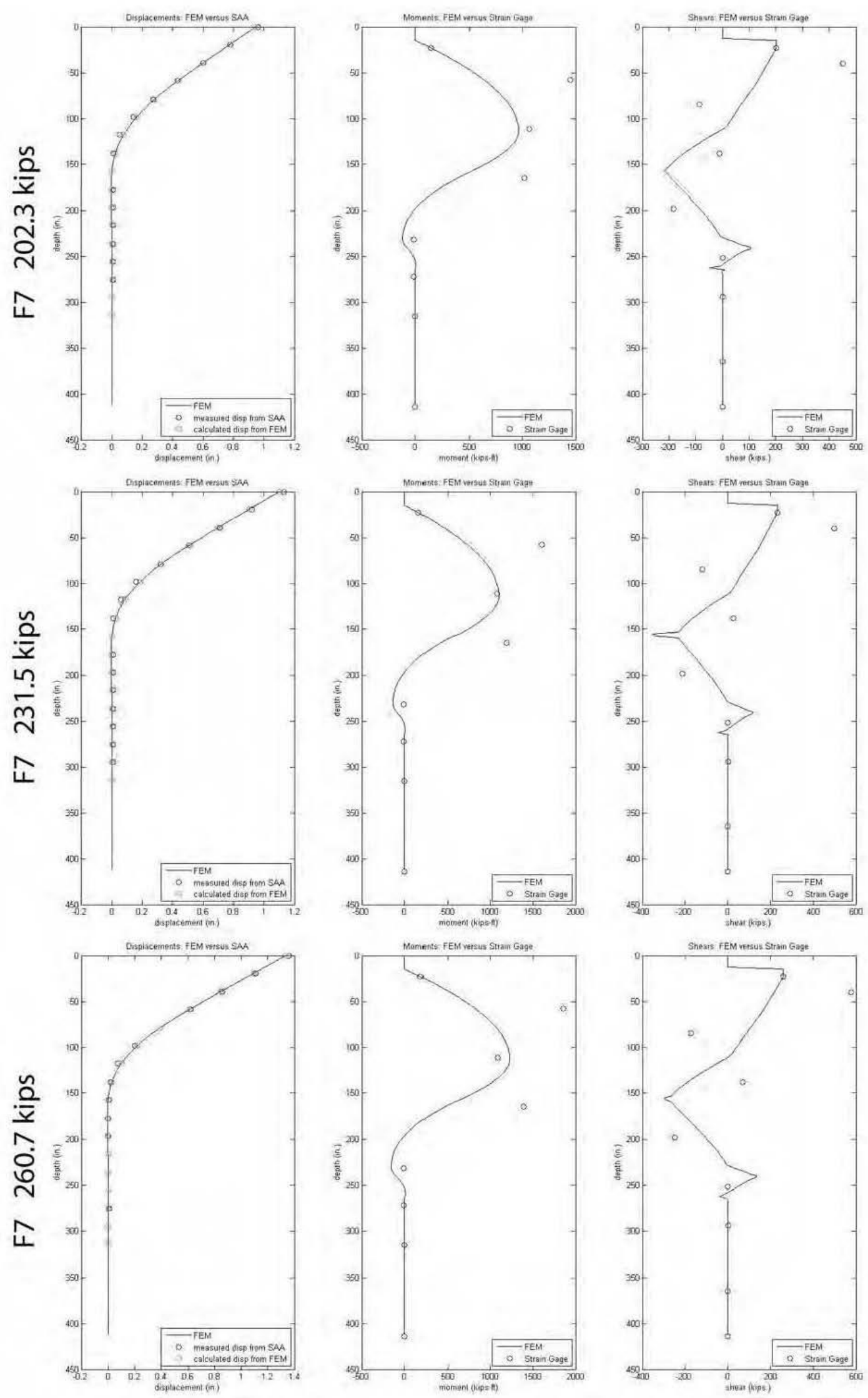

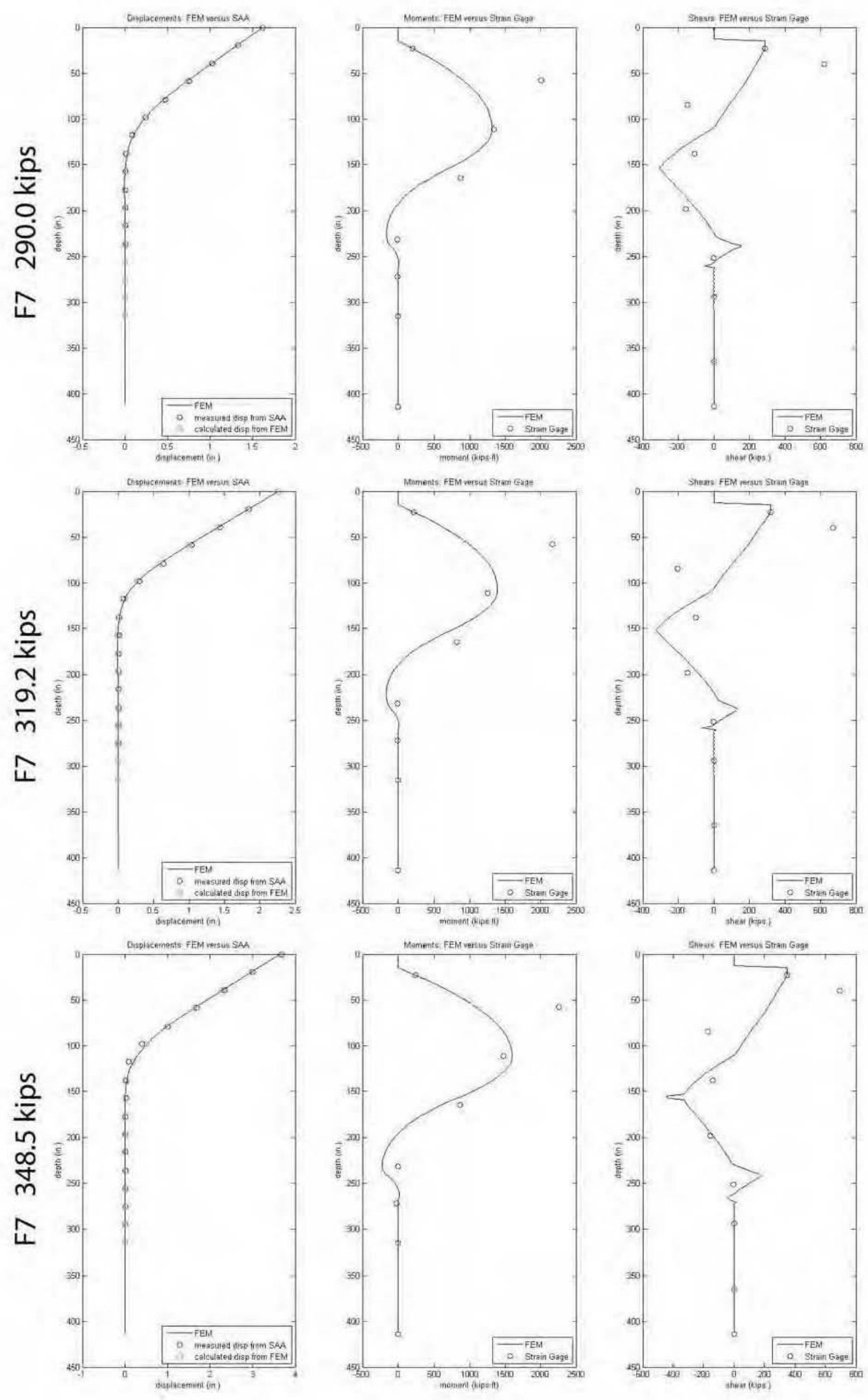

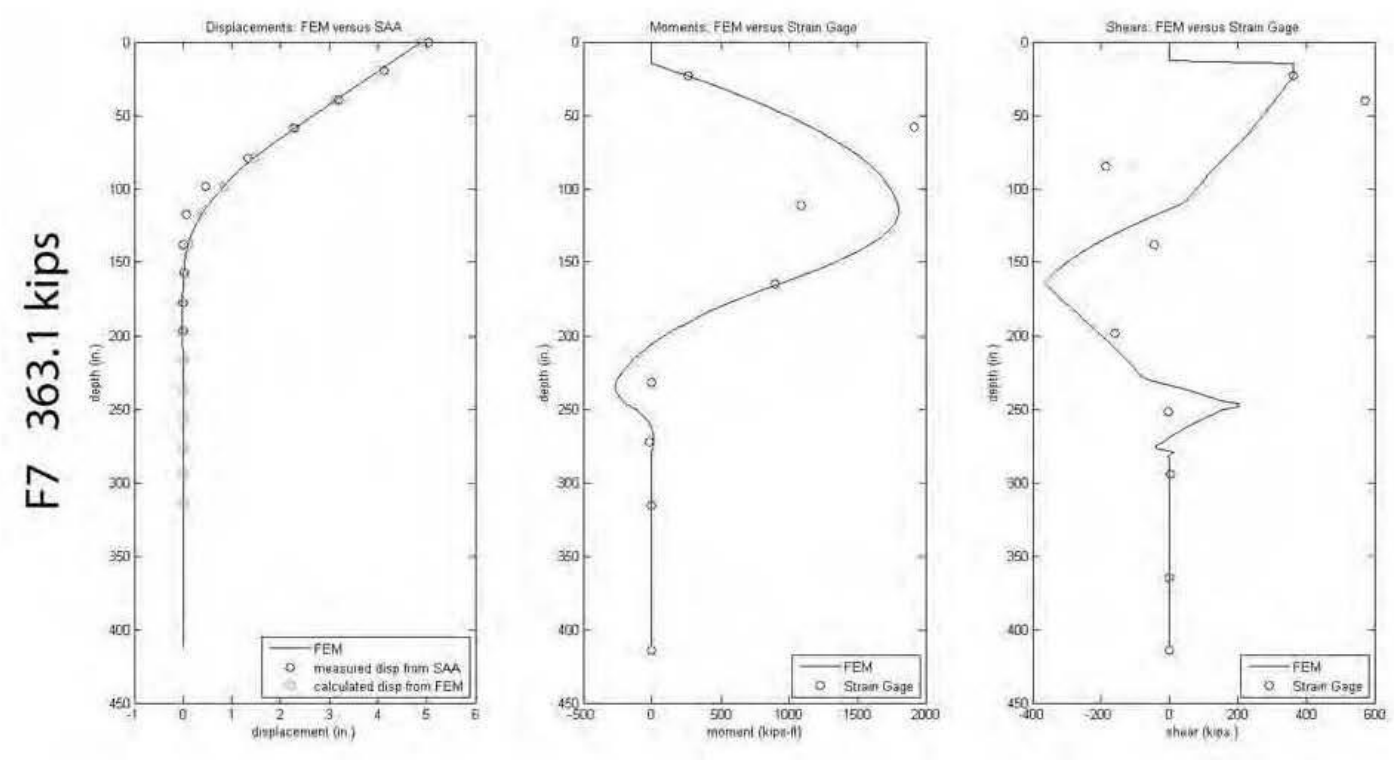

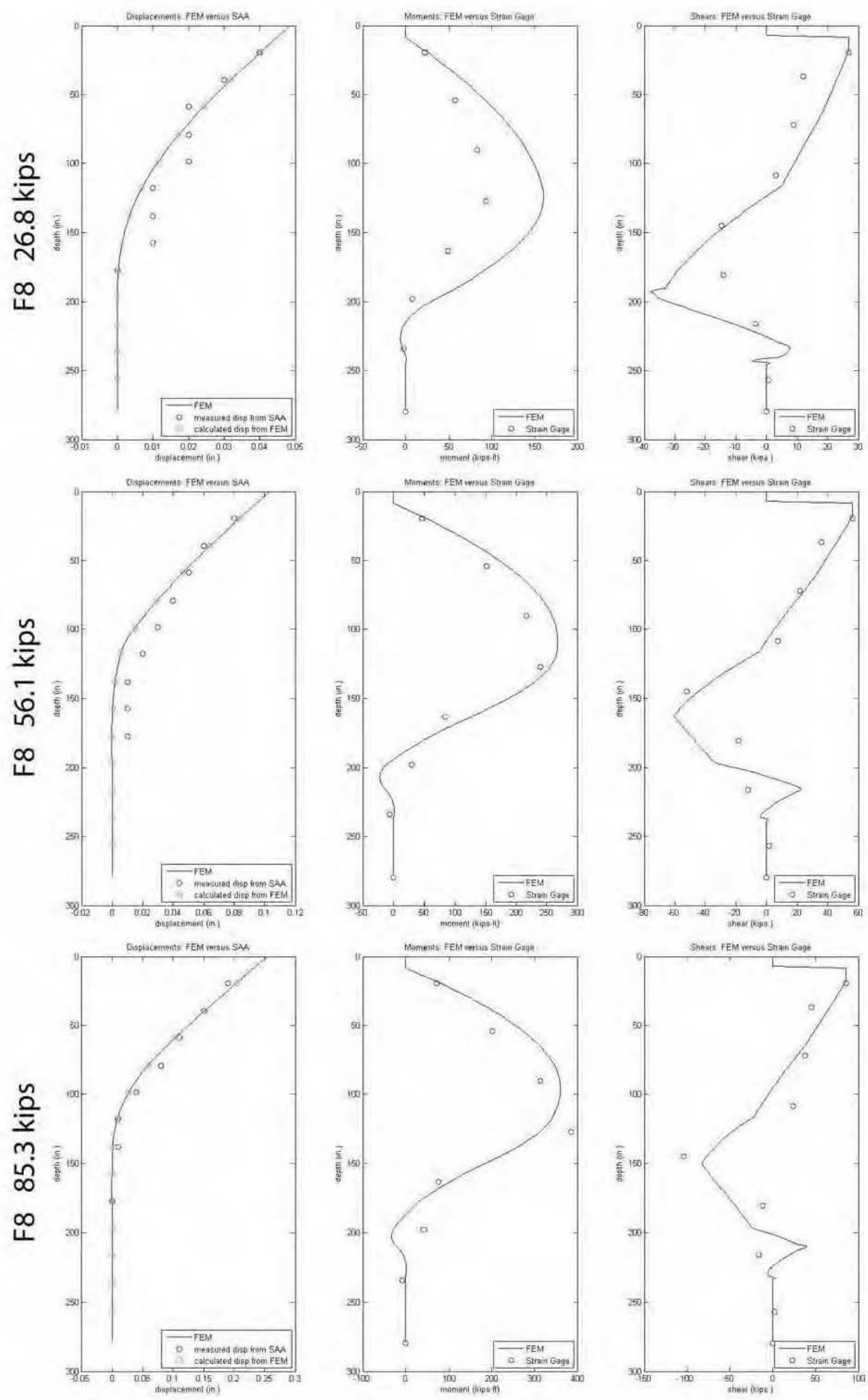

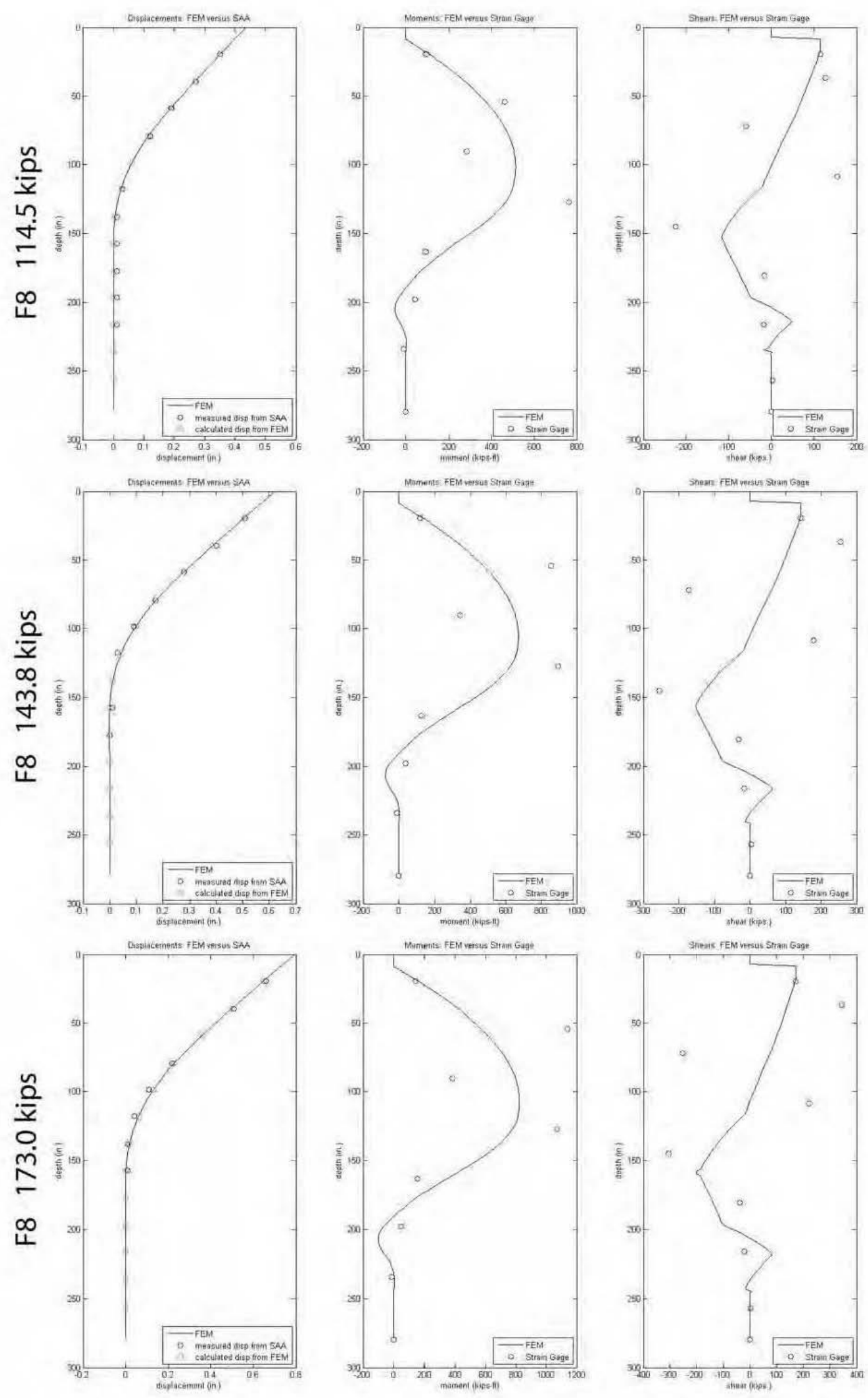

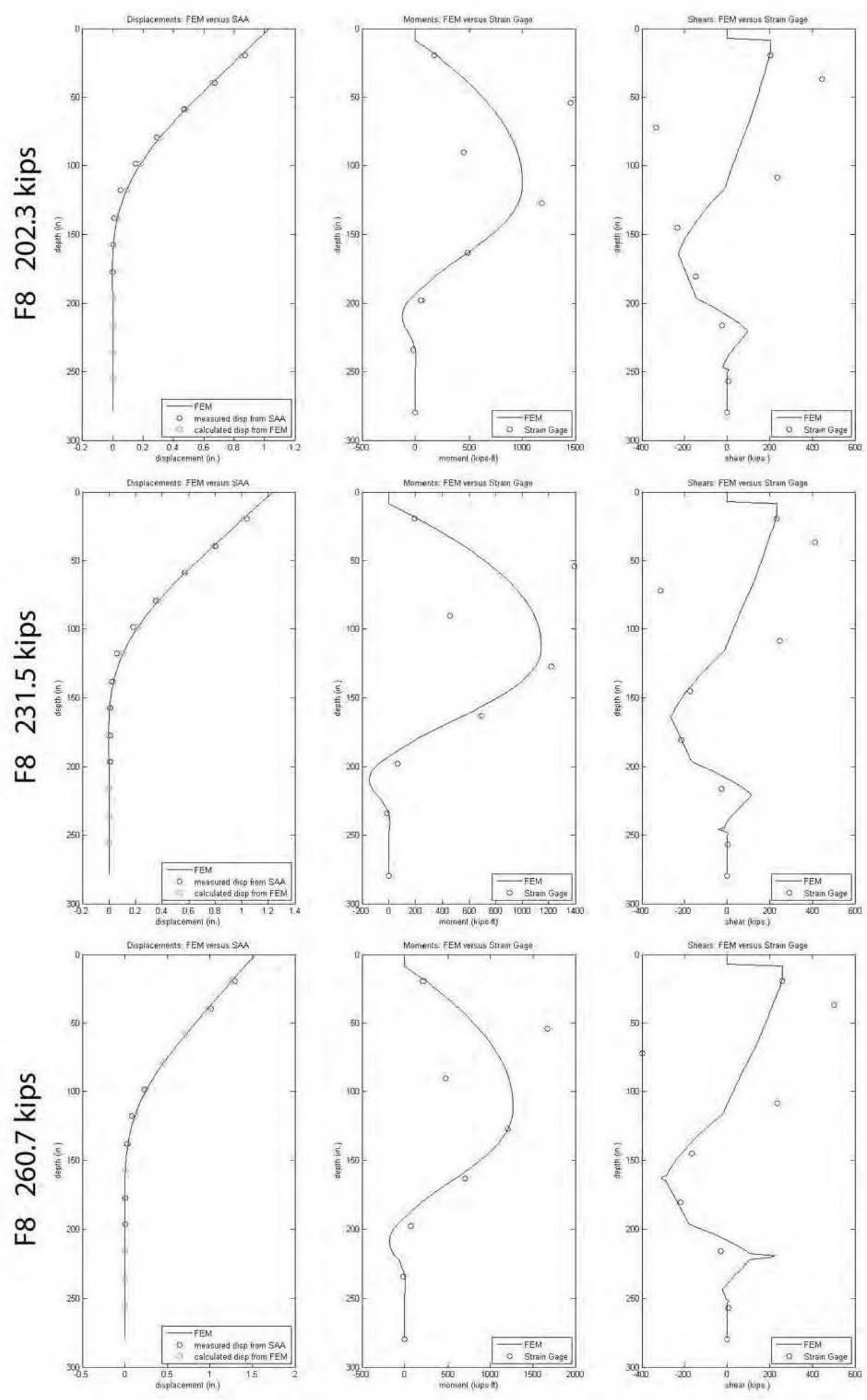

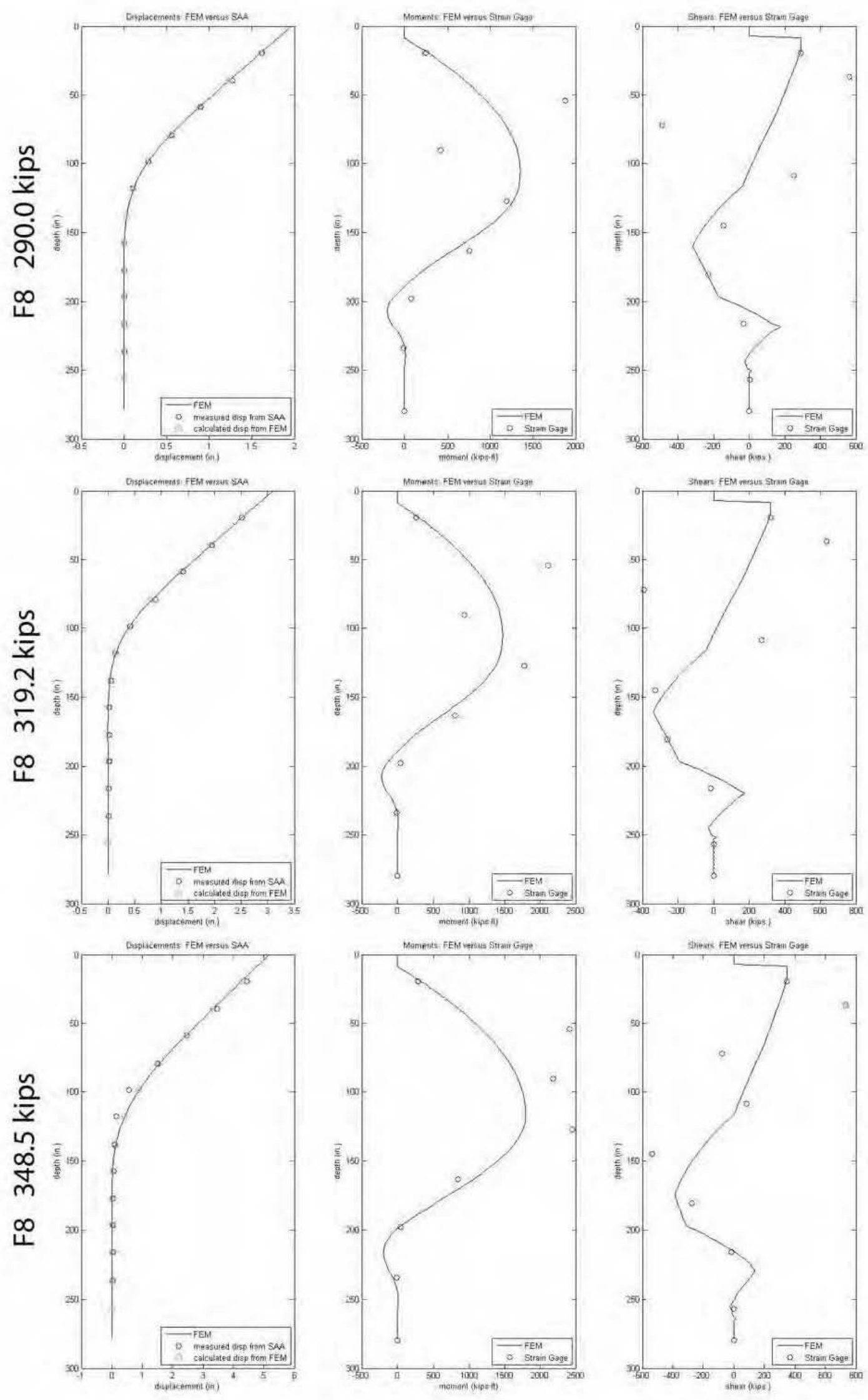

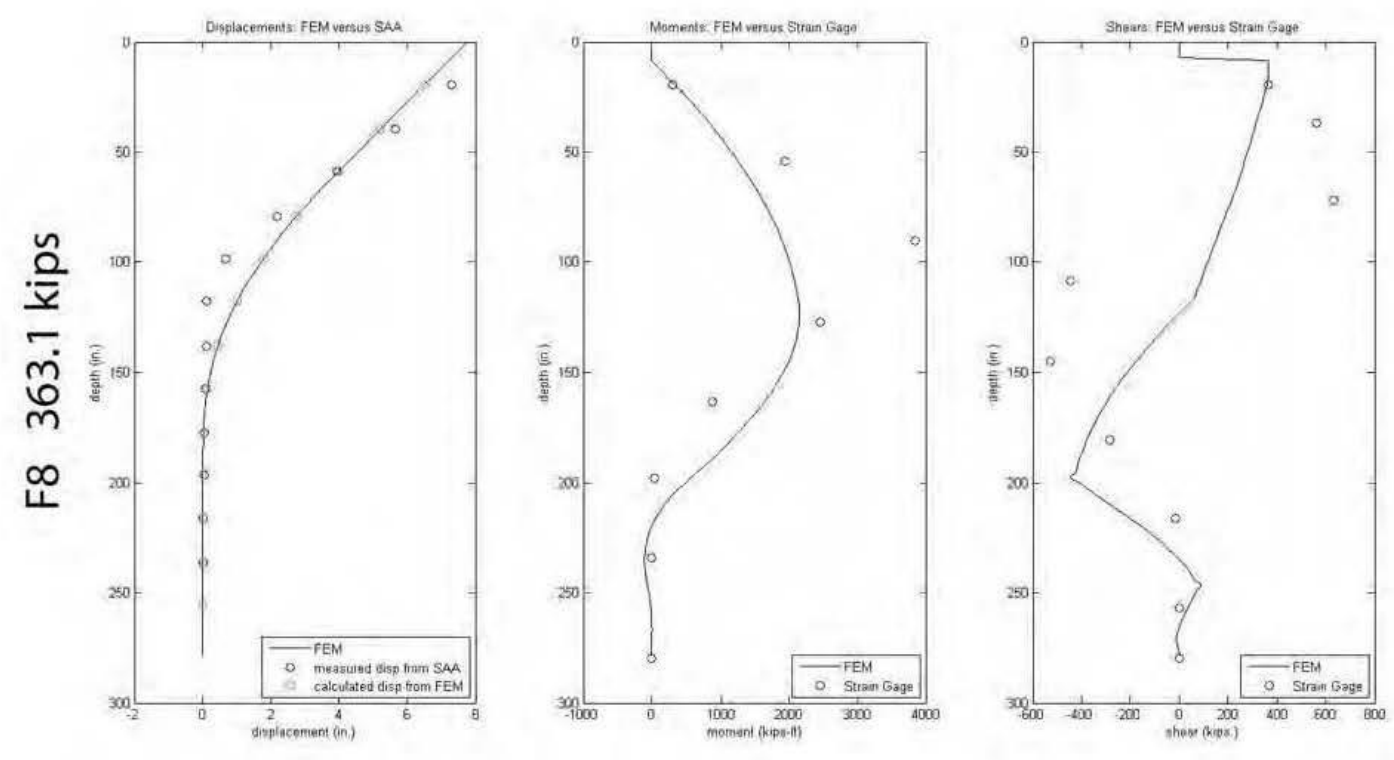

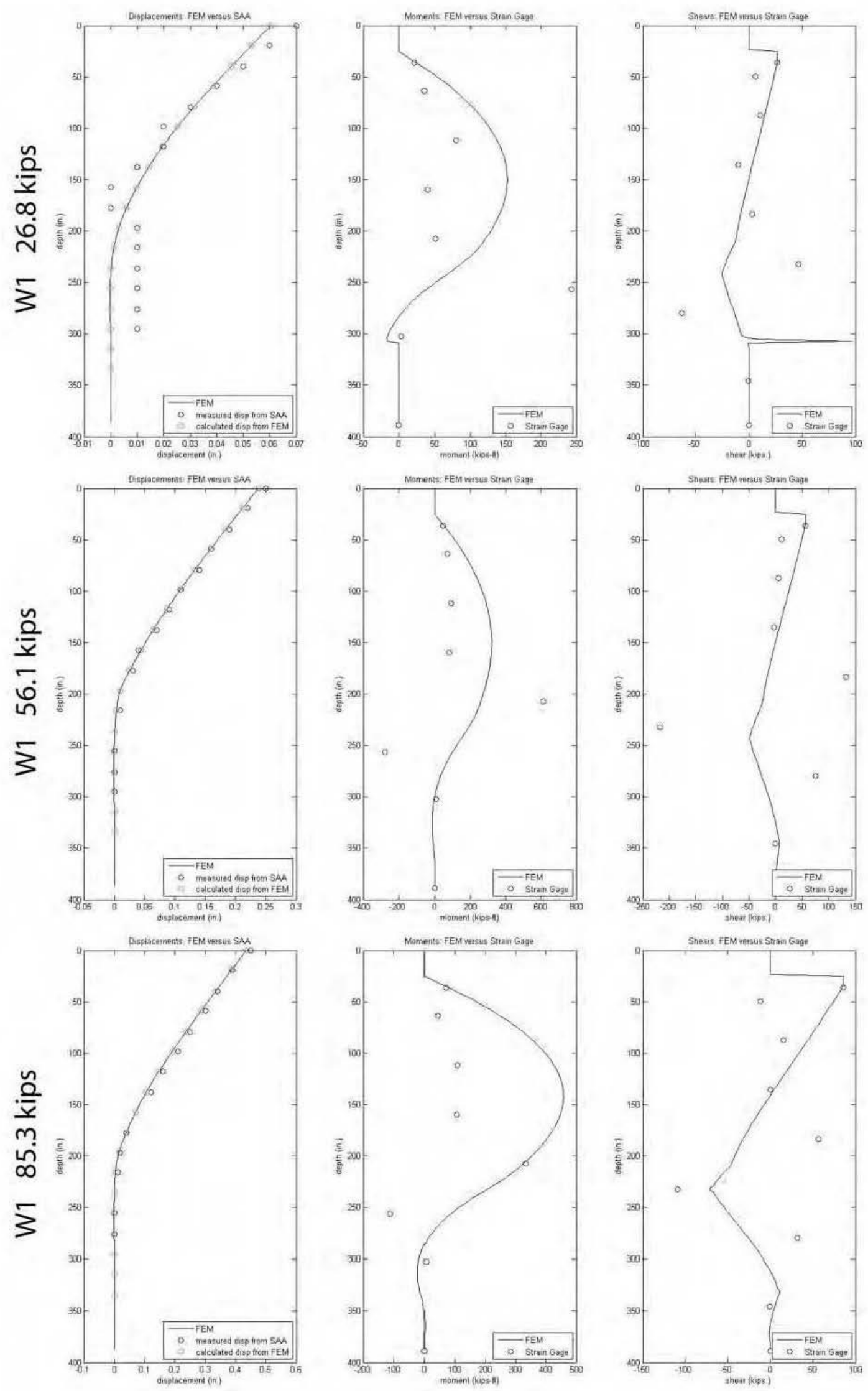

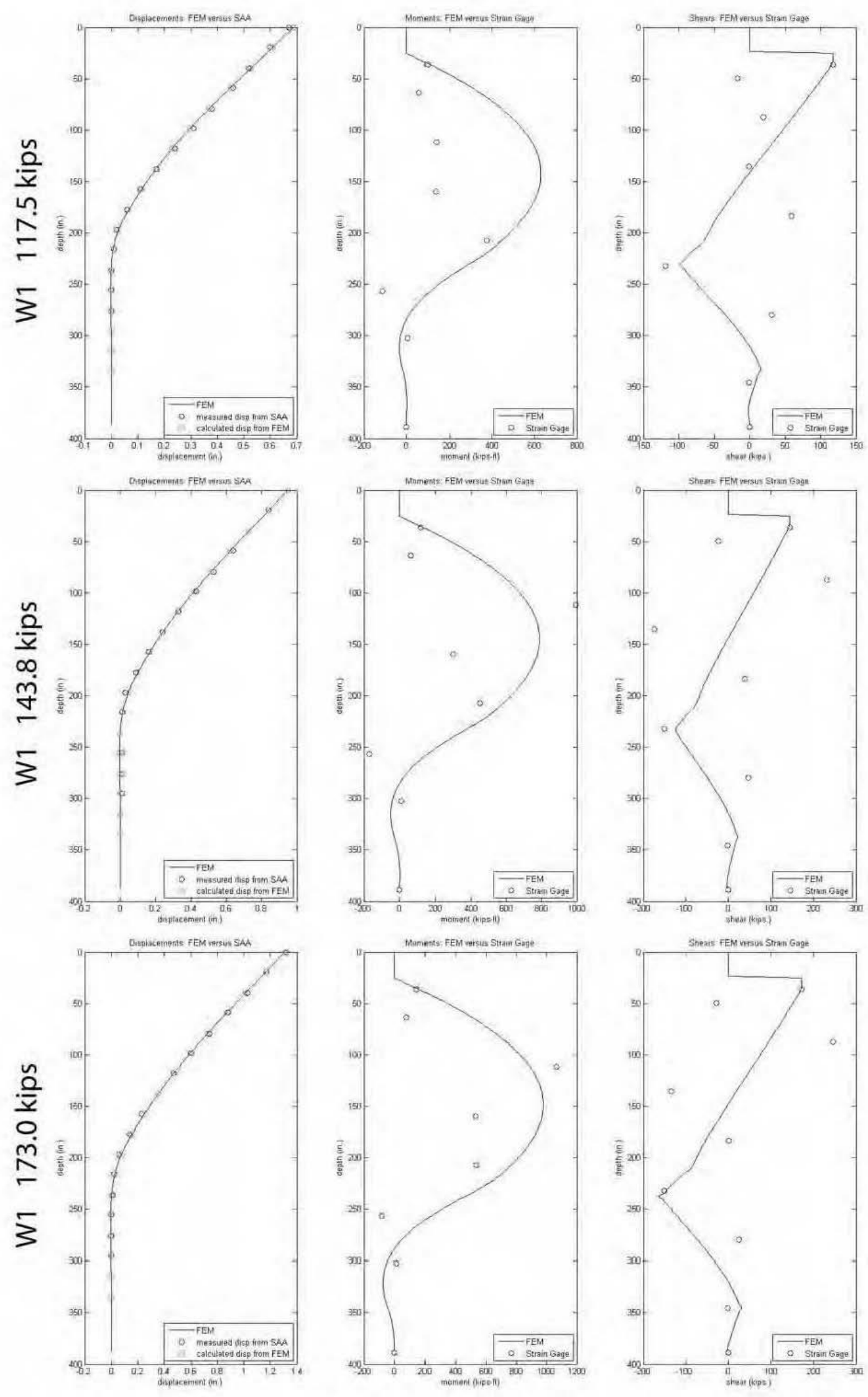

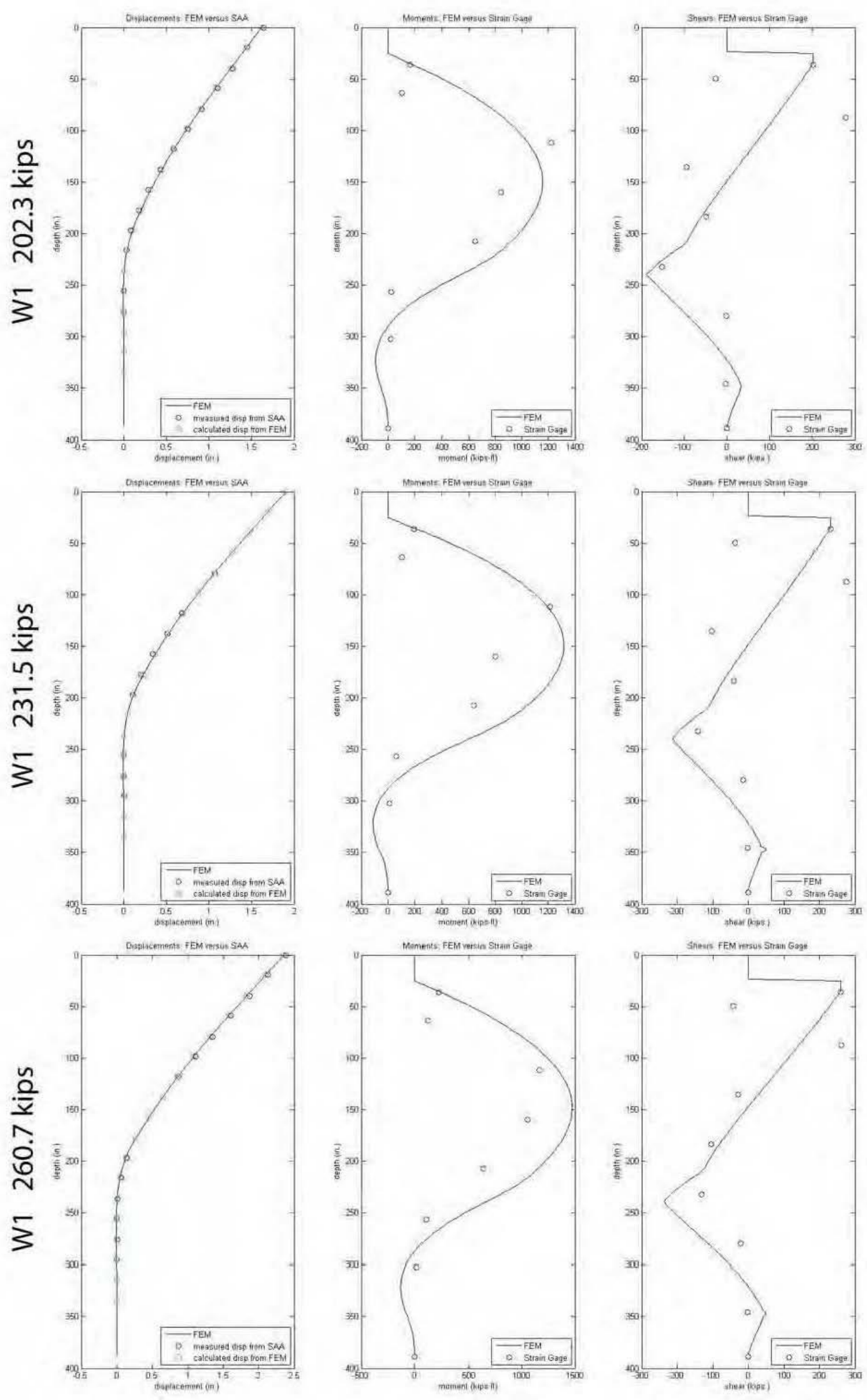

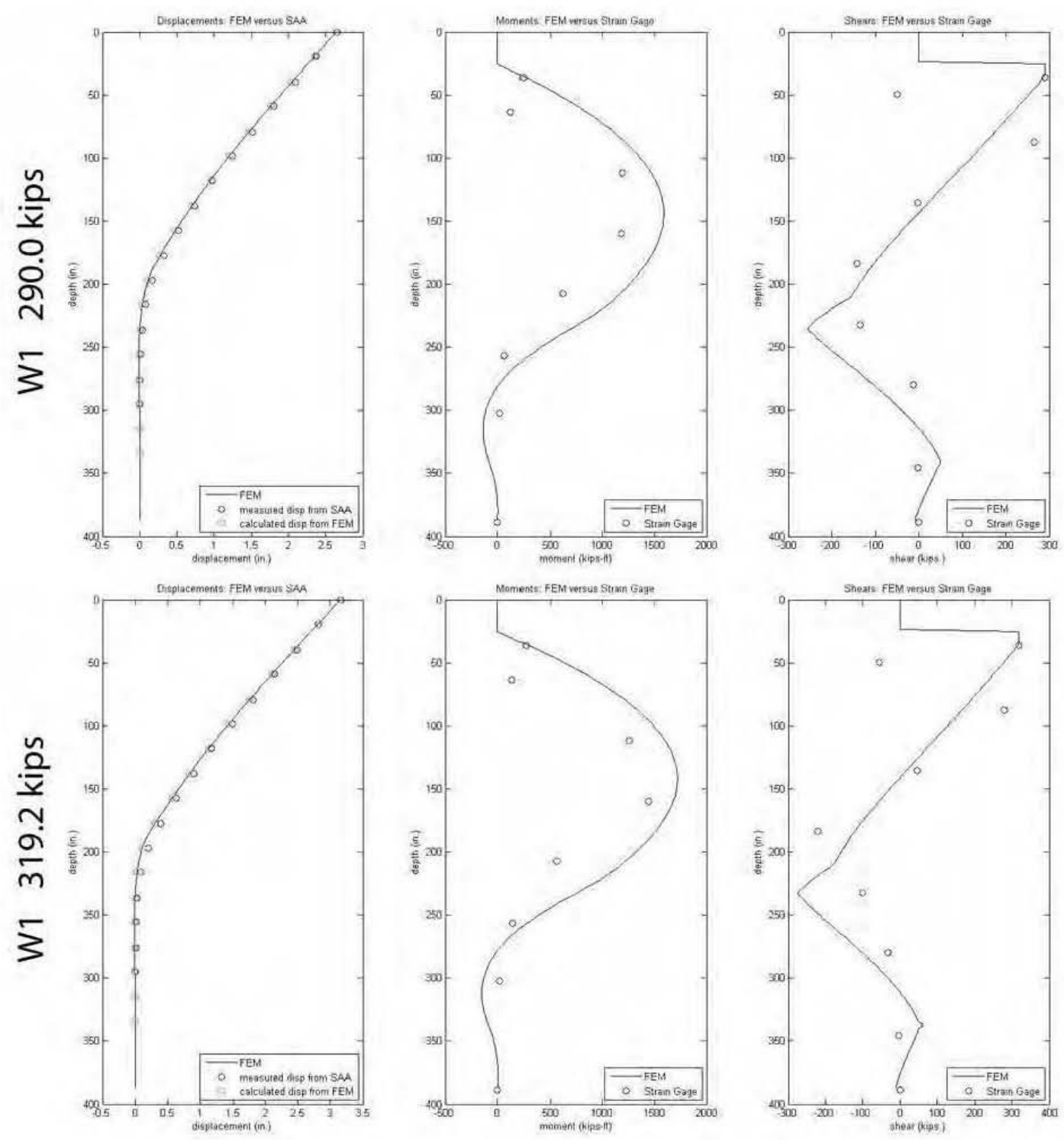

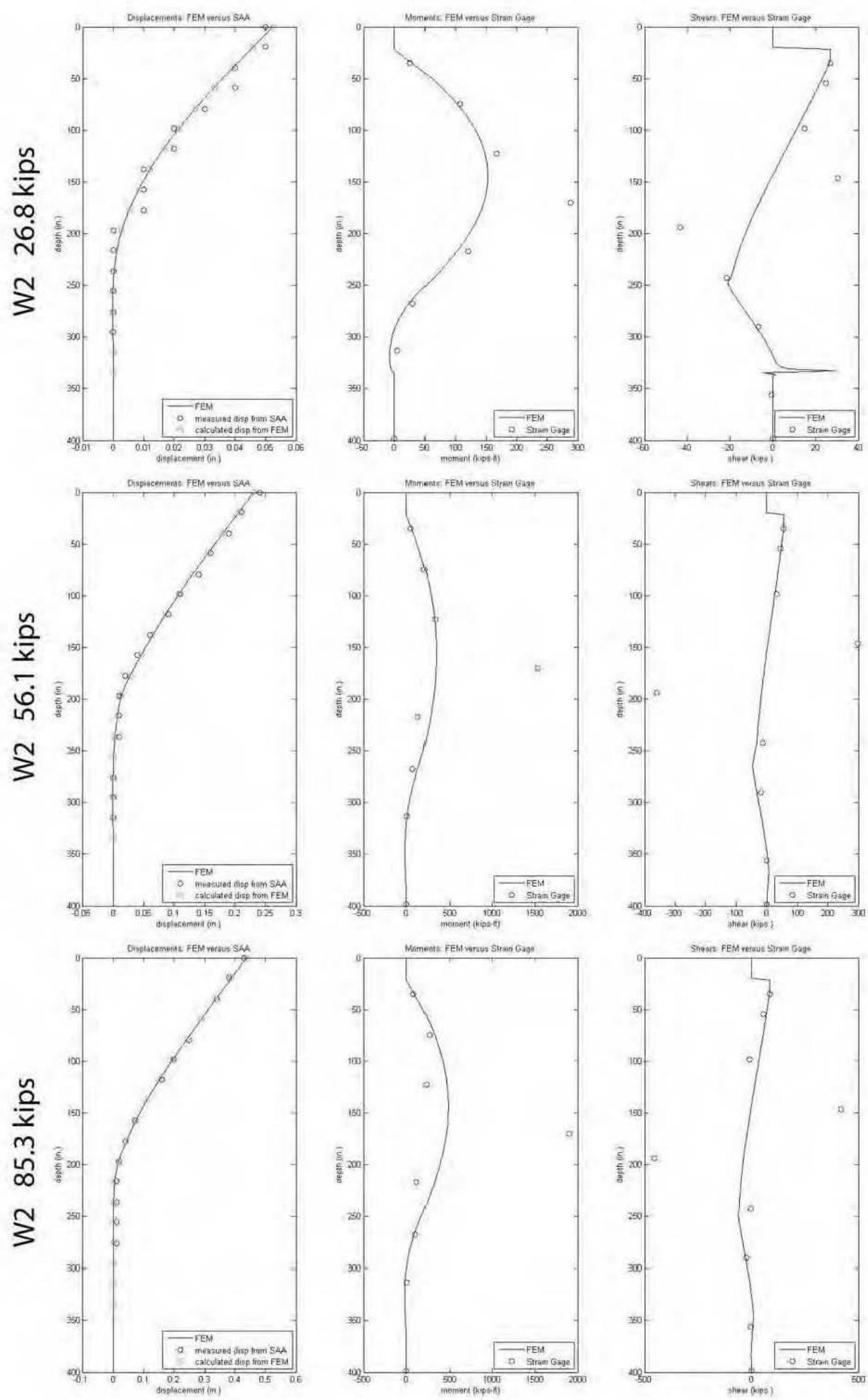

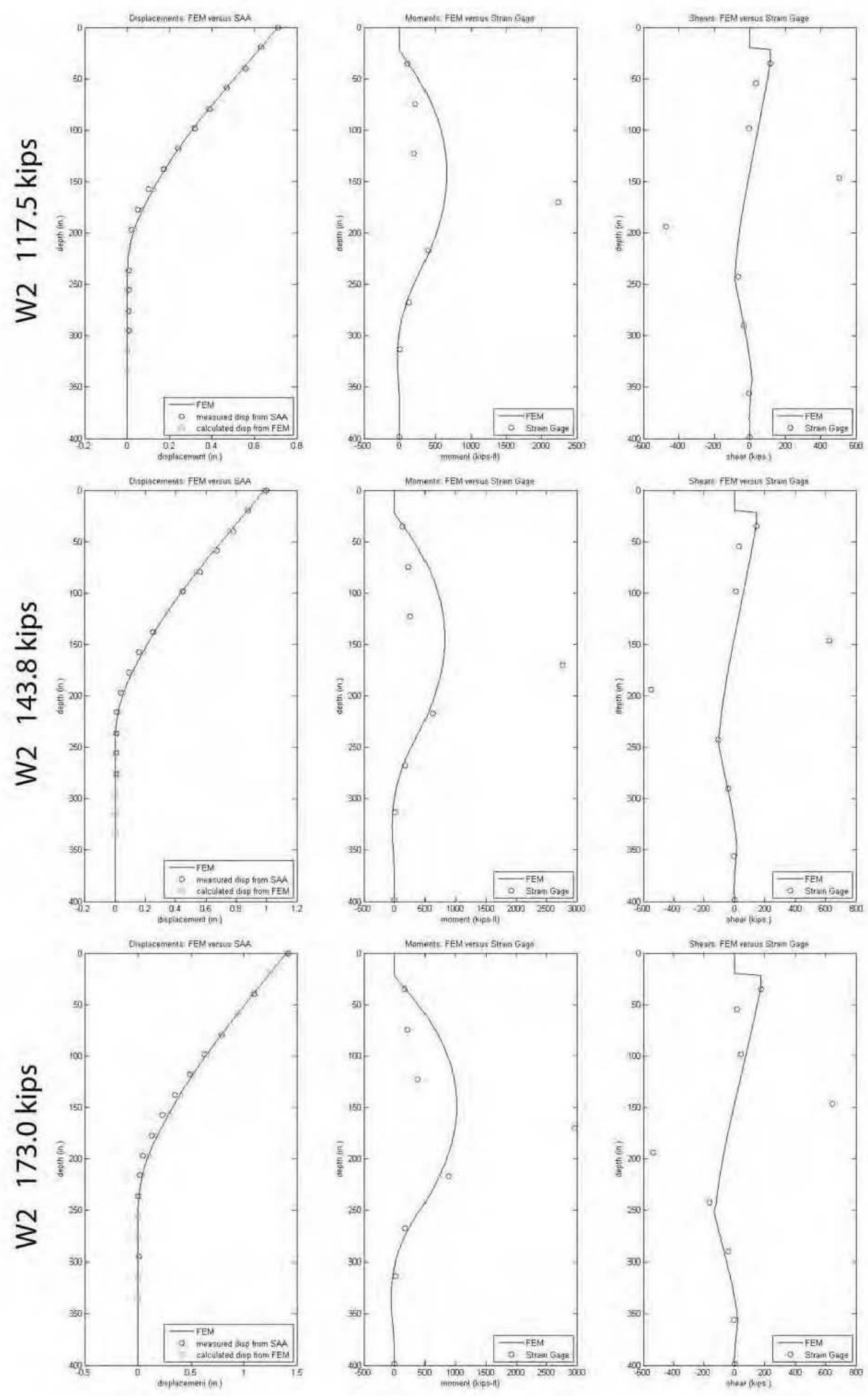

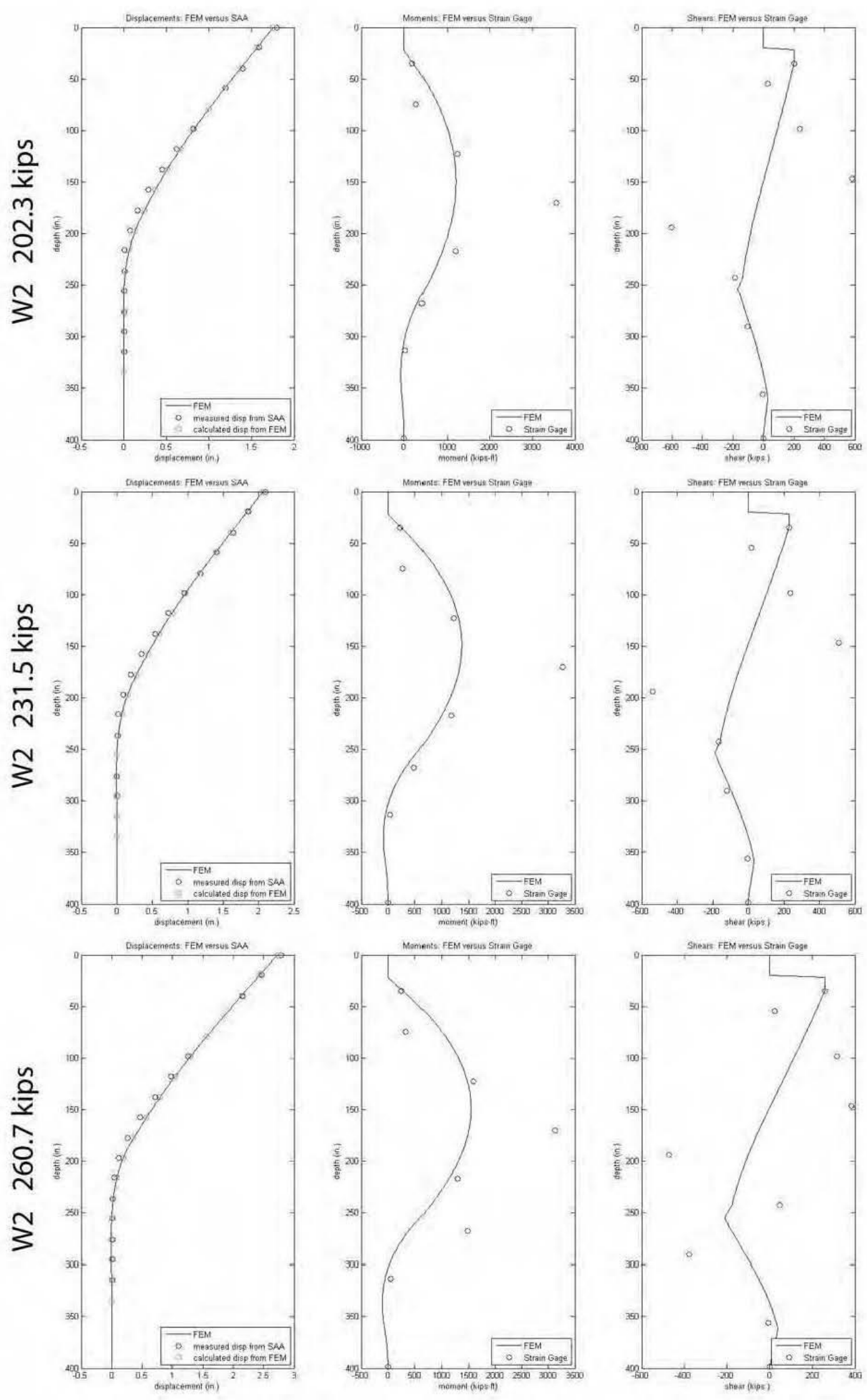

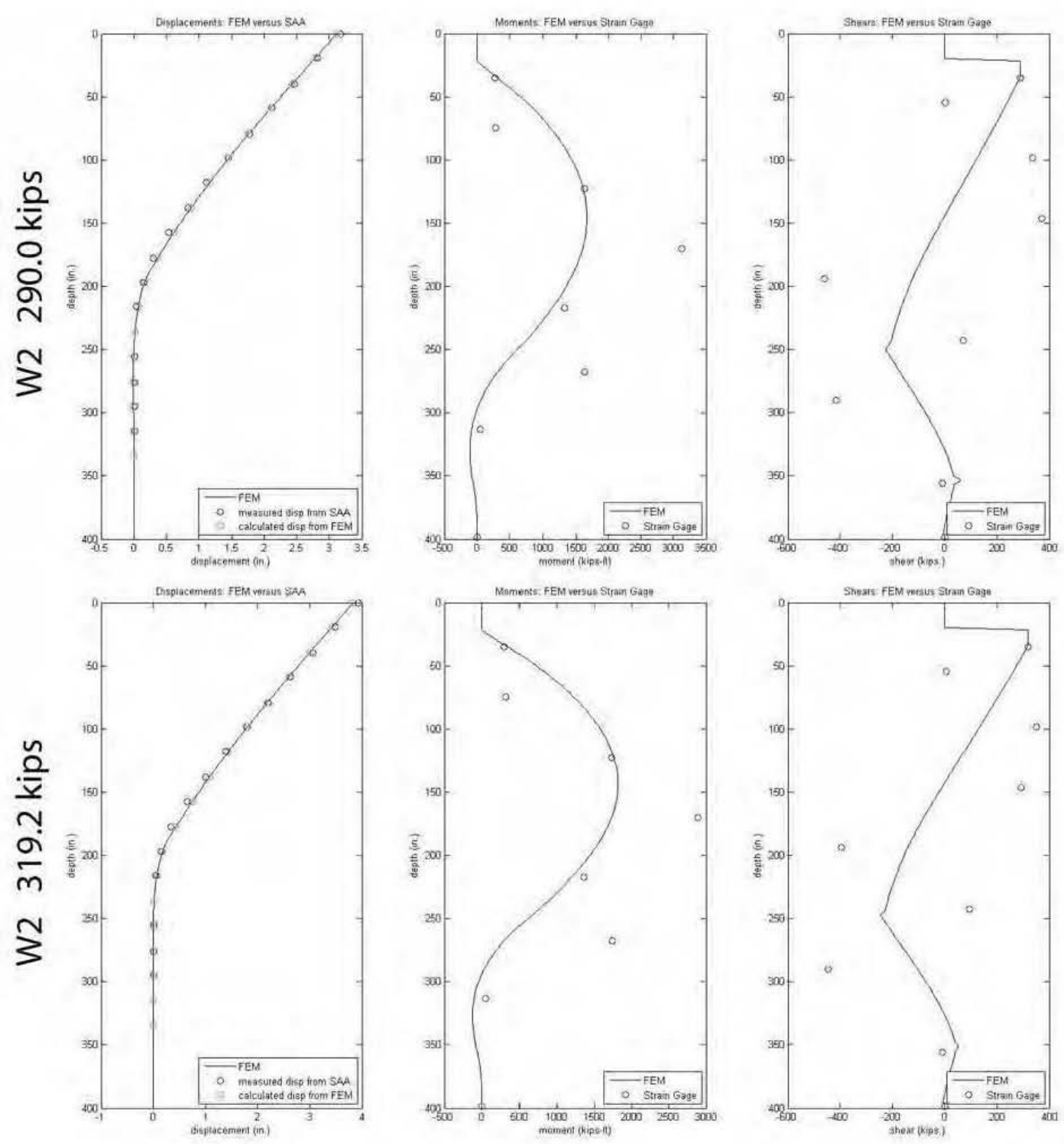

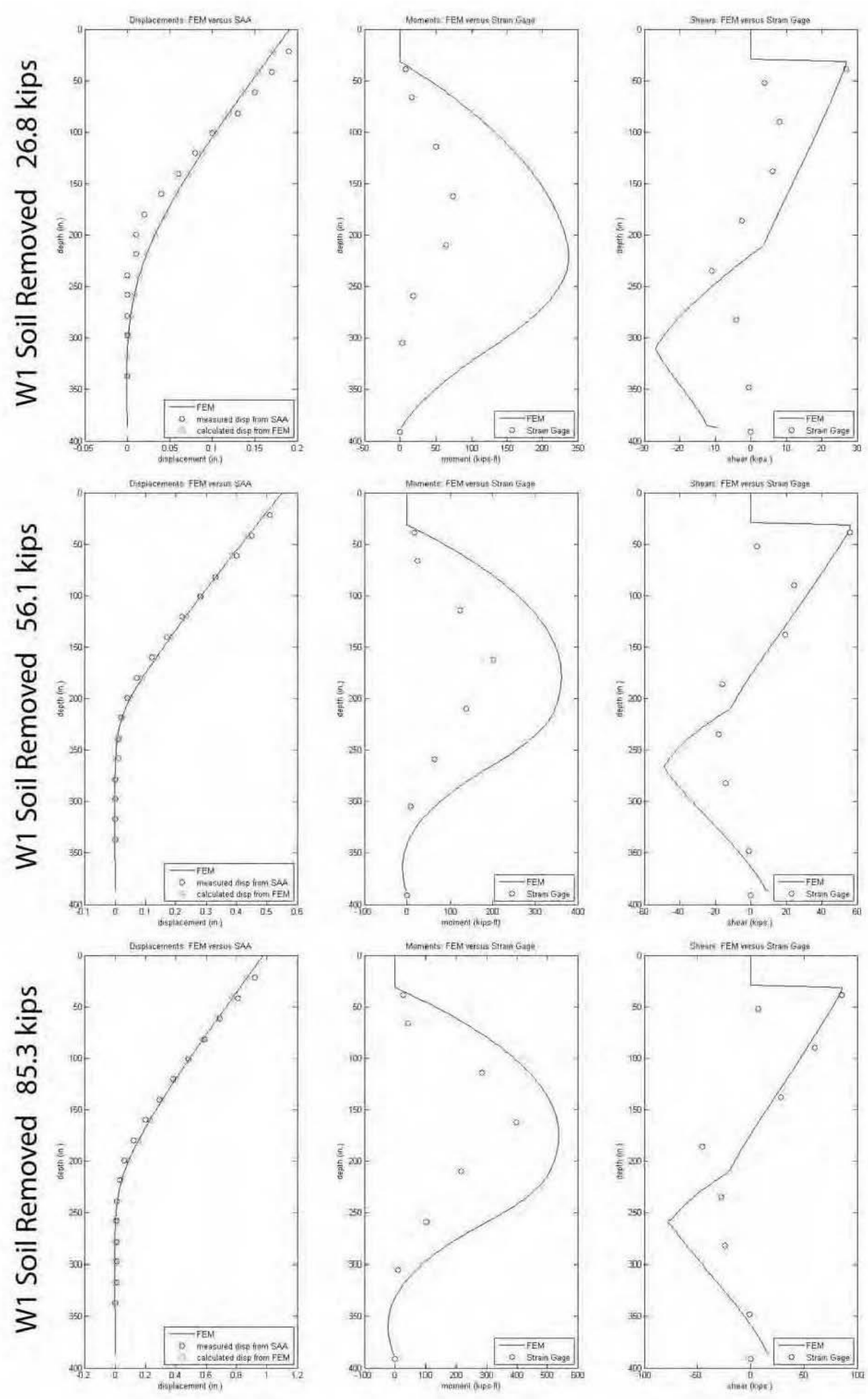

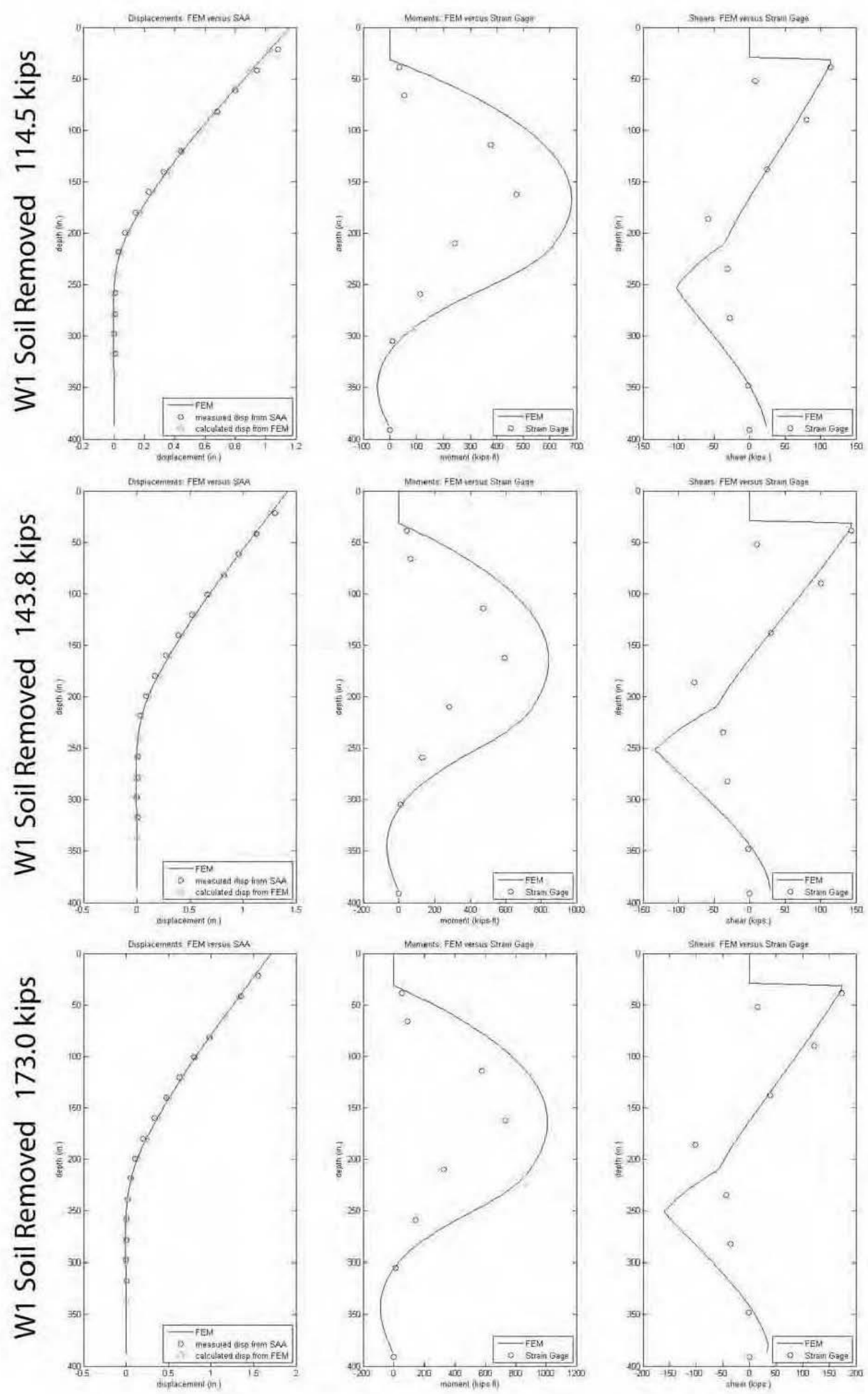

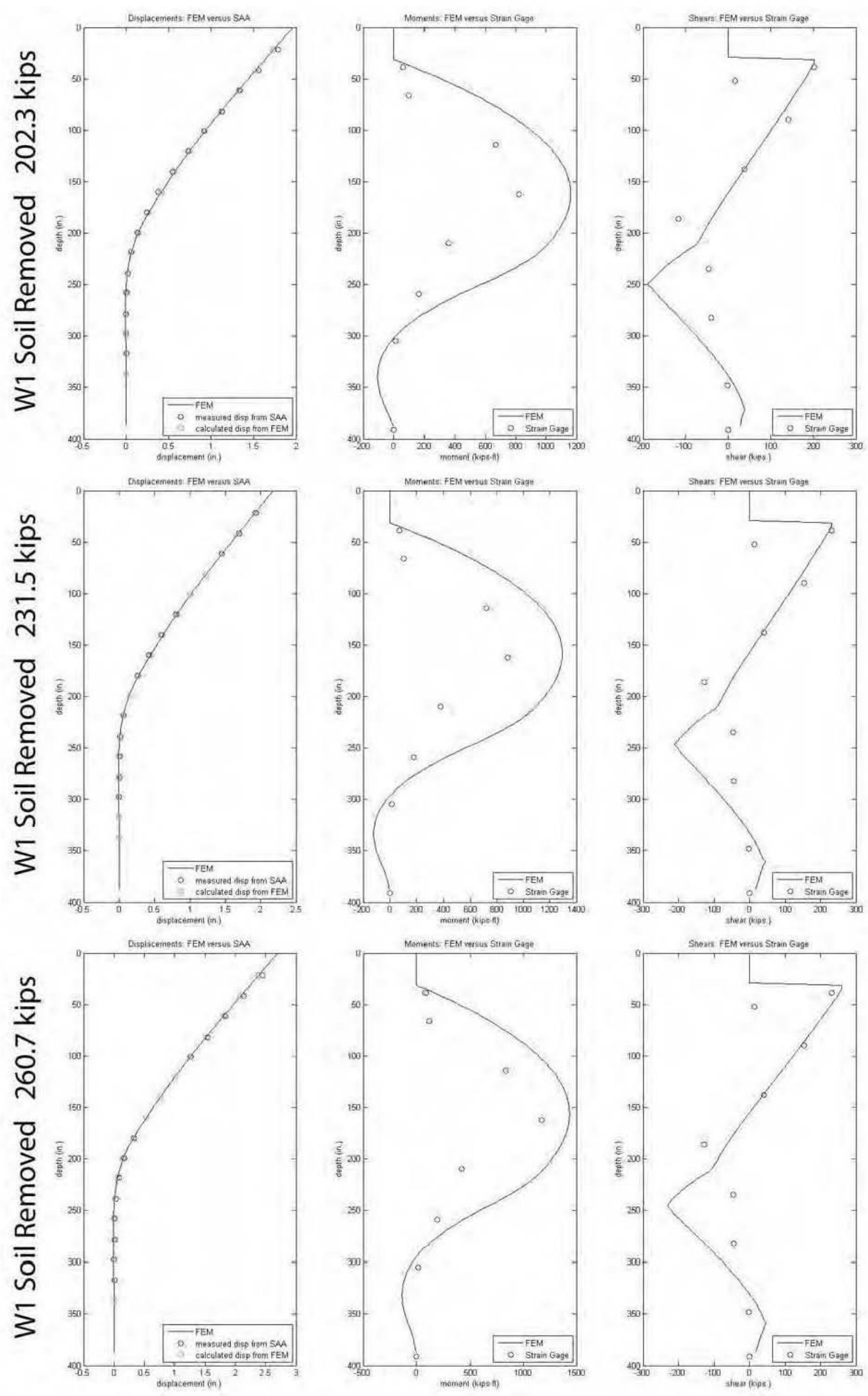

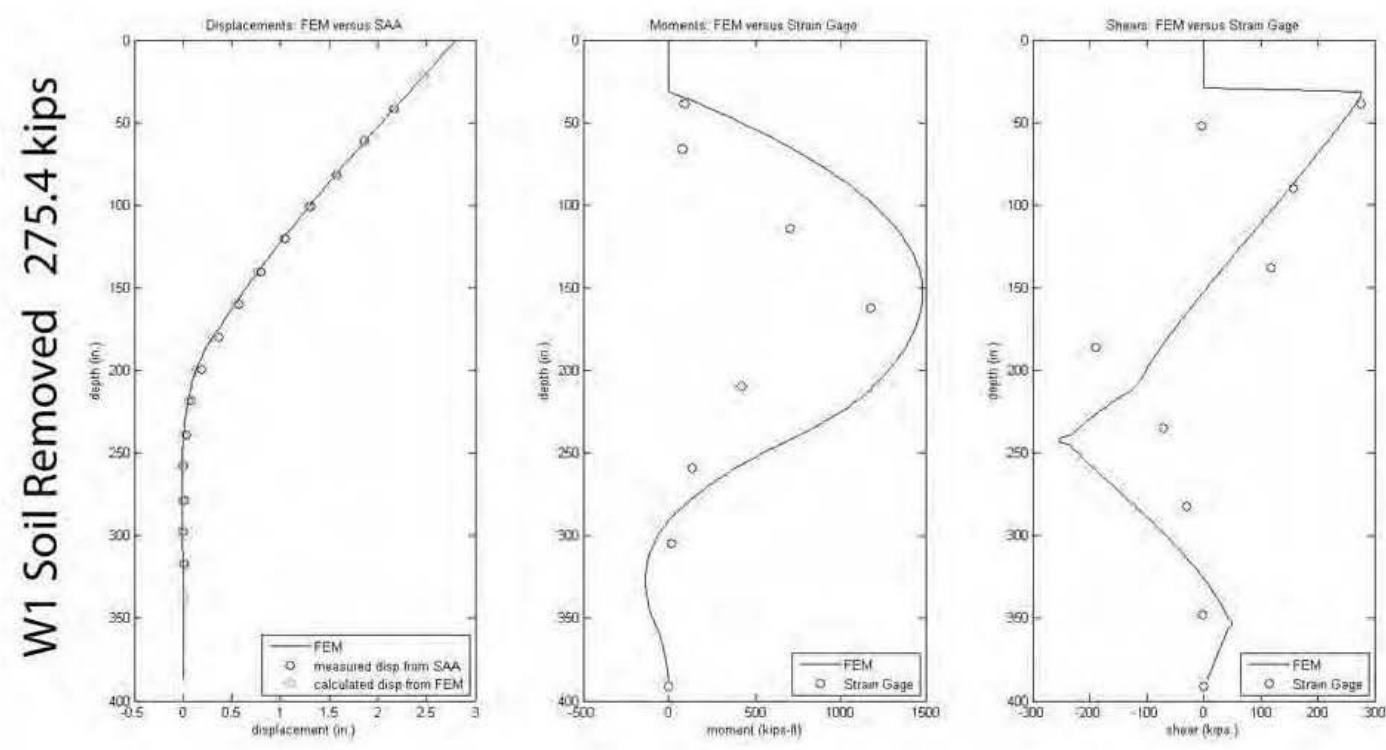

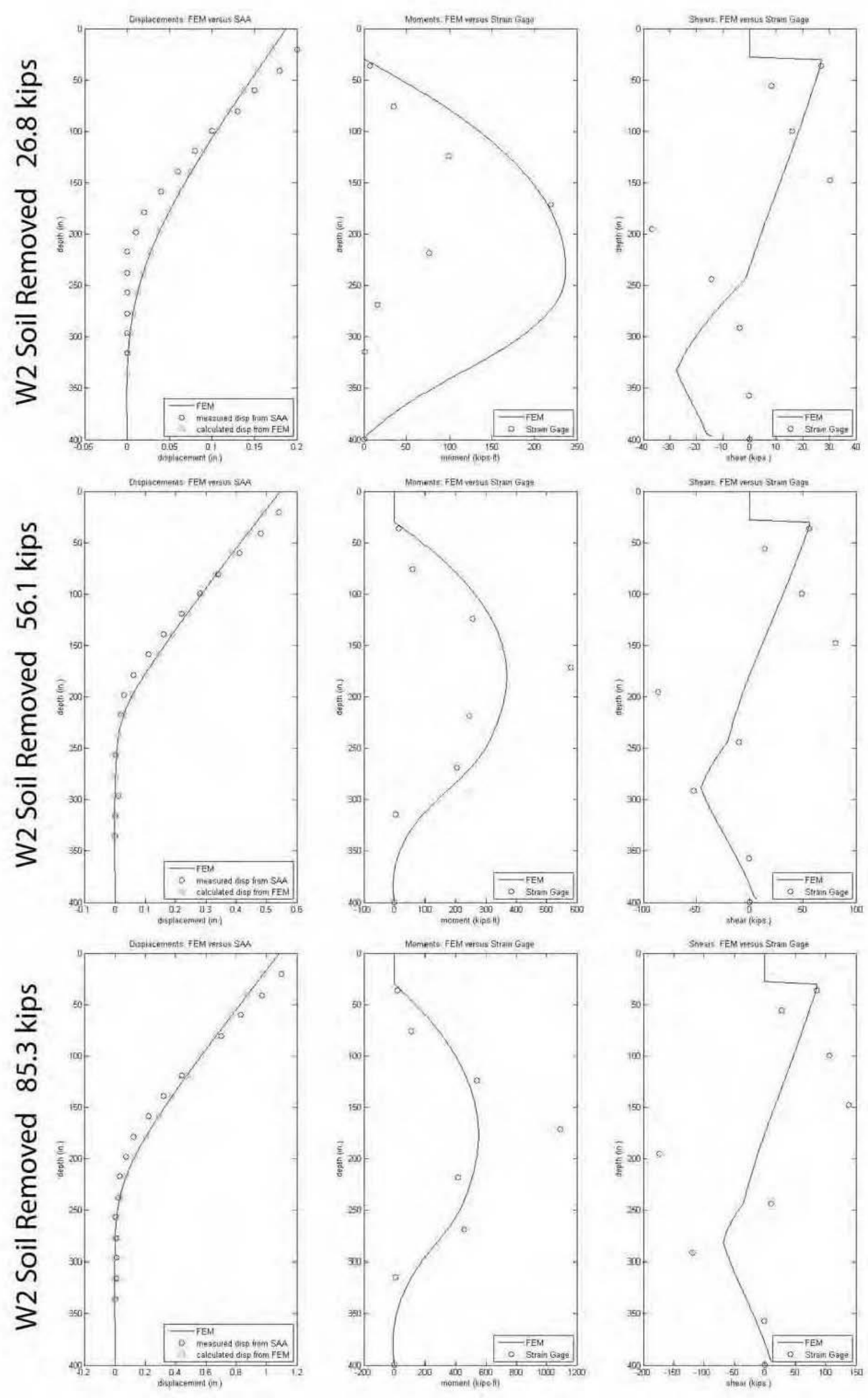

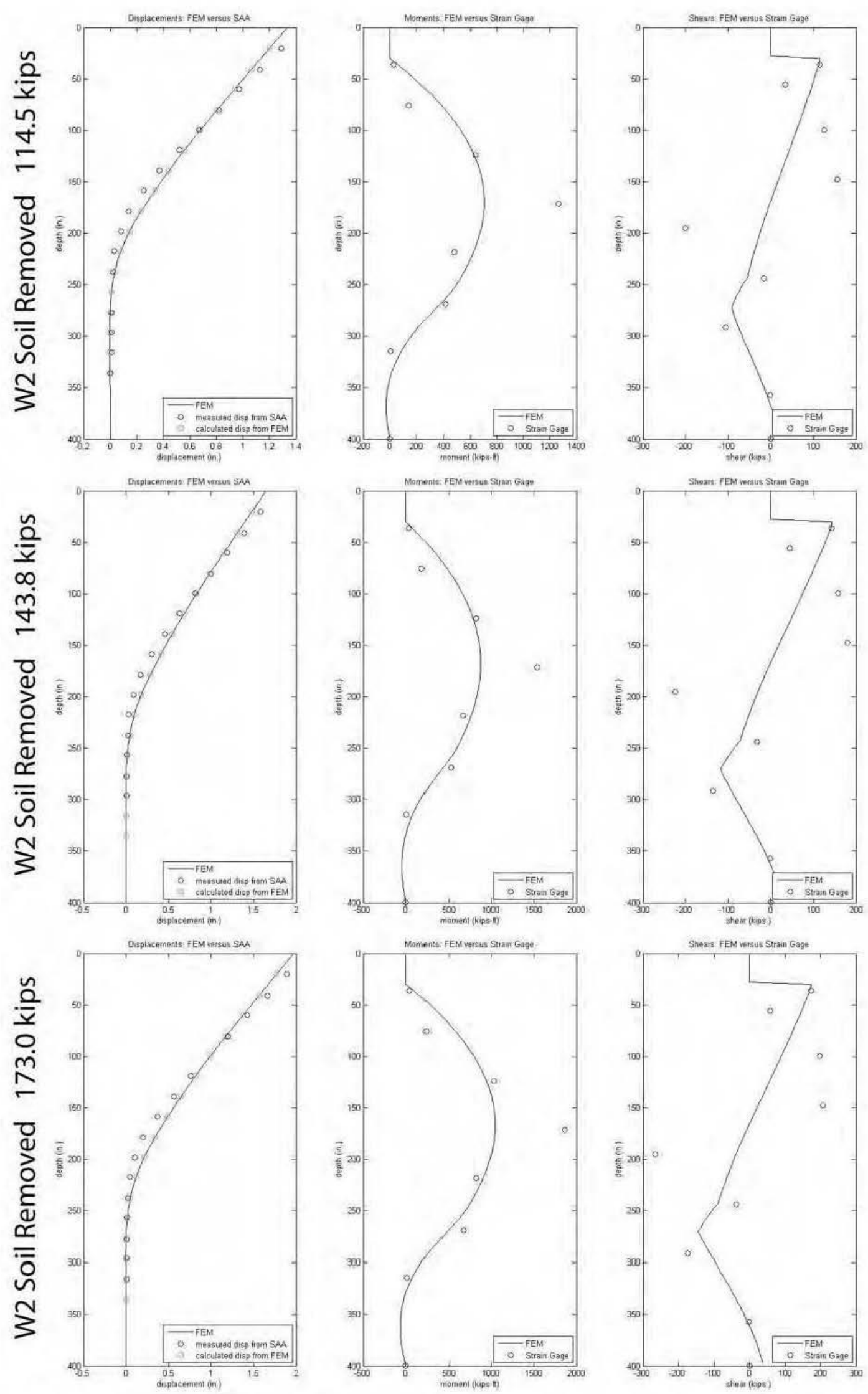

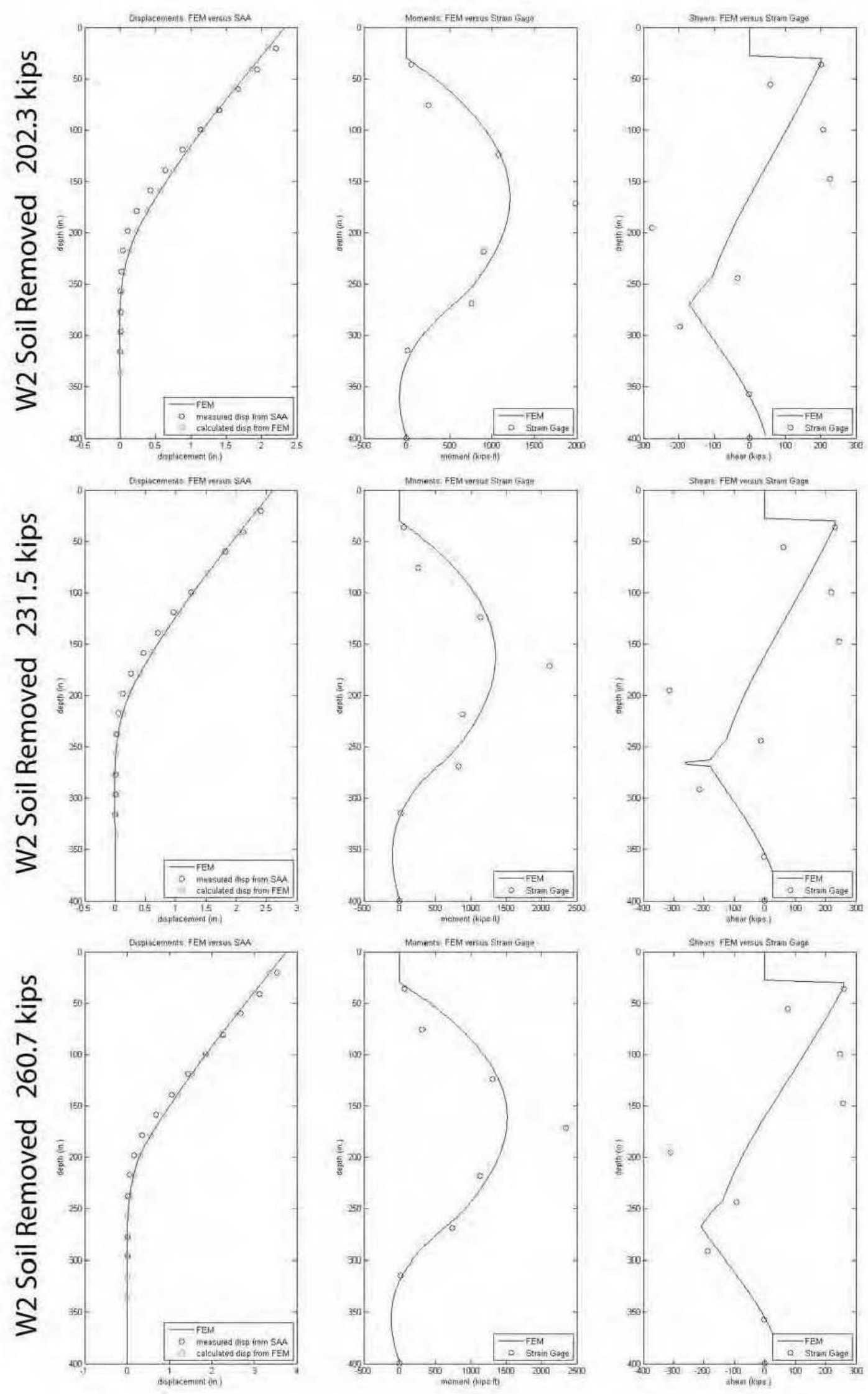

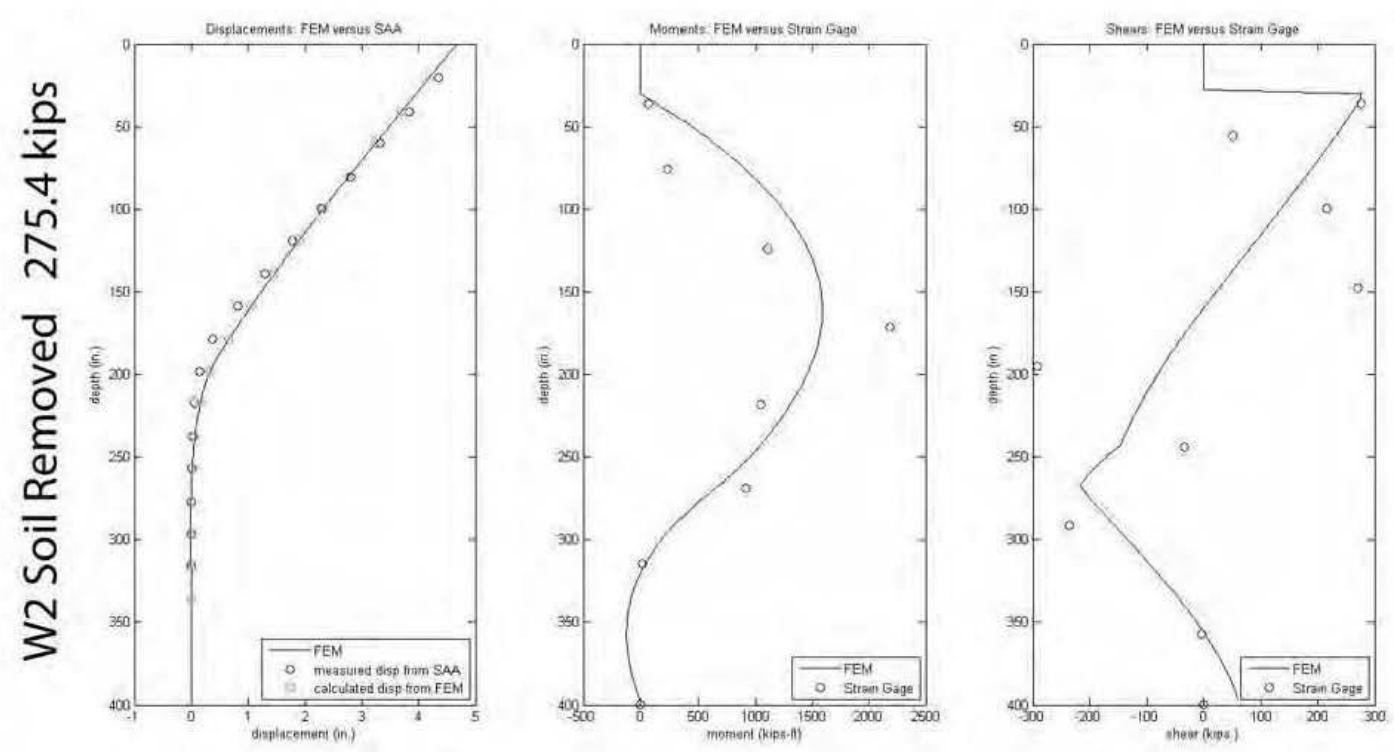

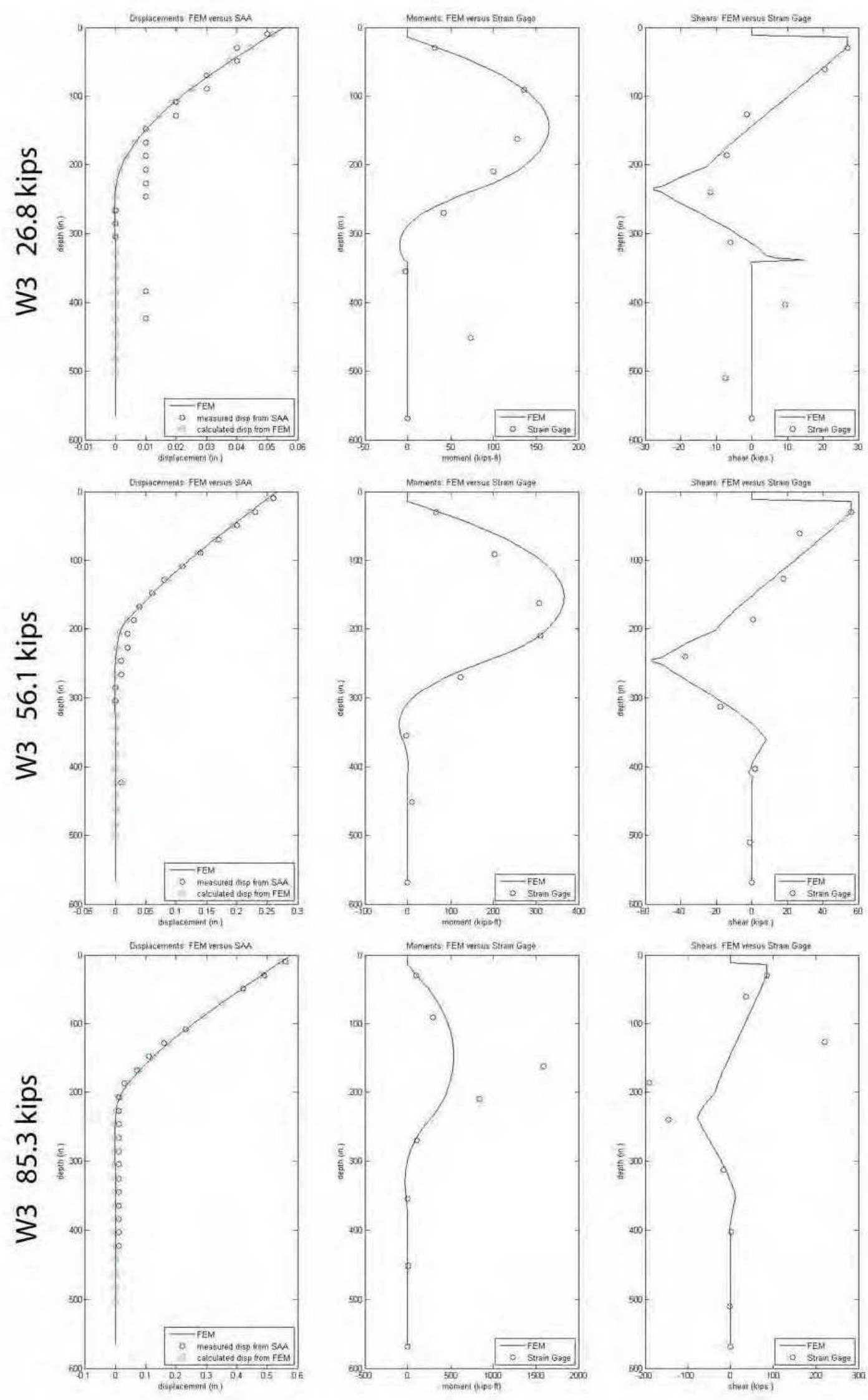

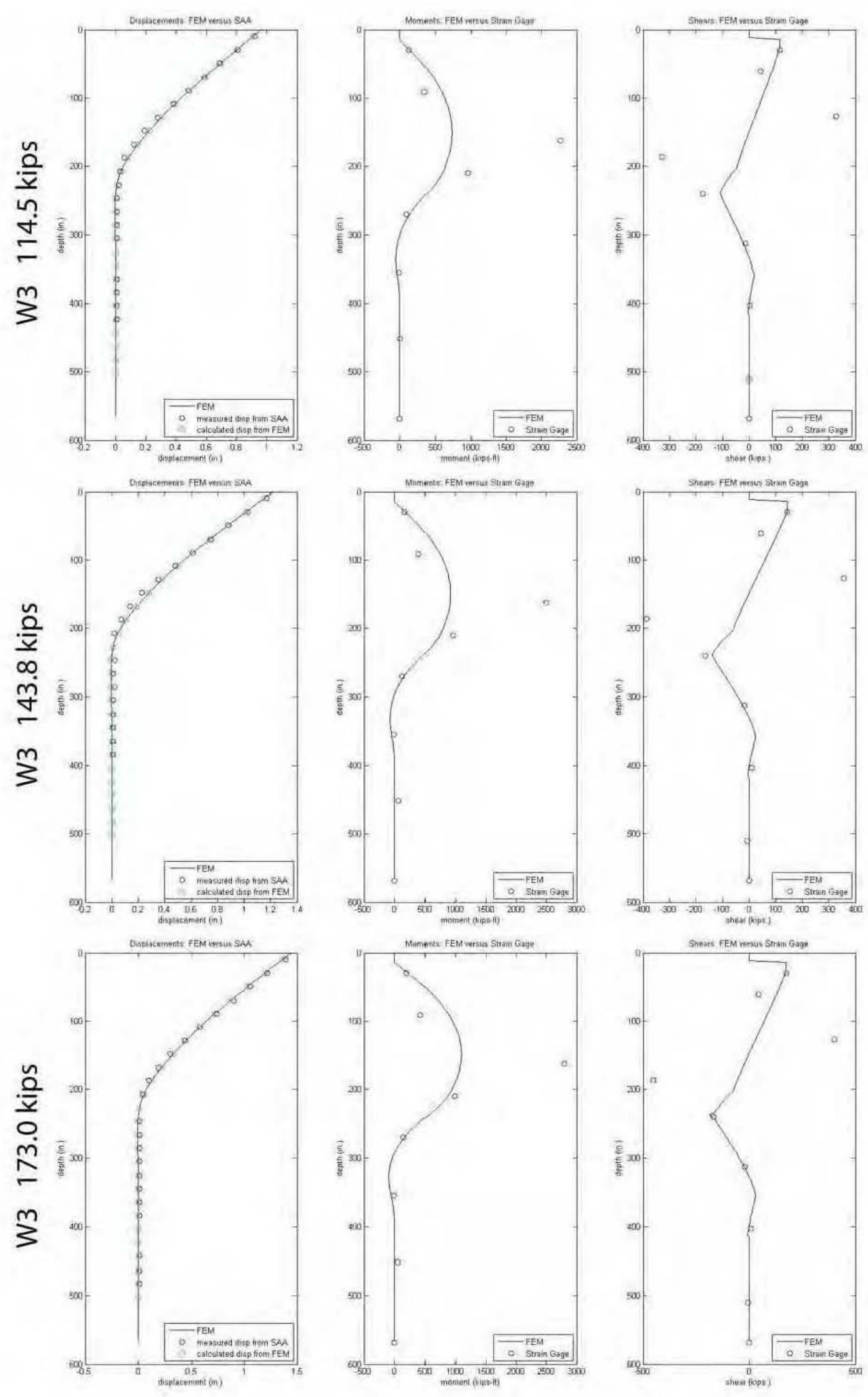

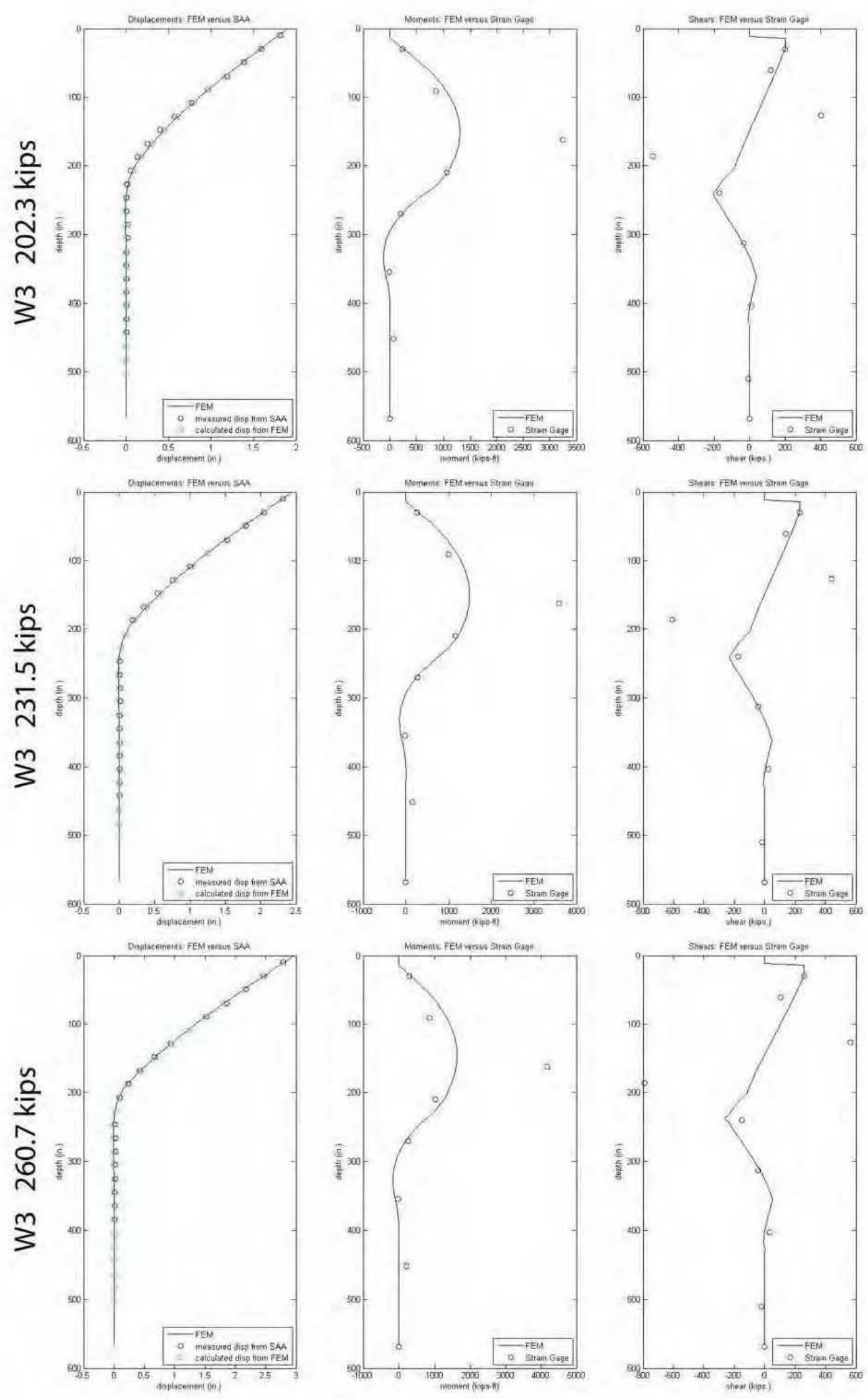

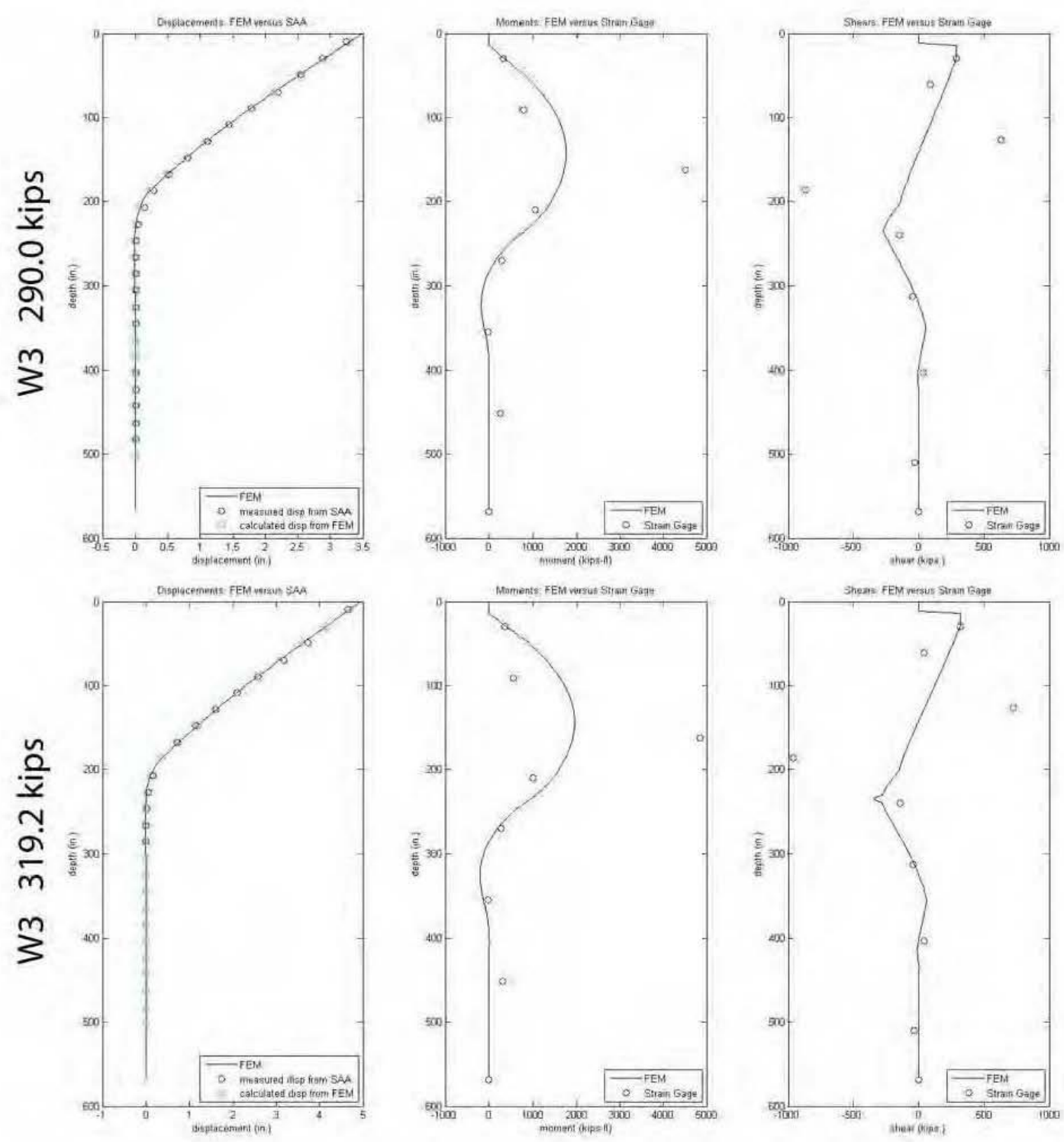

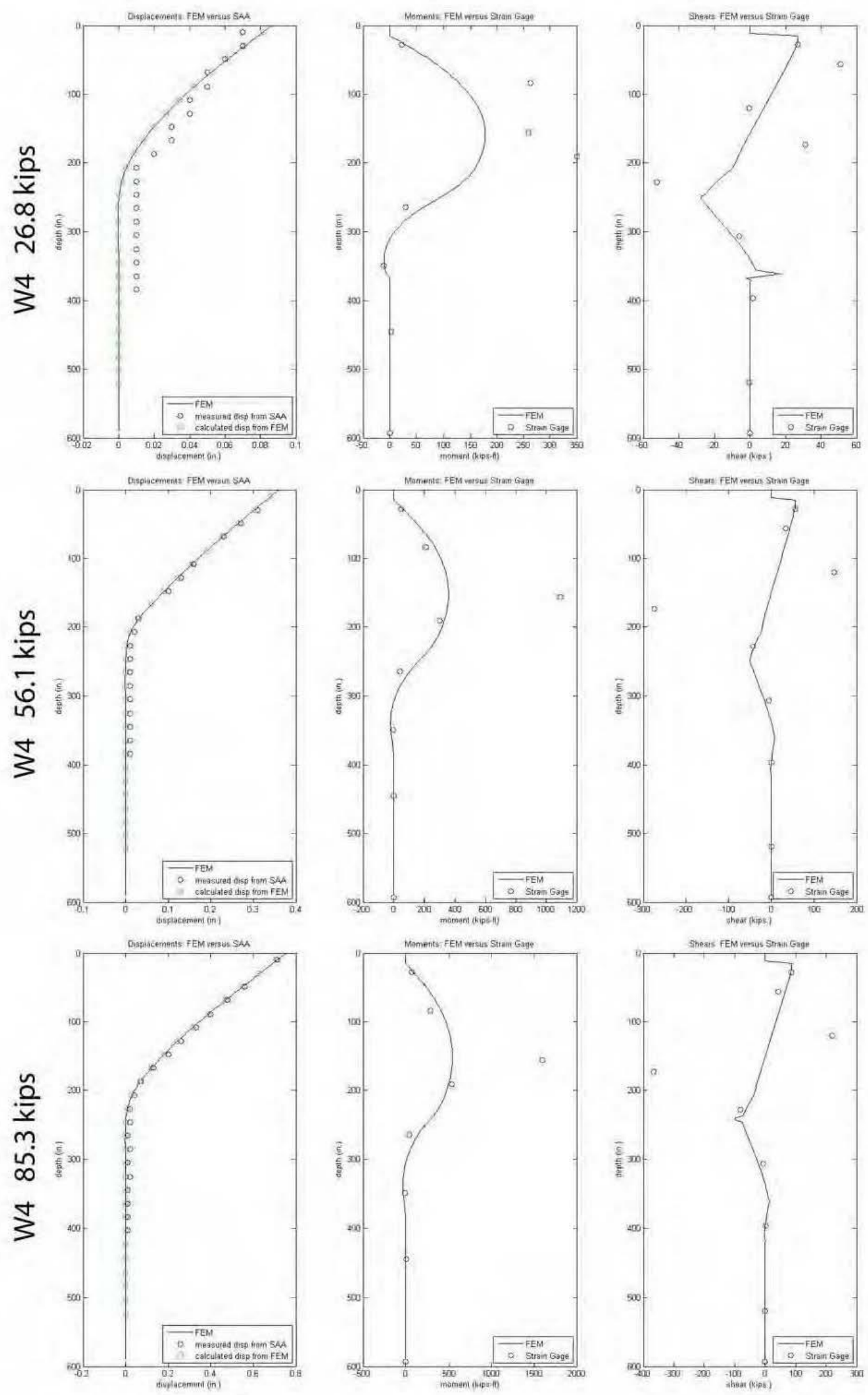

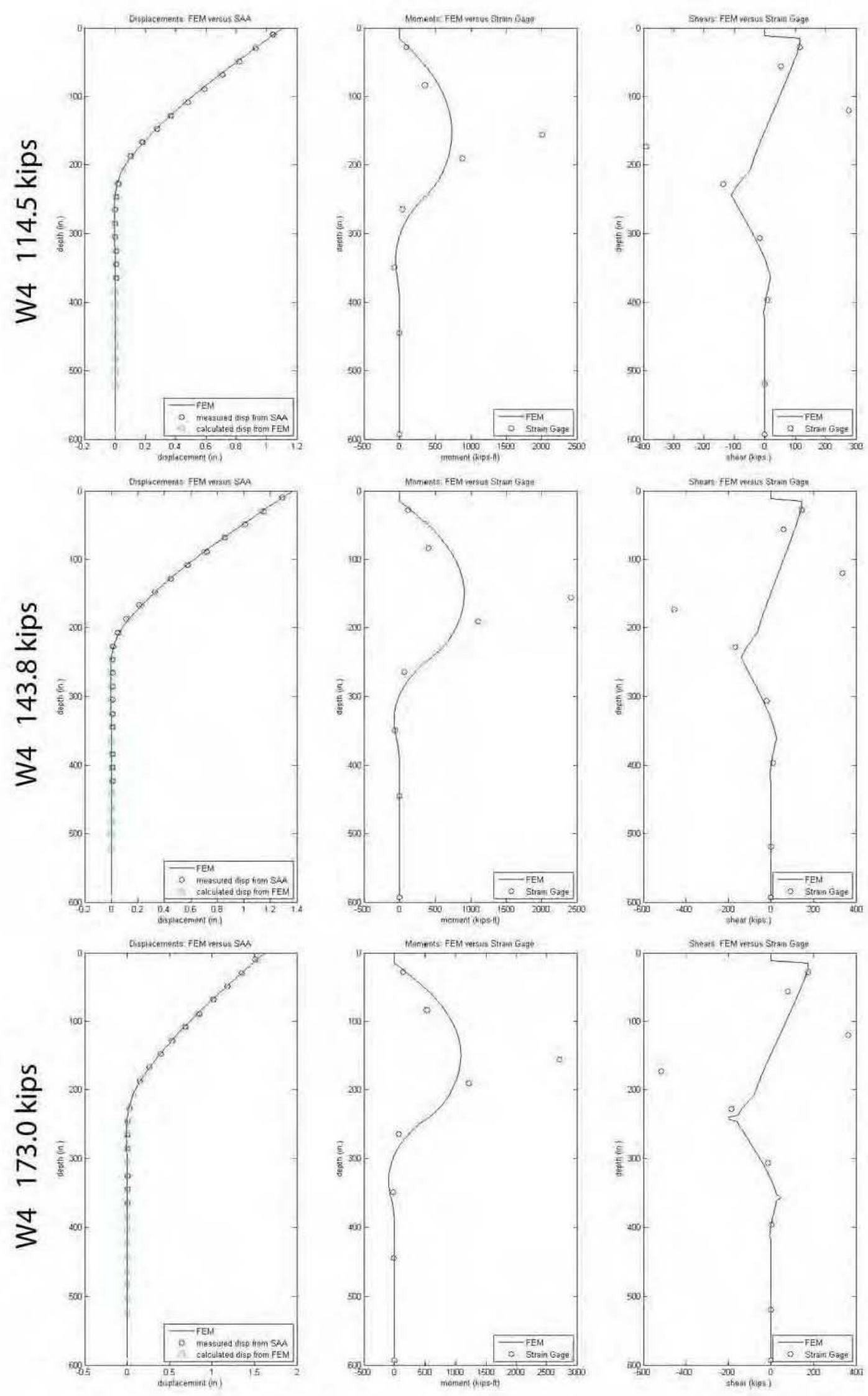

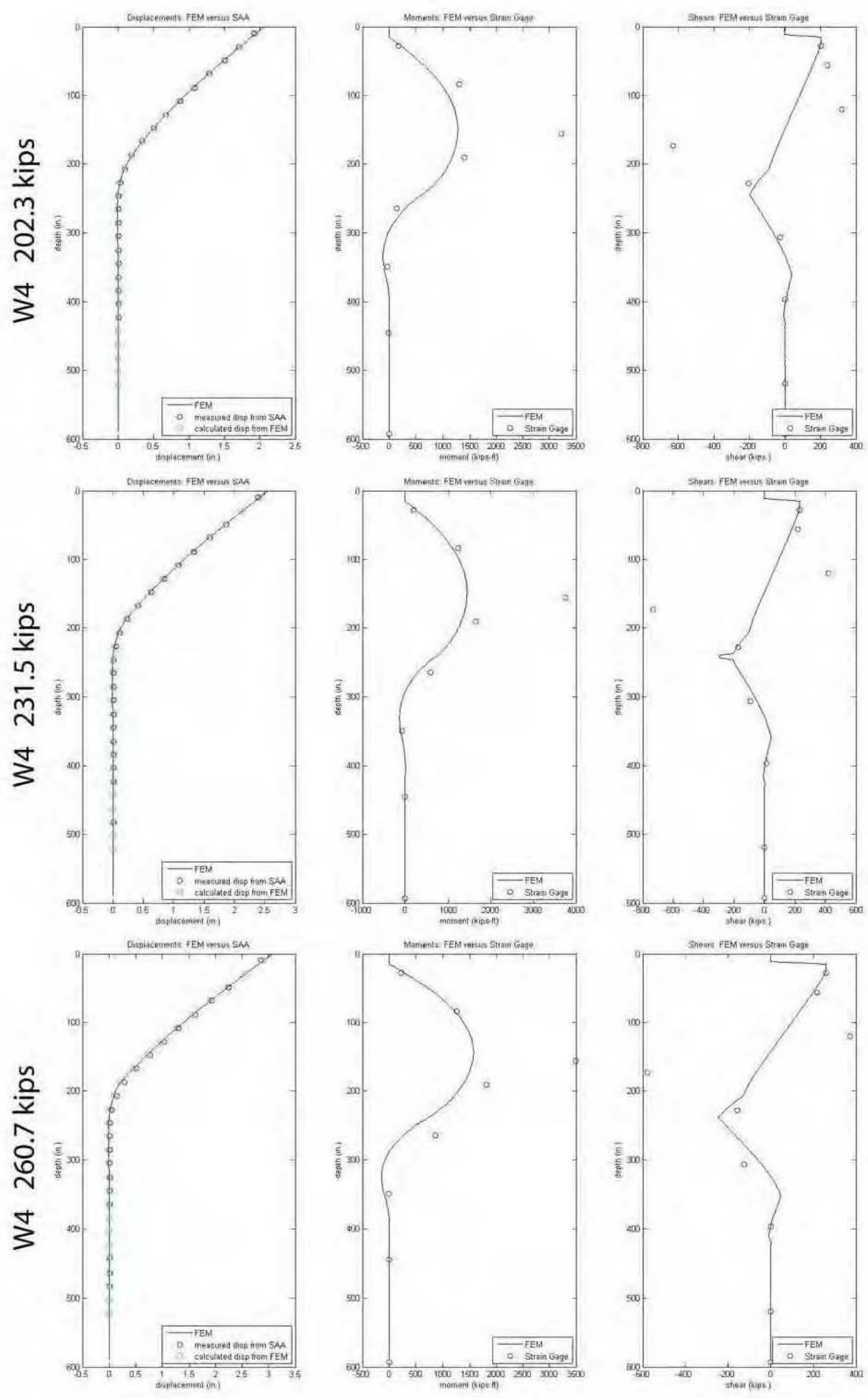

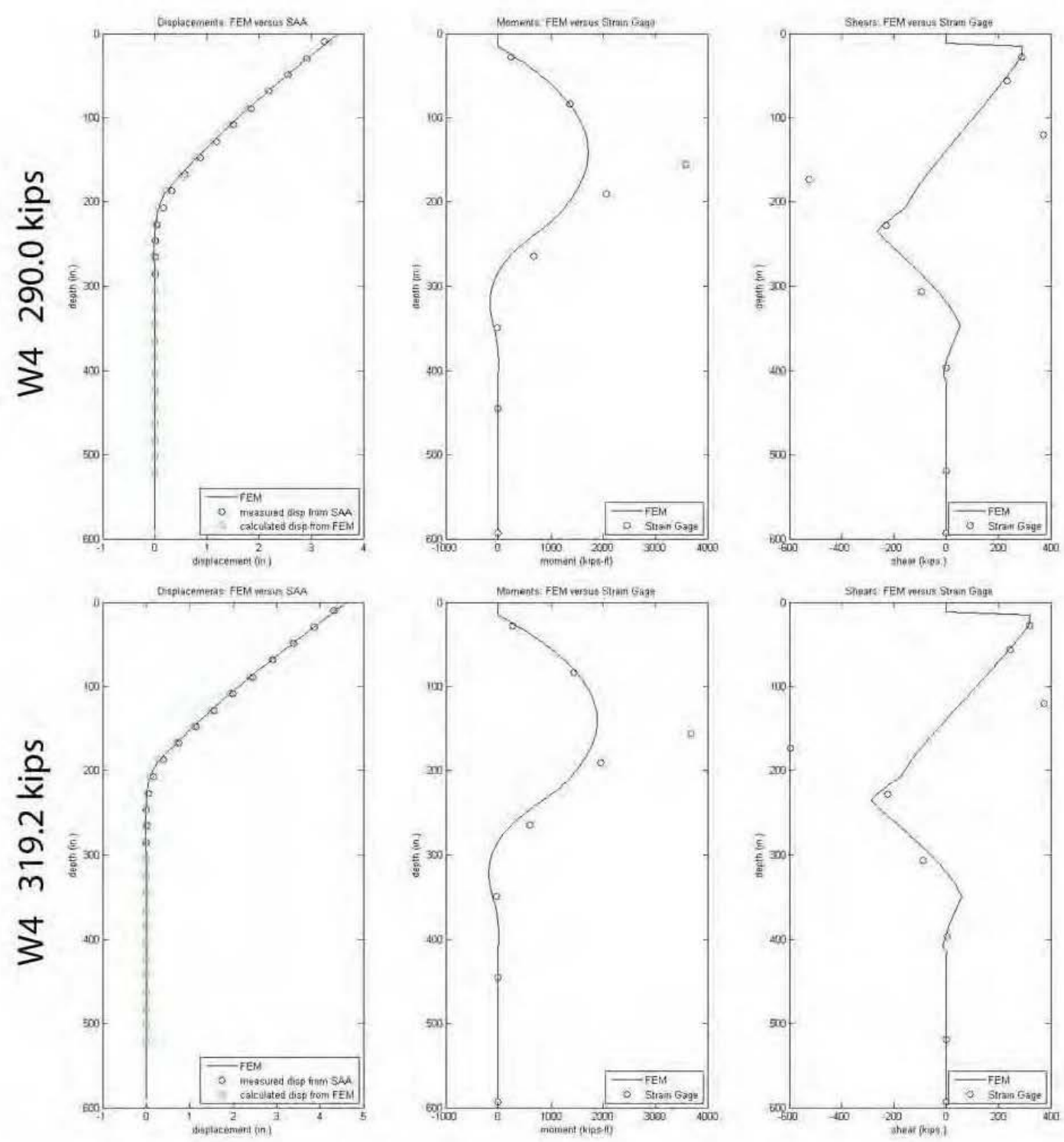

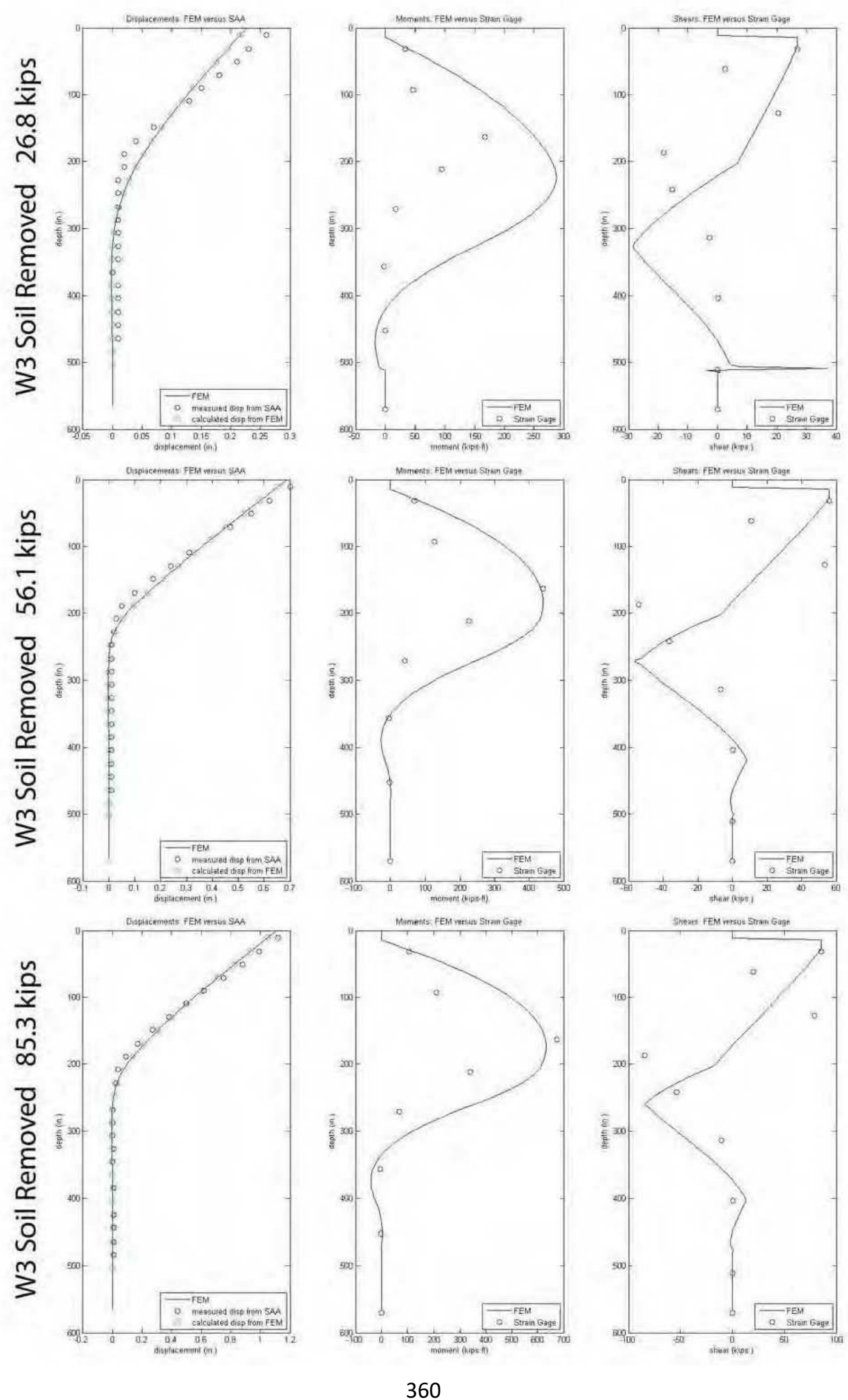

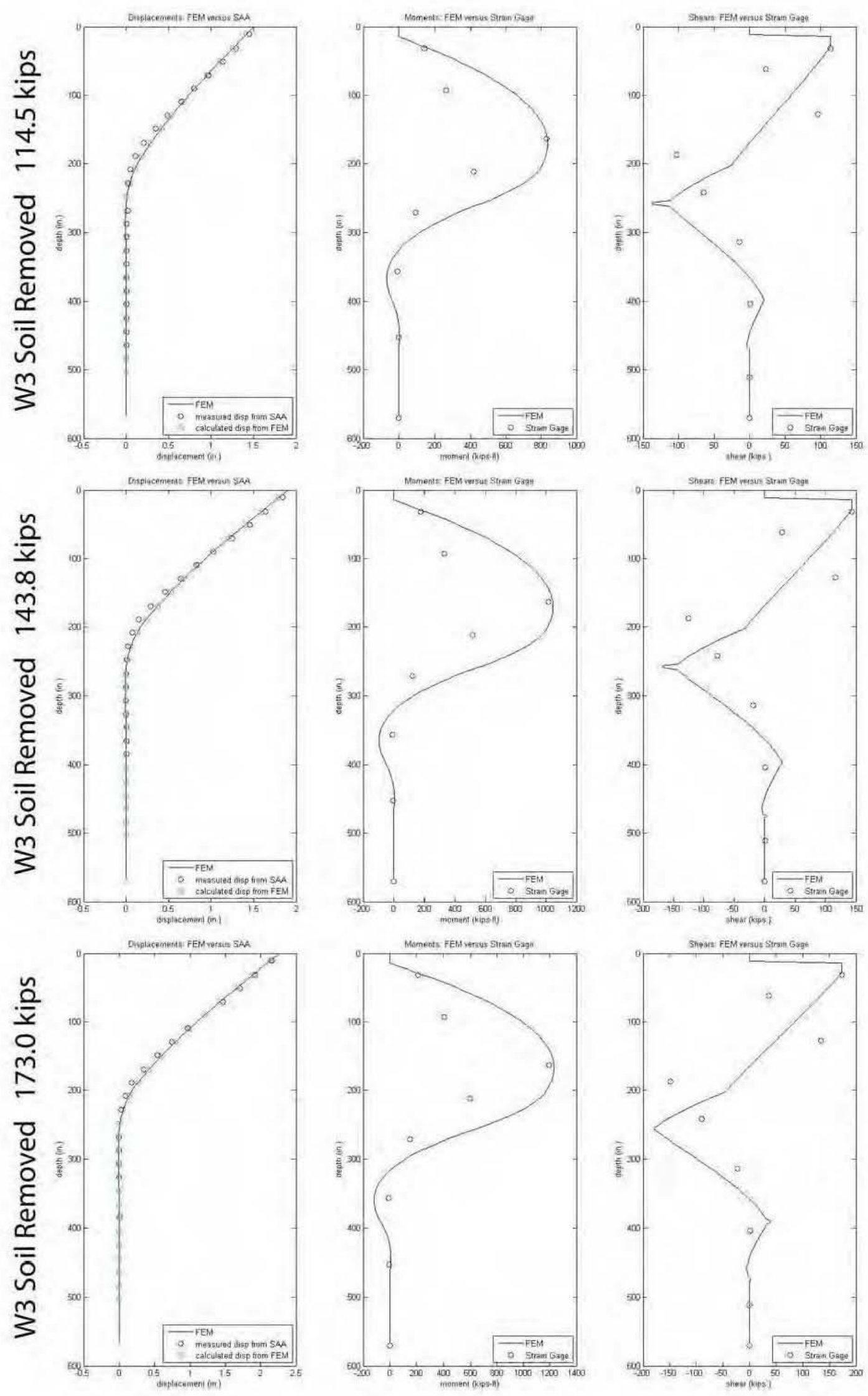

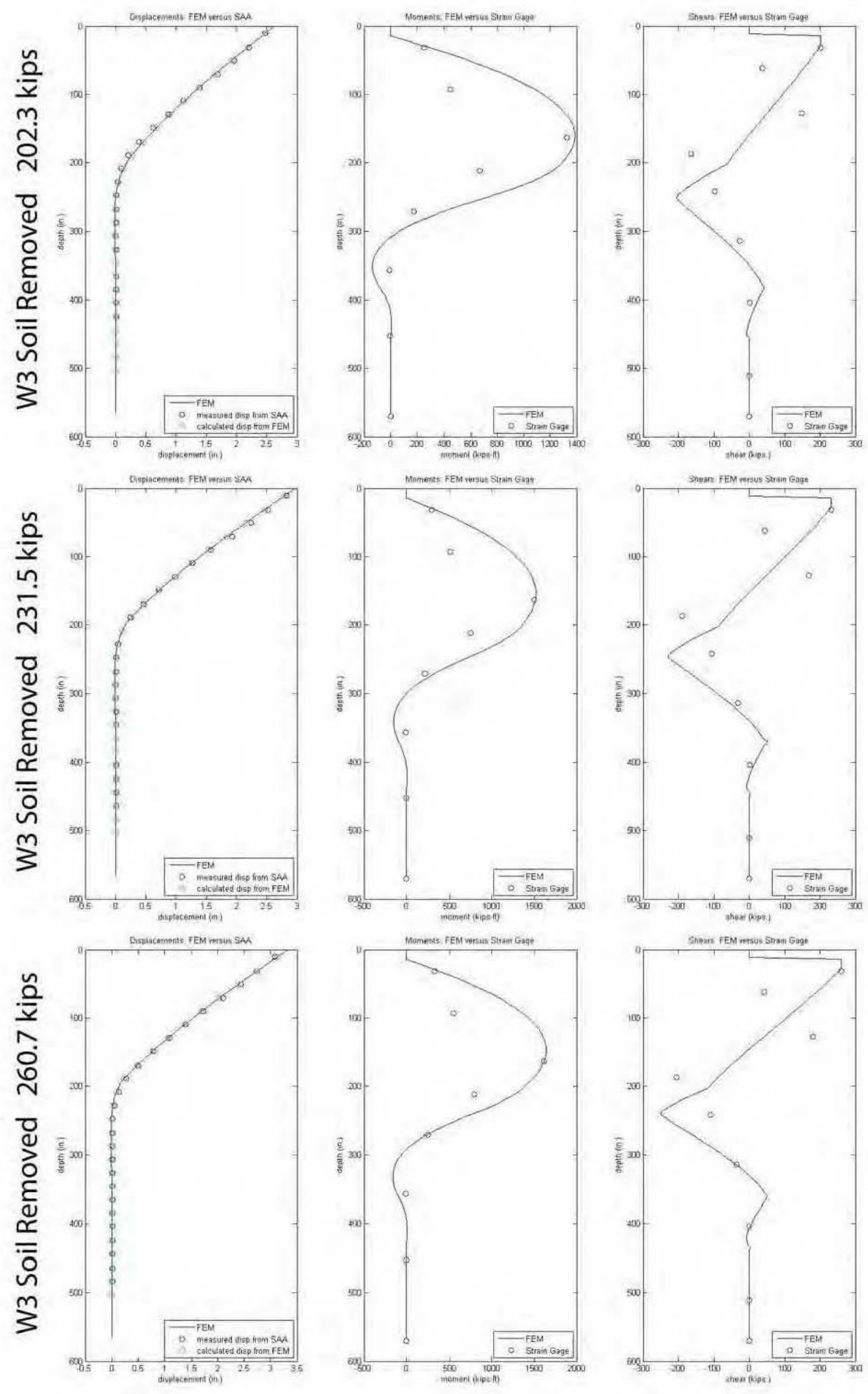

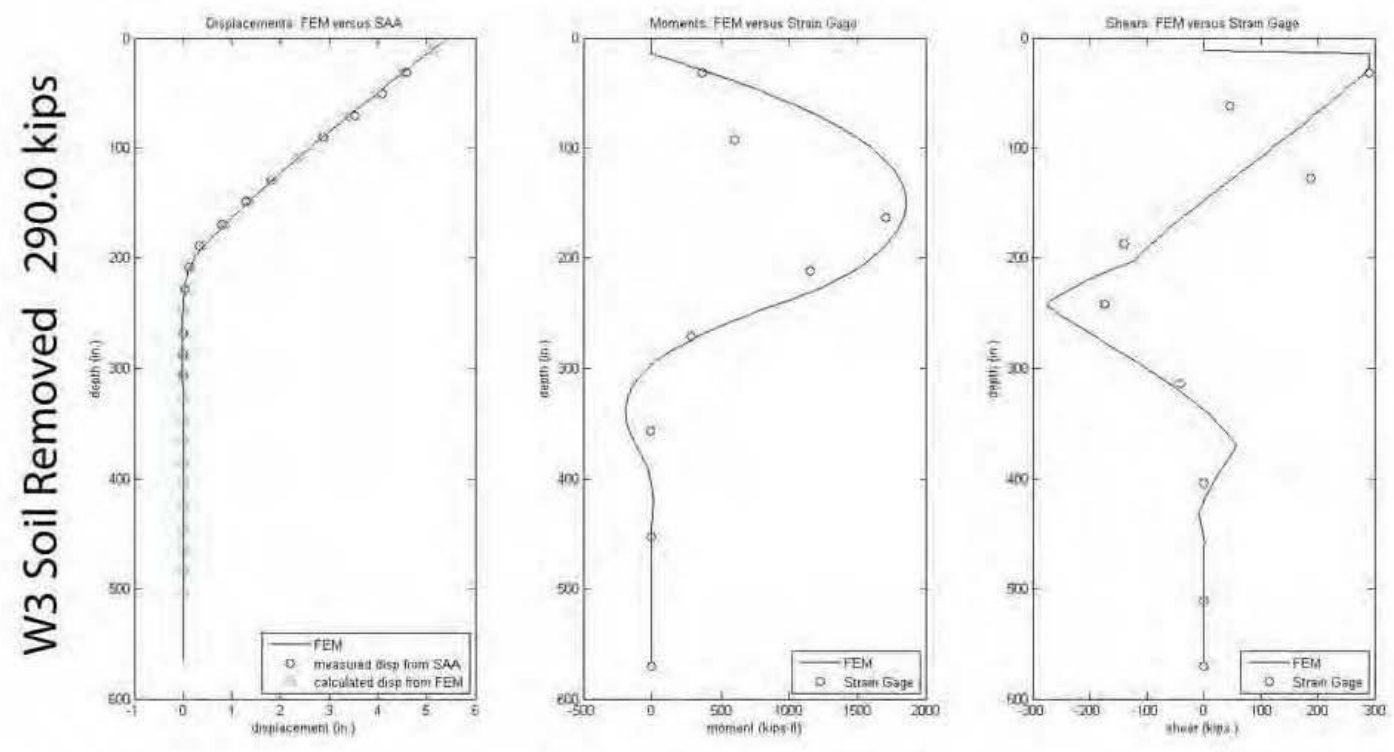

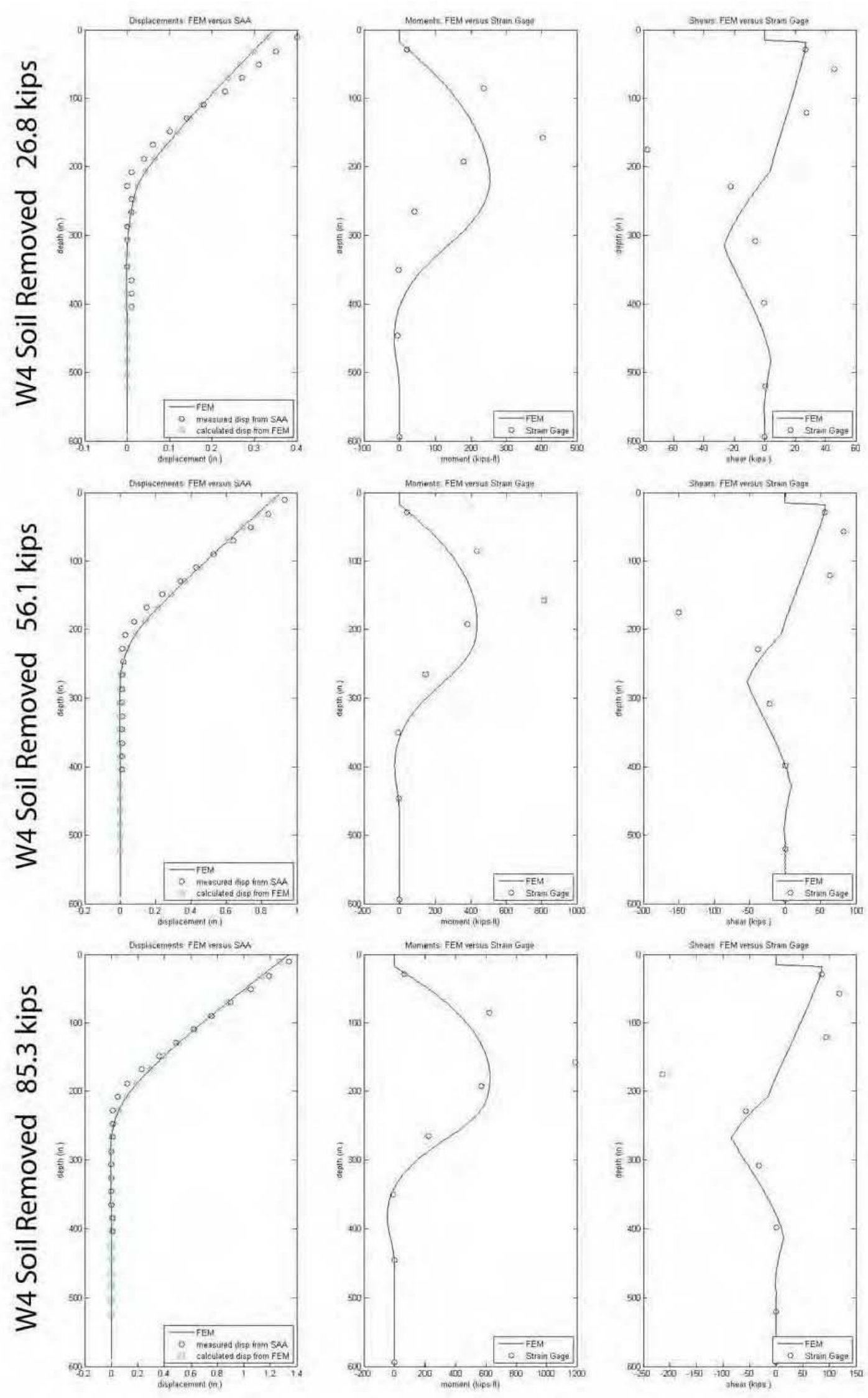

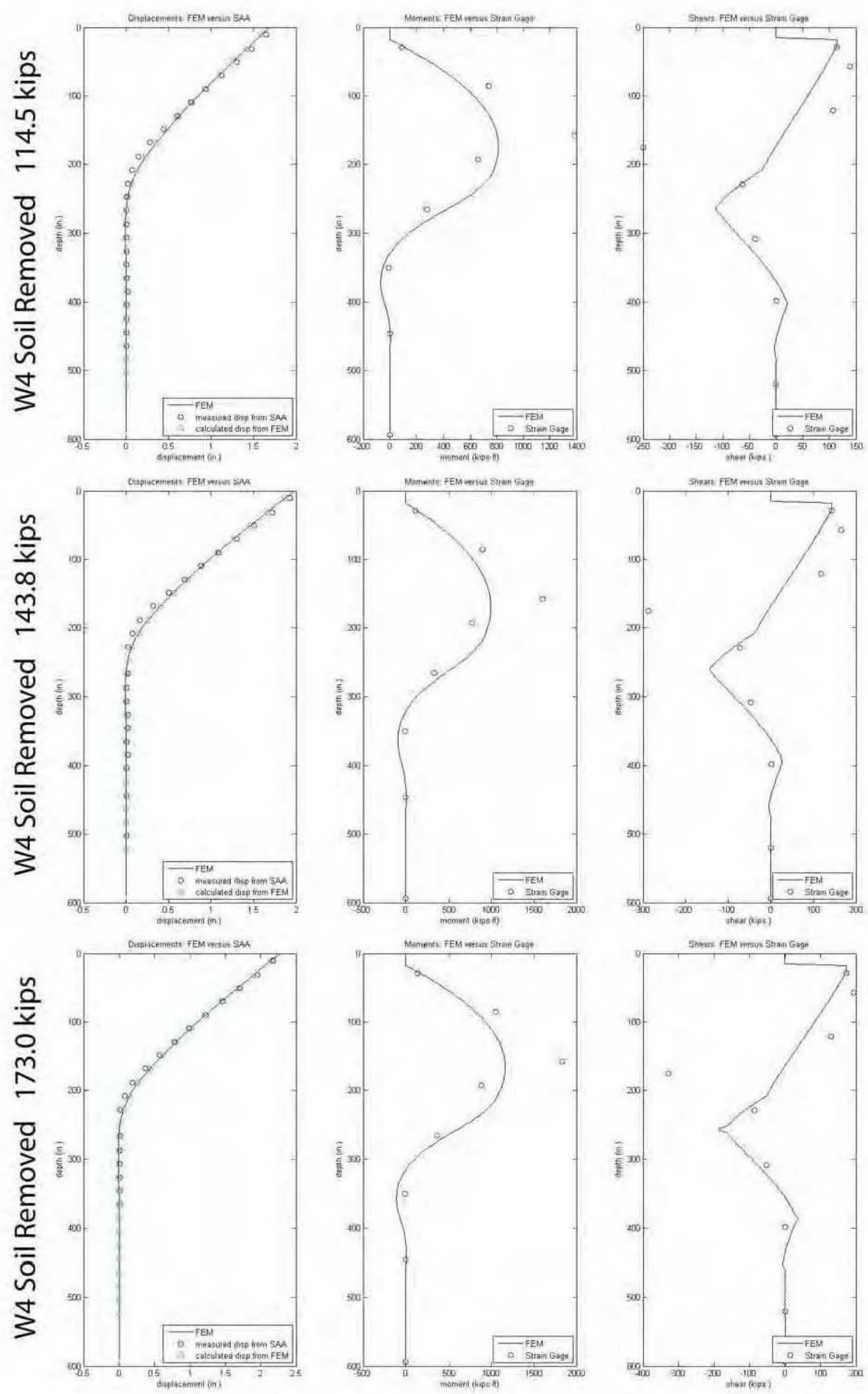

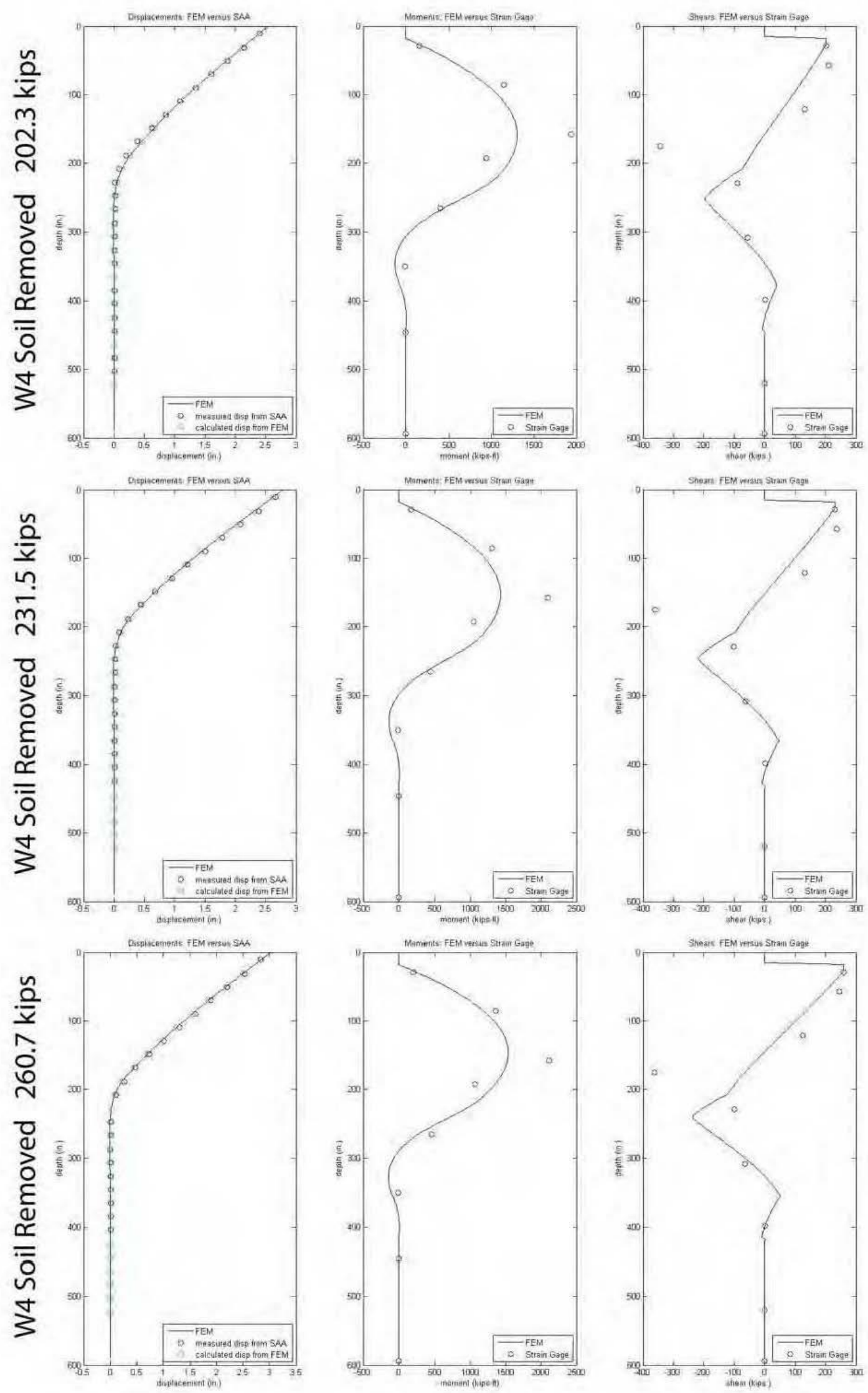

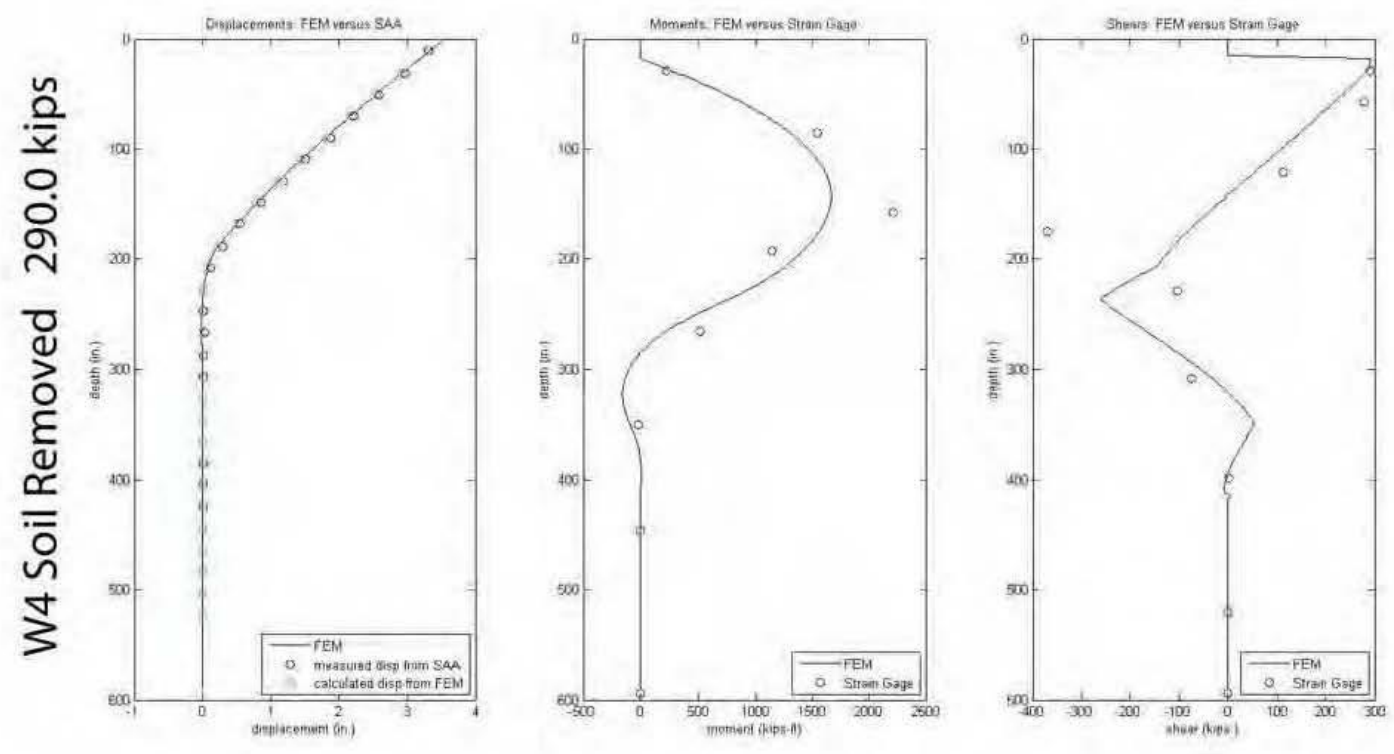

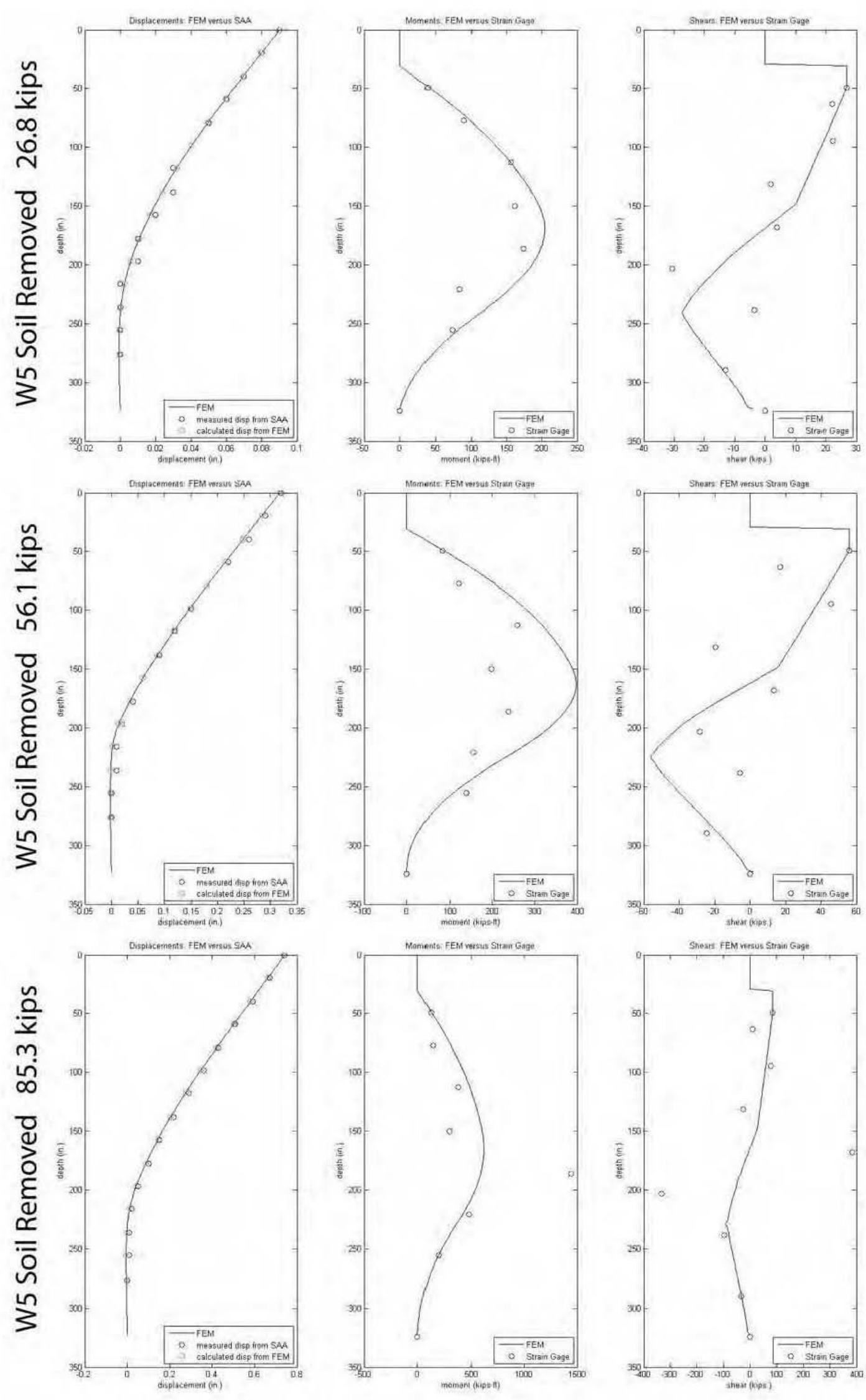

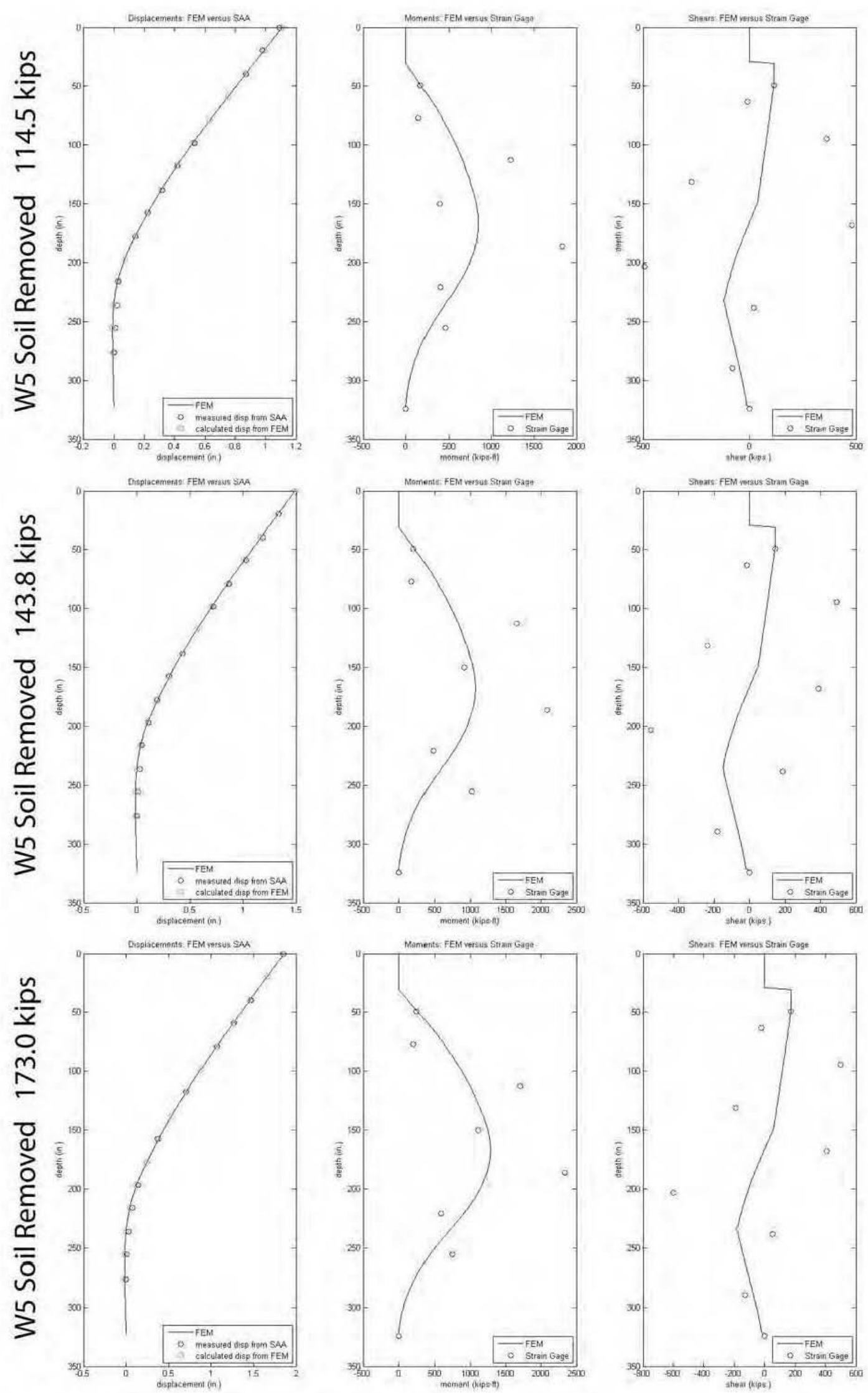

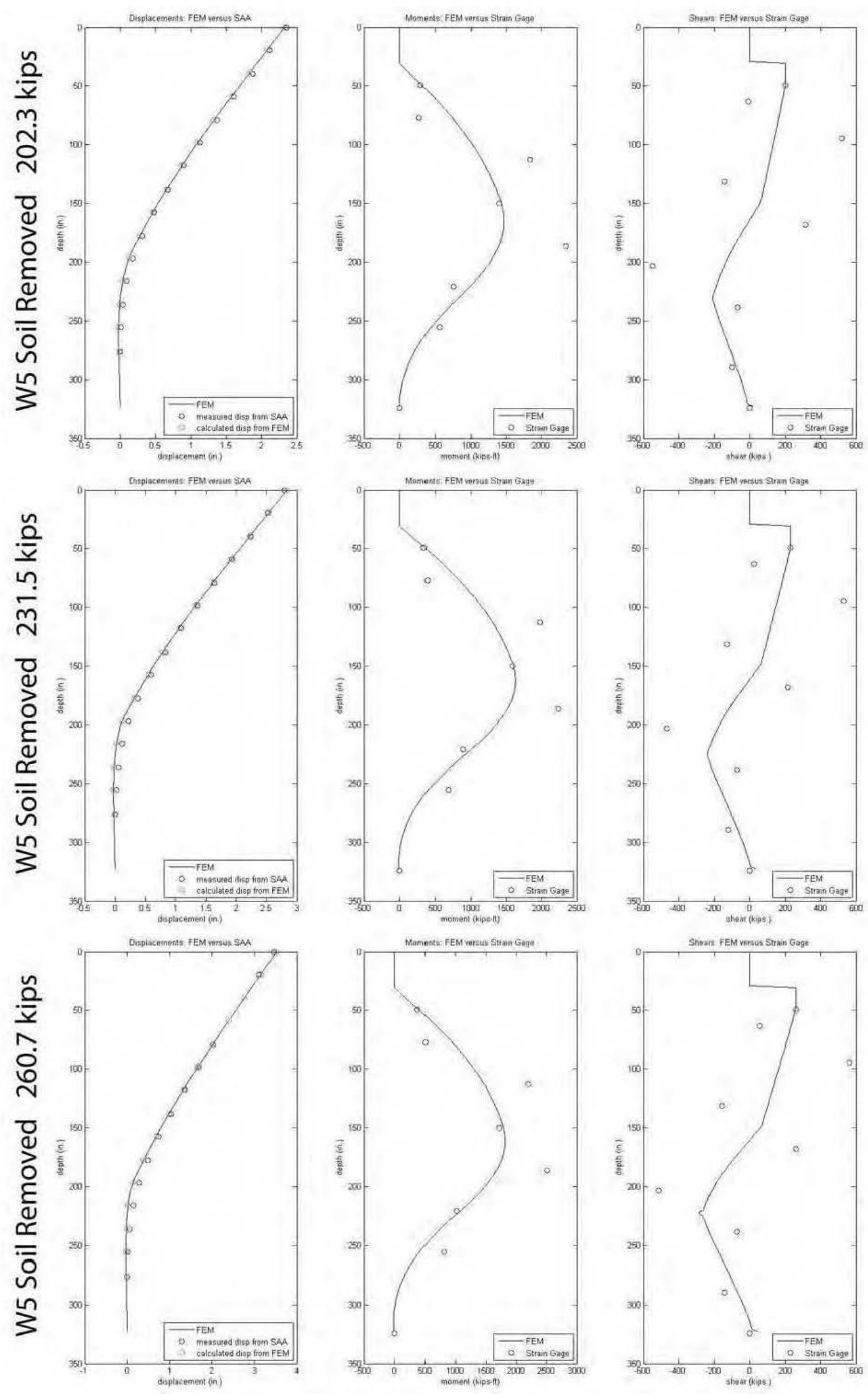

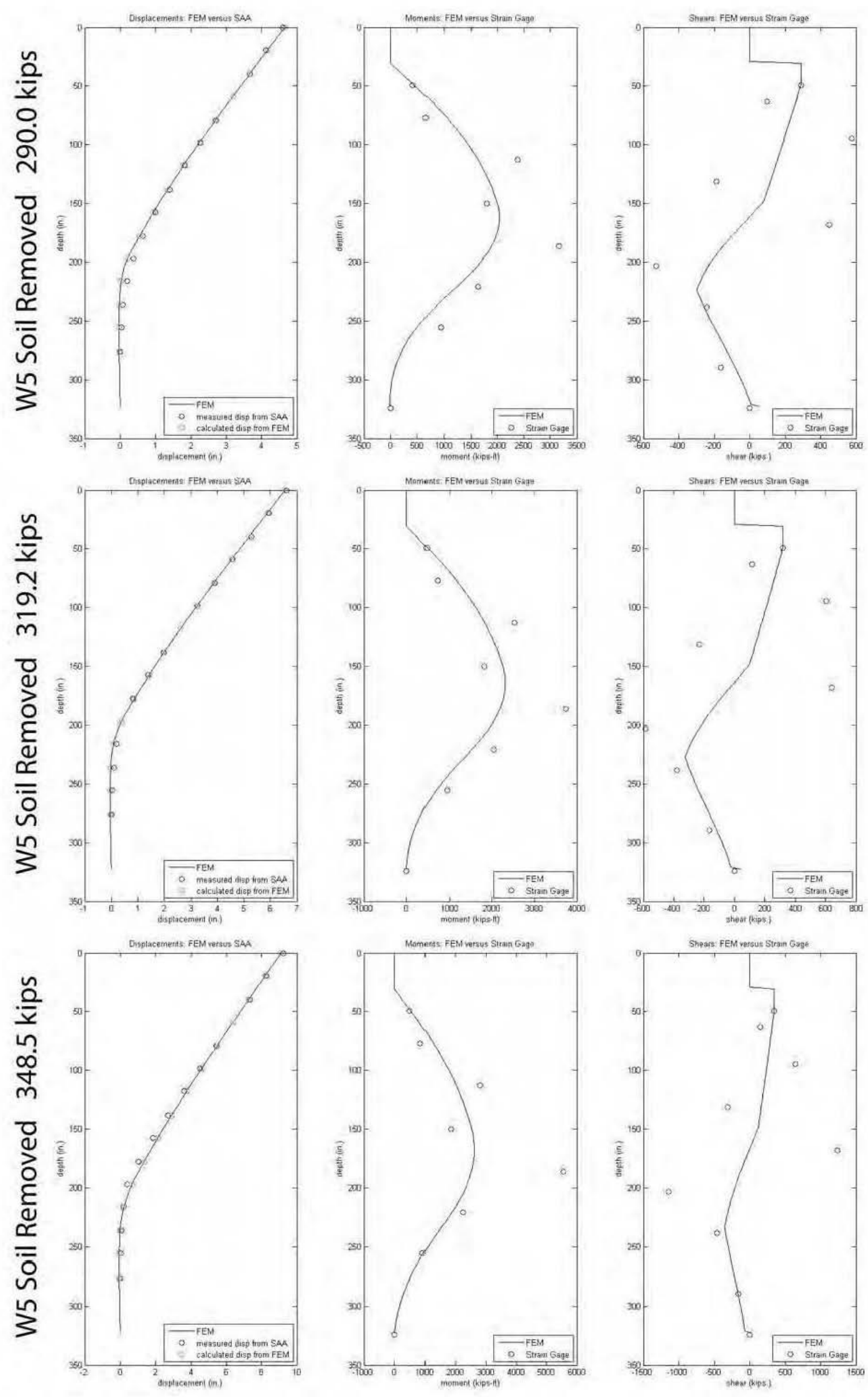

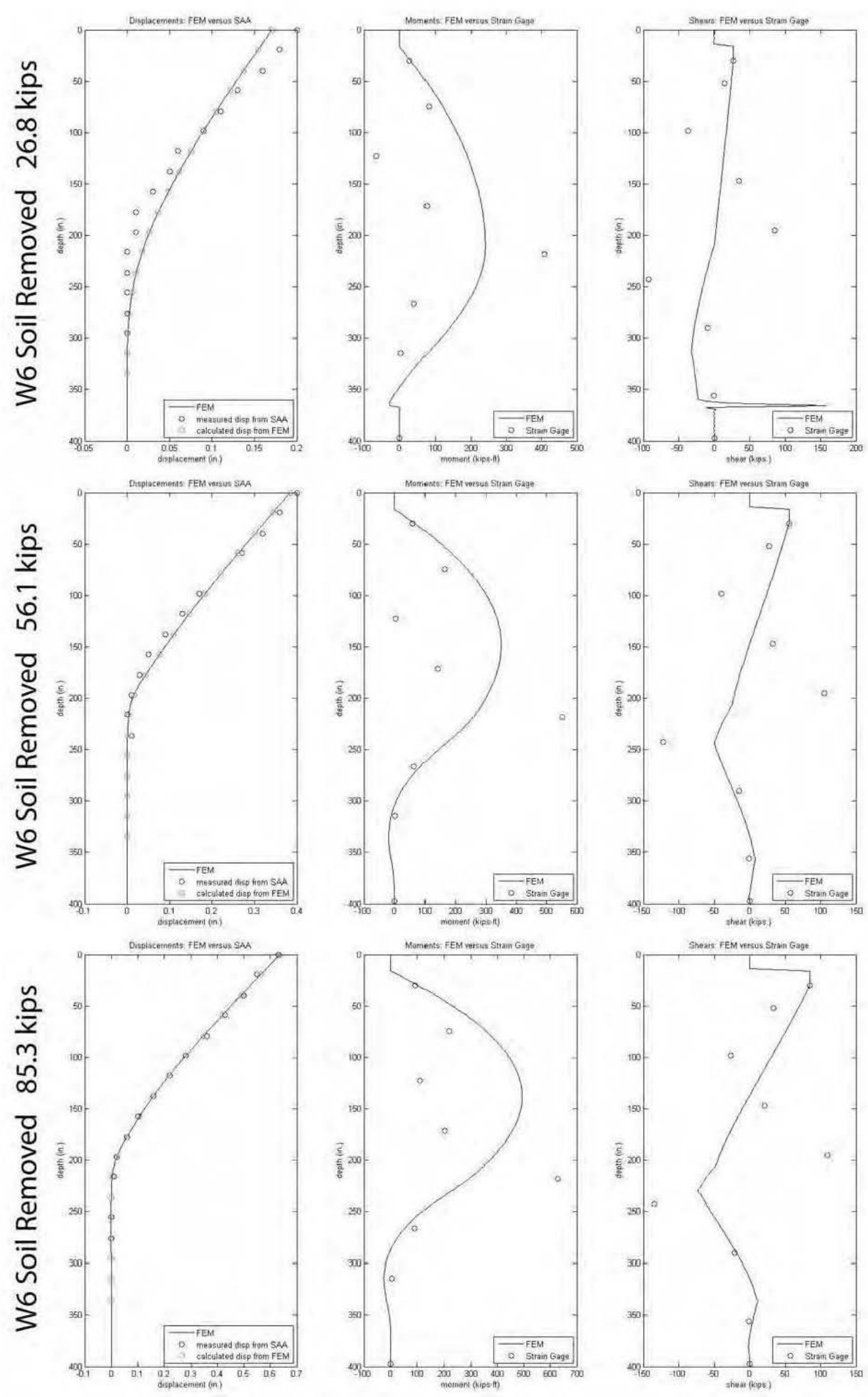

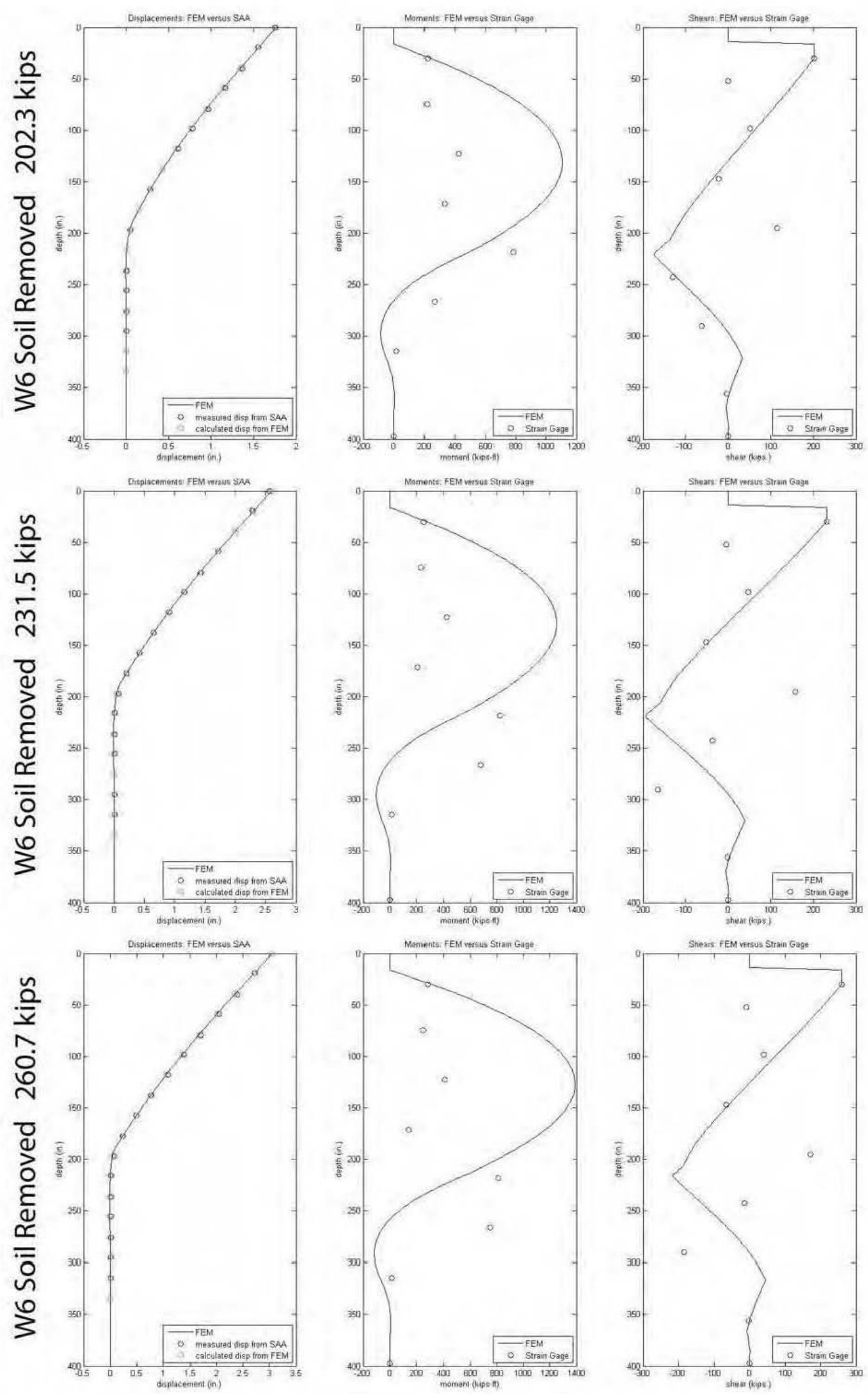

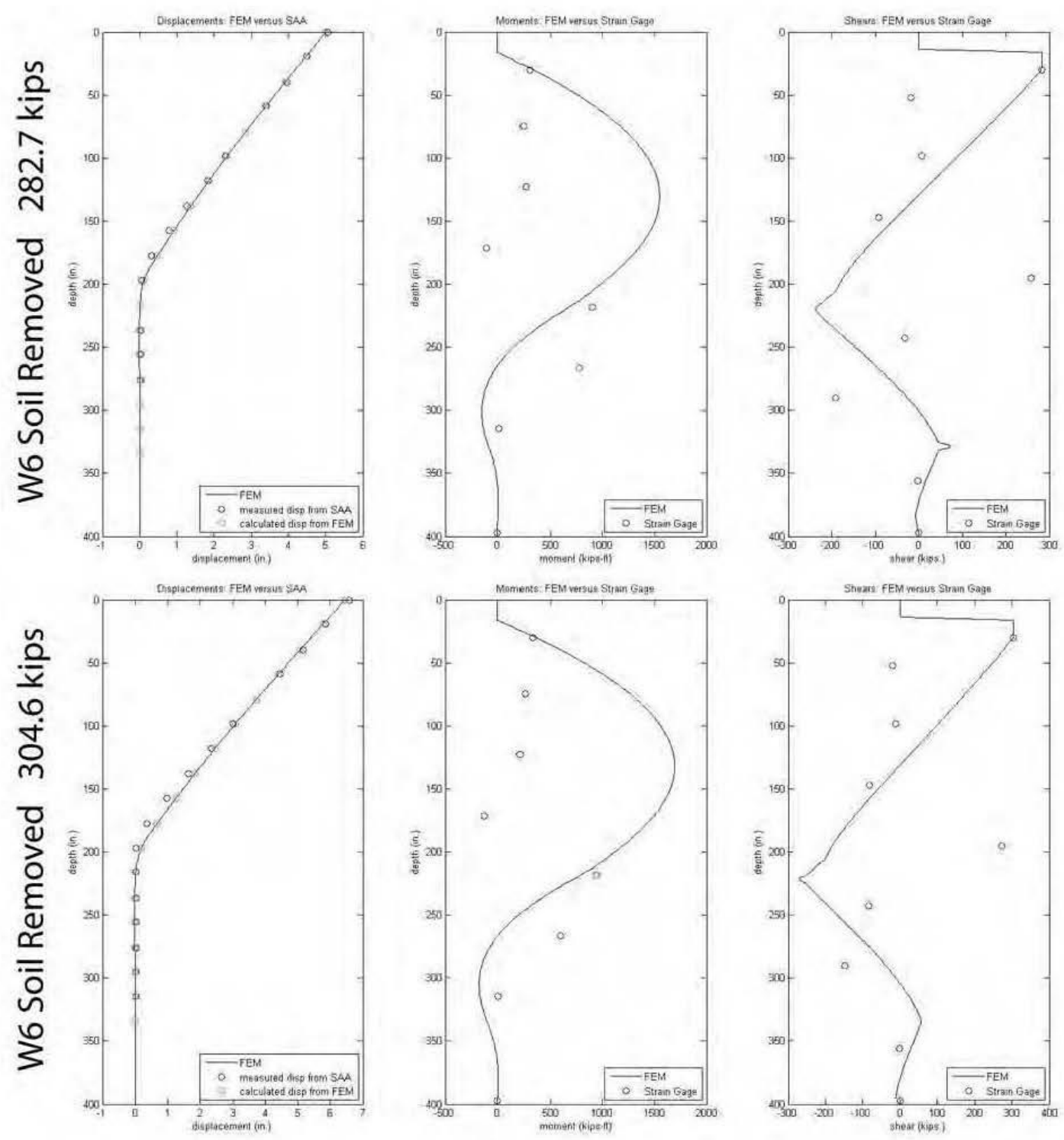

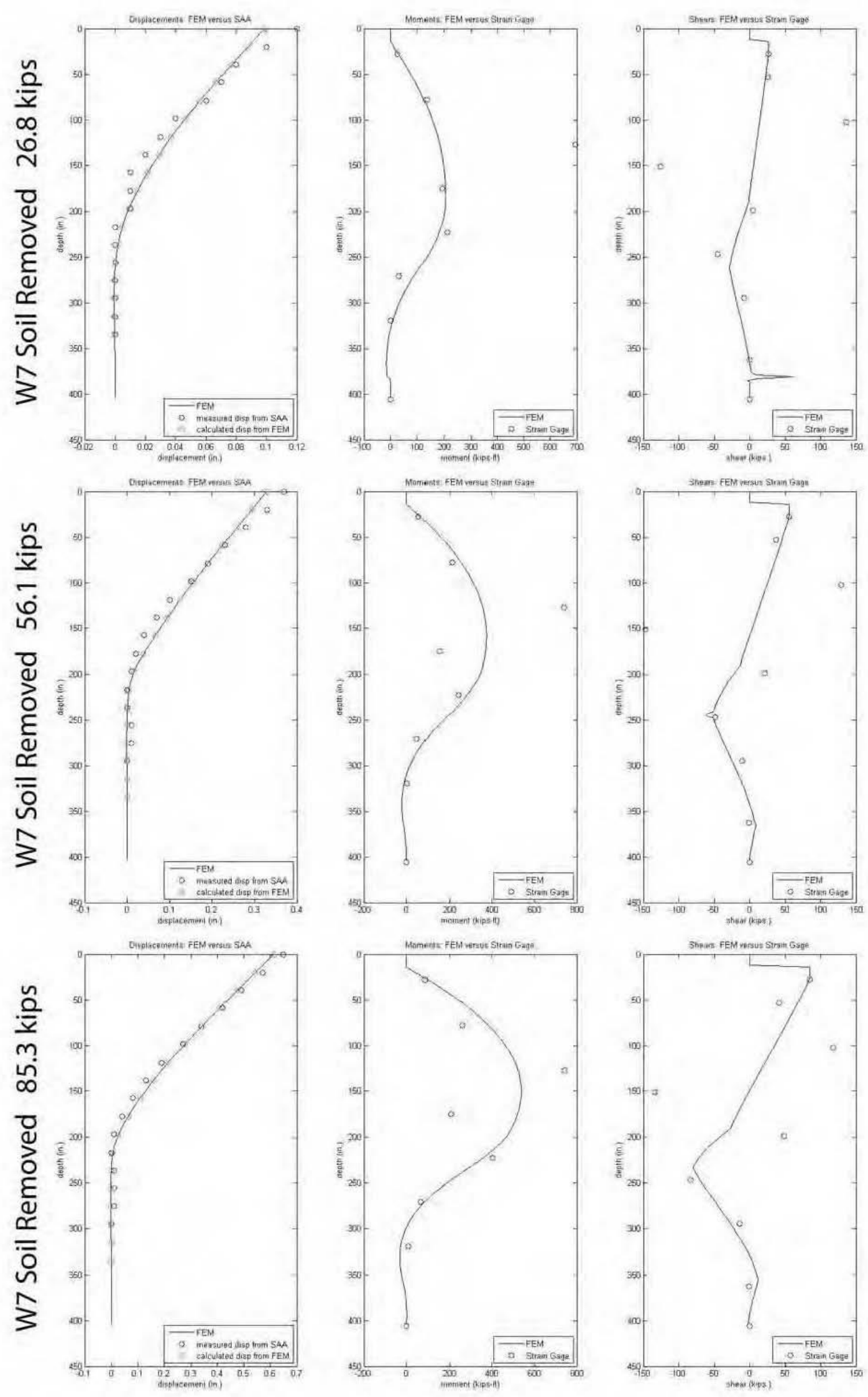

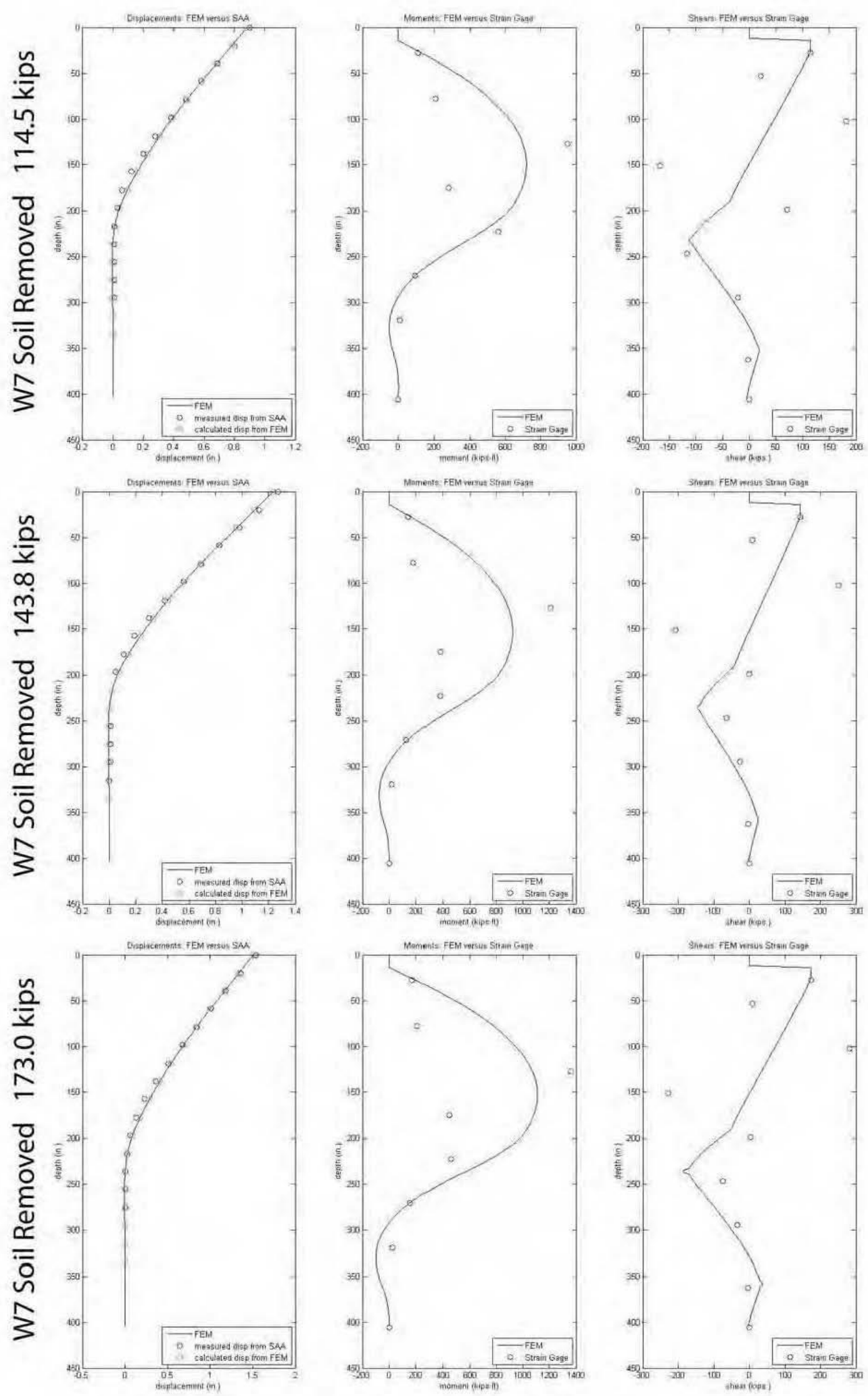

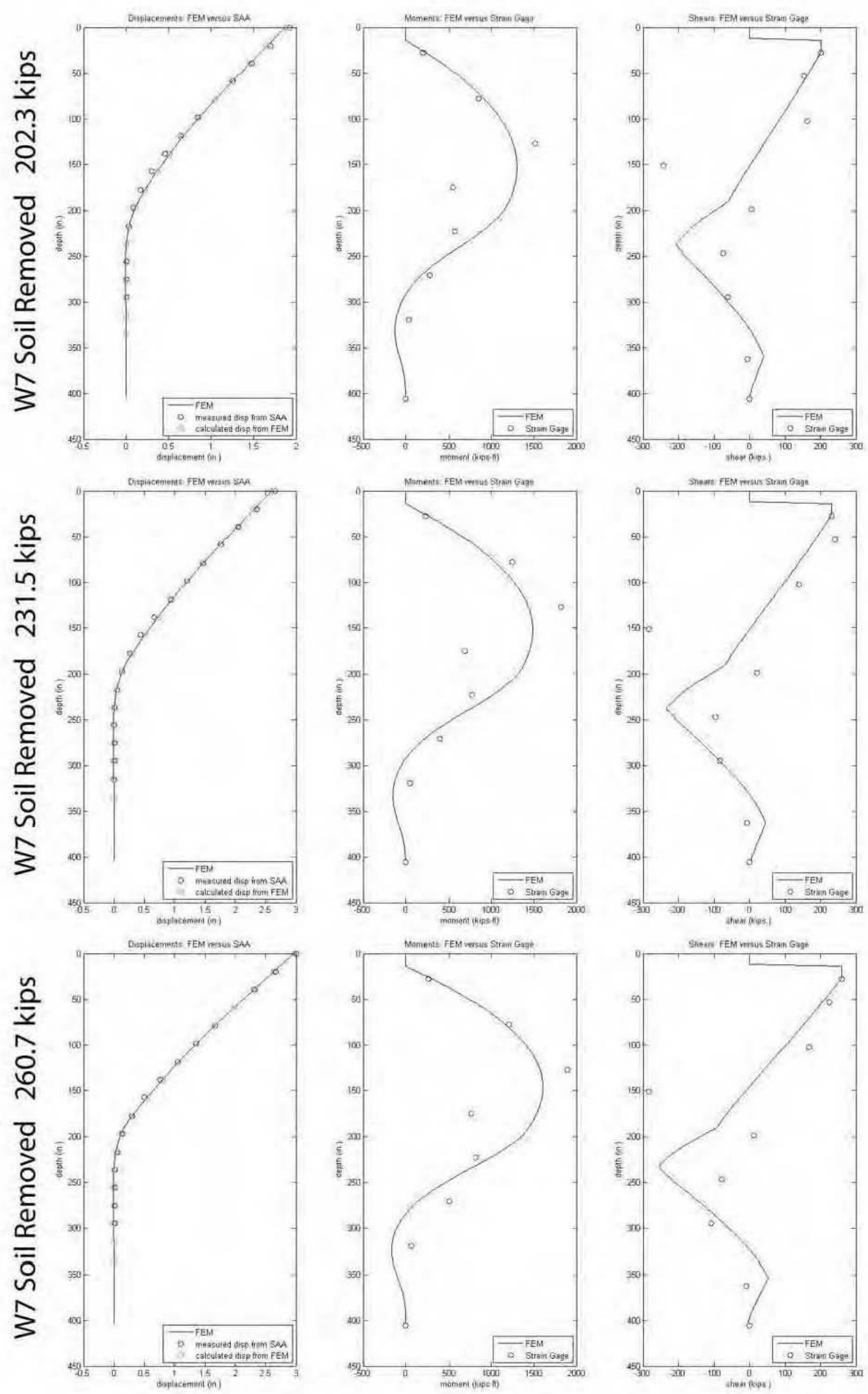

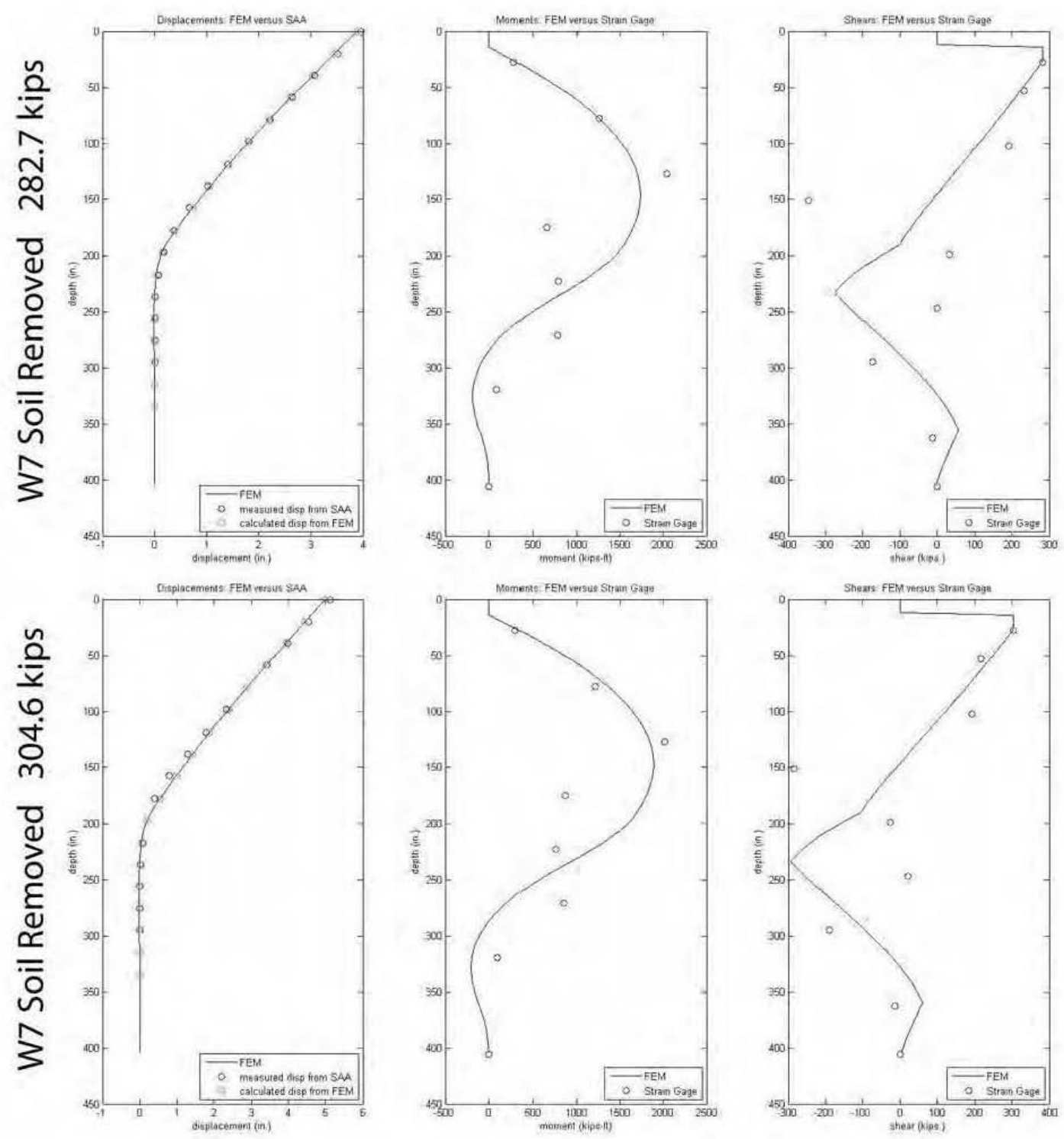

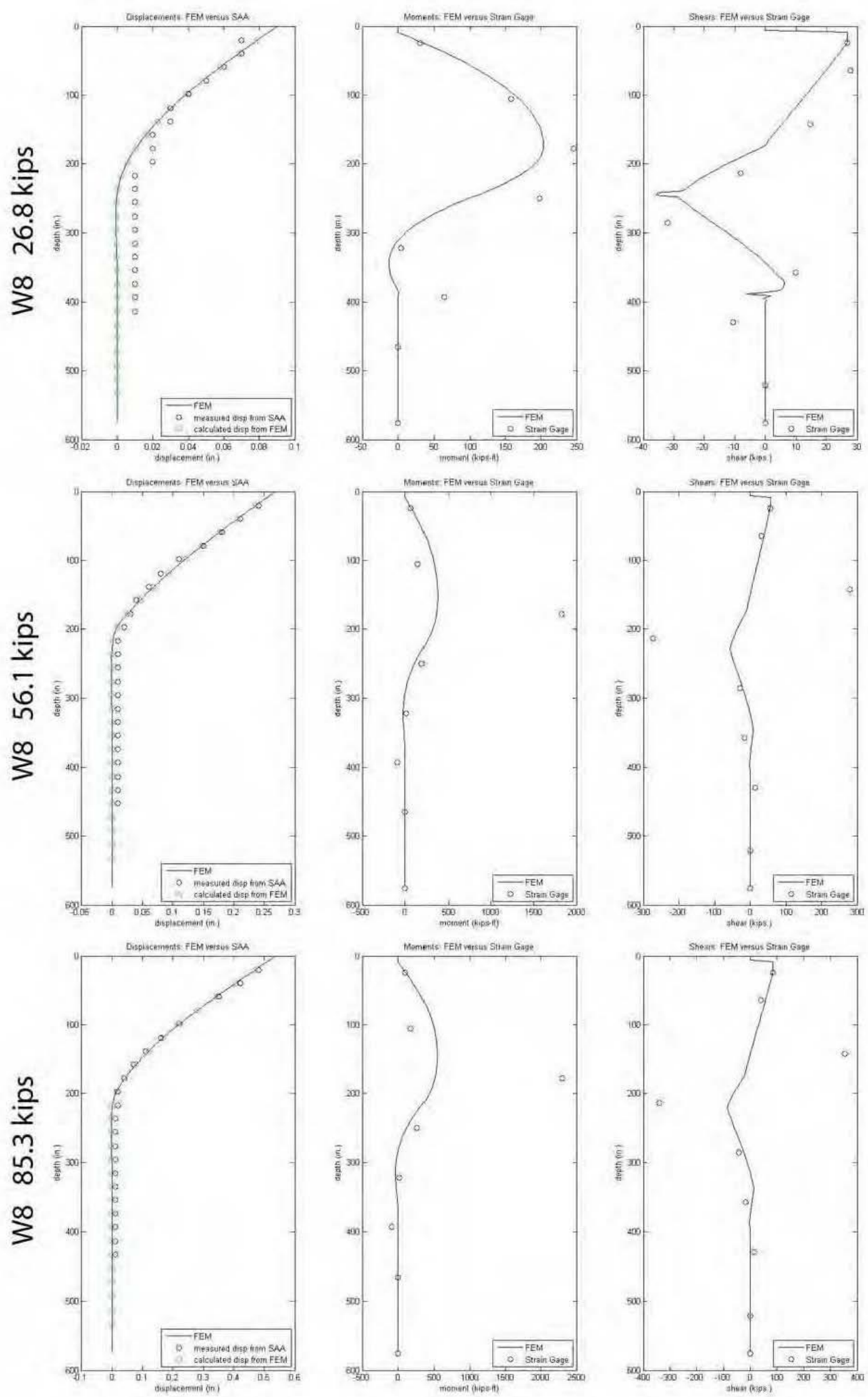

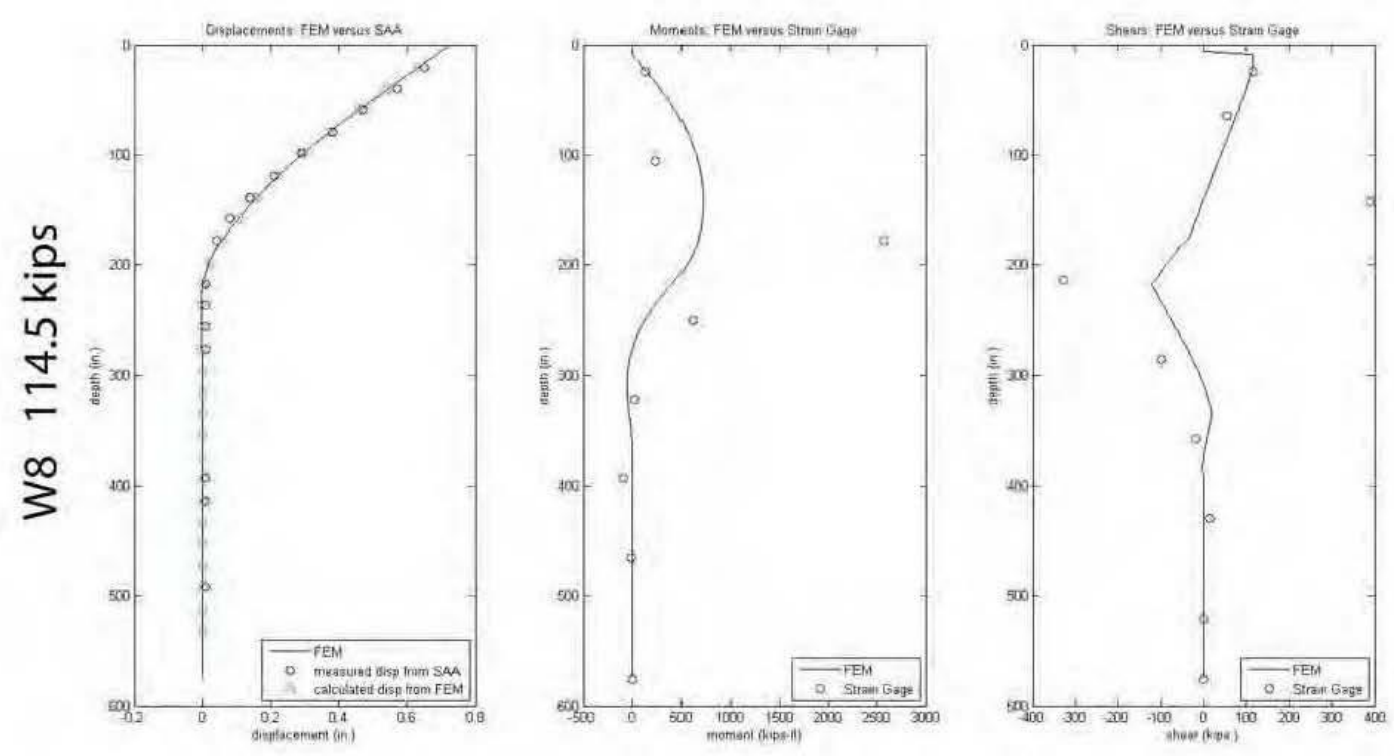

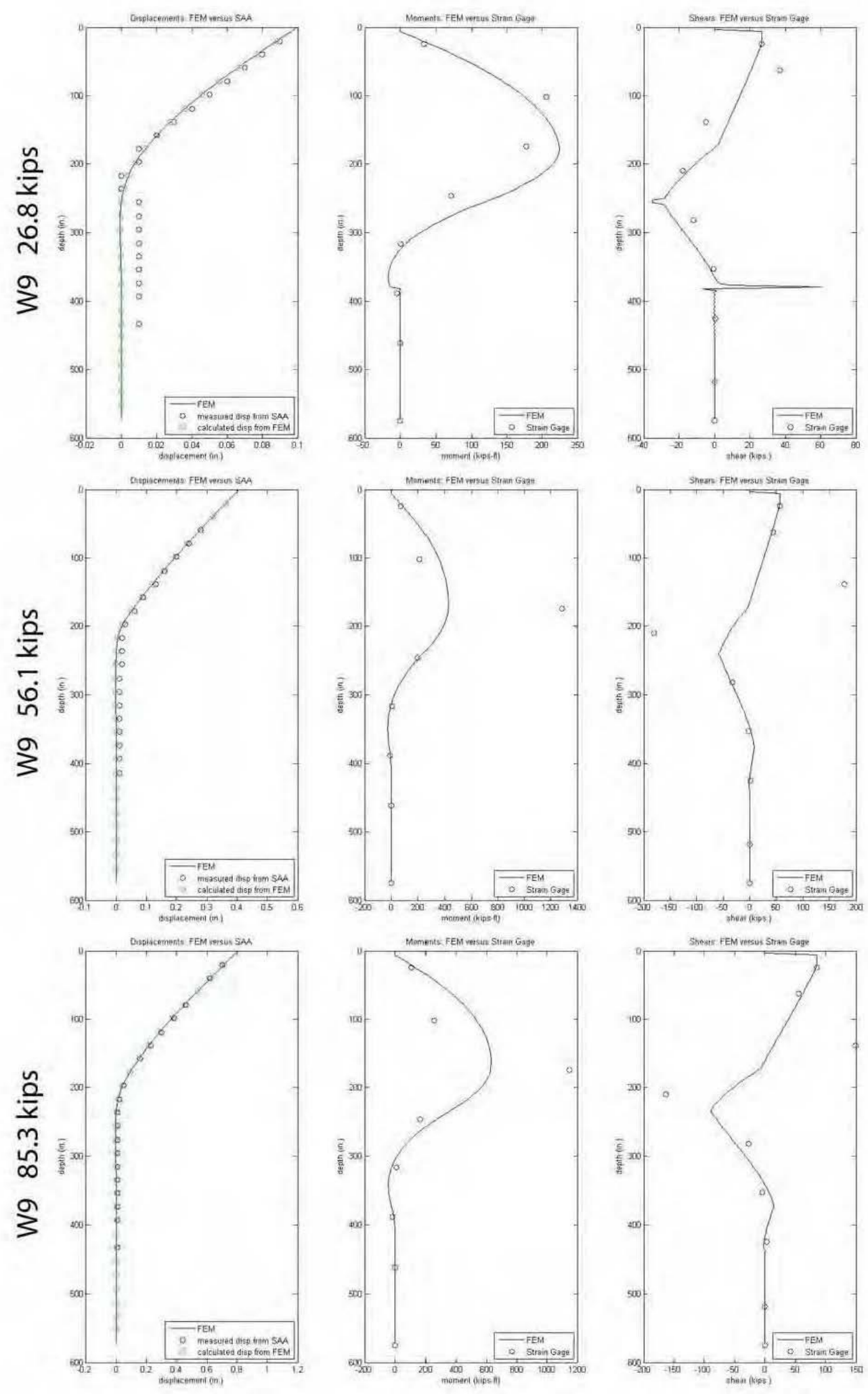

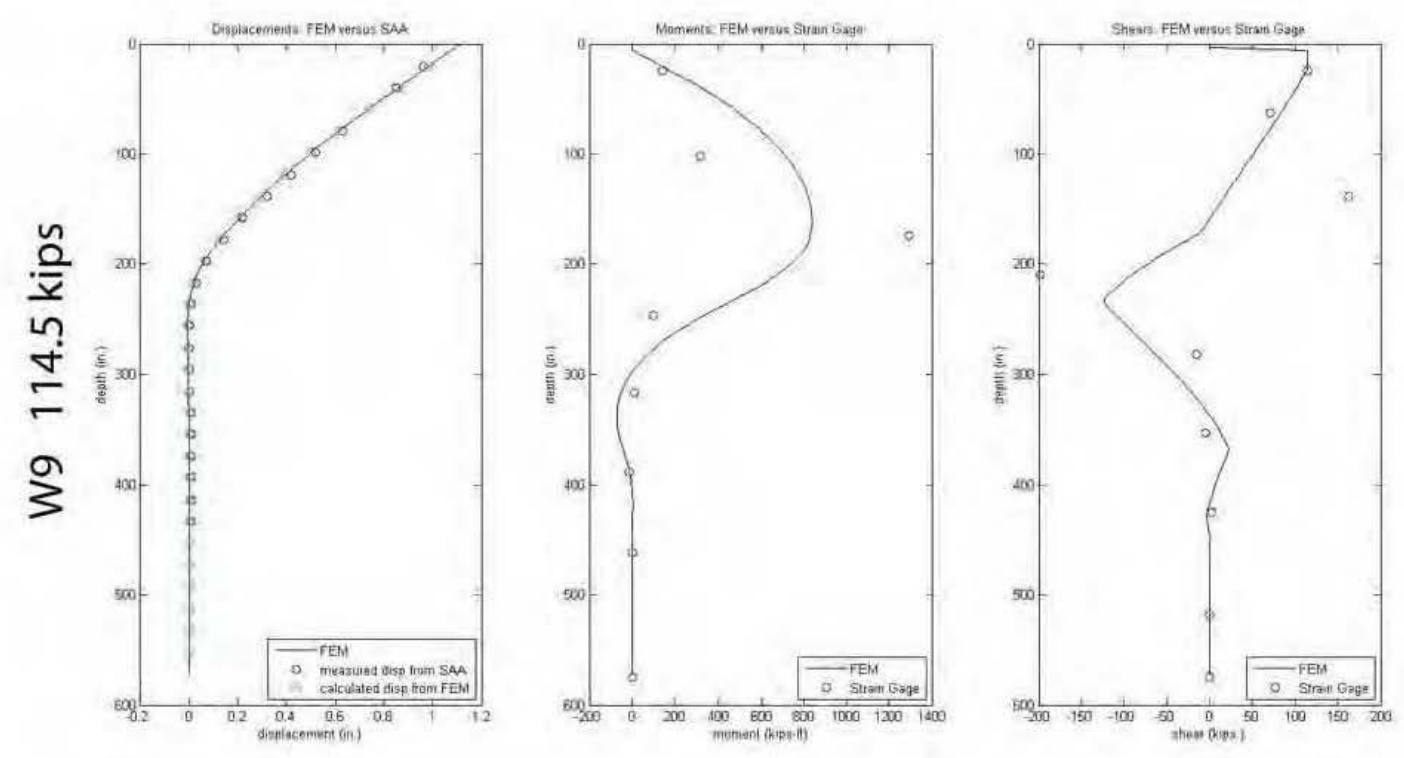

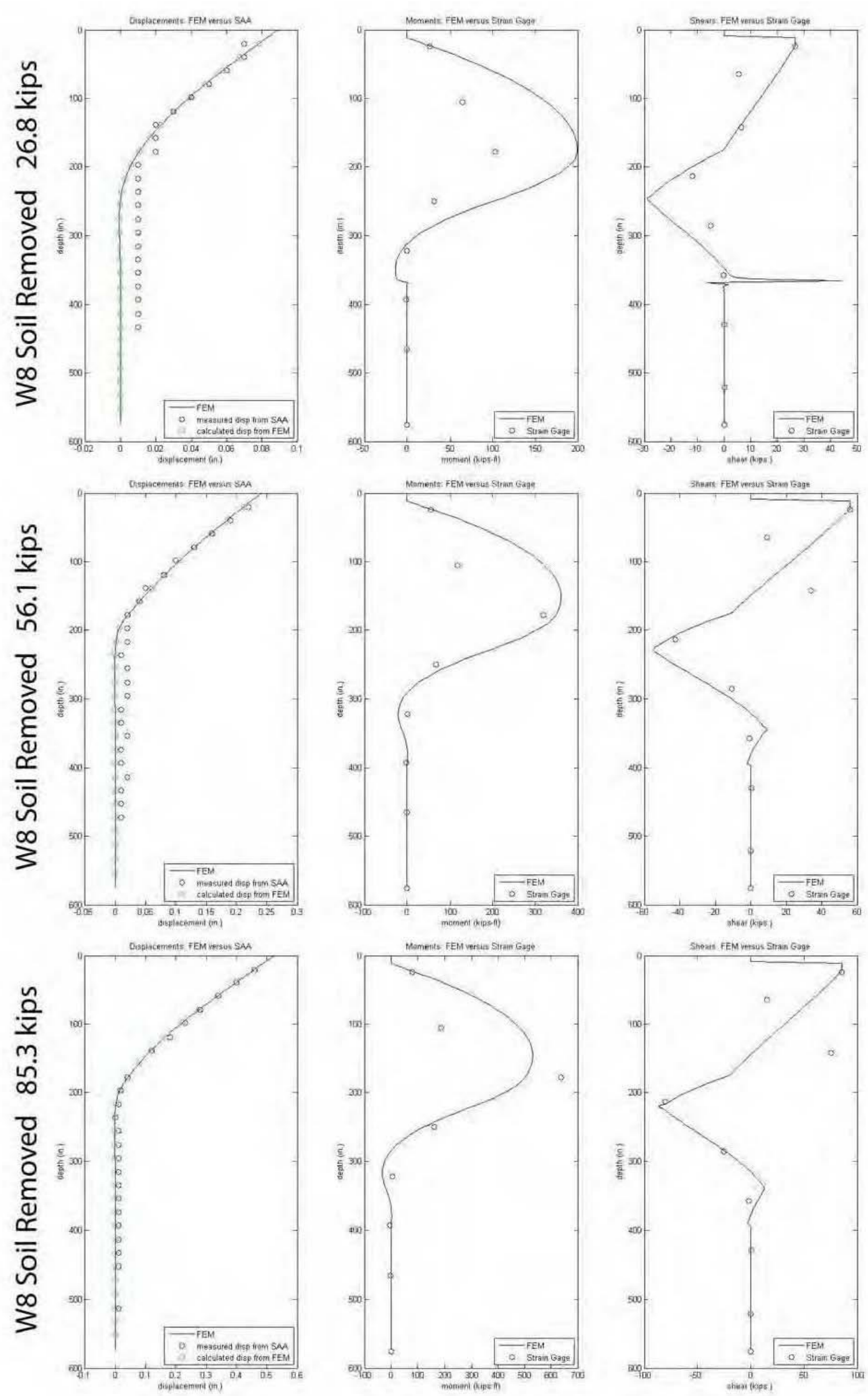

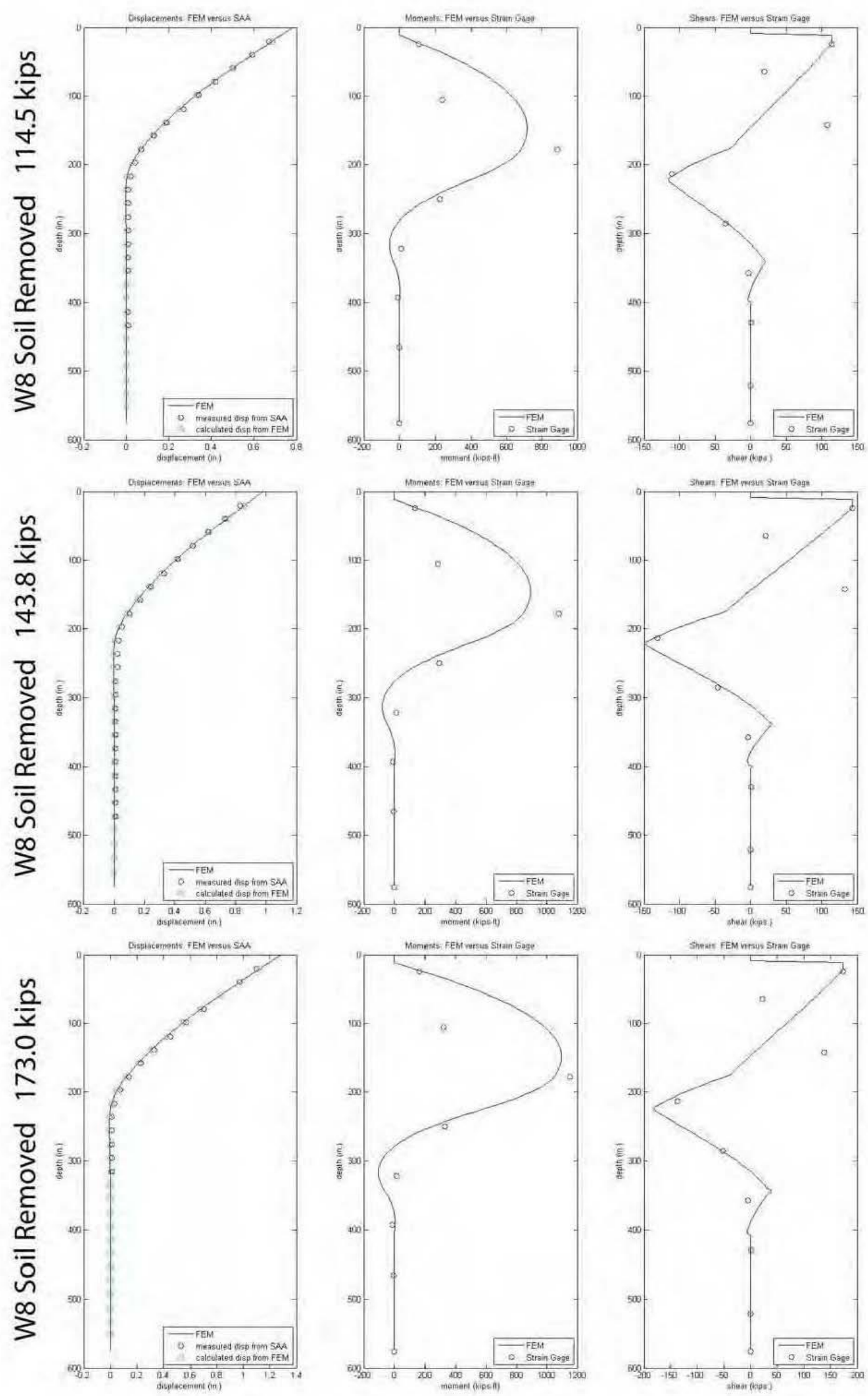

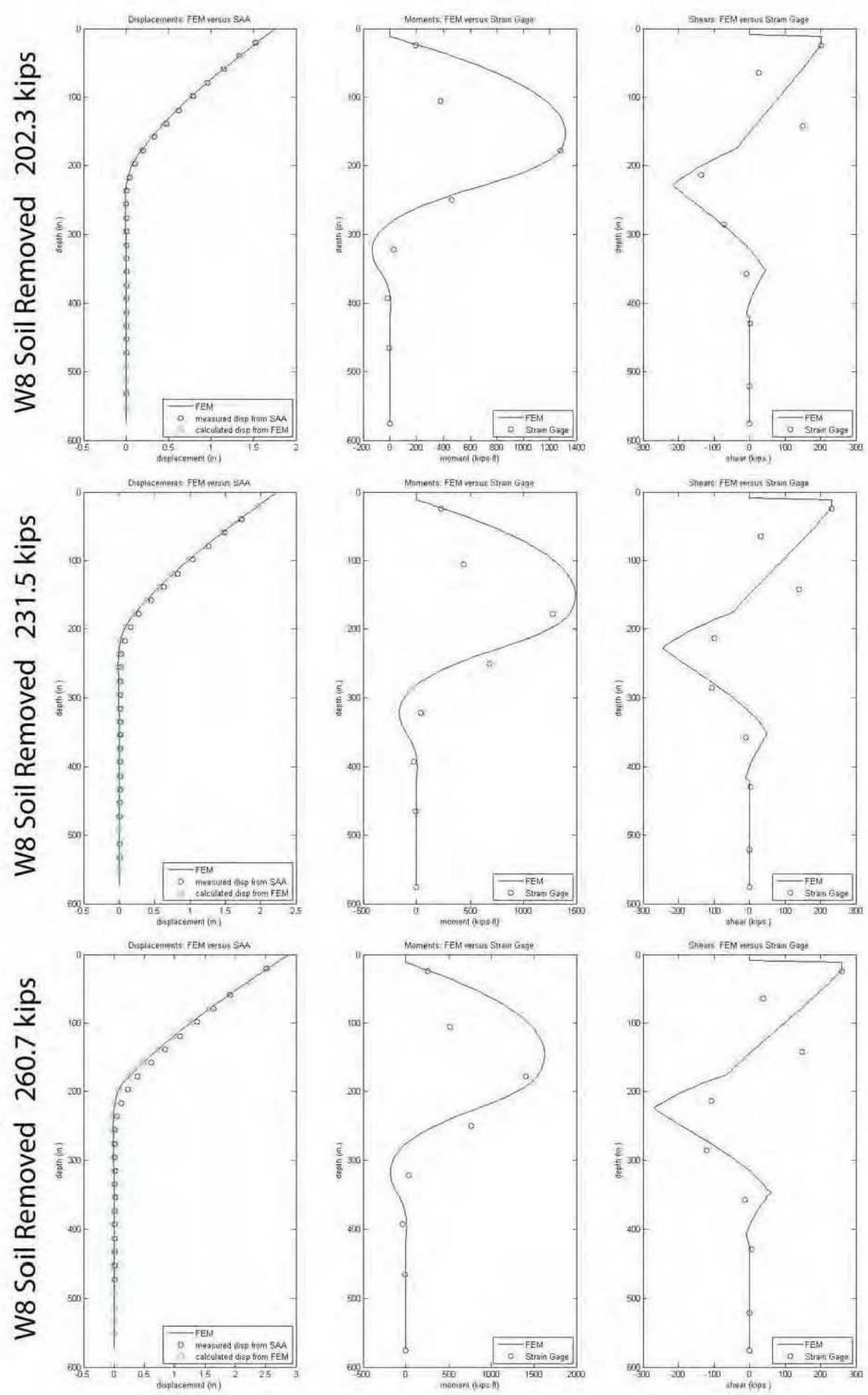

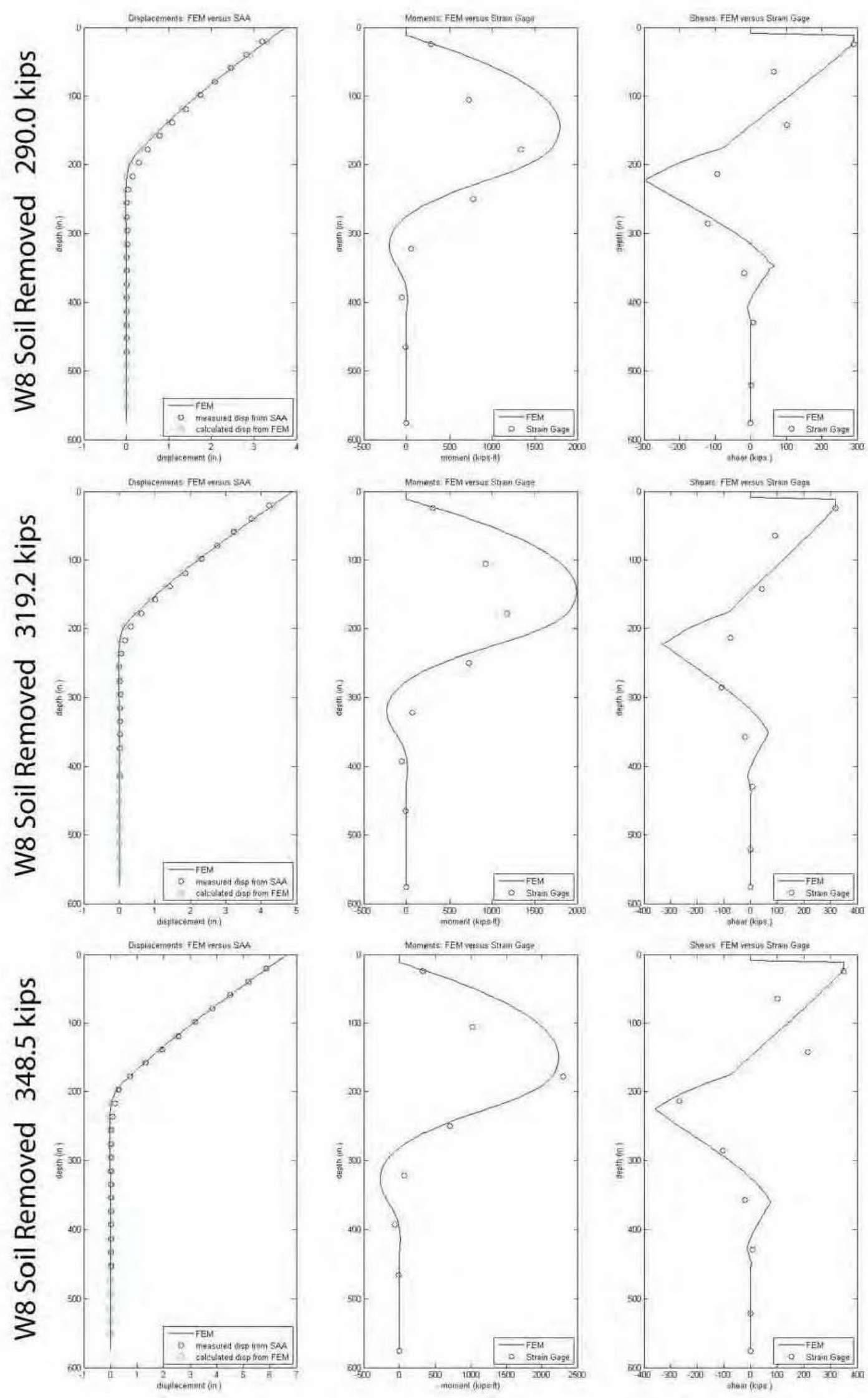

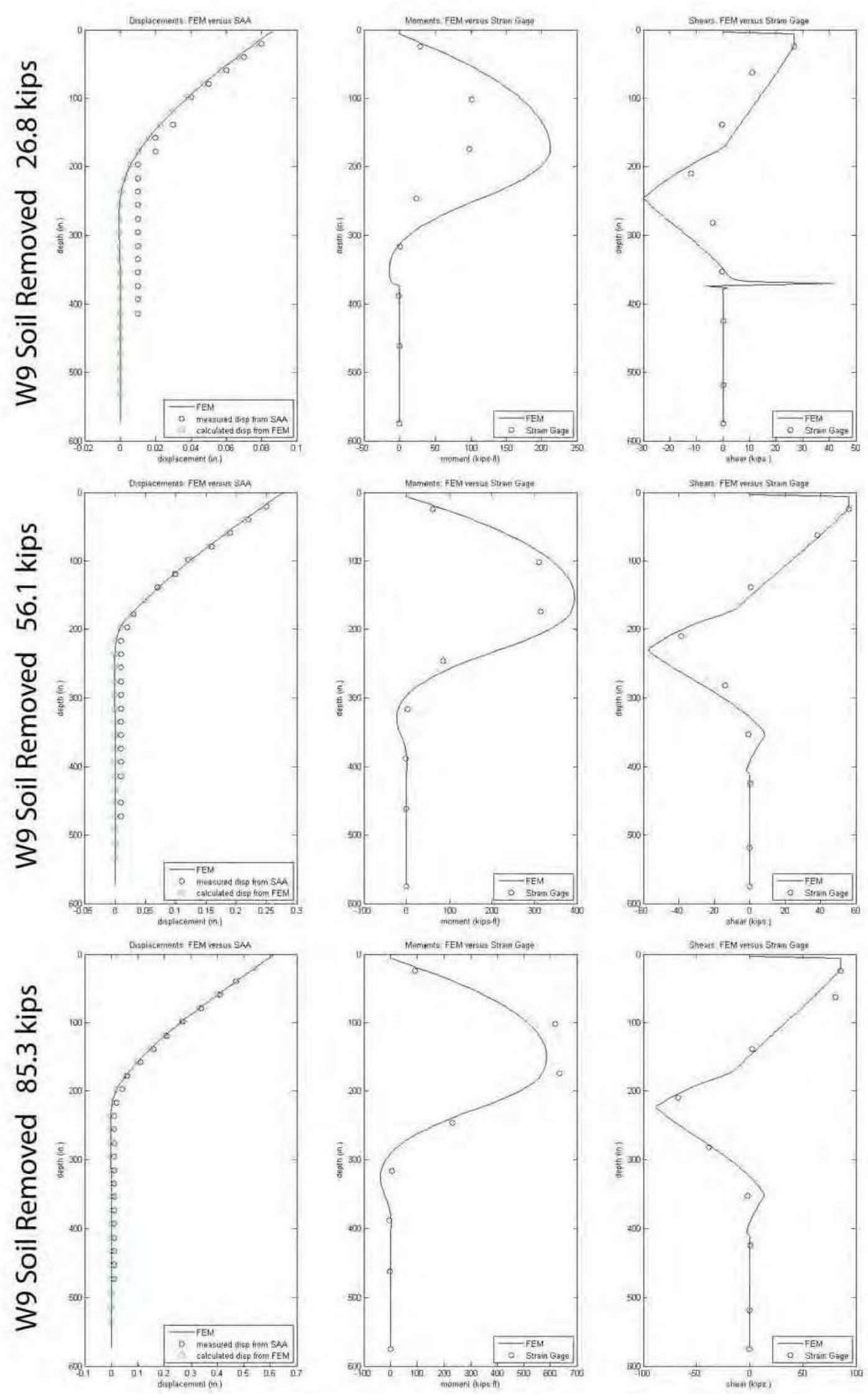

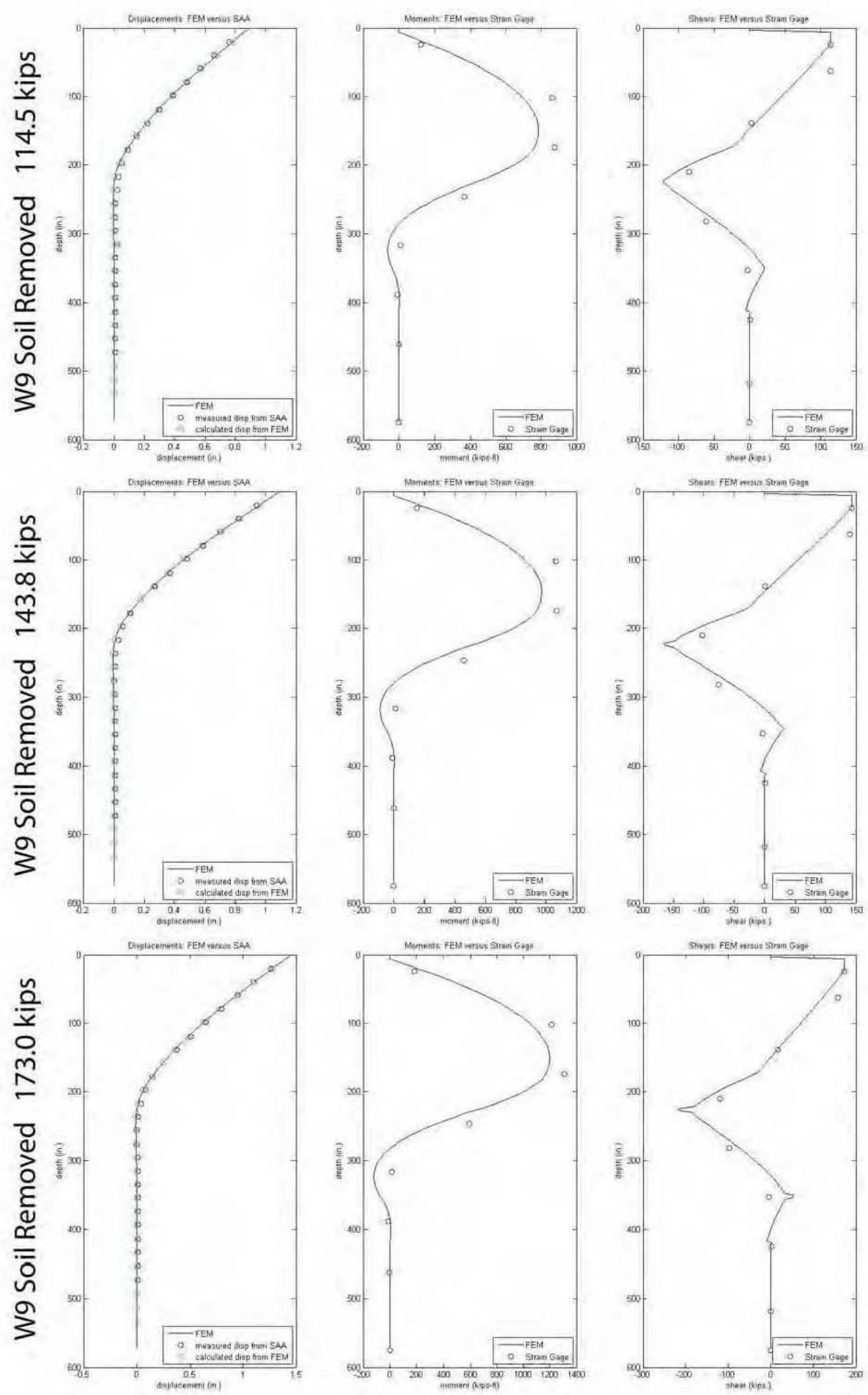

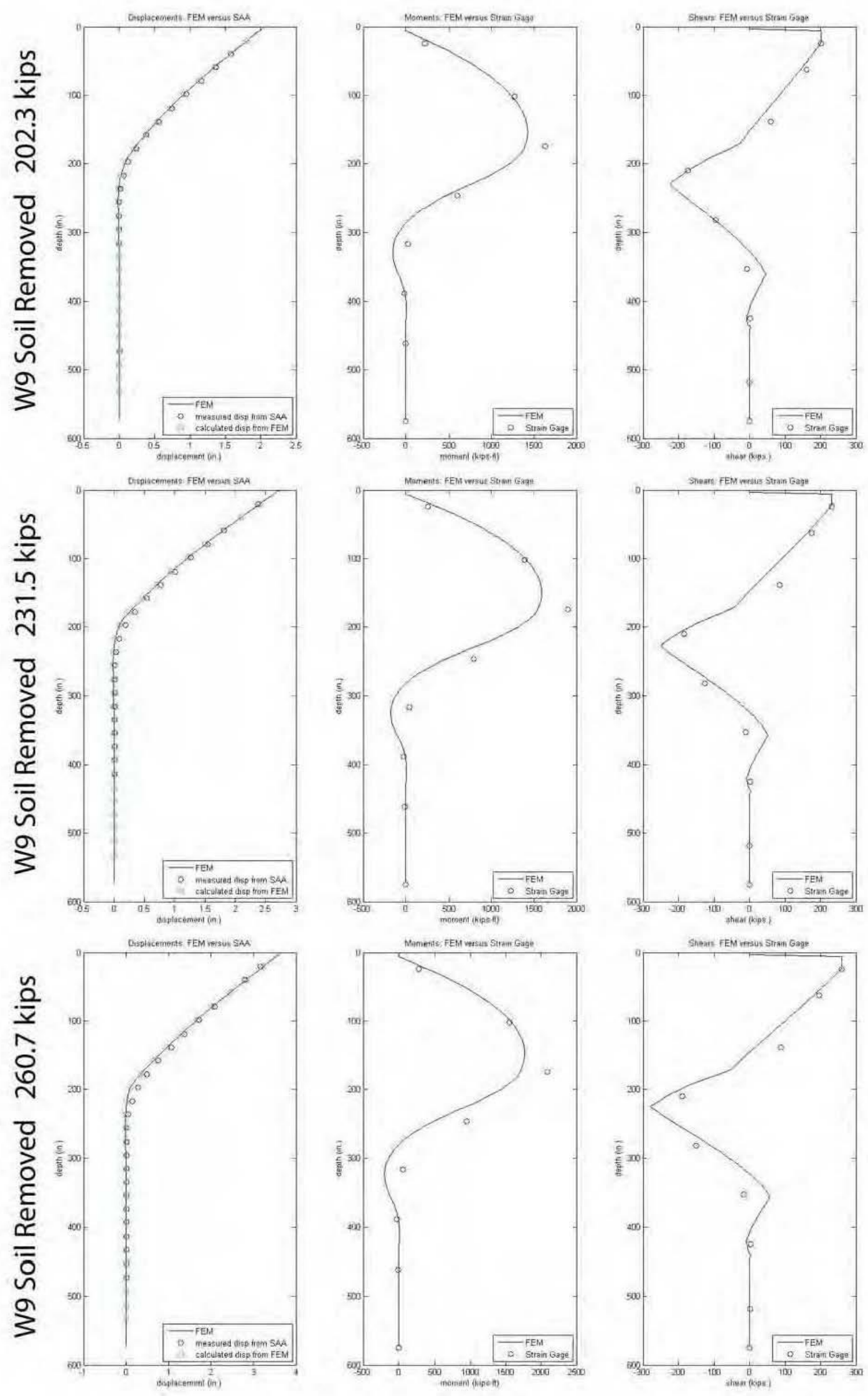

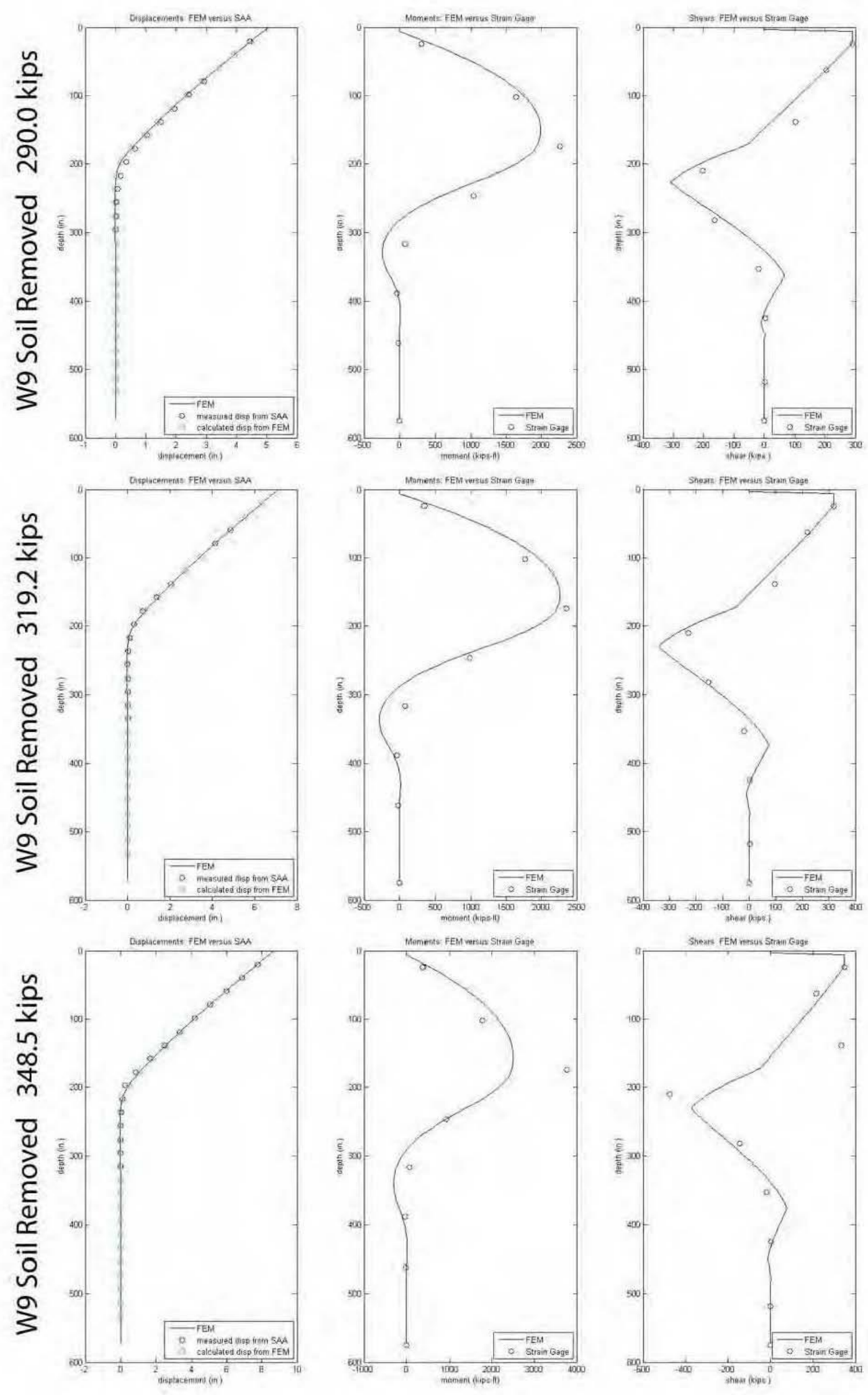

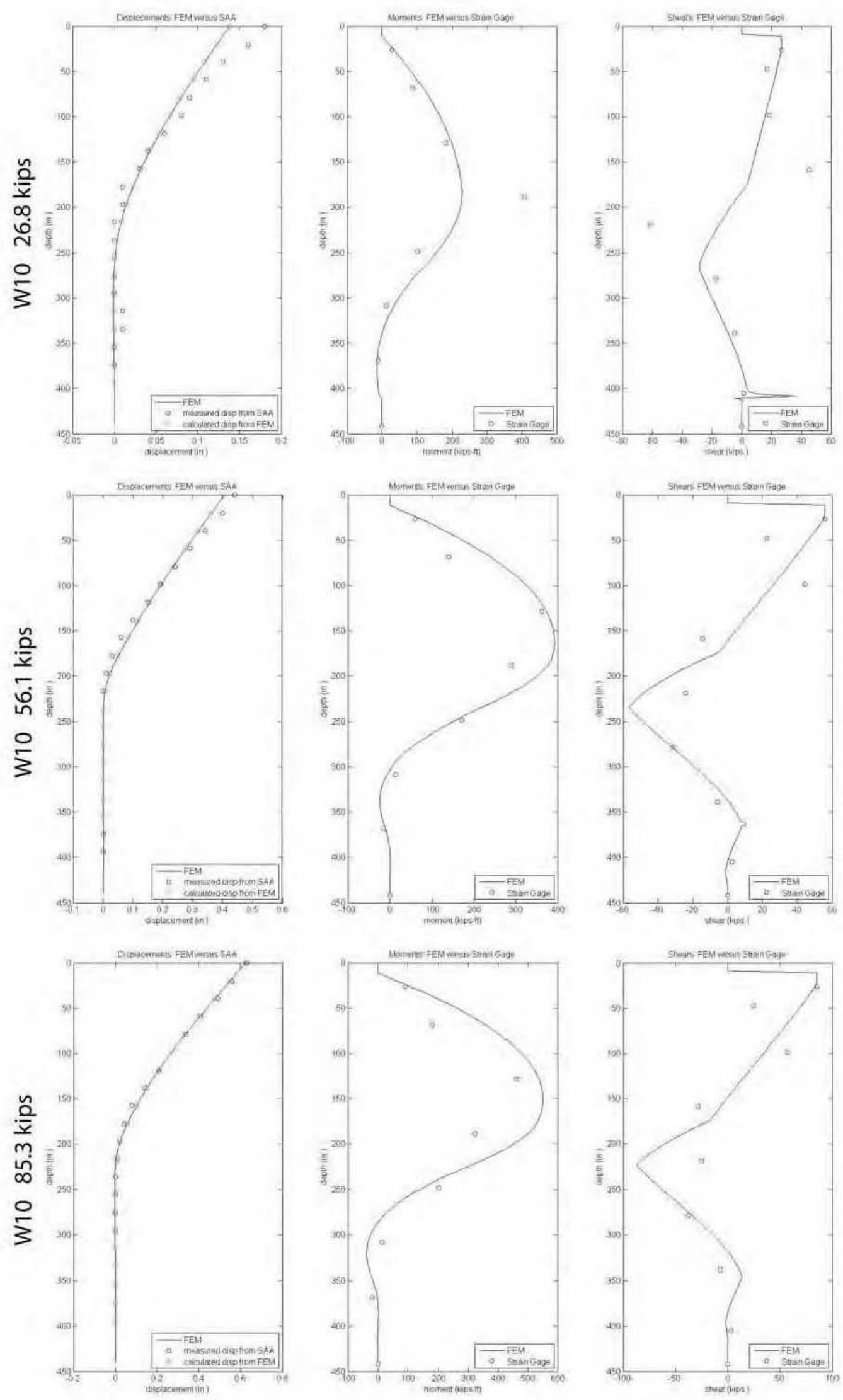

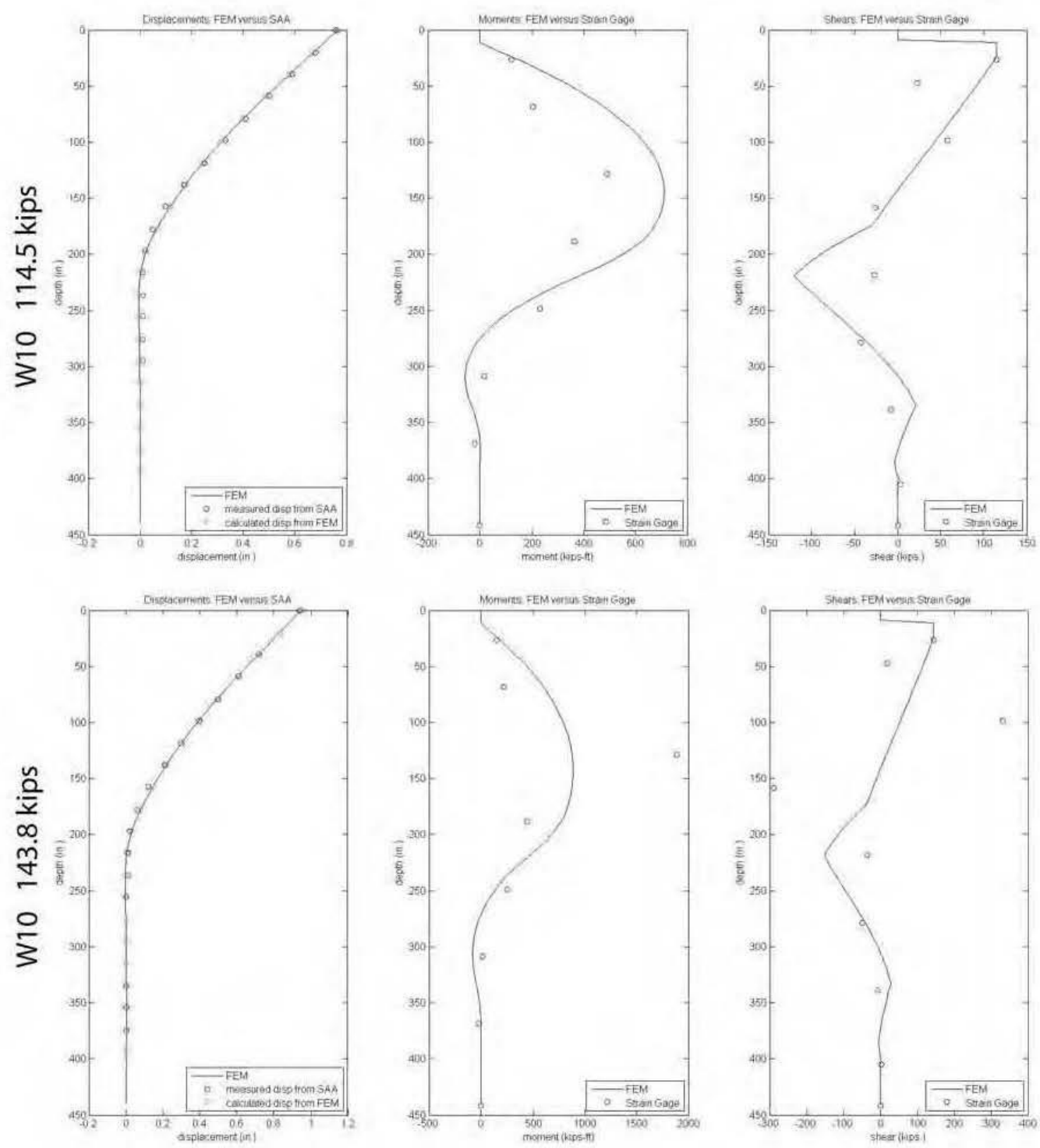

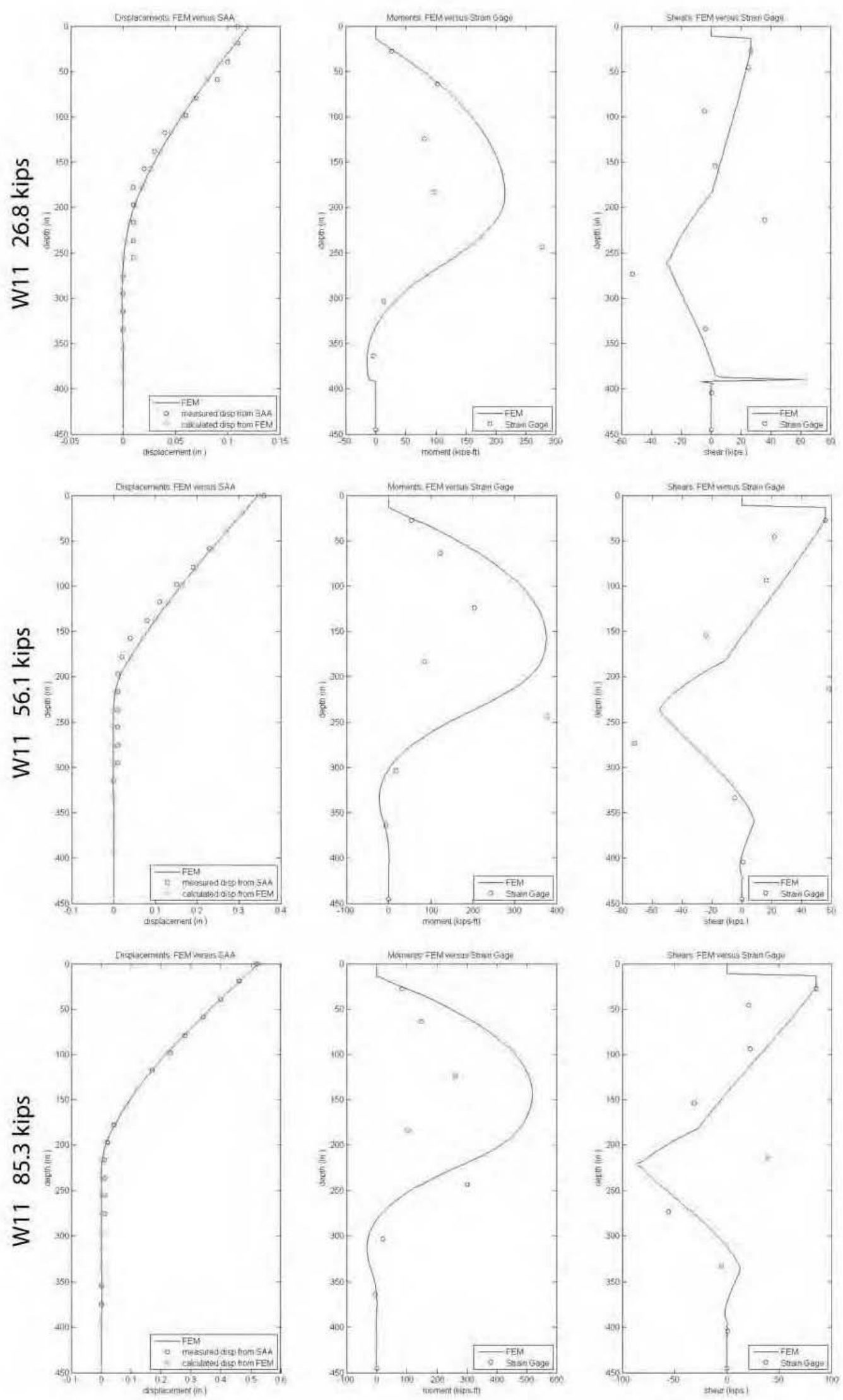

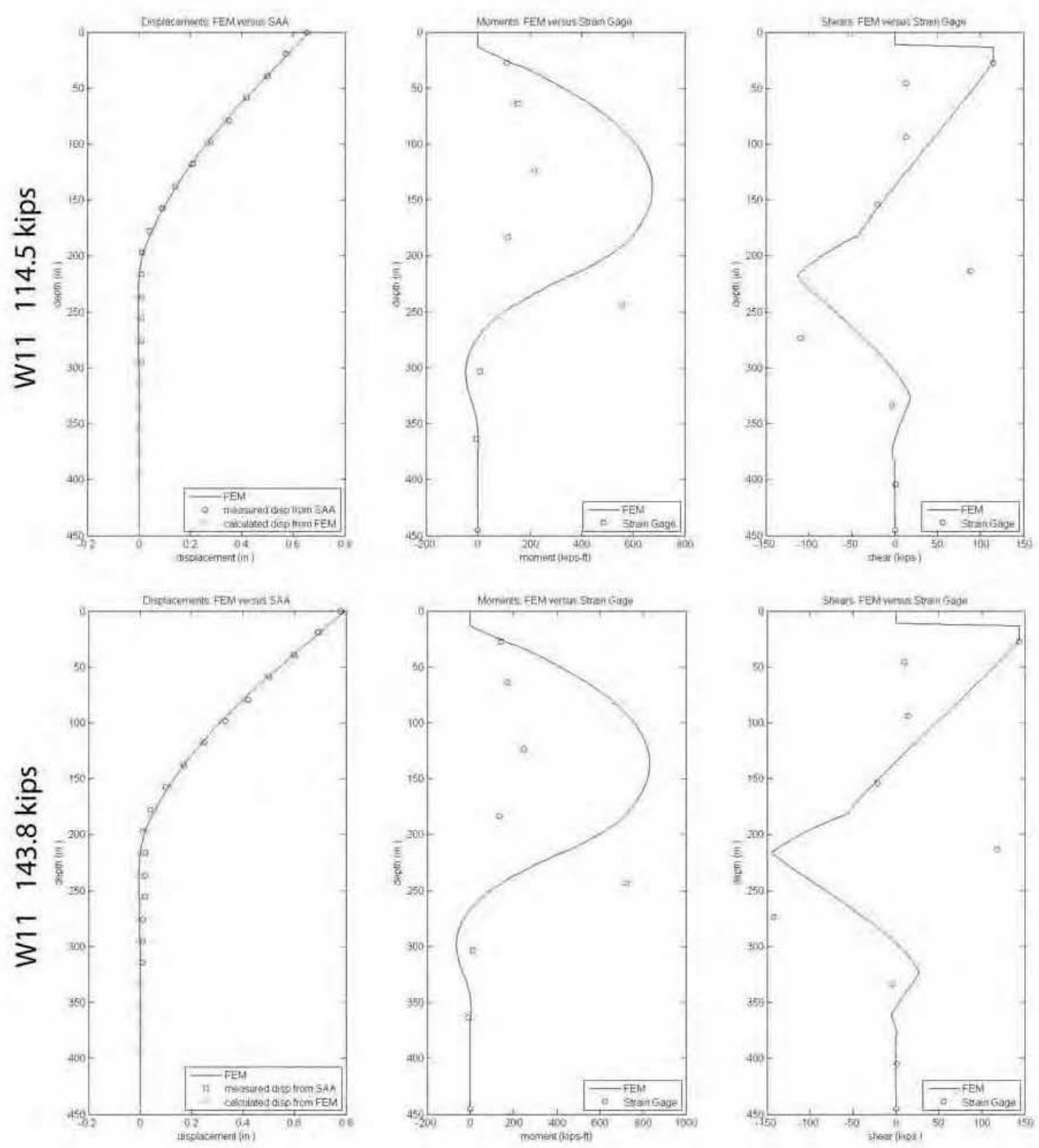

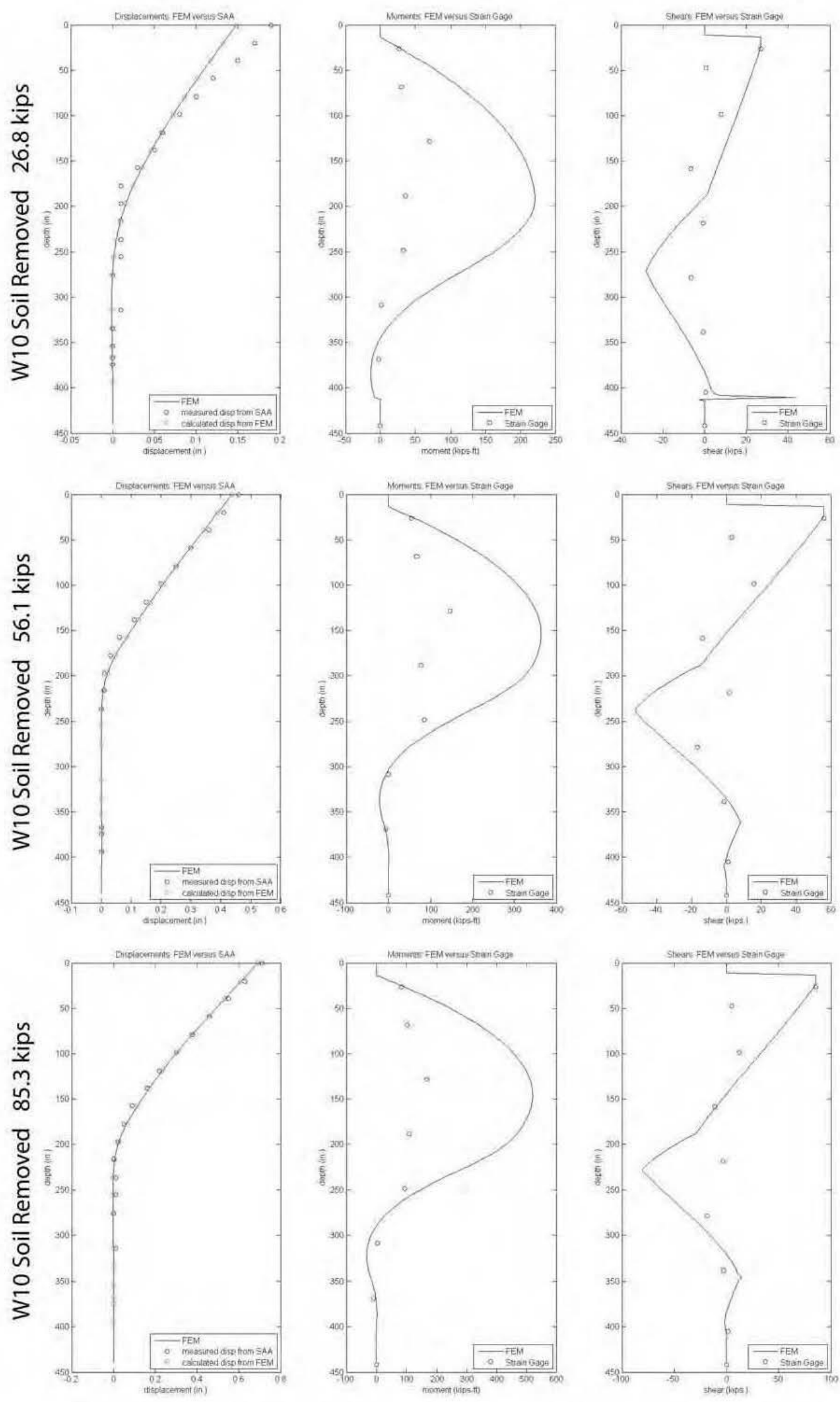

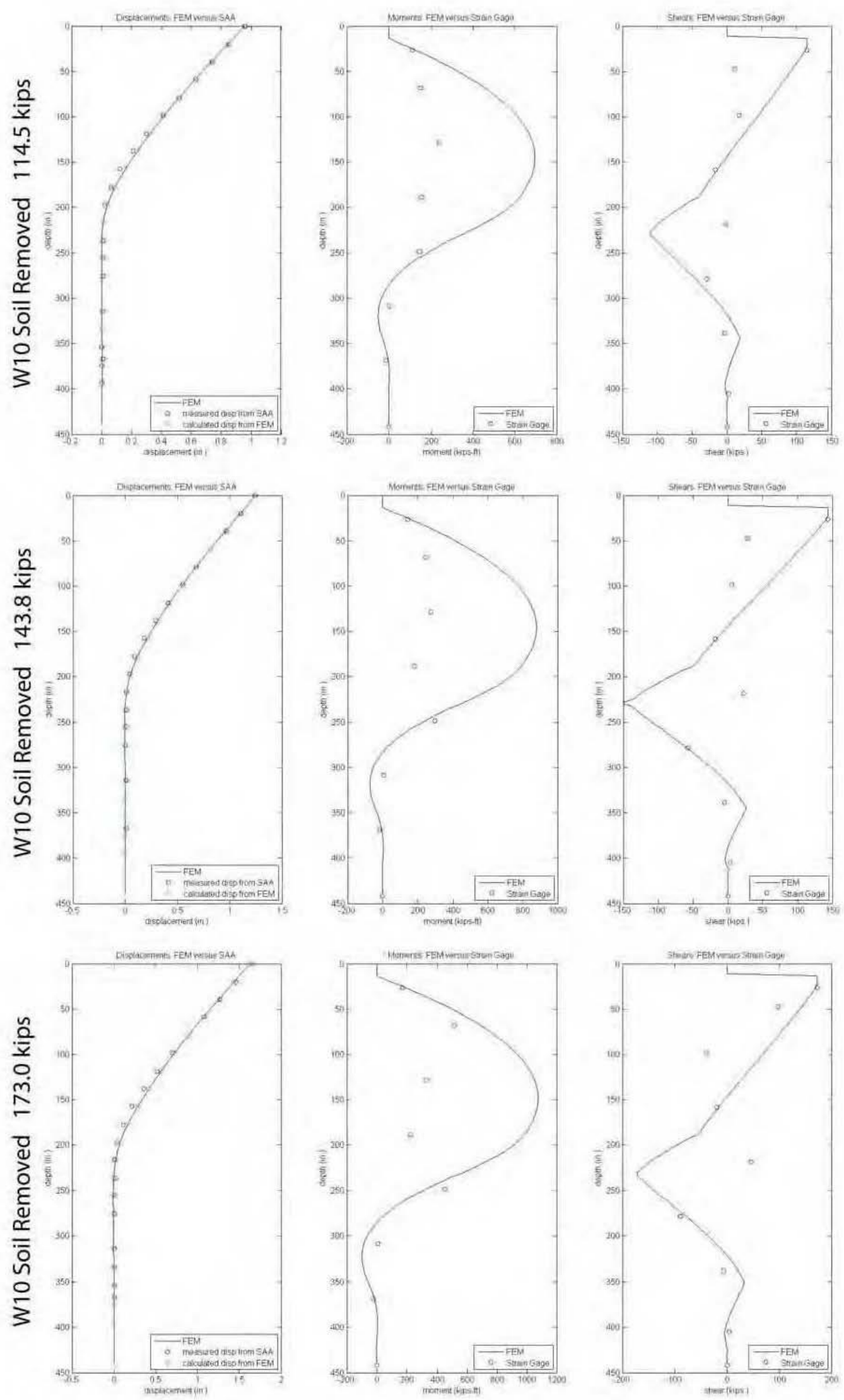

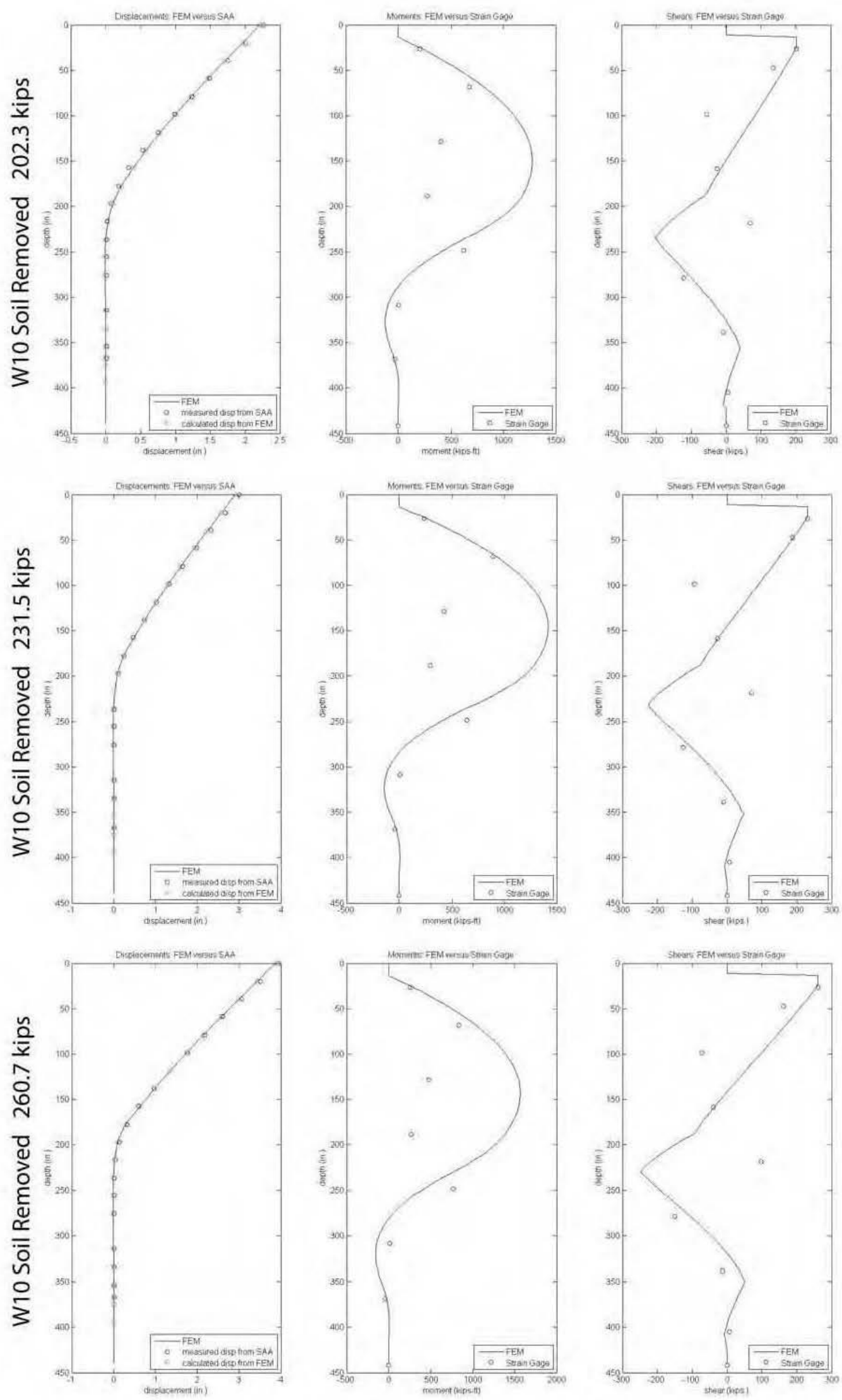

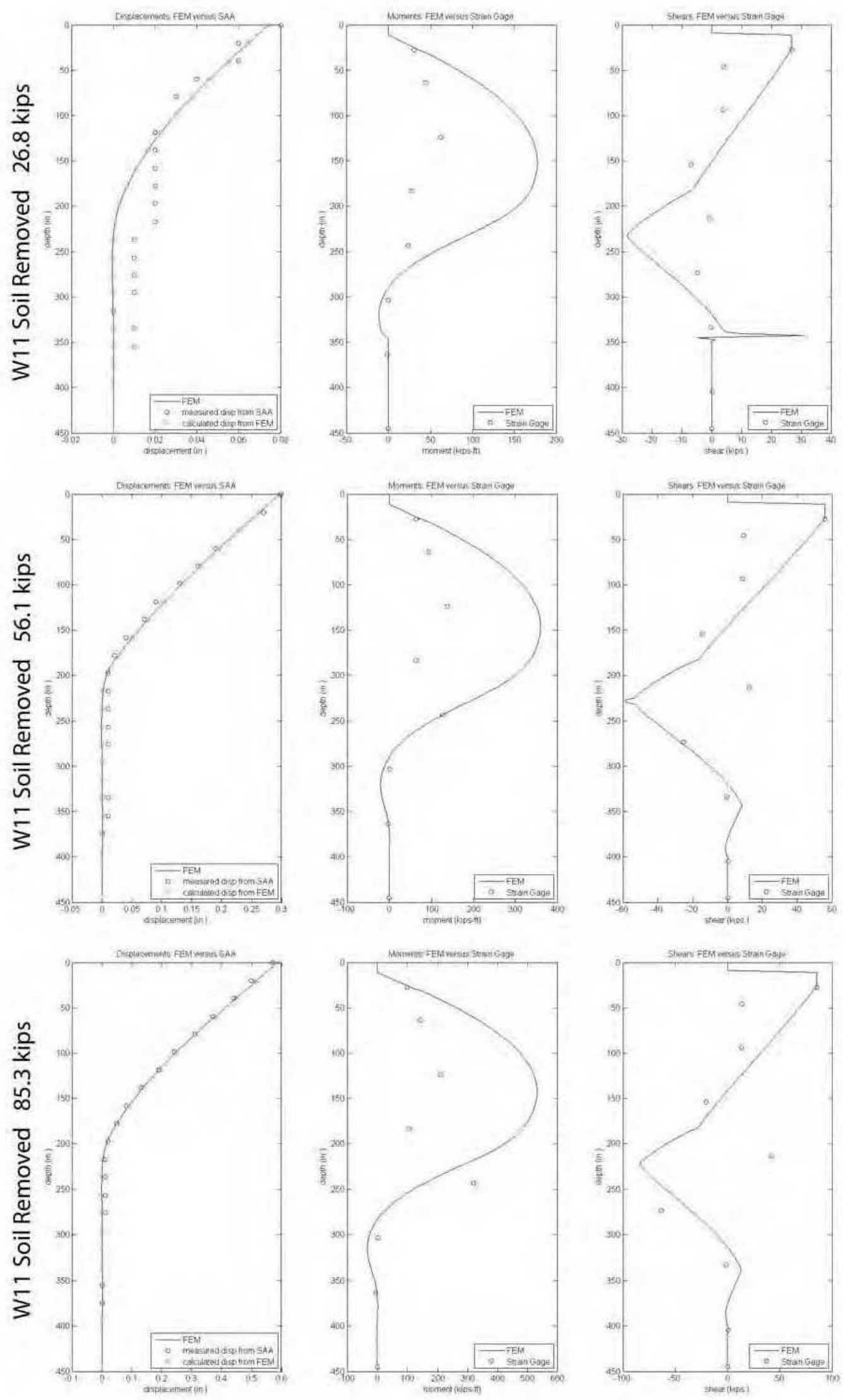

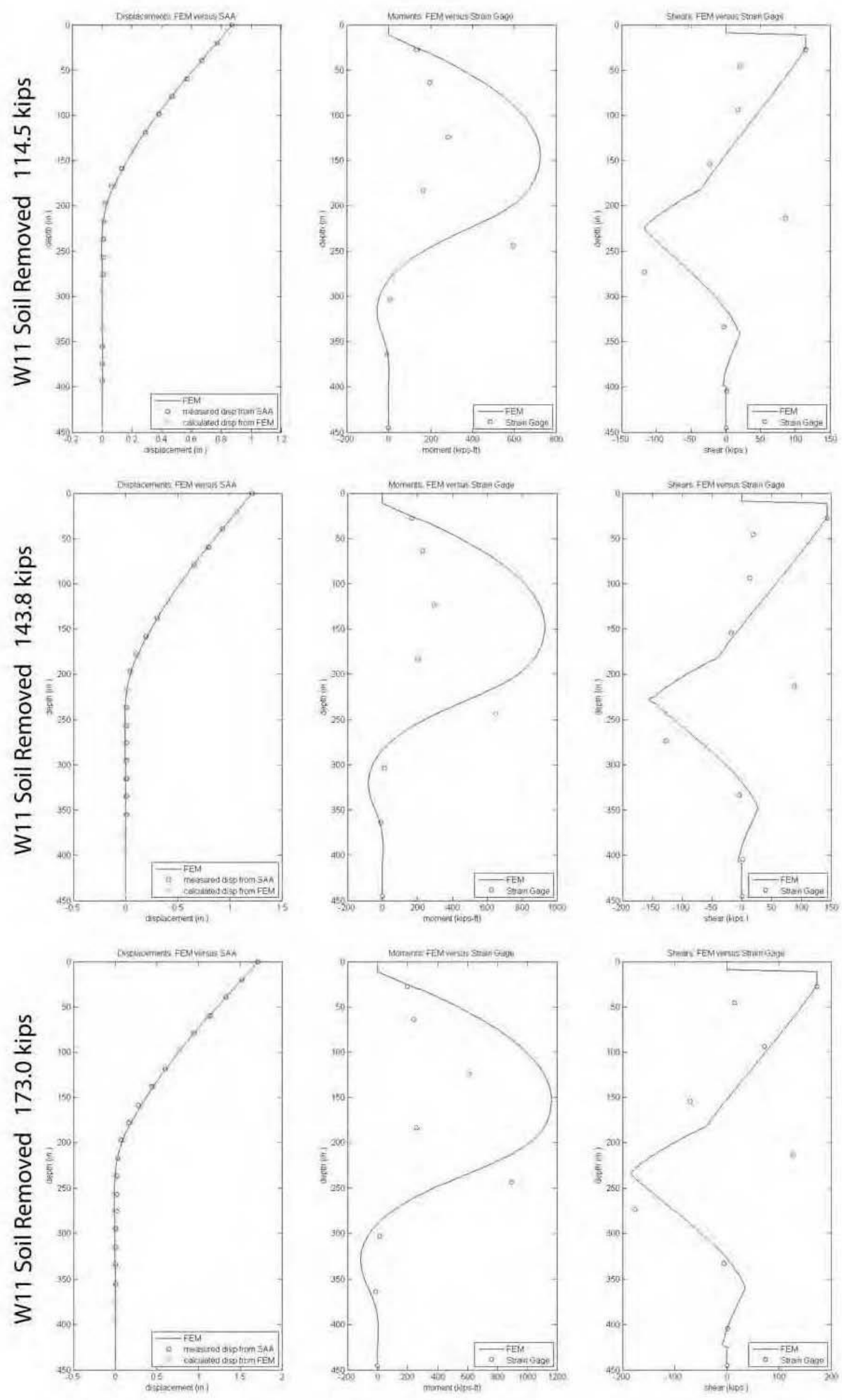

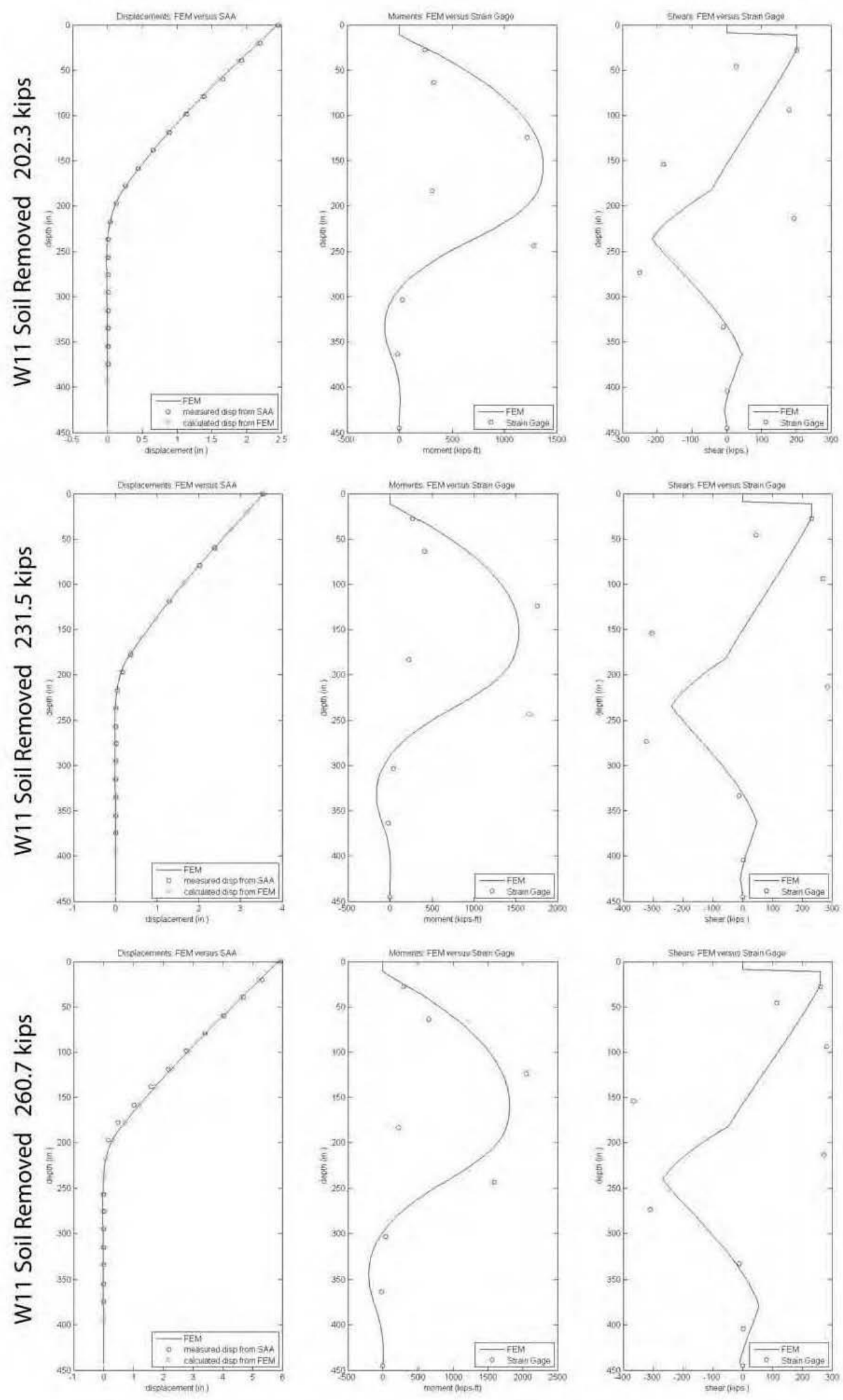

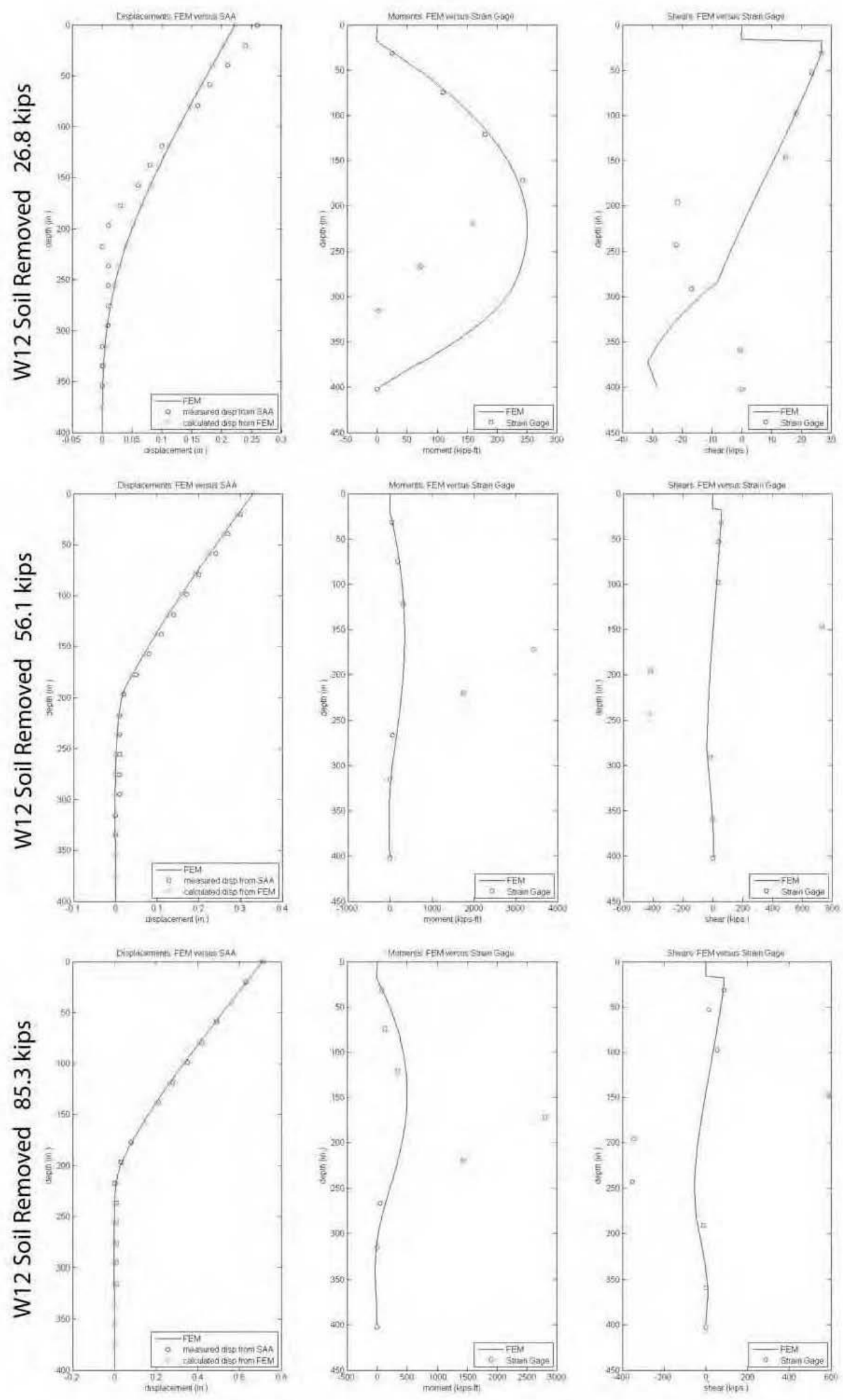

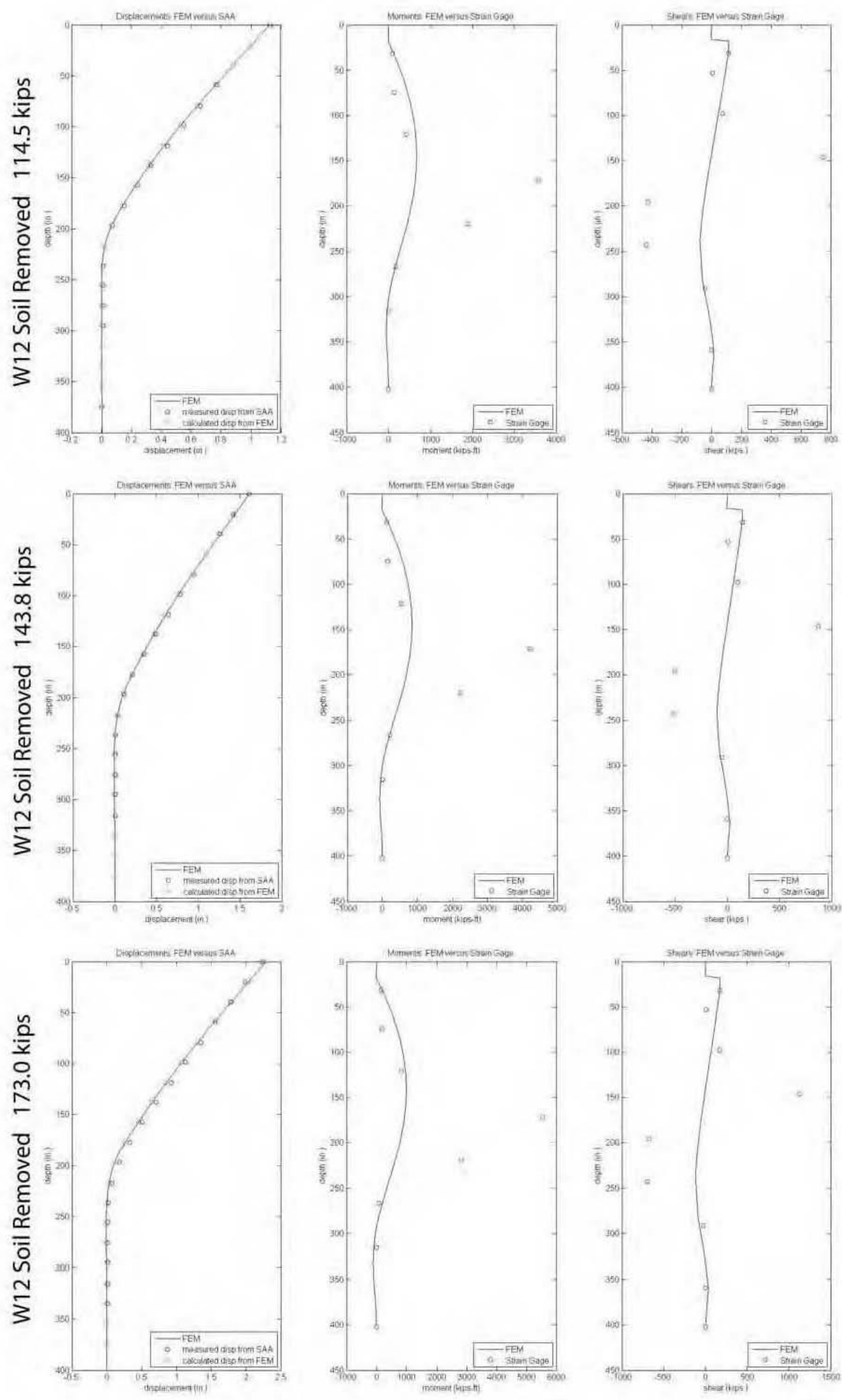

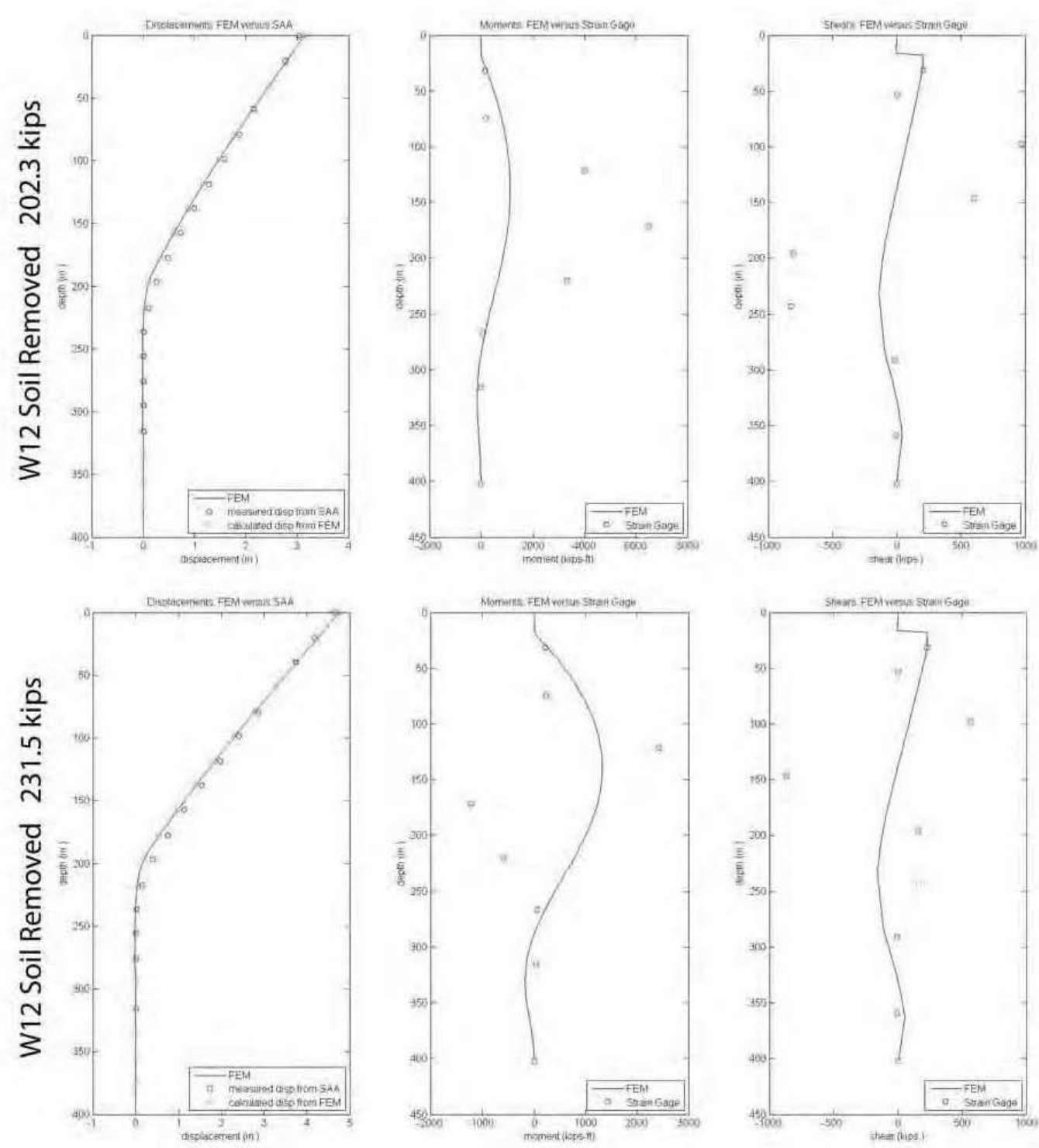

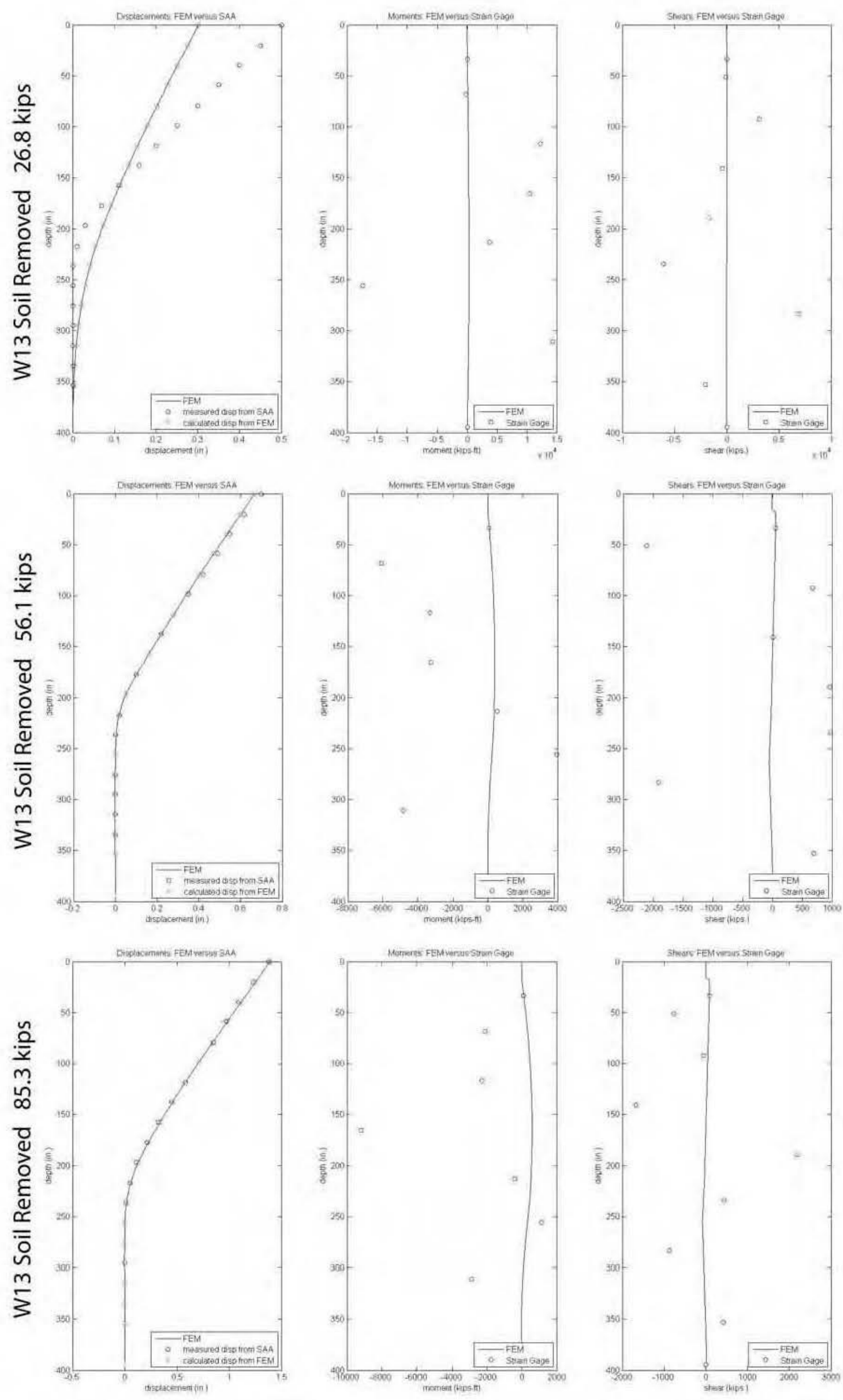

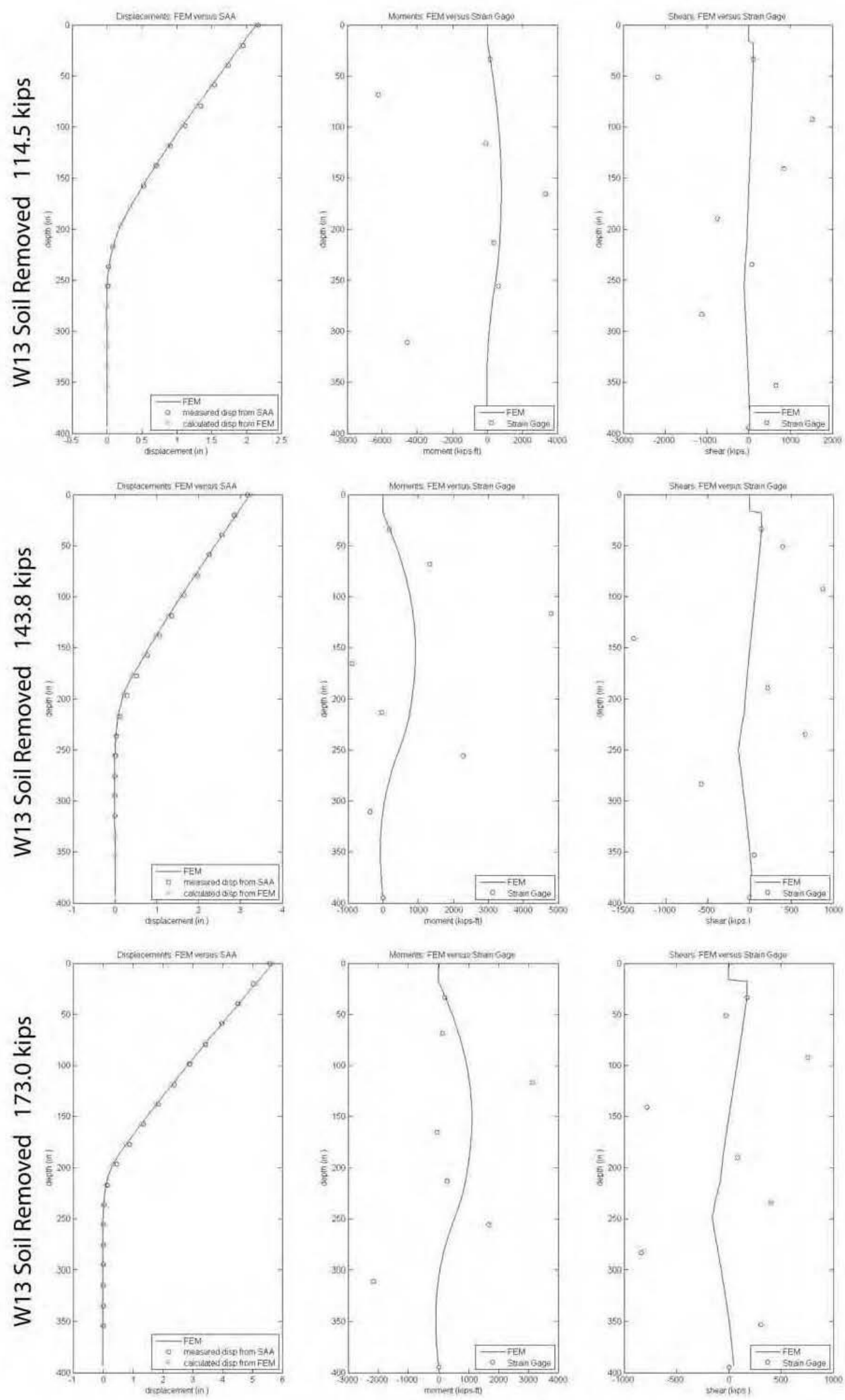

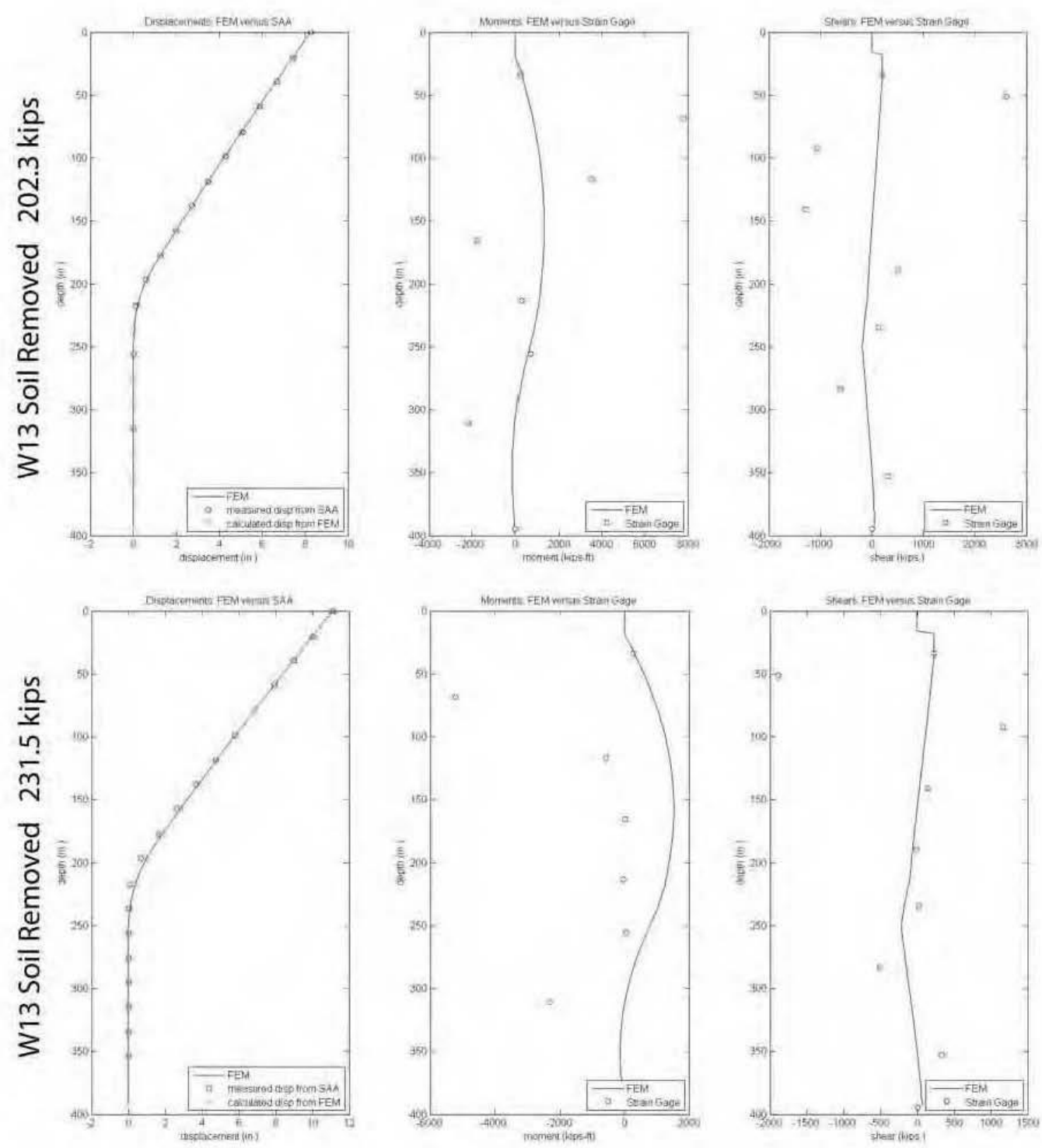

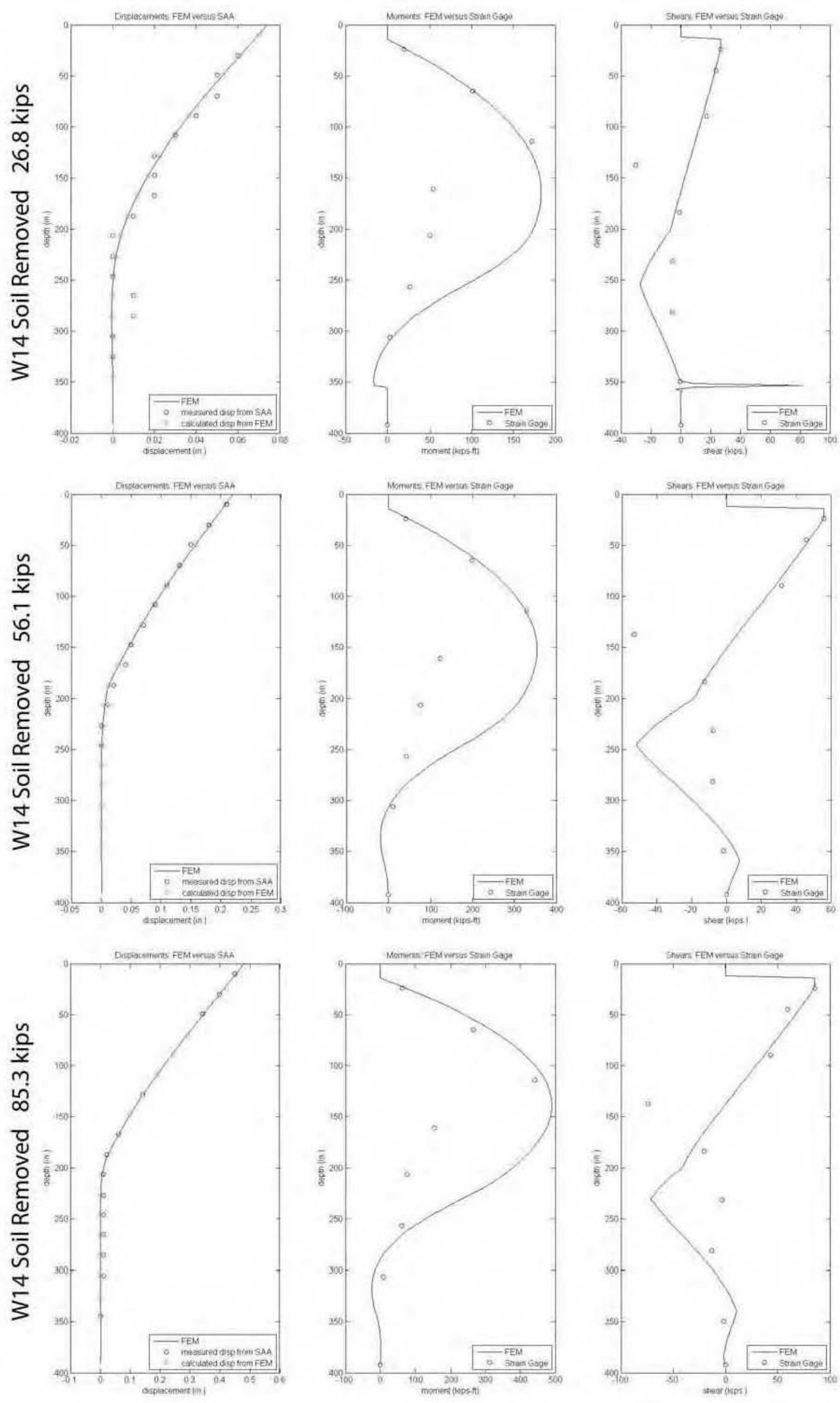

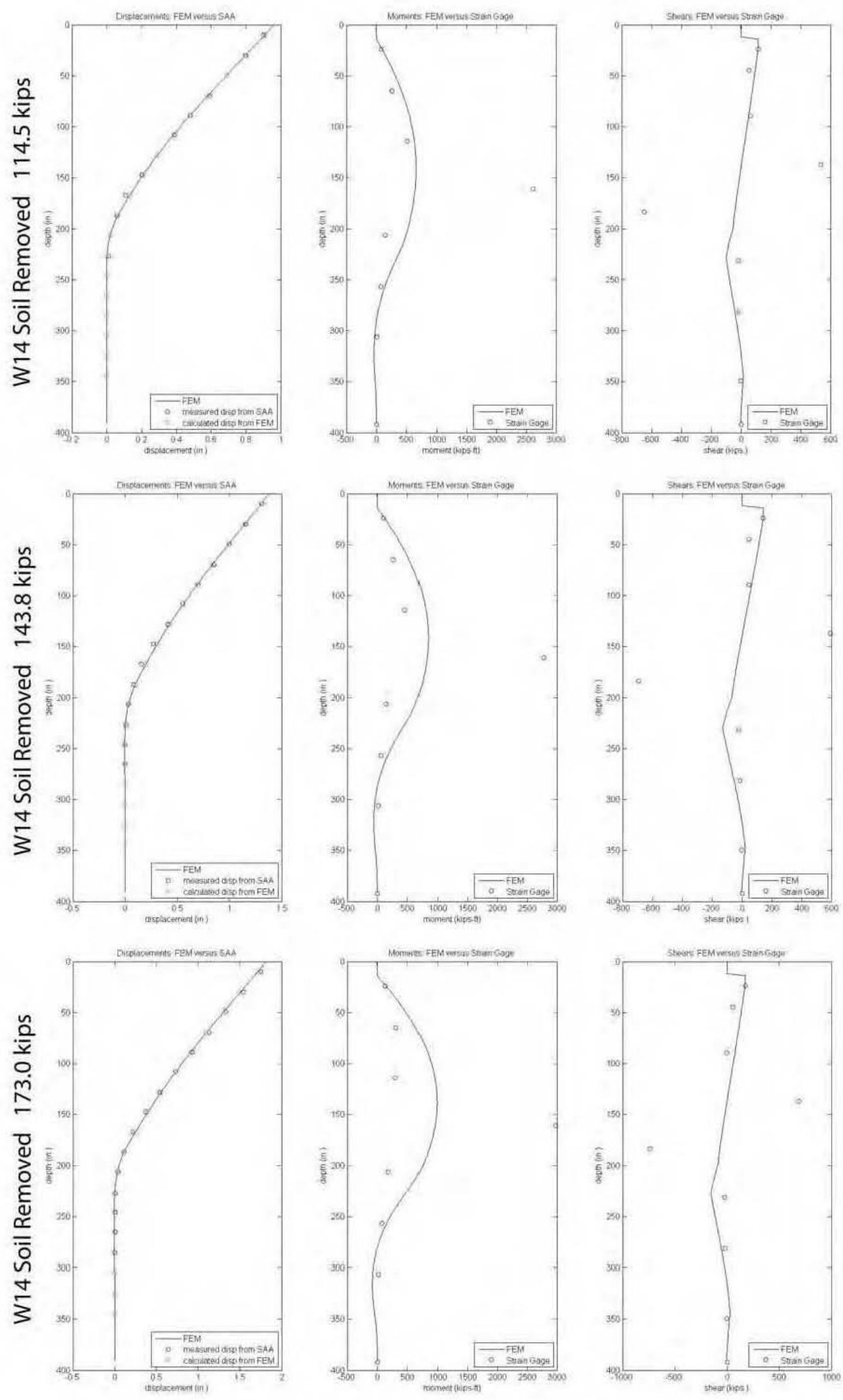

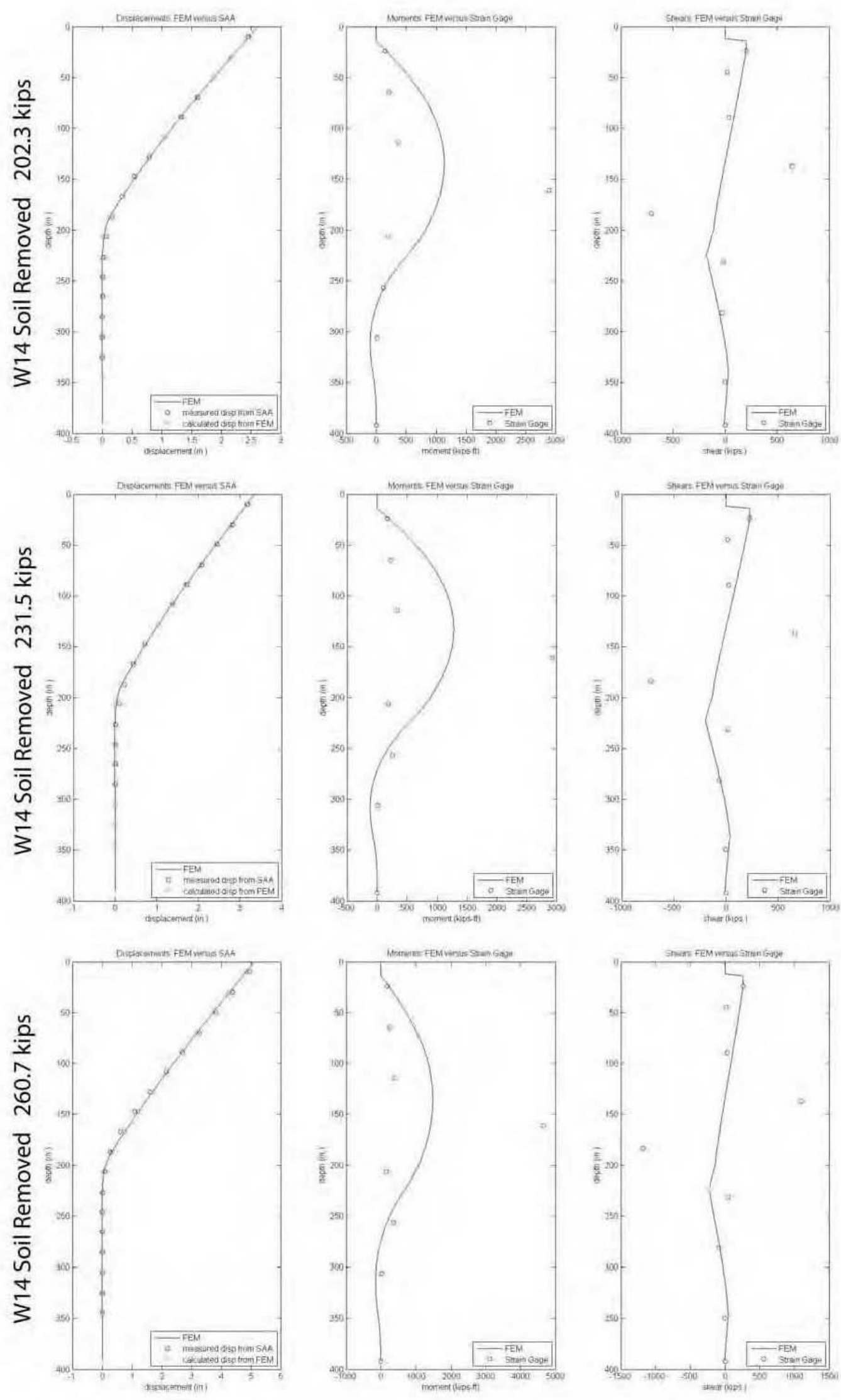

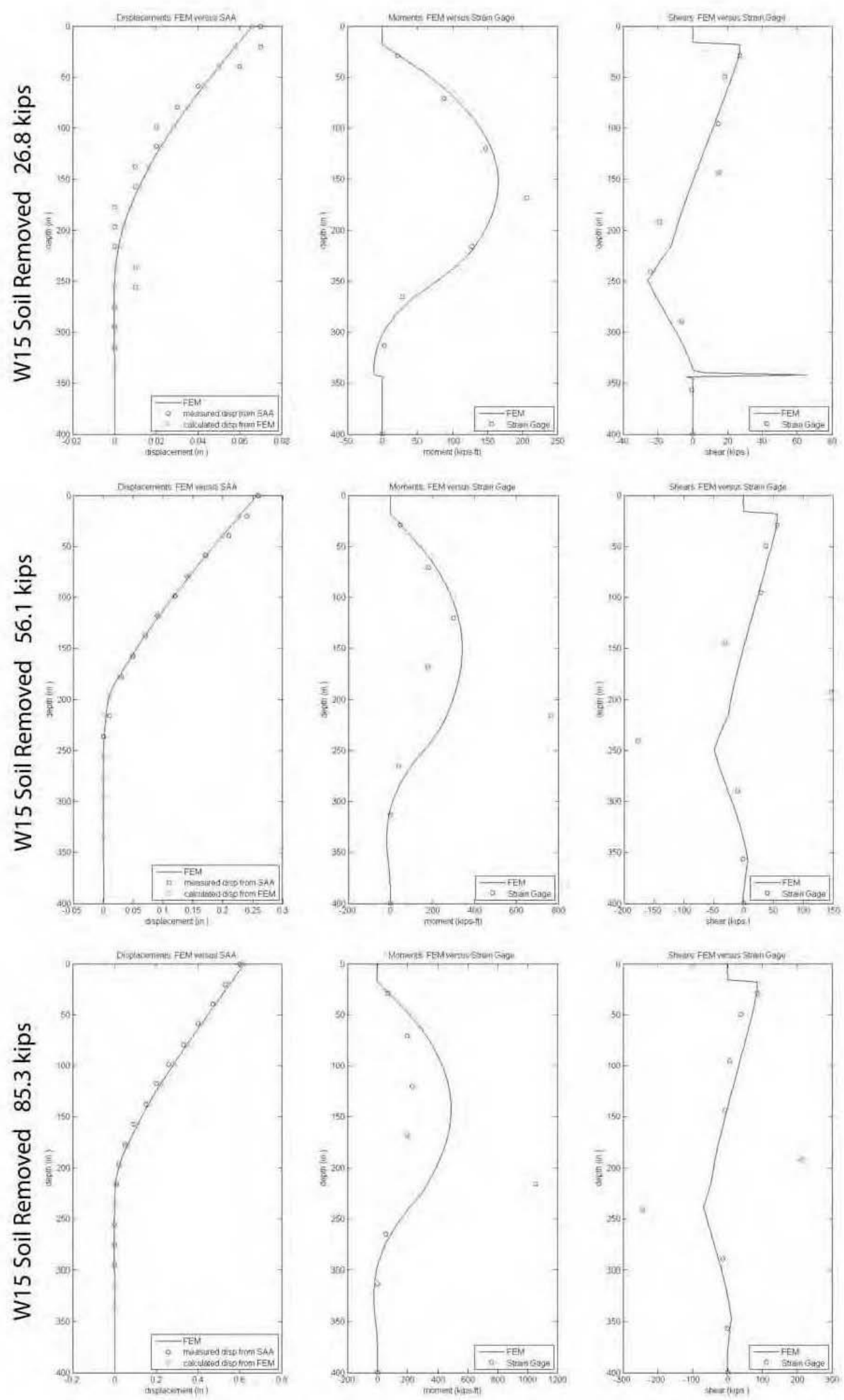

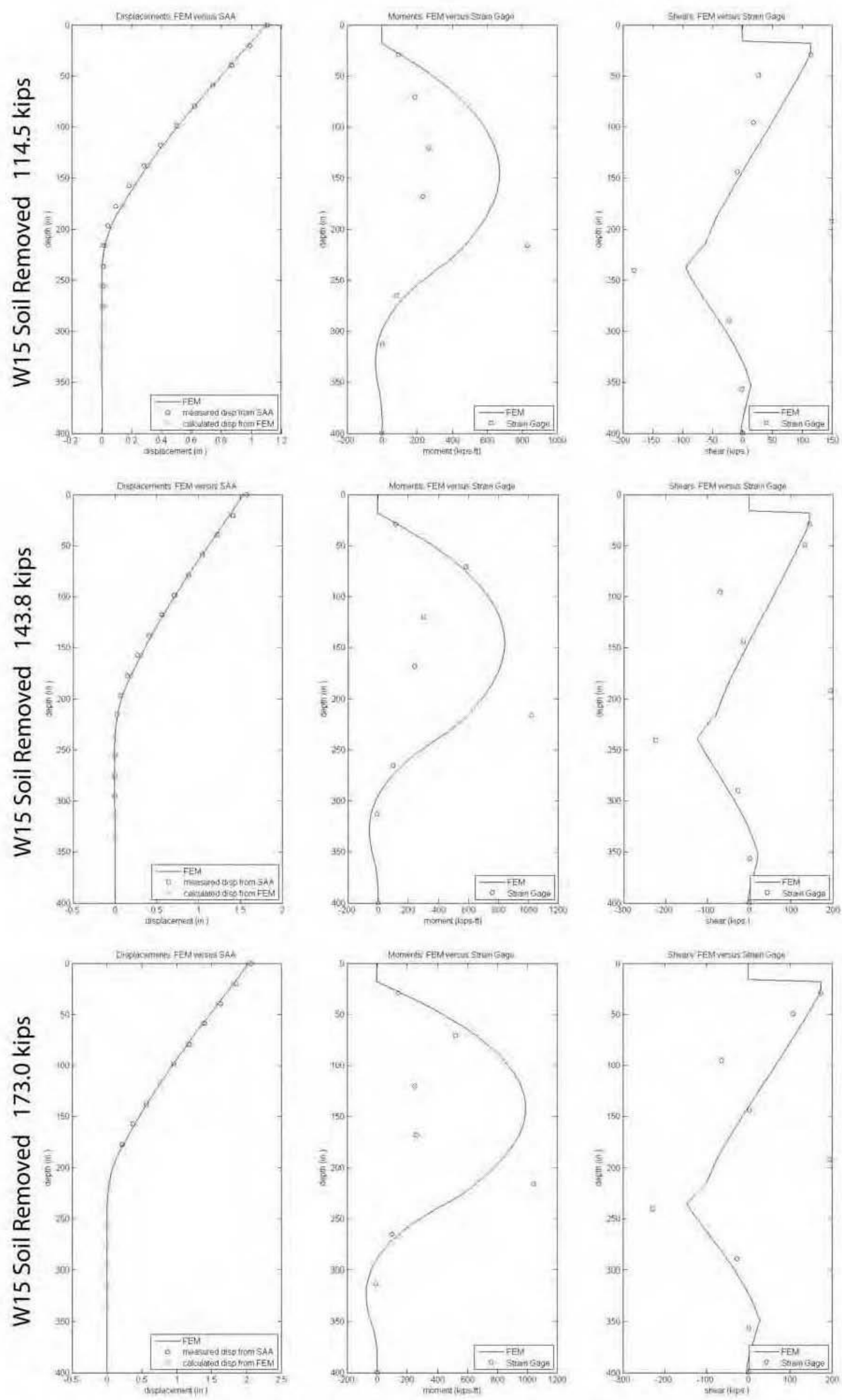

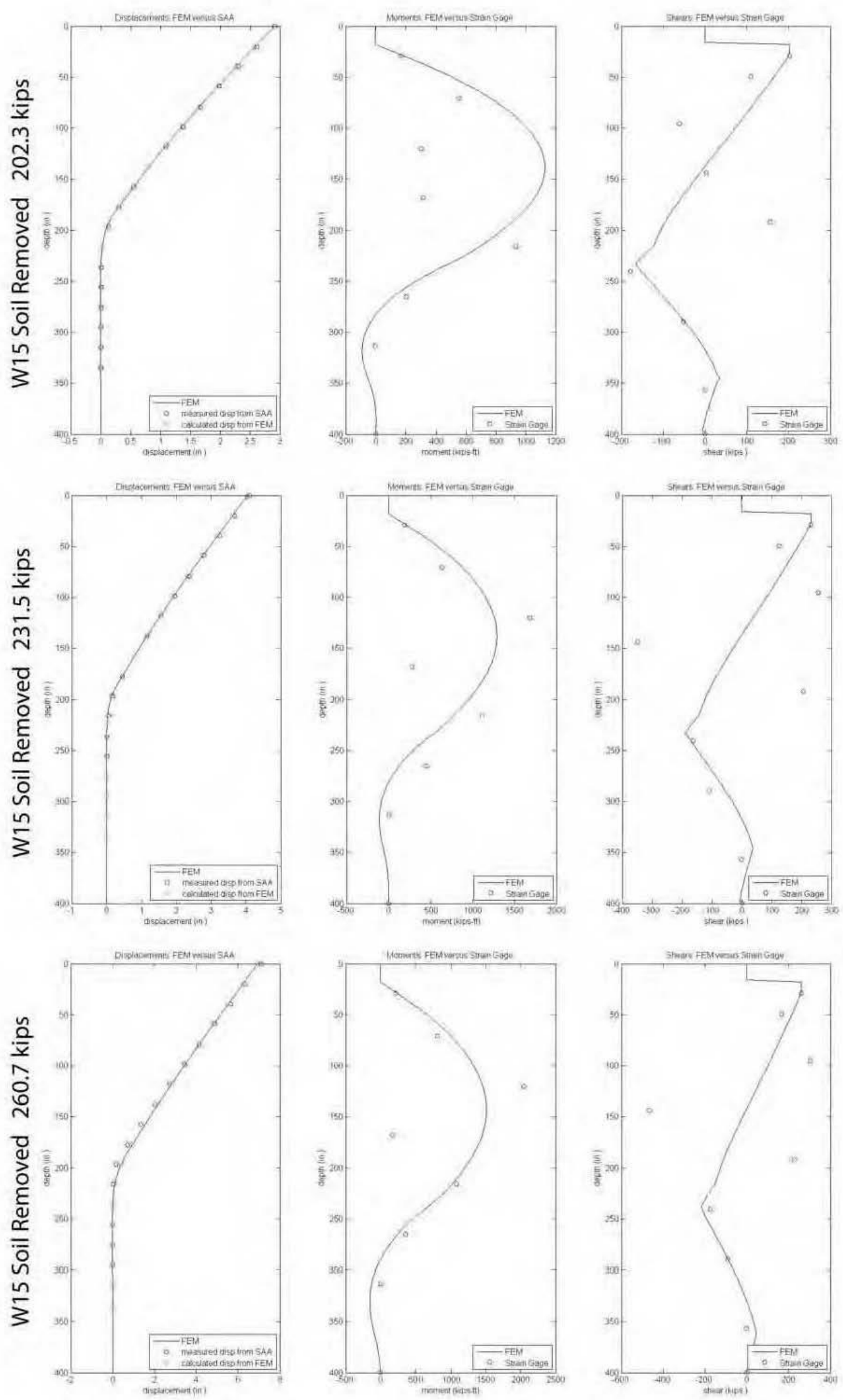
Appendix B

Interpreted p-y Responses and Fitted p-y Curves for each Load Test 


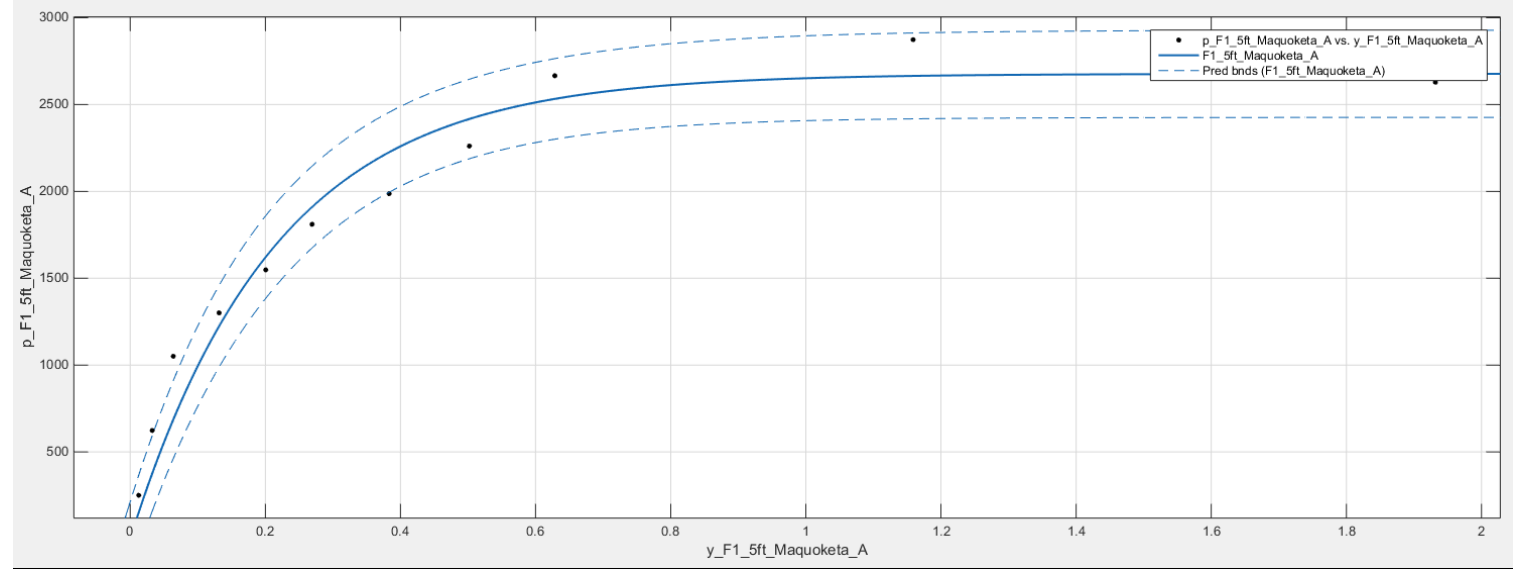

Interpreted $\mathrm{p}-\mathrm{y}$ Responses and Fitted $\mathrm{p}-\mathrm{y}$ curves for Lateral Load Test F-1 at depth=5ft

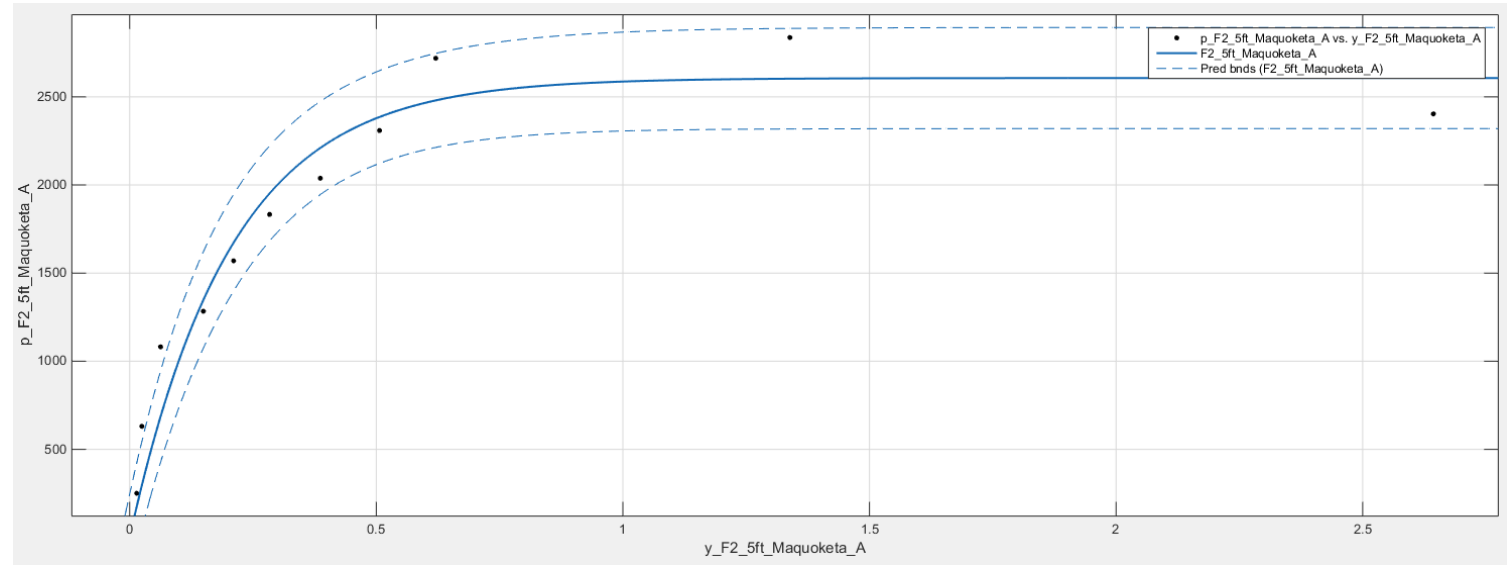

Interpreted p-y Responses and Fitted p-y curves for Lateral Load Test F-2 at depth=5ft

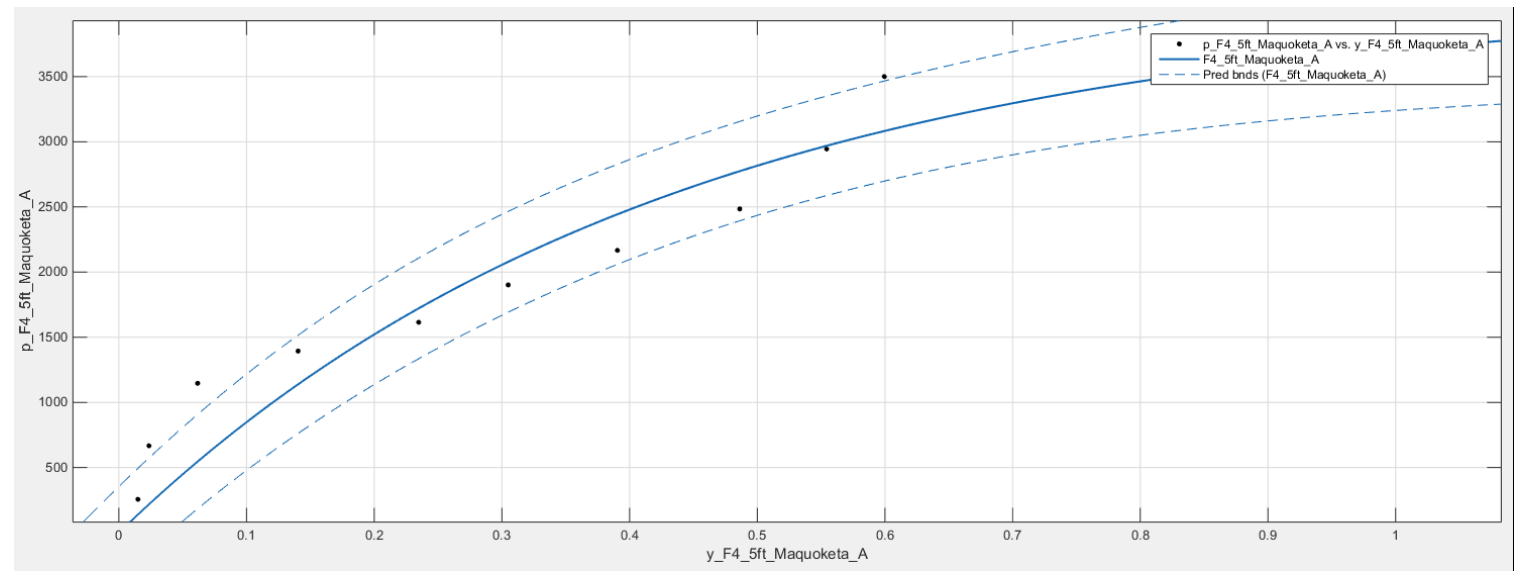

Interpreted p-y Responses and Fitted p-y curves for Lateral Load Test F-4 at depth=5ft 


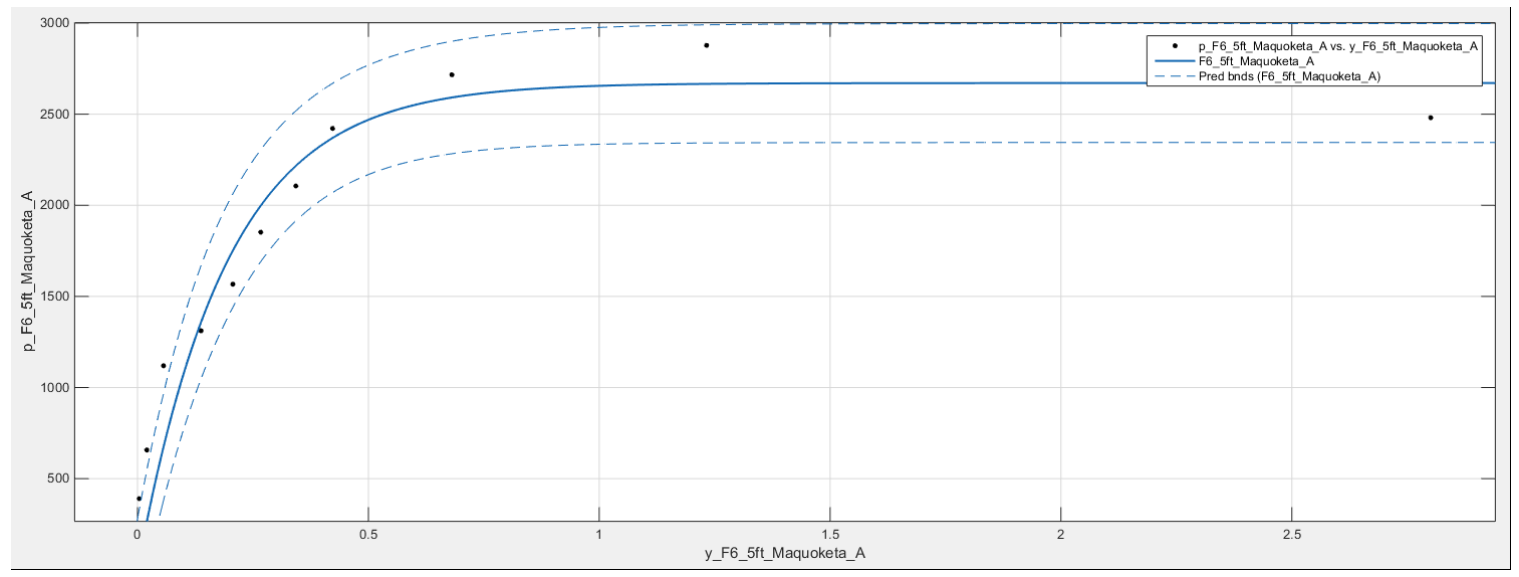

Interpreted p-y Responses and Fitted p-y curves for Lateral Load Test F- 6 at depth=5ft

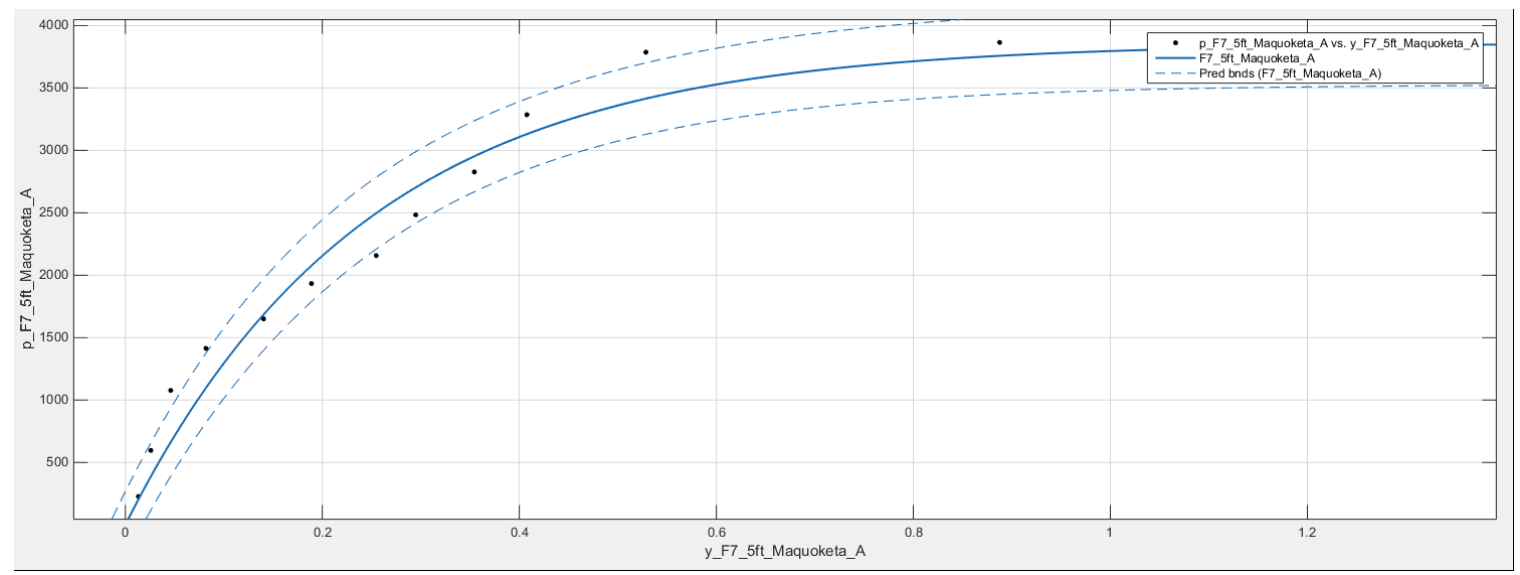

Interpreted p-y Responses and Fitted p-y curves for Lateral Load Test F-7 at depth=5ft

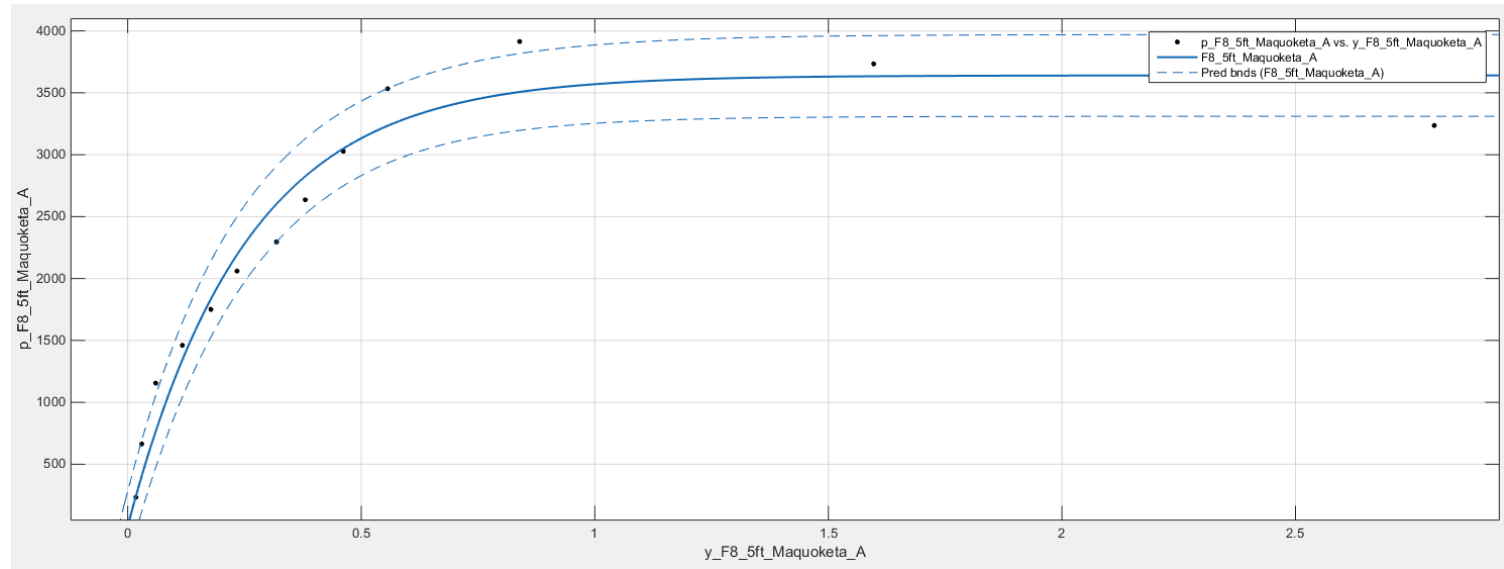

Interpreted $p$-y Responses and Fitted $p$-y curves for Lateral Load Test F-8 at depth $=5 \mathrm{ft}$ 


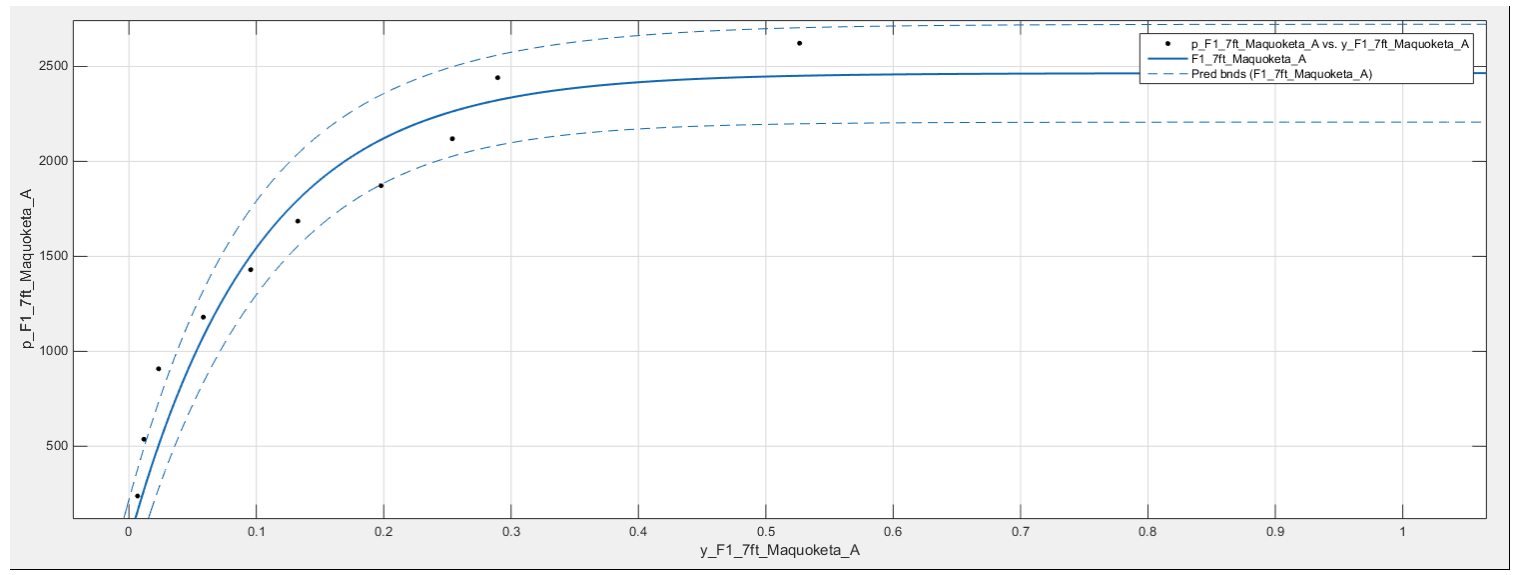

Interpreted p-y Responses and Fitted $\mathrm{p}-\mathrm{y}$ curves for Lateral Load Test F-1 at depth=7ft

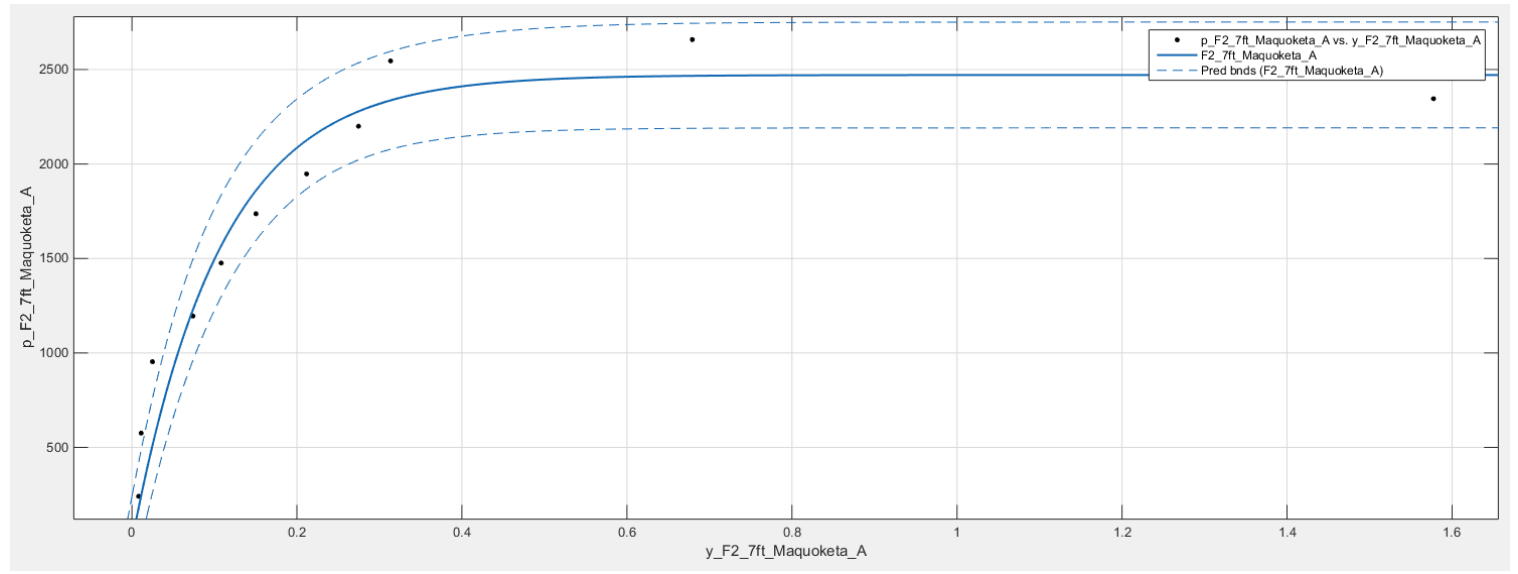

Interpreted p-y Responses and Fitted $p-y$ curves for Lateral Load Test F-2 at depth=7ft

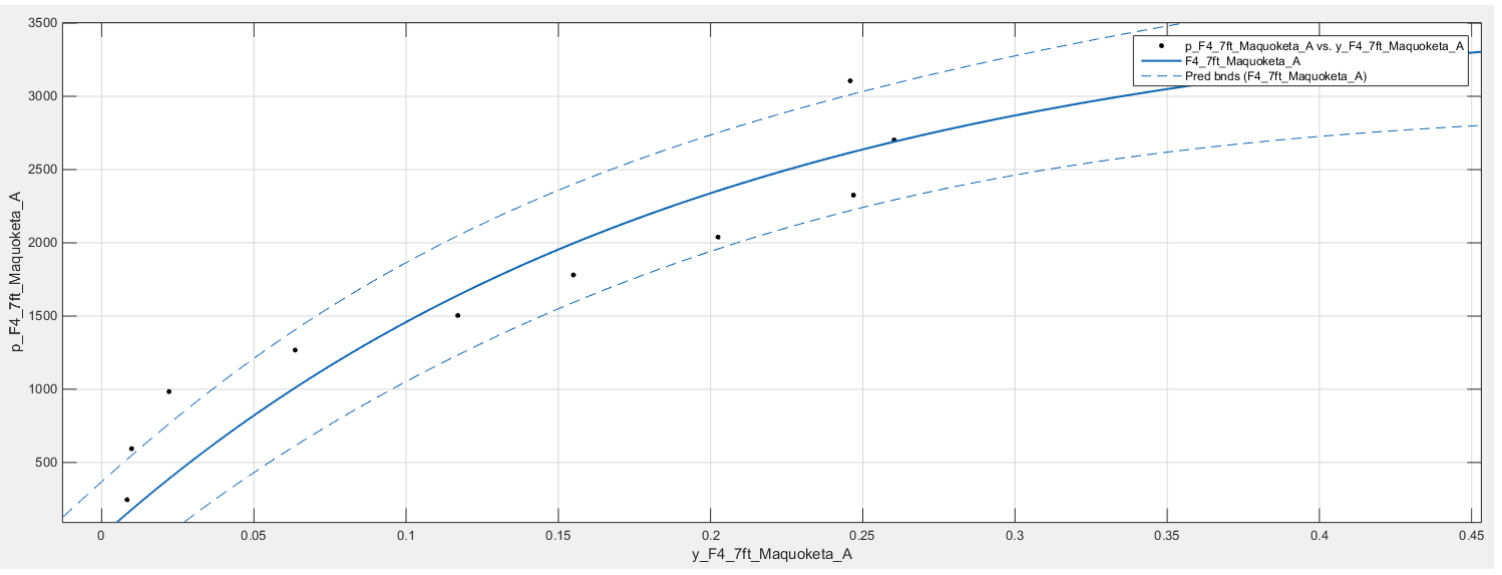

Interpreted p-y Responses and Fitted p-y curves for Lateral Load Test F-4 at depth=7ft 


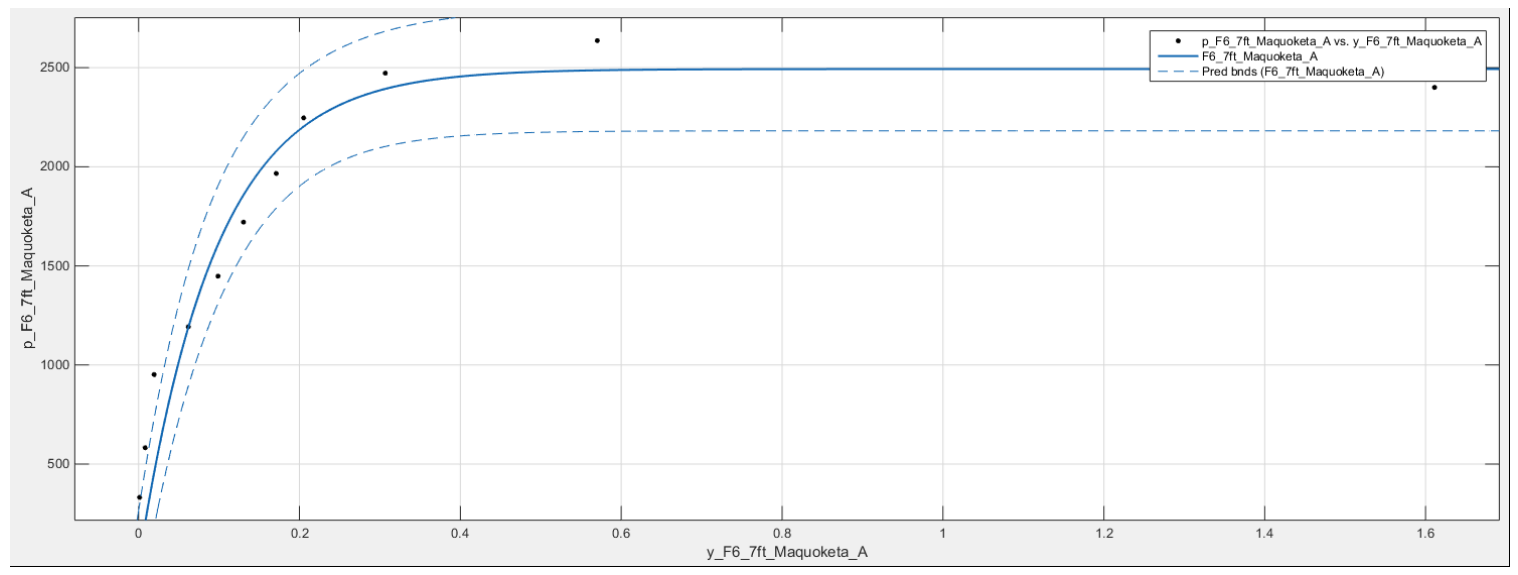

Interpreted p-y Responses and Fitted p-y curves for Lateral Load Test F-6 at depth=7ft

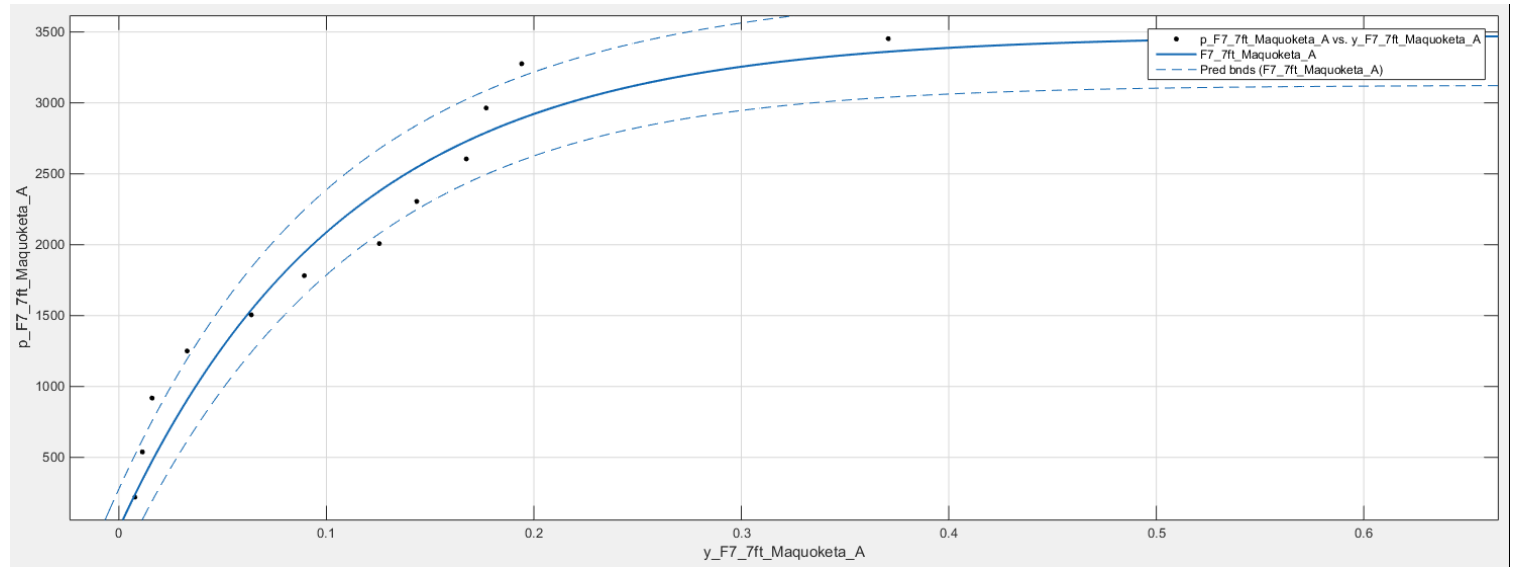

Interpreted $\mathrm{p}$-y Responses and Fitted $\mathrm{p}$-y curves for Lateral Load Test F-7 at depth=7ft

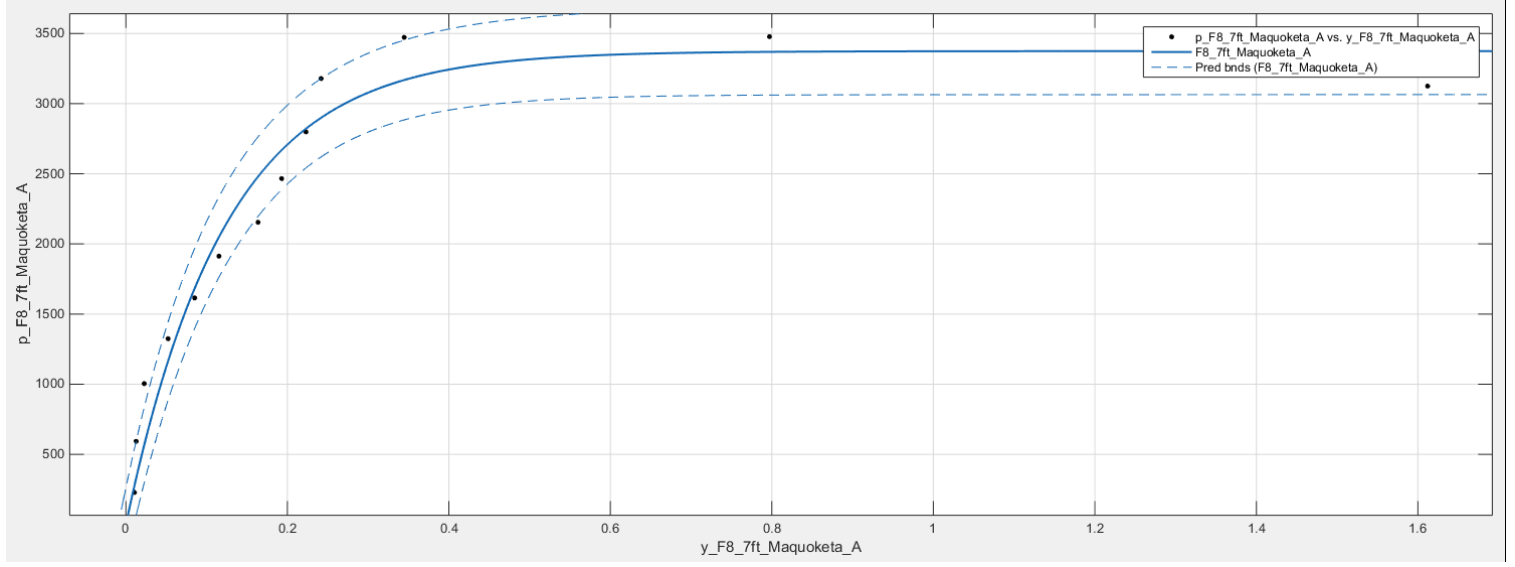

Interpreted p-y Responses and Fitted p-y curves for Lateral Load Test F-8 at depth=7ft 


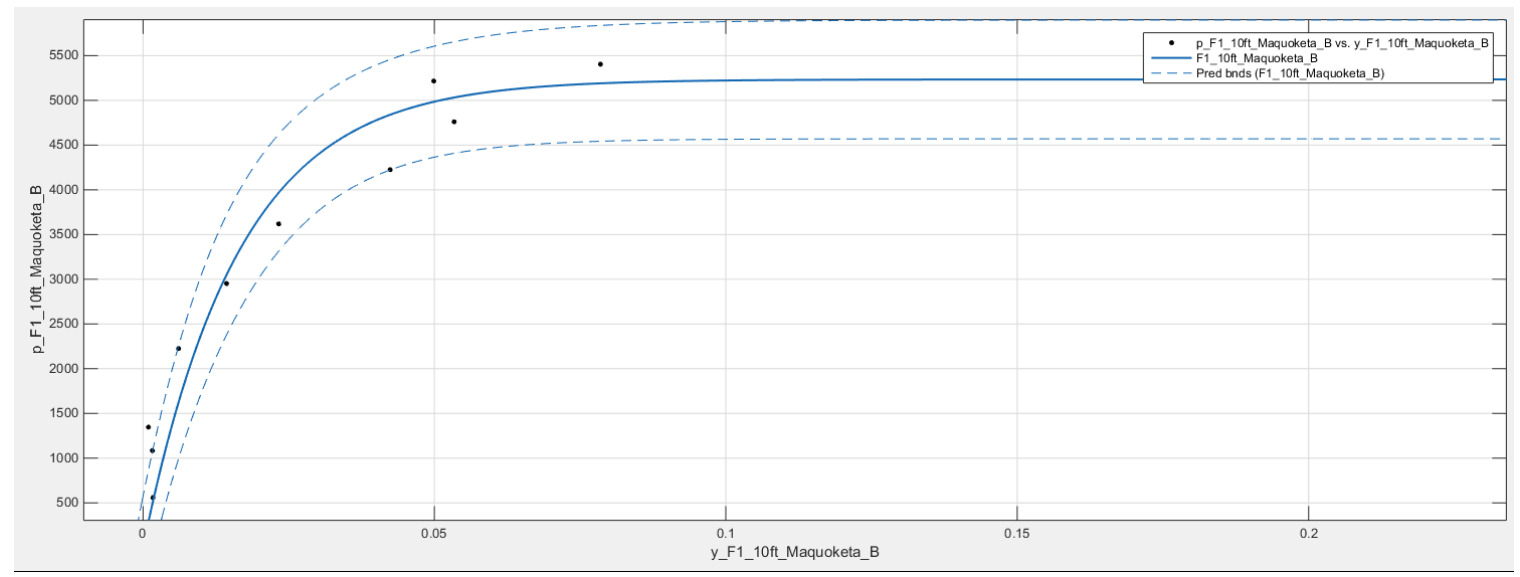

Interpreted p-y Responses and Fitted $p-y$ curves for Lateral Load Test F-1 at depth=10ft

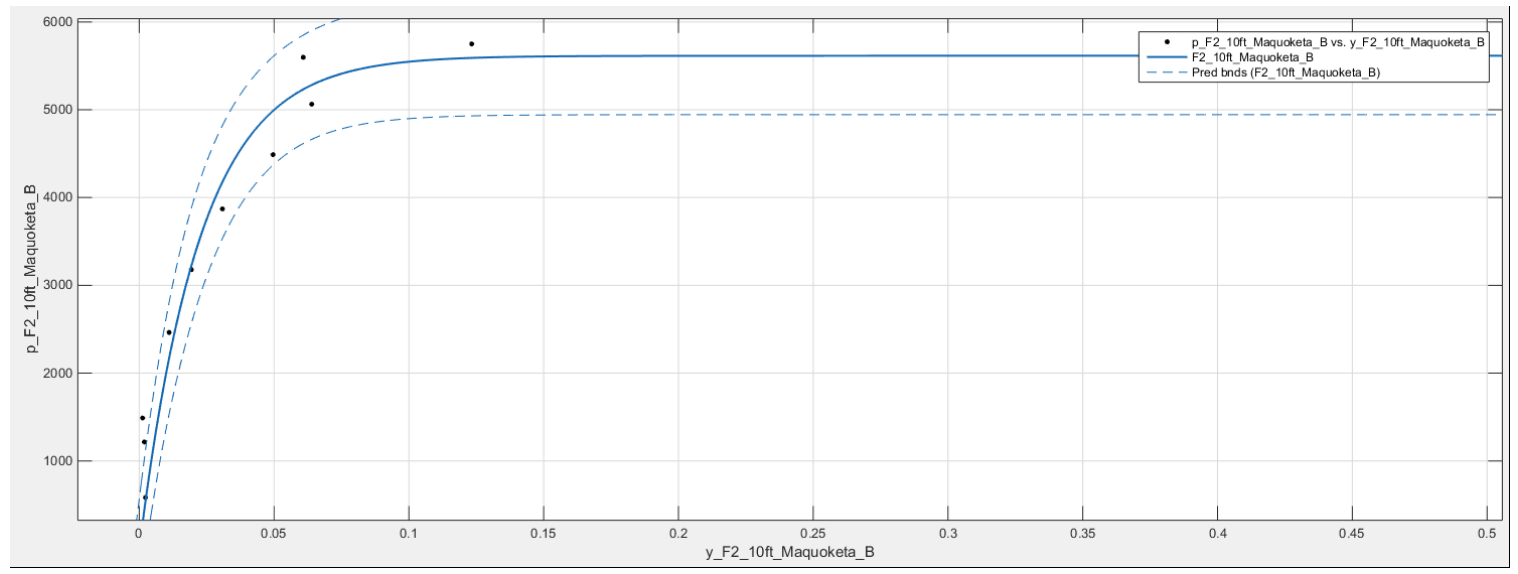

Interpreted p-y Responses and Fitted p-y curves for Lateral Load Test F-2 at depth=10ft

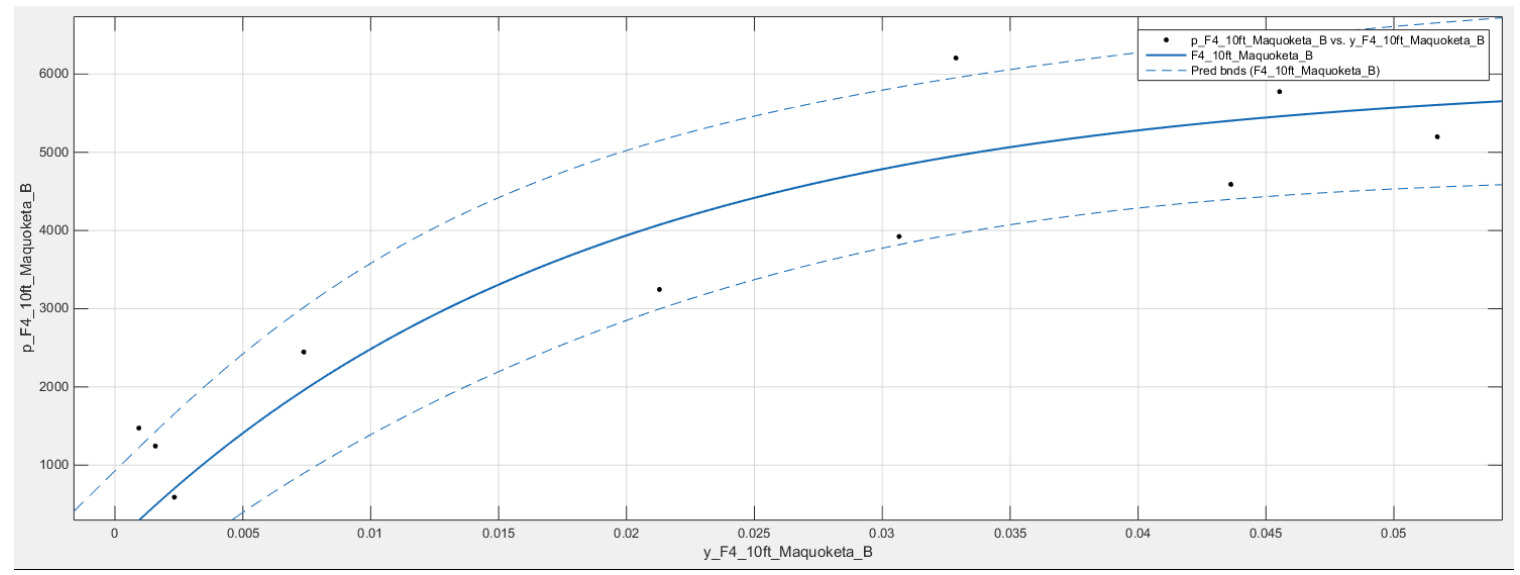

Interpreted p-y Responses and Fitted p-y curves for Lateral Load Test F-4 at depth=10ft 


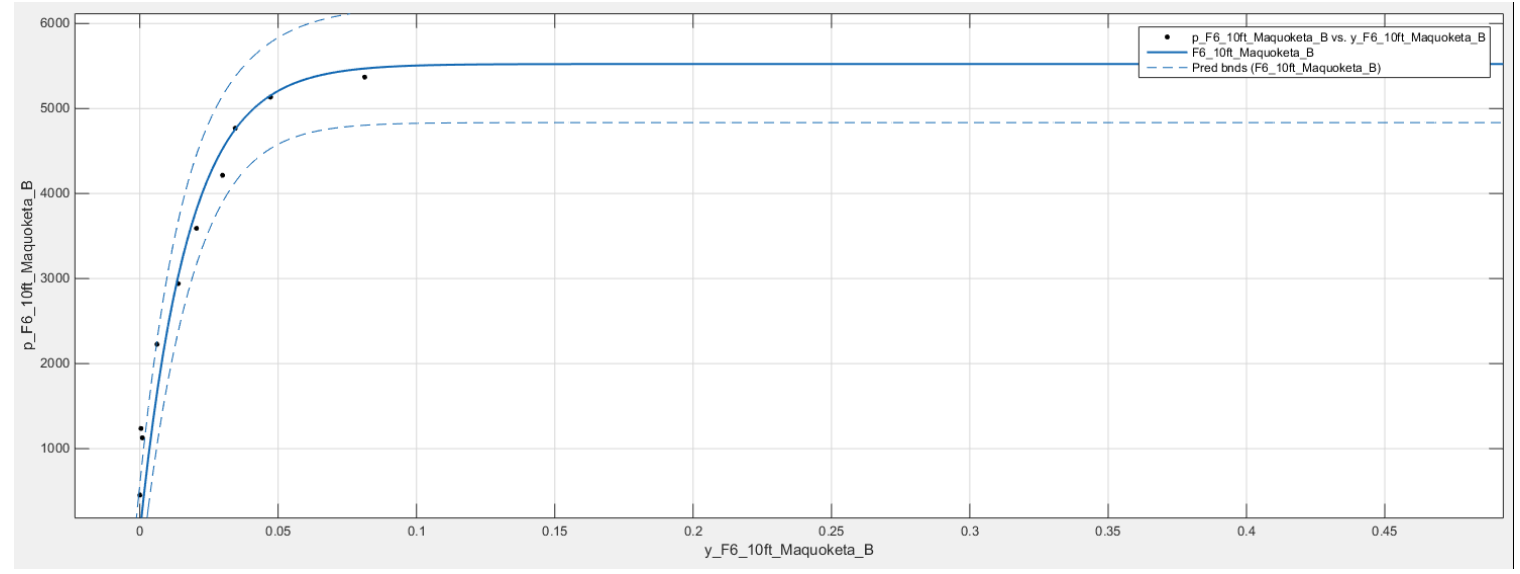

Interpreted p-y Responses and Fitted p-y curves for Lateral Load Test F- 6 at depth=10ft

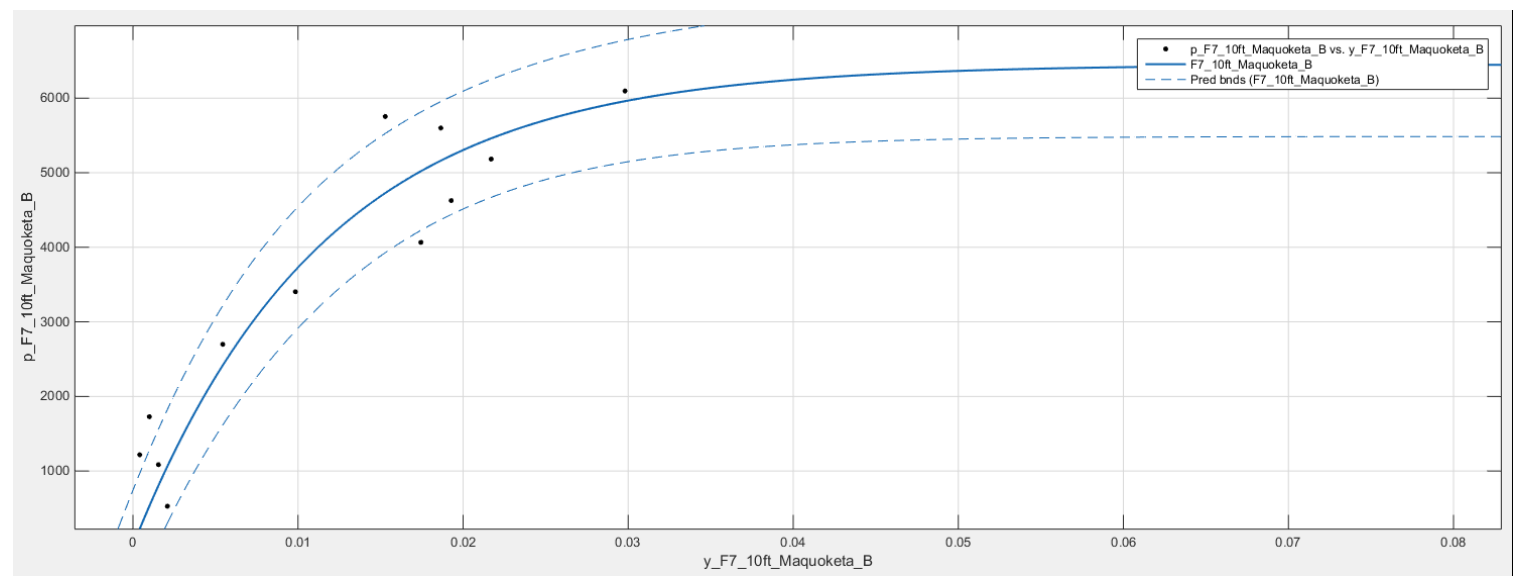

Interpreted p-y Responses and Fitted $p-y$ curves for Lateral Load Test F-7 at depth=10ft

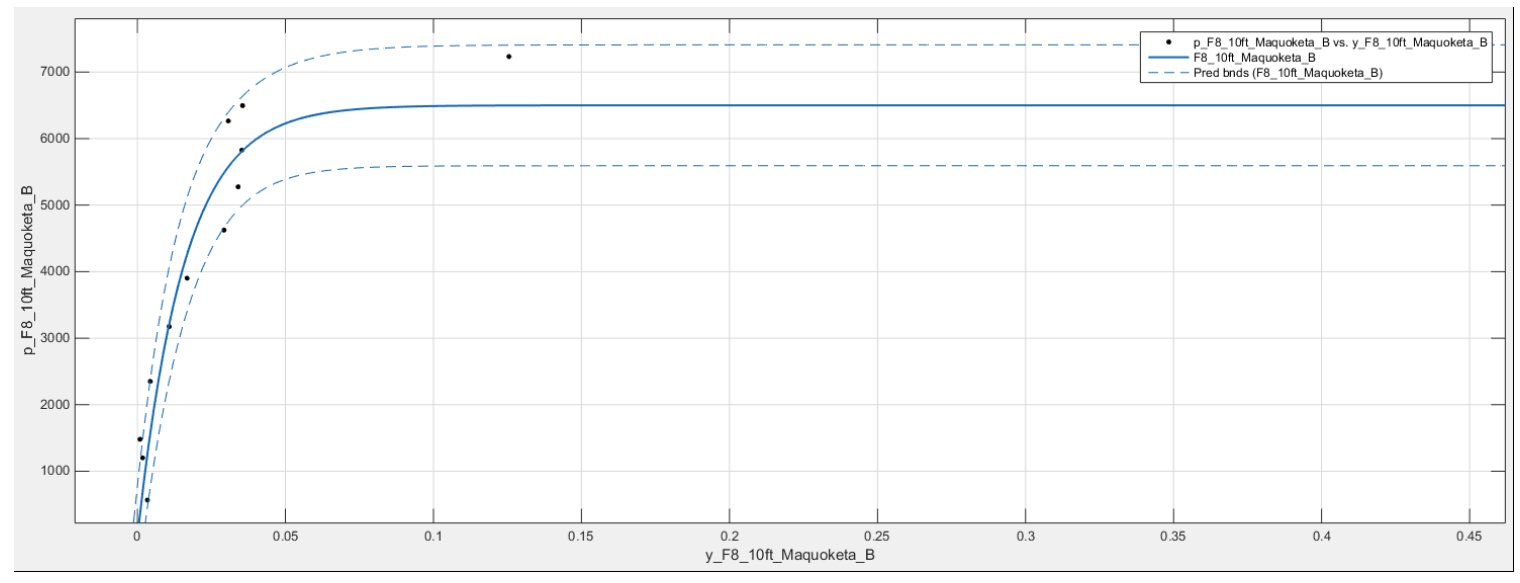

Interpreted p-y Responses and Fitted p-y curves for Lateral Load Test F-8 at depth=10ft 


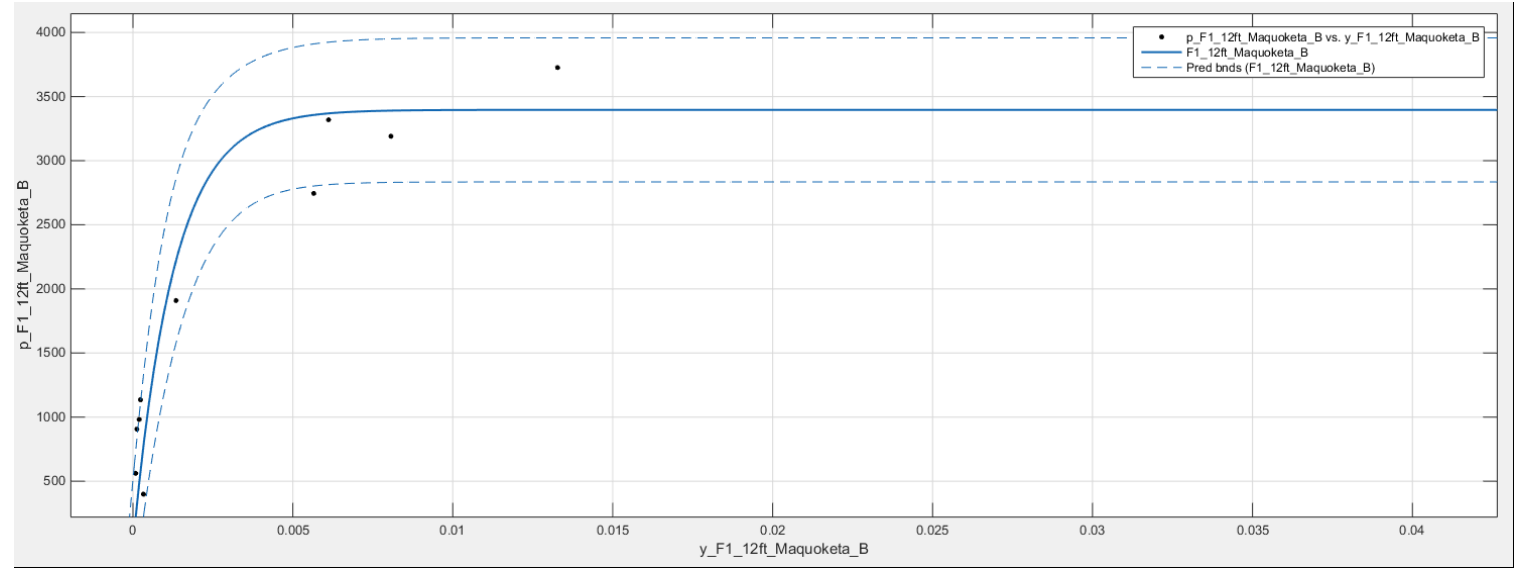

Interpreted p-y Responses and Fitted p-y curves for Lateral Load Test F-1 at depth=12ft

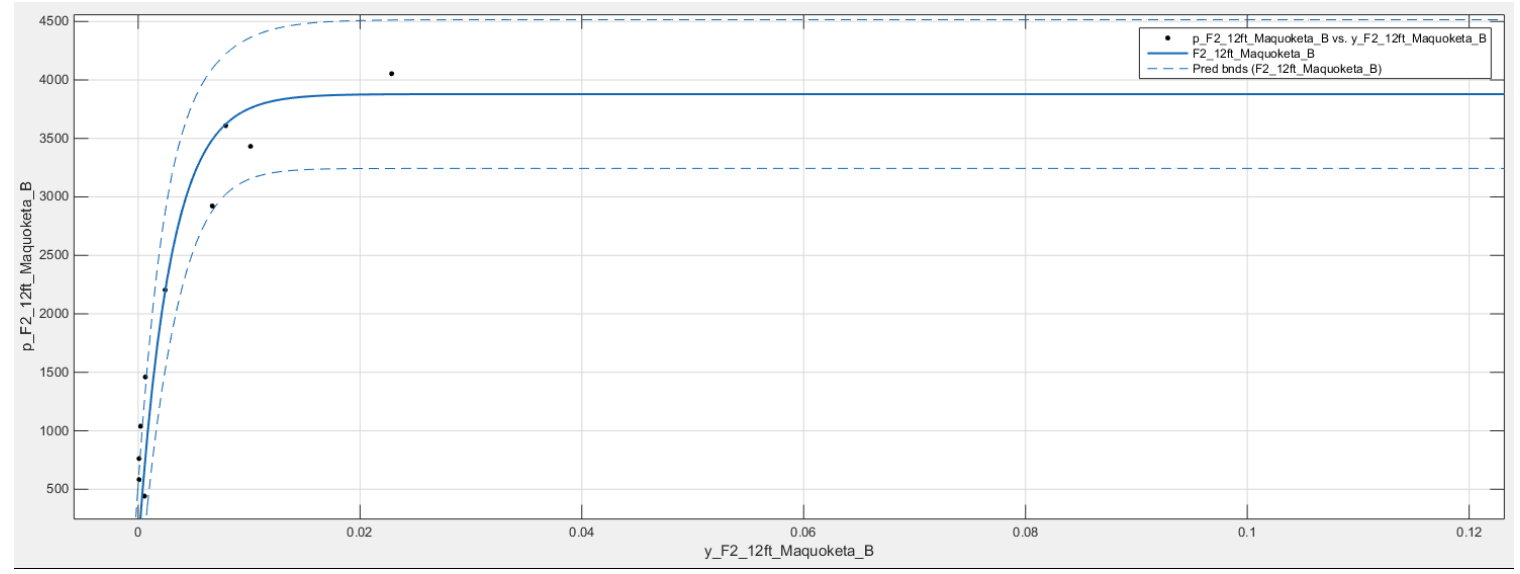

Interpreted $\mathrm{p}-\mathrm{y}$ Responses and Fitted $\mathrm{p}-\mathrm{y}$ curves for Lateral Load Test F- 2 at depth=12ft

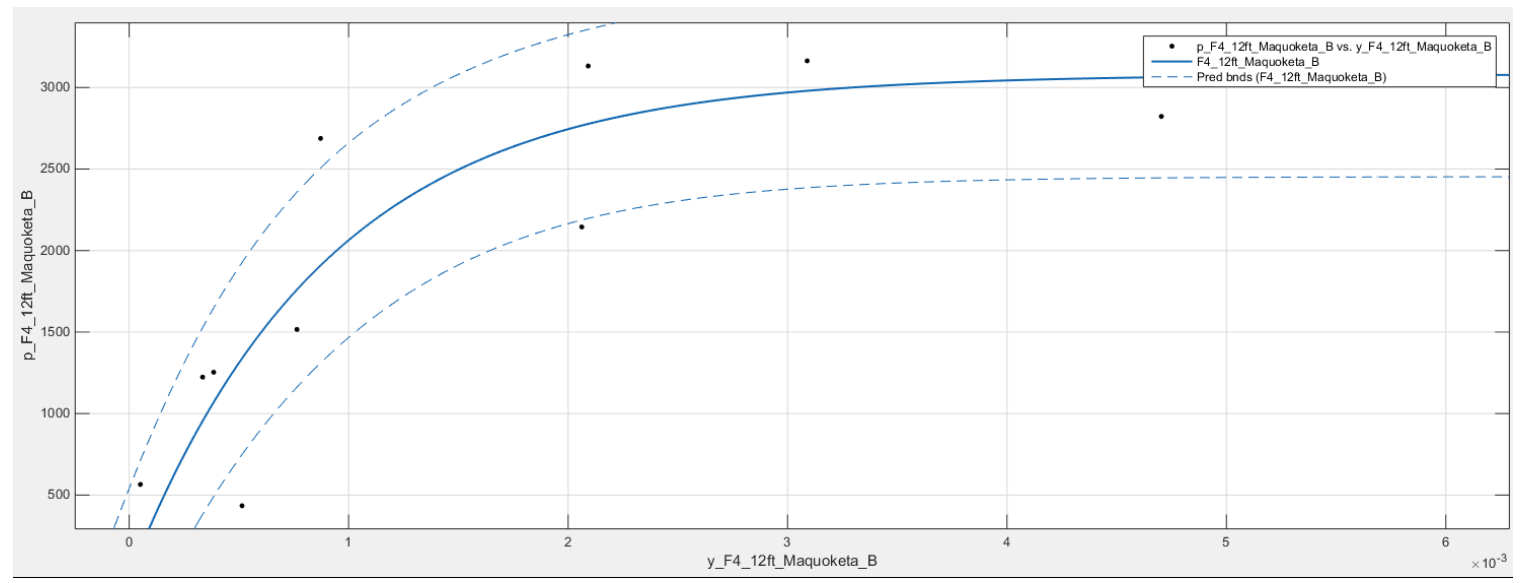

Interpreted p-y Responses and Fitted p-y curves for Lateral Load Test F-4 at depth=12ft 


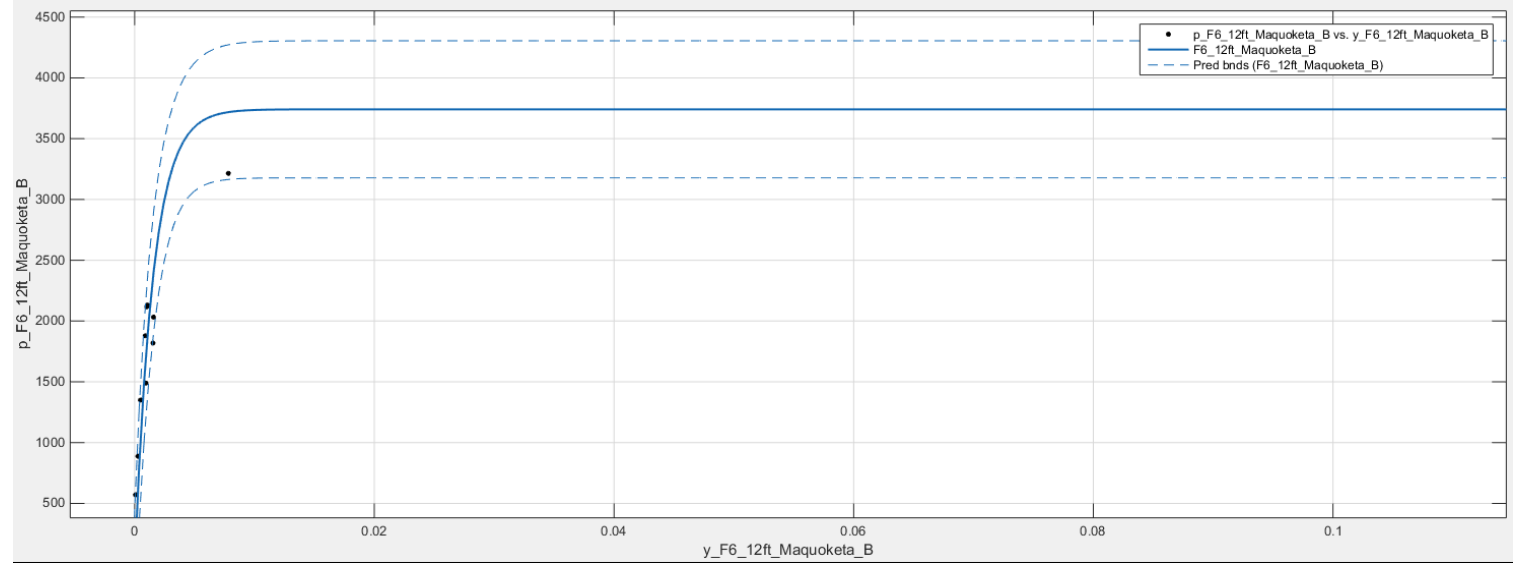

Interpreted p-y Responses and Fitted p-y curves for Lateral Load Test F- 6 at depth $=12 \mathrm{ft}$

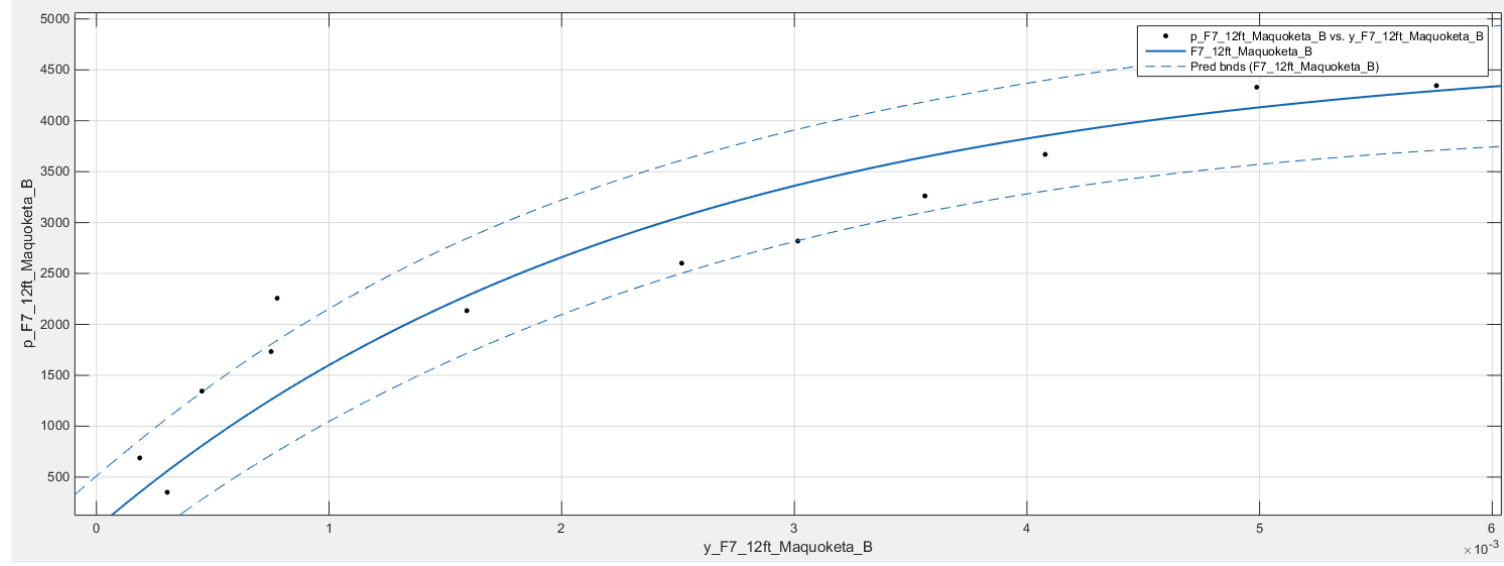

Interpreted $\mathrm{p}-\mathrm{y}$ Responses and Fitted $\mathrm{p}-\mathrm{y}$ curves for Lateral Load Test F-7 at depth=12ft

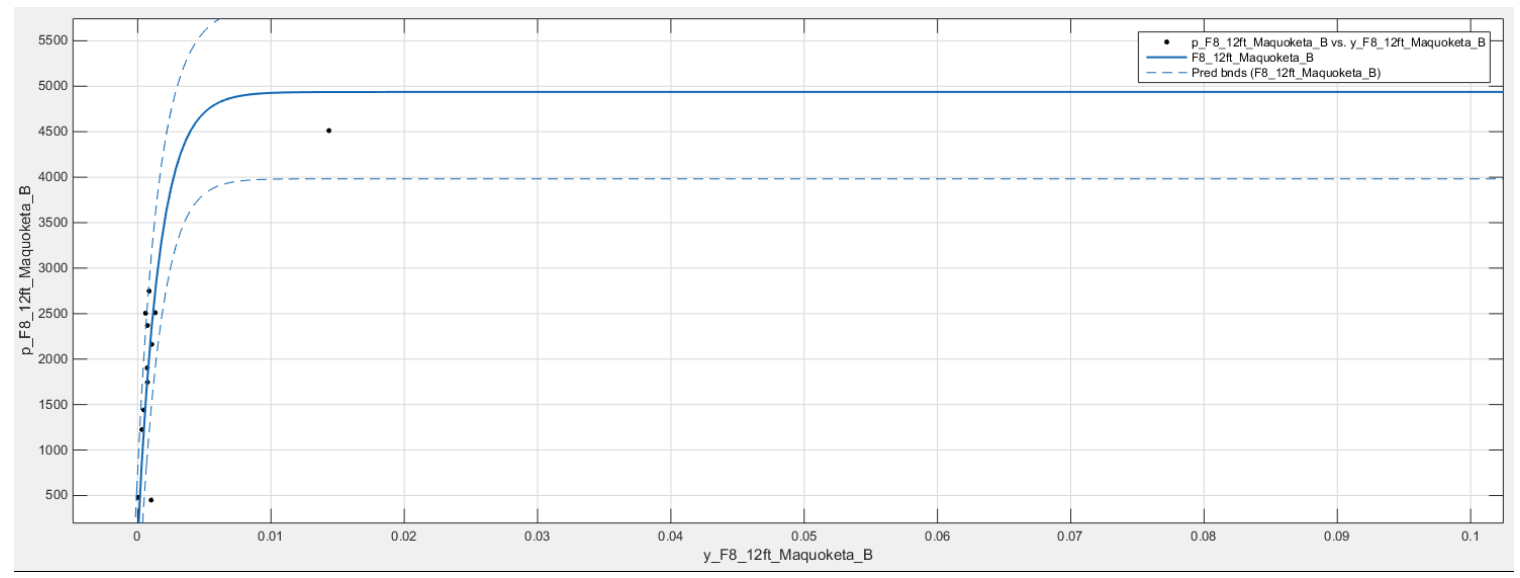

Interpreted $\mathrm{p}$-y Responses and Fitted $\mathrm{p}-\mathrm{y}$ curves for Lateral Load Test F- 8 at depth $=12 \mathrm{ft}$ 


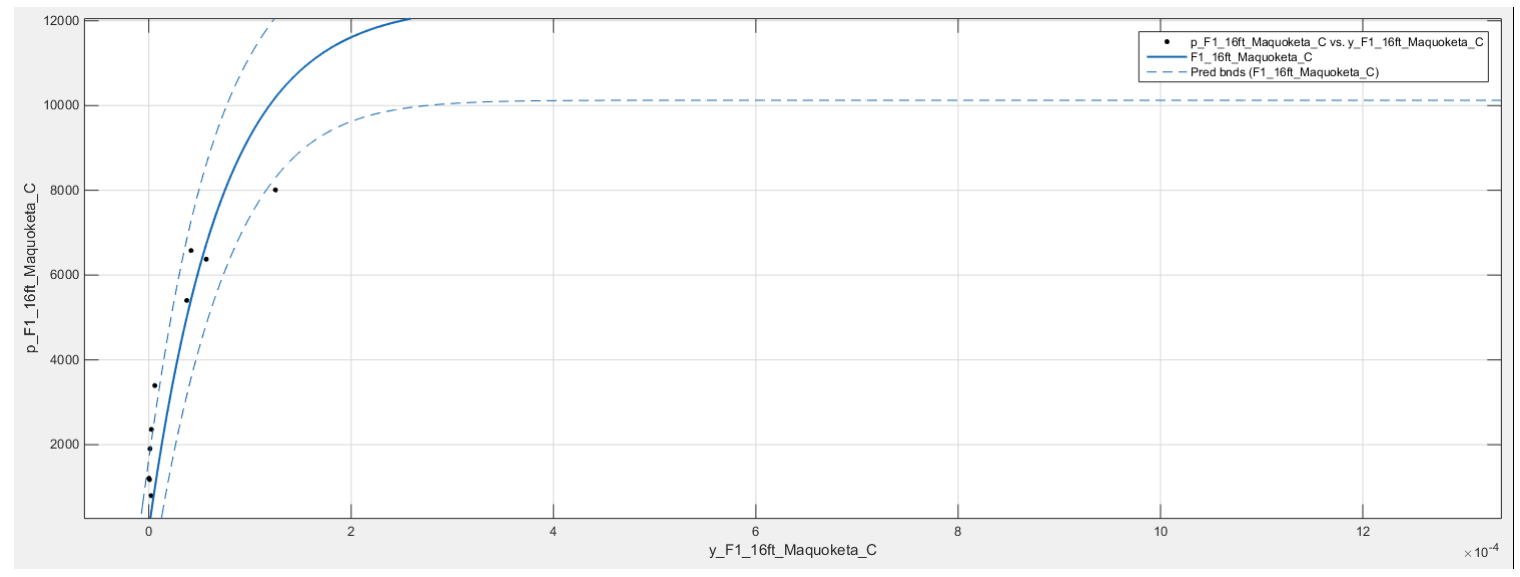

Interpreted p-y Responses and Fitted p-y curves for Lateral Load Test F-1 at depth=16ft

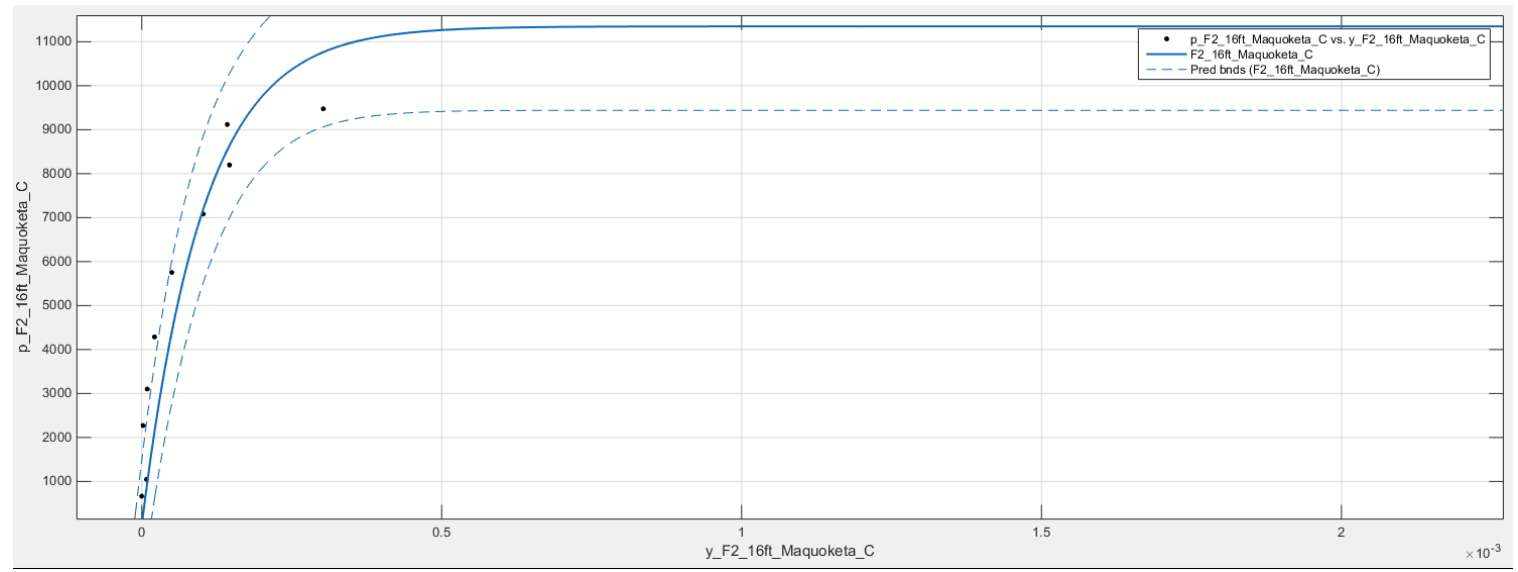

Interpreted $\mathrm{p}-\mathrm{y}$ Responses and Fitted $\mathrm{p}-\mathrm{y}$ curves for Lateral Load Test F- 2 at depth $=16 \mathrm{ft}$

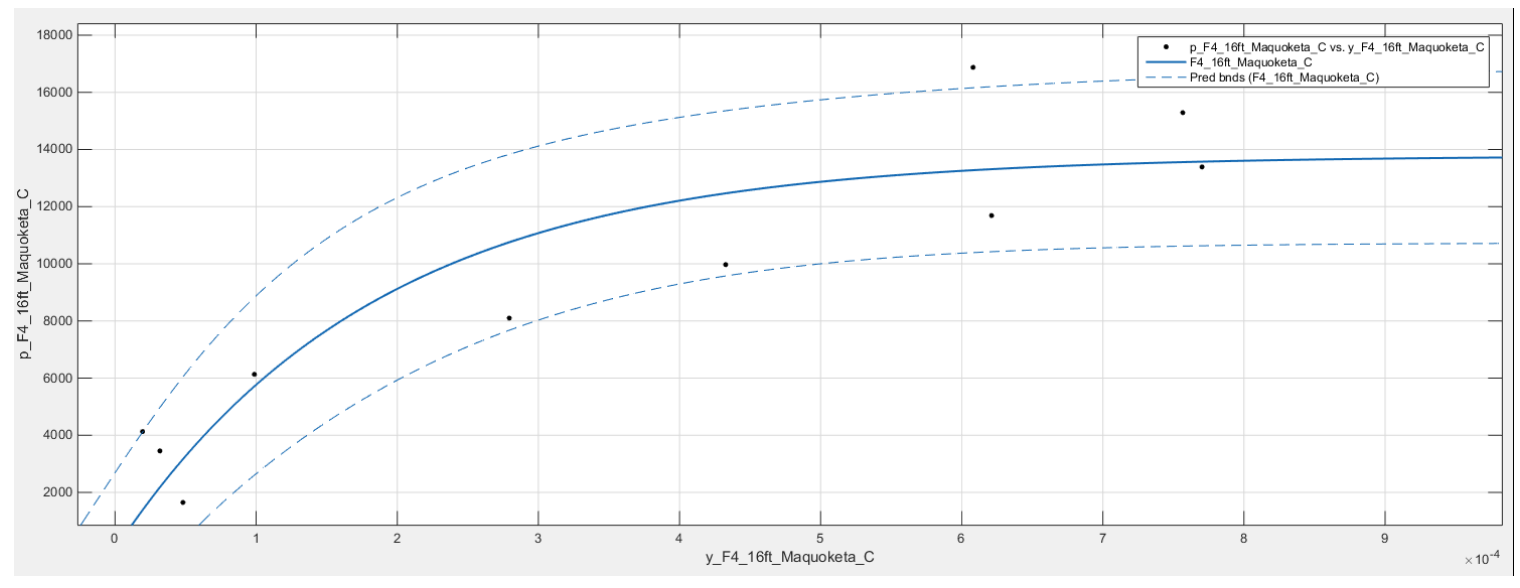

Interpreted p-y Responses and Fitted $p-y$ curves for Lateral Load Test F-4 at depth=16ft 


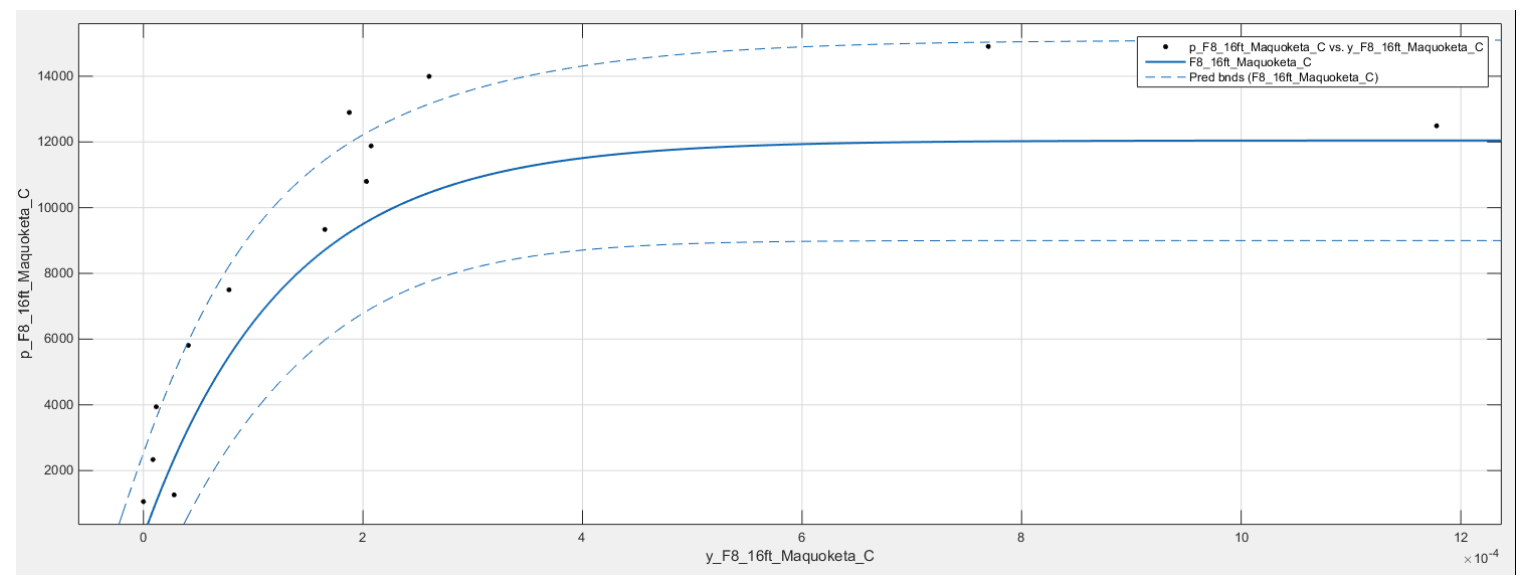

Interpreted p-y Responses and Fitted p-y curves for Lateral Load Test F-8 at depth=16ft

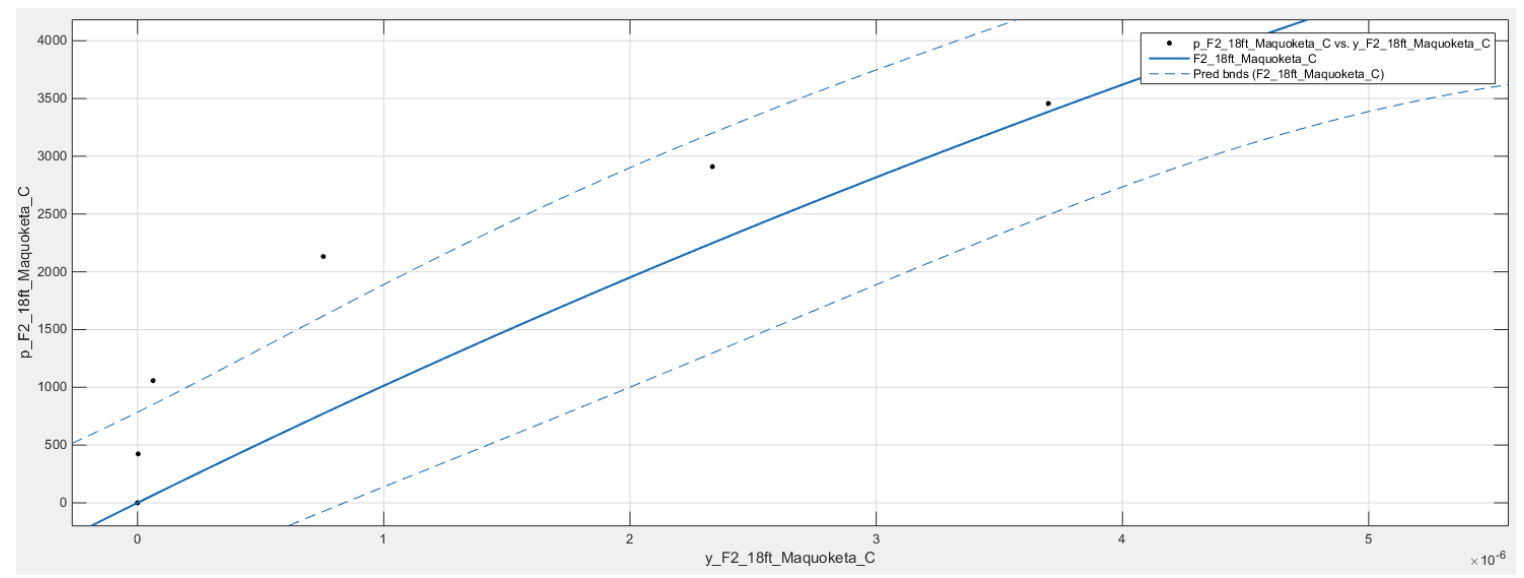

Interpreted p-y Responses and Fitted p-y curves for Lateral Load Test F-2 at depth=18ft

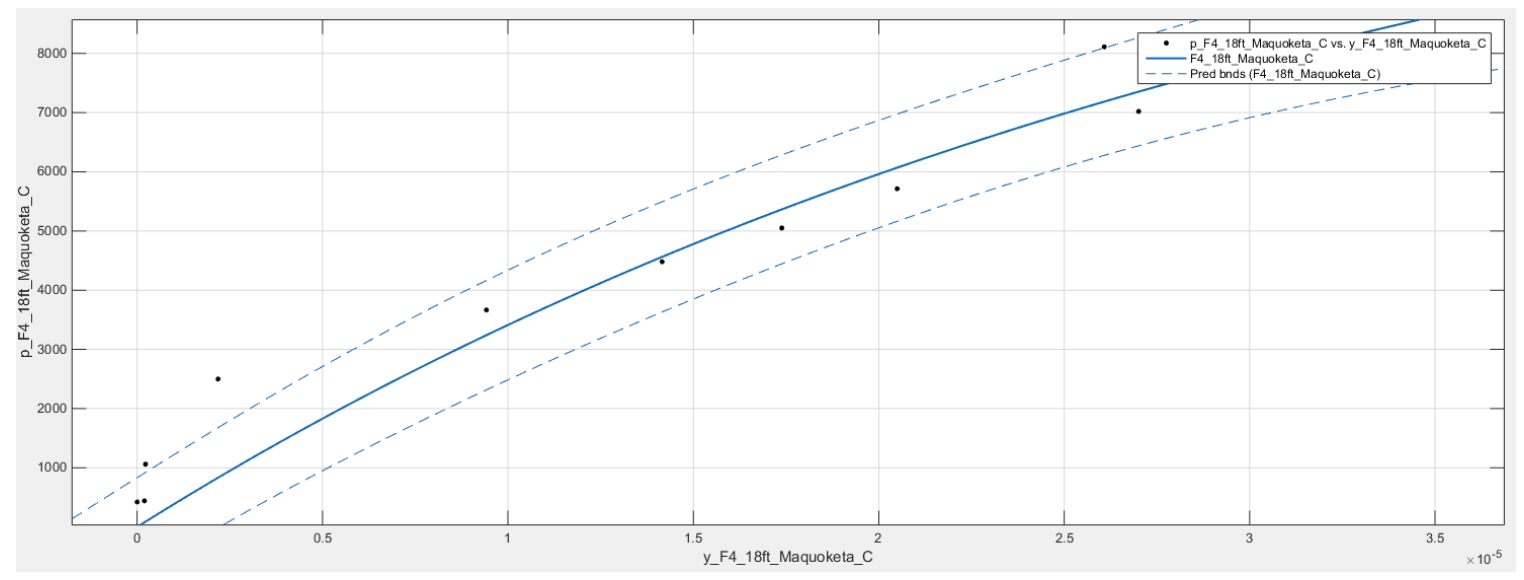

Interpreted $p-y$ Responses and Fitted $p-y$ curves for Lateral Load Test F-4 at depth=18ft 


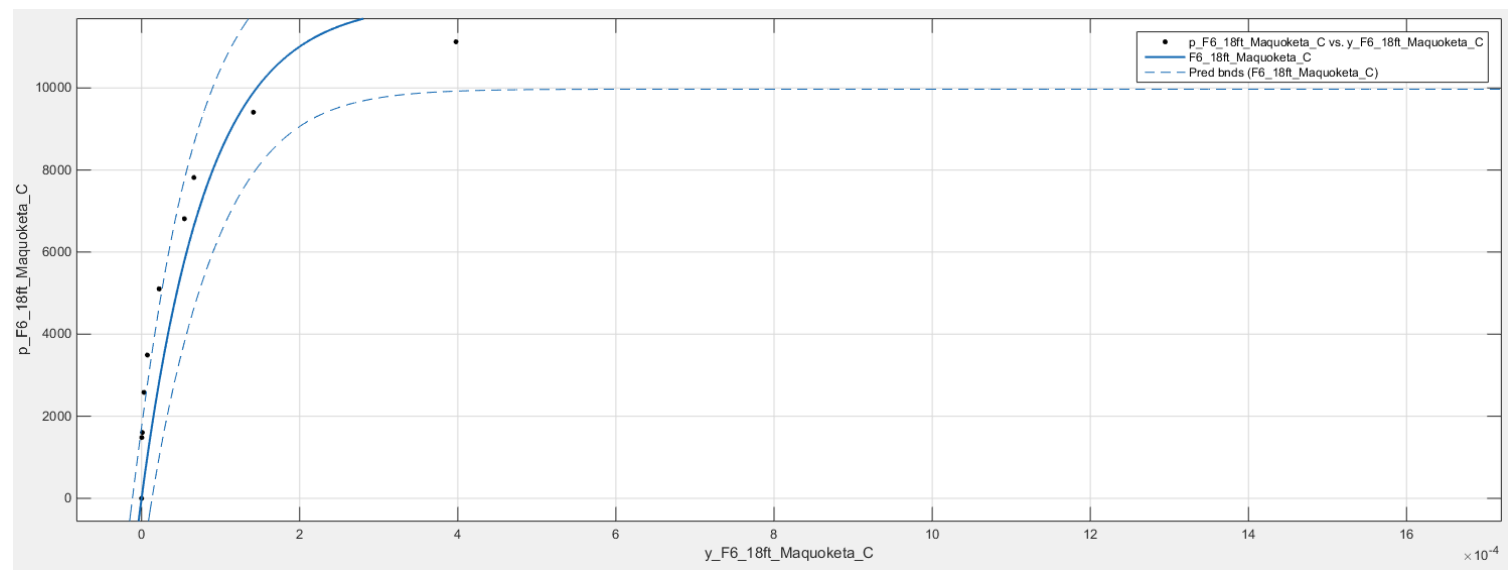

Interpreted $\mathrm{p}-\mathrm{y}$ Responses and Fitted $\mathrm{p}-\mathrm{y}$ curves for Lateral Load Test F- 6 at depth $=18 \mathrm{ft}$

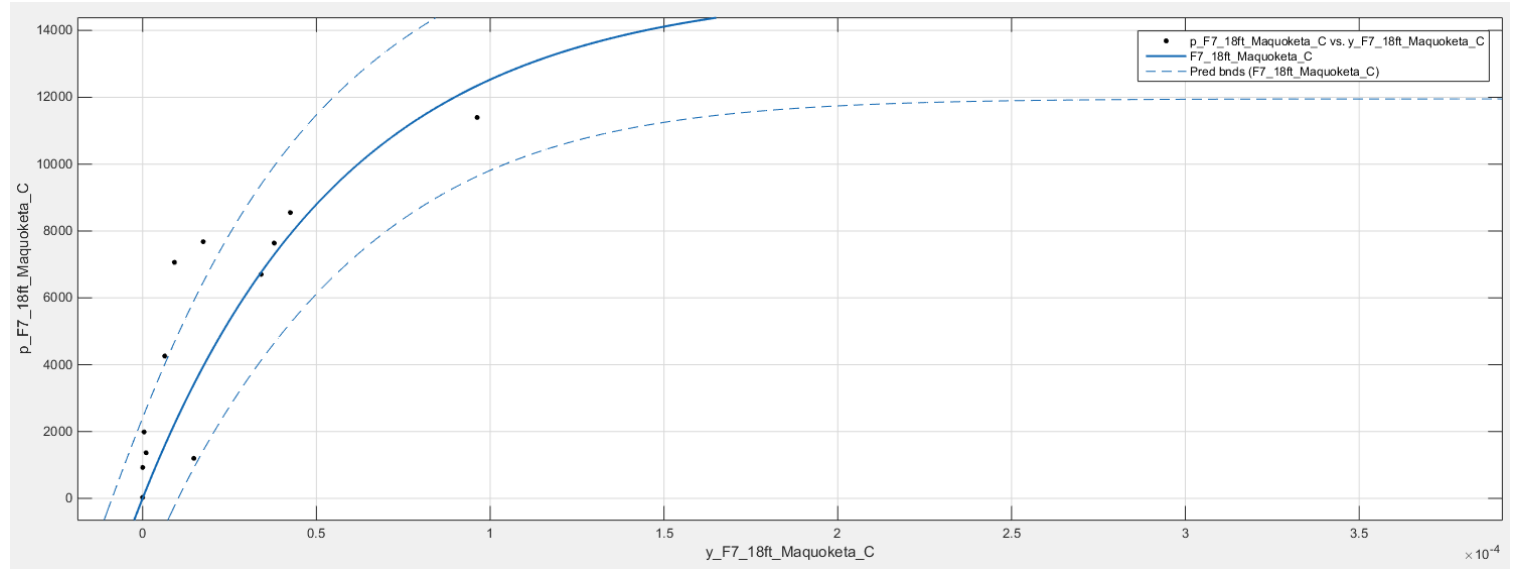

Interpreted $\mathrm{p}-\mathrm{y}$ Responses and Fitted $\mathrm{p}-\mathrm{y}$ curves for Lateral Load Test F-7 at depth $=18 \mathrm{ft}$

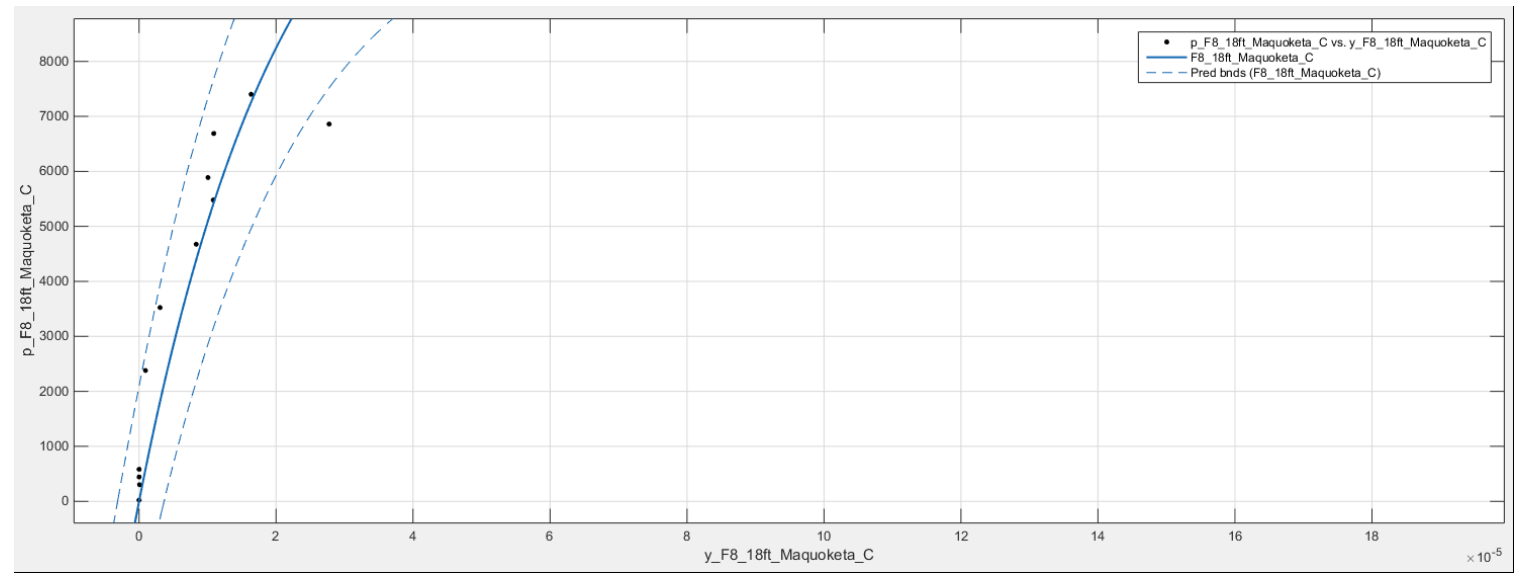

Interpreted $\mathrm{p}-\mathrm{y}$ Responses and Fitted $\mathrm{p}-\mathrm{y}$ curves for Lateral Load Test F-8 at depth $=18 \mathrm{ft}$ 


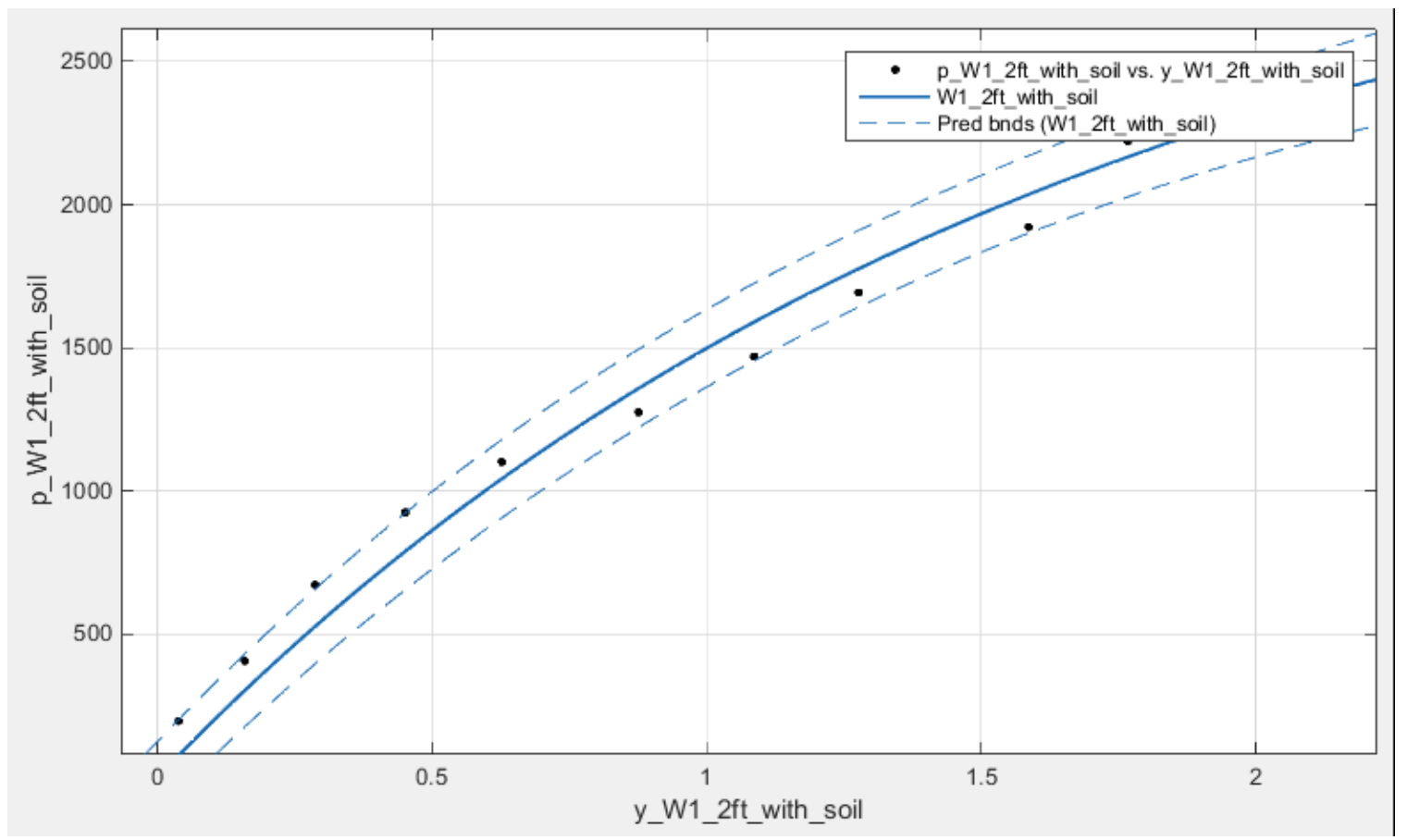

Interpreted $\mathrm{p}-\mathrm{y}$ Responses and Fitted $\mathrm{p}-\mathrm{y}$ curves for Lateral Load Test $\mathrm{W}-1$ at depth= $2 \mathrm{ft}$

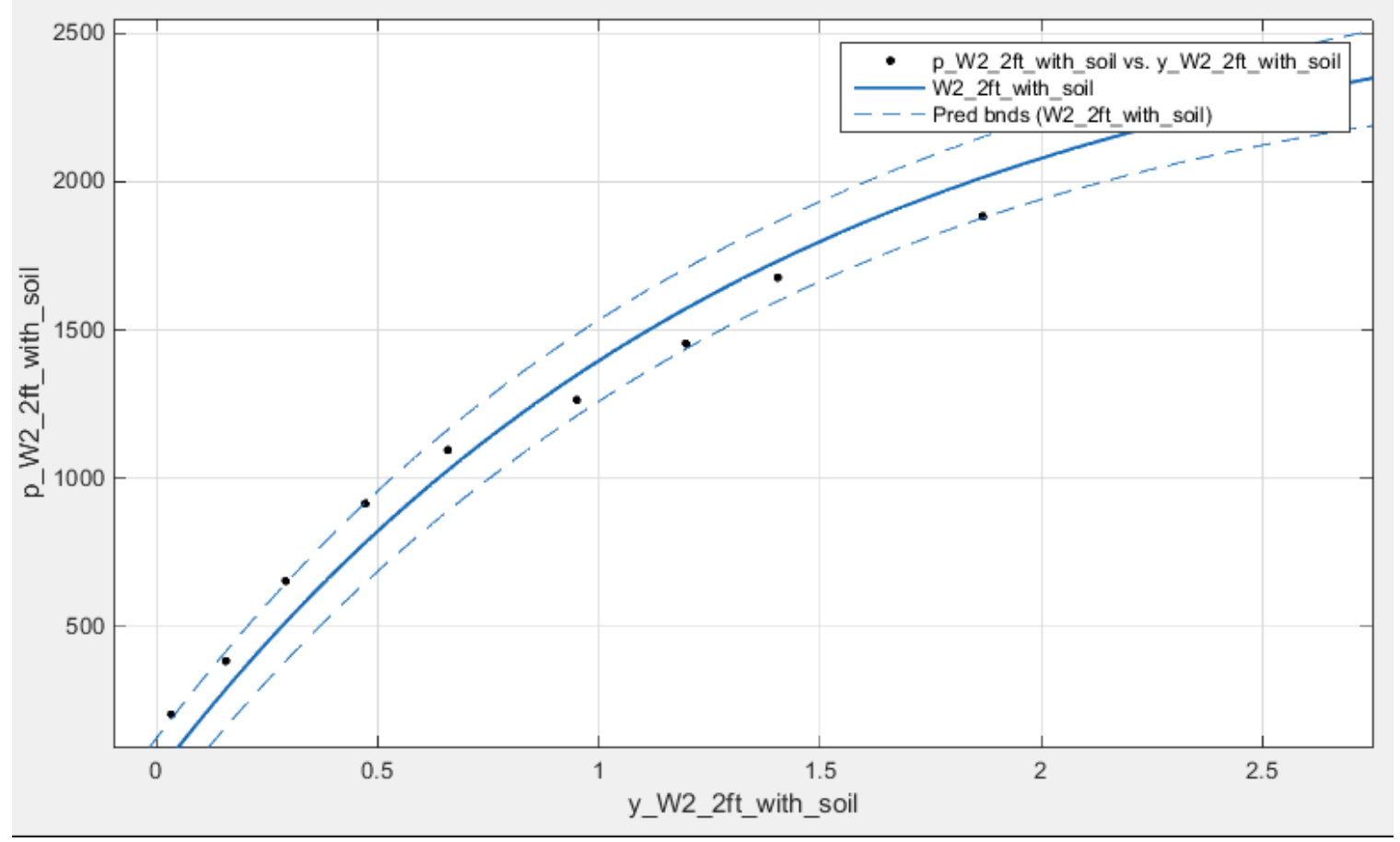

Interpreted $p-y$ Responses and Fitted $p-y$ curves for Lateral Load Test $\mathrm{W}-2$ at depth= $2 \mathrm{ft}$ 


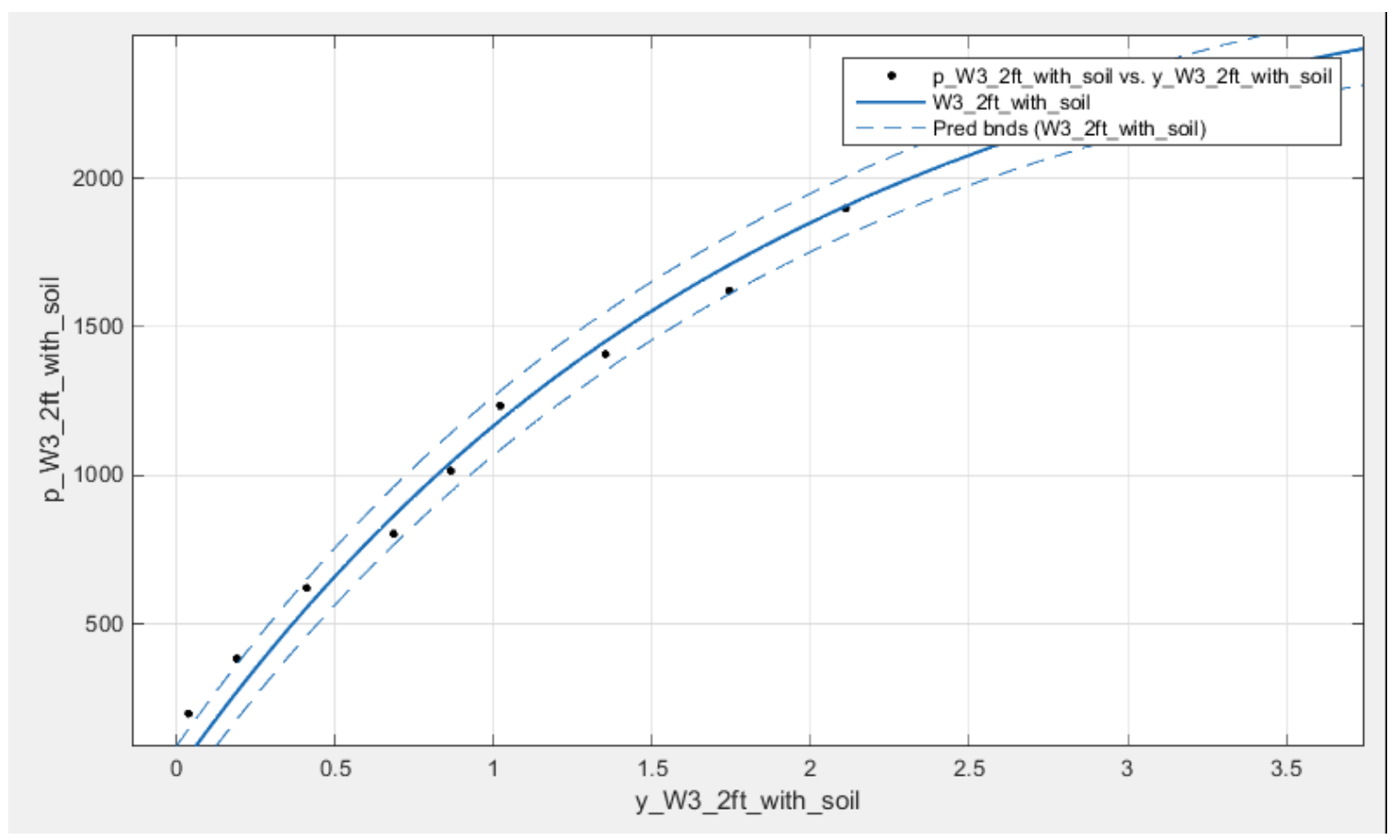

Interpreted $\mathrm{p}-\mathrm{y}$ Responses and Fitted $\mathrm{p}-\mathrm{y}$ curves for Lateral Load Test $\mathrm{W}-3$ at depth=2ft

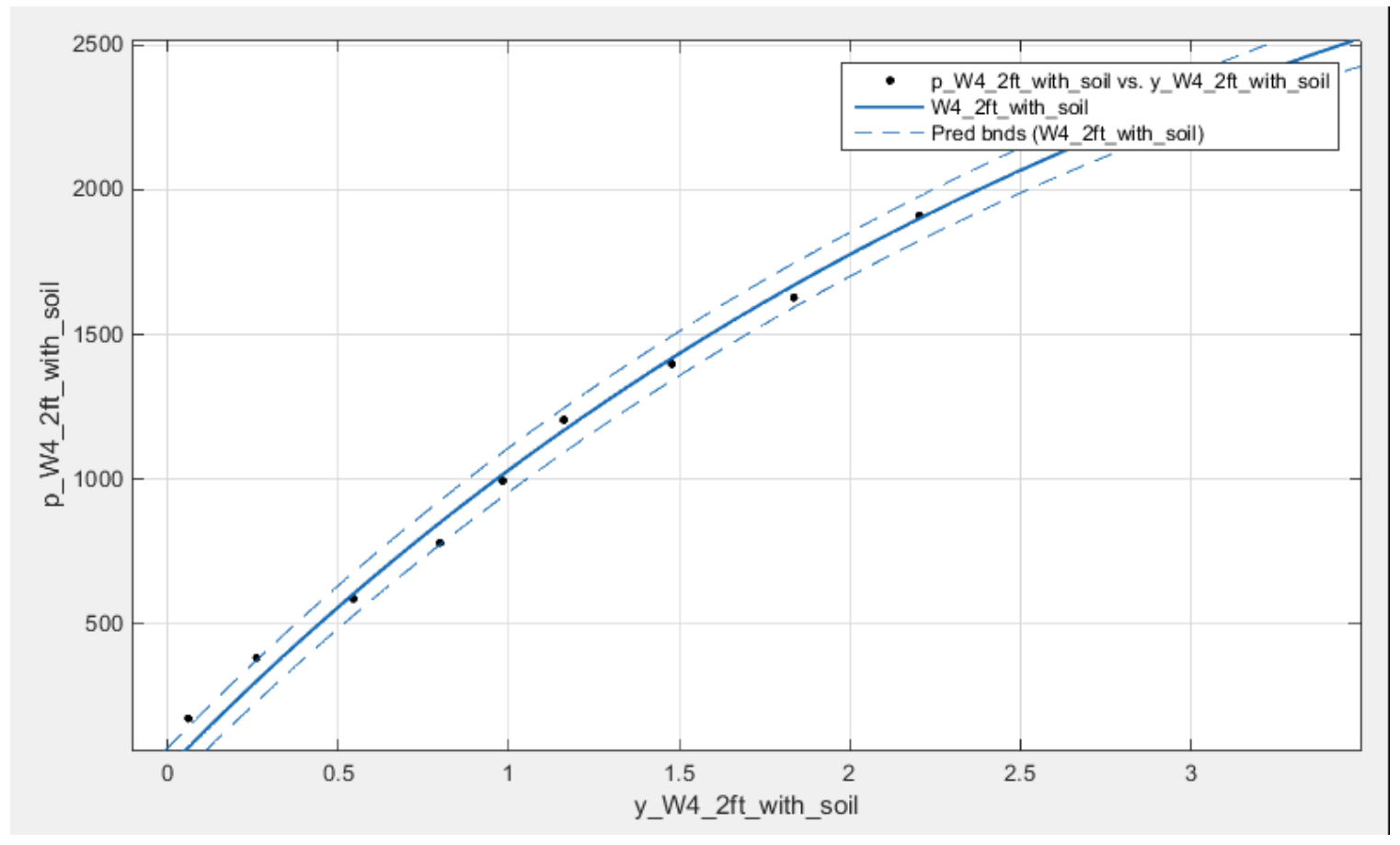

Interpreted p-y Responses and Fitted p-y curves for Lateral Load Test W-4 at depth=2ft 


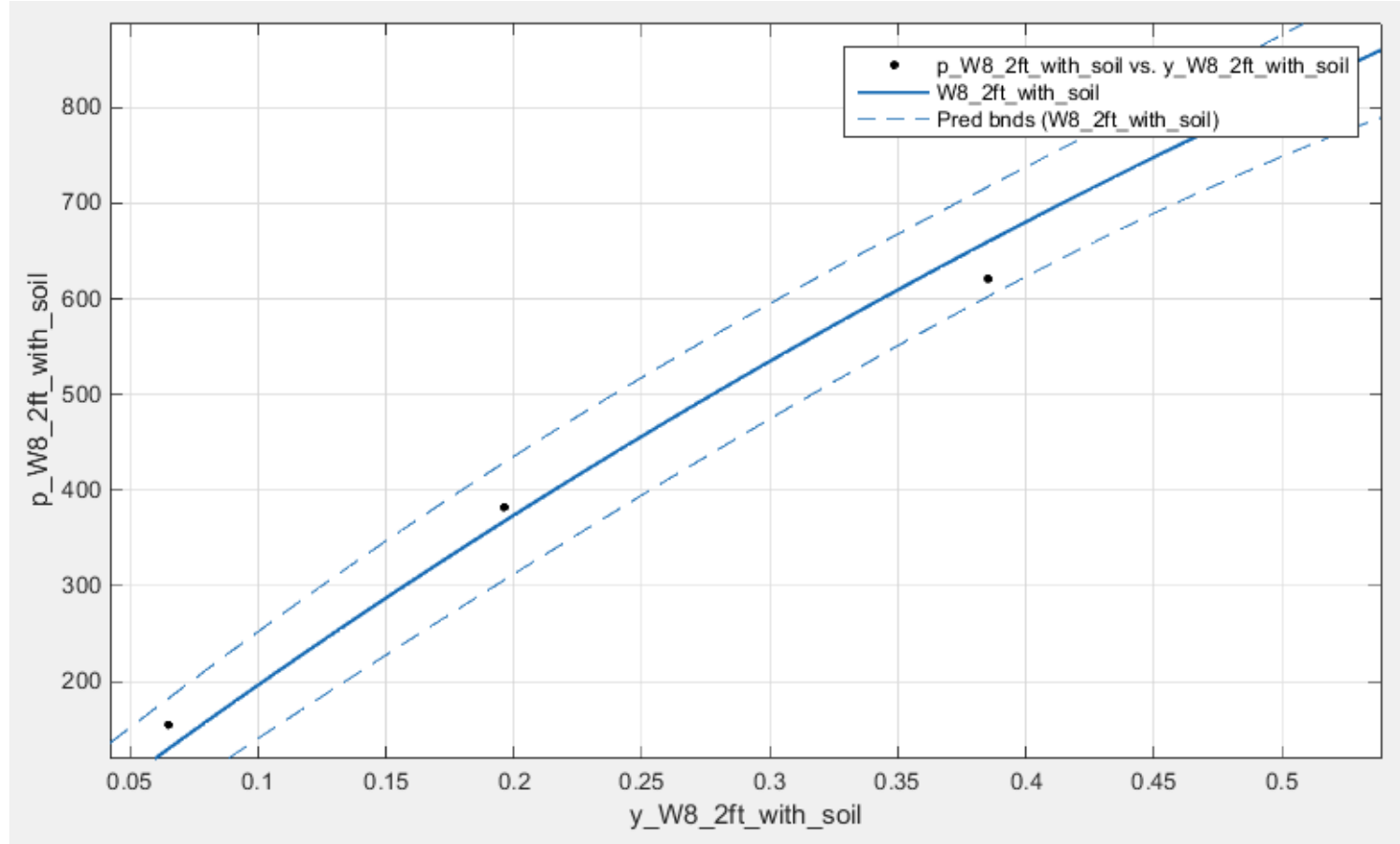

Interpreted $\mathrm{p}-\mathrm{y}$ Responses and Fitted $\mathrm{p}-\mathrm{y}$ curves for Lateral Load Test $\mathrm{W}-8$ at depth=2ft

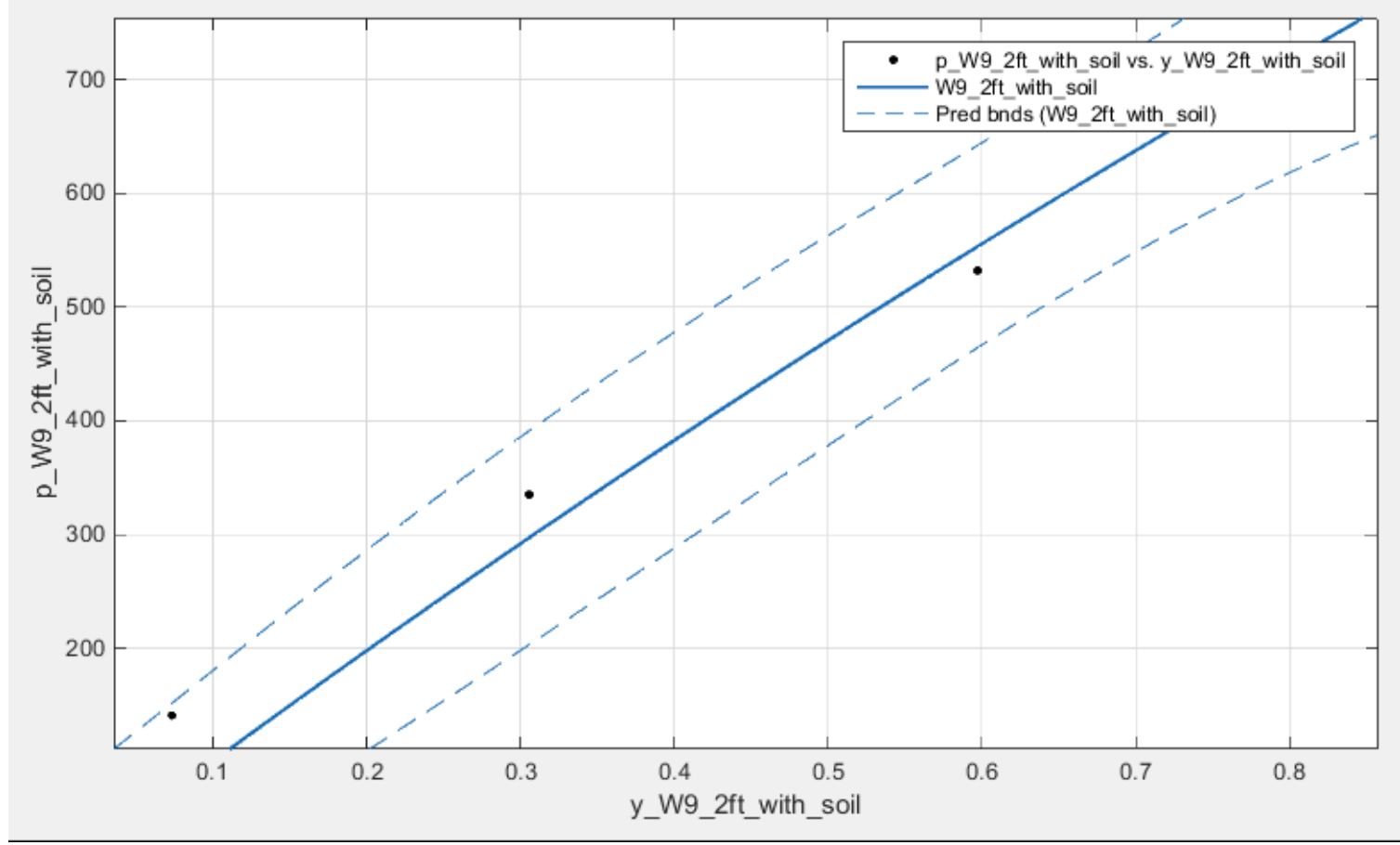

Interpreted $\mathrm{p}-\mathrm{y}$ Responses and Fitted $\mathrm{p}-\mathrm{y}$ curves for Lateral Load Test $\mathrm{W}-9$ at depth=2ft 


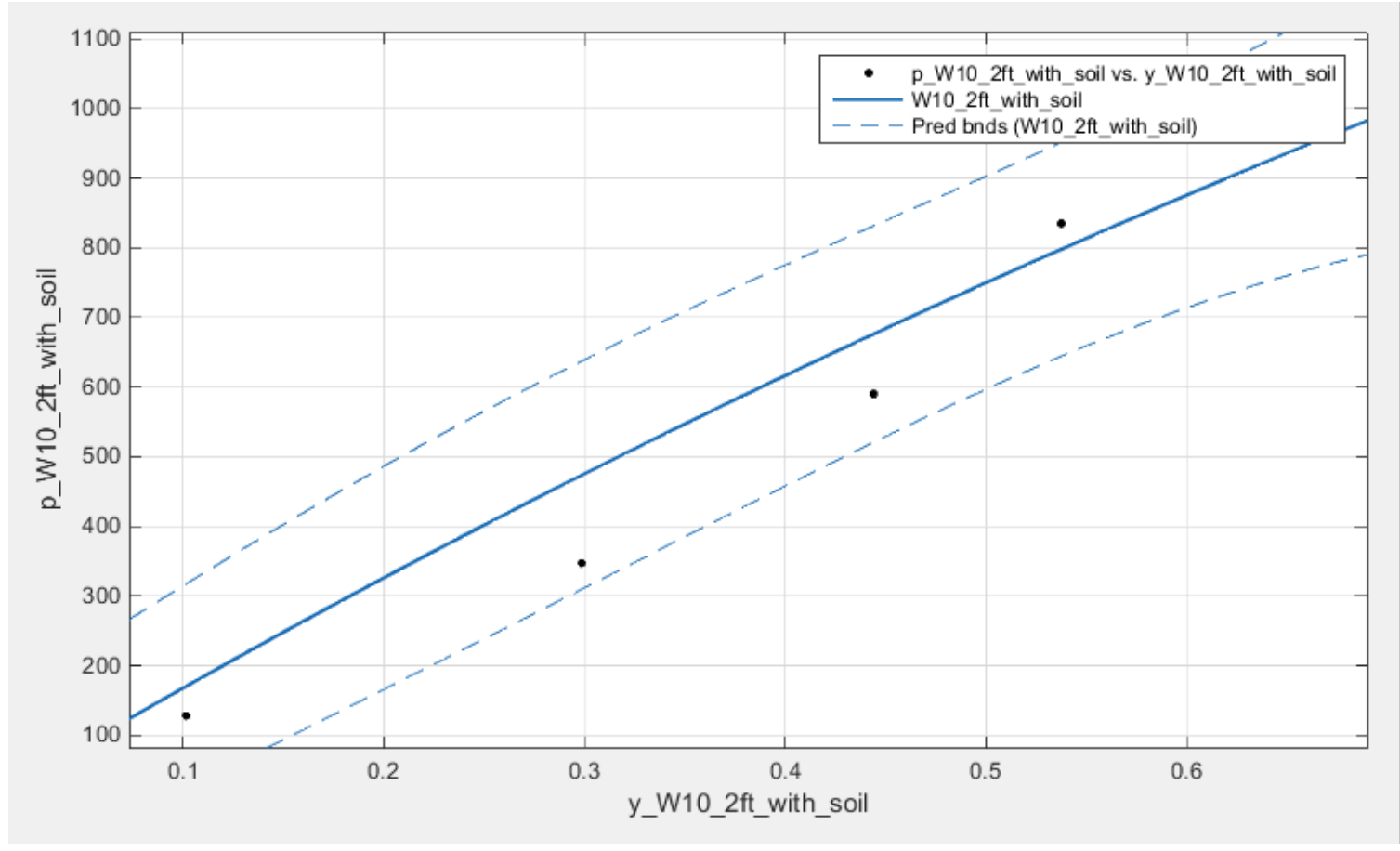

Interpreted $\mathrm{p}-\mathrm{y}$ Responses and Fitted $\mathrm{p}-\mathrm{y}$ curves for Lateral Load Test $\mathrm{W}-10$ at depth=2ft

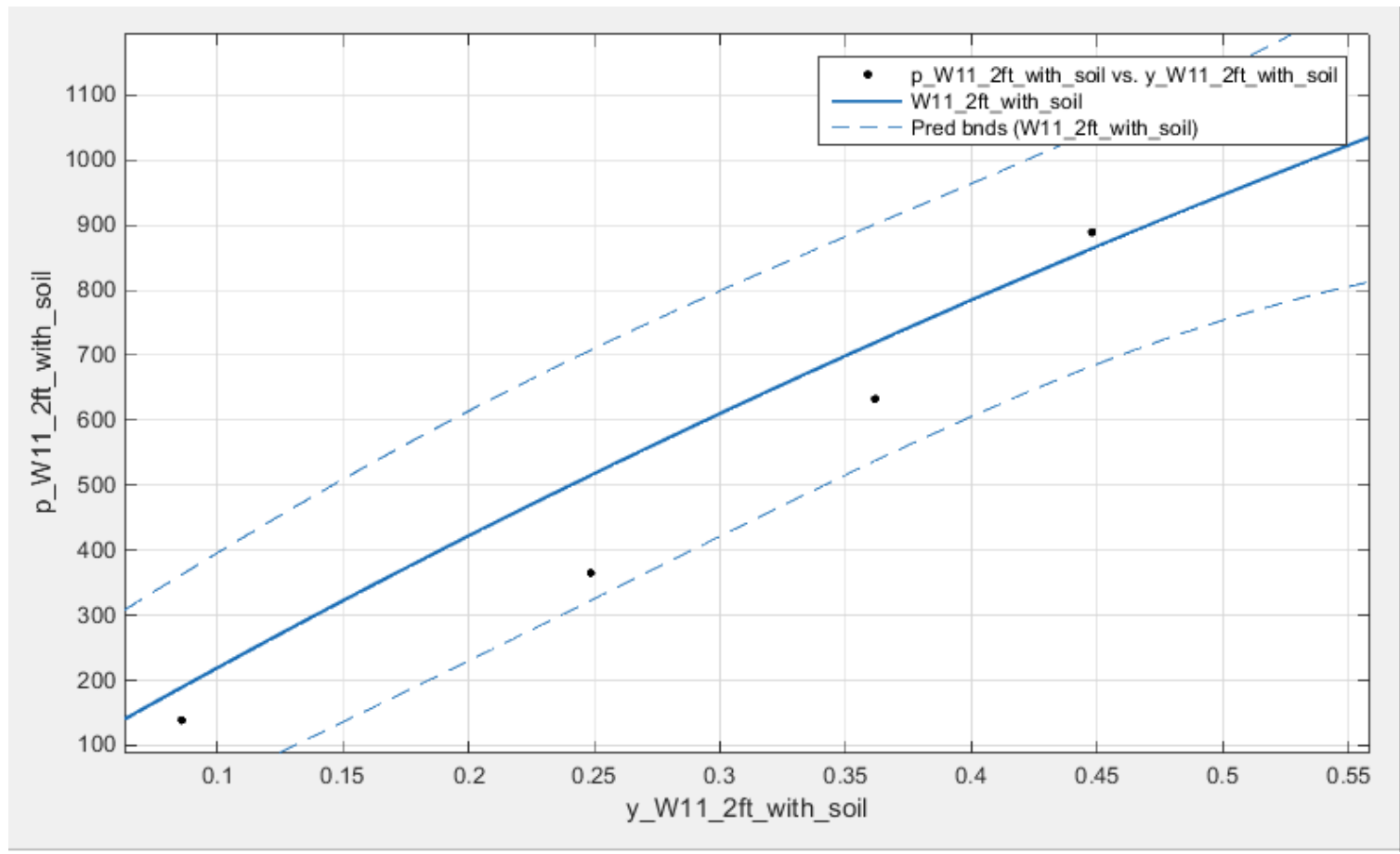

Interpreted $\mathrm{p}-\mathrm{y}$ Responses and Fitted $\mathrm{p}-\mathrm{y}$ curves for Lateral Load Test $\mathrm{W}-11$ at depth $=2 \mathrm{ft}$ 


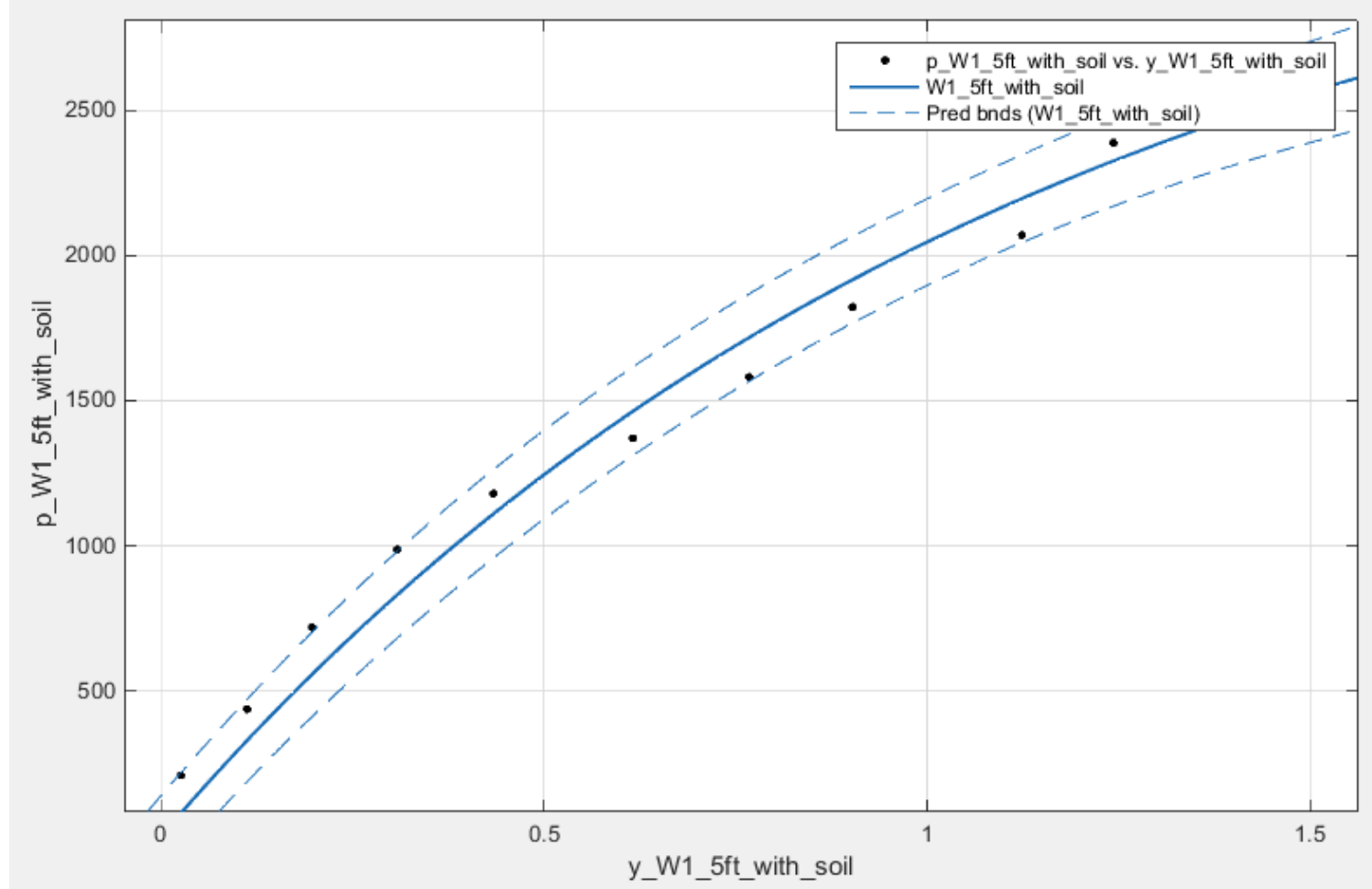

Interpreted $\mathrm{p}-\mathrm{y}$ Responses and Fitted $\mathrm{p}-\mathrm{y}$ curves for Lateral Load Test $\mathrm{W}-1$ at depth $=5 \mathrm{ft}$

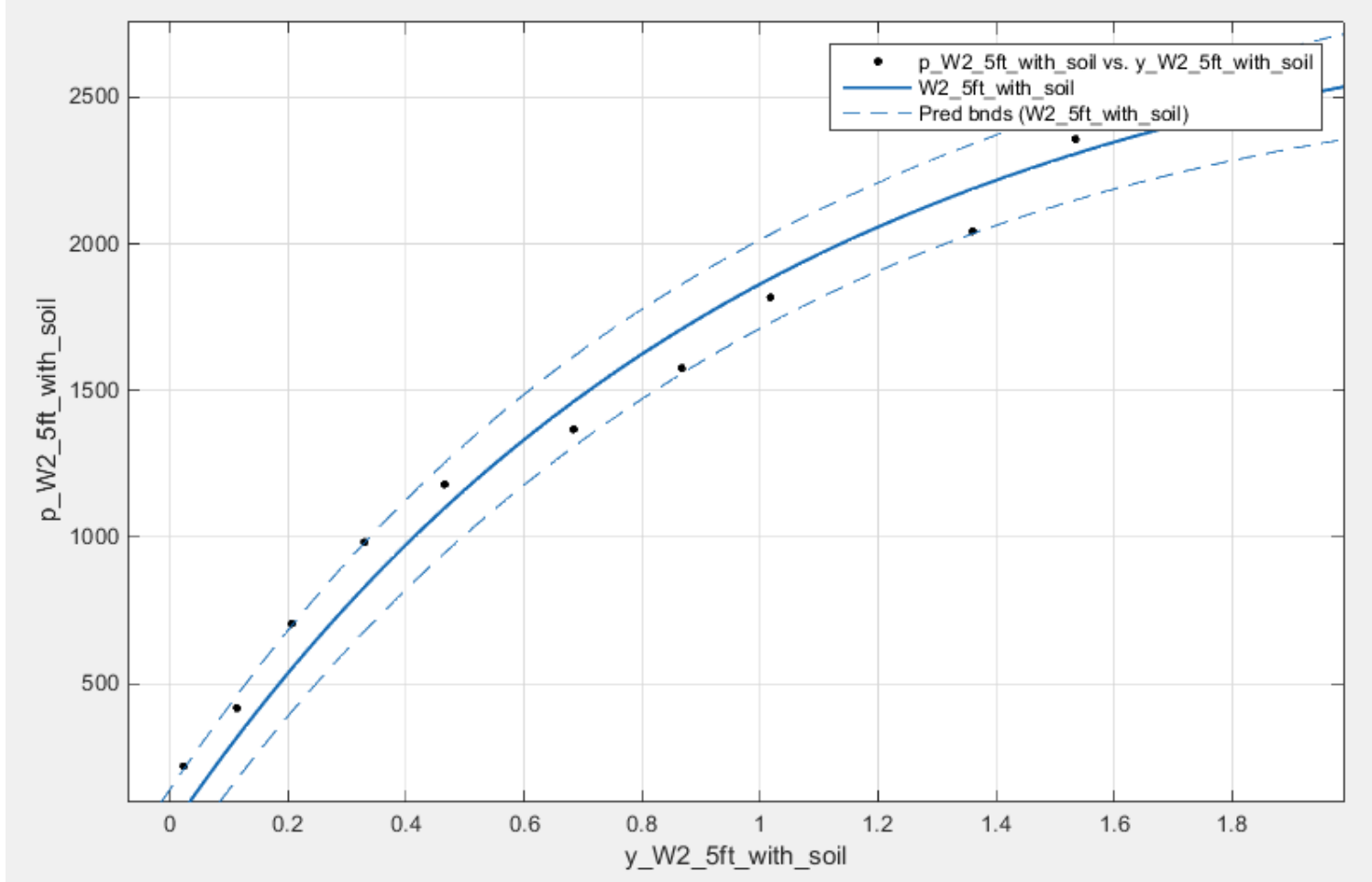

Interpreted $p-y$ Responses and Fitted $p-y$ curves for Lateral Load Test $\mathrm{W}-2$ at depth $=5 \mathrm{ft}$ 


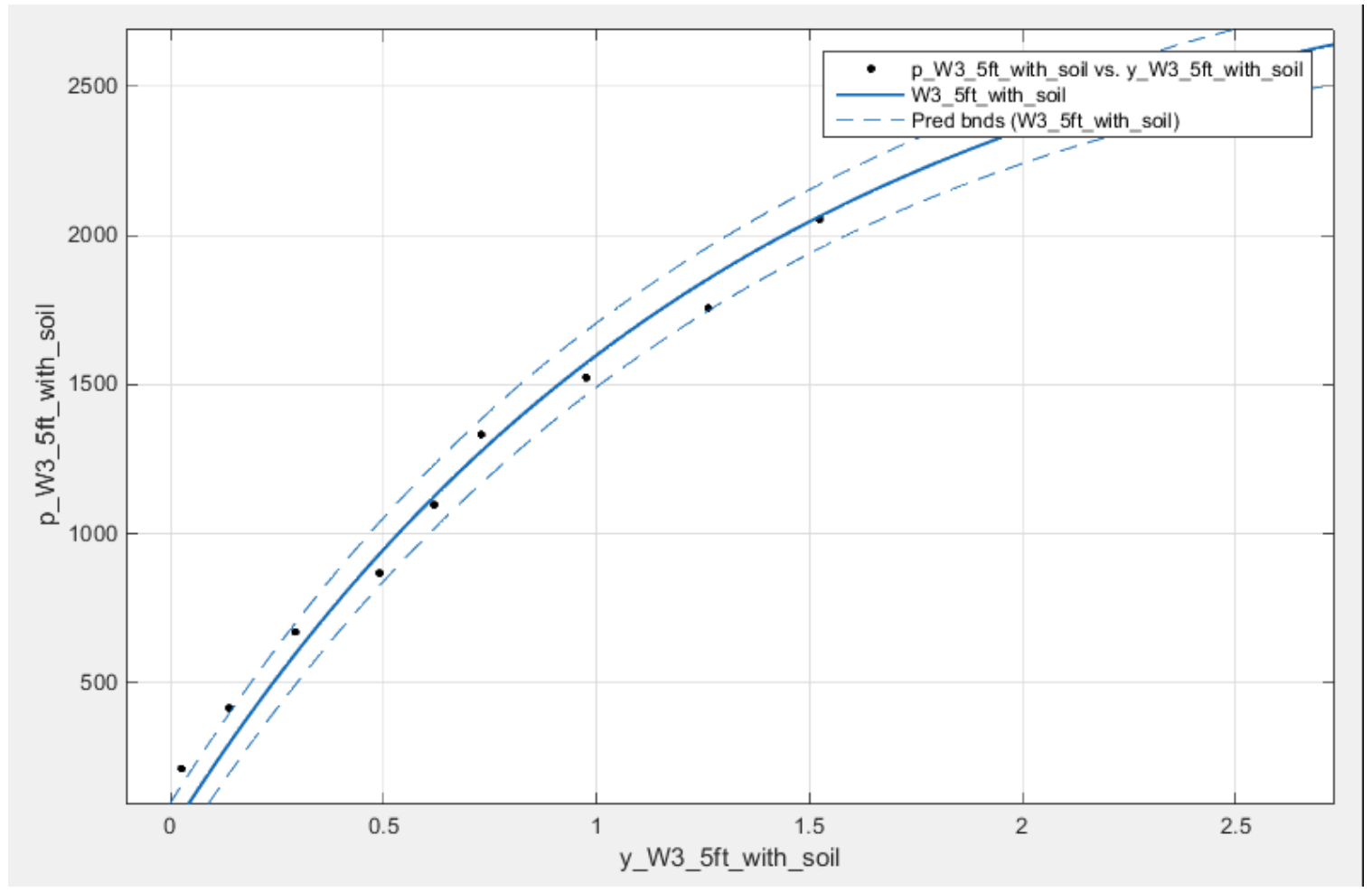

Interpreted $\mathrm{p}-\mathrm{y}$ Responses and Fitted $\mathrm{p}-\mathrm{y}$ curves for Lateral Load Test $\mathrm{W}-3$ at depth=5ft

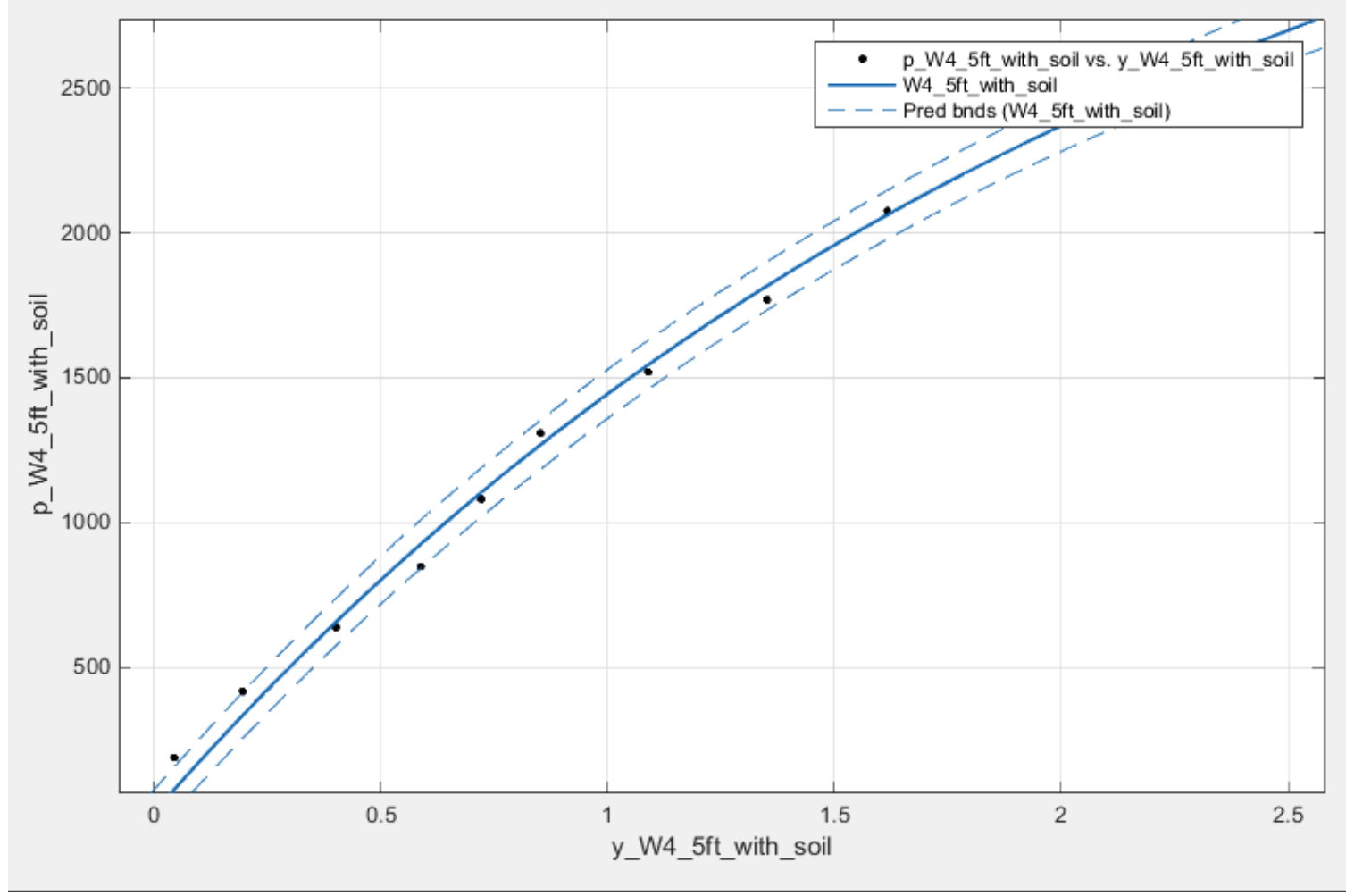

Interpreted $p-y$ Responses and Fitted $p-y$ curves for Lateral Load Test W-4 at depth $=5 \mathrm{ft}$ 


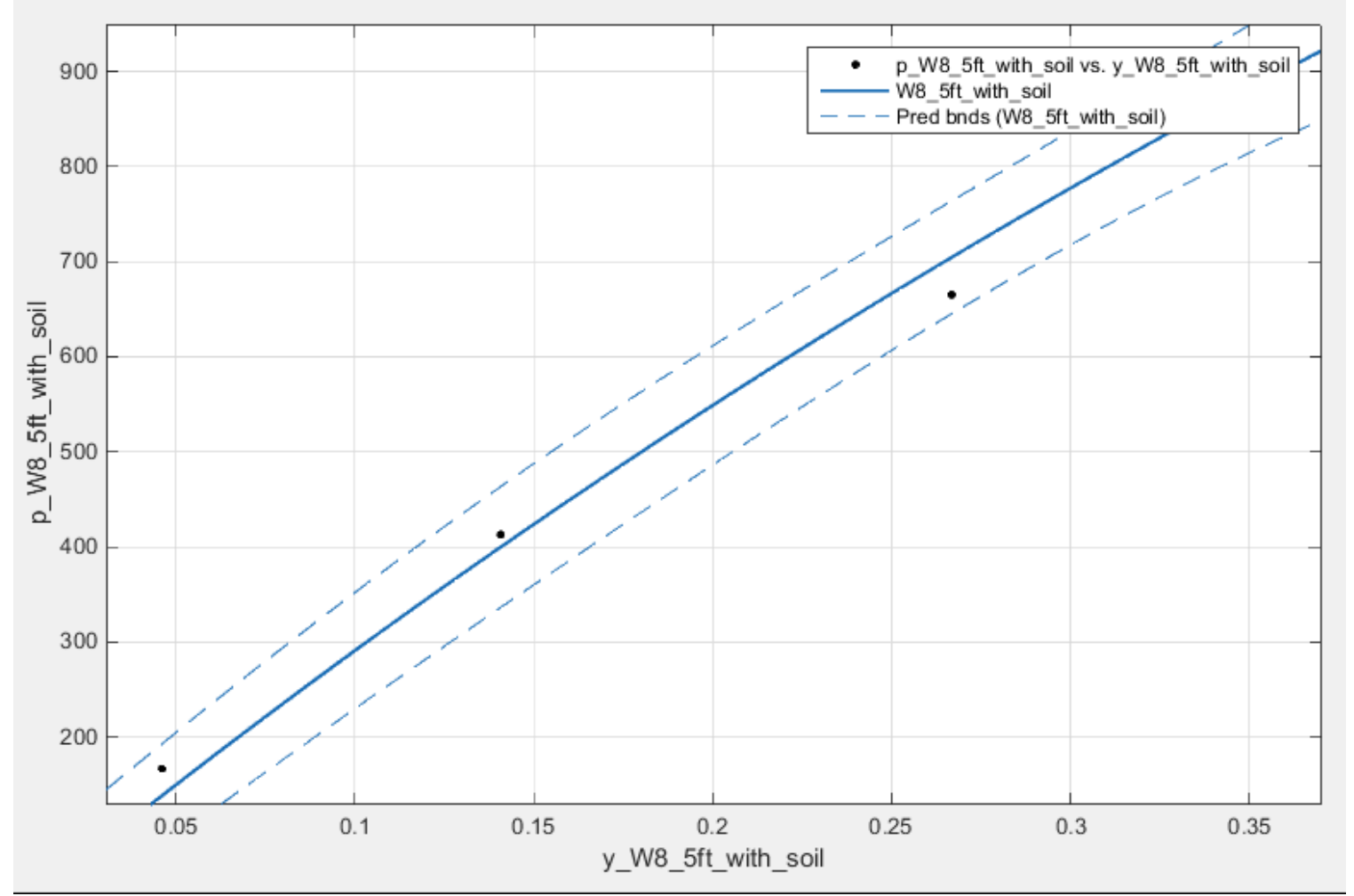

Interpreted $p-y$ Responses and Fitted $p-y$ curves for Lateral Load Test W-8 at depth $=5 \mathrm{ft}$

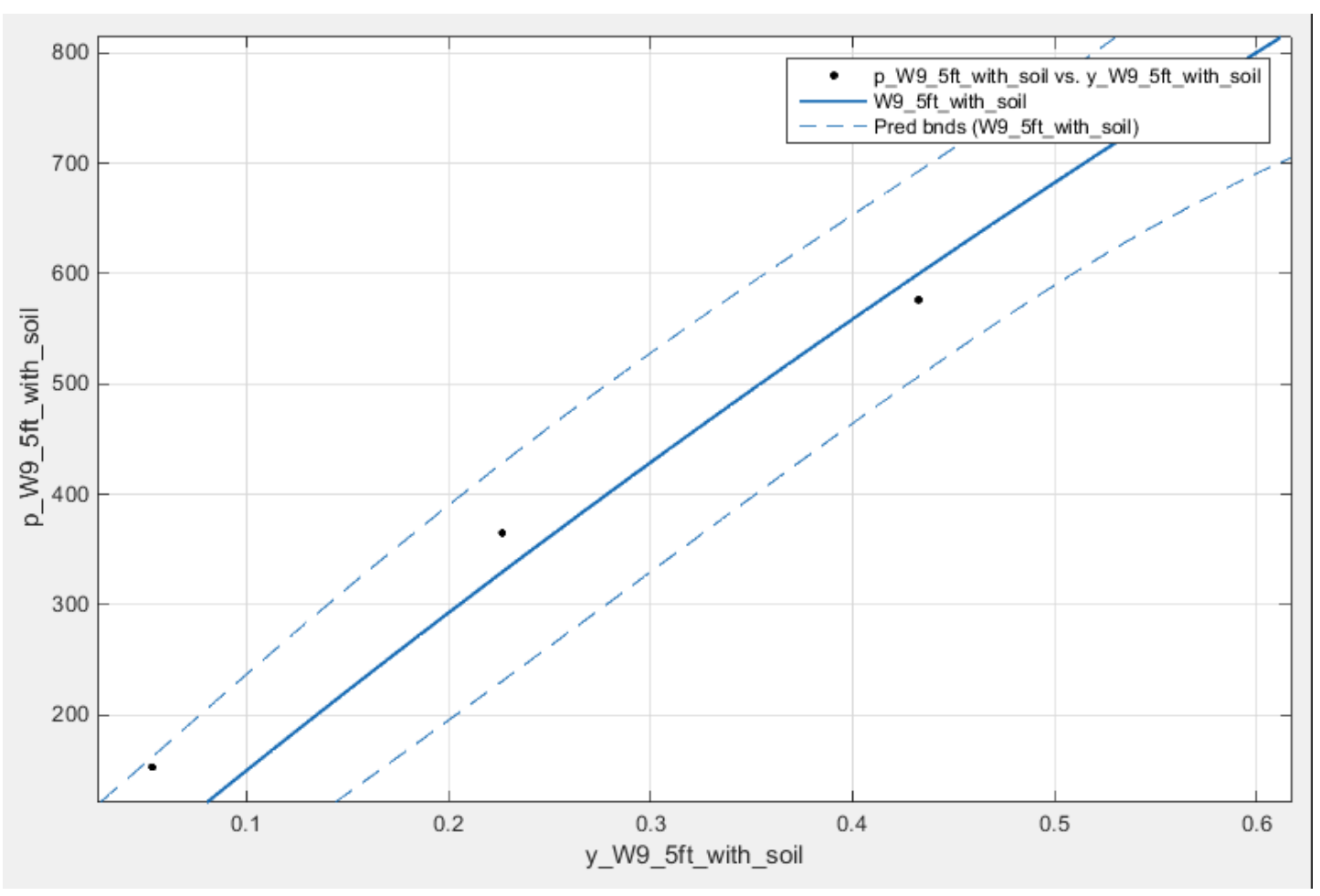

Interpreted $\mathrm{p}-\mathrm{y}$ Responses and Fitted $\mathrm{p}-\mathrm{y}$ curves for Lateral Load Test $\mathrm{W}-9$ at depth $=5 \mathrm{ft}$ 


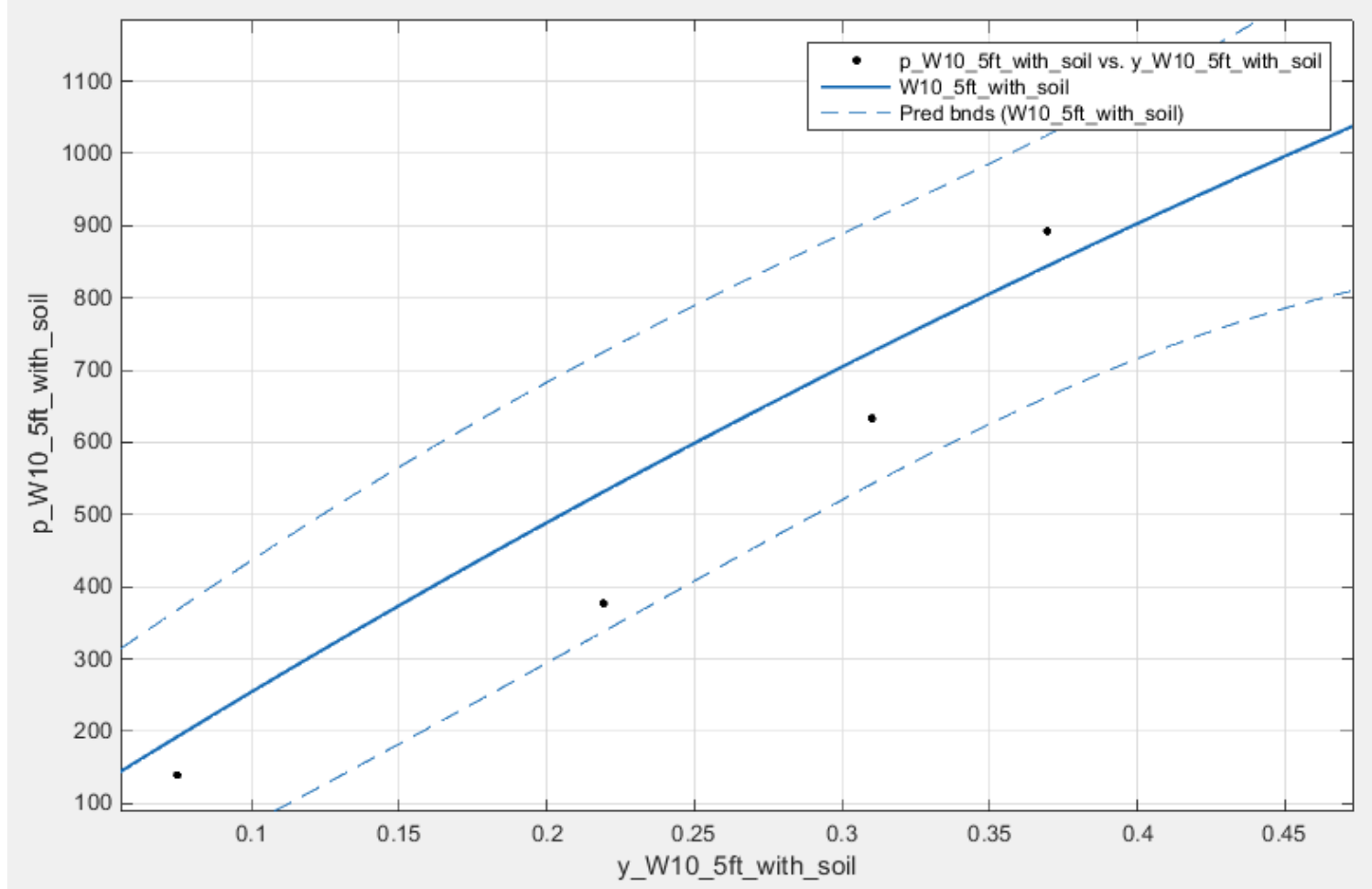

Interpreted $p-y$ Responses and Fitted $p-y$ curves for Lateral Load Test W-10 at depth=5ft

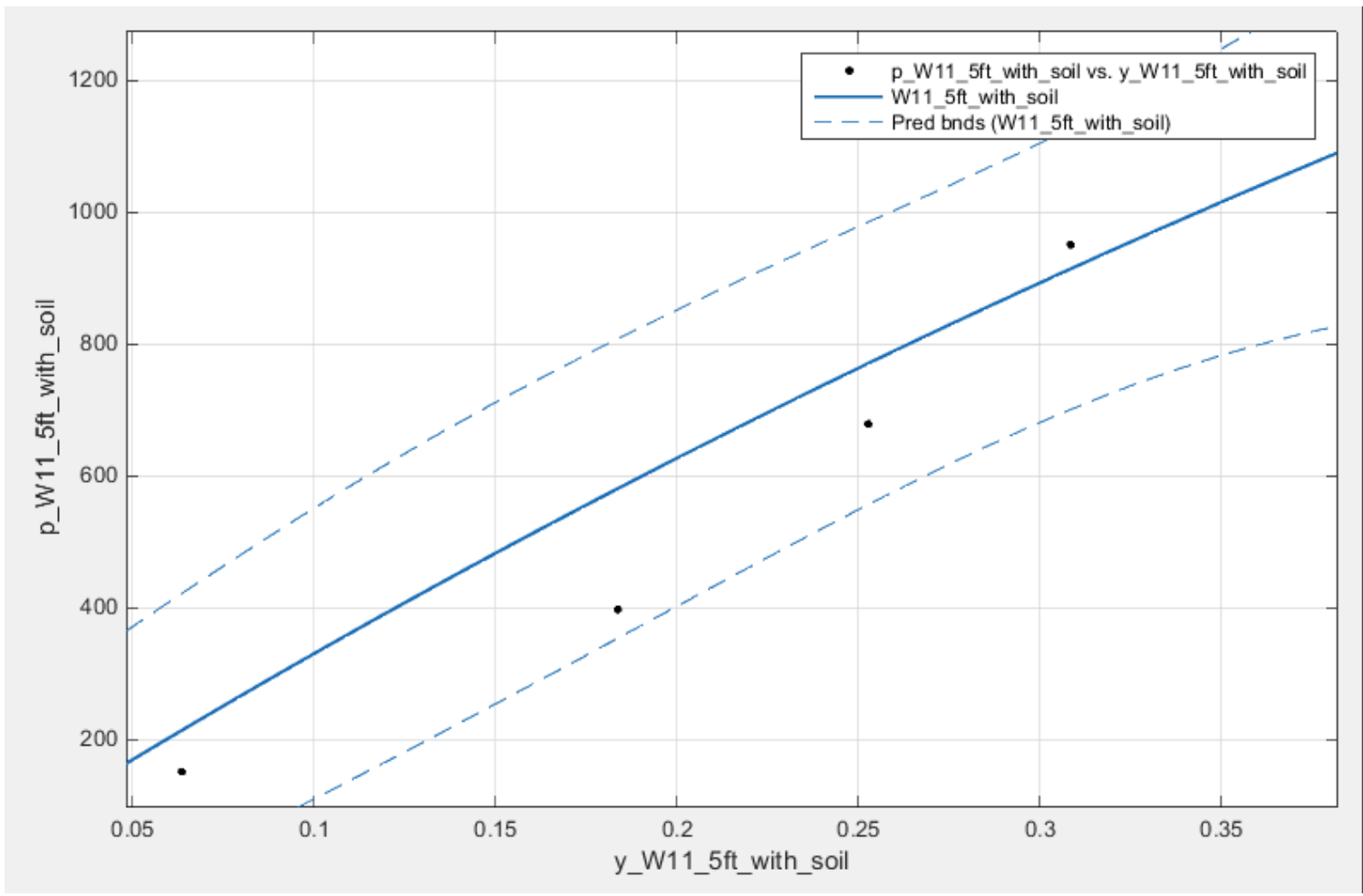

Interpreted $p-y$ Responses and Fitted $p$-y curves for Lateral Load Test W-11 at depth $=5 \mathrm{ft}$ 


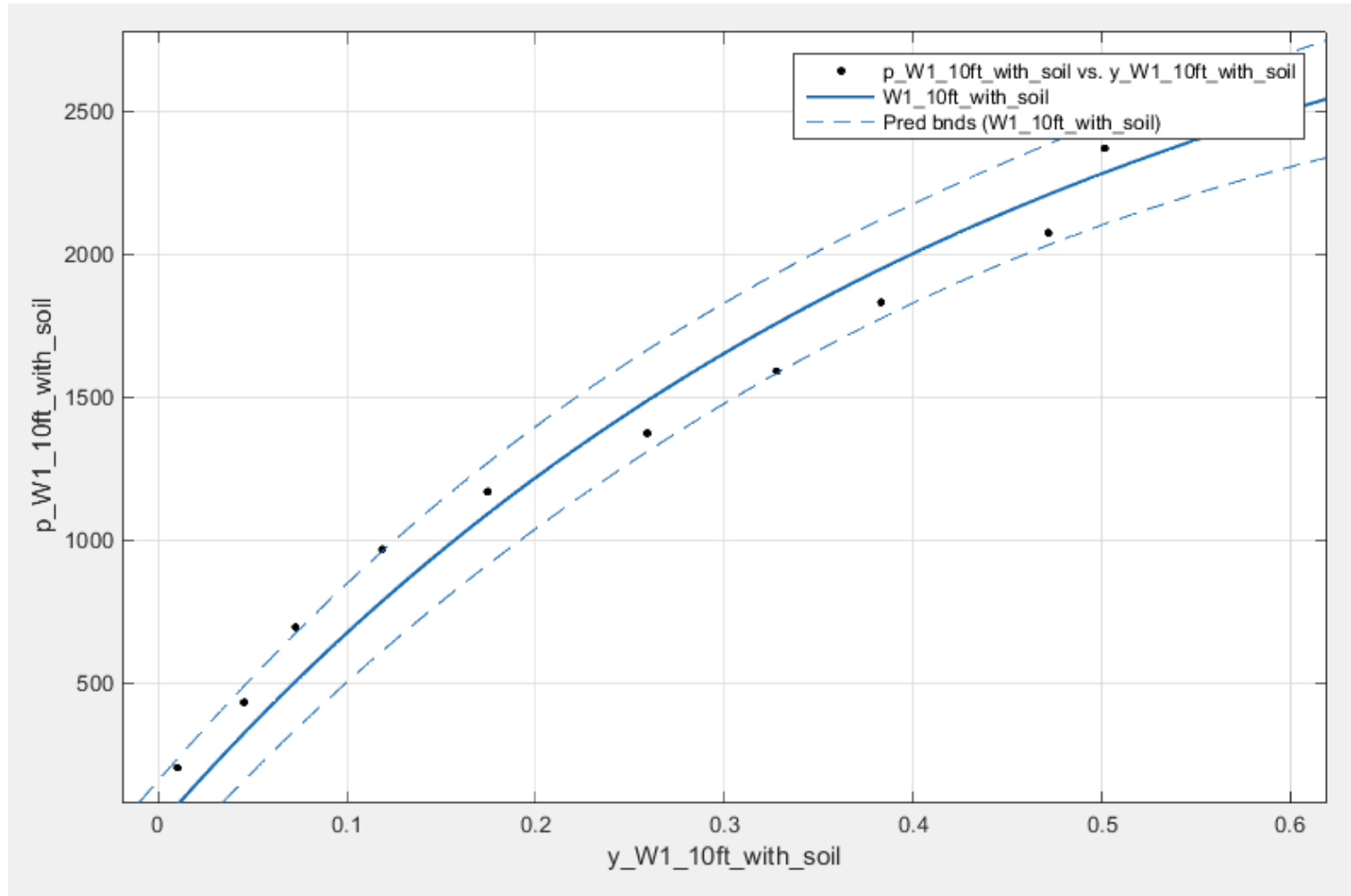

Interpreted p-y Responses and Fitted p-y curves for Lateral Load Test W-1 at $10 \mathrm{ft}$

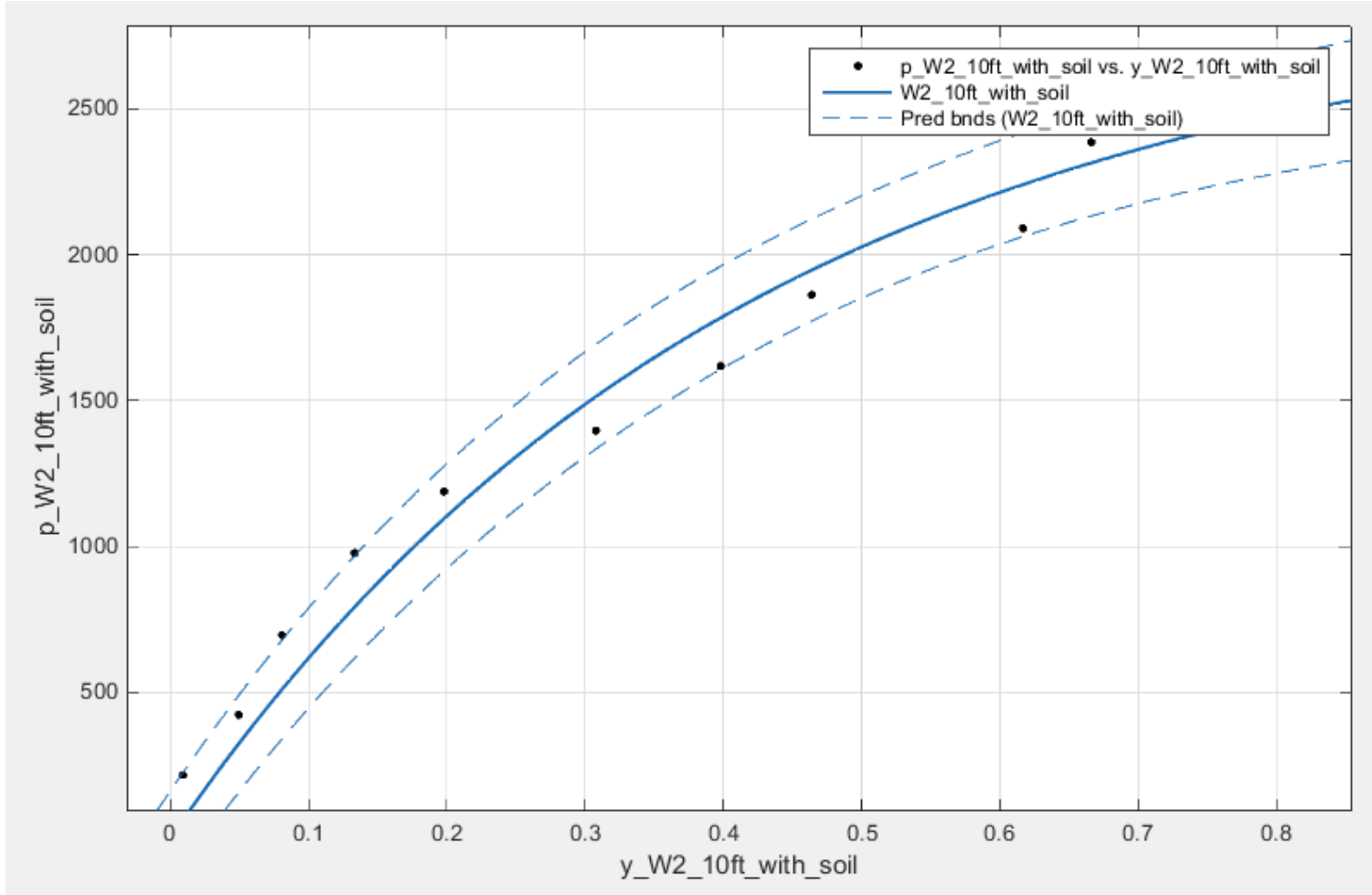

Interpreted p-y Responses and Fitted $\mathrm{p}-\mathrm{y}$ curves for Lateral Load Test W-2 at $10 \mathrm{ft}$ 


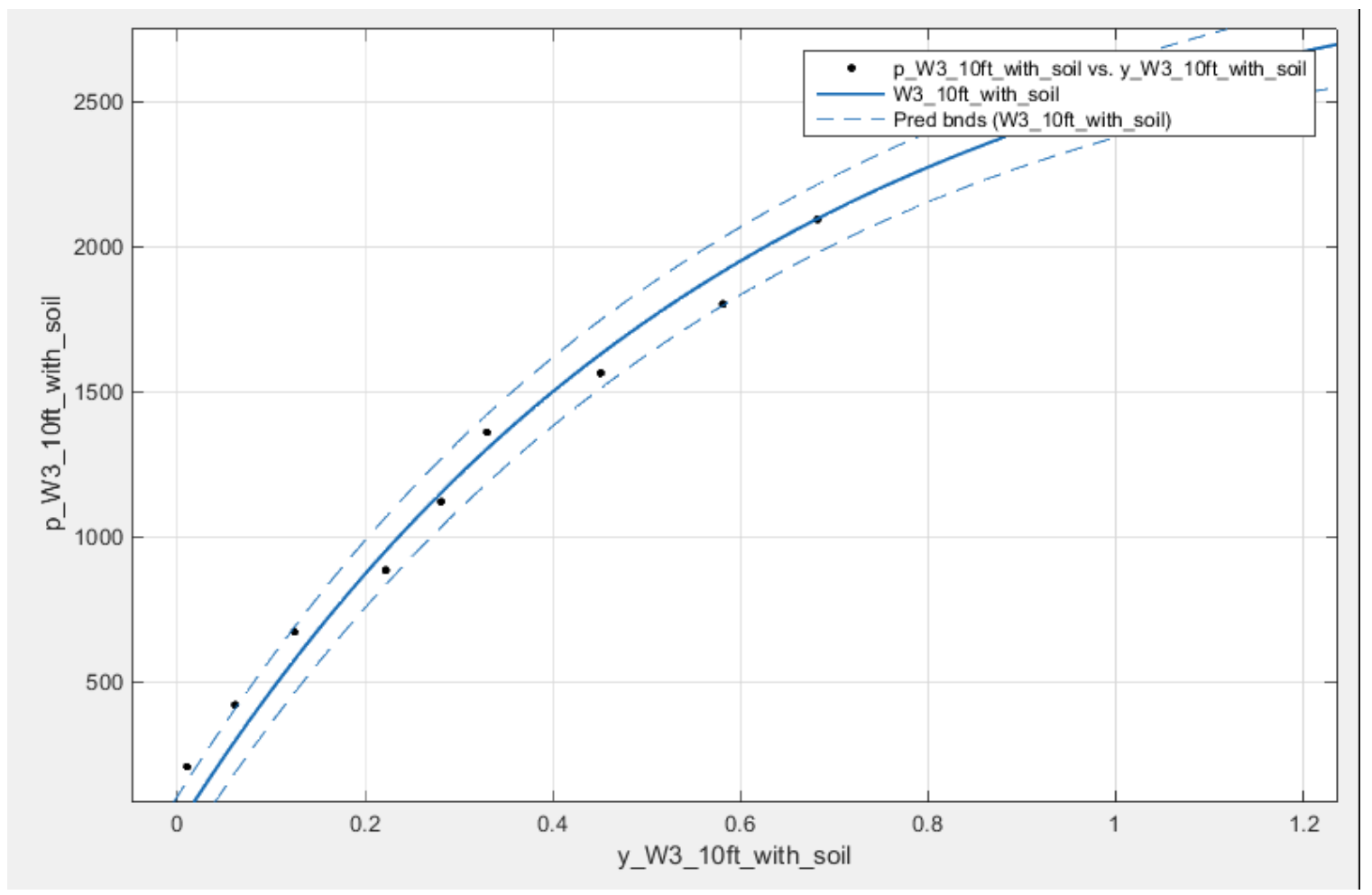

Interpreted p-y Responses and Fitted p-y curves for Lateral Load Test W-3 at $10 \mathrm{ft}$

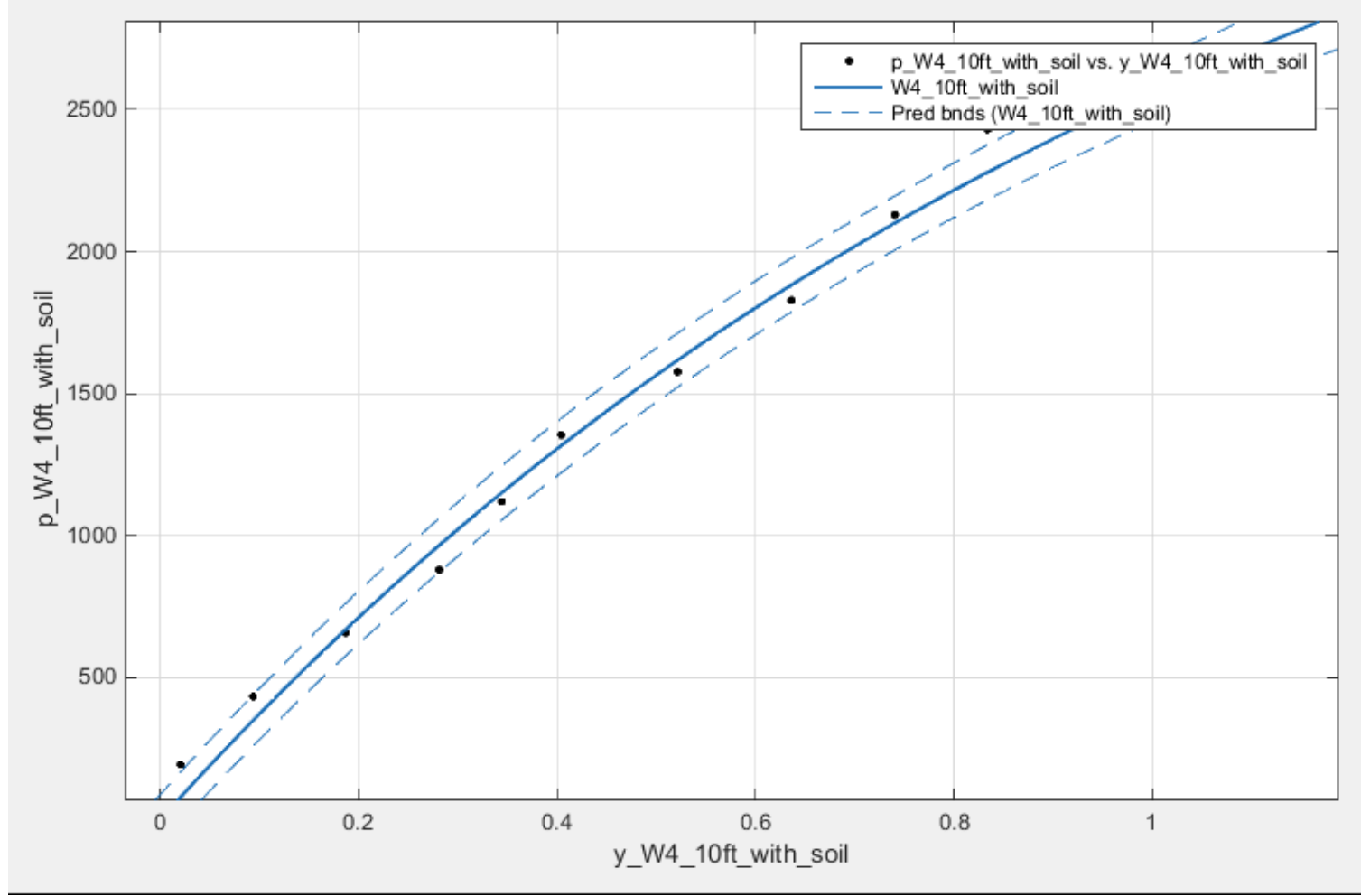

Interpreted $p-y$ Responses and Fitted $p-y$ curves for Lateral Load Test W-4 at $10 \mathrm{ft}$ 


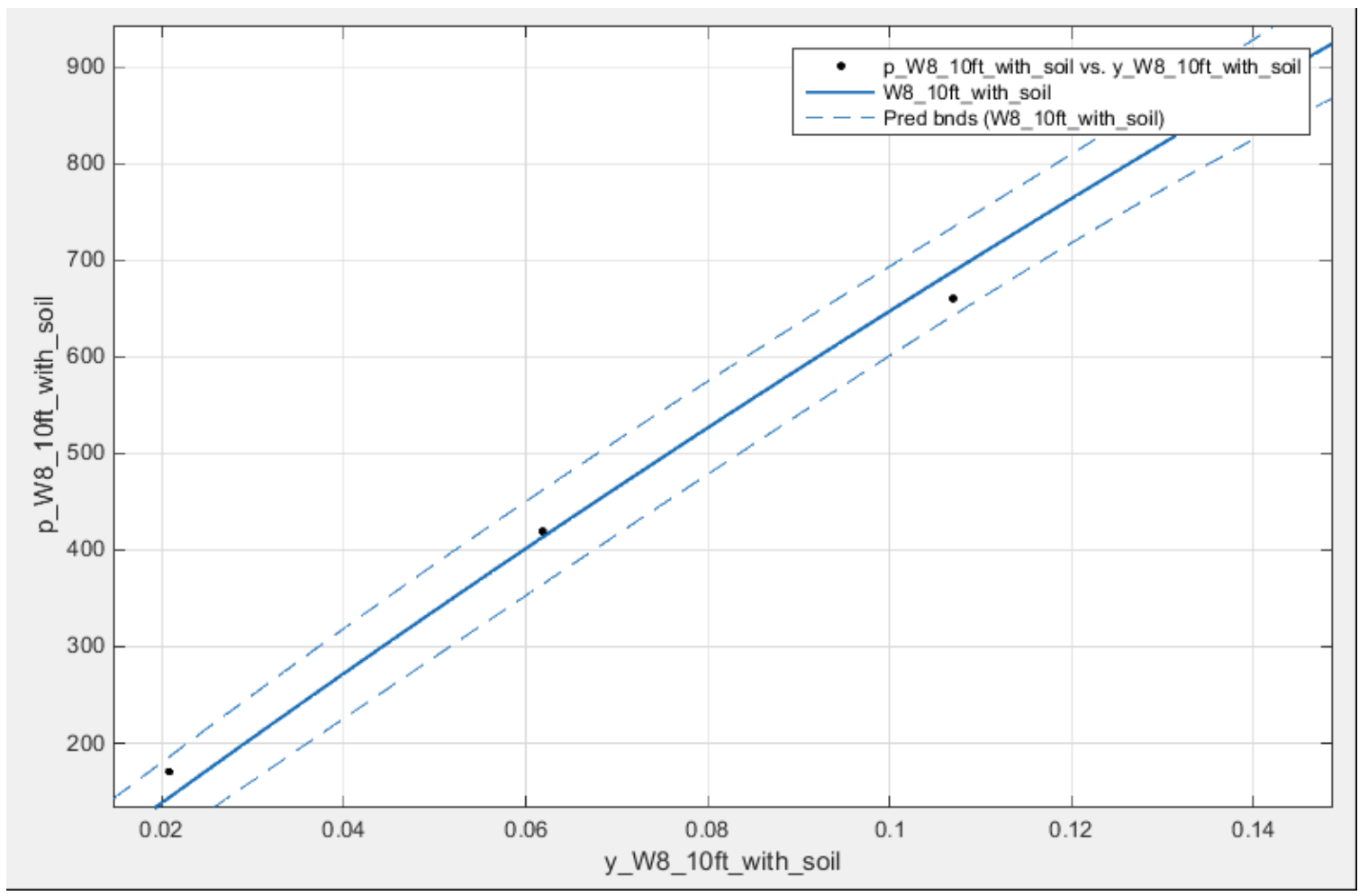

Interpreted p-y Responses and Fitted p-y curves for Lateral Load Test W-8 at $10 \mathrm{ft}$

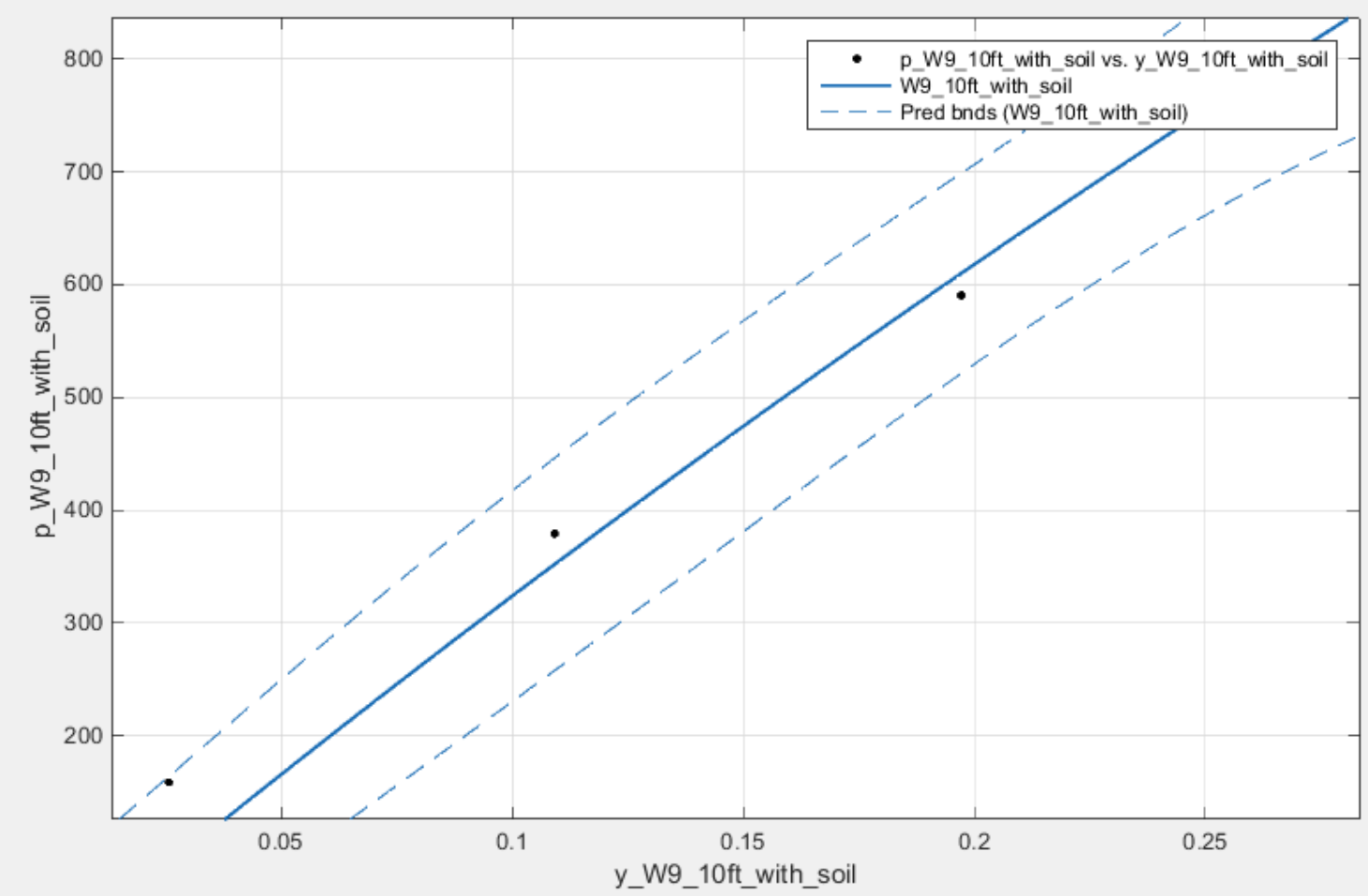

Interpreted p-y Responses and Fitted p-y curves for Lateral Load Test W-9 at $10 \mathrm{ft}$ 


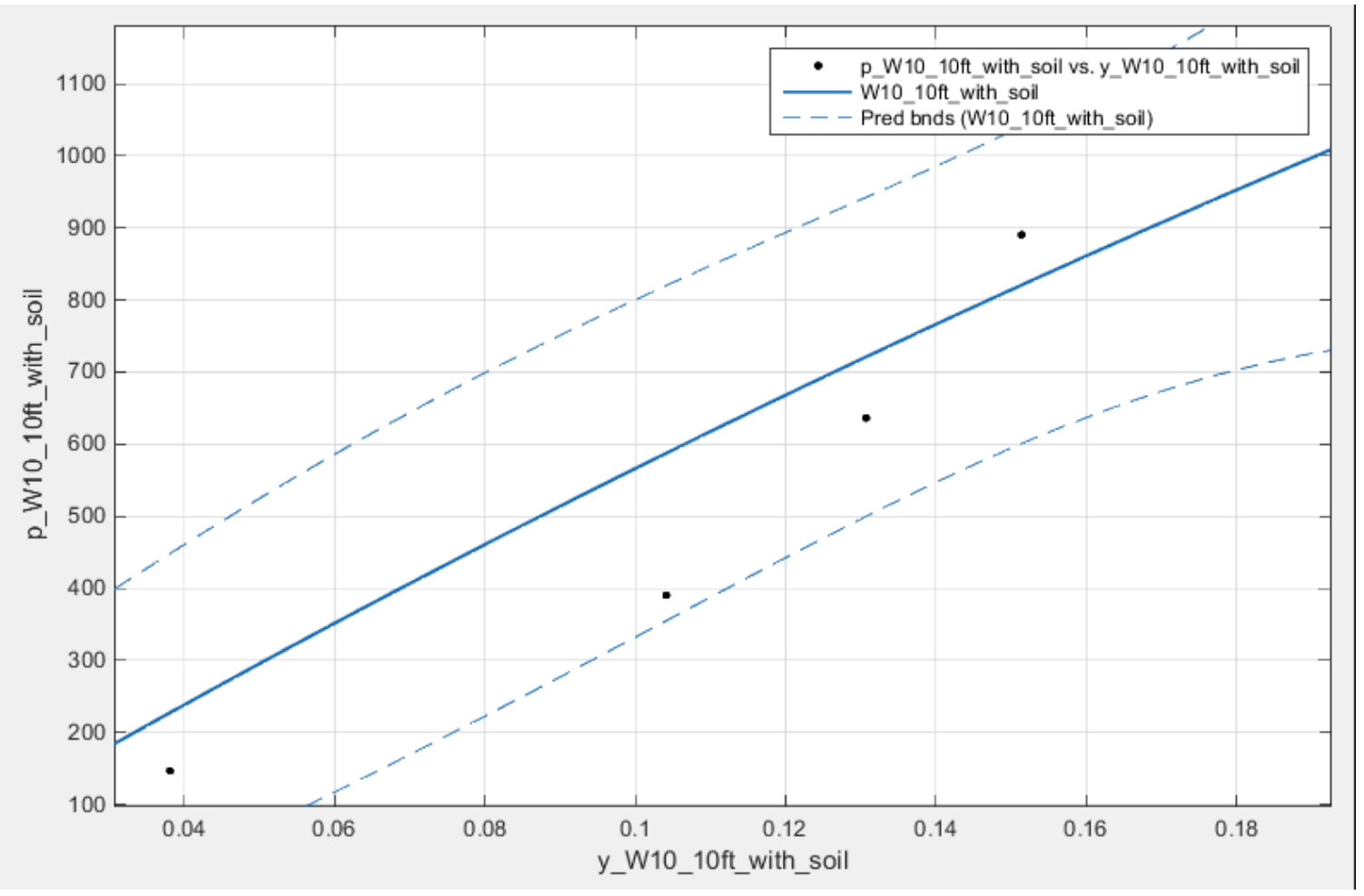

Interpreted $\mathrm{p}-\mathrm{y}$ Responses and Fitted $\mathrm{p}-\mathrm{y}$ curves for Lateral Load Test W-10 at $10 \mathrm{ft}$

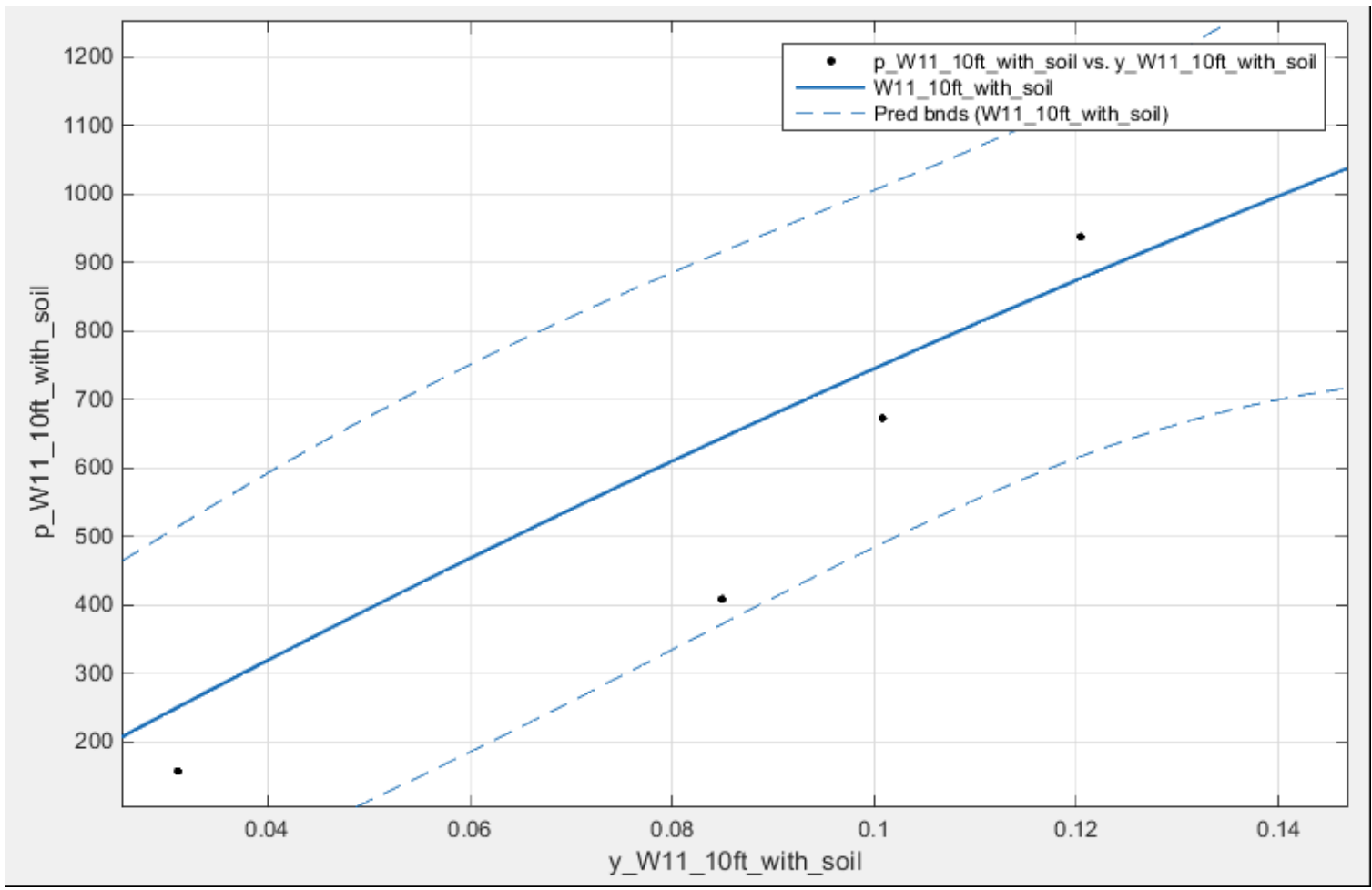

Interpreted p-y Responses and Fitted p-y curves for Lateral Load Test W-11 at $10 \mathrm{ft}$ 


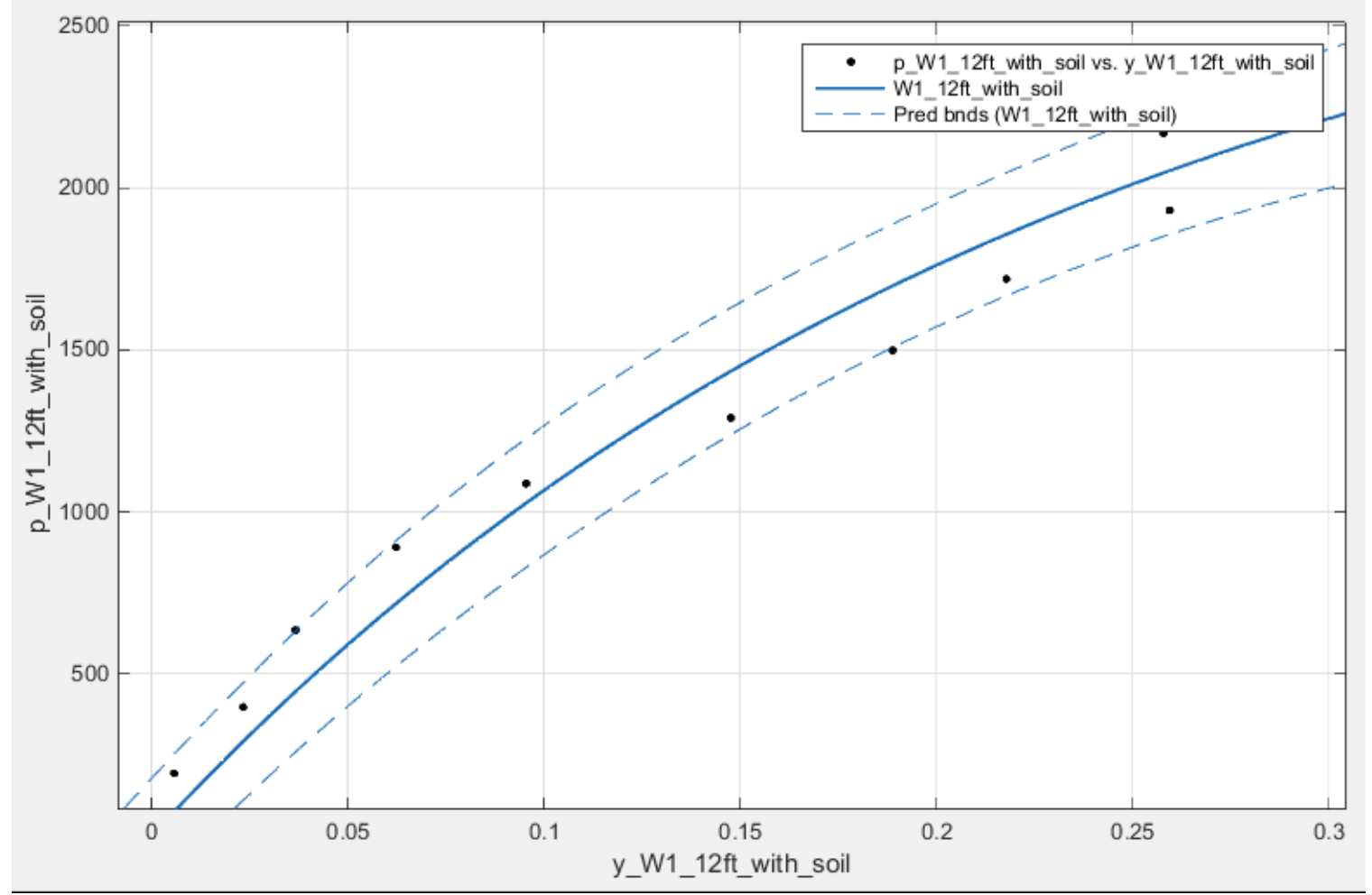

Interpreted $p-y$ Responses and Fitted $p-y$ curves for Lateral Load Test W-1 at $12 \mathrm{ft}$

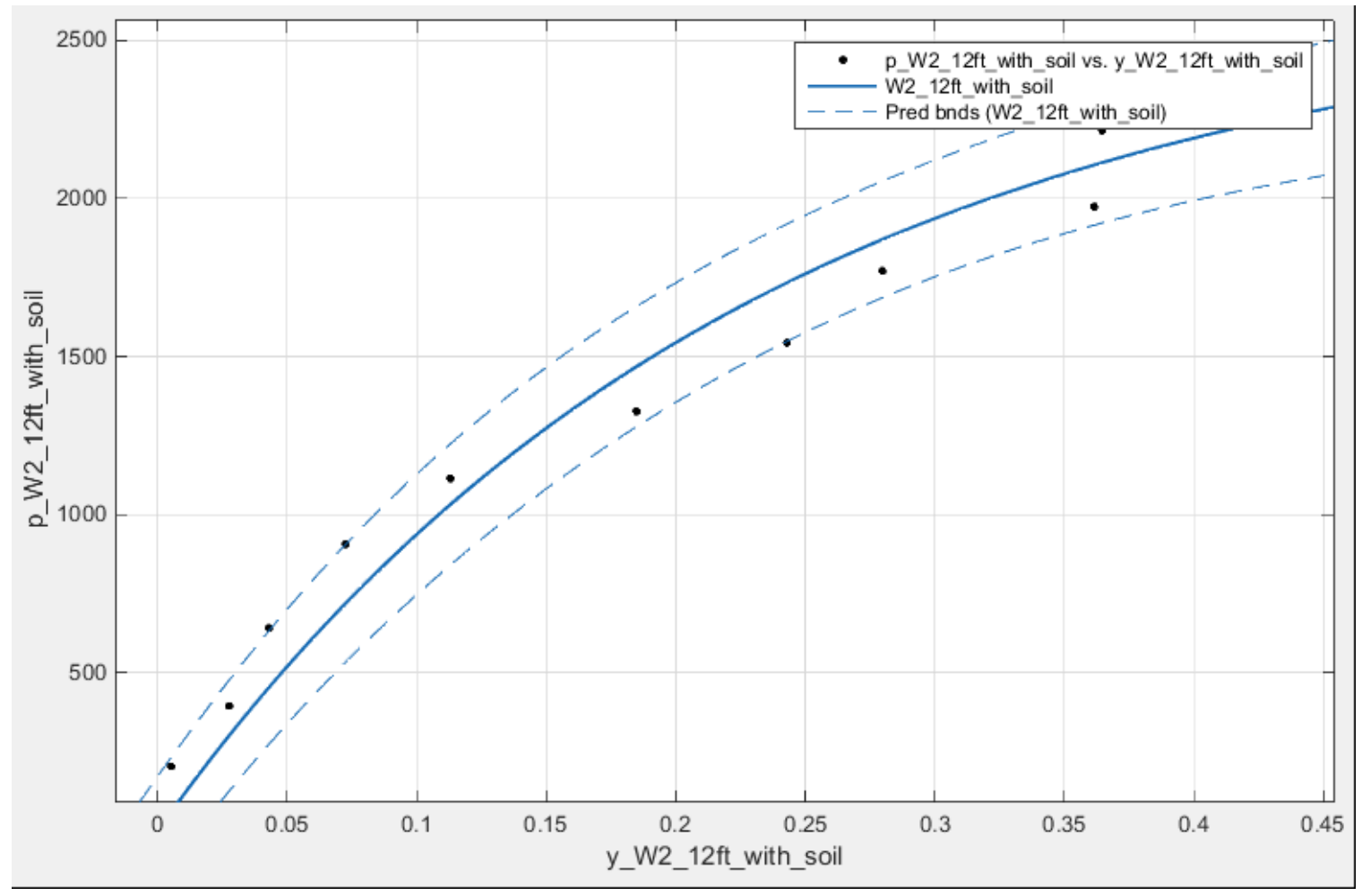

Interpreted $p-y$ Responses and Fitted $p-y$ curves for Lateral Load Test W-2 at $12 \mathrm{ft}$ 


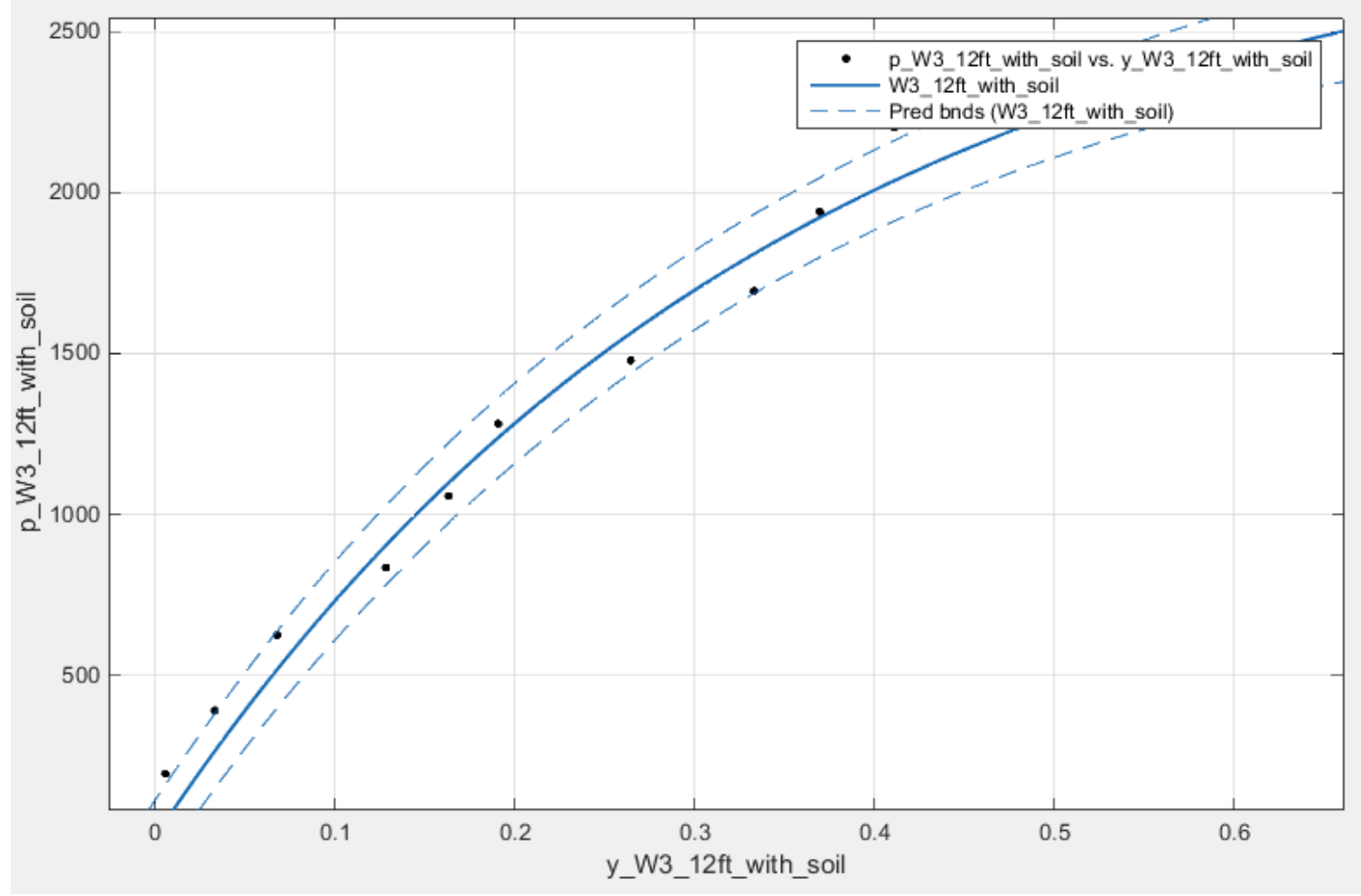

Interpreted p-y Responses and Fitted p-y curves for Lateral Load Test W-3 at $12 \mathrm{ft}$

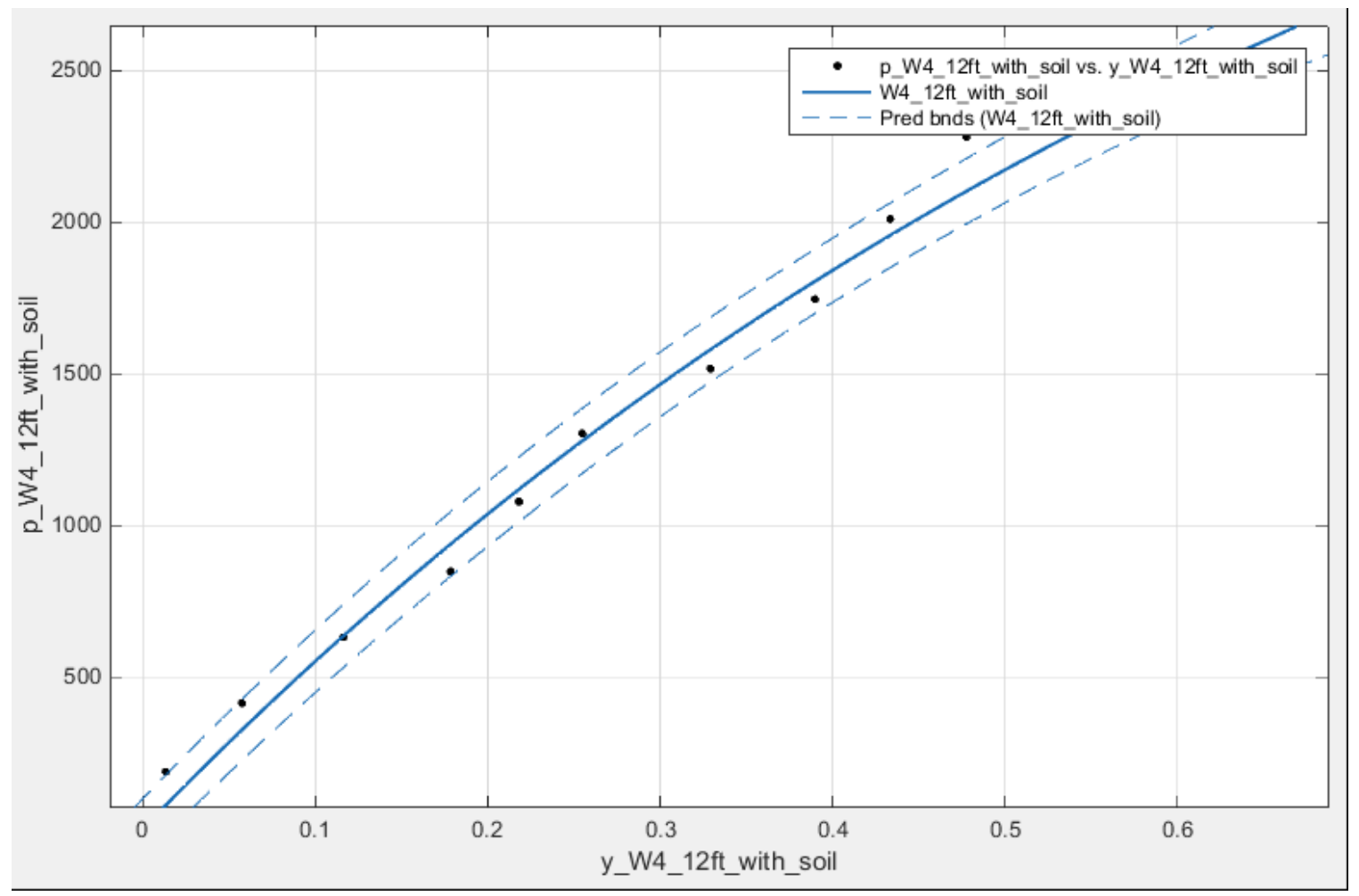

Interpreted p-y Responses and Fitted p-y curves for Lateral Load Test W-4 at $12 \mathrm{ft}$ 


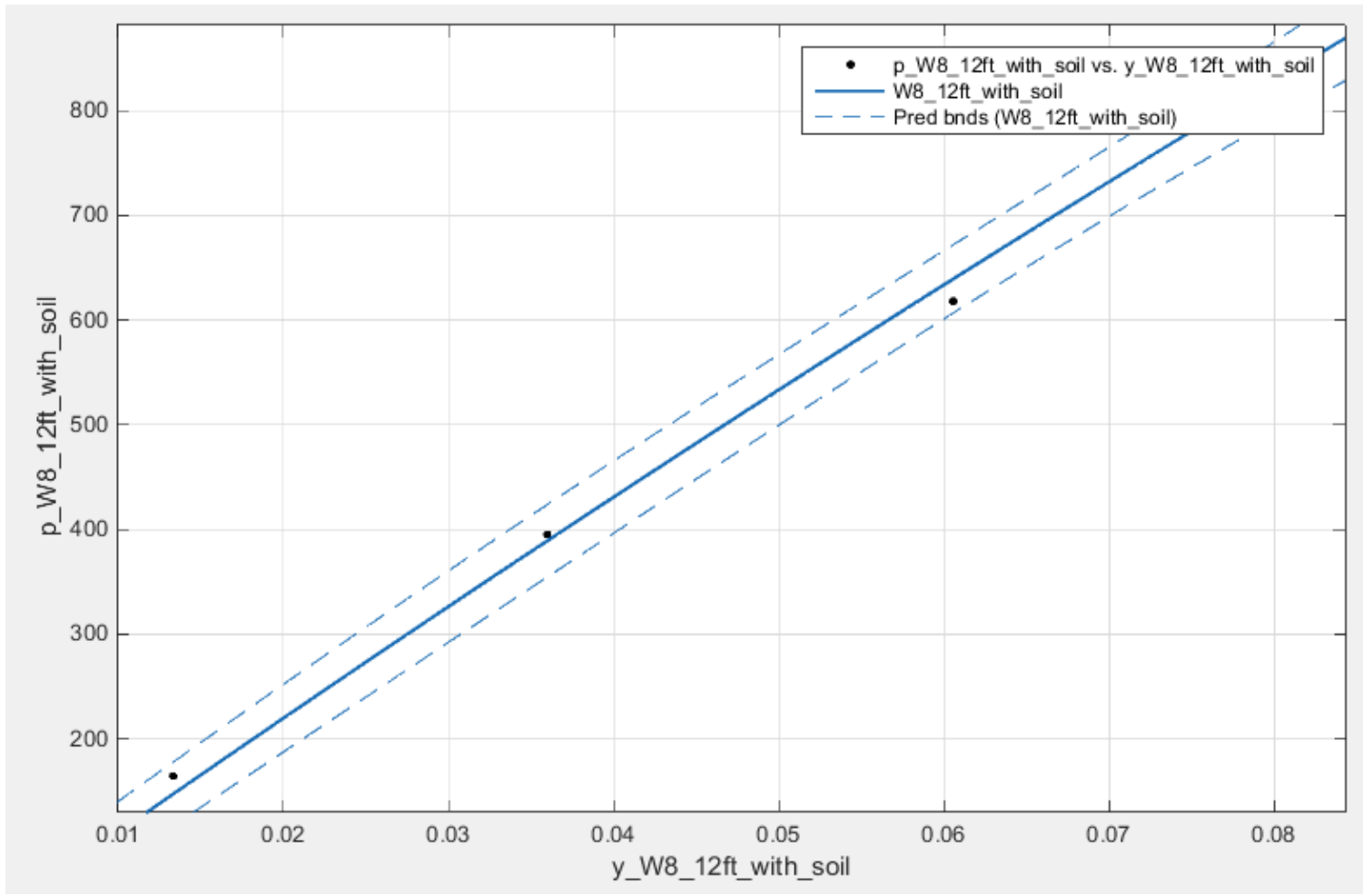

Interpreted p-y Responses and Fitted $p-y$ curves for Lateral Load Test W-8 at $12 \mathrm{ft}$

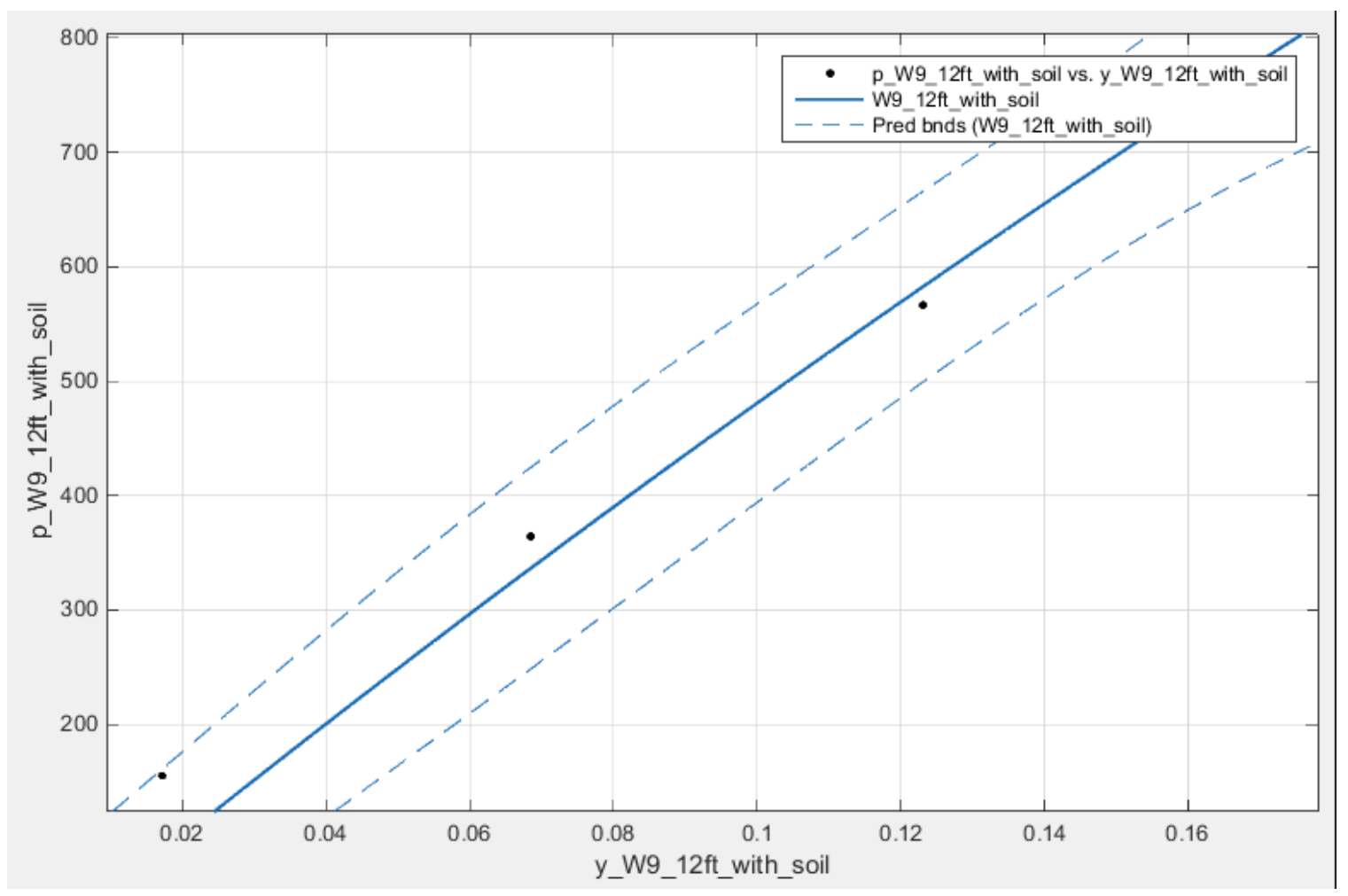

Interpreted p-y Responses and Fitted p-y curves for Lateral Load Test W-9 at $12 \mathrm{ft}$ 


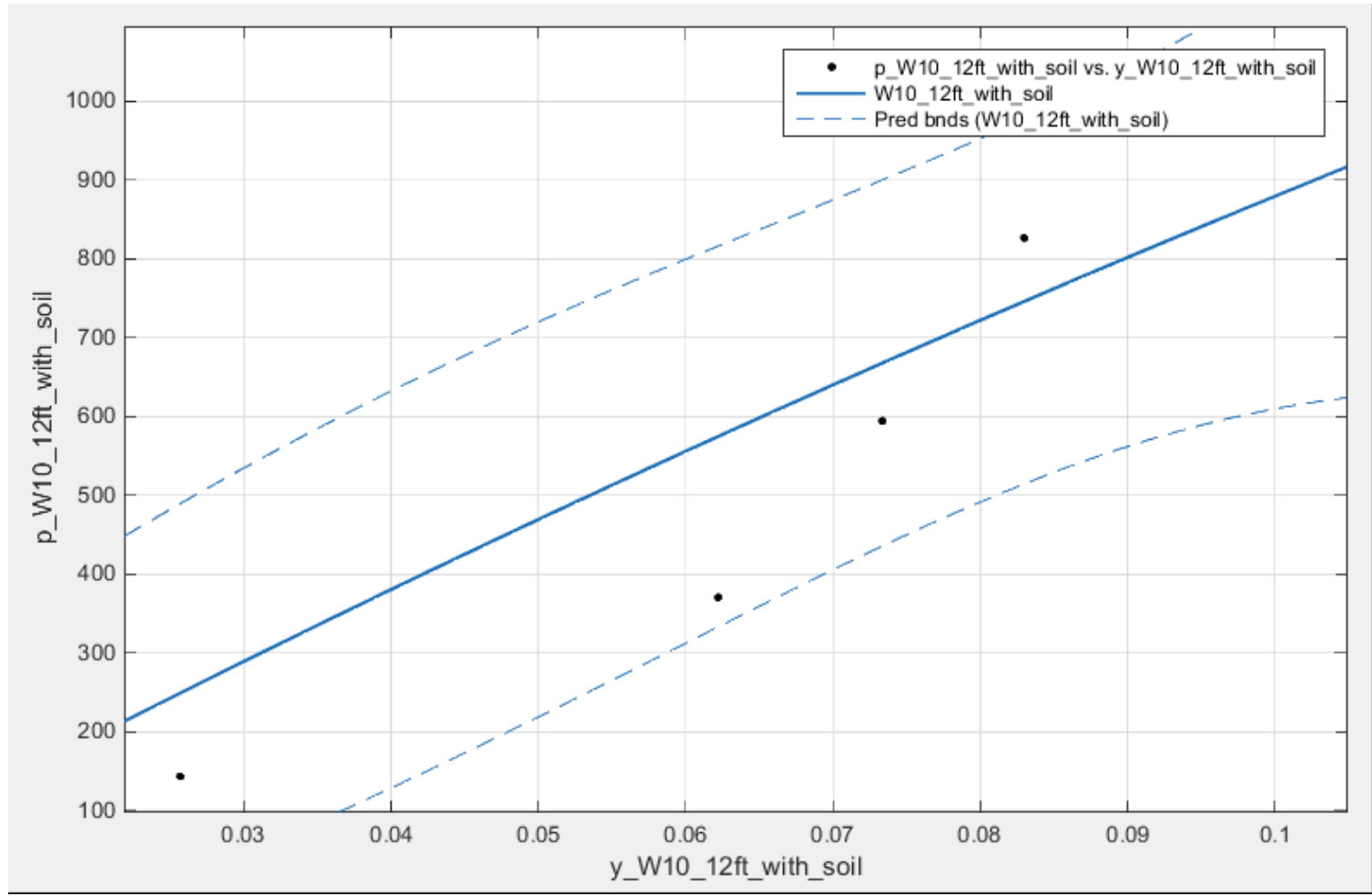

Interpreted p-y Responses and Fitted p-y curves for Lateral Load Test W-10 at $12 \mathrm{ft}$

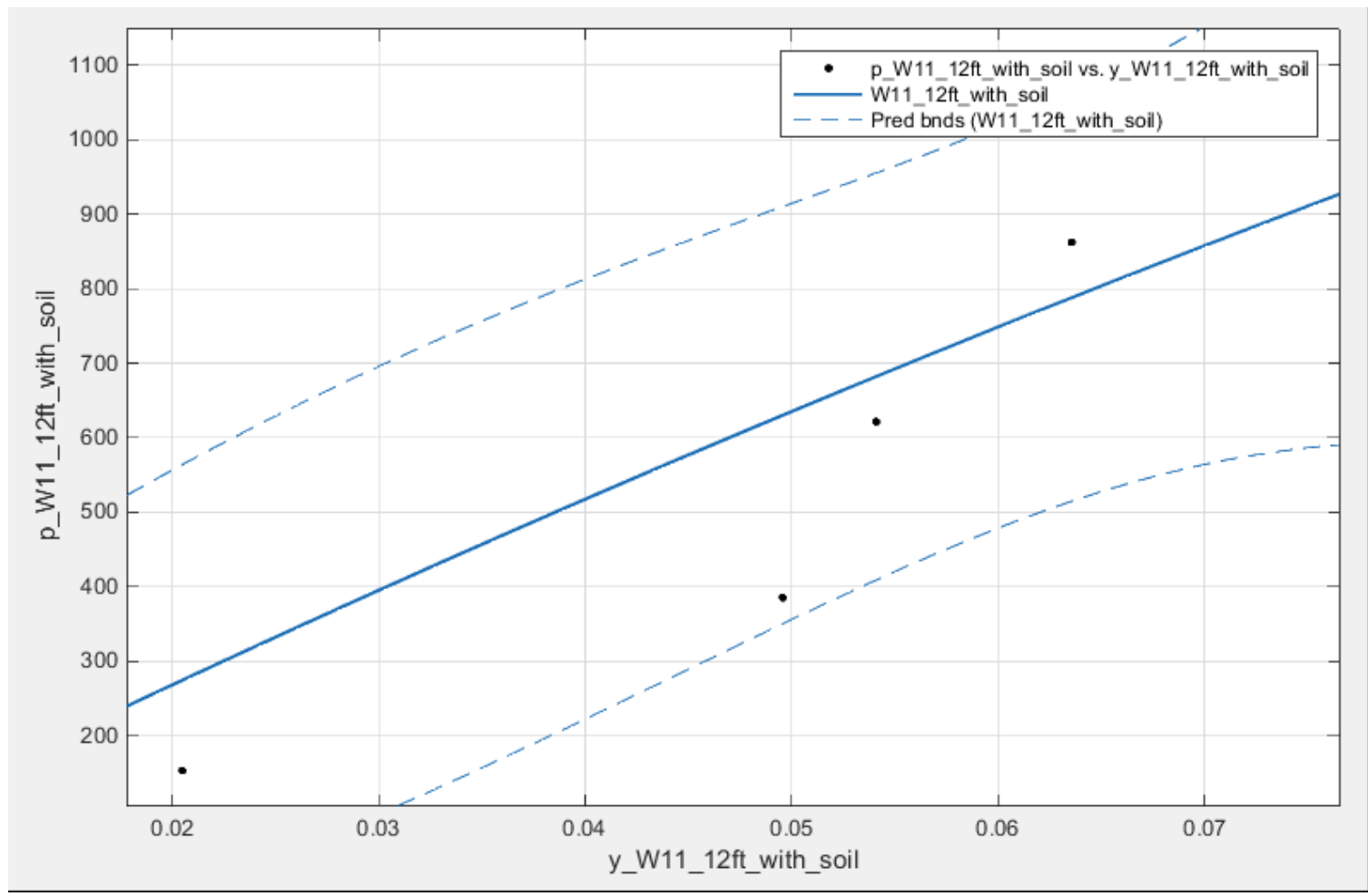

Interpreted p-y Responses and Fitted p-y curves for Lateral Load Test W-11 at $12 \mathrm{ft}$ 


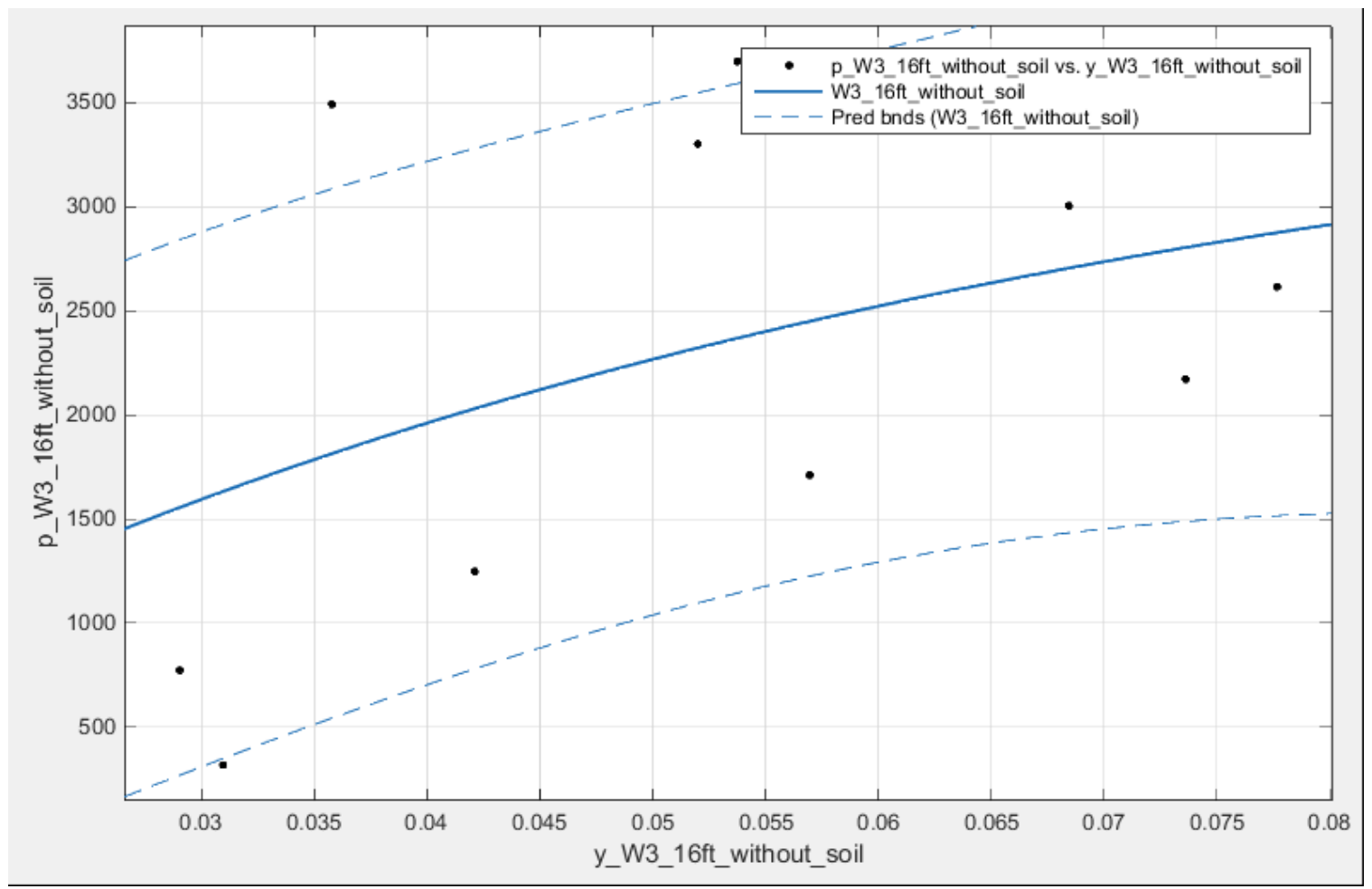

Interpreted p-y Responses and Fitted p-y curves for Lateral Load Test W-3 at $16 \mathrm{ft}$

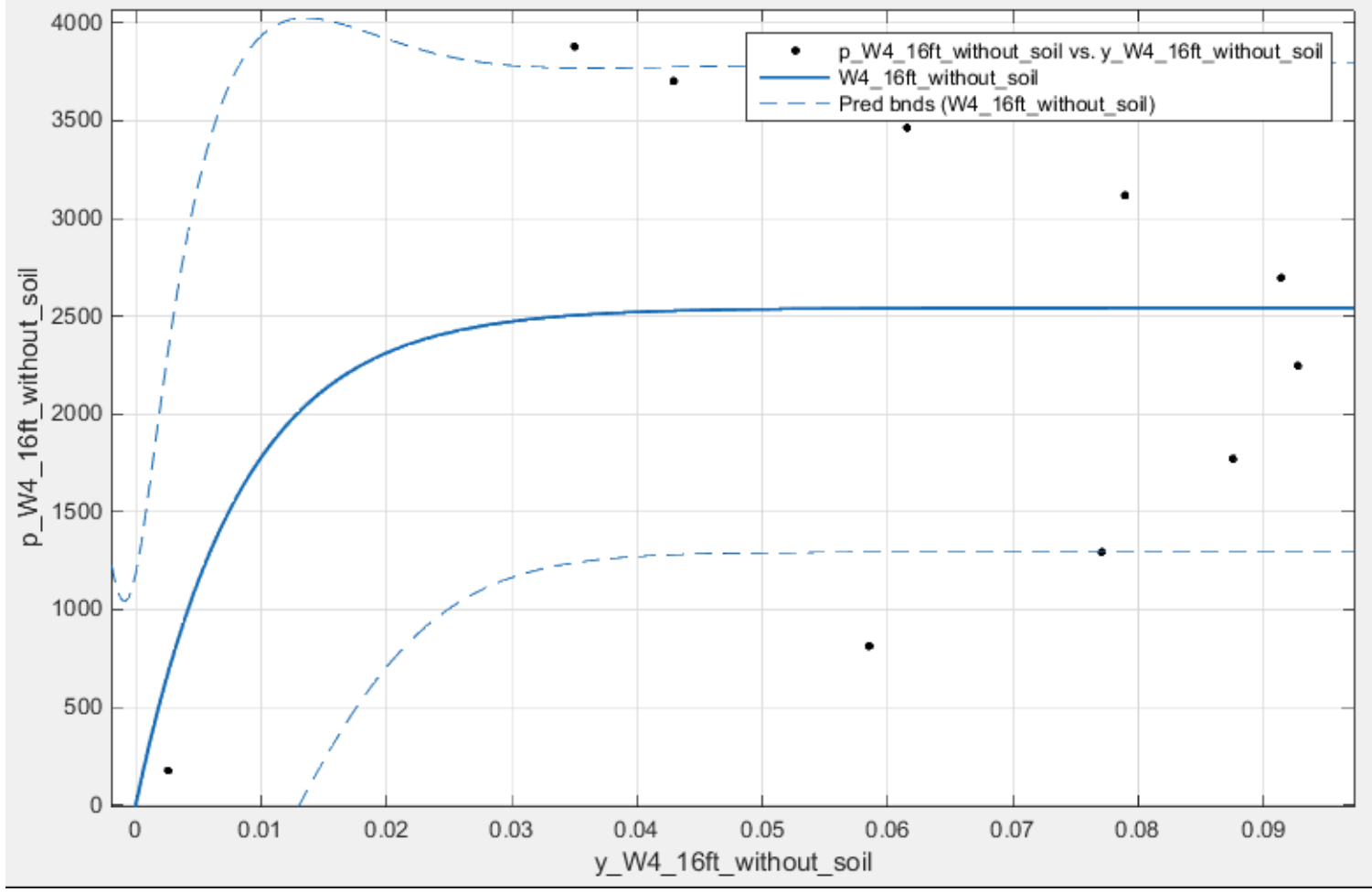

Interpreted p-y Responses and Fitted p-y curves for Lateral Load Test W-4 at $16 \mathrm{ft}$ 


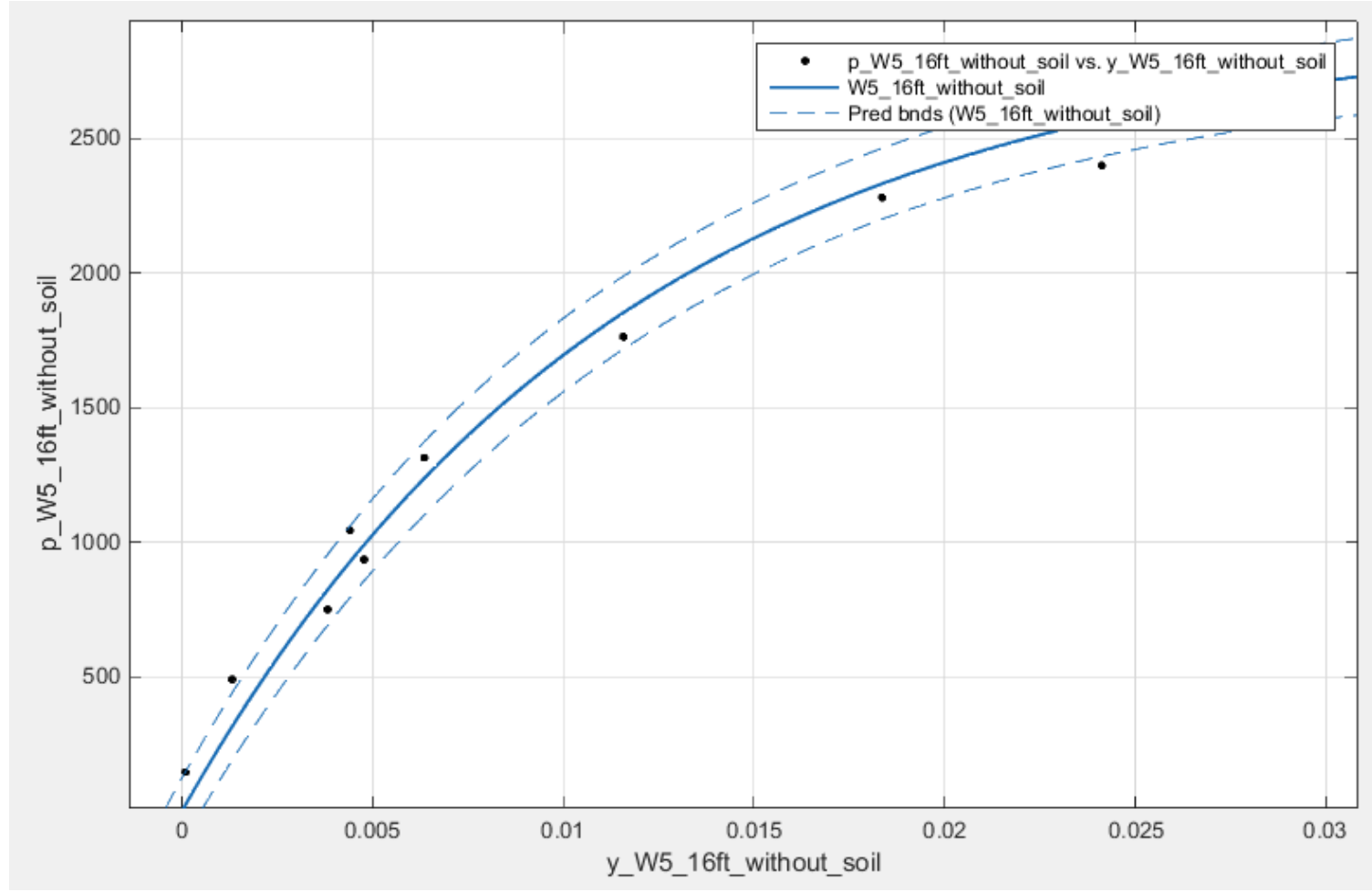

Interpreted $\mathrm{p}-\mathrm{y}$ Responses and Fitted $\mathrm{p}-\mathrm{y}$ curves for Lateral Load Test $\mathrm{W}-5$ at $16 \mathrm{ft}$

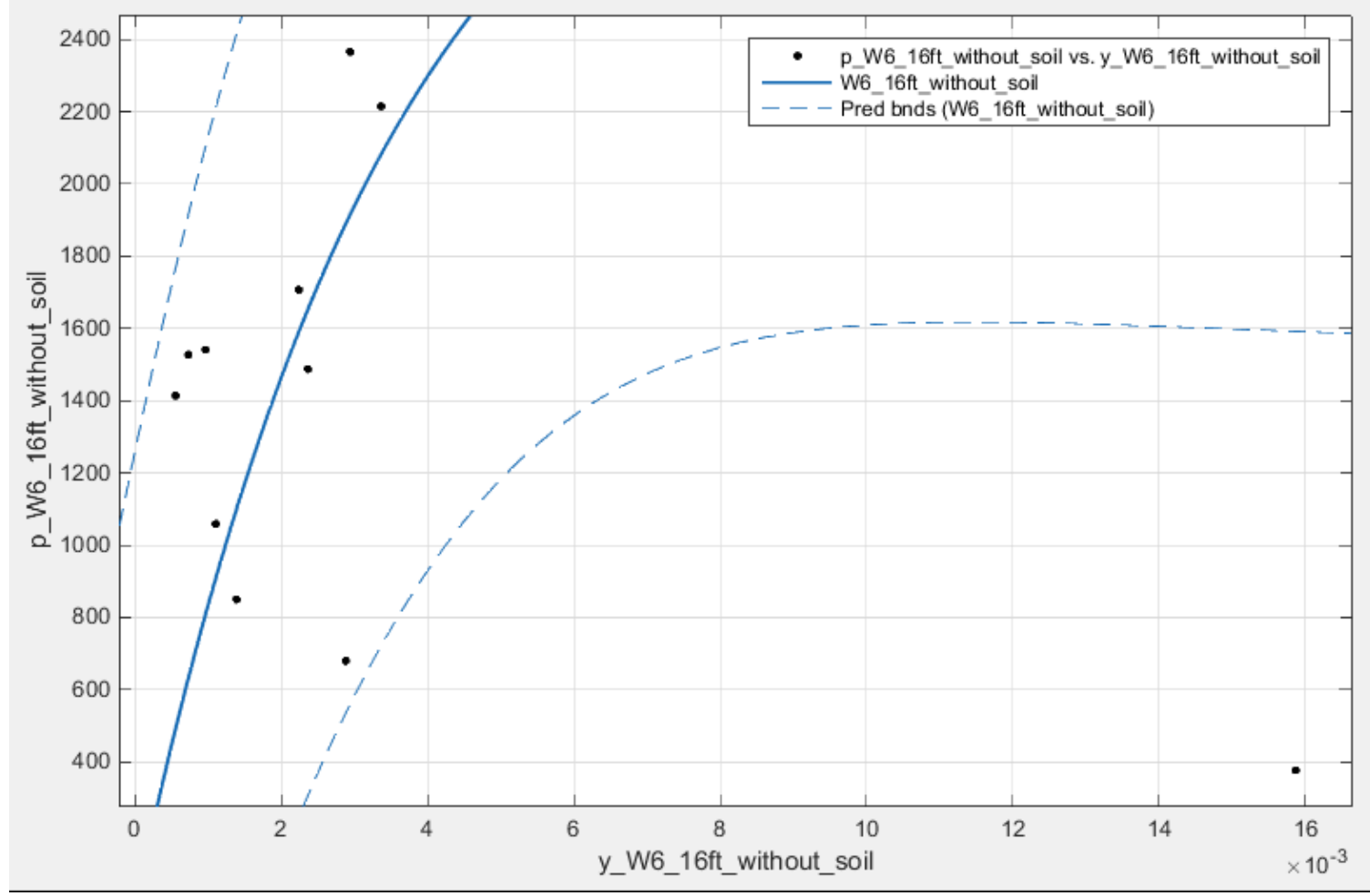

Interpreted p-y Responses and Fitted p-y curves for Lateral Load Test W- 6 at $16 \mathrm{ft}$ 


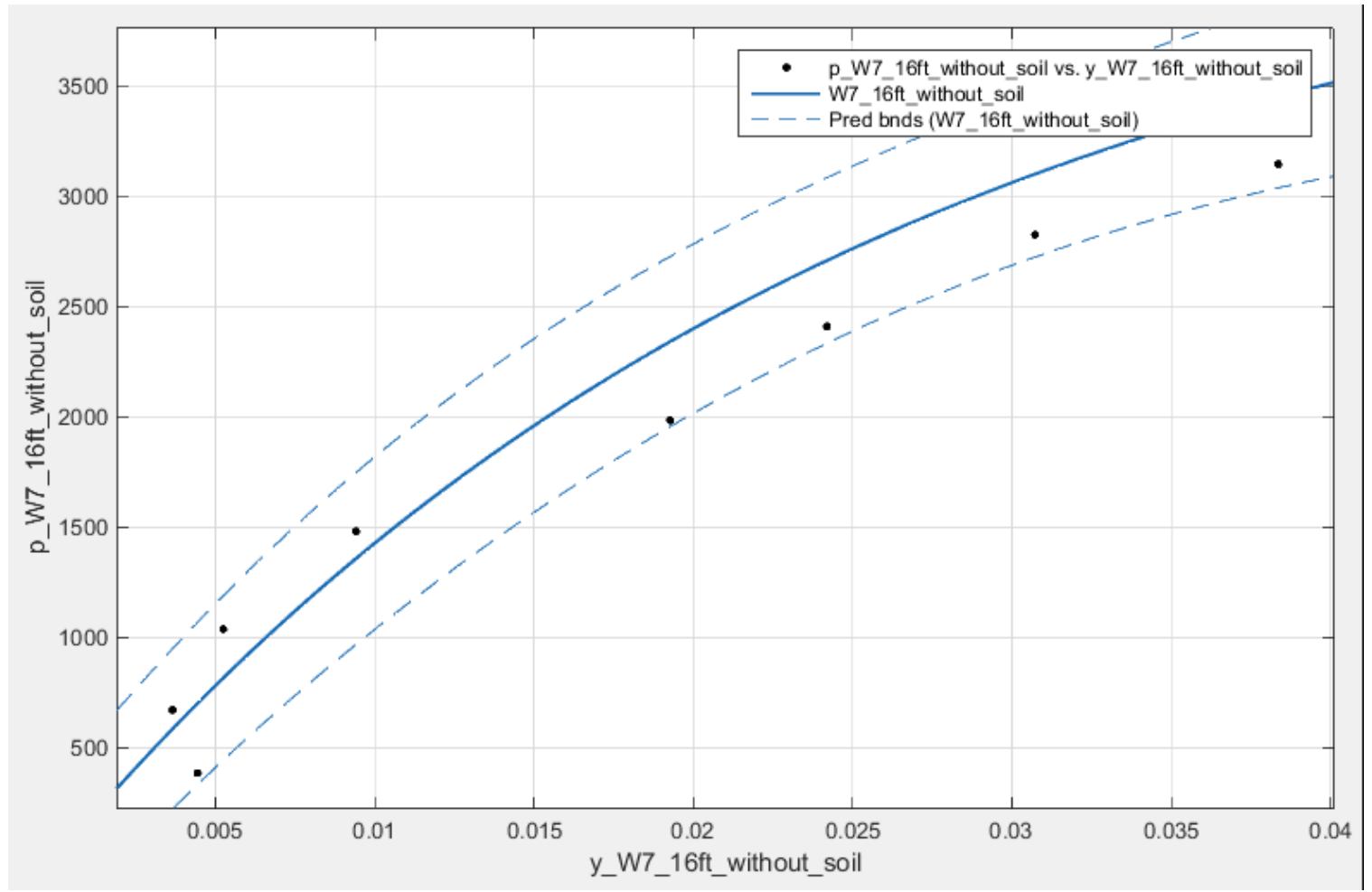

Interpreted p-y Responses and Fitted p-y curves for Lateral Load Test W-7 at $16 \mathrm{ft}$

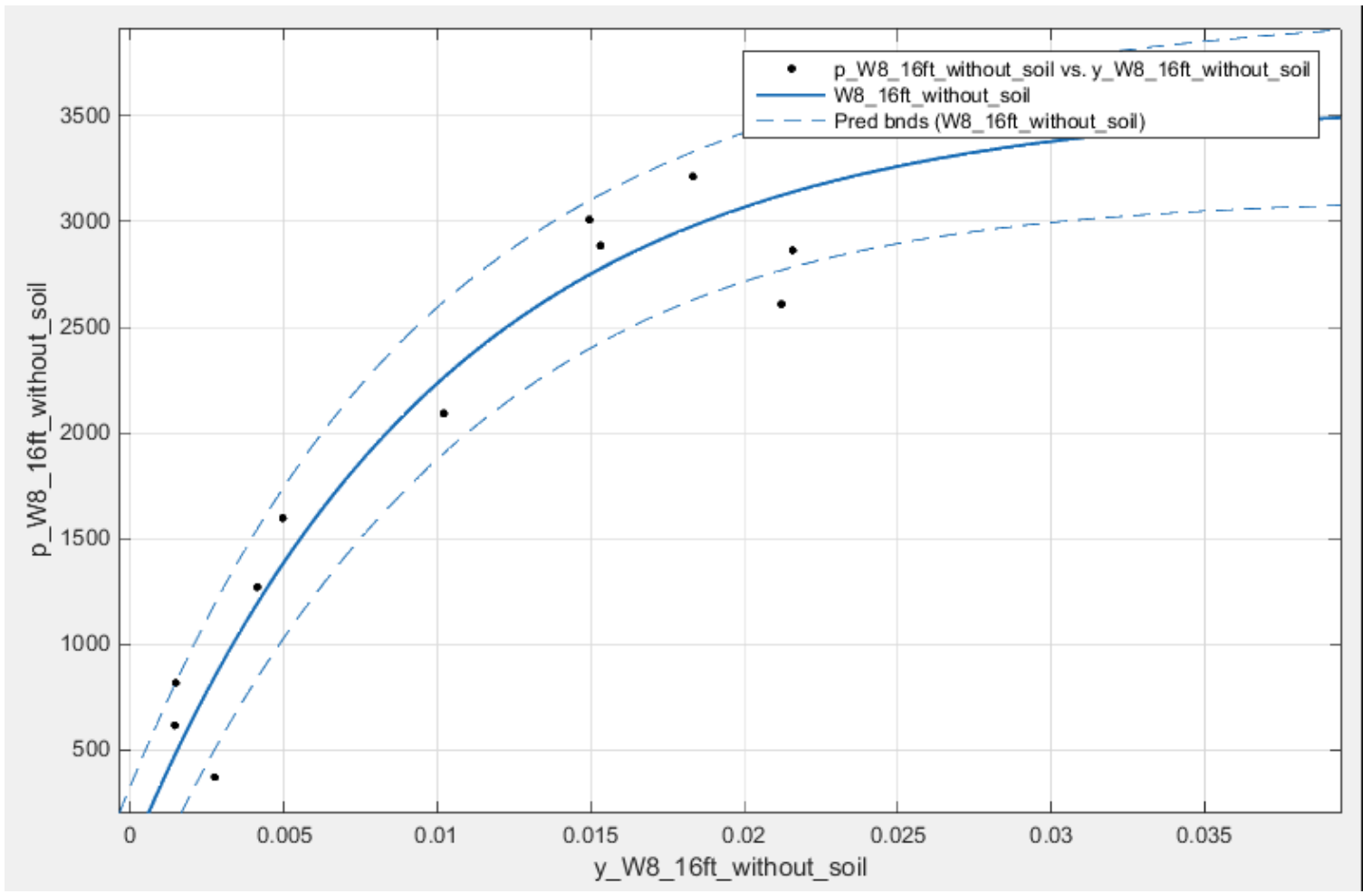

Interpreted p-y Responses and Fitted p-y curves for Lateral Load Test W-8 at $16 \mathrm{ft}$ 


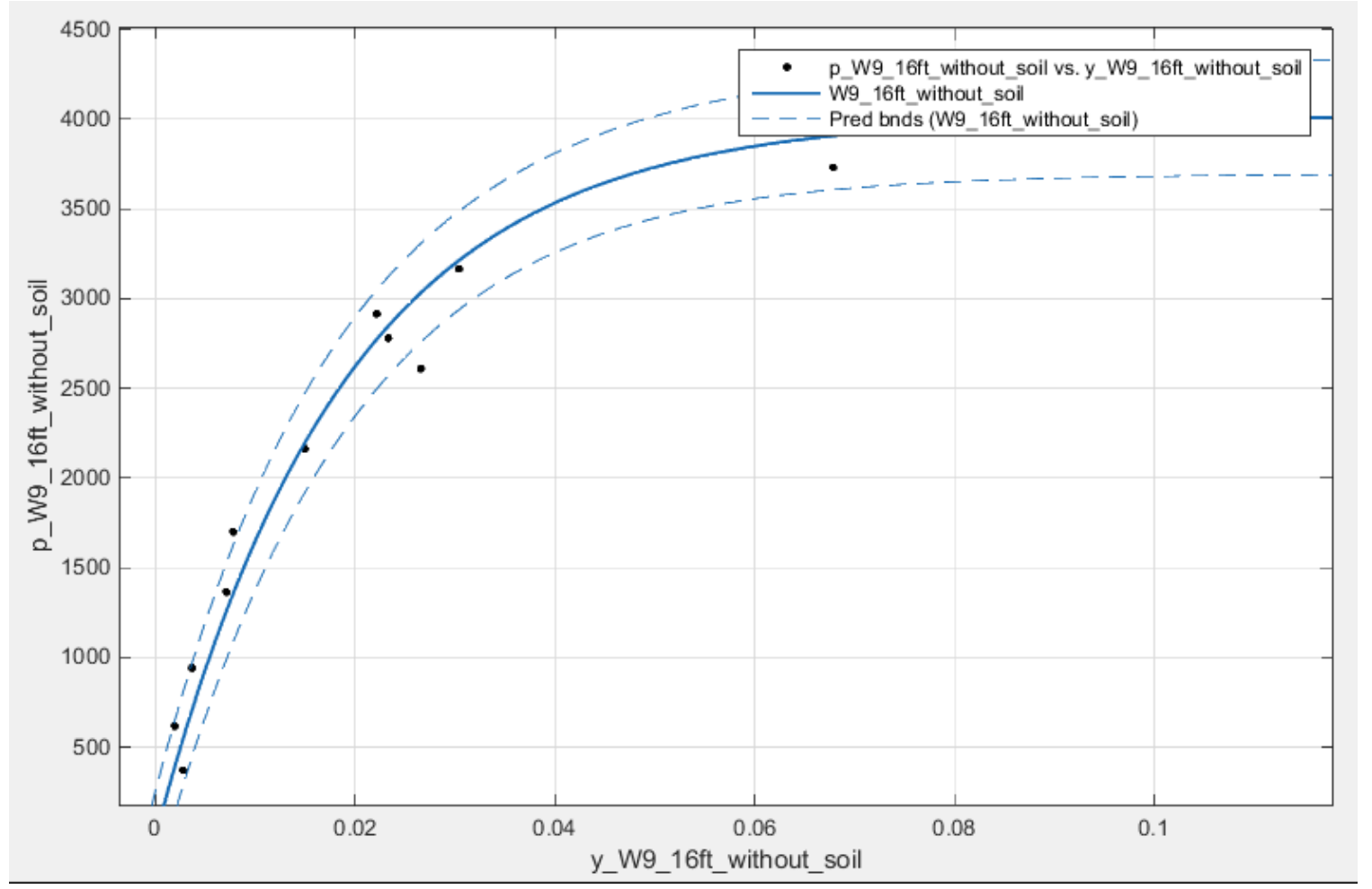

Interpreted p-y Responses and Fitted p-y curves for Lateral Load Test W-9 at $16 \mathrm{ft}$

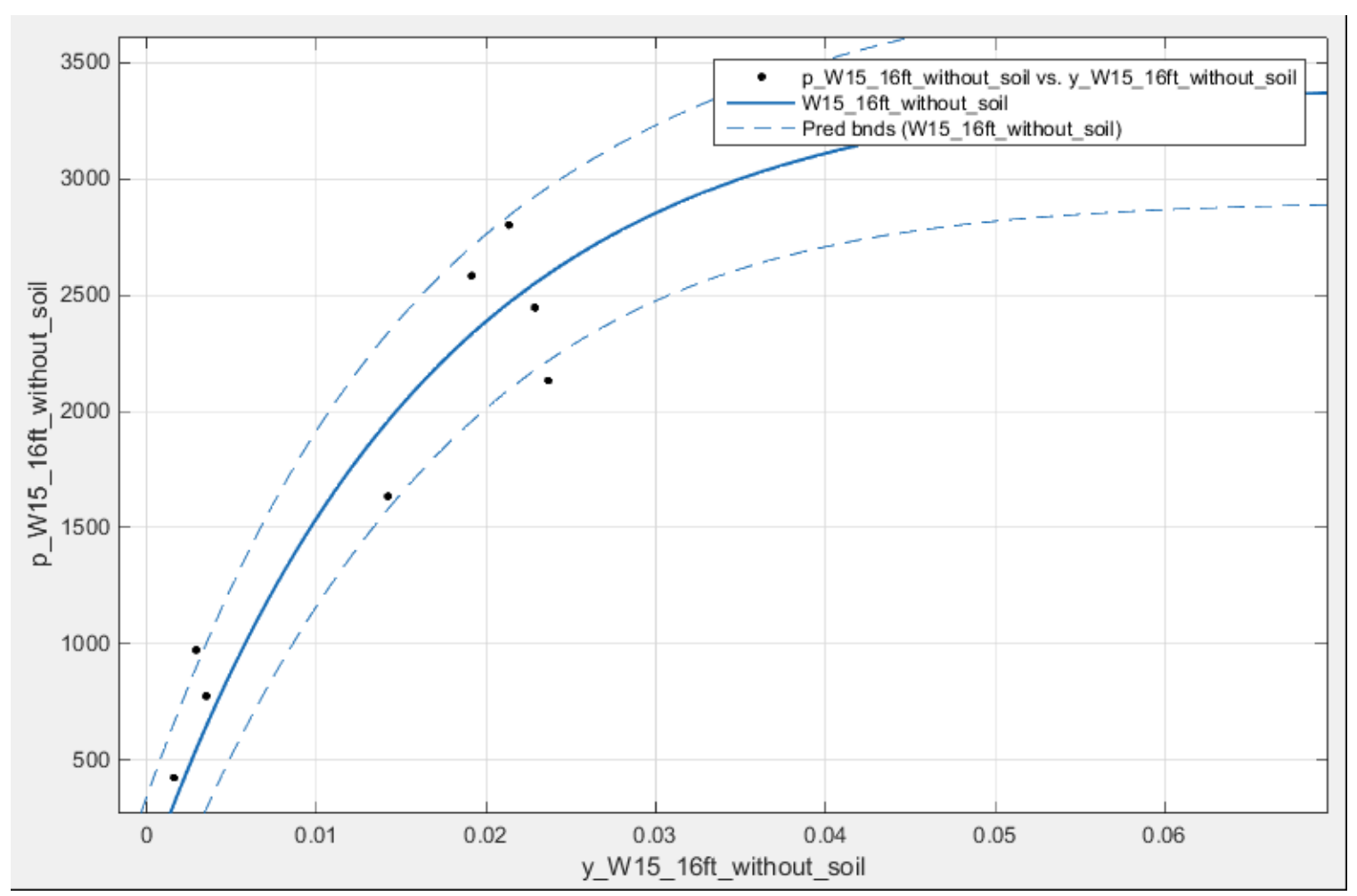

Interpreted p-y Responses and Fitted p-y curves for Lateral Load Test W-15 at $16 \mathrm{ft}$ 


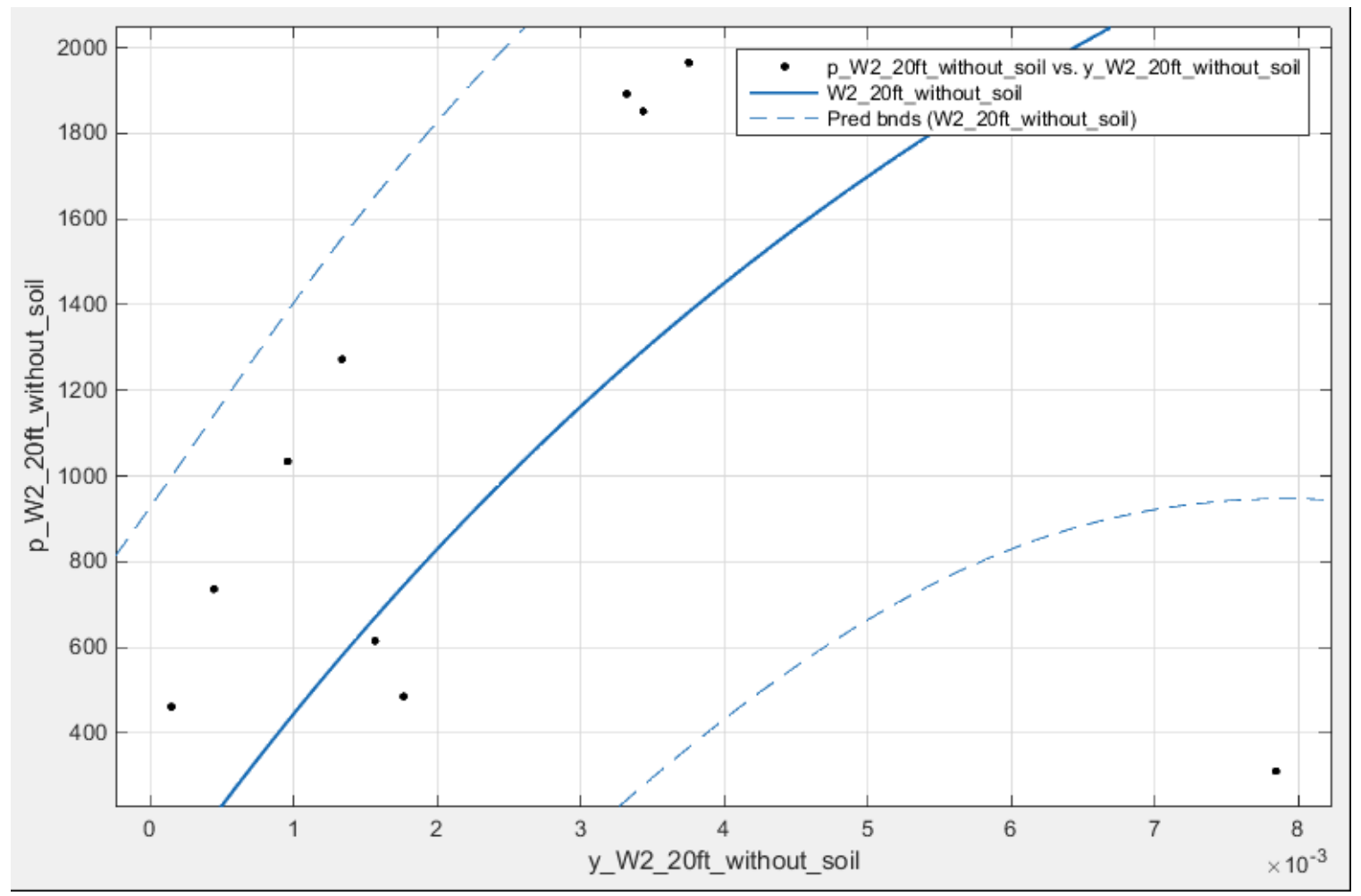

Interpreted p-y Responses and Fitted p-y curves for Lateral Load Test W-2 at $20 \mathrm{ft}$

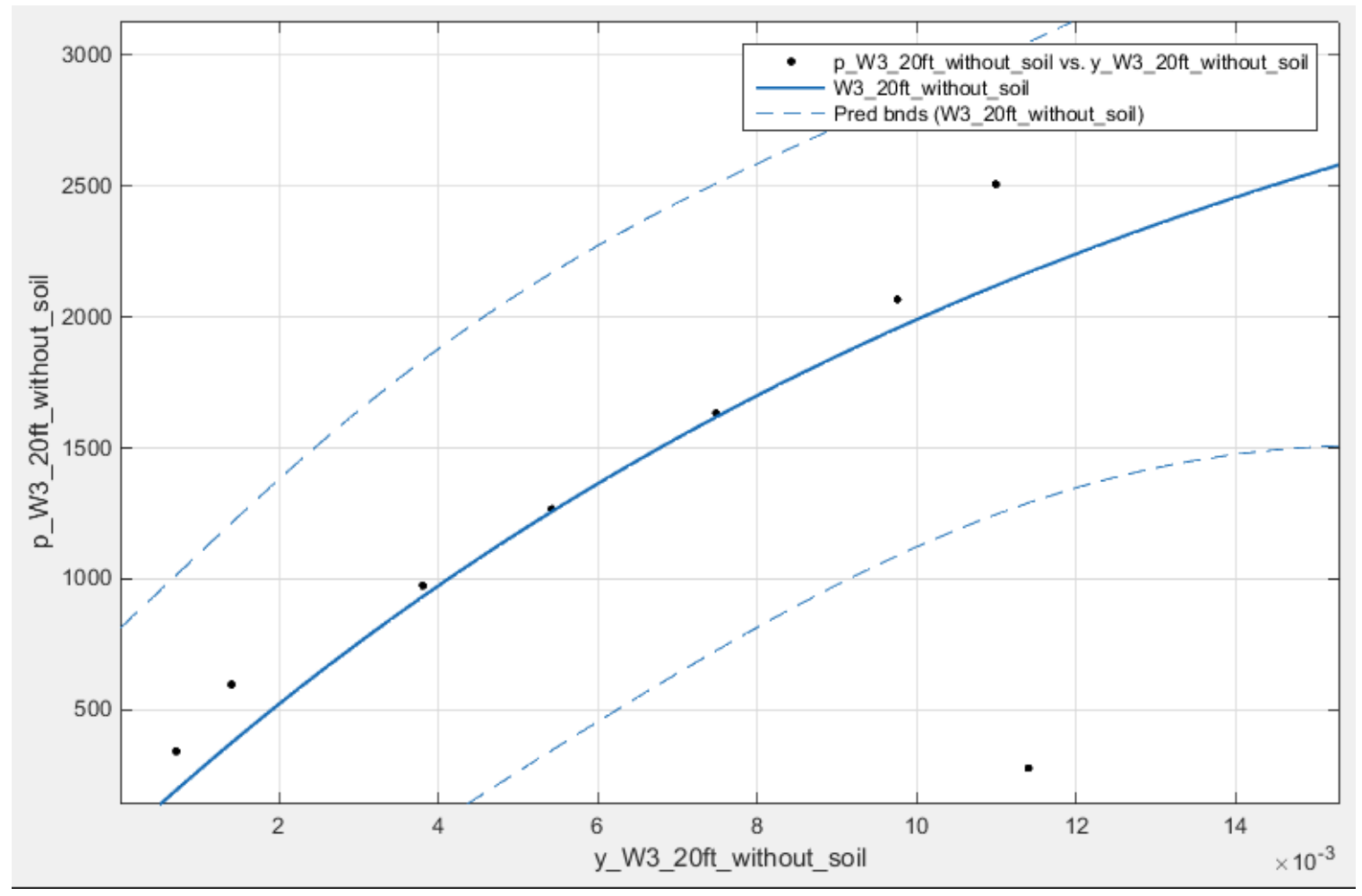

Interpreted p-y Responses and Fitted p-y curves for Lateral Load Test W-3 at 20ft 


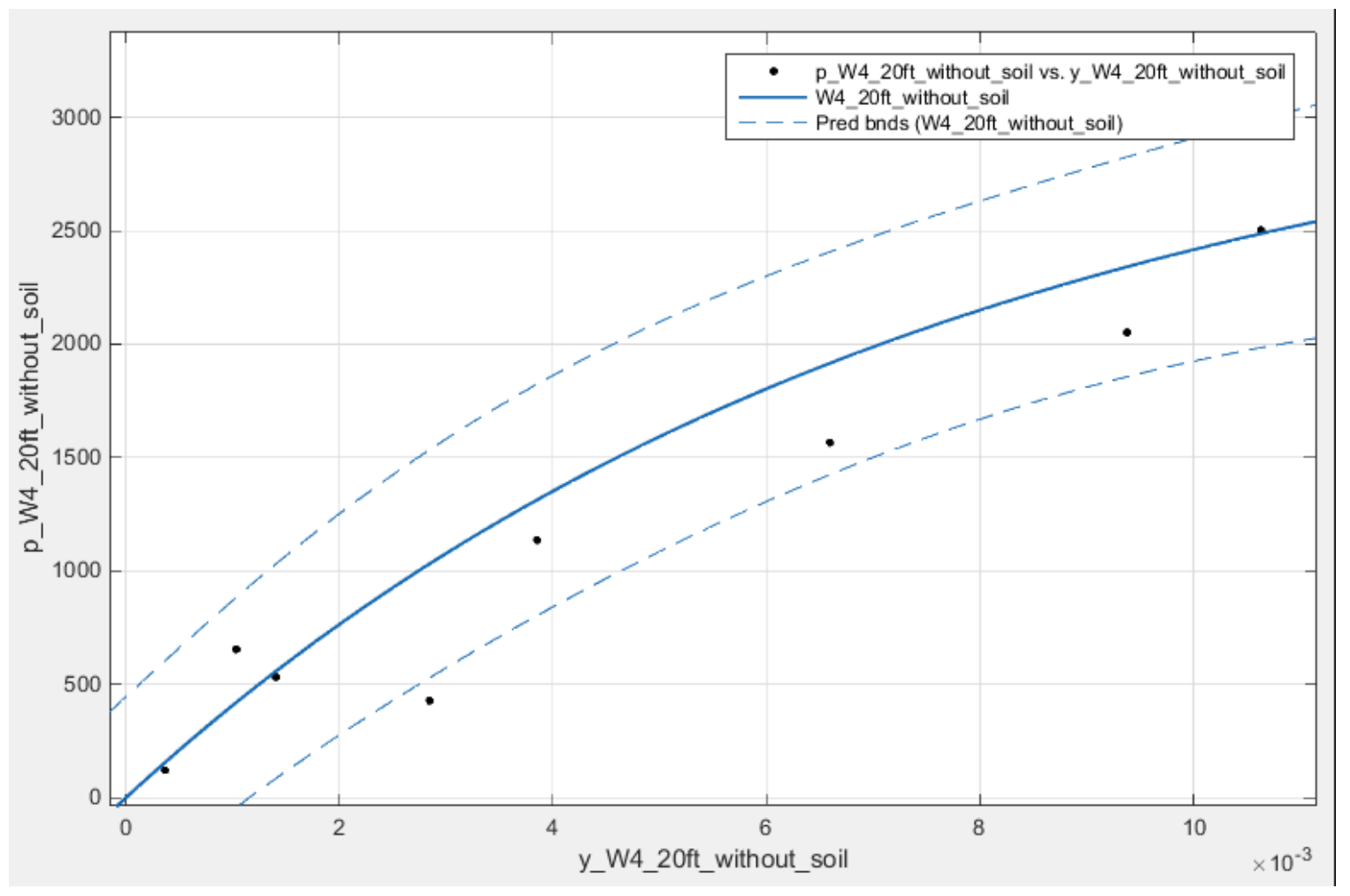

Interpreted p-y Responses and Fitted p-y curves for Lateral Load Test W-4 at $20 \mathrm{ft}$

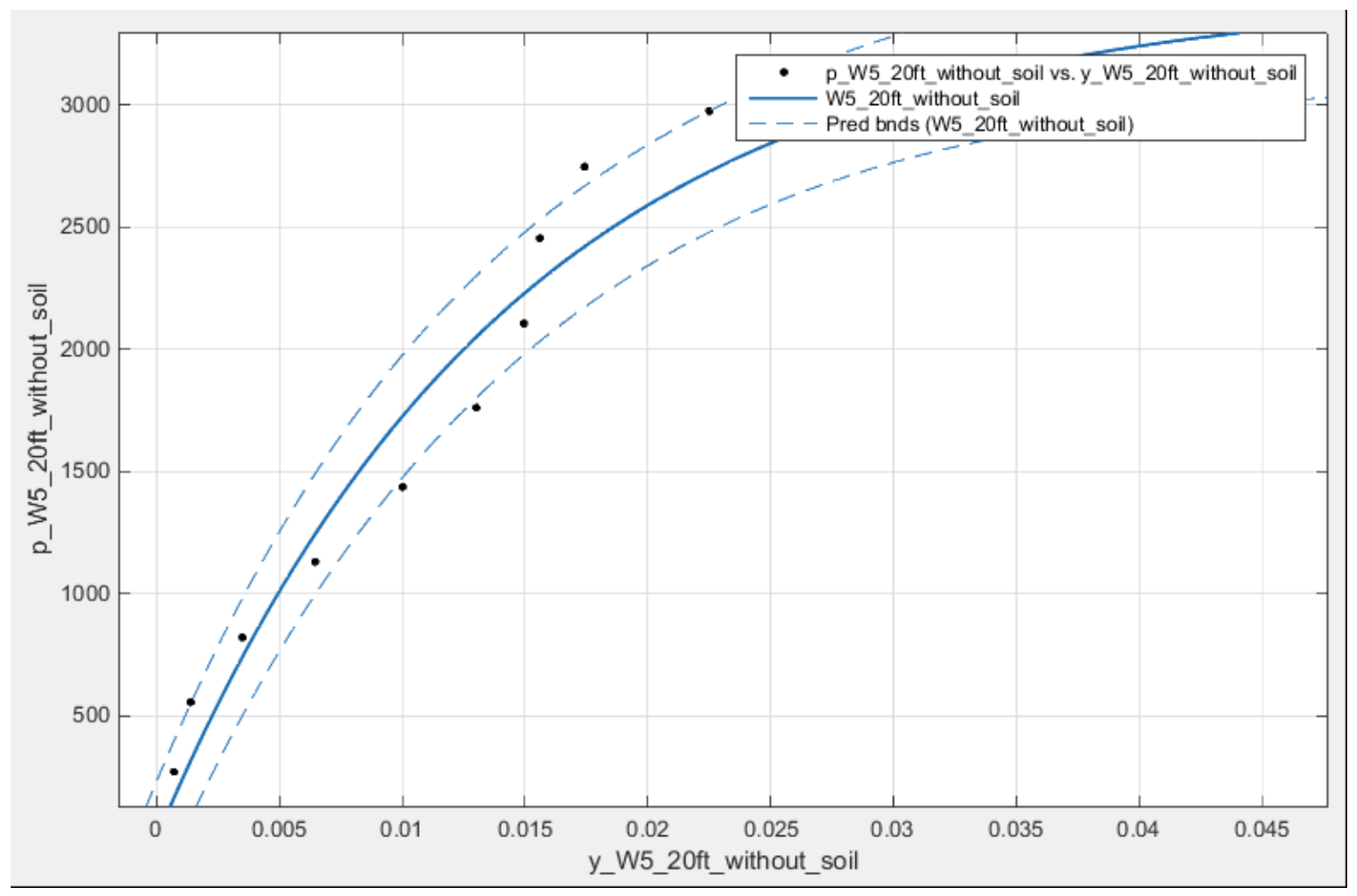

Interpreted p-y Responses and Fitted p-y curves for Lateral Load Test W-5 at $20 \mathrm{ft}$ 


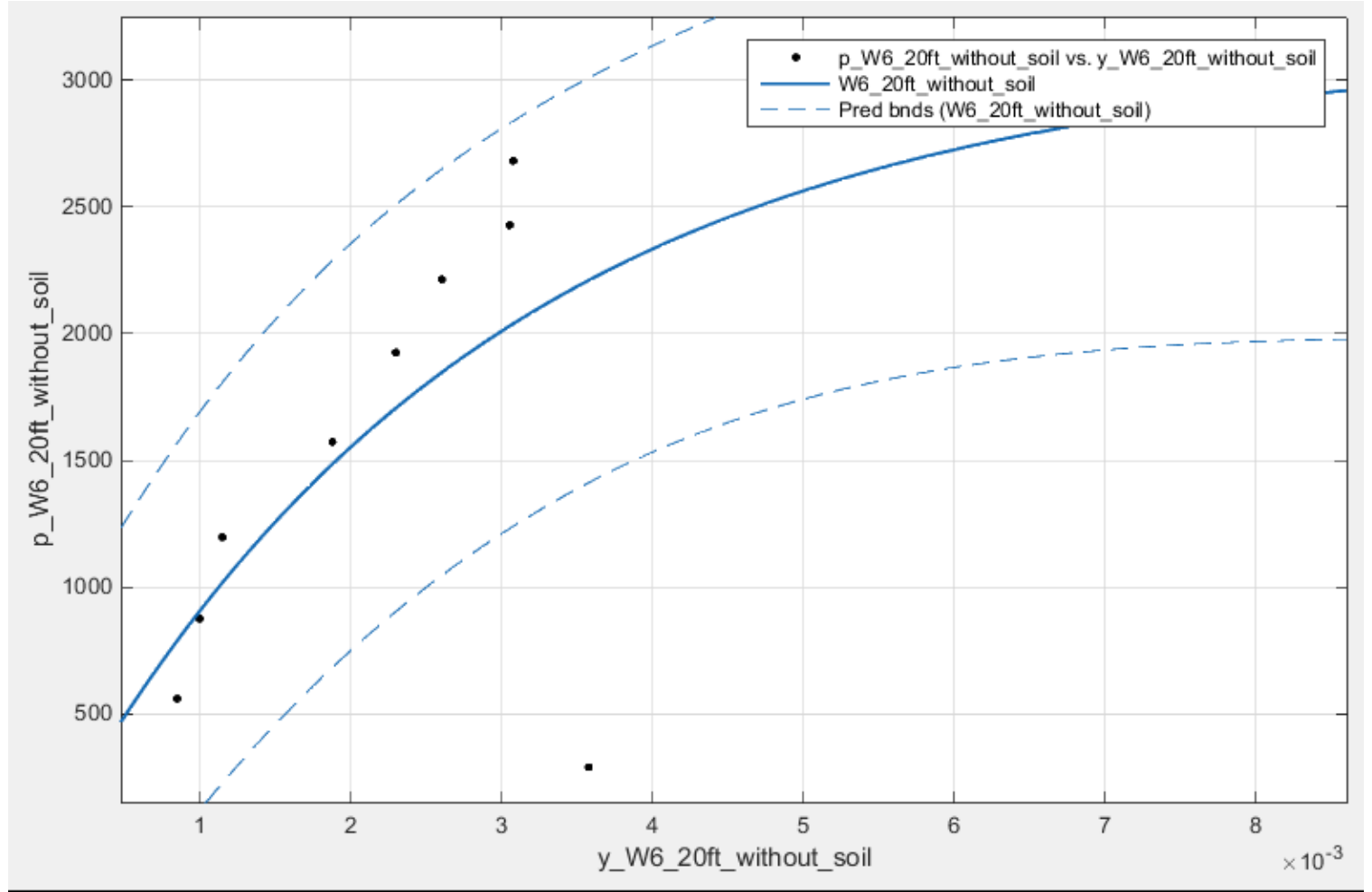

Interpreted p-y Responses and Fitted p-y curves for Lateral Load Test W-6 at 20ft

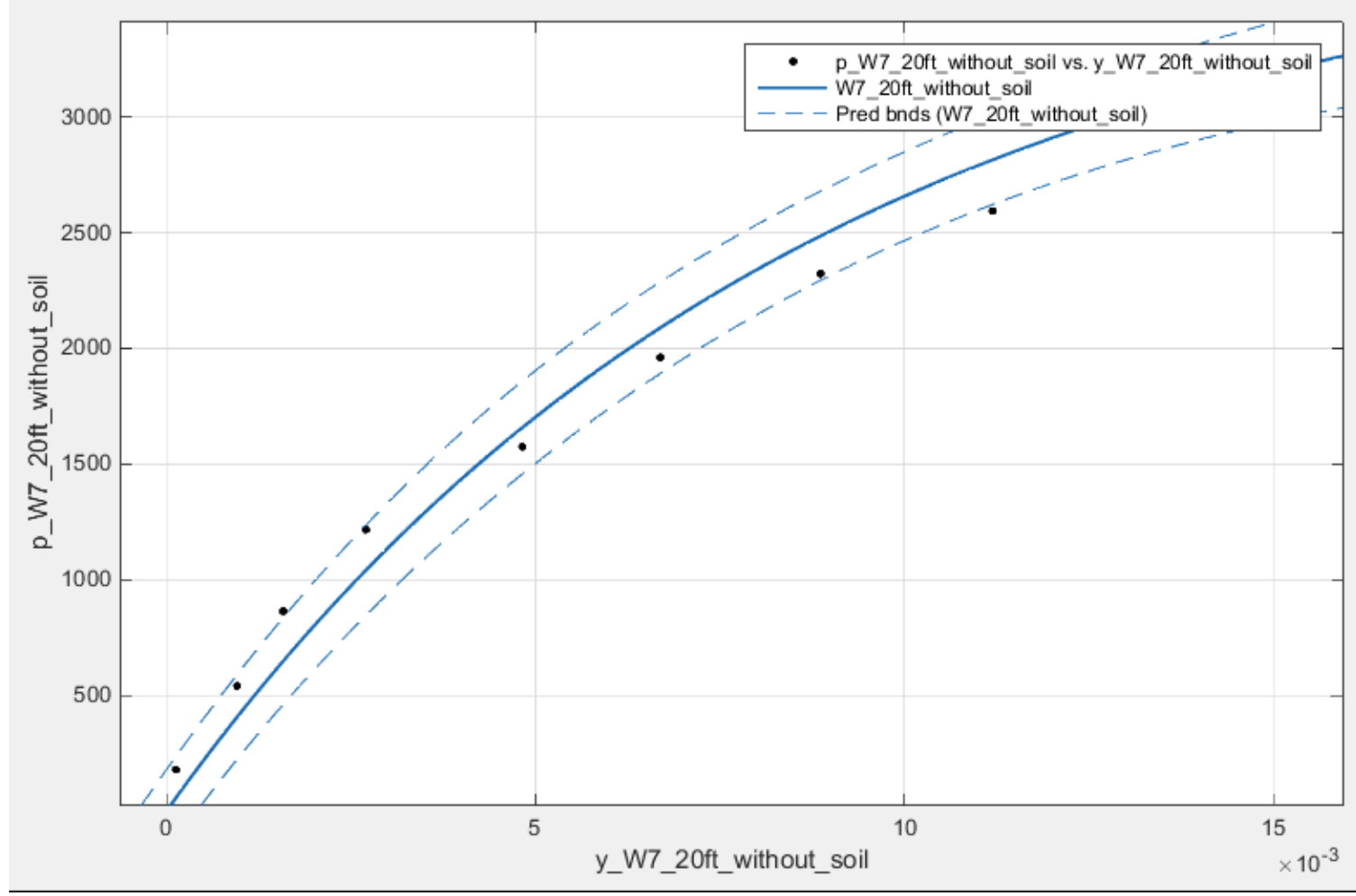

Interpreted p-y Responses and Fitted p-y curves for Lateral Load Test W-7 at $20 \mathrm{ft}$ 


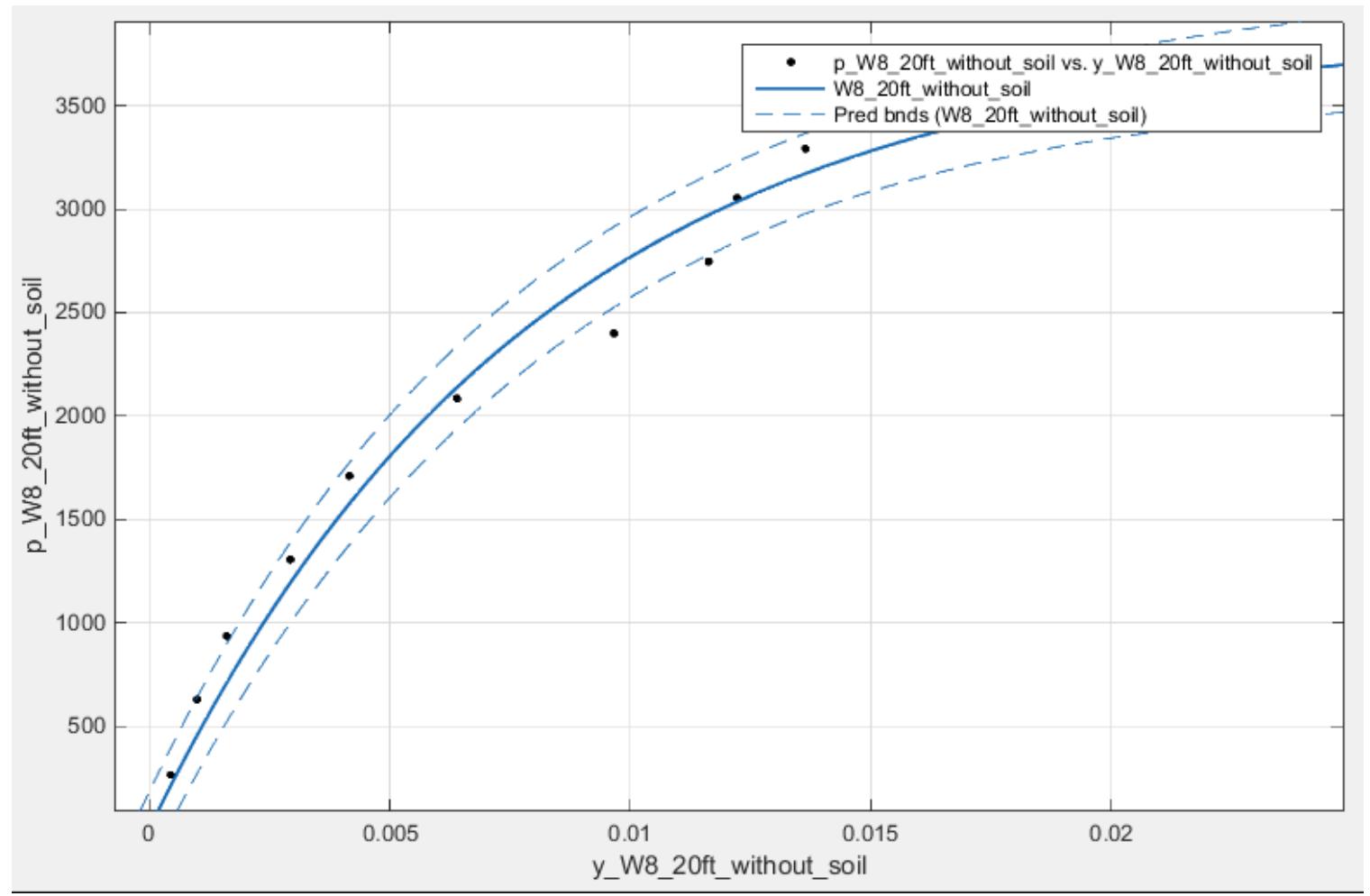

Interpreted p-y Responses and Fitted p-y curves for Lateral Load Test W-8 at 20ft

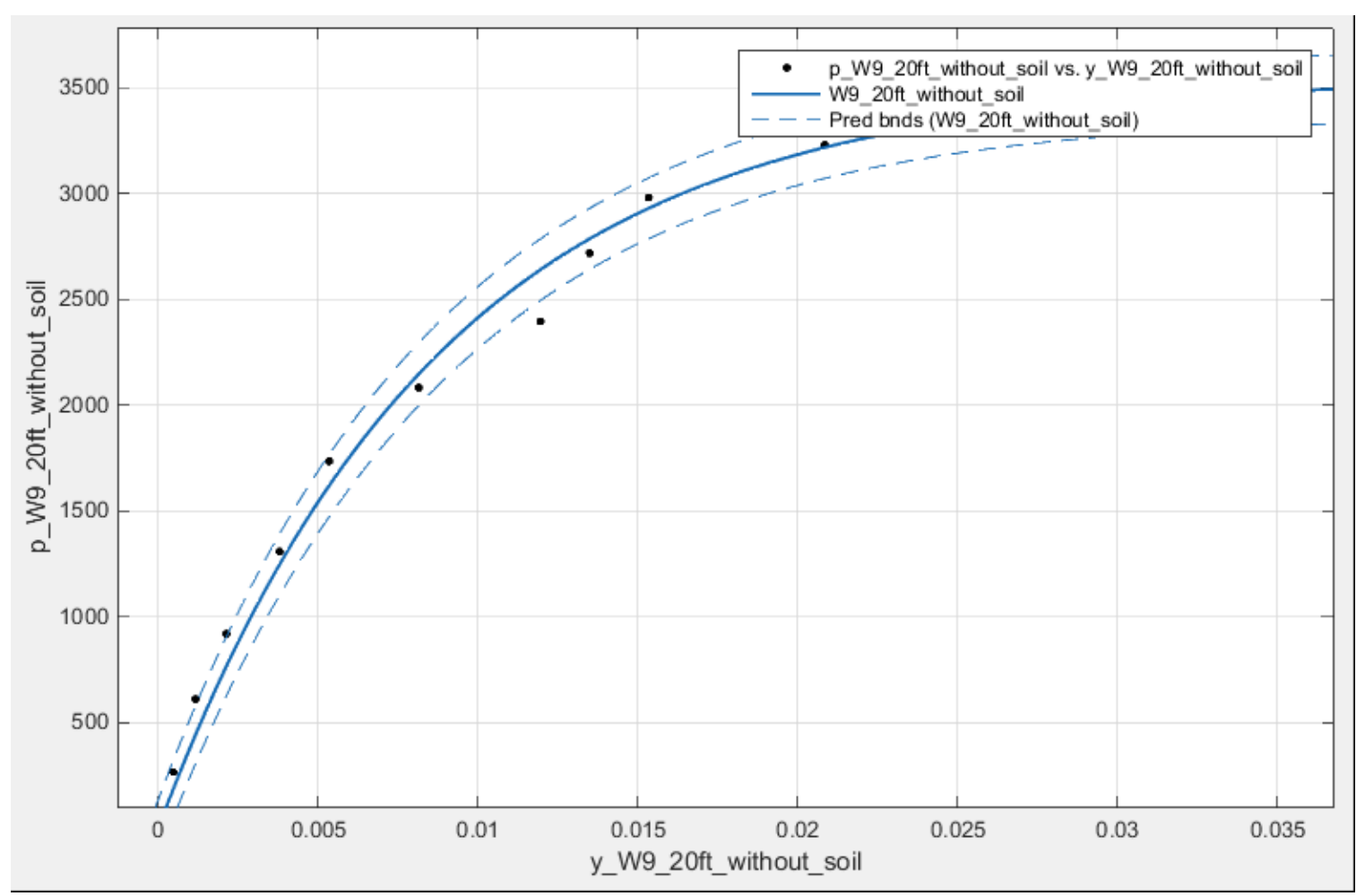

Interpreted p-y Responses and Fitted p-y curves for Lateral Load Test W-9 at 20ft 


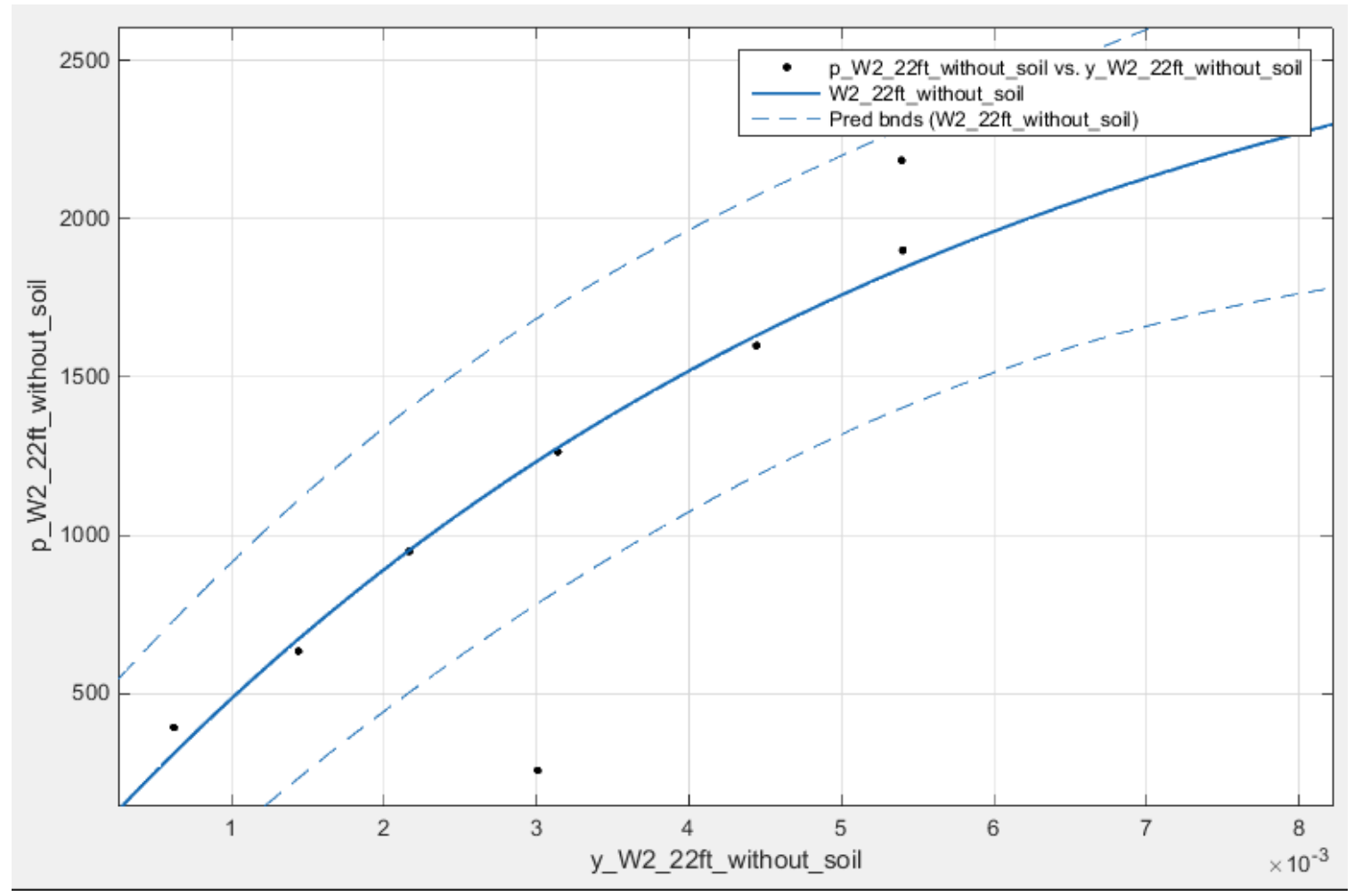

Interpreted p-y Responses and Fitted p-y curves for Lateral Load Test W-2 at $22 \mathrm{ft}$

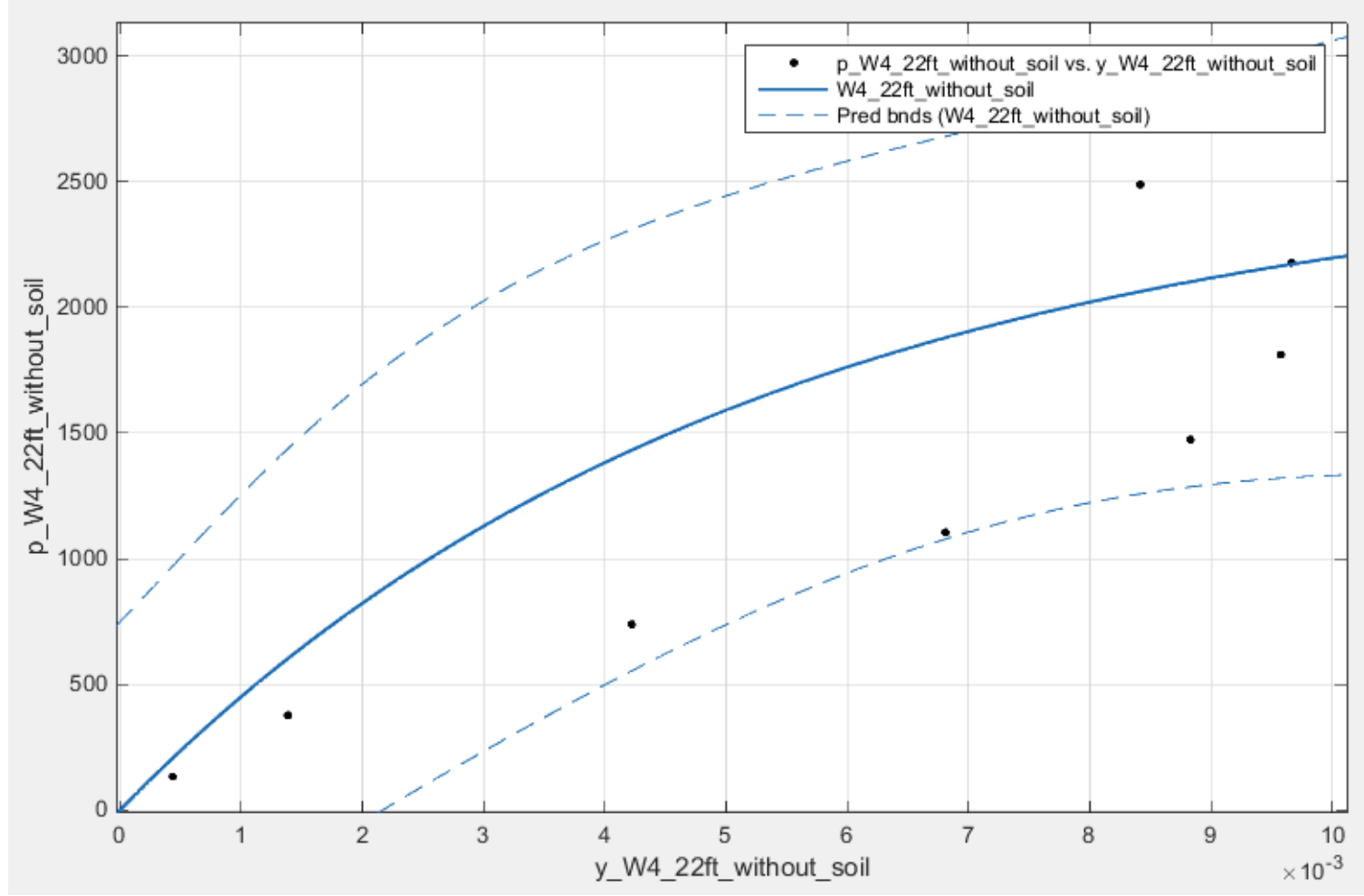

Interpreted $p-y$ Responses and Fitted $p-y$ curves for Lateral Load Test $W-4$ at $22 \mathrm{ft}$ 


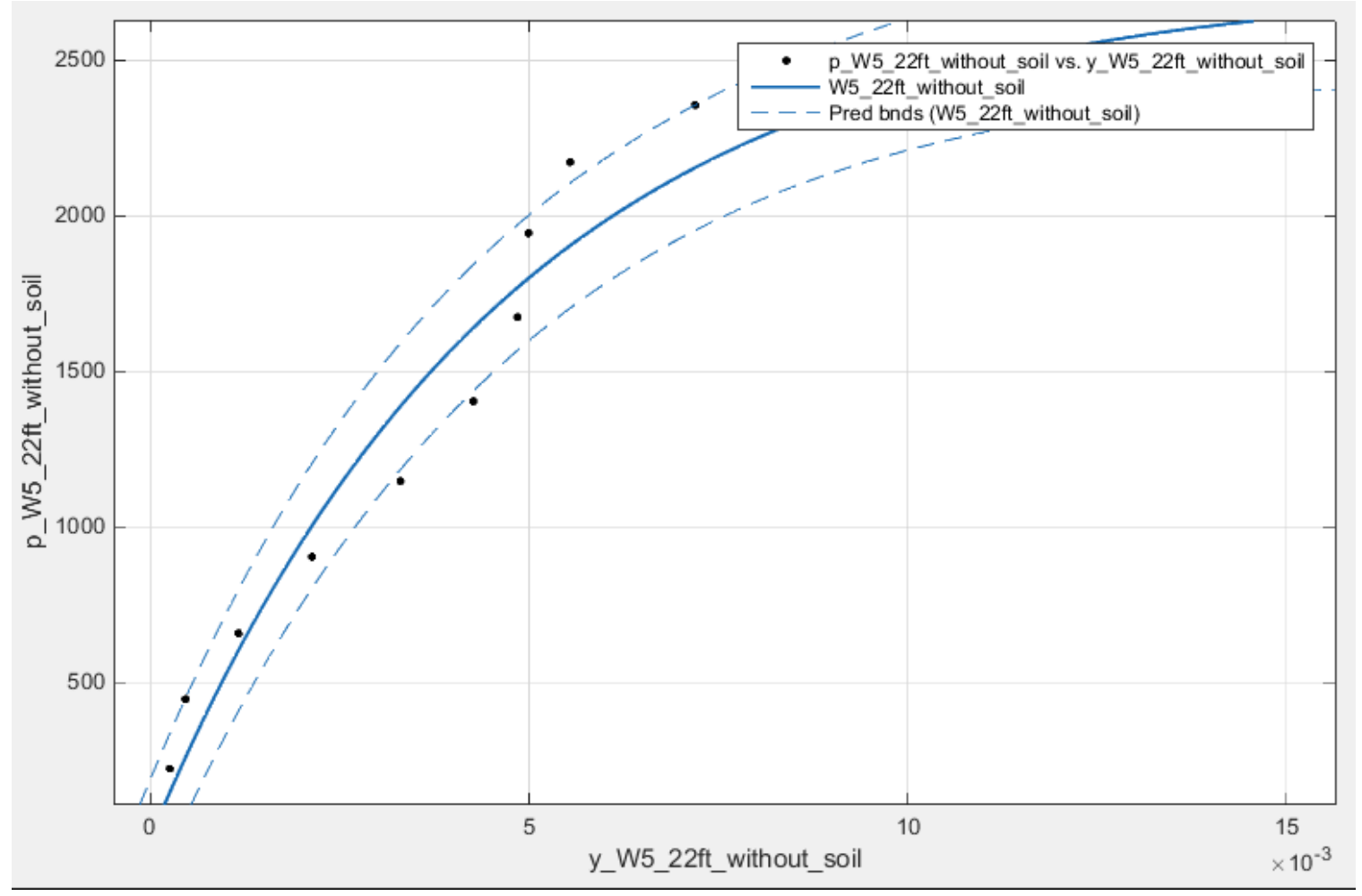

Interpreted $p-y$ Responses and Fitted $p-y$ curves for Lateral Load Test W-5 at $22 \mathrm{ft}$

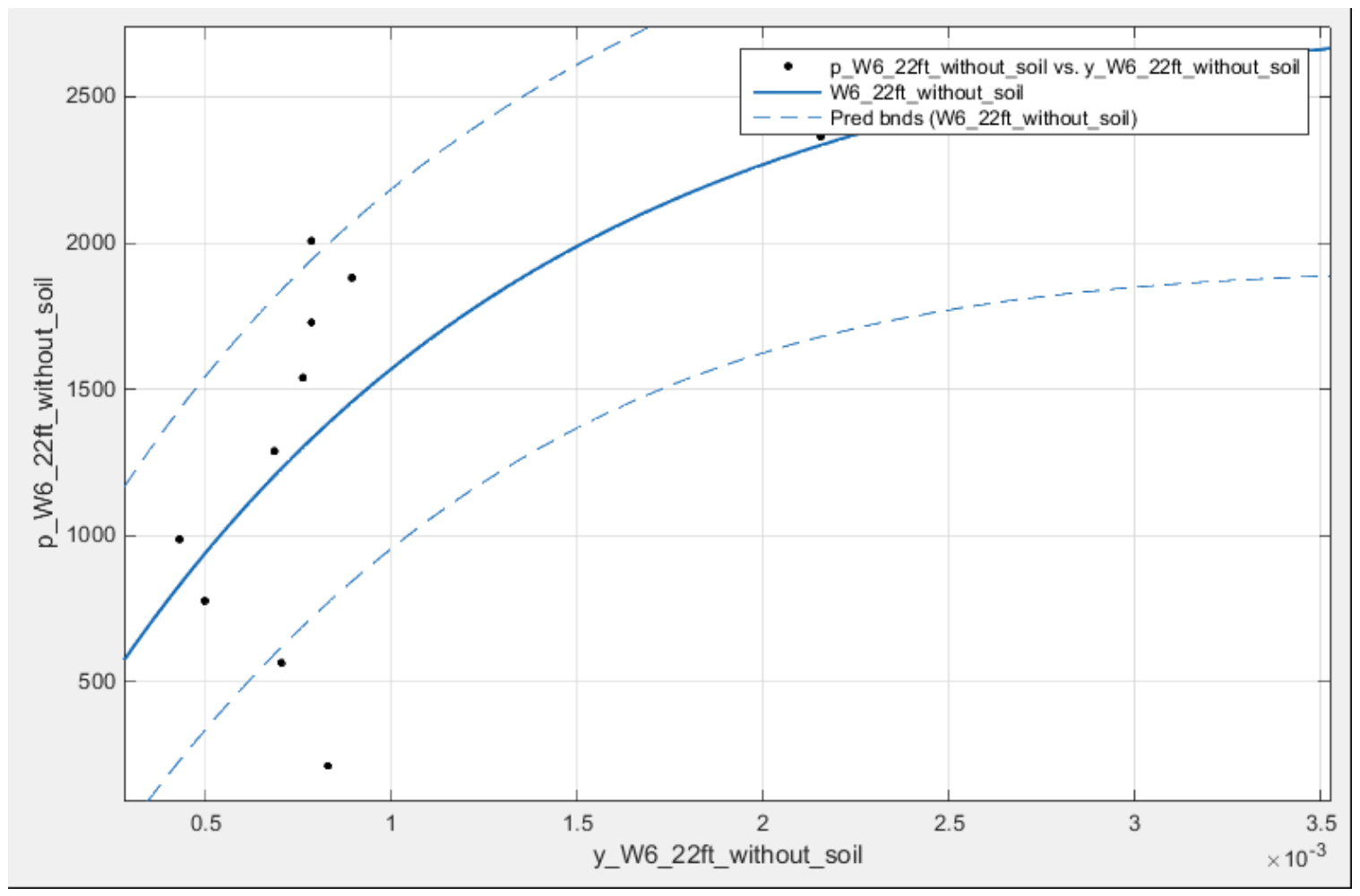

Interpreted p-y Responses and Fitted p-y curves for Lateral Load Test W-6 at 22ft 


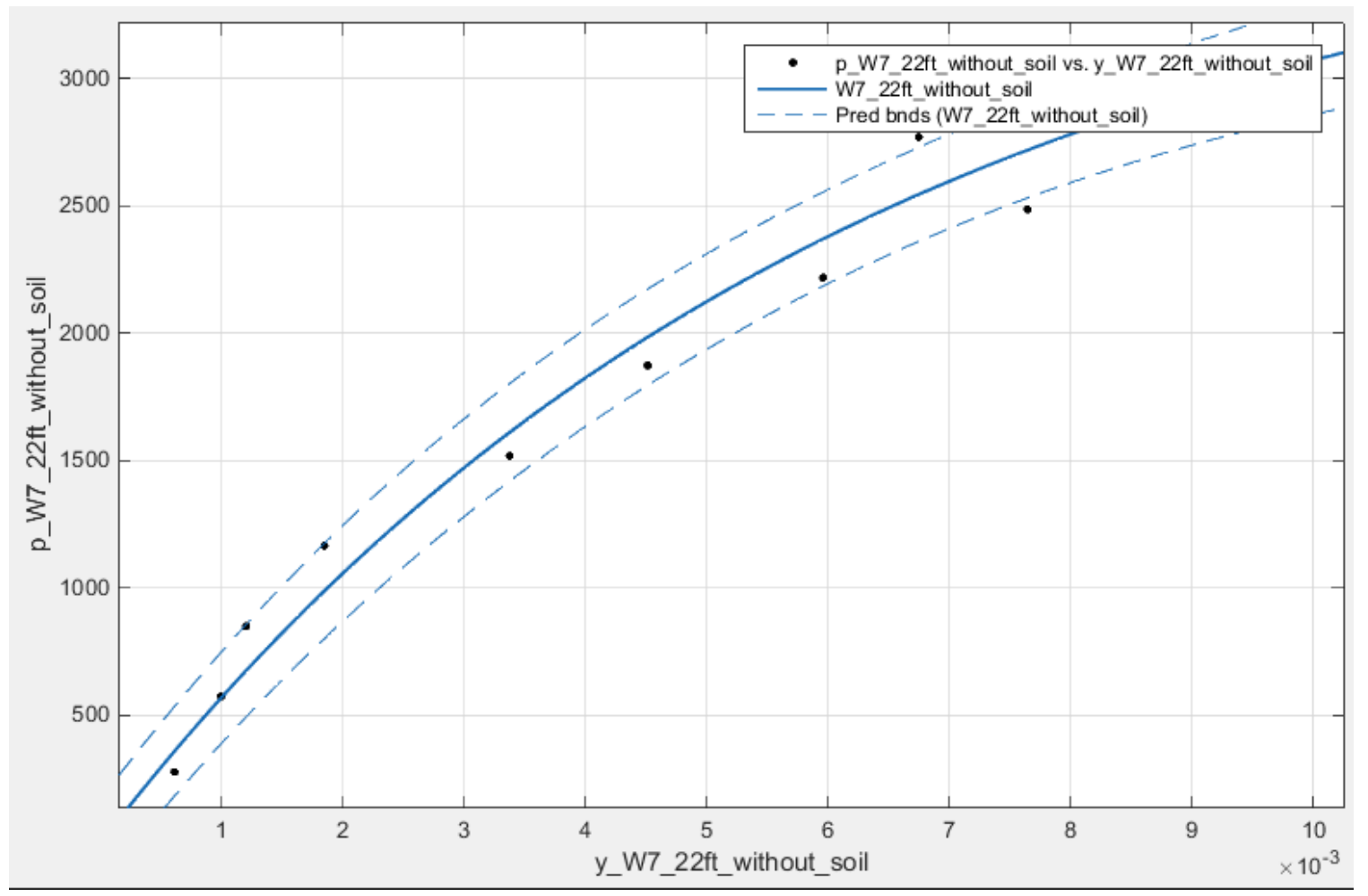

Interpreted p-y Responses and Fitted p-y curves for Lateral Load Test W-7 at $22 \mathrm{ft}$

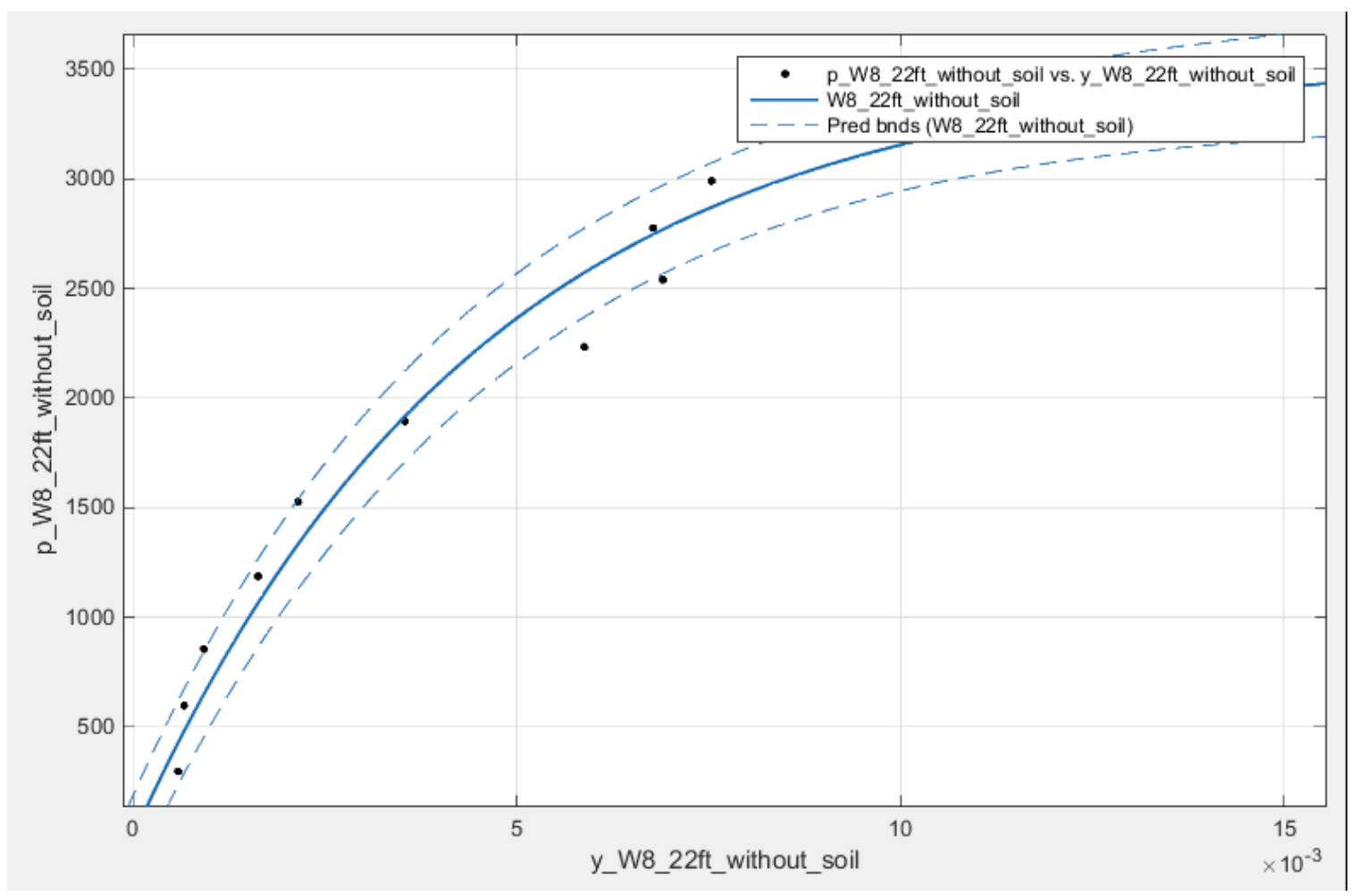

Interpreted p-y Responses and Fitted p-y curves for Lateral Load Test W-8 at $22 \mathrm{ft}$ 


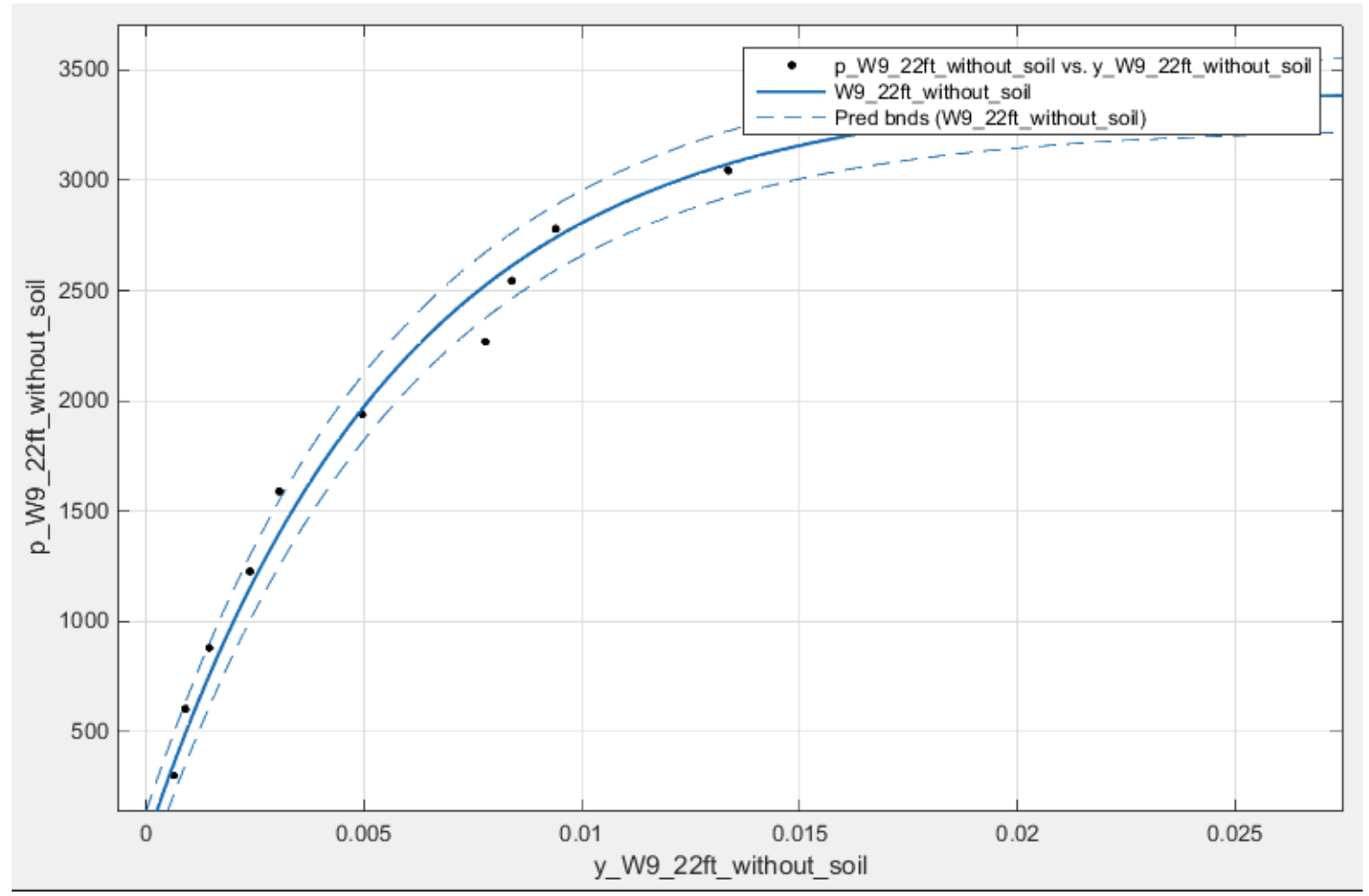

Interpreted p-y Responses and Fitted p-y curves for Lateral Load Test W-9 at $22 \mathrm{ft}$

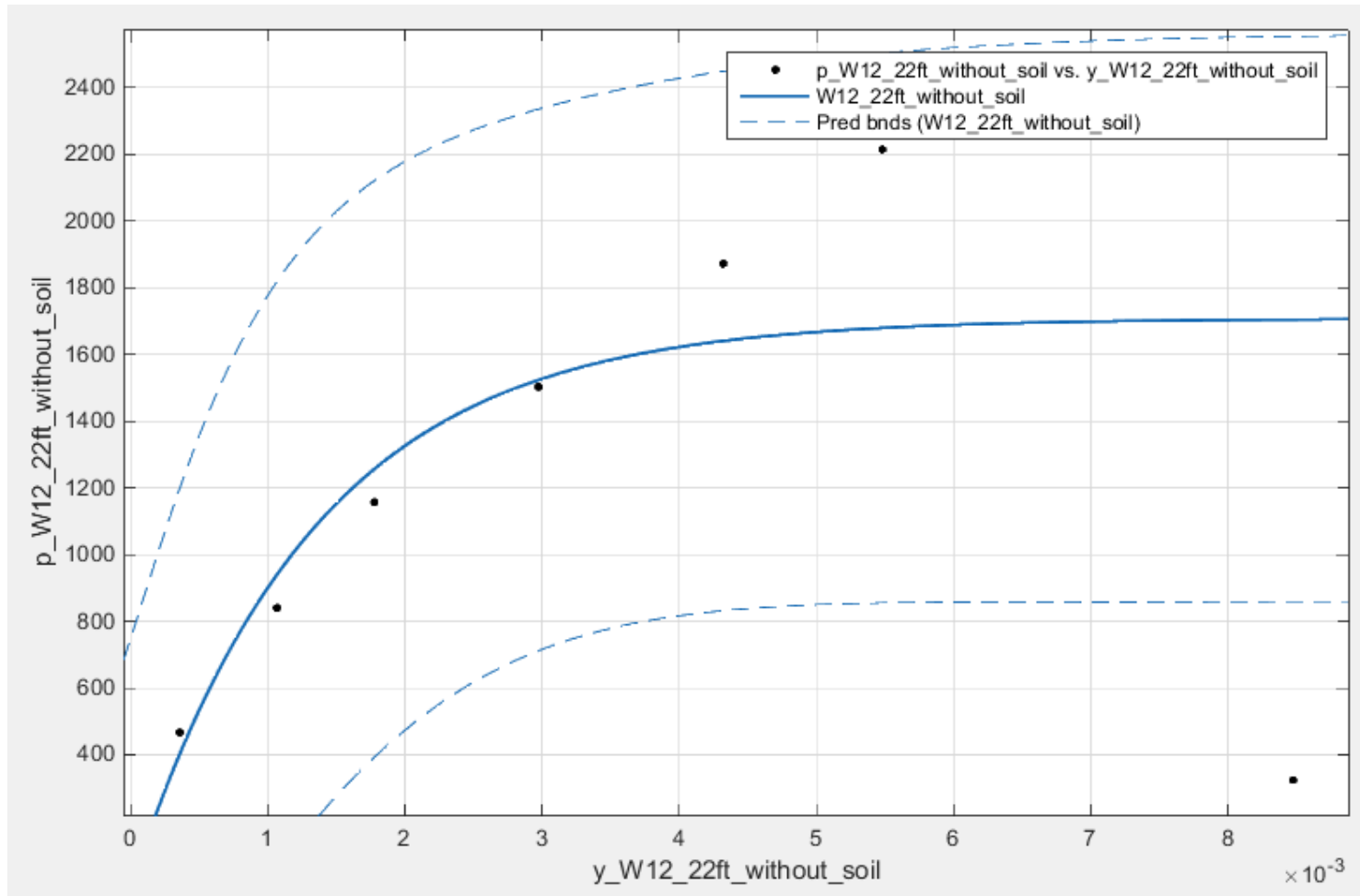

Interpreted p-y Responses and Fitted p-y curves for Lateral Load Test W-12 at 22ft 


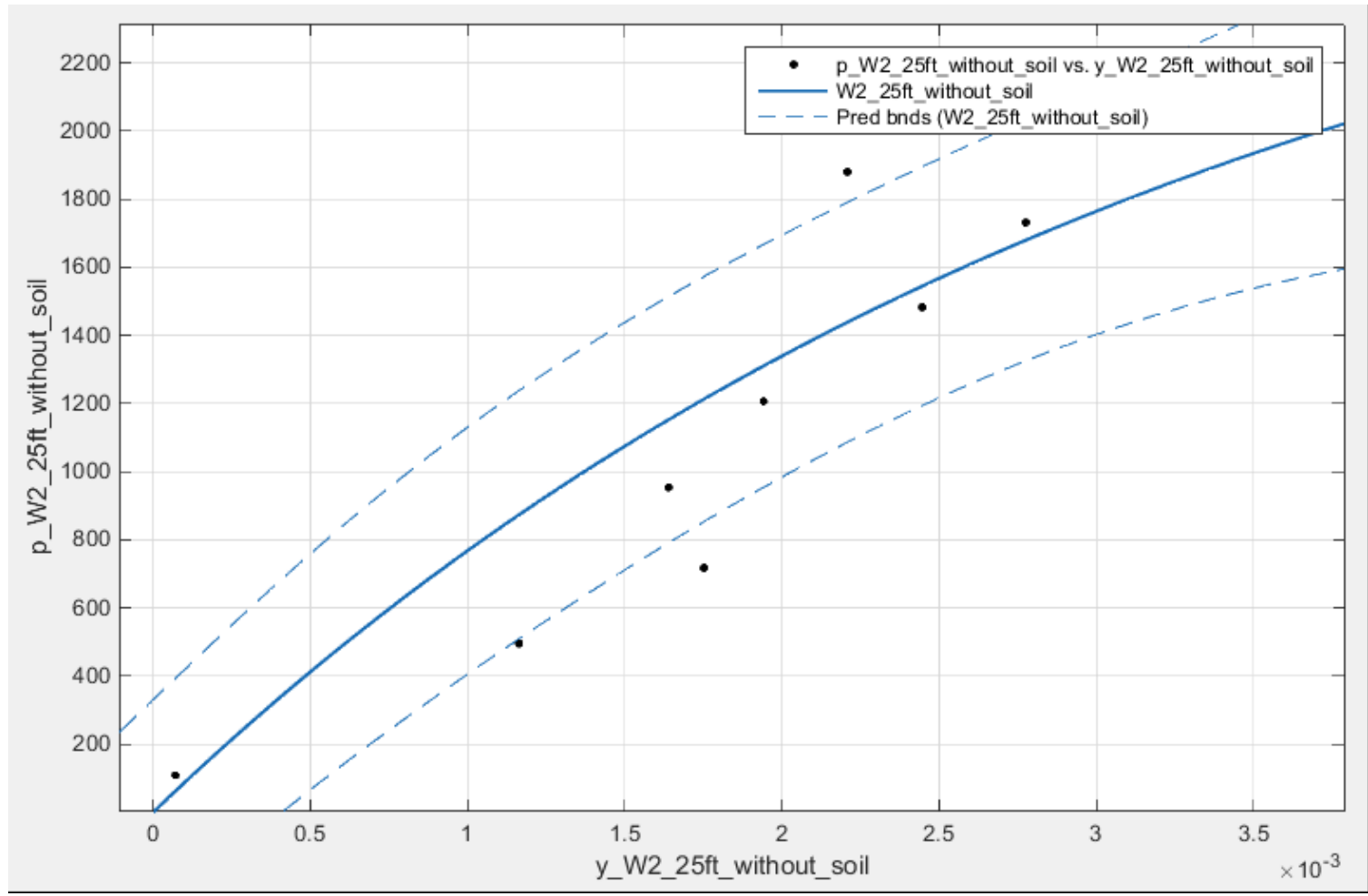

Interpreted p-y Responses and Fitted p-y curves for Lateral Load Test W-2 at $25 \mathrm{ft}$

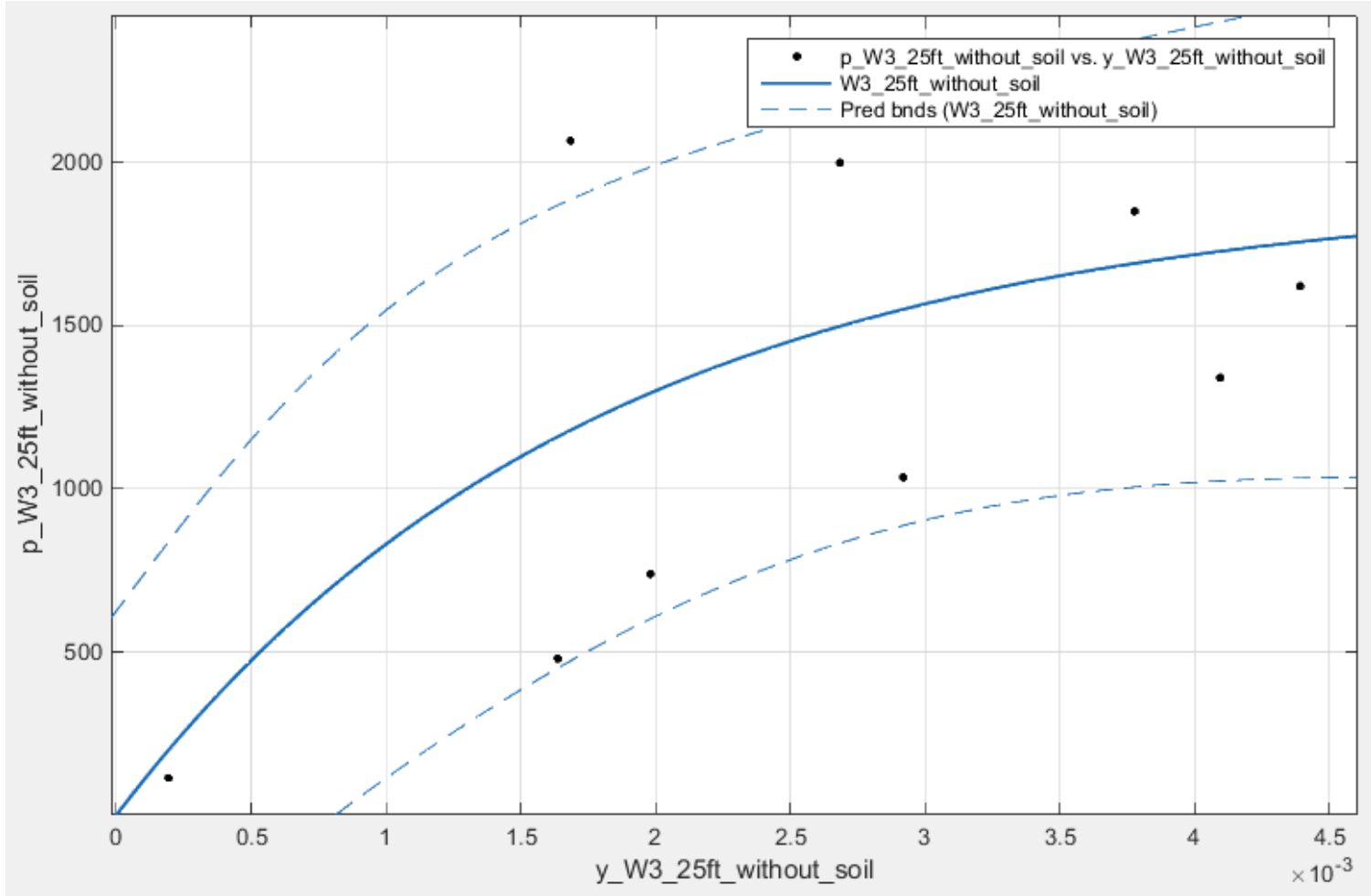

Interpreted p-y Responses and Fitted p-y curves for Lateral Load Test W-3 at $25 \mathrm{ft}$ 


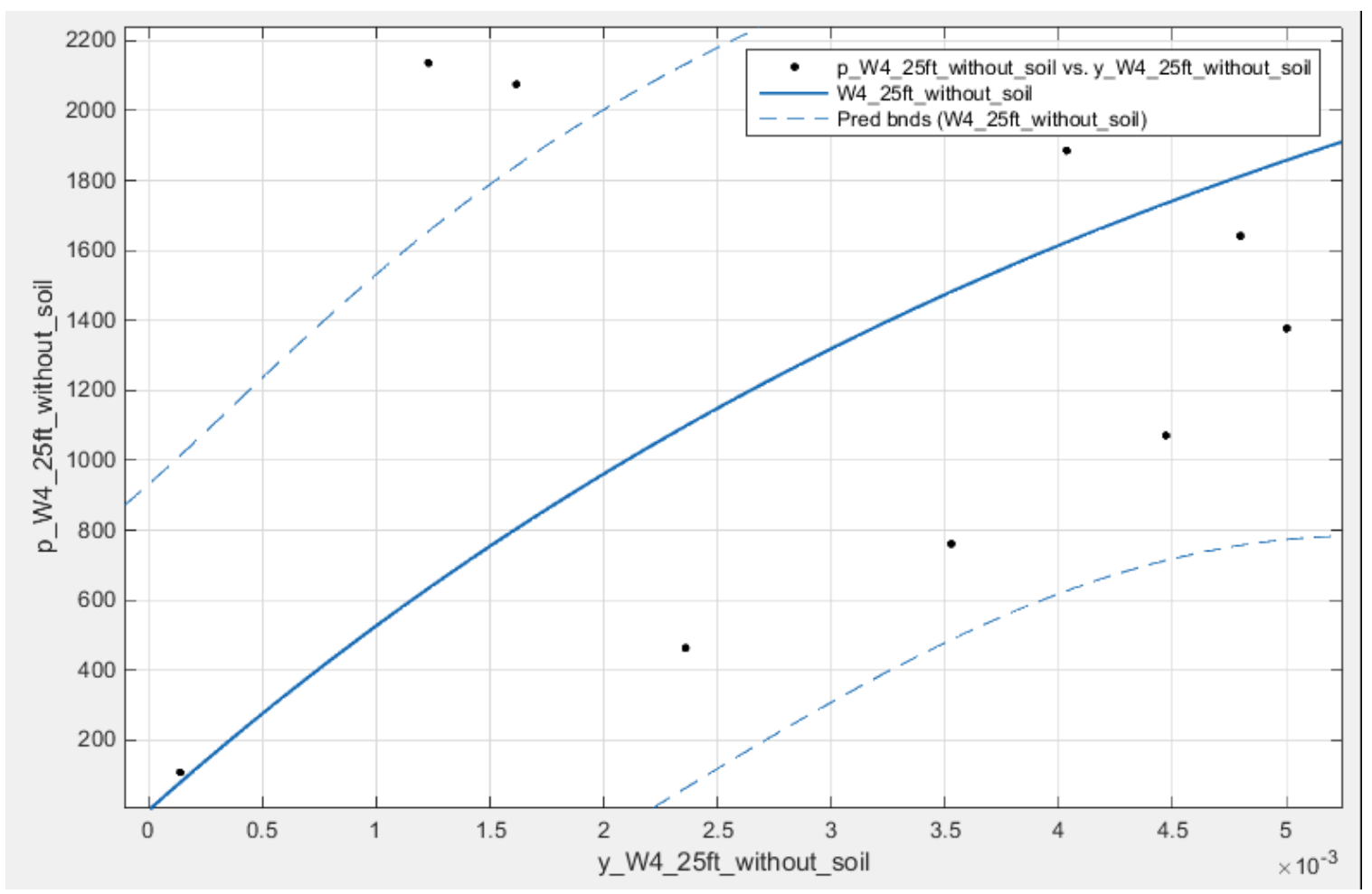

Interpreted $\mathrm{p}-\mathrm{y}$ Responses and Fitted $\mathrm{p}-\mathrm{y}$ curves for Lateral Load Test W-4 at $25 \mathrm{ft}$

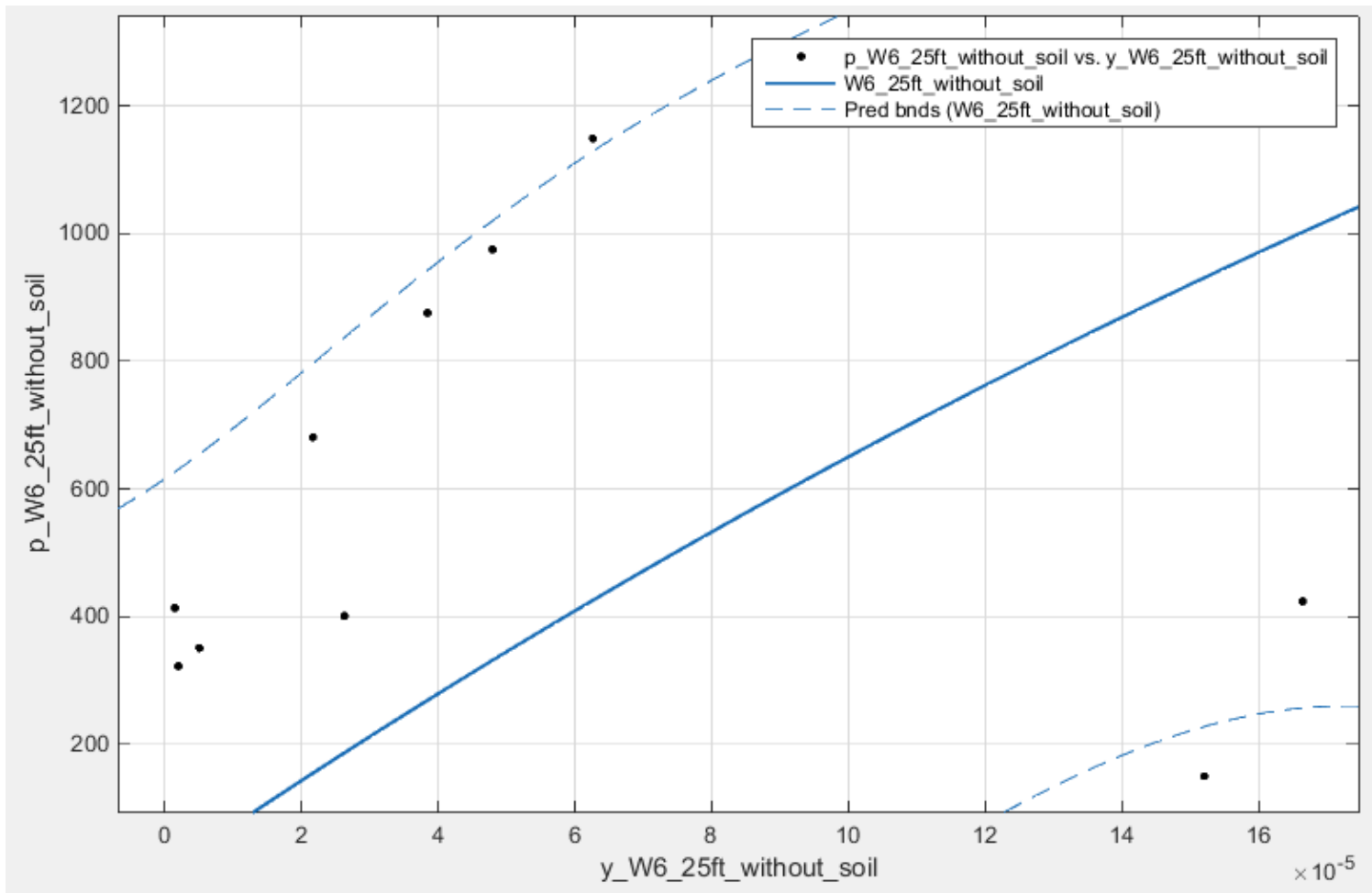

Interpreted p-y Responses and Fitted p-y curves for Lateral Load Test W-6 at $25 \mathrm{ft}$ 


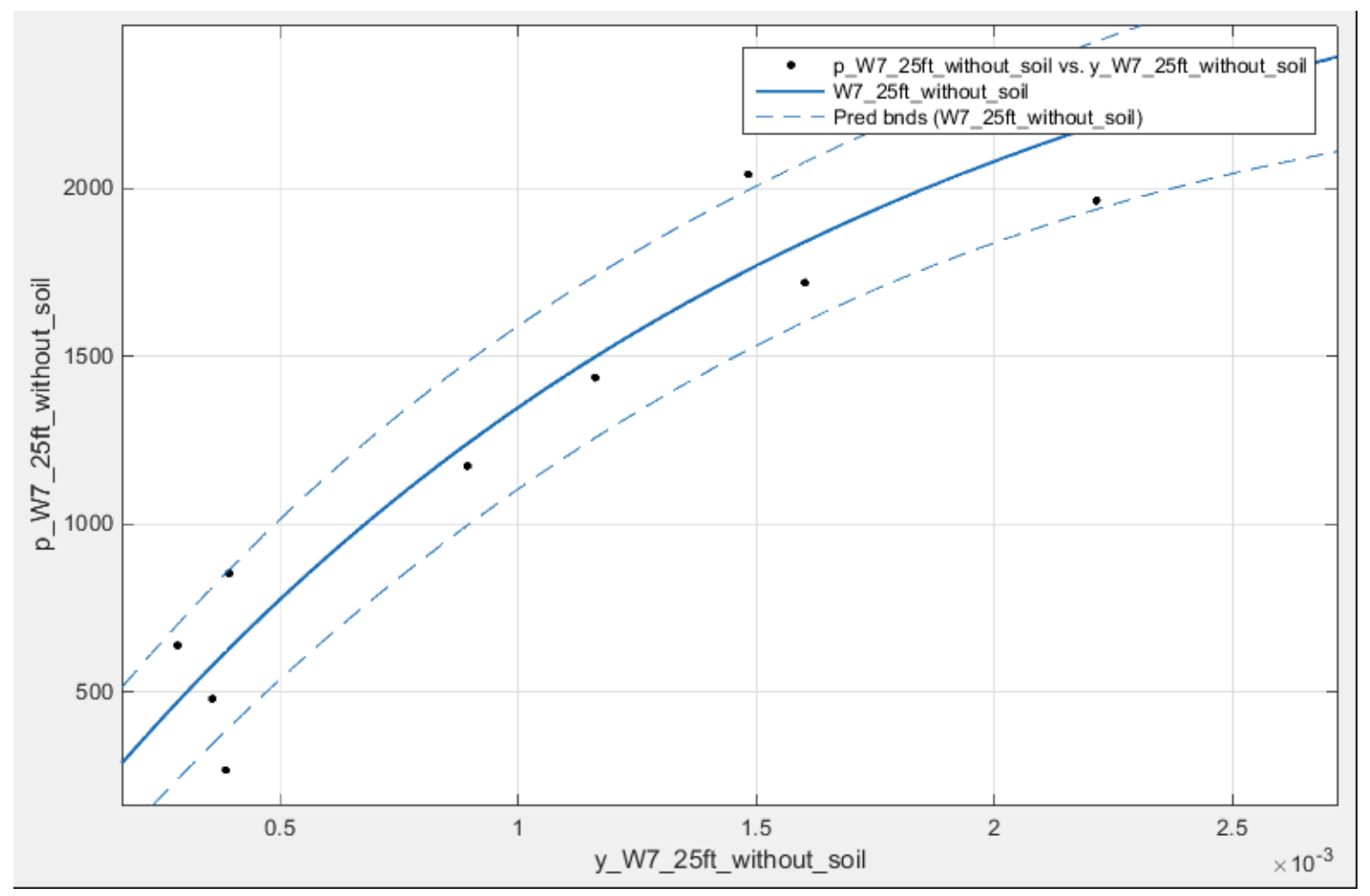

Interpreted p-y Responses and Fitted $p-y$ curves for Lateral Load Test W-7 at $25 \mathrm{ft}$

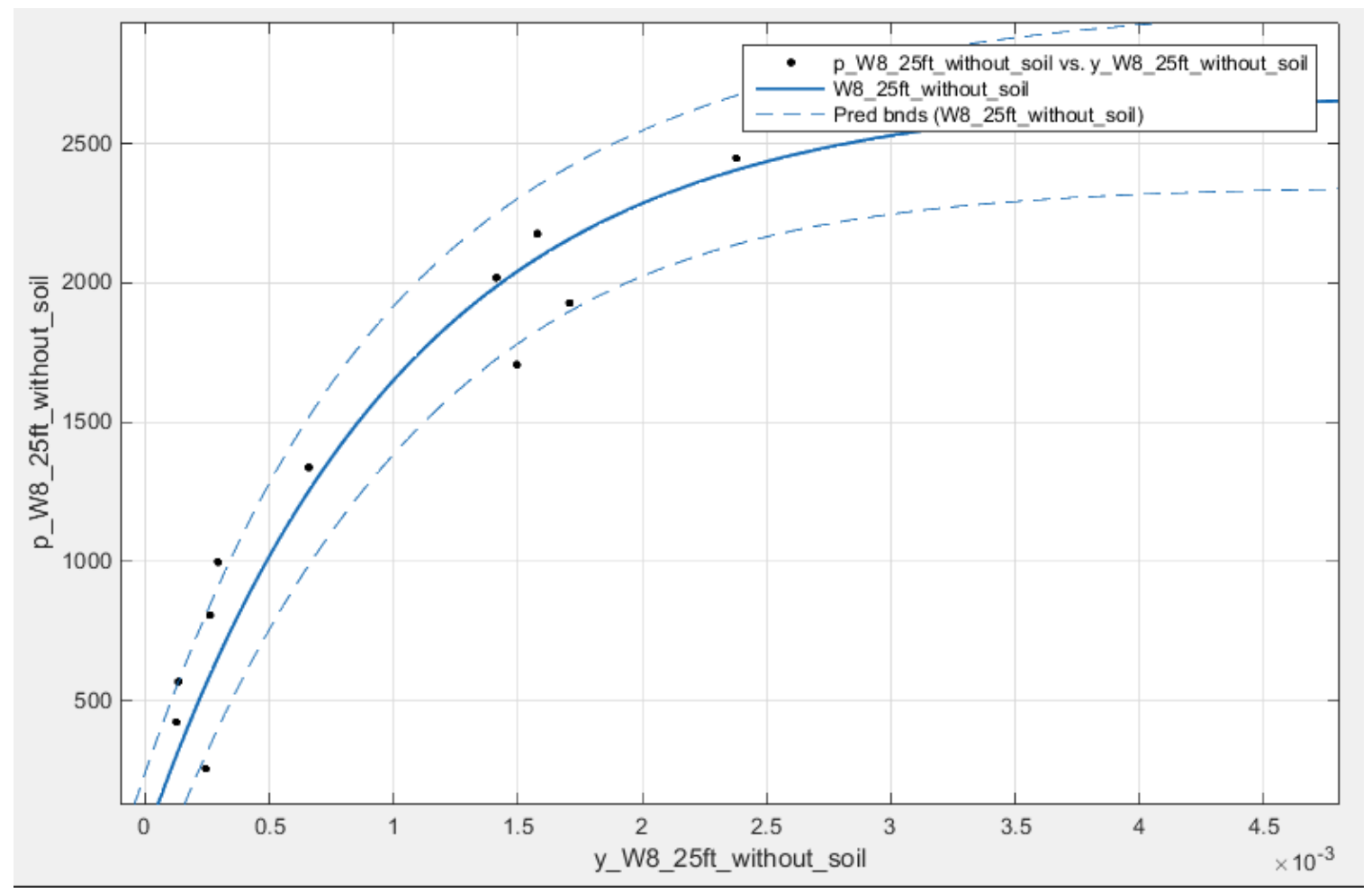

Interpreted p-y Responses and Fitted p-y curves for Lateral Load Test W-8 at $25 \mathrm{ft}$ 


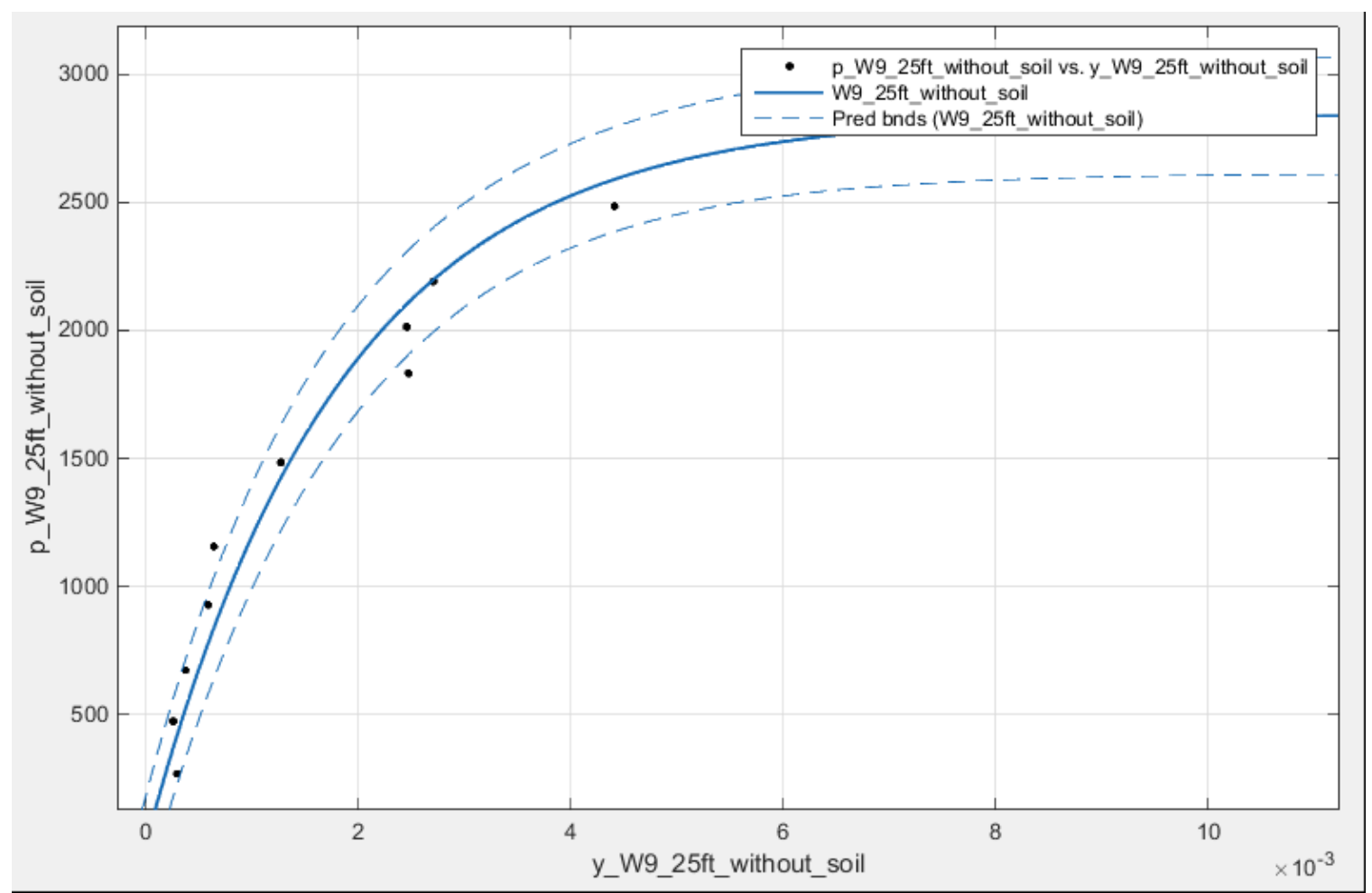

Interpreted p-y Responses and Fitted p-y curves for Lateral Load Test W-9 at $25 \mathrm{ft}$

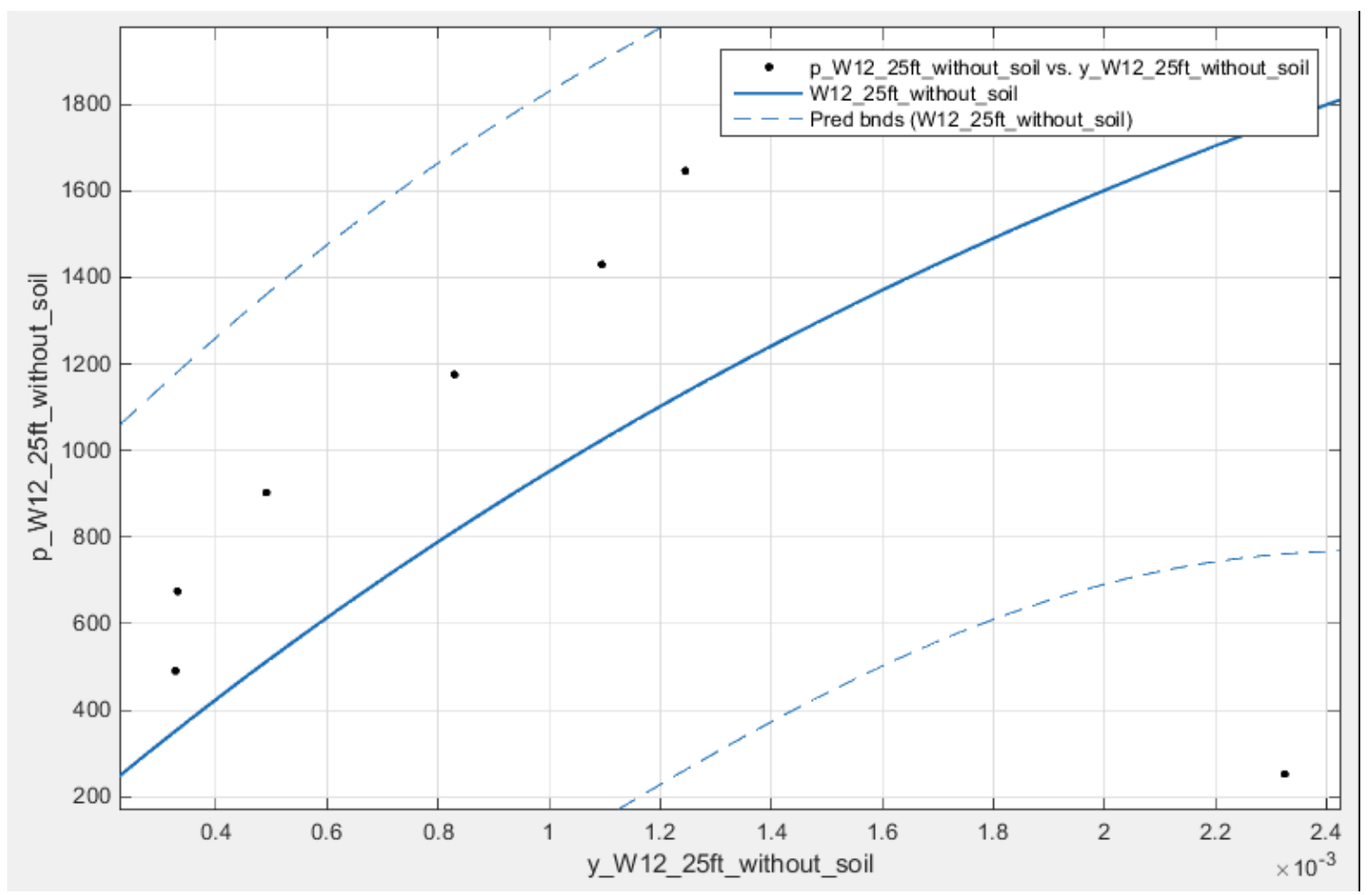

Interpreted p-y Responses and Fitted p-y curves for Lateral Load Test W-12 at $25 \mathrm{ft}$ 
Appendix C

Probabilistic Variables in p-y Responses using Three Approaches 


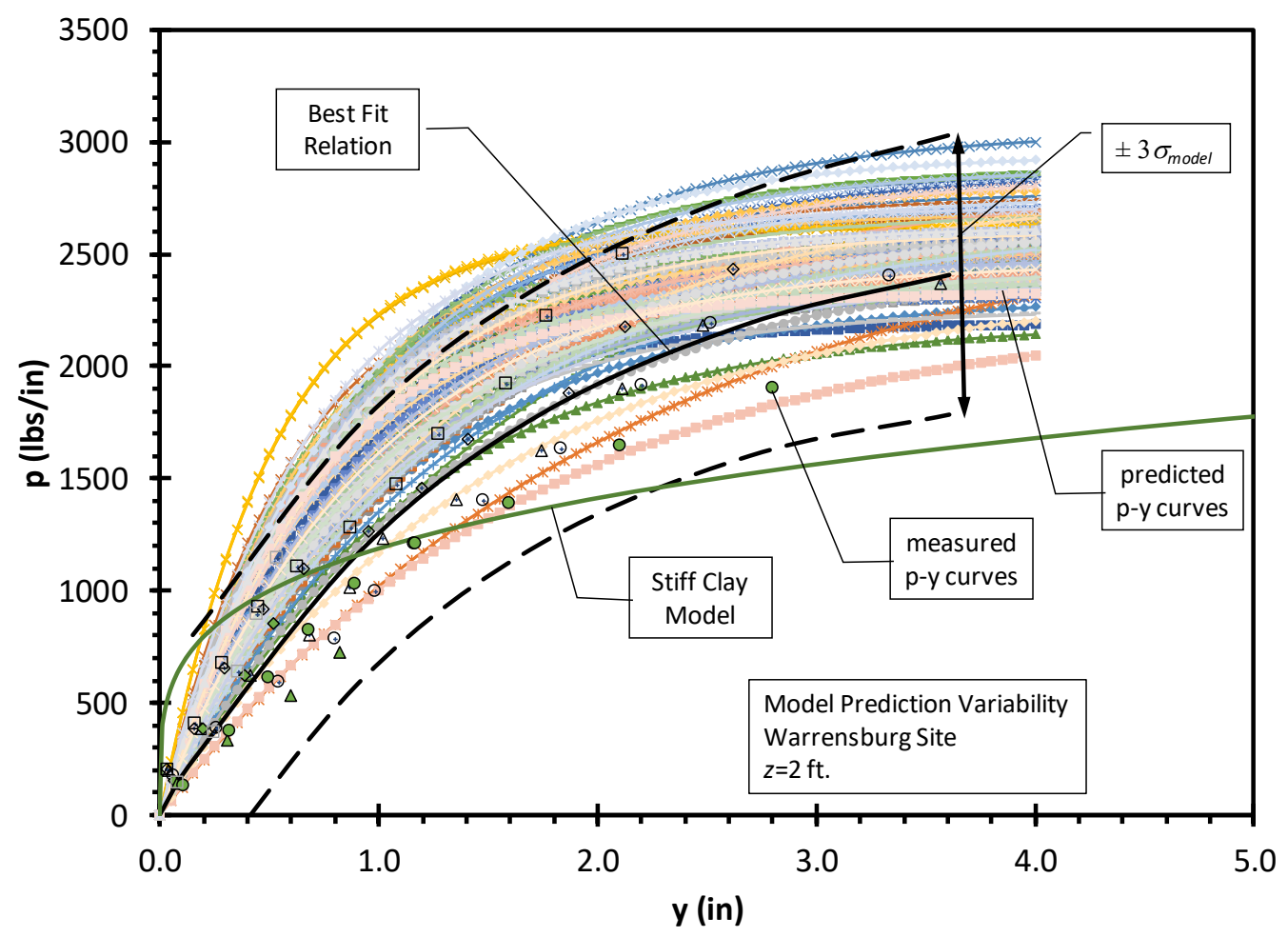

Approach-1 (using $\operatorname{COV}_{\text {Pult }}$ and $\operatorname{COV}_{K p y}$ ) for Model Uncertainty (Warrensburg, z=2ft)

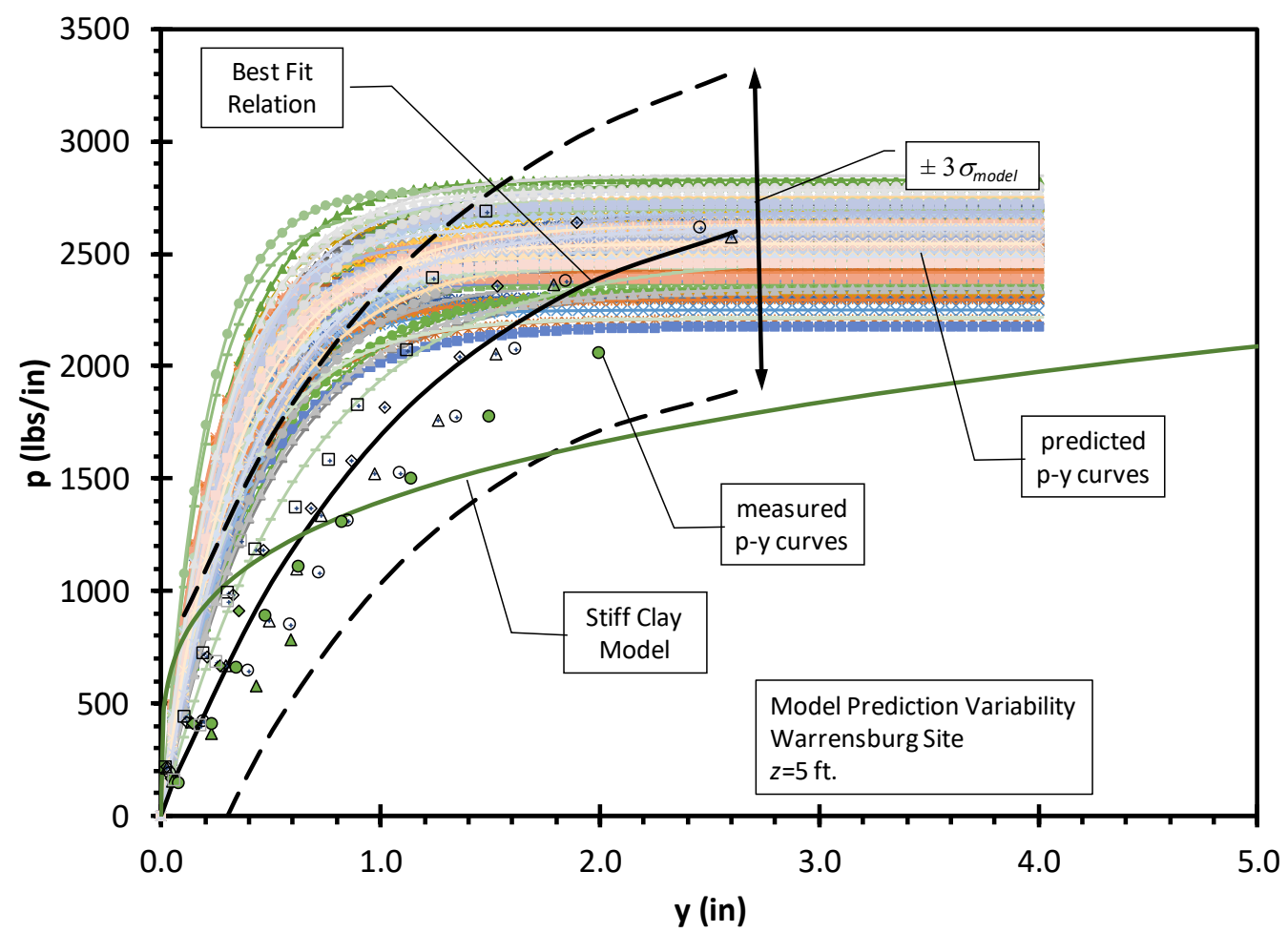

Approach-1 (using $\operatorname{COV}_{\text {Pult }}$ and $\operatorname{COV}_{K p y}$ ) for Model Uncertainty (Warrensburg, z=5ft) 


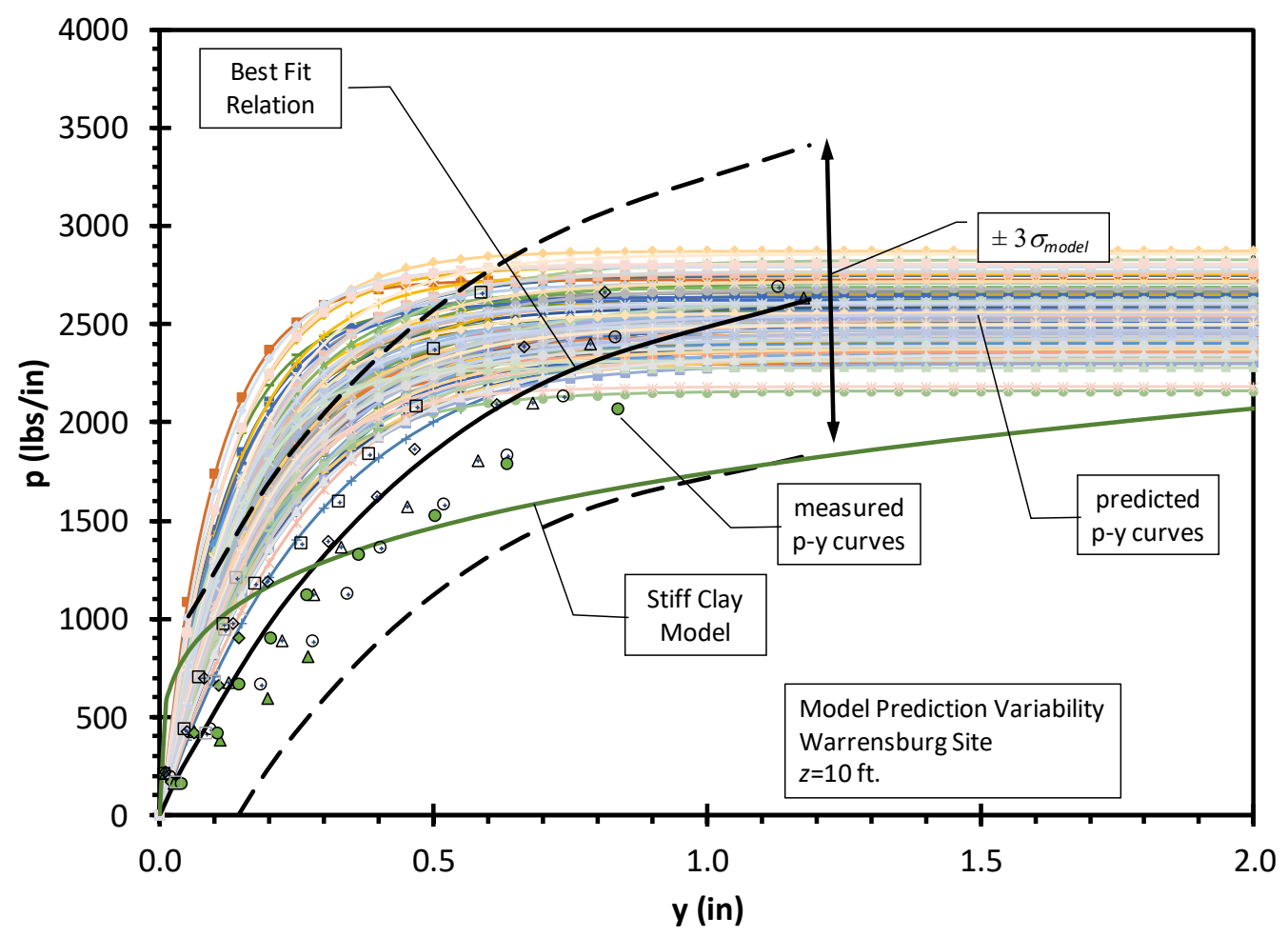

Approach-1 (using $\operatorname{COV}_{P u l t}$ and $\operatorname{COV}_{K p y}$ ) for Model Uncertainty (Warrensburg, z=10ft)

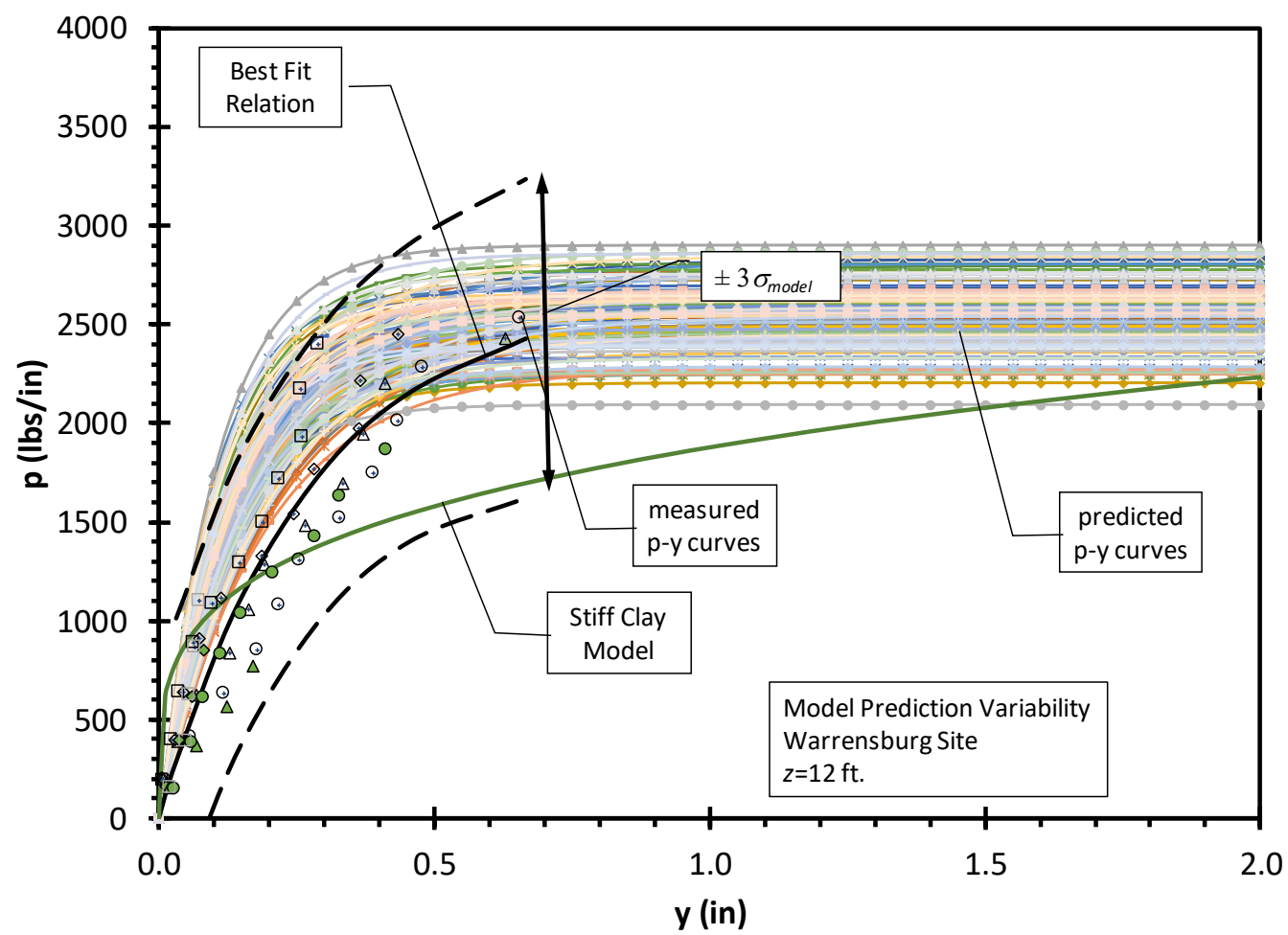

Approach-1 (using $\operatorname{COV}_{P u l t}$ and $\operatorname{COV}_{K p y}$ ) for Model Uncertainty (Warrensburg, z=12ft) 


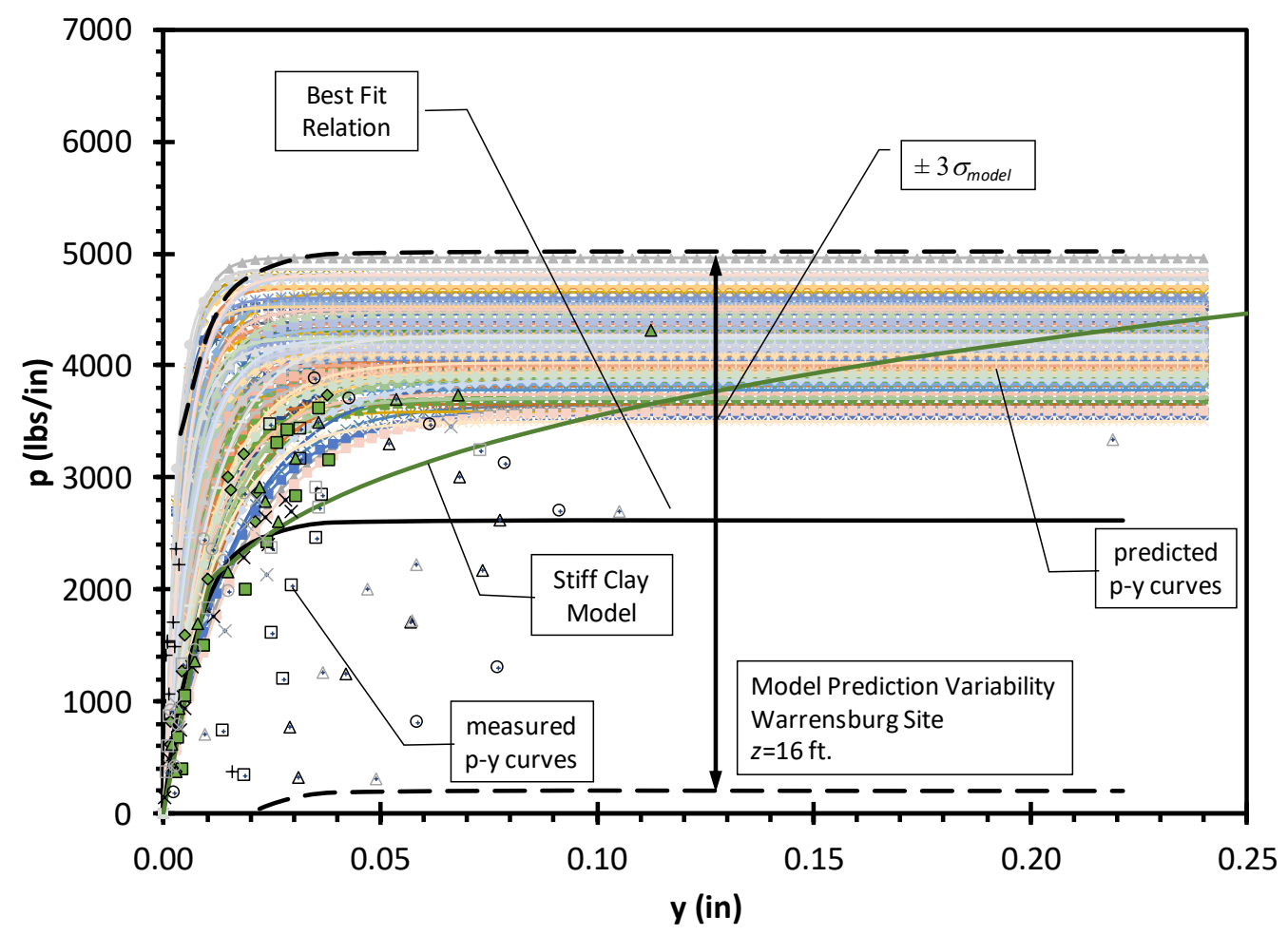

Approach-1 (using $\operatorname{COV}_{P u l t}$ and $\operatorname{COV}_{K p y}$ ) for Model Uncertainty (Warrensburg, z=16ft)

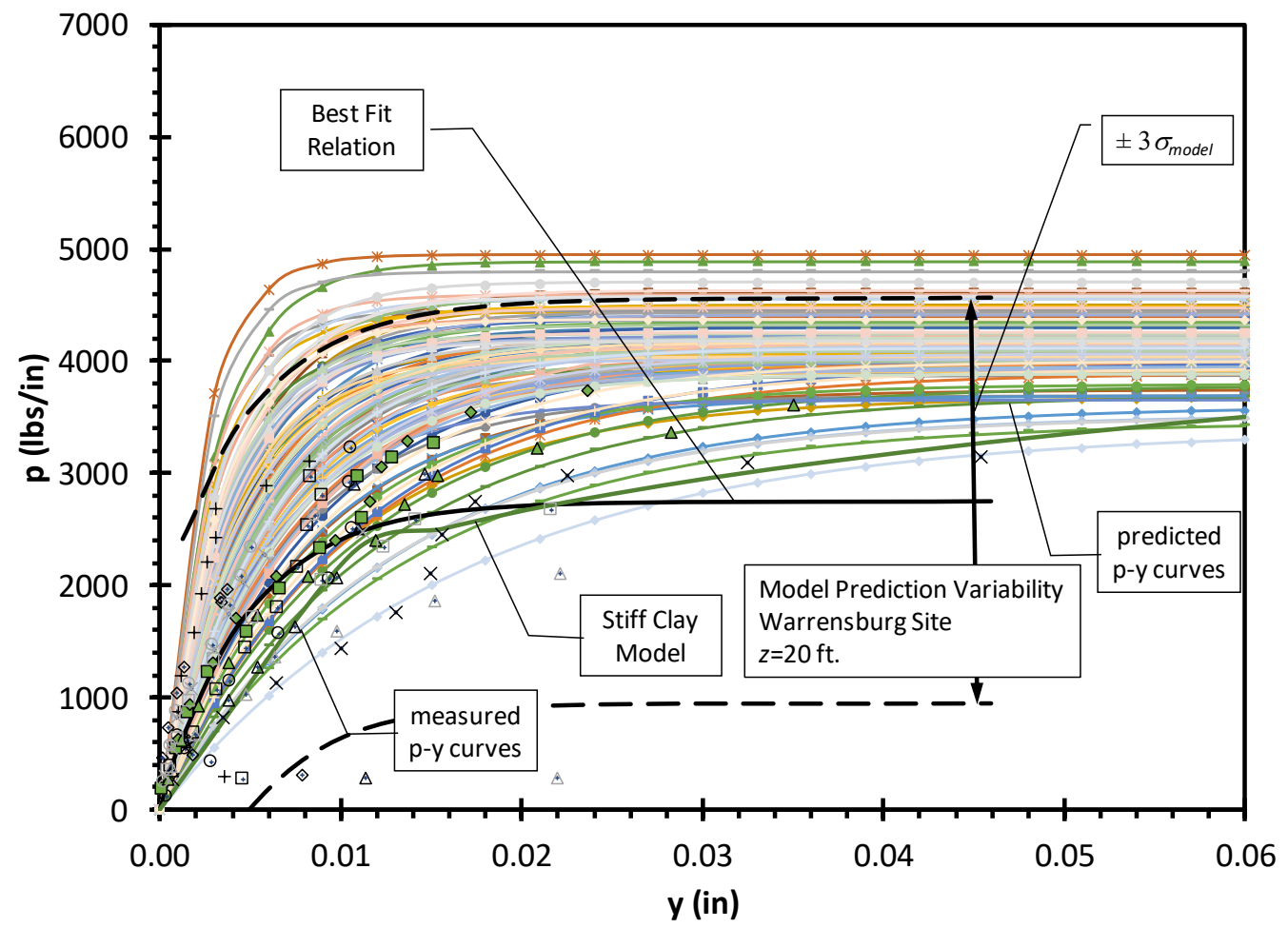

Approach-1 (using $\operatorname{COV}_{\mathrm{Pult}}$ and $\operatorname{COV}_{\mathrm{Kpy}}$ ) for Model Uncertainty (Warrensburg, z=20ft) 


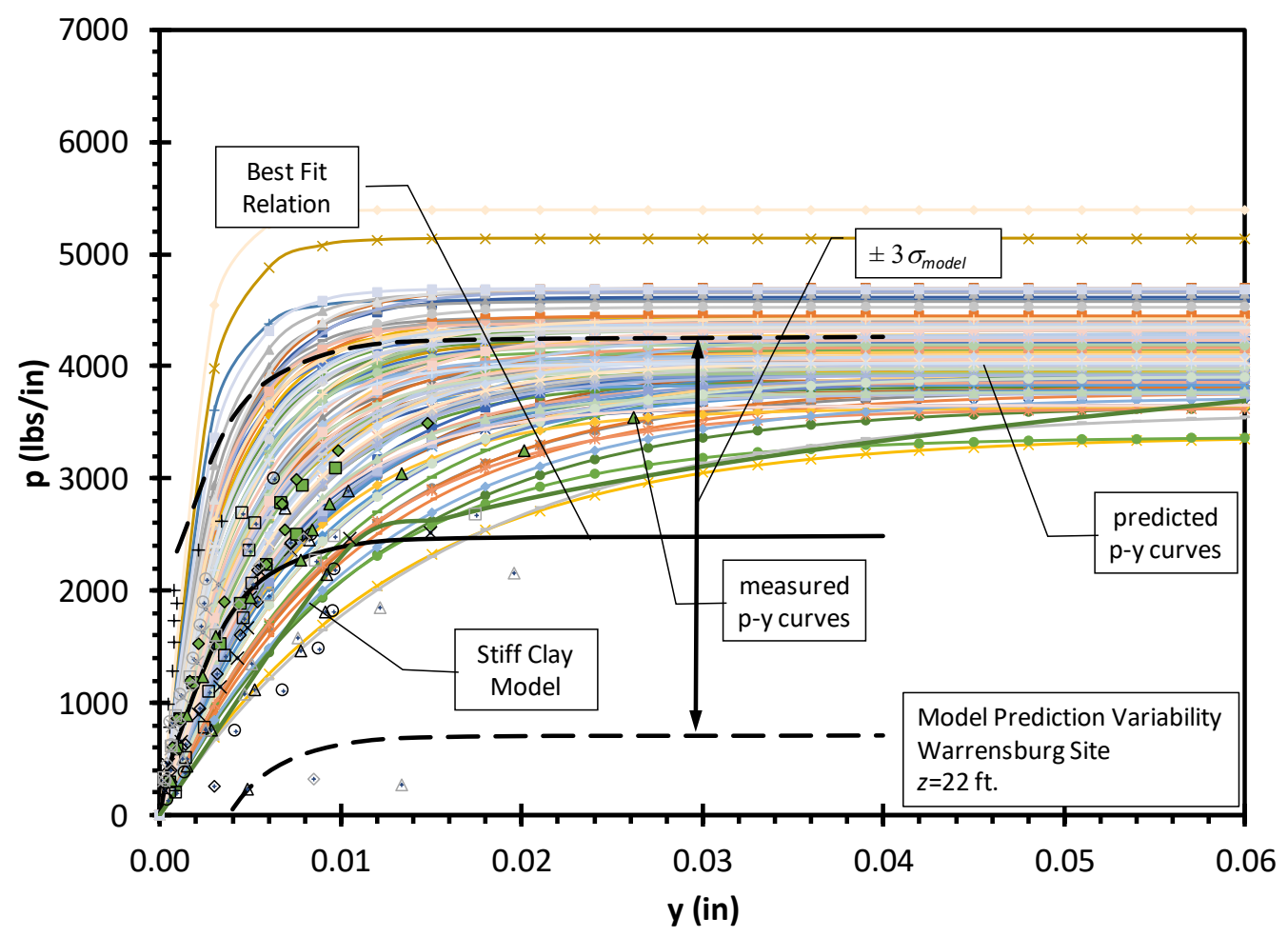

Approach-1 (using $\operatorname{COV}_{P u l t}$ and $\operatorname{COV}_{K p y}$ ) for Model Uncertainty (Warrensburg, z=22ft)

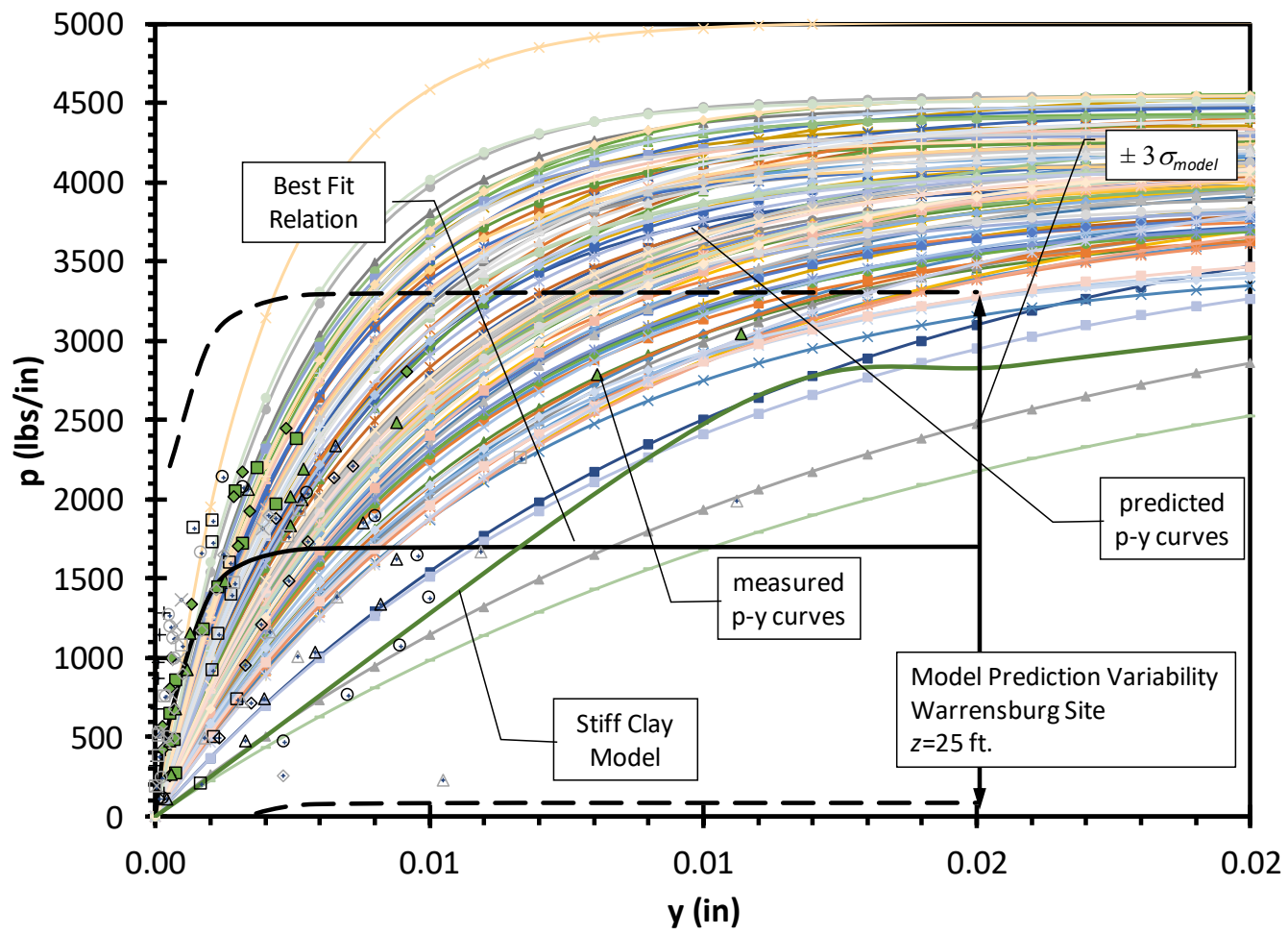

Approach-1 (using $\operatorname{COV}_{P u l t}$ and $\operatorname{COV}_{K p y}$ ) for Model Uncertainty (Warrensburg, z=25ft) 


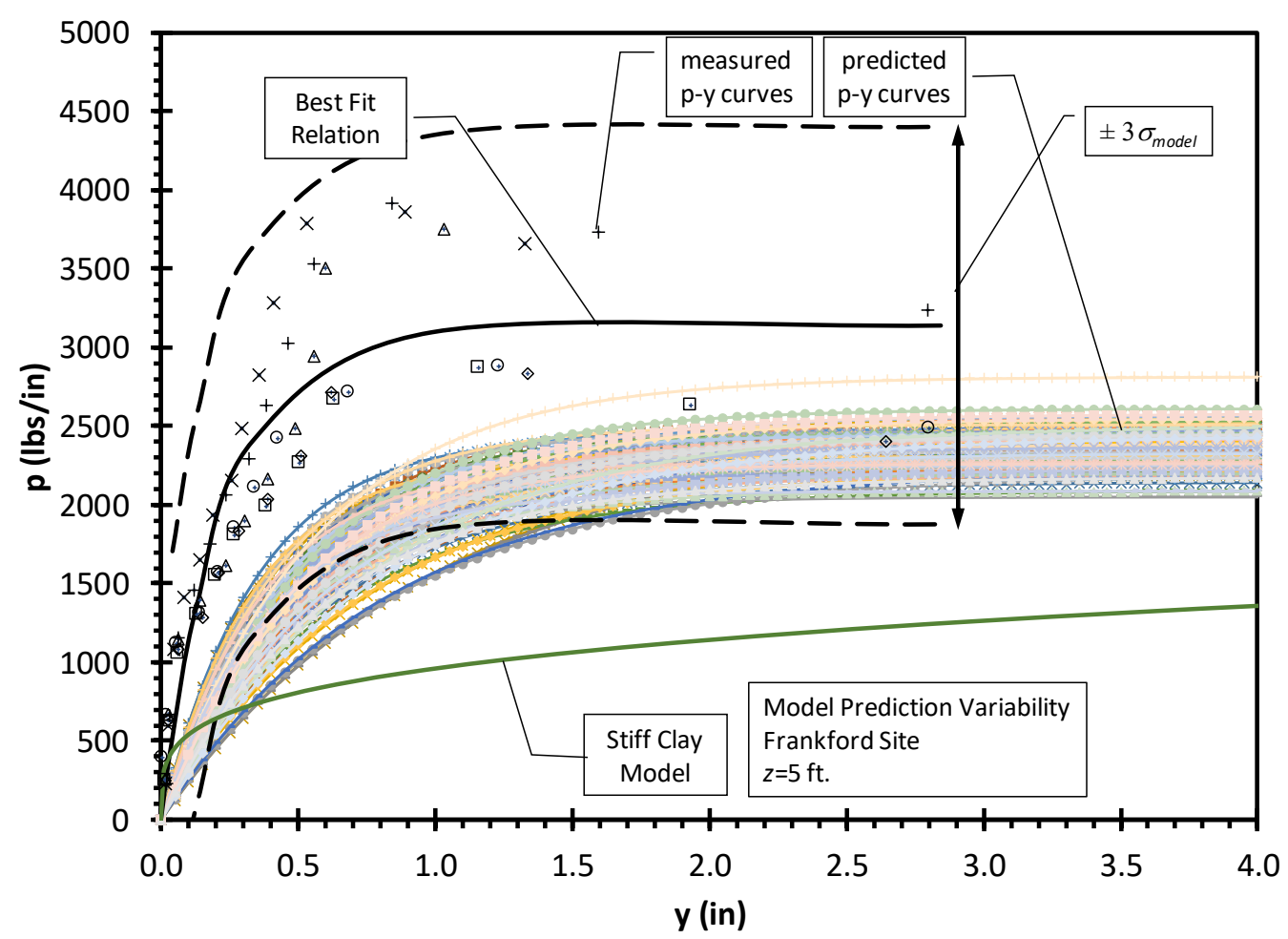

Approach-1 (using $C O V_{P u l t}$ and $C O V_{K p y}$ ) for Model Uncertainty (Frankford, $z=5 \mathrm{ft}$ )

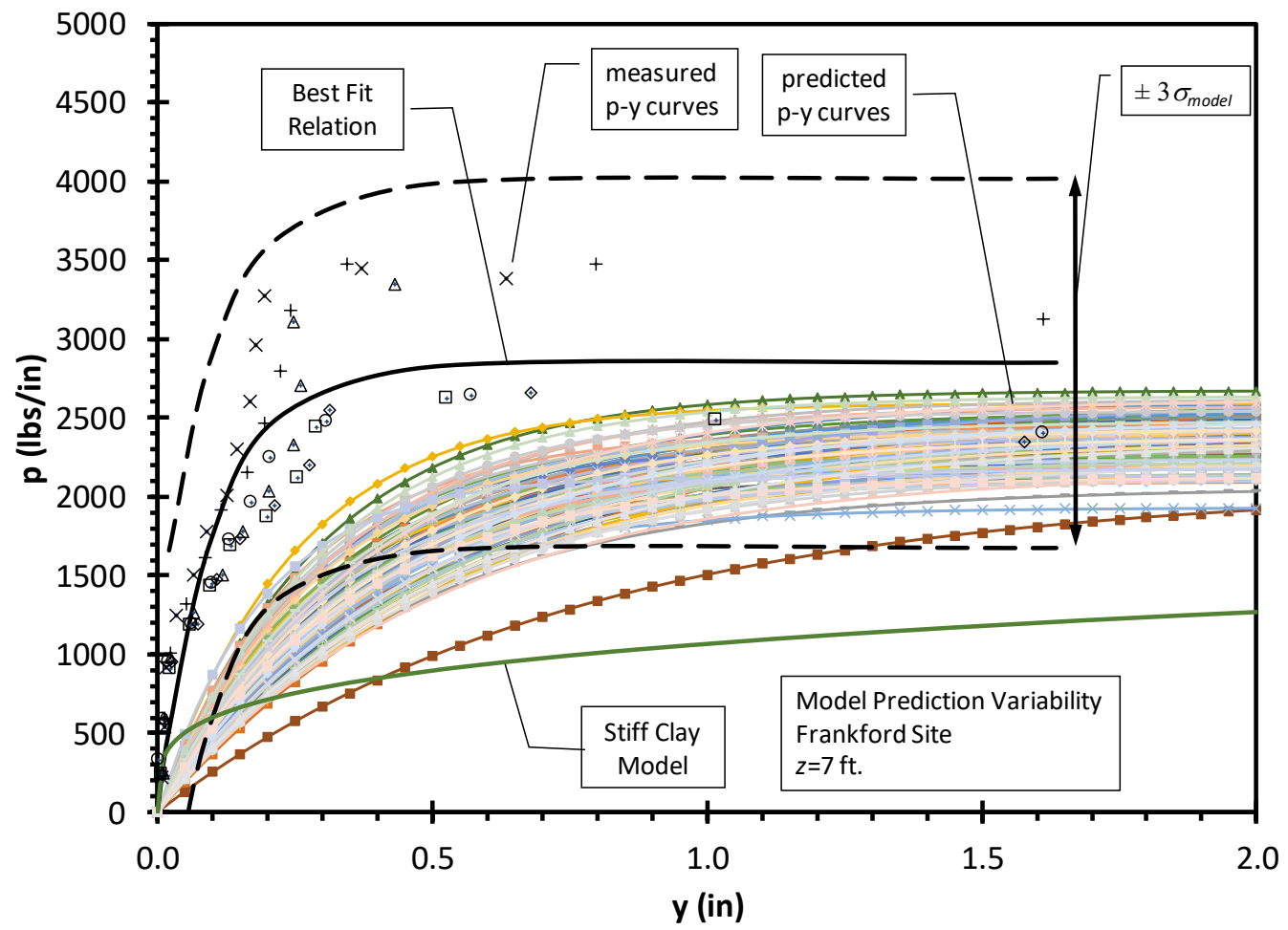

Approach-1 (using $C O V_{\text {Pult }}$ and $C O V_{K p y}$ ) for Model Uncertainty (Frankford, $\mathrm{z}=7 \mathrm{ft}$ ) 


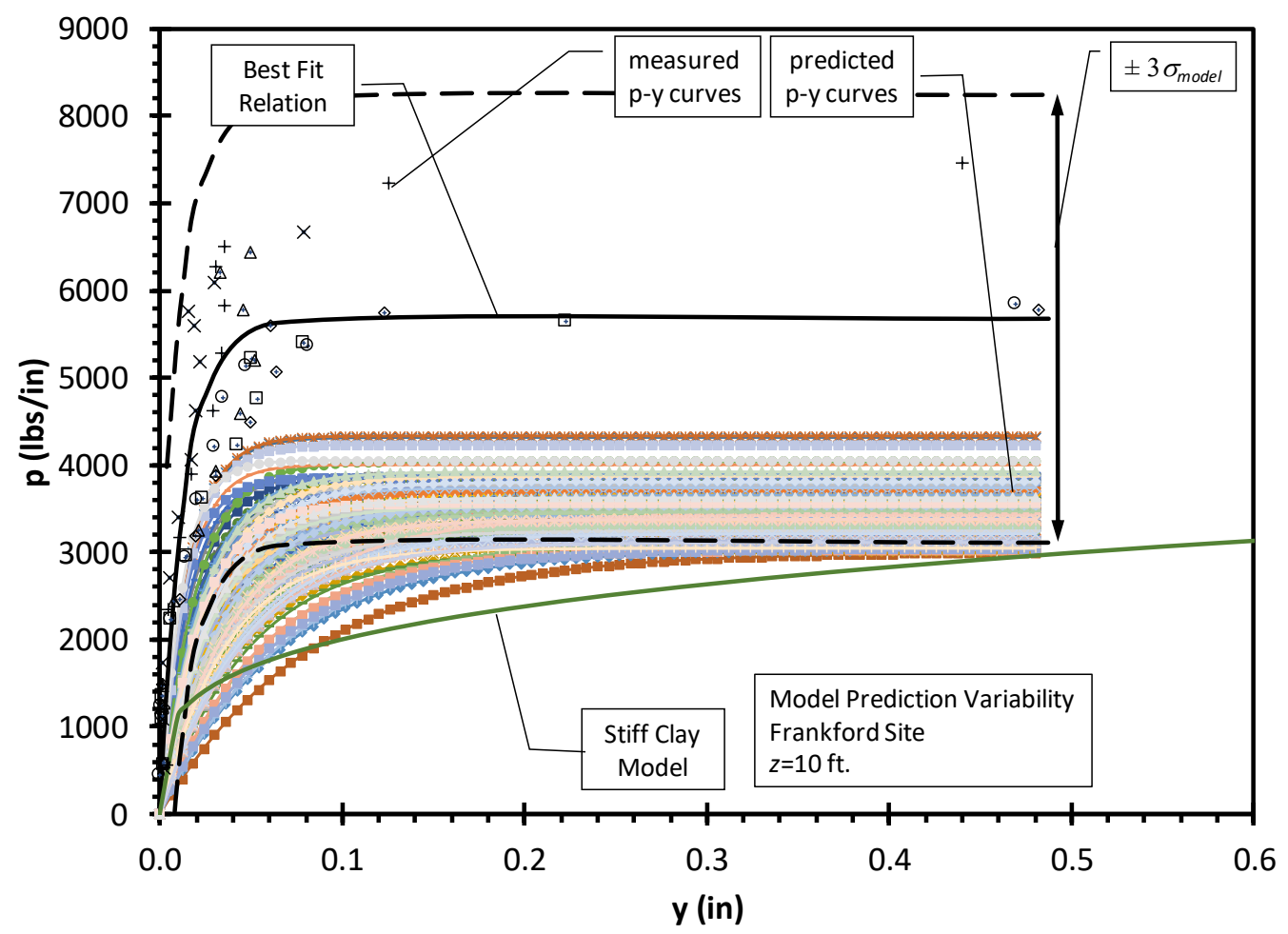

Approach-1 (using $\operatorname{COV}_{P u l t}$ and $C O V_{K p y}$ ) for Model Uncertainty (Frankford, z=10ft)

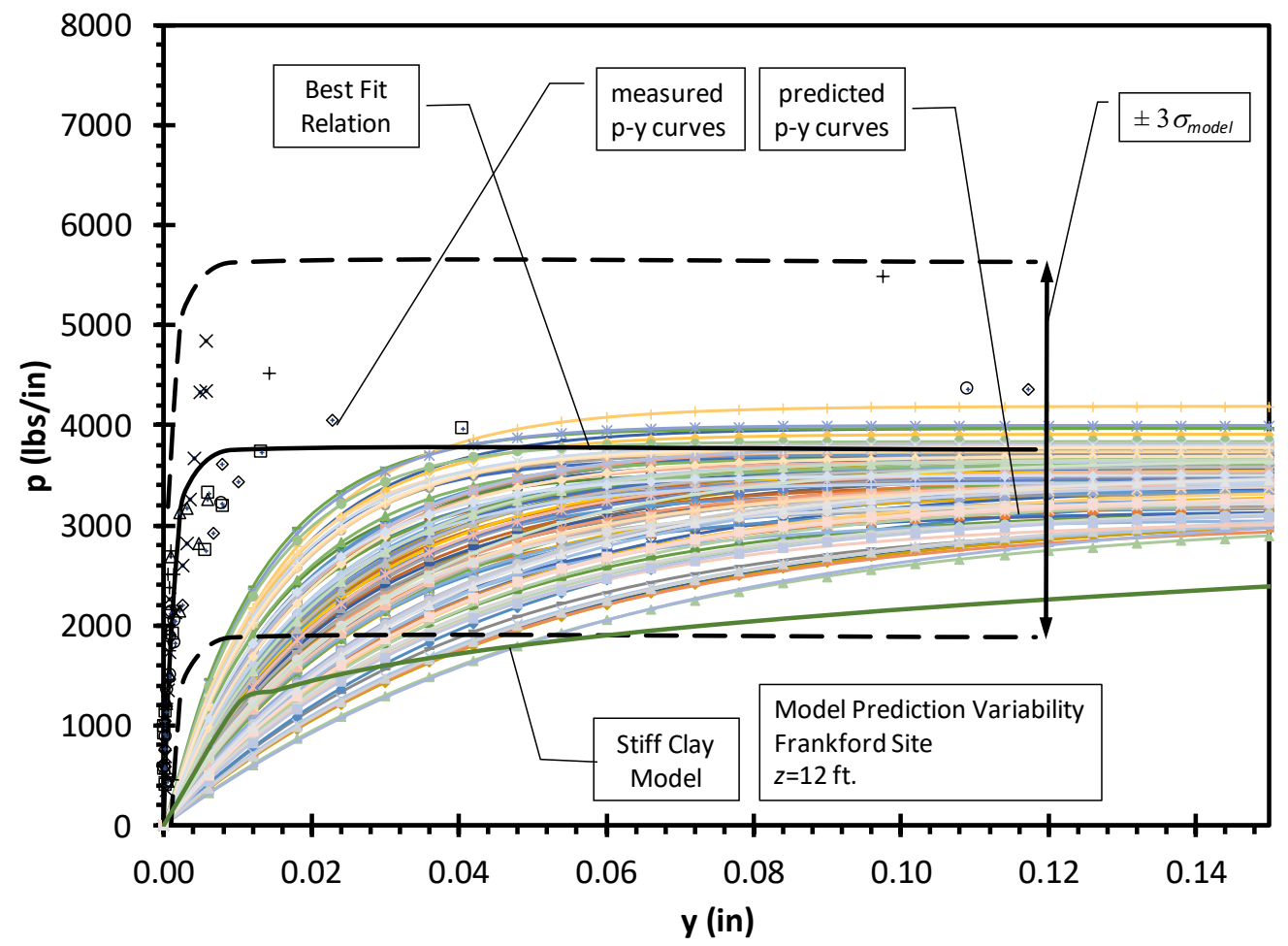

Approach-1 (using $\operatorname{COV}_{\text {Pult }}$ and $\operatorname{COV}_{K p y}$ ) for Model Uncertainty (Frankford, $\mathrm{z}=12 \mathrm{ft}$ ) 


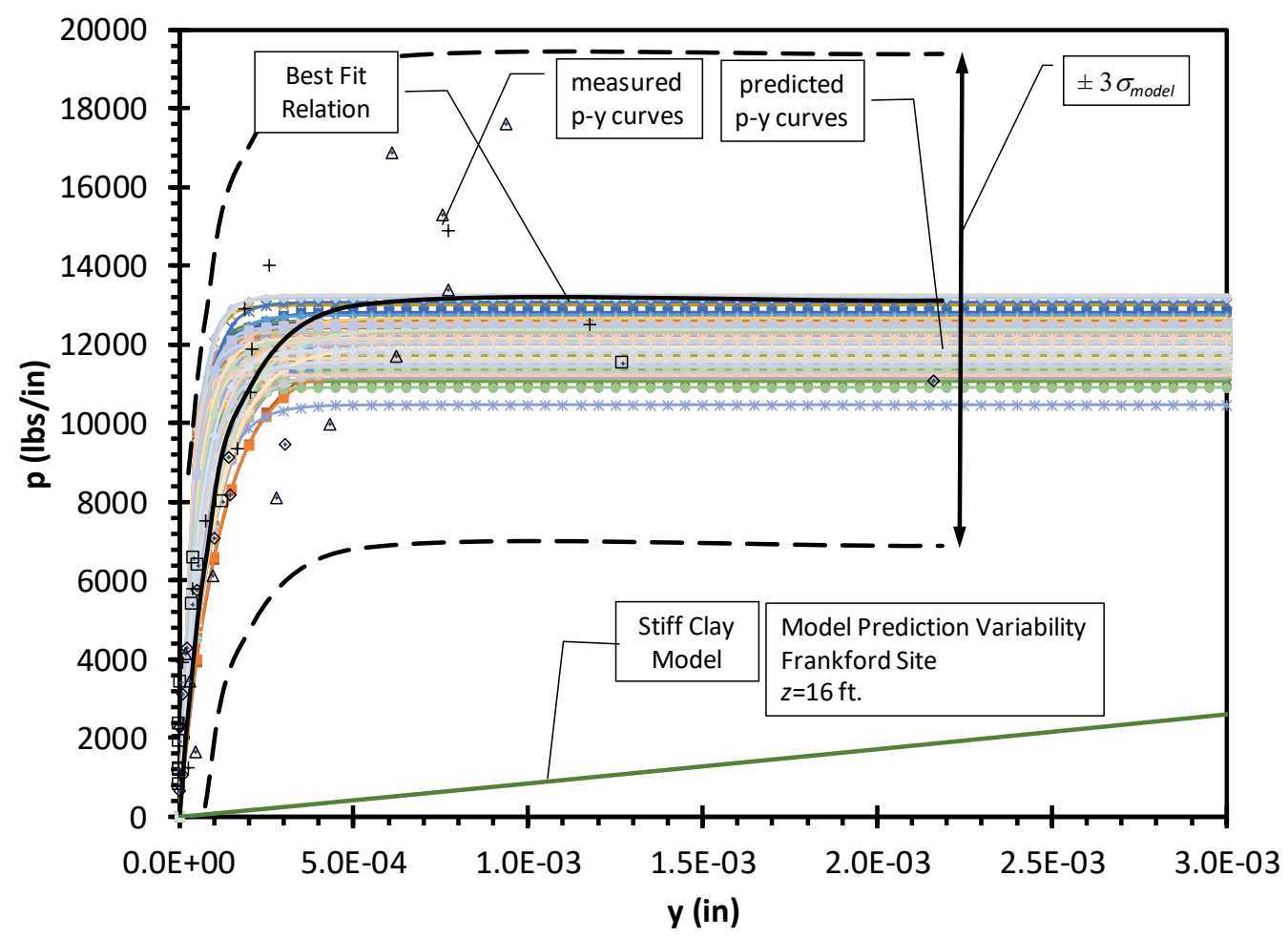

Approach-1 (using $\operatorname{COV}_{P u l t}$ and $C O V_{K p y}$ ) for Model Uncertainty (Frankford, z=16ft)

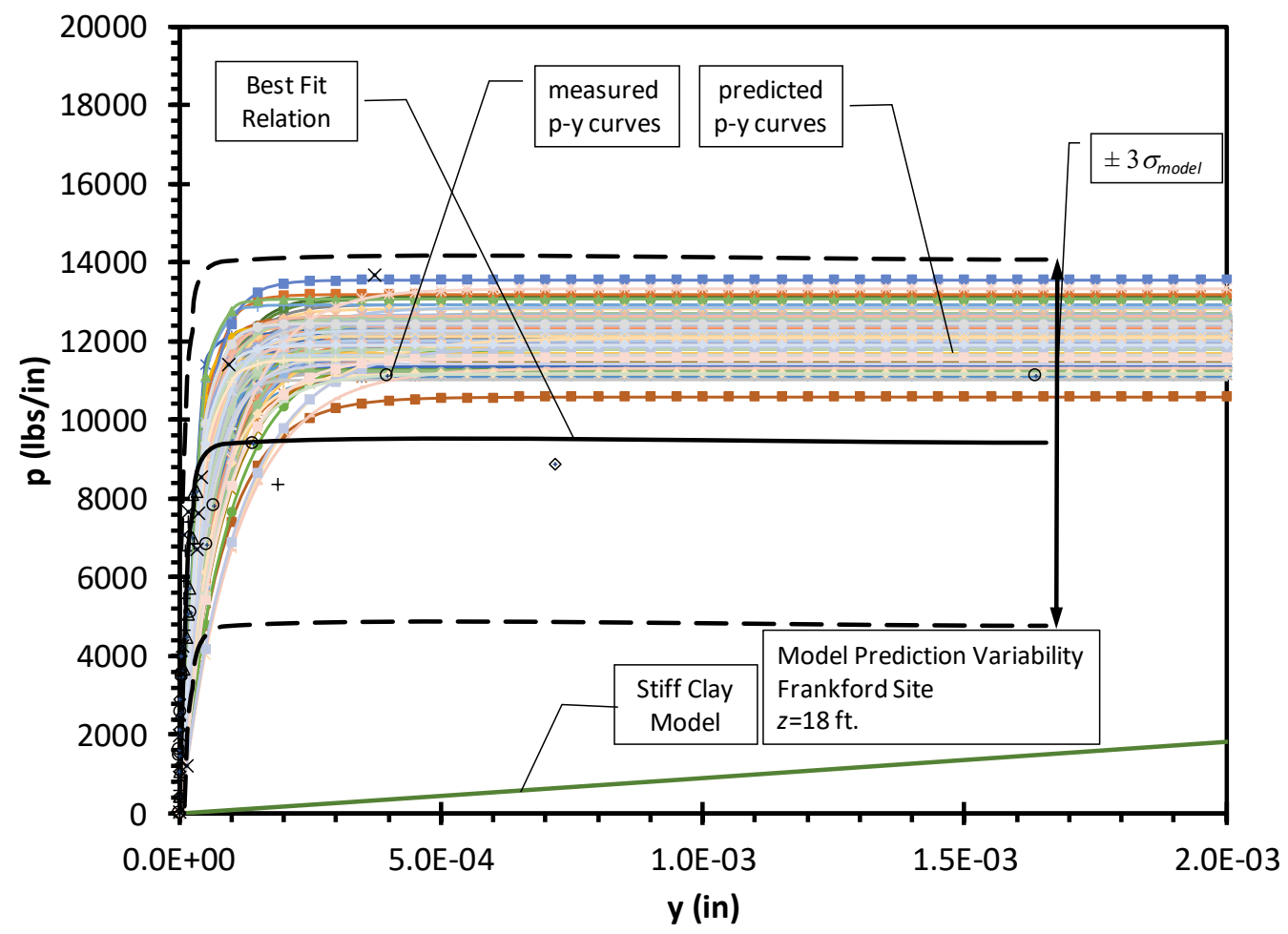

Approach-1 (using $\operatorname{COV}_{\text {Pult }}$ and $\operatorname{COV}_{K p y}$ ) for Model Uncertainty (Frankford, $\mathrm{z}=18 \mathrm{ft}$ ) 


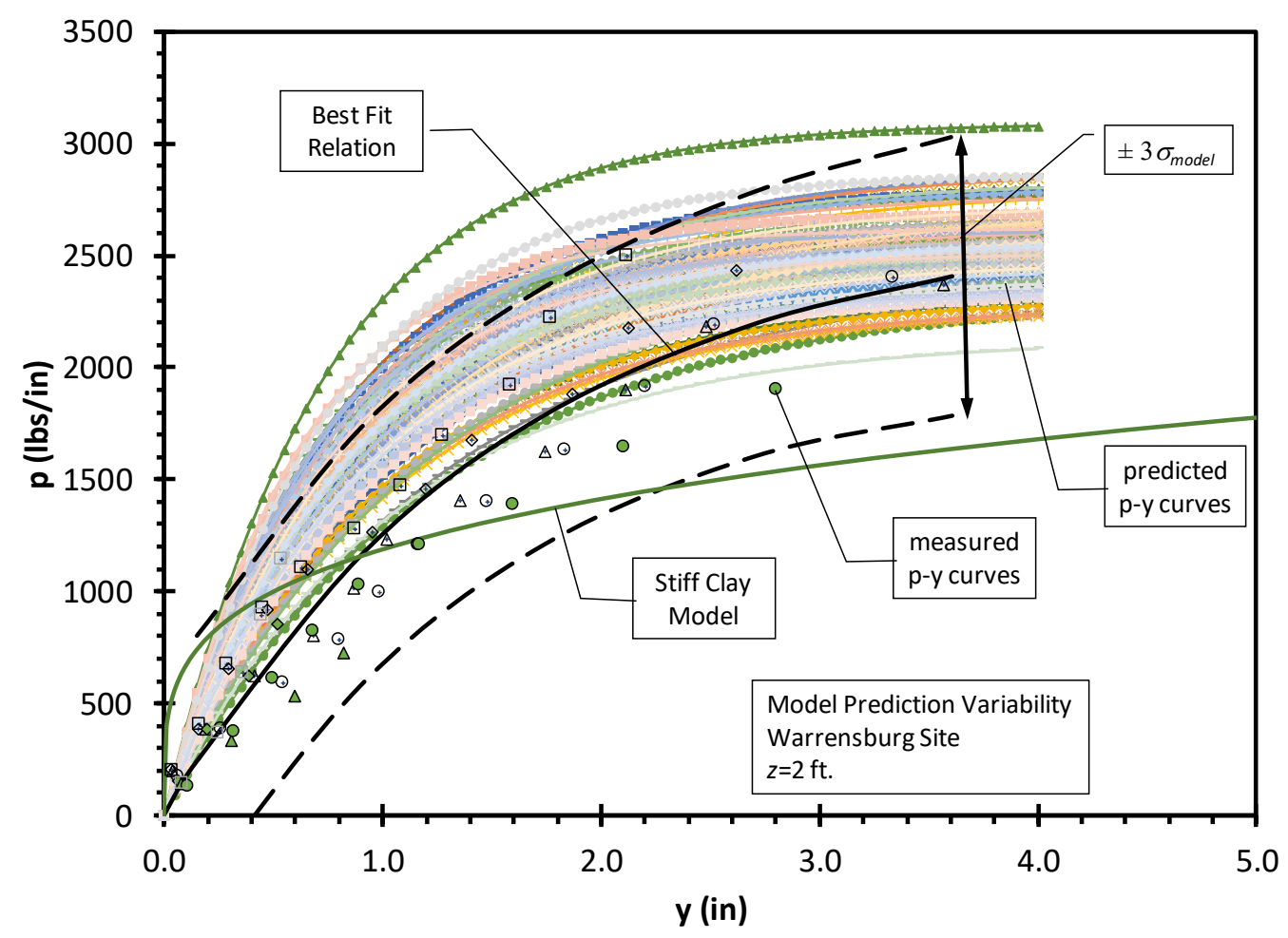

Approach-2 (using avgCOV) for Model Uncertainty (Warrensburg, z=2ft)

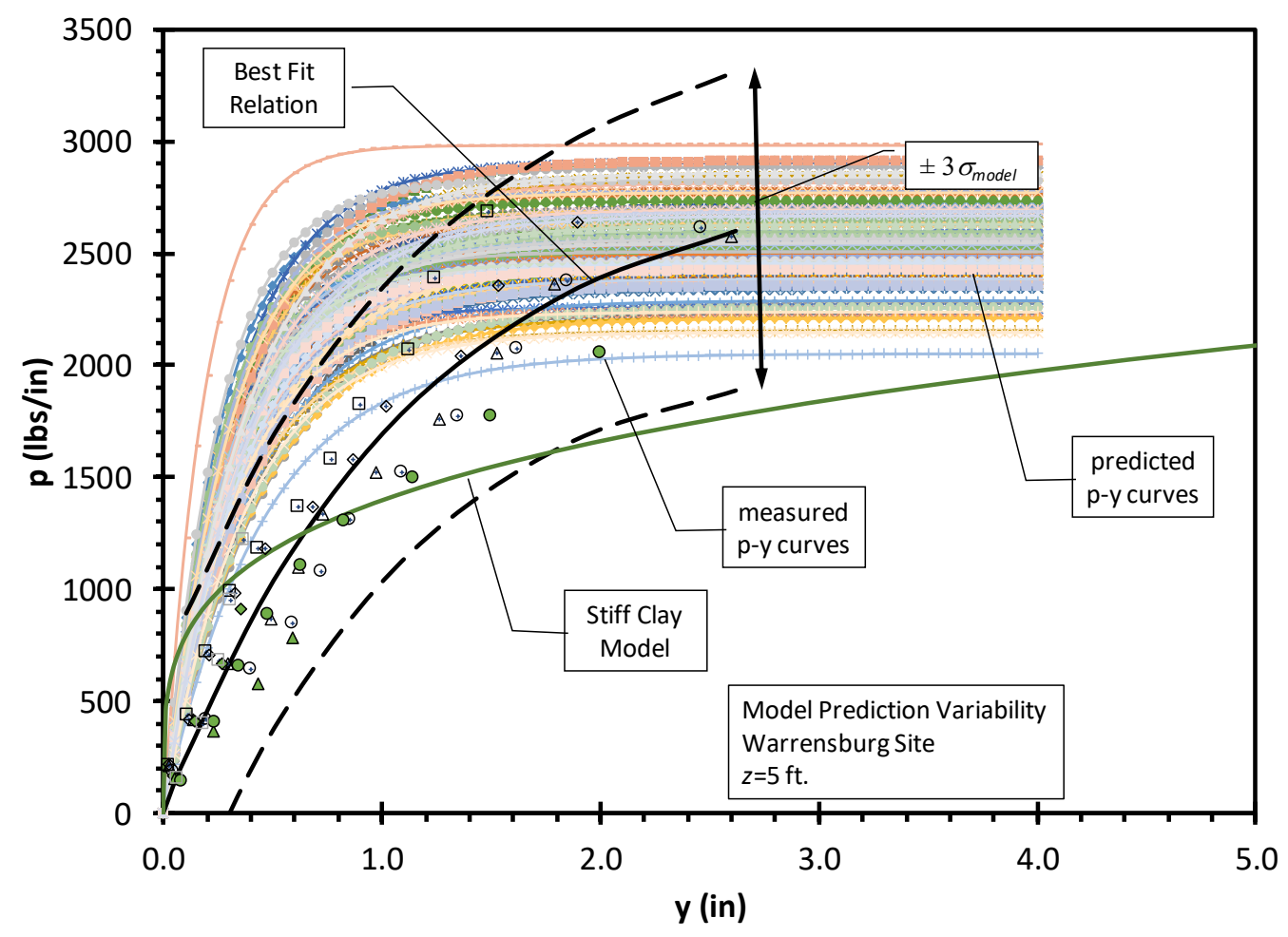

Approach-2 (using avgCOV) for Model Uncertainty (Warrensburg, z=5ft) 


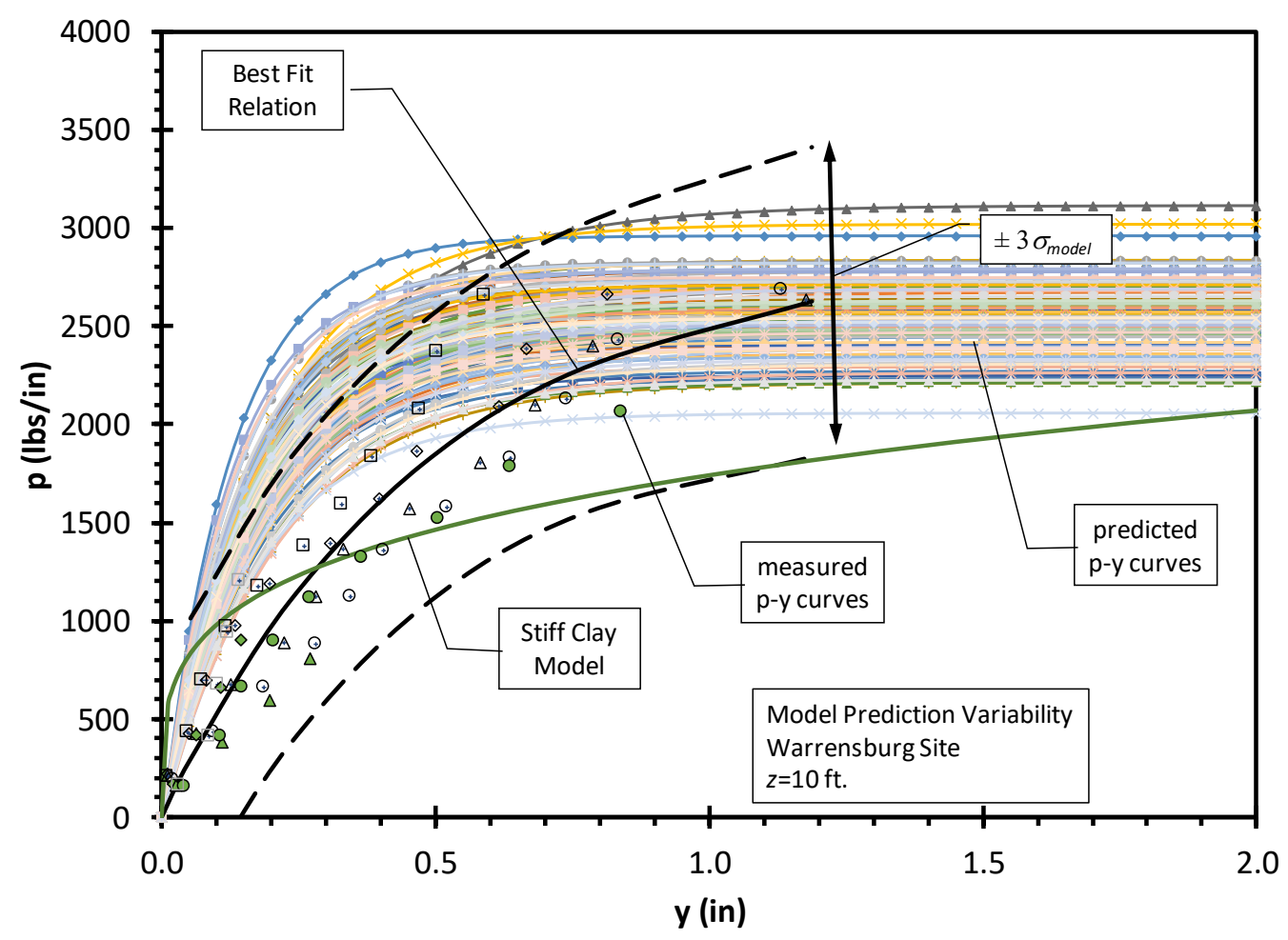

Approach-2 (using avg COV) for Model Uncertainty (Warrensburg, z=10ft)

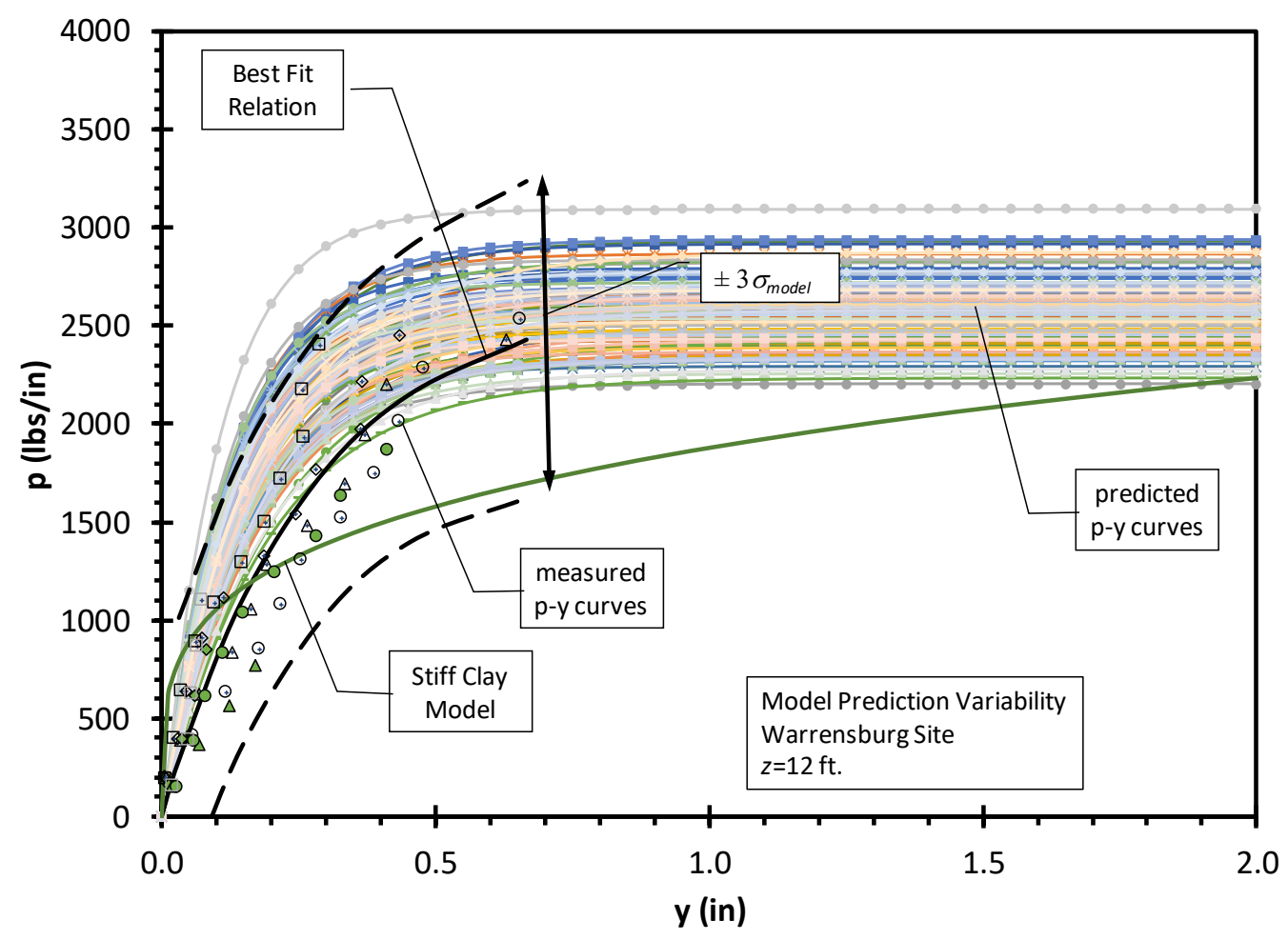

Approach-2 (using avgCOV) for Model Uncertainty (Warrensburg, $\mathrm{z}=12 \mathrm{ft}$ ) 


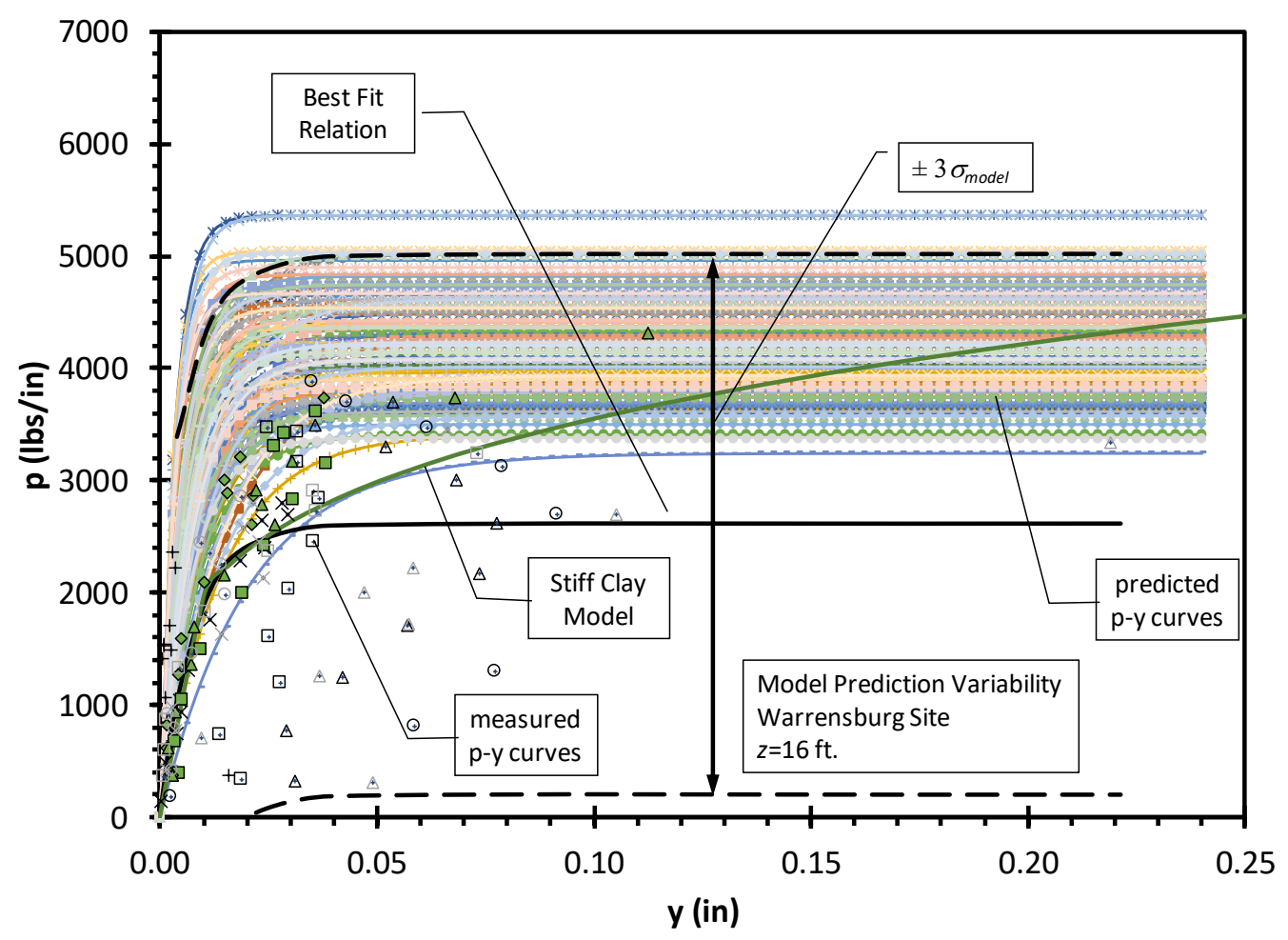

Approach-2 (using avgCOV) for Model Uncertainty (Warrensburg, z=16ft)

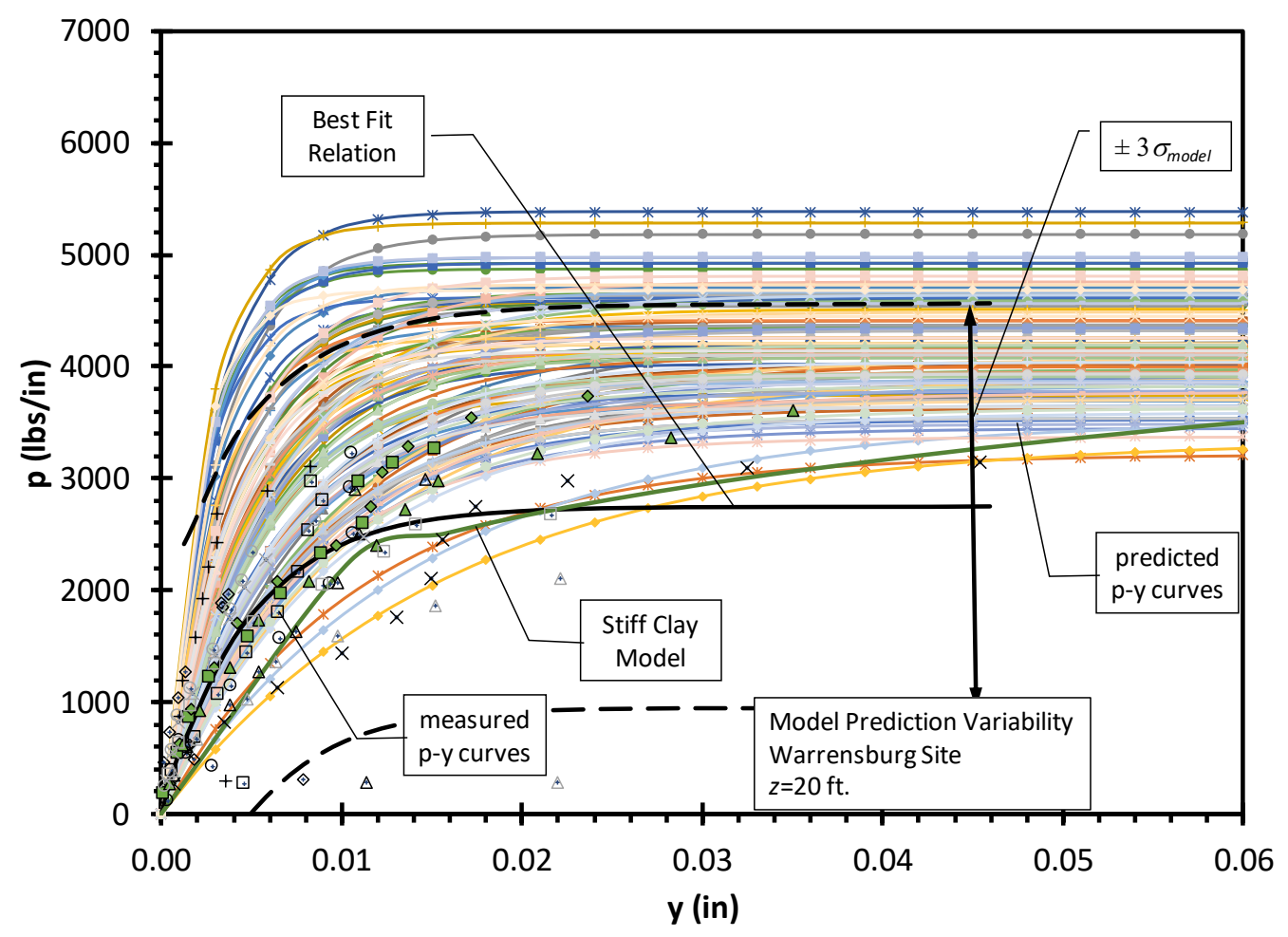

Approach-2 (using avgCOV) for Model Uncertainty (Warrensburg, z=20ft) 


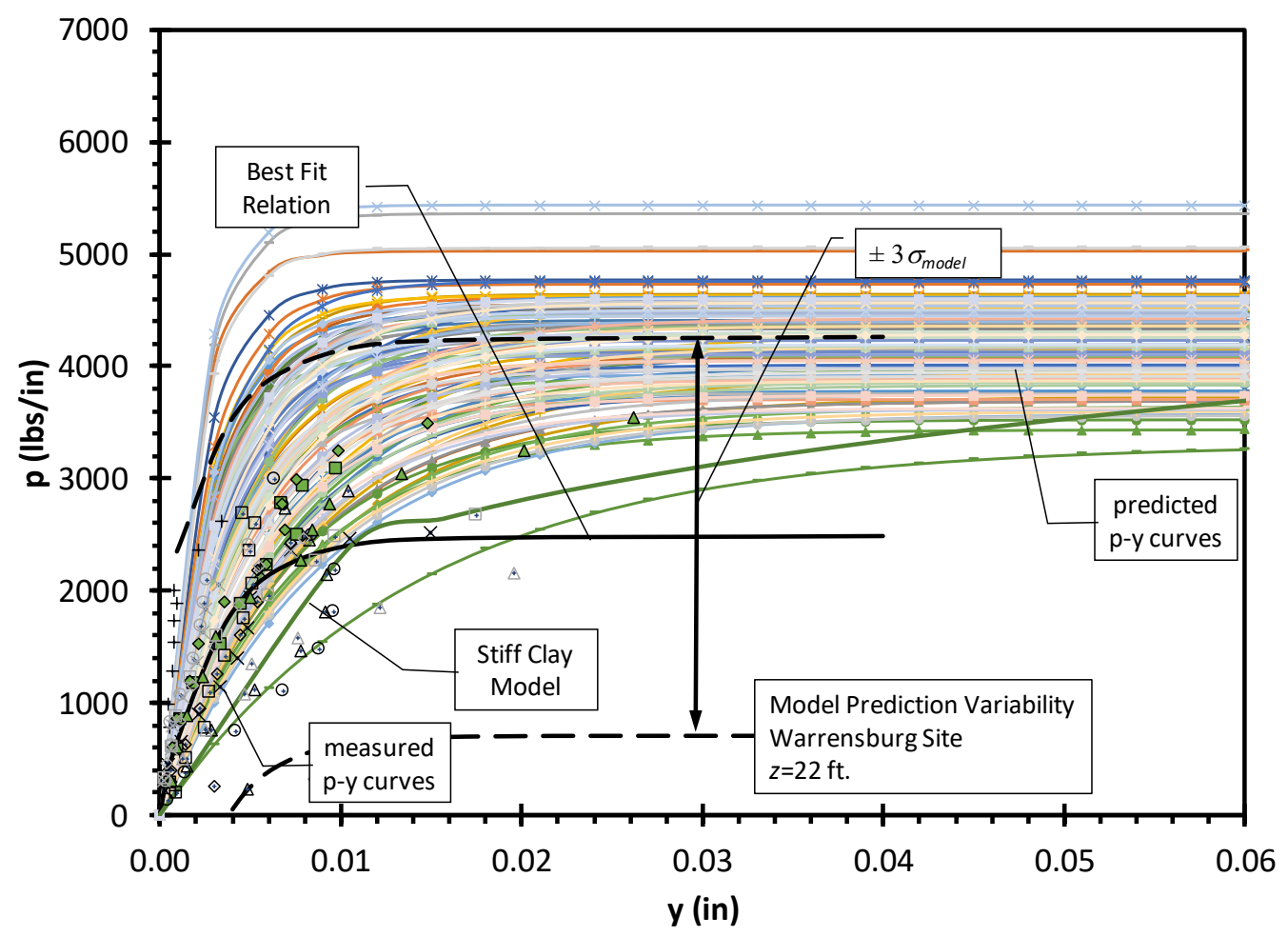

Approach-2 (using avgCOV) for Model Uncertainty (Warrensburg, z=22ft)

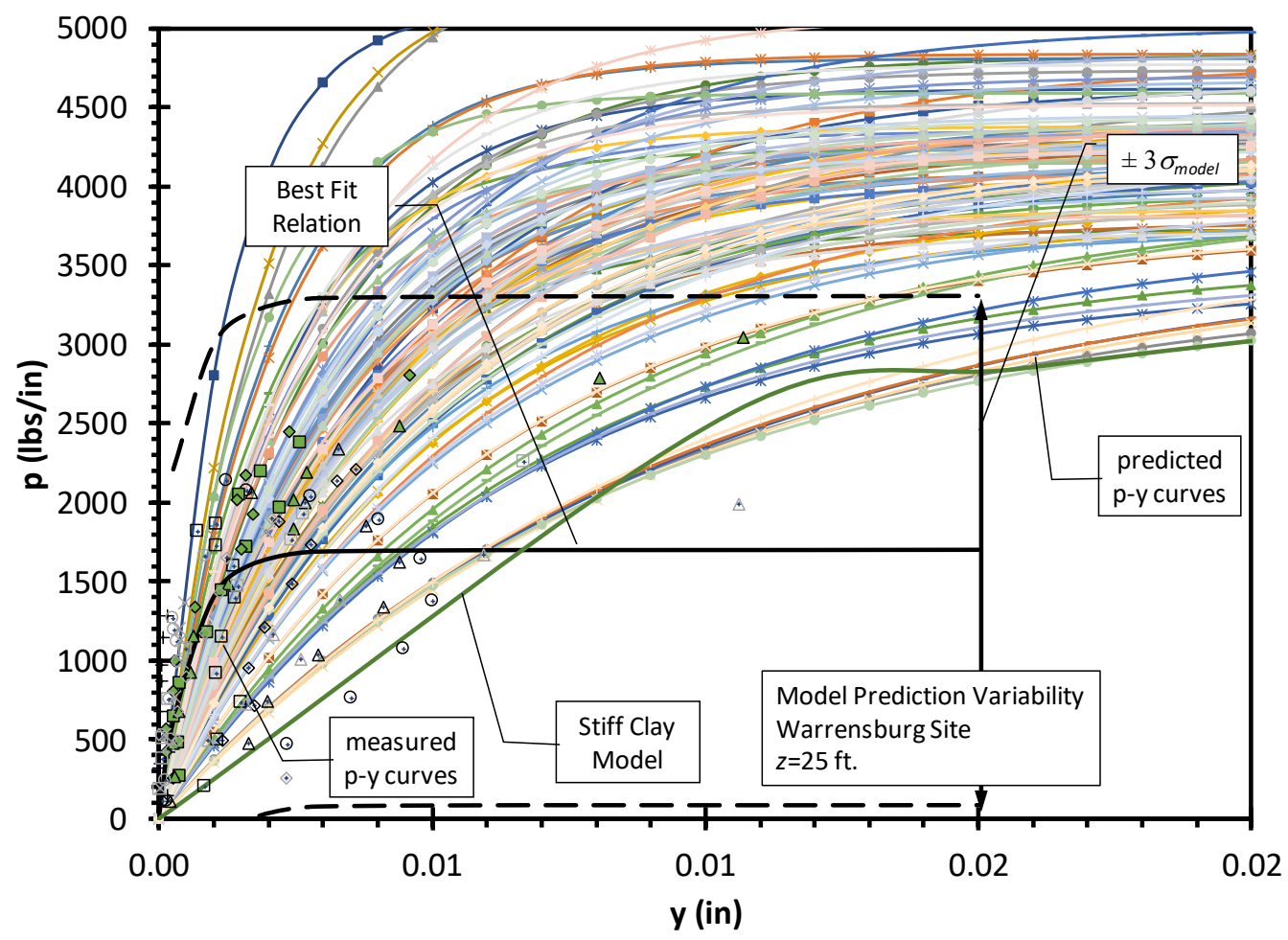

Approach-2 (using avgCOV) for Model Uncertainty (Warrensburg, $\mathrm{z}=25 \mathrm{ft}$ ) 


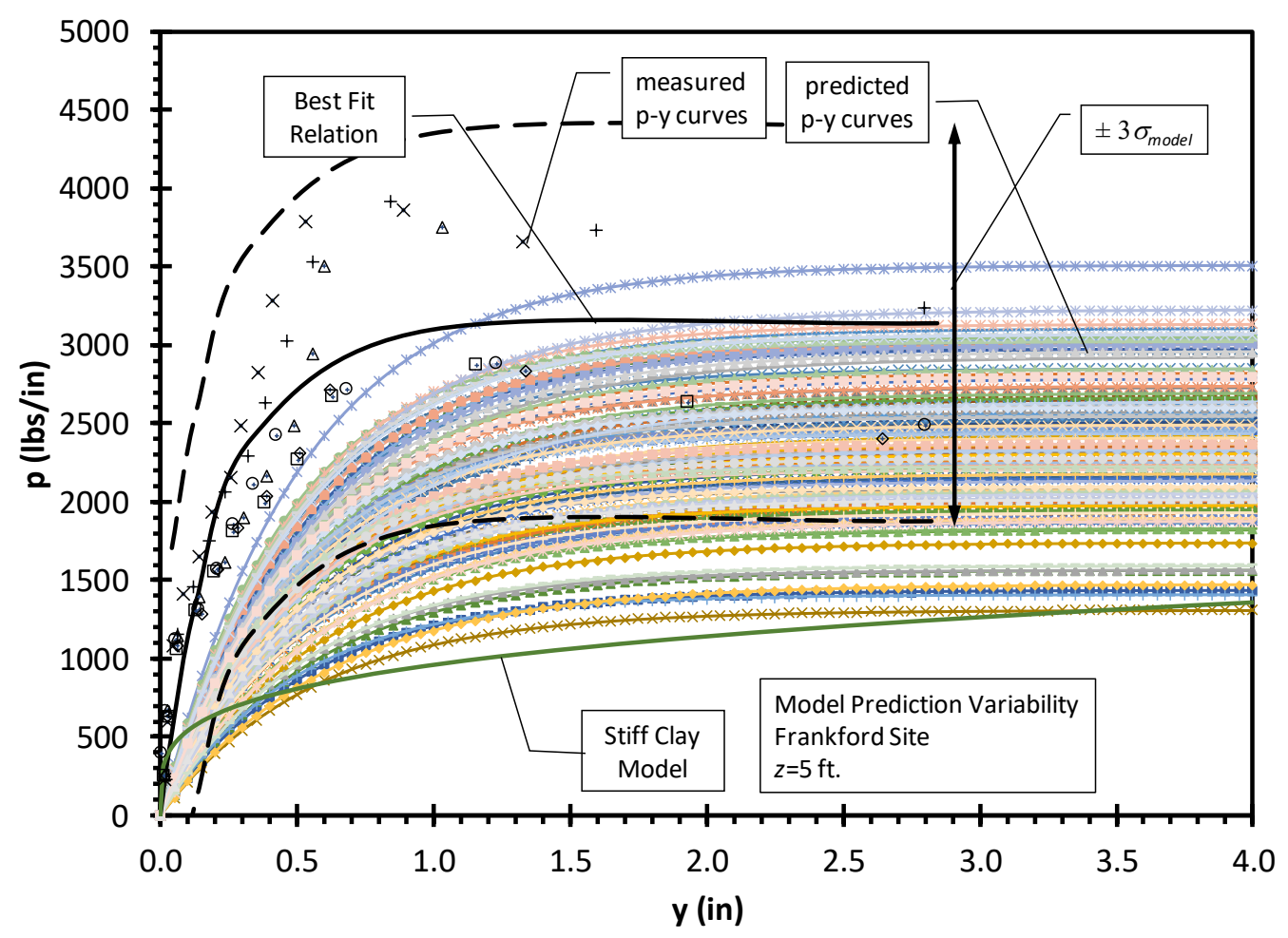

Approach-2 (using avg COV) for Model Uncertainty (Frankford, z=5ft)

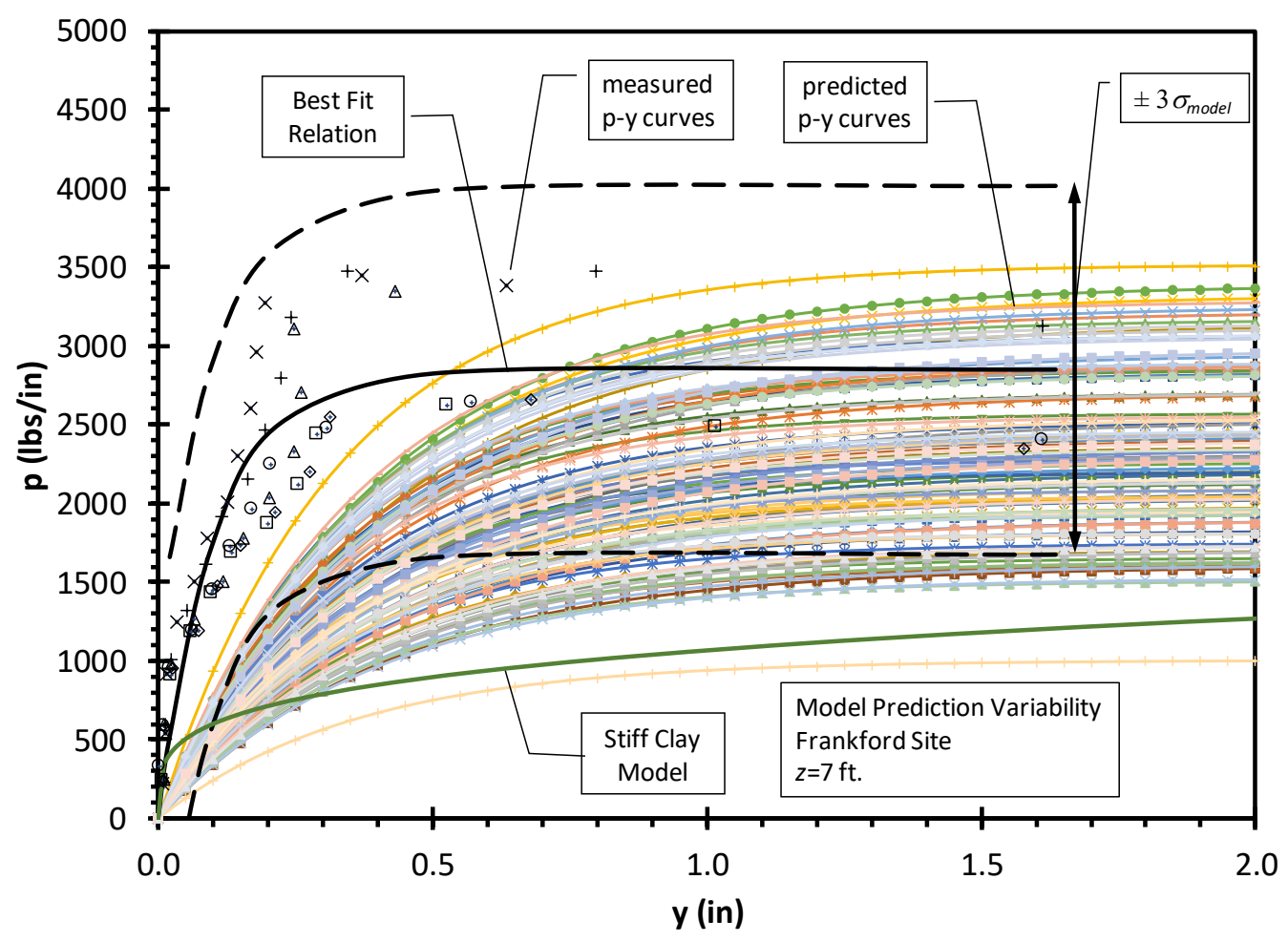

Approach-2 (using avg COV) for Model Uncertainty (Frankford, z=7ft) 


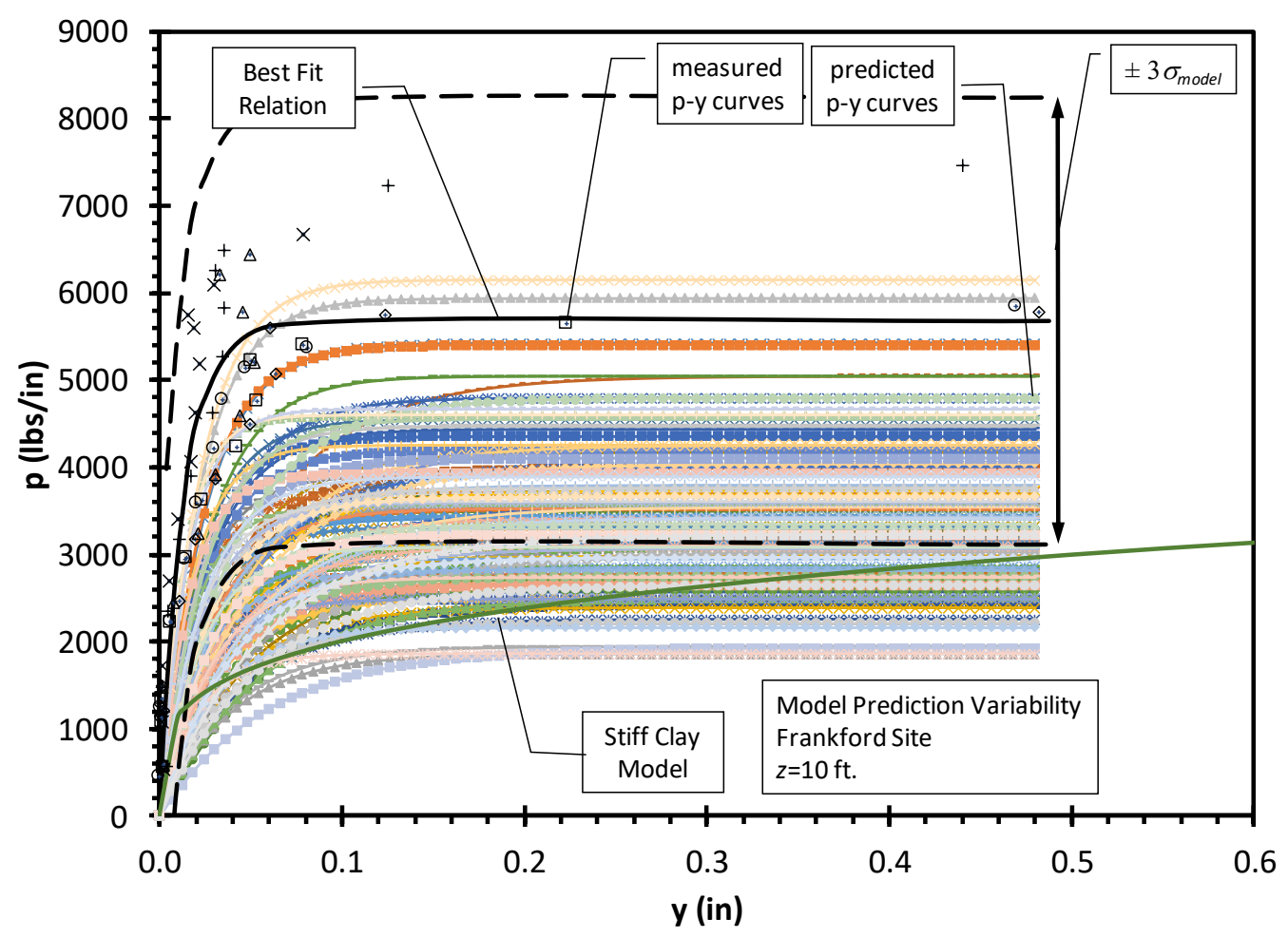

Approach-2 (using avgCOV) for Model Uncertainty (Frankford, $\mathrm{z}=10 \mathrm{ft}$ )

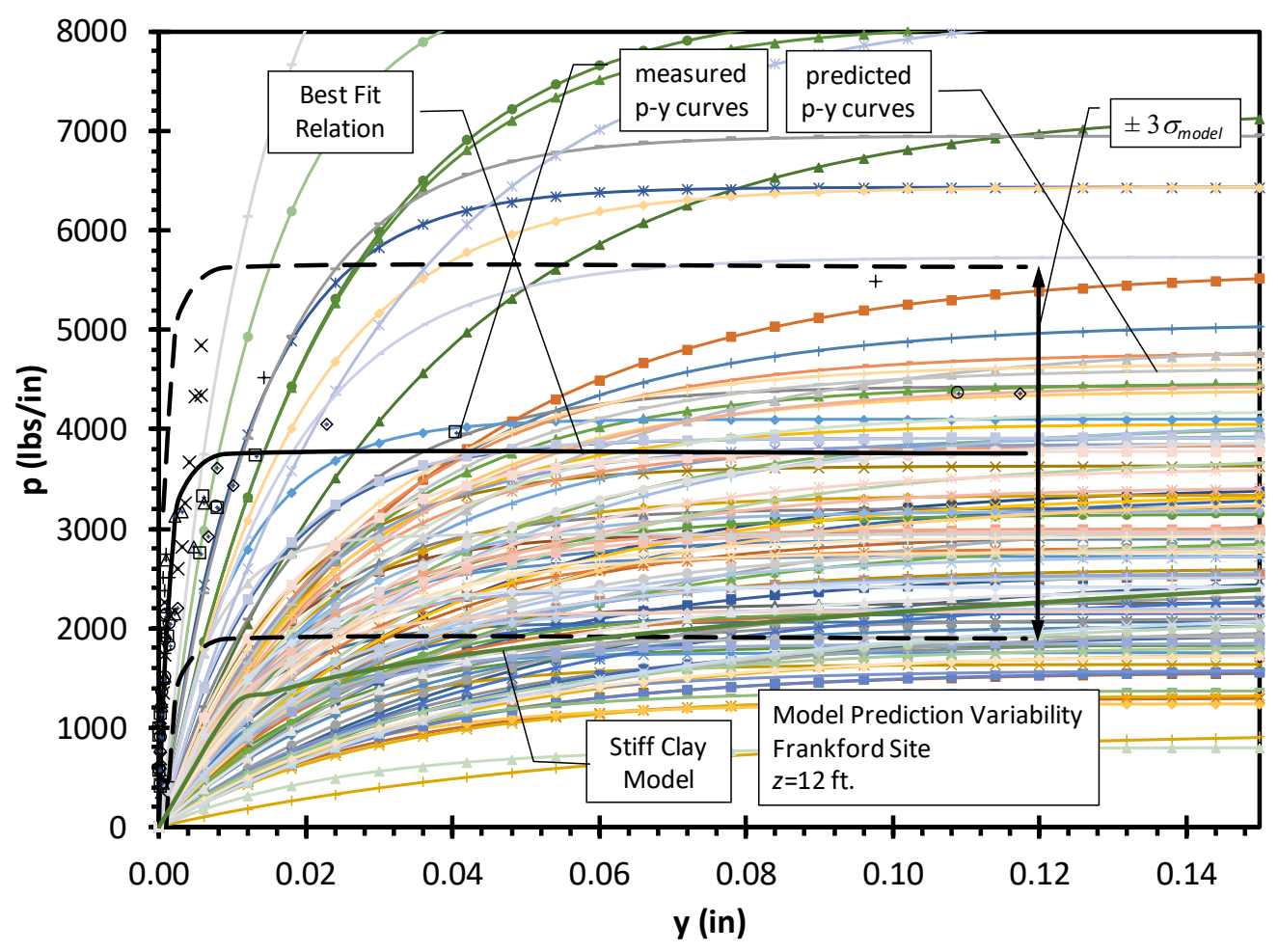

Approach-2 (using avgCOV) for Model Uncertainty (Frankford, $\mathrm{z}=12 \mathrm{ft}$ ) 


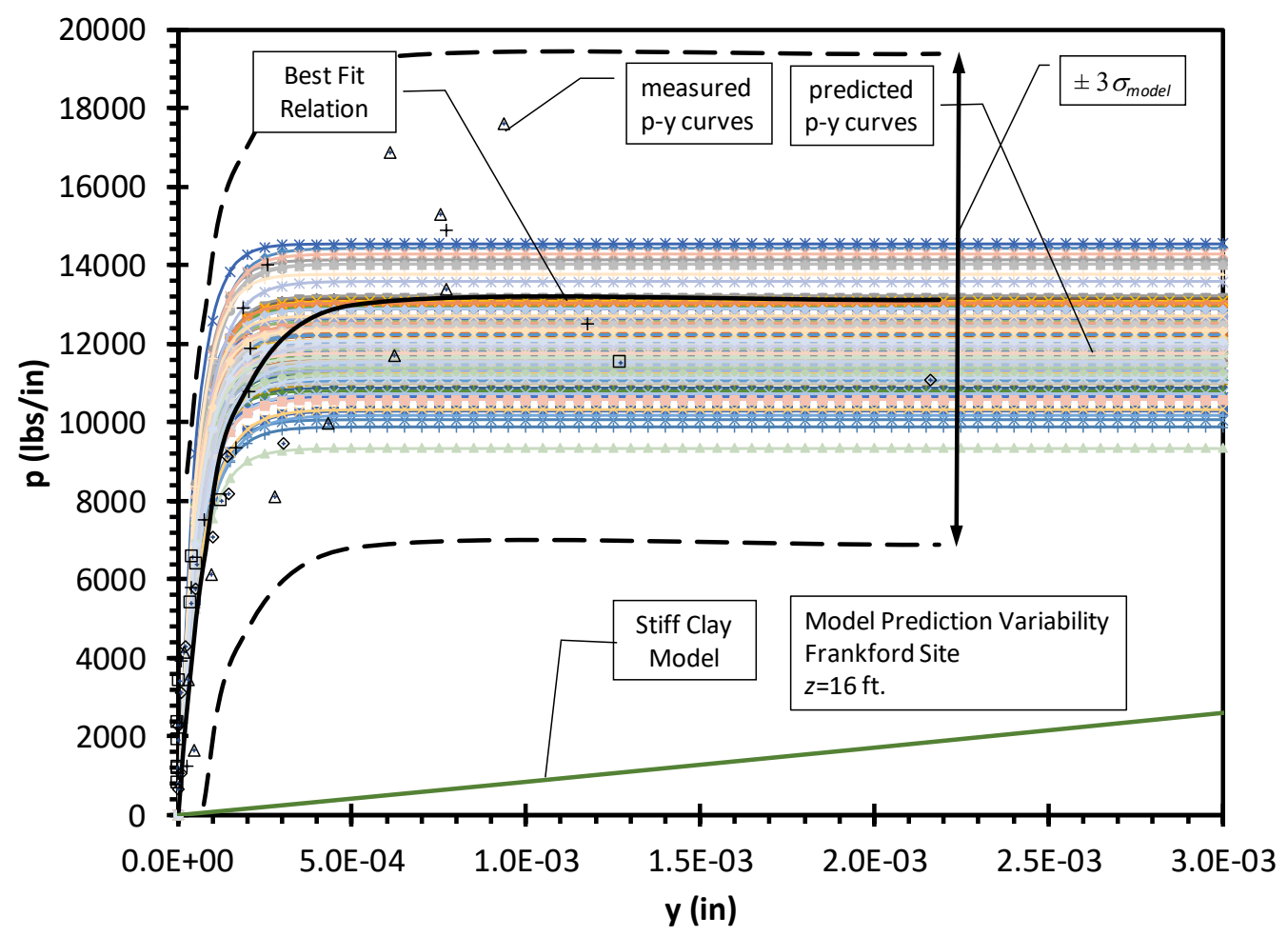

Approach-2 (using avgCOV) for Model Uncertainty (Frankford, $\mathrm{z}=16 \mathrm{ft}$ )

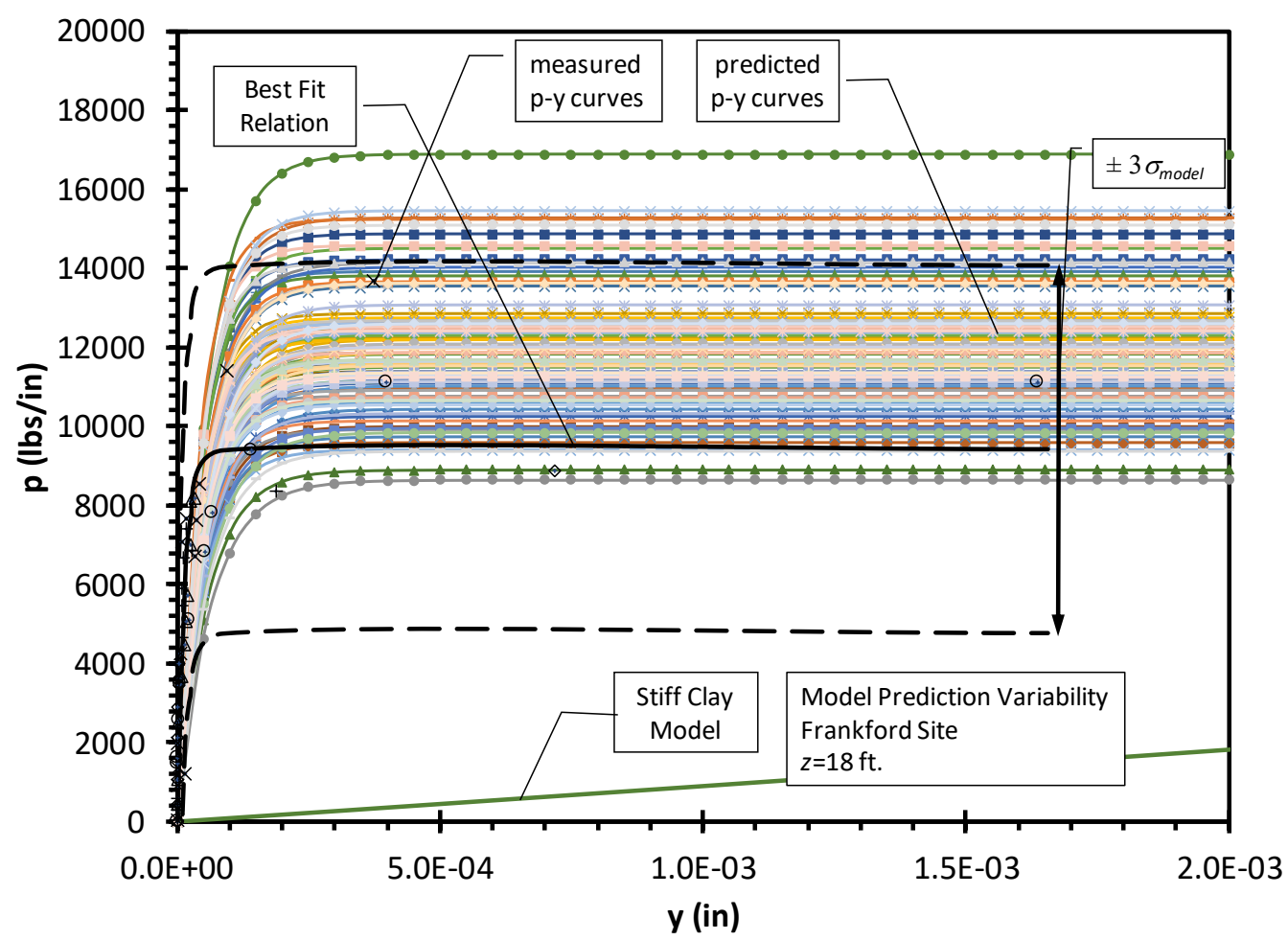

Approach-2 (using avgCOV) for Model Uncertainty (Frankford, z=18ft) 


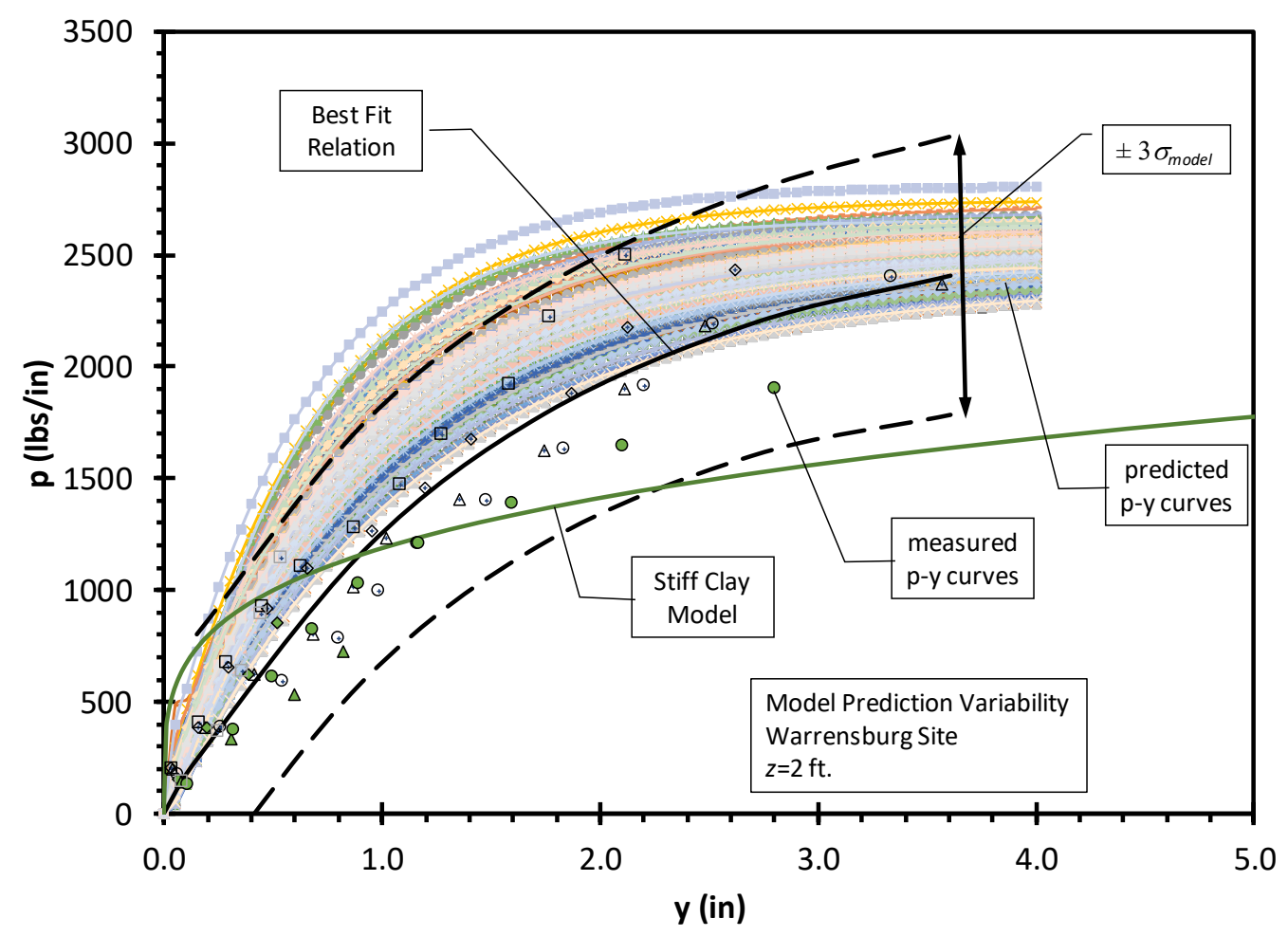

Approach-3 (using avgSTD) for Model Uncertainty (Warrensburg, z=2ft)

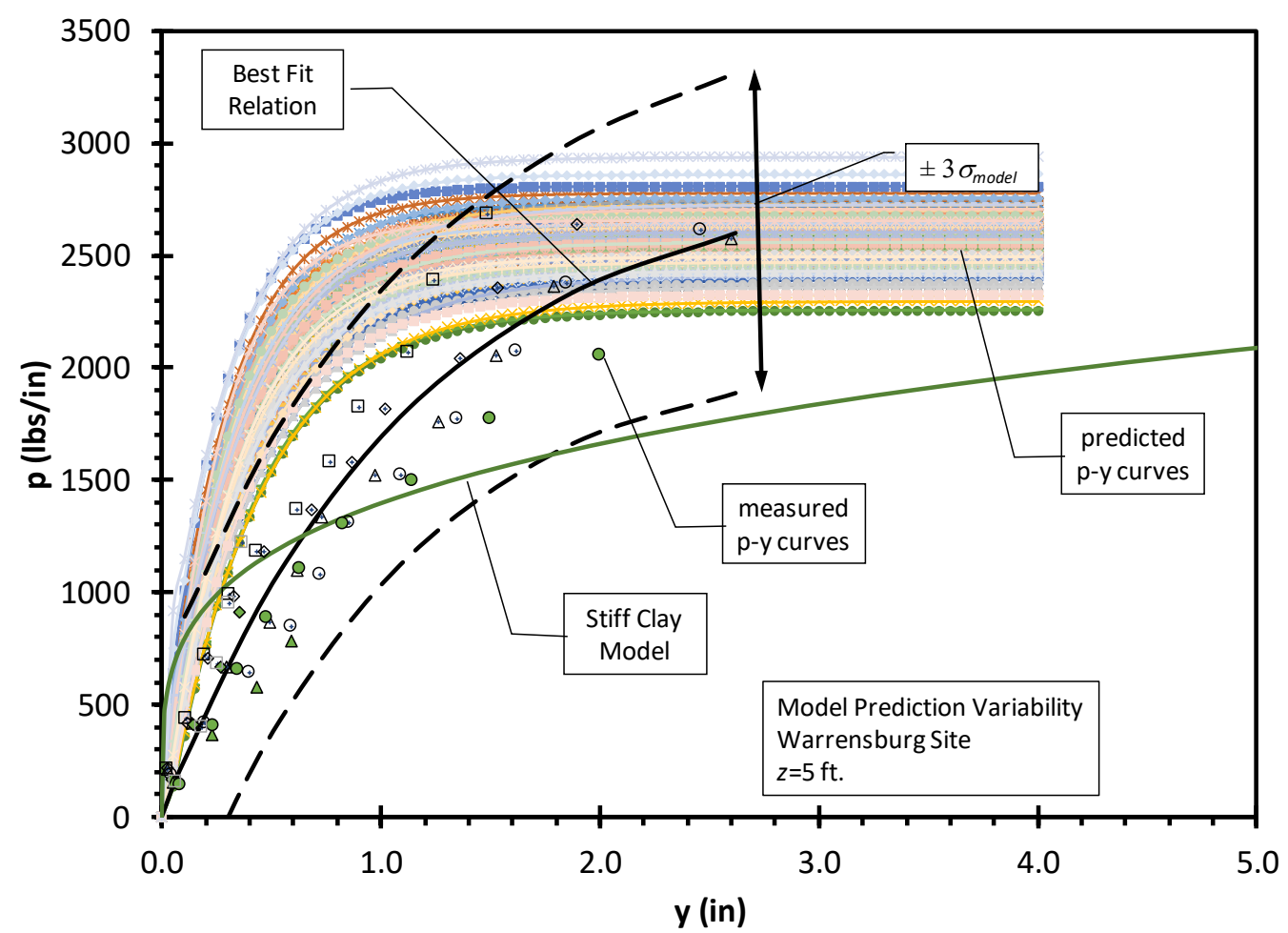

Approach-3 (using avgSTD) for Model Uncertainty (Warrensburg, $\mathrm{z}=5 \mathrm{ft}$ ) 


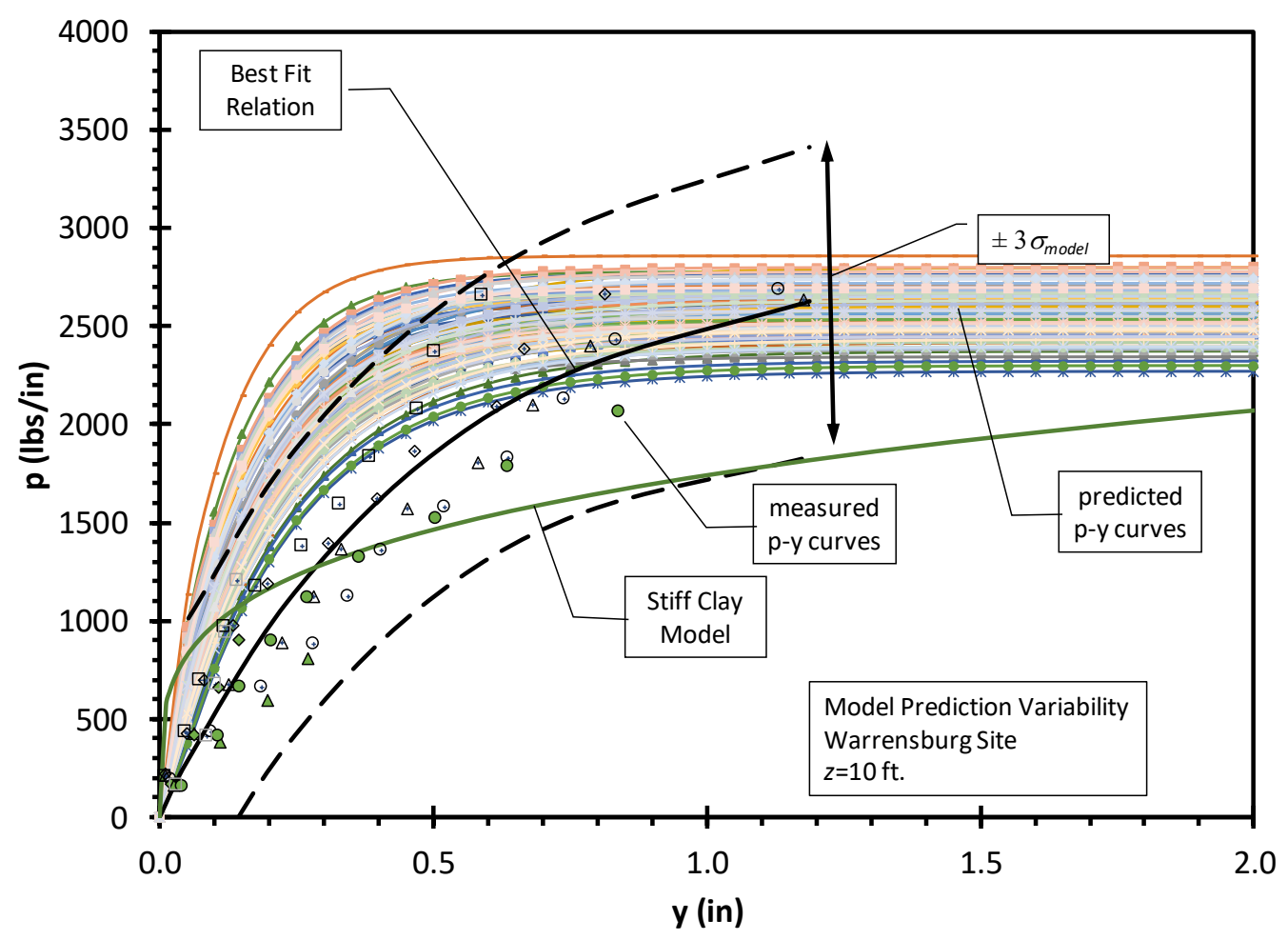

Approach-3 (using avgSTD) for Model Uncertainty (Warrensburg, z=10ft)

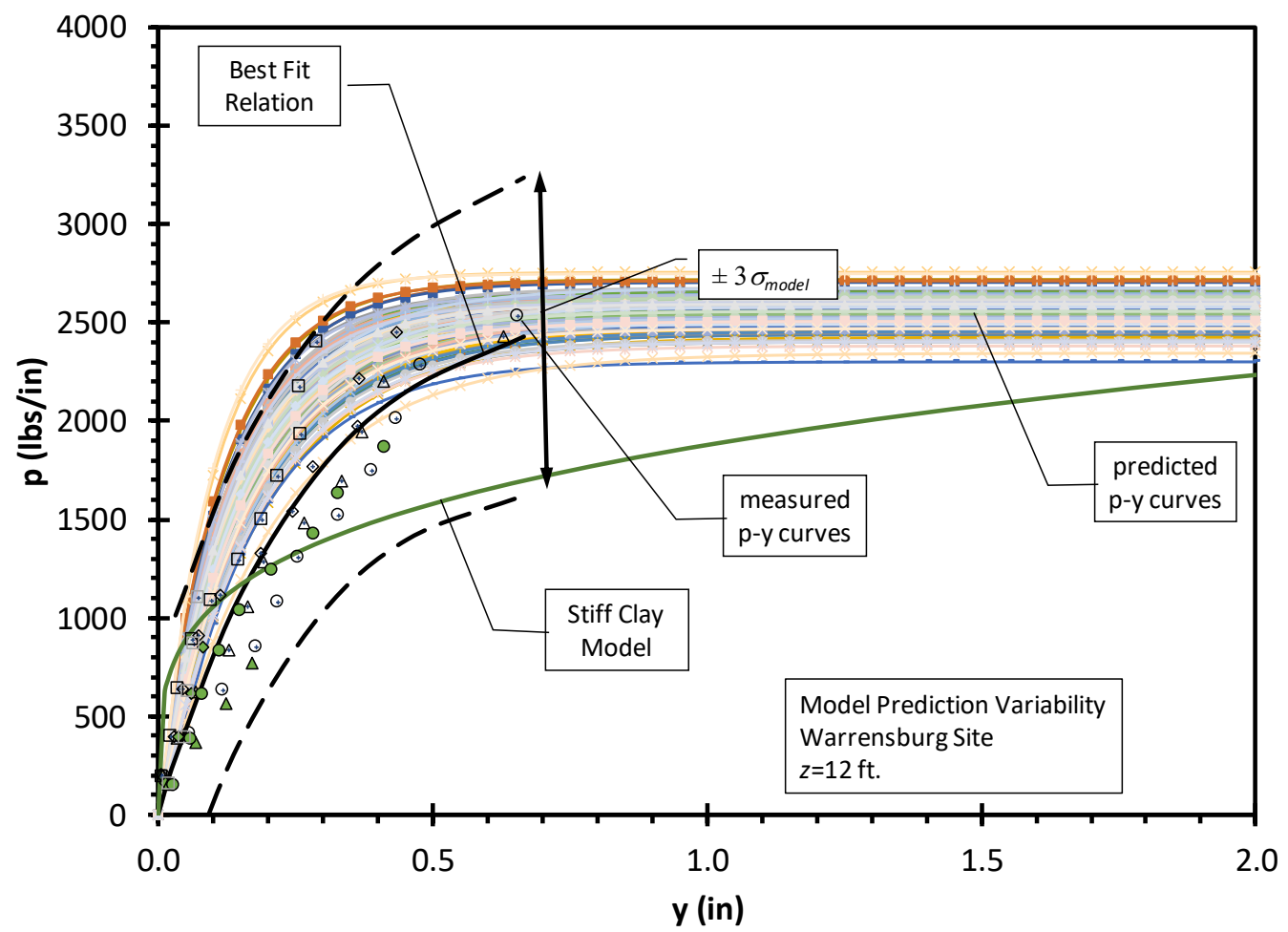

Approach-3 (using avgSTD) for Model Uncertainty (Warrensburg, z=12ft) 


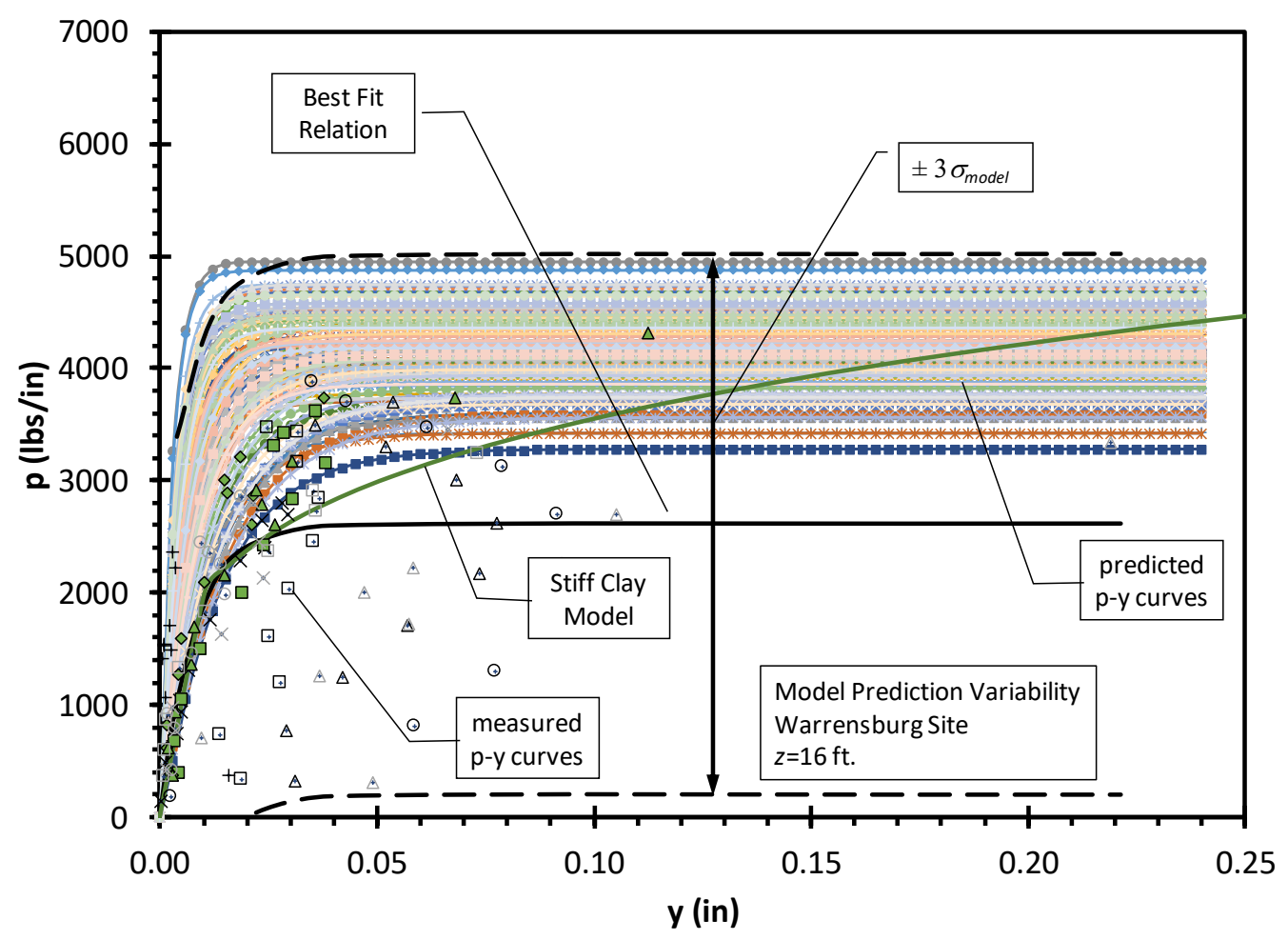

Approach-3 (using avgSTD) for Model Uncertainty (Warrensburg, z=16ft)

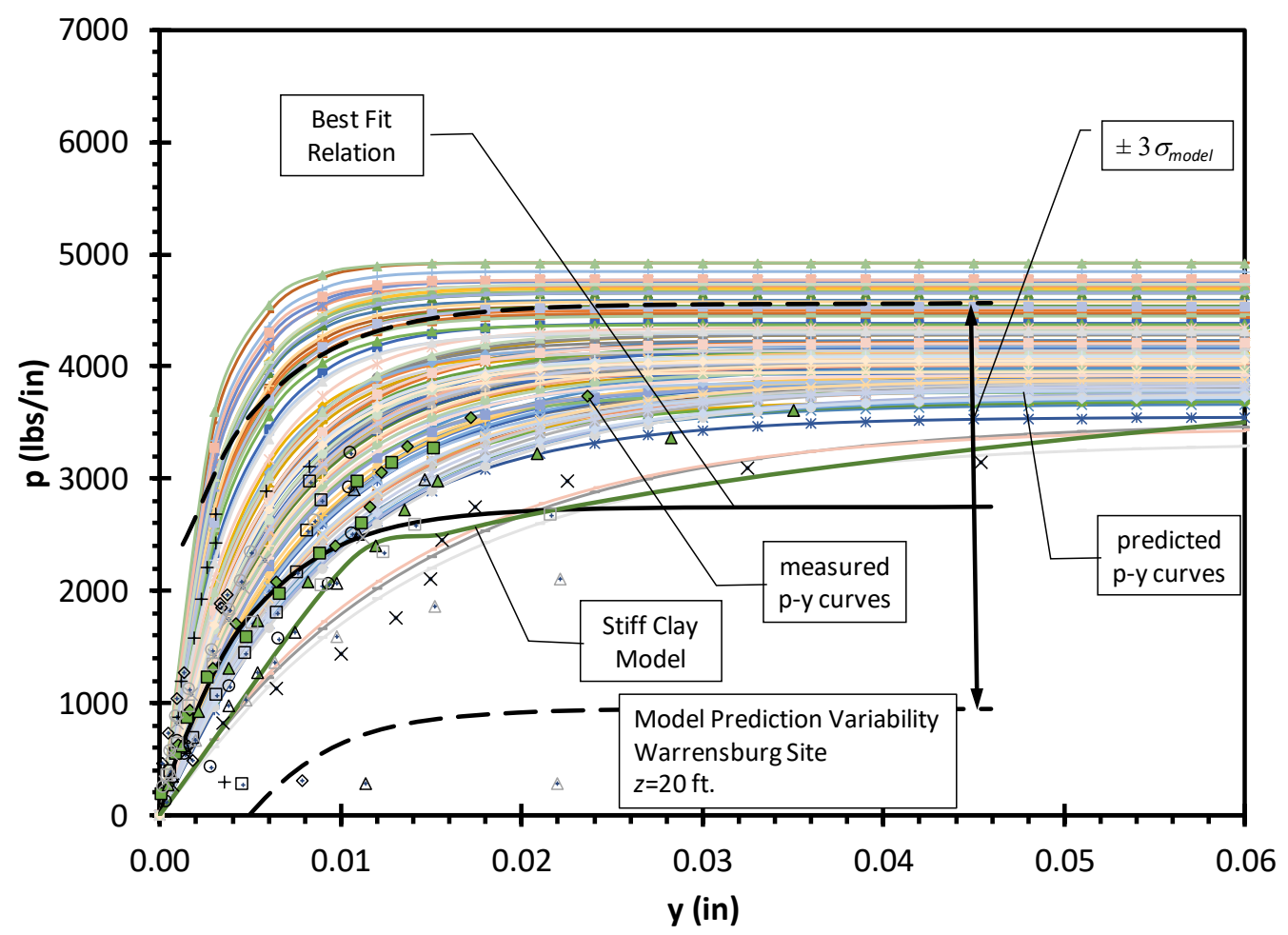

Approach-3 (using avgSTD) for Model Uncertainty (Warrensburg, z=20ft) 


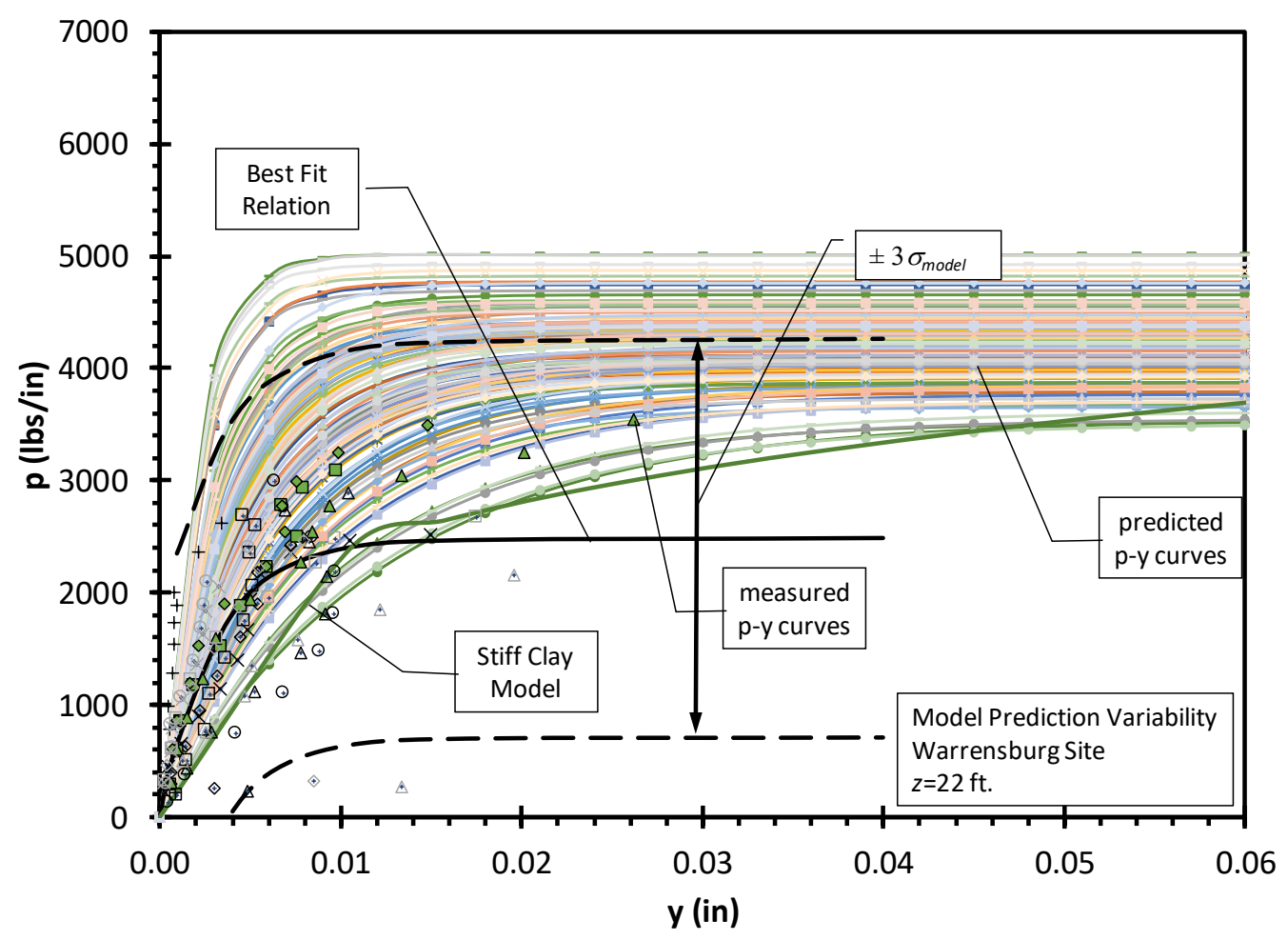

Approach-3 (using avgSTD) for Model Uncertainty (Warrensburg, z=22ft)

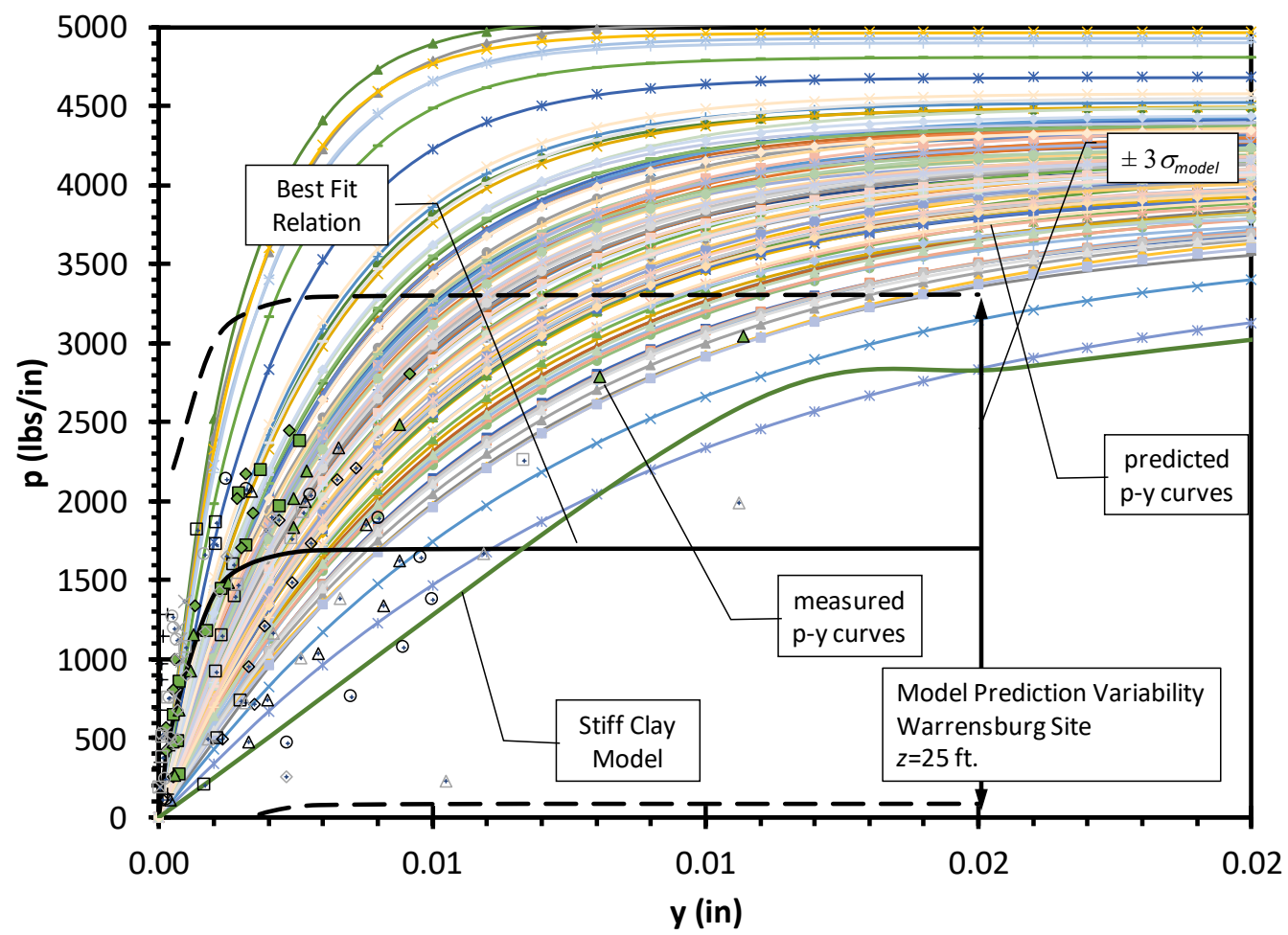

Approach-3 (using avgSTD) for Model Uncertainty (Warrensburg, z=25ft) 


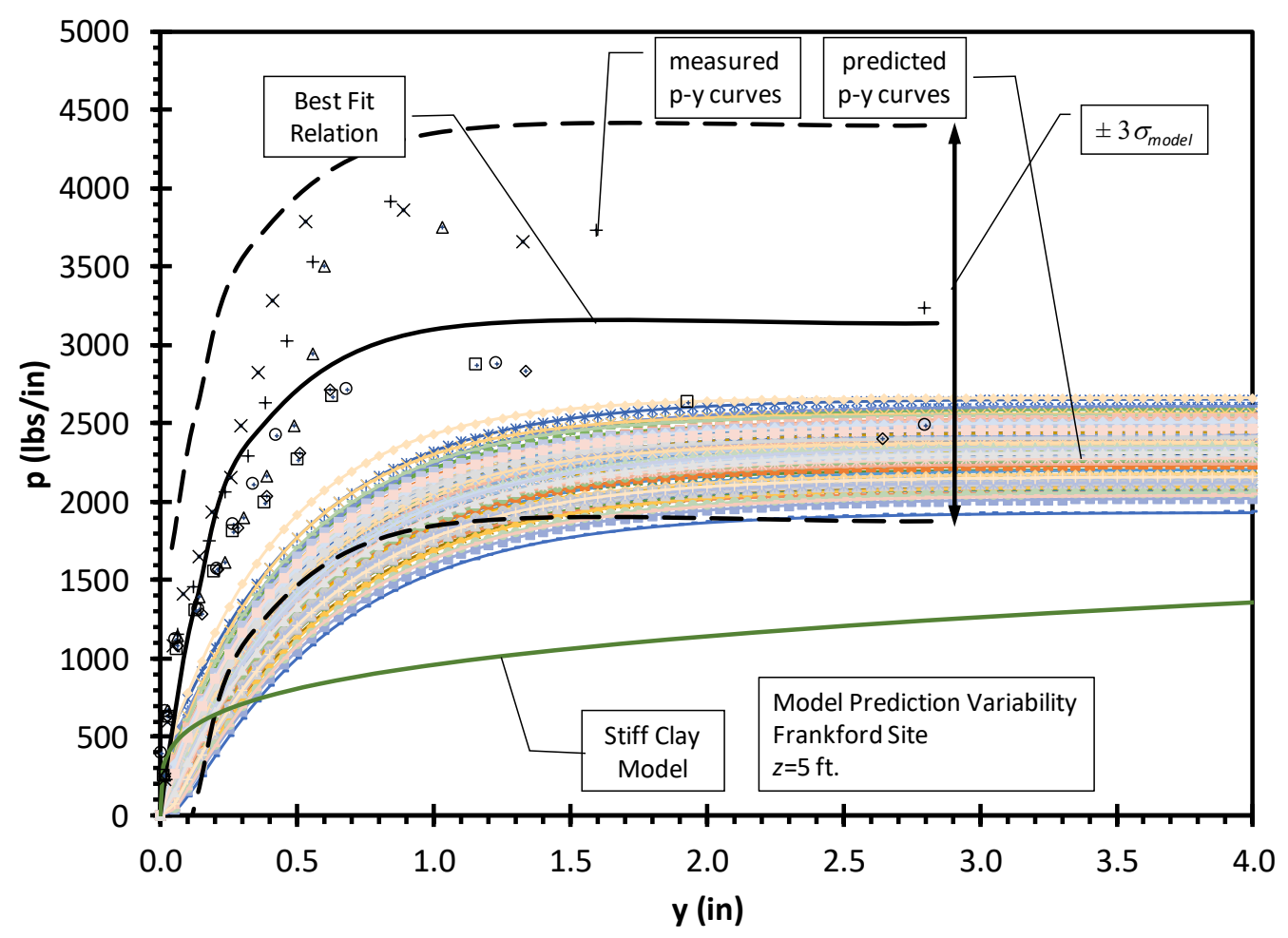

Approach-3 (using avgSTD) for Model Uncertainty (Frankford, z=5ft)

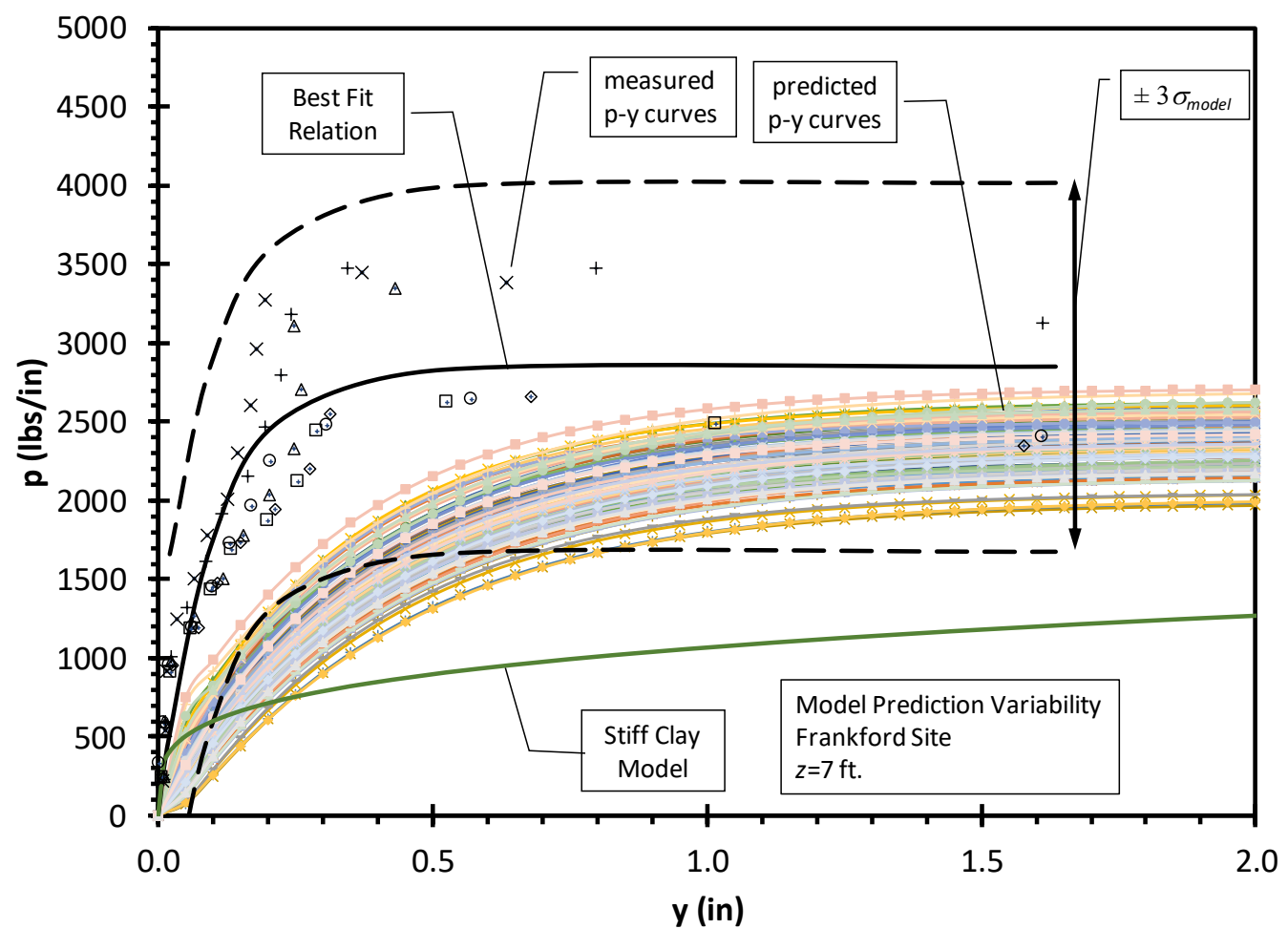

Approach-3 (using avgSTD) for Model Uncertainty (Frankford, z=7ft) 


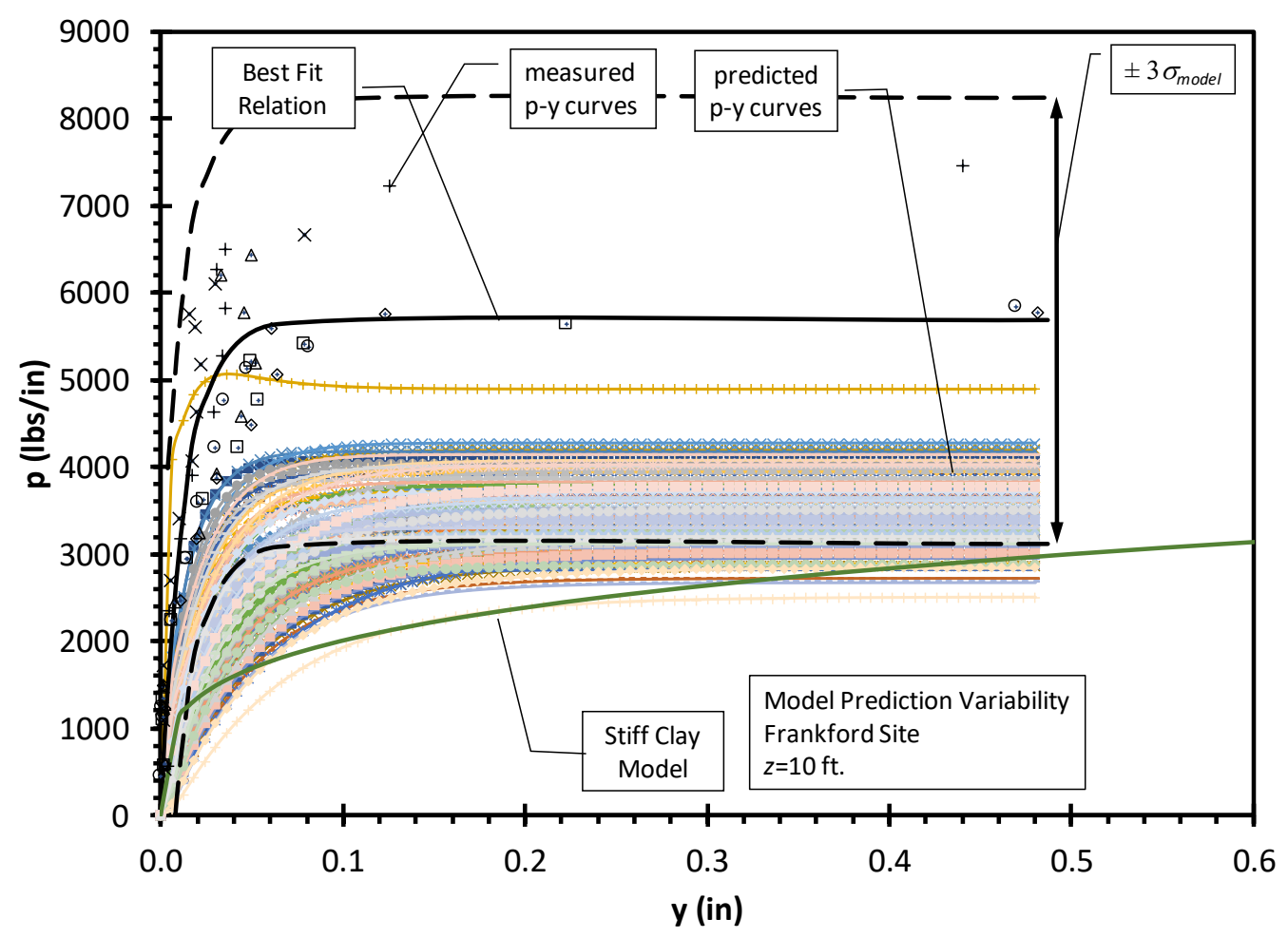

Approach-3 (using avgSTD) for Model Uncertainty (Frankford, $\mathrm{z}=10 \mathrm{ft}$ )

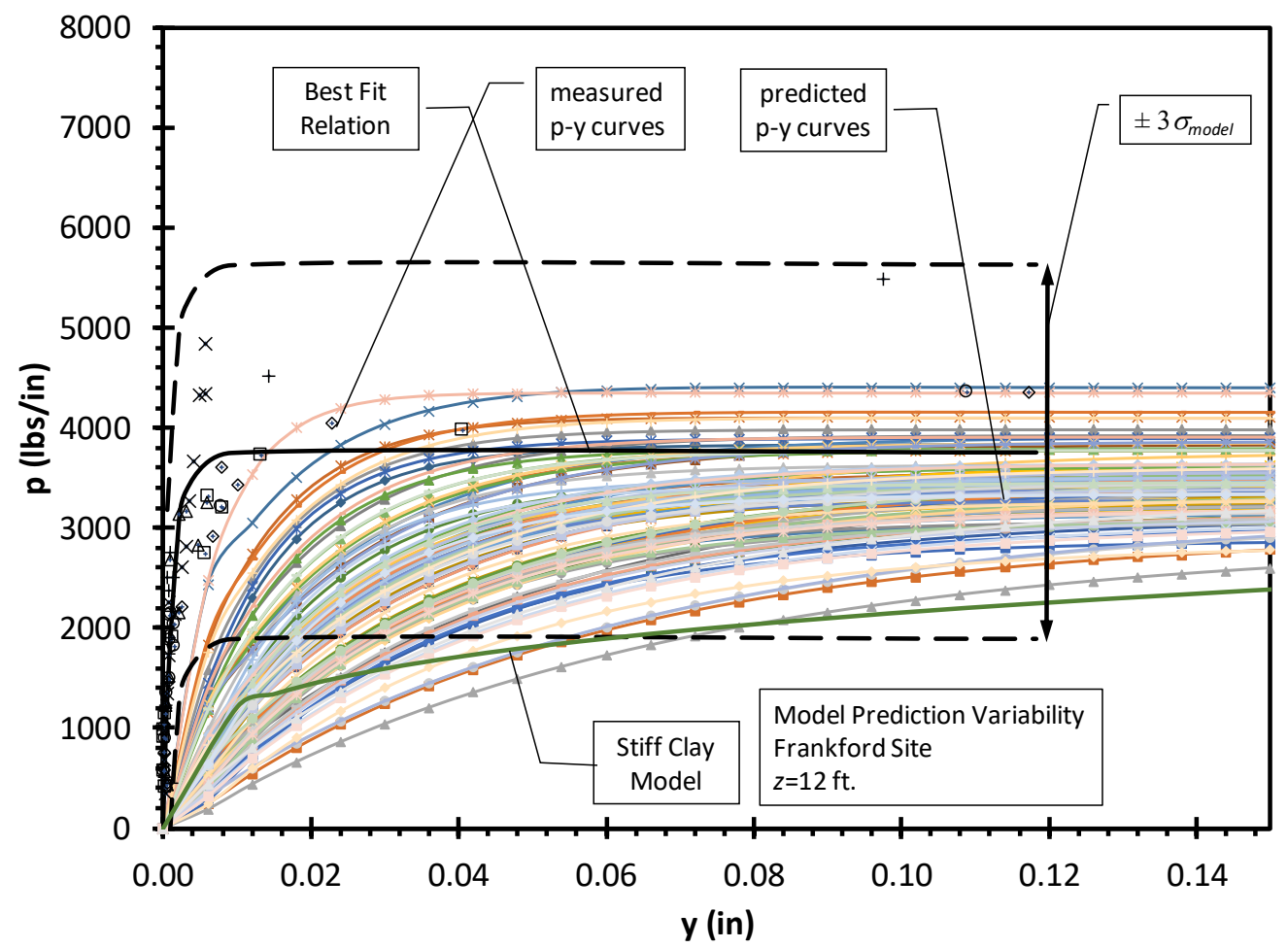

Approach-3 (using avgSTD) for Model Uncertainty (Frankford, z=12ft) 


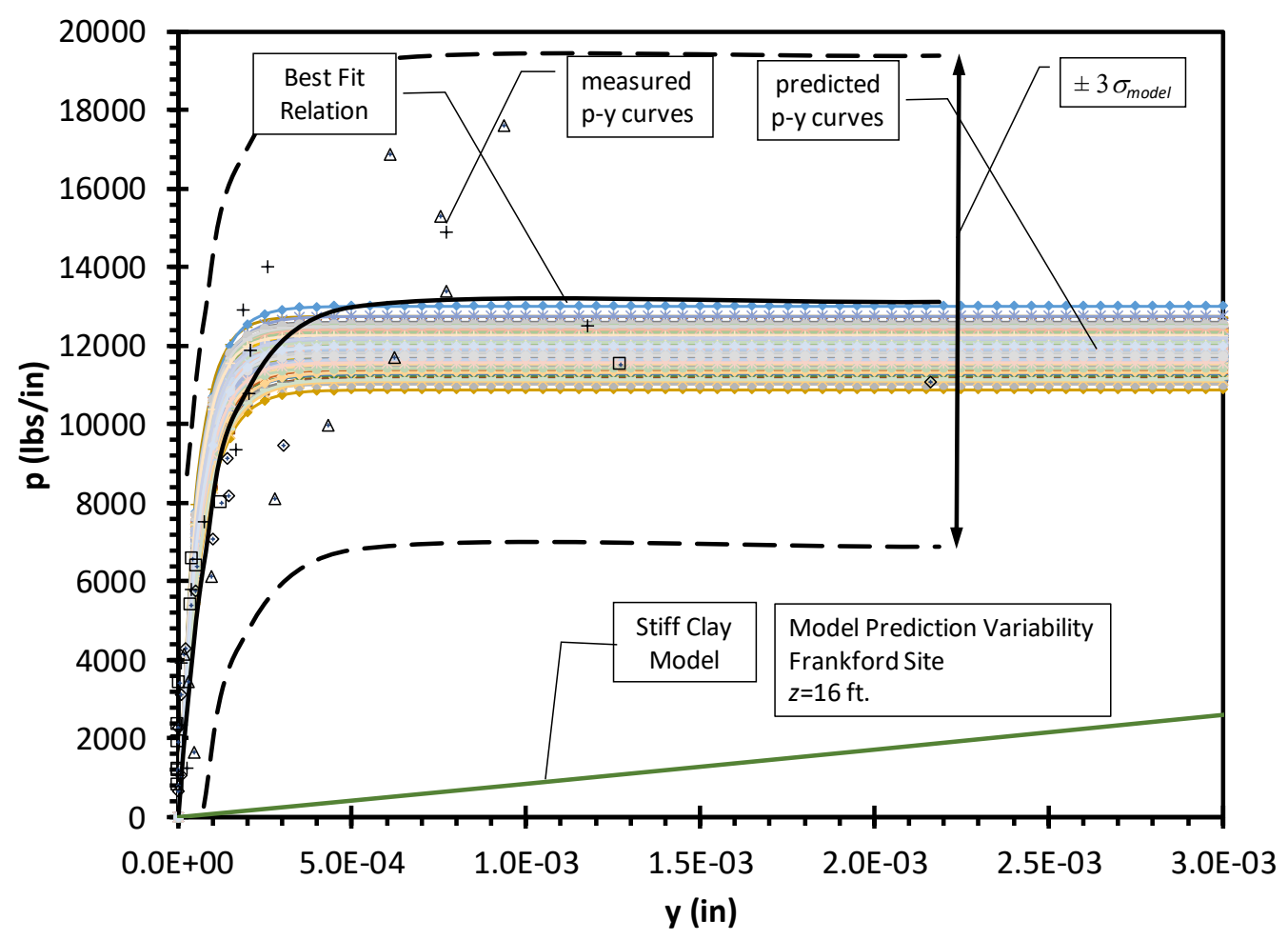

Approach-3 (using avgSTD) for Model Uncertainty (Frankford, z=16ft)

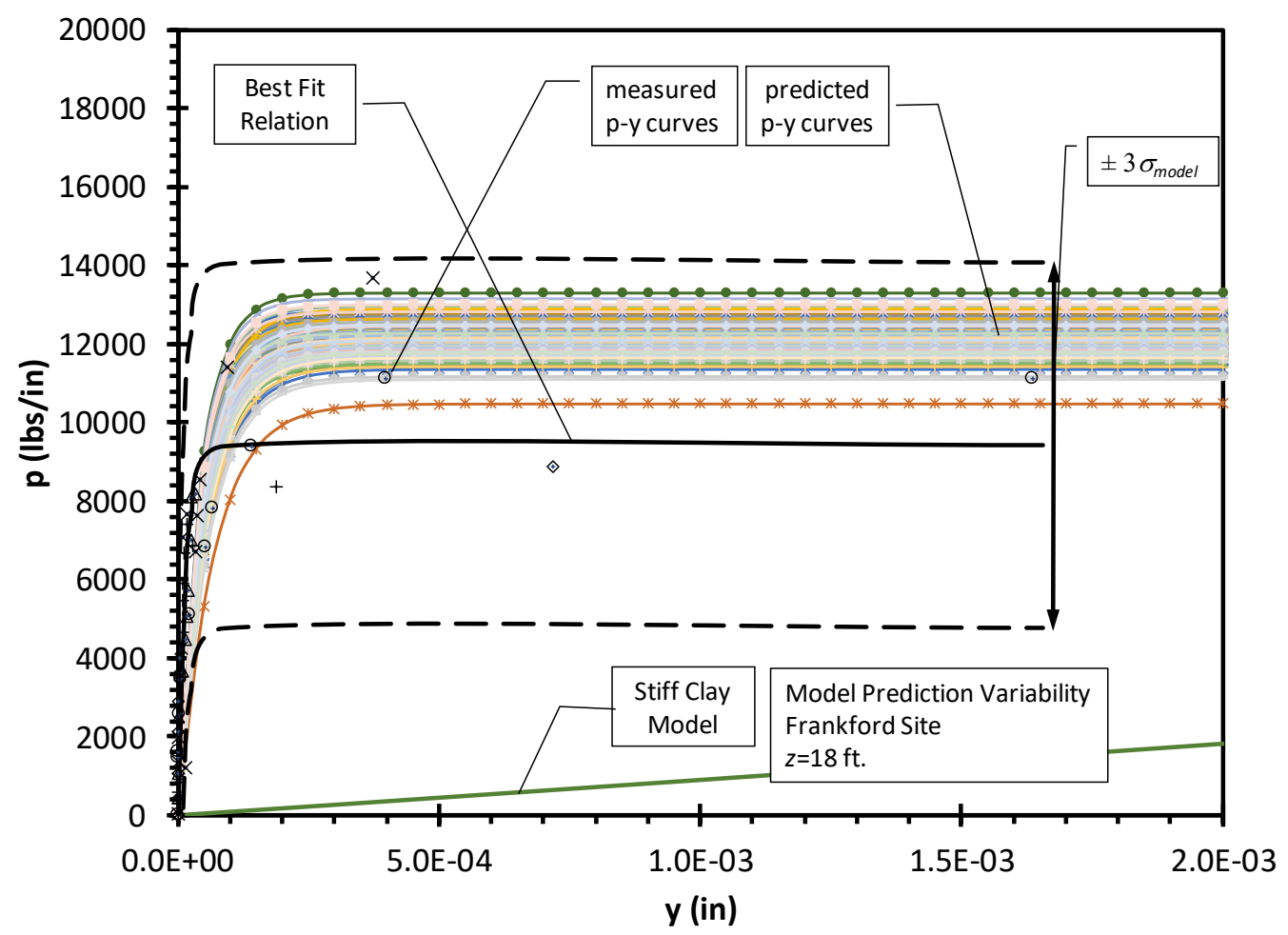

Approach-3 (using avgSTD) for Model Uncertainty (Frankford, z=18ft) 


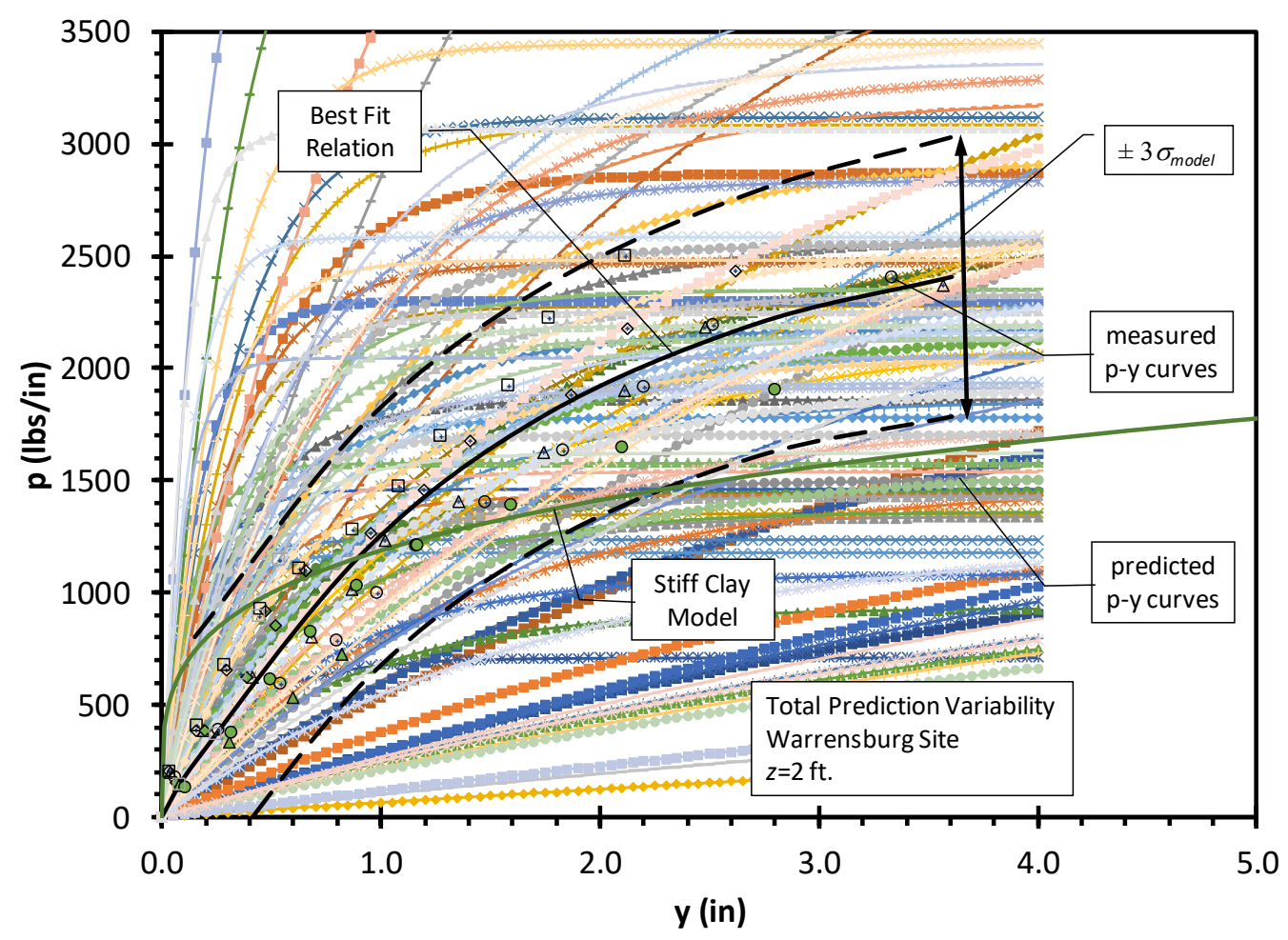

Approach-1 (using $\operatorname{COV}_{\text {Pult }}$ and $C O V_{K p y}$ ) for Total Uncertainty (Warrensburg, z=2ft)

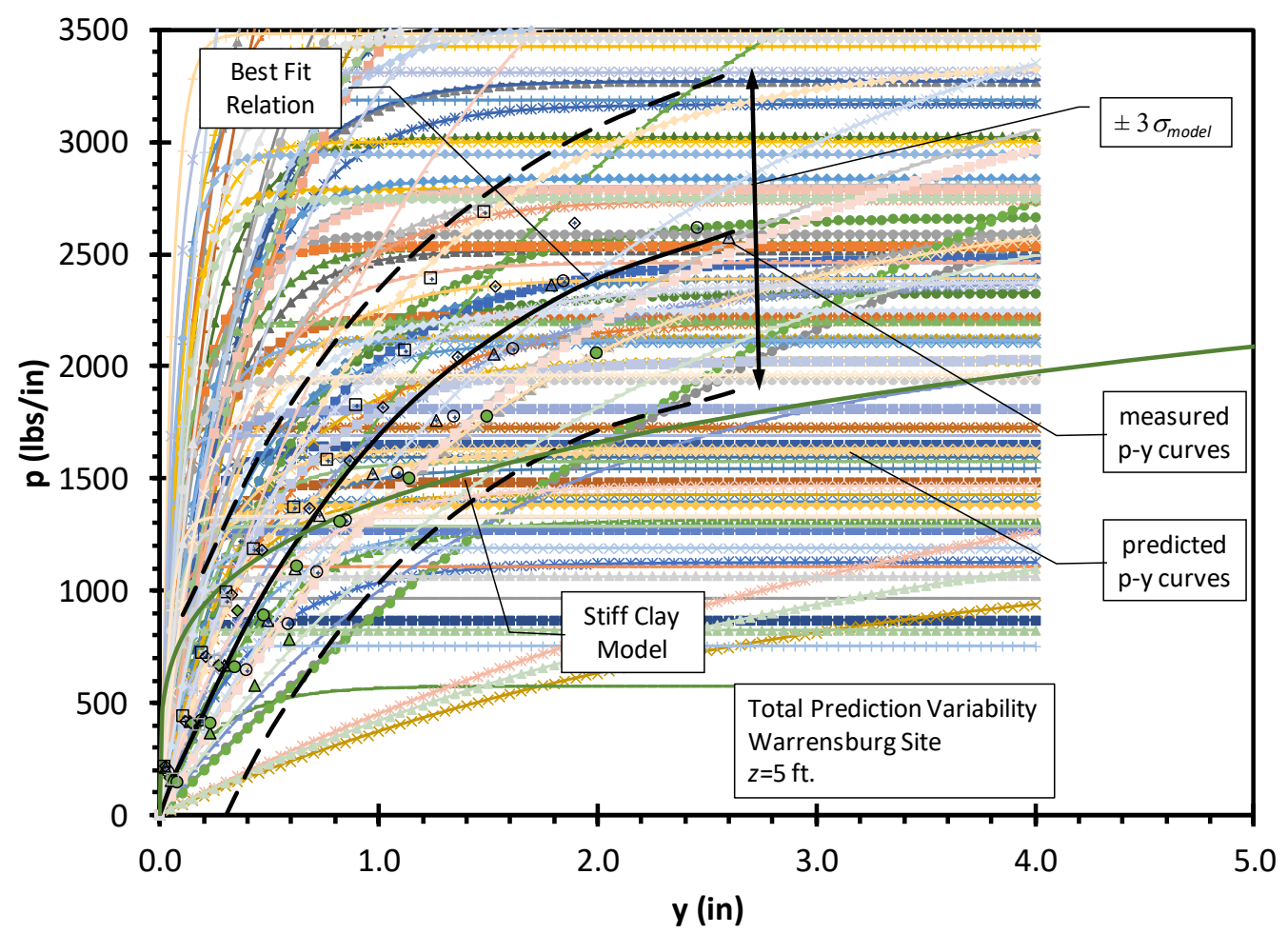

Approach-1 (using $\operatorname{COV}_{\text {Pult }}$ and $\operatorname{COV}_{K p y}$ ) for Total Uncertainty (Warrensburg, $\mathrm{z}=5 \mathrm{ft}$ ) 


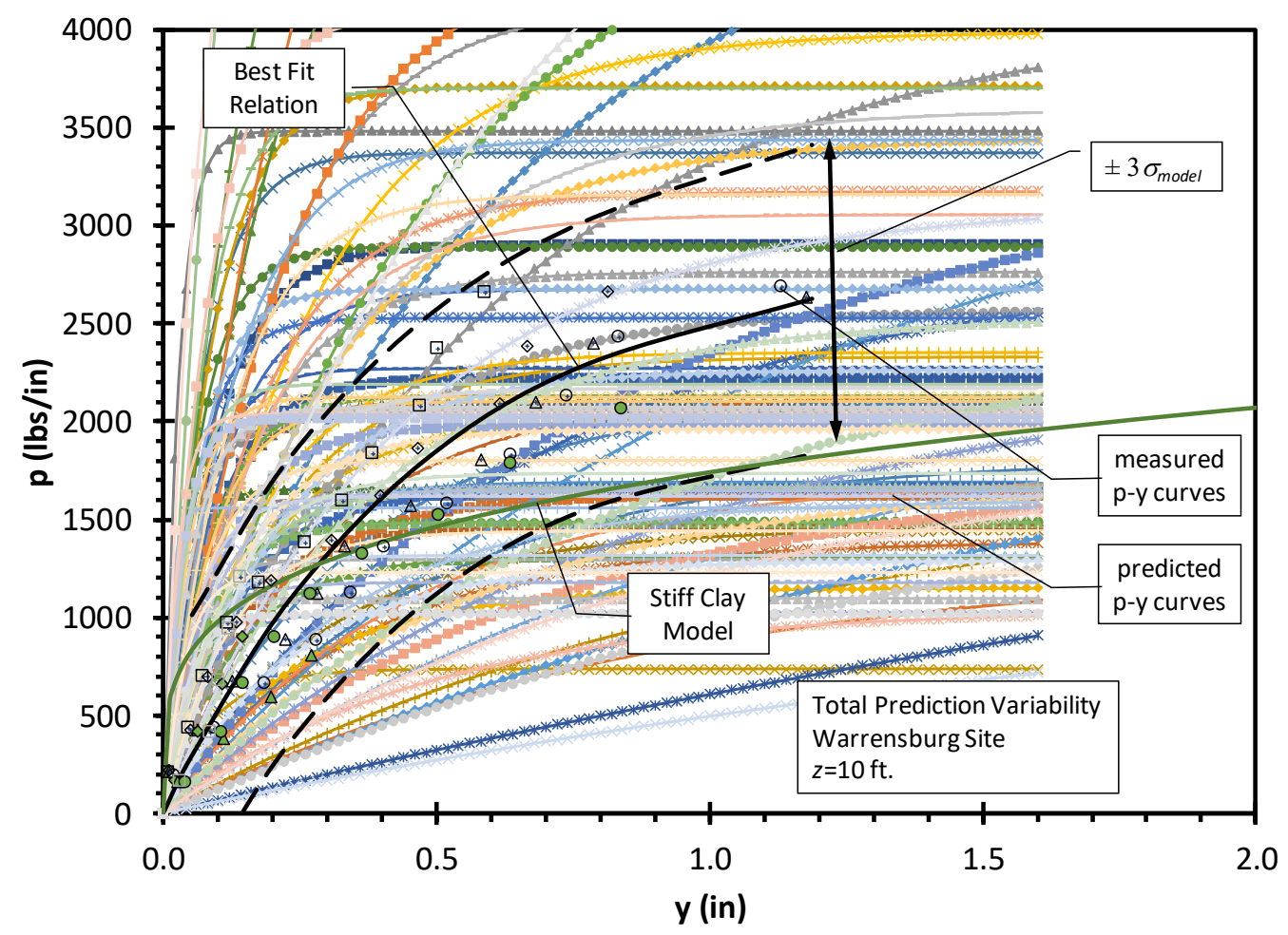

Approach-1 (using $\mathrm{COV}_{\mathrm{Pult}}$ and $\mathrm{COV}_{\mathrm{Kpy}}$ ) for Total Uncertainty (Warrensburg, $\mathrm{z}=10 \mathrm{ft}$ )

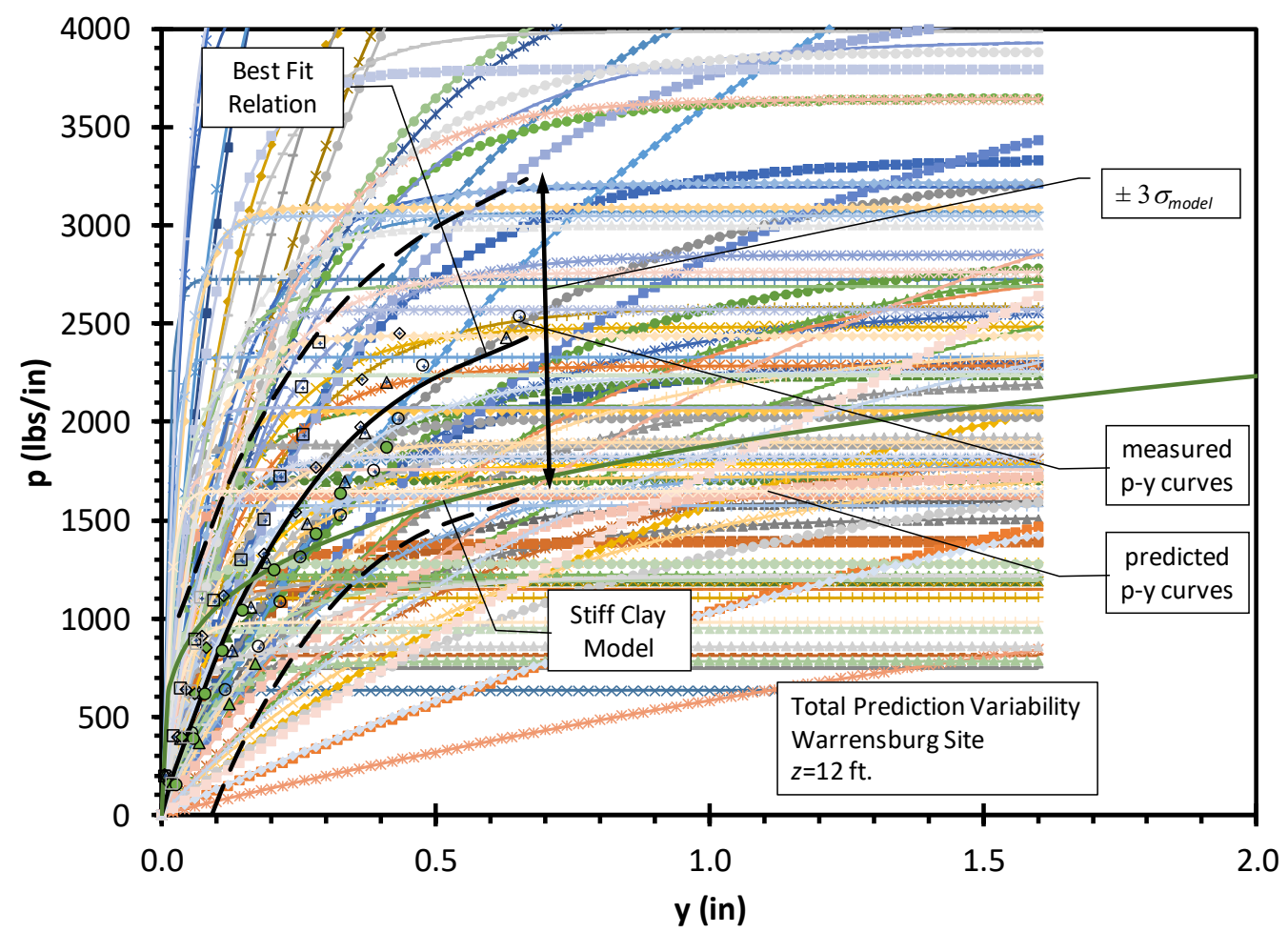

Approach-1 (using $\operatorname{COV}_{\text {Pult }}$ and $\operatorname{COV}_{\text {Kpy }}$ ) for Total Uncertainty (Warrensburg, z=12ft) 


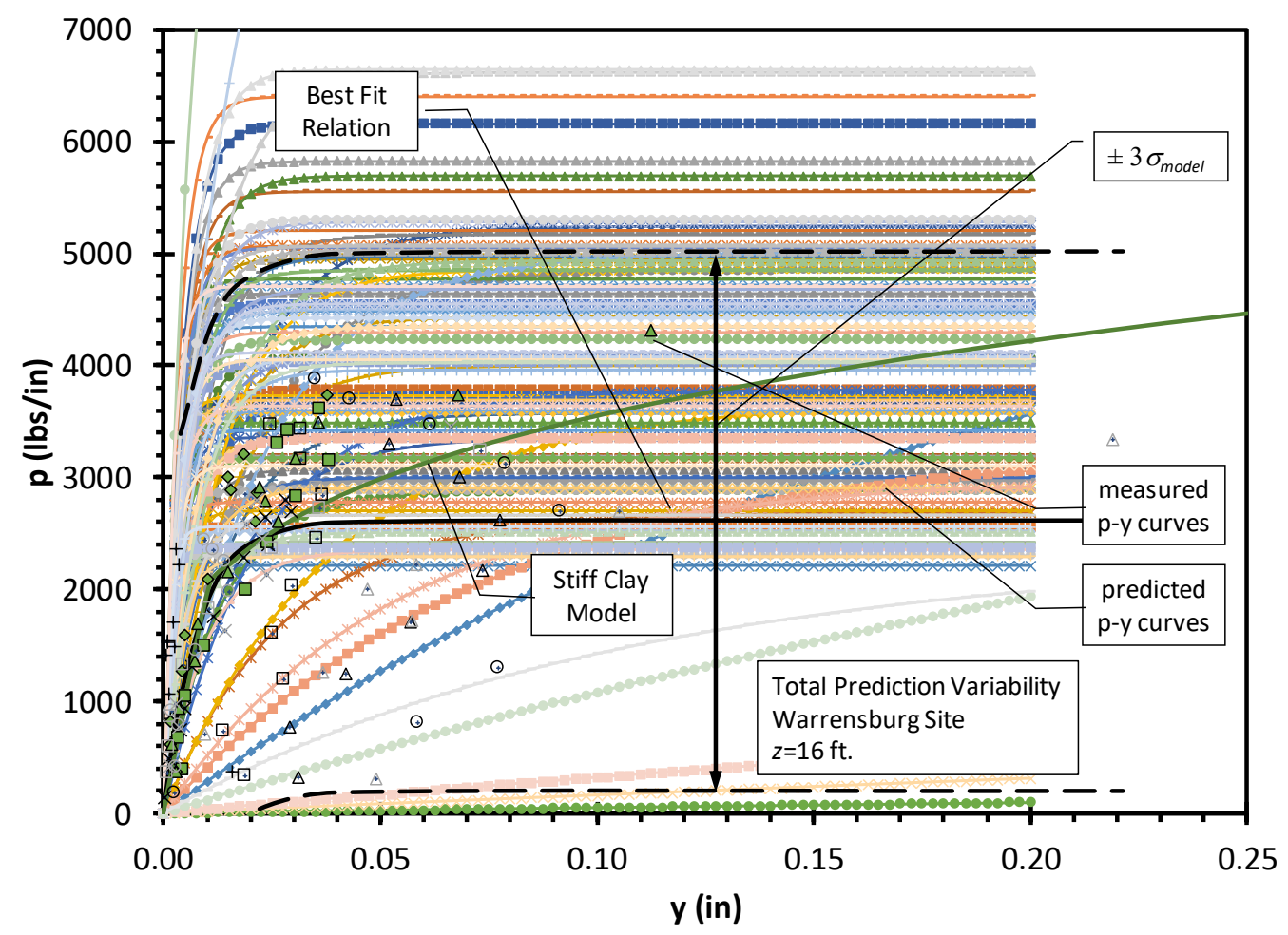

Approach-1 (using $\operatorname{COV}_{P u l t}$ and $\operatorname{COV}_{K p y}$ ) for Total Uncertainty (Warrensburg, z=16ft)

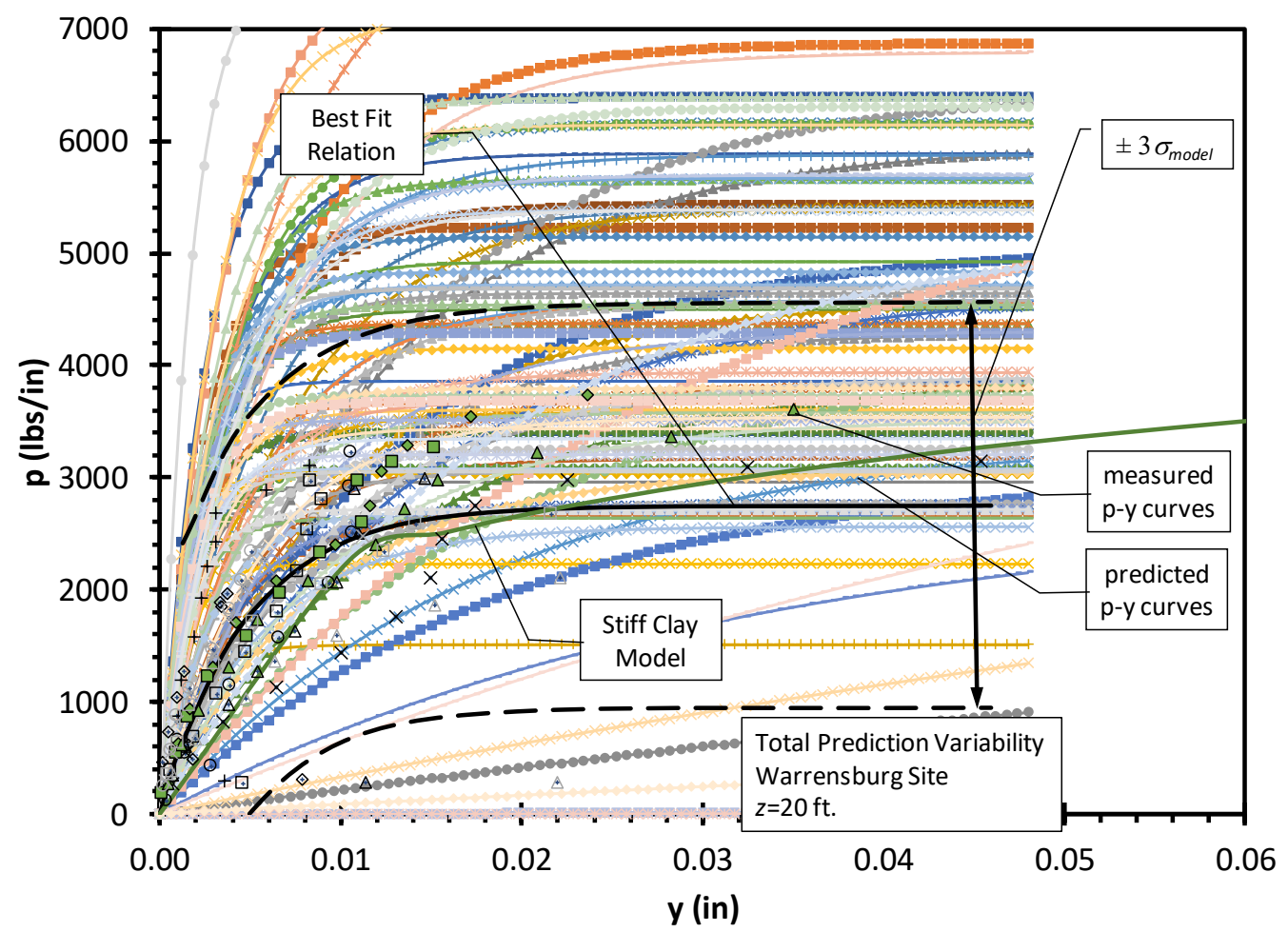

Approach-1 (using $\operatorname{COV}_{\text {Pult }}$ and $\operatorname{COV}_{\text {Kpy }}$ ) for Total Uncertainty (Warrensburg, z=20ft) 


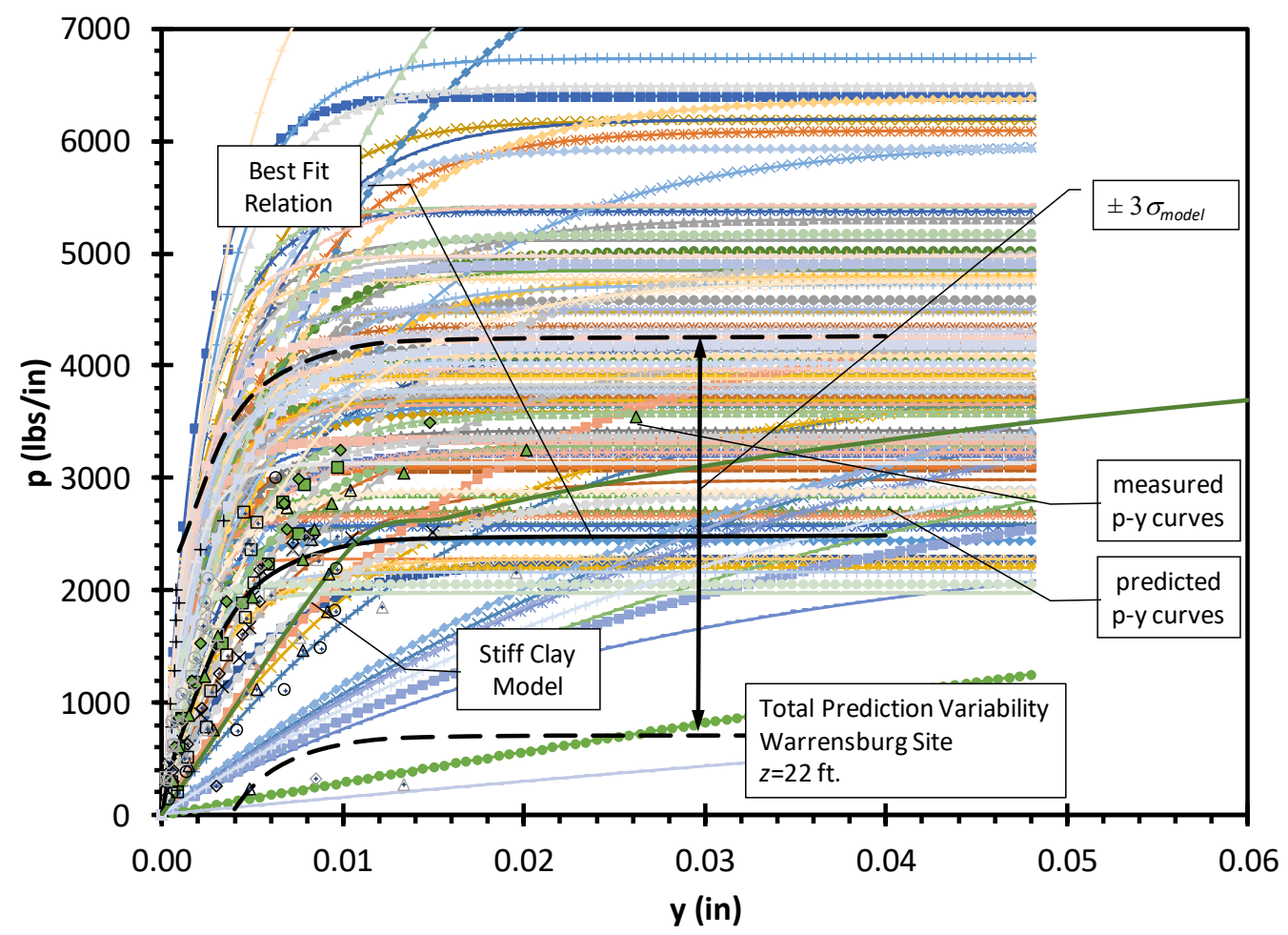

Approach-1 (using $\operatorname{COV}_{P u l t}$ and $\operatorname{COV}_{K p y}$ ) for Total Uncertainty (Warrensburg, z=22ft)

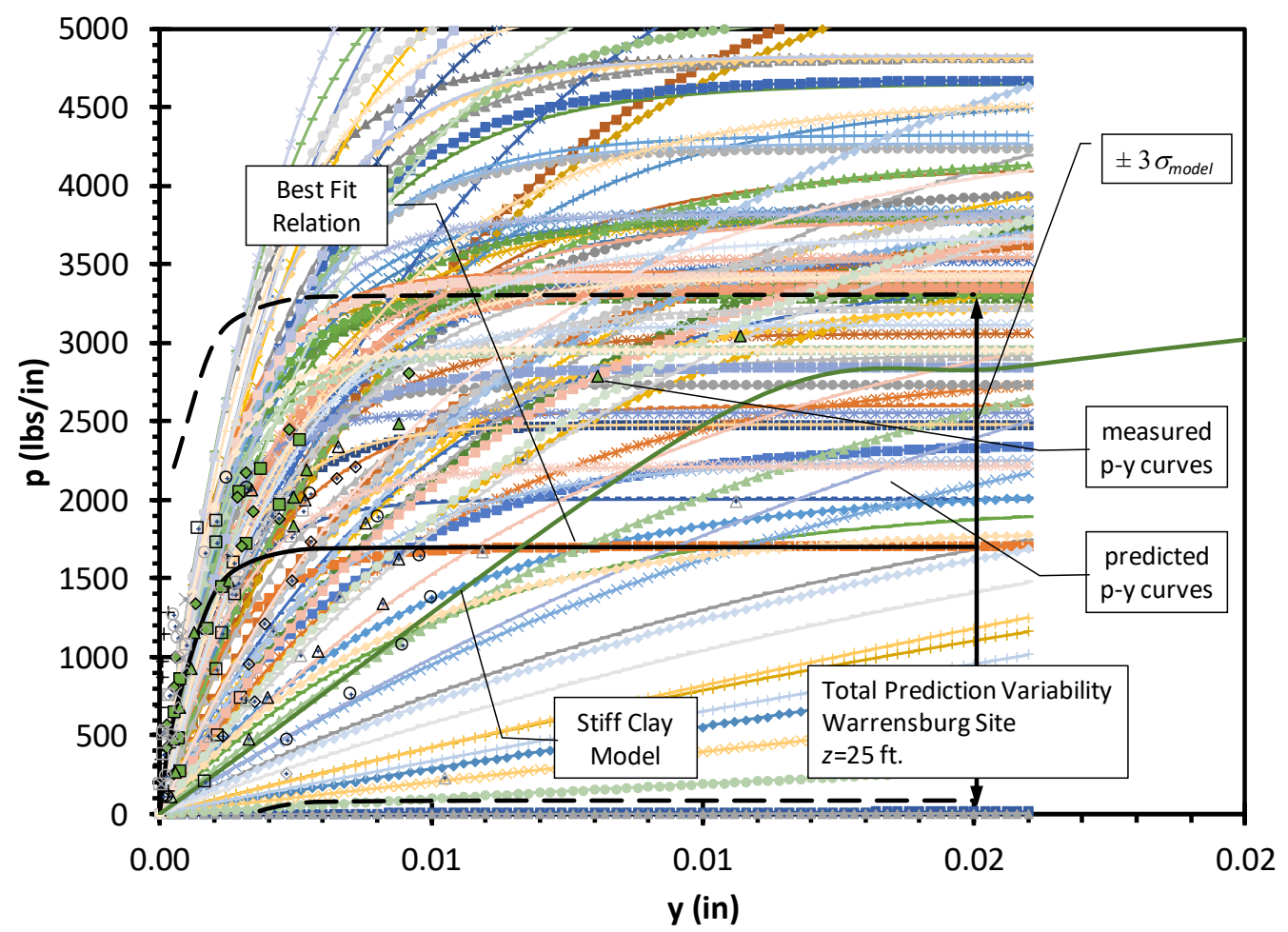

Approach-1 (using $\operatorname{COV}_{\text {Pult }}$ and $\operatorname{COV}_{\text {Kpy }}$ ) for Total Uncertainty (Warrensburg, z=25ft) 


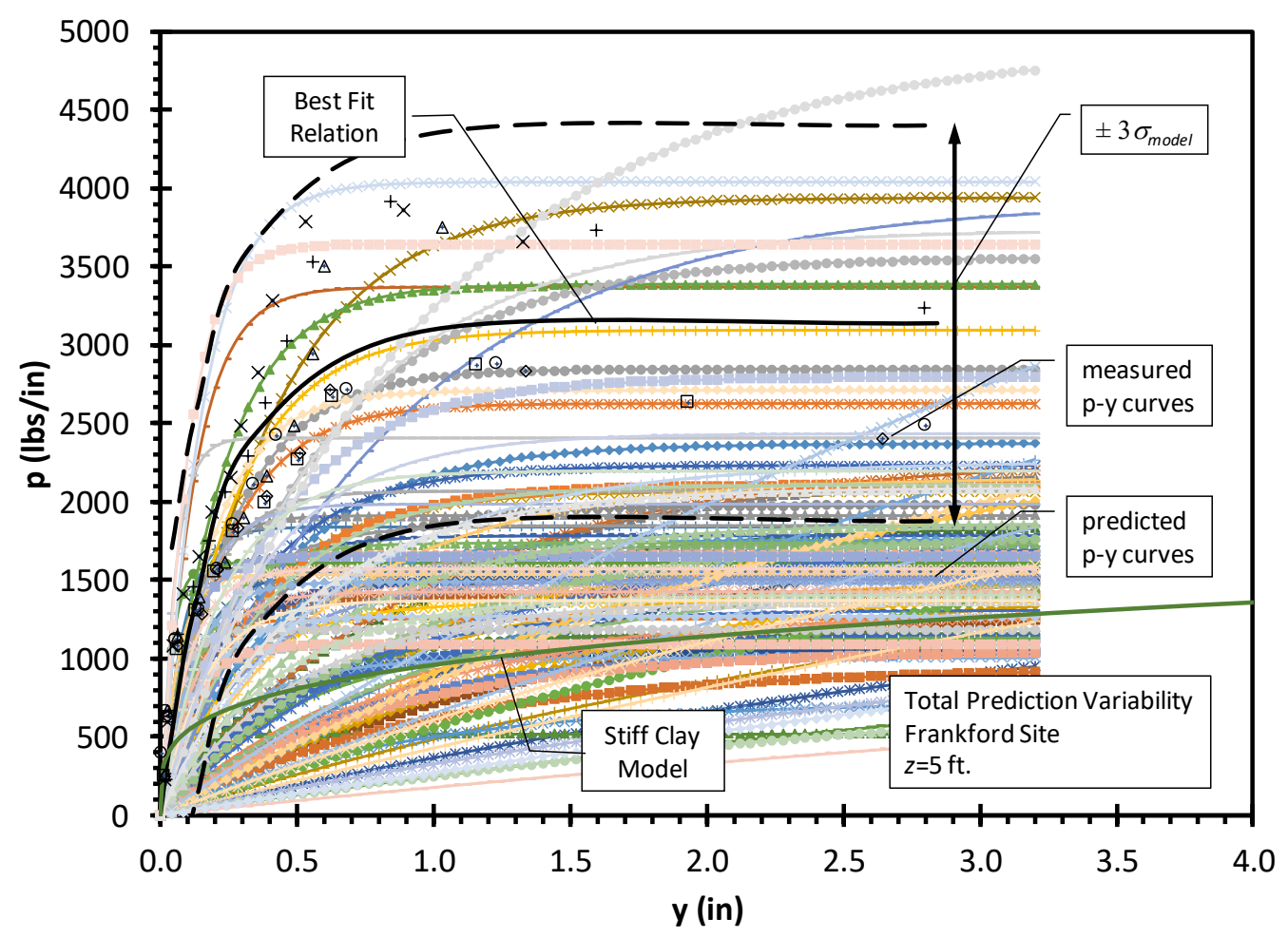

Approach-1 (using $\operatorname{COV}_{\text {Pult }}$ and $\operatorname{COV}_{K p y}$ ) for Total Uncertainty (Frankford, z=5ft)

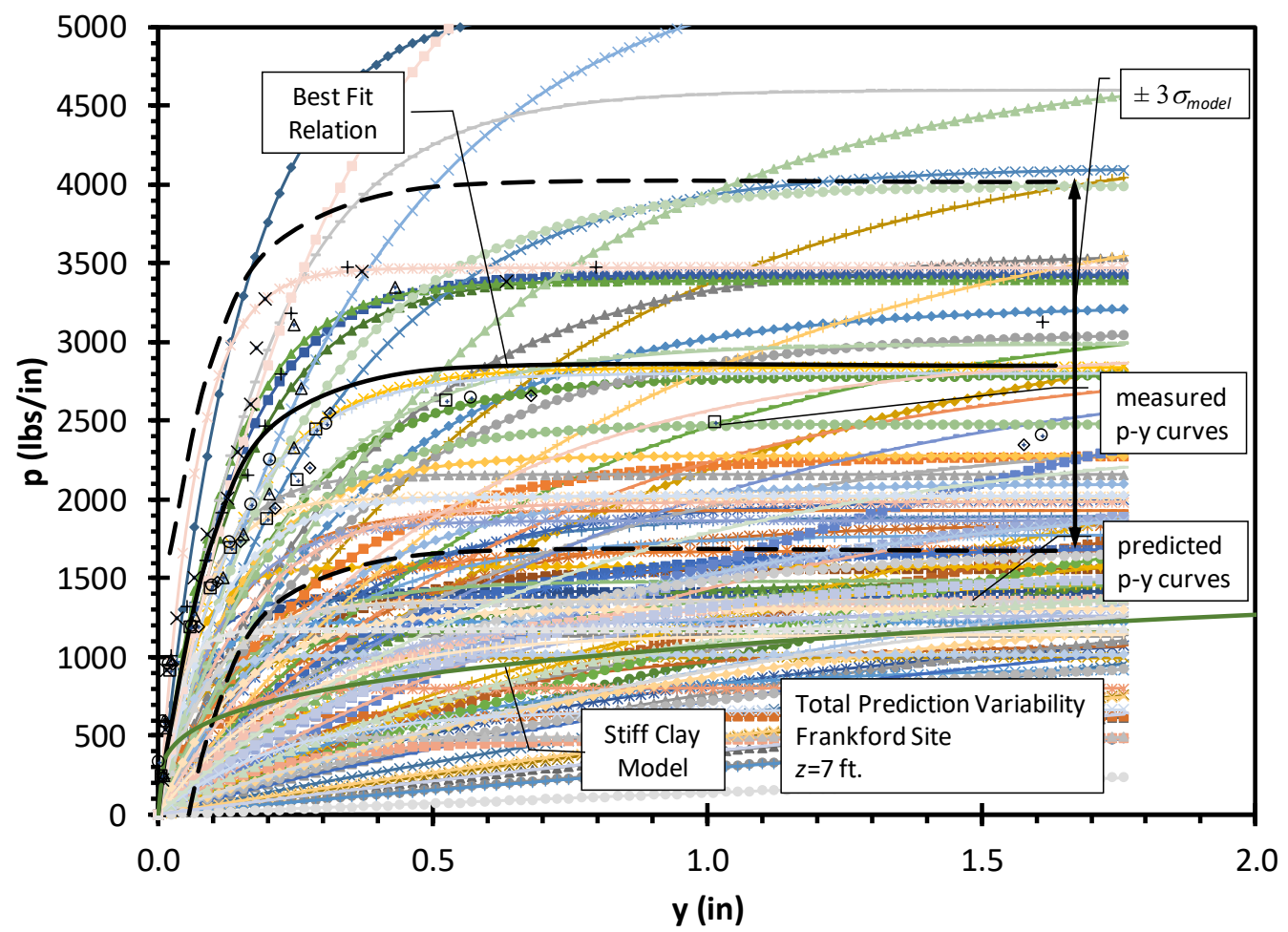

Approach-1 (using $\operatorname{COV}_{\text {Pult }}$ and $\operatorname{COV}_{K p y}$ ) for Total Uncertainty (Frankford, $\mathrm{z}=7 \mathrm{ft}$ ) 


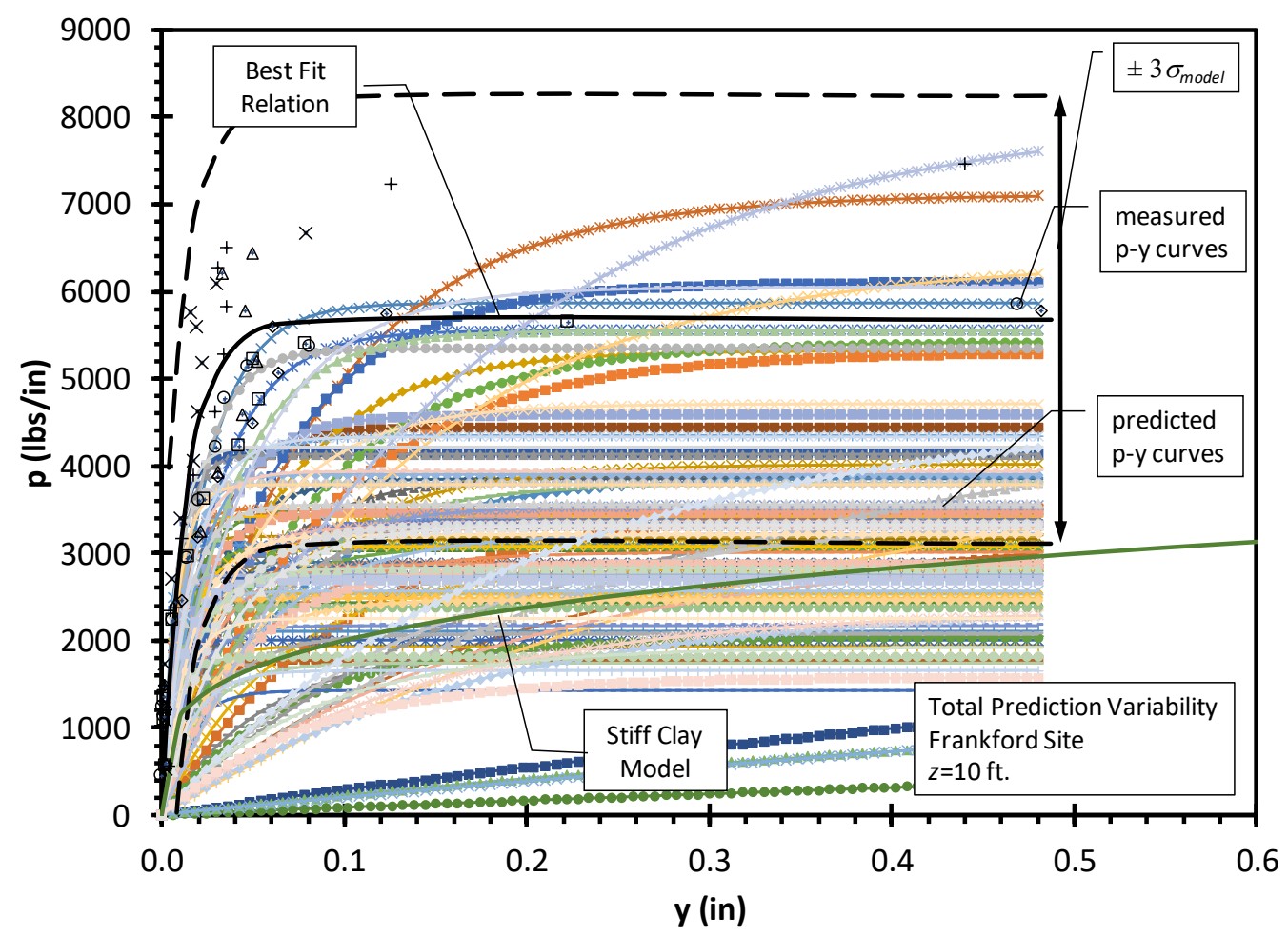

Approach-1 (using $C O V_{\text {Pult }}$ and $C O V_{K p y}$ ) for Total Uncertainty (Frankford, $\mathrm{z}=10 \mathrm{ft}$ )

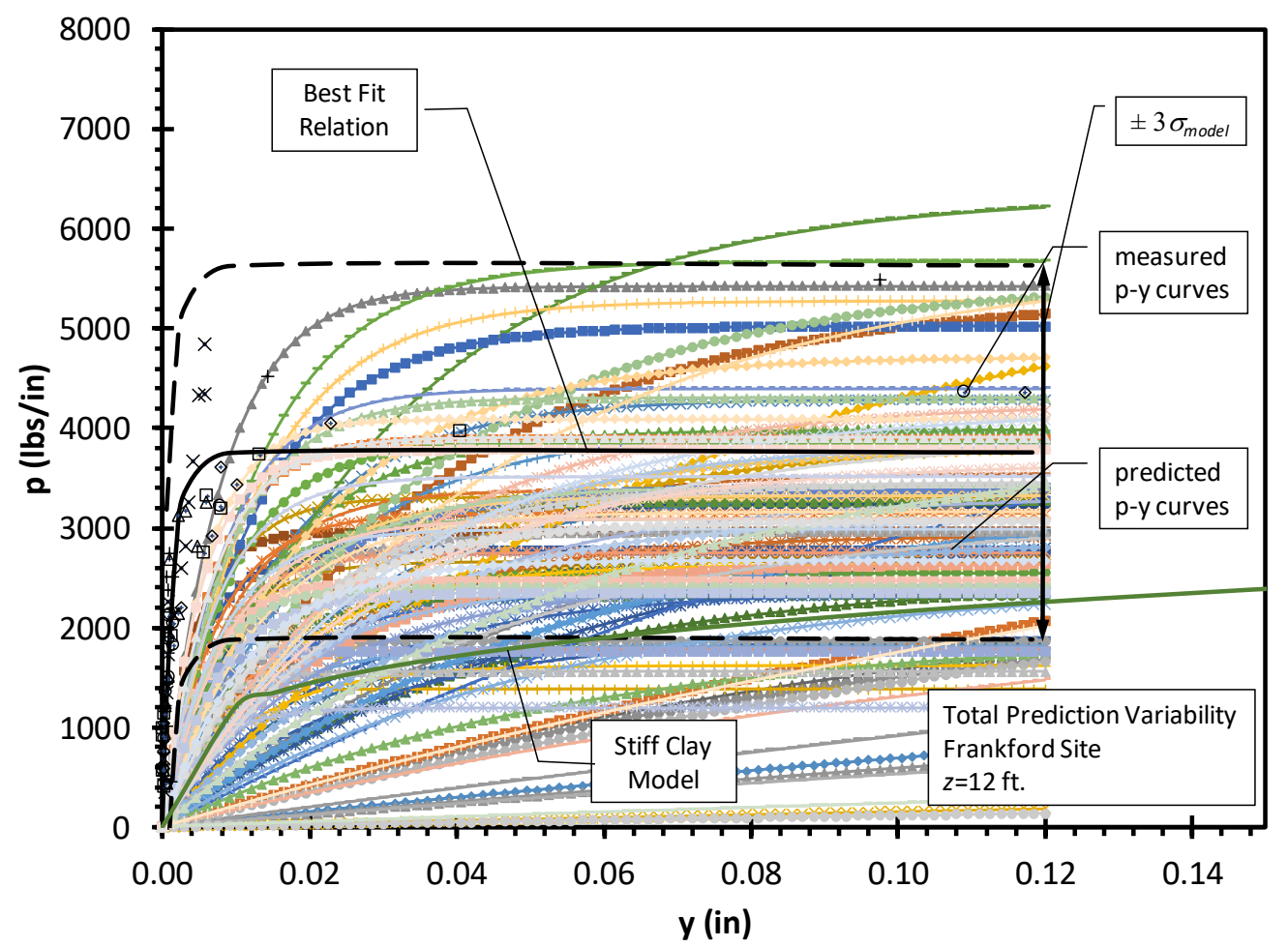

Approach-1 (using $C O V_{\text {Pult }}$ and $C O V_{K p y}$ ) for Total Uncertainty (Frankford, z=12ft) 


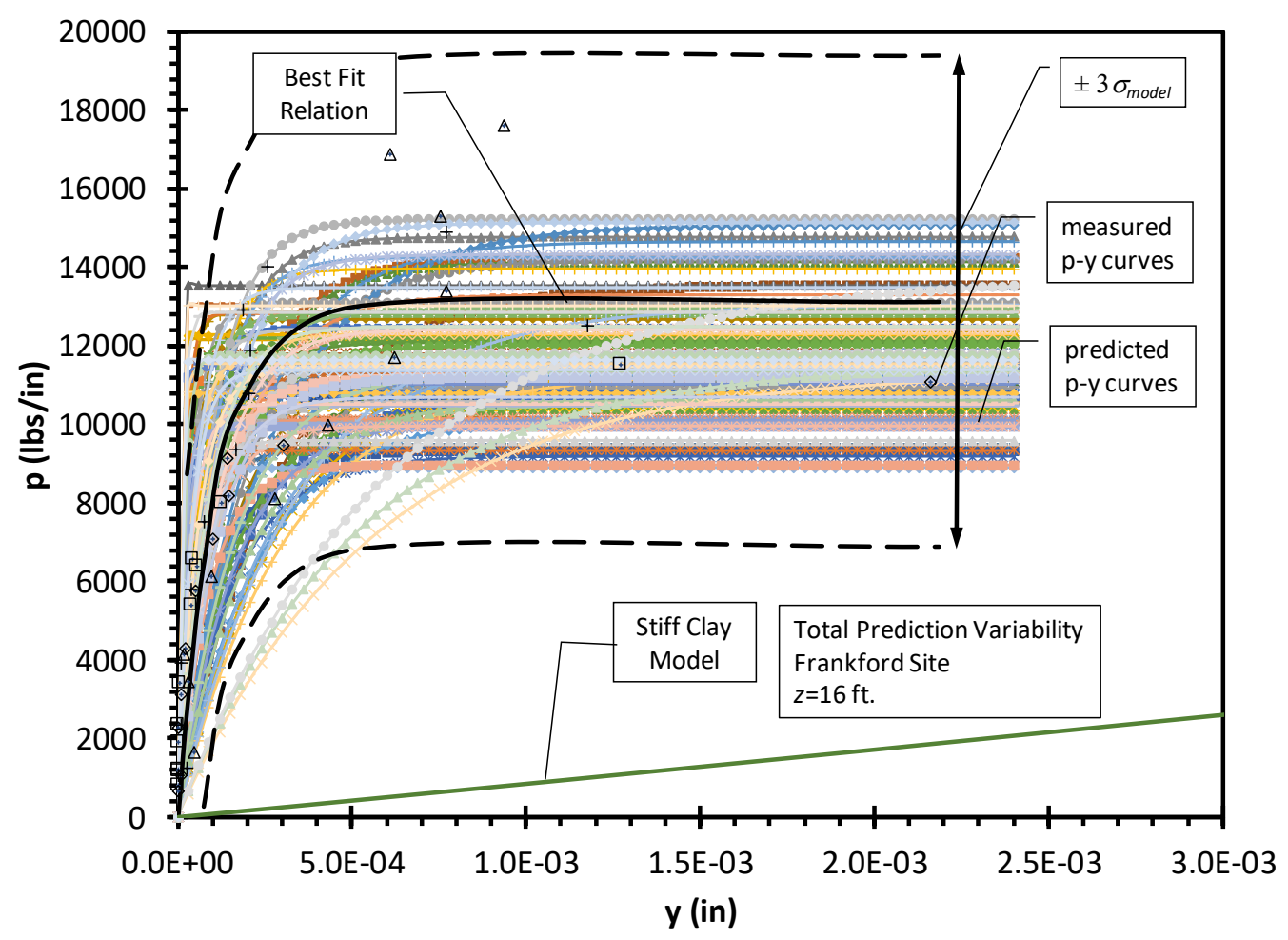

Approach-1 (using $C O V_{\text {Pult }}$ and $C O V_{K p y}$ ) for Total Uncertainty (Frankford, $\mathrm{z}=16 \mathrm{ft}$ )

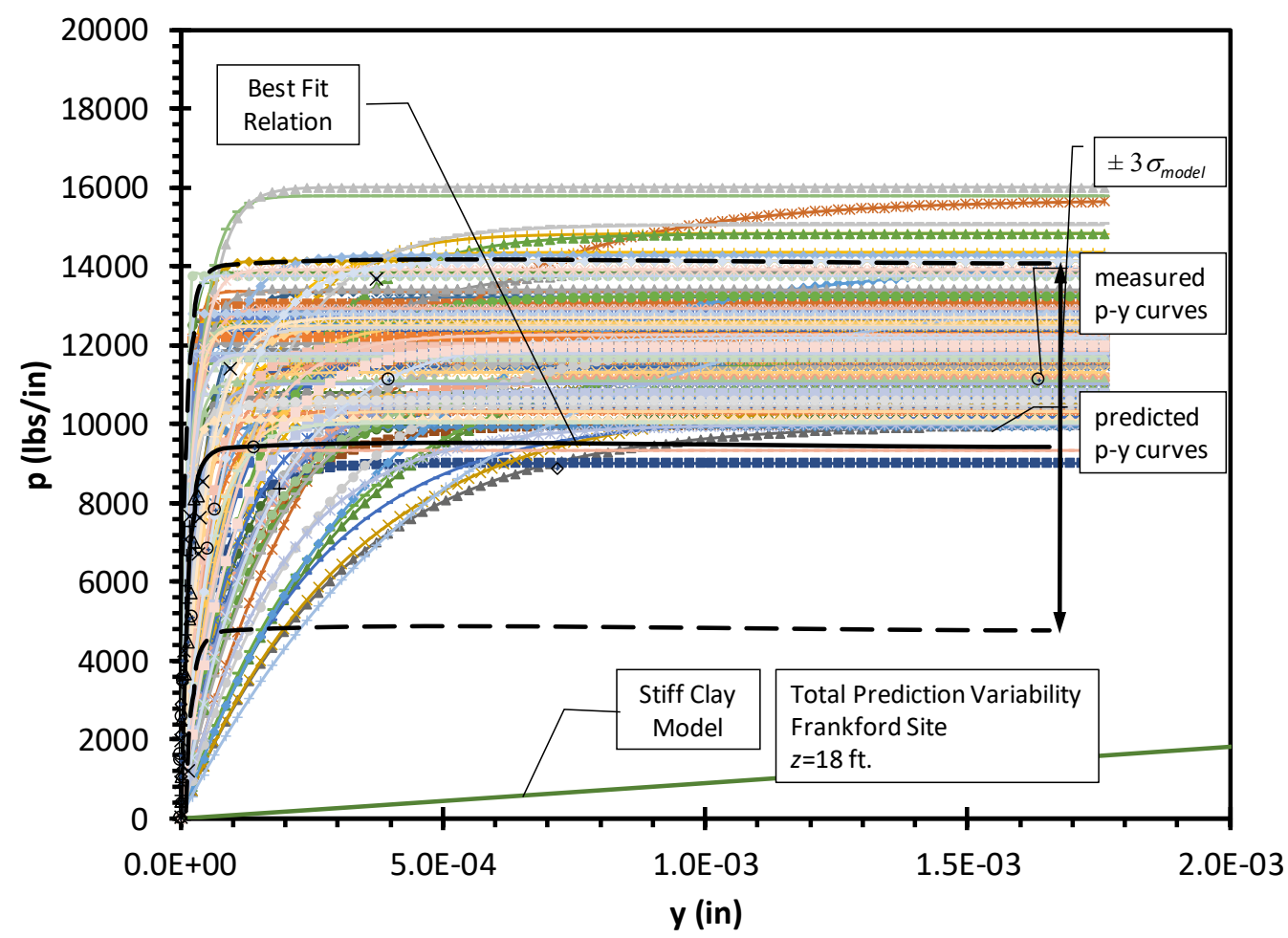

Approach-1 (using $C O V_{\text {Pult }}$ and $C O V_{K p y}$ ) for Total Uncertainty (Frankford, z=18ft) 


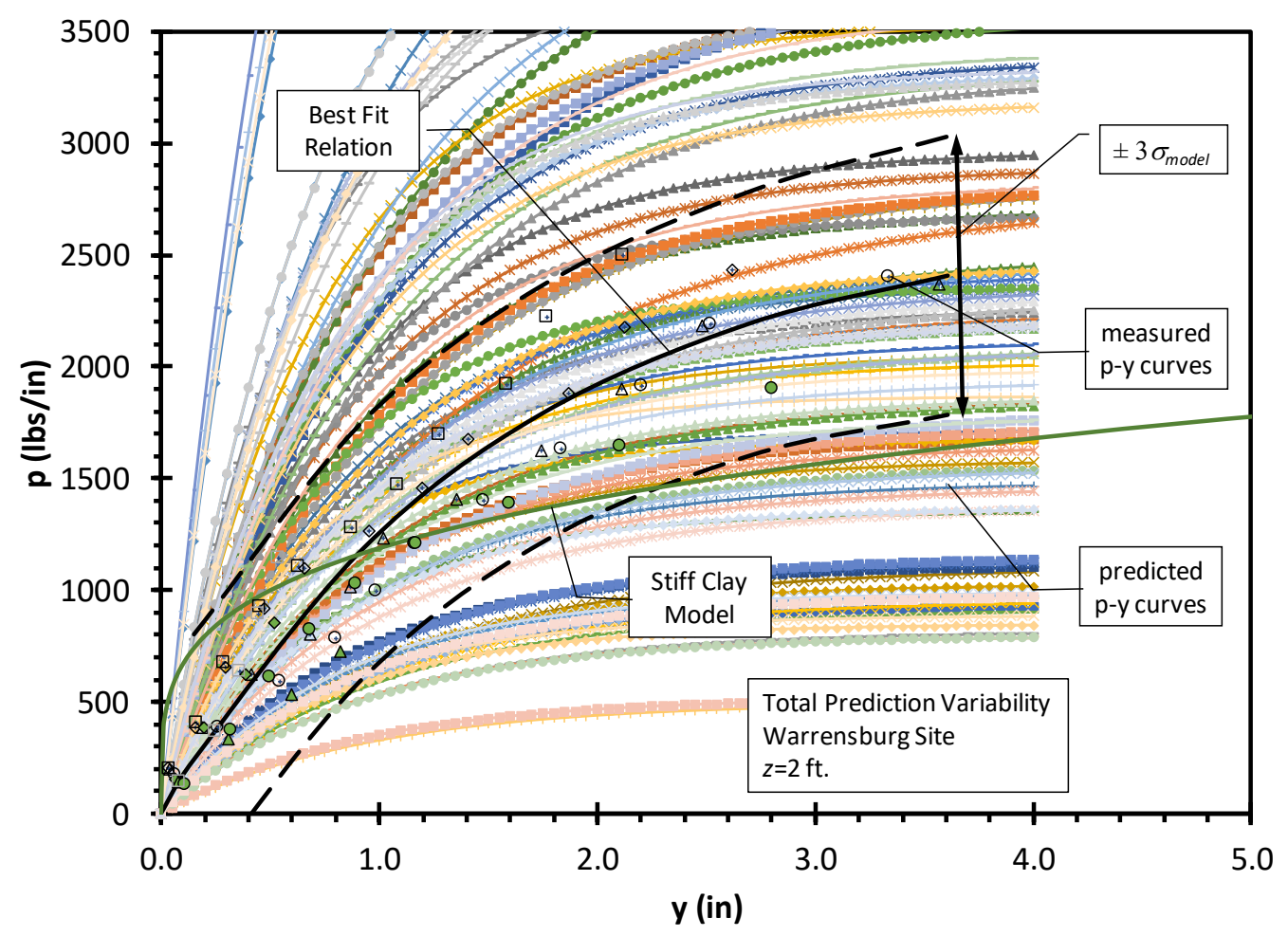

Approach-2 (using avgCOV) for Total Uncertainty (Warrensburg, z=2ft)

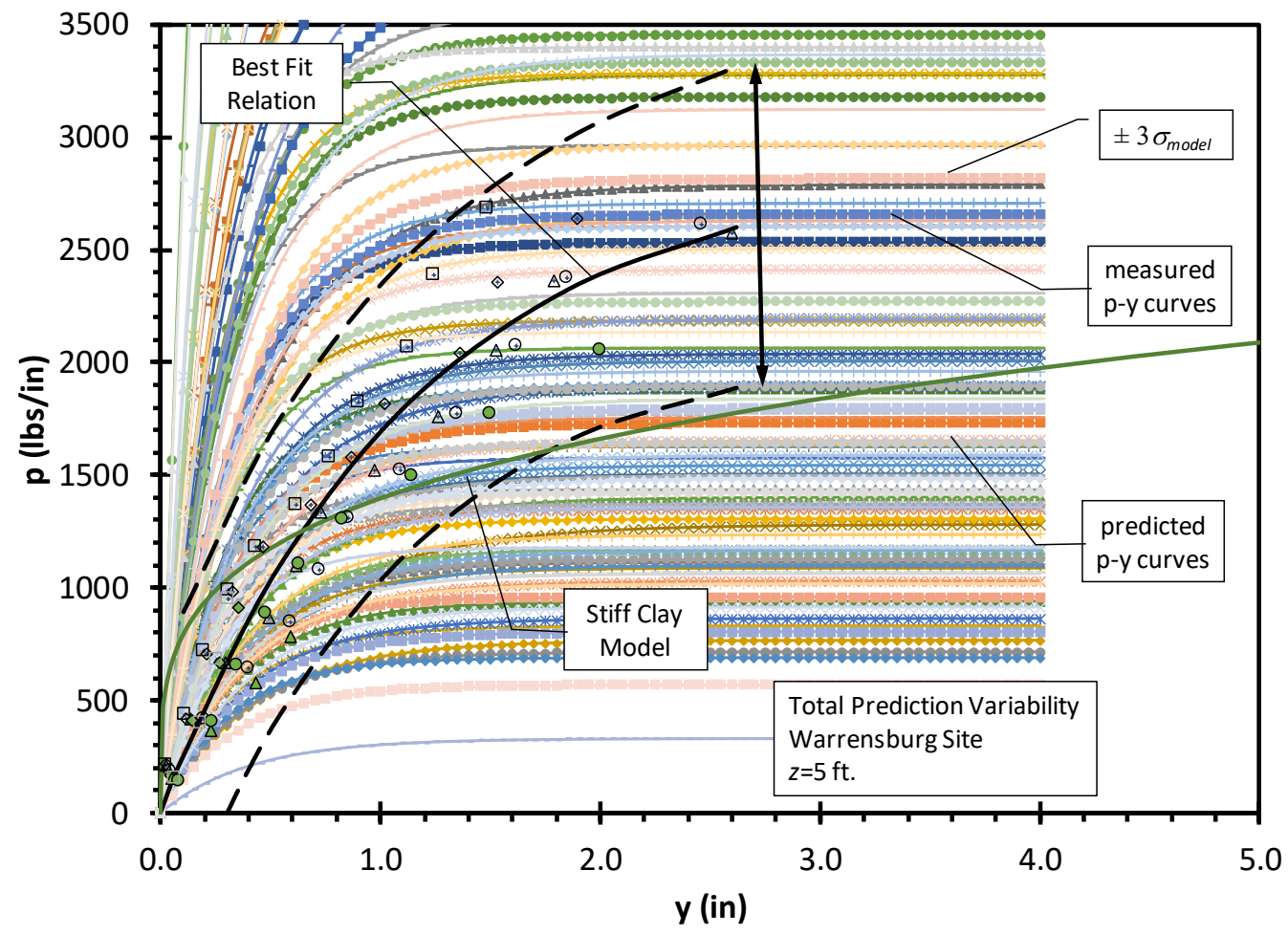

Approach-2 (using avgCOV) for Total Uncertainty (Warrensburg, $\mathrm{z}=5 \mathrm{ft}$ ) 


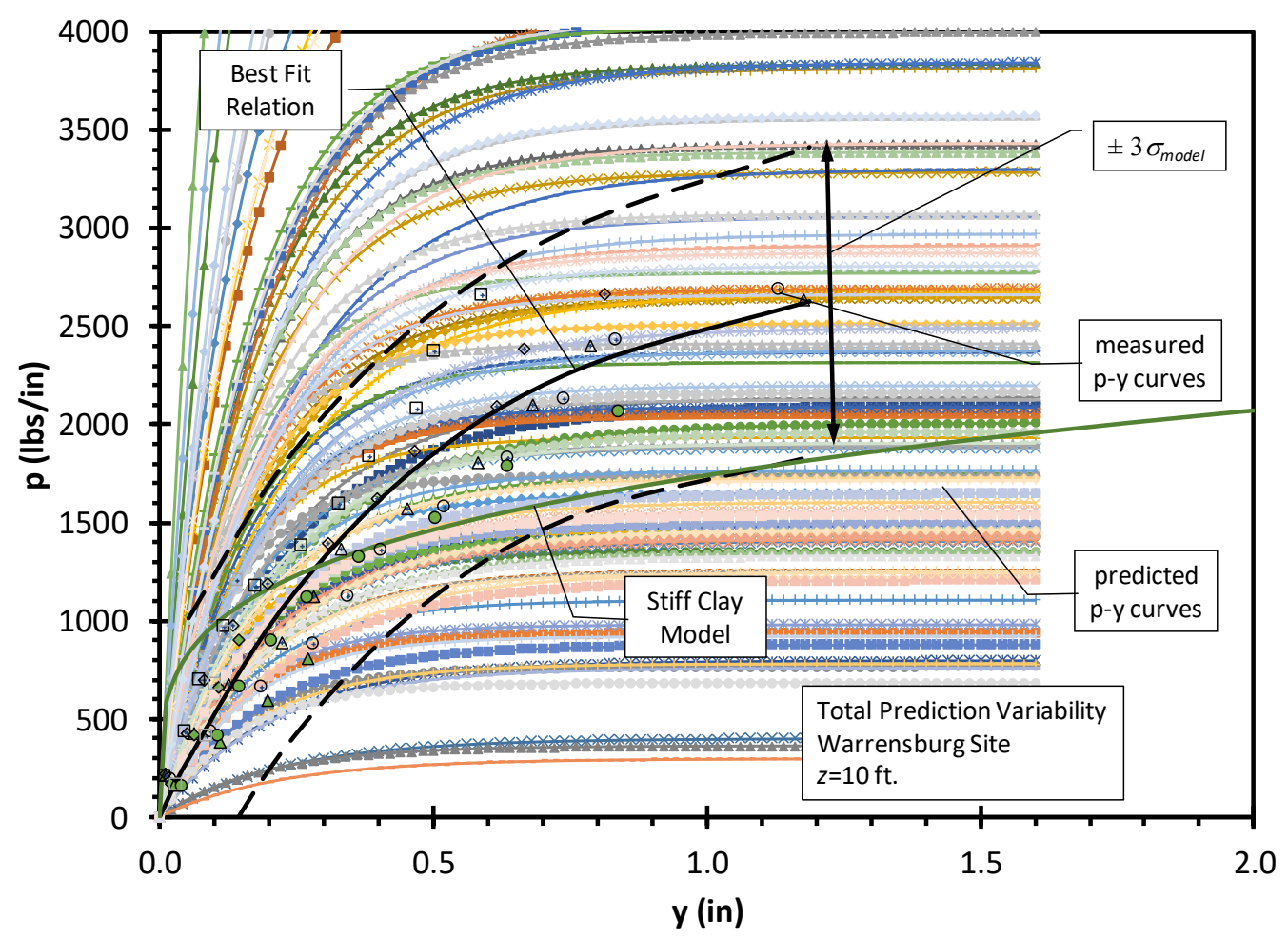

Approach-2 (using avgCOV) for Total Uncertainty (Warrensburg, z=10ft)

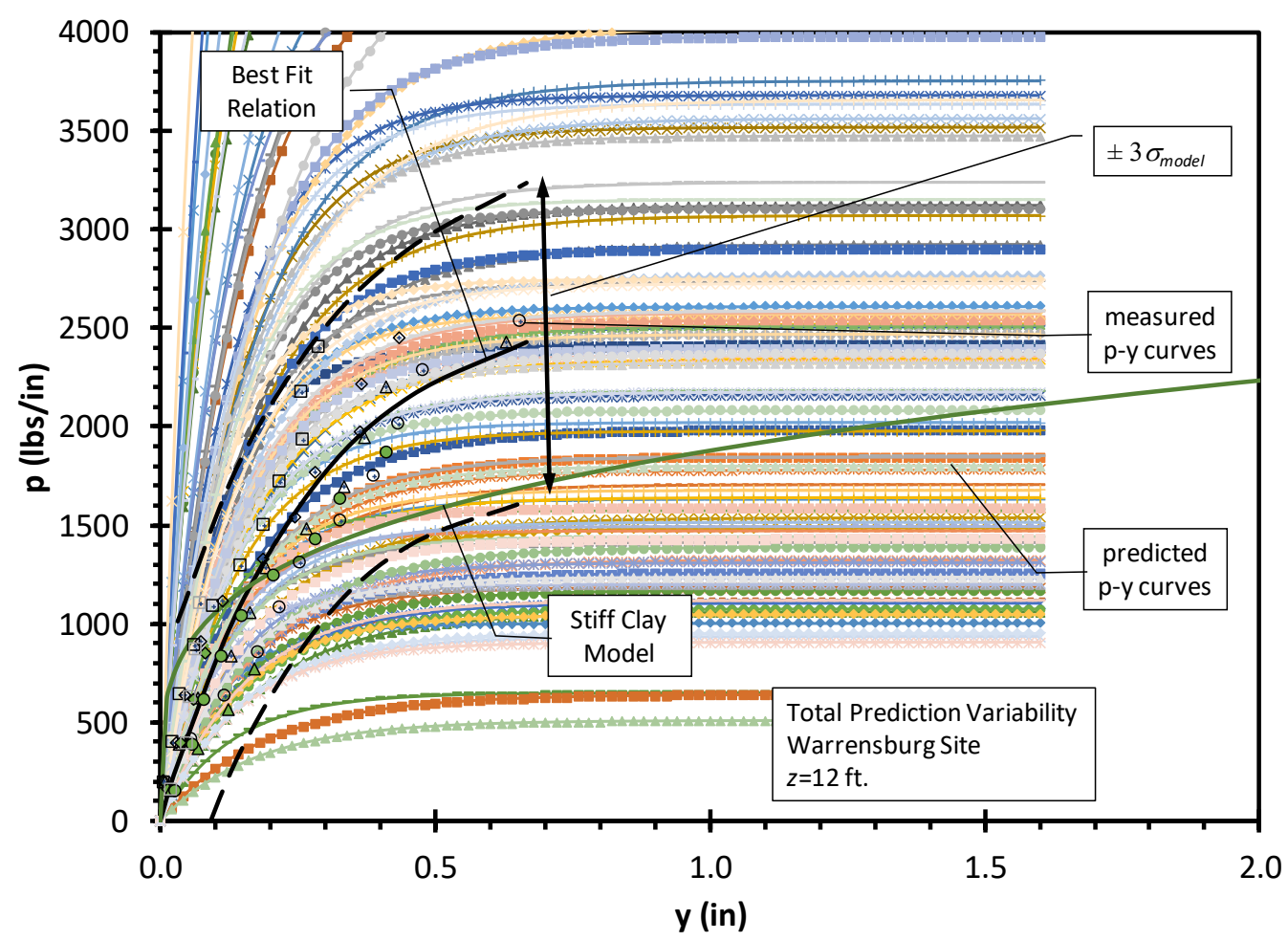

Approach-2 (using avgCOV) for Total Uncertainty (Warrensburg, z=12ft) 


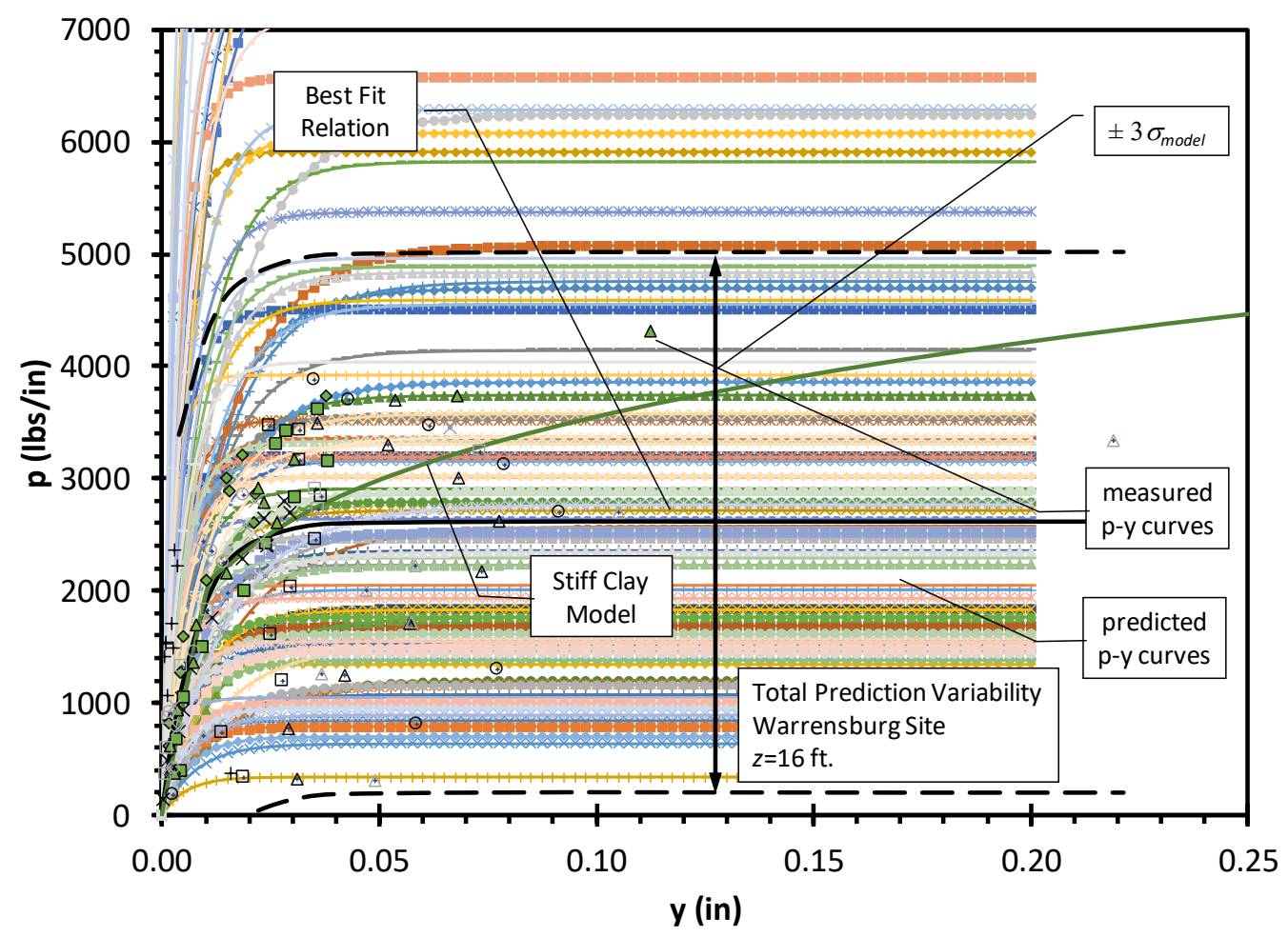

Approach-2 (using avgCOV) for Total Uncertainty (Warrensburg, z=16ft)

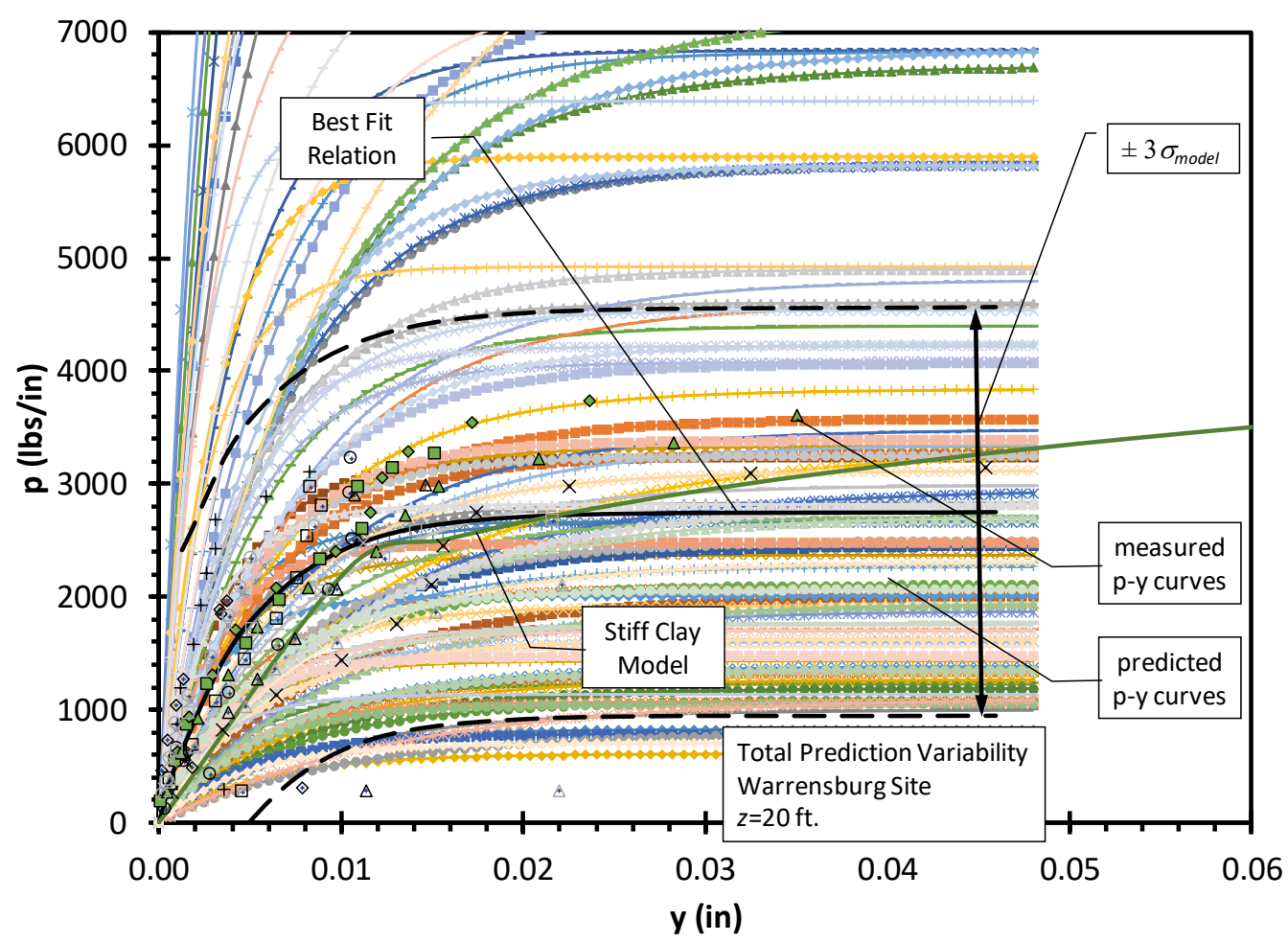

Approach-2 (using avgCOV) for Total Uncertainty (Warrensburg, z=20ft) 


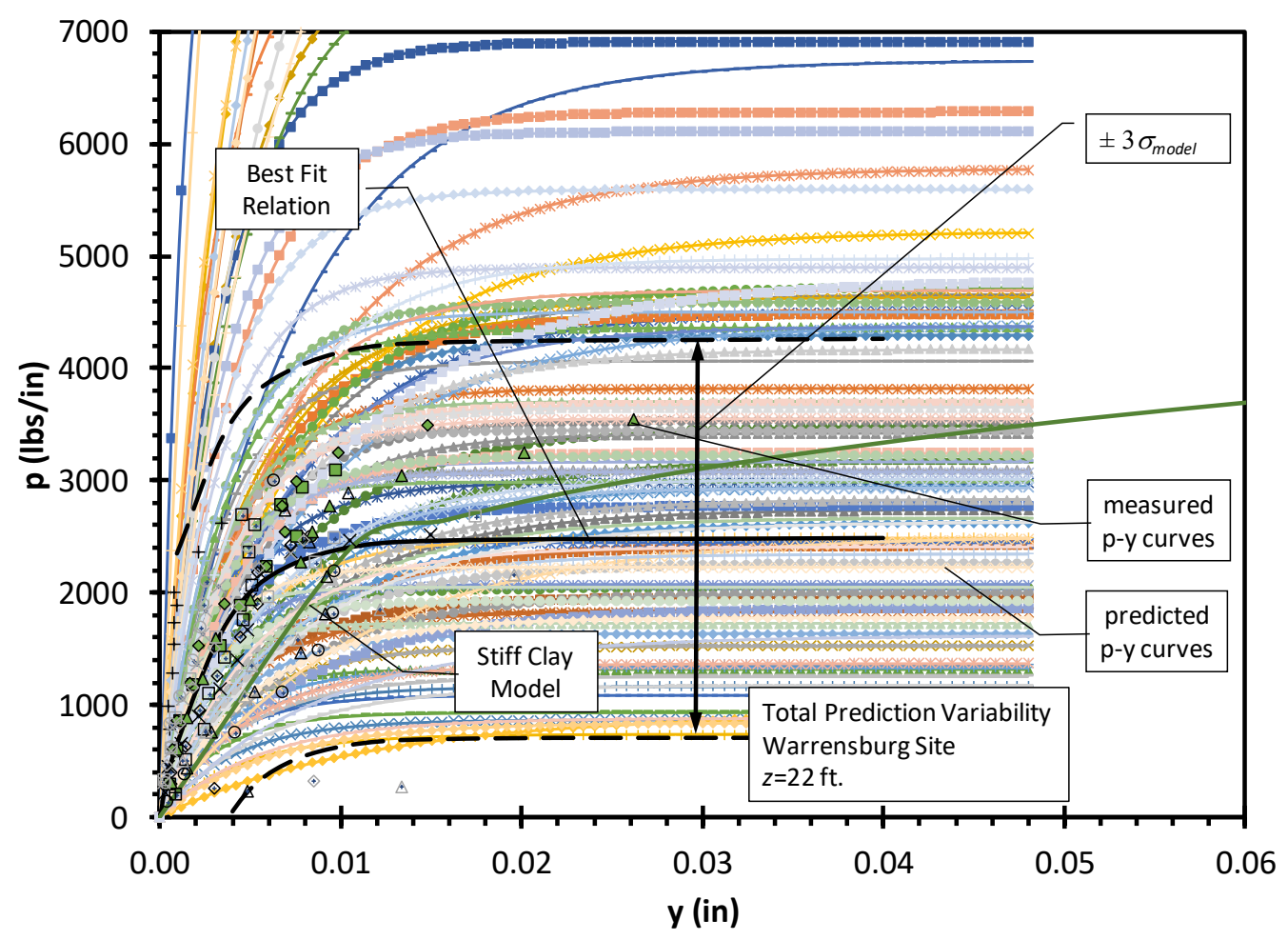

Approach-2 (using avgCOV) for Total Uncertainty (Warrensburg, z=22ft)

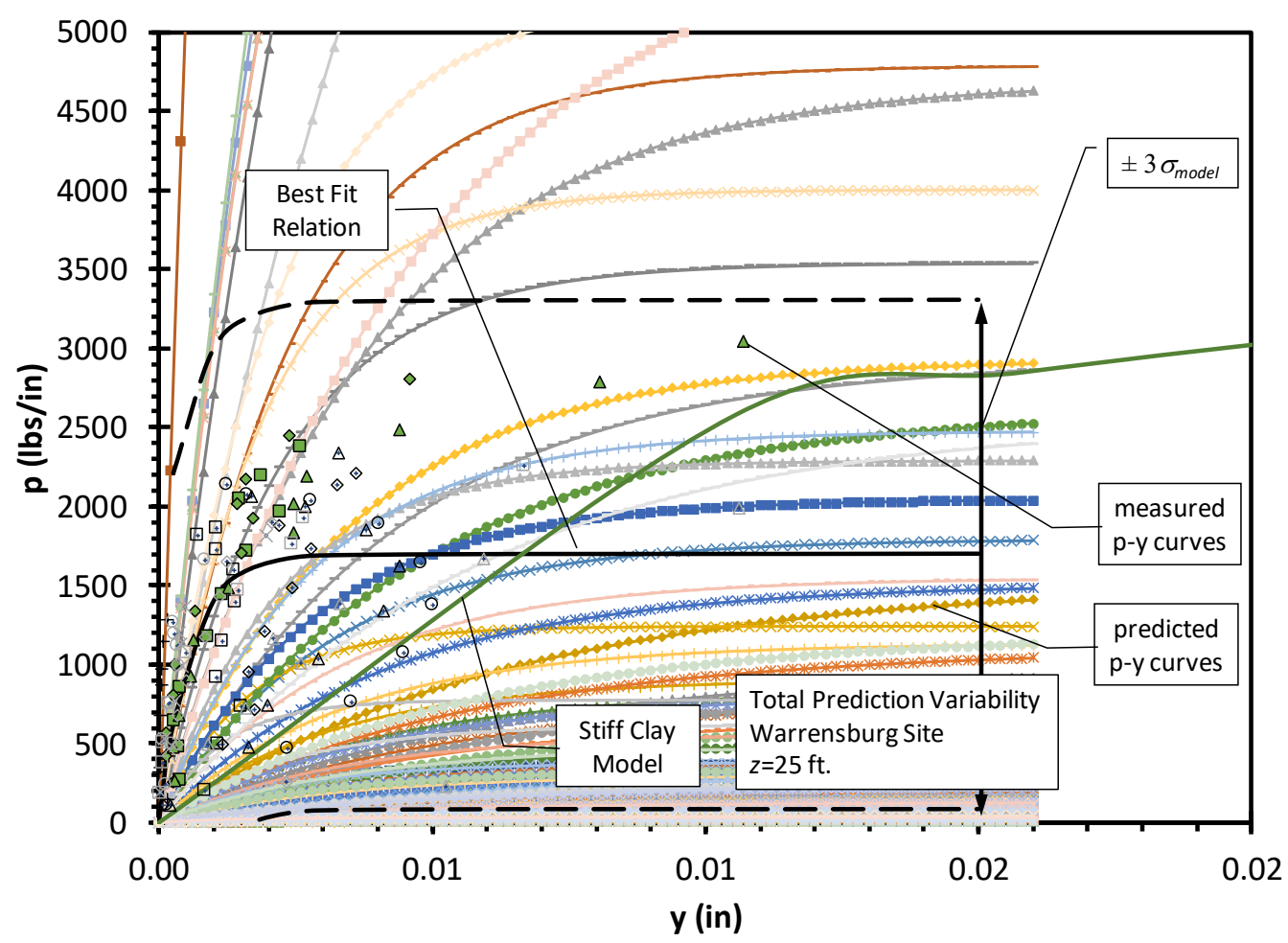

Approach-2 (using avgCOV) for Total Uncertainty (Warrensburg, z=25ft) 


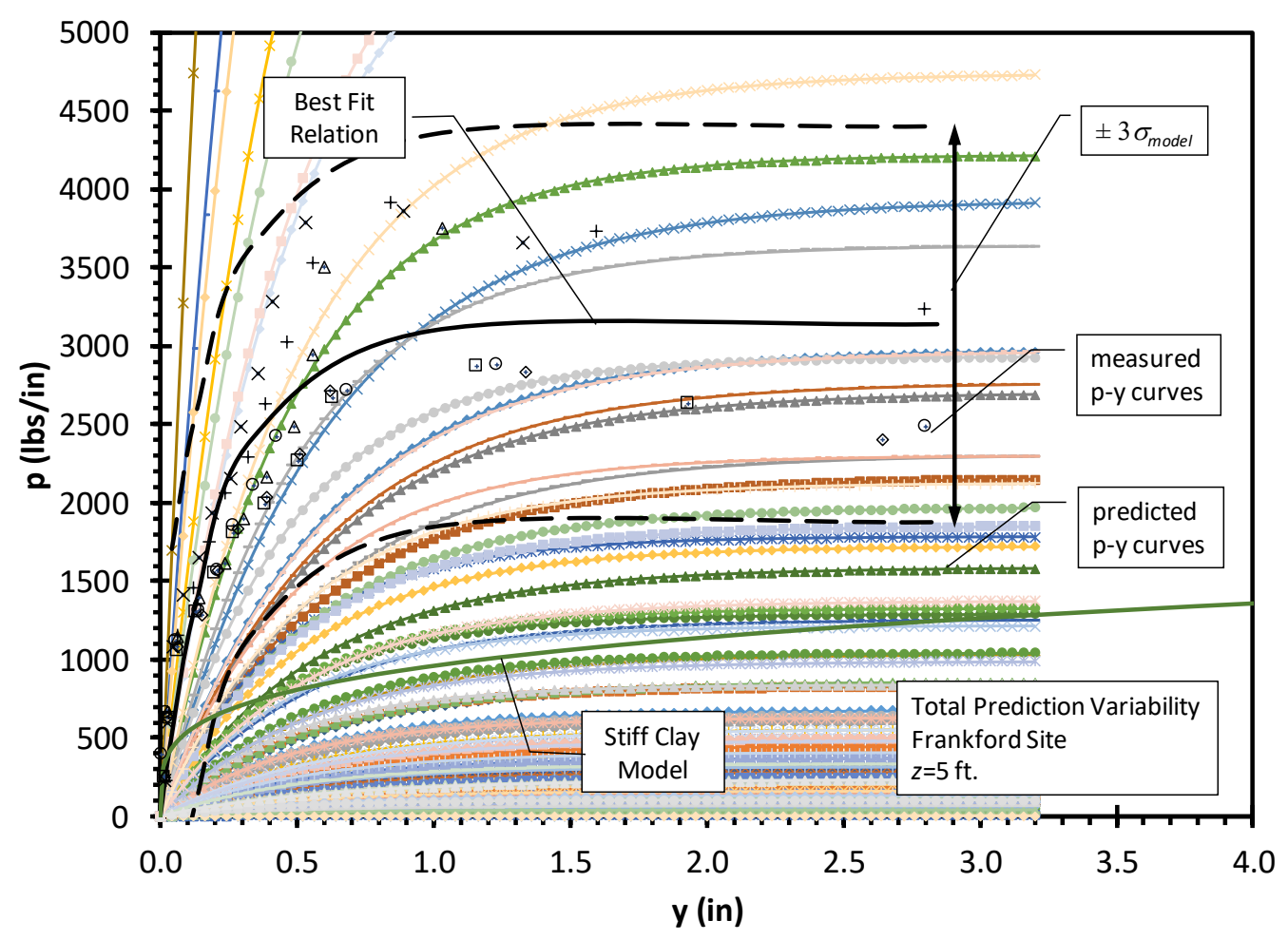

Approach-2 (using avg COV) for Total Uncertainty (Frankford, z=5ft)

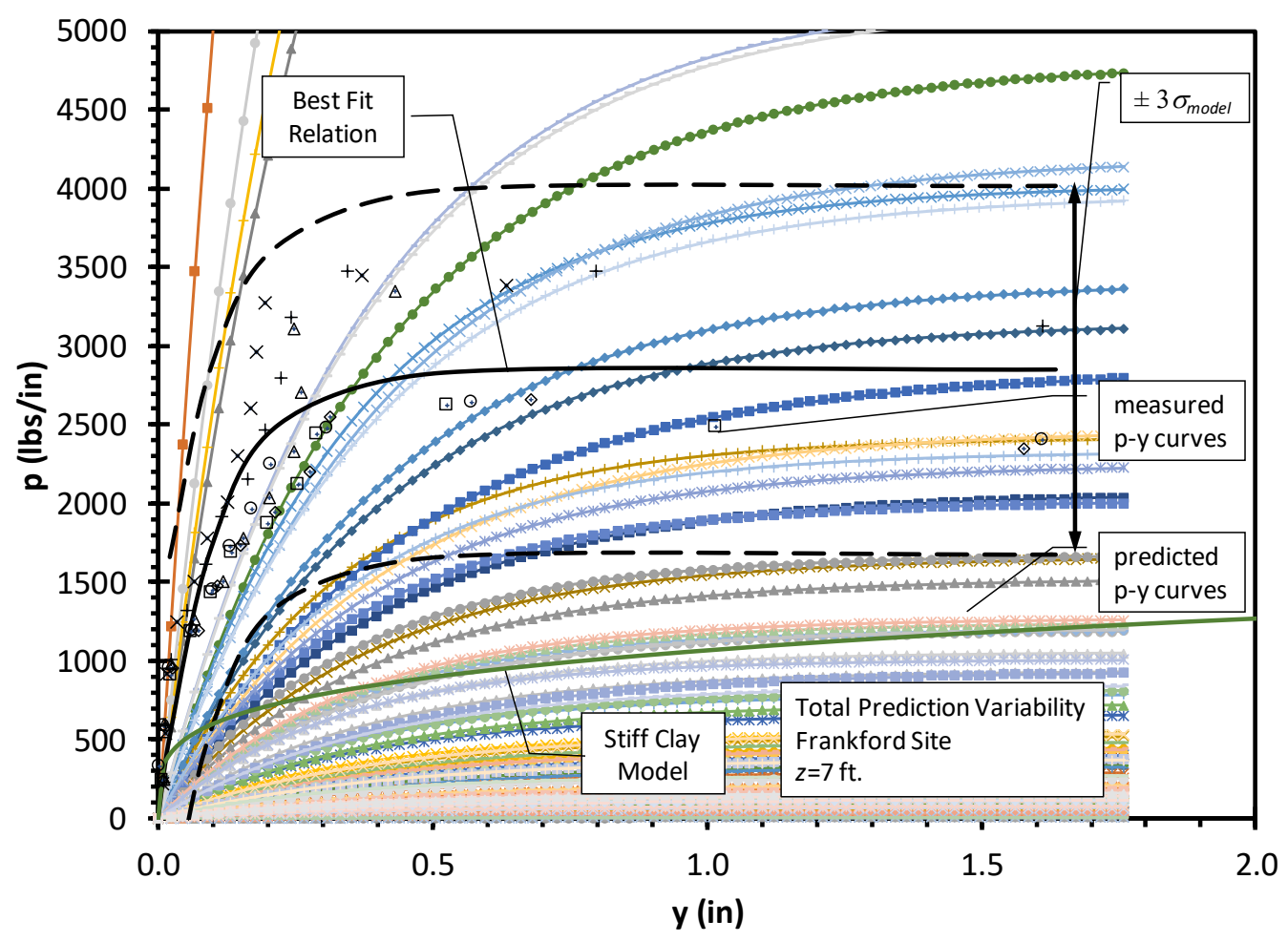

Approach-2 (using avg COV) for Total Uncertainty (Frankford, z=7ft) 


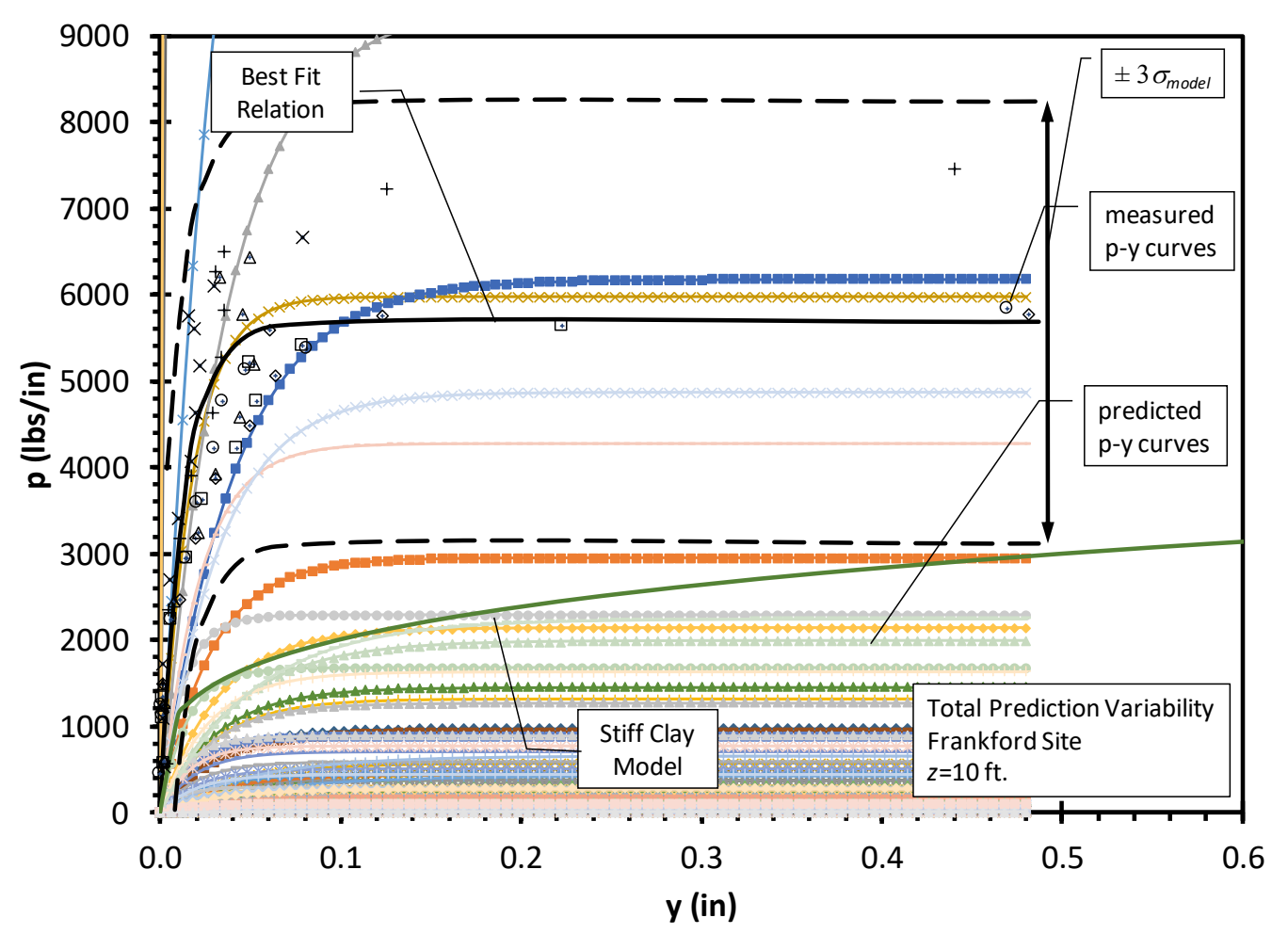

Approach-2 (using avgCOV) for Total Uncertainty (Frankford, z=10ft)

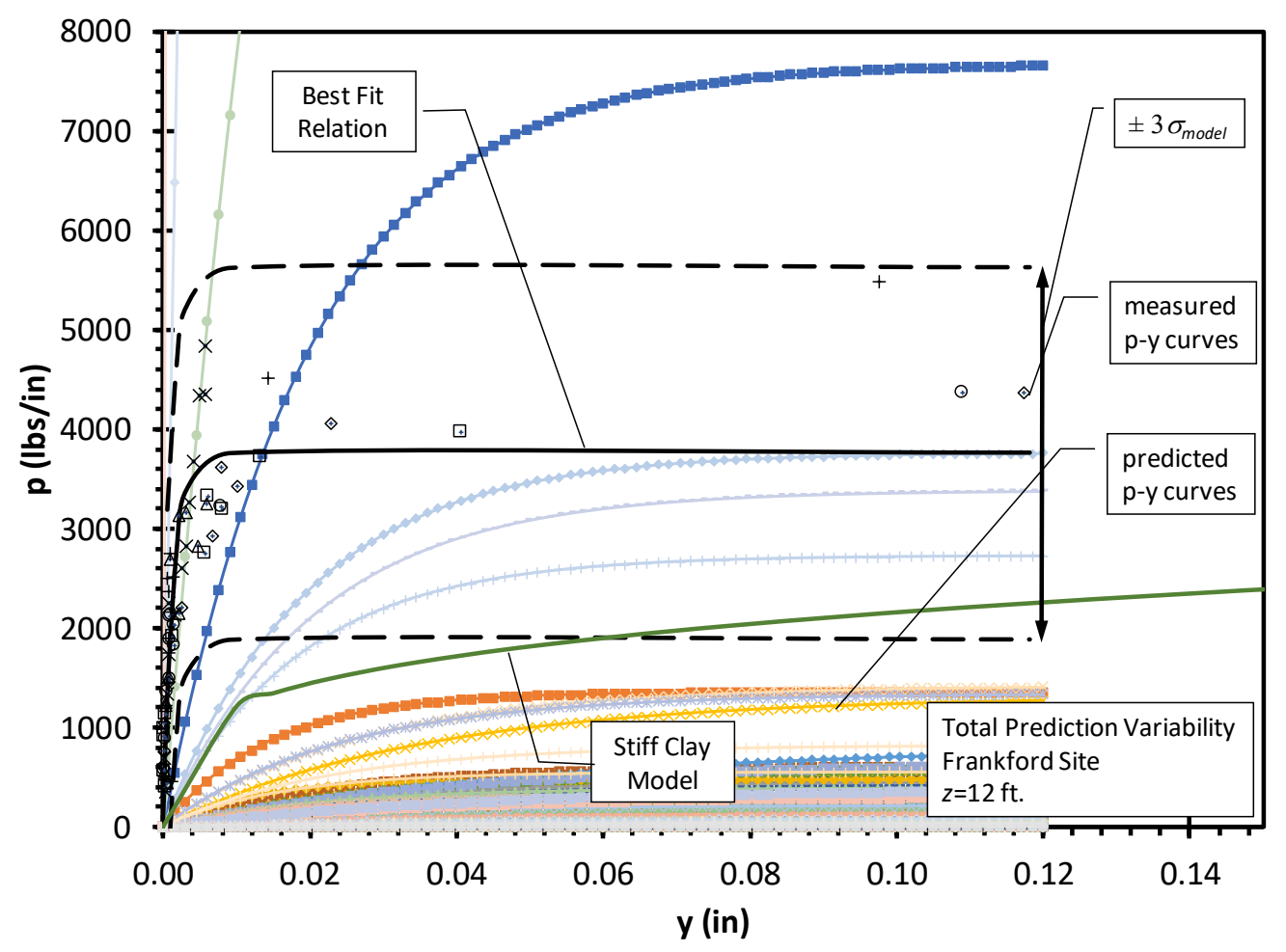

Approach-2 (using avgCOV) for Total Uncertainty (Frankford, z=12ft) 


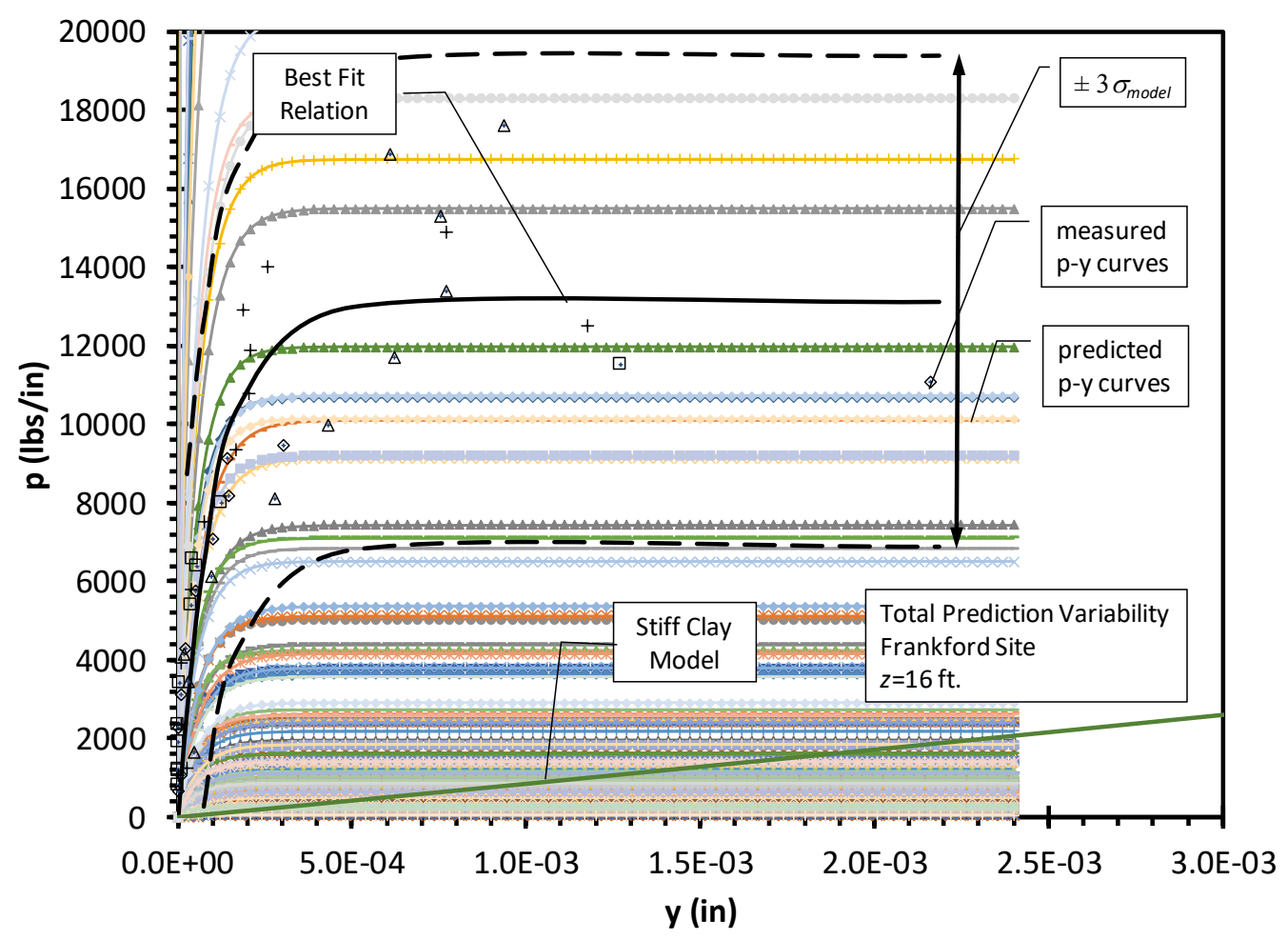

Approach-2 (using avgCOV) for Total Uncertainty (Frankford, z=16ft)

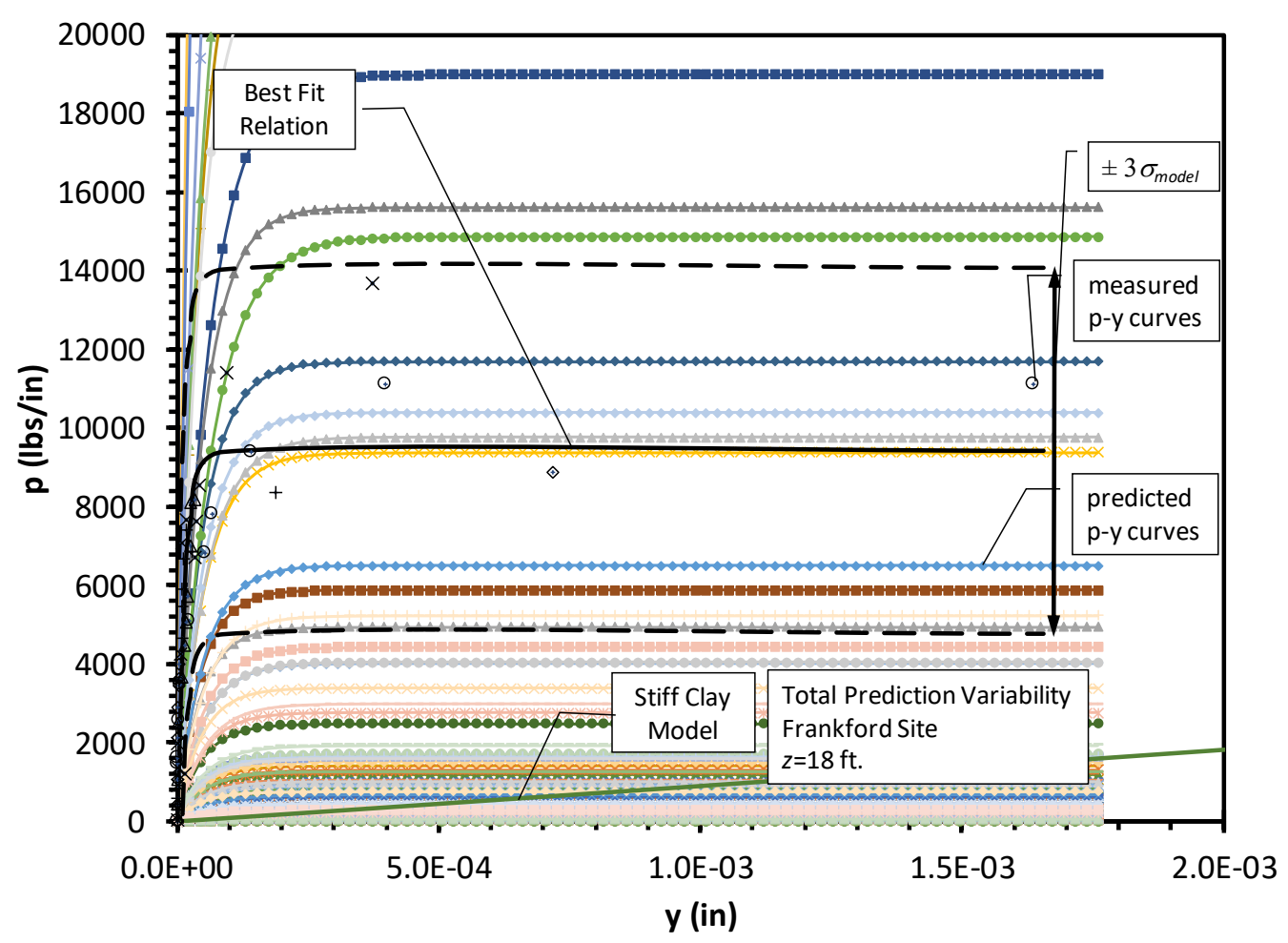

Approach-2 (using avgCOV) for Total Uncertainty (Frankford, z=18ft) 


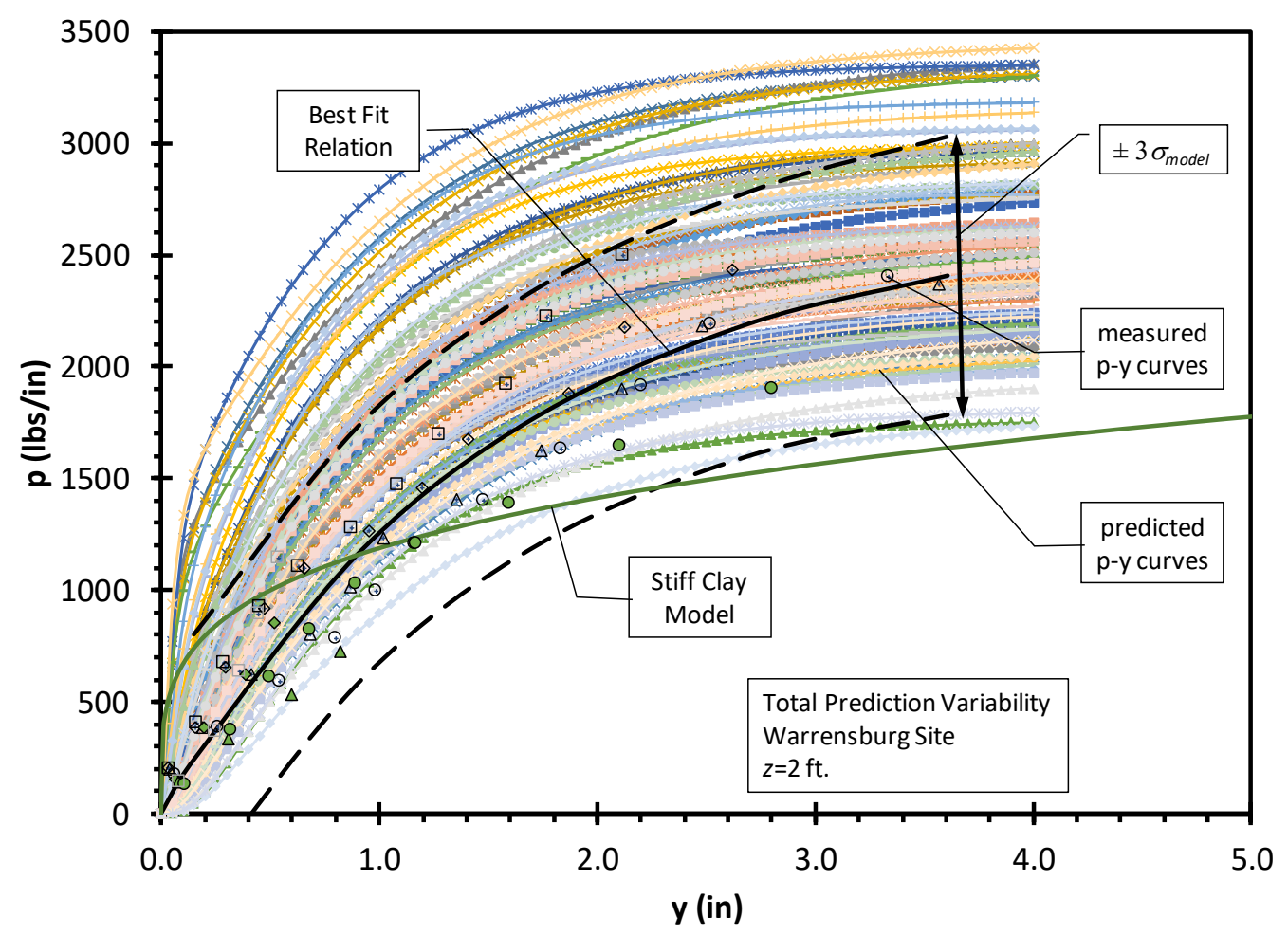

Approach-3 (using avgSTD) for Total Uncertainty (Warrensburg, z=2ft)

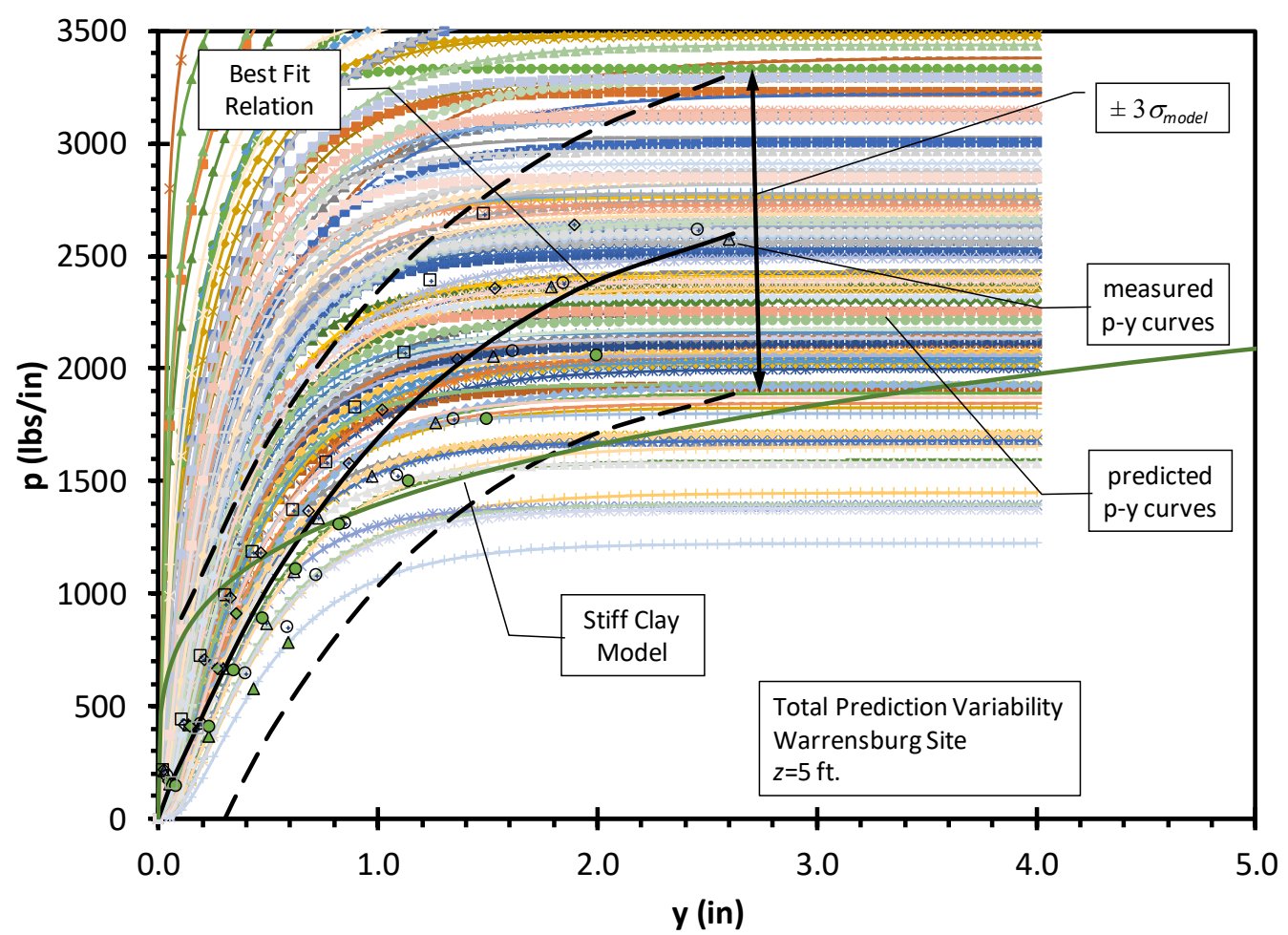

Approach-3 (using avgSTD) for Total Uncertainty (Warrensburg, z=5ft) 


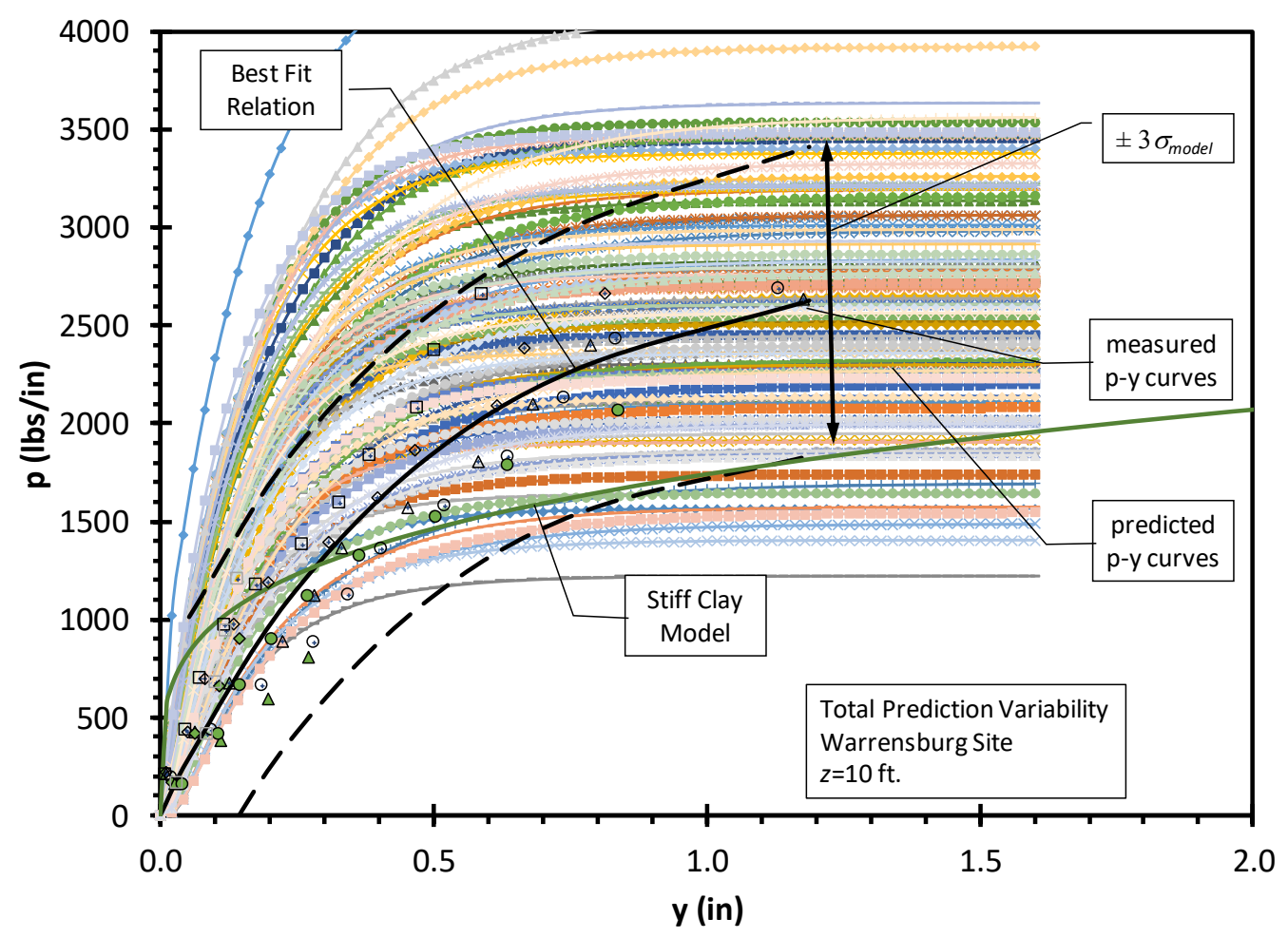

Approach-3 (using avgSTD) for Total Uncertainty (Warrensburg, z=10ft)

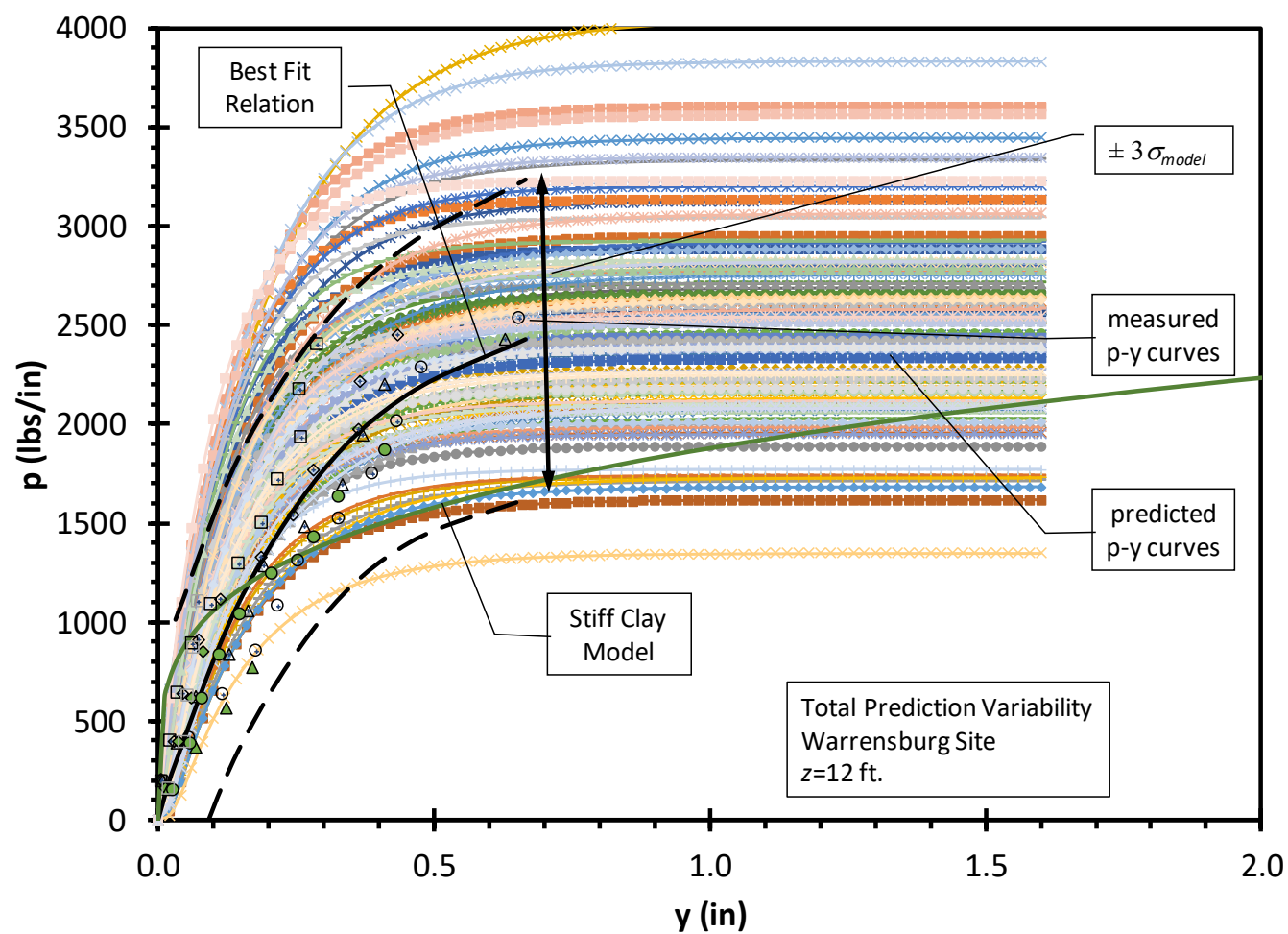

Approach-3 (using avgSTD) for Total Uncertainty (Warrensburg, $\mathrm{z}=12 \mathrm{ft}$ ) 


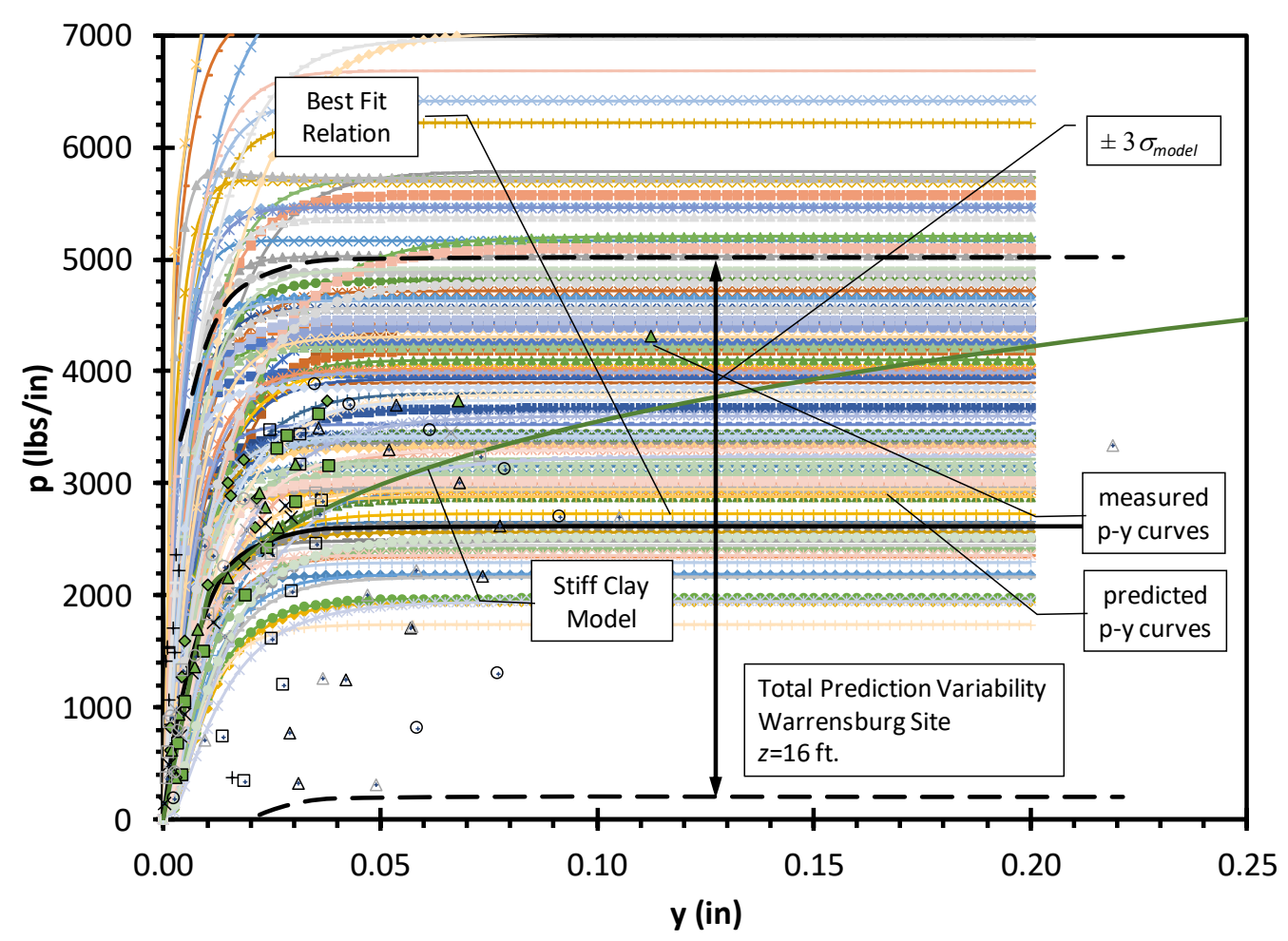

Approach-3 (using avgSTD) for Total Uncertainty (Warrensburg, $\mathrm{z}=16 \mathrm{ft}$ )

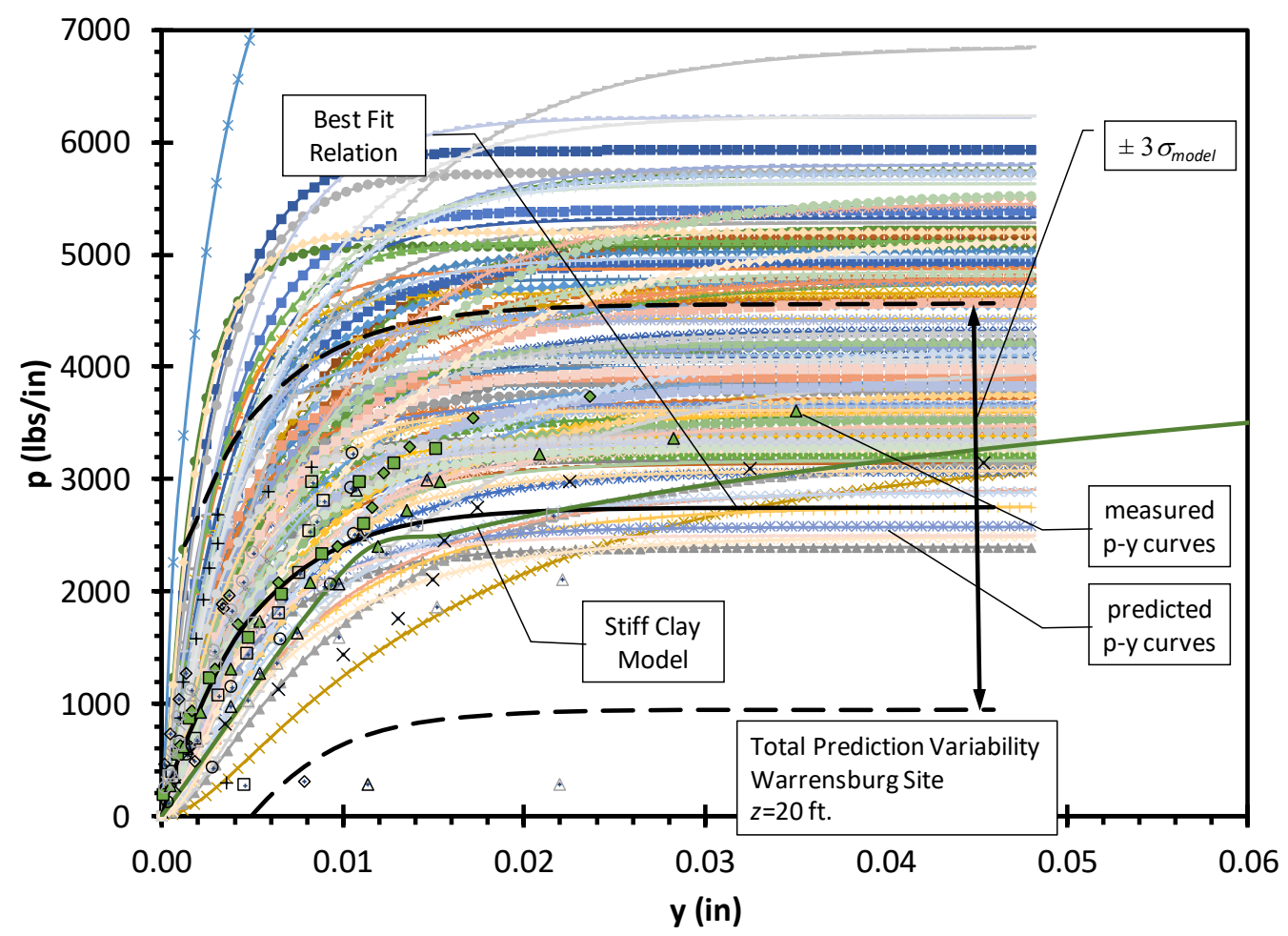

Approach-3 (using avgSTD) for Total Uncertainty (Warrensburg, $\mathrm{z}=20 \mathrm{ft}$ ) 


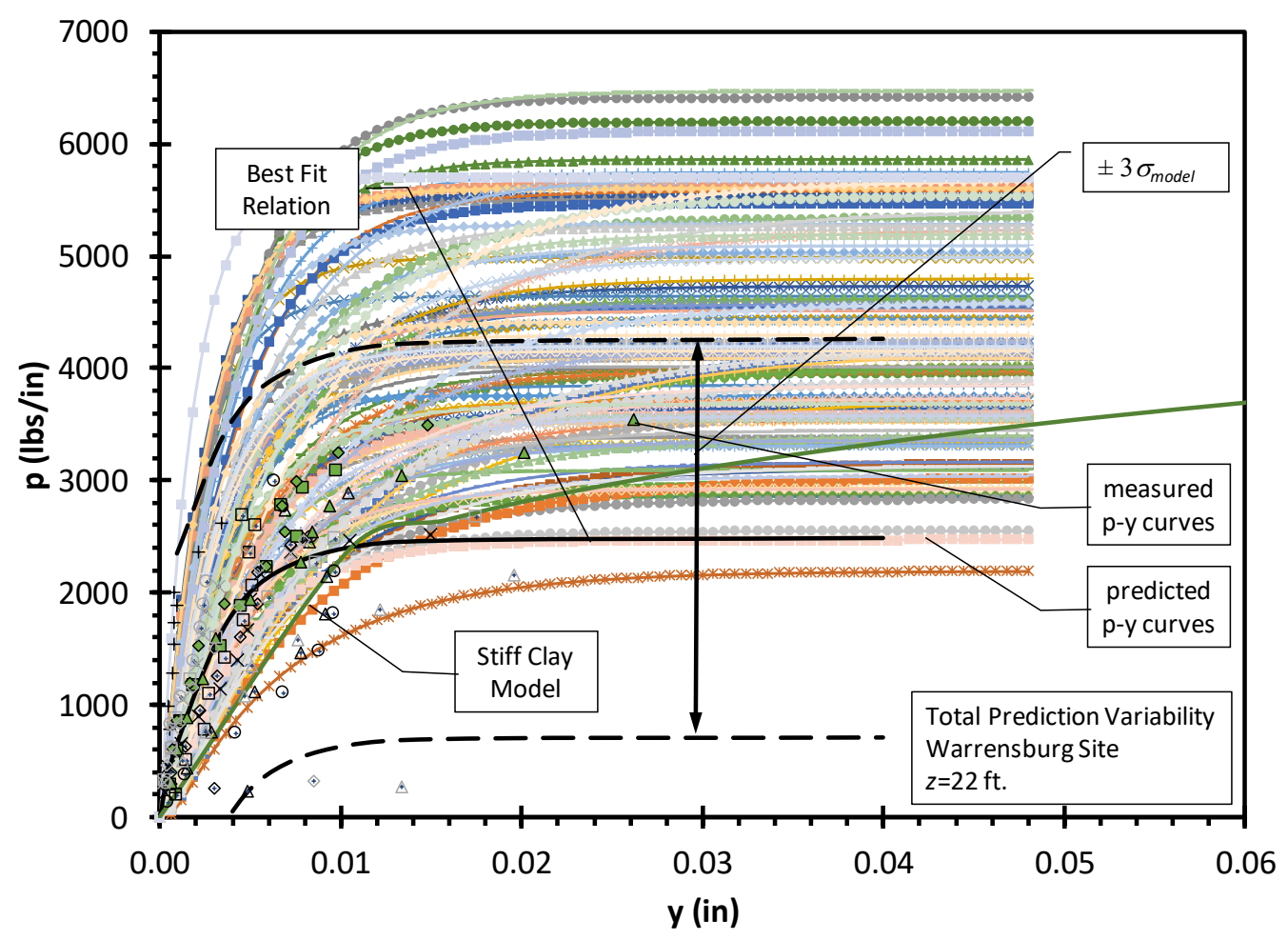

Approach-3 (using avgSTD) for Total Uncertainty (Warrensburg, z=22ft)

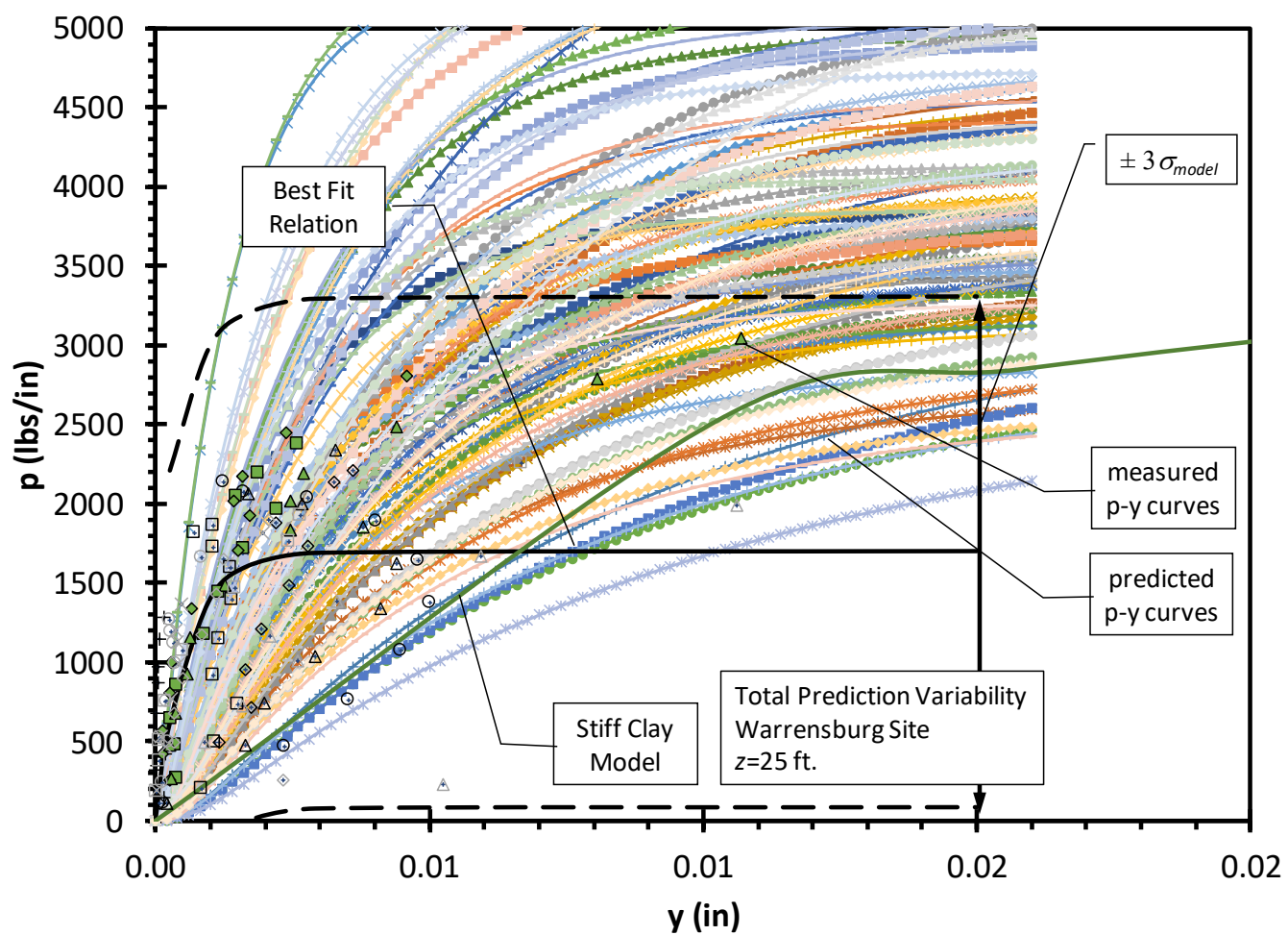

Approach-3 (using avgSTD) for Total Uncertainty (Warrensburg, $\mathrm{z}=25 \mathrm{ft}$ ) 


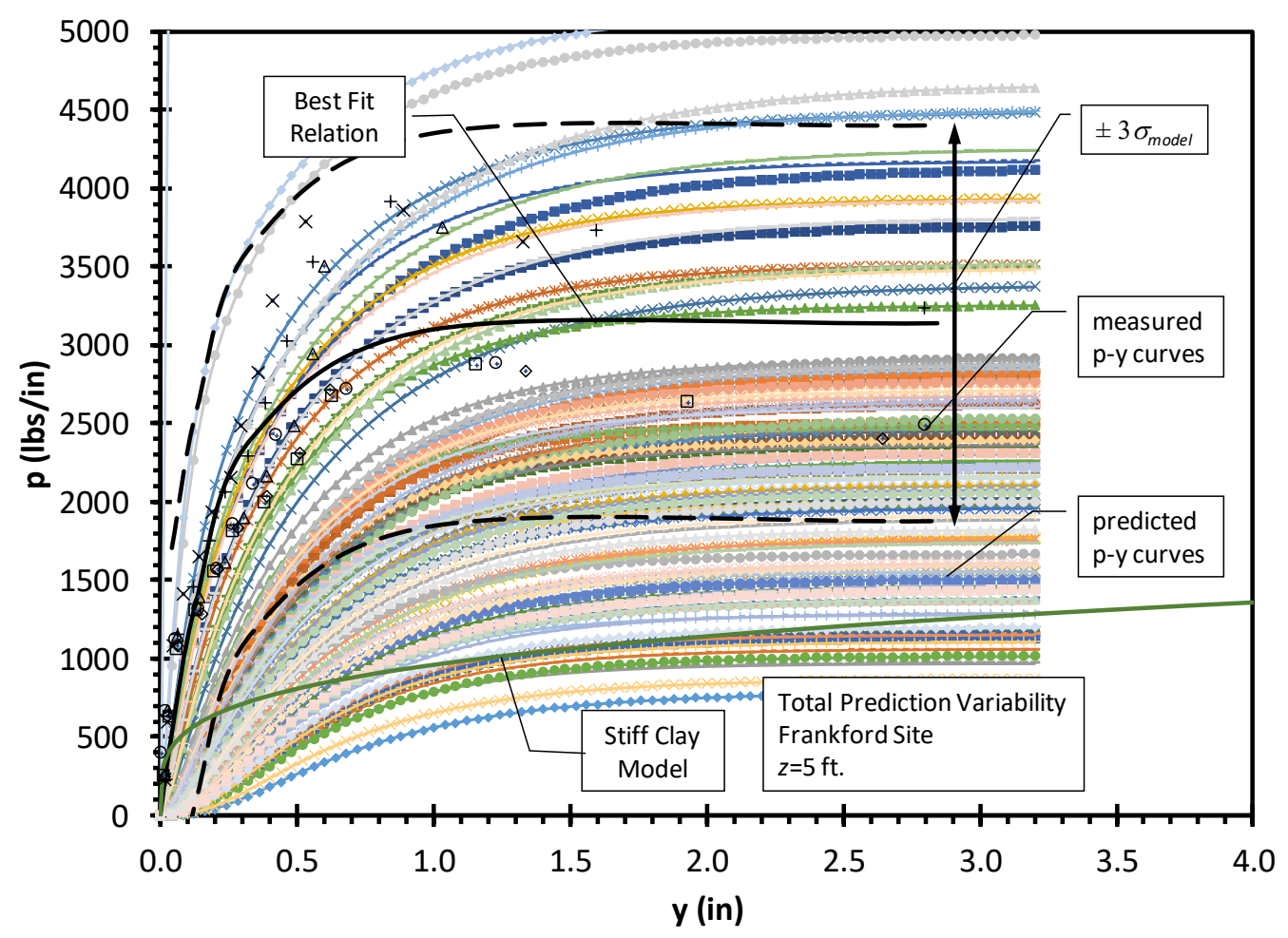

Approach-3 (using avgSTD) for Total Uncertainty (Frankford, $\mathrm{z}=5 \mathrm{ft}$ )

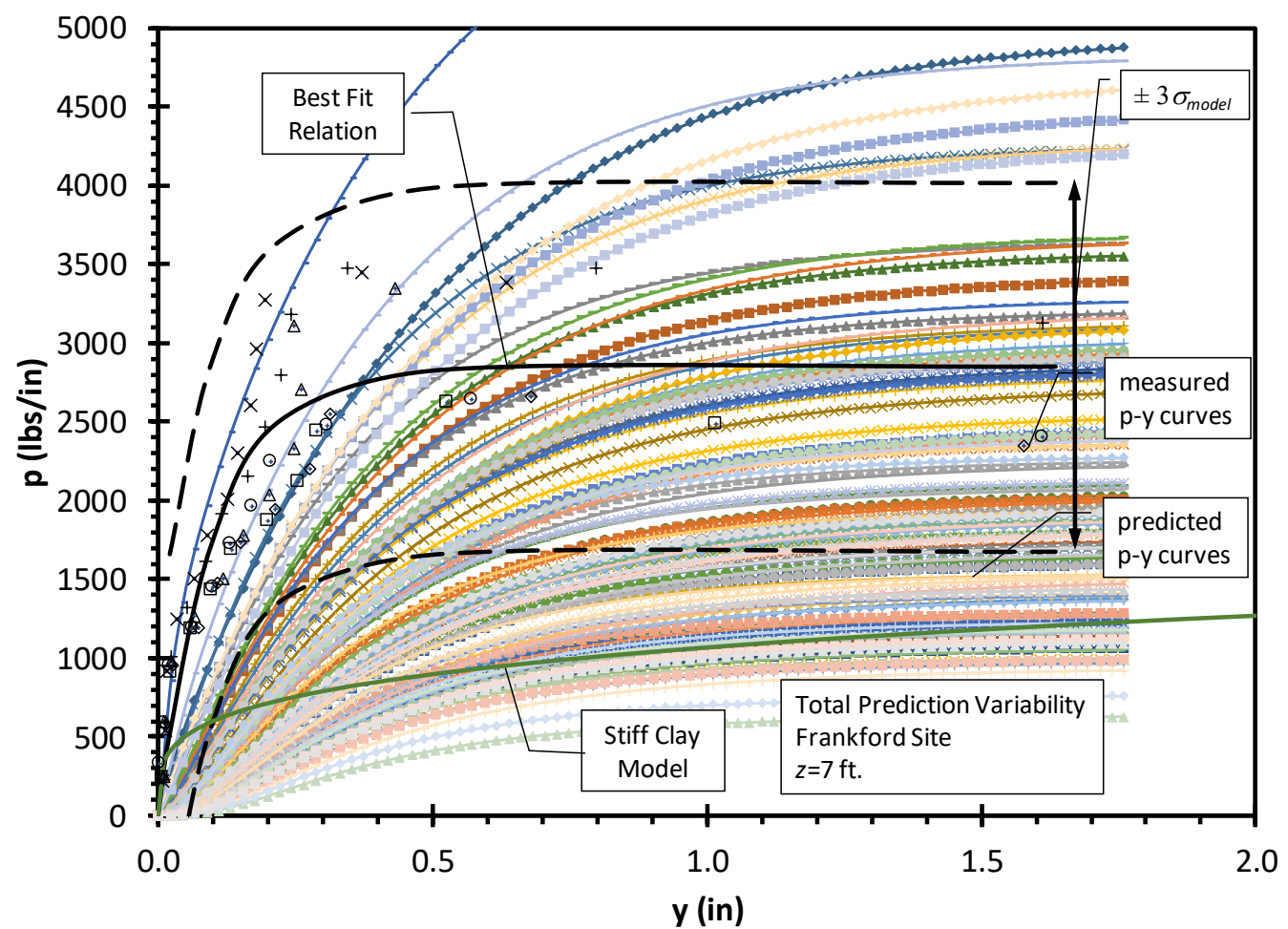

Approach-3 (using avgSTD) for Total Uncertainty (Frankford, z=7ft) 


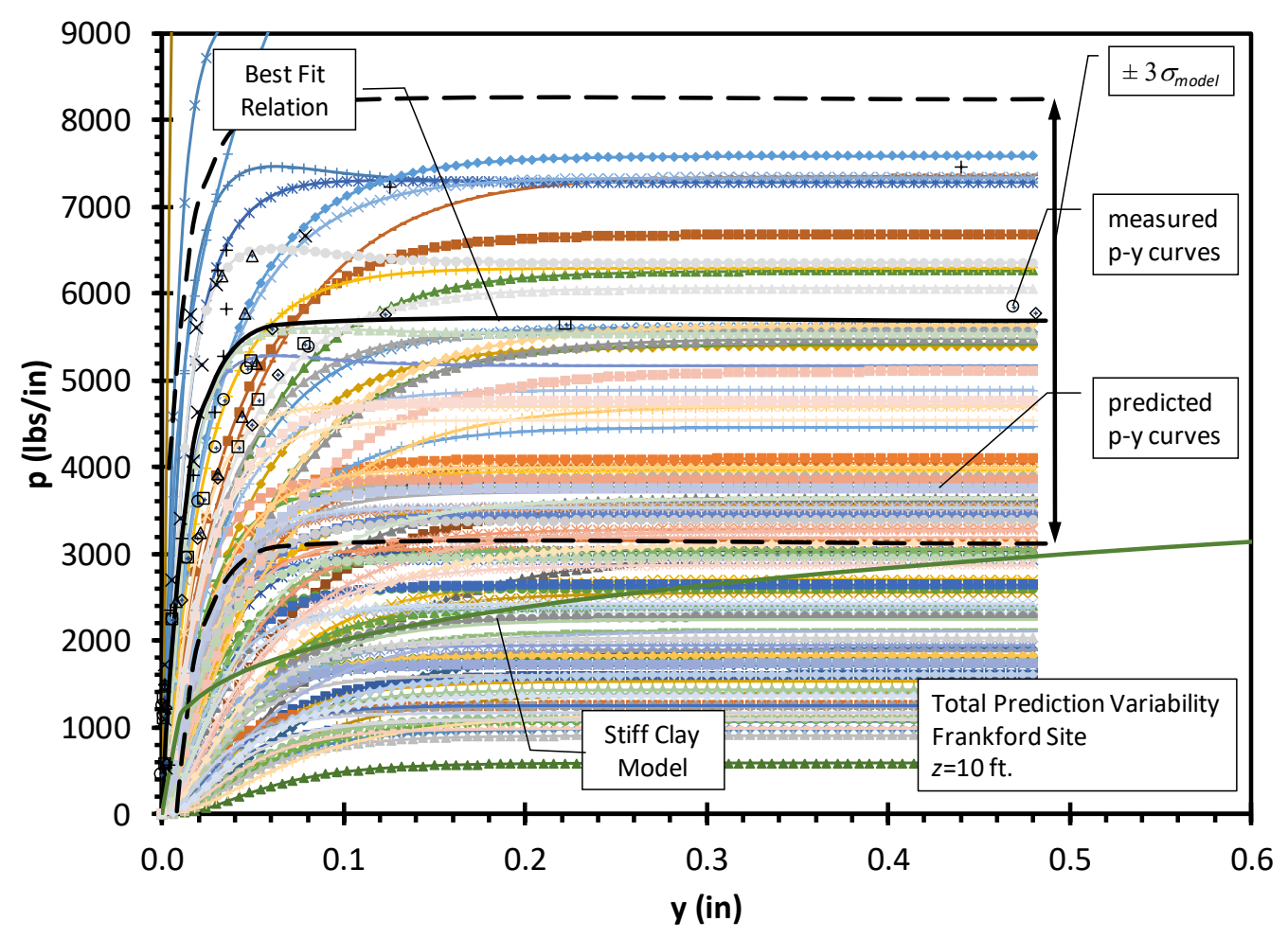

Approach-3 (using avgSTD) for Total Uncertainty (Frankford, z=10ft)

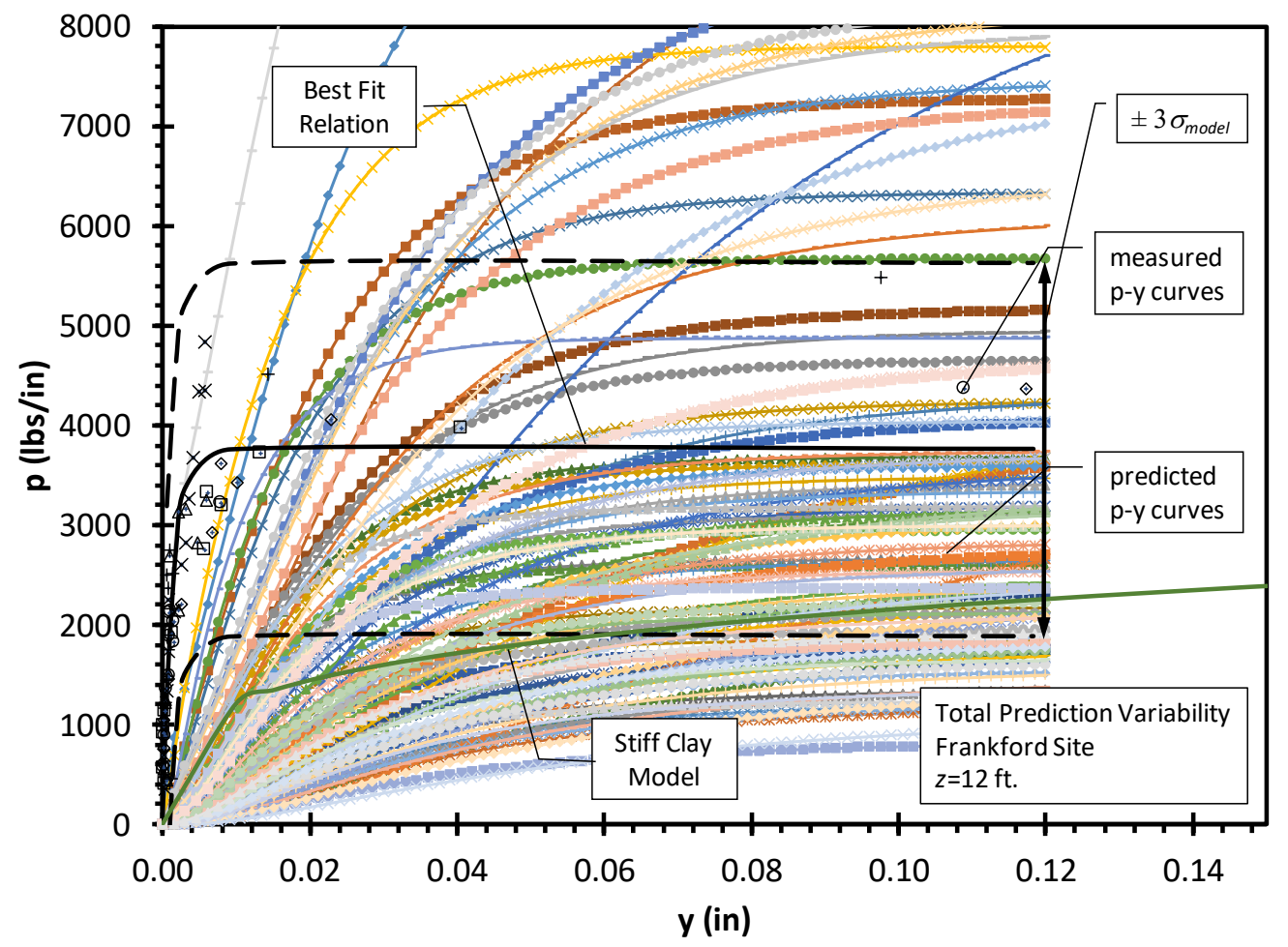

Approach-3 (using avgSTD) for Total Uncertainty (Frankford, z=12ft) 


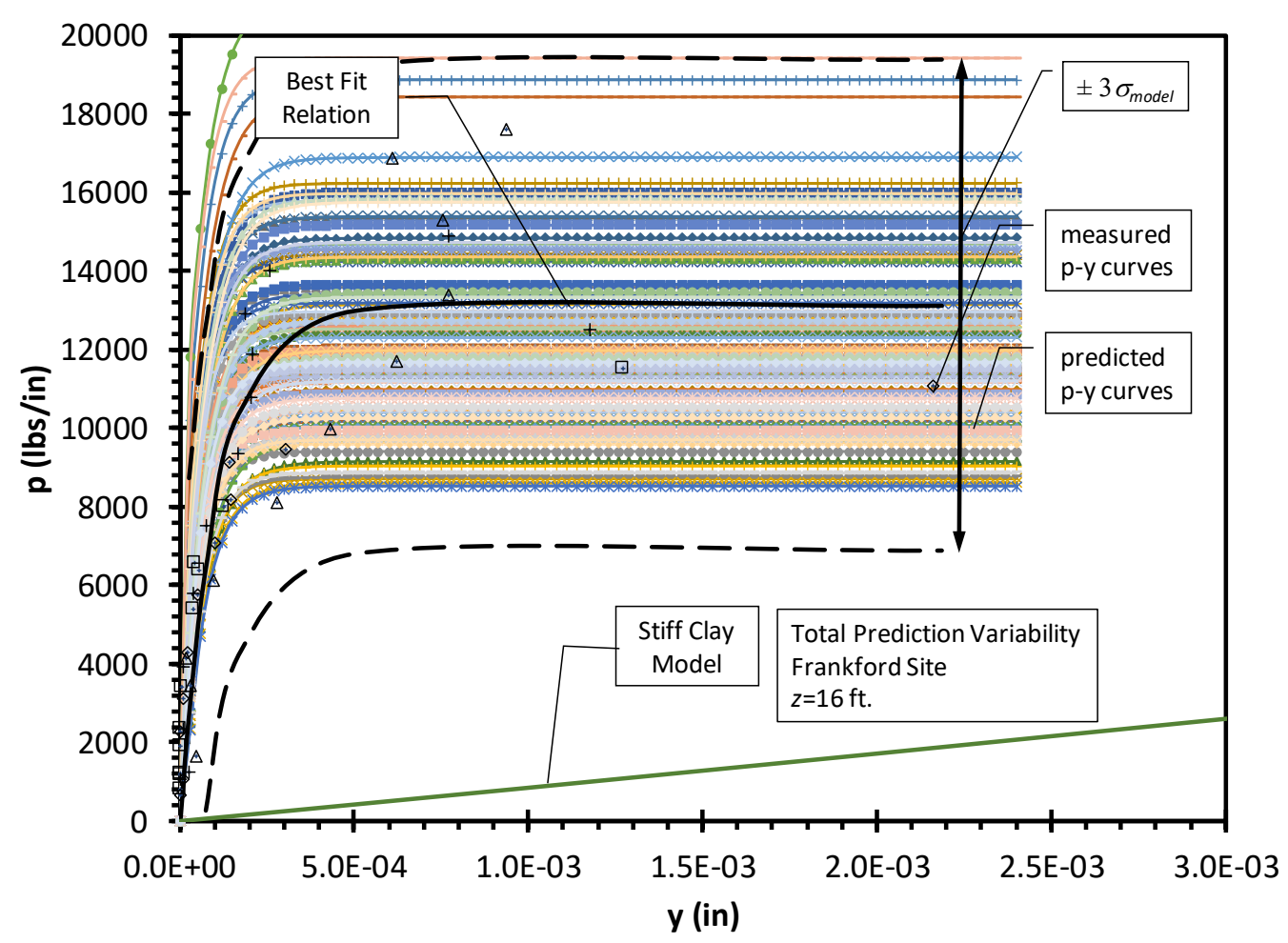

Approach-3 (using avgSTD) for Total Uncertainty (Frankford, z=16ft)

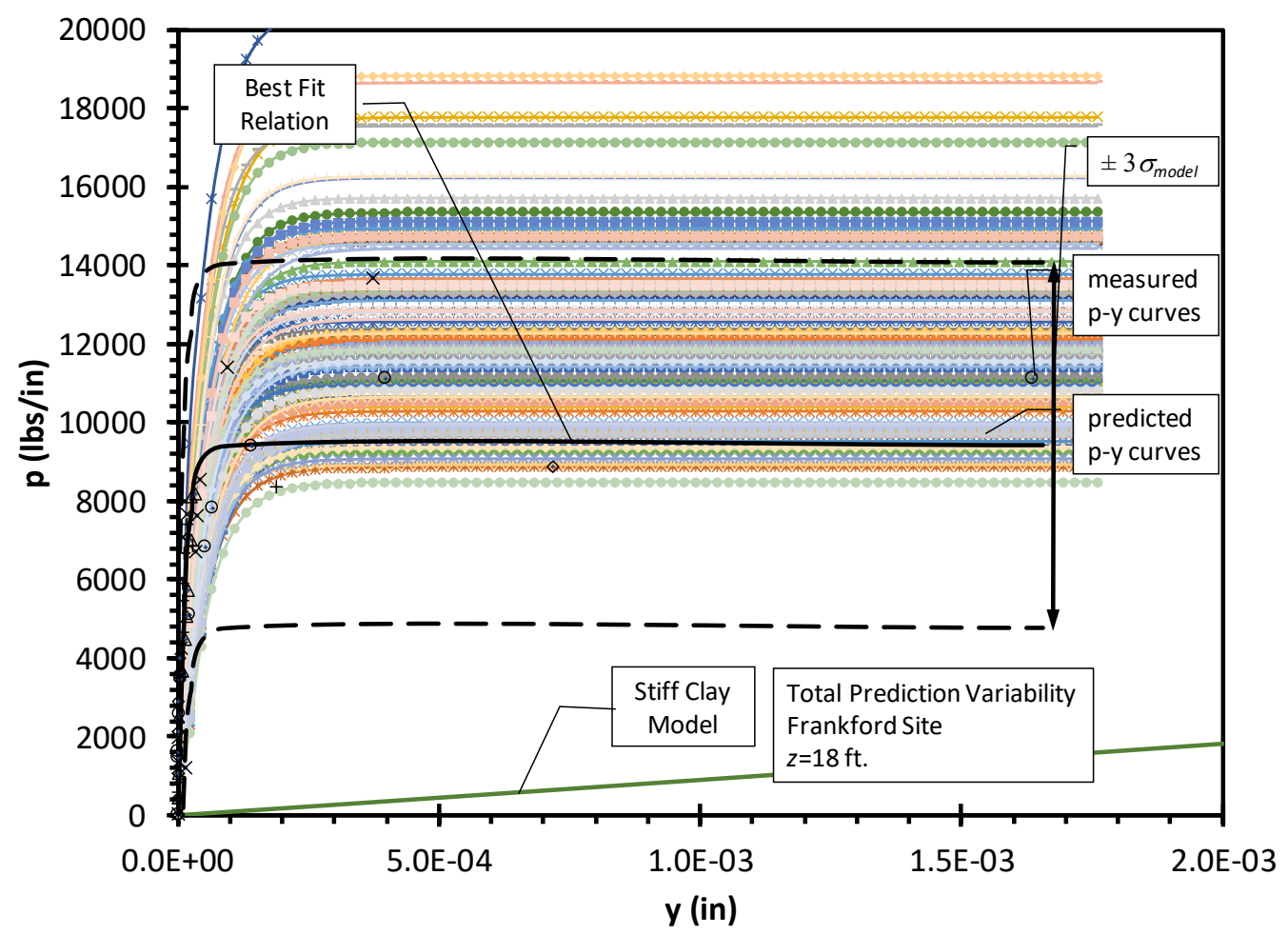

Approach-3 (using avgSTD) for Total Uncertainty (Frankford, z=18ft) 
Appendix D

Proposed LRFD, AASHTO LRFD and RBD methods with different $P / P_{\text {ult }}$ 


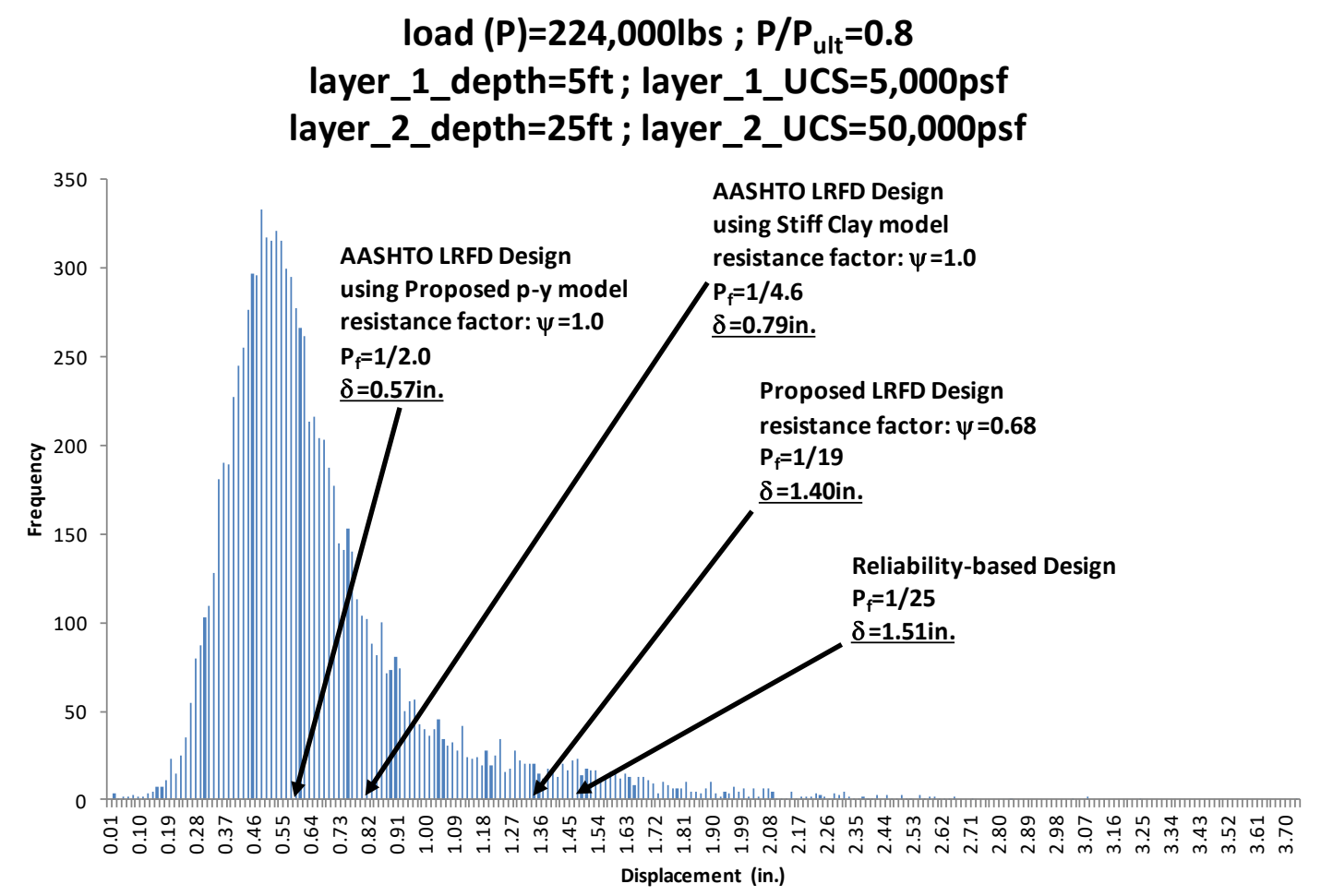

Case S- 1 with ratio $P / P_{\text {ult }}=0.8$ and target $P_{f}=1 / 25$

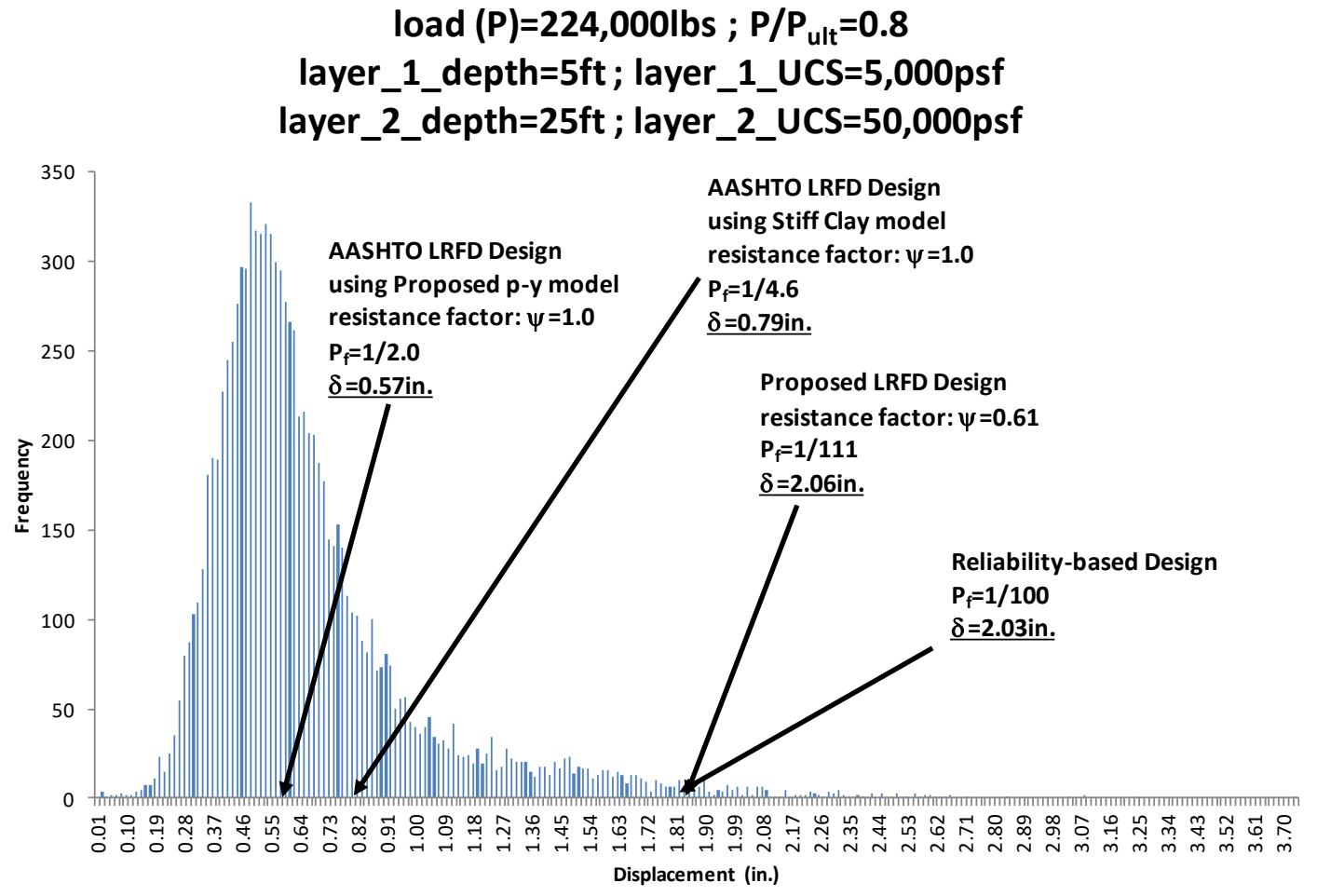

Case S- 1 with ratio $P / P_{\text {ult }}=0.8$ and target $P_{f}=1 / 100$ 


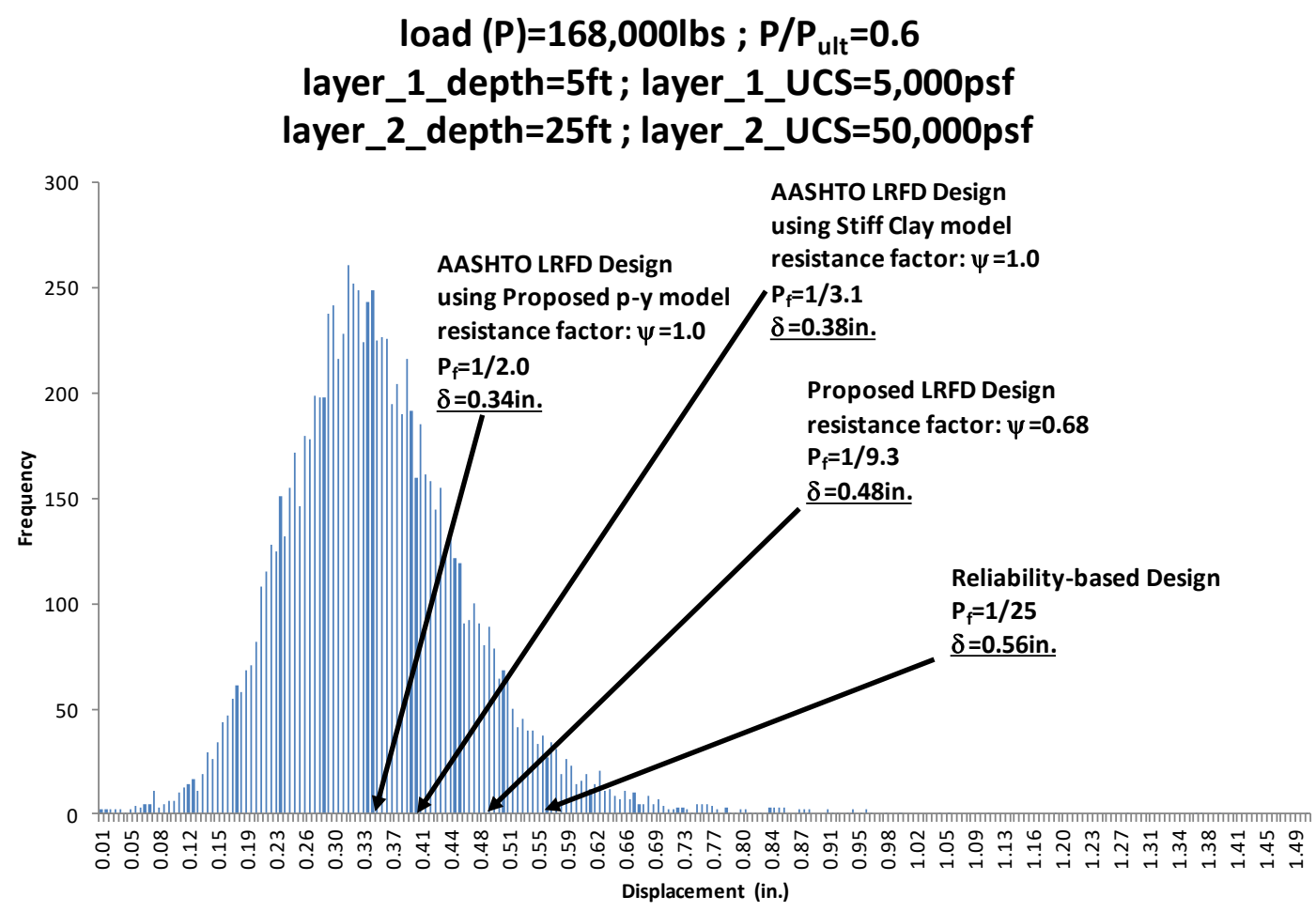

Case S-1 with ratio $\mathrm{P} / \mathrm{P}_{\text {ult }}=0.6$ and target $\mathrm{P}_{\mathrm{f}}=1 / 25$

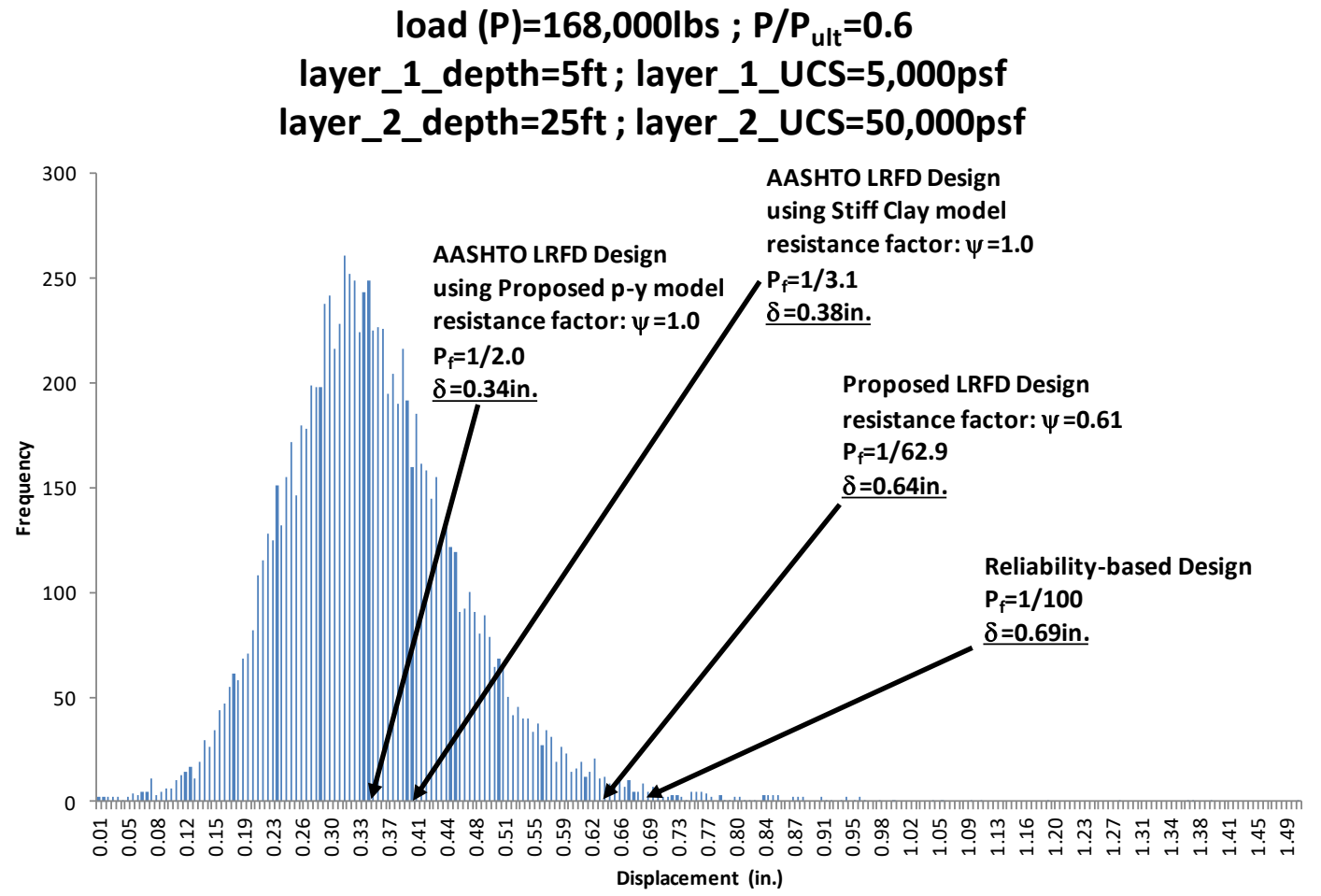

Case S- 1 with ratio $P / P_{\text {ult }}=0.6$ and target $P_{f}=1 / 100$ 


\section{load $(P)=112,000 \mathrm{lbs} ; P / P_{\text {ult }}=0.4$ \\ layer_1_depth $=5 \mathrm{ft}$; layer_1_UCS $=5,000 \mathrm{psf}$ \\ layer_2_depth $=25 \mathrm{ft}$; layer_2_UCS $=50,000 \mathrm{psf}$}

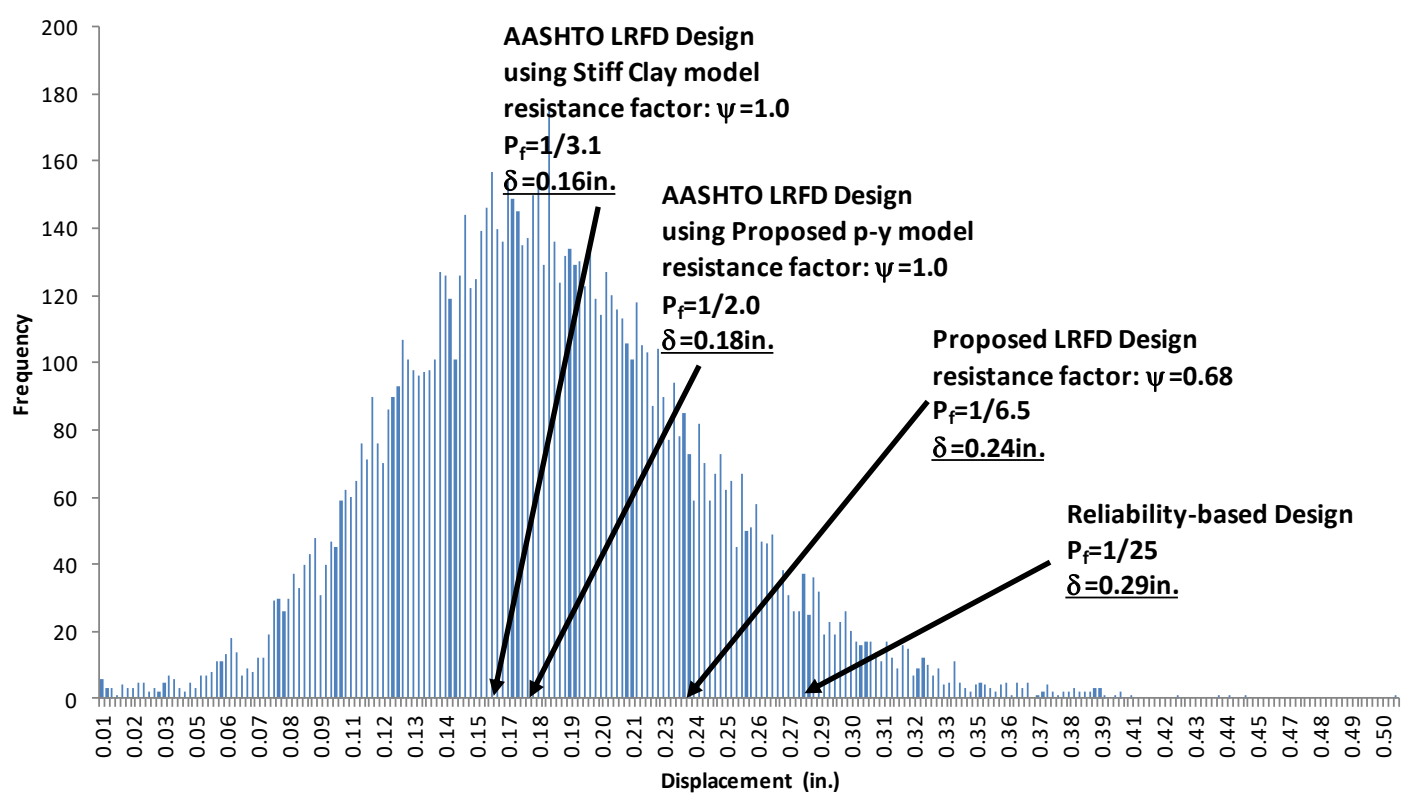

Case S- 1 with ratio $P / P_{\text {ult }}=0.4$ and target $P_{f}=1 / 25$

load $(P)=112,000 \mathrm{lbs} ; P / P_{\text {ult }}=0.4$

layer_1_depth $=5 \mathrm{ft}$; layer_1_UCS $=5,000 \mathrm{psf}$

layer_2_depth $=25 \mathrm{ft}$; layer_2_UCS=50,000psf

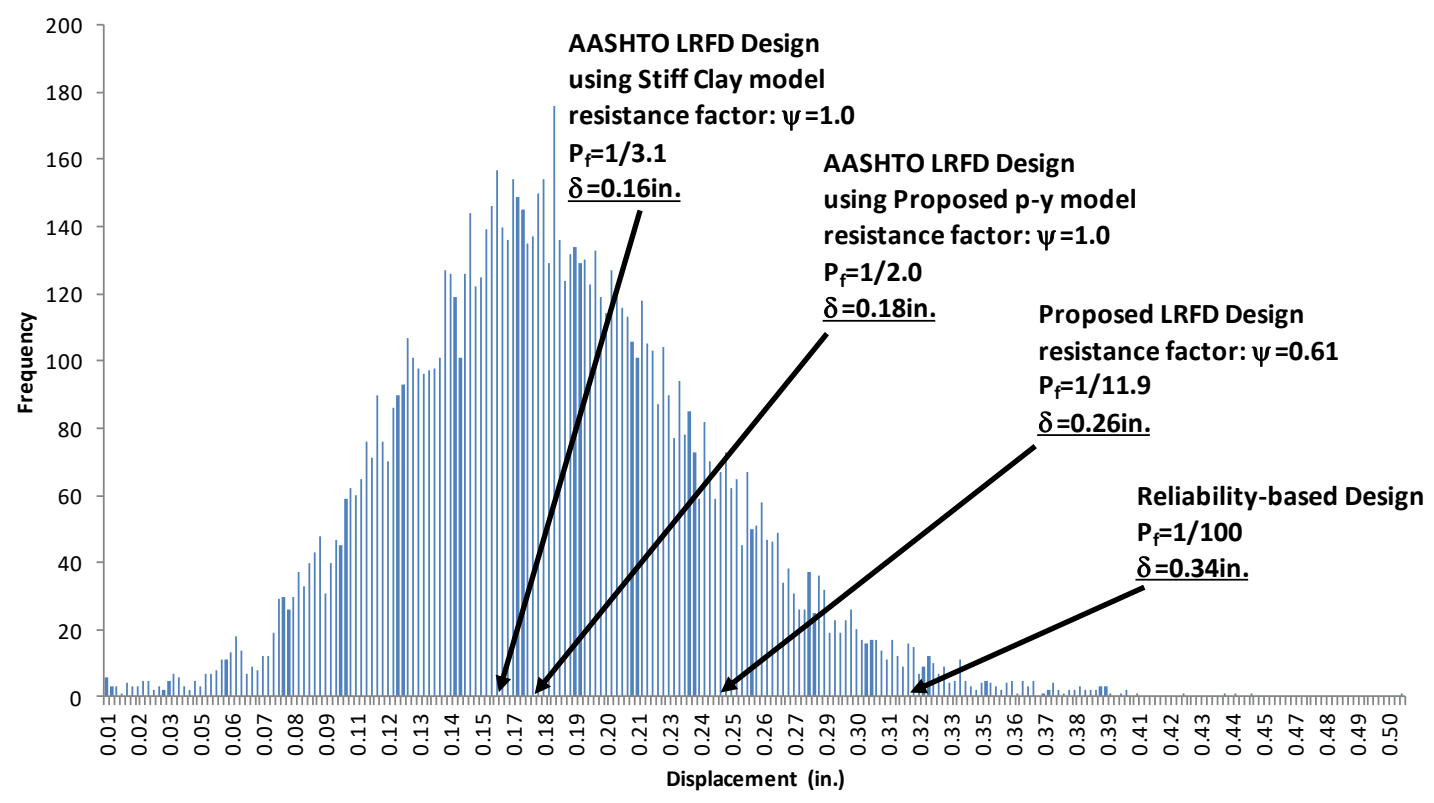

Case S- 1 with ratio $P / P_{\text {ult }}=0.4$ and target $P_{f}=1 / 100$ 


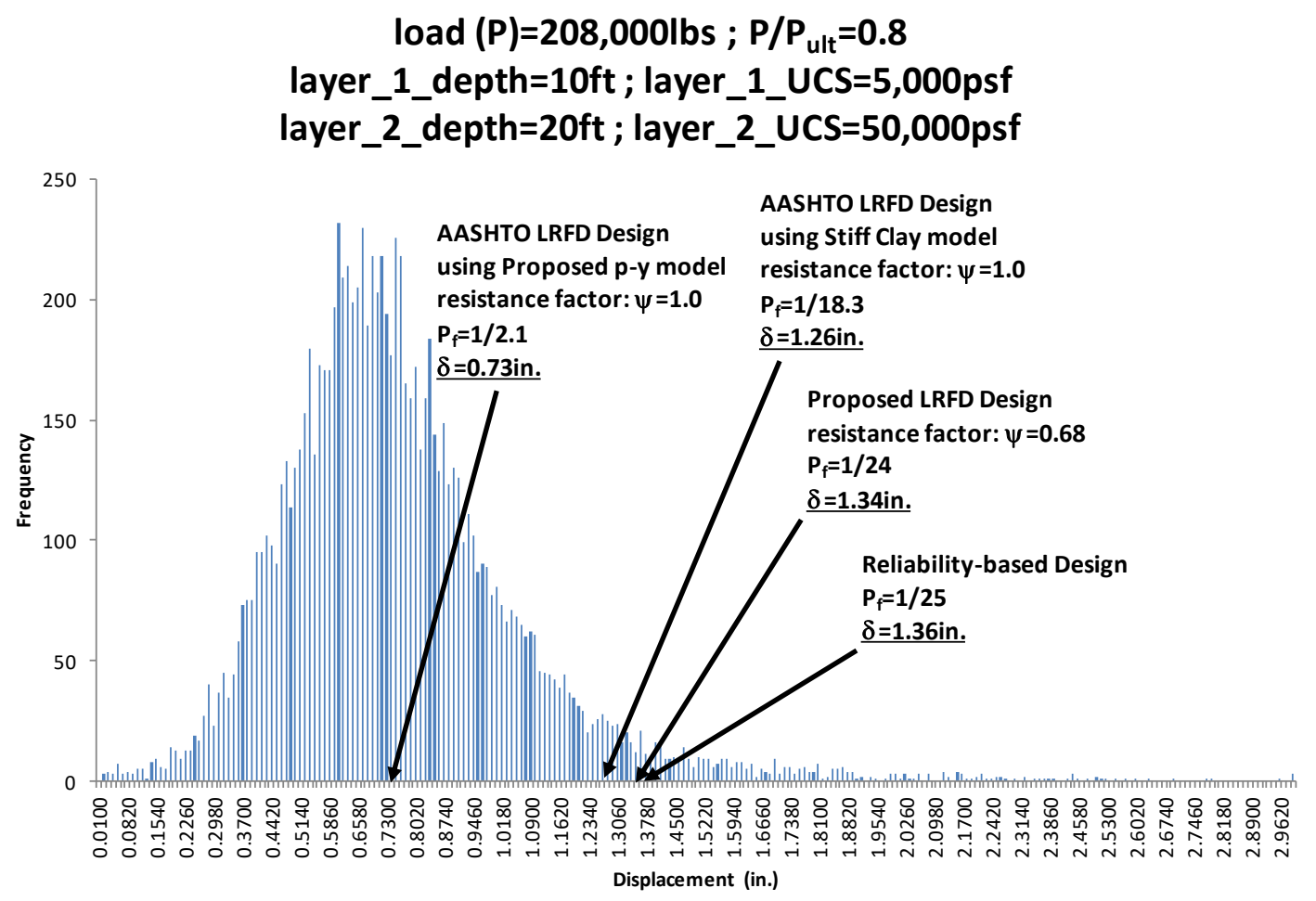

Case S- 2 with ratio $P / P_{\text {ult }}=0.8$ and target $P_{f}=1 / 25$

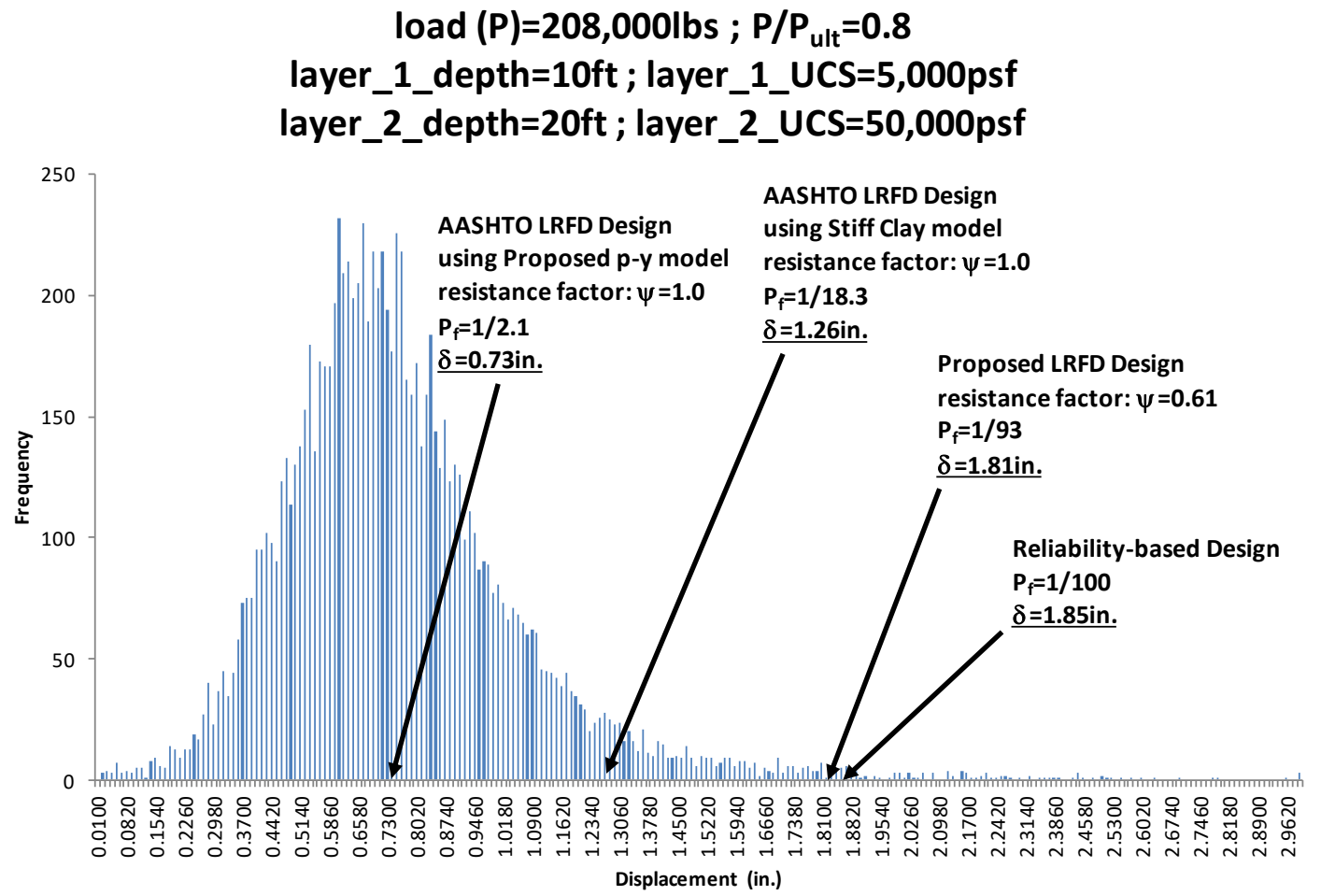

Case S- 2 with ratio $P / P_{\text {ult }}=0.8$ and target $P_{f}=1 / 100$ 


\section{load $(P)=156,000 \mathrm{lbs} ; \mathrm{P} / \mathrm{P}_{\mathrm{ult}}=\mathbf{0 . 6}$ \\ layer_1_depth=10ft ; layer_1_UCS=5,000psf \\ layer_2_depth=20ft ; layer_2_UCS=50,000psf}

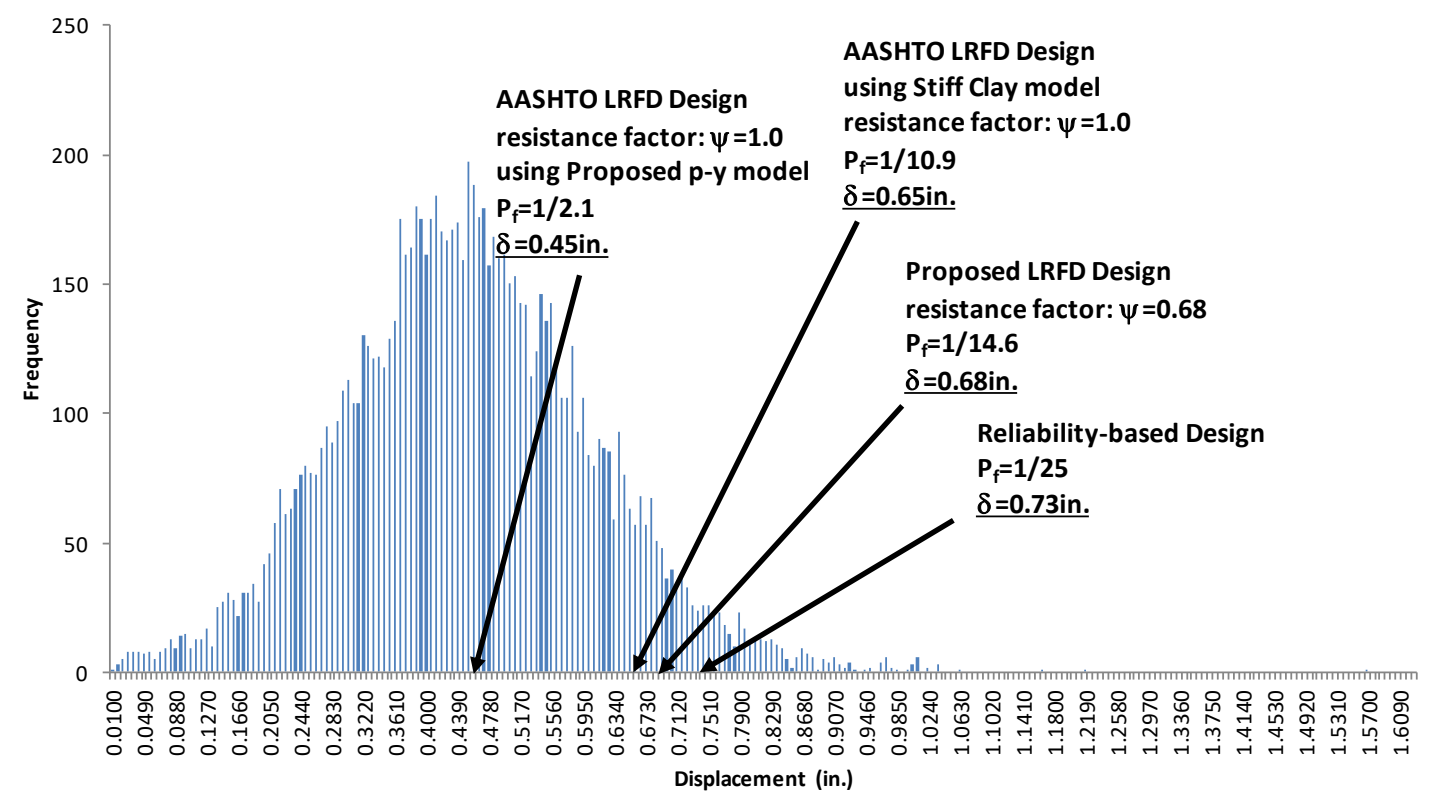

Case $\mathrm{S}-2$ with ratio $\mathrm{P} / \mathrm{P}_{\text {ult }}=0.6$ and target $\mathrm{P}_{\mathrm{f}}=1 / 25$
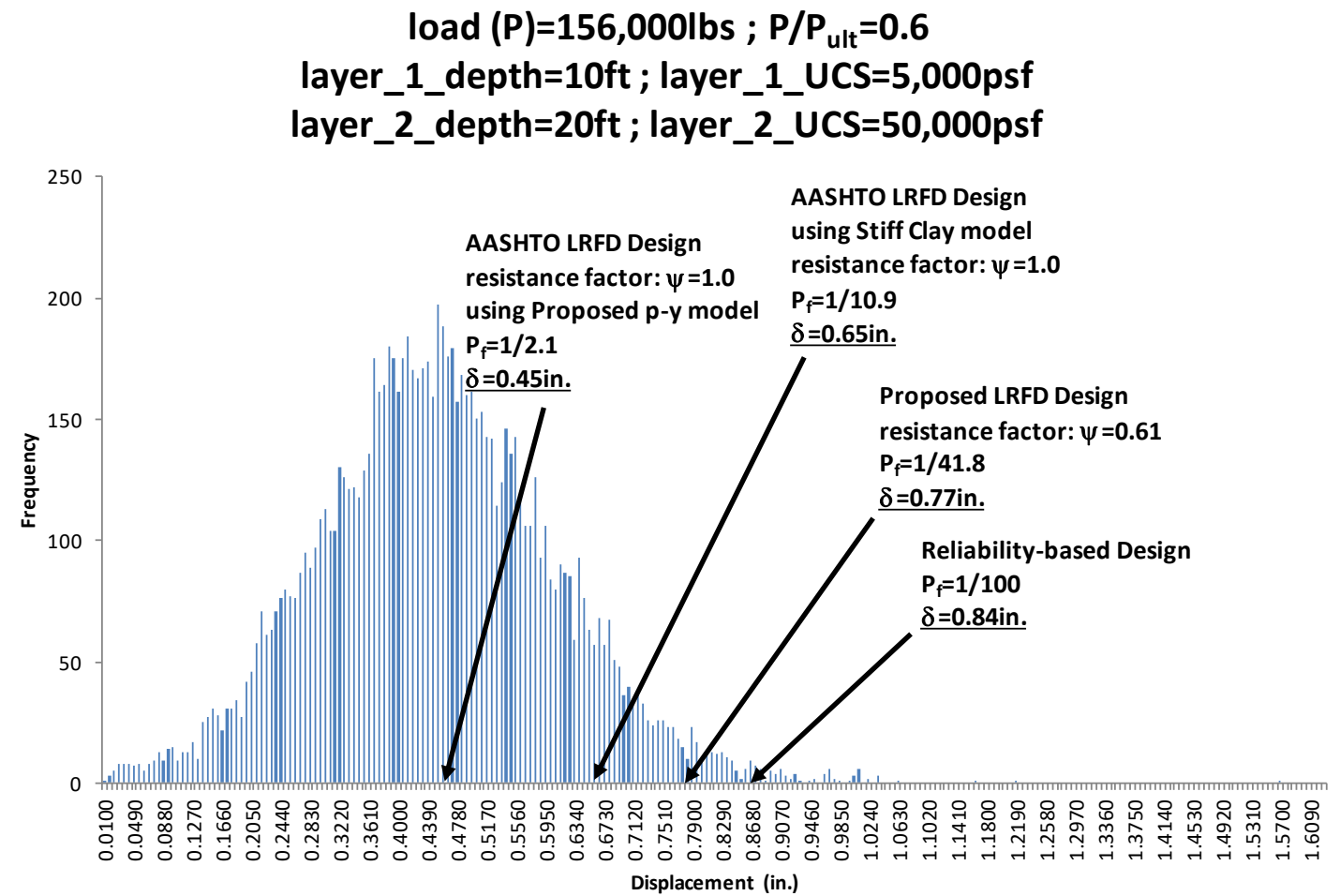

Case S- 2 with ratio $P / P_{\text {ult }}=0.6$ and target $P_{f}=1 / 100$ 


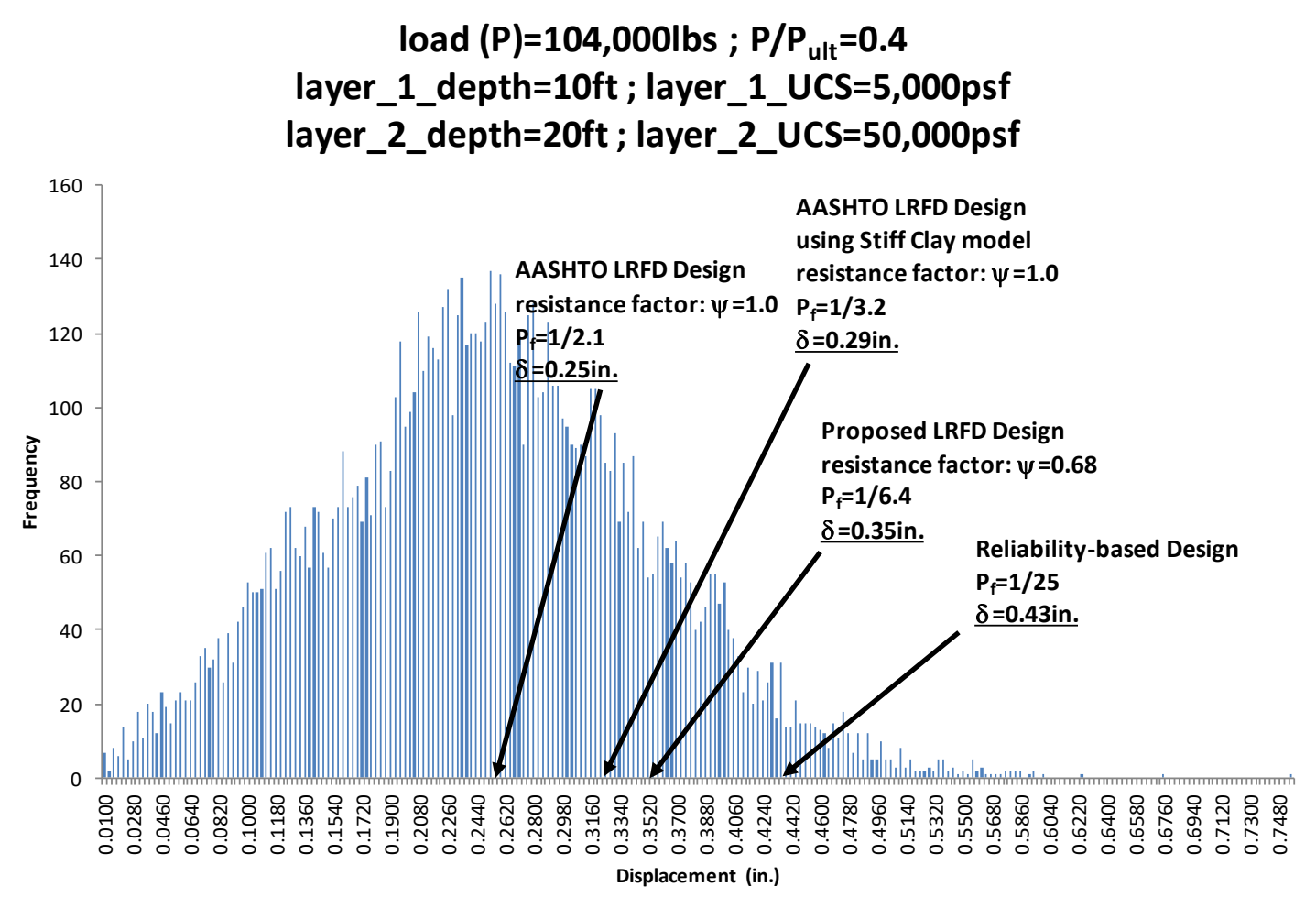

Case S- 2 with ratio $P / P_{\text {ult }}=0.4$ and target $P_{f}=1 / 25$

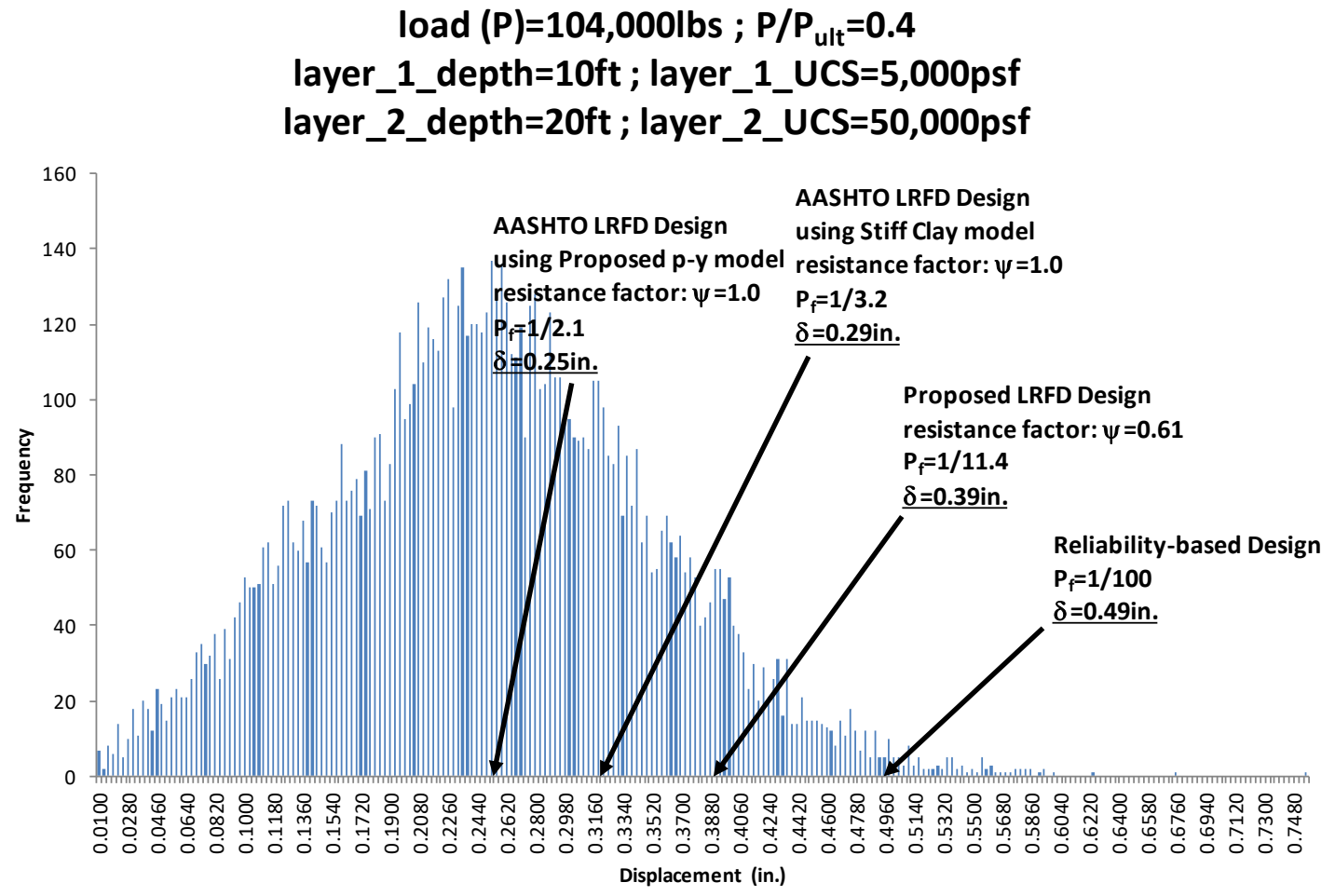

Case S- 2 with ratio $P / P_{\text {ult }}=0.4$ and target $P_{f}=1 / 100$ 


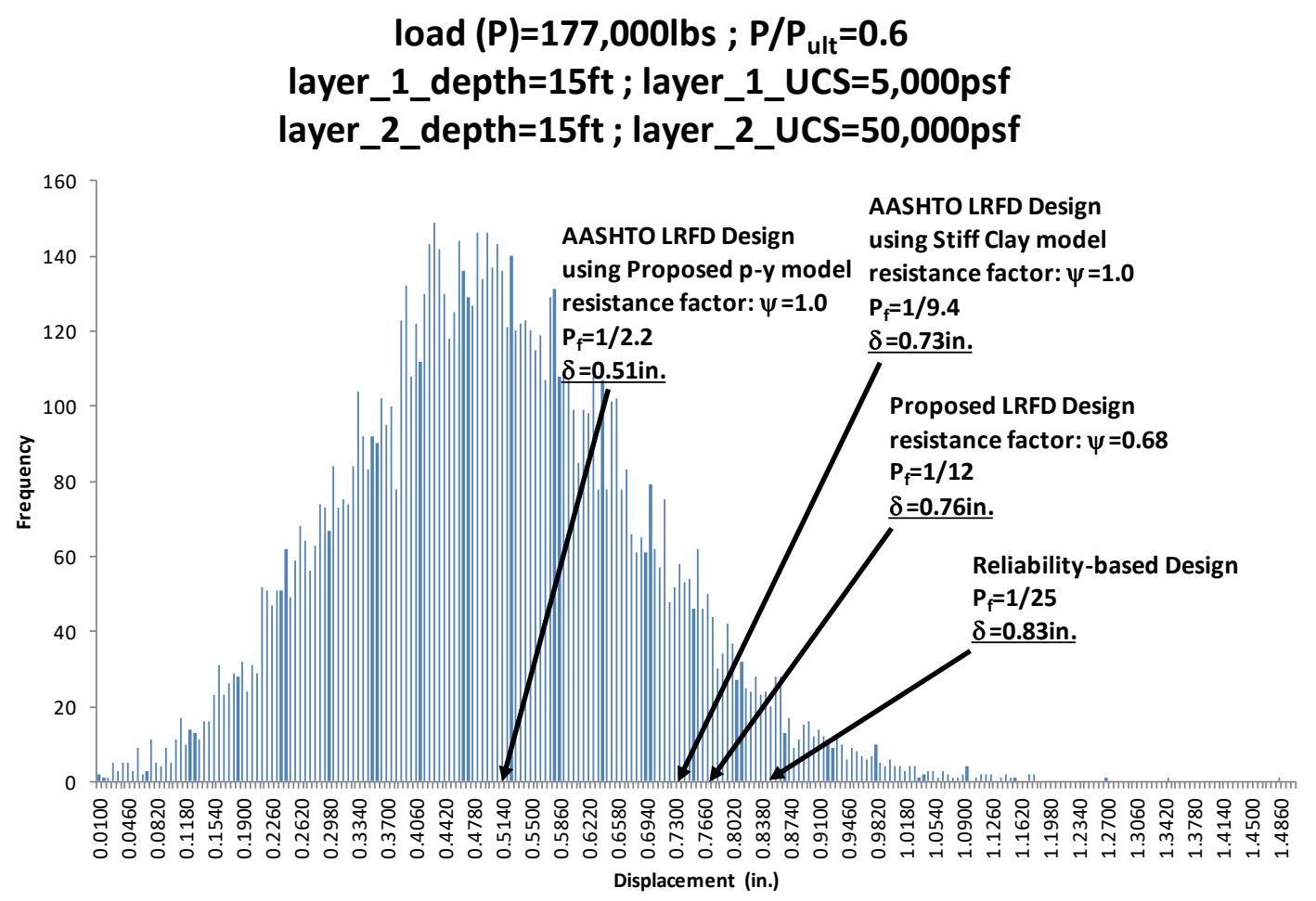

Case S-3 with ratio $P / P_{\text {ult }}=0.6$ and target $P_{f}=1 / 25$

\section{load $(P)=177,000 \mathrm{lbs} ; \mathrm{P} / \mathrm{P}_{\text {ult }}=\mathbf{0 . 6}$ \\ layer_1_depth $=15 \mathrm{ft}$; layer_1_UCS $=5,000 \mathrm{psf}$ \\ layer_2_depth $=15 \mathrm{ft}$; layer_2_UCS=50,000psf}

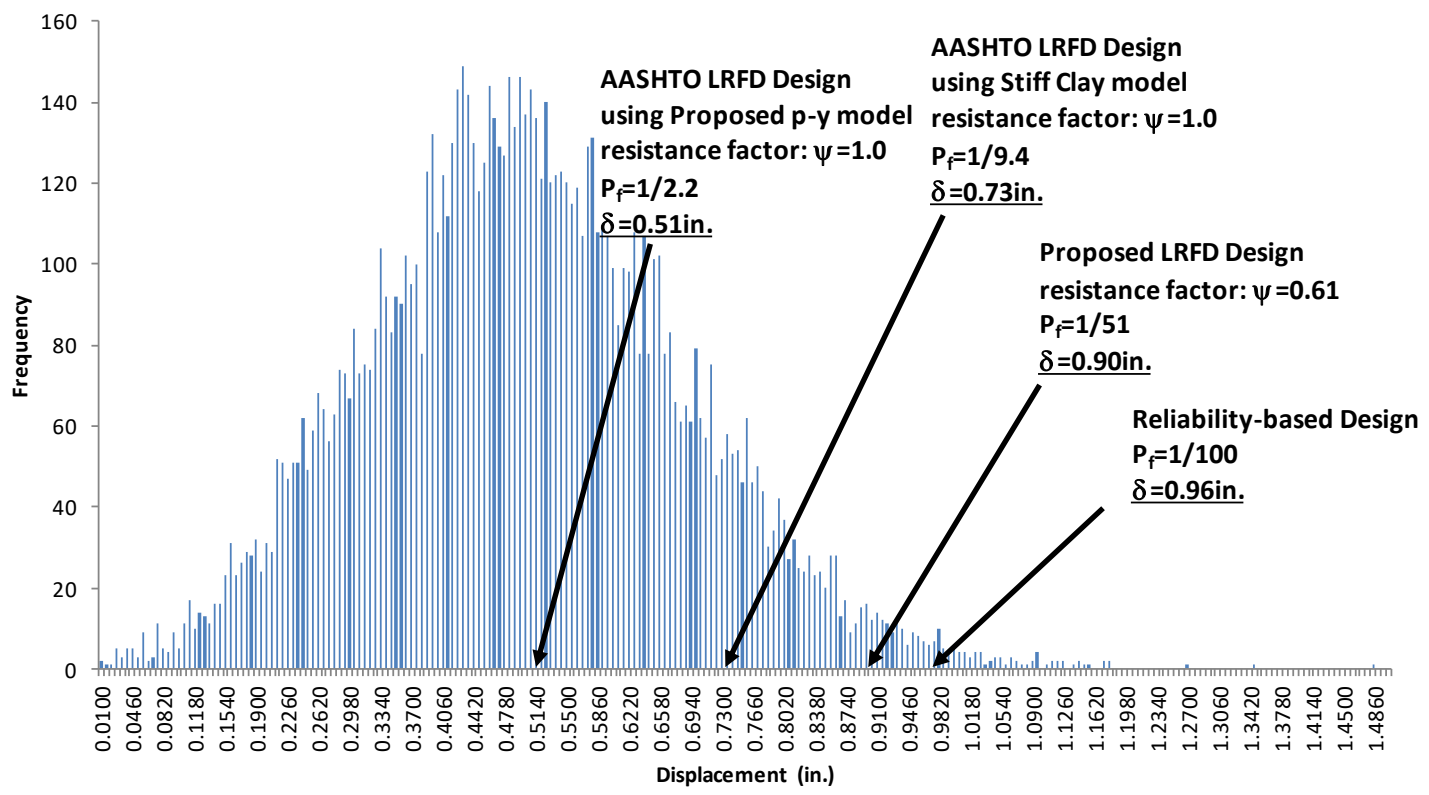

Case $\mathrm{S}-3$ with ratio $P / P_{\text {ult }}=0.6$ and target $P_{f}=1 / 100$ 


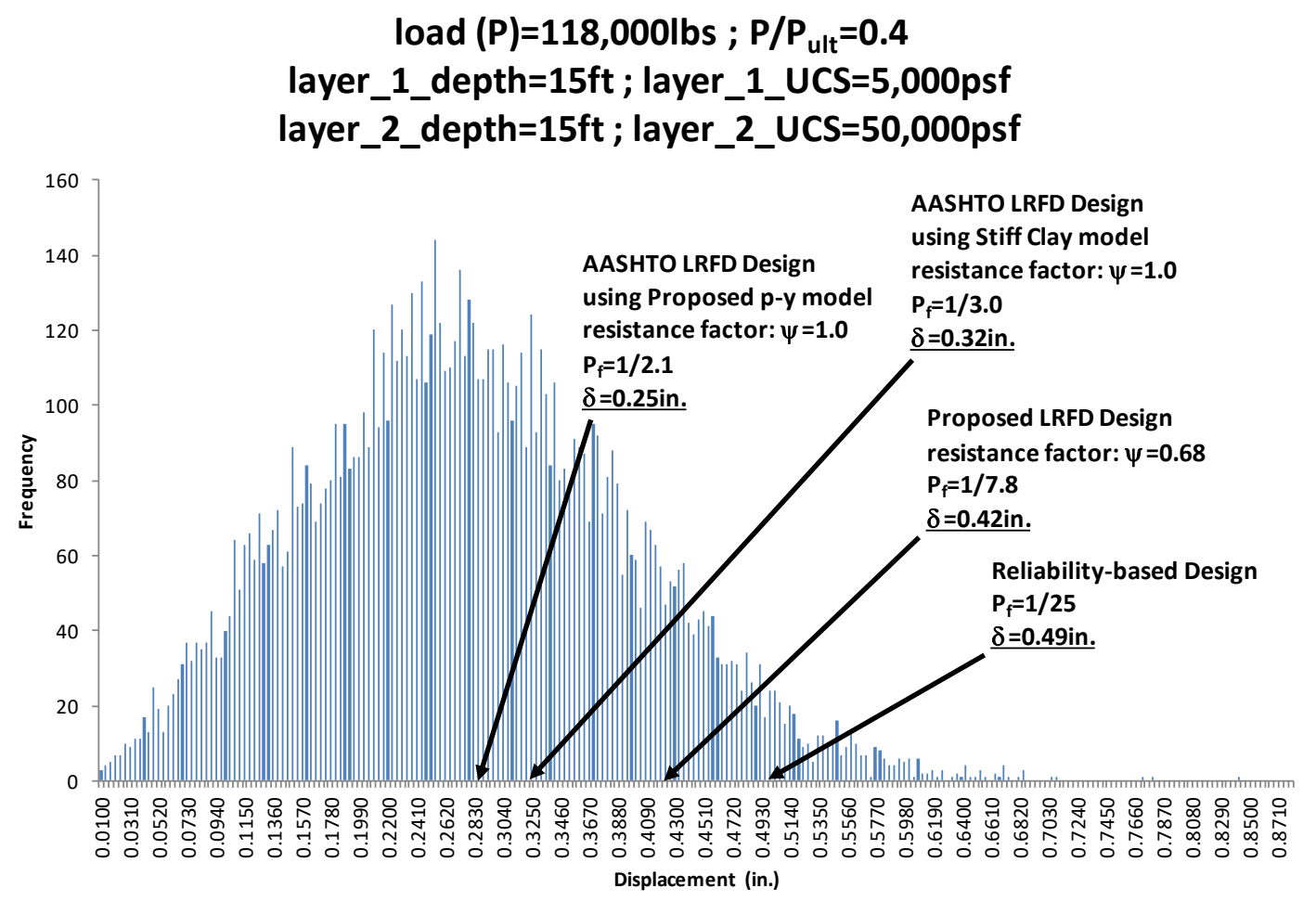

Case S-3 with ratio $P / P_{\text {ult }}=0.4$ and target $P_{f}=1 / 25$
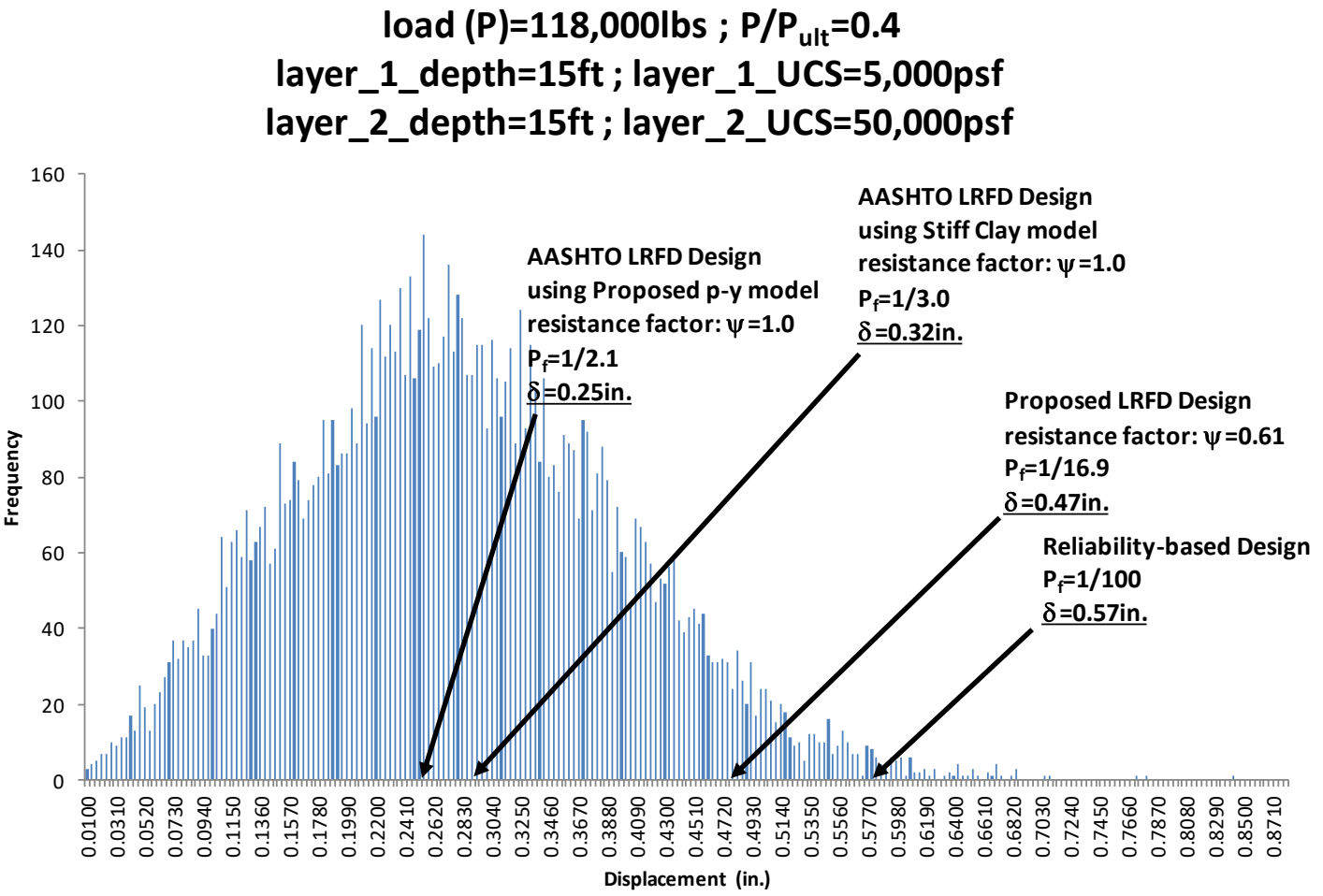

Case S-3 with ratio $P / P_{\text {ult }}=0.4$ and target $P_{f}=1 / 100$ 


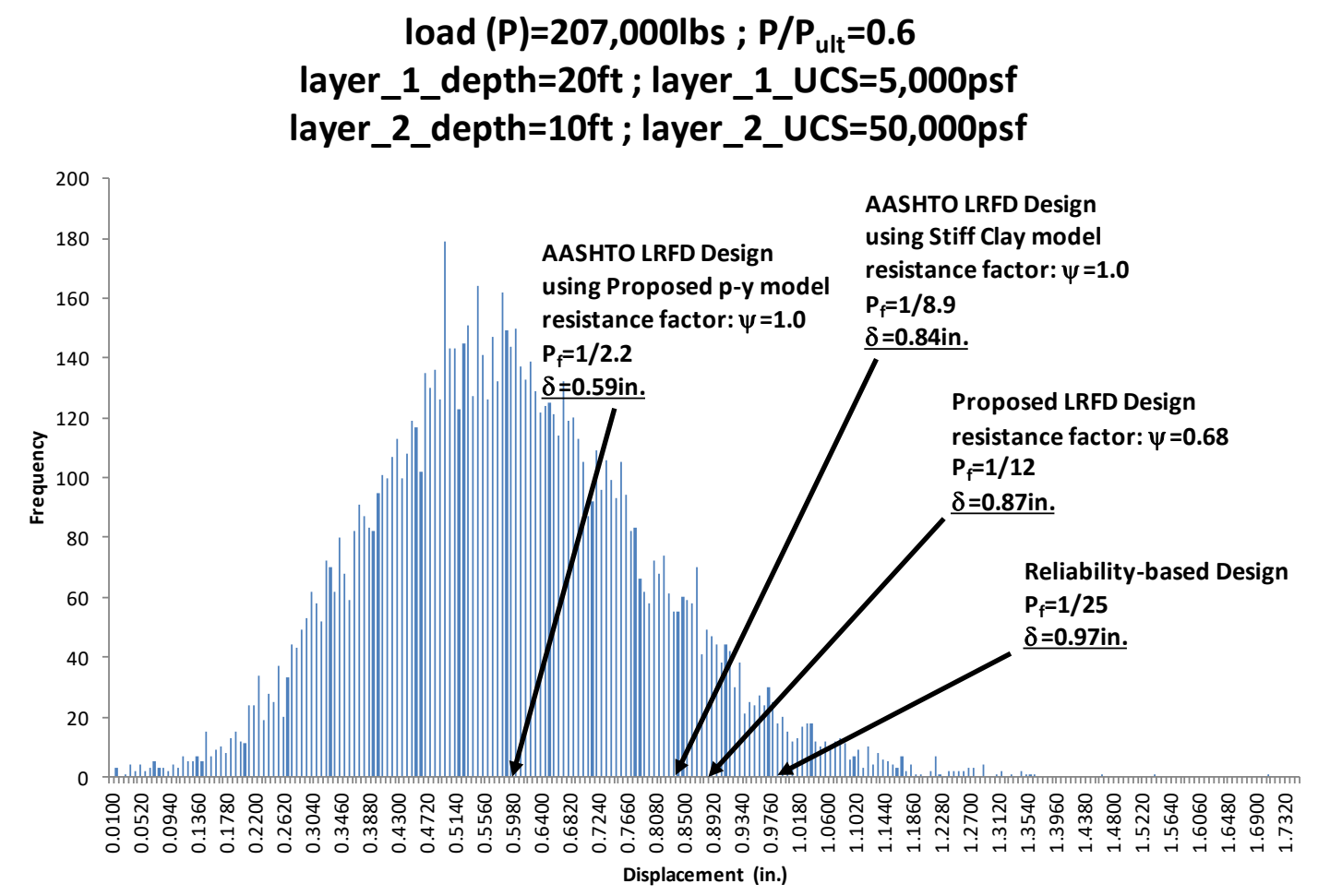

Case S- 4 with ratio $P / P_{\text {ult }}=0.6$ and target $P_{f}=1 / 25$
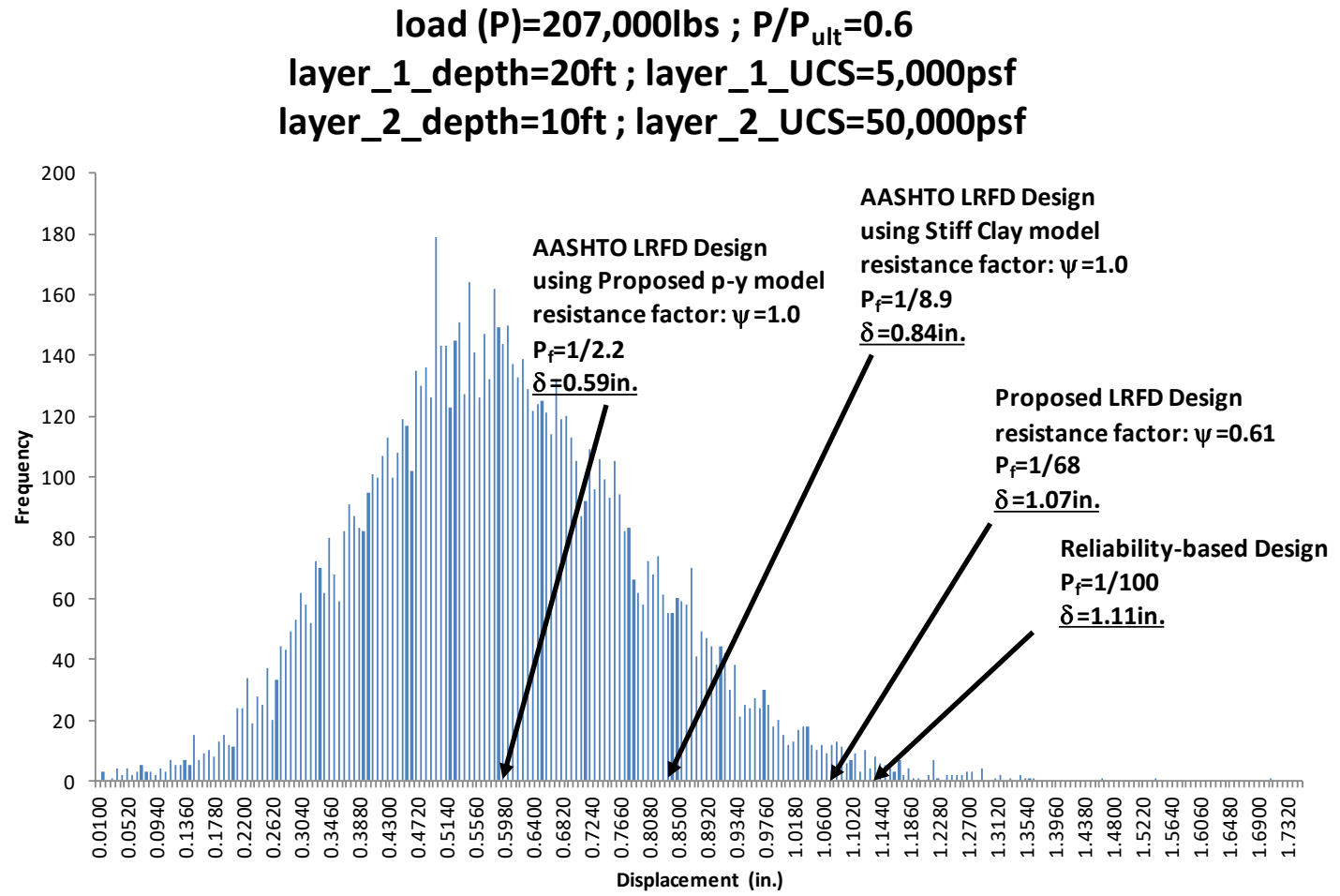

Case S- 4 with ratio $P / P_{\text {ult }}=0.6$ and target $P_{f}=1 / 100$ 


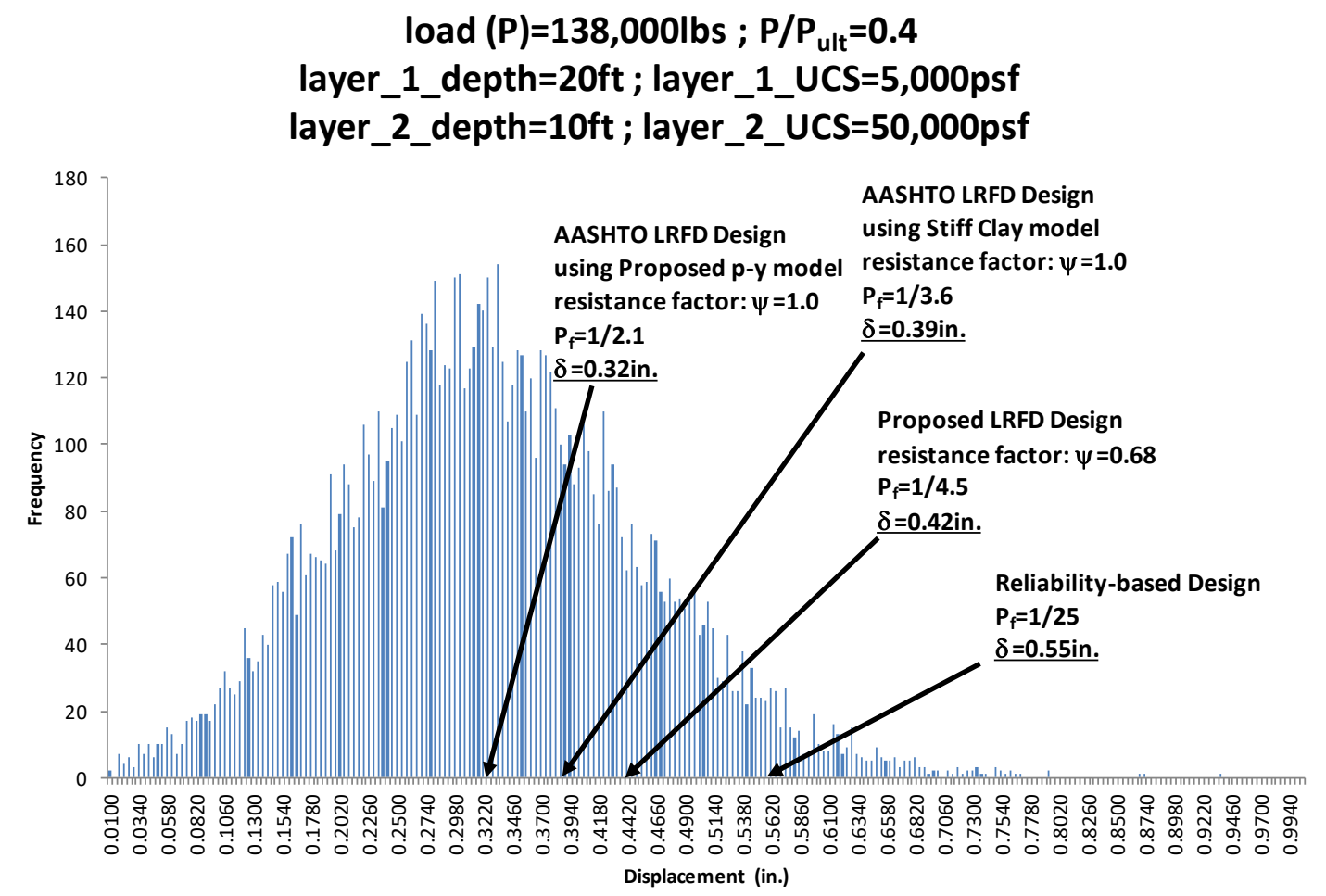

Case S- 4 with ratio $P / P_{\text {ult }}=0.4$ and target $P_{f}=1 / 25$
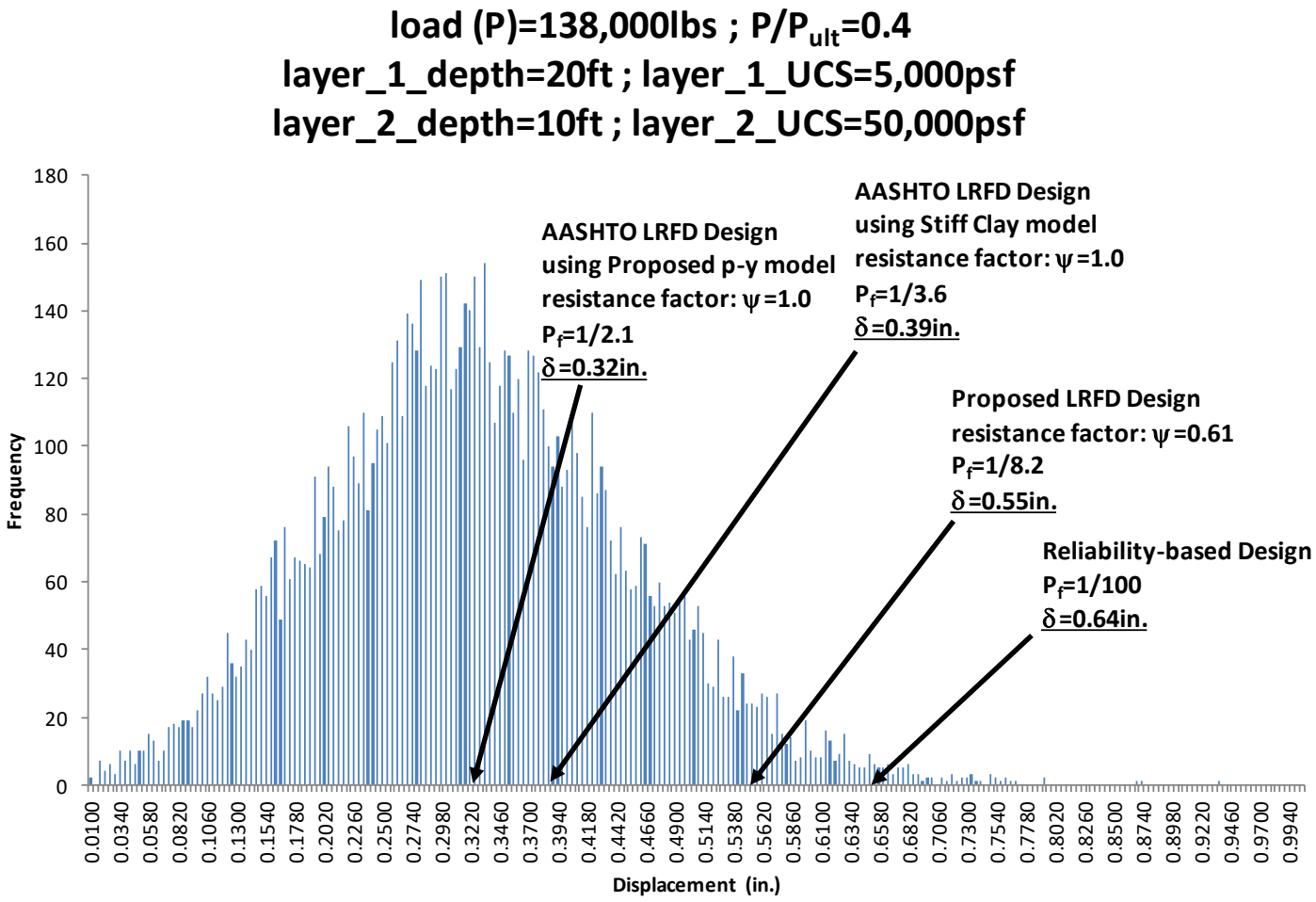

Case S- 4 with ratio $P / P_{\text {ult }}=0.4$ and target $P_{f}=1 / 100$ 


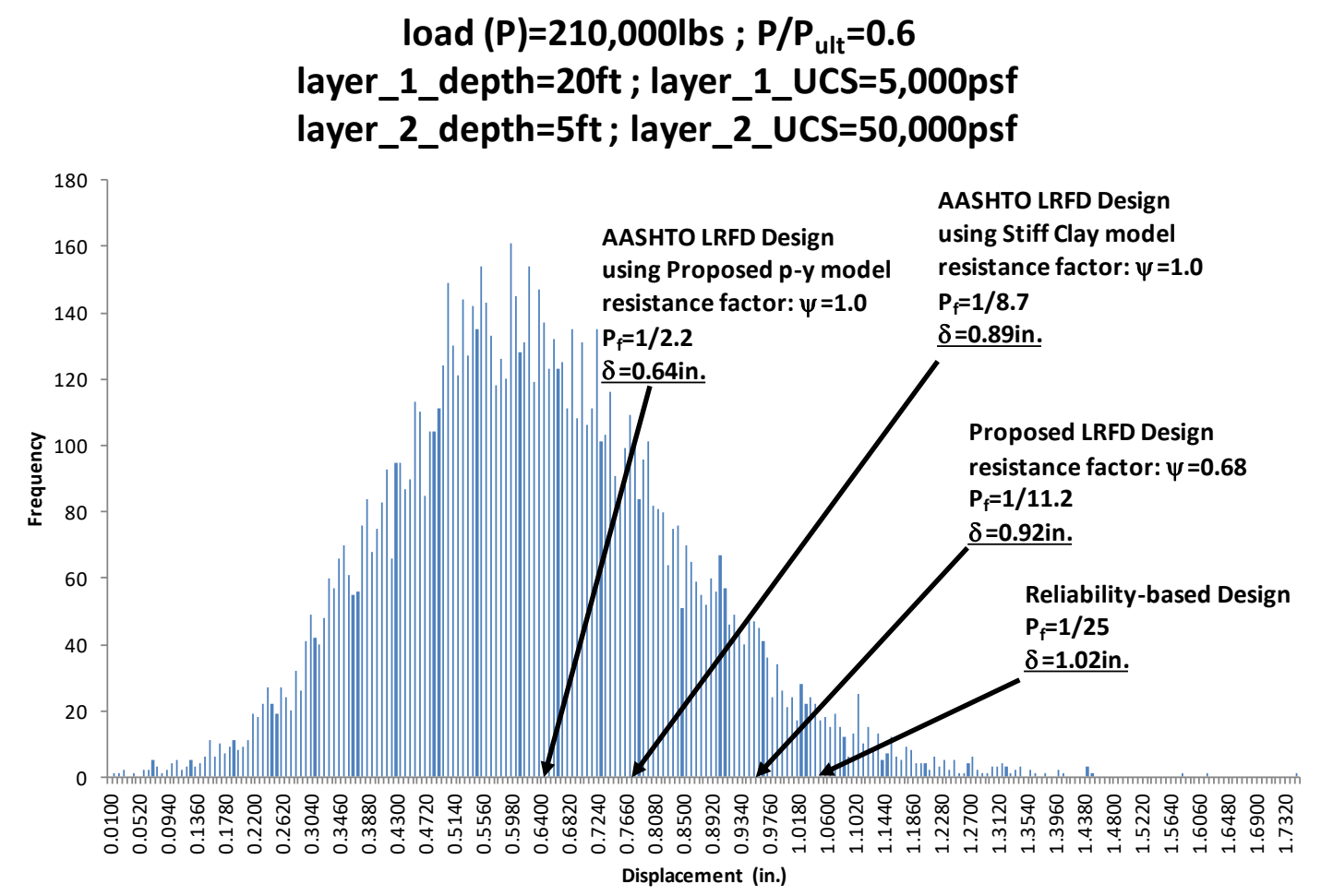

Case S- 5 with ratio $P / P_{\text {ult }}=0.6$ and target $P_{f}=1 / 25$
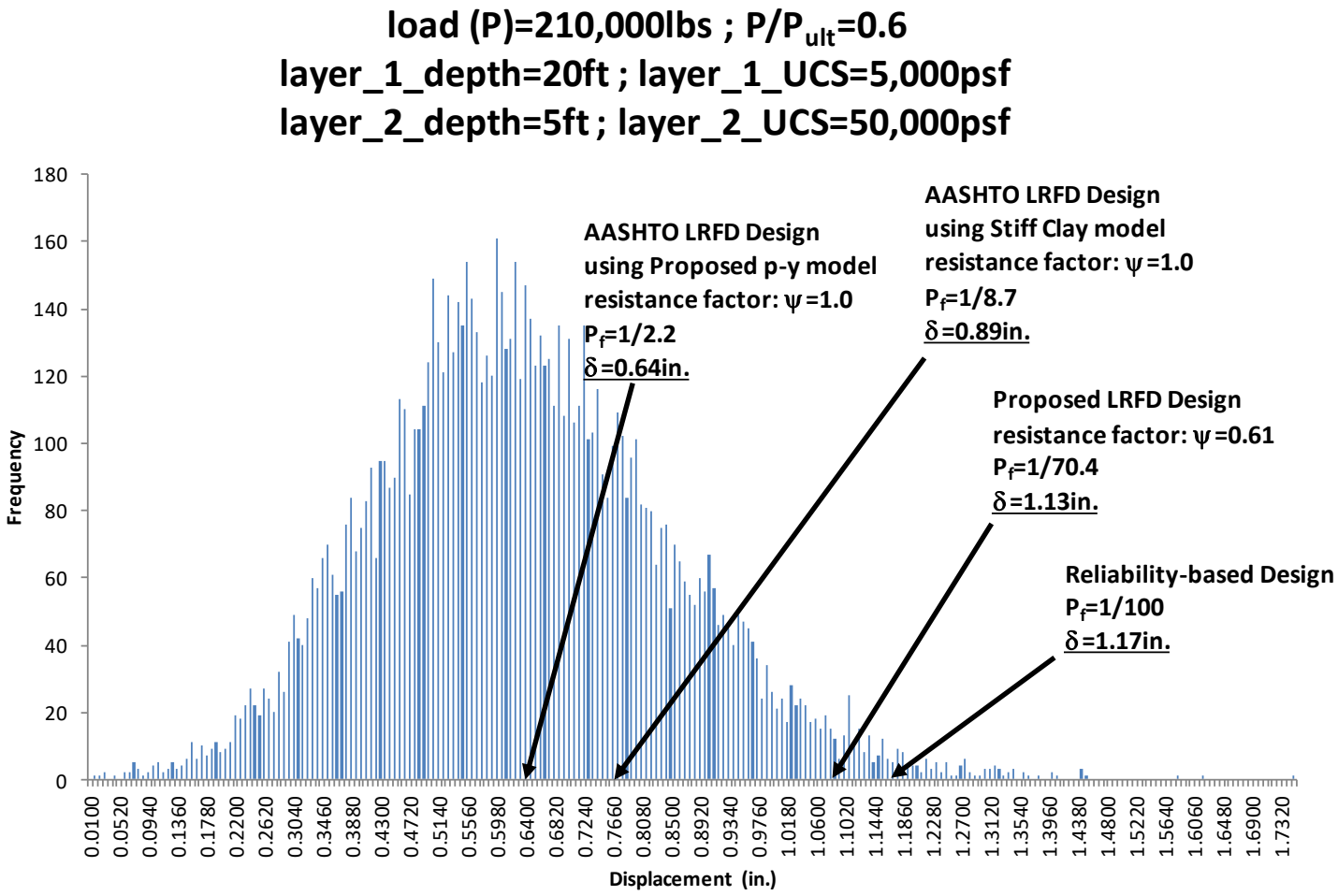

Case S-5 with ratio $P / P_{\text {ult }}=0.6$ and target $P_{f}=1 / 25$ 


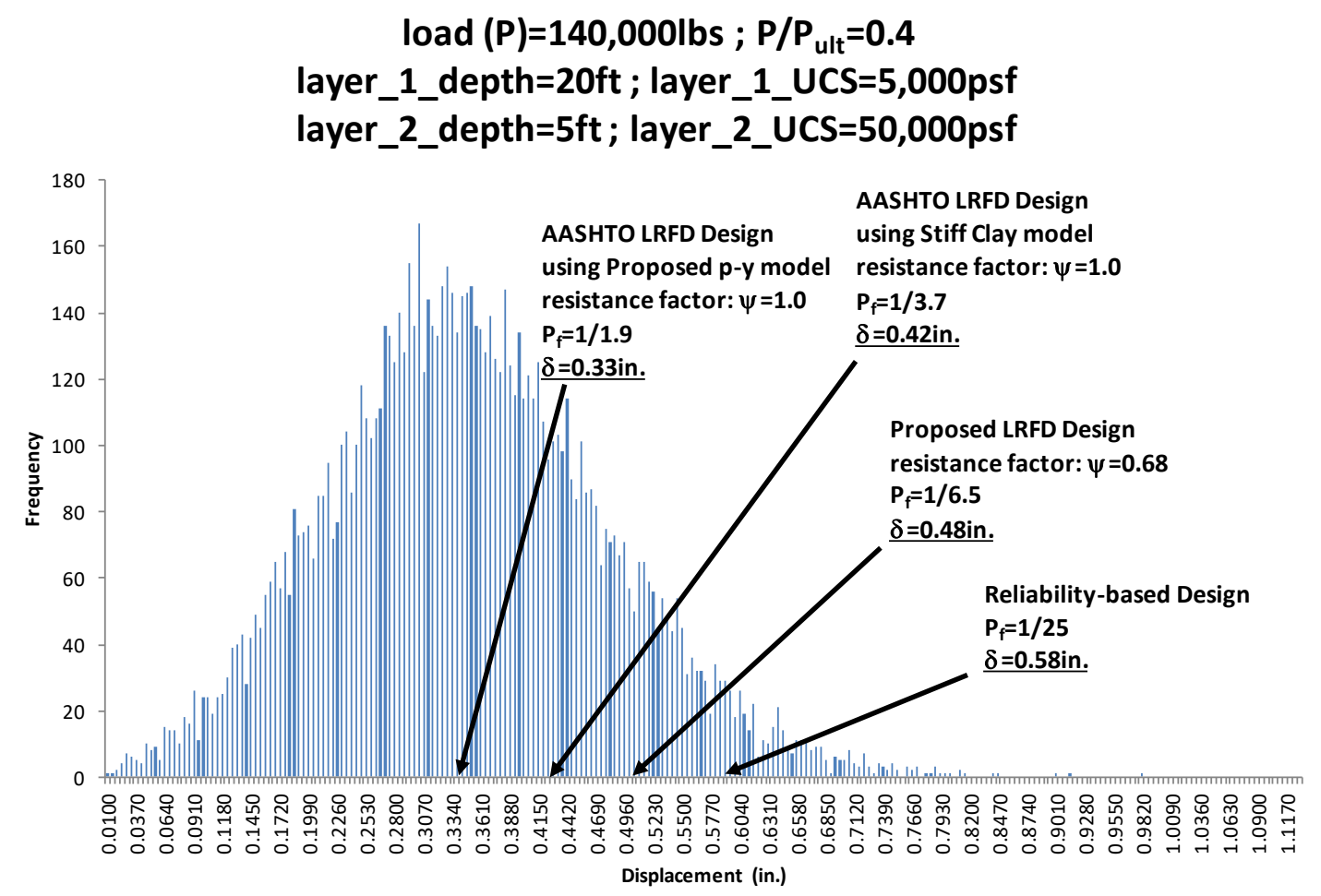

Case S- 5 with ratio $P / P_{\text {ult }}=0.4$ and target $P_{f}=1 / 25$
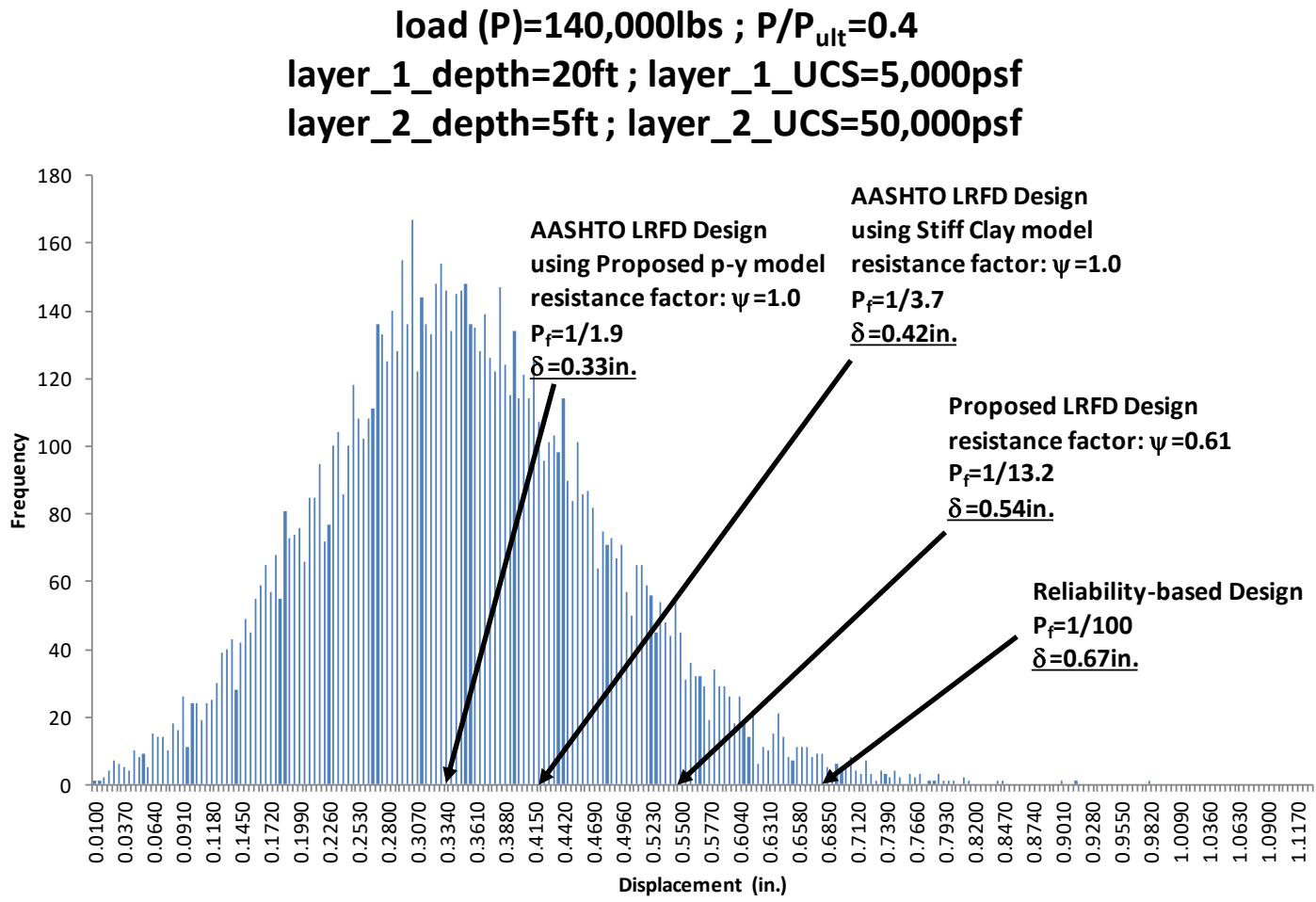

Case S- 5 with ratio $P / P_{\text {ult }}=0.4$ and target $P_{f}=1 / 100$ 


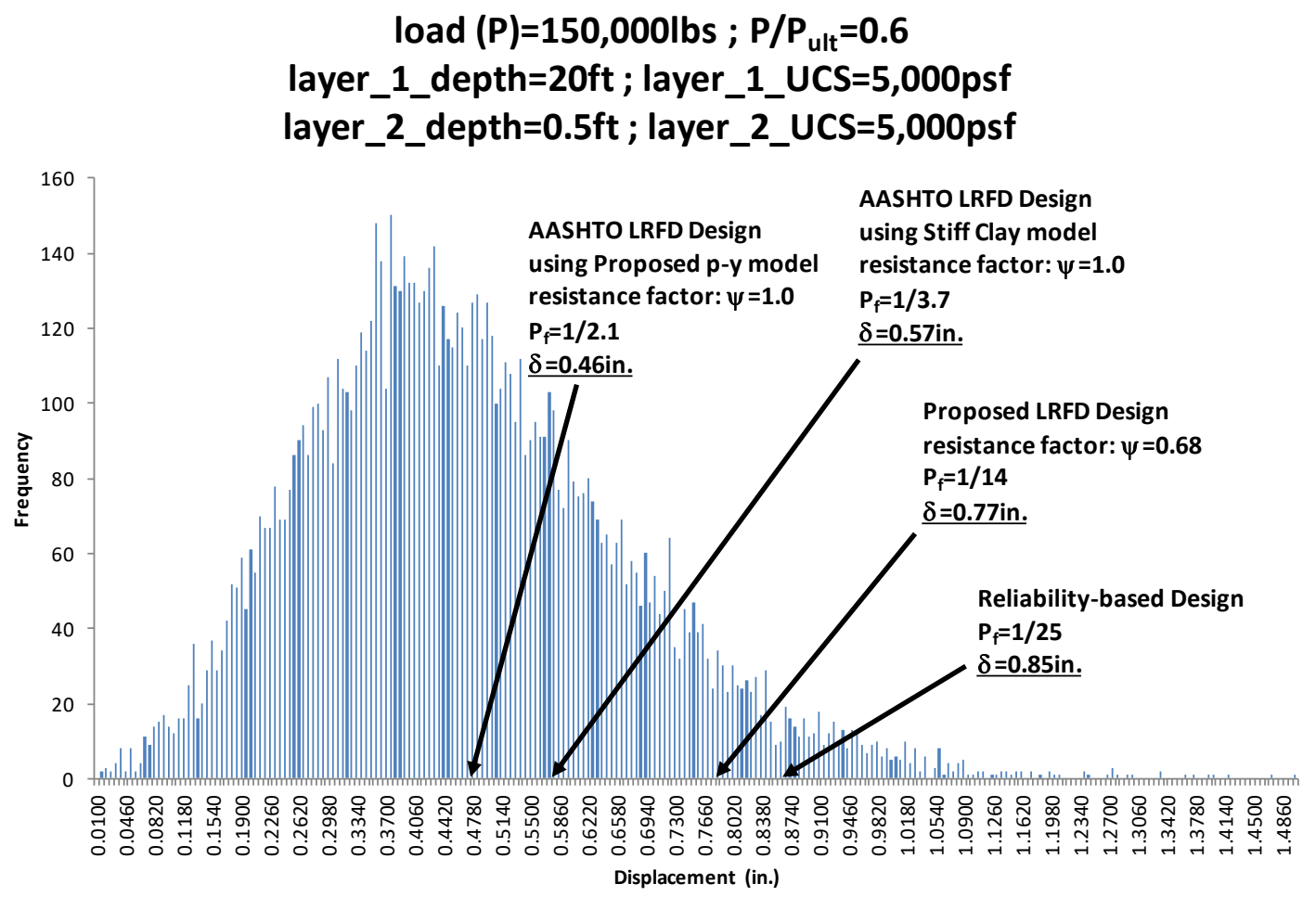

Case G- 6 with ratio $P / P_{\text {ult }}=0.6$ and target $P_{f}=1 / 25$
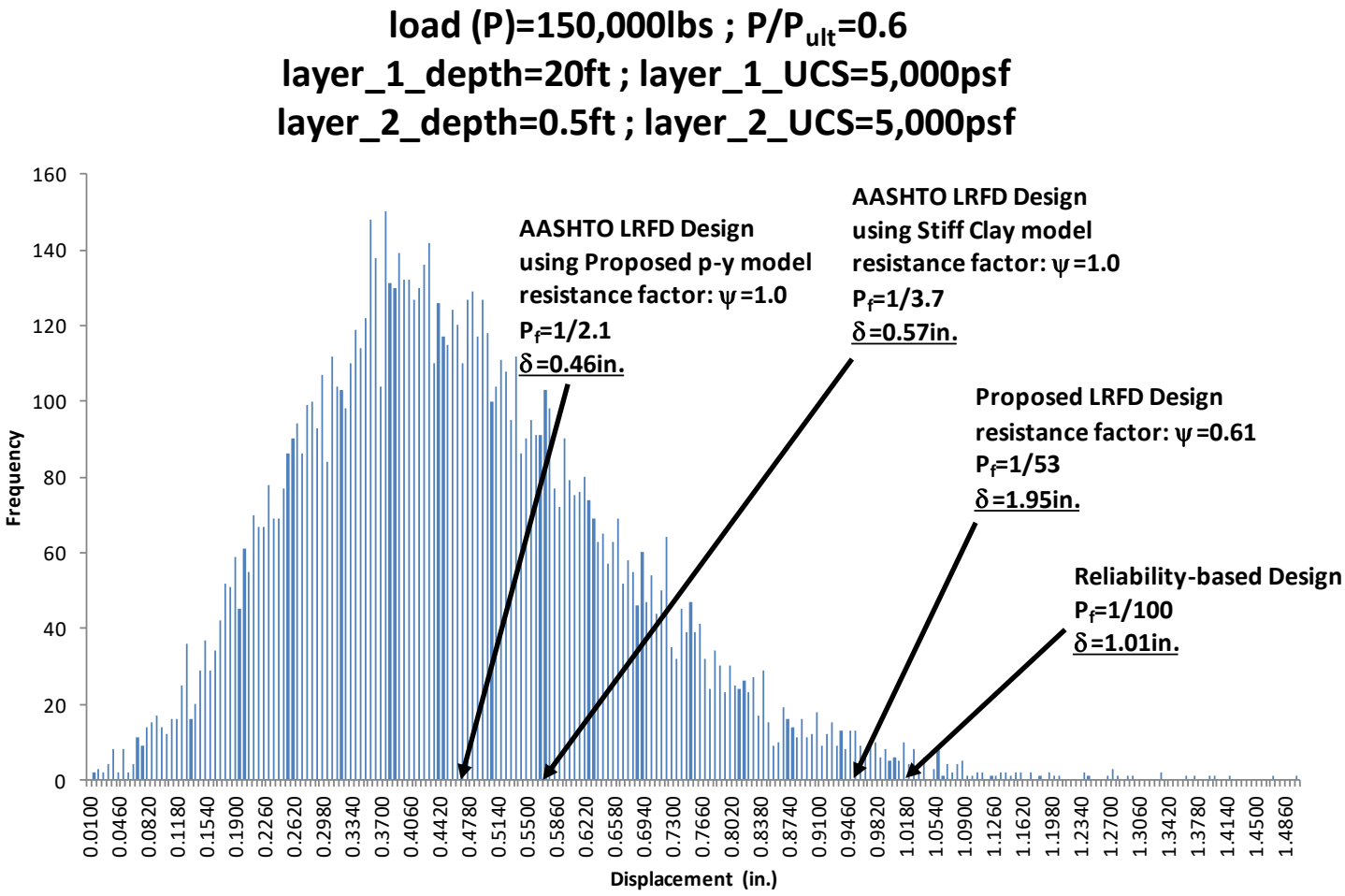

Case G-6 with ratio $P / P_{\text {ult }}=0.6$ and target $P_{f}=1 / 100$ 


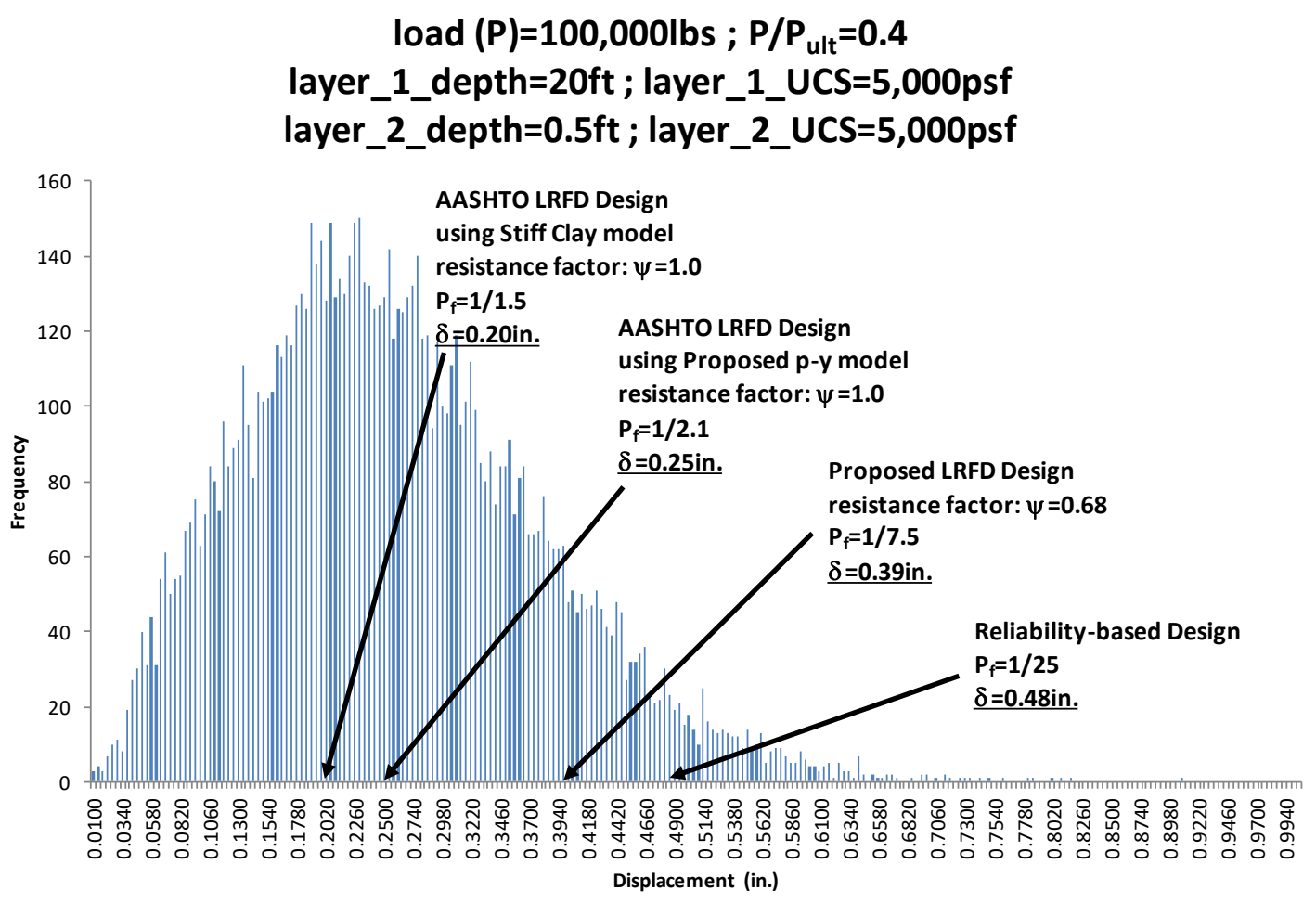

Case G- 6 with ratio $P / P_{\text {ult }}=0.4$ and target $P_{f}=1 / 25$

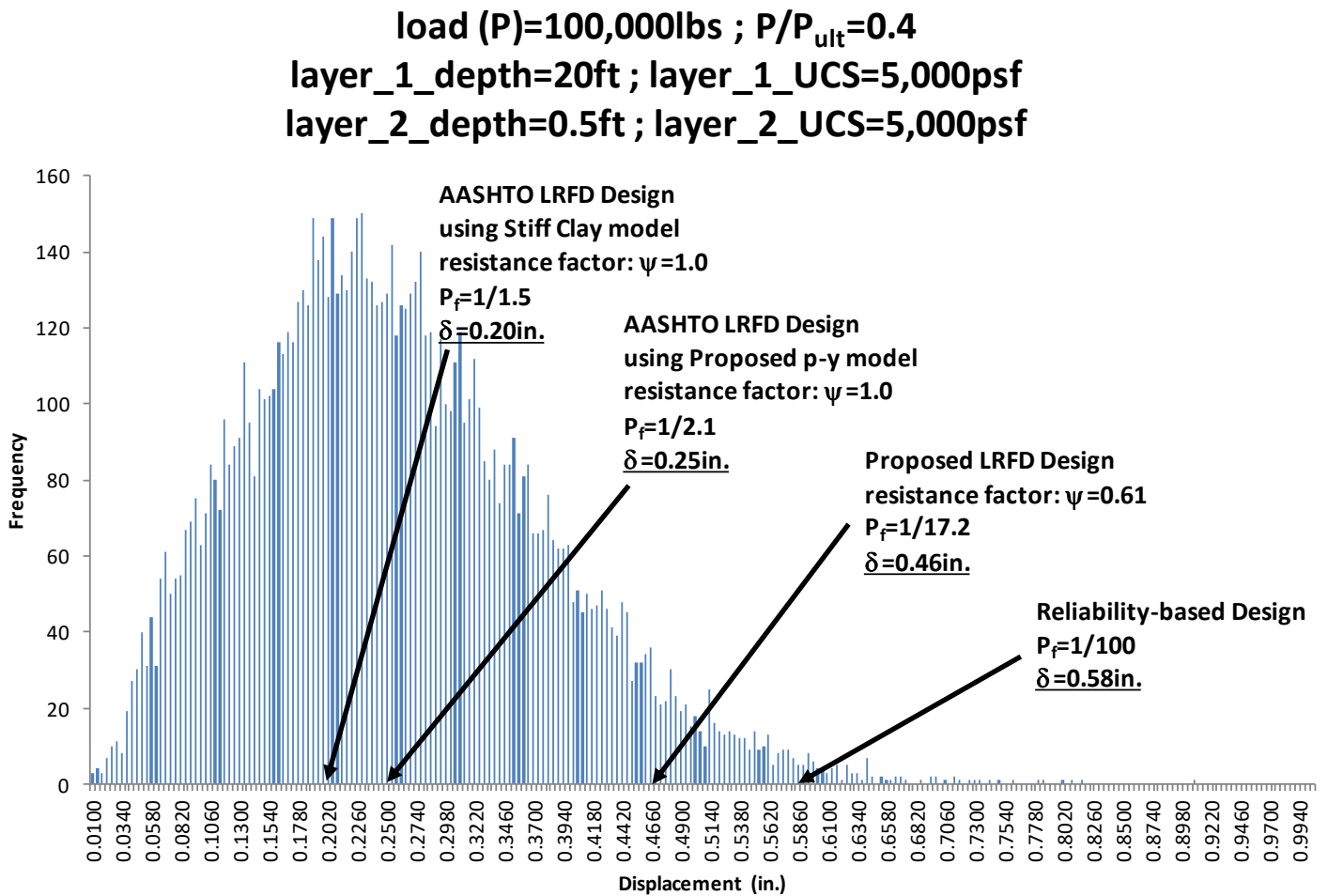

Case G-6 with ratio $P / P_{\text {ult }}=0.4$ and target $P_{f}=1 / 100$ 


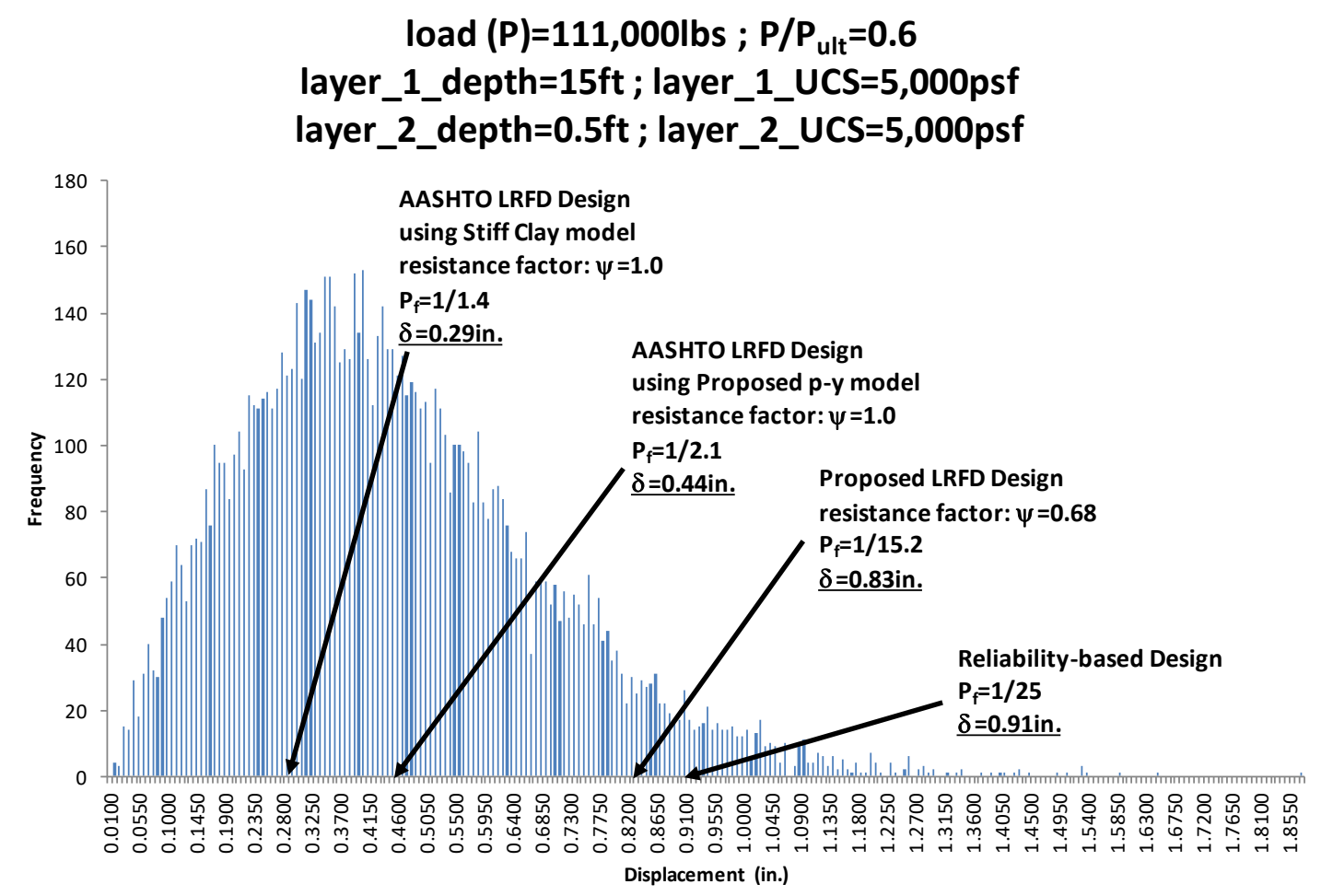

Case G-7 with ratio $P / P_{\text {ult }}=0.6$ and target $P_{f}=1 / 25$

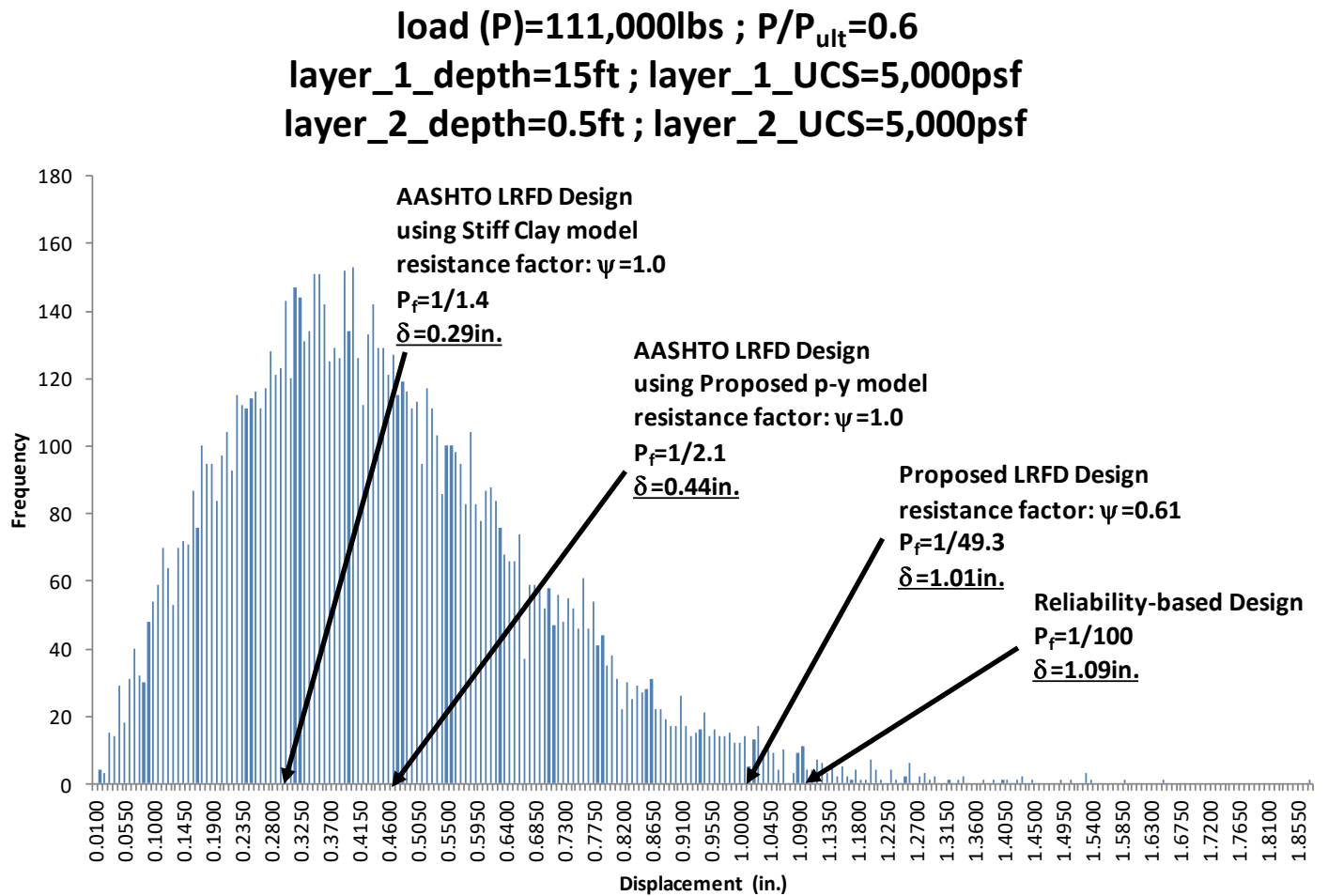

Case G-7 with ratio $P / P_{\text {ult }}=0.6$ and target $P_{f}=1 / 100$ 


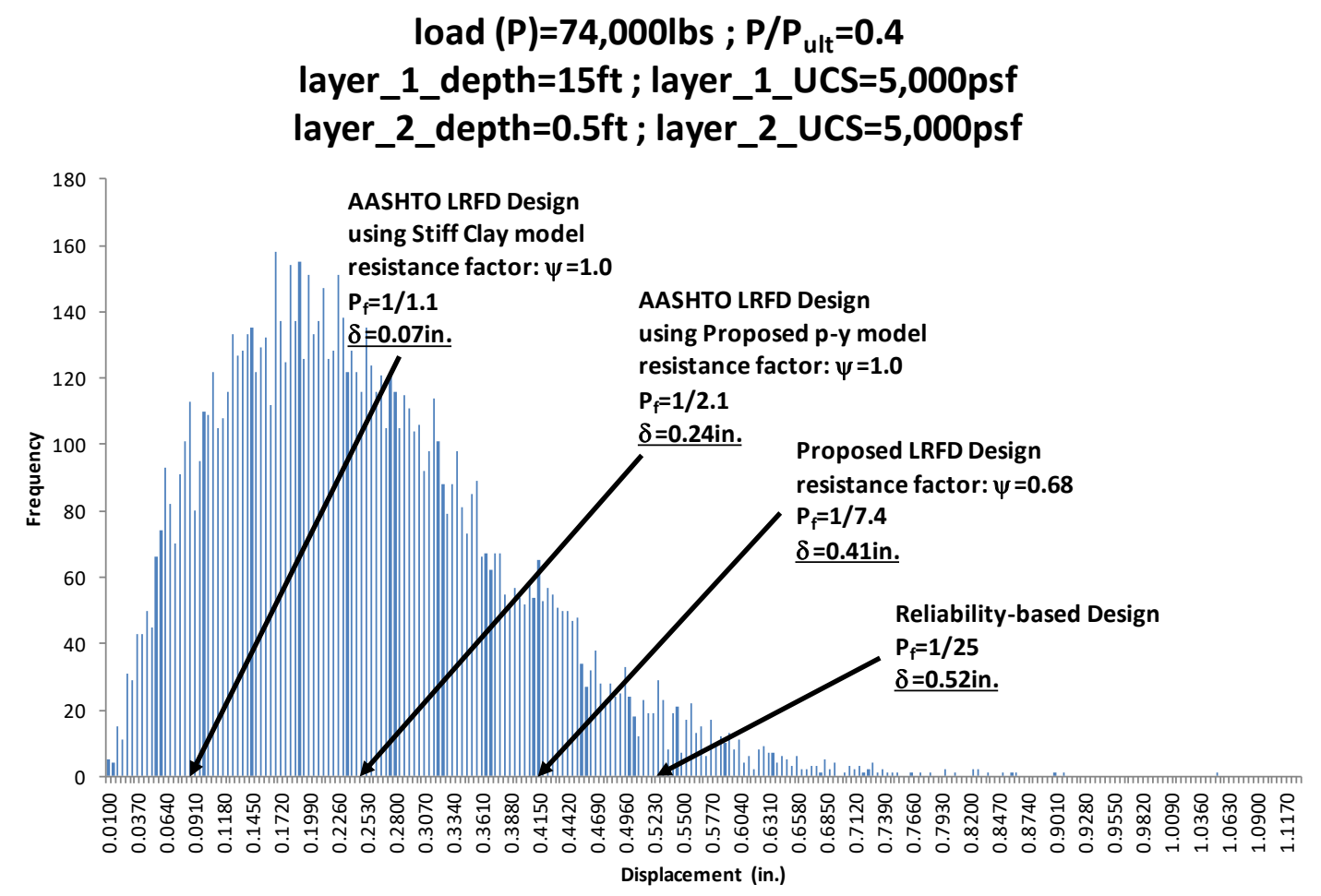

Case G-7 with ratio $P / P_{\text {ult }}=0.4$ and target $P_{f}=1 / 25$

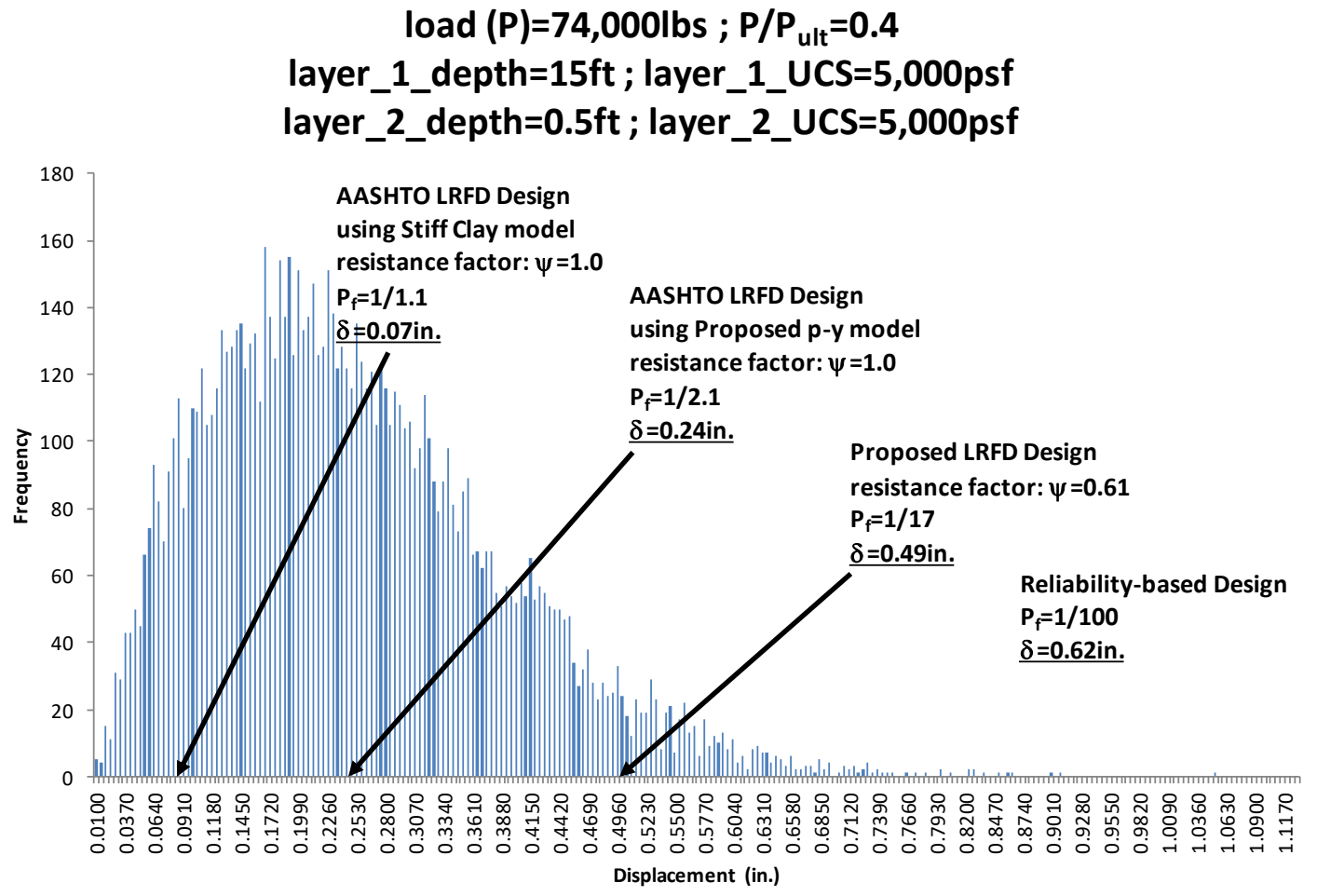

Case G-7 with ratio $P / P_{\text {ult }}=0.4$ and target $P_{f}=1 / 100$ 


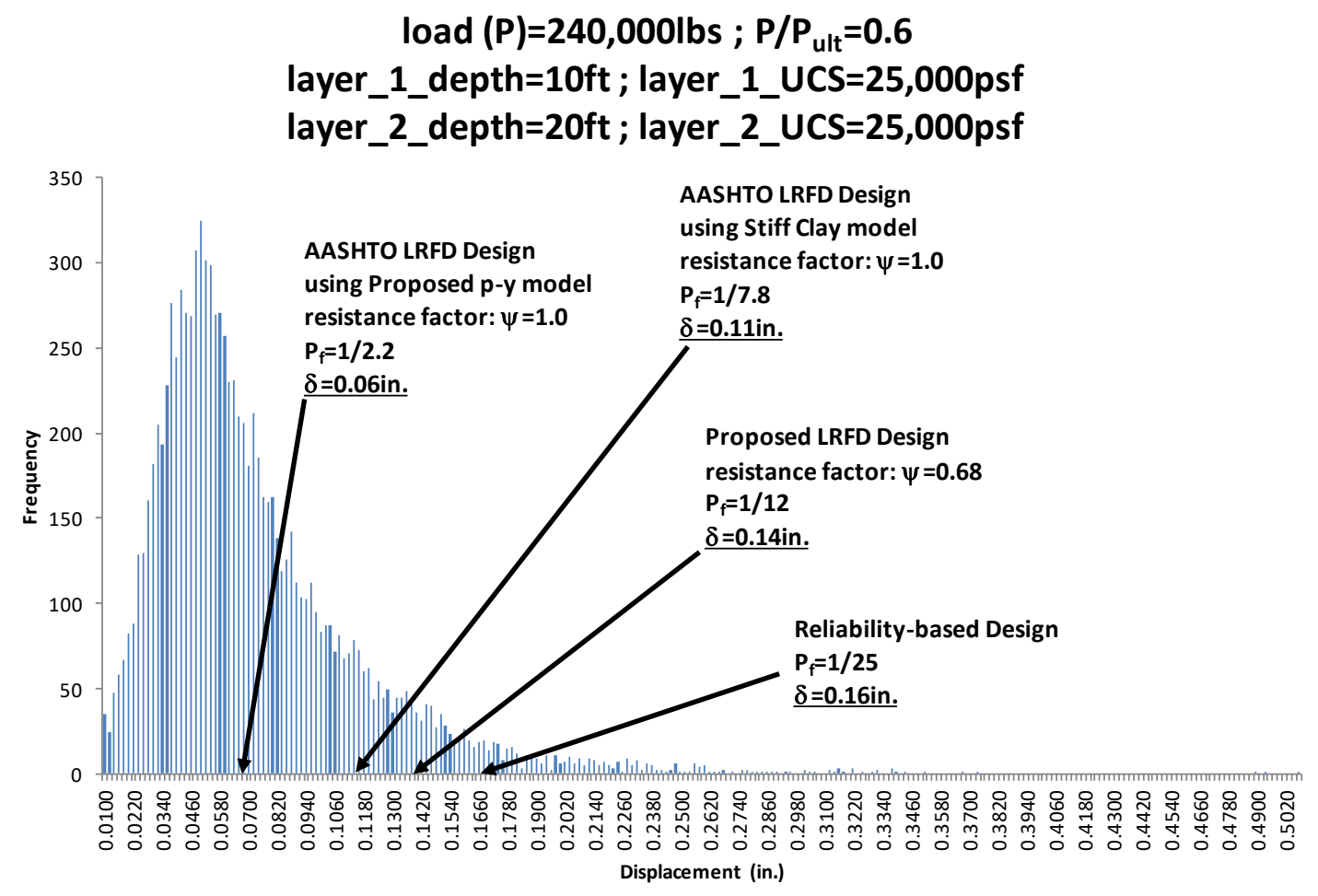

Case S-8 with ratio $\mathrm{P} / \mathrm{P}_{\text {ult }}=0.6$ and target $\mathrm{P}_{\mathrm{f}}=1 / 25$

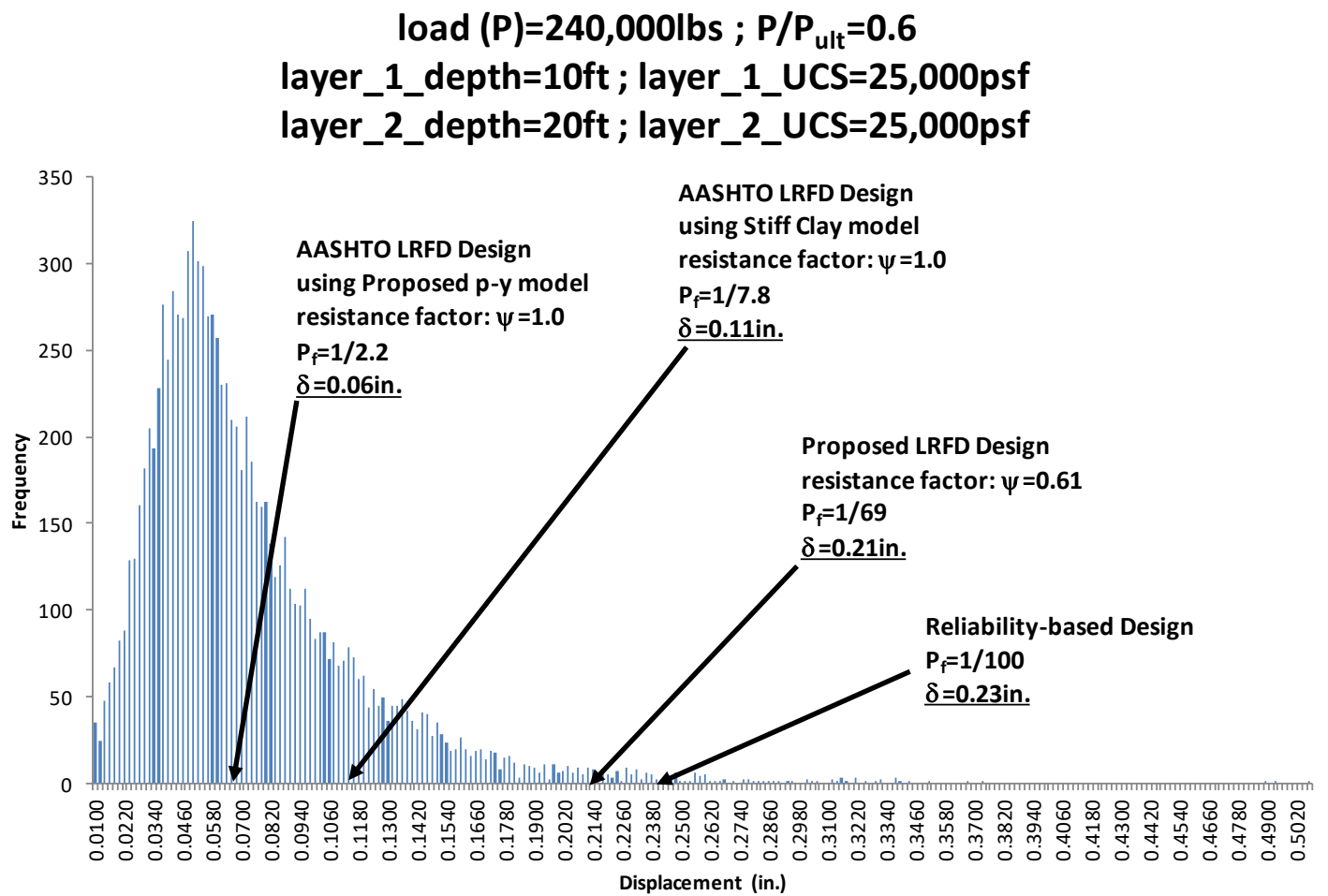

Case S- 8 with ratio $P / P_{\text {ult }}=0.6$ and target $P_{f}=1 / 100$ 


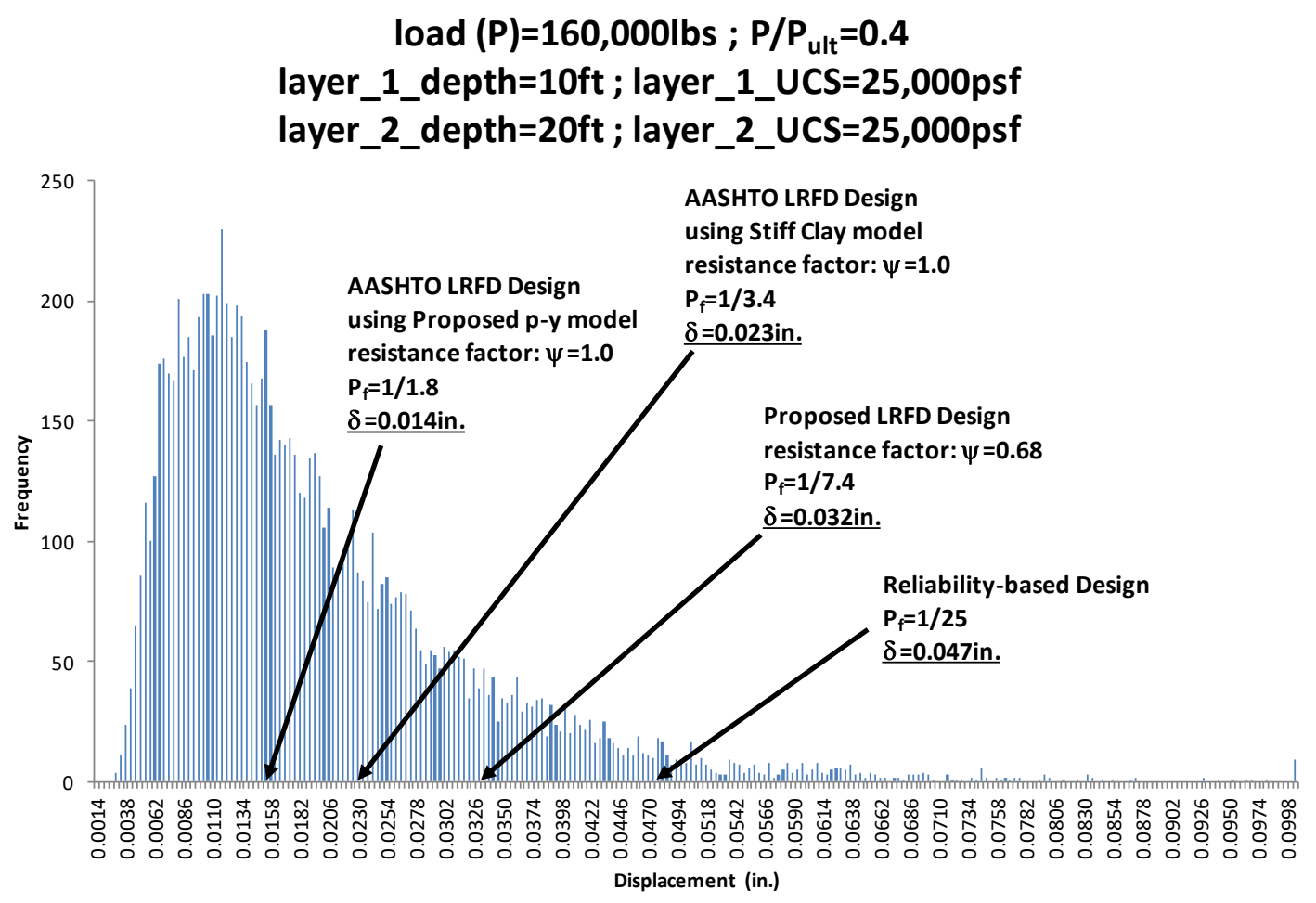

Case S- 8 with ratio $P / P_{\text {ult }}=0.4$ and target $P_{f}=1 / 25$

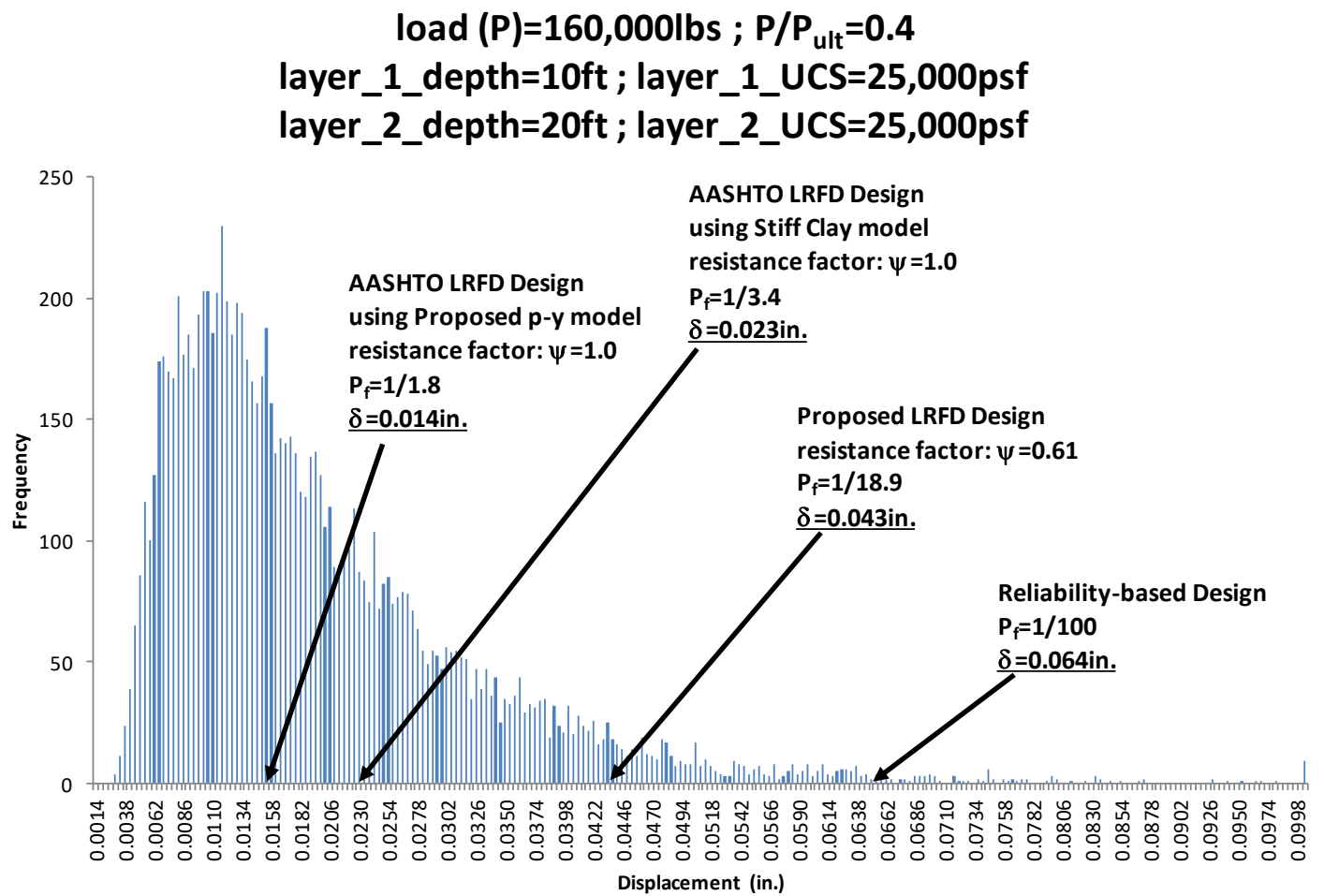

Case S- 8 with ratio $P / P_{\text {ult }}=0.4$ and target $P_{f}=1 / 100$ 


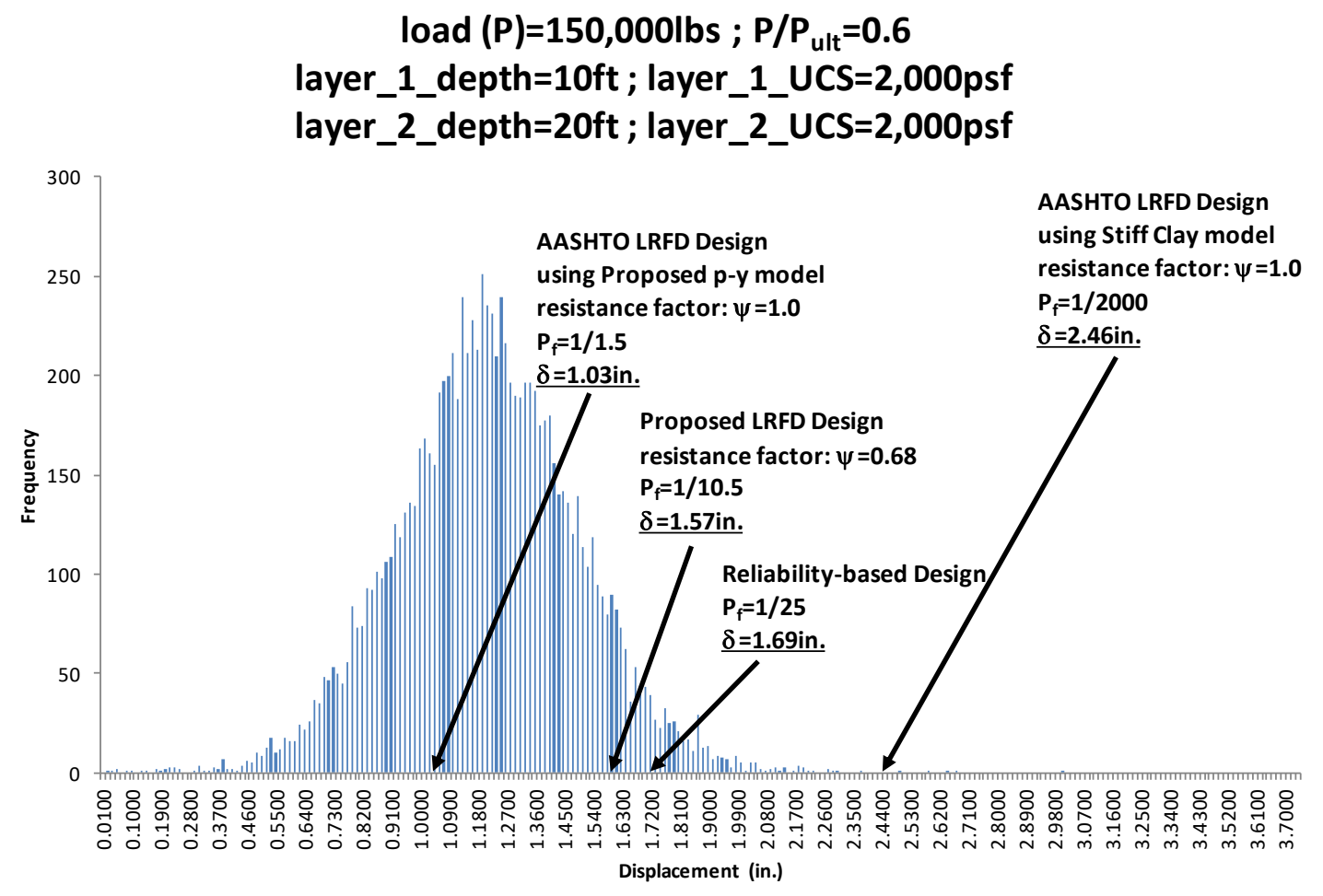

Case $\mathrm{S}-9$ with ratio $\mathrm{P} / \mathrm{P}_{\text {ult }}=0.6$ and target $\mathrm{P}_{\mathrm{f}}=1 / 25$
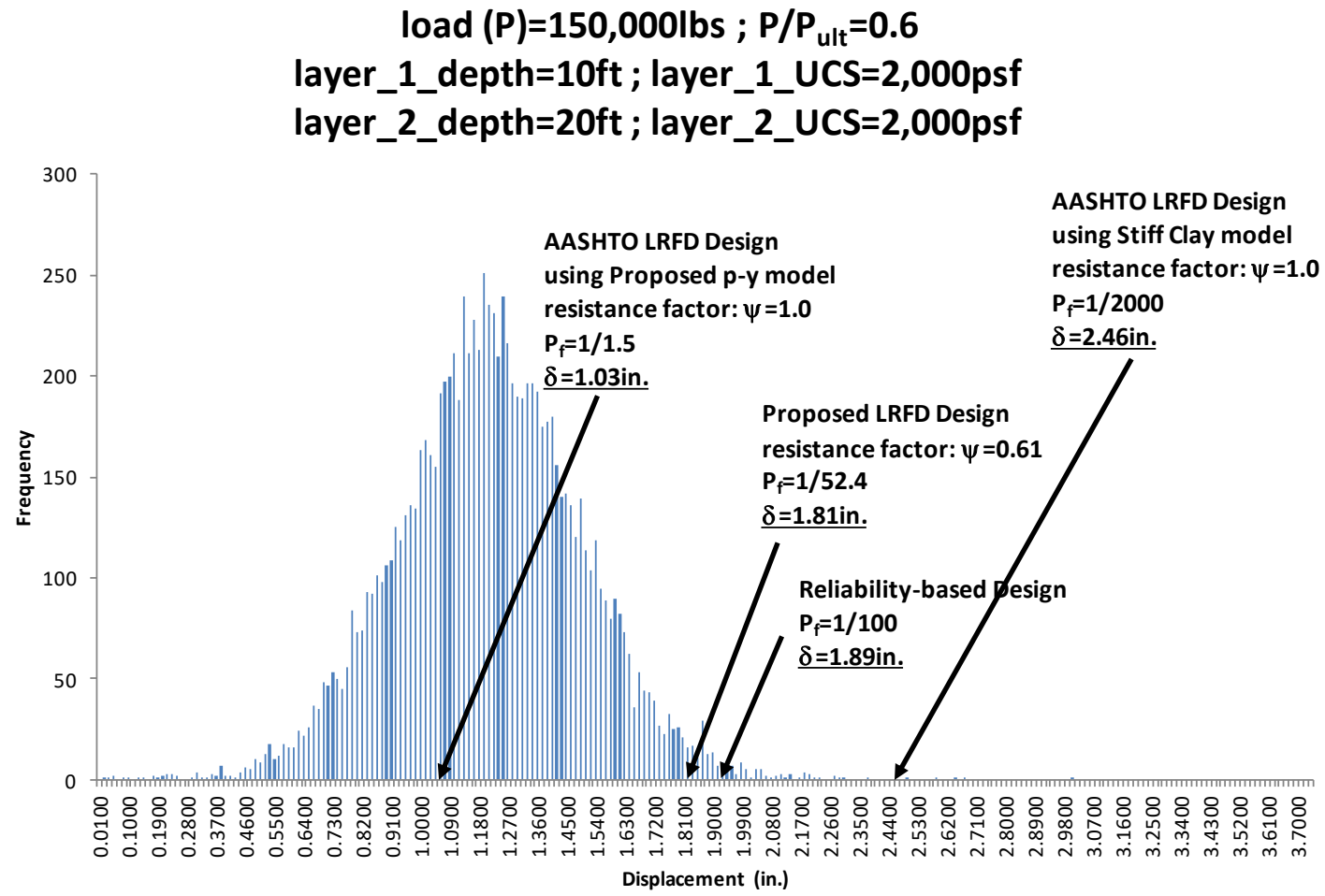

Case S- 9 with ratio $P / P_{\text {ult }}=0.6$ and target $P_{f}=1 / 100$ 
load $(P)=100,000$ lbs ; $P / P_{\text {ult }}=0.4$

layer_1_depth $=10 \mathrm{ft}$; layer_1_UCS $=2,000$ psf

layer_2_depth=20ft ; layer_2_UCS=2,000psf

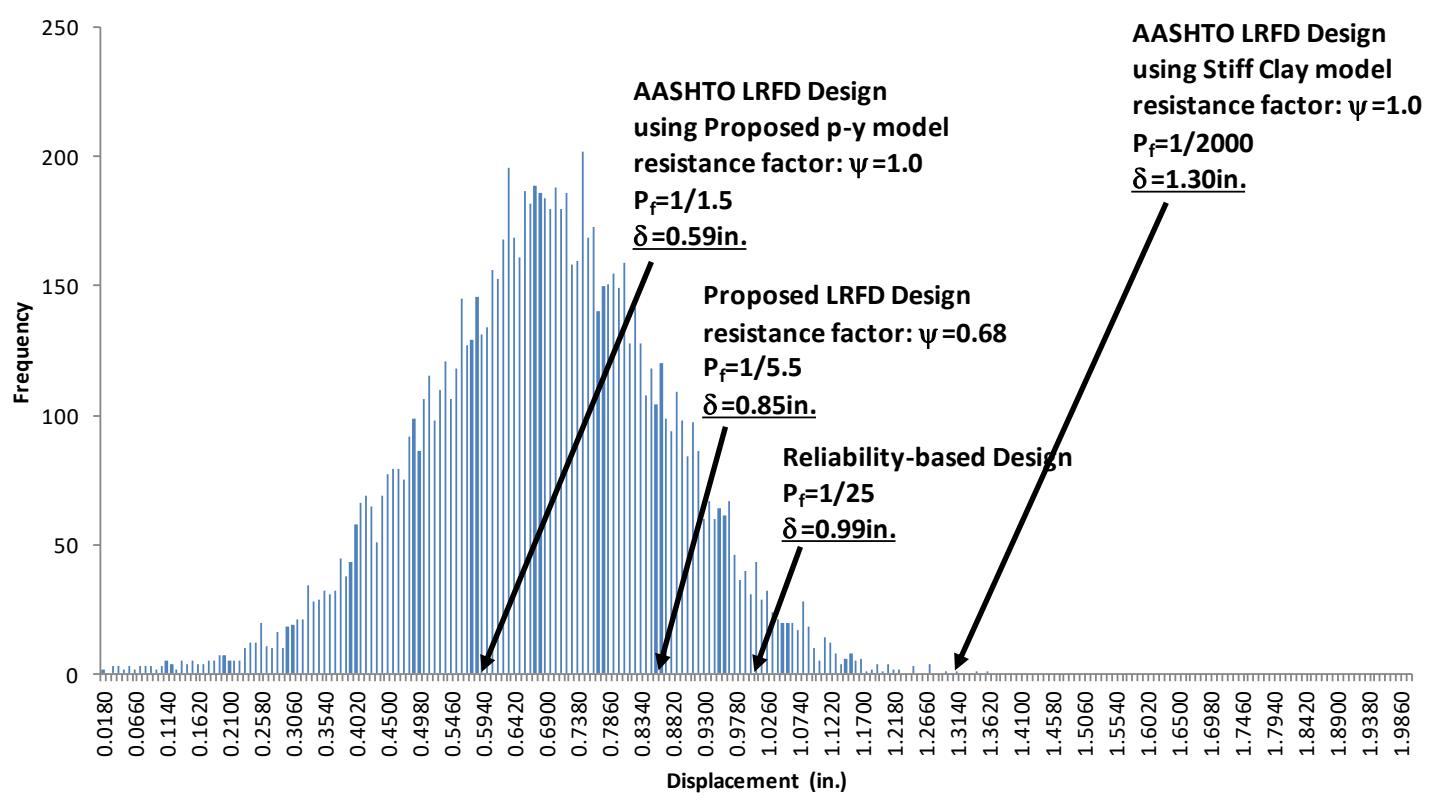

Case $\mathrm{S}-9$ with ratio $\mathrm{P} / \mathrm{P}_{\text {ult }}=0.4$ and target $\mathrm{P}_{\mathrm{f}}=1 / 25$
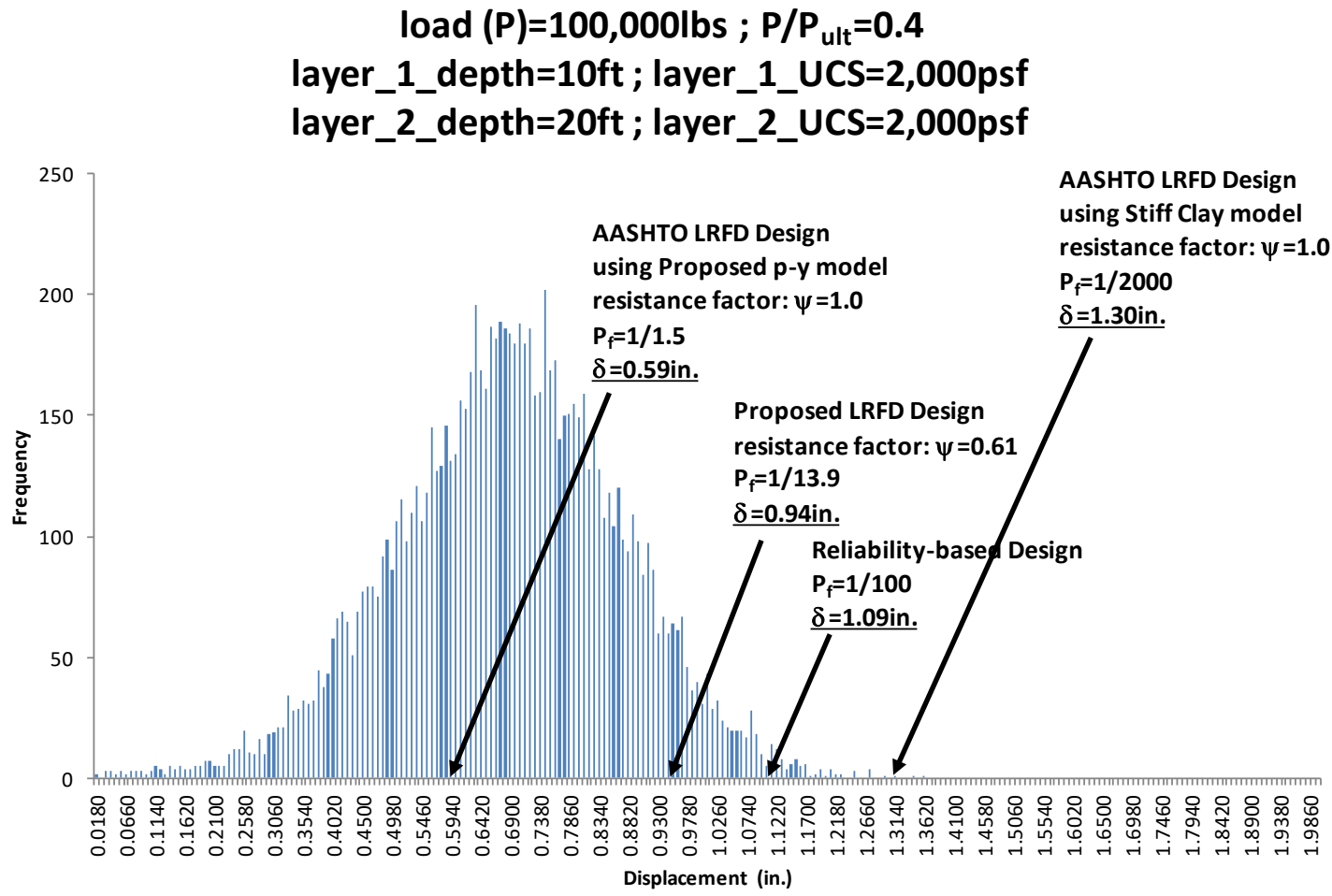

Case S- 9 with ratio $P / P_{\text {ult }}=0.4$ and target $P_{f}=1 / 100$ 


\section{VITA}

Minh D. Uong was born in Hanoi, Vietnam. He received his BS degree in Civil Engineering from Hanoi Architectural University (HAU), Hanoi, Vietnam in 2005 and started working as a geotechnical engineer at HAU's Construction Consultancy Firm. In 2006, he was rewarded full scholarship for a 2-year Master program in Civil Engineering from the University of Polytechnic (POLIMI), Milan, Italy and got his MS degree in 2008. Starting from 2008 to 2010, he was a lecturer at the Department of Civil Engineering, Hanoi Architectural University, where he taught Fundamentals of Soil Mechanics and Foundation Engineering courses.

In 2010, he joined the University of Missouri-Columbia (Mizzou) to pursue PhD degree in Civil/Geotechnical Engineering. During his studying at Mizzou, he had opportunities to work as a research assistant under the supervision of Dr. Erik Loehr on several research projects, and to be a lab instructor as well as teaching assistant for Fundamentals of Geotechnical Engineering and Intermediate Strength of Materials courses. In the summer of 2018 , he successfully defended his doctoral dissertation on LRFD of Drilled Shafts subjected to Lateral Loading at Service Limit State. He was a very active member of Mizzou geotechnical community and had served several organizations including: Vice-President of Geotechnical Engineering Organization at Mizzou (MUGEO), President of Vietnamese Student Association at Mizzou (VSA) and Co-founder, Board of Directors of the Association of Vietnamese Students and Professionals in the United States (AVSPUS).

Minh is married to Mai Vu and they are parents of Anna, Leah and Sophia Uong. 